\title{
Efficacy of Schoolwide Programs to Promote Social and Character Development and Reduce Problem Behavior in Elementary School Children
}

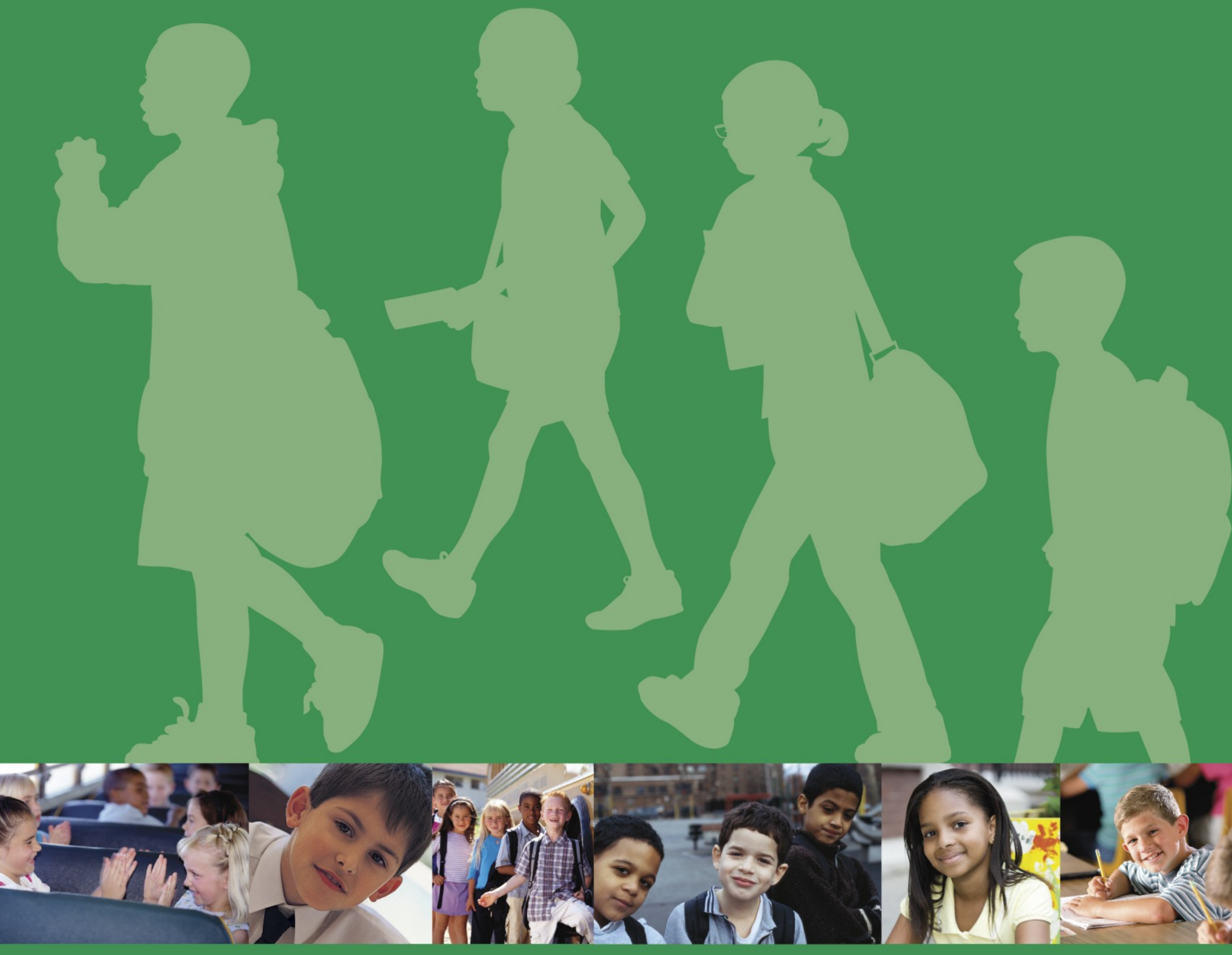

NCER 2011-2001

U.S. DEPARTMENT OF EDUCATION
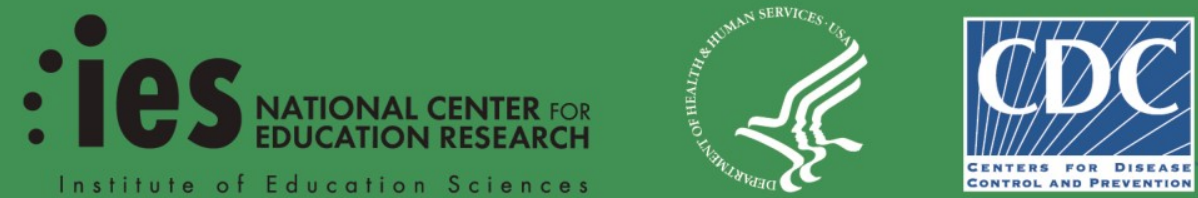


\section{Efficacy of Schoolwide Programs to Promote Social and Character Development and Reduce Problem Behavior in Elementary School Children}

Report From the Social and Character Development Research Program

\section{OCTOBER 2010}

Social and Character Development Research Consortium 
This report was prepared for the National Center for Education Research, Institute of Education Sciences, under Contract No. ED-01-CO-0039/0006 with Mathematica Policy Research, Inc. Synergy Enterprises, Inc., under Contract No. ED-04-CO-0076/0007, provided editorial and graphic support for the report.

\section{Disclaimer}

The findings and conclusions expressed in this report are the authors' and do not necessarily represent the opinions and positions of the Institute of Education Sciences, the U.S. Department of Education, or the Centers for Disease Control and Prevention.

\section{U.S. Department of Education}

Arne Duncan

Secretary

Institute of Education Sciences

John Q. Easton

Director

\section{National Center for Education Research}

Lynn Okagaki

Commissioner

\section{October 2010}

This is a report by the Social and Character Development Research Consortium. It was written by Allen Ruby and Emily Doolittle of the Institute of Education Sciences.

The report is in the public domain. Authorization to reproduce it in whole or in part is granted. While permission to reprint this publication is not necessary, the citation should be: Social and Character Development Research Consortium (2010). Efficacy of Schoolwide Programs to Promote Social and Character Development and Reduce Problem Behavior in Elementary School Children (NCER 2011-2001). Washington, DC: National Center for Education Research, Institute of Education Sciences, U.S. Department of Education.

To order copies of this report,

- Write to ED Pubs, Education Publications Center, U.S. Department of Education, P.O. Box 22207, Alexandria, VA 22304.

- Call in your request toll free to 1-877-4ED-Pubs. If 877 service is not available in your area, call 800-872-5327. Those who use a telecommunications device for the deaf (TDD) or a teletypewriter (TTY) should call 800-437-0833.

- Fax your request to 703-605-6794 or order online at www.edpubs.gov.

The report is also available on the IES website at http://ncer.ed.gov.

On request, this publication is available in alternate formats, such as Braille, large print, or computer diskette. For more information, contact the Department's Alternate Format Center at 202-260-0852 or 202-260-0818. 


\section{Social and Character Development Research Consortium}

\author{
Institute of Education Sciences (IES) \\ Caroline Ebanks \\ Edward C. Metz \\ Amy Silverman ${ }^{1}$ \\ Elizabeth R. Albro \\ Division of Violence Prevention, National Center \\ for Injury Prevention and Control, Centers for \\ Disease Control and Prevention (CDC) \\ Tamara M. Haegerich ${ }^{2}$ \\ Le'Roy Reese 3 \\ Corinne David-Ferdon \\ Mathematica Policy Research, Inc. (MPR) \\ Karen Needels \\ John A. Burghardt \\ Laura M. Kalb \\ Heather Koball \\ Peter Z. Schochet \\ Victor Battistich (University of Missouri-St. Louis)

\section{Children's Institute} \\ Deborah B. Johnson \\ Hugh F. Crean \\ New York University ${ }^{4}$ \\ J. Lawrence Aber \\ Stephanie M. Jones ${ }^{5}$ (Fordham University) \\ Joshua L. Brown ${ }^{6}$
}

\author{
Oregon State University ${ }^{7}$ \\ Brian R. Flay \\ Carol G. Allred (Positive Action) \\ David L. DuBois (University of Illinois at Chicago) \\ Michael L. Berbaum (University of Illinois at Chicago) \\ Peter Ji (University of Illinois at Chicago) \\ Vanessa Brechling (University of Illinois at Chicago) \\ University at Buffalo, The State University \\ of New York \\ William E. Pelham, Jr. \\ Greta M. Massetti ${ }^{8}$ \\ Daniel A. Waschbusch \\ University of Maryland \\ Gary D. Gottfredson \\ University of North Carolina at Chapel Hill \\ Mark W. Fraser \\ Thomas W. Farmer ${ }^{9}$ \\ Maeda J. Galinsky \\ Kim Dadisman \\ Vanderbilt University \\ Leonard Bickman \\ Ana Maria Brannan \\ Catherine Smith
}

\footnotetext{
${ }^{1}$ Amy Silverman is currently a clinical psychologist at the Jewish Family \& Career Services of Atlanta, Inc.

2 Tamara M. Haegerich served as IES Project Officer before joining the CDC.

${ }^{3}$ Le'Roy Reese is currently on the faculty at Morehouse School of Medicine.

4 This award was originally made to Columbia University and was transferred to New York University (NYU) when the principal investigator, J. Lawrence Aber, accepted a position at NYU.

${ }^{5}$ Stephanie M. Jones is now on the faculty at Harvard University.

${ }^{6}$ Joshua L. Brown is now on the faculty at Fordham University.

7 This award was originally made to the University of Illinois at Chicago, but was transferred to Oregon State University (OSU) when the principal investigator, Brian R. Flay, accepted a position at OSU.

${ }^{8}$ Greta M. Massetti is now at the Division of Violence Prevention, National Center for Injury Prevention and Control, CDC.

${ }^{9}$ Thomas W. Farmer was the principal investigator when the award was made to the University of North Carolina at Chapel Hill. During the project, he accepted a position at Pennsylvania State University, and Mark Fraser became the principal investigator.
} 
This page is intentionally blank. 


\section{Acknowledgments}

This report resulted from a collaboration among the scientists who are members of the Social and Character Development Research Consortium (SACD Research Consortium), school district personnel, and curriculum developers. Many school districts, principals, teachers, and school staff members assisted the evaluation by providing records and coordinating site visits for data collection. We appreciate their help and willingness to share critical information with the evaluation team.

The authors listed under the SACD Research Consortium represent only part of the research team involved in the project. We would like to thank the research staff at each research team's site, especially each team's site coordinator. These people worked closely with the local schools' staff and the contractors' data collection teams to facilitate the successful collection of the data.

We would also like to acknowledge the contribution of the many contract staff members who worked on the data collection and analysis. The authors wish to thank Mathematica Policy Research, Inc. (MPR) staff members Audrey McDonald and Carolyn Miller for their tireless efforts in managing data collection, and Shawn Marsh and Larry Snell for their development and maintenance of the tracking system. We give special thanks to Decision Information Resources, Inc., in particular Douglas Hermond and Carla Prince, for assisting in data collection and the development of coding protocols for analysis. We appreciate the contributions of Marvin Berkowitz and Mindy Bier at the University of Missouri-St. Louis to the evaluation. Finally, we wish to provide thanks to Clotilde Benitez and Ken Carlisle from Friday Systems, which provided support for the SACD working meetings.

The SACD Research Consortium would also like to remember Dr. Victor Battistich from the College of Education at the University of Missouri-St. Louis. Dr. Battistich, who passed away on June 20, 2008, served as a consultant to MPR during this project and was a leading researcher in children's social development and school-based programming.

The mention of trade names, commercial products, or organizations in the description of the projects, or the reporting of study findings, does not imply endorsement by the U.S. government. 
This page is intentionally blank. 


\section{Disclosure of Potential Conflicts of Interest}

The Social and Character Development (SACD) Research Consortium consists of research teams (principal investigators and co-principal investigators from each grantee site); Institute of Education Sciences (IES) staff; Centers for Disease Control and Prevention (CDC) staff; and the evaluation contractor, Mathematica Policy Research, Inc. (MPR). Except for the three exceptions described in the paragraph below, the grantee research teams, IES staff, CDC staff, and contractor staff from MPR have no interests that could be affected by findings from the evaluation of the intervention programs that are described in this report.

Three of the SACD program research teams were led by and/or included personnel who had developed the intervention programs implemented at their respective research sites. Dr. William E. Pelham, Jr. and his colleagues developed the Academic and Behavioral Competencies Program, which was implemented in elementary schools in New York. The Competence Support Program, implemented in North Carolina schools, is made up of three distinct interventions (Making Choices, Competence Enhancement Behavior Management, and Classroom Social Dynamics Training). Dr. Mark W. Fraser and his colleagues developed the Making Choices program. Dr. Thomas W. Farmer and his colleagues developed the Competence Enhancement Behavior Management and the Social Dynamics Training programs. The Positive Action program was developed by Carol G. Allred, who is a member of the research team that implemented the program in schools in Illinois and is married to Dr. Brian R. Flay, the leader of that team.

All seven teams of researchers were selected to receive funding for their SACD research projects in a competitive grant application process. Each research team implemented its intervention and conducted sitespecific analysis examining the effects of these interventions on student outcomes. MPR, the evaluation study contractor, conducted independent evaluations of all the intervention programs that were included in the SACD study. A data collection team from MPR independently collected the data for the evaluation presented in this report with the exception of the fidelity of implementation data, which were collected by the seven teams. The MPR data analysis team completed all descriptive and impact analyses. The developers/implementers of these interventions did not conduct the impact analyses that are summarized in this report. 
This page is intentionally blank. 


\section{Glossary}

4Rs-The 4Rs Program (Reading, Writing, Respect, and Resolution)

$\mathrm{ABC}$ - Academic and Behavioral Competencies Program

ADHD—attention deficit hyperactivity disorder

CDC_-Centers for Disease Control and Prevention

combined-program—all seven programs together

CR—Child Report

CSP_Competence Support Program

DIR—Decision Information Resources, Inc., a subcontractor to Mathematica Policy Research, Inc. (MPR), the contractor selected to do the independent evaluation of the SACD programs

ES—effect size

HHS-U.S. Department of Health and Human Services

HLM-hierarchical linear model

ICC-intraclass correlation

IES-Institute of Education Sciences, U.S. Department of Education

LBW-Love In a Big World

leavers - students who left schools that were participating in the study before the study was completed

MANOVA—multivariate analysis of variance

MDES - minimum detectable effect size

middle childhood - the developmental period from 6 to 12 years of age

MPR - Mathematica Policy Research, Inc., the contractor selected to do the independent evaluation of the SACD programs

multiprogram evaluation - the evaluation of the impact of the seven SACD programs on students' social and character development. The evaluation looked at the average impact of all seven SACD programs combined and the average impact of each SACD program individually.

named activities - activities carried out in the context of a named SACD program to support students' social and character development

named program—a specific SACD program

new entrants—students who entered schools participating in the study after the study had begun

outcome domain - a set of outcomes grouped together because they measure a similar school activity, teacher instructional behavior, or student behavior 


\section{Glossary}

outcomes-what the SACD programs were expected to change regarding school activities, teacher instructional behavior, or student behavior

PA-Positive Action

PATHS—Promoting Alternative Thinking Strategies

PCR—Primary Caregiver Report

SACD—social and character development

SACD activities-activities to support students' social and character development

SACD goals-six specific goals defined by the SACD Research Program and promoted through the use of SACD activities to support students' social and character development. The goals are (1) violence prevention and peace promotion, (2) social and emotional development, (3) character education, (4) tolerance and diversity, (5) risk prevention and health promotion, and (6) civic responsibility and community service.

SACD program - a specific program that has the purpose of improving the social and character development of students

SACD Research Consortium - the researchers responsible for the SACD Research Program. These include staff at the Institute of Education Sciences (IES) in the U.S. Department of Education; the Division of Violence Prevention in the National Center for Injury Prevention and Control, Centers for Disease Control and Prevention (CDC); and Mathematica Policy Research, Inc. (MPR), the contractor, selected to do the independent evaluation of the SACD programs; as well as the seven research teams that received funding under cooperative agreements to evaluate one SACD program of their choosing under an experimental design.

SACD Research Program - a collaboration between the Institute of Education Sciences (IES) in the U.S. Department of Education and the Division of Violence Prevention in the National Center for Injury Prevention and Control, Centers for Disease Control and Prevention (CDC). Its purpose is to evaluate multiple universal, elementary school-based programs that target student social development and behavior outcomes.

SACD training-professional development for teachers on instructional methods to promote student social and character development

school-based program — a program delivered in a school setting

site - the set of schools, both treatment and control, specific to each individual SACD program evaluation

SS-Second Step

stayers—-students who were in schools participating in the study for the entire study

targeted school-based programs-programs that are designed to address the needs of a subset of the children in a school

TRCS—Teacher Report on Classroom and School

TRS_-Teacher Report on Student

universal programs - programs that are designed to address the needs of all children in a school

WWC- the What Works Clearinghouse 


\section{Contents}

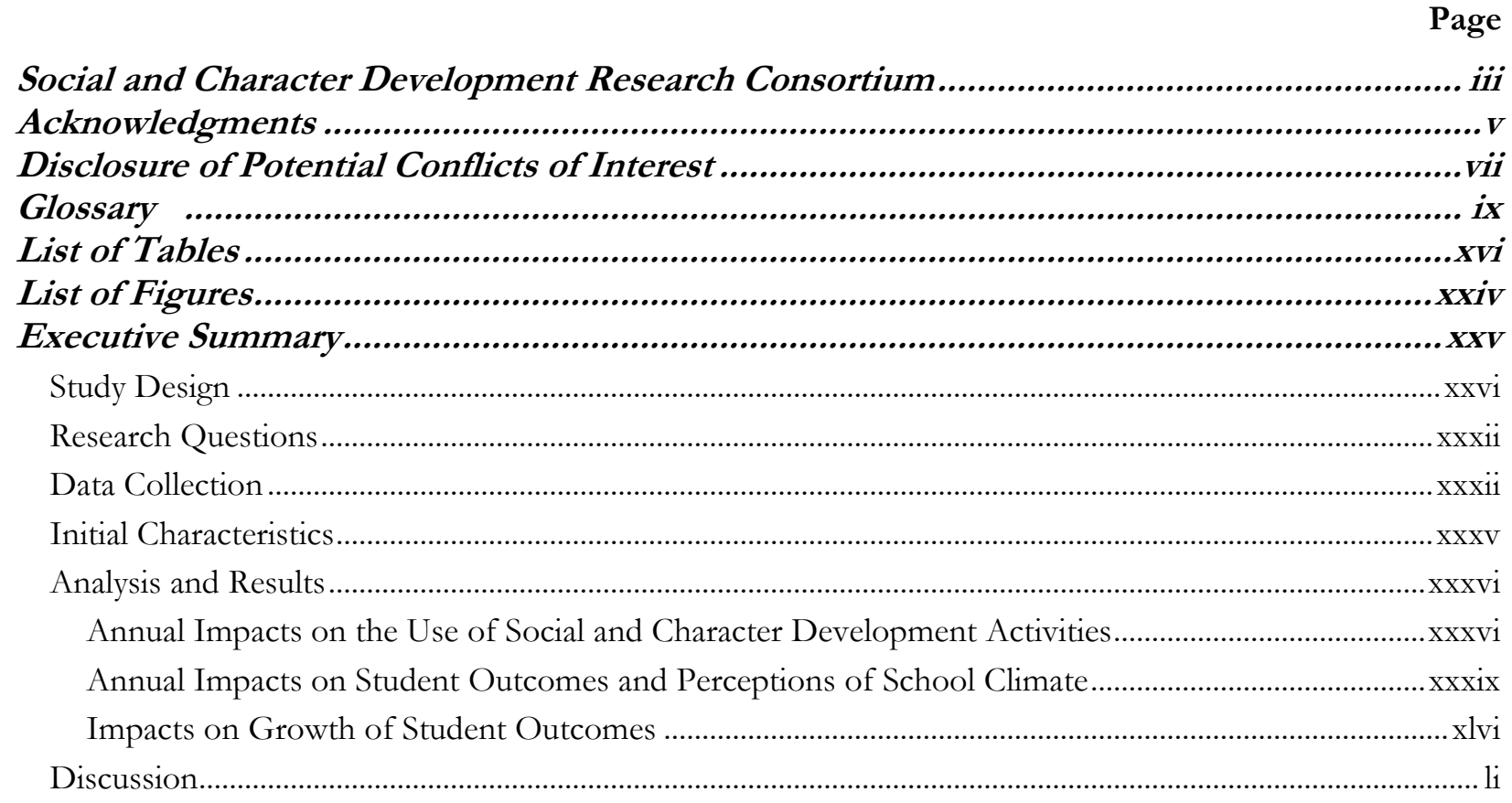

Chapter 1. The Social and Character Development Multiprogram Evaluation....................... 1

Social Development and Risk Prevention ................................................................................................ 3

Universal School-Based Social and Character Development Programs............................................................. 4

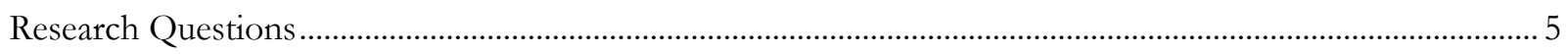

The Social and Character Development Research Program ........................................................................... 8

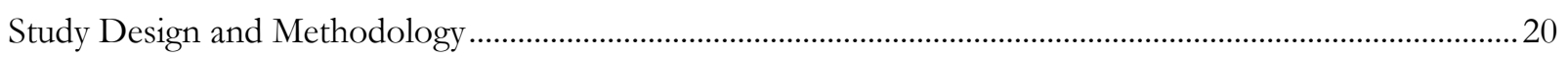

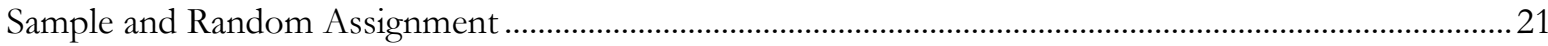

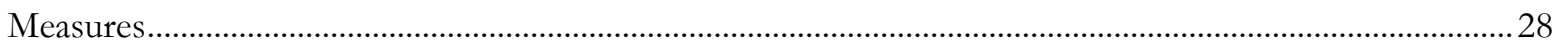

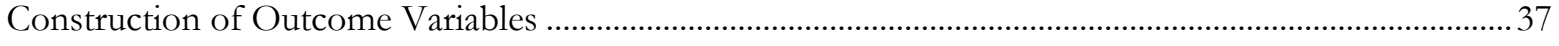

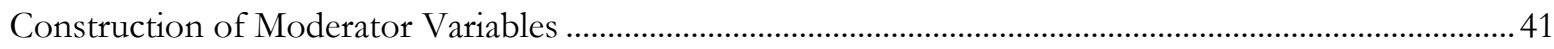

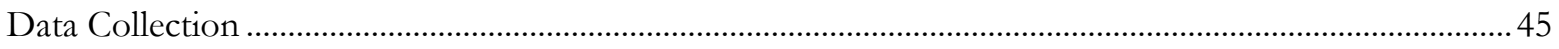

Consent Rates, Completion Rates, and Percentage of Sample With Data................................................... 49

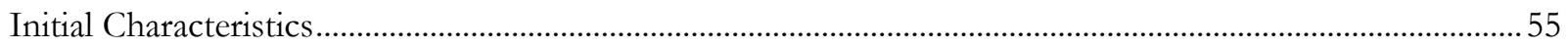

Characteristics of Children, Their Families, and Communities ....................................................................5 55

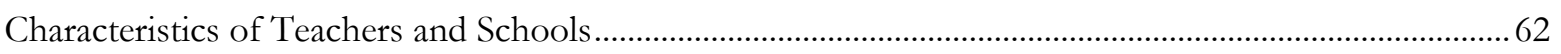

The Initial Level of Social and Character Development Activities in the Schools ......................................65

Year-by-Year Impacts on Use of Social and Character Development Activities .............................................. 70

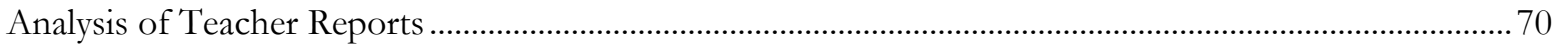

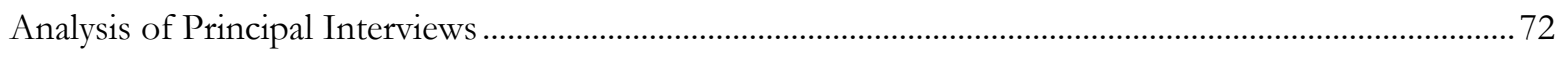

Results From Teacher Reports............................................................................................................ 72 


\section{Contents}

Page

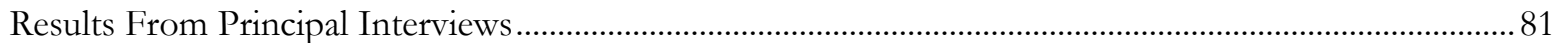

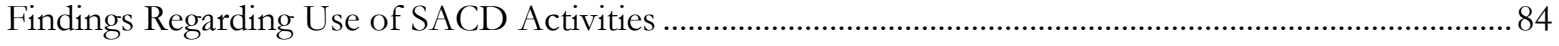

Year-by-Year Impacts on Students and Perceptions of School Climate ............................................................ 85

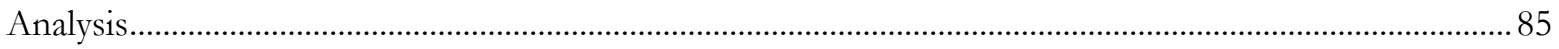

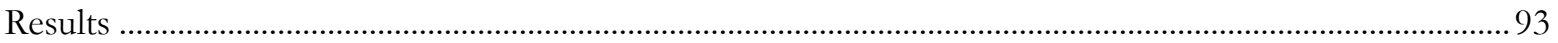

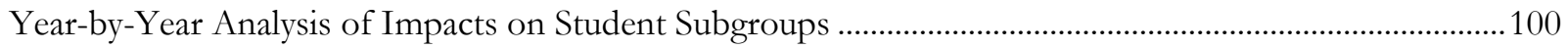

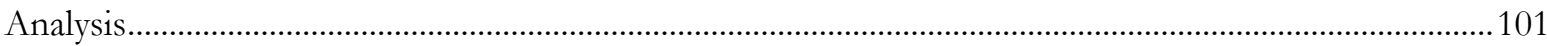

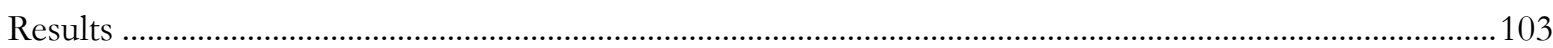

Summary of Results Regarding Year-by-Year Impacts ..............................................................................127

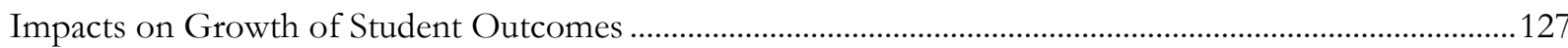

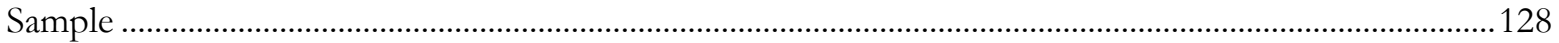

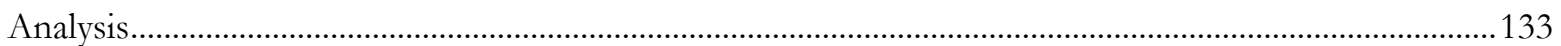

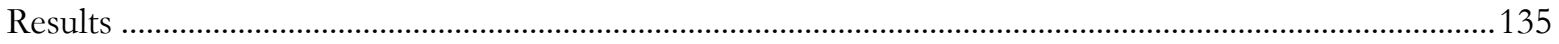

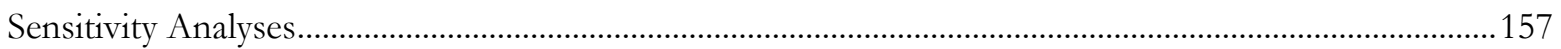

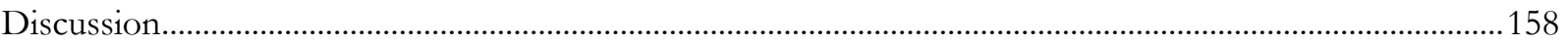

Chapter 2. Academic and Behavioral Competencies Program....................................... 163

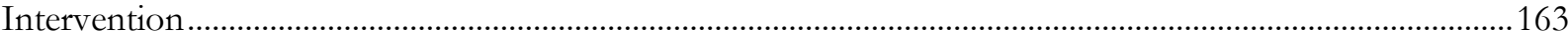

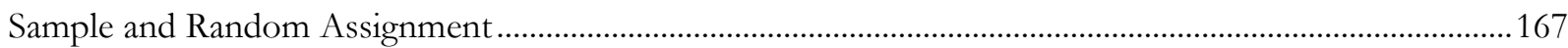

Implementation

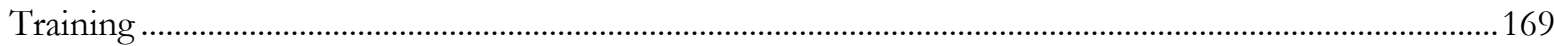

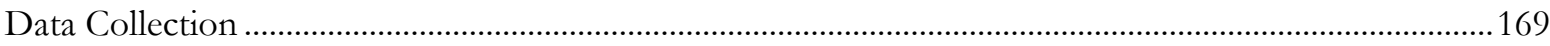

Consent Rates, Completion Rates, and Percentage of Sample With Data..................................................171

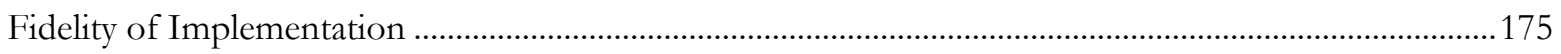

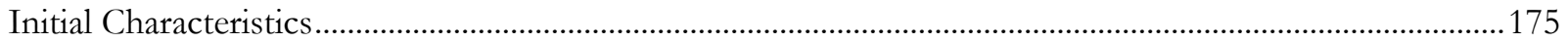

Characteristics of Children, Their Families, and Communities ..............................................................175

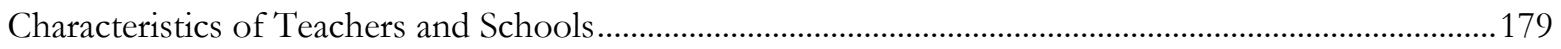

The Level of SACD in the Schools Near the Beginning of the Study ......................................................181

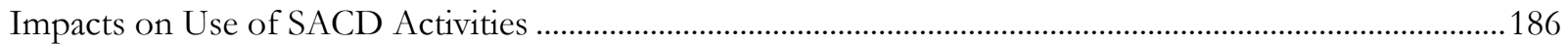

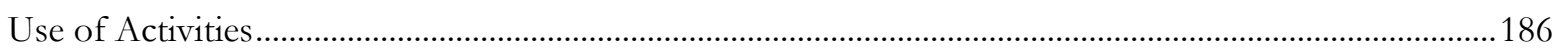

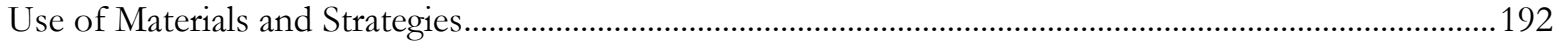

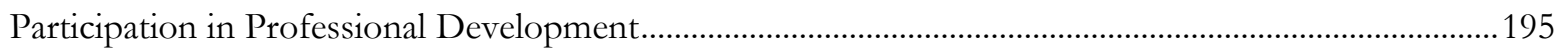

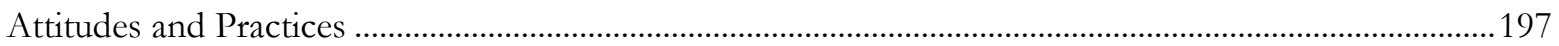

Year-by-Year Impacts on Students and Perceptions of School Climate ........................................................197

Impacts on Child Outcomes Over Time.....................................................................................................2205

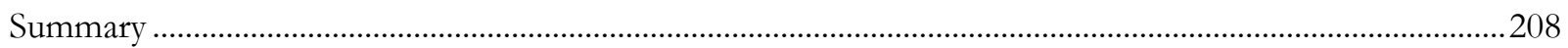

Chapter 3. Competence Support Program ..........................................................211

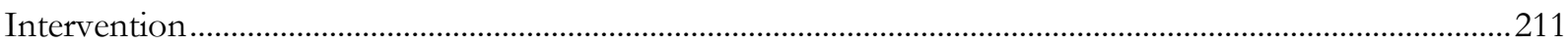

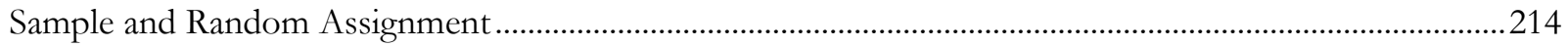

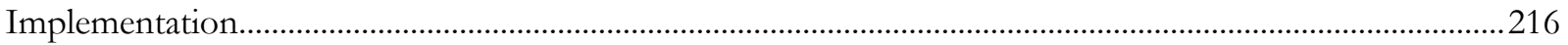

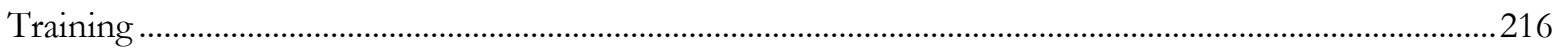




\section{Contents}

Page

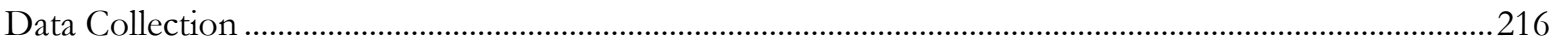

Consent Rates, Completion Rates, and Percentage of Sample With Data ..................................................218

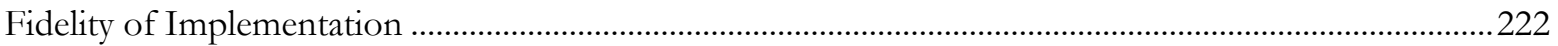

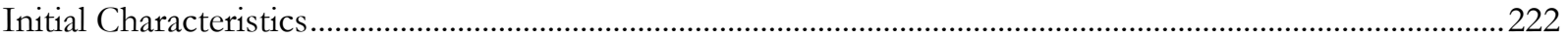

Characteristics of Children, Their Families, and Communities ................................................................222

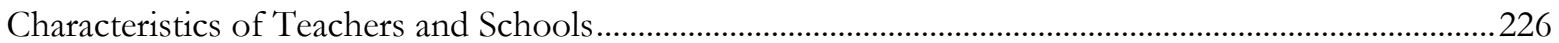

The Level of SACD in the Schools Near the Beginning of the Study ........................................................227

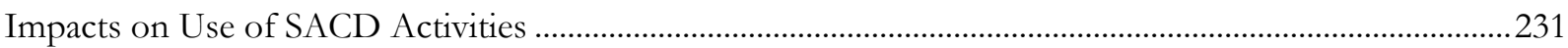

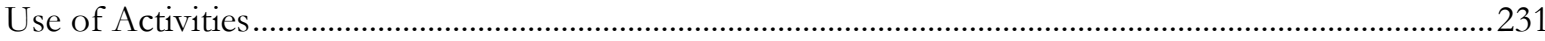

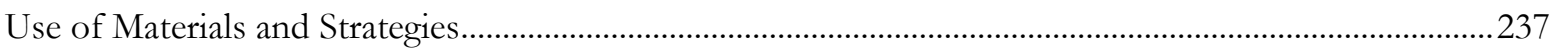

Participation in Professional Development.........................................................................................240

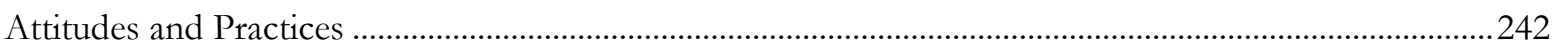

Year-by-Year Impacts on Students and Perceptions of School Climate ........................................................242

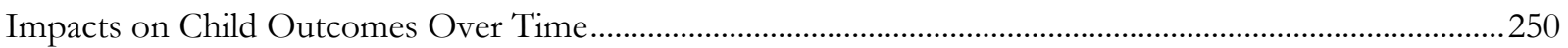

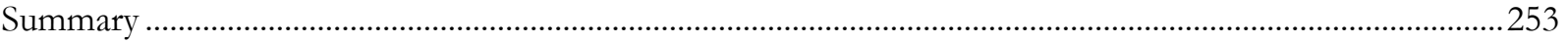

Chapter 4. Love In a Big World.................................................................... 255

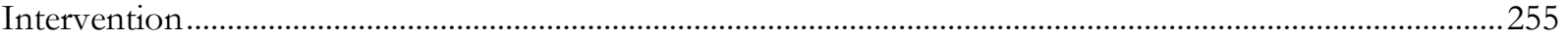

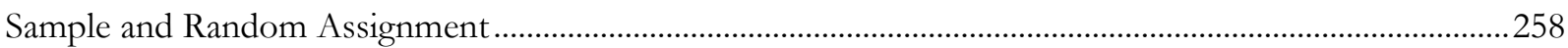

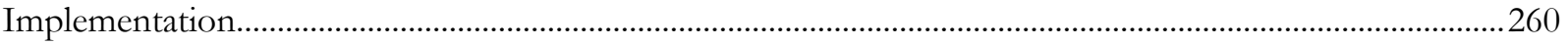

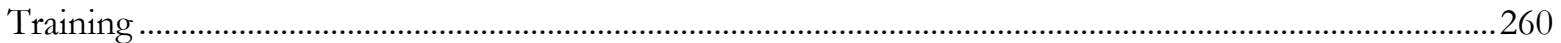

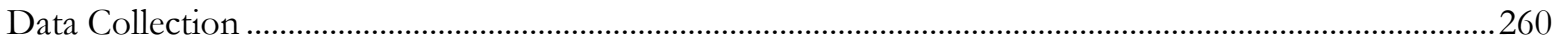

Consent Rates, Completion Rates, and Percentage of Sample With Data..................................................262

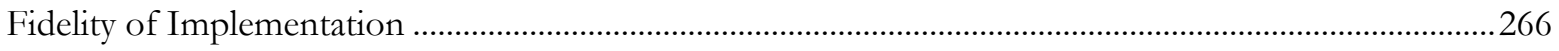

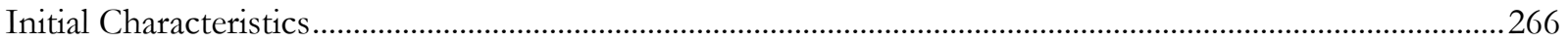

Characteristics of Children, Their Families, and Communities …………................................................266

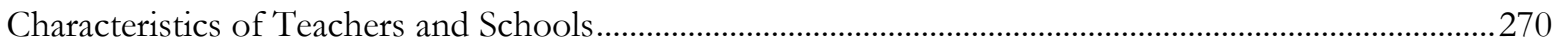

The Level of SACD in the Schools Near the Beginning of the Study .......................................................271

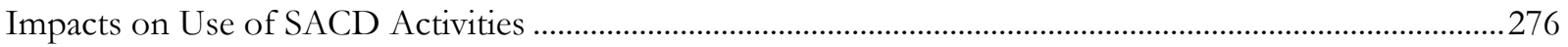

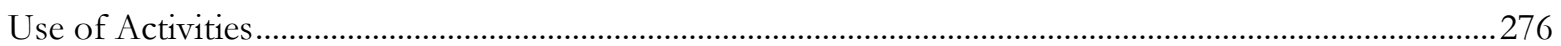

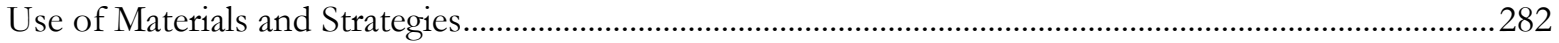

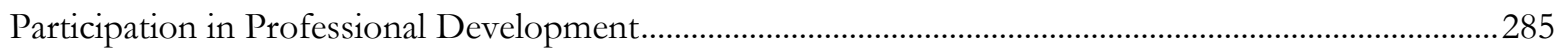

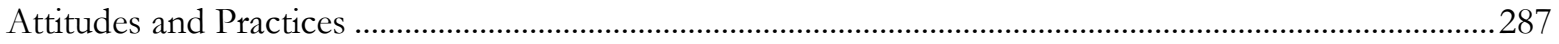

Year-by-Year Impacts on Students and Perceptions of School Climate ......................................................287

Impacts on Child Outcomes Over Time................................................................................................29

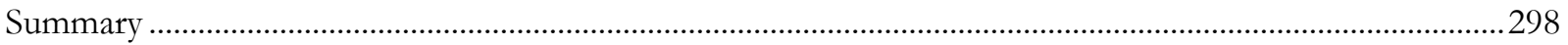

Chapter 5. Positive Action ...................................................................... 301

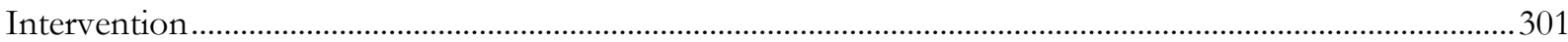

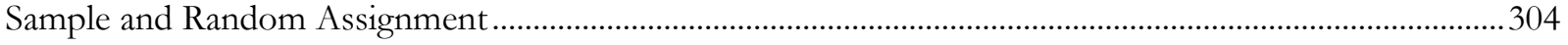

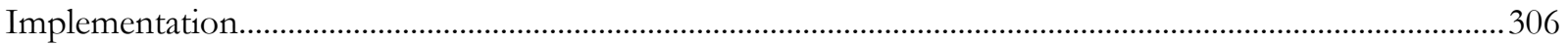

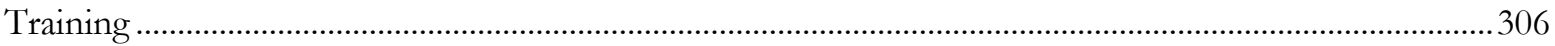

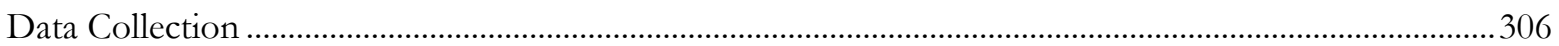




\section{Contents}

Page

Consent Rates, Completion Rates, and Percentage of Sample With Data.................................................308

Fidelity of Implementation ........................................................................................................... 312

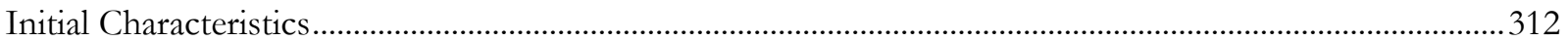

Characteristics of Children, Their Families, and Communities .................................................................312

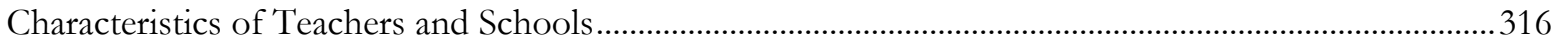

The Level of SACD in the Schools Near the Beginning of the Study ..........................................................317

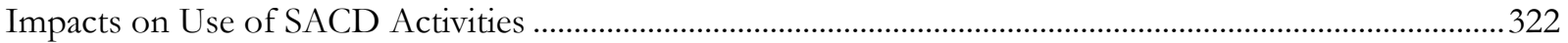

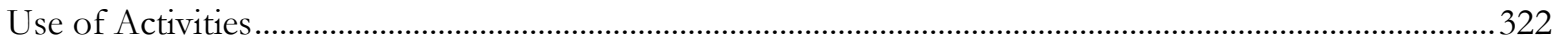

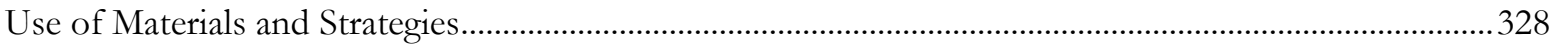

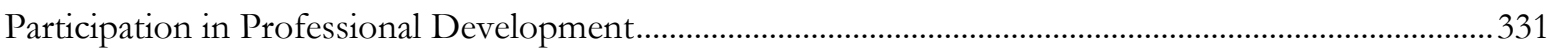

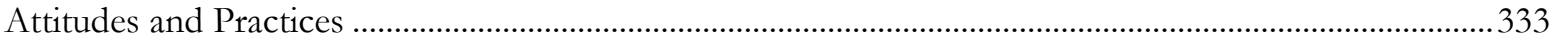

Year-by-Year Impacts on Students and Perceptions of School Climate ……...................................................333

Impacts on Child Outcomes Over Time ................................................................................................ 341

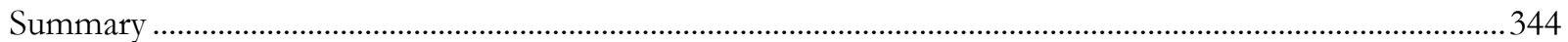

Chapter 6. Promoting Alternative Thinking Strategies (PATHS) ..................................347

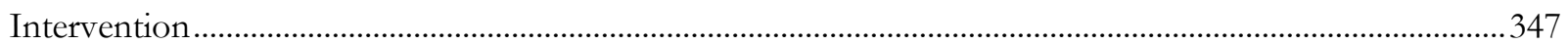

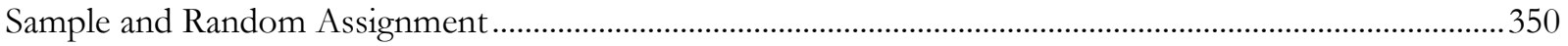

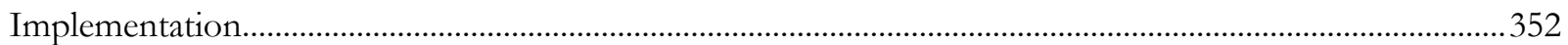

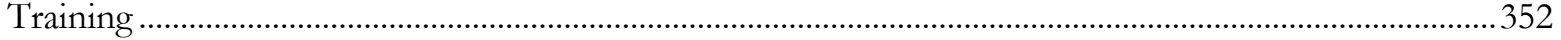

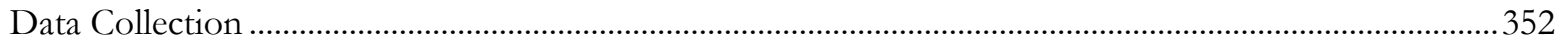

Consent Rates, Completion Rates, and Percentage of Sample With Data..................................................353

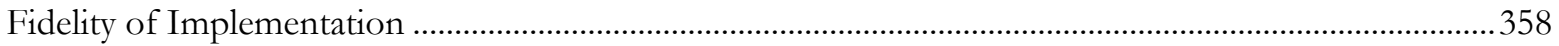

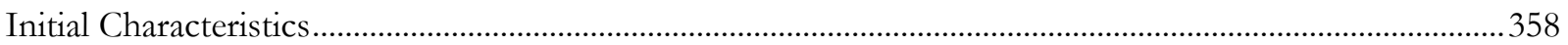

Characteristics of Children, Their Families, and Communities ....................................................................358

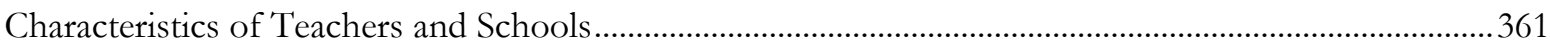

The Level of SACD in the Schools Near the Beginning of the Study ........................................................363

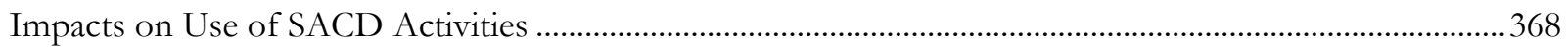

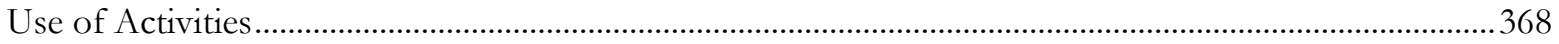

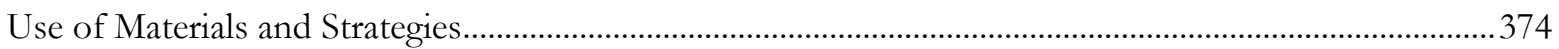

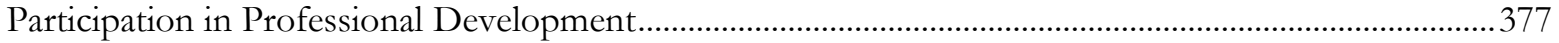

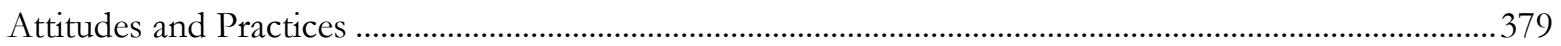

Year-by-Year Impacts on Students and Perceptions of School Climate ...........................................................379

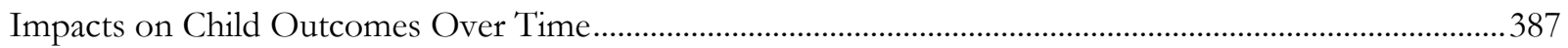

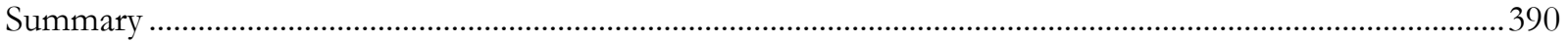

Chapter 7. The 4Rs Program (Reading, Writing, Respect, and Resolution)..................... 393

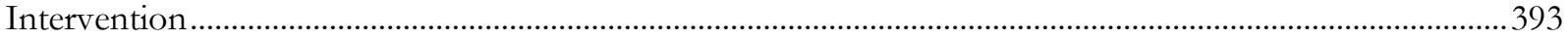

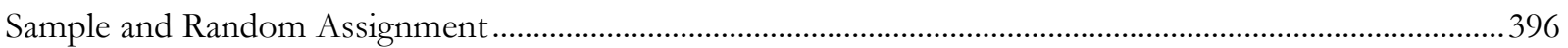

Implementation

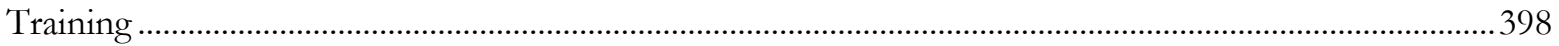

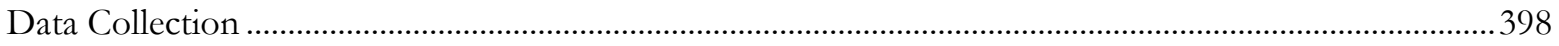

Consent Rates, Completion Rates, and Percentage of Sample With Data.................................................400 


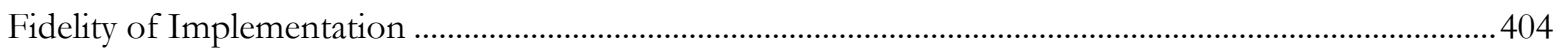

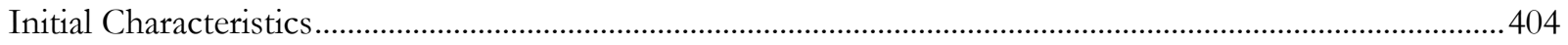

Characteristics of Children, Their Families, and Communities ..................................................................404

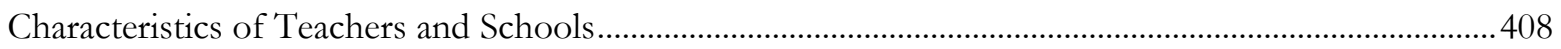

The Level of SACD in the Schools Near the Beginning of the Study ..........................................................409

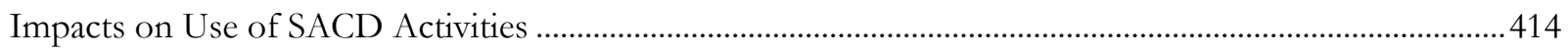

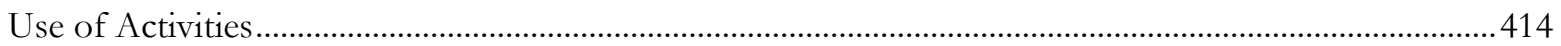

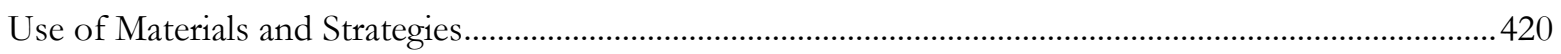

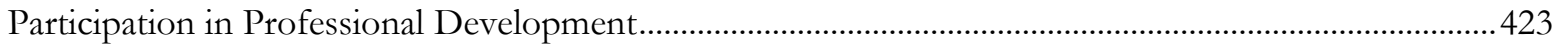

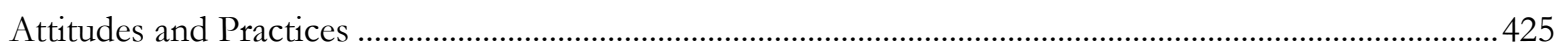

Year-by-Year Impacts on Students and Perceptions of School Climate .........................................................425

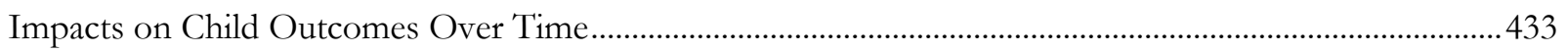

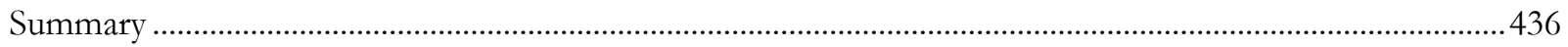

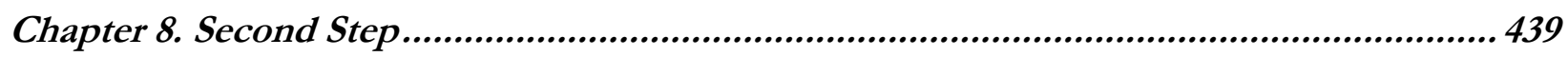

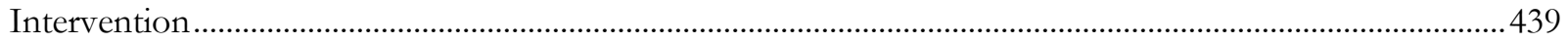

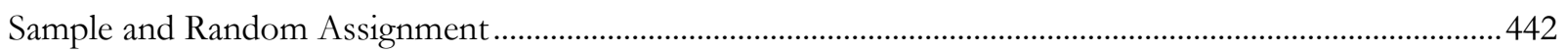

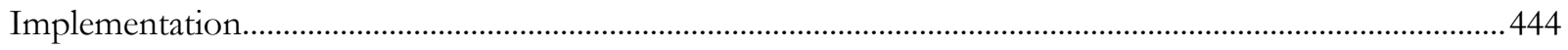

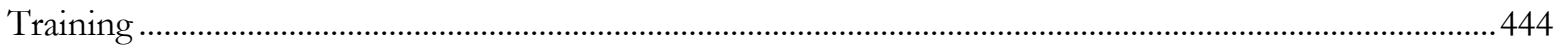

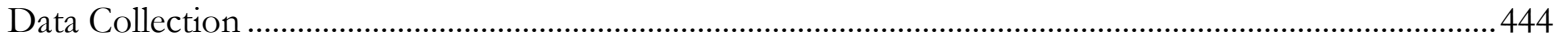

Consent Rates, Completion Rates, and Percentage of Sample With Data.................................................445

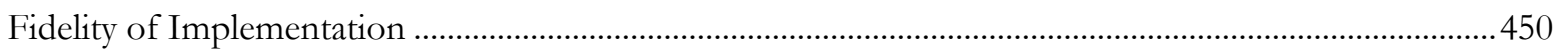

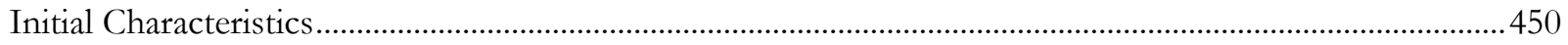

Characteristics of Children, Their Families, and Communities ................................................................ 450

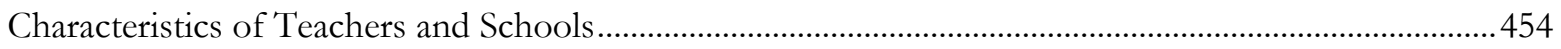

The Level of SACD in the Schools Near the Beginning of the Study .........................................................45

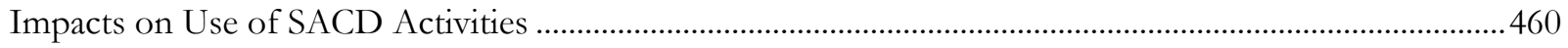

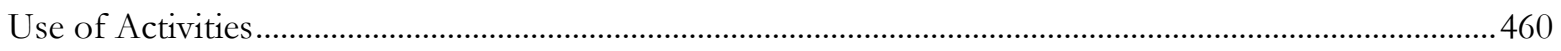

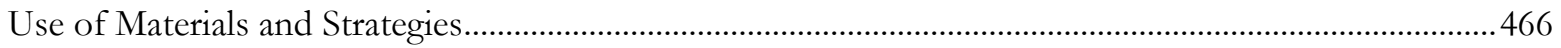

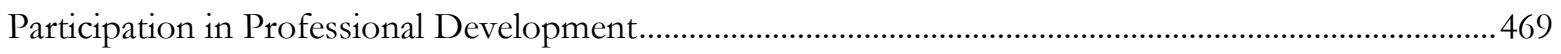

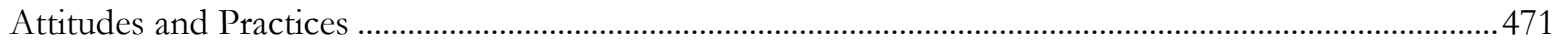

Year-by-Year Impacts on Students and Perceptions of School Climate ..........................................................471

Impacts on Child Outcomes Over Time ......................................................................................................

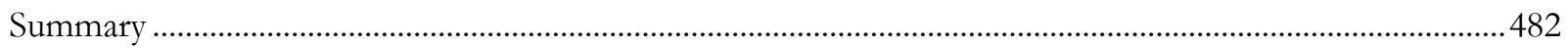

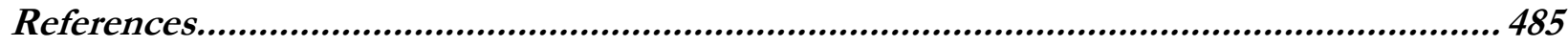

Appendix A: Analysis of Cohorts 1 and 2 ........................................................... A

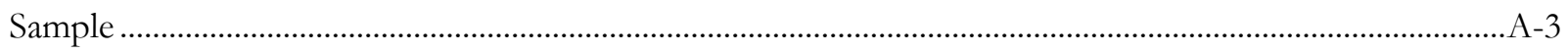

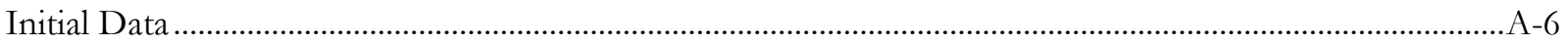

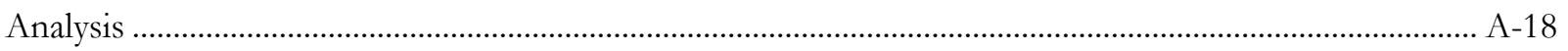

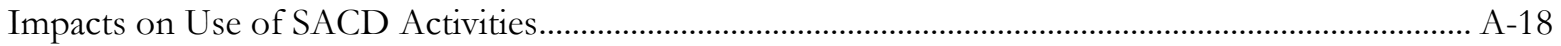


Impacts on Student Outcomes: Year-by-Year and Growth Analyses Results A-23

Growth Analysis

Summary A-45

Appendix B: Technical Notes on the Development of Outcome Measures, Selection of Covariates, Construction of Sample Weights, and Sensitivity Analyses...........................B-1

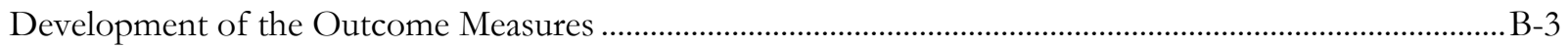

Confirmatory Factor Analyses of Student-Level Outcome Measures ............................................................ B-4

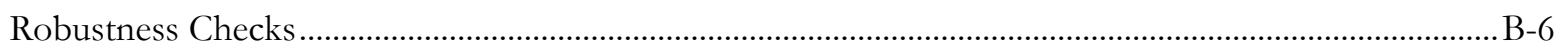

Construct and Reporter-Based Variance …………....................................................................... B-8

Psychometric Properties of School-Level Outcome Measures................................................................... B-8

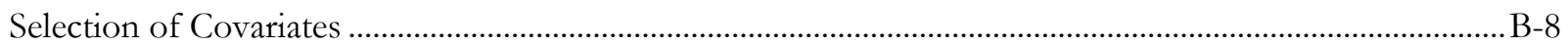

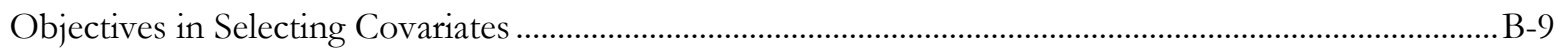

Tailoring Covariates to Specific Outcomes and Sites ................................................................................ B-9

Implementation of the Covariate Selection Procedure …………............................................................. B-10

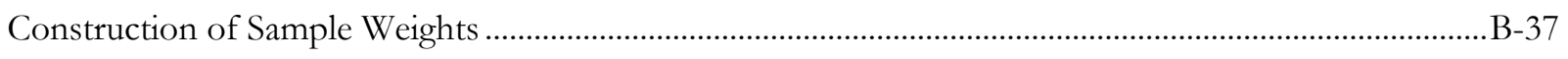

Base Weights .........................................................................................................................

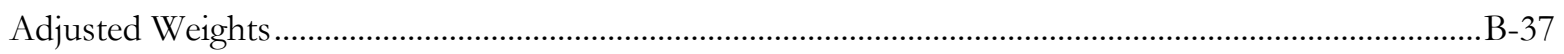

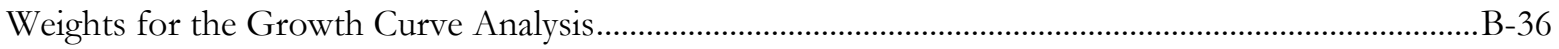

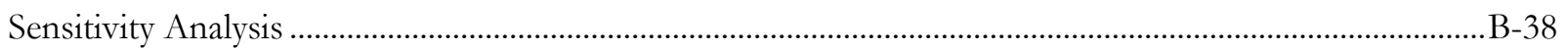

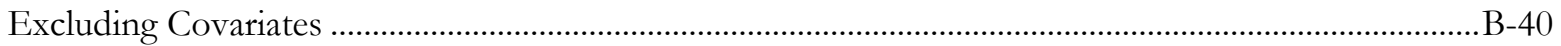

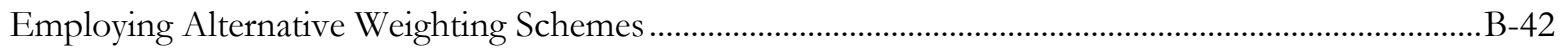

Including Classroom-Level Random Effects in the Error Structure ........................................................ B-45

Accounting for the Pairwise Matching of Schools .....................................................................................

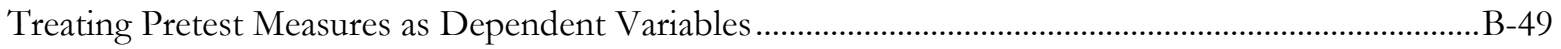

Using Alternative Software Packages …………………….................................................................... B-52

Imputing Missing Outcomes ..............................................................................................................

Averaging Program-Level Impact Estimates …………......................................................................

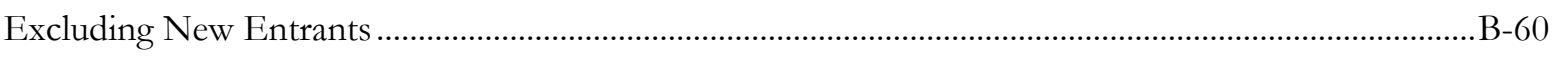

Including Restricted Sets of Covariates in the Regression Models ........................................................... B-61

\section{List of Tables}

Table

Page

Executive Summary

A. Research teams, SACD programs, and number of schools

xxvii

B. Student sample, overall and by program, for all students and for the treatment and control groups xxviii

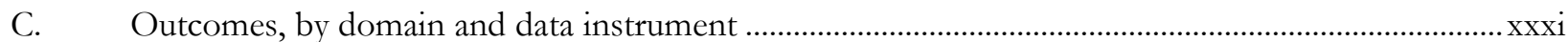

D. Consent rates, completion rates, and percentage of sample with data from each report .................xxxiv

E. Significant impacts on use of SACD activity domains, overall and by program ..............................xxxviii 


\section{List of Tables}

Table

Page

F. Significant impacts on student outcomes, overall and by program, for all 3 years

xlii

G. Individual program statistically significant impacts and nonsignificant but substantively important impacts...........................................................................................................................................

H. Impacts on growth of child outcomes from combined-program analysis ......................................... xlviii

I. Significant impacts from the growth curve analyses of the individual programs .....................................

\section{Chapter 1. The Social and Character Development Multiprogram Evaluation}

1.1. Social and Character Development programs.................................................................................. 9

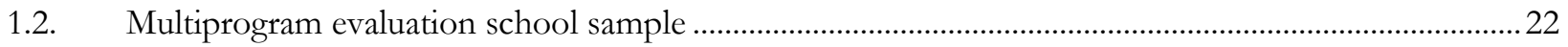

1.3. Characteristics of the student sample in the multiprogram evaluation ..................................................22

1.4. Student sample, overall and by program, for all students and for the treatment and control groups .26

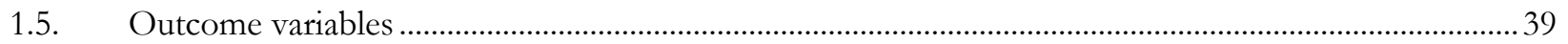

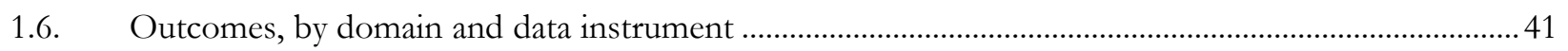

1.7. Fidelity ratings of program implementation at treatment schools ..........................................................4 44

1.8. Period between implementation and data collection and between data collections, by program ......... 47

1.9. Consent rates, completion rates, and percentage of sample with data from each report .....................51

1.10. Consent rates, completion rates, and percentage of sample with data: Stayers versus new entrants ... 52

1.11. Percentage of sample with data, by report and program........................................................................53

1.12. Initial characteristics of children, their families, and communities ........................................................57

1.13. Mean scores and standard deviations for initial outcome measures ........................................................60

1.14. Mean scores and standard deviations for initial risk factors .................................................................61

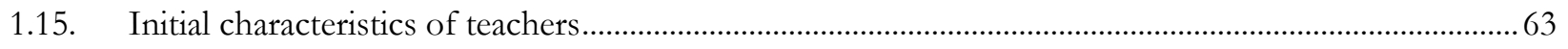

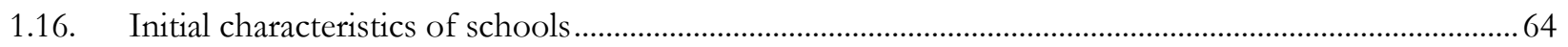

1.17. Principal and teacher initial reports on use of SACD programs or activities ..........................................66

1.18. Teacher initial reports on use of SACD materials and classroom strategies...........................................68

1.19. Principal and teacher initial reports on SACD professional development.............................................69

1.20. Impacts on teacher-reported SACD classroom activities .......................................................................74

1.21. Impacts on use of SACD classroom materials and teaching strategies...................................................... 77

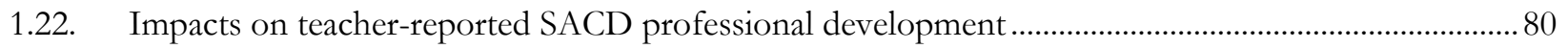

1.23. Significant impacts on use of SACD activity domains, overall and by program .................................... 82

1.24. Covariates used with outcomes from each report for combined-program analysis .............................. 88

1.25. Adjusted minimum detectable effect sizes for combined-program impact evaluation ......................... 92

1.26. Combined-program impacts on outcomes ............................................................................................ 94

1.27. Individual program statistically significant impacts and nonsignificant but substantively important

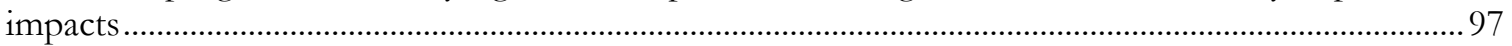

1.28. Combined-program impacts on child outcomes, by gender................................................................. 105

1.29. Combined-program impacts on child outcomes, by stayer versus new entrant..................................108

1.30. Combined-program impacts on child outcomes, by initial socioeconomic risk ..................................111

1.31. Combined-program impacts on child outcomes, by initial family risk ................................................114

1.32. Combined-program impacts on child outcomes, by initial perceptions of community risk ...............117 


\section{List of Tables}

Table

1.33. Combined-program impacts on child outcomes, by initial child behavior risk as reported by teacher.

1.34. Combined-program impacts on child outcomes, by child behavior risk as reported by primary caregiver..

1.35. Combined-program results for child outcomes, by fidelity of implementation

1.36. Growth curve analysis sample size, percentage of sample universe, and percentage of initial sample

1.37. Child-level outcomes, by survey period and treatment group status...................................................131

1.38. Impacts on growth of child outcomes from combined-program analysis ...........................................136

1.39. Significant impacts from the growth curve analyses of the individual programs ..................................138

1.40. Impacts on growth of child outcomes, by gender, from combined-program analysis ........................139

1.41. Impacts on growth of child outcomes for new entrants versus original members, from combinedprogram analysis

1.42. Impacts on growth of child outcomes, by initial socioeconomic risk …...............................................144

1.43. Impacts on growth of child outcomes, by initial family risk..................................................................146

1.44. Impacts on growth of child outcomes, by initial perceptions of community risk...............................148

1.45. Impacts on growth of child outcomes, by child behavior risk as reported by teacher.........................150

1.46. Impacts on growth of child outcomes, by child behavior risk as reported by primary caregiver....... 152

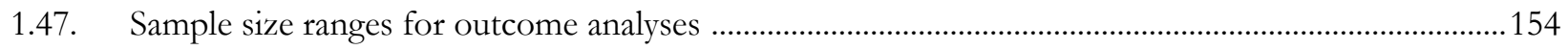

\section{Chapter 2. Academic and Behavior Competencies Program}

2.1. Academic and Behavior Competencies Program ……....................................................................................165

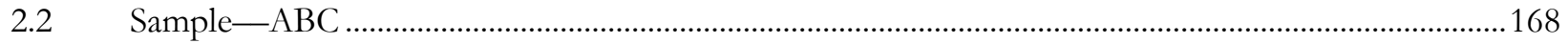

2.3. Data collection dates-ABC ...................................................................................................... 170

2.4. Consent rates, completion rates, and percentage of sample with data from each report-ABC.......172

2.5. Consent rates, completion rates, and percentage of sample with data: Stayers versus new

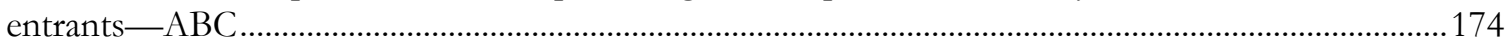

2.6. Initial characteristics of children, their families, and communities - ABC .......................................176

2.7. Mean scores and standard deviations for initial outcome measures of sample-ABC.......................178

2.8. Initial characteristics of teachers in sample - ABC ............................................................................. 180

2.9. Initial characteristics of schools in sample-ABC ...........................................................................181

2.10. Principal and teacher initial reports on use of SACD programs or activities in sample-ABC........182

2.11. Teacher initial reports on use of SACD materials and classroom strategies in sample-ABC ..........184

2.12. Principal and teacher initial reports on SACD professional development in sample - ABC .............185

2.13. Impacts on teacher-reported SACD classroom activities_ABC .........................................................188

2.14. Impacts on use of SACD classroom materials and teaching strategies_ABC ..................................193

2.15. Impacts on teacher-reported SACD professional development-ABC..............................................196

2.16. Covariates used with outcomes from each report for analysis_ ABC …………...................................198

2.17. Adjusted minimum detectable effect sizes for impact evaluation — ABC ..............................................201

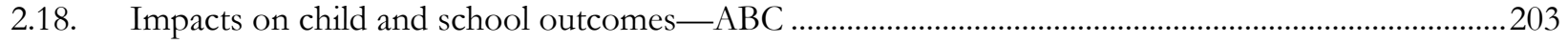

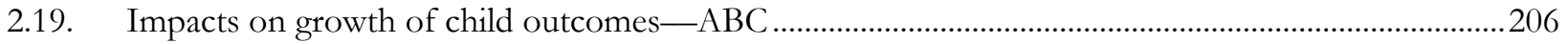




\section{Chapter 3. Competence Support Program}

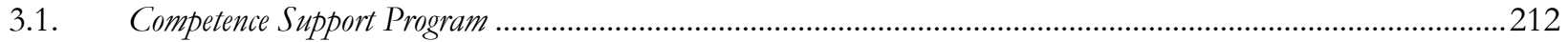

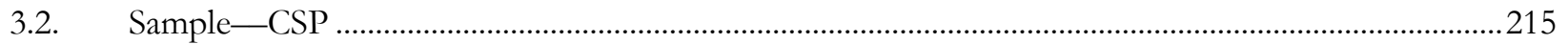

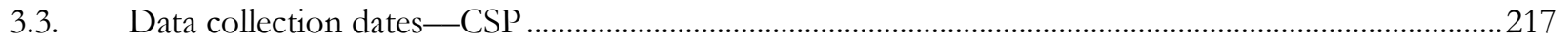

3.4. Consent rates, completion rates, and percentage of sample with data from each report —CSP ........219

3.5. Consent rates, completion rates, and percentage of sample with data: Stayers versus new

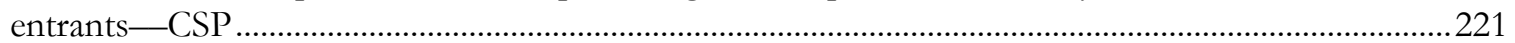

3.6. Initial characteristics of children, their families, and communities - CSP.........................................223

3.7. Mean scores and standard deviations for initial outcome measures of sample - CSP ........................225

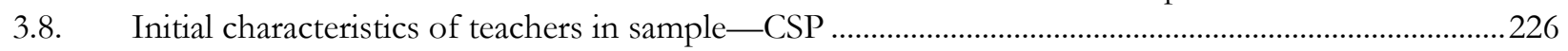

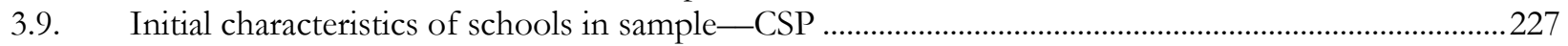

3.10. Principal and teacher initial reports on use of SACD programs or activities in sample-CCSP ..........228

3.11. Teacher initial reports on use of SACD materials and classroom strategies in sample - CSP............229

3.12. Principal and teacher initial reports on SACD professional development in sample-CSP...............230

3.13. Impacts on teacher-reported SACD classroom activities - CSP .........................................................233

3.14. Impacts on use of SACD classroom materials and teaching strategies - CSP .....................................238

3.15. Impacts on teacher-reported SACD professional development_CSP .................................................241

3.16. Covariates used with outcomes from each report for analysis — CSP ...................................................243

3.17. Adjusted minimum detectable effect sizes for impact evaluation —CSP ..............................................246

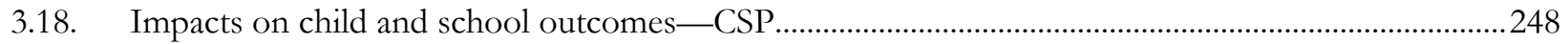

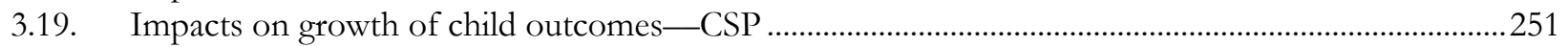

\section{Chapter 4. Love In a Big World}

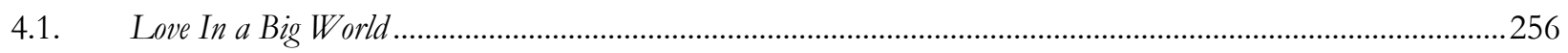

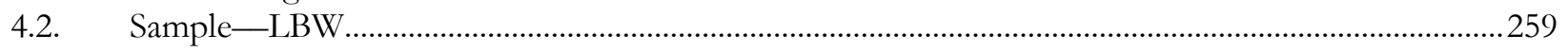

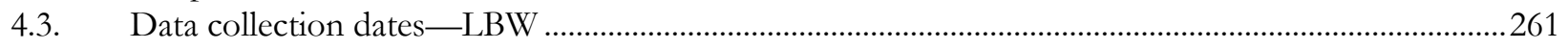

4.4. Consent rates, completion rates, and percentage of sample with data from each repor-LBW ........263

4.5. Consent rates, completion rates, and percentage of sample with data: Stayers versus new

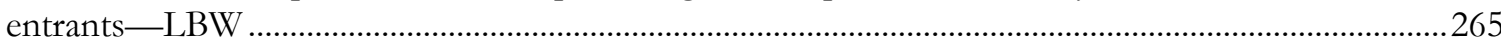

4.6. Initial characteristics of children, their families, and communities — LBW ........................................267

4.7. Mean scores and standard deviations for initial outcome measures of sample-LBW ......................269

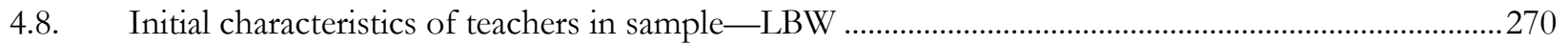

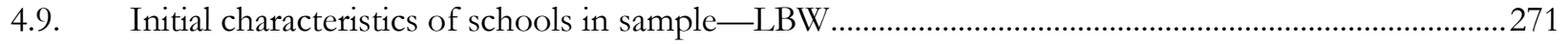

4.10. Principal and teacher initial reports on use of SACD programs or activities in sample--LBW ........272

4.11. Teacher initial reports on use of SACD materials and classroom strategies in sample-LBW..........274

4.12. Principal and teacher initial reports on SACD professional development in sample-LBW .............275

4.13. Impacts on teacher-reported SACD classroom activities - LBW ........................................................278

4.14. Impacts on use of SACD classroom materials and teaching strategies_- LBW ...................................283

4.15. Impacts on teacher-reported SACD professional development-LBW ...............................................286

4.16. Covariates used with outcomes from each report for analysis_LBW ..................................................28

4.17. Adjusted minimum detectable effect sizes for impact evaluation — LBW ............................................291

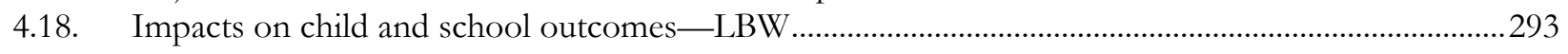

4.19. Impacts on growth of child outcomes — LBW ..................................................................................296 


\section{Chapter 5. Positive Action}

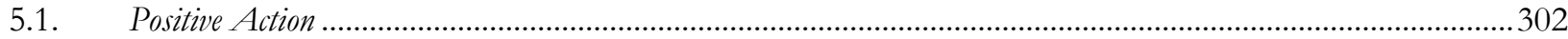

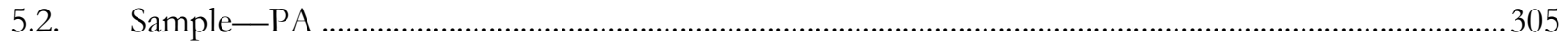

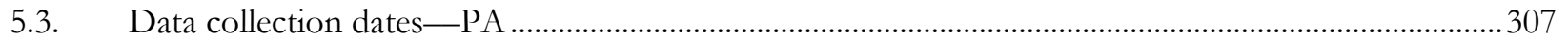

5.4. Consent rates, completion rates, and percentage of sample with data from each report-PA .309

5.5. Consent rates, completion rates, and percentage of sample with data: Stayers versus new

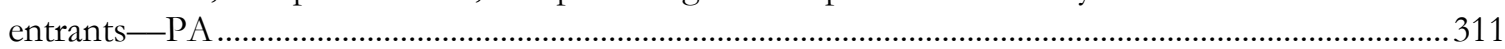

5.6. Initial characteristics of children, their families, and communities_-PA..............................................313

5.7. Mean scores and standard deviations for initial outcome measures of sample-PA..........................315

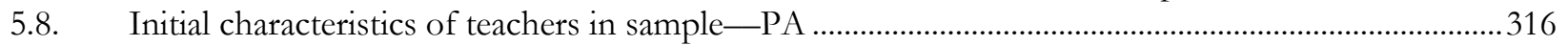

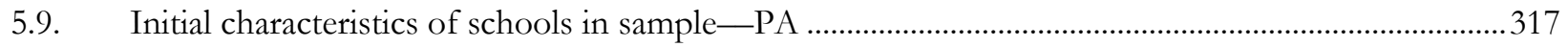

5.10. Principal and teacher initial reports on use of SACD programs or activities in sample_-PA ............318

5.11. Teacher initial reports on use of SACD materials and classroom strategies in sample-PA..............320

5.12. Principal and teacher initial reports on SACD professional development in sample-PA..................321

5.13. Impacts on teacher-reported SACD classroom activities-PA ..............................................................324

5.14. Impacts on use of SACD classroom materials and teaching strategies - PA ......................................329

5.15. Impacts on teacher-reported SACD professional development-PA..................................................332

5.16. Covariates used with outcomes from each report for analysis_-PA........................................................334

5.17. Adjusted minimum detectable effect sizes for impact evaluation — PA .................................................337

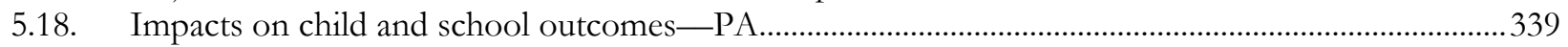

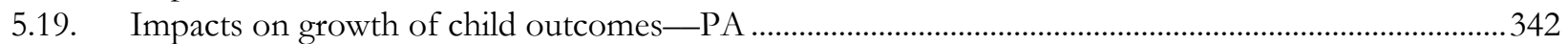

\section{Chapter 6. Promoting Alternative Thinking Strategies (PATHS)}

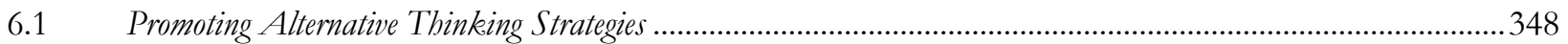

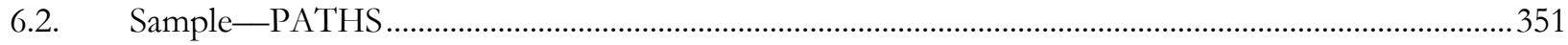

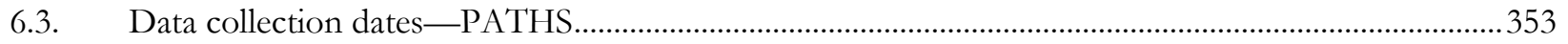

6.4. Consent rates, completion rates, and percentage of sample with data from each

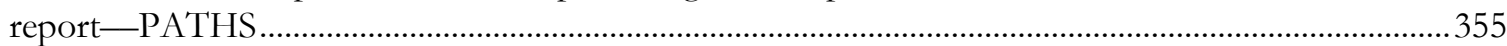

6.5. Consent rates, completion rates, and percentage of sample with data: Stayers versus new

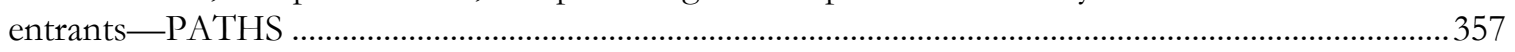

6.6. Initial characteristics of children, their families, and communities_-PATHS .....................................359

6.7. Mean scores and standard deviations for initial outcome measures of sample-PATHS ..................361

6.8. Initial characteristics of teachers in sample_PATHS ............................................................................362

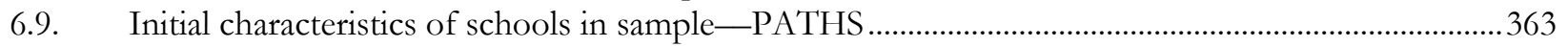

6.10. Principal and teacher initial reports on use of SACD programs or activities in sample--PATHS....364

6.11. Teacher initial reports on use of SACD materials and classroom strategies in sample-PATHS .....366

6.12. Principal and teacher initial reports on SACD professional development in sample-PATHS .........367

6.13. Impacts on teacher-reported SACD classroom activities_-PATHS ..........................................................

6.14. Impacts on use of SACD classroom materials and teaching strategies_-PATHS ...............................375

6.15. Impacts on teacher-reported SACD professional development-PATHS .........................................378

6.16. Covariates used with outcomes from each report for analysis_-PATHS ..............................................380

6.17. Adjusted minimum detectable effect sizes for impact evaluation_-PATHS ........................................383

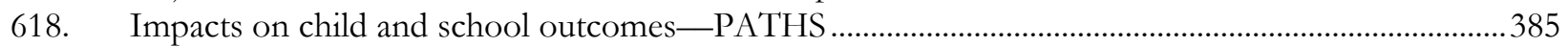

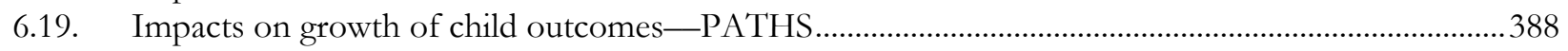




\section{Chapter 7. The 4Rs Program (Reading, Writing, Respect, and Resolution)}

7.1 The 4Rs Program (Reading, Writing, Respect, and Resolution) .......................................................................394

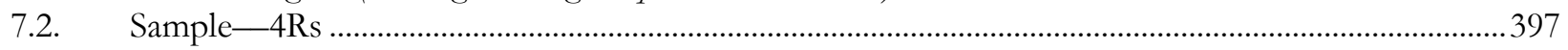

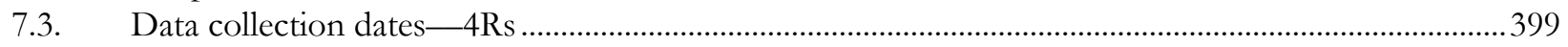

7.4. Consent rates, completion rates, and percentage of sample with data from each report - 4Rs .........401

7.5. Consent rates, completion rates, and percentage of sample with data: Stayers versus new

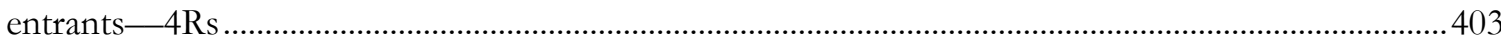

7.6. Initial characteristics of children, their families, and communities - 4Rs.............................................405

7.7. Mean scores and standard deviations for initial outcome measures of sample-4Rs .........................407

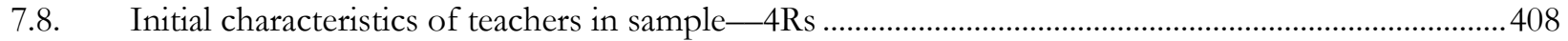

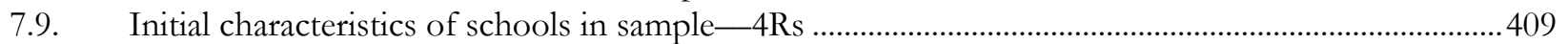

7.10. Principal and teacher initial reports on use of SACD programs or activities in sample-_-4Rs ...........410

7.11. Teacher initial reports on use of SACD materials and classroom strategies in sample-4Rs.............412

7.12. Principal and teacher initial reports on SACD professional development in sample - 4Rs................413

7.13. Impacts on teacher-reported SACD classroom activities - 4Rs ...............................................................416

7.14. Impacts on use of SACD classroom materials and teaching strategies - 4Rs .....................................421

7.15. Impacts on teacher-reported SACD professional development - 4Rs..................................................424

7.16. Covariates used with outcomes from each report for analysis_-4Rs......................................................426

7.17. Adjusted minimum detectable effect sizes for impact evaluation — 4Rs ...............................................429

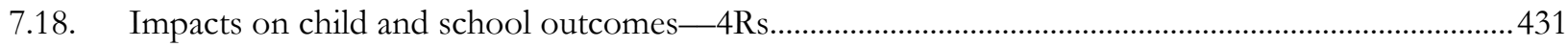

7.19. Impacts on growth of child outcomes - 4Rs ..................................................................................... 434

\section{Chapter 8. Second Step}

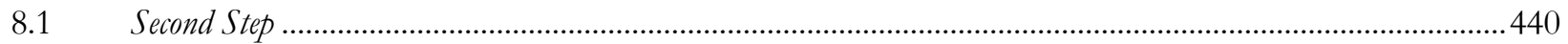

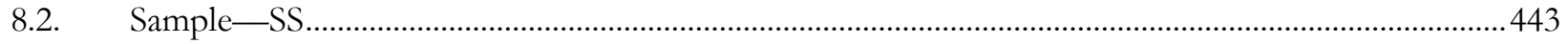

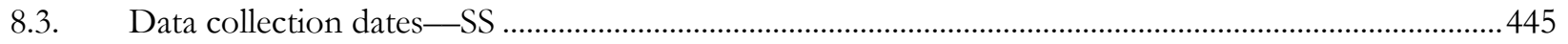

8.4. Consent rates, completion rates, and percentage of sample with data from each report - SS ...........447

8.5. Consent rates, completion rates, and percentage of sample with data: Stayers versus new entrants-SS.

8.6. Initial characteristics of children, their families, and communities_SS .............................................. 451

8.7. Mean scores and standard deviations for initial outcome measures of sample - SS ........................... 453

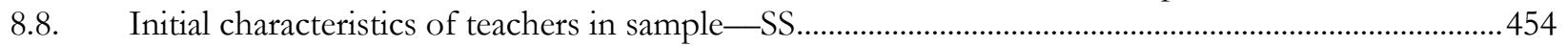

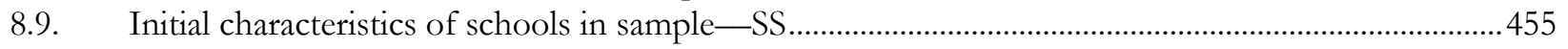

8.10. Principal and teacher initial reports on use of SACD programs or activities in sample-_SS .............456

8.11. Teacher initial reports on use of SACD materials and classroom strategies in sample-SS...............458

8.12. Principal and teacher initial reports on SACD professional development in sample-SS.................459

8.13. Impacts on teacher-reported SACD classroom activities — SS ..............................................................462

8.14. Impacts on use of SACD classroom materials and teaching strategies - SS.........................................467

8.15. Impacts on teacher-reported SACD professional development - SS ....................................................470

8.16. Covariates used with outcomes from each report for analysis_-SS ........................................................472

8.17. Adjusted minimum detectable effect sizes for impact evaluation —SS...................................................475

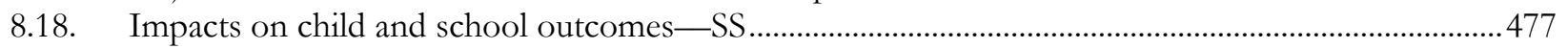

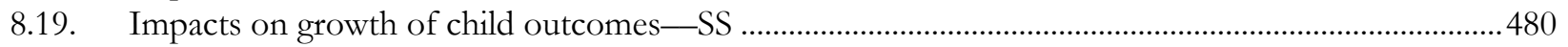




\section{List of Tables}

Table

Page

\section{Appendix A. Analysis of Cohorts 1 and 2}

A.1. Combined Cohorts 1 and 2: Sample size and percentage of sample universe for fourth-graders, by program and by treatment group status .......................................................................................

A.2. Combined Cohorts 1 and 2: Initial characteristics of children, their families, and communities ........A-7

A.3. Combined Cohorts 1 and 2: Mean scores and standard deviations for initial outcome measures .....A-9

A.4. Combined Cohorts 1 and 2: Initial characteristics of teachers ....................................................... A-10

A.5. Combined Cohorts 1 and 2: Initial characteristics of schools ............................................................ A-11

A.6. Combined Cohorts 1 and 2: Teacher initial reports on use of SACD activities and training in SACD activities

A.7. Cohort 1 versus combined Cohorts 1 and 2: Comparison of consent rates, completion rates, and percentage of sample with data .............................................................................................. A-15

A.8. Comparison of Cohort 1 and Cohorts 1 and 2: Adjusted minimum detectable effect sizes for fourth-grade outcomes for combined-program evaluation ...................................................... A-17

A.9. Combined Cohorts 1 and 2: Impacts on classroom activities ........................................................... A-19

A.10. Combining Cohorts 1 and 2: Impacts on use of SACD classroom materials and teaching

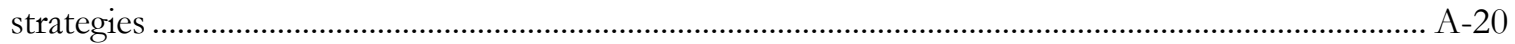

A.11. Combined Cohorts 1 and 2: Impacts on teacher-reported SACD professional development ........ A-21

A.12. Combined Cohorts 1 and 2: Significant impacts on domains of use of SACD activity overall

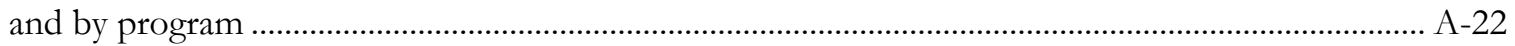

A.13. Combined Cohorts 1 and 2: Combined-program impacts on outcomes for fourth-graders ........... A-24

A.14. Comparison of individual program's statistically significant impacts and nonsignificant substantive impacts between Cohort 1 and combined Cohort 1 and Cohort 2 fourth-graders .......................... A-26

A.15. Cohort 1 and combined Cohorts 1 and 2: Comparison of program effects ..................................... A-28

A.16. Cohort 1 versus Cohorts 1 and 2: Comparison of significant impacts by subgroup......................... A-34

A.17. Combined Cohorts 1 and 2: Impacts on growth of child outcomes from combined-program

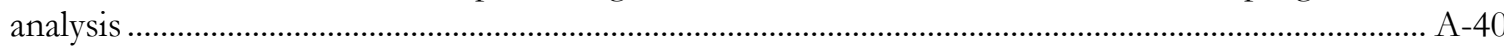

A.18. Combined Cohorts 1 and 2: Statistically significant impacts from the growth curve analyses of

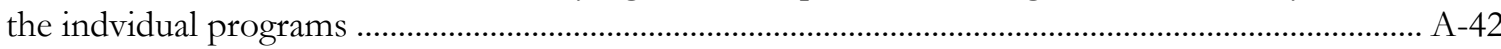

A.19. Combined Cohorts 1 and 2: Statistically significant impacts from the growth curve analyses of

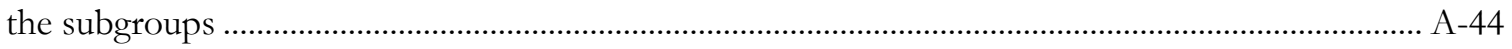

A.20 Sample size ranges for outcome analyses .......................................................................................... A-46

\section{Appendix B. Technical Notes on the Development of Outcome Measures, Selection of Covariates, Construction of Sample Weights, and Sensitivity Analyses}

B.1. Scales and internal consistency for child outcomes, by reporter type...

B.2. Fit indexes from confirmatory factor analyses five-factor measurement model: First four waves of data collection, by respondent type.

B.3. Child and school outcomes used for covariate selection and the percentage missing at spring 2005 (Year 1) analysis

B.4. Potential covariates and the percentage missing at spring 2005 (Year 1) analysis............................. B-12

B.5. Child and school outcomes used for covariate selection and the percentage missing at spring

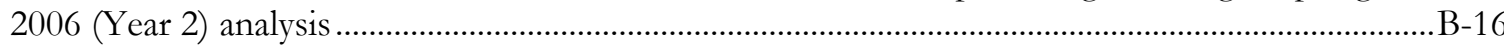

B.6. Potential covariates and the percentage missing at spring 2006 (Year 2) analysis............................. B-17

B.7. Child and school outcomes used for covariate selection and the percentage missing at spring 2007 (Year 3) analysis

B.8. Potential covariates and the percentage missing at spring 2007 (Year 3) analysis............................. B-20 


\section{List of Tables}

Table

Page

B.9. Covariates selected for child-reported outcomes, for the combined-program sample and program-

specific samples.

B.10. Covariates selected for primary caregiver-reported child outcomes, for the combined-program and program-specific samples.

B.11. Covariates selected for teacher-reported child outcomes, for the combined-program and program-specific samples

B.12. Covariates selected for teacher-reported class and school outcomes, for the combined-program and program-specific samples.

B.13. Adjusted $\mathrm{R}^{2}$ values from models using spring 2005 (Year 1) outcomes, with pretest only and with the full covariate set, for the combined-program sample

B.14. Adjusted $\mathrm{R}^{2}$ values from models using spring 2005 (Year 1) outcomes, with pretest only and with the full covariate set, by site

B.15. Adjusted $\mathrm{R}^{2}$ values from models using spring 2006 (Year 2) outcomes, with pretest only and with the full covariate set, for the combined-program sample

B.16. Adjusted $\mathrm{R}^{2}$ values from models using spring 2006 (Year 2) outcomes, with pretest only and with the full covariate set selected for each program, by program.

B.17. Adjusted $\mathrm{R}^{2}$ values from models using spring 2007 (Year 3) outcomes, with pretest only and with the full covariate set, for the combined-program sample.

B.18. Adjusted $\mathrm{R}^{2}$ values from models using spring 2007 (Year 3) outcomes, with pretest only and with the full covariate set selected for each program, by program.

B.19. Combined-program impacts in effect size units when baseline covariates are excluded from the models

B.20. Combined-program impacts in effect size units when weights are not adjusted for study nonconsent or survey nonresponse

B.21. Combined-program impacts in effect size units when weights not used ..............................................

B.22. Combined-program impacts in effect size units when accounting for classroom-level clustering... B-46

B.23. Combined-program impacts in effect size units when accounting for pairwise matching ................ B-48

B.24. Combined-program impacts in effect size units when dependent variable is the pretest-posttest difference (gain score)

B.25. Combined-program impacts in effect size units when posttest and pretest are treated as separate dependent variables

B.26. Combined-program impacts in effect size units when using different statistical software packages.

B.27. Combined-program impacts in effect size units when using imputation procedures for missing outcome data

B.28. Combined-program impacts in effect size units using averages of program-specific impacts.......... B-58

B.29. Combined-program impacts in effect size units when excluding new entrants ................................. B-61

B.30. Combined-program impacts in effect size units using restricted sets of covariates (pretest of outcomes only and child and primary caregiver demographic measures only) 


\section{List of Figures}

\section{List of Figures}

Figure

1.1 Conceptual model for social and character development interventions
Page

.... 6 


\section{Executive Summary}

A variety of universal school-based programs designed to help elementary schools foster positive student behaviors, reduce negative behaviors, and, ultimately, improve academic performance are available; however, more evidence from rigorous evaluations is needed to better understand their effects. Such information is important because the development of social competencies during middle childhood has been linked to adjustment to schooling and academic success, while the failure to develop such competencies can lead to problem behavior that interferes with success in school (Bennett et al. 2003; Carlson et al. 1999; Farrington 1989; Fors, Crepaz, and Hayes 1999; Malecki and Elliot 2002; McCord et al. 2000; Najaka, Gottfredson, and Wilson 2001; O’Donnell, Hawkins, and Abbott 1995; Trzesniewski et al. 2006; Wentzel 1993). ${ }^{1}$

The Institute of Education Sciences (IES) and the Division of Violence Prevention in the National Center for Injury Prevention and Control, Centers for Disease Control and Prevention (CDC) collaborated to conduct a rigorous impact evaluation of programs aimed at improving students' behavior. For this evaluation, such programs were termed Social and Character Development (SACD) programs. ${ }^{2}$ Seven programs were evaluated, and all were coherent in that their activities were integrated and logically organized based on a theory of action (that differed among the programs), school-based in that they were implemented in the schools by school personnel, and universal in that they were to be implemented for all students in all elementary classrooms in a school.

This report provides the results from the evaluation of the seven SACD programs on one cohort of students as they moved from third through fifth grades starting in fall 2004 and ending in spring $2007 .{ }^{3}$ The evaluation examined the effects on these students of the seven programs, together and separately, after 1, 2, and 3 school years and also estimated the impact on students' growth in social and character development over the 3 years. Chapter 1 discusses the evaluation of the programs when considered together and provides summary results for each program. Chapters 2 through 8 detail the findings for each of the programs individually. There are two appendixes: appendix A examines whether the addition of the smaller second cohort of students to the study affected the results, and appendix B contains additional technical information concerning the analyses.

\footnotetext{
${ }^{1}$ More information on the value of, evidence for, and theories behind these programs can be found in the second and third sections of chapter 1 .

2 Activities carried out by these programs in support of students' social and character development are termed SACD activities. The SACD evaluation examined SACD activities intended to promote six goals (termed SACD goals) and behavior management. The six SACD goals included (1) violence prevention and peace promotion, (2) social and emotional development, (3) character education, (4) tolerance and diversity, (5) risk prevention and health promotion, and (6) civic responsibility and community service.

${ }^{3}$ From 2005 to 2007, a smaller, second cohort of students was followed from third through fourth grades in a separate set of schools. This cohort is discussed in appendix A. The Executive Summary and chapters 1 through 8 describe the analysis of Cohort 1 only.
} 


\section{Executive Summary}

\section{Study Design}

Through a competitive application process that included a scientific peer review, seven research teams received funding under cooperative agreements to evaluate one SACD program of their choosing under an experimental design. Each research team recruited 10 to 14 schools $^{4}$ (for a total of 84), with half of the schools implementing one of the seven SACD programs for the 3 years of the study (the treatment group) and the other half continuing with their traditional SACD activities (the control group). Each team's schools were randomly assigned to the treatment or control group through a stratified sampling process. All but one school (a control school) participated in the study for the full 3 years. Table A lists the research teams, the SACD program each evaluated, key features of each program, and the number of treatment and control schools. $^{5}$

Under a separate peer-reviewed competition, Mathematica Policy Research, Inc. (MPR) received a contract to carry out a multiprogram evaluation of the seven SACD programs using (1) standardized data collection for all sites, (2) a common set of descriptive measures on the types and level of school-based activities (i.e., SACD activities) that targeted social and behavioral outcomes at both the treatment and control schools, (3) a common set of outcome measures, and (4) a uniform statistical analysis. ${ }^{6}$ The evaluation examined the impacts of all seven programs together, assessed the effect of each program separately to identify any contrasts with the overall findings across programs, and tested differences in effects on student subgroups.

Data were first collected from students, their primary caregivers, teachers, and principals in the fall of 2004 when students were starting third grade. Follow-up data were collected at four time points: (1) end of third grade (spring 2005), (2) beginning of fourth grade (fall 2005), (3) end of fourth grade (spring 2006), and (4) end of fifth grade (spring 2007). Some students stayed at the schools in the study for the full 3 years (stayers), others left (leavers) and were not followed, and new students entered the schools in the first (after the initial data collection), second, or third years of the study (new entrants). All students in each grade of the cohort were included in the sample. Table B describes the student sample overall and by program for all students and for the treatment and control groups. The study began with about 6,600 students in third grade and ended with about 6,200 in fifth grade. By the end of the fifth grade, 31 percent of the original sample had left and new entrants made up 28 percent of the fifth-graders. There were no statistically significant differences in the percentages of leavers and new entrants between the treatment and control groups overall, though there were some such differences within the individual programs. ${ }^{7}$

\footnotetext{
${ }^{4}$ New York University recruited 18 schools but only 14 were included in this evaluation.

${ }^{5}$ A longer version of table A with more detail on the programs appears as table 1 in chapter 1 . Chapters 2 through 8 provide greater discussion of each program.

${ }^{6}$ Research teams carried out program-specific evaluations using their own procedures and measures. These are to be published separately in the literature.

${ }^{7}$ Greater detail on the experimental design and on the sample is provided in chapter 1 under Study Design and Methodology.
} 
Table A. Research teams, SACD programs, and number of schools

\begin{tabular}{|c|c|c|c|c|}
\hline Research team & Program & Program features & $\begin{array}{r}\text { Number of } \\
\text { Treatment } \\
\text { schools } \\
\end{array}$ & $\begin{array}{r}\text { Number of } \\
\text { Control } \\
\text { schools } \\
\end{array}$ \\
\hline $\begin{array}{l}\text { University at Buffalo, } \\
\text { State University of } \\
\text { New York }\end{array}$ & $\begin{array}{l}\text { Academic and } \\
\text { Behavioral } \\
\text { Competencies } \\
\text { Program }\end{array}$ & $\begin{array}{l}\text { Social skills training and behavior } \\
\text { management }\end{array}$ & 6 & 6 \\
\hline $\begin{array}{l}\text { University of North } \\
\text { Carolina at Chapel } \\
\text { Hill }\end{array}$ & $\begin{array}{l}\text { Competence Support } \\
\text { Program }\end{array}$ & $\begin{array}{l}\text { Social and emotional learning, } \\
\text { social dynamics training, and } \\
\text { behavior management: social } \\
\text { information processing, social } \\
\text { problem solving, peer networks }\end{array}$ & 5 & 5 \\
\hline Vanderbilt University & Love In a Big World & $\begin{array}{l}\text { Character education: courage, } \\
\text { honesty, kindness, caring }\end{array}$ & 6 & $6^{1}$ \\
\hline $\begin{array}{l}\text { Oregon State } \\
\text { University }\end{array}$ & Positive Action & $\begin{array}{l}\text { Social and emotional learning: } \\
\text { values, empathy, self-control, } \\
\text { social skills, social bonding, self- } \\
\text { efficacy, honesty, goal setting }\end{array}$ & 7 & 7 \\
\hline $\begin{array}{l}\text { The Children's } \\
\text { Institute }\end{array}$ & $\begin{array}{l}\text { Promoting Alternative } \\
\text { Thinking Strategies }\end{array}$ & $\begin{array}{l}\text { Social and emotional learning: } \\
\text { emotional literacy, self-control, } \\
\text { social competence, peer } \\
\text { relations, interpersonal problem } \\
\text { solving }\end{array}$ & 5 & 5 \\
\hline New York University & $\begin{array}{l}\text { The 4Rs Program } \\
\text { (Reading, Writing, } \\
\text { Respect, and } \\
\text { Resolution) }\end{array}$ & $\begin{array}{l}\text { Conflict resolution and literacy: } \\
\text { social problem solving, anger } \\
\text { management, mediation }\end{array}$ & 7 & 7 \\
\hline $\begin{array}{l}\text { University of } \\
\text { Maryland, College } \\
\text { Park }\end{array}$ & Second Step & $\begin{array}{l}\text { Violence prevention and social } \\
\text { and emotional learning: empathy, } \\
\text { anger management, impulse } \\
\text { control, and problem solving }\end{array}$ & 6 & 6 \\
\hline
\end{tabular}

\footnotetext{
${ }^{1}$ Dropped to five after one control school became a magnet school and dropped out of the study prior to Year 2.
} SOURCE: The Social and Character Development (SACD) Research Program. 
Table B.

Student sample, overall and by program, for all students and for the treatment and control groups

\begin{tabular}{|c|c|c|c|c|c|c|c|c|c|c|c|c|c|c|c|c|}
\hline \multirow[b]{3}{*}{ Intervention program } & \multirow{3}{*}{$\begin{array}{r}\text { Year } 1 \\
\text { (Fall 3rd grade) } \\
\text { All } \\
\text { students }\end{array}$} & \multicolumn{5}{|c|}{$\begin{array}{c}\text { Year } 1 \\
\text { (Spring 3rd grade) } \\
\end{array}$} & \multicolumn{5}{|c|}{$\begin{array}{c}\text { Year } 2 \\
\text { (Spring 4th grade) }\end{array}$} & \multicolumn{5}{|c|}{$\begin{array}{c}\text { Year } 3 \\
\text { (Spring 5th grade) }\end{array}$} \\
\hline & & \multirow{2}{*}{$\begin{array}{r}\text { All } \\
\text { students }\end{array}$} & \multirow{2}{*}{\multicolumn{2}{|c|}{$\begin{array}{r}\text { Leavers } \\
\# \%{ }^{1}\end{array}$}} & \multicolumn{2}{|c|}{$\begin{array}{r}\text { New } \\
\text { entrants } \\
\end{array}$} & \multirow{2}{*}{$\begin{array}{r}\text { All } \\
\text { students }\end{array}$} & \multicolumn{2}{|c|}{ Leavers } & \multicolumn{2}{|c|}{$\begin{array}{r}\mathrm{New} \\
\text { entrants } \\
\end{array}$} & \multirow{2}{*}{$\begin{array}{r}\text { All } \\
\text { students }\end{array}$} & \multicolumn{2}{|c|}{ Leavers } & \multicolumn{2}{|c|}{$\begin{array}{r}\mathrm{New} \\
\text { entrants }\end{array}$} \\
\hline & & & & & & $\%^{2}$ & & \# & $\%^{1}$ & \# & $\%^{2}$ & & \# & $\%^{1}$ & \# & $\%^{2}$ \\
\hline All programs & 6,567 & 6,597 & 364 & 6 & 394 & 6 & 6,415 & 1,457 & 22 & 1,305 & 20 & 6,249 & 2,067 & 31 & 1,749 & 28 \\
\hline Treatment group & 3,367 & 3,388 & 179 & 5 & 200 & 6 & 3,327 & 742 & 22 & 702 & 21 & 3,172 & 1,078 & 32 & 883 & 28 \\
\hline Control group & 3,200 & 3,209 & 185 & 6 & 194 & 6 & 3,088 & 715 & 22 & 603 & 20 & 3,077 & 989 & 31 & 866 & 28 \\
\hline $\mathrm{ABC}$ & 879 & 875 & 43 & 5 & 39 & 4 & 877 & 160 & 18 & 158 & 18 & 871 & 289 & 33 & 281 & 32 \\
\hline Treatment group & 380 & 373 & 17 & 4 & 10 & $3^{* *}$ & 367 & 72 & 19 & 59 & 16 & 353 & 135 & 36 & 108 & 31 \\
\hline Control group & 499 & 502 & 26 & 5 & 29 & 6 & 510 & 88 & 18 & 99 & 19 & 518 & 154 & 31 & 173 & 33 \\
\hline CSP & 959 & 975 & 36 & 4 & 52 & 5 & 969 & 230 & 24 & 240 & 25 & 947 & 238 & 25 & 226 & 24 \\
\hline Treatment group & 476 & 485 & 20 & 4 & 29 & 6 & 474 & 135 & $28^{* *}$ & 133 & $28^{*}$ & 458 & 139 & $29^{* *}$ & 121 & 26 \\
\hline Control group & 483 & 490 & 16 & 3 & 23 & 5 & 495 & 95 & 20 & 107 & 22 & 489 & 99 & 20 & 105 & 21 \\
\hline LBW & 986 & 1,007 & 60 & 6 & 81 & 8 & 959 & 228 & 23 & 201 & 21 & 944 & 308 & 31 & 266 & 28 \\
\hline Treatment group & 548 & 565 & 25 & $5^{\star *}$ & 42 & 7 & 556 & 110 & 20 & 118 & 21 & 567 & 145 & $26^{* *}$ & 164 & 29 \\
\hline Control group & 438 & 442 & 35 & 8 & 39 & 9 & 403 & 118 & 27 & 83 & 21 & 377 & 163 & 37 & 102 & 27 \\
\hline PA & 811 & 812 & 74 & 9 & 75 & 9 & 764 & 251 & 31 & 204 & 27 & 655 & 408 & 50 & 252 & 38 \\
\hline Treatment group & 410 & 416 & 33 & 8 & 39 & 9 & 425 & 108 & $26^{* *}$ & 123 & 29 & 327 & 209 & 51 & 126 & 39 \\
\hline Control group & 401 & 396 & 41 & 10 & 36 & 9 & 339 & 143 & 36 & 81 & 24 & 328 & 199 & 50 & 126 & 38 \\
\hline PATHS & 786 & 783 & 39 & 5 & 36 & 5 & 778 & 150 & 19 & 142 & 18 & 778 & 243 & 31 & 235 & 30 \\
\hline Treatment group & 377 & 374 & 21 & 6 & 18 & 5 & 373 & 66 & 18 & 62 & 17 & 378 & 114 & 30 & 115 & 30 \\
\hline Control group & 409 & 409 & 18 & 4 & 18 & 4 & 405 & 84 & 21 & 80 & 20 & 400 & 129 & 32 & 120 & 30 \\
\hline 4Rs & 1,202 & 1,194 & 86 & 7 & 78 & 7 & 1,109 & 320 & 27 & 227 & 20 & 1,065 & 492 & 41 & 355 & 33 \\
\hline Treatment group & 652 & 647 & 49 & 8 & 44 & 7 & 599 & 183 & 28 & 130 & 22 & 556 & 279 & 43 & 183 & 33 \\
\hline Control group & 550 & 547 & 37 & 7 & 34 & 6 & 510 & 137 & 25 & 97 & 19 & 509 & 213 & 39 & 172 & 34 \\
\hline
\end{tabular}


Table B. Student sample, overall and by program, for all students and for the treatment and control groups-Continued

\begin{tabular}{|c|c|c|c|c|c|c|c|c|c|c|c|}
\hline \multirow[b]{2}{*}{ Intervention program } & \multirow{2}{*}{$\begin{array}{r}\text { Year } 1 \\
\text { (Fall 3rd grade) } \\
\text { All } \\
\text { students }\end{array}$} & \multicolumn{3}{|c|}{$\begin{array}{c}\text { Year } 1 \\
\text { (Spring 3rd grade) }\end{array}$} & \multicolumn{3}{|c|}{$\begin{array}{c}\text { Year } 2 \\
\text { (Spring 4th grade) }\end{array}$} & \multicolumn{4}{|c|}{$\begin{array}{c}\text { Year } 3 \\
\text { (Spring 5th grade) }\end{array}$} \\
\hline & & $\begin{array}{r}\text { All } \\
\text { students }\end{array}$ & $\begin{array}{r}\text { Leavers } \\
\# \%{ }^{1}\end{array}$ & $\begin{array}{r}\text { New } \\
\text { entrants } \\
\# \%{ }^{2}\end{array}$ & $\begin{array}{r}\text { All } \\
\text { students }\end{array}$ & $\begin{array}{r}\text { Leavers } \\
\# \%{ }^{1}\end{array}$ & $\begin{array}{r}\text { New } \\
\text { entrants } \\
\# \%{ }^{2}\end{array}$ & $\begin{array}{r}\text { All } \\
\text { students }\end{array}$ & $\begin{array}{r}\text { Lea } \\
\#\end{array}$ & & $\begin{array}{r}\text { New } \\
\text { entrants } \\
\# \%^{2}\end{array}$ \\
\hline SS & 944 & 951 & $26 \quad 3$ & $33 \quad 3$ & 959 & 11813 & 13314 & 989 & 89 & 9 & $134 \quad 14$ \\
\hline Treatment group & 524 & 528 & 14 & 18 & 533 & 68 & $77 \quad 14$ & 533 & 57 & $11^{*}$ & $66 \quad 12$ \\
\hline Control group & 420 & 423 & 12 & 15 & 426 & 50 & $56 \quad 13$ & 456 & 32 & 8 & 68 \\
\hline
\end{tabular}

* Treatment group significantly different from control group at the .05 level.

** Treatment group significantly different from control group at the .01 level.

${ }^{1}$ Leavers as a percentage of fall 2004 enrollment (these values are cumulative over the years).

${ }^{2}$ New entrants as a percentage of spring enrollment.

NOTE: Abbreviations are

ABC: Academic and Behavioral Competencies Program

CSP: Competence Support Program

LBW: Love In a Big World

PA: Positive Action

PATHS: Promoting Alternative Thinking Strategies

4Rs: The 4Rs Program (Reading, Writing, Respect, and Resolution)

SS: Second Step

SOURCE: The Social and Character Development (SACD) Research Program. 


\section{Executive Summary}

Twenty student and school outcomes related to social and character development were used to evaluate the impact of the SACD programs on student outcomes and perceptions of school climate. ${ }^{8}$ These were grouped into four domains: (1) Social and Emotional Competence, which contained three outcomes; (2) Behavior, which contained nine outcomes; (3) Academics, which contained two outcomes; 9 and (4) Perceptions of School Climate, which contained six outcomes. Four major data collection instruments were used to collect the scales on which the outcome measures were based. For the Child Report, students individually completed a set of 10 scales during school, and these contributed to 10 outcomes that fell across all four domains. For the Primary Caregiver Report, primary caregivers (usually parents) filled in a written survey (or completed a phone interview if they failed to complete the written version) that contained 12 scales. Six of these contributed to three outcomes in the Behavior domain (the other 6 were used to develop measures of characteristics associated with greater prevalence of child behavior problems). In the Teacher Report on Student, each student's teacher reported on 10 scales regarding a student's typical behavior in the past 30 days, and these were converted into five outcomes in the Behavior and Academics domains. In the Teacher Report on Classroom and School, the third-, fourth-, and fifth-grade teachers in a school reported on two scales that were converted into two outcomes that described their Perceptions of School Climate. In addition, they completed items that described the level of SACD activity in the classroom and school. Table $\mathrm{C}$ lists the 20 outcomes by domain and the reports from which they were obtained. Three of the outcomes in the Behavior domain were measured in more than one report. Altruistic Behavior and Problem Behavior were separately measured three times using responses from children, primary caregivers, and teachers; Positive Social Behavior was separately measured twice using responses from primary caregivers and teachers.

\footnotetext{
8 The original scales and the outcomes are described in chapter 1 under Measures.

9 The Academics domain was planned to but did not include student grades and standardized test scores; not all research teams were able to collect these data from their schools and districts, and the data that were collected varied in quality.
} 
Table C. Outcomes, by domain and data instrument

\begin{tabular}{|c|c|c|c|c|}
\hline \multirow[b]{2}{*}{ Domain/Outcome } & \multicolumn{4}{|c|}{ Instrument } \\
\hline & Child Report & $\begin{array}{c}\text { Primary } \\
\text { Caregiver } \\
\text { Report } \\
\end{array}$ & $\begin{array}{c}\text { Teacher Report } \\
\text { on Student }\end{array}$ & $\begin{array}{c}\text { Teacher Report } \\
\text { on Classroom } \\
\text { and School }\end{array}$ \\
\hline \multicolumn{5}{|l|}{ Social and Emotional Competence Domain } \\
\hline Self-Efficacy for Peer Interaction (+) & $\checkmark$ & & & \\
\hline Normative Beliefs About Aggression (-) & $\checkmark$ & & & \\
\hline Empathy (+) & $\checkmark$ & & & \\
\hline \multicolumn{5}{|l|}{ Behavior Domain } \\
\hline Altruistic Behavior (+) & $\checkmark$ & $\checkmark$ & $\checkmark$ & \\
\hline Positive Social Behavior (+) & & $\checkmark$ & $\checkmark$ & \\
\hline Problem Behavior (-) & $\checkmark$ & $\checkmark$ & $\checkmark$ & \\
\hline ADHD-Related Behavior (-) & & & $\checkmark$ & \\
\hline \multicolumn{5}{|l|}{ Academics Domain } \\
\hline Engagement with Learning $(+)$ & $\checkmark$ & & & \\
\hline Academic Competence and Motivation (+) & & & $\checkmark$ & \\
\hline \multicolumn{5}{|l|}{ Perceptions of School Climate Domain } \\
\hline Positive School Orientation (+) & $\checkmark$ & & & \\
\hline Negative School Orientation (-) & $\checkmark$ & & & \\
\hline Student Afraid at School (-) & $\checkmark$ & & & \\
\hline Victimization at School (-) & $\checkmark$ & & & \\
\hline Feelings of Safety $(+)$ & & & & $\checkmark$ \\
\hline Student Support for Teachers (+) & & & & $\checkmark$ \\
\hline
\end{tabular}

NOTE: Abbreviations are

ADHD: Attention deficit hyperactivity disorder

$\checkmark$ : Outcome addressed

Blank cell: Outcome not addressed

The +/- signs in parentheses indicate the direction of a beneficial outcome.

SOURCE: The Social and Character Development (SACD) Research Program. 


\section{Executive Summary}

\section{Research Questions}

The purpose of the SACD evaluation was to determine whether seven coherent, universal, school-based programs improved student social and emotional competence; improved behavior, including reducing negative behavior; improved student achievement; and improved student and teacher perceptions of school climate. The evaluation considered the programs together and individually. In addition, the evaluation considered the programs' impacts on students with different backgrounds that have been found to increase the risk of poor outcomes and possibly change student responses to the SACD programs. Also, the evaluation took into account findings from previous work showing that the level of implementation of a program affects its impact. In addition, the expectation of a positive impact on student outcomes raised the issue of whether and in what ways the programs increased the prevalence of SACD instruction. These issues led to the development of five research questions:

1. What is the average effect of the seven universal, school-based, social and character development programs on social and character development instruction in the schools?

2. What is the average effect of the seven universal, school-based, social and character development programs on students' social and emotional competence, behavior, and academics, and on perceptions of school climate?

3. What is the average effect of each specific social and character development program on students' social and emotional competence, behavior, and academics, and on perceptions of school climate?

4. Do the average effects of the seven universal, school-based social and character development programs differ by (a) students' gender and (b) students' initial risk factors (socioeconomic, family, community, and earlier child behavior)?

5. In the treatment schools, is there an association between the level of implementation of the social and character development programs and student outcomes?

\section{Data Collection}

Three issues regarding the conduct of the data collection have implications for the analysis: (1) timing of data collection, (2) percentages of the sample for which data were available for analysis, and (3) students who left the study (leavers).

Ideally, the first fall data collection would have started at the very beginning of the year to reduce the possibility that program implementation could have affected responses to the student, primary caregiver, and teacher surveys. For practical reasons, fall data collection was often delayed for several weeks to allow school populations to settle, to obtain primary caregiver consent, and to avoid disrupting planned school activities. As a result, program implementation began before initial data collection for six of the research teams (Vanderbilt University was the exception). This interval ranged from 2 to 6 weeks. In addition, at all schools teachers and principals received training on the intervention before the fall 2004 data collection. As a result, the fall 2004 reports from teachers and principals, and possibly students, are unlikely to reflect the true preintervention condition but instead capture what was being done at the beginning of the evaluation. ${ }^{10}$

Data were not successfully collected from all students, primary caregivers, and teachers. Data were not collected when written consent was not provided by primary caregivers or teachers, or when respondents refused to take part (even after consent had been given) or were unavailable at the time of data collection. Table D presents the overall consent and completion rates for each report by year and by treatment versus control group. This table also presents the percentages of the sample for which there are data for each report. These are calculated by multiplying the consent rate by the completion rate. Table $\mathrm{D}$ shows that 60 percent to

\footnotetext{
10 Additional details on timing issues can be found under Data Collection in chapter 1.
} 


\section{Executive Summary}

65 percent of students had data supplied by themselves over the 3 years, 46 percent to 59 percent had data provided by their primary caregivers, and 61 percent to 67 percent had data provided by teachers. In Year 1 (third grade), a statistically significant larger percentage of the treatment group had data than the control group; there were no significant differences in Years 2 and 3. Table D also shows that data on classrooms and schools were obtained from 86 percent to 90 percent of the teachers. ${ }^{11}$

The evaluation did not follow all students originally assigned to the treatment or control groups (what is known as an "intent to treat" study) because data were not collected from students who left the schools. If the SACD programs caused differential student mobility in the treatment schools versus the control schools, then the impact of this mobility would be combined with the impact of the programs and the two could not be disentangled. Descriptive analyses, presented in chapter 1, did not identify statistically significant differential mobility in the treatment and control schools, but this is not definitive evidence that it does not exist.

\footnotetext{
${ }^{11}$ For additional comparisons see Consent Rates in chapter 1 and chapters 2 through 8 regarding each program.
} 
Table D. Consent rates, completion rates, and percentage of sample with data from each report

\begin{tabular}{|c|c|c|c|c|c|c|c|c|c|c|c|c|}
\hline \multirow[b]{2}{*}{ Report } & \multicolumn{3}{|c|}{$\begin{array}{c}\text { Year } 1 \\
\text { (Fall 3rd grade) }\end{array}$} & \multicolumn{3}{|c|}{$\begin{array}{c}\text { Year } 1 \\
\text { (Spring 3rd grade) }\end{array}$} & \multicolumn{3}{|c|}{$\begin{array}{c}\text { Year } 2 \\
\text { (Spring 4th grade) }\end{array}$} & \multicolumn{3}{|c|}{$\begin{array}{c}\text { Year } 3 \\
\text { (Spring 5th grade) }\end{array}$} \\
\hline & Total & $\begin{array}{c}\text { Treat- } \\
\text { ment }\end{array}$ & Control & Total & $\begin{array}{c}\text { Treat- } \\
\text { ment }\end{array}$ & Control & Total & $\begin{array}{c}\text { Treat- } \\
\text { ment }\end{array}$ & Control & Total & $\begin{array}{c}\text { Treat- } \\
\text { ment }\end{array}$ & Control \\
\hline Student sample size & 6,567 & 3,367 & 3,200 & 6,597 & 3,388 & 3,209 & 6,415 & 3,327 & 3,088 & 6,249 & 3,172 & 3,077 \\
\hline \multicolumn{13}{|l|}{ Child Report (percent) } \\
\hline Primary caregiver consent rate & 65 & $67^{* *}$ & 63 & 66 & $68^{* *}$ & 64 & 67 & 67 & 66 & 66 & 67 & 66 \\
\hline Student completion rate & 94 & $93^{*}$ & 94 & 96 & 96 & 96 & 95 & 96 & 95 & 96 & 97 & 96 \\
\hline Students with data ${ }^{1}$ & 61 & $62^{*}$ & 60 & 63 & $65^{* *}$ & 61 & 63 & 65 & 62 & 64 & 65 & 63 \\
\hline \multicolumn{13}{|l|}{ Primary Caregiver Report (percent) } \\
\hline Primary caregiver consent rate & 63 & $64^{* *}$ & 61 & 64 & $66^{* *}$ & 62 & 64 & 65 & 63 & 64 & 65 & 64 \\
\hline Primary caregiver completion rate & 92 & 92 & 92 & 80 & 80 & 81 & 78 & 78 & 77 & 72 & 71 & 72 \\
\hline Primary caregivers with data ${ }^{1}$ & 57 & $59^{*}$ & 56 & 51 & 52 & 50 & 50 & 51 & 49 & 46 & 46 & 46 \\
\hline \multicolumn{13}{|l|}{ Teacher Report on Student (percent) } \\
\hline Primary caregiver consent rate ${ }^{2}$ & 65 & $67^{* *}$ & 63 & 66 & $68^{* *}$ & 64 & 67 & 67 & 66 & 66 & 67 & 66 \\
\hline Teacher completion rate & 96 & 96 & 96 & 99 & 99 & 99 & 100 & $100^{* *}$ & 99 & 98 & 98 & 99 \\
\hline Students with data ${ }^{1}$ & 62 & $64^{* *}$ & 61 & 65 & $67^{* *}$ & 63 & 66 & 67 & 65 & 65 & 66 & 65 \\
\hline \multicolumn{13}{|l|}{$\begin{array}{l}\text { Teacher Report on Classroom and } \\
\text { School (3rd- to 5th-grade teachers) } \\
\text { (percent) }\end{array}$} \\
\hline Teacher consent rate & 96 & $98^{* * *}$ & 92 & 95 & $97^{*}$ & 94 & 95 & 97 & 94 & 96 & 97 & 95 \\
\hline Teacher completion rate & 91 & 90 & 93 & 91 & 90 & 91 & 94 & 94 & 94 & 92 & 91 & 93 \\
\hline Teachers with data $^{1}$ & 87 & 88 & 86 & 87 & 88 & 86 & 90 & 90 & 89 & 89 & 88 & 89 \\
\hline
\end{tabular}

* Treatment group significantly different than control group at the .05 level.

** Treatment group significantly different than control group at the .01 level.

*** Treatment group significantly different than control group at the .001 level.

${ }^{1}$ Calculated as consent rate $\mathrm{x}$ completion rate.

${ }^{2}$ The primary caregiver consent rates for the Child Report and the Teacher Report on Student are identical, as the primary caregiver gave consent to both together.

SOURCE: The Social and Character Development (SACD) Research Program. 


\section{Executive Summary}

\section{Initial Characteristics}

An examination of the initial characteristics of the students, families, teachers, and schools found that the treatment and control groups were similar on a set of observed characteristics (with the exception of the use of SACD activities in the schools), providing evidence that the random assignment of schools within programs created similar groups. ${ }^{12}$ The data for this examination were collected in fall 2004 from enrolled third-grade students, their primary caregivers, and their third-grade teachers. In addition, third-, fourth-, and fifth-grade teachers and principals in the study schools provided information about SACD activities being used in the classroom and school. The initial data were collected after the staff at the treatment schools began receiving training in their programs and, for six of the programs, after implementation had begun.

The sample's treatment and control groups were similar along the observed student, primary caregiver, and community characteristics. These included (1) student gender, race/ethnicity, and age; (2) primary caregiver race/ethnicity, age, employment, marital status, education, and household income; and (3) community risks and resources. In addition, there were no significant differences between the treatment and control groups for the 20 outcome measures and the five measures of initial risk, showing that the two groups of students started, on average, at the same place in third grade.

The teachers in the treatment and control schools were similar in gender, race/ethnicity, years of teaching, and certification. The only statistically significant difference concerned degree attainment, as a larger percentage of treatment teachers $(60 \%)$ had a master's or doctoral degree than did control teachers $(52 \%)$. There was no significant difference between the treatment and control schools with regard to student composition (race/ethnicity and school lunch eligibility), number of students, number of full-time teachers, Title I status, highest and lowest grades, urbanicity, and number of years the principal had been at the school. There was also no significant difference in teacher reports on nine dimensions concerning their school environment: feelings of safety, resource adequacy, student support, staff freedom to teach as desired, affiliation with and ties to colleagues, innovation regarding trying new approaches to teaching, professional interest, participatory decisionmaking, and work pressure.

An examination of the initial level of activities to promote social and character development in the classroom and schoolwide, and of the materials and methods used in these activities, revealed that the control condition for the evaluation was not a "no treatment" control. Rather, it was a "standard practice" control condition, in which more than half of teachers and 80 percent to 90 percent of principals reported schoolwide and classroom activities designed to promote social and character development. Standard practice at the control schools included the use of specific materials and practices to promote social and character development, as well as professional development related to social and character development of students for staff. Many kinds of activities and strategies were provided at rates and in types and amounts similar to those reported in treatment schools.

Treatment teachers reported greater use of and training in SACD activities than control teachers more often than would be expected by chance. This may reflect actual differences in the use of SACD activities prior to implementation of the programs, or it may reflect that program implementation (for six programs) and program training for staff had started before initial data collection. ${ }^{13}$

\footnotetext{
12 For greater detail, see Initial Characteristics in chapter 1.

${ }^{13}$ For details on these comparisons, see The Initial Level of Social and Character Development in the Schools in chapter 1.
} 


\section{Analysis and Results}

Four sets of analyses were done to evaluate the impacts of the SACD programs. ${ }^{14}$ First, the effects of the adoption of the programs on the use of SACD activities in the classroom and school were examined on an annual basis for Years 1 to 3. Second, the programs' impacts on student outcomes and perceptions of school climate were analyzed at the end of each of the 3 years of the study (i.e., from the start of third grade to the end of third grade, to the end of fourth grade, and to the end of fifth grade). Third, subgroup analyses were done on the same annual basis to examine whether the programs' impacts on student outcomes, when combined, differed by four subgroups: (1) girls versus boys, (2) stayers versus new entrants, (3) students with different levels of baseline risk, and (4) students in treatment schools with high versus low fidelity of implementation. Fourth, a growth curve analysis was done to determine impacts on annual student growth in the outcomes over the 3 years. All but the third analysis were done for the combination of all seven programs and for each program separately.

\section{Annual Impacts on the Use of Social and Character Development Activities}

The SACD programs were expected to increase the use of activities to promote social and character development in the classroom and school. The analysis of activity use was based on data from the Teacher Report on Classroom and School (TRCS), which was filled out by all the third-, fourth-, and fifth-grade teachers. Data from the TRCS were used to create 83 SACD activity outcome measures, and these were grouped into six domains: (1) teacher use of any activities to promote social and character development, which had 16 variables; (2) teacher use of any activities associated with a specific SACD program (known as a "named" program), which had 14 variables; (3) teacher use of materials and classroom strategies for SACD activities, which had 29 variables; (4) use of schoolwide strategies, which had 6 variables; (5) teacher involvement in related professional development, which had 9 variables; and (6) teacher support for SACD efforts in the school and the prevalence of an environment conducive to the social and character development of students, which had 9 variables.

To estimate the impact of the SACD programs on use of SACD activities, the statistical significance of the differences in means between the treatment and control groups was tested for each of the 83 SACD activity outcome measures..$^{15}$ For the overall analysis, the data were first weighted to give equal weight to each program and to each school within a site. For the program-by-program analyses, each school within a site received equal weight (school weights differed between program analyses, as the number of schools was not constant among programs).

In addition to estimating the impacts of the SACD programs on the individual outcome measures, the impacts on the six domains were also examined. Testing the impact on the domains was done to adjust for the multiple comparisons made within each domain in order to address the increased chances of finding a spurious outcome when more than one test was done. As a result, two sets of results were obtained: (1) the

\footnotetext{
14 The analytical techniques used for each of the four sets of analyses are summarized in the following sections and discussed in detail in chapter 1.

15 Three factors contributed to the decision to use differences in means. First, because of random assignment, simple treatment-control contrasts provided unbiased estimates of program impacts. Second, only initial values (rather than true baseline values) for these outcomes were available to use in a model because training (at all treatment schools) and program implementation (at 36 treatment schools) began before data collection. The decision to use initial values in an analysis partly depends on whether the initial training and implementation occurring before data collection would be expected to have immediate and large impacts on the outcomes (Schochet 2008b). For this analysis, the outcomes are based on teacher actions and so would likely be upwardly influenced by the teacher training and short period of teacher implementation before pretesting (in contrast to student outcomes, which would be less likely to be so influenced). For this reason, a model-based analysis using the initial values as covariates was not chosen. Third, preliminary analyses indicated no gain in precision from the inclusion of other covariates.
} 


\section{Executive Summary}

impacts on the individual outcomes unadjusted for multiple comparisons, and (2) the impacts on the domains that serve as the multiple comparison adjustment. To test whether the SACD programs had a statistically significant impact on each of the six domains, a set of three heuristics was used and a significant effect on the domain was found if any one of the heuristics was met. ${ }^{16}$

The results provide evidence that the SACD programs increased the reported implementation of SACD activities in the classroom. Over the 3 years, 249 comparisons (83 outcome variables times 3 years) of treatment and control teachers were tested, with 12 to 13 expected to be statistically significant by chance. The analysis found 127 comparisons were statistically significant, with all showing greater reported use of SACD activities by treatment teachers. When examining the individual outcomes within each domain, the analysis found the following: (1) treatment teachers reported significantly greater use of SACD activities in the classroom for 31 of the 48 comparisons, (2) treatment teachers reported significantly greater use of SACD activities linked to a named SACD program for 39 of the 42 comparisons, (3) treatment teachers reported significantly greater use of materials and instructional methods to promote social and character development for 40 of the 87 comparisons, (4) there were no significant differences for the 18 comparisons made regarding the use of schoolwide strategies, (5) treatment teachers reported significantly greater receipt of training to promote social and character development for 13 of the 27 comparisons, and (6) treatment teachers reported significantly greater use of practices conducive to social and character development but similar attitudes toward it for 4 of the 27 comparisons. ${ }^{17}$

The results from the analysis of the individual outcomes also provide further evidence that the control group was a "standard practice" rather than a "no treatment" control. Over the 3 years, control teachers continued to report use of SACD activities. For example, over the 3 years, 86 percent to 90 percent of control teachers reported using a SACD activity to address any one of the six SACD goals versus 95 percent to 96 percent of the treatment teachers. Similarly, over the 3 years, 20 percent to 36 percent of control teachers reported using a SACD activity linked to a named SACD program to address any one of the six SACD goals versus 68 percent to 72 percent of the treatment teachers. ${ }^{18}$

The findings from the analysis of the six domains are consistent with the results from the individual outcome analysis. For all 3 years, treatment teachers reported statistically significant greater implementation in four of the six SACD activity domains: (1) use of any SACD activities in the classroom, (2) use of SACD activities from named programs in the classroom, (3) use of materials and teaching strategies for SACD activities, and (4) participation in relevant professional development. No evidence was found that the programs affected the other two domains - the use of schoolwide strategies and attitudes and practices that create an environment conducive to students' social and character development. Table E shows where statistically significant impacts on the use of SACD activities occurred by domain for all seven programs and for each program by year. In table E, a plus sign indicates a significant positive impact on the domain, and superscript numerals show which heuristics identified the domain as significant.

\footnotetext{
16 The three heuristics included (1) determining if more than half of the individual outcomes within a domain had a similar and statistically significant impact, (2) doing one overall test of impact on all outcomes within a domain, and (3) checking for any statistically significant results among the outcomes within a domain after applying a specific statistical adjustment for multiple comparisons (Benjamini-Hochberg 1995) to each one. See Year-by-Year Impacts on Use of Social and Character Development Activities in chapter 1 for longer descriptions of these heuristics and how they were used.

${ }^{17}$ For more details on the impacts on the individual outcomes making up the domains see Year-by-Year Impacts on Use of Social and Character Development Activities in chapter 1.

${ }^{18}$ For more details on the percent of treatment and control teachers reporting on the use of SACD activities see Yearby-Year Impacts on Use of Social and Character Development Activities in chapter 1.
} 
Table E. Significant impacts on use of SACD activity domains, overall and by program

\begin{tabular}{|c|c|c|c|c|c|c|}
\hline \multirow[b]{2}{*}{ Program } & \multicolumn{6}{|c|}{ SACD activity domain } \\
\hline & $\begin{array}{r}\text { SACD } \\
\text { activities }\end{array}$ & $\begin{array}{r}\text { SACD activities } \\
\text { linked to named } \\
\text { programs }\end{array}$ & $\begin{array}{r}\text { Classroom } \\
\text { materials and } \\
\text { strategies } \\
\end{array}$ & $\begin{array}{r}\text { Schoolwide } \\
\text { strategies }\end{array}$ & $\begin{array}{r}\text { Professional } \\
\text { development }\end{array}$ & $\begin{array}{r}\text { Attitudes } \\
\text { and } \\
\text { practices }\end{array}$ \\
\hline \multicolumn{7}{|l|}{ Overall } \\
\hline Year 1 & $++^{1,2,3}$ & $++^{1,2,3}$ & $+^{2,3}$ & & $++^{1,2,3}$ & \\
\hline Year 2 & $++^{1,2,3}$ & $++^{1,2,3}$ & $++^{1,2,3}$ & & $+^{2,3}$ & \\
\hline Year 3 & $+^{1,2,3}$ & $++^{1,2,3}$ & $+^{1,2,3}$ & & $+^{2,3}$ & \\
\hline \multicolumn{7}{|l|}{$A B C$} \\
\hline Year 1 & $+^{2}$ & & & $+^{1}$ & & \\
\hline \multicolumn{7}{|l|}{ Year 2} \\
\hline Year 3 & & & & & & $+^{3}$ \\
\hline \multicolumn{7}{|l|}{ CSP } \\
\hline Year 1 & $+^{2}$ & $++^{1,3}$ & & & $++^{3}$ & \\
\hline Year 2 & & $+^{3}$ & & & & \\
\hline Year 3 & & $+^{3}$ & & & & \\
\hline \multicolumn{7}{|l|}{ LBW } \\
\hline Year 1 & $t^{2,3}$ & $t^{3}$ & $t^{3}$ & & $+^{3}$ & \\
\hline Year 2 & $+^{3}$ & $+^{3}$ & & $t^{2}$ & & \\
\hline \multicolumn{7}{|l|}{ Year 3} \\
\hline \multicolumn{7}{|l|}{ PA } \\
\hline Year 1 & $+^{2,3}$ & $+^{1,3}$ & $+^{3}$ & & & $+^{3}$ \\
\hline Year 2 & & $+^{1,3}$ & & & & \\
\hline Year 3 & $t^{3}$ & $+^{3}$ & & & & \\
\hline \multicolumn{7}{|l|}{ PATHS } \\
\hline Year 1 & $++^{2,3}$ & $+^{1,3}$ & & & $+^{1,3}$ & \\
\hline Year 2 & $+^{3}$ & $+1,3$ & & & & \\
\hline Year 3 & & $+^{1,3}$ & & & & \\
\hline \multicolumn{7}{|l|}{ 4Rs } \\
\hline Year 1 & $+^{1,2,3}$ & $+^{1,2,3}$ & $+^{3}$ & & $+^{1,3}$ & \\
\hline Year 2 & $+^{1,3}$ & $++^{1,3}$ & & & & \\
\hline Year 3 & $+^{1,3}$ & $+^{1,2,3}$ & $t^{3}$ & & $t^{3}$ & \\
\hline
\end{tabular}


Table E. Significant impacts on use of SACD activity domains, overall and by programContinued

\begin{tabular}{|c|c|c|c|c|c|c|}
\hline \multirow[b]{2}{*}{ Program } & \multicolumn{6}{|c|}{ SACD activity domain } \\
\hline & $\begin{array}{r}\text { SACD } \\
\text { activities }\end{array}$ & $\begin{array}{r}\text { SACD activities } \\
\text { linked to named } \\
\text { programs }\end{array}$ & $\begin{array}{r}\text { Classroom } \\
\text { materials and } \\
\text { strategies }\end{array}$ & $\begin{array}{r}\text { Schoolwide } \\
\text { strategies }\end{array}$ & $\begin{array}{l}\text { Professional } \\
\text { development }\end{array}$ & $\begin{array}{r}\text { Attitudes } \\
\text { and } \\
\text { practices }\end{array}$ \\
\hline \multicolumn{7}{|l|}{ SS } \\
\hline Year 1 & $+^{3}$ & $++^{1,3}$ & $t^{3}$ & & & \\
\hline Year 2 & $++^{1,3}$ & $++^{1,3}$ & $+^{3}$ & & & \\
\hline Year 3 & $t^{3}$ & $++^{1,3}$ & $++^{3}$ & & & \\
\hline
\end{tabular}

${ }^{1}$ Based on univariate statistical tests, at least half of the impacts were positive and statistically significant and no impact was negative and statistically significant.

${ }^{2}$ The omnibus impact for all the outcomes measured together was positive and statistically significant on the basis of a multivariate statistical test.

${ }^{3}$ At least one outcome remained positive and statistically significant and no outcome was negative and statistically significant after applying the Benjamini-Hochberg (1995) procedure to adjust significance levels downward to account for the multiple testing of impacts.

NOTE: Abbreviations are

ABC: Academic and Behavioral Competencies Program

CSP: Competence Support Program

LBW: Love In a Big World

PA: Positive Action

PATHS: Promoting Alternative Thinking Strategies

4Rs: The 4Rs Program (Reading, Writing, Respect, and Resolution)

SS: Second Step

Abbreviations of the findings are

+ : Statistically significant beneficial impact on domain

Blank cell: Finding of no statistically significant impact

Significance is based on $p \leq .05$. No detrimental impact was found statistically significant at or below the .05 level. Description of SACD Activity Domains and the heuristics used to determine the statistically significant beneficial impact on the domain (for more detail, see the Measures section in chapter 1):

SACD activities: based on 16 teacher-reported measures on the use of SACD activities in the classroom.

SACD activities linked to named programs: based on 14 teacher-reported measures on the use of SACD activities associated with a named program in the classroom.

Classroom materials and strategies: based on 29 teacher-reported measures, 7 concerning materials used in the classroom and 22 concerning classroom strategies.

Schoolwide strategies: based on six teacher-reported measures concerning strategies to promote SACD schoolwide.

Professional development: based on nine teacher-reported measures concerning their participation in SACD-related training. Attitudes and practices: based on nine teacher-reported measures, three concerning teacher attitudes toward SACD efforts in the school and six concerning school practices conducive to the social and character development of students.

SOURCE: The Social and Character Development (SACD) Research Program.

\section{Annual Impacts on Student Outcomes and Perceptions of School Climate}

The SACD programs were expected to improve children's social and emotional competence, behavior, academics, and perceptions of school climate as measured by 20 outcome variables. One test of these hypotheses was to examine the year-by-year impacts of the SACD programs on these outcomes over the 3 years as the students progressed from third through fifth grades. The examination of year-by-year impacts entailed three sets of analyses resulting in three sets of impacts. The first set of analyses compared the outcomes of treatment and control students from the fall of third grade to the spring of third grade. The second set compared the outcomes from the fall of third grade to the spring of fourth grade, and the third set compared outcomes from the fall of third grade to the spring of fifth grade. Within each set of year-by-year analyses, an analysis of all the programs together provided impact results for the set of seven coherent, universal, school-based programs, and separate analyses of each individual program provided results specific to each program. The combined analysis was able to detect smaller statistically significant impacts, because of 


\section{Executive Summary}

its larger sample size and the associated greater power, than the analyses of each SACD program, which were based on smaller samples. ${ }^{19}$

The random assignment of schools ensured that unbiased estimates of the average impacts of the SACD programs (relative to the social and character development activities offered in the control schools) could be computed as the differences in the average outcomes of students and teachers in the treatment and control schools. However, regression procedures were used rather than simple differences-in-means procedures to estimate impacts to improve the statistical precision of the estimates; to address the clustering of students within schools; and to adjust for differences between treatment and control group observable characteristics due to random selection, study nonconsent, and interview nonresponse. A hierarchical linear model (HLM) was used to estimate regression-adjusted impacts (Bryk and Raudenbush 1992). The basic model consisted of two levels that were indexed by students or teachers and by schools. The model included covariates that adjusted for statistically significant treatment and control differences at initial data collection. These covariates were chosen because they had predictive power across a broad range of outcomes. Sample weights were used in the analyses in order to (1) give each site equal weight in the calculation of pooled impact estimates, (2) give each school equal weight in each site, and (3) adjust for missing outcome data due to nonconsent and nonresponse. The model was estimated using data from all seven programs together (using all three types of weights) and individually for each program (using the second and third types of weights). A set of analyses to examine differences by subgroup for the combined data was done by examining the significance of a coefficient on an interaction term between the treatment status indicator variable and subgroup indicator variable (or multiple coefficients and multiple interaction terms when there were more than two subgroups) when the subgroup variables were included. The association of fidelity of implementation with the outcomes was examined in a similar way, using a fidelity indicator variable and an interaction term between the fidelity variable and the treatment status variable. ${ }^{20}$

Results from estimating the model were provided in effect sizes. ${ }^{21} \mathrm{~A}$ standard two-tailed test was used to determine the $p$-value for the coefficient of each outcome measure. Coefficients with $p$-values of .05 or below were considered statistically significant and identified as such. Impacts that were not statistically significant but were .25 standard deviation units or more in magnitude were identified as "substantively important," following the practice used by the What Works Clearinghouse. ${ }^{22}$ Substantively important impacts identify effects that may be large enough to have practical importance but are not found to be statistically significant, potentially because of sample size constraints.

The 20 outcome variables were grouped under a set of four domains: (1) Social and Emotional Competence, which contained 3 outcomes; (2) Behavior, which contained 9 outcomes; (3) Academics, which contained 2 outcomes; and (4) Perceptions of School Climate, which contained 6 outcomes. As in the case of the SACD activities domains, a set of heuristics was used to test the significance of the impacts on the four outcome

\footnotetext{
${ }^{19}$ The combined analysis provided a sample size sufficient to detect student-level impacts at minimum detectable effect sizes ranging from 0.03 to 0.24 standard deviations (see table 1.25 in chapter 1 for details).

${ }^{20}$ For a discussion of the regression model, see Analysis under the section Year-by-Year Impacts on Use of Social and Character Development Activities in chapter 1.

${ }^{21}$ Effect sizes were calculated by dividing the estimated impact (the coefficient estimated by the regression model) by the standard deviation of the outcome measure for the control group. The standard deviation was calculated using data for the weighted control group. It was calculated at the time of data collection for which the effect size (impact) was estimated.

22 The What Works Clearinghouse was established in 2002 by the U.S. Department of Education's Institute of Education Sciences to provide educators, policymakers, researchers, and the public with a central and trusted source of scientific evidence of what works in education.
} 


\section{Executive Summary}

domains to adjust for the multiple comparisons made within each domain. ${ }^{23}$ The analysis of the year-by-year impacts then produced two sets of results: (1) the impacts on the individual outcomes unadjusted for multiple comparisons, and (2) the impacts on the domains that served as the multiple comparison adjustment.

Column 2 of table $\mathrm{F}$ reports the number of statistically significant and substantively important impacts found for the year-by-year analysis of all seven programs together. Specifically, 2 of 60 estimated impacts on the outcomes for the seven SACD programs combined for the 3 years were found statistically significant (versus 3 expected by chance). The 2 statistically significant impacts were that the combined SACD programs had a beneficial impact on the teacher-reported measure for Student Support for Teachers in Years 1 and 2, with effect sizes of 0.12 and 0.16 , respectively. None of the remaining 58 estimated impacts were found to be substantively important. ${ }^{24}$ In addition, 12 impacts on the domains were estimated (4 domains times 3 years), with 1 expected to be statistically significant by chance. The analysis found 2 significant negative impacts on the domain of Social and Emotional Competence in Years 2 and 3 (these data are not shown in a table). The results for the individual outcomes and the domains provide no evidence that the SACD programs improved student outcomes and perceptions of school climate.

The lack of statistically significant impacts found in the combined-program analysis was not due to offsetting beneficial and detrimental impacts among the individual programs. For the individual SACD programs, 16 significant impacts were found over the 3 years ( 9 beneficial and 7 detrimental) versus 21 expected by chance from the 420 statistical tests done (see column 3 of table F). In only one program did a significant impact occur on an outcome in more than one year, and in this case the impact was beneficial in Year 1 and detrimental in Year 2. In addition, 19 substantively important impacts were found $(10$ beneficial and 9 detrimental). There was little replication of the substantively important impacts: one program had a substantively important beneficial impact on one outcome for all 3 years. Table $G$ identifies the statistically significant and nonsignificant substantively important results by program, outcome, and year. It provides a visual view of the balance between beneficial and detrimental impacts and of the lack of persistence in impacts by program across the years.

\footnotetext{
${ }^{23}$ The heuristics were used to determine whether the results for the multiple outcomes within each domain showed a statistically significant impact on the domain as a whole. A significant effect on the domain was found if any one of the heuristics was met. In addition to the three heuristics mentioned in footnote 16, a fourth heuristic (not applicable to the analysis of teacher-reported SACD activities) was used. For this heuristic, the statistical model used to estimate impacts on the individual outcomes was re-estimated using a composite of all the outcome variables within a domain. The composite was formed by standardizing each outcome variable using its standard deviation, combining the values of the outcome variables, and taking the average of the final value.

${ }^{24}$ For the actual effect size and significance level of each outcome, see table 1.26 in chapter 1.
} 
Table F. Significant impacts on student outcomes, overall and by program, for all 3 years

\begin{tabular}{|c|c|c|}
\hline Domain (number of outcomes) & $\begin{array}{c}\text { Combined-program analysis } \\
\text { (all seven programs together) } \\
\left(60 \text { impact estimates) }{ }^{1}\right.\end{array}$ & 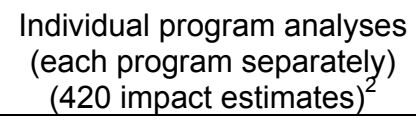 \\
\hline \multicolumn{3}{|l|}{ Total } \\
\hline \multirow[t]{2}{*}{ Statistically significant outcomes } & 2 & 16 \\
\hline & (Beneficial) & (9 Beneficial, 7 Detrimental) \\
\hline Substantively important outcomes & 0 & $\begin{array}{c}19 \\
\text { (10 Beneficial, } 9 \text { Detrimental) }\end{array}$ \\
\hline \multicolumn{3}{|l|}{ Social and Emotional Competence (3) } \\
\hline Statistically significant outcomes & 0 & 0 \\
\hline Substantively important outcomes & 0 & 0 \\
\hline \multicolumn{3}{|l|}{ Behavior (9) } \\
\hline Statistically significant outcomes & 0 & $\begin{array}{c}8 \\
\text { (6 Beneficial, } 2 \text { Detrimental) }\end{array}$ \\
\hline Substantively important outcomes & 0 & $\begin{array}{c}6 \\
\text { (2 Beneficial, } 4 \text { Detrimental) }\end{array}$ \\
\hline \multicolumn{3}{|l|}{ Academics (2) } \\
\hline Statistically significant outcomes & 0 & $\begin{array}{c}4 \\
\text { (1 Beneficial, } 3 \text { Detrimental) }\end{array}$ \\
\hline Substantively important outcomes & 0 & 0 \\
\hline \multicolumn{3}{|l|}{ Perceptions of School Climate (6) } \\
\hline Statistically significant outcomes & $\begin{array}{c}2 \\
\text { (Beneficial) }\end{array}$ & $\begin{array}{c}4 \\
\text { (2 Beneficial, } 2 \text { Detrimental) }\end{array}$ \\
\hline Substantively important outcomes & 0 & $\begin{array}{c}13 \\
\text { (8 Beneficial, } 5 \text { Detrimental) }\end{array}$ \\
\hline \multicolumn{3}{|c|}{$\begin{array}{l}{ }^{1} \text { For each year, } 20 \text { impacts (on } 20 \text { outcomes) were estimated and } 1 \text { statistically significant impact would be expected each year by } \\
\text { chance (for a total of } 3 \text { ). } \\
{ }^{2} \text { For each year, } 140 \text { impacts were estimated ( } 7 \text { programs by } 20 \text { outcomes) and } 7 \text { statistically significant impacts would be expecte } \\
\text { each year by chance (for a total of } 21 \text { ). } \\
\text { NOTE: For each outcome, a finding of "beneficial" indicates the program(s) had a beneficial impact on that particular outcome; a } \\
\text { finding of "detrimental" indicates a detrimental impact on that outcome. Significance is based on } p \leq .05 \text {. The number of results } \\
\text { found significant was no more than expected by chance. } \\
\text { SOURCE: The Social and Character Development (SACD) Research Program. }\end{array}$} \\
\hline
\end{tabular}


Table G. Individual program statistically significant impacts and nonsignificant but substantively important impacts

\begin{tabular}{|c|c|c|c|c|}
\hline Program & \multicolumn{2}{|c|}{ Statistically significant $^{1}$} & \multicolumn{2}{|c|}{ Nonstatistically significant but substantive ${ }^{2}$} \\
\hline Total & 9 & 7 & 10 & 9 \\
\hline Year 1 & 3 & 2 & 2 & 0 \\
\hline Year 2 & 5 & 2 & 6 & 1 \\
\hline Year 3 & 1 & 3 & 2 & 8 \\
\hline $\begin{array}{l}\mathrm{ABC} \\
\quad \text { Year } 1\end{array}$ & $\begin{array}{l}\text { Altruistic Behavior } \\
\text { (TRS) (.39) (.026) }\end{array}$ & & & \\
\hline Year 3 & $\begin{array}{l}\text { Positive Social Behavior } \\
\text { (PCR) }(.21)(.041)\end{array}$ & & $\begin{array}{c}\text { Feelings of Safety } \\
\text { (TRCS) (.31) (.235) }\end{array}$ & \\
\hline $\begin{array}{l}\text { CSP } \\
\quad \text { Year } 1\end{array}$ & & & & \\
\hline Year 3 & & & & $\begin{array}{l}\text { Altruistic Behavior } \\
\text { (TRS) }(-.41)(.132) \\
\text { Feelings of Safety } \\
(\text { TRCS) }(-.36)(.246)\end{array}$ \\
\hline $\begin{array}{l}\text { LBW } \\
\quad \text { Year } 1\end{array}$ & $\begin{array}{c}\text { Altruistic Behavior } \\
\text { (PCR) (.31) (.005) } \\
\text { Student Support } \\
\text { for Teachers } \\
\text { (TRCS) }(.52)(.022)\end{array}$ & & & \\
\hline Year 2 & & & $\begin{array}{c}\text { Student Support } \\
\text { for Teachers } \\
\text { (TRCS) (.28) (.428) }\end{array}$ & $\begin{array}{l}\text { Altruistic Behavior } \\
\text { (TRS) }(-.34)(.270)\end{array}$ \\
\hline
\end{tabular}


Table G. Individual program statistically significant impacts and nonsignificant but substantively important impacts—Continued

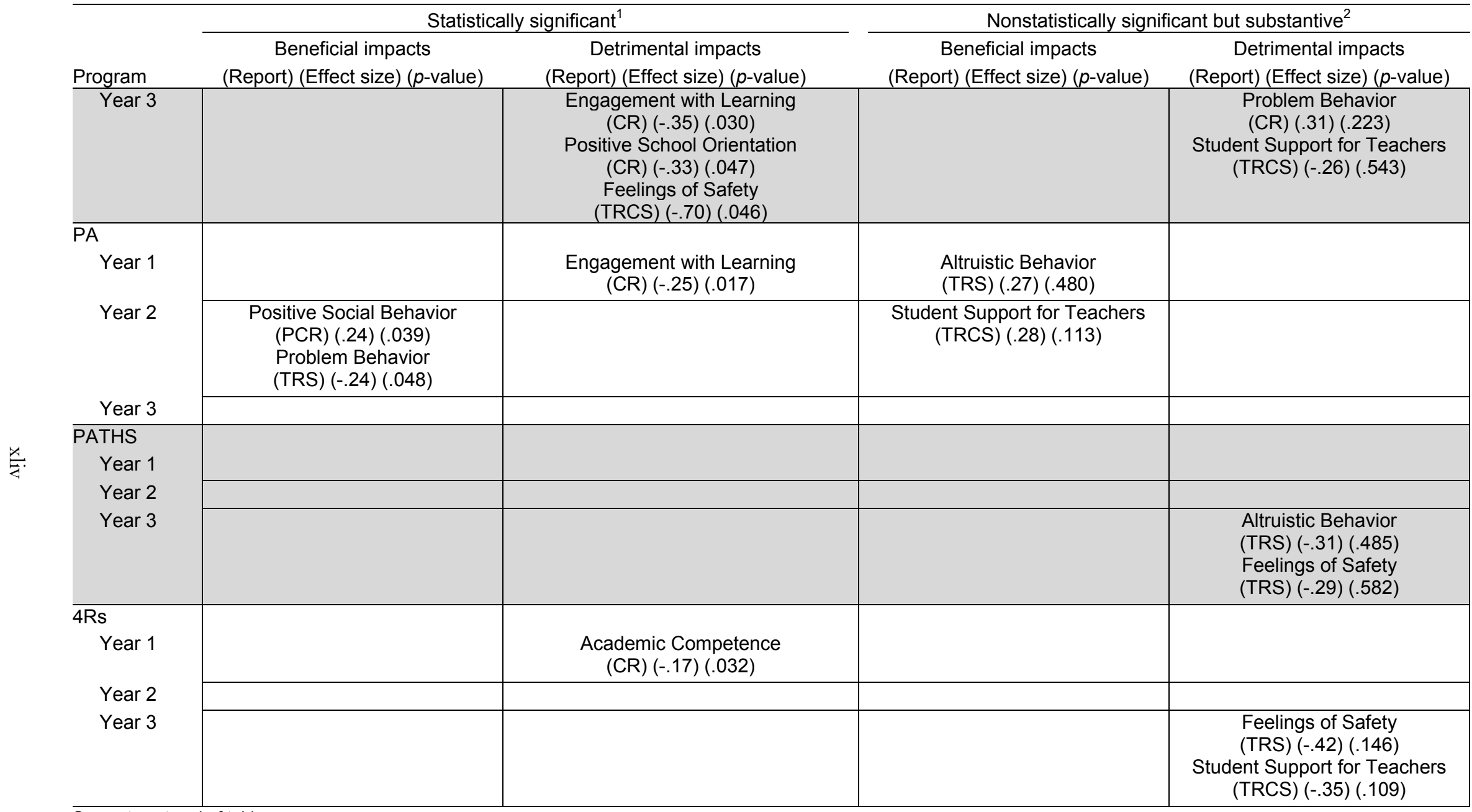


Table G. Individual program statistically significant impacts and nonsignificant but substantively important impacts—Continued

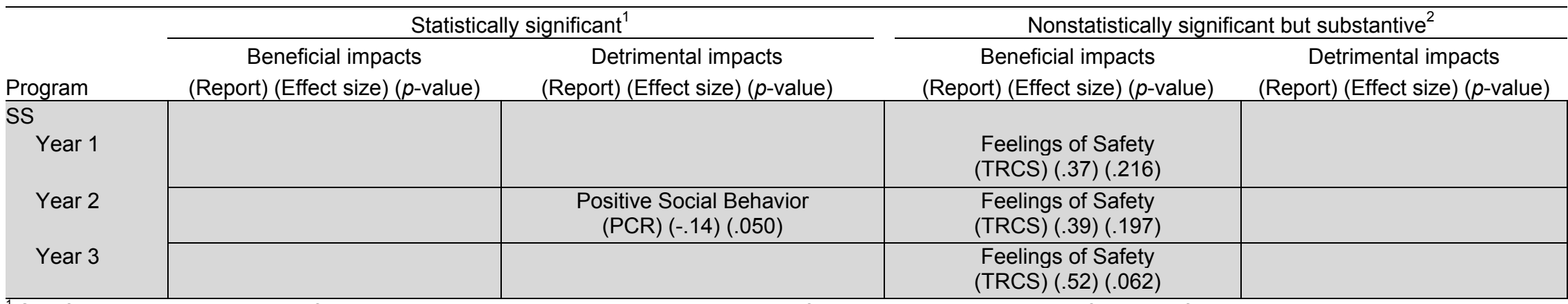

${ }^{1}$ Out of the 140 comparisons made for each year, 7 would be expected to be statistically significant at the .05 level by chance (for a total of 21).

${ }^{2}$ Defined as impacts that were not statistically significant but were .25 standard deviation units (absolute value) or more in magnitude.

NOTE: Abbreviations are

ABC: Academic and Behavioral Competencies Program

CSP: Competence Support Program

LBW: Love In a Big World

PA: Positive Action

PATHS: Promoting Alternative Thinking Strategies

4Rs: The 4Rs Program (Reading, Writing, Respect, and Resolution)

SS: Second Step

CR: Child Report

PCR: Primary Caregiver Report

TRS: Teacher Report on Student

TRCS: Teacher Report on Classroom and School

Blank cell: Finding of no impact

All impact estimates were calculated using regression models in which each school within a program was weighted equally. The standard errors of all estimates account for design effects due to unequal weighting and the clustering of students within schools. Significance is based on $p \leq .05$. The number of results found significant was no more than expected by chance.

SOURCE: The Social and Character Development (SACD) Research Program. 


\section{Executive Summary}

The lack of statistically significant impacts found in the combined-program analysis was not due to offsetting impacts among subgroups defined by gender, stayer versus new entrant status, and different levels of initial student risk. A greater number of significant differences were found than would be expected by chance in the gender and initial student risk analyses (but not in the stayer analysis); however, the differences did not favor any one subgroup, and only in seven cases were they replicated across the years (these data are not shown in a table). The analysis by gender found 8 statistically significant differences between the genders out of 54 possible, where 3 would be expected by chance; half of the significant impacts were beneficial impacts and half were detrimental impacts (one of the detrimental impacts was replicated in Years 2 and 3). The analysis of stayers versus new entrants found no statistically significant differences in the 36 comparisons. For the five types of different initial risk, the analysis found 41 statistically significant differences among three levels of student risk (low, average, and high) out of the 270 possible (13 or 14 would have been expected to be significant by chance); of these, 26 showed more beneficial impacts for higher risk students versus lower risk students (4 of these were replications across years), and 15 showed more detrimental impacts for higher risk students ( 2 of these were replications across years). ${ }^{25}$

The analysis of the fidelity data found little evidence of a relationship between high fidelity and more beneficial outcomes (these data are not shown in a table). The number of significant associations found between fidelity and beneficial outcomes was higher than expected by chance ( 5 associations found compared to 3 that might be expected by chance out of 54 estimated impacts) but 4 of the 5 significant results were due to detrimental associations between low fidelity and outcomes (rather than beneficial associations between high fidelity and outcomes).

In conclusion, the analysis of the year-by-year impacts did not yield evidence that the seven SACD programs, combined and individually, improved student social and character development. A small number of findings were statistically significant (but no more than would be expected by chance, except for several of the subgroups) or substantively important. These results were split into similar numbers of beneficial and detrimental impacts; that is, the SACD programs improved some outcomes but worsened others. In the majority of cases, the results (both beneficial and detrimental) occurred in only 1 year and were not replicated across the 3 years of the study.

\section{Impacts on Growth of Student Outcomes}

A growth curve analysis was done to examine the change over time in the impacts on the outcomes between fall 2004 and spring 2007. ${ }^{26}$ The growth curve analysis used the same covariates and compared results across the same subgroups as the cross-sectional analyses to ensure the comparability of the results. However, it differed from the cross-sectional analyses by examining the estimated impacts on the trajectories of student outcomes over time, rather than at a point in time. The sample of students for the growth curve analysis included all students who were enrolled in one of the study schools during the study period and who completed a survey during the initial data collection or at any of the four follow-up survey points. The percentages of the sample with responses were similar for treatment and control schools in most survey waves; however, the percentages were statistically significantly higher for the treatment group on the Child Report and Primary Caregiver Report in fall 2004 and on the Child Report in spring 2005. There was considerable turnover within the sample by spring 2007. Across the three survey instruments that reported on students, about two-thirds of the sample had taken part in the original fall 2004 survey $(66 \%$ for the Child Report and the Primary Caregiver Report, and 68\% for the Teacher Report on Student). There were no statistically significant differences in the level of turnover by treatment status. ${ }^{27}$ The 18 child-level outcome measures collected from the Child Report, Primary Caregiver Report, and Teacher Report on Student were used in the growth curve analysis. The 2 other outcomes, Feelings of Safety and Student Support for Teacher,

\footnotetext{
25 The section Year-By-Year Subgroup Analysis of Impacts on Students in chapter 1 provides the details on these results.

${ }^{26}$ See Impacts on Growth of Student Outcomes in chapter 1 for more detail on the growth curve analysis and results.

${ }^{27}$ For details see table 1.36 in chapter 1.
} 


\section{Executive Summary}

collected by the Teacher Report on Classroom and School were not used because they were measured at the teacher level.

The impacts over time were estimated using growth curve models (with time since implementation of the program as the time metric) by examining treatment and control group differences in the trajectories of student outcomes during the study while accounting for clustering at the school level. The growth curve models were estimated using a three-level hierarchical linear model, where Level 1 corresponded to time since implementation of the program, Level 2 to students, and Level 3 to schools. The models included the same set of covariates that were used for the cross-sectional analysis except they excluded the initial outcome measure as a covariate because it was used as the outcome measure for the growth curve analysis at time 1 (fall 2004). Similarly, sample weights were used in all analyses to (1) give each program equal weight within each time period; (2) give each school equal weight in each program (within each time period); and (3) give each time period equal weight in the analysis. However, the weights were not adjusted for consent and response differences across classrooms or schools because the population of students within the schools changed over time as students entered and left the schools. Similar to the year-by-year analyses, the growth model was estimated for the seven programs combined and for each program individually. In addition, the effects of the combined programs by subgroup were estimated by including interaction terms between treatment status, time since implementation, and indicators of membership in subgroups.

Growth curve effect sizes were calculated by dividing the estimated impact of the treatment on the outcome growth trajectory by the standard deviation of that outcome. ${ }^{28}$ The growth curve estimates the change in outcomes over 1 year, so the estimated impact of the treatment on the growth trajectory equals the difference between the treatment group's outcome and the control group's outcome, on average, after 1 year of the study. ${ }^{29}$ The effect size measures the number of standard deviations the treatment group differs from the control group after 1 average year of the study, making it analogous to the effect size calculations for the cross-sectional analysis.

The growth curve analysis found no significant effects of the seven SACD programs when combined (table $\mathrm{H})$. None of the 18 estimated impacts on the trajectories of child outcomes from the average of the seven SACD programs were statistically significant. The estimated effect sizes all fell below .07 (absolute value).

The lack of significant effects reflected in the analysis of the seven programs together was not found to be due to differences among the individual programs. The results from the analysis of individual programs indicate that the lack of significant impacts in the overall evaluation reflected the lack of significant impacts at the program level. Six statistically significant impacts were found in the program analyses, the same number expected by chance given that 126 impacts were estimated. Two were beneficial impacts and four were detrimental impacts (table I).

\footnotetext{
${ }^{28}$ The standard deviation was calculated using data for the weighted control group. It was calculated at the time of data collection for which the effect size (impact) was estimated.

${ }^{29}$ This impact estimate takes into account differences between the initial levels of the outcome for the treatment and control groups, differences in their covariates, and the effects of clustering at the school level.
} 
Table H. Impacts on growth of child outcomes from combined-program analysis

\begin{tabular}{|c|c|c|c|c|c|c|c|}
\hline \multirow[b]{2}{*}{ Scale-Report } & \multicolumn{7}{|c|}{ Average growth in the score per year ${ }^{1}$} \\
\hline & $\begin{array}{r}\text { Mean score at } \\
\text { implementation }^{2} \\
\end{array}$ & $\begin{array}{r}\text { Treatment } \\
\text { group }\end{array}$ & $\begin{array}{r}\text { Control } \\
\text { group } \\
\end{array}$ & $\begin{array}{l}\text { Impact on } \\
\text { growth }^{3} \\
\end{array}$ & $\begin{array}{l}\text { Effect } \\
\text { size }^{4}\end{array}$ & $\begin{array}{r}\text { Standard } \\
\text { error of } \\
\text { impact }\end{array}$ & $\begin{array}{r}p \text {-value of } \\
\text { impact }\end{array}$ \\
\hline \multicolumn{8}{|l|}{ Social and Emotional Competence Domain } \\
\hline Self-Efficacy for Peer Interactions-CR (+) & 2.95 & 0.13 & 0.13 & 0.00 & 0.00 & 0.01 & 0.942 \\
\hline Normative Beliefs About Aggression-CR (-) & 1.23 & 0.10 & 0.07 & 0.02 & 0.04 & 0.01 & 0.115 \\
\hline Empathy-CR (+) & 2.41 & $-0.14^{\wedge}$ & -0.12 & -0.02 & -0.05 & 0.01 & 0.070 \\
\hline \multicolumn{8}{|l|}{ Behavior Domain } \\
\hline Altruistic Behavior-CR (+) & 1.41 & -0.17 & -0.16 & -0.01 & -0.01 & 0.02 & 0.681 \\
\hline Altruistic Behavior-PCR (+) & 2.32 & -0.03 & -0.03 & 0.01 & 0.01 & 0.01 & 0.616 \\
\hline Altruistic Behavior-TRS (+) & 1.40 & -0.04 & 0.00 & -0.04 & -0.07 & 0.03 & 0.224 \\
\hline Positive Social Behavior-PCR (+) & 2.99 & 0.04 & 0.03 & 0.01 & 0.02 & 0.01 & 0.217 \\
\hline Positive Social Behavior-TRS (+) & 3.00 & 0.00 & 0.01 & -0.01 & -0.01 & 0.03 & 0.671 \\
\hline Problem Behavior-CR (-) & 0.24 & 0.10 & 0.08 & 0.01 & 0.02 & 0.01 & 0.351 \\
\hline Problem Behavior-PCR (-) & 1.58 & -0.01 & -0.01 & 0.00 & 0.00 & 0.01 & 0.843 \\
\hline Problem Behavior-TRS (-) & 1.38 & 0.05 & 0.05 & 0.00 & 0.00 & 0.01 & 0.909 \\
\hline ADHD-Related Behavior-TRS (-) & 1.75 & -0.02 & -0.01 & -0.01 & -0.01 & 0.02 & 0.707 \\
\hline \multicolumn{8}{|l|}{ Academics Domain } \\
\hline Engagement with Learning-CR (+) & 3.69 & -0.03 & -0.03 & 0.00 & -0.01 & 0.01 & 0.707 \\
\hline Academic Competence and Motivation-TRS (+) & 2.87 & 0.02 & 0.03 & -0.01 & -0.01 & 0.02 & 0.590 \\
\hline
\end{tabular}


Table H. Impacts on growth of child outcomes from combined-program analysis-Continued

\begin{tabular}{|c|c|c|c|c|c|c|c|}
\hline \multirow[b]{2}{*}{ Scale-Report } & \multicolumn{7}{|c|}{ Average growth in the score per year ${ }^{1}$} \\
\hline & $\begin{array}{r}\text { Mean score at } \\
\text { implementation }\end{array}$ & $\begin{array}{r}\text { Treatment } \\
\text { group }\end{array}$ & $\begin{array}{r}\text { Control } \\
\text { group } \\
\end{array}$ & $\begin{array}{l}\text { Impact on } \\
\text { growth }^{3} \\
\end{array}$ & $\begin{array}{l}\text { Effect } \\
\text { size }^{4}\end{array}$ & $\begin{array}{r}\text { Standard } \\
\text { error of } \\
\text { impact }\end{array}$ & $\begin{array}{r}p \text {-value of } \\
\text { impact }\end{array}$ \\
\hline \multicolumn{8}{|l|}{ Perceptions of School Climate Domain } \\
\hline Positive School Orientation-CR (+) & 3.09 & -0.24 & -0.21 & -0.03 & -0.03 & 0.02 & 0.163 \\
\hline Negative School Orientation-CR (-) & 1.84 & 0.10 & 0.09 & 0.01 & 0.01 & 0.02 & 0.696 \\
\hline Student Afraid at School-CR (-) & 2.38 & -0.08 & -0.08 & 0.00 & 0.00 & 0.02 & 0.956 \\
\hline Victimization at School-CR (-) & 0.76 & -0.03 & -0.02 & -0.01 & -0.01 & 0.02 & 0.368 \\
\hline
\end{tabular}

$\wedge$ Treatment group significantly different from control group at the .10 to $>.05$ level.

${ }^{1}$ Pertains to the estimated slope of the outcome for the treatment or control groups.

${ }^{2}$ The average score at implementation is calculated across treatment and control groups, using regression models for adjustment on covariates.

${ }^{3}$ Estimated difference between the slope of the treatment and control groups.

${ }^{4}$ The slope of the treatment group minus the slope of the control group divided by the standard deviation of the outcome for the combined-program control group (the standard

deviation is calculated without accounting for school-level clustering or regression adjustments)

NOTE: Abbreviations are

CR: Child Report

PCR: Primary Caregiver Report

$\triangle \quad$ TRS: Teacher Report on Student

ADHD: Attention deficit hyperactivity disorder

The $+/$ - signs in parentheses indicate the direction of a beneficial outcome. No findings were found statistically significant at or below the .05 level. All impact estimates were calculated using HLM 6.06.

SOURCE: The Social and Character Development (SACD) Research Program. 
Table I. Significant impacts from the growth curve analyses of the individual programs

\begin{tabular}{|c|c|c|c|}
\hline Program & $\begin{array}{l}\text { Significant beneficial impacts } \\
\text { (Report) (Effect size) ( } p \text {-value) }\end{array}$ & $\begin{array}{l}\text { Significant detrimental impacts } \\
\text { (Report) (Effect size) ( } p \text {-value) }\end{array}$ & $\begin{array}{l}\text { Total significant*1 } \\
\text { impacts }\end{array}$ \\
\hline Total & 2 & 4 & 6 \\
\hline$A B C$ & & & 0 \\
\hline CSP & $\begin{array}{l}\text { Victimization at School } \\
\quad(C R)(-.09)(.050)\end{array}$ & & 1 \\
\hline LBW & & $\begin{array}{l}\text { Positive School Orientation } \\
\text { (CR) (-.13) (.016) }\end{array}$ & 1 \\
\hline PA & & & 0 \\
\hline PATHS & $\begin{array}{l}\text { Academic Competence } \\
\text { (TRS) (.08) (.048) }\end{array}$ & & 1 \\
\hline 4Rs & & & 0 \\
\hline SS & & $\begin{array}{c}\text { Engagement with Learning } \\
\text { (CR) (-.09) (.021) } \\
\text { Positive Social Behavior } \\
\text { (TRS) }(-.19)(.019) \\
\text { Empathy } \\
\text { (CR) }(-0.13)(.028)\end{array}$ & 3 \\
\hline
\end{tabular}

* Significantly different from zero at the .05 level.

${ }^{1}$ Out of the 126 comparisons made (7 programs times 18 outcomes), 6 would be expected to be statistically significant at the .05 level by chance.

NOTE: Abbreviations are

ABC: Academic and Behavioral Competencies Program

CSP: Competence Support Program

LBW: Love In a Big World

PA: Positive Action

PATHS: Promoting Alternative Thinking Strategies

4Rs: The 4Rs Program (Reading, Writing, Respect, and Resolution)

SS: Second Step

CR: Child Report

TRS: Teacher Report on Student

Blank cell: Finding of no impact

The number of results found significant was no more than expected by chance.

SOURCE: The Social and Character Development (SACD) Research Program. 


\section{Executive Summary}

The lack of findings from the combined-program analysis was not found to be due to differences among subgroups (these data are not shown in a table). The subgroup analyses did not find evidence regarding differential impacts of the seven SACD programs, combined, on the subgroups. For the gender subgroup analysis, none of the 36 estimated impacts were statistically significant. For the analysis of new entrants, 1 impact was found to differ significantly and detrimentally from the impact on members of the original sample, which was no more than would be expected by chance. There were 6 outcomes out of 90 estimated for which growth trajectories differed significantly across initial risk levels (4 to 5 would have been expected by chance); for 4 of the 6 outcomes, the programs had more beneficial impacts for children with higher initial risk levels, while for 2 outcomes they had more detrimental impacts for children with higher initial risk levels.

\section{Discussion}

The year-by-year analysis and the growth curve analysis did not find that the seven SACD programs improved student outcomes when considered together, individually by program, or for specific subgroups. For the combined-program analyses, the year-by-year analysis found fewer significant impacts than expected by chance ( 2 out of 60 estimated impacts) and the growth curve analysis found no significant impacts. For the individual program analyses, the year-by-year analysis found fewer significant impacts than expected by chance ( 16 out of 420 estimated impacts), with 9 having beneficial impacts and 7 having detrimental impacts. The growth curve analyses of the individual programs found the same number of impacts as expected by chance ( 6 out of 126 estimated impacts), with 2 having beneficial impacts and 4 having detrimental impacts. For the subgroup analyses, the year-by-year analyses found more significant impacts than expected by chance for gender (8 out of 54 estimated impacts) and initial risk levels (41 out of 270 estimated impacts). For gender, half of the significant impacts showed a beneficial impact of the intervention and half showed a detrimental impact. For initial risk levels, 26 showed a beneficial impact of the intervention on high-risk students and 15 showed a detrimental impact on high-risk students. The growth analysis found fewer significant impacts than expected by chance for all the subgroups except those based on initial risk levels (6 out of 90 estimated impacts). Four of the 6 significant impacts were beneficial and 2 were detrimental. In sum, the SACD combined-program evaluation provides no evidence that the seven universal, schoolwide programs improved students' social and character development.

Several explanations for this finding can be considered: (1) failure of the conceptualization and design of the intervention, (2) weak implementation of the intervention, (3) nonsubstantial differences in the level of SACD activities in the treatment and control schools, and (4) methodological limitations of the evaluation.

Failure of the conceptualization and design of the intervention refers to the possibility that the seven programs tested might not have altered students' social and character development in the expected ways because the theories underlying them or the combinations of activities chosen to bring about the desired changes in students' attitudes and behaviors were inadequate for the purpose. For example, one alternative view to that adopted in the SACD evaluation is that only a subset of elementary-aged children has deficits in social behavior and character, and these deficits require a more targeted, more intensive intervention than schoolwide programs can provide. Therefore, for a school-based program to be effective, a combination of schoolwide and targeted activities might be required for the intervention to make a significant difference in student outcomes (e.g., see Conduct Problems Prevention Research Group 1999). Such explanations, if confirmed by other studies, would lead toward focusing more effort on understanding how social and character development occurs among elementary-aged children, how this development can be affected, and what types of practices in classrooms and schools can be used to bring about desired effects.

Weak implementation of the intervention refers to the possibility that, although the intervention might have been well conceived and well designed, the treatment schools did not implement the practices effectively on average. Weakly implemented programs may not have positive impacts on students. The SACD evaluation examined seven different SACD programs, each with unique features, and the fidelity rating that was used measured fidelity of implementation relative to the targets established for each specific intervention. In this 


\section{Executive Summary}

way, the ratings were standardized relative to each site's program-specific benchmarks, allowing them to be compared across programs and years. The analysis of the fidelity data found little evidence of a relationship between high fidelity and more beneficial outcomes. The number of significant associations found between fidelity and beneficial outcomes was higher than expected by chance ( 5 found, with 3 expected by chance out of 54 estimated impacts), but 4 of the 5 significant results were due to detrimental associations between low fidelity and outcomes rather than beneficial associations between high fidelity and outcomes. The approach used to obtain comparable ratings required two compromises. First, it could not account for differences among the programs' implementation standards - for example, whether programs differed in how difficult they were to implement. Second, it provided little information about why implementation was of a certain quality. As a result, the SACD evaluation fidelity measure may not provide adequate information about whether low fidelity might have been the reason behind the lack of significant findings. The fidelity measures used by each research team, which used team-chosen criteria, may provide additional information on how well each program was implemented in each treatment school.

Nonsubstantial differences in the level of SACD activities refers to the possibility that the implementation differences between the treatment and control schools were not great enough to generate statistically significant differences in student outcomes. Like the treatment schools, the control schools joined the study with a willingness to implement a SACD program showing a willingness to promote social and character development. In addition, some of the sites were located in states where legislation required or promoted such activities. The control group represented "standard practice," which included the reported use of SACD activities in the classroom. For example, 86 percent to 90 percent of control teachers reported using activities to promote any one of the six SACD goals. While a statistically significant larger percentage of teachers in the treatment schools $(95 \%$ to $96 \%$ ) reported conducting such activities, the 5- to 10-percentage-point differences may not have been large enough to lead to improved student outcomes. At the same time, the significant differences between treatment and control teacher reports were larger than 5 to 10 percentage points for other responses regarding the use of SACD activities. For example, the differences between treatment and control teachers regarding the use of activities from specifically named programs were 29 to 34 percentage points across the 3 years. These results, plus the finding that treatment teachers reported greater use of some instructional materials and methods to promote SACD goals, provide evidence that the treatment teachers were making a more intensive effort to promote social and character development.

There are three methodological limitations of the evaluation that may have contributed to the finding of no impacts on student outcomes.

First, the evaluation relied on self-reported data by teachers and principals regarding the use of SACD activities. Observational studies were not done to validate these reports. If treatment teachers over-reported their use of SACD activities (possibly because they felt an expectation to report high use given that a SACD program was being implemented in their school), the impacts of the treatment could be misestimated. That is, if there really were no differences in the levels of SACD activities between the treatment and control groups, then a lack of effects might be expected. However, treatment teachers did differ in their reported use of any activities to promote one of the six SACD goals (95\% to $96 \%$ reported such use) versus their reported use of any activities from named programs $(68 \%$ to $72 \%)$ This, while not ruling out the possibility of systematic over-reporting, might suggest that some teachers were candid in their reporting on their use of the treatment programs. The research teams used observations or product measures to check implementation of their specific programs, and the results from this work may provide additional evidence about the potential importance of over-reporting of implementation by treatment teachers.

A second methodological limitation was that student-provided data (used for 12 of the 20 outcomes) were not available for 36 percent to 39 percent of students, depending on the year, because primary caregivers did not provide written consent or students did not assent to take part in the study (primary caregiver data, used for three outcomes, were not available for $49 \%$ to $54 \%$ of students). It is possible that students included in the study differed from those not included due to an absence of data. As the study did not collect descriptive 


\section{Executive Summary}

data on the nonobserved students, the existence of such differences could not be determined, and how the inclusion of these students in the study would have affected the findings is unknown. Given the few statistically significant and substantively important impacts found with the existing sample, there would need to be a large and consistent impact on the nonobserved students (had they been included) to change the findings. For example, because two-thirds of the population who were observed received an average impact of zero, the nonobserved one-third would need to have received an average impact of nearly one-third of a standard deviation to bring the overall mean to one-tenth of a standard deviation unit. In addition, because the subgroup analyses did not find systematically significant impacts, there is no evidence that should these missing students come from one of the subgroups (e.g., higher initial risk) their inclusion would change the findings.

A third methodological limitation was the sample size for the individual program evaluations. The combined analysis of all seven programs provided a sample size sufficient to detect student-level impacts at minimum detectable effect sizes (MDES) ranging from 0.03 to 0.23 standard deviations (with more than $75 \%$ of them below 0.10 standard deviations). The power to detect impacts at the level of the individual programs was more limited (the MDES ranged from 0.09 to 1.04 over the 3 years), and individual program-level effects might have been missed. To address this limitation at the program level, nonsignificant impacts of at least 0.25 standard deviations were identified as substantively important results. Only a small number of these were identified, with an almost equal division into beneficial and detrimental effects.

The seven programs tested in the SACD evaluation were similar in being coherent, universal, school-based programs to promote social and character development of third- to fifth-grade students. They were diverse both in their specific goals and in their approaches to promoting social and character development for all students. In addition, they were evaluated in diverse types of locales in which schools served communities with very different ethnic and socioeconomic compositions. On average, the seven programs did not improve students' social and emotional competence, behavior, academic achievement, and student and teacher perceptions of school climate. In addition, although the numbers of schools and students in each program were not always sufficient to support firm conclusions at the program level, the patterns of estimated impacts for each program were largely similar: students' outcomes were not affected. 


\section{Chapter 1. The Social and Character Development Multiprogram Evaluation}

The Social and Character Development (SACD) Research Program was created in response to the need for rigorous evaluations of universal school-based programs designed to help schools foster positive behaviors among students (e.g., behaviors illustrating good character and social-emotional competence), reduce negative behaviors (e.g., aggression and conduct problems), and ultimately improve students' academic performance. For this evaluation, such programs were termed SACD programs, the goals they intended to promote were termed SACD goals, and the activities they employed to promote those goals were termed SACD activities. ${ }^{1}$

The SACD Research Program built on advances in understanding the development of social competence and problem behaviors occurring in the fields of developmental, social, community, behavioral, and cognitive psychology (e.g., Damon 1999; Eisenberg 2000; Larson 2000; Seligman and Csikszentmihalyi 2000), and from intervention and evaluation research in the areas of prevention science, public health, youth development, and character education (e.g., Catalano et al. 2004; Dahlberg and Simon 2006; Emler 1996; Flay 2002). Both federal legislation (such as the No Child Left Behind Act of 2001) and state legislation (Limber and Small 2003) have supported prevention and intervention programs, and the SACD Research Program sought to add to the research base underlying such efforts.

In 2003, the Institute of Education Sciences (IES) in collaboration with the Division of Violence Prevention (DVP) in the National Center for Injury Prevention and Control, Centers for Disease Control and Prevention (CDC) began the SACD Research Program to evaluate multiple school-based programs in a consistent manner. Under a competitive application process, applicants proposed programs to be evaluated as long as the programs (a) had either preliminary evidence of success or a history of previous implementation in schools, (b) aimed to influence social development and behavior outcomes, and (c) utilized a universal approach to be implemented in all elementary school classrooms. Applications submitted to IES were peer reviewed, and seven research institutions were funded under cooperative agreements for a 3-year evaluation of seven universal school-based SACD programs. At each of seven sites, one research team recruited and randomized 10 to 18 schools to either continue their current practice or implement a coherent program targeting social and behavioral outcomes. The programs employed activities to promote six SACD goals (character education, violence prevention and peace promotion, social and emotional development, tolerance and diversity, risk prevention and health promotion, and civic responsibility and community service) as well as behavior management. The programs were coherent in that their activities were integrated and logically organized based on a theory of action (that differed among the programs), school-based in that they were implemented in the schools by school personnel, and universal in that they were to be implemented for all students in all elementary classrooms. ${ }^{2}$ The research institutions participating in the study and the programs evaluated included the following:

\footnotetext{
1 The SACD evaluation examined seven SACD programs that employed SACD activities to promote behavior management and six SACD goals: (1) violence prevention and peace promotion, (2) social and emotional development, (3) character education, (4) tolerance and diversity, (5) risk prevention and health promotion, and (6) civic responsibility and community service.

2 As used here, "elementary classrooms" refers to grades K-5. During the study, there were five exceptions to implementation in all elementary classrooms in the treatment schools. In Year 1 (the 2004-05 school year), all treatment schools implemented the intervention in their K-5 classrooms. In Year 2 (2005-06), one school implemented the full intervention in fourth grade only (the cohort grade that year), and one school could not implement in fifth grade because that grade had been transferred to a middle school. In Year 3 (2006-07), one school implemented the intervention in
} 


\section{Chapter 1. The Social and Character Development Multiprogram Evaluation}

\section{Research Institution}

University at Buffalo, The State University of New York

University of North Carolina at Chapel Hill

Vanderbilt University

Oregon State University

The Children's Institute

New York University

University of Maryland

\section{Program Evaluated}

Academic and Behavioral Competencies Program

$(\mathrm{ABC})$

Competence Support Program (CSP)

Love In a Big World (LBW)

Positive Action (PA)

Promoting Alternative Thinking Strategies (PATHS)

The 4Rs Program (Reading, Writing, Respect \&

Resolution) (4Rs)

Second Step (SS)

In addition to conducting their own program evaluations, applicants were expected to participate in the collection of data, facilitated by an independent evaluation contractor. Under another competitive peer-review process, Mathematica Policy Research, Inc. (MPR) was selected to independently evaluate the seven programs.

The evaluation of the SACD programs thus occurred at both the program-specific and multiprogram level. In the program-specific studies, each research team collected data to answer questions that were specific to the program under evaluation. For example, in the program-specific studies, investigators sought to answer questions about the effects of the program on targeted proximal outcomes and about the importance of program implementation quality. Research teams designed their own studies and were expected to report their findings in the relevant literature.

For the multiprogram evaluation, an independent team from MPR assessed the effect of the seven SACD programs through an evaluation of all programs together using (1) standardized data collection for all sites; (2) a common set of descriptive measures on the types and level of SACD activities taking place at both the treatment and control schools; (3) a common set of outcome measures grouped under four outcome domains: Social and Emotional Competence, Behavior, Academics, and Perceptions of School Climate; and (4) a uniform statistical analysis. The effects of each program were also assessed separately to identify any contrasts with the overall findings across programs. The evaluation followed one cohort of third-grade students at 84 schools for 3 years through fifth grade. Initial data were collected in fall 2004, and follow-up data were collected in spring 2005, fall 2005, spring 2006, and spring 2007. In addition, four research teams added a second cohort of third-graders at 12 schools, where initial data were collected in fall 2005 and followup data collected in spring 2006 and spring 2007 (at the end of third and fourth grades) in order to increase sample sizes and the associated power of the program-specific analyses.

This report contains the results for the 3-year multiprogram evaluation and focuses on the first cohort of students. It details the impacts of the seven SACD programs after 1, 2, and 3 school years of implementation in the treatment schools and also estimates the effect of the programs on students' growth in social and character development over the 3 years. Chapter 1 discusses the evaluation of the seven programs when considered together as a subset of universal school-based programs that aim to affect student social development and behavior. Chapter 1 also provides summary results for each program. The seven chapters that follow detail the findings for each individual program. There are two appendixes: appendix A examines whether the addition of the smaller second cohort of students for four of the seven programs affected the results and appendix B contains additional technical information concerning the analyses.

third through fifth grades, one school implemented in fifth grade only (the cohort grade that year), and one school's fifth grade attended a middle school so it was not able to implement the intervention with its cohort grade. 


\section{Social Development and Risk Prevention}

By 8 to 12 years of age, children typically have well-developed skills of self-regulation, perspective taking, emotional understanding, and caring for others. Middle childhood is also a time when children's beliefs about aggression and conflict resolution skills are developing (e.g., Samples and Aber 1998). Because these social competencies underlie many primary developmental tasks of middle childhood (e.g., development of mutual friendships), researchers predict that deficits in these social skills will likely lead to the emergence of problem behaviors.

Research points to several key intrapersonal factors that increase a child's risk for behavior problems, including children's beliefs about the acceptability of aggression (Guerra et al. 1995), lack of problem-solving skills (Slaby and Guerra 1988), attention problems and hyperactivity (Farrington 1989; Rey, Sawyer, and Prior 2005), and attribution of aggression to others' innocuous behavior (Dodge and Coie 1987). Family, peer, and community risk factors also increase the likelihood of behavior problems. These risk factors include poor parental supervision and monitoring (Gorman-Smith et al. 1996), association with aggressive peers (Farrington and Hawkins 1991; Henry, Tolan, and Gorman-Smith 2001), community disorganization (Sampson 2000), and exposure to community violence (Schwartz and Proctor 2000).

Researchers have hypothesized that programs targeting the risk factors described above will be effective in reducing problem behaviors among children. Over time, however, there has been increasing recognition that prevention efforts should not focus on risk alone but take an integrative approach to reducing risk and simultaneously fostering protective factors by developing social competence in young people (Catalano et al. 2004; Weissberg, Kumpfer, and Seligman 2003). Many protective factors that are hypothesized to promote social competence are also thought to inoculate children from developing externalizing behavior problems. Although the research literature on protective factors that relate to risk has been slow in developing, evidence suggests that socially adaptive interpersonal problem-solving (Wentzel 1991), empathy (Schultz, Izard, and Bear 2004), and parental use of positive rewards and encouragement to support appropriate behavior (Gorman-Smith et al. 2000) are related to a lower occurrence of problem behaviors, such as aggression and delinquency.

From an interventionist and public health perspective, schools are an obvious site for addressing positive youth development and prevention efforts because of universal access to children over time that, in turn, allows for efficient distribution of these efforts to a comprehensive population of youth. Elementary school is thought to be a critical time for prevention; 7 is the average age at which students start down the path of problem behavior (Thornberry, Huizinga, and Loeber 2004). Most types of antisocial behavior are already evident by third grade (Loeber and Stouthamer-Loeber 1998), and problem behaviors in childhood are predictive of violence and other antisocial behavior later in adolescence and adulthood (Moffitt 1993).

Programs that address social development and behavior are also attractive to school administrators because of the prevalence of problem behaviors that teachers perceive as interfering with their ability to teach and students' ability to learn (Mansfield et al. 1991). For example, in the 2005-06 school year, 21 percent of primary schools reported occurrences of student bullying at least once per week, 12 percent of schools reported student acts of disrespect for teachers once per week, and 28 percent of 12- to 18-year-old students reported that they had been bullied at school during the 6 months prior to the survey (Dinkes, Cataldi, and Lin-Kelly 2007). A substantial body of literature has shown that disruptive classroom behavior, conduct problems, aggression, delinquency, and substance use are associated with poor academic achievement and with a lack of student feelings of school connectedness and involvement (Bennett et al. 2003; Farrington 1989; Fors, Crepaz, and Hayes 1999; McCord et al. 2000; Najaka, Gottfredson, and Wilson 2001; O’Donnell, Hawkins, and Abbott 1995; Trzesniewski et al. 2006). On the positive side, social competencies have been linked with higher levels of achievement and school adjustment (Carlson et al. 1999; Malecki and Elliot 2002; Wentzel 1993). 
One school element that has gained increasing attention in recent years is the creation of a positive school climate. Researchers have theorized that the development of a warm, caring community within a school might reduce student problem behaviors, such as aggression and bullying (Battistich et al. 1997; McEvoy and Welker 2000; Orpinas and Horne 2006); however, research directly testing this hypothesis is limited. Overall, the abundance of evidence supporting relations among social competence, problem behavior, and achievement, and the development of theories surrounding the potential effects of a positive school climate on student outcomes, has motivated the development and, in turn, evaluation of school-based programs.

\section{Universal School-Based Social and Character Development Programs}

Schools commonly use support services, intervention curricula, and discipline management strategies to promote social and character development and prevent problem behavior (Crosse et al. 2001; Gottfredson and Gottfredson 2001). Many of these programs are targeted programs; that is, they focus on addressing behavior problems for children who are at risk or for children who are already exhibiting adjustment difficulties (see Mytton et al. 2006 for a review of the effectiveness of such approaches). Alternatively, a universal approach can be taken to influence the attitudes and behaviors of all children in the general student population. Universal approaches focus on preventing problems before they occur by addressing factors that place youth at risk for problem behavior and promoting factors that foster positive youth development (Walker and Shinn 2002).

Universal school-based prevention programs have followed different theoretical traditions. Character education programs teach moral values through the curriculum and attempt to create a climate of caring and moral discipline (Lickona 1993). Social and emotional learning programs stress goal-setting, emotion identification, responsible decisionmaking, perspective-taking, and effective interpersonal skills, within a caring and engaging school climate (Greenberg et al. 2003; Stage and Quiroz 1997). Through systematic assessment and evaluation of behavior, Behavior management approaches utilize learning theory to apply strategies such as positive reinforcement, consistent schoolwide discipline, and antecedent control to minimize disruptive and aggressive behaviors and promote prosocial behaviors in all settings in the school (Kazdin 2001). Primary youth violence prevention approaches identify the individual, relationship, and environmental factors that place youth at risk for engaging in violence-related behaviors. They implement strategies that modify those risk factors, such as by changing attitudes, beliefs, behaviors, and environments, to disrupt developmental pathways to violence (e.g., through cognitive-behavioral and social skill training, changing peer group norms, and modifying school settings via teacher training and setting school administrative policies and rules; Dahlberg 1998). What each of these universal school-based approaches has in common is the desired goal of promoting students' social development and reducing engagement in problem behavior. As a group, these approaches aim to improve social and character development.

Evidence of the effectiveness of universal school-based programs to promote social and character development is mixed. Some recent meta-analyses suggest that universal school-based approaches to preventing aggressive behavior can be effective (Hahn et al. 2007; Wilson and Lipsey 2007). Other rigorous studies and meta-analyses have shown significantly positive effects on some outcomes of interest but indeterminate or non-statistically significant effects on other outcomes, no significant effects at all, and even potentially negative effects (e.g., CPPRG 1999; Grossman et al. 1997; Flannery et al. 2003, Park-Higgerson et al. 2008, Merrell et al. 2008).

In addition, some universal, school-based SACD programs have yet to be evaluated, while others have been evaluated using nonrigorous methodology, design, and analysis (e.g., small sample sizes and low statistical power, severe attrition, lack of randomization to condition, and inappropriate level of analysis). For example, at the time this report was written, the What Works Clearinghouse had reviewed 55 evaluation studies of 13 character education programs and found that two-thirds of these studies either did not meet Clearinghouse 


\section{Chapter 1. The Social and Character Development Multiprogram Evaluation}

standards or met its standards with reservations (What Works Clearinghouse, n.d.-a). ${ }^{3}$ The What Works Clearinghouse also identified 14 additional character education programs for which no evaluations were found.

Given the methodological limitations of many previously conducted studies, the mixed findings from previous rigorous evaluations, and the theoretical rationales for conducting school-based programs, researchers have called for further evaluation of prevention programs in the elementary school years to assist in our understanding of whether middle childhood is an optimal time for prevention (Tolan, Guerra, and Kendall 1995). In particular, there has been a call for more rigorous evaluation of school-based programs in which a universal approach to development and prevention is used, including random assignment to condition; documentation of control group practice; reliable, valid, and age-appropriate measures from multiple data sources; short- and long-term follow-up of students; sufficient statistical power; appropriate multilevel analyses; and exploration of mediator and moderator variables (Farrell and Camou 2006; Greenberg 2004; Weissberg, Kumpfer, and Seligman 2003).

One difficulty with interpreting the results of the existing evaluation literature has been the use of different measurement strategies to assess similar social and behavioral outcomes. That is, similar outcomes have been assessed using different measures across evaluations. Meta-analyses have been used as one approach to summarizing the effectiveness of universal programs on behavior by clustering outcomes by conceptual domains (e.g., aggression, disruptive behavior; Wilson and Lipsey 2007). Another approach, one taken by the SACD Research Program, is to use a common set of measures to evaluate multiple programs on the same outcomes of interest.

Universal SACD programs both share and differ in their structures, approaches, and theories of change. To assist in developing hypotheses and selecting measures for the multiprogram evaluation, a global conceptual model was developed within which all seven programs could be included, although none would strictly follow the entire model. The model was used to help in the design of the multiprogram evaluation but was not to be tested itself. Figure 1.1 shows the set of common structures and approaches on which the seven SACD programs draw. It identifies a set of moderating factors expected to influence the success of all programs; these include characteristics of the student, the student's family, the school, and the community, as well as the program. The model shows the four outcome domains (Social and Emotional Competence, Behavior, Academics, and Perceptions of School Climate) expected to be affected by the SACD programs and the specific outcomes that were to be examined within each domain. The pathways in the model show that, in general, the programs were expected to increase the proximal domains of improving social competencies and perceptions of school climate and, directly and indirectly through the proximal domains, to affect the distal domains of improving students' behavior and academics.

\section{Research Questions}

All seven of the programs in the SACD multiprogram evaluation were universal, school-based interventions that targeted social and behavioral outcomes. The evaluation examined both the average effect of all seven programs combined and the average effect of each specific program on student outcomes and on student and teacher perceptions of school climate.

The primary research questions for the evaluation were as follows:

1. What is the average effect of the seven universal, school-based, social and character development programs on social and character development instruction in the schools?

\footnotetext{
3 The What Works Clearinghouse was established in 2002 by the U.S. Department of Education's Institute of Education Sciences to assess the rigor of research evidence on the effectiveness of educational interventions.
} 
Figure 1.1. Conceptual model for social and character development interventions

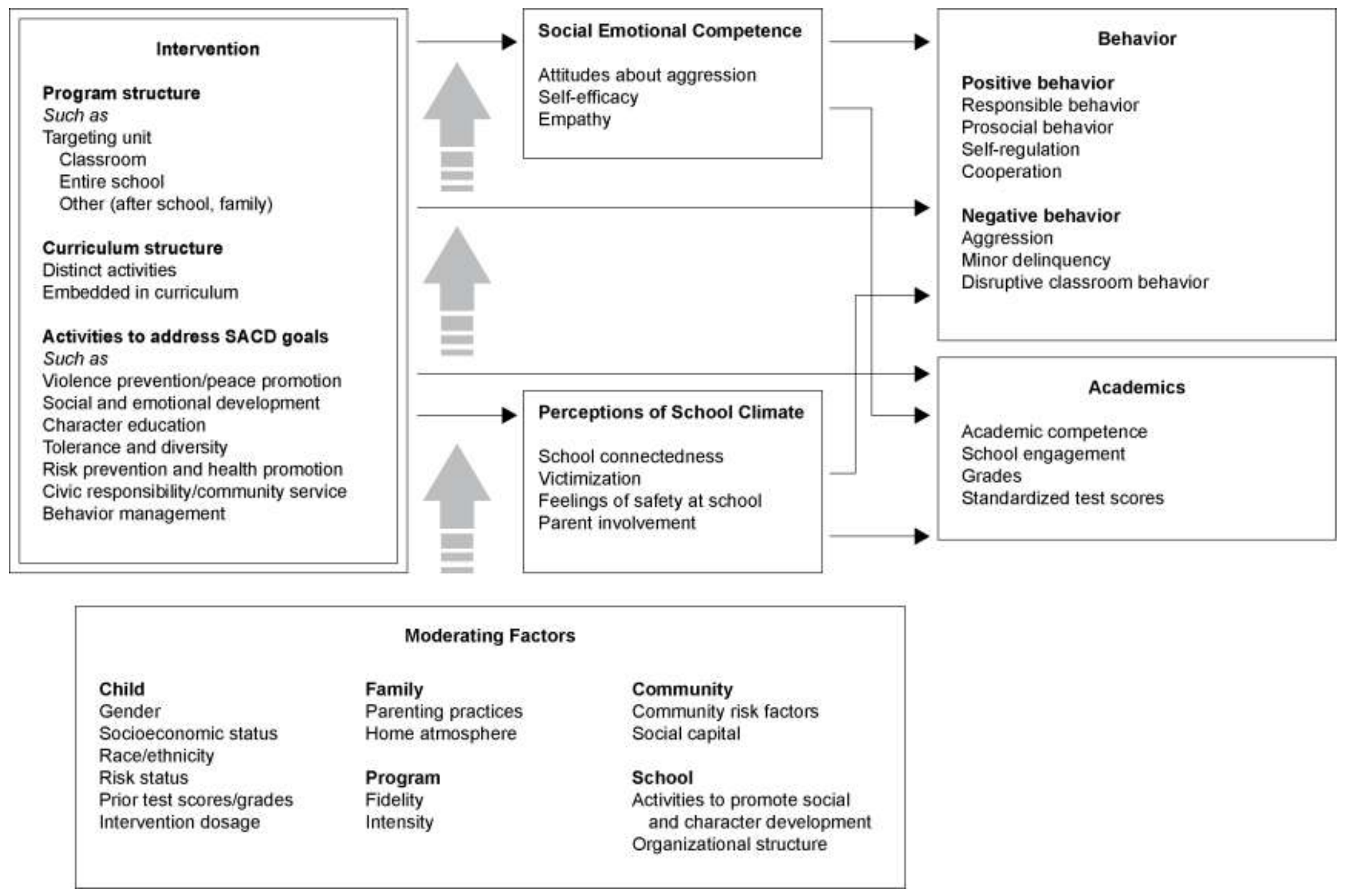




\section{Chapter 1. The Social and Character Development Multiprogram Evaluation}

2. What is the average effect of the seven universal, school-based, social and character development programs on students' social and emotional competence, behavior, and academics, and on perceptions of school climate?

3. What is the average effect of each specific social and character development program on students' social and emotional competence, behavior, and academics, and on perceptions of school climate?

As noted in figure 1.1, a set of moderating factors was expected to affect the success of any SACD program. The potential impact of these factors raised secondary research questions concerning the differential impact of a SACD program on student subgroups and by the quality of implementation of the program.

Subgroups of students may differ enough in their behaviors that the impact of a SACD program may have differential impacts on those subgroups. Significant gender differences exist in the frequency of cooperative, prosocial behaviors and problem behaviors among young children. Aggression and hyperactive behaviors tend to be more common among boys. Among violence prevention programs that have examined whether programs are differentially effective for boys and girls, four have indicated significant effects for boys but not for girls (Farrell and Meyer 1997; Flay et al. 2004; Kellam et al. 1998). Given these observed differences, the average effects of the seven programs were expected to differ by student gender.

Previous research has also documented that certain family and community characteristics are associated with greater prevalence of behavioral problems for children. Regarding the family, children from poor families are at greater risk for behavioral or emotional problems (Brooks-Gunn and Duncan 1997) and show difficulties with aspects of social competence such as self-regulation and impulsivity (Takeuchi, Williams, and Adair 1991). Poor parental supervision and monitoring are associated with the development of problem behaviors in children (Gorman-Smith et al. 1996), and parental involvement has been linked to children's overall behavior in school, motivation to learn, grades and test scores, and long-term achievement (Griffith 1996; Grolnick, Ryan and Deci 1991; Shaver and Walls 1998; Zellman and Waterman 1998). At the community level, disorganization (Sampson 2000) and exposure to community violence (Schwartz and Proctor 2000) are associated with greater risk for behavior problems. Neighborhood disadvantage has also been consistently linked with increased levels of child aggression, emotional problems, inattention problems, and conduct problems (Caspi et al. 2000; Gershoff and Aber 2006). As a consequence, the average effect of the seven programs was expected to differ for children experiencing different levels of family and community risk.

Early childhood conduct problems and aggressive behaviors are another risk factor for later problem behaviors such as fighting, delinquency, and drug involvement (Dodge and Pettit 2003). Meta-analytic studies that have examined the effect of school-based programs on problem behaviors indicate larger effect sizes for programs targeting "high-risk" populations than general school populations (Wilson, Gottfredson, and Najaka 2001; Wilson, Lipsey, and Derzon 2003).

The differential behavior found among certain student subgroups and some evidence of differential responses by these subgroups to programs led to the fourth research question:

4. Do the average effects of the seven universal, school-based social and character development programs differ by (a) students' gender and (b) students' initial risk factors (socioeconomic, family, community, and earlier child behavior)?

Fidelity of program implementation has been found to strongly affect the impacts of interventions of all types. A number of studies show that programs delivered with high fidelity lead to better outcomes than programs implemented with lower fidelity (e.g., Crandall et al. 1982; Stringfield et al. 1997). This raised a fifth research question:

5. In the treatment schools, is there an association between the level of implementation of the social and character development programs and impacts on student outcomes? 


\section{The Social and Character Development Research Program}

In 2003, IES, in collaboration with DVP, conducted a peer-reviewed research grant competition in which applicants proposed to (1) implement a universal, school-based intervention for elementary school children intended to promote positive behaviors and attitudes and/or reduce negative or antisocial behaviors and attitudes and (2) evaluate the intervention using a cluster randomized design in which schools would be the unit of assignment. Applicants were encouraged to both identify measures that assessed the specific attitudes and behaviors that their proposed intervention was designed to improve and to take into account the fact that the implementation and evaluation of the intervention would take place within the context of a larger multiprogram evaluation in which a third party would collect comparable outcomes from all schools participating in the evaluation. That is, in addition to whatever measures the applicants proposed to use, all of the interventions in the SACD Research Program would be evaluated on a set of measures that would be collected by an evaluation team that would be separate from the research teams involved in implementing the interventions.

Seven research teams were selected through a peer-review process, and they entered into cooperative agreements with IES to randomize schools to either implement an elementary school SACD program or continue with their existing educational practice. Each research team evaluated one program in its chosen site by following one cohort of students from third through fifth grades, with the treatment students receiving the program in all 3 years (students in the other elementary grades in the treatment schools also received the program but were not part of the evaluation). Six of the programs had separate curriculum units for each grade, and one program (ABC) had a single standard unit with modifications for each grade. Programs were not randomized across teams or their sites; schools were randomized to treatment or control conditions within a team and its site. The six panels of table 1.1 identify each program and its research team ${ }^{4}$ and sites; describe general program characteristics, strategies, and type and amount of professional development provided; outline the SACD goals addressed by program activities; and note the outcomes addressed by the evaluation. The key point here is that the panels demonstrate how the seven programs drew from a common set of characteristics, techniques, goals, and outcomes, while differing in which of these each program used or addressed. For example, Panel 2 shows that four programs included behavior management while three did not, and that all provided either a manual or scripted lessons but that programs differed in the degree of teacher adaptation. Panel 3 shows that programs used many of the same activities and often addressed similar content (e.g., problem solving), but each program had specific content that it alone covered. Panel 4 shows that all programs used the combination of pre-implementation training plus ongoing consultation but that training time, nonteacher personnel included, and frequency and method of consultation varied among them. Panels 5 and 6 note that some programs addressed all the SACD goals and outcomes (described later in this chapter) while others focused on a selection of these. More detailed descriptions of the programs are included in the program-specific chapters of this report.

\footnotetext{
${ }^{4}$ Members of two of the seven research teams had developed the interventions they were evaluating (University at Buffalo, The State University of New York, and the University of North Carolina at Chapel Hill), and one team included a developer of its intervention (Oregon State University).
} 


\section{Table 1.1. Social and Character Development programs}

Panel 1: The seven programs

\begin{tabular}{|c|c|c|c|c|}
\hline Program/Source & Features & $\begin{array}{l}\text { Curriculum } \\
\text { structure }\end{array}$ & Research team & Site \\
\hline $\begin{array}{l}\text { Academic and Behavioral Competencies Program } \\
\text { Center for Children and Families } \\
\text { University at Buffalo, State University of New York }\end{array}$ & $\begin{array}{l}\text { Social skills training and behavior } \\
\text { management }\end{array}$ & $\begin{array}{l}\text { Classroom } \\
\text { curriculum and } \\
\text { targeted } \\
\text { component }\end{array}$ & $\begin{array}{l}\text { University at } \\
\text { Buffalo, State } \\
\text { University of } \\
\text { New York }\end{array}$ & $\begin{array}{l}\text { Buffalo, New York, } \\
\text { and two charter } \\
\text { schools }\end{array}$ \\
\hline $\begin{array}{l}\text { Competence Support Program } \\
\text { School of Social Work } \\
\text { University of North Carolina-Chapel Hill }\end{array}$ & $\begin{array}{l}\text { Social and emotional learning, social } \\
\text { dynamics training, and behavior } \\
\text { management: social information } \\
\text { processing, social problem solving, } \\
\text { peer networks }\end{array}$ & $\begin{array}{l}\text { Classroom } \\
\text { curriculum and } \\
\text { intensive teacher } \\
\text { training }\end{array}$ & $\begin{array}{l}\text { University of } \\
\text { North Carolina } \\
\text { at Chapel Hill }\end{array}$ & $\begin{array}{l}\text { Hoke and Wayne } \\
\text { Counties, North } \\
\text { Carolina }\end{array}$ \\
\hline $\begin{array}{l}\text { Love In a Big World } \\
\qquad \text { Love In a Big World } \\
\text { Nashville, Tennessee }\end{array}$ & $\begin{array}{l}\text { Character education: courage, honesty, } \\
\text { kindness, caring }\end{array}$ & $\begin{array}{l}\text { Classroom } \\
\text { curriculum and } \\
\text { whole-school } \\
\text { approach }\end{array}$ & $\begin{array}{l}\text { Vanderbilt } \\
\text { University }\end{array}$ & $\begin{array}{l}\text { Maury and } \\
\text { Murfreesboro } \\
\text { Counties, } \\
\text { Tennessee }\end{array}$ \\
\hline $\begin{array}{l}\text { Positive Action } \\
\text { Positive Action, Inc. } \\
\text { Twin Falls, Idaho }\end{array}$ & $\begin{array}{l}\text { Social and emotional learning: values, } \\
\text { empathy, self-control, social skills, } \\
\text { social bonding, self-efficacy, honesty, } \\
\text { goal setting }\end{array}$ & $\begin{array}{l}\text { Classroom } \\
\text { curriculum and } \\
\text { whole-school } \\
\text { approach }\end{array}$ & $\begin{array}{l}\text { Oregon State } \\
\text { University }\end{array}$ & Chicago, Illinois \\
\hline $\begin{array}{l}\text { Promoting Alternative Thinking Strategies } \\
\text { Channing Bete Company } \\
\text { South Deerfield, Massachusetts }\end{array}$ & $\begin{array}{l}\text { Social and emotional learning: } \\
\text { emotional literacy, self-control, social } \\
\text { competence, peer relations, } \\
\text { interpersonal problem solving }\end{array}$ & $\begin{array}{l}\text { Classroom } \\
\text { curriculum }\end{array}$ & $\begin{array}{l}\text { The Children's } \\
\text { Institute }\end{array}$ & $\begin{array}{l}\text { Robbinsdale, } \\
\text { Minnesota, and } \\
\text { Rochester and } \\
\text { Rush-Henrietta, } \\
\text { New York }\end{array}$ \\
\hline $\begin{array}{l}\text { The 4Rs Program (Reading, Writing, Respect, and } \\
\text { Resolution) } \\
\text { Morningside Center for Teaching Social Responsibility } \\
\text { New York, New York }\end{array}$ & $\begin{array}{l}\text { Conflict resolution and literacy: social } \\
\text { problem solving, anger management, } \\
\text { mediation }\end{array}$ & $\begin{array}{l}\text { Classroom } \\
\text { curriculum }\end{array}$ & $\begin{array}{l}\text { New York } \\
\text { University }\end{array}$ & $\begin{array}{l}\text { New York City, } \\
\text { New York }\end{array}$ \\
\hline $\begin{array}{l}\text { Second Step } \\
\text { Committee for Children } \\
\text { Seattle, Washington }\end{array}$ & $\begin{array}{l}\text { Violence prevention and social and } \\
\text { emotional learning: empathy, anger } \\
\text { management, impulse control, and } \\
\text { problem solving }\end{array}$ & $\begin{array}{l}\text { Classroom } \\
\text { curriculum }\end{array}$ & $\begin{array}{l}\text { University of } \\
\text { Maryland, } \\
\text { College Park }\end{array}$ & $\begin{array}{l}\text { Anne Arundel } \\
\text { County, Maryland }\end{array}$ \\
\hline
\end{tabular}


Table 1.1. Social and Character Development programs-Continued

Panel 2: General characteristics

\begin{tabular}{|c|c|c|c|c|c|c|c|c|c|c|}
\hline \multirow[b]{2}{*}{ Program } & \multirow{2}{*}{$\begin{array}{l}\text { Target } \\
\text { population }\end{array}$} & \multicolumn{6}{|c|}{ Program components } & \multirow{2}{*}{$\begin{array}{l}\text { Level of } \\
\text { integration }\end{array}$} & \multicolumn{2}{|c|}{ Flexibility } \\
\hline & & Peer & Parent & Classroom & Schoolwide & Community & Training & & Manualized & Adaptability \\
\hline$\overline{A B C}$ & $\begin{array}{l}\text { Universal } \\
\text { and } \\
\text { targeted }\end{array}$ & $\begin{array}{l}\text { In class } \\
\text { and out } \\
\text { of class }\end{array}$ & Contact & $\begin{array}{l}\text { Lessons and } \\
\text { behavior } \\
\text { management }\end{array}$ & $\begin{array}{l}\text { Planned } \\
\text { events, reward } \\
\text { programs, } \\
\text { schoolwide } \\
\text { rules, } \\
\text { discipline } \\
\text { policies }\end{array}$ & $\begin{array}{l}\text { None or } \\
\text { not major } \\
\text { focus }\end{array}$ & $\begin{array}{l}\text { Pretraining } \\
\text { and } \\
\text { ongoing }\end{array}$ & $\begin{array}{l}\text { Add-on } \\
\text { curriculum } \\
\text { and } \\
\text { schoolwide } \\
\text { activities }\end{array}$ & $\begin{array}{l}\text { Manual } \\
\text { includes } \\
\text { modules for all } \\
\text { program } \\
\text { components }\end{array}$ & $\begin{array}{l}\text { Program may } \\
\text { be } \\
\text { individualized } \\
\text { by school, } \\
\text { classroom, and } \\
\text { student }\end{array}$ \\
\hline CSP & Universal & In class & No contact & $\begin{array}{l}\text { Lessons, } \\
\text { behavior } \\
\text { management, } \\
\text { and social } \\
\text { dynamics }\end{array}$ & $\begin{array}{l}\text { None or not } \\
\text { major focus }\end{array}$ & $\begin{array}{l}\text { None or } \\
\text { not major } \\
\text { focus }\end{array}$ & $\begin{array}{l}\text { Pretraining } \\
\text { and } \\
\text { ongoing for } \\
\text { teachers } \\
\text { and } \\
\text { counselors }\end{array}$ & $\begin{array}{l}\text { Add-on } \\
\text { curriculum }\end{array}$ & $\begin{array}{l}\text { Scripted } \\
\text { lessons for } \\
\text { teachers }\end{array}$ & $\begin{array}{l}\text { Teachers may } \\
\text { adapt program } \\
\text { to setting }\end{array}$ \\
\hline LBW & Universal & $\begin{array}{l}\text { In class } \\
\text { and out } \\
\text { of class }\end{array}$ & $\begin{array}{l}\text { Contact and } \\
\text { involvement }\end{array}$ & $\begin{array}{l}\text { Lessons and } \\
\text { behavior } \\
\text { management }\end{array}$ & $\begin{array}{l}\text { Planned } \\
\text { events, } \\
\text { modeling, } \\
\text { program } \\
\text { artifacts }\end{array}$ & $\begin{array}{l}\text { None or } \\
\text { not major } \\
\text { focus }\end{array}$ & $\begin{array}{l}\text { Pretraining } \\
\text { and } \\
\text { ongoing }\end{array}$ & $\begin{array}{l}\text { Add-on } \\
\text { curriculum } \\
\text { and } \\
\text { schoolwide } \\
\text { activities }\end{array}$ & $\begin{array}{l}\text { Curriculum } \\
\text { guidebook }\end{array}$ & Less adaptable \\
\hline PATHS & Universal & In class & $\begin{array}{l}\text { Contact and } \\
\text { involvement }\end{array}$ & Lessons & $\begin{array}{l}\text { Planned } \\
\text { events, } \\
\text { program } \\
\text { artifacts }\end{array}$ & $\begin{array}{l}\text { None or } \\
\text { not major } \\
\text { focus }\end{array}$ & $\begin{array}{l}\text { Pretraining } \\
\text { and } \\
\text { ongoing }\end{array}$ & $\begin{array}{l}\text { Add-on } \\
\text { curriculum } \\
\text { and } \\
\text { schoolwide } \\
\text { activities }\end{array}$ & $\begin{array}{l}\text { Scripted } \\
\text { curriculum } \\
\text { guidebook }\end{array}$ & Less adaptable \\
\hline
\end{tabular}

See notes at end of table. 
Table 1.1. Social and Character Development programs-Continued

Panel 2: General characteristics-Continued

\begin{tabular}{|c|c|c|c|c|c|c|c|c|c|c|}
\hline \multirow[b]{2}{*}{ Program } & \multirow{2}{*}{$\begin{array}{l}\text { Target } \\
\text { population }\end{array}$} & \multicolumn{6}{|c|}{ Program components } & \multirow{2}{*}{$\begin{array}{l}\text { Level of } \\
\text { integration }\end{array}$} & \multicolumn{2}{|c|}{ Flexibility } \\
\hline & & Peer & Parent & Classroom & Schoolwide & Community & Training & & Manualized & Adaptability \\
\hline $\mathrm{PA}$ & Universal & $\begin{array}{l}\text { In class } \\
\text { and out } \\
\text { of class }\end{array}$ & $\begin{array}{l}\text { Training, } \\
\text { contact, } \\
\text { and } \\
\text { involvement }\end{array}$ & $\begin{array}{l}\text { Lessons and } \\
\text { behavior } \\
\text { management }\end{array}$ & $\begin{array}{l}\text { Planned events, } \\
\text { includes } \\
\text { program } \\
\text { artifacts PA } \\
\text { coordinator and } \\
\text { PA committee }\end{array}$ & $\begin{array}{l}\text { None or not } \\
\text { major focus }\end{array}$ & $\begin{array}{l}\text { Pretraining } \\
\text { and } \\
\text { ongoing }\end{array}$ & $\begin{array}{l}\text { Add-on } \\
\text { curriculum } \\
\text { and } \\
\text { schoolwide } \\
\text { activities }\end{array}$ & $\begin{array}{l}\text { Curriculum } \\
\text { guidebook with } \\
\text { scripted lessons } \\
\text { and materials, } \\
\text { schoolwide } \\
\text { guidebooks, } \\
\text { parent manual, } \\
\text { and support } \\
\text { staff manual }\end{array}$ & $\begin{array}{l}\text { Program staff } \\
\text { and principal } \\
\text { adapt activities } \\
\text { to needs and } \\
\text { setting }\end{array}$ \\
\hline 4Rs & Universal & In class & $\begin{array}{l}\text { Contact } \\
\text { and } \\
\text { involvement }\end{array}$ & Lessons & $\begin{array}{l}\text { None or not } \\
\text { major focus }\end{array}$ & $\begin{array}{l}\text { None or not } \\
\text { major focus }\end{array}$ & $\begin{array}{l}\text { Pretraining } \\
\text { and } \\
\text { ongoing }\end{array}$ & $\begin{array}{l}\text { Core } \\
\text { curriculum } \\
\text { (language } \\
\text { arts) }\end{array}$ & $\begin{array}{l}\text { Curriculum } \\
\text { guidebook }\end{array}$ & Less adaptable \\
\hline SS & Universal & In class & Contact & Lessons & $\begin{array}{l}\text { Program } \\
\text { artifacts and } \\
\text { modeling }\end{array}$ & $\begin{array}{l}\text { None or not } \\
\text { major focus }\end{array}$ & $\begin{array}{l}\text { Pretraining } \\
\text { and } \\
\text { ongoing }\end{array}$ & $\begin{array}{l}\text { Add-on } \\
\text { curriculum }\end{array}$ & $\begin{array}{l}\text { Curriculum } \\
\text { guidebook }\end{array}$ & $\begin{array}{l}\text { Character } \\
\text { development } \\
\text { planning teams }\end{array}$ \\
\hline
\end{tabular}

See notes at end of table. 
Table 1.1. Social and Character Development programs-Continued

Panel 3: Description of strategies

\begin{tabular}{|c|c|c|c|c|c|c|c|c|c|}
\hline \multirow[b]{3}{*}{ Program } & \multicolumn{7}{|c|}{ Classroom } & \multirow[b]{3}{*}{$\begin{array}{l}\text { Supplement to } \\
\text { classroom }\end{array}$} & \multirow[b]{3}{*}{$\begin{array}{l}\text { Schoolwide } \\
\text { activities }\end{array}$} \\
\hline & \multicolumn{4}{|c|}{ Lessons } & \multicolumn{3}{|c|}{ Strategies } & & \\
\hline & $\begin{array}{l}\text { Who } \\
\text { delivers }\end{array}$ & $\begin{array}{l}\text { Activities } \\
\text { and tools }\end{array}$ & Content & Frequency & $\begin{array}{l}\text { Who } \\
\text { delivers }\end{array}$ & $\begin{array}{l}\text { Activities } \\
\text { and tools }\end{array}$ & Frequency & & \\
\hline $\mathrm{ABC}$ & Teacher & $\begin{array}{l}\text { Social skill of } \\
\text { the day } \\
\text { description and } \\
\text { classroom or } \\
\text { schoolwide } \\
\text { role-play }\end{array}$ & $\begin{array}{l}\text { Social skills, } \\
\text { problem solving, } \\
\text { classroom } \\
\text { management, } \\
\text { peer } \\
\text { relationships }\end{array}$ & $\begin{array}{l}\text { Daily } 5-10 \\
\text { minutes plus } \\
\text { reinforcement; } \\
\text { twice a week } \\
\text { 45-minute peer } \\
\text { program }\end{array}$ & Teacher & $\begin{array}{l}\text { Recognition } \\
\text { and } \\
\text { reinforcement } \\
\text { of good } \\
\text { behavior } \\
\text { (e.g., positive } \\
\text { notes, } \\
\text { behavior } \\
\text { reports, time } \\
\text { out, fun } \\
\text { activities) }\end{array}$ & Daily & $\begin{array}{l}\text { Homework, } \\
\text { peer } \\
\text { mediation, and } \\
\text { parenting } \\
\text { program }\end{array}$ & $\begin{array}{l}\text { Schoolwide } \\
\text { rules, recording } \\
\text { of rule violations, } \\
\text { positive } \\
\text { affirmation, } \\
\text { afterschool } \\
\text { program }\end{array}$ \\
\hline
\end{tabular}

\begin{tabular}{|c|c|c|c|c|c|c|c|c|c|}
\hline CSP & Teacher & $\begin{array}{l}\text { Story reading, } \\
\text { discussion, } \\
\text { role-playing, } \\
\text { worksheets, } \\
\text { games, artifacts } \\
\text { (e.g., turtle } \\
\text { puppet), art } \\
\text { projects }\end{array}$ & $\begin{array}{l}\text { Problem } \\
\text { solving, emotion } \\
\text { identification } \\
\text { and regulation, } \\
\text { identifying } \\
\text { social cues, } \\
\text { goal formation, } \\
\text { choosing } \\
\text { options, and } \\
\text { behavior } \\
\text { regulation }\end{array}$ & $\begin{array}{l}45 \text { minutes, } \\
\text { once per } \\
\text { week; } 28 \\
\text { lessons }\end{array}$ & Teacher & $\begin{array}{l}\text { Prevention of } \\
\text { social } \\
\text { hierarchies } \\
\text { that promote } \\
\text { conflict; social } \\
\text { reinforcement } \\
\text { for positive } \\
\text { behavior }\end{array}$ & Daily & None & None \\
\hline LBW & Teacher & $\begin{array}{l}\text { Story reading, } \\
\text { writing, } \\
\text { interdisciplinary } \\
\text { activities, } \\
\text { rewards, singing }\end{array}$ & $\begin{array}{l}\text { Character traits } \\
\text { and moral } \\
\text { virtues }\end{array}$ & $\begin{array}{l}\text { Daily } 10 \text { - to } \\
15 \text {-minute } \\
\text { lessons, } 30 \\
\text { weeks }\end{array}$ & Teacher & $\begin{array}{l}\text { Recognition } \\
\text { and } \\
\text { reinforcement } \\
\text { of good } \\
\text { behavior; } \\
\text { Modeling of } \\
\text { character } \\
\text { traits }\end{array}$ & Daily & $\begin{array}{l}\text { Parent } \\
\text { newsletters }\end{array}$ & $\begin{array}{l}\text { Weekly } \\
\text { announcements; } \\
\text { occasional } \\
\text { assemblies; two } \\
\text { service projects; } \\
\text { program artifacts }\end{array}$ \\
\hline
\end{tabular}


Table 1.1. Social and Character Development programs-Continued

Panel 3: Description of strategies-Continued

\begin{tabular}{|c|c|c|c|c|c|c|c|c|c|}
\hline \multirow[b]{3}{*}{ Program } & \multicolumn{7}{|c|}{ Classroom } & \multirow[b]{3}{*}{$\begin{array}{l}\text { Supplement to } \\
\text { classroom }\end{array}$} & \multirow[b]{3}{*}{$\begin{array}{l}\text { Schoolwide } \\
\text { activities }\end{array}$} \\
\hline & \multicolumn{4}{|c|}{ Lessons } & \multicolumn{3}{|c|}{ Strategies } & & \\
\hline & $\begin{array}{l}\text { Who } \\
\text { delivers }\end{array}$ & $\begin{array}{l}\text { Activities } \\
\text { and tools }\end{array}$ & Content & Frequency & $\begin{array}{l}\text { Who } \\
\text { delivers }\end{array}$ & $\begin{array}{l}\text { Activities } \\
\text { and tools }\end{array}$ & Frequency & & \\
\hline PATHS & Teacher & $\begin{array}{l}\text { Direct } \\
\text { instruction, } \\
\text { storytelling, } \\
\text { discussion, } \\
\text { role-playing, } \\
\text { utilization of } \\
\text { artifacts (e.g., } \\
\text { posters, turtle } \\
\text { puppet), } \\
\text { worksheets }\end{array}$ & $\begin{array}{l}\text { Emotion } \\
\text { understanding } \\
\text { and control, } \\
\text { behavior } \\
\text { regulation, } \\
\text { problem solving, } \\
\text { making friends }\end{array}$ & $\begin{array}{l}20-30 \\
\text { minutes per } \\
\text { day, } 3-5 \text { days } \\
\text { per week }\end{array}$ & Teacher & $\begin{array}{l}\text { Modeling of } \\
\text { skills }\end{array}$ & Daily & $\begin{array}{l}\text { Parent } \\
\text { newsletter } \\
\text { and } \\
\text { engagement } \\
\text { in homework }\end{array}$ & $\begin{array}{l}\text { End-of-year } \\
\text { PATHS party } \\
\text { and program } \\
\text { artifacts }\end{array}$ \\
\hline PA & Teacher & $\begin{array}{l}\text { Direct } \\
\text { instruction, } \\
\text { story reading, } \\
\text { writing, role- } \\
\text { playing, } \\
\text { discussion, } \\
\text { singing, games, } \\
\text { worksheets, } \\
\text { puppets, plays } \\
\text { and poems }\end{array}$ & $\begin{array}{l}\text { Self-concept, } \\
\text { physical health, } \\
\text { intellectual } \\
\text { growth, } \\
\text { emotional and } \\
\text { behavioral self- } \\
\text { regulation, } \\
\text { getting along with } \\
\text { others (social } \\
\text { skills), self- } \\
\text { honesty, self- } \\
\text { improvement, } \\
\text { goal setting, } \\
\text { character traits }\end{array}$ & $\begin{array}{l}15 \text { - to } 20 \text { - } \\
\text { minute } \\
\text { lessons, } 4 \\
\text { days per } \\
\text { week }\end{array}$ & Teacher & $\begin{array}{l}\text { Teaches, } \\
\text { practices, } \\
\text { recognizes, } \\
\text { and models } \\
\text { positive } \\
\text { actions with } \\
\text { curriculum } \\
\text { and climate } \\
\text { activities and } \\
\text { materials }\end{array}$ & Daily & $\begin{array}{l}\text { Parent } \\
\text { newsletters; } \\
\text { parent manual } \\
\text { with PA } \\
\text { activities, } \\
\text { letters, and } \\
\text { strategies; } \\
\text { and parent } \\
\text { night }\end{array}$ & $\begin{array}{l}\text { Occasional } \\
\text { assemblies; } \\
\text { service projects; } \\
\text { PA days and } \\
\text { year-end event; } \\
\text { Principal climate } \\
\text { program with } \\
\text { reinforcement } \\
\text { recognition } \\
\text { activities }\end{array}$ \\
\hline
\end{tabular}


Table 1.1. Social and Character Development programs-Continued

Panel 3: Description of strategies-Continued

\begin{tabular}{|c|c|c|c|c|c|c|c|c|c|}
\hline \multirow[b]{3}{*}{ Program } & \multicolumn{7}{|c|}{ Classroom } & \multirow[b]{3}{*}{$\begin{array}{l}\text { Supplement to } \\
\text { classroom }\end{array}$} & \multirow[b]{3}{*}{$\begin{array}{l}\text { Schoolwide } \\
\text { activities }\end{array}$} \\
\hline & \multicolumn{4}{|c|}{ Lessons } & \multicolumn{3}{|c|}{ Strategies } & & \\
\hline & $\begin{array}{l}\text { Who } \\
\text { delivers }\end{array}$ & $\begin{array}{l}\text { Activities } \\
\text { and tools }\end{array}$ & Content & Frequency & $\begin{array}{l}\text { Who } \\
\text { delivers }\end{array}$ & $\begin{array}{l}\text { Activities } \\
\text { and tools }\end{array}$ & Frequency & & \\
\hline 4Rs & Teacher & $\begin{array}{l}\text { Story reading, } \\
\text { role-playing, } \\
\text { discussions, } \\
\text { reflections, } \\
\text { sharing } \\
\text { exercises, } \\
\text { brain- } \\
\text { storming, } \\
\text { songs, } \\
\text { worksheets }\end{array}$ & $\begin{array}{l}\text { Literacy focus; } \\
\text { building } \\
\text { community, } \\
\text { feelings, } \\
\text { listening, } \\
\text { assertiveness, } \\
\text { problem solving, } \\
\text { diversity, making } \\
\text { a difference }\end{array}$ & $\begin{array}{l}\text { 1-hour } \\
\text { lessons at } \\
\text { least once } \\
\text { per week; } \\
31 \text { lessons }\end{array}$ & Teacher & $\begin{array}{l}\text { Modeling of } \\
\text { skills }\end{array}$ & Daily & $\begin{array}{l}\text { Parent-child } \\
\text { connections } \\
\text { homework and } \\
\text { parent } \\
\text { workshops }\end{array}$ & None \\
\hline SS & Teacher & $\begin{array}{l}\text { Storytelling, } \\
\text { discussion, } \\
\text { videos, } \\
\text { role-playing, } \\
\text { anticipation, } \\
\text { recall, } \\
\text { learning } \\
\text { points }\end{array}$ & $\begin{array}{l}\text { Empathy, } \\
\text { impulse control, } \\
\text { problem solving, } \\
\text { anger } \\
\text { management }\end{array}$ & $\begin{array}{l}\text { 30-minute } \\
\text { lessons, } \\
\text { 1-2 days } \\
\text { per week }\end{array}$ & Teacher & $\begin{array}{l}\text { Modeling of } \\
\text { and } \\
\text { reinforcement } \\
\text { of skills }\end{array}$ & $\begin{array}{l}\text { Weekly } \\
\text { lessons: } \\
\text { daily } \\
\text { generalization }\end{array}$ & $\begin{array}{l}\text { Take-home } \\
\text { letters, } \\
\text { homework, } \\
\text { family guide } \\
\text { and video }\end{array}$ & $\begin{array}{l}\text { Program artifacts, } \\
\text { training of school } \\
\text { staff }\end{array}$ \\
\hline
\end{tabular}

See notes at end of table. 
Table 1.1. Social and Character Development programs-Continued

Panel 4: Professional development

\begin{tabular}{|c|c|c|c|c|c|c|c|c|}
\hline \multirow[b]{3}{*}{ Program } & \multicolumn{4}{|c|}{ Pre-implementation } & \multicolumn{4}{|c|}{ Ongoing consultation } \\
\hline & \multicolumn{2}{|c|}{ Teachers } & \multicolumn{2}{|c|}{ Other } & \multicolumn{2}{|c|}{ Teachers } & \multicolumn{2}{|c|}{ Other } \\
\hline & Content & Duration & Content & Duration & Content & Duration & Content & Duration \\
\hline $\mathrm{ABC}$ & $\begin{array}{l}\text { Behavioral } \\
\text { management } \\
\text { techniques, } \\
\text { schoolwide rules, } \\
\text { discipline } \\
\text { policies, } \\
\text { classroom } \\
\text { management } \\
\text { policies }\end{array}$ & 9 hours & $\begin{array}{l}\text { Staff receive } \\
\text { teacher training }\end{array}$ & 9 hours & $\begin{array}{l}\text { Teacher } \\
\text { consultation, } \\
\text { and coaching } \\
\text { on use of } \\
\text { classroom } \\
\text { management }\end{array}$ & $\begin{array}{l}\text { Monthly or } \\
\text { more } \\
\text { frequently per } \\
\text { teacher or } \\
\text { school } \\
\text { request }\end{array}$ & $\begin{array}{l}\text { School } \\
\text { consultation on } \\
\text { policies and } \\
\text { procedures }\end{array}$ & $\begin{array}{l}\text { As needed, with } \\
\text { regular follow- } \\
\text { up }\end{array}$ \\
\hline CSP & $\begin{array}{l}\text { Training on } \\
\text { curriculum } \\
\text { implementation, } \\
\text { behavior } \\
\text { management, } \\
\text { and social } \\
\text { dynamics }\end{array}$ & 4 hours & $\begin{array}{l}\text { Principal } \\
\text { consultation on } \\
\text { development of } \\
\text { schoolwide } \\
\text { management } \\
\text { policy }\end{array}$ & As requested & $\begin{array}{l}\text { Consultations } \\
\text { on use of } \\
\text { program } \\
\text { materials }\end{array}$ & $\begin{array}{l}2 \text { times } \\
\text { monthly }\end{array}$ & None & None \\
\hline LBW & $\begin{array}{l}\text { Workshop on } \\
\text { lesson plans and } \\
\text { logistics of } \\
\text { program } \\
\text { implementation }\end{array}$ & 1 day; 3 hours & $\begin{array}{l}\text { Principal and } \\
\text { staff; Same as } \\
\text { teacher training }\end{array}$ & 1 day; 3 hours & $\begin{array}{l}\text { Faculty } \\
\text { boosters with } \\
\text { reminders } \\
\text { about program } \\
\text { implementation } \\
\text { and discussion } \\
\text { of challenges }\end{array}$ & $\begin{array}{l}24 \text { weekly } \\
\text { sessions; } \\
\text { biannual } \\
\text { meeting }\end{array}$ & $\begin{array}{l}\text { Program } \\
\text { coordinator; } \\
\text { calls with } \\
\text { program } \\
\text { developer to } \\
\text { improve } \\
\text { schoolwide } \\
\text { implementation }\end{array}$ & $\begin{array}{l}\text { Once every } 6 \\
\text { months }\end{array}$ \\
\hline
\end{tabular}

See notes at end of table. 
Table 1.1. Social and Character Development programs-Continued

Panel 4: Professional development-Continued

\begin{tabular}{|c|c|c|c|c|c|c|c|c|}
\hline \multirow[b]{3}{*}{ Program } & \multicolumn{4}{|c|}{ Pre-implementation } & \multicolumn{4}{|c|}{ Ongoing consultation } \\
\hline & \multicolumn{2}{|c|}{ Teachers } & \multicolumn{2}{|c|}{ Other } & \multicolumn{2}{|c|}{ Teachers } & \multicolumn{2}{|c|}{ Other } \\
\hline & Content & Duration & Content & Duration & Content & Duration & Content & Duration \\
\hline PATHS & $\begin{array}{l}\text { Training on } \\
\text { concepts, } \\
\text { curriculum } \\
\text { implementation, } \\
\text { how to integrate } \\
\text { activities with } \\
\text { traditional } \\
\text { instruction }\end{array}$ & 2 days & $\begin{array}{l}\text { Principal and } \\
\text { school mental } \\
\text { health staff; } \\
\text { same as } \\
\text { teacher training }\end{array}$ & 2 days & $\begin{array}{l}\text { Technical } \\
\text { assistance and } \\
\text { implementation } \\
\text { consultation, } \\
\text { individual } \\
\text { meetings with } \\
\text { each teacher, } \\
\text { attendance at } \\
\text { grade-level } \\
\text { meetings, } \\
\text { planning for } \\
\text { following year }\end{array}$ & $\begin{array}{l}\text { Weekly } \\
\text { consultations; } \\
\text { 2-day summer } \\
\text { meeting }\end{array}$ & $\begin{array}{l}\text { Principal and } \\
\text { school staff; } \\
\text { model lessons, } \\
\text { team teaching, } \\
\text { general } \\
\text { feedback; } \\
\text { planning for } \\
\text { following year }\end{array}$ & $\begin{array}{l}\text { Biweekly calls; } \\
\text { 2-day summer } \\
\text { meeting }\end{array}$ \\
\hline PA & $\begin{array}{l}\text { Training on } \\
\text { concepts and } \\
\text { delivery of } \\
\text { curriculum, } \\
\text { school climate } \\
\text { activities to } \\
\text { reinforce positive } \\
\text { behaviors and } \\
\text { parent } \\
\text { involvement }\end{array}$ & $1 / 2$ day & $\begin{array}{l}\text { Principal } \\
\text { training on } \\
\text { appointing } \\
\text { committees } \\
\text { and } \\
\text { coordinating } \\
\text { school climate } \\
\text { activities with } \\
\text { family groups }\end{array}$ & $1 / 2$ day & $\begin{array}{l}\text { Group session } \\
\text { to provide } \\
\text { technical } \\
\text { assistance and } \\
\text { share } \\
\text { experiences } \\
\text { and challenges; } \\
\text { visits for } \\
\text { technical } \\
\text { support }\end{array}$ & $\begin{array}{l}\text { Up to } 1 / 2 \text { day } \\
\text { once per year, } \\
\text { and up to } 1 / 2 \\
\text { day visits to } \\
\text { schools } \\
\text { monthly }\end{array}$ & $\begin{array}{l}\text { Meeting of } \\
\text { principals and } \\
\text { coordinators to } \\
\text { provide } \\
\text { technical } \\
\text { assistance and } \\
\text { share } \\
\text { successes and } \\
\text { challenges }\end{array}$ & $\begin{array}{l}\text { One session of } \\
3 \text { hours per } \\
\text { year }\end{array}$ \\
\hline
\end{tabular}


Table 1.1. Social and Character Development programs-Continued

Panel 4: Professional development-Continued

\begin{tabular}{|c|c|c|c|c|c|c|c|c|}
\hline \multirow[b]{3}{*}{ Program } & \multicolumn{4}{|c|}{ Pre-implementation } & \multicolumn{4}{|c|}{ Ongoing consultation } \\
\hline & \multicolumn{2}{|c|}{ Teachers } & \multicolumn{2}{|c|}{ Other } & \multicolumn{2}{|c|}{ Teachers } & \multicolumn{2}{|c|}{ Other } \\
\hline & Content & Duration & Content & Duration & Content & Duration & Content & Duration \\
\hline 4Rs & $\begin{array}{l}\text { Course to learn } \\
\text { curriculum, } \\
\text { improve on own } \\
\text { skills, create a } \\
\text { vision of } \\
\text { community, set } \\
\text { consistent rules, } \\
\text { behavior } \\
\text { management }\end{array}$ & 25 hours & None & None & $\begin{array}{l}\text { Training and } \\
\text { support in } \\
\text { mediation, } \\
\text { negotiation, } \\
\text { role-playing, } \\
\text { class meetings, } \\
\text { behavior } \\
\text { management }\end{array}$ & $\begin{array}{l}\text { Individualized } \\
\text { coaching } 12 \\
\text { times per year; } \\
\text { 3-day summer } \\
\text { institute }\end{array}$ & None & None \\
\hline SS & $\begin{array}{l}\text { Training on child } \\
\text { development, } \\
\text { social skills, and } \\
\text { curriculum } \\
\text { delivery }\end{array}$ & 2 days & $\begin{array}{l}\text { Character } \\
\text { development } \\
\text { planning team, } \\
\text { school } \\
\text { counselor, and } \\
\text { other staff; } \\
\text { training on child } \\
\text { development, } \\
\text { social skills, and } \\
\text { curriculum } \\
\text { content }\end{array}$ & 2.5 hours & $\begin{array}{l}\text { Year-end } \\
\text { workshop to } \\
\text { review student } \\
\text { outcome data } \\
\text { and plan for } \\
\text { following year }\end{array}$ & 1 day & $\begin{array}{l}\text { School } \\
\text { counselor } \\
\text { guidance on } \\
\text { strategies and } \\
\text { challenges; } \\
\text { principal and } \\
\text { staff review of } \\
\text { student } \\
\text { outcome data } \\
\text { and plan for } \\
\text { following year }\end{array}$ & $\begin{array}{l}1 / 2 \text { day } \\
\text { counselor } \\
\text { meetings about } \\
\text { monthly; 1-day } \\
\text { year-end } \\
\text { workshop }\end{array}$ \\
\hline
\end{tabular}

See notes at end of table. 
Table 1.1. Social and Character Development programs-Continued

Panel 5: Activities to promote the six SACD goals and behavior management

\begin{tabular}{|c|c|c|c|c|c|c|c|}
\hline Program & $\begin{array}{l}\text { Violence prevention } \\
\text { and peace } \\
\text { promotion }\end{array}$ & $\begin{array}{c}\text { Social and emotional } \\
\text { development }\end{array}$ & Character education & $\begin{array}{c}\text { Tolerance and } \\
\text { diversity }\end{array}$ & $\begin{array}{l}\text { Risk prevention and } \\
\text { health promotion }\end{array}$ & $\begin{array}{l}\text { Civic responsibility } \\
\text { and community } \\
\text { service }\end{array}$ & $\begin{array}{c}\text { Behavior } \\
\text { management }\end{array}$ \\
\hline $\mathrm{ABC}$ & $\checkmark$ & $\checkmark$ & & & & & $\checkmark$ \\
\hline CSP & $\checkmark$ & $\checkmark$ & & & & & $\checkmark$ \\
\hline LBW & $\checkmark$ & $\checkmark$ & $\checkmark$ & $\checkmark$ & & $\checkmark$ & \\
\hline PATHS & $\checkmark$ & $\checkmark$ & $\checkmark$ & $\checkmark$ & $\checkmark$ & $\checkmark$ & $\checkmark$ \\
\hline PA & $\checkmark$ & $\checkmark$ & $\checkmark$ & $\checkmark$ & $\checkmark$ & $\checkmark$ & $\checkmark$ \\
\hline 4Rs & $\checkmark$ & $\checkmark$ & $\checkmark$ & $\checkmark$ & $\checkmark$ & $\checkmark$ & $\checkmark$ \\
\hline SS & $\checkmark$ & $\checkmark$ & $\checkmark$ & & & & \\
\hline
\end{tabular}

See notes at end of table. 
Table 1.1. Social and Character Development programs-Continued

\begin{tabular}{|c|c|c|c|c|c|c|c|c|c|c|c|c|c|c|}
\hline Program & $\begin{array}{l}\text { Self-Efficacy } \\
\text { for Peer } \\
\text { Interactions }\end{array}$ & $\begin{array}{l}\text { Normative } \\
\text { Beliefs About } \\
\text { Aggression }\end{array}$ & Empathy & $\begin{array}{l}\text { Altruistic } \\
\text { Behavior }\end{array}$ & $\begin{array}{l}\text { Positive } \\
\text { Social } \\
\text { Behavior }\end{array}$ & $\begin{array}{l}\text { Problem } \\
\text { Behavior }\end{array}$ & $\begin{array}{l}\text { Engage- } \\
\text { ment with } \\
\text { Learning }\end{array}$ & $\begin{array}{c}\text { Academic } \\
\text { Competence } \\
\text { and Motivation }\end{array}$ & $\begin{array}{c}\text { Positive } \\
\text { School } \\
\text { Orientation }\end{array}$ & $\begin{array}{l}\text { Negative } \\
\text { School } \\
\text { Orientation }\end{array}$ & $\begin{array}{c}\text { Student } \\
\text { Afraid at } \\
\text { School }\end{array}$ & $\begin{array}{l}\text { Victimization } \\
\text { at School }\end{array}$ & $\begin{array}{l}\text { Feelings } \\
\text { of Safety }\end{array}$ & $\begin{array}{l}\text { Student } \\
\text { Support for } \\
\text { Teachers }\end{array}$ \\
\hline$\overline{A B C}$ & & & & & $\checkmark$ & $\checkmark$ & & & & & & $\checkmark$ & $\checkmark$ & $\checkmark$ \\
\hline CSP & $\checkmark$ & $\checkmark$ & $\checkmark$ & & $\checkmark$ & $\checkmark$ & $\checkmark$ & & & & & $\checkmark$ & & $\checkmark$ \\
\hline LBW & & & $\checkmark$ & $\checkmark$ & $\checkmark$ & $\checkmark$ & & & $\checkmark$ & $\checkmark$ & $\checkmark$ & & $\checkmark$ & $\checkmark$ \\
\hline PA & $\checkmark$ & $\checkmark$ & $\checkmark$ & $\checkmark$ & $\checkmark$ & $\checkmark$ & $\checkmark$ & $\checkmark$ & $\checkmark$ & $\checkmark$ & $\checkmark$ & $\checkmark$ & $\checkmark$ & $\checkmark$ \\
\hline PATHS & $\checkmark$ & $\checkmark$ & $\checkmark$ & $\checkmark$ & $\checkmark$ & $\checkmark$ & $\checkmark$ & $\checkmark$ & $\checkmark$ & $\checkmark$ & & & $\checkmark$ & \\
\hline 4Rs & $\checkmark$ & $\checkmark$ & $\checkmark$ & & $\checkmark$ & $\checkmark$ & $\checkmark$ & $\checkmark$ & & & & $\checkmark$ & $\checkmark$ & \\
\hline SS & $\checkmark$ & & $\checkmark$ & $\checkmark$ & $\checkmark$ & $\checkmark$ & & & & & & & & \\
\hline
\end{tabular}

NOTE: Abbreviations are

ABC: Academic and Behavioral Competencies Program

CSP: Competence Support Program

LBW: Love In a Big World

PA: Positive Action

PATHS: Promoting Alternative Thinking Strategies

4Rs: The 4Rs Program (Reading, Writing, Respect, and Resolution)

SS: Second Step

$\checkmark$ : Outcome addressed

Blank cell: Outcome not addressed

SOURCE: The Social and Character Development (SACD) Research Program. 
The commonalities and differences among the seven SACD programs are important for several reasons. They make clear that there is no single SACD universal schoolwide program, but a set of them that are in many ways similar but also different enough to distinguish them. The commonalities justify this study's evaluation approach of both combining results from all seven programs and examining the results from each program separately for a common set of outcome measures for measuring students' social and character development. At the same time, it is important to keep in mind the differences when considering the results for each of the seven programs.

To standardize the evaluation, a competitive peer-review process was used to select a third party to collect and analyze the common set of data from all the schools. MPR was selected for this role.

As in most evaluations of education interventions, the SACD programs were not compared to a no-treatment control. The control schools continued to implement the social and character development activities that constituted their standard practice. A number of researchers have observed that schools commonly use support services, intervention curricula, and discipline management strategies to promote social and character development and prevent problem behavior (e.g., Crosse et al. 2001; Gottfredson and Gottfredson 2001), and in many states, schools are required by law to implement such programs and practices. For example, under the Student Citizen Act of 2001, character education was made part of the standard curriculum for North Carolina schools starting in the 2002-03 school year; in New York, the Safe Schools Against Violence in Education Act of 2001 encouraged districts to promote instruction in civility, citizenship, and character education; and Illinois' Children's Mental Health Act required all school districts to develop a policy for incorporating social and emotional competence into the district's educational program by August 31, 2004. For this reason, data were collected on the implementation of social and character development activities from all schools. These data provide contextual information on the prevalence of social and character development activities occurring in both the treatment and control schools.

\section{Study Design and Methodology}

The SACD multiprogram evaluation was a 3-year longitudinal study following one cohort of students from third through fifth grades. ${ }^{5}$ It was designed to determine the effects of seven SACD programs on the social and character development of students attending the schools in which the interventions were implemented. This design stems in part from the programs being chosen by the quality of the grant applications, so they are not necessarily representative of the full set of universal school-based SACD interventions. The results, then, are not generalizable beyond the seven programs.

The evaluation examined the average effect of the programs on a common set of student outcomes including social and emotional competence, behavior, academics, and perceptions of school climate. Initial data were collected on consenting students in the third grade during fall 2004. Follow-up data were collected at subsequent time points: (1) in spring 2005 from third-grade students, (2) in fall 2005 when the original thirdgrade cohort began fourth grade, (3) in spring 2006 when the original third-grade cohort completed fourth grade, and (4) in spring 2007 when the original third-grade cohort completed fifth grade. Data for the study included survey data from students, students' primary caregivers, teachers, and interview responses from principals.

\footnotetext{
5 The multiprogram evaluation also included 12 additional schools recruited in the second year of the study. This second cohort of third-grade students was followed for 2 years through the fourth grade. Initial data were collected in fall 2005 , and follow-up data in spring 2006 and spring 2007. These schools were recruited by the Children's Institute $(n=4)$, University at Buffalo, The State University of New York $(n=2)$, University of North Carolina at Chapel Hill $(n=4)$, and Vanderbilt University $(n=2)$. Appendix A describes the combined analysis of Cohorts 1 and 2. The Executive Summary and chapters 1-8 describe the analysis of Cohort 1 only.
} 


\section{Chapter 1. The Social and Character Development Multiprogram Evaluation}

\section{Sample and Random Assignment}

Schools were the unit of assignment, in part because the programs were applied at the school level (or at least in multiple grades in a school). As a result, contamination from the treatment group to the control group was unlikely because of the physical separation of schools. From each school, data were collected from students in grades 3, 4, and then 5 in consecutive years. Data were also collected from students' primary caregivers, from the principals of the schools, and from the teachers in all three grades. Parents or primary caregivers, principals, and teachers all had to give their consent before taking part in the study. Students gave assent after their primary caregivers had provided consent. Beginning in the spring and early fall of 2004, consent forms were sent home with students for primary caregivers to review and sign, if desired, indicating their consent for their own participation in the study and for the student's participation in the study. The consent process continued at each follow-up for students who were new entrants to the schools, or who did not return a consent form in fall 2004. During each data collection, students themselves were asked whether they would assent to participate in the study. The research teams carried out the consent process and other procedures concerning human subjects after their review and approval by institutional review boards at each participating institution and by the Public/Private Ventures Institutional Review Board.

Each research team set the eligibility criteria for schools within its site and recruited 10 to 14 schools for the study. ${ }^{6}$ In general, schools were purposively selected based on (1) their lack of schoolwide institutionalized programs addressing social and character development, (2) their willingness to participate in random assignment and engage in data collection activities, and (3) their ability to implement the program schoolwide (all elementary grades) if assigned to the treatment condition. Additional eligibility criteria employed by individual teams included relatively low performance on standardized tests, a relatively high percentage of students eligible for free and reduced-price lunch, low student mobility rates, and a sufficient number of students per school to meet sample size requirements.

The research teams recruited a total of 84 schools into the study beginning with the initial data collection in fall 2004 (table 1.2). Eighty-three schools completed the evaluation, with one (a control school) dropping out before the start of the second year after converting to a magnet school. Some schools changed their grade structures over time but in only one school did this lead to the students in the study not receiving the intervention (the loss of students in fifth grade at one CSP school). In Year 1, the highest grade was fourth or fifth grade at 46 schools, sixth or seventh grade at 18 schools, and eighth grade at 20 schools. In Years 2 and 3 , these figures were 47 and 49 schools having fourth or fifth grade as the highest grade; 15 and 12 schools with sixth or seventh grade; and 21 and 22 schools with eighth grade, respectively.

After recruiting the schools, each research team created five to seven matched pairs of schools. Within each pair, one school was randomly assigned to the treatment group and the other to the control group. Stratified sampling was used to guard against the possibility that random assignment of a small number of schools could produce sets of treatment and control schools that had markedly different characteristics. An algorithm was developed to select the best pairs by minimizing the distance between several measurable characteristics for schools within each pair. A set of candidate pairs was selected such that the overall quality of matches across all the schools remained as high as possible, without creating any serious mismatches for any subset of the individual pairs. Each team executed the matching algorithm with somewhat different school characteristic variables, depending on what data were available, and exercised its best judgment, based on knowledge of the schools involved, as to which candidate pairing was the best one. After the best pairing was established, one member of each pair was randomly selected to be in the treatment group and the other was assigned to the control group.

${ }^{6}$ The New York University research team recruited 18 schools but only 14 were included in the multiprogram evaluation. 
Table 1.2. Multiprogram evaluation school sample

\begin{tabular}{|c|c|c|c|c|c|c|c|c|c|}
\hline \multirow[b]{2}{*}{ Program } & \multicolumn{3}{|c|}{$\begin{array}{c}\text { Year 1 } \\
\text { (Spring/Fall 3rd grade) }\end{array}$} & \multicolumn{3}{|c|}{$\begin{array}{c}\text { Year 2 } \\
\text { (Spring/Fall 4th grade) }\end{array}$} & \multicolumn{3}{|c|}{$\begin{array}{c}\text { Year 3 } \\
\text { (Spring/Fall 5th grade) }\end{array}$} \\
\hline & Total & Treatment & Control & Total & Treatment & Control & Total & Treatment & Control \\
\hline Total number of schools & 84 & 42 & 42 & 83 & 42 & 41 & 83 & 42 & 41 \\
\hline$A B C$ & 12 & 6 & 6 & 12 & 6 & 6 & 12 & 6 & 6 \\
\hline CSP & 10 & 5 & 5 & 10 & 5 & 5 & 10 & 5 & 5 \\
\hline LBW $^{1}$ & 12 & 6 & 6 & 11 & 6 & 5 & 11 & 6 & 5 \\
\hline PA & 14 & 7 & 7 & 14 & 7 & 7 & 14 & 7 & 7 \\
\hline PATHS & 10 & 5 & 5 & 10 & 5 & 5 & 10 & 5 & 5 \\
\hline 4Rs & 14 & 7 & 7 & 14 & 7 & 7 & 14 & 7 & 7 \\
\hline SS & 12 & 6 & 6 & 12 & 6 & 6 & 12 & 6 & 6 \\
\hline
\end{tabular}

${ }^{1}$ One control school became a magnet school and dropped out of the evaluation.

NOTE: Abbreviations are

ABC: Academic and Behavioral Competencies Program

CSP: Competence Support Program

LBW: Love In a Big World

PA: Positive Action

PATHS: Promoting Alternative Thinking Strategies

4Rs: The 4Rs Program (Reading, Writing, Respect, and Resolution)

SS: Second Step

SOURCE: The Social and Character Development (SACD) Research Program. 


\section{Chapter 1. The Social and Character Development Multiprogram Evaluation}

The teacher sample for the evaluation included the teachers in the grade that the student cohort attended in order to obtain teacher reports on students and all the third-, fourth-, and fifth-grade teachers in the participating schools during all 3 school years in order to measure the level of SACD activities in the schools. The principal sample included the principals at each of the 84 schools.

The student sample for the multiprogram evaluation included students enrolled in the third grade during the 200405 school year, students enrolled in the fourth grade during the 2005-06 school year, and students enrolled in the fifth grade during the 2006-07 school year, with "enrollment" defined as being present in the study schools at the time of student data collection. Thus, the sample included a cohort of third-grade students as they progressed through their fifth-grade year. In addition, it included students who entered the study schools over the course of the study (i.e., students who entered study schools as third graders during the 2004-05 academic year, or as fourth graders in the 2005-06 academic year, or as fifth graders in the 2006-07 academic year). Thus, the specific students in the sample changed between the beginning of data collection during fall 2004 and subsequent rounds of data collection. Up to the time of a specific data collection follow-up, students exposed to an intervention were from one of three groups:

1. Children enrolled in third grade at a study school in fall 2004 and during the subsequent rounds of data collection—original sample who remained at the schools (stayers);

2. Children enrolled in third grade at a study school in fall 2004 but not enrolled during a subsequent data collection period-original sample who left between fall 2004 data collection and a subsequent data collection (leavers); and

3. Children who enrolled in the grade of the student cohort at a study school after the fall 2004 data collection but before the subsequent data collection initiative (new entrants).

A total of 6,567 third-graders were initially enrolled in the study schools in fall 2004 (table 1.3). Due to the combination of leavers and new entrants, the total was 6,597 in spring 2005. It fell to 6,415 in spring 2006 and to 6,249 in spring 2007. Over this period the treatment group made up 51 percent to 52 percent of the sample. The average number of students per school ranged from 75 to 81 ; however, the actual number per school varied across the programs from 23 to 164. Over time, new entrants grew as a percentage of the sample from 6 percent to 20 percent to 28 percent, and there were no statistically significant differences each year between the percentages of new entrants in the treatment and control groups. The percentage of the original sample that left also grew from follow-up to follow-up, going from 6 percent to 22 percent to 32 percent, again with no statistically significant differences each year between the treatment and control groups. Leavers were not tracked once they left the study schools. ${ }^{7}$ That is, if a third-grade student was enrolled in a study school during fall 2004 but then left before spring 2005, that student was not tracked into the new school and new data from that student were not collected in spring 2005. As a result of this turnover, 69 percent of the original students (stayers) remained in the study and they made up 72 percent of the Year 3 student sample.

\footnotetext{
${ }^{7}$ A small percentage of leavers moved to another school in the study and so remained in the study. For descriptive purposes, they took on the assignment of their school to treatment or control. For analysis purposes, they retained their initial assignment. The percentages of Cohort 1 students who switched status at each round grew at each follow-up point but remained relatively small (growing from about $0.2 \%$ to $1.4 \%$ ).
} 
Table 1.3. Characteristics of the student sample in the multiprogram evaluation

\begin{tabular}{|c|c|c|c|c|c|c|c|c|c|c|c|c|}
\hline \multirow[b]{2}{*}{ Characteristic } & \multicolumn{3}{|c|}{$\begin{array}{c}\text { Year } 1 \\
\text { (Fall 3rd grade) }\end{array}$} & \multicolumn{3}{|c|}{$\begin{array}{c}\text { Year } 1 \\
\text { (Spring 3rd grade) }\end{array}$} & \multicolumn{3}{|c|}{$\begin{array}{c}\text { Year } 2 \\
\text { (Spring 4th grade) }\end{array}$} & \multicolumn{3}{|c|}{$\begin{array}{c}\text { Year } 3 \\
\text { (Spring 5th grade) }\end{array}$} \\
\hline & Total & $\begin{array}{r}\text { Treat- } \\
\text { ment }\end{array}$ & Control & Total & $\begin{array}{r}\text { Treat- } \\
\text { ment }\end{array}$ & Control & Total & $\begin{array}{r}\text { Treat- } \\
\text { ment }\end{array}$ & Control & Total & $\begin{array}{r}\text { Treat- } \\
\text { ment }\end{array}$ & Control \\
\hline School sample size & 84 & 42 & 42 & 84 & 42 & 42 & 83 & 42 & 41 & 83 & 42 & 41 \\
\hline Student sample size & 6,567 & 3,367 & 3,200 & 6,597 & 3,388 & 3,209 & 6,415 & 3,327 & 3,088 & 6,249 & 3,172 & 3,077 \\
\hline Stayers & $\dagger$ & $\dagger$ & $\dagger$ & 6,203 & 3,188 & 3,015 & 5,110 & 2,625 & 2,485 & 4,500 & 2,289 & 2,211 \\
\hline New entrants & $\dagger$ & $\dagger$ & $\dagger$ & 394 & 200 & 194 & 1,305 & 702 & 603 & 1,749 & 883 & 866 \\
\hline $\begin{array}{l}\text { New entrants as percent of spring } \\
\text { enrollment }^{1}\end{array}$ & $\dagger$ & $\dagger$ & $\dagger$ & 6.0 & 5.9 & 6.0 & 20.3 & 21.1 & 19.5 & 27.9 & 27.8 & 28.1 \\
\hline Total leavers (from original cohort) & $\dagger$ & $\dagger$ & $\dagger$ & 364 & 179 & 185 & 1,457 & 742 & 715 & 2,067 & 1,078 & 989 \\
\hline $\begin{array}{l}\text { Leavers as percent of fall } 2004 \\
\text { enrollment }\end{array}$ & $\dagger$ & $\dagger$ & $\dagger$ & 5.5 & 5.3 & 5.8 & 22.2 & 22.0 & 22.3 & 31.5 & 32.0 & 30.9 \\
\hline Number of students per school (mean) & 78 & 80 & 76 & 79 & 81 & 76 & 77 & 80 & 76 & 75 & 76 & 75 \\
\hline Range of number of students per school & 23-149 & $38-149$ & $23-148$ & $26-155$ & $35-147$ & $26-155$ & $25-151$ & $36-151$ & $25-144$ & $25-164$ & 28-164 & 25-139 \\
\hline
\end{tabular}


Because leavers were not followed, the SACD evaluation is not an intent-to-treat impact analysis (an analysis that follows all students originally assigned to the treatment or control groups). Therefore, there is the possibility that the SACD programs caused differential student and teacher mobility in the treatment schools versus mobility in the control schools. If this occurred, the estimates of the impact of the programs would include both the extent to which the programs improved the outcomes of the average student and the mobility effects resulting from any differences in the average outcomes of treatment and control students who entered or left the schools after random assignment was completed in third grade. Descriptive analyses, presented later, do not identify differential mobility in the treatment and control schools, although this cannot be definitively established.

Table 1.4 provides information on the student sample by program. The same trends in the growth in the percentages of leavers and new entrants were apparent but there were differences among programs in this growth. For example, by Year 3 the percentages of leavers ranged from 9 percent to 50 percent, and the percentages of new entrants ranged from 14 percent to 38 percent among programs. The table also shows that over all 3 years there was a statistically significant difference between the treatment and control groups within a program for the percentage of leavers in six cases and the percentage of new entrants in one case.

Student turnover could have affected the results of the evaluation. First, if the SACD programs affected turnover-and thus altered the composition of the student population-then the difference between the treatment and control groups would reflect (1) the changes in student behavior that were due to the intervention, and (2) the changes that arose indirectly because the student population changed. Second, students had differing amounts of exposure to the program, and this may have affected the benefits to students. In response to these issues, sensitivity analyses were conducted to address whether there were differences between the estimated impacts of the SACD programs for the stayers and for the new entrant subgroups. 
Table 1.4. Student sample overall and by program for all students and for the treatment and control groups

\begin{tabular}{|c|c|c|c|c|c|c|c|c|c|c|c|c|c|c|c|c|}
\hline \multirow[b]{3}{*}{ Intervention program } & \multirow{3}{*}{$\begin{array}{r}\text { Year } 1 \\
\text { (Fall 3rd grade) } \\
\text { All } \\
\text { students }\end{array}$} & \multicolumn{5}{|c|}{$\begin{array}{c}\text { Year } 1 \\
\text { (Spring 3rd grade) }\end{array}$} & \multicolumn{5}{|c|}{$\begin{array}{c}\text { Year } 2 \\
\text { (Spring 4th grade) }\end{array}$} & \multicolumn{5}{|c|}{$\begin{array}{c}\text { Year } 3 \\
\text { (Spring 5th grade) }\end{array}$} \\
\hline & & \multirow{2}{*}{$\begin{array}{r}\text { All } \\
\text { students } \\
\end{array}$} & \multicolumn{2}{|c|}{ Leavers } & \multicolumn{2}{|c|}{$\begin{array}{l}\mathrm{New} \\
\text { entrants }\end{array}$} & \multirow{2}{*}{$\begin{array}{r}\text { All } \\
\text { students }\end{array}$} & \multicolumn{2}{|c|}{ Leavers } & \multicolumn{2}{|c|}{$\begin{array}{c}\text { New } \\
\text { entrants } \\
\end{array}$} & \multirow{2}{*}{$\begin{array}{r}\text { All } \\
\text { students } \\
\end{array}$} & \multicolumn{2}{|c|}{ Leavers } & \multicolumn{2}{|c|}{$\begin{array}{c}\text { New } \\
\text { entrants } \\
\end{array}$} \\
\hline & & & $\#$ & $\%^{1}$ & $\#$ & $\%^{2}$ & & $\#$ & $\%^{1}$ & $\#$ & $\%^{2}$ & & \# & $\%^{1}$ & $\#$ & $\%^{2}$ \\
\hline All programs & 6,567 & 6,597 & 364 & 6 & 394 & 6 & 6,415 & 1,457 & 22 & 1,305 & 20 & 6,249 & 2,067 & 31 & 1,749 & 28 \\
\hline Treatment group & 3,367 & 3,388 & 179 & 5 & 200 & 6 & 3,327 & 742 & 22 & 702 & 21 & 3,172 & 1,078 & 32 & 883 & 28 \\
\hline Control group & 3,200 & 3,209 & 185 & 6 & 194 & 6 & 3,088 & 715 & 22 & 603 & 20 & 3,077 & 989 & 31 & 866 & 28 \\
\hline$A B C$ & 879 & 875 & 43 & 5 & 39 & 4 & 877 & 160 & 18 & 158 & 18 & 871 & 289 & 33 & 281 & 32 \\
\hline Treatment group & 380 & 373 & 17 & 4 & 10 & $3^{* *}$ & 367 & 72 & 19 & 59 & 16 & 353 & 135 & 36 & 108 & 31 \\
\hline Control group & 499 & 502 & 26 & 5 & 29 & 6 & 510 & 88 & 18 & 99 & 19 & 518 & 154 & 31 & 173 & 33 \\
\hline CSP & 959 & 975 & 36 & 4 & 52 & 5 & 969 & 230 & 24 & 240 & 25 & 947 & 238 & 25 & 226 & 24 \\
\hline Treatment group & 476 & 485 & 20 & 4 & 29 & 6 & 474 & 135 & $28^{* *}$ & 133 & $28^{*}$ & 458 & 139 & $29^{* *}$ & 121 & 26 \\
\hline Control group & 483 & 490 & 16 & 3 & 23 & 5 & 495 & 95 & 20 & 107 & 22 & 489 & 99 & 20 & 105 & 21 \\
\hline LBW & 986 & 1,007 & 60 & 6 & 81 & 8 & 959 & 228 & 23 & 201 & 21 & 944 & 308 & 31 & 266 & 28 \\
\hline Treatment group & 548 & 565 & 25 & $5^{* *}$ & 42 & 7 & 556 & 110 & 20 & 118 & 21 & 567 & 145 & $26^{* *}$ & 164 & 29 \\
\hline Control group & 438 & 442 & 35 & 8 & 39 & 9 & 403 & 118 & 27 & 83 & 21 & 377 & 163 & 37 & 102 & 27 \\
\hline PA & 811 & 812 & 74 & 9 & 75 & 9 & 764 & 251 & 31 & 204 & 27 & 655 & 408 & 50 & 252 & 38 \\
\hline Treatment group & 410 & 416 & 33 & 8 & 39 & 9 & 425 & 108 & $26^{* *}$ & 123 & 29 & 327 & 209 & 51 & 126 & 39 \\
\hline Control group & 401 & 396 & 41 & 10 & 36 & 9 & 339 & 143 & 36 & 81 & 24 & 328 & 199 & 50 & 126 & 38 \\
\hline PATHS & 786 & 783 & 39 & 5 & 36 & 5 & 778 & 150 & 19 & 142 & 18 & 778 & 243 & 31 & 235 & 30 \\
\hline Treatment group & 377 & 374 & 21 & 6 & 18 & 5 & 373 & 66 & 18 & 62 & 17 & 378 & 114 & 30 & 115 & 30 \\
\hline Control group & 409 & 409 & 18 & 4 & 18 & 4 & 405 & 84 & 21 & 80 & 20 & 400 & 129 & 32 & 120 & 30 \\
\hline 4Rs & 1,202 & 1,194 & 86 & 7 & 78 & 7 & 1,109 & 320 & 27 & 227 & 20 & 1,065 & 492 & 41 & 355 & 33 \\
\hline Treatment group & 652 & 647 & 49 & 8 & 44 & 7 & 599 & 183 & 28 & 130 & 22 & 556 & 279 & 43 & 183 & 33 \\
\hline Control group & 550 & 547 & 37 & 7 & 34 & 6 & 510 & 137 & 25 & 97 & 19 & 509 & 213 & 39 & 172 & 34 \\
\hline
\end{tabular}


Table 1.4. Student sample overall and by program for all students and for the treatment and control groups-Continued

\begin{tabular}{|c|c|c|c|c|c|c|c|c|c|c|c|c|c|c|c|}
\hline \multirow[b]{3}{*}{ Intervention program } & \multirow{3}{*}{$\begin{array}{r}\text { Year } 1 \\
\text { (Fall 3rd grade) } \\
\text { All } \\
\text { students }\end{array}$} & \multicolumn{5}{|c|}{$\begin{array}{c}\text { Year } 1 \\
\text { (Spring 3rd grade) }\end{array}$} & \multicolumn{5}{|c|}{$\begin{array}{c}\text { Year } 2 \\
\text { (Spring 4th grade) }\end{array}$} & \multicolumn{4}{|c|}{$\begin{array}{c}\text { Year } 3 \\
\text { (Spring 5th grade) }\end{array}$} \\
\hline & & \multirow{2}{*}{$\begin{array}{r}\text { All } \\
\text { students } \\
\end{array}$} & \multicolumn{2}{|c|}{ Leavers } & \multicolumn{2}{|c|}{$\begin{array}{c}\text { New } \\
\text { entrants }\end{array}$} & \multirow{2}{*}{$\begin{array}{r}\text { All } \\
\text { students } \\
\end{array}$} & \multicolumn{2}{|c|}{ Leavers } & \multicolumn{2}{|c|}{$\begin{array}{c}\text { New } \\
\text { entrants }\end{array}$} & \multirow{2}{*}{$\begin{array}{r}\text { All } \\
\text { students } \\
\end{array}$} & Leavers & \multicolumn{2}{|c|}{$\begin{array}{c}\mathrm{New} \\
\text { entrants }\end{array}$} \\
\hline & & & \# & $\%^{1}$ & \# & $\%^{2}$ & & \# & $\%^{1}$ & \# & $\%^{2}$ & & $\# \%^{1}$ & \# & $\%^{2}$ \\
\hline SS & 944 & 951 & 26 & 3 & 33 & 3 & 959 & 118 & 13 & 133 & 14 & 989 & $89 \quad 9$ & 134 & 14 \\
\hline Treatment group & 524 & 528 & 14 & 3 & 18 & 3 & 533 & 68 & 13 & 77 & 14 & 533 & $11^{*}$ & 66 & 12 \\
\hline Control group & 420 & 423 & 12 & 3 & 15 & 4 & 426 & 50 & 12 & 56 & 13 & 456 & 32 & 68 & 15 \\
\hline
\end{tabular}

${ }^{*}$ Treatment group significantly different from control group at the .05 level.

** Treatment group significantly different from control group at the .01 level.

${ }_{2}^{1}$ Leavers as a percentage of fall 2004 enrollment (these values are cumulative over the years).

${ }^{2}$ New entrants as a percentage of spring enrollment.

NOTE: Abbreviations are

ABC: Academic and Behavioral Competencies Program

CSP: Competence Support Program

LBW: Love In a Big World

PA: Positive Action

PATHS: Promoting Alternative Thinking Strategies

4Rs: The 4Rs Program (Reading, Writing, Respect, and Resolution)

SS: Second Step

SOURCE: The Social and Character Development (SACD) Research Program. 


\section{Chapter 1. The Social and Character Development Multiprogram Evaluation}

\section{Measures}

The SACD multiprogram evaluation included six data collection reports: (a) Child Report; (b) Primary Caregiver Report; (c) Teacher Report on Student; (d) Teacher Report on Classroom and School; (e) Principal Interview; and (f) Implementation Fidelity Rating. ${ }^{8}$ The measures included in these reports were largely taken from instruments used in previous research. Four measures (child responsibility, child and teacher perceptions of school safety, and primary caregiver perceptions of community resources) were developed for the SACD evaluation due to a lack of adequate existing measures. Modifications were made to some of the measures to enhance readability, reduce the number of items, or reduce the number of possible responses to each item. Children were asked to respond based on their experiences in the past couple of weeks; primary caregivers and teachers responded based on their experiences in the past 30 days. The surveys were pilottested in December 2003, and revisions were made prior to the initial administration in fall 2004. A series of exploratory and confirmatory factor analyses using the initial data collapsed the scales into a smaller number of more reliable measures that were used as outcome or moderator variables in the impact analyses. In addition to developing the outcome variables, these analyses provided a check of how well the measures fit under the outcome domains as set out in the conceptual model (Social and Emotional Competence, Behavior, Academics, and Perceptions of School Climate). The discussion of the measures is broken into two parts. First, the scales collected are described by report and domain. Their published reliabilities, if available, are reported.9 Second, the outcome and moderator measures developed through the factor analyses and then used in the analyses for the SACD evaluation are described.

\section{Child Report}

The Child Report was a group-administered questionnaire consisting of a battery of measures that are described below. The instrument was delivered to groups averaging 15 to 20 students in classrooms at each school during a 1- to 2-day visit (or during a make-up session) by the MPR data collection team. A proctor read the directions aloud as children followed along in their survey booklets during a 50-minute classroom session. Children reported on their own thoughts, feelings, and behaviors. There is some evidence in the literature that self-reports of behavior problems are not valid in elementary-age aggressive and ADHD children (McMahon and Frick 2005; Pelham, Fabiano, and Massetti 2005), which may limit the value of such measures for this type of student (though similar measures were used with primary caregivers and teachers). The following measures (grouped by domain) were included in the battery:

I. Social and Emotional Competence

A. Beliefs about aggression. This measure is an 8-item modified version of the Normative Beliefs About Aggression Scale (Huesmann and Guerra 1997). Children responded on a 4-point scale, indicating their beliefs about the acceptability of verbal and physical aggression, either proactive or in retaliation for others' behavior (e.g., how wrong or okay it is to hit, shove, fight with, or verbally assault others). Its reliability has been evaluated through internal consistency (0.90).

B. Self-efficacy for peer interaction. This measure is a 12-item modified version of the Self-Efficacy for Peer Interaction Scale (Wheeler and Ladd 1982). Children responded on a 4-point scale,

\footnotetext{
${ }^{8}$ In addition, the SACD evaluation intended to include two additional reports for each program: a cost report and a report on the presence of artifacts indicating the use of SACD activities. For the cost report, a common training on collection of cost data was provided for the research teams; however, all teams did not collect such data and the data collected were not consistent. As a result, cost reports were not generated and the SACD evaluation did not include a cost analysis. For the artifact study, school and classroom observations were done in Year 1. However inter-rater reliability was considered too low, so the observations were not continued in later years and the Year 1 results are not reported.
}

${ }^{9}$ Five of the measures have no published reliabilities, and no reliabilities were computed for these measures based on the study data. Items from these measures were used to create the outcome measures. The outcome measures they contributed to and the reliabilities of those outcome measures calculated from the study data are shown in table 5. 
indicating their perceived ability to perform verbal or persuasive prosocial skills in conflict and nonconflict peer interactions (e.g., how hard or easy it is to engage in play with other children or resist negative social pressures). Its reliability has been evaluated through internal consistency $(0.85)$ and test-retest ( 0.90 for boys and 0.80 for girls).

C. Empathy. This measure is a 16-item modified version of the Children's Empathy Questionnaire (Funk et al. 2003). Children responded on a 3-point scale about the degree to which they would respond empathically to hypothetical and actual anticipated events (e.g., whether other people's problems bother them or if they would feel happy when a friend gets a good grade). Its reliability has been evaluated through internal consistency (0.72).

II. Behavior

A. Altruistic behavior. The Altruism Scale, Child Version (Soloman et al. 2000) is an 8-item measure to which children responded on a 4-point scale about how often they engage in helping behavior (e.g., cheer someone up who is feeling sad or help someone who is being picked on). Its reliability has been evaluated through internal consistency (0.82).

B. Aggression. The Aggression Scale (Orpinas and Frankowski 2001) is a 6-item measure to which children responded on a 4-point scale about how often they engage in verbal or physical aggression (e.g., tease others, shove others). Its reliability has been evaluated through internal consistency (0.87).

C. Minor delinquency. The modified Frequency of Delinquent Behavior (Dahlberg, Toal, and Behrens 1998; Dunford and Elliott 1984) Scale was modified for the SACD multiprogram evaluation. Children responded to 6 items on a 4-point scale about how often they engage in minor delinquency in school (e.g., taking something that belongs to others, skipping class). There is no published or study-based reliability for this scale.

III. Academics

A. School engagement. The Engagement vs. Disaffection with Learning Scale, (Furrer and Skinner 2003) is a 10-item measure to which children responded on a 4-point scale, indicating how much they agree with statements indicative of their behavioral and emotional engagement, effort, attention, and persistence in the classroom (e.g., paying attention in class, listening carefully, joining in class discussion). Its reliability has been evaluated through internal consistency ( 0.75 to $0.86)$.

B. Standardized test scores and grades. The research teams were to collect student standardized test scores and grades. However, not all teams were able to collect these data from their schools and districts, and the data that were collected varied in quality. As a result, neither standardized test scores nor grades could be used as outcome measures in the evaluation, although they had been proposed for such use in the conceptual model.

IV. Perceptions of School Climate

A. School connectedness. The Sense of School as a Community Scale (Roberts, Horn, and Battistich $1995)$ is a 14-item measure to which children responded on a 4-point scale about how much they agree with statements indicative of the social relationships among students, teachers, and staff within a school (e.g., students care about each other, students and teachers treat each other with respect). Its reliability has been evaluated through internal consistency (0.91).

B. Safety. The Feelings of Safety at School Scale was developed for the SACD multiprogram evaluation and is a 5-item measure to which children responded on a 4-point scale about how much they agree with statements that are indicative of students' feelings of safety at school (e.g., students feel safe, students are afraid someone will hurt them, students are afraid someone will 


\section{Chapter 1. The Social and Character Development Multiprogram Evaluation}

tease them). The scale was constructed by IES and DVP staff for the SACD multiprogram evaluation. There is no published or study-based reliability for this scale.

C. Victimization. The Victimization Scale (Orpinas and Kelder 1995) is a 6-item measure to which children responded on a 4-point scale about how often they are victimized at school (e.g., teased, pushed, or threatened). Its reliability has been evaluated through internal consistency (0.90).

\section{Primary Caregiver Report}

The Primary Caregiver Report was a self-administered survey that took primary caregivers approximately 15 minutes to complete. Primary caregivers, who were usually but not always parents, reported on the target child's behavior, demographic factors, and home and community environment. Primary caregivers completed the questionnaire at home and returned it to school in a sealed envelope. If a completed Primary Caregiver Report was not returned within 3 or 4 weeks, MPR attempted to complete a computer-assisted telephone interview with the primary caregiver. Primary caregivers were offered a small financial incentive as a thankyou. The following measures (grouped by domain or type of moderator) were used:

I. Behavior

A. Responsibility. The Responsibility Scale is an 8-item measure developed for the SACD multiprogram evaluation to which primary caregivers responded on a 4-point scale about the degree to which a child takes responsibility for his or her own actions (e.g., how often a child asks permission, apologizes, takes care of property, or denies responsibility for wrongdoing). The scale was constructed by IES and DVP staff for the SACD multiprogram evaluation. There is no published or study-based reliability for this scale.

B. Self-regulation, cooperation, and prosocial behavior. The Social Competence Scale (CPPRG 1999) is a 19item measure to which primary caregivers responded on a 4-point scale about a child's emotional and behavioral regulation, cooperative behavior, and prosocial behavior (e.g., how often a child calms down when wound up, works well in groups, and acts friendly toward others). Its reliability has been evaluated through internal consistency (0.87).

C. Altruistic behavior. The Altruism Scale, Primary Caregiver Version (Soloman et al. 2000) is an 8item measure to which primary caregivers responded on a 4-point scale about how often their child engages in helping behavior (e.g., cheers someone up who is feeling sad or helps someone who is being picked on). Its reliability has been evaluated through internal consistency (0.82).

D. Aggression. The Behavior Assessment System for Children (BASC) Aggression Subscale, Parent Version (Reynolds and Kamphaus 1998) is a 13-item assessment to which primary caregivers responded on a 4-point scale about how often their child engages in verbal or physical aggression (e.g., teases others, hits other children). Its reliability has been evaluated through internal consistency (0.83) and test-retest (0.84).

E. Conduct problems. The BASC Conduct Problems Subscale, Parent Version (Reynolds and Kamphaus 1998) is an 11-item assessment to which primary caregivers responded on a 4-point scale about how often their child engages in socially deviant and disruptive behaviors (e.g., lies, gets into trouble). Its reliability has been evaluated through internal consistency (0.82) and testretest (0.92).

II. Perceptions of School Climate

A. Parent involvement. The modified Parent and Teacher Involvement Questionnaire, Parent Version (CPPRG 1991) is a 9-item measure to which primary caregivers responded on a 4-point scale about how often they interact with teachers and school staff, participate in school activities, and are involved in their children's academic lives (e.g., call the child's teacher, attend parent-teacher 


\section{Chapter 1. The Social and Character Development Multiprogram Evaluation}

conferences, take the child to the library). Its reliability has been evaluated through internal consistency (0.77).

III. Family Moderators

A. Parenting practices. The Alabama Parenting Questionnaire, Positive Parenting, and Poor Monitoring and Supervision Subscales (Shelton, Frick, and Wootton 1996) is a 16-item measure to which primary caregivers responded on a 4-point scale about how often they support and reward their child, and monitor and supervise their child (e.g., praise the child for good behavior, check when the child comes home). Its reliability has been evaluated through internal consistency ( 0.75 for monitoring and 0.85 for positive parenting).

B. Home atmosphere. The modified Confusion, Hubbub, and Order Scale (Matheny et al. 1995) is a 14-item measure to which primary caregivers responded on a 5-point scale about how much they agree or disagree with statements that reflect disorganization in the home (e.g., can find things when you need them, there is always a fuss going on, there is a regular routine). Its reliability has been evaluated through internal consistency (0.79) and through test-retest (0.74).

C. Socioeconomic risk. Primary caregivers completed a series of questions indicating ethnicity, education, employment status, household composition, and income.

IV. Community Moderators

A. Perceptions of community risks and protective factors. The Community Risks and Protective Factors Scale is a 12-item measure developed for the multiprogram evaluation based on research on community risks by Forehand, Brody, and Armistead (2000) and supplemented with items to assess community resources constructed by researchers involved in the SACD evaluation. Primary caregivers indicated on a 4-point scale how much statements about community characteristics described the neighborhood the primary caregiver and child live in (e.g., trash pickup is a problem in the neighborhood, there are safe outdoor parks for children to play in). Seven of the items were taken from the original Community Risks Scale whose reliability has been evaluated through internal consistency (0.89). The other five items were from the Community Resources Scale constructed by IES and DVP staff for the SACD multiprogram evaluation and for which there is no published or study-based reliability.

B. Intergenerational closure. The Intergenerational Closure Scale (Sampson, Morenoff, and Earls 1999) is a 5-item measure to which primary caregivers responded on a 4-point scale to statements about adults' connections with children in the neighborhood (e.g., parents know their children's friends, there are adults for kids to look up to). Its reliability has been evaluated through internal consistency (0.72).

C. Child-centered social control. The Child-Centered Social Control Scale (Sampson, Morenoff, and Earls 1999) is a 5-item measure on which primary caregivers indicated on a 5-point scale how likely it is that neighbors could be counted on to "do something" if something occurred in the neighborhood (e.g., youth sprayed graffiti, children were hurt, neighbors were in need). Its reliability has been evaluated through internal consistency (0.74).

\section{Teacher Report on Student}

The Teacher Report on Student was a self-administered survey completed by teachers of the student cohort in the study (i.e., third-grade teachers in 2004-05, fourth-grade teachers in 2005-06, and fifth-grade teachers in 2006-07). Teachers reported on each consented student's typical behavior in the past 30 days. Teachers completed the questionnaires independently and returned the surveys to a central point in the school for collection by the research team. The survey took approximately 15 minutes for teachers to complete for each 


\section{Chapter 1. The Social and Character Development Multiprogram Evaluation}

consented student in their classroom. Teachers were offered a small financial incentive as a thank-you. The following measures (grouped by domain) were used:

\section{Behavior}

A. Responsibility. The Responsibility Scale is an 8-item measure developed for the SACD multiprogram evaluation. It uses teachers' responses on a 4-point scale to measure the degree to which a child takes responsibility for his or her own actions (e.g., how often a child asks permission, apologizes, takes care of property, or denies responsibility for wrongdoing) for the SACD multiprogram evaluation. The scale was constructed by IES and DVP staff for the SACD multiprogram evaluation. There is no published or study-based reliability for this scale.

B. Self-regulation, cooperation, and prosocial behavior. The Social Competence Scale (CPPRG 1999) is an 19-item measure to which teachers responded on a 4-point scale about a child's emotional and behavioral regulation, cooperative behavior, and prosocial behavior (e.g., how often a child calms down when wound up, works well in groups, and acts friendly toward others). Its reliability has been evaluated through internal consistency $(0.87)$.

C. Altruistic behavior. The Altruism Scale (Soloman et al. 2000) is an 8-item measure to which teachers responded on a 4-point scale about how often a student engages in helping behavior (e.g., cheers someone up who is feeling sad or helps someone who is being picked on). Its reliability has been evaluated through internal consistency (0.82).

D. Aggression. The BASC Aggression Subscale, Teacher Version (Reynolds and Kamphaus 1998) is a 14-item assessment to which teachers responded on a 4-point scale about how often a student engages in verbal or physical aggression (e.g., bullies others, calls other children names). Its reliability has been evaluated through internal consistency (0.95) and through test-retest (0.91).

E. Conduct problems. The BASC Conduct Problems Subscale, Teacher Version (Reynolds and Kamphaus 1998) is a 10-item assessment to which teachers responded on a 4-point scale about how often a student engages in socially deviant or disruptive behavior in school (e.g., skips class, cheats, steals). Its reliability has been evaluated through internal consistency (0.77) and through test-retest (0.80).

F. Attention deficit hyperactivity disorder (ADHD)-related behavior. This measure is a set of 10 items that assess a range of symptoms of attention deficits and hyperactivity such as inattention, distractibility, verbal and physical impulsivity, losing things, and difficulty organizing activities. It draws on two sources. Five inattention/overactivity items were taken from the IOWA Conners Teacher Rating Scale (Loney and Milich 1982). The reliability of the original Conners scale has been evaluated through internal consistency ( 0.89 to 0.92$)$. Five items were based on diagnostic criteria for ADHD from the Diagnostic and Statistical Manual for Mental Disorders, fourth edition (American Psychiatric Association 2000) that have been shown to be among the most powerful for predicting ADHD diagnoses in school settings (Pelham et al. 1992).

II. Academics

A. Academic competence. The Academic Competence and Motivation Scale was developed for the SACD multiprogram evaluation and is based on the academic competency subscales of the Social Skills Rating System (Gresham and Elliott 1990) and items from the Teacher's Report Form (Achenbach 1991). On this 5-item measure, teachers indicated how a student performed overall, performed in reading, performed in math, and functioned intellectually compared to grade-level expectations; and indicated how motivated a student was compared to the average student at grade level. The reliability of the Social Skills Rating System has been evaluated through internal consistency (0.96) and through test-retest (0.93). The reliability of the Teacher 


\section{Chapter 1. The Social and Character Development Multiprogram Evaluation}

Report Form has been evaluated through internal consistency (0.72 to 0.95$)$ and through testretest (0.62 to 0.96$)$.

III. Perceptions of School Climate

A. Parent and teacher involvement. This measure is a 7-item modified version of the Parent and Teacher Involvement Questionnaire, Teacher Version (CPPRG 1991). Teachers responded on a 4-point scale indicating how often a student's primary caregiver interacts with the teachers at school and attends school events (e.g., calls on the phone, attends parent-teacher conferences). Teachers also responded to three questions about communication with a student's parents, the degree of involvement a parent has in a student's life, and the academic encouragement provided to a student. Its reliability has been evaluated through internal consistency $(0.77)$.

\section{Teacher Report on Classroom and School}

The Teacher Report on Classroom and School was a self-administered questionnaire that took a teacher approximately 30 minutes to complete. Teachers reported on the organizational climates of their schools, the social and character development activities they had implemented in their classrooms, and their own professional backgrounds. The questionnaire was distributed to third-, fourth-, and fifth-grade teachers at each school. The following measures (grouped by domain or type of moderator) were used:

I. Perceptions of School Climate

A. Organizational climate. The School-Level Environment Questionnaire (Rentoul and Fraser 1983) is a 56-item measure to which teachers responded on a 5-point scale about the degree to which teachers are supported and valued by administration officials, are provided adequate resources, are autonomous in managing their own activities, are collegial with one another, and have a voice in school policy decisions. Its reliability has been evaluated through internal consistency (0.82).

B. Safety. The Feelings of Safety at School Scale was developed for the SACD multiprogram evaluation and is a 4-item measure. Teachers responded on a 4-point scale about how much they agree with statements that are indicative of students' feelings of safety at school (e.g., students feel safe at this school, students are afraid someone will hurt them at school, students are afraid someone will tease them at school). This scale was constructed by IES and DVP staff for the SACD multiprogram evaluation. There is no published or study-based reliability for this scale.

II. Level of SACD in the School

The SACD Activities Teacher Survey is a self-report questionnaire constructed by SACD Research Consortium members. Teachers indicated the SACD-related programs and activities occurring in the classroom and school, and the degree to which teachers and staff incorporated SACD-like qualities in their professional relationships and styles. The questionnaire consisted of 11 major questions, each with multiple parts. A set of 83 SACD activities variables was created from teacher responses to individual questions. These variables were used to describe the level of social and character development formally occurring in every school. As such, they were also used as outcome variables (no additional construction was done for their use in the analysis) to evaluate the impact of the SACD programs on the use of SACD activities in the schools. The individual outcomes were grouped under six domains: ${ }^{10}$ (1) use of SACD activities, (2) use of SACD activities associated with a named SACD program, (3) use of classroom materials and strategies to promote social and character development, (4) use of schoolwide strategies to promote social and character development, (5) professional development of teachers to promote social and character development, and (6) teachers' attitudes toward the promotion of social and character development and school practices conducive

\footnotetext{
10 Outcomes were grouped into the six domains based on face validity alone. No psychometric procedures were used, and no measures of reliability or validity were obtained.
} 


\section{Chapter 1. The Social and Character Development Multiprogram Evaluation}

to such promotion. Below is a description of each of the SACD Activities' variables developed from the survey and grouped by domain.

A. Use of Social and Character Development Activities. Teachers reported whether they engaged in activities to promote six SACD goals and behavior management. The six SACD goals were defined as follows:

1. Violence Prevention and Peace Promotion: to make students and schools safer and more peaceful (e.g., reducing verbal and physical aggression, weapons, and bullying while promoting conflict resolution and peacemaking);

2. Social and Emotional Competence: to foster positive emotional, behavioral, and interpersonal skill (e.g., anger management, recognizing emotions, empathy, respectful communication, and building and maintaining friendships);

3. Character Education: to encourage the development of desirable traits, values, and ethics (e.g., respect, responsibility, honesty, fairness, and caring);

4. Tolerance and Diversity: to promote understanding of and respect for the ways in which people differ (e.g., promote acceptance of others, celebrate cultural and ethnic differences, and reduce prejudice);

5. Risk Prevention and Health Promotion: to reduce unhealthy behaviors and promote healthy ones (e.g., prevent alcohol, tobacco, and drug use and promote healthy life choices); and

6. Civic Responsibility and Community Service: to promote participation in and commitment to the common good including service to the classroom, school, and community (e.g., raising resources for charity, recycling, and promoting understanding of one's role in creating community).

For each goal, teachers were asked to provide a brief description of any activity that addressed the goal in their class since the beginning of the school year, to indicate whether they did the activity with all or some students, and the frequency and amount of time devoted to these activities. Two sets of seven variables were developed from these responses. The first set of seven variables was composed of binary variables (yes or no) as to whether teachers reported that they had engaged in a SACD activity for each SACD goal separately (six variables) and whether they reported that they had engaged in a SACD activity for any of the SACD goals (one variable). The second set of seven variables was composed of binary variables as to whether teachers reported that they had engaged in a SACD activity for at least 1 hour per week for each SACD goal separately (six variables) and whether they reported that they had engaged in a SACD activity for at least 1 hour per week for any of the SACD goals (one variable). One hour was chosen as the cutoff point because most of the programs expected teachers to conduct weekly lessons that would require approximately this much time.

In addition, respondents also reported separately on the use and amount of time devoted to behavior management activities. These reports were used to create two binary variables: (1) whether teachers reported that they had engaged in activities to support behavior management, and (2) whether teachers reported that they had engaged in activities to support behavior management for at least 1 hour per week.

In total, this domain contains 16 outcome variables: (1) Six variables regarding teachers' reported use of SACD activities to promote each of the six SACD goals; (2) six variables regarding teachers' reported use of SACD activities for more than an hour per week to promote each of the six SACD goals, (3) two variables regarding teachers' reported promotion of any of the six SACD goals using SACD activities or using SACD activities for at least an hour per week, and (4) two variables 


\section{Chapter 1. The Social and Character Development Multiprogram Evaluation}

regarding teachers' reported promotion of behavior management using activities or using activities for at least an hour per week

B. Use of Social and Character Development Activities Associated With a Named Program. When teachers provided the data described above, regarding their engagement in activities to promote the six SACD goals and behavior management, they also could note whether the activity was associated with a specific SACD program. Two sets of 7 variables were developed from these responses for a total of 14 variables within this domain. The first set of seven variables was composed of binary variables (yes or no) as to whether teachers reported that they had engaged in a SACD activity linked to a named SACD program for each SACD goal separately (6 variables) and whether they reported that they had engaged in a SACD activity linked to a named SACD program for any of the SACD goals (1 variable). The second set of 7 variables was composed of binary variables as to whether teachers reported that they had engaged in a SACD activity linked to a named SACD program for at least 1 hour per week for each SACD goal separately (6 variables) and whether they reported that they had engaged in a SACD activity linked to named SACD program for at least 1 hour per week for any of the SACD goals (1 variable). Few respondents mentioned a specific behavior management program by name, so no measures were created for use of behavior management associated with a named program.

C. Classroom Materials and Strategies Used to Promote Social and Character Development. Teachers were asked about their use of six specific types of materials and 20 specific classroom strategies to promote social and character development in the classroom. Responses to these questions were used to create variables indicating the teacher-reported use of each type of material and strategy. Twenty-nine outcome variables are contained under this domain, including 28 binary variables (yes or no) and 1 count variable: (1) 7 binary variables regarding reported use of materials, with 1 for each of the six types of materials plus a binary variable for no report of using any of the six materials; (2) 21 binary variables regarding reported use of the strategies, with 1 for each of the 20 types of strategies plus a binary variable for reported use of any of the 20 strategies; and (3) 1 count variable for the average number of strategies reported used.

D. Schoolwide Strategies Used to Promote Social and Character Development. Teachers were asked whether their school used six specific types of schoolwide strategies to promote social and character development. These included morning announcements or videos, school assemblies, school newspapers or bulletins, special school days, special events, or other activities. Responses to these questions were used to create six binary variables for whether or not the teacher reported that the school used each specific schoolwide strategy.

E. Professional Development of Teachers to Promote Social and Character Development. Teachers were asked about the training they received in instructional methods related to social and character development during the prior 12 months. Information was collected on whether any training was received, the total number of hours of training, whether training was received in each of the six SACD goal areas, and whether teachers participated in behavior management training. Nine outcome variables (eight binary and one count) were developed from these responses: (1) one binary variable as to whether teachers reported any such training within the past 12 months, (2) seven binary variables as to whether teachers reported any such training within the past 12 months linked to each of the six SACD goals separately or to behavior management, and (3) one count variable as to the number of reported hours spent in such training during the past 12 months.

F. Attitudes Toward SACD Efforts and School Practices Conducive to SACD. Teachers were asked to characterize their own attitudes about efforts to promote social and character development (enthusiastic, cooperative, or in open dislike) and to characterize whether the culture of their school reflected the use of six practices (most of the time) conducive to the social and character 


\section{Chapter 1. The Social and Character Development Multiprogram Evaluation}

development of students. These practices included teacher modeling of positive character and behavior with students and with other staff, involvement of students in discussions, students' voice in governance, school encouragement of parent involvement, and discipline practices that included promoting development rather than only punishing misbehavior. Nine binary outcome variables were developed from these responses: (1) three regarding whether teachers reported being enthusiastic, cooperative, and in open dislike to promoting social and character development, and (2) six regarding the reported use of each school practice.

\section{Teacher Experience}

The Teacher Survey on Professional Development and Training was developed for the SACD multiprogram evaluation as a 10 -item questionnaire to which teachers responded about their demographic background, education, teaching experience, and engagement in professional development activities. Items for this survey were drawn from those used in an earlier study on teacher quality carried out by the National Center for Education Statistics (Lewis et al. 1999).

\section{Principal Interview}

Principals were individually interviewed in a 45-minute period about the prevalence and characteristics of the activities used to promote social and character development and about the percentage of staff trained in them and staff support of their use. Interviewers used both open-ended prompts and questions with defined answers. In fall 2004 and spring 2005, interviews were conducted in person. However, the recording of the open-ended responses was not of acceptable quality, including differences in the level of detail provided by interviewers. For the second and third years of the project, principal interviews were done by a smaller group of more experienced staff through phone interviews. Because of the quality concerns, the spring 2005 openended data are not reported. The principal interviews were used to develop six measures of the SACD implementation in all the schools.

I. Percentages of Schools Using Activities to Address Each SACD Goal

The percentages of treatment and control schools for which the principal noted that social and character development activities were directed toward each of the following six SACD goals: (1) Violence Prevention and Peace Promotion, (2) Social and Emotional Development, (3) Character Education, (4) Tolerance and Diversity, (5) Risk Prevention and Health Promotion, and (6) Civic Responsibility and Community Service. In addition, principals reported on the number of activities per goal. Both open- and closed-ended questions were used.

II. Delivery Method

Both open- and closed-ended questions were used to code data into yes or no variables on 13 methods and seven actors used to deliver activities to promote social and character development. Delivery methods included the use of assemblies, structured lessons, targeted reading or writing, and words of the day; and the actors included the classroom teacher, other teachers, and guidance counselors or social workers.

III. Targeting

Principals were asked to specify whether the SACD activities were targeted to the whole school, specific grades, or other. If the principal selected other, he or she was asked to describe which students the activity targeted. Both open- and closed-ended questions were used.

IV. Teacher Professional Development

Data about teacher training were collected in both open- and closed-ended questions. In the openended responses, principals described the training teachers received for each activity designed to promote social and character development. These responses were coded to indicate whether a teacher received guided or self-guided training. In the closed-ended responses, principals reported, at 


\section{Chapter 1. The Social and Character Development Multiprogram Evaluation}

the school level, the percentages of teachers and staff who received training in activities to promote social and character development and how many hours of training teachers received.

\section{Staff Response}

Data about the staff response and support of SACD were collected in the closed-ended questions. Principals reported, at the school level, on the level of staff enthusiasm for activities to promote social and character development. Principals also reported on whether teachers and staff modeled positive behaviors, whether students were involved in decisionmaking at the school, and whether discipline strategies focused on promoting development rather than only punishing misbehavior.

VI. Parental Involvement

Data on whether parents were actively or passively involved in activities to promote social and character development were coded from responses to open-ended questions that asked principals to describe how parents were involved in these activities.

\section{Implementation Fidelity Rating}

In order to develop a common implementation measure for the multiprogram evaluation, the SACD Research Program Global Fidelity Ratings form was provided to each grantee for each of the 3 study years. The form contained a request that each grantee rate the fidelity with which the SACD program was implemented in each treatment school during each school year. The instructions explained that, for the fidelity ratings, the standard of comparison should be program standards or benchmarks. Furthermore, the instructions explained that the basis of all fidelity ratings should be the site-specific fidelity data collected as part of the grantee's own evaluation work, ${ }^{11}$ the program benchmarks, and the rater's own judgment. In addition to rating each school, each grantee was asked to provide a justification for each rating. Two individuals with the most experience in monitoring program implementation in the SACD treatment schools and interpreting the site-specific fidelity data were to complete the ratings independently, discuss each rating, and then decide on a final consensus rating for each treatment school.

For each school, each rater was to rate the amount of implementation and the quality of implementation. After making individual ratings, each pair was to discuss their ratings and arrive at a consensus rating. The rating values ranged from 1 to 5. For example, a rating of 1 for the amount of implementation at a school indicated that "On average, the program was delivered at a level substantially below program benchmarks." A rating of 2 indicated "On average, the program was delivered at a level somewhat below program benchmarks." A rating of 3 indicated the program met benchmarks; while ratings of 4 and 5 were for delivery at levels somewhat above and substantially above program benchmarks, respectively. The ratings for the quality of implementation at a school were analogous. For example, a rating of 1 for the quality of implementation at a school indicated that "On average, the program was delivered with quality substantially below program benchmarks."

\section{Construction of Outcome Variables}

To develop a set of student and school climate outcome measures with better psychometric characteristics and to determine whether a smaller number of scales could represent them, ${ }^{12}$ a set of exploratory factor analyses using the fall 2004 survey data for each group of respondents (children, primary caregivers, and

\footnotetext{
${ }^{11}$ For their independent evaluations, the research teams developed their own approaches and used a variety of methods (including training logs, teacher reports, and classroom observations) to measure the implementation fidelity of their separate programs.

12 A preliminary factor analysis of the fall 2004 data indicated that certain scales had poor internal consistency while others were highly intercorrelated.
} 
teachers) was done on a randomly selected half of the sample. ${ }^{13}$ Exploratory analysis of data for each reporter found that the item responses of children, primary caregivers, and teachers were optimally represented by 10 , 3 , and 5 underlying factors, respectively, for a total of 18 constructs. Factors representing 2 constructs (Altruistic Behavior and Problem Behavior) were identified for all three respondent groups. A factor representing a third construct (Positive Social Behavior) was identified for both primary caregivers and teachers, and a factor representing 2 highly related constructs was identified for teachers and children (Academic Competence and Motivation, and Engagement with Learning). The remaining identified factors were specific to each responding group. These 18 factors were subjected to a confirmatory factor analysis with the remaining half of the fall 2004 sample using structural equation modeling procedures. Two additional constructs (Feelings of Safety, and Student Support for Teachers) were developed through a principal component analysis of the Teacher Report on Classroom and School. Further analysis determined that the results were robust across gender and race/ethnic subgroups, individually for each of the seven SACD programs, when missing item responses were imputed, and when the full fall 2004 and spring 2005 data were used. As a result of these analyses, 20 constructs were identified and these were used as the outcome measures for the SACD evaluation. Table 1.5 lists the outcome measures by report and details the number of items in each, their reliability, and the original measures that provided the items for them. Changes in these measures may be beneficial or detrimental depending on the specific outcome, so a positive change does not automatically reflect an improvement or a negative change a decline. The $+/-$ sign in parentheses next to each outcome in the first column of table 1.6 notes whether a gain or loss can be interpreted as beneficial for each outcome (as do the first columns of all tables reporting impacts on the outcomes). The 20 outcome measures were grouped under four domains based on the conceptual model: Social and Emotional Competence, Behavior, Academics, and Perceptions of School Climate (table 1.6). ${ }^{14}$

\footnotetext{
${ }^{13}$ See appendix B for details on the development of the outcome measures.

14 One further analysis was done to determine whether the multiple reports for each of three constructs within the Behavior domain could be combined: Altruistic Behavior (child, caregiver, and teacher), Positive Social Behavior (caregiver and teacher), and Negative Behavior (child, caregiver, and teacher). A series of exploratory multitrait, multirespondent analyses found that these outcomes were affected by both the behavior construct being assessed and by the reporter. As a result, separate outcome measures for each reporter (child, caregiver, and teacher) were retained.
} 
Table 1.5. Outcome variables

\begin{tabular}{|c|c|c|c|c|}
\hline Report/Outcome variable & Items & Range & Reliability $^{1}$ & Original measure from which items were taken \\
\hline \multicolumn{5}{|l|}{ Child Report } \\
\hline Altruistic Behavior & 8 & $0-3$ & 0.88 & Altruism Scale, Child Version \\
\hline Engagement with Learning & 4 & $1-4$ & 0.84 & 4 items from Engagement vs. Disaffection with Learning Scale \\
\hline $\begin{array}{l}\text { Normative Beliefs About } \\
\text { Aggression }\end{array}$ & 8 & $1-4$ & 0.83 & Normative Beliefs About Aggression Scale \\
\hline Self-Efficacy for Peer Interaction & 12 & $1-4$ & 0.83 & Self-Efficacy for Peer Interaction Scale \\
\hline Empathy & 11 & $1-3$ & 0.78 & 11 items from the Children's Empathy Questionnaire \\
\hline Problem Behavior & 12 & $0-3$ & 0.86 & $\begin{array}{l}6 \text { items from Frequency of Delinquent Behavior Scale and } 6 \text { items from } \\
\text { Aggression Scale }\end{array}$ \\
\hline Positive School Orientation & 10 & $1-4$ & 0.86 & $\begin{array}{l}9 \text { items from Sense of School as a Community Scale and } 1 \text { item from Feelings of } \\
\text { Safety at School Scale }\end{array}$ \\
\hline Negative School Orientation & 8 & $1-4$ & 0.78 & $\begin{array}{l}4 \text { items from Engagement vs. Disaffection with Learning Scale and } 4 \text { items from } \\
\text { Sense of School as a Community Scale }\end{array}$ \\
\hline Student Afraid at School & 4 & $1-4$ & 0.79 & 4 items from Feelings of Safety at School Scale \\
\hline Victimization at School & 6 & $0-3$ & 0.86 & Victimization Scale \\
\hline \multicolumn{5}{|l|}{ Primary Caregiver Report } \\
\hline Altruistic Behavior & 8 & $1-4$ & 0.88 & Altruism Scale, Primary Caregiver Version \\
\hline Positive Social Behavior & 25 & $1-4$ & 0.93 & 6 items from Responsibility Scale and 19 items from Social Competence Scale \\
\hline Problem Behavior & 20 & $1-4$ & 0.86 & $\begin{array}{l}12 \text { items from BASC Aggression Subscale, } 6 \text { items from BASC Conduct } \\
\text { Problems Subscale, and } 2 \text { items from the Responsibility Scale }\end{array}$ \\
\hline
\end{tabular}

See notes at end of table. 
Table 1.5. Outcome variables-Continued

\begin{tabular}{|c|c|c|c|c|}
\hline Report/Outcome variable & Items & Range & Reliability $^{1}$ & Original measure from which items taken \\
\hline \multicolumn{5}{|l|}{ Teacher Report on Student } \\
\hline Altruistic Behavior & 8 & $1-4$ & 0.89 & Altruism Scale, Teacher Version \\
\hline $\begin{array}{l}\text { Academic Competence and } \\
\text { Motivation }\end{array}$ & 5 & $1-5$ & 0.95 & Academic Competence and Motivation Scale \\
\hline Positive Social Behavior & 25 & $1-4$ & 0.97 & $\begin{array}{l}6 \text { items from Responsibility Scale and } 19 \text { items from the Social Competence } \\
\text { Scale }\end{array}$ \\
\hline Problem Behavior & 23 & $1-4$ & 0.95 & $\begin{array}{l}14 \text { items from BASC Aggression Subscale, Teacher Version, } 7 \text { items from BASC } \\
\text { Conduct Problems Subscale, Teacher Version and } 2 \text { items from Responsibility } \\
\text { Scale }\end{array}$ \\
\hline ADHD-Related Behavior & 10 & $1-4$ & 0.91 & $\begin{array}{l}5 \text { items from DSM-IV Criteria for ADHD and } 5 \text { items from IOWA Conners } \\
\text { Teacher Rating Scale }\end{array}$ \\
\hline \multicolumn{5}{|l|}{$\begin{array}{l}\text { Teacher Report on Classroom } \\
\text { and School }\end{array}$} \\
\hline Feelings of Safety & 4 & $1-5$ & 0.89 & Feelings of Safety at School Scale \\
\hline Student Support for Teachers & 7 & $1-5$ & 0.89 & 7 items from the School-Level Environment Questionnaire \\
\hline
\end{tabular}

Internal consistency as measured by Cronbach's alpha.

SOURCE: The Social and Character Development (SACD) Research Program. 
Table 1.6. Outcomes, by domain and data instrument

\begin{tabular}{|c|c|c|c|c|}
\hline \multirow[b]{2}{*}{ Domain/Outcome } & \multicolumn{4}{|c|}{ Instrument } \\
\hline & Child Report & $\begin{array}{l}\text { Primary } \\
\text { Caregiver } \\
\text { Report }\end{array}$ & $\begin{array}{l}\text { Teacher } \\
\text { Report on } \\
\text { Student } \\
\end{array}$ & $\begin{array}{l}\text { Teacher } \\
\text { Report on } \\
\text { Classroom } \\
\text { and School }\end{array}$ \\
\hline \multicolumn{5}{|l|}{ Social and Emotional Competence Domain } \\
\hline Self-Efficacy for Peer Interaction (+) & $\checkmark$ & & & \\
\hline Normative Beliefs About Aggression (-) & $\checkmark$ & & & \\
\hline Empathy $(+)$ & $\checkmark$ & & & \\
\hline \multicolumn{5}{|l|}{ Behavior Domain } \\
\hline Altruistic Behavior (+) & $\checkmark$ & $\checkmark$ & $\checkmark$ & \\
\hline Positive Social Behavior (+) & & $\checkmark$ & $\checkmark$ & \\
\hline Problem Behavior (-) & $\checkmark$ & $\checkmark$ & $\checkmark$ & \\
\hline ADHD-Related Behavior (-) & & & $\checkmark$ & \\
\hline \multicolumn{5}{|l|}{ Academics Domain } \\
\hline Engagement with Learning $(+)$ & $\checkmark$ & & & \\
\hline Academic Competence and Motivation (+) & & & $\checkmark$ & \\
\hline \multicolumn{5}{|l|}{ Perceptions of School Climate Domain } \\
\hline Positive School Orientation (+) & $\checkmark$ & & & \\
\hline Negative School Orientation (-) & $\checkmark$ & & & \\
\hline Student Afraid at School (-) & $\checkmark$ & & & \\
\hline Victimization at School (-) & $\checkmark$ & & & \\
\hline Feelings of Safety $(+)$ & & & & $\checkmark$ \\
\hline Student Support for Teachers (+) & & & & $\checkmark$ \\
\hline $\begin{array}{l}\text { NOTE: Abbreviations are } \\
\text { ADHD: Attention deficit hyperactivity disorder } \\
\checkmark: \text { Outcome addressed } \\
\text { Blank cell: Outcome not addressed }\end{array}$ & & & & \\
\hline $\begin{array}{l}\text { The +/- signs in parentheses indicate the direction o } \\
\text { SOURCE: The Social and Character Development }\end{array}$ & $\begin{array}{l}\text { loutcome. } \\
\text { earch Program. }\end{array}$ & & & \\
\hline
\end{tabular}

\section{Construction of Moderator Variables}

The impact of the SACD programs was hypothesized to vary by student, family, and community characteristics and by the level of implementation. Collected student demographic characteristics (such as gender) could be directly used in the analysis. Other characteristics required the use of scales and the construction of moderator variables for use in the analysis.

\section{Initial Risk Factors}

Certain individual, family, and community characteristics are associated with greater prevalence of child behavior problems. Students with these characteristics began the SACD study with initial risks that were hypothesized to lead to more negative outcomes. To help determine the impact of these initial risks on the effects of the SACD programs, four risk factors were constructed to represent (1) socioeconomic risk, (2) family risk, (3) perceived community risk, and (4) child behavior risk. To select the measures to be included in the first three risk domains, associations were examined between the risk measures and a set of baseline outcome measures.

Socioeconomic risk was defined as the number of the following risk factors present in the child's life at the initial data collection: (1) the child was in a single-parent household, (2) the child was in a low-income household (below 135\% of the poverty level), and (3) the child's primary caregiver had failed to graduate from high school. A cumulative risk index across the three risk factors was calculated by adding the number 


\section{Chapter 1. The Social and Character Development Multiprogram Evaluation}

of these factors each child had: 0 (no risk factors), 1 (one risk factor), and 2 (two or three risk factors). Scores ranged from 0 to 2, with a mean of 0.73 and a standard deviation of 0.74 . The fourth measure of socioeconomic risk collected, employment status of the child's caregiver, was not included in the socioeconomic risk measure because it was not found predictive of baseline outcomes when the other three measures were included.

Family risk was measured using the Poor Monitoring and Supervision Subscale from the Alabama Parenting Questionnaire (Shelton et al. 1996) collected in the Primary Caregiver Report. Scores ranged from 1 to 3.5, with a mean of 1.1 and standard deviation of 0.20 . The other two measures of family risk collected, the Positive Parenting Subscale and the Confusion, Hubbub, and Order Scale, appeared to reflect reporter variance rather than construct variance and so were not included in family risk measure.

Perceived community risk was measured using items on the Community Risk Scale (Forehand et al. 2000), collected in the Primary Caregiver Report. Scores ranged from 1 to 4, with a mean of 1.5 and a standard deviation of 0.64. The other two measures of community risk collected, the Community Resources Scale and the Child-Centered Social Control Scale were less consistently related to the outcome variables and so were not included in the community risk measure.

Child behavior risk was measured using the Conduct Problem Subscales from the BASC (Reynolds and Kamphaus 1998) collected in the Teacher Report on Student and the Primary Caregiver Report. For the teacher-reported child behavior risk variable, scores ranged from 42 to 120, with a mean of 50.82 and a standard deviation of 9.78. For the parent-reported child behavior risk variable, scores ranged from 36 to 113 , with a mean of 50.33 and a standard deviation of 9.02 .

\section{Fidelity of Implementation}

How well an intervention was implemented was hypothesized to be associated with how the SACD programs affected the outcomes. The constructs used for the fidelity data analysis were developed so that the SACD evaluation would be able to examine whether impacts on student outcomes were estimated to be larger in treatment group schools that achieved high-fidelity implementation of their SACD program (relative to their matched control group counterparts) than were impacts in treatment group schools that achieved lower fidelity implementation (relative to their control group counterparts). Data collection was designed in such a way that each program was to be assessed relative to the benchmarks or expectations established for the specific program. Consensus ratings on a quality-of-implementation 5-point scale and on a quantity-ofimplementation 5-point scale were to be used to categorize the treatment schools as high in implementation fidelity (high-fidelity subgroup) or low in implementation fidelity (low-fidelity subgroup) (see Measures section). The ratings on quality and quantity of implementation were found to be highly correlated for each school (0.78 in Year 1, 0.82 in Year 2, and 0.83 in Year 3). As a result, they were combined into a single 10point composite measure of fidelity of implementation, which was used to create the high-and low-fidelity subgroups.

The cutoff point on the consensus score used to place the schools into the two fidelity subgroups was established using two criteria. First, every year a pair of raters independently rated each school within a specific program and then agreed on a consensus score for each school. ${ }^{15}$ The cutoff point was to be set so that the individual ratings were to agree on the placement for the largest possible percentage of schools. The agreement between the two raters' individual scores on their schools' placement was measured using Cohen's kappa, which adjusts the empirical match rate by the expected number of exact matches that would occur by chance. Second, a sufficient number of schools were to be placed in each subgroup so that the size of each

\footnotetext{
15 Over the 3 years, the ratings were not always consistently provided by the research teams. In Year 1, four teams provided both the ratings from the independent raters and the consensus ratings, two teams provided only the independent ratings, and one team provided a single rating. In Year 2, all teams provided the requested ratings. In Year 3, six teams provided the requested ratings and one team provided only the independent ratings.
} 


\section{Chapter 1. The Social and Character Development Multiprogram Evaluation}

was sufficient to generate precise estimates. When applying these two criteria to the spring 2005 data, placement into the high- versus low-fidelity subgroup was defined using a cutoff of 7 for the consensus score: high implementers had consensus scores that were 7 or greater; and low implementers had consensus scores less than 7 . The cutoff value of 7 led to the highest agreement rate between the raters and the most balanced division of the sample. ${ }^{16}$

The seven rater pairs placed 30 of the 36 schools in the same fidelity group, and there was an overall kappa value of 0.67. ${ }^{17}$ Twenty schools were categorized as high implementers and 22 were categorized as low implementers. Replication of this procedure with the 2006 and 2007 data yielded similar results, including kappas of 0.71 and 0.76 , respectively, and 20 and 19 high-implementing schools and 22 and 23 lowimplementing schools, respectively. Table 1.7 shows these results by program and provides the inter-rater reliability for the two raters in each program, the agreement rate between raters for the categorization of schools as high implementers, and Cohen's kappa for this rate. The overall inter-rater reliability coefficients (Cronbach's alpha) were 0.71 in Year 1 ( 0.83 if the LBW's alpha of -0.08 is excluded), 0.90 in Year 2, and 0.94 in Year 3. The program-specific alphas were 0.70 or higher in Year 1 (except for LBW and SS, for which only a single rating was provided), 0.74 or higher in Year 2, and 0.72 or higher in Year 3. These findings suggest that, in most programs, the variance of ratings across observers was small relative to the variance of mean ratings across schools.

\footnotetext{
16 Alternative cutoff values led to lower kappa values (almost half the size) and less balanced groups.

17 While there were 42 treatment schools, one research team did not provide rater-specific information for the spring 2005 fidelity data so there were only 36 schools for which rater-specific information was available.
} 
Chapter 1. The Social and Character Development Multiprogram Evaluation

Table 1.7. Fidelity ratings of program implementation at treatment schools

\begin{tabular}{|c|c|c|c|c|}
\hline Program & $\begin{array}{r}\text { Number of } \\
\text { treatment schools }\end{array}$ & $\begin{array}{l}\text { Inter-rater reliability } \\
\text { (Cronbach's alpha) }\end{array}$ & $\begin{array}{r}\text { Rater fidelity } \\
\text { agreement rate (\%) }\end{array}$ & Cohen's kappa ${ }^{1}$ \\
\hline \multicolumn{5}{|l|}{ Year 1} \\
\hline Total & 42 & 0.71 & 83 & 0.67 \\
\hline$A B C$ & 6 & 1.00 & 100 & 1.00 \\
\hline CSP & 5 & 0.70 & 80 & 0.62 \\
\hline LBW & 6 & -0.08 & 67 & - \\
\hline PA & 7 & 0.85 & 86 & 0.72 \\
\hline PATHS & 5 & 0.78 & 80 & 0.55 \\
\hline 4Rs & 7 & 0.84 & 86 & 0.70 \\
\hline$S S^{2}$ & 6 & - & - & - \\
\hline \multicolumn{5}{|l|}{ Year 2} \\
\hline Total & 42 & 0.90 & 86 & 0.71 \\
\hline$A B C$ & 6 & 0.98 & 100 & 1.00 \\
\hline CSP & 5 & 0.80 & 80 & 0.55 \\
\hline LBW & 6 & 0.83 & 100 & 1.00 \\
\hline $\mathrm{PA}$ & 7 & 0.74 & 71 & 0.46 \\
\hline PATHS & 5 & 0.93 & 60 & 0.17 \\
\hline 4Rs & 7 & 0.78 & 86 & 0.59 \\
\hline SS & 6 & 1.00 & 100 & 1.00 \\
\hline \multicolumn{5}{|l|}{ Year 3} \\
\hline Total & 42 & 0.94 & 88 & 0.76 \\
\hline$A B C$ & 6 & 0.99 & 83 & 0.67 \\
\hline CSP & 5 & 0.99 & 100 & 1.00 \\
\hline LBW & 6 & 0.97 & 100 & 1.00 \\
\hline PA & 7 & 0.98 & 100 & 1.00 \\
\hline PATHS & 5 & 0.86 & 60 & 0.29 \\
\hline 4Rs & 7 & 0.72 & 71 & 0.30 \\
\hline SS & 6 & 0.99 & 100 & 1.00 \\
\hline
\end{tabular}

- Not available.

${ }^{1}$ Cohen's kappa adjusts the agreement rate for the expected number of Rater 1 and Rater 2 exact matches that would occur because of chance.

${ }^{2}$ In Year 1, Second Step provided a single consensus rating.

NOTE: Abbreviations are

ABC: Academic and Behavioral Competencies Program

CSP: Competence Support Program

LBW: Love In a Big World

PA: Positive Action

PATHS: Promoting Alternative Thinking Strategies

4Rs: The 4Rs Program (Reading, Writing, Respect, and Resolution)

SS: Second Step

SOURCE: The Social and Character Development (SACD) Research Program. 


\section{Chapter 1. The Social and Character Development Multiprogram Evaluation}

In Year 1, these high- or low-fidelity subgroups were used directly in the analysis. In Years 2 and 3, the actual subgroups used in the analysis were based on a school's assignment to the high- or low-fidelity subgroup in each year. This was done to address the possibility that a program's fidelity over time might have cumulative effects on students. As a result, three subgroups were created for Year 2 and Year 3 by combining the annual results: (1) high: placement in the high-fidelity subgroup in all years; (2) low: placement in the low-fidelity subgroup in all years; and (3) mixed: placement in the high- and low-fidelity subgroups in different years.

The multiprogram evaluation examined seven different SACD programs, each with unique features, and the fidelity rating measured fidelity of implementation relative to the targets established for each specific intervention. ${ }^{18}$ In this way, the ratings were standardized relative to each site's program-specific benchmarks and could be compared across programs and years. Thus, for example, a rating of 6 at a school using one program shows higher fidelity to implementation of that program than a rating of 4 at another school using a different program (relative to that program's benchmarks). The compromise in developing this fidelity measure was that basing the ratings on implementation relative to each program's standards allows for crossprogram comparisons but it cannot account for differences among the programs' implementation standards. For example, one SACD program might be simple to implement and so require a less intensive implementation, which would make high fidelity easier to reach. Another program might be very difficult to fully implement and require intensive implementation, which would make high fidelity difficult. As a result, schools using the first program might score higher on the fidelity rating scale than schools using the second program because high fidelity was easier for them to obtain. However, if the second program was more effective than the first, even when not fully implemented, then an analysis comparing the fidelity subgroups might erroneously lead to the conclusion that it is better to implement programs with a low level of fidelity.

In addition, high and low fidelity were not randomly assigned, therefore programs and schools were not necessarily represented in the fidelity subgroups by chance. Instead, they may have ended up in their subgroup because of pre-existing characteristics. Comparisons of the estimated impacts at high-fidelity schools to those of low-fidelity schools would lead to an erroneous conclusion regarding the effect of fidelity of implementation if the impact of fidelity was due to other differences between the subgroups. In other words, if high and low fidelity occurred because of differences among schools and these differences also had an impact on the student outcomes, then fidelity would be an outcome of these differences between the schools rather than a cause of student outcomes. These differences might be more observable (e.g., schools with high fidelity had students who, on average, had a different socioeconomic status than schools with low fidelity) or less observable (e.g., differences in the talent and dedication of the staff or strength of school leadership).

In sum, the fidelity ratings provided an indicator of the extent to which the SACD programs were implemented according to program benchmarks. Because of how the ratings were constructed and the possibility that program and school characteristics may have contributed to each school's rating, differences in estimated impacts by implementation group could reflect differences in the level of implementation and/or underlying differences between the students, the schools, and the SACD programs. As these effects cannot be fully disentangled, the analysis making use of the fidelity data was considered exploratory rather than definitive.

\section{Data Collection}

The SACD study had five data collection points, beginning with the initial collection of data in fall 2004 (start of third grade) and followed by four follow-up points: spring 2005 (end of third grade), fall 2005 (start of

\footnotetext{
18 One drawback of this approach is that the fidelity data provide little information about why implementation was of a certain quality. The fidelity data collected by each research team using team-chosen criteria were expected to provide this type of information rather than facilitate the multiprogram analysis.
} 


\section{Chapter 1. The Social and Character Development Multiprogram Evaluation}

fourth grade), spring 2006 (end of fourth grade) and spring 2007 (end of fifth grade). ${ }^{19}$ Ideally, fall data collections would have occurred at the very beginning of the school year to reduce the possibility that the implementation of the program could affect the data (for fall 2004) and to maximize the length of time that the intervention would have to affect the annually collected outcomes. Spring data collections would ideally have occurred near the end of the school year in order to maximize the length of time the program had to affect annually collected outcomes.

For practical reasons, fall data collections were often delayed for several weeks to allow school populations to settle, to obtain primary caregiver consent, and to avoid disrupting planned school activities. Spring data collections occurred earlier than the end of school to fit into school schedules that included spring district testing and vacations.

Across the seven SACD programs, the fall 2004 data collection encompassed a 3-month period, although onsite data collection in each program typically took 2 to 4 weeks (table 1.8). The earliest fall 2004 data collection started on August 23, 2004 (LBW), and the last ended on November 12, 2004 (ABC). In all programs except LBW, implementation of the program started before the fall 2004 data collection visit. In the other six programs, the interval between program implementation and fall 2004 data collection was 2 to 6 weeks, which may have had some effect on student reports. Teachers and principals received training on the intervention before the fall 2004 data collection, and this could have affected their reports on the use of activities to promote social and character development in their classrooms and schools. As a result, the fall 2004 reports, especially those from teachers and principals, are unlikely to reflect the true pre-intervention conditions but instead capture what was being done near the beginning of the evaluation. For this reason, the fall 2004 data are termed "initial data" rather than "baseline data."

The spring 2005 data follow-up occurred between March 21 and June 3, with most of it concentrated in April and May. On-site data collection in each program typically took 2 to 4 weeks. Because of differences in the start dates of implementation and the dates of spring data collection, there was variation among the programs in terms of how long they had been implemented by the time of the spring data collection. This interval ranged from a low of 26 weeks for 4Rs to a high of 36 weeks for CSP. These differences should be kept in mind when viewing the results of the analysis comparing the outcomes of students at spring 2005 in treatment schools with those of students at spring 2005 in control schools (while controlling for the fall value of the relevant outcome measure), although they did not affect individual program evaluations as each program's treatment and control group was compared over the same period.

The fall 2005 data collection encompassed a 3-month period from August to November, with on-site data collection in each program typically taking 3 to 4 weeks. The gap between the start of school and the fall data collection was 5 weeks for six of the programs and 8 weeks for the seventh, SS. The 2006 spring data collection lasted for approximately a 2-month period, occurring between March 20, 2006, and May 26, 2006. The length of the data collection ranged from less than 2 weeks to about 6 weeks. The time between the start of the school year and the spring data collection varied from 29 to 40 weeks across the programs.

The spring 2007 data collection lasted approximately 2 months and occurred between March 26 and June 1. On-site data collection in each program took 2 to 5 weeks. The time between the start of the school year and spring data collection ranged from 29 to 40 weeks, similar to Year 2.

\footnotetext{
19 Data collection for the second cohort (discussed in appendix A) began in fall 2005 (start of third grade) with followups in spring 2006 (end of third grade), and spring 2007 (end of fourth grade).
} 
Table 1.8. Period between implementation and data collection and between data collections, by program

\begin{tabular}{|c|c|c|c|c|c|c|c|}
\hline Data collection schedule & $\mathrm{ABC}$ & CSP & LBW & $\mathrm{PA}$ & PATHS & 4Rs & SS \\
\hline \multicolumn{8}{|l|}{ Fall 2004 data collection } \\
\hline Start date & $10 / 18 / 04^{1}$ & $8 / 30 / 04$ & $8 / 23 / 04$ & $10 / 12 / 04$ & $10 / 18 / 04$ & $10 / 18 / 04$ & $10 / 11 / 04$ \\
\hline End date & $11 / 12 / 04$ & $9 / 16 / 04$ & 9/9/04 & $10 / 28 / 04$ & $10 / 28 / 04$ & $11 / 10 / 04$ & $10 / 29 / 04$ \\
\hline Calendar weeks from program implementation & 6 & 4 & $t^{2}$ & 2 & 6 & 4 & 5 \\
\hline \multicolumn{8}{|l|}{ Spring 2005 data collection } \\
\hline Start date & $4 / 11 / 05$ & $4 / 11 / 05$ & $5 / 2 / 05$ & $5 / 16 / 05$ & $3 / 28 / 05$ & $3 / 21 / 05$ & $4 / 25 / 05$ \\
\hline End date & $5 / 6 / 05$ & $4 / 29 / 05$ & $5 / 20 / 05$ & $6 / 3 / 05$ & $4 / 28 / 05$ & $5 / 5 / 05$ & $5 / 13 / 05$ \\
\hline Calendar weeks from end of fall data collection & 21 & 30 & 34 & 29 & 22 & 17 & 25 \\
\hline Calendar weeks from program implementation & 31 & 36 & 33 & 33 & 29 & 26 & 33 \\
\hline \multicolumn{8}{|l|}{ Fall 2005 data collection } \\
\hline Start date & $10 / 10 / 05^{1}$ & $9 / 26 / 05^{3}$ & $8 / 29 / 05$ & $10 / 11 / 05$ & $10 / 11 / 05$ & $10 / 11 / 05$ & $10 / 24 / 05$ \\
\hline End date & $10 / 27 / 05$ & $10 / 20 / 05$ & $9 / 23 / 05$ & $11 / 2 / 05$ & $10 / 27 / 05$ & $11 / 16 / 05$ & $11 / 11 / 05$ \\
\hline Calendar weeks from start of school & 5 & 5 & $5^{4}$ & 5 & 5 & 5 & 8 \\
\hline \multicolumn{8}{|l|}{ Spring 2006 data collection } \\
\hline Start date & $3 / 27 / 06$ & $4 / 24 / 06$ & $5 / 1 / 06$ & $5 / 1 / 06$ & $3 / 20 / 06$ & $3 / 27 / 06$ & $4 / 24 / 06$ \\
\hline End date & $5 / 1 / 06$ & $5 / 5 / 06$ & $5 / 19 / 06$ & $5 / 26 / 06$ & $4 / 11 / 06$ & $5 / 8 / 06$ & $5 / 12 / 06$ \\
\hline Calendar weeks from end of fall data collection & 21 & 27 & 31 & 26 & 20 & 20 & 23 \\
\hline Calendar weeks from start of school & 29 & 35 & 40 & 34 & 29 & 29 & 34 \\
\hline
\end{tabular}

See notes at end of table. 
Table 1.8. Period between implementation and data collection and between data collections, by program-Continued

\begin{tabular}{|c|c|c|c|c|c|c|c|}
\hline Data collection schedule & $\mathrm{ABC}$ & CSP & LBW & PA & PATHS & 4Rs & SS \\
\hline \multicolumn{8}{|l|}{ Spring 2007 data collection } \\
\hline Start date & $4 / 18 / 07$ & $4 / 26 / 07$ & $5 / 1 / 07$ & $5 / 7 / 07$ & $3 / 26 / 07$ & $3 / 26 / 07$ & $4 / 23 / 07$ \\
\hline End date & $5 / 8 / 07$ & $5 / 10 / 07$ & $5 / 16 / 07$ & $6 / 1 / 07$ & $4 / 27 / 07$ & $4 / 26 / 07$ & $5 / 10 / 07$ \\
\hline Calendar weeks from start of school & $32^{5}$ & 35 & $40^{6}$ & 35 & 29 & 29 & 34 \\
\hline
\end{tabular}

Tot applicable.
${ }_{1}$ At two schools data collection began the week of 9/20 in 2004 and 2005.

${ }^{2}$ Data collection occurred before program implementation.

${ }^{3}$ Data collection at one school occurred 3 weeks earlier.

${ }^{4}$ One-third of the schools started 2 weeks later.

${ }^{5}$ Two schools started several weeks earlier.

${ }^{6}$ Two schools started 2 weeks later.

NOTE: Abbreviations are

ABC: Academic and Behavioral Competencies Program

CSP: Competence Support Program

LBW: Love In a Big World

PA: Positive Action

PATHS: Promoting Alternative Thinking Strategies

4Rs: The 4Rs Program (Reading, Writing, Respect, and Resolution)

SS: Second Step

There may be slight discrepancies in the end dates for field data collection due to scheduling of Child Report make-up sessions and principal interviews. SOURCE: The Social and Character Development (SACD) Research Program. 


\section{Training of Data Collectors}

Data collection was done by MPR (along with its subcontractor Decision Information Resources, Inc. [DIR]) and the research teams. MPR established on-site data collection teams to administer and collect the Child Report from the study schools. These teams were trained by senior MPR and DIR data collection managers at one of two 4-day training sessions held August 7-10, 2004, in Tennessee and September 18-21, 2004, in New Jersey. At these sessions, data collectors were introduced to the study objectives, reviewed data collection procedures, discussed working in schools, and reviewed the distribution and collection of all survey materials. To monitor quality and consistency of data collection across all sites, senior MPR and DIR data collection managers observed the first day or two of on-site data collection at each site in fall 2004 and spring 2005. Because most of the data collectors from fall 2004 returned for spring 2005 data collection, MPR held a refresher training session in spring 2005. This refresher training included several activities: (1) distribution of a revised training manual, (2) a videotape and detailed memorandum on changes in procedures and/or instruments since fall data collection for home study, (3) a telephone conference call to review home study materials, and (4) an in-person half-day meeting a few days before the beginning of data collection. Ninetythree percent of the collectors returned for the fall 2005 data collection; at one site it proved difficult to hire new collectors so a team was composed of collectors from other sites. MPR provided training through a review memo mailed to collectors, conference calls, and a 4-hour refresher course with each team prior to data collection. Again an MPR or DIR representative worked with each team for the first day or two of data collection. By spring 2006, turnover was high enough that new collectors were provided a 2-day training in March or April. Each team also went through the 4-hour refresher course prior to data collection. A similar approach was taken for spring 2007, with a 2-day training for new data collectors and a 4-hour refresher course before data collection.

The two teacher reports and the primary caregiver report were self-administered questionnaires prepared by MPR. They were distributed either by MPR or the research team during on-site data collection (in some sites teachers received their questionnaires before spring on-site data collection). Teachers received their surveys directly and sent the primary caregiver surveys home with students. If a completed Primary Caregiver Report was not returned within 2 to 4 weeks, MPR attempted to contact the child's primary caregiver by telephone, and if the primary caregiver was willing, the Primary Caregiver Report was administered as a computerassisted telephone interview.

\section{Consent Rates, Completion Rates, and Percentage of Sample With Data}

Data collection required a two-part process: consent and completion of data reports. First, written consent had to be obtained from primary caregivers before their children could fill out the Child Report, their children's teachers could fill out the Teacher Report on Student, and they themselves could fill out the Primary Caregiver Report. Written consent from teachers had to be obtained before they could fill out the Teacher Report on Classroom and School. Second, even when consent was received, reports might not be completed for other reasons. Students may have decided not to complete the Child Report or were absent on the days of the data collection and make-up sessions. Primary caregivers may have failed to complete the Primary Caregiver Report or did not complete the follow-up phone interview. Teachers may have failed to complete the Teacher Report on Student or the Teacher Report on Classroom and School.

The percentage of the sample for which there are data is calculated by multiplying the consent rate and the completion rate for each report. This section discusses the percentage of the sample for which there are data as follows: (1) the overall sample, which includes treatment and control groups; (2) students from the original cohort (stayers) versus new entrants; and (3) by individual SACD program. The consent and completion rates are also provided for the first two and are available in chapters 2 to 8 by program.

Table 1.9 presents the percentage of sample for which there are data for each report by year and by treatment versus control group. For the Child Report and the Teacher Report on Student, between 61 percent and 65 percent of students have data over the 3 years. In Year 1 (third grade), the treatment group had statistically 
significantly larger percentages of data but this was not the case in Years 2 and 3. For the Primary Caregiver Report, the percentage of primary caregivers with data ranged from 57 percent in Year 1 to 46 percent in Year 3, due to declines in completion rates. The treatment group had a significantly higher percentage of primary caregivers with data in the fall of Year 1 but not thereafter. For the Teacher Report on Classroom and Schools, the percentage of teachers with data ranged from 87 percent to 90 percent over the 3 years, with no significant difference between the treatment and control schools.

Table 1.10 examines differences for stayers versus new entrants. For all three reports on students (student, primary caregiver, and teacher) stayers had statistically significantly higher percentages of data than new entrants due to higher consent rates.

Table 1.11 presents the percentage of sample with data for treatment versus control group by SACD program. Out of 112 comparisons, 18 showed statistically significant differences (6 such differences would be expected by chance) with all but 2 favoring the treatment group. These break out as 6 differences in the Child Report, 3 differences in the Primary Caregiver Report, 7 differences in the Teacher Report on Student, and 2 differences in the Teacher Report on Classroom and School.

In sum, over the 3 years of the SACD evaluation, 61 percent to 65 percent of the student sample had data (with $46 \%$ to $57 \%$ having primary caregiver data). ${ }^{20}$

20 The majority of the students without data (67\% to $97 \%$, depending on report) did not have consent to take part in the study. As data could not be collected on these students, no comparisons could be made to determine whether they significantly differed from those taking part in the study. 
Table 1.9. Consent rates, completion rates, and percentage of sample with data from each report

\begin{tabular}{|c|c|c|c|c|c|c|c|c|c|c|c|c|}
\hline \multirow[b]{2}{*}{ Report } & \multicolumn{3}{|c|}{$\begin{array}{c}\text { Year } 1 \\
\text { (Fall 3rd grade) }\end{array}$} & \multicolumn{3}{|c|}{$\begin{array}{c}\text { Year } 1 \\
\text { (Spring 3rd grade) } \\
\end{array}$} & \multicolumn{3}{|c|}{$\begin{array}{c}\text { Year } 2 \\
\text { (Spring 4th grade) }\end{array}$} & \multicolumn{3}{|c|}{$\begin{array}{c}\text { Year } 3 \\
\text { (Spring 5th grade) }\end{array}$} \\
\hline & Total & $\begin{array}{c}\text { Treat- } \\
\text { ment }\end{array}$ & Control & Total & $\begin{array}{c}\text { Treat- } \\
\text { ment }\end{array}$ & Control & Total & $\begin{array}{c}\text { Treat- } \\
\text { ment }\end{array}$ & Control & Total & $\begin{array}{r}\text { Treat- } \\
\text { ment }\end{array}$ & Control \\
\hline Student sample size & 6,567 & 3,367 & 3,200 & 6,597 & 3,388 & 3,209 & 6,415 & 3,327 & 3,088 & 6,249 & 3,172 & 3,077 \\
\hline \multicolumn{13}{|l|}{ Child Report (percent) } \\
\hline Primary caregiver consent rate & 65 & $67^{* *}$ & 63 & 66 & $68^{* *}$ & 64 & 67 & 67 & 66 & 66 & 67 & 66 \\
\hline Student completion rate & 94 & $93^{*}$ & 94 & 96 & 96 & 96 & 95 & 96 & 95 & 96 & 97 & 96 \\
\hline Students with data ${ }^{1}$ & 61 & $62^{*}$ & 60 & 63 & $65^{\star *}$ & 61 & 63 & 65 & 62 & 64 & 65 & 63 \\
\hline \multicolumn{13}{|l|}{ Primary Caregiver Report (percent) } \\
\hline Primary caregiver consent rate & 63 & $64^{* *}$ & 61 & 64 & $66^{* *}$ & 62 & 64 & 65 & 63 & 64 & 65 & 64 \\
\hline Primary caregiver completion rate & 92 & 92 & 92 & 80 & 80 & 81 & 78 & 78 & 77 & 72 & 71 & 72 \\
\hline Primary caregiver with data ${ }^{1}$ & 57 & $59^{*}$ & 56 & 51 & 52 & 50 & 50 & 51 & 49 & 46 & 46 & 46 \\
\hline \multicolumn{13}{|l|}{ Teacher Report on Student (percent) } \\
\hline Primary caregiver consent rate ${ }^{2}$ & 65 & $67^{* *}$ & 63 & 66 & $68^{* *}$ & 64 & 67 & 67 & 66 & 66 & 67 & 66 \\
\hline Teacher completion rate & 96 & 96 & 96 & 99 & 99 & 99 & 100 & $100^{* *}$ & 99 & 98 & 98 & 99 \\
\hline Students with data ${ }^{1}$ & 62 & $64^{* *}$ & 61 & 65 & $67^{* *}$ & 63 & 66 & 67 & 65 & 65 & 66 & 65 \\
\hline \multicolumn{13}{|c|}{$\begin{array}{l}\text { Teacher Report on Classroom and School } \\
\text { (3rd- to 5th-grade teachers) (percent) }\end{array}$} \\
\hline Teacher consent rate & 96 & $98^{* * *}$ & 92 & 95 & $97^{*}$ & 94 & 95 & 97 & 94 & 96 & 97 & 95 \\
\hline Teacher completion rate & 91 & 90 & 93 & 91 & 90 & 91 & 94 & 94 & 94 & 92 & 91 & 93 \\
\hline Teachers with data $^{1}$ & 87 & 88 & 86 & 87 & 88 & 86 & 90 & 90 & 89 & 89 & 88 & 89 \\
\hline
\end{tabular}

* Treatment group significantly different from control group at the .05 level.

** Treatment group significantly different from control group at the .01 level.

*** Treatment group significantly different from control group at the .001 level.

${ }^{1}$ Calculated as consent rate $x$ completion rate.

${ }^{2}$ The primary caregiver consent rates for the Child Report and the Teacher Report on Student are identical, as the primary caregiver gave consent to both together.

SOURCE: The Social and Character Development (SACD) Research Program. 
Table 1.10. Consent rates, completion rates, and percentage of sample with data: Stayers versus new entrants

\begin{tabular}{|c|c|c|c|c|c|c|c|c|c|}
\hline \multirow[b]{2}{*}{ Report } & \multicolumn{3}{|c|}{$\begin{array}{c}\text { Year } 1 \\
\text { (Spring 3rd grade) }\end{array}$} & \multicolumn{3}{|c|}{$\begin{array}{c}\text { Year } 2 \\
\text { (Spring 4th grade) }\end{array}$} & \multicolumn{3}{|c|}{$\begin{array}{c}\text { Year } 3 \\
\text { (Spring 5th grade) }\end{array}$} \\
\hline & Total & Stayers & $\begin{array}{r}\text { New } \\
\text { entrants }\end{array}$ & Total & Stayers & $\begin{array}{r}\text { New } \\
\text { entrants }\end{array}$ & Total & Stayers & $\begin{array}{r}\mathrm{New} \\
\text { entrants }\end{array}$ \\
\hline Student sample size & 6,597 & 6,203 & 394 & 6,415 & 5,110 & 1,305 & 6,249 & 4,500 & 1,749 \\
\hline \multicolumn{10}{|l|}{ Child Report (percent) } \\
\hline Primary caregiver consent rate & 65.9 & $66.5^{\star * *}$ & 56.1 & 66.5 & $69.4^{* * *}$ & 55.2 & 66.4 & $69.1^{* * *}$ & 59.7 \\
\hline Student completion rate & 95.9 & 96.0 & 94.6 & 95.4 & 95.2 & 96.7 & 96.2 & 96.1 & 96.4 \\
\hline Students with data ${ }^{1}$ & 63.2 & $63.8^{* * *}$ & 53.0 & 63.5 & $66.0^{* * *}$ & 53.4 & 63.9 & $66.4^{* * *}$ & 57.5 \\
\hline \multicolumn{10}{|l|}{ Primary Caregiver Report (percent) } \\
\hline Primary caregiver consent rate & 63.8 & $64.5^{\star * *}$ & 53.8 & 64.2 & $66.7^{\star * *}$ & 54.1 & 64.2 & $66.3^{* * *}$ & 58.8 \\
\hline Primary caregiver completion rate & 80.3 & 80.2 & 81.6 & 77.7 & 77.5 & 78.6 & 71.7 & $70.7^{*}$ & 74.5 \\
\hline Primary caregivers with data ${ }^{1}$ & 51.3 & $51.7^{* *}$ & 43.9 & 49.9 & $51.7^{* * *}$ & 42.5 & 46.0 & $46.9^{*}$ & 43.8 \\
\hline \multicolumn{10}{|l|}{ Teacher Report on Student (percent) } \\
\hline Primary caregiver consent rate ${ }^{2}$ & 65.9 & $66.5^{* * *}$ & 56.1 & 66.5 & $69.4^{* * *}$ & 55.2 & 66.4 & $69.1^{* * *}$ & 59.7 \\
\hline Teacher completion rate & 98.8 & $98.9^{*}$ & 97.3 & 99.7 & 99.7 & 99.4 & 98.5 & 98.6 & 98.0 \\
\hline Students with data ${ }^{1}$ & 65.1 & $65.7^{* * *}$ & 54.6 & 66.3 & $69.2^{\star * *}$ & 54.9 & 65.4 & $68.1^{* * *}$ & 58.5 \\
\hline
\end{tabular}

* Treatment group significantly different from control group at the 05 level.

** Treatment group significantly different from control group at the .01 level.

*** Treatment group significantly different from control group at the .001 level.

${ }^{1}$ Calculated as consent rate $\mathrm{x}$ completion rate.

${ }^{2}$ The primary caregiver consent rates for the Child Report and the Teacher Report on Student are identical, as the primary caregiver gave consent to both together.

SOURCE: The Social and Character Development (SACD) Research Program. 
Table 1.11. Percentage of sample with data by report and program ${ }^{1}$

\begin{tabular}{|c|c|c|c|c|c|c|c|c|c|c|c|c|}
\hline \multirow[b]{2}{*}{ Report } & \multicolumn{3}{|c|}{$\begin{array}{c}\text { Year } 1 \\
\text { (Fall 3rd grade) } \\
\end{array}$} & \multicolumn{3}{|c|}{$\begin{array}{c}\text { Year } 1 \\
\text { (Spring 3rd grade) } \\
\end{array}$} & \multicolumn{3}{|c|}{$\begin{array}{c}\text { Year } 2 \\
\text { (Spring 4th grade) }\end{array}$} & \multicolumn{3}{|c|}{$\begin{array}{c}\text { Year } 3 \\
\text { (Spring 5th grade) } \\
\end{array}$} \\
\hline & Total & $\begin{array}{c}\text { Treat- } \\
\text { ment }\end{array}$ & Control & Total & $\begin{array}{c}\text { Treat- } \\
\text { ment }\end{array}$ & Control & Total & $\begin{array}{c}\text { Treat- } \\
\text { ment }\end{array}$ & Control & Total & $\begin{array}{c}\text { Treat- } \\
\text { ment }\end{array}$ & Control \\
\hline \multicolumn{13}{|c|}{ Child Report } \\
\hline$A B C$ & 59.4 & $62.7^{*}$ & 56.7 & 62.5 & 66.0 & 60.0 & 62.3 & 62.7 & 62.0 & 63.4 & $69.1^{* *}$ & 59.5 \\
\hline CSP & 64.8 & 62.8 & 66.6 & 67.8 & 67.2 & 68.4 & 66.5 & 66.2 & 66.7 & 65.4 & $59.2^{* * *}$ & 71.2 \\
\hline LBW & 60.1 & 61.5 & 58.4 & 60.8 & 61.4 & 60.0 & 60.4 & 60.4 & 60.3 & 58.6 & 59.1 & 57.8 \\
\hline PA & 74.4 & 73.9 & 74.8 & 71.2 & 71.6 & 70.7 & 66.6 & 66.8 & 66.4 & 76.5 & 78.3 & 74.7 \\
\hline PATHS & 52.2 & 54.4 & 50.1 & 56.1 & 58.6 & 53.8 & 55.8 & 59.0 & 52.8 & 55.4 & $59.5^{*}$ & 51.5 \\
\hline 4Rs & 54.9 & 56.0 & 53.6 & 59.1 & $62.3^{*}$ & 55.4 & 61.2 & 62.8 & 59.4 & 62.4 & 63.5 & 61.3 \\
\hline SS & 62.3 & $65.7^{*}$ & 58.0 & 65.6 & 68.4 & 62.2 & 71.0 & 72.4 & 69.2 & 68.0 & 70.4 & 65.4 \\
\hline \multicolumn{13}{|c|}{ Primary Caregiver Report } \\
\hline $\mathrm{ABC}$ & 56.6 & 60.0 & 53.9 & 48.1 & 52.5 & 44.8 & 45.8 & 45.8 & 45.9 & 44.3 & 47.3 & 42.3 \\
\hline CSP & 59.6 & $56.3^{*}$ & 62.9 & 53.9 & 50.9 & 56.9 & 52.1 & 50.2 & 53.9 & 46.7 & 43.4 & 49.7 \\
\hline LBW & 62.6 & 64.8 & 59.8 & 53.1 & 54.0 & 52.0 & 51.2 & 52.9 & 48.9 & 46.9 & 45.7 & 48.8 \\
\hline PA & 72.3 & 72.7 & 71.8 & 58.9 & 58.9 & 58.8 & 52.2 & 50.6 & 54.3 & 50.5 & 51.7 & 49.4 \\
\hline PATHS & 53.6 & 56.0 & 51.3 & 48.3 & 52.9 & 44.0 & 45.5 & $49.6^{* *}$ & 41.7 & 43.4 & 45.2 & 41.8 \\
\hline 4Rs & 41.0 & 42.2 & 39.6 & 41.7 & 41.9 & 41.5 & 41.0 & 40.9 & 41.2 & 33.1 & 32.0 & 34.4 \\
\hline SS & 62.3 & $65.7^{*}$ & 57.8 & 57.3 & 58.0 & 56.5 & 61.8 & 63.2 & 60.1 & 56.7 & 58.3 & 54.8 \\
\hline \multicolumn{13}{|c|}{ Teacher Report on Student } \\
\hline $\mathrm{ABC}$ & 59.7 & $65.3^{* *}$ & 55.5 & 63.7 & 66.8 & 61.4 & 64.7 & 65.4 & 64.1 & 67.2 & $73.7^{*}$ & 62.7 \\
\hline CSP & 66.4 & 64.1 & 68.7 & 68.7 & 67.8 & 69.6 & 68.3 & 67.3 & 69.3 & 62.8 & $55.0^{* * *}$ & 70.1 \\
\hline LBW & 64.3 & 66.3 & 61.9 & 66.1 & 67.8 & 63.8 & 64.4 & 65.5 & 63.0 & 63.7 & 63.8 & 63.4 \\
\hline PA & 74.6 & 72.9 & 76.3 & 74.8 & 73.3 & 76.3 & 72.4 & 71.1 & 74.0 & 78.3 & 79.5 & 77.1 \\
\hline PATHS & 56.4 & 58.6 & 54.3 & 58.4 & $62.0^{*}$ & 55.0 & 57.6 & 60.9 & 54.6 & 56.3 & $60.3^{*}$ & 52.5 \\
\hline 4Rs & 53.8 & 55.5 & 51.8 & 59.6 & $62.4^{*}$ & 56.3 & 65.5 & 67.3 & 63.3 & 64.1 & 64.4 & 63.9 \\
\hline SS & 64.8 & $68.5^{\star *}$ & 60.2 & 65.6 & 68.4 & 62.2 & 70.8 & 72.0 & 69.2 & 68.1 & 70.4 & 65.6 \\
\hline
\end{tabular}


Table 1.11. Percentage of sample with data by report and program ${ }^{1}-$ Continued

\begin{tabular}{|c|c|c|c|c|c|c|c|c|c|c|c|c|}
\hline \multirow[b]{2}{*}{ Report } & \multicolumn{3}{|c|}{$\begin{array}{c}\text { Year } 1 \\
\text { (Fall 3rd grade) } \\
\end{array}$} & \multicolumn{3}{|c|}{$\begin{array}{c}\text { Year } 1 \\
\text { (Spring 3rd grade) }\end{array}$} & \multicolumn{3}{|c|}{$\begin{array}{c}\text { Year } 2 \\
\text { (Spring 4th grade) }\end{array}$} & \multicolumn{3}{|c|}{$\begin{array}{c}\text { Year } 3 \\
\text { (Spring 5th grade) }\end{array}$} \\
\hline & Total & $\begin{array}{c}\text { Treat- } \\
\text { ment }\end{array}$ & Control & Total & $\begin{array}{c}\text { Treat- } \\
\text { ment }\end{array}$ & Control & Total & $\begin{array}{r}\text { Treat- } \\
\text { ment }\end{array}$ & Control & Total & $\begin{array}{r}\text { Treat- } \\
\text { ment }\end{array}$ & Control \\
\hline \multicolumn{13}{|c|}{$\begin{array}{l}\text { Teacher Report on Classroom and } \\
\text { School (3rd- to 5th-grade teachers) }\end{array}$} \\
\hline $\mathrm{ABC}$ & 85.6 & 91.8 & 80.8 & 84.2 & 83.6 & 84.6 & 86.0 & 84.7 & 87.0 & 81.6 & 86.7 & 77.8 \\
\hline CSP & 84.1 & 83.1 & 85.2 & 78.5 & 77.9 & 79.0 & 88.0 & 85.1 & 90.9 & 90.6 & 86.3 & 95.4 \\
\hline LBW & 88.4 & 84.0 & 93.8 & 95.9 & 95.2 & 96.9 & 87.9 & 89.7 & 85.2 & 91.9 & 90.4 & 94.3 \\
\hline PA & 89.5 & 90.0 & 88.9 & 82.6 & 82.0 & 83.3 & 86.3 & 86.0 & 86.7 & 83.7 & 78.0 & 90.5 \\
\hline PATHS & 78.7 & $88.9^{\star \star}$ & 69.9 & 80.1 & $92.1^{\star \star}$ & 69.9 & 83.6 & 90.0 & 78.4 & 83.5 & 81.7 & 84.9 \\
\hline $4 \mathrm{Rs}$ & 92.7 & 92.0 & 93.4 & 90.6 & 89.0 & 92.4 & 97.2 & 96.8 & 97.6 & 96.4 & 97.8 & 94.9 \\
\hline SS & 92.2 & 90.3 & 94.4 & 93.1 & 93.5 & 92.6 & 96.6 & 96.8 & 96.2 & 89.0 & 90.8 & 86.8 \\
\hline
\end{tabular}

* Treatment group significantly different from control group at the .05 level.

** Treatment group significantly different from control group at the .01 level.

*** Treatment group significantly different from control group at the .001 level.

${ }^{1}$ Calculated as consent rate $x$ completion rate.

u NOTE: Abbreviations are

ABC: Academic and Behavioral Competencies Program

CSP: Competence Support Program

LBW: Love In a Big World

PA: Positive Action

PATHS: Promoting Alternative Thinking Strategies

4Rs: The 4Rs Program (Reading, Writing, Respect, and Resolution)

SS: Second Step

SOURCE: The Social and Character Development (SACD) Research Program. 


\section{Initial Characteristics}

This section examines the initial characteristics of the students, primary caregivers, teachers, and schools participating in the SACD evaluation. These characteristics were collected from students who were enrolled in the third grade at the study schools in fall 2004, as well as from their primary caregivers and third-grade teachers. In addition, third-, fourth-, and fifth-grade teachers and principals in the study schools provided information about activities related to social and character development in these schools. Documenting the characteristics of students, primary caregivers and the students' households, teachers, and schools — and initial measures of key outcomes at a point before the programs had been operating for an extended period-helps to determine whether the random assignment of schools to treatment and control status produced treatment and control groups with similar distributions of observed characteristics.

For the treatment schools that were implementing six of the seven programs ( 36 of the 42 treatment schools), implementation began 2 to 6 weeks before the fall 2004 data were collected (as shown in table 1.8). The implementation of the six programs, and the training of teachers that preceded the implementation of all seven programs, could have affected the student, primary caregiver, and teacher reports from the treatment schools. If such effects occurred, they could not be disentangled from pre-existing differences between the treatment and control schools. The likelihood of an implementation effect differed by the type of characteristic reported on. Some characteristics could not be affected (e.g., gender and race/ethnicity). Some were unlikely to be affected (e.g., primary caregiver's highest education level) and others could have been affected (e.g., student outcomes and risk factors) but the likelihood was low given how short the time the students were exposed to the programs before the data collection. Other characteristics were likely to have been affected (e.g., teacher reports of SACD activities and professional development over the past year) given that teachers prepared for implementation and implemented the programs before data collection. How likely a characteristic was to have been affected should be kept in mind when considering how similar the treatment and control groups appeared from the fall 2004 data collection. For example, the lack of significant differences in family characteristics discussed below appears to provide valid evidence that the treatment and control groups were similar, while the lack of differences in student outcomes and risk factors gives similar but perhaps less valid evidence. On the other hand, the findings that treatment teachers used more SACD activities in the classroom and received more SACD training provide evidence of a difference between the treatment and control schools before the study began, but the training in and implementation of the programs before data collection lead to less confidence in this finding.

\section{Characteristics of Children, Their Families, and Communities}

The sample's treatment and control groups were similar along the observed student, primary caregiver, and community characteristics (table 1.12). For the comparison of 21 characteristics, the expectation would be that 1 would be significant by chance. For all seven programs together, there was only 1 statistically significant difference (treatment group students were more likely to come from smaller households than control group students: 4.5 versus 4.7 people per household). At the program level, there was only 1 statistically significant difference (control group primary caregivers had significantly higher levels of education than treatment group primary caregivers for the SS program) versus the 7 that would be expected by chance. ${ }^{21}$ For students, the mean age was 8 years. The sample contained more girls than boys ( $53 \%$ versus $48 \%$, respectively) but the difference was not statistically significant. This pattern prevailed in five of the seven programs. The sample was ethnically diverse. White non-Hispanic students made up 42 percent of the sample, Black non-Hispanic students made up 31 percent, and Hispanic students made up 19 percent. In four programs, a single ethnic group comprised the majority of all students (White non-Hispanics made up $83 \%$ of SS students, $65 \%$ of LBW students, and $56 \%$ of PATHS students, while $51 \%$ of PA students were Black non-Hispanic).

${ }^{21}$ Program-level results are detailed in the program-specific chapters. 
The sample was also diverse in levels of family income, education levels of primary caregivers, and family situation. Thirty-nine percent of children lived in a household in which the income was 135 percent of the federal poverty level or lower, which is the income threshold for eligibility for free school meals. About 15 percent of primary caregivers had not completed high school. Sixty percent of the children lived with both their father and their mother. Programs varied in their economic diversity. Three of the programs operated in schools in which the majority of children were in families that had incomes below 135 percent of the federal poverty level $(66 \%$ for $\mathrm{PA}, 58 \%$ for $4 \mathrm{Rs}$, and $50 \%$ for $\mathrm{ABC}$ ). These three programs also had between 47 percent and 50 percent of children living with both parents; 27 percent to 28 percent of primary caregivers lacked a high school diploma in 4Rs and PA. On the other hand, for SS, only 5 percent of children were from families with incomes below 135 percent of the federal poverty level, only 4 percent of primary caregivers reported not having a high school diploma, and 80 percent of children lived with both parents. 
Table 1.12. Initial characteristics of children, their families, and communities

\begin{tabular}{|c|c|c|c|}
\hline Characteristic & Total & Treatment & Control \\
\hline Student sample size & 3,774 & 1,980 & 1,794 \\
\hline \multicolumn{4}{|l|}{ Student demographics } \\
\hline \multicolumn{4}{|l|}{ Gender (percent) } \\
\hline Male & 47.5 & 46.9 & 48.1 \\
\hline Female & 52.5 & 53.1 & 51.9 \\
\hline \multicolumn{4}{|l|}{ Race/ethnicity (percent) } \\
\hline White (non-Hispanic) & 42.1 & 39.7 & 44.5 \\
\hline Black (non-Hispanic) & 31.0 & 34.2 & 27.9 \\
\hline Hispanic & 19.2 & 18.5 & 20.0 \\
\hline Other & 7.7 & 7.7 & 7.6 \\
\hline Age (in years) (mean) & 8.1 & 8.1 & 8.1 \\
\hline \multicolumn{4}{|l|}{ Primary caregiver and family characteristics } \\
\hline Primary caregiver's age (in years) (mean) & 36.0 & 36.0 & 36.0 \\
\hline \multicolumn{4}{|l|}{ Primary caregiver's race/ethnicity (percent) } \\
\hline White (non-Hispanic) & 46.1 & 43.8 & 48.4 \\
\hline Black (non-Hispanic) & 30.7 & 33.8 & 27.6 \\
\hline Hispanic & 17.6 & 16.9 & 18.3 \\
\hline Other & 5.6 & 5.5 & 5.6 \\
\hline \multicolumn{4}{|l|}{ Primary caregiver's education (percent) } \\
\hline Did not complete high school & 14.7 & 13.5 & 15.9 \\
\hline Completed high school or equivalent & 24.3 & 23.3 & 25.4 \\
\hline Some college & 39.7 & 41.3 & 38.1 \\
\hline Bachelor's or higher degree & 21.2 & 21.9 & 20.5 \\
\hline \multicolumn{4}{|l|}{ Primary caregiver's employment (percent) } \\
\hline Full-time & 48.3 & 48.6 & 48.0 \\
\hline Part-time & 14.7 & 14.5 & 14.9 \\
\hline Student and employed & 4.6 & 5.1 & 4.1 \\
\hline Not employed & 31.3 & 30.8 & 31.8 \\
\hline Other & 1.1 & 1.0 & 1.2 \\
\hline \multicolumn{4}{|l|}{ Primary caregiver's marital status (percent) } \\
\hline Single & 23.9 & 24.5 & 23.2 \\
\hline Married & 57.0 & 56.4 & 57.7 \\
\hline Separated or divorced & 12.7 & 12.6 & 12.9 \\
\hline Widowed & 1.2 & 1.2 & 1.1 \\
\hline Other $^{1}$ & 5.2 & 5.2 & 5.2 \\
\hline Students who live in one household (percent) & 93.6 & 93.6 & 93.6 \\
\hline Number of individuals in household (mean) & 4.6 & $4.5^{*}$ & 4.7 \\
\hline
\end{tabular}


Table 1.12. Initial characteristics of children, their families, and communities-Continued

\begin{tabular}{|c|c|c|c|}
\hline Characteristic & Total & Treatment & Control \\
\hline \multicolumn{4}{|l|}{ Primary caregiver's relationship to child (percent) } \\
\hline Mother (stepmother) & 86.1 & 86.3 & 85.9 \\
\hline Father (stepfather) & 9.0 & 8.1 & 9.8 \\
\hline Grandparent & 2.9 & 3.2 & 2.6 \\
\hline Other relative & 1.3 & 1.4 & 1.1 \\
\hline Nonrelative & 0.8 & 1.0 & 0.6 \\
\hline \multicolumn{4}{|l|}{ Student lives with (percent) } \\
\hline Mother (stepmother) and father (stepfather) & 60.0 & 58.5 & 61.6 \\
\hline Mother (stepmother) only; father (stepfather) not present & 33.6 & 34.9 & 32.3 \\
\hline Father (stepfather) only; mother (stepmother) not present & 2.5 & 2.3 & 2.8 \\
\hline Other relative/nonrelative, parents not present & 3.9 & 4.4 & 3.3 \\
\hline \multicolumn{4}{|l|}{ Highest education of anyone in household (percent) } \\
\hline Did not complete high school & 10.0 & 8.7 & 11.4 \\
\hline Completed high school or equivalent & 21.9 & 20.8 & 23.0 \\
\hline Some college & 40.3 & 42.4 & 38.2 \\
\hline Bachelor's or higher degree & 27.8 & 28.1 & 27.5 \\
\hline \multicolumn{4}{|l|}{ Total household income (percent) } \\
\hline Less than $\$ 20,000$ & 33.2 & 31.7 & 34.7 \\
\hline$\$ 20,000$ to $\$ 39,999$ & 24.4 & 25.3 & 23.4 \\
\hline$\$ 40,000$ to $\$ 59,999$ & 15.1 & 15.9 & 14.4 \\
\hline$\$ 60,000$ or more & 27.3 & 27.1 & 27.5 \\
\hline \multicolumn{4}{|l|}{ Household income-to-poverty threshold ratio (percent) } \\
\hline Below 135 percent & 39.0 & 37.0 & 41.0 \\
\hline 135 to 185 percent & 18.2 & 18.9 & 17.5 \\
\hline Above 185 percent & 42.8 & 44.1 & 41.5 \\
\hline \multicolumn{4}{|l|}{ Alabama Parenting Questionnaire-Poor Monitoring and } \\
\hline Supervision Subscale (mean) & 1.2 & 1.1 & 1.2 \\
\hline \multicolumn{4}{|l|}{ Alabama Parenting Questionnaire-Positive Parenting } \\
\hline Subscale (mean) & 3.5 & 3.5 & 3.5 \\
\hline Confusion, Hubbub, and Order Scale (mean) & 2.2 & 2.2 & 2.2 \\
\hline \multicolumn{4}{|l|}{ Community characteristics (mean) } \\
\hline Community Risks Scale & 1.5 & 1.5 & 1.5 \\
\hline Community Resources Scale & 2.7 & 2.7 & 2.7 \\
\hline Child-Centered Social Control Scale & 3.1 & 3.1 & 3.1 \\
\hline
\end{tabular}

${ }^{*}$ Treatment group significantly different from control group at the .05 level.

${ }^{1}$ Categories combined to protect confidentiality.

NOTE: Weights, which assign equal weight to each school within each of the programs and to each program across programs, were used in producing the treatment, control, and overall means. Statistical tests were conducted using regressions that included program indicators to account for the sample design and adjusted for clustering at the school level.

SOURCE: The Social and Character Development (SACD) Research Program. 
The mean values of the outcome measures for children's behavior and attitudes as reported by the primary caregiver, child, and teacher in fall 2004, along with each measure's range, are shown in table 1.13. The values were similar for the treatment and control groups. There were three statistically significant differences at the program level (these data are not shown in a table) but their number and pattern suggest that they may have been due to chance; at the 5 percent significance level, 6 of the 126 comparisons made would have been expected to show statistical significance by chance. Table 1.13 also addresses the issue of whether students had room to improve from their initial scores on the outcome measures. Five of the mean outcomes were within 0.4 units of the minimum or maximum outcome range (Normative Beliefs About Aggression; Altruistic Behavior, Teacher Report on Student; Problem Behavior, Child Report and Teacher Report on Student; and Engagement with Learning). However, these five were more than half a standard deviation from their minimum or maximum value, which is larger than the minimal detectable impacts for the study. In addition, the other mean outcomes were one or more standard deviations from their boundaries. In sum, the evaluation had enough power to identify a minimum detectable effect for all the outcomes before potential ceiling and floor effects could occur.

The mean values of the five risk factors as reported in fall 2004 showed no statistically significant difference between the treatment and control groups (table 1.14). In addition, there were no statistically significant differences at the program level (these data are not shown in a table). 
Table 1.13. Mean scores and standard deviations for initial outcome measures

\begin{tabular}{|c|c|c|c|c|c|c|c|}
\hline \multirow[b]{2}{*}{ Outcome measure-Report } & \multirow[b]{2}{*}{ Range } & \multicolumn{2}{|c|}{ Total } & \multicolumn{2}{|c|}{ Treatment } & \multicolumn{2}{|c|}{ Control } \\
\hline & & Mean & $S D$ & Mean & $S D$ & Mean & $S D$ \\
\hline \multicolumn{8}{|l|}{ Social and Emotional Competence Domain } \\
\hline Self-Efficacy for Peer Interaction-CR & $1-4$ & 2.9 & 0.6 & 2.9 & 0.6 & 2.9 & 0.6 \\
\hline Normative Beliefs About Aggression-CR & $1-4$ & 1.2 & 0.4 & 1.2 & 0.4 & 1.2 & 0.4 \\
\hline Empathy-CR & $1-3$ & 2.4 & 0.4 & 2.4 & 0.4 & 2.4 & 0.4 \\
\hline \multicolumn{8}{|l|}{ Behavior Domain } \\
\hline Altruistic Behavior-CR & $0-3$ & 1.5 & 0.8 & 1.5 & 0.9 & 1.4 & 0.8 \\
\hline Altruistic Behavior-TRS & $1-4$ & 1.4 & 0.5 & 1.4 & 0.5 & 1.4 & 0.4 \\
\hline Altruistic Behavior-PCR & $1-4$ & 2.3 & 0.7 & 2.3 & 0.7 & 2.3 & 0.7 \\
\hline Positive Social Behavior-TRS & $1-4$ & 3.0 & 0.7 & 3.0 & 0.7 & 3.0 & 0.7 \\
\hline Positive Social Behavior-PCR & $1-4$ & 3.0 & 0.5 & 3.0 & 0.5 & 3.0 & 0.5 \\
\hline Problem Behavior-CR & $0-3$ & 0.2 & 0.4 & 0.2 & 0.4 & 0.2 & 0.4 \\
\hline Problem Behavior-TRS & $1-4$ & 1.4 & 0.4 & 1.4 & 0.4 & 1.3 & 0.4 \\
\hline Problem Behavior-PCR & $1-4$ & 1.6 & 0.3 & 1.6 & 0.3 & 1.6 & 0.3 \\
\hline ADHD-Related Behavior-TRS & $1-4$ & 1.7 & 0.6 & 1.7 & 0.7 & 1.7 & 0.6 \\
\hline \multicolumn{8}{|l|}{ Academics Domain } \\
\hline Academic Competence and Motivation-TRS & $1-5$ & 2.9 & 0.9 & 2.9 & 0.9 & 2.9 & 0.9 \\
\hline Engagement with Learning-CR & $1-4$ & 3.7 & 0.6 & 3.7 & 0.6 & 3.7 & 0.6 \\
\hline \multicolumn{8}{|l|}{ Perceptions of School Climate Domain } \\
\hline Positive School Orientation-CR & $1-4$ & 3.2 & 0.7 & 3.2 & 0.7 & 3.2 & 0.6 \\
\hline Negative School Orientation-CR & $1-4$ & 1.8 & 0.7 & 1.9 & 0.7 & 1.8 & 0.7 \\
\hline Student Afraid at School-CR & $1-4$ & 2.4 & 0.9 & 2.4 & 0.9 & 2.4 & 0.9 \\
\hline Victimization at School-CR & $0-3$ & 0.8 & 0.8 & 0.8 & 0.8 & 0.8 & 0.8 \\
\hline Sample size-PCR ${ }^{1}$ & & \multicolumn{2}{|c|}{3,774} & \multicolumn{2}{|c|}{1,980} & \multicolumn{2}{|c|}{1,794} \\
\hline Sample size-CR ${ }^{1}$ & & \multicolumn{2}{|c|}{3,997} & \multicolumn{2}{|c|}{2,092} & \multicolumn{2}{|c|}{1,905} \\
\hline Sample size-TRS ${ }^{1}$ & & \multicolumn{2}{|c|}{4,104} & \multicolumn{2}{|c|}{2,158} & \multicolumn{2}{|c|}{1,946} \\
\hline
\end{tabular}

\footnotetext{
${ }^{1}$ Sample size may differ for some outcomes due to nonresponse.

NOTE: Abbreviations are

CR: Child Report

PCR: Primary Caregiver Report

TRS: Teacher Report on Student

$S D$ : Standard deviation

ADHD: Attention deficit hyperactivity disorder

No findings were found statistically significant at or below the .05 level. Weights, which assign equal weight to each school within each of the programs and to each program across programs, were used in producing the treatment, control, overall means, and standard deviations. Statistical tests were conducted using regressions that included program indicators to account for the sample design and adjusted for clustering at the school level.

SOURCE: The Social and Character Development (SACD) Research Program.
} 
Table 1.14. Mean scores and standard deviations for initial risk factors

\begin{tabular}{|c|c|c|c|c|c|c|}
\hline \multirow[b]{2}{*}{ Risk factor } & \multicolumn{2}{|c|}{ Total } & \multicolumn{2}{|c|}{ Treatment } & \multicolumn{2}{|c|}{ Control } \\
\hline & Mean & $S D$ & Mean & $S D$ & Mean & $S D$ \\
\hline Family risk & 1.2 & 0.2 & 1.1 & 0.2 & 1.2 & 0.2 \\
\hline Community risk & 1.5 & 0.7 & 1.5 & 0.7 & 1.5 & 0.7 \\
\hline Child behavior risk-TRS & 50.9 & 10.3 & 51.2 & 10.4 & 50.5 & 10.2 \\
\hline Child behavior risk-PCR & 50.5 & 10.1 & 50.5 & 9.8 & 50.6 & 10.3 \\
\hline \multicolumn{7}{|l|}{ Socioeconomic risk ${ }^{2}$} \\
\hline No risk factors & 58.8 & 49.2 & 60.9 & 48.8 & 56.8 & 49.5 \\
\hline One risk factor & 29.8 & 45.7 & 29.0 & 45.4 & 30.6 & 46.1 \\
\hline Two or three risk factors & 11.4 & 31.7 & 10.1 & 30.1 & 12.6 & 33.2 \\
\hline Sample size-PCR ${ }^{1}$ & \multicolumn{2}{|c|}{3,774} & \multicolumn{2}{|c|}{1,980} & \multicolumn{2}{|c|}{1,794} \\
\hline Sample size-CR ${ }^{1}$ & \multicolumn{2}{|c|}{3,997} & \multicolumn{2}{|c|}{2,092} & \multicolumn{2}{|c|}{1,905} \\
\hline Sample size-TRS ${ }^{1}$ & \multicolumn{2}{|c|}{4,103} & \multicolumn{2}{|c|}{2,157} & \multicolumn{2}{|c|}{1,946} \\
\hline
\end{tabular}

${ }^{1}$ Sample size may differ for some outcomes due to nonresponse.

${ }^{2}$ As a sensitivity test, the index was also treated as a continuous variable and no significant differences were found. NOTE: Abbreviations are

CR: Child Report

PCR: Primary Caregiver Report

TRS: Teacher Report on Student

$S D$ : Standard deviation

No findings were found statistically significant at or below the .05 level. Weights, which assign equal weight to each school within each of the programs and to each program across programs, were used in producing the treatment, control, overall means, and standard deviations. Statistical tests were conducted using regressions that included program indicators to account for the sample design and adjusted for clustering at the school level.

SOURCE: The Social and Character Development (SACD) Research Program. 


\section{Characteristics of Teachers and Schools}

The third-, fourth-, and fifth-grade teachers at the study schools were predominantly White non-Hispanic (75\%), female (88\%), and had an average of nearly 13 years of total teaching experience. About 60 percent held an advanced or specialist degree (table 1.15). Six characteristics were compared, with less than one expected to be significant by chance. The only statistically significant difference between the treatment and control group of teachers concerned degree attainment: a test of the distribution of teachers' education levels across five categories yielded a $p$-value of 0.043 . Among the programs there was one significant difference versus six expected by chance: for PATHS, male teachers made up a smaller percentage of the treatment teachers than the control teachers $(17 \%$ versus $35 \%)$.

Data regarding school characteristics were drawn from the U.S. Department of Education's Common Core of Data (2003-04) in order to compare treatment versus control schools (table 1.16). Comparisons were made on nine characteristics, with less than one expected to be found significant by chance. These characteristics included student composition (race/ethnicity and school lunch eligibility), number of students, number of full-time teachers, Title I status, highest and lowest grades, school location, and years the principal had been at the school. Overall, one significant difference was found: a smaller percentage of treatment schools than control schools $(50 \%$ versus $67 \%$ ) had prekindergarten. No significant differences were found among the programs.

In the Teacher Report on Classroom and School, teachers reported on nine dimensions concerning their school environment, including feelings of safety, resource adequacy, student support, staff freedom to teach as desired, affiliation with and ties to colleagues, innovation regarding trying new approaches to teaching, professional interest, participatory decisionmaking, and work pressure. There were no statistically significant differences (these data are not shown in a table) in these reports between treatment and control schools, overall or at the program level. 
Table 1.15. Initial characteristics of teachers

\begin{tabular}{|c|c|c|c|}
\hline Characteristic & Total & Treatment & Control \\
\hline Teacher sample size & 847 & 436 & 411 \\
\hline \multicolumn{4}{|l|}{ Gender (percent) } \\
\hline Male & 12.3 & 11.9 & 12.7 \\
\hline Female & 87.7 & 88.1 & 87.3 \\
\hline \multicolumn{4}{|l|}{ Race/ethnicity (percent) } \\
\hline White (non-Hispanic) & 75.2 & 73.1 & 77.4 \\
\hline Black (non-Hispanic) & 16.8 & 18.6 & 15.1 \\
\hline Hispanic & 4.9 & 5.9 & 3.8 \\
\hline Other & 3.1 & 2.4 & 3.7 \\
\hline Number of years teaching (mean) & 12.8 & 12.5 & 13.0 \\
\hline Number of years teaching in this school (mean) & 7.3 & 6.8 & 7.7 \\
\hline \multicolumn{4}{|l|}{ Type of teaching certificate (percent) } \\
\hline Regular state certificate or advanced professional certificate & 84.7 & 83.4 & 86.0 \\
\hline Provisional certificate (for those in alternative certification programs) & 6.2 & 6.8 & 5.5 \\
\hline $\begin{array}{l}\text { Probationary certificate (for those who have satisfied all } \\
\text { requirements except for completing the probationary period) }\end{array}$ & 4.9 & 5.7 & 4.2 \\
\hline $\begin{array}{l}\text { Emergency certificate or waiver (for those who must } \\
\text { complete a certification program to continue teaching) }\end{array}$ & 0.0 & 0.0 & 0.0 \\
\hline Other $^{1}$ & 4.1 & 4.1 & 4.2 \\
\hline Education (percent) & & \multicolumn{2}{|c|}{$*^{2}$} \\
\hline Less than a bachelor's degree & 0.0 & 0.0 & 0.0 \\
\hline Bachelor's degree & 40.2 & 37.6 & 42.8 \\
\hline Master's degree, Ph.D. & 56.2 & 60.2 & 52.3 \\
\hline Specialist degree & 2.1 & 1.0 & 3.2 \\
\hline Other & 1.5 & 1.3 & 1.7 \\
\hline
\end{tabular}

${ }^{*}$ Treatment group significantly different from control group at the .05 level.

${ }^{1}$ Categories, including no certificate and temporary certificate, combined to protect confidentiality.

${ }^{2} \mathrm{~A}$ test of the distribution of teachers' education levels across all five categories yielded a $p$-value of 0.043 .

NOTE: Weights, which assign equal weight to each school within each of the programs and to each program across programs, were used in producing the treatment, control, and overall means. Statistical tests were conducted using regressions that included program indicators to account for the sample design and adjusted for clustering at the school level. SOURCE: The Social and Character Development (SACD) Research Program. 
Table 1.16. Initial characteristics of schools

\begin{tabular}{|c|c|c|c|}
\hline Characteristic & Total & Treatment & Control \\
\hline School sample size & 84 & 42 & 42 \\
\hline \multicolumn{4}{|l|}{ Student race/ethnicity (percent) } \\
\hline White (non-Hispanic) & 37.3 & 36.4 & 38.3 \\
\hline Black (non-Hispanic) & 39.7 & 40.9 & 38.5 \\
\hline Hispanic & 18.7 & 18.0 & 19.5 \\
\hline Other & 4.2 & 4.6 & 3.8 \\
\hline Students eligible for free or reduced-price lunch (percent) & 61.3 & 62.3 & 60.4 \\
\hline Number of students enrolled (mean) & 567.1 & 555.7 & 578.9 \\
\hline Number of full-time teachers (mean) & 38.5 & 37.3 & 39.6 \\
\hline \multicolumn{4}{|l|}{ Title I status (percent) } \\
\hline Title I eligible school & 74.2 & 73.2 & 75.2 \\
\hline Schoolwide Title I & 63.7 & 61.2 & 66.2 \\
\hline \multicolumn{4}{|l|}{ Lowest grade offered (percent) } \\
\hline Prekindergarten & 58.5 & $50.4^{*}$ & 66.7 \\
\hline Kindergarten & 41.5 & 49.6 & 33.3 \\
\hline \multicolumn{4}{|l|}{ Highest grade offered (percent) } \\
\hline Fifth grade & 55.4 & 58.1 & 52.8 \\
\hline Sixth grade & 22.0 & 19.0 & 25.1 \\
\hline Eighth grade & 22.5 & 22.9 & 22.1 \\
\hline \multicolumn{4}{|l|}{ Location of school (percent) } \\
\hline City & 56.2 & 58.6 & 53.8 \\
\hline Suburbs & 26.7 & 25.2 & 28.1 \\
\hline Rural & 17.1 & 16.2 & 18.1 \\
\hline Number of years principal has been at this school (mean) & 5.5 & 4.8 & 6.1 \\
\hline \multicolumn{4}{|c|}{$\begin{array}{l}\text { * Treatment group significantly different from control group at the } .05 \text { level. } \\
\text { NOTE: Weights, which assign equal weight to each school within each of the programs and to each program across programs, were } \\
\text { used in producing the treatment, control, and overall means. Statistical tests were conducted using regressions that included } \\
\text { program indicators to account for the sample design and adjusted for clustering at the school level. Data are missing from Love In a } \\
\text { Big World for student race/ethnicity, percentage of students eligible for free or reduced-price lunch, and number of full-time teachers. } \\
\text { SOURCE: NCES Common Core of Data (2003-04). The Social and Character Development (SACD) Research Program. }\end{array}$} \\
\hline
\end{tabular}




\section{The Initial Level of Social and Character Development Activities in the Schools}

During the initial data collection in fall 2004, principals and teachers reported on the SACD activities used in the schools and classrooms, the availability of SACD materials and instructional practices used, and the professional development teachers received on SACD over the past 12 months. These reports were likely to have been influenced by the implementation of six programs (in 36 of the 42 treatment schools) and the training of treatment teachers in all schools that preceded the data collection. For this reason, the fall 2004 data did not provide baseline data on how the use of SACD activities differed between treatment and control before the intervention but, instead, provided data on how this use differed early on in the study.

Table 1.17 shows that most school principals reported activities to promote six social and character development goals: violence prevention and peace promotion $(93 \%)$, social and emotional development (95\%), character education (96\%), tolerance and diversity (86\%), risk prevention and health promotion (81\%), and civic responsibility and community service (90\%). In addition, most (91\%) also reported activities directed toward behavior management. There were no statistically significant differences in the percentages of principals who reported, in the treatment group schools and the control group schools, that their school had programs or activities to promote each of these goals.

Most teachers reported the use of these activities in their classroom to promote the six social and character development goals and behavior management (ranging from 53\% to 87\%). From the eight comparisons made (including a "none of the above" comparison) less than one significant difference would have been expected. Unlike the principals, a significantly larger percentage of treatment teachers than control teachers reported using activities to promote three SACD goals: violence prevention and peace promotion activities $(70 \%$ versus 59\%), social and emotional development activities (79\% versus 68\%), and behavior management (90\% versus $84 \%$ ). In addition, seven comparisons were made as to whether teachers used the activities for each of the six SACD goals and behavior management with all, some, or no students (less than one significant difference would be expected by chance). Treatment teachers were statistically significantly more likely to report engaging all students, as opposed to some or no students, with activities to promote the same three SACD goals (these data are not shown in a table).

The majority of teachers reported that their schools used schoolwide activities to promote social and character development. These activities included morning announcements or videos (reported by $80 \%$ of teachers), school assemblies (71\%), school newspapers or bulletins (67\%), special school days (54\%), and special events $(72 \%)$. Only 13 percent reported the use of other activities. There were no significant differences in the percent of treatment versus control teachers reporting the use of these six activities. 
Table 1.17. Principal and teacher initial reports on use of SACD programs or activities

\begin{tabular}{crrr}
\hline SACD program or activity & Total & Treatment & Control \\
\hline Principal sample size & 84 & 42 & 42 \\
Teacher sample size & 847 & 436 & 411
\end{tabular}

Principals reporting that school had programs or activities

to promote the following SACD goals (percent)

Violence prevention and peace promotion

$\begin{array}{lll}92.8 & 92.9 & 92.7 \\ 95.0 & 95.3 & 94.7 \\ 96.4 & 95.6 & 97.1 \\ 85.8 & 84.7 & 87.0 \\ 80.8 & 85.1 & 76.5 \\ 89.7 & 92.3 & 87.0 \\ 91.4 & 93.9 & 89.0\end{array}$

Social and emotional development

Character education

Tolerance and diversity

93.9

89.0

Teachers reporting on using programs or activities in their class to promote the following SACD goals (percent)

Violence prevention and peace promotion

$\begin{array}{rlr}64.6 & 69.8^{*} & 59.4 \\ 73.2 & 78.5^{\star *} & 67.9 \\ 82.5 & 84.4 & 80.5 \\ 63.3 & 64.4 & 62.1 \\ 52.9 & 51.7 & 54.1 \\ 59.2 & 59.6 & 58.7 \\ 86.8 & 89.6^{*} & 83.9 \\ 2.4 & 1.6 & 3.2\end{array}$

Social and emotional development

Character education

Tolerance and diversity

Risk prevention and health promotion

Civic responsibility and community service

Behavior management

None of the above

Teachers reporting schoolwide use of the following activities to promote SACD (percent)

Morning announcements or videos

\begin{tabular}{lll}
80.2 & 77.2 & 83.3 \\
71.0 & 69.1 & 72.9 \\
66.7 & 62.3 & 71.1 \\
53.8 & 53.8 & 53.9 \\
71.5 & 72.5 & 70.5 \\
12.8 & 12.5 & 13.1 \\
\hline
\end{tabular}

School assemblies

School newspapers or bulletins

Special school days

Special events

12.8

* Treatment group significantly different from control group at the .05 level.

** Treatment group significantly different from control group at the .01 level.

NOTE: Weights, which assign equal weight to each school within each of the programs and to each program across programs, were used in producing the treatment, control, and overall means. Statistical tests were conducted using regressions that included program indicators to account for the sample design and adjusted for clustering at the school level. Sample size may differ for some outcomes due to nonresponse.

SOURCE: The Social and Character Development (SACD) Research Program. 
Teachers reported on their use of a broad range of teaching materials (table 1.18). The materials most used with SACD activities were teacher guides (used by $65 \%$ of teachers), student materials (used by $50 \%$ ), and children's literature (used by 50\%). Of the seven materials reported on, teachers at treatment schools had three reports of use that statistically significantly differed from teachers in control schools (versus less than one by chance): teacher guides ( $72 \%$ versus $59 \%$ ), instructional aids such as games or videos $(37 \%$ versus $29 \%)$, and other types of materials (11\% versus $16 \%)$. There were no significant differences in the reported use of student materials, children's literature, giveaway materials, or in not using any of these materials.

Teachers reported using a wide variety of instructional strategies (table 1.18). Treatment teachers reported significantly higher use on 5 of the 22 items than control teachers (1 significant difference would have been expected by chance). These included role-playing (73\% versus $59 \%$ ), direct instruction of social and character development $(87 \%$ versus $76 \%$ ), incorporating social and character development into the academic curriculum ( $80 \%$ versus $69 \%$ ), targeted story reading or writing on social and character development themes ( $80 \%$ versus $71 \%$ ), and the average number of strategies used (12.2 versus 11.3$)$. 
Table 1.18. Teacher initial reports on use of SACD materials and classroom strategies

\begin{tabular}{crrr}
\hline SACD material and strategy & Total & Treatment & Control \\
\hline Teacher sample size & 847 & 436 & 411
\end{tabular}

Teachers using the following materials in conjunction with social and character development activities (percent)

Teacher guides (manuals, curricula)

$\begin{array}{lll}65.3 & 71.6^{* *} & 59.1 \\ 50.1 & 53.1 & 47.1 \\ 33.2 & 37.4^{*} & 28.9 \\ 47.2 & 45.3 & 49.1 \\ 50.0 & 53.5 & 46.6 \\ 13.2 & 10.6^{*} & 15.8 \\ 10.1 & 9.1 & 11.1\end{array}$

Teachers using any of the strategies listed below to promote social and character development in the classroom (percent)

99.8

99.6

100.0

Number of strategies (listed below) used by teachers to promote social and character development in the classroom (mean)

Teachers using each of the following strategies to promote social and character development (percent)

Role-playing

Cooperative learning

65.7

$72.5^{* *}$

58.9

Peer group discussions

Direct instruction of social and character development

87.7

90.3

85.1

Skill training

81.6

$87.4^{* *}$

75.9

Incorporating social and character development into academic curriculum

43.1

46.8

39.5

Parent training

74.7

$80.3^{* *}$

69.2

Parent/community involvement in program development or delivery

Mentoring

24.0

Good behavior notes sent home daily or weekly

Presenting role models

Targeted story reading or writing on SACD themes

Peer mediation

Honor roll for positive behavior

Pledges or recitations on social and character development themes

Guided visualization

38.1

38.6

37.6

Student-led/student-assisted instruction

Journaling

Time out for negative behavior

* Treatment group significantly different from control group at the .05 level.

** Treatment group significantly different from control group at the .01 level.

NOTE: Weights, which assign equal weight to each school within each of the programs and to each program across programs, were used in producing the treatment, control, and overall means. Statistical tests were conducted using regressions that included program indicators to account for the sample design and adjusted for clustering at the school level. Sample size may differ for some outcomes due to nonresponse.

SOURCE: The Social and Character Development (SACD) Research Program. 
Principals and teachers reported on participation in and amount of SACD training and staff development provided over the previous 12 months (table 1.19). This period overlapped with the time that treatment schools received training in the SACD programs. Principals reported staff participation rates of 92 percent and a mean of 8.3 hours of training, with no significant difference between treatment and control principals.

On the nine training items asked of teachers, treatment teachers' reports were statistically significantly higher for five of them (versus less than one expected by chance). These included staff participation rates in SACD training over the past 12 months $(86 \%$ for treatment teachers versus $63 \%$ for control teachers), number of training hours received (9.5 versus 6.4), and participation rates in training in specific areas: social and emotional development (39\% versus 17\%), character education (55\% versus $27 \%$ ), and behavior management (42\% versus $32 \%)$.

Table 1.19. Principal and teacher initial reports on SACD professional development

\begin{tabular}{|c|c|c|c|}
\hline SACD professional development & Total & Treatment & Control \\
\hline Principal sample size & 84 & 42 & 42 \\
\hline Teacher sample size & 847 & 436 & 411 \\
\hline $\begin{array}{l}\text { Principals reporting that staff participated in social and character } \\
\text { development training within the past year (percent) }\end{array}$ & 92.0 & 97.5 & 86.2 \\
\hline $\begin{array}{l}\text { Teachers reporting participation in social and character } \\
\text { development training within the past } 12 \text { months (percent) }\end{array}$ & 74.3 & $86.1^{* *}$ & 62.5 \\
\hline $\begin{array}{l}\text { Number of hours of social and character development training } \\
\text { principals report were provided to each staff person last year (mean) }\end{array}$ & 8.3 & 9.4 & 7.1 \\
\hline $\begin{array}{l}\text { Number of hours of social and character development training } \\
\text { teachers report receiving during the past } 12 \text { months (mean) }\end{array}$ & 7.9 & $9.5^{* *}$ & 6.4 \\
\hline $\begin{array}{l}\text { Teachers reporting receiving training in the past } 12 \text { months } \\
\text { in the following areas (percent) }\end{array}$ & & & \\
\hline Violence prevention and peace promotion & 22.6 & 23.8 & 21.5 \\
\hline Social and emotional development & 27.9 & $38.5^{* *}$ & 17.2 \\
\hline Character education & 40.9 & $54.8^{* *}$ & 26.9 \\
\hline Tolerance and diversity & 18.8 & 20.8 & 16.9 \\
\hline Risk prevention and health promotion & 11.3 & 11.5 & 11.1 \\
\hline Civic responsibility and community service & 6.6 & 6.4 & 6.7 \\
\hline Behavior management & 36.8 & $41.6^{*}$ & 32.0 \\
\hline
\end{tabular}

${ }^{*}$ Treatment group significantly different from control group at the .05 level.

** Treatment group significantly different from control group at the .01 level.

NOTE: Weights, which assign equal weight to each school within each of the programs and to each program across programs, were used in producing the treatment, control, and overall means. Statistical tests were conducted using regressions that included program indicators to account for the sample design and adjusted for clustering at the school level. Sample size may differ for some outcomes due to nonresponse.

SOURCE: The Social and Character Development (SACD) Research Program. 
The data on the initial level of SACD activity led to two findings. First, treatment teachers reported greater use of and training in SACD activities than control teachers more often than would be expected by chance. There are two potential causes for this finding, and the analysis cannot be used to determine whether the reason for such a difference was that the two groups did differ on their initial use of SACD activities (i.e., that randomization did not create similar treatment and control groups) or that the training of all treatment teachers and the implementation of six of the programs before the initial data were collected influenced the teacher reports. Because it is likely (though unproven) that the training and implementation affected the teacher reports, these data were not considered appropriate for use as a baseline measure of SACD activities and training in the treatment schools.

Second, these data indicate that the control condition for the SACD project was not a "no treatment" control but a "standard practice" control. Because the control teachers were not affected by the implementation of the SACD programs before data collection, their reports reflect standard practice in the control schools. Standard practice at the control schools included reports of 54 percent to 84 percent of teachers using SACD activities, 89 percent of teachers reporting the use of specific materials in conjunction with these activities, 100 percent reporting the use of at least one of the specified instructional strategies, and 63 percent reporting participation in SACD training over the past 12 months.

\section{Year-by-Year Impacts on Use of Social and Character Development Activities}

Under the first research questions, the SACD programs were expected to increase the use of SACD activities in the treatment schools in comparison to the control schools. Two analyses of this impact were done: one based on teacher reports and the other on principal reports.

\section{Analysis of Teacher Reports}

Every spring, third-, fourth-, and fifth-grade teachers provided information through the Teacher Report on Classroom and School about the social and character development activities they used in their classroom. As described in the Measures section, 83 variables were derived from individual items on the Teacher Report on Classroom and School. These were grouped under six domains and used to determine the difference between treatment and control teachers:

1. The use of SACD activities in their classrooms to promote the six social and character development goals (separately and all together) and behavior management, and the use of such activities for at least 1 hour per week for the same purposes;

2. The use of SACD activities linked to named SACD programs in their classrooms to promote the six social and character development goals (separately and all together), and the use of such activities for at least 1 hour per week for the same purposes;

3. The use of materials and strategies to implement the activities in the classroom;

4. The use of six schoolwide strategies to promote social and character development;

5. The use of staff development to support the teachers; and

6. Staff attitudes toward SACD activities and the use of practices conducive to the development of social and character development.

Teacher Report on Classroom and School consent and completion rates (presented in table 1.9) led to 87 percent to 90 percent of all teachers having data for the 3 years (varying by $1 \%$ to $2 \%$ for treatment versus control teachers). At the program level, the data available ranged from 83 percent to 100 percent of all teachers for the 3 years. 


\section{Chapter 1. The Social and Character Development Multiprogram Evaluation}

To estimate the impacts of the SACD programs for each of the outcome measures, testing the statistical significance of the differences in means between the treatment and the control teachers was used. ${ }^{22}$ Before differences in the means were tested, the data were weighted such that each school received equal weight within a program and each program received equal weight in the combined-program estimates. Standard errors of the impact estimates accounted both for unequal weighting and for the clustering of teachers within schools.

In addition to estimating the impacts of the SACD programs on the individual outcome measures, the impacts on the six domains were also examined. Testing the impact on the domains was done to adjust for the multiple comparisons made within each domain in order to address the increased chances of finding a spurious outcome when more than one test was done. As a result, this section provides two sets of results: (1) the impacts on the individual outcomes unadjusted for multiple comparisons, and (2) the impacts on the domains that serve as the multiple comparison adjustment. ${ }^{23}$

The testing of the significance of the impacts on the domains was based on a set of three heuristics modeled on the approach used by the U.S. Department of Education's What Works Clearinghouse for determining whether domain-level effects are statistically significant when there are multiple outcome measures within a single domain (What Works Clearinghouse n.d.b). Each domain was checked using the three heuristics, and a statistically significant positive impact was found if any of the three were met. ${ }^{24}$ The three heuristics were as follows:

1. Based on the results from the statistical test of each outcome variable within a domain (unadjusted for multiple comparisons), at least half of the impacts were positive and statistically significant and no impact was negative and statistically significant.

2. The omnibus impact for all the outcomes measured together was positive and statistically significant on the basis of a multivariate statistical test. ${ }^{25}$

22 Three factors contributed to the decision to use differences in means. First, because of random assignment, simple treatment-control contrasts provided unbiased estimates of program impacts. Second, only initial values (rather than true baseline values) for these outcomes were available to use in a model because training (at all treatment schools) and program implementation (at 36 treatment schools) began before data collection. The decision to use initial values in an analysis partly depends on whether the initial training and implementation occurring before data collection would be expected to have immediate and large impacts on the outcomes (Schochet 2008b). For this analysis, the outcomes are based on teacher actions and so would likely be upwardly influenced by the teacher training and short period of teacher implementation before pretesting (in contrast to student outcomes, which would be less likely to be so influenced). For this reason a model-based analysis using the initial values as covariates was not chosen. Third, preliminary analyses indicated no gain in precision from the inclusion of other covariates.

${ }^{23}$ When the SACD evaluation was designed, there was no general agreement in the field about how best to adjust for multiple comparisons, and this approach was seen by the SACD Research Consortium as the best method available. For a more recent discussion of the issue, see Schochet 2008a.

${ }^{24}$ For ease of discussion, this section describes detecting positive significant impacts. These heuristics were also used to detect a significant negative impact on a domain.

${ }^{25}$ A multivariate analysis of variance (MANOVA) procedure (Harris 1975) was used. Suppose there are $p$ domain outcomes (the dependent variables), $n$ sample members, and for each dependent variable there is one treatment effect parameter and $k$ parameters for other covariates. The MANOVA model can then be expressed as follows:

$$
Y=T a+X b+e
$$

where $Y$ is a $n \times p$ matrix of domain outcomes, $T$ is an $n \times 1$ vector of treatment indicators, $a$ is a $1 \times p$ parameter vector of treatment effects, $X$ is an $n \times k$ matrix of covariates (a limited set of covariates that included indicator variables for the programs and the intervention) with associated parameter matrix $b$, and $e$ is a $n \times p$ matrix of error terms that accounts for school-level clustering. The omnibus F-test uses the MANOVA model to test the joint null hypothesis of zero treatment effects for each domain outcome (that is, $\mathrm{H}_{0}: a=0$ ). Wilks' lambda was used to assess statistical significance. 
3. After applying the Benjamini-Hochberg (Benjamini and Hochberg 1995) procedure to each outcome under a domain, at least one of the outcomes remained positive and statistically significant and no outcome was negative and statistically significant. The Benjamini-Hochberg procedure adjusts significance levels downward to account for the multiple testing of impacts.

A statistically significant impact on a domain was recognized if one or more of the three heuristics was met. There could be situations in which one or more of the heuristics indicated a statistically significant impact of the intervention on the domain, when the preponderance (or all) of the individual outcomes did not indicate statistically significant impacts. For example, this type of situation might have arisen when a test captured a latent construct underlying the individual outcomes within the domain; the latent construct might have had less statistical noise than did the individual outcomes and thus been more likely to have indicated statistical significance. There also could be situations in which one or more of the individual outcomes showed statistically significant impacts but none of the heuristics showed a significant impact on the domain.

\section{Analysis of Principal Interviews}

Every spring principals were individually interviewed about the prevalence and characteristics of the activities used to promote social and character development along with the percentage of staff trained in them and staff support of their use. As discussed in the Measures section, information from the interviews could be used to determine the difference in reports between treatment and control principals regarding (1) the percentages of schools using activities to address each of the six SACD goals, (2) the delivery methods for these SACD activities, (3) targeting of the activities, (4) teacher professional development, and (5) staff support for the promotion of social and character development.

The interviews had an almost perfect response rate; all principals completed them in Years 1 and 2 and all but one control school principal completed them in Year 3. Because of inconsistencies in the quality of interviewers' recording of answers to the open-ended questions during the spring 2005 interviews, the results from the spring 2005 open-ended data are not included.

The interview data on activity level for the six SACD goals were transformed in two ways: (1) an indicator of whether the school had any activities that addressed each SACD goal was created, and (2) the number of activities in a school that addressed each SACD goal was calculated. Logistic regression was used to determine whether there were differences between treatment and control schools in the likelihood of each implementation measure that was measured through a dichotomous school-level variable. Ordinary least squares regression was used to determine whether there were differences between the treatment and control schools in the number of activities to promote SACD goals within schools. The research team-specific characteristics were controlled for in the model by including indicator variables for each team. An indicator variable of school-level treatment status was included in the model. No other covariates were used in the models because of the small sample size. The What Works Clearinghouse heuristics were not used in this analysis, and the analysis was not done for each individual SACD program because of the small sample sizes.

\section{Results From Teacher Reports}

The SACD programs were expected to increase the use of SACD activities in the classroom and school, broaden the types of materials and instructional strategies used to implement these activities in the classroom and schoolwide, increase the amount of staff development for such activities, and generate positive attitudes and schoolwide practices. Eighty-three outcomes were measured each year for a total of 249 comparisons between treatment and control teachers tested over the 3 years (with 12 to 13 expected to be found statistically significant by chance). The analysis found 127 statistically significant differences in these 249 comparisons, with all showing greater reported use of SACD activities by treatment teachers. Here, the impacts on the outcomes (organized by domain) are described and followed by a discussion of the analysis of the impacts on the domains. 


\section{Chapter 1. The Social and Character Development Multiprogram Evaluation}

\section{Use of Activities and Activities Linked to Named SACD Programs}

Two patterns of findings emerged from a comparison of treatment-control group differences in teacherreported activities to promote social and character development goals in the classroom and the use of behavior management. First, treatment teachers were more likely than control teachers to report implementing these activities in their classrooms and more likely to report conducting these activities for at least 1 hour per week in general and when reporting on activities linked to named SACD programs. Second, control group teachers also reported conducting activities to promote social and character development.

Table 1.20 shows the percentages of teachers who reported activities to promote each of six social and character development goals, the percentages who reported activities to promote any one of the six goals, and the percentages who reported that they used behavior management techniques. Impact estimates (which represent the difference in percentile points between treatment and control teachers who reported positively) are presented for each school year. The table is divided into four panels: (1) engagement in any activity, (2) engagement in any activity for at least an hour per week on average, (3) engagement in any activity as part of a named program, and (4) engagement in any activity as part of a named program for at least an hour a week.

Measuring teacher activity in these diverse ways contributes to an understanding of all activities that a teacher considered as promoting one of the six social and character development goals, distinguishes between activities that were conducted intensively (defined as at least 1 hour per week) ${ }^{26}$ from those that might have been done only occasionally, and distinguishes between activities that were conducted as part of a named program and activities that might have been less structured and had less institutional support.

The first pattern of a larger percentage of treatment teachers than control teachers reporting engagement in SACD activities can be seen throughout table 1.20. In regard to teachers' reported use of SACD activities (panels 1 and 2), 48 comparisons were made over the 3 years, with 3 expected to be significant by chance. A significantly greater percentage of treatment teachers reported using SACD activities than control teachers in 31 of these 48 comparisons. In regard to teachers' reported use of SACD activities linked to named SACD programs (panels 3 and 4), 42 comparisons were made over the 3 years with 2 expected to be significant by chance. A significantly greater percentage of treatment teachers reported using the SACD activities in 39 of these 42 comparisons. In all 3 years, the percentages of treatment teachers reporting engagement in SACD activities were statistically significantly greater than for control teachers in regard to promoting any of the SACD goals and promoting four of the six individual SACD goals (violence prevention and peace promotion, social and emotional development, character education, and tolerance and diversity). For example, when looking at activities to support any SACD goal, the statistically significant difference favoring treatment teachers ranged from 5 to 10 percentage points for engagement in any activities (panel 1, Any SACD goal), 7 to 24 percentage points for engagement in any activity for at least an hour per week (panel 2, Any SACD goal), 29 to 34 percentage points for engagement in any activity linked to a named SACD program (panel 3, Any SACD goal), and 26 to 34 percentage points for engagement in any activity linked to a named SACD program for at least an hour per week (panel 4, Any SACD goal).

The second pattern of control teachers reporting engagement in SACD activities is most obvious in panel 1 (Any SACD goal), which shows that 86 percent to 90 percent of control teachers reported engaging in SACD activities to promote any SACD goal (and more than 50 percent reported engaging in SACD activities to promote each of the six individual SACD goals). More than half of the control teachers reported engaging in such activities for at least an hour a week (52\% to 76\%: panel 2, Any SACD goal) and 36 percent to 43 percent reported engaging in any activity linked to a named SACD program to promote any SACD goal (panel 3, Any SACD goal).

\footnotetext{
${ }^{26}$ Intensity was defined as being for at least 1 hour per week because this was about the amount of time that the SACD programs being evaluated considered desirable as part of their models.
} 
Table 1.20. Impacts on teacher-reported SACD classroom activities

Panel 1: Engagement in any activities to promote SACD goals

\begin{tabular}{|c|c|c|c|c|c|c|c|c|c|c|c|c|}
\hline \multirow[b]{2}{*}{ SACD activity } & \multicolumn{4}{|c|}{$\begin{array}{c}\text { Year } 1 \\
\text { (Spring 3rd grade) }\end{array}$} & \multicolumn{4}{|c|}{$\begin{array}{c}\text { Year 2 } \\
\text { (Spring 4th grade) }\end{array}$} & \multicolumn{4}{|c|}{$\begin{array}{c}\text { Year } 3 \\
\text { (Spring 5th grade) }\end{array}$} \\
\hline & $\begin{array}{r}\text { Treat- } \\
\text { ment }\end{array}$ & Control & Impact & $p$-value & $\begin{array}{r}\text { Treat- } \\
\text { ment }\end{array}$ & Control & Impact & $p$-value & $\begin{array}{r}\text { Treat- } \\
\text { ment }\end{array}$ & Control & Impact & $p$-value \\
\hline Teacher sample size & 441 & 409 & & & 425 & 404 & & & 425 & 396 & & \\
\hline Violence prevention and peace promotion (percent) & $76.7^{*}$ & 64.7 & 12.0 & 0.005 & $76.1^{*}$ & 64.3 & 11.8 & 0.002 & $76.9^{*}$ & 63.0 & 13.9 & 0.001 \\
\hline Social and emotional development (percent) & $81.3^{*}$ & 64.2 & 17.1 & 0.000 & $84.4^{*}$ & 60.4 & 24.0 & 0.000 & $81.1^{*}$ & 62.5 & 18.6 & 0.000 \\
\hline Character education (percent) & $92.3^{*}$ & 79.3 & 13.0 & 0.000 & $92.3^{*}$ & 75.7 & 16.6 & 0.000 & $86.8^{*}$ & 72.6 & 14.2 & 0.000 \\
\hline Tolerance and diversity (percent) & $75.7^{*}$ & 62.1 & 13.6 & 0.001 & $75.7^{*}$ & 59.8 & 15.9 & 0.000 & $73.8^{*}$ & 57.4 & 16.4 & 0.000 \\
\hline Risk prevention and health promotion (percent) & 60.9 & 62.2 & -1.3 & 0.795 & 63.5 & 61.9 & 1.6 & 0.744 & 63.7 & 62.3 & 1.4 & 0.778 \\
\hline Civic responsibility and community service (percent) & 63.4 & 61.7 & 1.7 & 0.687 & 60.2 & 58.4 & 1.8 & 0.669 & 60.3 & 59.1 & 1.2 & 0.795 \\
\hline Any SACD goal (percent) & $95.3^{*}$ & 88.2 & 7.1 & 0.006 & $95.4^{*}$ & 90.3 & 5.1 & 0.007 & $95.5^{*}$ & 86.0 & 9.5 & 0.000 \\
\hline Behavior management (percent) & 88.5 & 85.6 & 2.9 & 0.285 & $92.3^{*}$ & 82.1 & 10.2 & 0.000 & 85.0 & 82.4 & 2.6 & 0.389 \\
\hline
\end{tabular}

\begin{tabular}{|c|c|c|c|c|c|c|c|c|c|c|c|c|}
\hline \multirow[b]{2}{*}{ SACD activity } & \multicolumn{4}{|c|}{$\begin{array}{c}\text { Year } 1 \\
\text { (Spring 3rd grade) }\end{array}$} & \multicolumn{4}{|c|}{$\begin{array}{c}\text { Year } 2 \\
\text { (Spring 4th grade) }\end{array}$} & \multicolumn{4}{|c|}{$\begin{array}{c}\text { Year } 3 \\
\text { (Spring 5th grade) }\end{array}$} \\
\hline & $\begin{array}{r}\text { Treat- } \\
\text { ment }\end{array}$ & Control & Impact & $p$-value & $\begin{array}{r}\text { Treat- } \\
\text { ment }\end{array}$ & Control & Impact & $p$-value & $\begin{array}{r}\text { Treat- } \\
\text { ment }\end{array}$ & Control & Impact & $p$-value \\
\hline Teacher sample size & 441 & 409 & & & 425 & 404 & & & 425 & 396 & & \\
\hline Violence prevention and peace promotion (percent) & $39.4^{*}$ & 21.9 & 17.5 & 0.000 & $41.9^{*}$ & 24.9 & 17.0 & 0.000 & $38.0^{*}$ & 24.2 & 13.8 & 0.002 \\
\hline Social and emotional development (percent) & $46.9^{*}$ & 23.4 & 23.5 & 0.000 & $49.5^{*}$ & 24.7 & 24.8 & 0.000 & $42.6^{*}$ & 25.9 & 16.7 & 0.000 \\
\hline Character education (percent) & $60.9^{*}$ & 31.3 & 29.5 & 0.000 & $60.4^{*}$ & 30.6 & 29.8 & 0.000 & $50.2^{*}$ & 30.5 & 19.7 & 0.000 \\
\hline Tolerance and diversity (percent) & $36.7^{*}$ & 21.3 & 15.4 & 0.000 & $36.0^{*}$ & 23.1 & 12.9 & 0.001 & $32.8^{*}$ & 18.4 & 14.4 & 0.000 \\
\hline Risk prevention and health promotion (percent) & 25.9 & 20.5 & 5.4 & 0.138 & 28.0 & 24.1 & 3.9 & 0.293 & 24.5 & 22.8 & 1.8 & 0.657 \\
\hline Civic responsibility and community service (percent) & 18.8 & 14.7 & 4.0 & 0.179 & 19.7 & 16.1 & 3.6 & 0.252 & $20.6^{\wedge}$ & 14.6 & 6.0 & 0.087 \\
\hline Any SACD goal (percent) & $75.2^{*}$ & 51.7 & 23.5 & 0.000 & $83.7^{*}$ & 72.6 & 11.1 & 0.003 & $83.0^{*}$ & 76.0 & 7.0 & 0.037 \\
\hline Behavior management (percent) & 68.7 & 66.2 & 2.5 & 0.666 & $75.0^{*}$ & 58.9 & 16.1 & 0.001 & 68.6 & 64.9 & 3.7 & 0.377 \\
\hline
\end{tabular}


Table 1.20. Impacts on teacher-reported SACD classroom activities-Continued

Panel 3: Engagement in activities to promote SACD goals linked to named SACD programs

\begin{tabular}{|c|c|c|c|c|c|c|c|c|c|c|c|c|}
\hline \multirow[b]{2}{*}{ SACD activity } & \multicolumn{4}{|c|}{$\begin{array}{c}\text { Year } 1 \\
\text { (Spring 3rd grade) }\end{array}$} & \multicolumn{4}{|c|}{$\begin{array}{c}\text { Year } 2 \\
\text { (Spring 4th grade) }\end{array}$} & \multicolumn{4}{|c|}{$\begin{array}{c}\text { Year 3 } \\
\text { (Spring 5th grade) }\end{array}$} \\
\hline & $\begin{array}{c}\text { Treat- } \\
\text { ment }\end{array}$ & Control & Impact & $p$-value & $\begin{array}{c}\text { Treat- } \\
\text { ment }\end{array}$ & Control & Impact & $p$-value & $\begin{array}{c}\text { Treat- } \\
\text { ment }\end{array}$ & Control & Impact & $p$-value \\
\hline Teacher sample size & 441 & 409 & & & 425 & 404 & & & 425 & 396 & & \\
\hline Violence prevention and peace promotion (percent) & $42.0^{*}$ & 17.0 & 25.0 & 0.000 & $48.1^{*}$ & 17.3 & 30.8 & 0.000 & $48.0^{*}$ & 17.4 & 30.6 & 0.000 \\
\hline Social and emotional development (percent) & $48.9^{*}$ & 8.3 & 40.7 & 0.000 & $54.8^{*}$ & 11.2 & 43.6 & 0.000 & $48.8^{*}$ & 13.0 & 35.7 & 0.000 \\
\hline Character education (percent) & $54.4^{*}$ & 15.5 & 38.8 & 0.000 & $58.8^{*}$ & 13.4 & 45.4 & 0.000 & $49.4^{*}$ & 13.3 & 36.1 & 0.000 \\
\hline Tolerance and diversity (percent) & $34.3^{*}$ & 6.2 & 28.2 & 0.000 & $37.6^{*}$ & 7.2 & 30.4 & 0.000 & $33.4^{*}$ & 5.8 & 27.7 & 0.000 \\
\hline Risk prevention and health promotion (percent) & 27.7 & 21.7 & 6.0 & 0.151 & $31.3^{*}$ & 21.7 & 9.6 & 0.013 & $28.5^{*}$ & 20.1 & 8.4 & 0.048 \\
\hline Civic responsibility and community service (percent) & $\ddagger^{*}$ & $\ddagger$ & 4.4 & 0.009 & $13.3^{*}$ & 4.7 & 8.6 & 0.000 & $13.5^{*}$ & 7.2 & 6.4 & 0.021 \\
\hline Any SACD goal (percent) & $70.0^{*}$ & 36.3 & 33.6 & 0.000 & $72.4^{*}$ & 42.6 & 29.8 & 0.000 & $68.4^{*}$ & 39.7 & 28.7 & 0.000 \\
\hline
\end{tabular}

Panel 4: Engagement in activities to promote SACD goals linked to named SACD programs for at least 1 hour per week

\begin{tabular}{|c|c|c|c|c|c|c|c|c|c|c|c|c|}
\hline \multirow[b]{2}{*}{ SACD activity } & \multicolumn{4}{|c|}{$\begin{array}{c}\text { Year 1 } \\
\text { (Spring 3rd grade) }\end{array}$} & \multicolumn{4}{|c|}{$\begin{array}{c}\text { Year 2 } \\
\text { (Spring 4th grade) }\end{array}$} & \multicolumn{4}{|c|}{$\begin{array}{c}\text { Year } 3 \\
\text { (Spring 5th grade) } \\
\end{array}$} \\
\hline & $\begin{array}{c}\text { Treat- } \\
\text { ment }\end{array}$ & Control & Impact & $p$-value & $\begin{array}{r}\text { Treat- } \\
\text { ment }\end{array}$ & Control & Impact & $p$-value & $\begin{array}{r}\text { Treat- } \\
\text { ment }\end{array}$ & Control & Impact & $p$-value \\
\hline Teacher sample size & 441 & 409 & & & 425 & 404 & & & 425 & 396 & & \\
\hline Violence prevention and peace promotion (percent) & $29.4^{*}$ & 8.5 & 20.9 & 0.000 & $31.5^{*}$ & 11.2 & 20.3 & 0.000 & $29.2^{*}$ & 10.1 & 19.1 & 0.000 \\
\hline Social and emotional development & $34.6^{*}$ & 4.0 & 30.7 & 0.000 & $36.9^{*}$ & 6.3 & 30.6 & 0.000 & $30.0^{*}$ & 6.9 & 23.1 & 0.000 \\
\hline Character education (percent) & $41.3^{*}$ & 6.3 & 35.0 & 0.000 & $43.3^{*}$ & 6.7 & 36.5 & 0.000 & $33.2^{*}$ & 7.0 & 26.2 & 0.000 \\
\hline Tolerance and diversity (percent) & $22.8^{*}$ & 1.4 & 21.3 & 0.000 & $24.1^{*}$ & 3.4 & 20.7 & 0.000 & $22.0^{*}$ & 2.7 & 19.3 & 0.000 \\
\hline Risk prevention and health promotion (percent) & 15.8 & 11.2 & 4.6 & 0.132 & 18.4 & 13.9 & 4.5 & 0.197 & $15.8^{*}$ & 9.3 & 6.5 & 0.043 \\
\hline Civic responsibility and community service (percent) & $\ddagger^{*}$ & $\ddagger$ & 3.5 & 0.021 & $7.6^{*}$ & 1.5 & 6.1 & 0.010 & $8.1^{*}$ & 1.3 & 6.8 & 0.024 \\
\hline Any SACD goal (percent) & $52.7^{*}$ & 18.6 & 34.1 & 0.000 & $51.8^{*}$ & 23.4 & 28.5 & 0.000 & $46.0^{*}$ & 19.6 & 26.3 & 0.000 \\
\hline
\end{tabular}

Any SACD goal (percent)

$527^{*} \quad 18.6 \quad 34.1 \quad 0.000$

$518^{*} \quad 23.4 \quad 28.5 \quad 0.000$

$46.0^{*} \quad 19.6 \quad 26.3 \quad 0.000$

$¥$ Reporting standards not met. Value suppressed to protect confidentiality.

* Treatment group significantly different from control group at the .05 level.

$\wedge$ Treatment group significantly different from control group at the .10 to $>.05$ level.

NOTE: Impact is the percentile point difference between treatment and control groups. Weights, which assign equal weight to each school within each of the programs and to each program across programs, were used in producing the treatment, control, and overall means.

SOURCE: The Social and Character Development (SACD) Research Program. 


\section{Use of Materials and Strategies}

The SACD programs had a statistically significant positive effect on teacher-reported use of specific materials and classroom strategies to promote social and character development (table 1.21). Over the 3 years, 87 comparisons were made between treatment and control teacher use of materials and strategies, with 4 expected to be significant by chance. A significantly greater percentage of treatment teachers reported using these materials and strategies to support SACD goals in 40 of these comparisons. Treatment teachers were significantly more likely than control teachers to report use of four of the five specific materials asked about in at least 2 of the 3 years. In all years, treatment teachers were significantly more likely than control teachers to report using teacher guides (by 22 to 24 percentage points) and children's literature (by 9 to 15 percentage points). In Years 2 and 3, treatment teachers were significantly more likely to report using student materials and instructional aids (by 10 to 12 percentage points). In addition, treatment teachers were significantly less likely to report not using any of these materials (by 7 to 10 percentage points) in all years. Control teachers reported rates of usage of materials from 36 percent for instructional aids to 60 percent for teacher guides, and they reported higher rates for not using any of the materials (13\% to $14 \%)$.

Of the 20 teaching strategies asked about, 13 strategies were reported as being used by a statistically significant greater percentage of treatment teachers ( 2 to 22 percentage points more) for at least one of the years, and no strategy was reported as being used by a significantly greater percentage of control teachers. Treatment teachers reported using, on average, one more strategy than control teachers, and this was a significant difference. 
Table 1.21. Impacts on use of SACD classroom materials and teaching strategies

\begin{tabular}{|c|c|c|c|c|c|c|c|c|c|c|c|c|}
\hline \multirow[b]{2}{*}{ SACD material and teaching strategy } & \multicolumn{4}{|c|}{$\begin{array}{c}\text { Year } 1 \\
\text { (Spring 3rd grade) }\end{array}$} & \multicolumn{4}{|c|}{$\begin{array}{c}\text { Year } 2 \\
\text { (Spring 4th grade) }\end{array}$} & \multicolumn{4}{|c|}{$\begin{array}{c}\text { Year } 3 \\
\text { (Spring 5th grade) }\end{array}$} \\
\hline & $\begin{array}{c}\text { Treat- } \\
\text { ment }\end{array}$ & Control & Impact & $p$-value & $\begin{array}{c}\text { Treat- } \\
\text { ment }\end{array}$ & Control & Impact & $p$-value & $\begin{array}{c}\text { Treat- } \\
\text { ment }\end{array}$ & Control & Impact & $p$-value \\
\hline Teacher sample size & 441 & 409 & & & 425 & 404 & & & 425 & 396 & & \\
\hline \multicolumn{13}{|l|}{ Use of SACD materials (percent) } \\
\hline Teacher guides (manuals, curricula) & $82.4^{*}$ & 58.1 & 24.2 & 0.000 & $82.3^{*}$ & 60.4 & 21.8 & 0.000 & $79.9^{*}$ & 58.0 & 21.9 & 0.000 \\
\hline Student materials (workbooks or sheets) & 61.3 & 57.0 & 4.3 & 0.289 & $68.3^{*}$ & 56.1 & 12.2 & 0.002 & $66.2^{*}$ & 55.2 & 11.0 & 0.002 \\
\hline Instructional aids (games, software, videos) & 43.9 & 39.1 & 4.9 & 0.294 & $46.3^{*}$ & 36.7 & 9.6 & 0.017 & $47.6^{*}$ & 35.7 & 11.9 & 0.001 \\
\hline Giveaways (bookmarks, stickers) & 52.2 & 54.2 & -1.9 & 0.688 & 52.9 & 47.3 & 5.6 & 0.157 & 49.9 & 52.6 & -2.7 & 0.485 \\
\hline Children's literature & $60.7^{*}$ & 46.2 & 14.6 & 0.002 & $60.4^{*}$ & 46.5 & 13.9 & 0.002 & $53.4^{*}$ & 44.6 & 8.8 & 0.013 \\
\hline Other types of materials & 8.2 & 8.5 & -0.4 & 0.854 & 9.1 & 12.2 & -3.1 & 0.201 & 9.0 & 6.9 & 2.1 & 0.360 \\
\hline Did not use any of these materials & $3.8^{*}$ & 14.2 & -10.4 & 0.001 & $4.3^{*}$ & 13.5 & -9.2 & 0.000 & $6.3^{*}$ & 13.1 & -6.7 & 0.003 \\
\hline \multicolumn{13}{|l|}{ Use of teaching strategies (percent) } \\
\hline Role-playing & $85.5^{*}$ & 65.2 & 20.3 & 0.000 & $86.6^{*}$ & 65.1 & 21.5 & 0.000 & $87.1^{*}$ & 80.0 & 7.1 & 0.028 \\
\hline Cooperative learning & 96.3 & 96.1 & 0.2 & 0.883 & 98.0 & 96.8 & 1.3 & 0.250 & $99.8^{*}$ & 97.7 & 2.1 & 0.022 \\
\hline Peer group discussions & $92.9^{*}$ & 87.7 & 5.2 & 0.011 & $92.5^{\wedge}$ & 88.2 & 4.3 & 0.060 & $97.5^{\wedge}$ & 95.1 & 2.4 & 0.096 \\
\hline Direct instruction of SACD & $91.8^{*}$ & 78.8 & 13.0 & 0.000 & $93.6^{*}$ & 75.9 & 17.6 & 0.000 & $97.1^{*}$ & 87.9 & 9.2 & 0.000 \\
\hline Skill training & $63.0^{*}$ & 43.2 & 19.8 & 0.000 & $62.9^{*}$ & 40.5 & 22.4 & 0.000 & $82.1^{*}$ & 75.5 & 6.6 & 0.037 \\
\hline Incorporating SACD into academic curriculum & $86.5^{\star}$ & 73.6 & 12.9 & 0.000 & $85.3^{*}$ & 71.3 & 14.0 & 0.000 & 92.9 & 90.3 & 2.5 & 0.225 \\
\hline Parent training & 8.1 & 8.9 & -0.8 & 0.702 & 8.6 & 7.2 & 1.4 & 0.531 & $30.8^{*}$ & 21.5 & 9.3 & 0.016 \\
\hline Parent/community involvement & 22.9 & 27.0 & -4.1 & 0.237 & $26.5^{\wedge}$ & 19.8 & 6.7 & 0.087 & $48.3^{*}$ & 39.7 & 8.6 & 0.022 \\
\hline Mentoring & 44.8 & 44.5 & 0.3 & 0.909 & 43.8 & 43.1 & 0.7 & 0.821 & $68.1^{*}$ & 58.3 & 9.8 & 0.016 \\
\hline Good behavior notes sent home daily or weekly & 75.8 & 72.5 & 3.3 & 0.409 & 78.2 & 71.9 & 6.3 & 0.108 & 91.7 & 89.5 & 2.1 & 0.270 \\
\hline Presenting role models & 76.4 & 73.3 & 3.1 & 0.335 & $75.7^{*}$ & 68.4 & 7.2 & 0.026 & 85.3 & 81.6 & 3.7 & 0.175 \\
\hline
\end{tabular}

See notes at end of table. 
Table 1.21. Impacts on use of SACD classroom materials and teaching strategies-Continued

\begin{tabular}{|c|c|c|c|c|c|c|c|c|c|c|c|c|}
\hline \multirow[b]{2}{*}{ SACD material and teaching strategy } & \multicolumn{4}{|c|}{$\begin{array}{c}\text { Year } 1 \\
\text { (Spring 3rd grade) }\end{array}$} & \multicolumn{4}{|c|}{$\begin{array}{c}\text { Year } 2 \\
\text { (Spring 4th grade) }\end{array}$} & \multicolumn{4}{|c|}{$\begin{array}{c}\text { Year } 3 \\
\text { (Spring 5th grade) }\end{array}$} \\
\hline & $\begin{array}{c}\text { Treat- } \\
\text { ment }\end{array}$ & Control & Impact & $p$-value & $\begin{array}{r}\text { Treat- } \\
\text { ment }\end{array}$ & Control & Impact & $p$-value & $\begin{array}{c}\text { Treat- } \\
\text { ment }\end{array}$ & Control & Impact & $p$-value \\
\hline \multicolumn{13}{|l|}{ Use of teaching strategies-Continued (percent) } \\
\hline $\begin{array}{l}\text { Targeted story reading or writing on socia } \\
\text { and character development themes }\end{array}$ & $88.2^{*}$ & 75.9 & 12.3 & 0.000 & $88.2^{*}$ & 78.0 & 10.2 & 0.000 & 93.6 & 90.6 & 3.0 & 0.125 \\
\hline Peer mediation & 51.2 & 45.8 & 5.4 & 0.205 & 54.4 & 48.5 & 6.0 & 0.190 & 68.8 & 65.0 & 3.8 & 0.337 \\
\hline Honor roll for positive behavior & 55.1 & 57.9 & -2.9 & 0.569 & 59.8 & 57.2 & 2.6 & 0.585 & 73.6 & 68.3 & 5.3 & 0.235 \\
\hline $\begin{array}{l}\text { Pledges or recitations on social and } \\
\text { character development themes }\end{array}$ & 41.3 & 42.8 & -1.4 & 0.802 & 43.4 & 44.6 & -1.2 & 0.849 & 57.3 & 59.1 & -1.8 & 0.721 \\
\hline Guided visualization & $60.9^{*}$ & 45.7 & 15.2 & 0.000 & $60.5^{*}$ & 47.3 & 13.2 & 0.003 & $70.8^{*}$ & 59.0 & 11.9 & 0.001 \\
\hline Student-led/student-assisted instruction & $56.0^{\wedge}$ & 49.8 & 6.2 & 0.094 & $57.3^{*}$ & 49.0 & 8.3 & 0.028 & 75.9 & 70.3 & 5.6 & 0.113 \\
\hline Journaling & 77.7 & 72.3 & 5.5 & 0.138 & 76.8 & 71.4 & 5.4 & 0.149 & $87.1^{\wedge}$ & 82.1 & 5.0 & 0.093 \\
\hline Time out for negative behavior & 86.2 & 85.3 & 0.8 & 0.803 & 85.5 & 83.0 & 2.4 & 0.349 & $94.1^{*}$ & 89.0 & 5.1 & 0.040 \\
\hline Daily or weekly rewards for positive & & & & & & & & & & & & \\
\hline behavior & $91.0^{\wedge}$ & 86.8 & 4.1 & 0.098 & 92.1 & 89.7 & 2.4 & 0.307 & $98.2^{\wedge}$ & 96.0 & 2.2 & 0.092 \\
\hline Any strategy & 100.0 & 99.7 & 0.3 & $\dagger$ & 100.0 & 100.0 & 0.0 & $\dagger$ & 99.8 & 99.4 & 0.4 & 0.429 \\
\hline Number of strategies (mean) & $13.4^{*}$ & 12.3 & 1.1 & 0.000 & $13.6^{*}$ & 12.1 & 1.5 & 0.000 & $15.7^{*}$ & 14.6 & 1.1 & 0.000 \\
\hline
\end{tabular}

\begin{tabular}{l} 
Number of strategies (mean) $13.4^{*} 12.3$ \\
\hline Not applicable. \\
${ }^{*}$ Treatment group significantly different from control group at the .05 level. \\
$\wedge$ Treatment group significantly different from control group at the .10 to $>.05$ level.
\end{tabular}

NOTE: Weights, which assign equal weight to each school within each of the programs and to each program across programs, were used in producing the treatment, control, and overall means.

SOURCE: The Social and Character Development (SACD) Research Program. 


\section{Use of Schoolwide Strategies}

The SACD programs did not have an impact on the reported use of schoolwide strategies for supporting social and character development. Teachers were asked to report on the use of six schoolwide strategies to promote social and character development. including morning announcements or videos, assemblies, newspapers or bulletins, special school days, special events, and other activities. Over the 3 years, 18 comparisons were made, with 1 expected to be significant by chance. The SACD programs did not have a statistically significant effect on the use of any of these schoolwide strategies (these data are not shown in a table).

\section{Participation in Professional Development}

The SACD programs had a statistically significant positive effect on teachers' reports of participation in professional development for activities related to social and character development. Over the 3 years, 27 comparisons were made, with 1 expected to be significant by chance. A significantly greater percentage of treatment teachers reported such professional development in 13 of the comparisons (table 1.22). The percentage difference in treatment and control teacher reports on receiving SACD training in the previous 12 months ranged from 32 percentage points in Year 1 to 9 percentage points in Year 3. Mirroring the decline in effect over time, only in Year 1 was there a significant impact on the number of hours of professional development received ( 9 hours versus 4 hours). The significance of the impacts on percentages of teachers receiving training to help meet each of the six SACD goals varied by year: impacts were significant for four goals in Year 1, one goal in Year 2, and three goals in Year 3, with the differences ranging from 7 to 34 percentage points. In Year 1, there was a significant difference in reports on behavior management training (11 percentage points). 
Table 1.22. Impacts on teacher-reported SACD professional development

\begin{tabular}{|c|c|c|c|c|c|c|c|c|c|c|c|c|}
\hline \multirow[b]{2}{*}{ SACD professional development } & \multicolumn{4}{|c|}{$\begin{array}{c}\text { Year } 1 \\
\text { (Spring 3rd grade) }\end{array}$} & \multicolumn{4}{|c|}{$\begin{array}{c}\text { Year } 2 \\
\text { (Spring 4th grade) }\end{array}$} & \multicolumn{4}{|c|}{$\begin{array}{c}\text { Year } 3 \\
\text { (Spring 5th grade) }\end{array}$} \\
\hline & $\begin{array}{c}\text { Treat- } \\
\text { ment }\end{array}$ & Control & Impact & $p$-value & $\begin{array}{l}\text { Treat- } \\
\text { ment }\end{array}$ & Control & Impact & $p$-value & $\begin{array}{c}\text { Treat- } \\
\text { ment }\end{array}$ & Control & Impact & $p$-value \\
\hline Teacher sample size & 441 & 409 & & & 425 & 404 & & & 425 & 396 & & \\
\hline SACD training in past 12 months (percent) & $85.6^{*}$ & 53.8 & 31.8 & 0.000 & $64.1^{*}$ & 52.4 & 11.7 & 0.003 & $56.6^{*}$ & 47.3 & 9.3 & 0.027 \\
\hline Hours of SACD training (mean) & $9.1^{*}$ & 4.3 & 4.9 & 0.000 & 5.3 & 4.8 & 0.6 & 0.580 & 4.5 & 3.7 & 0.8 & 0.196 \\
\hline \multicolumn{13}{|l|}{ Training by goal (percent) } \\
\hline Violence prevention and peace promotion & $26.9^{*}$ & 17.3 & 9.6 & 0.009 & 18.2 & 14.3 & 3.9 & 0.241 & $17.8^{*}$ & 10.0 & 7.8 & 0.012 \\
\hline Social and emotional development & $36.3^{*}$ & 19.4 & 17.0 & 0.000 & 22.6 & 18.0 & 4.6 & 0.209 & $18.2^{*}$ & 11.2 & 7.0 & 0.044 \\
\hline Character education & $60.9^{*}$ & 26.7 & 34.2 & 0.000 & $36.2^{*}$ & 19.3 & 16.9 & 0.000 & $28.0^{*}$ & 14.8 & 13.2 & 0.001 \\
\hline Tolerance and diversity & $21.0^{*}$ & 12.3 & 8.7 & 0.017 & 16.8 & 19.0 & -2.2 & 0.486 & 16.8 & 15.5 & 1.3 & 0.741 \\
\hline Risk prevention and health promotion & 13.3 & 14.3 & -1.0 & 0.738 & 13.6 & 14.8 & -1.2 & 0.707 & 14.4 & 12.0 & 2.4 & 0.404 \\
\hline Civic responsibility and community service & 9.8 & 7.0 & 2.7 & 0.221 & 7.5 & 4.8 & 2.7 & 0.130 & 3.9 & 4.8 & -0.9 & 0.562 \\
\hline Behavior management & $36.4^{*}$ & 25.0 & 11.4 & 0.023 & 26.7 & 25.6 & 1.1 & 0.784 & 23.5 & 21.4 & 2.1 & 0.613 \\
\hline
\end{tabular}

* Treatment group significantly different from control group at the .05 level.

NOTE: Weights, which assign equal weight to each school within each of the programs and to each program across programs, were used in producing the treatment, control, and overall means.

SOURCE: The Social and Character Development (SACD) Research Program. 


\section{Attitudes and Practices}

The SACD programs had a statistically significant positive effect on teachers' reports on the use of six practices $^{27}$ considered conducive to the social and character development of students but not on teacher attitudes toward social and character development. Twenty-seven comparisons were made over the 3 years, with 1 expected to be found significant by chance. A significantly greater percentage of treatment teachers reported that these practices were being used in 4 of these comparisons (these data are not shown in a table). In all 3 years, a significantly larger percentage of treatment teachers reported students having a voice in school governance $(9 \%$ to $10 \%$ versus $4 \%$ to $5 \%$ of control teachers). In Year 3, treatment teachers reported significantly greater use of discipline for promoting development (57\% versus $47 \%$ of control teachers).

There were no statistically significant estimated impacts on teachers' enthusiasm for SACD efforts in their schools in any of the years (these data are not shown in a table). For the 3 years, between 67 percent and 71 percent of treatment and control teachers reported that they were enthusiastic about their schools' efforts to promote social and character development and another 27 percent to 31 percent reported being cooperative (but not enthusiastic). Fewer than 2 percent reported an open dislike of the SACD efforts in their schools.

\section{Domain Results}

As discussed in the Analysis section, a set of heuristics was applied to determine whether the six outcome domains were statistically significant after adjustments were made for the multiple tests performed under each domain. These heuristics were applied to both the combined-program data and to each individual program's data. Table 1.23 shows the statistically significant impacts on the use of SACD activities by domain for all seven programs combined and for each program. In table 1.23, a plus sign stands for a significant positive impact on the domain, and numeral superscripts show which heuristics identified the domain as significant. For all seven programs combined, a significant positive impact was found for each of the 3 years on the reports of use of any SACD activities, the use of SACD activities linked to named SACD programs, the use of classroom materials and teaching strategies, and professional development.

Table 1.23 also shows the impacts on domain by individual program. In all cases, when a program's impact was significant it was also positive. Five of the programs had at least 2 years of significant impacts on teachers' reported use of activities, as did six programs for teachers' use of activities linked to named SACD programs. Two programs had at least 2 years of significant impacts on reported use of classroom materials and strategies. No programs showed impacts on reported use of schoolwide strategies or on attitudes and practices in at least 2 years. One program showed 2 years of impacts on reported professional development.

\section{Results From Principal Interviews}

The principal interviews in 2005, 28 2006, and 2007 echoed the findings from the teacher survey that there was a high usage of SACD activities in both the treatment and control schools (these data are not shown in a table). Over the years, 88 percent to 100 percent of treatment principals and 71 percent to 98 percent of control principals reported that their schools used SACD activities to promote each of the six SACD goals. Classroom teachers were reported as having a major role in delivering SACD activities by 91 percent to 98 percent of treatment school principals and 64 percent to 90 percent of control school principals. SACD activities were being provided universally to all students rather than to targeted populations, as reported by 98

\footnotetext{
27 These included teacher modeling of positive character and behavior with students, similar modeling with other staff, involvement of students in discussions, students having a voice in governance, school encouragement of parent involvement, and discipline practices that included promoting development.

28 Only the results from the closed-ended items are reported for Year 1 because of problems with inter-rater reliability regarding the open-ended items. Results from both the closed- and open-ended items are reported for Years 2 and 3.
} 
Chapter 1. The Social and Character Development Multiprogram Evaluation

Table 1.23. Significant impacts on use of SACD activity domains, overall and by program

\begin{tabular}{|c|c|c|c|c|c|c|}
\hline \multirow[b]{2}{*}{ Program } & \multicolumn{6}{|c|}{ SACD activity domain } \\
\hline & $\begin{array}{r}\text { Any SACD } \\
\text { activities }\end{array}$ & $\begin{array}{l}\text { Named } \\
\text { SACD } \\
\text { program } \\
\text { activities }\end{array}$ & $\begin{array}{r}\text { Classroom } \\
\text { materials } \\
\text { and } \\
\text { strategies } \\
\end{array}$ & $\begin{array}{r}\text { Schoolwide } \\
\text { strategies }\end{array}$ & $\begin{array}{r}\text { Professional } \\
\text { development }\end{array}$ & $\begin{array}{r}\text { Attitudes } \\
\text { and } \\
\text { practices } \\
\end{array}$ \\
\hline \multicolumn{7}{|l|}{ Overall } \\
\hline Year 1 & $+^{1,2,3}$ & $++^{1,2,3}$ & $++^{2,3}$ & & $++^{1,2,3}$ & \\
\hline Year 2 & $+^{1,2,3}$ & $+^{1,2,3}$ & $+^{1,2,3}$ & & $t^{2,3}$ & \\
\hline Year 3 & $+^{1,2,3}$ & $+^{1,2,3}$ & $+^{1,2,3}$ & & $+^{2,3}$ & \\
\hline \multicolumn{7}{|l|}{$\mathrm{ABC}$} \\
\hline Year 1 & $+^{2}$ & & & +1 & & \\
\hline Year 2 & & & & & & \\
\hline Year 3 & & & & & & $+^{3}$ \\
\hline \multicolumn{7}{|l|}{ CSP } \\
\hline Year 1 & $+^{2}$ & $+^{1,3}$ & & & $t^{3}$ & \\
\hline Year 2 & & $+^{3}$ & & & & \\
\hline Year 3 & & $+^{3}$ & & & & \\
\hline \multicolumn{7}{|l|}{ LBW } \\
\hline Year 1 & $+^{2,3}$ & $+^{3}$ & $+^{3}$ & & $+^{3}$ & \\
\hline Year 2 & $+^{3}$ & $+^{3}$ & & $+^{2}$ & & \\
\hline Year 3 & & & & & & \\
\hline \multicolumn{7}{|l|}{ PA } \\
\hline Year 1 & $+2,3$ & $+^{1,3}$ & $+^{3}$ & & & $+^{3}$ \\
\hline Year 2 & & $++^{1,3}$ & & & & \\
\hline Year 3 & $+^{3}$ & $+^{3}$ & & & & \\
\hline \multicolumn{7}{|l|}{ PATHS } \\
\hline Year 1 & $+2,3$ & $++^{1,3}$ & & & $+^{1,3}$ & \\
\hline Year 2 & $+^{3}$ & $++^{1,3}$ & & & & \\
\hline Year 3 & & $+^{1,3}$ & & & & \\
\hline \multicolumn{7}{|l|}{ 4Rs } \\
\hline Year 1 & $+^{1,2,3}$ & $+^{1,2,3}$ & $+^{3}$ & & $++^{1,3}$ & \\
\hline Year 2 & $+^{1,3}$ & $++^{1,3}$ & & & & \\
\hline Year 3 & $+^{1,3}$ & $++^{1,2,3}$ & $+^{3}$ & & $+^{3}$ & \\
\hline
\end{tabular}


Table 1.23. Significant impacts on use of SACD activity domains, overall and by programContinued

\begin{tabular}{|c|c|c|c|c|c|c|}
\hline \multirow[b]{2}{*}{ Program } & \multicolumn{6}{|c|}{ SACD activity domain } \\
\hline & $\begin{array}{r}\text { Any SACD } \\
\text { activities }\end{array}$ & $\begin{array}{l}\text { Named } \\
\text { SACD } \\
\text { program } \\
\text { activities }\end{array}$ & $\begin{array}{r}\text { Classroom } \\
\text { materials } \\
\text { and } \\
\text { strategies } \\
\end{array}$ & $\begin{array}{r}\text { Schoolwide } \\
\text { strategies }\end{array}$ & $\begin{array}{l}\text { Professional } \\
\text { development }\end{array}$ & $\begin{array}{r}\text { Attitudes } \\
\text { and } \\
\text { practices } \\
\end{array}$ \\
\hline \multicolumn{7}{|l|}{ SS } \\
\hline Year 1 & $t^{3}$ & $++^{1,3}$ & $t^{3}$ & & & \\
\hline Year 2 & $+1,3$ & $++^{1,3}$ & $++^{3}$ & & & \\
\hline Year 3 & $+^{3}$ & $++^{1,3}$ & $t^{3}$ & & & \\
\hline
\end{tabular}

${ }^{1}$ Based on univariate statistical tests, at least half of the impacts were positive and statistically significant and no impact was negative and statistically significant.

${ }^{2}$ The omnibus impact for all the outcomes measured together was positive and statistically significant on the basis of a multivariate statistical test.

${ }^{3}$ At least one outcome remained positive and statistically significant and no outcome was negative and statistically significant after applying the Benjamini-Hochberg (1995) procedure to adjust significance levels downward to account for the multiple testing of impacts.

NOTE: Abbreviations are

ABC: Academic and Behavioral Competencies Program

CSP: Competence Support Program

LBW: Love In a Big World

PA: Positive Action

PATHS: Promoting Alternative Thinking Strategies

4Rs: The 4Rs Program (Reading, Writing, Respecting, and Resolution)

SS: Second Step

+: Statistically significant beneficial impact on domain

Blank cell: Finding of no impact

Significance is based on $p \leq .05$. No detrimental impact was found statistically significant at or below the .05 level. Description of SACD activity domains and the heuristics used to determine the statistically significant beneficial impact on the domain.

SACD activities: based on 16 teacher-reported measures on the use of SACD activities in the classroom.

SACD activities linked to named programs: based on 14 teacher-reported measures on the use of SACD activities associated with a named program in the classroom.

Classroom materials and strategies: based on 29 teacher-reported measures, 7 concerning materials used in the classroom and 22 concerning classroom strategies.

Schoolwide strategies: based on six teacher-reported measures concerning strategies to promote SACD schoolwide.

Professional development: based on nine teacher-reported measures concerning their participation in SACD-related training Attitudes and practices: based on nine teacher-reported measures, three concerning teacher attitudes toward SACD efforts in the school and six concerning school practices conducive to the social and character development of students.

SOURCE: The Social and Character Development (SACD) Research Program. 
percent to 100 percent of treatment school principals and 91 percent to 94 percent of control school principals. Unlike the findings from the teacher surveys, the principal surveys did not show a significantly greater use of SACD activities among the treatment schools, although this might be due to the inability to perform significance tests in seven cases as discussed below. In regard to whether principals of treatment schools reported greater use of activities to promote each of the six SACD goals than principals of control schools, 18 comparisons were made over the 3 years, with 1 expected to be significant by chance. In two cases (both in Year 2), a significantly greater percentage of treatment principals reported the use of SACD activities to support SACD goals: (1) tolerance and diversity (98\% of treatment school principals versus $83 \%$ of control school principals, with a $p$-value of 0.036$)$ and (2) risk prevention and health promotion $(88 \%$ versus $71 \%$, with a $p$-value of 0.044 ). These results do not provide evidence in support of the SACD programs' impact on schools' use of SACD activities because they are small in number and are not replicated over multiple years. However, for five of the comparisons significance testing could not be done because 100 percent of the treatment principals reported that their schools had activities promoting a specific SACD goal.

In regard to staff development, 27 comparisons were made over the 3 years, with 1 expected to be found significant by chance. In two cases (both in Year 2), there was a significant difference favoring the treatment schools. First, the mean percentage of teachers per school reported by their principals to have received training in social and character development in the past year was significantly higher for treatment schools versus control schools $(55 \%$ versus $31 \%$, with a $p$-value of 0.003$)$. Second, the percentage of principals reporting that only 0 percent to 25 percent of their faculty had received such training treatment was significantly smaller among treatment school principals than control school principals $33 \%$ versus $67 \%$, with a $p$-value of 0.002). These results do not provide evidence in support of the SACD programs' impact on teacher training because they are small in number and are not replicated over multiple years. However, for two of the comparisons significance testing could not be done because 100 percent of the treatment principals gave the same report.

\section{Findings Regarding Use of SACD Activities}

The analysis of use of SACD activities had two main findings: (1) the SACD programs increased the reported use of and training in activities to promote students' social and character development in the classroom compared to what reportedly occurred in the control schools, and (2) the reports from the control schools identified them as a standard practice control in that their staffs reported the use of and training in similar activities as the treatment staff.

Evidence for the first finding came primarily from the teacher reports. Treatment teachers reported significantly greater implementation of activities than control teachers for 127 of the 249 outcomes measured and for four of the six SACD activity domains during the 3 years. Evidence for the second finding came from both the principal and teacher reports. The principals reported similar levels of SACD activities and teacher training among treatment and control schools (though statistical difficulties in testing all the comparisons may have contributed to this finding). The treatment teachers' reports were statistically significantly greater than those of the control teachers but the practical differences varied. For example, the significantly greater percentage of treatment teachers reporting use of activities to promote any SACD goal was 5 to 10 percentage points greater than the percentage of control teachers $(86 \%$ to $90 \%$ of whom reported engaging in such activities), while the significant difference for the reported use of activities linked to named programs to promote any SACD goal ranged between 29 and 34 percentage points (with $36 \%$ to $42 \%$ of control teachers reporting engaging in these activities). 


\section{Year-by-Year Impacts on Students and Perceptions of School Climate}

The second and third of the primary research questions for the SACD evaluation were as follows:

What is the average effect of the seven universal, school-based, social and character development programs on students' social and emotional competence, behavior, academics, and on perceptions of school climate?

What is the average effect of each specific SACD program on students' social and emotional competence, behavior, academics, and on perceptions of school climate?

One method to answer these questions was to examine the year-by-year impacts of the SACD programs on these outcomes over the 3 years as the students progressed from third through fifth grades. The examination of year-by-year impacts entailed three sets of analyses resulting in three sets of impacts. The first set of analyses compared the outcomes of treatment and control students from the fall of third grade to the spring of third grade. The second set compared the outcomes from the fall of third grade to the spring of fourth grade, and the third set compared the fall of third grade to the spring of fifth grade. Within each set of yearby-year analyses, an analysis of all the programs together provided impact results for the set of seven coherent, universal, school-based programs, and individual program analysis provided results specific to each program. In answering the first question above, the analysis of the combined seven programs was able to detect smaller statistically significant impacts because of its larger sample size and associated greater power than the analysis of individual SACD programs, which were based on the smaller samples available to answer the second question above.

\section{Analysis}

The random assignment design ensured that the main difference between the treatment and control group schools at the point of random assignment was exposure to the mix of classroom-based and other activities that comprised the SACD program being tested in each site. Thus, unbiased estimates of the average impacts of the SACD programs (relative to the social and character development activities offered in the control schools) could be computed as the difference in the average outcomes of students and teachers in the treatment and control schools. Because of the repeated cross-sectional design, this approach yielded unbiased estimates of the combined effects of the SACD programs on student outcomes and on potential treatmentinduced school entry and exit effects that could have influenced the composition of students and teachers in the schools at the follow-up points.

Statistical precision was a concern for the SACD multiprogram evaluation because of design effects due to the clustering of students within schools (students shared the same teachers and school environment) and the relatively small numbers of schools available for program-level analyses. Therefore, regression procedures were used rather than simple differences-in-means procedures to estimate impacts to improve the statistical precision of the estimates and to adjust for differences between the treatment and control groups' observable characteristics due to random selection, study nonconsent, and interview nonresponse. ${ }^{29}$

Two analyses are discussed in this section. The first is the overall analysis combining results from all programs. The overall analysis was done to determine if providing schools with a SACD program (as reflected in the average results from seven different programs) improved student outcomes. The seven

\footnotetext{
${ }^{29}$ The use of regression models raised the issue of the distribution of the outcome variables. Calculated $p$-values rely on the assumption of normality, and a violation of this condition may cause biases in $p$-values, thus leading to invalid hypothesis testing. However, if the sample size is sufficiently large, the large sample approximation for the distribution of the estimates can be used and the normality assumption can be relaxed as it was for the SACD evaluation.
} 


\section{Chapter 1. The Social and Character Development Multiprogram Evaluation}

programs sought to change a common set of student behaviors by providing school-based instruction (drawing upon a common set of methods and approaches) through the teacher to all students. The focus of the programs differed in terms of specific instructional approaches and student outcomes so they did not represent a unified, single approach to improving student social and character development. Therefore the combined-program analysis was not an evaluation of a general SACD approach (though the results could contribute to such an evaluation) nor does it have any direct application to similar SACD programs not included in this study. Second, individual analysis of each program was done to evaluate them separately. Besides providing an evaluation of each program, these analyses were used to examine the possibility that results for a subset of the programs led to the results from the combined-program analysis.

\section{The Combined-Program Model and the Program-Level Models}

For the combined-program analysis, pooled impact estimates from all the programs were obtained from each year of the study to examine the extent to which, taken together, the seven SACD programs, on average, changed student and school outcomes relative to what they would have been otherwise. A hierarchical linear model (HLM) was used to estimate regression-adjusted impacts (Bryk and Raudenbush 1992). The basic model consisted of two levels that were indexed by students or teachers $(i)$ and schools $(s)$, and where fixed site effects were indexed by $d$ :

$$
\begin{array}{ll}
\text { (1) Level 1: Students /Teachers: } & Y_{i s d}=\alpha_{0 s d}+X_{i s d} \beta+e_{i s d} \\
\text { Level 2: Schools: } & \alpha_{0 s d}=\gamma_{0}+\gamma_{1} T_{s d}+\theta_{d}+Z_{s d} \delta+u_{s d} .
\end{array}
$$

In this model, $Y_{\text {isd }}$ is an outcome measure (from spring of Year 1, Year 2, or Year 3) for a student or teacher; $\alpha_{0 s d}$ is a school-level random intercept; $X_{i s d}$ are student- or teacher-level initial covariates ${ }^{30} ; T_{s d}$ is a binary variable equal to 1 for treatment group schools and 0 for control schools; $\theta_{d}$ are program-specific fixed effects; $Z_{s d}$ are school-level initial covariates (and teacher-level initial covariates for student outcomes) ${ }^{31} ; \beta, \gamma_{0}, \gamma_{1}$, and $\delta$ are fixed parameter vectors to be estimated; $e_{i s d}$ are assumed to be independent and identically distributed $N\left(0, \sigma_{e}^{2}\right)$ student- or teacher-level random error terms; and $u_{s d}$ are independent and identically distributed $N\left(0, \sigma_{u}^{2}\right)$ school-specific error terms that capture the correlation between the outcomes of students (teachers) in the same schools and are assumed to be distributed independently of the Level 1 error terms.

Inserting the Level 2 equation into the Level 1 equation creates the following single level model:

$$
\text { (2) } Y_{i s d}=\gamma_{0}+\gamma_{1} T_{s d}+\theta_{d}+Z_{s d} \delta+X_{i s d} \beta+\left[u_{s d}+e_{i s d}\right] \text {. }
$$

In this formulation, the estimate of the parameter, $\gamma_{1}$, is the regression-adjusted, combined-program impact estimate. The standard error of this estimate accounts for design effects due to the clustering of students in schools, as well as precision gains from the inclusion of initial covariates that explain some of the variation in

\footnotetext{
${ }^{30}$ The $X$ vector refers to initial covariates for students when student outcomes are used and to initial covariates for teachers when teacher-level outcomes are used. For new entrants, most covariates were considered time-invariate and so could be used as initial values when collected later in the study. Imputation was used to estimate the values for timevariate covariates (such as initial scores on outcomes) using information from similar students who were in the sample in Year 1. In addition, for students in the sample during Year 1, some of the covariates, such as the student outcome scores, could have changed between the start of program implementation and data collection in fall 2004. Sensitivity analyses reported in appendix B show that the point estimates of the impacts are similar when the covariates are included or excluded in the model.

${ }^{31}$ Conceptually, the $Z$ vector referred to both school-level and teacher-level covariates. However, the final model did not use school-level covariates so $Z$ actually includes only teacher-level initial covariates for the analysis of student outcomes.
} 


\section{Chapter 1. The Social and Character Development Multiprogram Evaluation}

outcomes between and within schools. $T$ tests were used to gauge the statistical significance of the impact estimates.

This model produces impact estimates that are internally valid but not necessarily externally valid to a broader population of sites. This stems from treating site effects as fixed rather than random (between-site variance terms are not accounted for in the variance calculations), which was done because sites were selected intentionally for the study. In addition, because all classrooms within the study schools were included in the evaluation (there was no sampling of classrooms and the model does not include classroom error terms), the estimated student-level impact findings generalize to the classrooms in the study schools at the time of the evaluation.

For the evaluation of each program, impact estimates were generated by estimating equation (2) separately for each program. Each model included program-specific covariates and random school effects but excluded the program fixed effects $\left(\theta_{d}\right)$. Sample weights were used in all analyses. $F$ tests were used to test for differences in estimated impacts across programs and $t$ tests were used to determine the statistical significance of the program-specific impact estimates.

\section{Covariates}

The $X$ and $Z$ covariates in equation (2) were constructed using the fall 2004 surveys. The covariates were selected based on two main criteria: (1) they should adjust for statistically significant treatment and control differences at initial data collection; and (2) they should have predictive power across a broad range of outcomes. Using stepwise regression procedures, a separate set of covariates were selected for the outcomes from each of the four data sources for the combined-program analysis (see appendix B for details). Table 1.24 lists the covariates used with the outcomes from each report (child, primary caregiver, teacher on student, and teacher on classroom and school). These covariates were used for the analysis of the Year 1, Year 2, and Year 3 data. As a sensitivity check, the same covariate selection process was used with the Year 2 data and the model re-estimated using the alternative covariates. The use of the alternative covariates did not lead to different patterns of results, although the statistical significance of some of the program-level impact estimates changed. For all 3 years, missing covariates were imputed using mean values for nonmissing cases, by school, gender, and race/ethnicity.

For the individual evaluations of each program, covariates were identified using the same procedure as above but were allowed to vary between programs. This led to 28 different sets of covariates (seven programs by four reports providing outcomes). The covariates used in the models for the specific programs are detailed in the program chapters. 
Table 1.24. Covariates used with outcomes from each report for combined-program analysis

\begin{tabular}{|c|c|c|c|c|}
\hline Potential covariate & $\begin{array}{c}\text { CR } \\
\text { outcome }\end{array}$ & $\begin{array}{c}\text { PCR } \\
\text { outcome }\end{array}$ & $\begin{array}{c}\text { TRS } \\
\text { outcome }\end{array}$ & $\begin{array}{c}\text { TRCS } \\
\text { outcome }\end{array}$ \\
\hline Total number & 26 & 35 & 28 & 8 \\
\hline \multicolumn{5}{|l|}{ Child-reported } \\
\hline Female & $\checkmark$ & $\checkmark$ & $\checkmark$ & \\
\hline Hispanic (non-White) & $\checkmark$ & $\checkmark$ & $\checkmark$ & \\
\hline Black (non-Hispanic) & $\checkmark$ & $\checkmark$ & $\checkmark$ & \\
\hline Other ethnicity & $\checkmark$ & $\checkmark$ & $\checkmark$ & \\
\hline Age in years & $\checkmark$ & $\checkmark$ & $\checkmark$ & \\
\hline \multicolumn{5}{|l|}{ Scales } \\
\hline \multicolumn{5}{|l|}{ Afraid at School } \\
\hline Altruistic Behavior & $\checkmark$ & & $\checkmark$ & \\
\hline Empathy & $\checkmark$ & & & \\
\hline Engagement with Learning & $\checkmark$ & $\checkmark$ & $\checkmark$ & \\
\hline Negative School Orientation & $\checkmark$ & $\checkmark$ & & \\
\hline Normative Beliefs About Aggression & & $\checkmark$ & & \\
\hline Sense of School as a Community & $\checkmark$ & $\checkmark$ & & \\
\hline Problem Behavior & & & $\checkmark$ & \\
\hline Self-Efficacy for Peer Interactions & $\checkmark$ & $\checkmark$ & & \\
\hline Victimization at School & $\checkmark$ & & & \\
\hline \multicolumn{5}{|l|}{ Primary caregiver-reported } \\
\hline Completed high school or equivalent & $\checkmark$ & $\checkmark$ & $\checkmark$ & \\
\hline Some college & $\checkmark$ & $\checkmark$ & $\checkmark$ & \\
\hline Bachelor's or higher degree & $\checkmark$ & $\checkmark$ & $\checkmark$ & \\
\hline \multicolumn{5}{|l|}{ Highest level of education in household } \\
\hline Completed high school or equivalent & $\checkmark$ & $\checkmark$ & $\checkmark$ & \\
\hline Some college & $\checkmark$ & $\checkmark$ & $\checkmark$ & \\
\hline Bachelor's or higher degree & $\checkmark$ & $\checkmark$ & $\checkmark$ & \\
\hline Mother present in home life & & $\checkmark$ & $\checkmark$ & \\
\hline Mother and father present & $\checkmark$ & $\checkmark$ & $\checkmark$ & \\
\hline Respondent someone other than mother or father & $\checkmark$ & $\checkmark$ & $\checkmark$ & \\
\hline Number of people in household & $\checkmark$ & $\checkmark$ & $\checkmark$ & \\
\hline Household income: $\$ 20,000$ to $\$ 40,000$ & $\checkmark$ & $\checkmark$ & & \\
\hline Household income: $\$ 40,000$ to $\$ 60,000$ & $\checkmark$ & $\checkmark$ & & \\
\hline Household income: More than $\$ 60,000$ & $\checkmark$ & $\checkmark$ & & \\
\hline Income-to-poverty-threshold ratio: Below 135 percent & & $\checkmark$ & $\checkmark$ & \\
\hline Income-to-poverty-threshold ratio: 135 to 185 percent & & $\checkmark$ & $\checkmark$ & \\
\hline Full-time employment & & $\checkmark$ & & \\
\hline Part-time employment & & $\checkmark$ & & \\
\hline
\end{tabular}


Table 1.24. Covariates used with outcomes from each report for combined-program analysis-Continued

\begin{tabular}{|c|c|c|c|c|}
\hline Potential covariate & $\begin{array}{c}\text { CR } \\
\text { outcome }\end{array}$ & $\begin{array}{c}\text { PCR } \\
\text { outcome }\end{array}$ & $\begin{array}{c}\text { TRS } \\
\text { outcome }\end{array}$ & $\begin{array}{c}\text { TRCS } \\
\text { outcome }\end{array}$ \\
\hline \multicolumn{5}{|l|}{ Parental scales } \\
\hline APQ_Positive Parenting Subscale & & $\checkmark$ & $\checkmark$ & \\
\hline \multicolumn{5}{|l|}{ Child-Centered Social Control } \\
\hline Confusion, Hubbub, and Order & & $\checkmark$ & & \\
\hline \multicolumn{5}{|l|}{ Community Resources } \\
\hline Community Risk & & $\checkmark$ & & \\
\hline \multicolumn{5}{|l|}{ Parent and teacher Involvement } \\
\hline \multicolumn{5}{|l|}{ Child scales } \\
\hline Positive Social Behavior & & $\checkmark$ & $\checkmark$ & \\
\hline Problem Behavior & & $\checkmark$ & $\checkmark$ & \\
\hline \multicolumn{5}{|l|}{ Teacher-reported } \\
\hline Hispanic (non-White) & & & & $\checkmark$ \\
\hline Black (non-Hispanic) & & & & $\checkmark$ \\
\hline Other ethnicity & & & & $\checkmark$ \\
\hline Total teaching experience & & & & $\checkmark$ \\
\hline \multicolumn{5}{|l|}{ Total experience in current school } \\
\hline Regular certificate & & & & $\checkmark$ \\
\hline Other certificate & & & & $\checkmark$ \\
\hline $\begin{array}{l}\text { Child scales } \\
\text { Academic Competence and Motivation }\end{array}$ & & & $\checkmark$ & \\
\hline ADHD-Related Behavior & $\checkmark$ & & $\checkmark$ & \\
\hline Altruistic Behavior & & $\checkmark$ & $\checkmark$ & \\
\hline Positive Social Behavior & $\checkmark$ & $\checkmark$ & & \\
\hline Problem Behavior & & $\checkmark$ & & \\
\hline Parent and Teacher Involvement & & & $\checkmark$ & \\
\hline
\end{tabular}

NOTE: Abbreviations are

CR: Child Report

PCR: Primary Caregiver Report

TRS: Teacher Report on Student

TRCS: Teacher Report on Classroom and School

ADHD: Attention deficit hyperactivity disorder

APQ: Alabama Parenting Questionnaire

$\checkmark$ : Covariate used

Blank cell: Covariate not used

SOURCE: The Social and Character Development (SACD) Research Program. 


\section{Chapter 1. The Social and Character Development Multiprogram Evaluation}

\section{Sample Weights}

Sample weights were used in all analyses, and they were constructed for three main reasons: (1) to give each site equal weight in the calculation of combined-program impact estimates, (2) to give each school equal weight in each site, and (3) to adjust for missing outcome data due to study nonconsent and survey nonresponse. ${ }^{32}$ To adjust for missing student data, the assumption was made that students in a specific classroom with spring follow-up data were representative of all students in that classroom. Weights were constructed to be inversely proportional to the combined consent and response rates within each classroom (see appendix B). These weights were constructed separately for original cohort stayers and for new entrants because nonconsent rates were higher for the new entrants. For the teacher-level weights, the assumption was made that responding teachers were representative of all third-, fourth-, and fifth-grade teachers in that school. The standard errors of all estimated impacts were adjusted for design effects due to unequal weighting.

\section{Statistical Significance and Substantively Important Effects}

Results are provided in effect sizes that were calculated by dividing the estimated impact (the coefficient estimated by the regression model) by the standard deviation of the outcome measure for the control group. The standard deviation was calculated using the initial data for the weighted control group. The statistical significance and substantive importance of each result were identified. A standard two-tailed test was used to determine the $p$-value for the impact coefficient of each outcome measure. Coefficients with $p$-values of 0.05 or below were considered statistically significant and identified as such. In addition, coefficients with $p$-values between 0.05 and 0.10 were identified in the tables to identify where there may have been additional significant results found if a larger sample had been used. However, these results were not considered in the text or compilations of statistically significant results.

Individual outcomes having non-statistically significant effect sizes of 0.25 or above (and -0.25 or below) were identified as having substantively positive (negative) importance, following the practice used by the What Works Clearinghouse. Substantive importance may identify impacts of practical importance that might have been found statistically significant if the sample size were larger.

In addition to estimating the impacts of the SACD programs on the individual outcome measures, the impacts on the four domains (Social and Emotional Competence, Behavior, Academics, and Perceptions of School Climate) were also examined. Testing the impact on the domains was done to adjust for the multiple comparisons made within each domain in order to address the increased chances of finding a spurious outcome when more than one test was done. As a result, this section reports two sets of results: (1) the impacts on the individual outcomes unadjusted for multiple comparisons; and (2) the impacts on the domains that serve as the multiple comparison adjustment.

The testing of the significance of the impacts on the domains was based on a set of four heuristics that were modeled on the approach used by the U.S. Department of Education's What Works Clearinghouse for determining whether domain-level effects are statistically significant when there are multiple outcome measures within a single domain (What Works Clearinghouse n.d.-b). The first three of these heuristics were also applied in the earlier analysis of the SACD programs' impacts on the use of SACD activities to six outcome domains. ${ }^{33}$ Each domain was checked using the four heuristics and a statistically significant positive impact was found if any of the four were met. ${ }^{34}$ The four heuristics were as follows:

\footnotetext{
32 This weighting approach produced unbiased estimates of the average treatment effect for the study schools and programs that were purposively selected for the evaluation. See appendix B for more information.

33 The fourth heuristic was appropriate for use with the student-level outcomes but not with the teacher-level use of SACD activities outcomes, so it was not applied to the six domains containing the individual outcomes of SACD activity use.

${ }^{34}$ For ease of discussion, this section describes detecting positive significant impacts. These heuristics were also used to detect any negative impact on a domain.
} 


\section{Chapter 1. The Social and Character Development Multiprogram Evaluation}

1. Based on the results from the statistical test of each outcome variable within a domain (unadjusted for multiple comparisons), at least half of the impacts were positive and statistically significant and no impact was negative and statistically significant.

2. The omnibus impact for all the outcomes measured together was positive and statistically significant on the basis of a multivariate statistical test (see footnote 25).

3. After applying the Benjamini-Hochberg (Benjamini and Hochberg 1995) procedure to each outcome under a domain, at least one of the outcomes remained positive and statistically significant and no outcome was negative and statistically significant. The Benjamini-Hochberg procedure adjusts significance levels downward to account for the multiple testing of impacts.

4. The statistical model used to estimate impacts on the individual outcomes was re-estimated using a composite of all the outcome variables under a domain. The domain was found significant if the impact on the composite was significant. The composite was formed by standardizing each outcome variable using its standard deviation, combining the values of the outcome variables, and taking the average of the final value.

\section{Statistical Power}

To assess the statistical power of the combined-program and individual program impact estimates under the SACD design, minimum detectable impacts in effect size (MDES) units for each outcome measure were calculated. MDES represent the smallest impacts in effect size (standard deviation) units that can be detected with a high probability. The MDES were primarily a function of study sample sizes, the degrees of freedom available for statistical tests, and design effects due to clustering (Schochet 2005). Clustering effects are measured by intraclass correlations (ICCs) that reflect the percentage of the total variance in the outcomes that is between clusters (schools). These MDES were calculated at 80 percent power. Thus, it is possible to find a statistically significant impact estimate on an outcome when the true impact is smaller than the relevant MDES, although the chance that this will occur is less than 80 percent. Similarly, it is possible to find an impact estimate that is not statistically significant when the true impact is as large as the MDES, although the chance that this will occur is 20 percent or less.

Table 1.25 displays the MDES using the ICCs from equation (2) that adjusted them using the covariates (assuming a two-tailed test and a 5 percent significance level). For the outcomes from the Child Report, the MDES fell below 0.1 except for Positive School Orientation in Years 2 and 3, which reached about 0.13. For outcomes from the Primary Caregiver Report, MDES fell below 0.05 for all 3 years. MDES for outcomes from the Teacher Report on Student ranged from 0.05 to 0.24 , while those for the Teacher Report on Classroom and School ranged from 0.15 to 0.21 .

The MDES for the individual programs were considerably higher, ranging from 0.1 to 0.9 over the 3 years, due to smaller sample sizes. They varied somewhat across sites with no consistent pattern. MDES for the specific programs can be found in the program chapters. 
Table 1.25. Adjusted minimum detectable effect sizes for combined-program impact evaluation

\begin{tabular}{|c|c|c|c|}
\hline Outcome measure-Report & Year 1 & Year 2 & Year 3 \\
\hline \multicolumn{4}{|l|}{ Social and Emotional Competence Domain } \\
\hline Self-Efficacy for Peer Interaction-CR & 0.048 & 0.048 & 0.035 \\
\hline Normative Beliefs About Aggression-CR & 0.045 & 0.081 & 0.076 \\
\hline Empathy-CR & 0.068 & 0.078 & 0.063 \\
\hline \multicolumn{4}{|l|}{ Behavior Domain } \\
\hline Altruistic Behavior-CR & 0.041 & 0.057 & 0.043 \\
\hline Altruistic Behavior-PCR & 0.035 & 0.044 & 0.047 \\
\hline Altruistic Behavior-TRS & 0.155 & 0.238 & 0.204 \\
\hline Positive Social Behavior-PCR & 0.027 & 0.042 & 0.042 \\
\hline Positive Social Behavior-TRS & 0.078 & 0.115 & 0.112 \\
\hline Problem Behavior-CR & 0.056 & 0.086 & 0.075 \\
\hline Problem Behavior-PCR & 0.047 & 0.040 & 0.046 \\
\hline Problem Behavior-TRS & 0.084 & 0.086 & 0.101 \\
\hline ADHD-Related Behavior-TRS & 0.071 & 0.082 & 0.101 \\
\hline \multicolumn{4}{|l|}{ Academics Domain } \\
\hline Engagement with Learning-CR & 0.029 & 0.036 & 0.054 \\
\hline Academic Competence and Motivation-TRS & 0.053 & 0.077 & 0.097 \\
\hline \multicolumn{4}{|l|}{ Perceptions of School Climate Domain } \\
\hline Positive School Orientation-CR & 0.088 & 0.123 & 0.128 \\
\hline Negative School Orientation-CR & 0.033 & 0.070 & 0.087 \\
\hline Student Afraid at School-CR & 0.048 & 0.064 & 0.059 \\
\hline Victimization at School-CR & 0.046 & 0.063 & 0.065 \\
\hline Feelings of Safety-TRCS & 0.171 & 0.179 & 0.207 \\
\hline Student Support for Teachers-TRCS & 0.151 & 0.154 & 0.188 \\
\hline
\end{tabular}

NOTE: Abbreviations are

CR: Child Report

PCR: Primary Caregiver Report

TRS: Teacher Report on Student

TRCS: Teacher Report on Classroom and School

ADHD: Attention deficit hyperactivity disorder

The minimum detectable effect (MDE) formula used in the calculations is as follows:

$$
M D E=\operatorname{factor}(d f) * \sqrt{\rho_{1}\left(\frac{1}{s_{T}}+\frac{1}{s_{C}}\right)+\left(1-\rho_{1}\right)\left(\frac{1}{s_{T} n_{T}}+\frac{1}{s_{C} n_{C}}\right)}
$$

where $s_{T}$ and $s_{C}$ are the number of treatment and comparison schools; $n_{T}$ and $n_{C}$ are the average number of students per classroom; $\rho_{1}$ is the intraclass correlation (ICC) at the school level; and factor(df) is a constant that depends on the number of degrees of freedom ( $d f$ ) available for analysis (and is $\mathbf{2 . 8 0 2}$ for the pooled analysis). Estimates were adjusted for fixed program effects as well as baseline covariates.

SOURCE: The Social and Character Development (SACD) Research Program. 


\section{Results}

Table 1.26 provides the estimates of the overall impact on each of the 20 outcome measures over each of the 3 years. ${ }^{35}$ For the third-graders in Year 1 (using the spring 2005 data), there was one statistically significant impact of the SACD programs, when combined, on the teacher-reported Student Support for Teachers measure, which had an effect size of 0.12 standard deviations. Effect sizes ranged from 0.00 to 0.12 (absolute value), so there were no substantively important effects. For the fourth-graders in Year 2 (using spring 2006 data), there was one statistically significant impact, again on the Student Support for Teachers measure, which had an effect size of 0.16 standard deviations. The other effect sizes ranged from 0.00 to 0.13 (absolute value), and there were no substantively important effects. For the fifth-graders in Year 3 (using spring 2007 data), there were no statistically significant impacts of the SACD programs on any of the 20 outcome measures. Effect sizes ranged from 0.00 to 0.08 (absolute value), and there were no substantively important effects. With 2 of 60 coefficients found statistically significant (less than the 3 that would be expected by chance), and none found substantively important, the combined-program evaluation provides no support for an average SACD program effect on student outcomes. Regarding statistically significant impacts on the domains, the fourth heuristic indicated a statistically significant detrimental effect of the SACD programs on the domain of Social and Emotional Competence in Years 2 and 3.

\footnotetext{
35 Sample sizes are not reported in the results tables because they vary by outcome and by year. Table 1.47 provides the range of sample sizes for the outcomes within each report by year.
} 
Table 1.26. Combined-program impacts on outcomes

\begin{tabular}{|c|c|c|c|c|c|c|c|c|c|c|c|c|}
\hline \multirow[b]{2}{*}{ Scale-Report } & \multicolumn{4}{|c|}{$\begin{array}{c}\text { Year 1 } \\
\text { (Spring 3rd grade) }\end{array}$} & \multicolumn{4}{|c|}{$\begin{array}{c}\text { Year 2 } \\
\text { (Spring 4th grade) }\end{array}$} & \multicolumn{4}{|c|}{$\begin{array}{c}\text { Year 3 } \\
\text { (Spring 5th grade) }\end{array}$} \\
\hline & $\begin{array}{r}\text { Treat- } \\
\text { ment }\end{array}$ & Control & $\begin{array}{r}\text { Effect } \\
\text { size }\end{array}$ & $p$-value & $\begin{array}{c}\text { Treat- } \\
\text { ment }\end{array}$ & Control & $\begin{array}{r}\text { Effect } \\
\text { size }\end{array}$ & $p$-value & $\begin{array}{r}\text { Treat- } \\
\text { ment }\end{array}$ & Control & $\begin{array}{r}\text { Effect } \\
\text { size }\end{array}$ & $p$-value \\
\hline \multicolumn{13}{|l|}{ Social and Emotional Competence Domain ${ }^{1,2}$} \\
\hline Self-Efficacy for Peer Interactions-CR (+) & 3.04 & 3.06 & -0.03 & 0.476 & $3.18^{\wedge}$ & 3.22 & -0.07 & 0.096 & 3.22 & 3.25 & -0.04 & 0.233 \\
\hline Normative Beliefs About Aggression-CR (-) & 1.29 & 1.30 & -0.01 & 0.826 & 1.35 & 1.36 & -0.02 & 0.667 & 1.46 & 1.46 & -0.01 & 0.913 \\
\hline Empathy-CR (+) & 2.32 & 2.30 & 0.06 & 0.197 & 2.18 & 2.19 & -0.02 & 0.739 & 2.08 & 2.10 & -0.05 & 0.343 \\
\hline \multicolumn{13}{|l|}{ Behavior Domain } \\
\hline Altruistic Behavior-CR (+) & $1.24^{\wedge}$ & 1.29 & -0.06 & 0.094 & 1.05 & 1.09 & -0.06 & 0.168 & 1.04 & 1.06 & -0.04 & 0.368 \\
\hline Altruistic Behavior-PCR (+) & $2.27^{\wedge}$ & 2.22 & 0.07 & 0.055 & 2.24 & 2.24 & 0.00 & 0.992 & 2.25 & 2.27 & -0.02 & 0.691 \\
\hline Altruistic Behavior-TRS (+) & 1.43 & 1.39 & 0.08 & 0.380 & 1.36 & 1.35 & 0.01 & 0.935 & 1.35 & 1.37 & -0.04 & 0.733 \\
\hline Positive Social Behavior-PCR (+) & 3.02 & 3.03 & -0.01 & 0.726 & 3.08 & 3.05 & 0.05 & 0.183 & 3.10 & 3.08 & 0.03 & 0.436 \\
\hline Positive Social Behavior-TRS (+) & 3.03 & 3.02 & 0.02 & 0.659 & 3.02 & 3.04 & -0.02 & 0.747 & 3.10 & 3.07 & 0.03 & 0.606 \\
\hline Problem Behavior-CR (-) & 0.30 & 0.30 & 0.01 & 0.849 & 0.34 & 0.35 & 0.00 & 0.940 & 0.48 & 0.47 & 0.03 & 0.518 \\
\hline Problem Behavior-PCR (-) & 1.56 & 1.56 & 0.00 & 0.914 & 1.53 & 1.54 & -0.03 & 0.359 & 1.53 & 1.54 & -0.04 & 0.335 \\
\hline Problem Behavior-TRS (-) & 1.46 & 1.45 & 0.02 & 0.620 & 1.44 & 1.45 & -0.02 & 0.667 & 1.45 & 1.47 & -0.04 & 0.467 \\
\hline ADHD-Related Behavior-TRS (-) & 1.75 & 1.75 & 0.00 & 0.925 & 1.68 & 1.70 & -0.04 & 0.474 & 1.65 & 1.70 & -0.08 & 0.205 \\
\hline \multicolumn{13}{|l|}{ Academics Domain } \\
\hline Engagement with Learning-CR (+) & 3.66 & 3.68 & -0.04 & 0.193 & 3.67 & 3.68 & -0.03 & 0.462 & 3.59 & 3.61 & -0.04 & 0.411 \\
\hline Academic Competence and Motivation-TRS (+) & 2.98 & 3.00 & -0.02 & 0.353 & 2.96 & 2.98 & -0.02 & 0.659 & 2.98 & 2.98 & 0.00 & 0.960 \\
\hline
\end{tabular}

See notes at end of table. 
Table 1.26. Combined-program impacts on outcomes-Continued

\begin{tabular}{|c|c|c|c|c|c|c|c|c|c|c|c|c|}
\hline \multirow[b]{2}{*}{ Scale-Report } & \multicolumn{4}{|c|}{$\begin{array}{c}\text { Year } 1 \\
\text { (Spring 3rd grade) } \\
\end{array}$} & \multicolumn{4}{|c|}{$\begin{array}{c}\text { Year } 2 \\
\text { (Spring 4th grade) }\end{array}$} & \multicolumn{4}{|c|}{$\begin{array}{c}\text { Year } 3 \\
\text { (Spring 5th grade) }\end{array}$} \\
\hline & $\begin{array}{c}\text { Treat- } \\
\text { ment }\end{array}$ & Control & $\begin{array}{r}\text { Effect } \\
\text { size }\end{array}$ & $p$-value & $\begin{array}{c}\text { Treat- } \\
\text { ment }\end{array}$ & Control & $\begin{array}{r}\text { Effect } \\
\text { size }\end{array}$ & $p$-value & $\begin{array}{r}\text { Treat- } \\
\text { ment }\end{array}$ & Control & $\begin{array}{r}\text { Effect } \\
\text { size }\end{array}$ & $p$-value \\
\hline \multicolumn{13}{|l|}{ Perceptions of School Climate Domain } \\
\hline Positive School Orientation-CR (+) & 2.87 & 2.85 & 0.03 & 0.573 & 2.66 & 2.64 & 0.03 & 0.717 & 2.51 & 2.56 & -0.07 & 0.411 \\
\hline Negative School Orientation-CR (-) & 1.88 & 1.91 & -0.04 & 0.168 & 1.96 & 1.98 & -0.03 & 0.466 & 2.09 & 2.10 & -0.01 & 0.857 \\
\hline Student Afraid at School-CR (-) & 2.26 & 2.31 & -0.05 & 0.165 & 2.21 & 2.26 & -0.06 & 0.223 & 2.20 & 2.21 & -0.01 & 0.818 \\
\hline Victimization at School-CR (-) & 0.76 & 0.76 & -0.01 & 0.760 & 0.66 & 0.69 & -0.04 & 0.382 & 0.72 & 0.73 & -0.01 & 0.913 \\
\hline Feelings of Safety-TRCS (+) & 3.47 & 3.42 & 0.06 & 0.472 & 3.47 & 3.36 & 0.13 & 0.127 & 3.31 & 3.38 & -0.08 & 0.445 \\
\hline Student Support for Teachers-TRCS (+) & $3.50^{*}$ & 3.39 & 0.12 & 0.046 & $3.55^{*}$ & 3.41 & 0.16 & 0.036 & 3.43 & 3.47 & -0.05 & 0.546 \\
\hline
\end{tabular}

* Treatment group significantly different from control group at the .05 level.

$\wedge$ Treatment group significantly different from control group at the .10 to $>.05$ level.

${ }^{1}$ Impact on domain found statistically significant and detrimental in Year 2 based on the fourth heuristic, in which the statistical model used to estimate impacts on the individual outcomes was re-estimated using a composite of all the outcome variables under a domain. The domain was found significant if the impact on the composite was significant. The composite was formed by standardizing each outcome variable using its standard deviation, combining the values of the outcome variables, and taking the average of the final value.

${ }^{2}$ Impact on domain found statistically significant and detrimental in Year 3 based on the fourth heuristic.

NOTE: Abbreviations are

CR: Child Report

PCR: Primary Caregiver Report

TRS: Teacher Report on Student

TRCS: Teacher Report on Classroom and School

ADHD: Attention deficit hyperactivity disorder

The +/- signs in parentheses indicate the direction of a beneficial outcome. All impact estimates were calculated using regression models where each program and school within a program was weighted equally. The standard errors of all estimates account for design effects due to unequal weighting and the clustering of students within schools. The effect size was calculated by dividing the estimated impact by the standard deviation of the outcome measure for the control group. Significance is based on $p \leq .05$. See table 1.5 for information about the measures used to create the outcome variables. The number of results found significant was no more than expected by chance.

SOURCE: The Social and Character Development (SACD) Research Program. 
The lack of statistically significant beneficial impact estimates at the overall level might have been due to beneficial impacts in some programs that were offset by detrimental impacts in others. Estimated impacts could have differed across programs if some SACD programs were more effective than others, or if the types of children or settings in some programs were more conducive to positive program effects than others. To investigate this possibility, differences in estimated impacts across programs were tested, as was the statistical significance of program-specific impact estimates.

Impact estimates, however, did not differ significantly across programs. Using an $F$ test to test for differences in estimated impacts across programs led to the finding that none of the differences in pooled impact estimates across programs was statistically significant at the 5 percent level in any of the 3 years. This result provided evidence that it was not the case that one or two programs drove or masked the estimated impacts in the combined data.

Table 1.27 lists the outcomes on which each individual program had statistically significant impacts in each year (a program's impacts on all the outcomes are given in the program-specific chapters). There were 5 significant program impacts ( 3 beneficial and 2 detrimental) in Year 1, 7 ( 5 beneficial and 2 detrimental) in Year 2, and 4 ( 1 beneficial and 3 detrimental) in Year 3, for a total of 16 (9 beneficial and 7 detrimental) program-level impacts. As a comparison, 7 of the 140 comparisons made for each year would be expected to be statistically significant by chance, which would produce a total of 21 expected significant impacts. Table 1.27 also lists the 19 nonsignificant substantive impacts by program; 10 were beneficial and 9 were detrimental. 
Table 1.27. Individual program statistically significant impacts and nonsignificant but substantively important impacts

\begin{tabular}{|c|c|c|c|c|}
\hline \multirow[b]{2}{*}{ Program } & \multicolumn{2}{|c|}{ Statistically significant ${ }^{1}$} & \multicolumn{2}{|c|}{ Nonstatistically significant but substantive ${ }^{2}$} \\
\hline & $\begin{array}{c}\text { Beneficial impacts } \\
\text { (Report) (Effect size) ( } p \text {-value) }\end{array}$ & $\begin{array}{c}\text { Detrimental impacts } \\
\text { (Report) (Effect size) ( } p \text {-value) }\end{array}$ & $\begin{array}{c}\text { Beneficial impacts } \\
\text { (Report) (Effect size) ( } p \text {-value) }\end{array}$ & $\begin{array}{c}\text { Detrimental impacts } \\
\text { (Report) (Effect size) ( } p \text {-value) }\end{array}$ \\
\hline Total & 9 & 7 & 10 & 9 \\
\hline \multicolumn{5}{|l|}{ All programs } \\
\hline Year 1 & 3 & 2 & 2 & 0 \\
\hline Year 2 & 5 & 2 & 6 & 1 \\
\hline Year 3 & 1 & 3 & 2 & 8 \\
\hline \multicolumn{5}{|l|}{$\overline{A B C}$} \\
\hline Year 1 & $\begin{array}{l}\text { Altruistic Behavior } \\
\text { (TRS) (.39) (.026) }\end{array}$ & & & \\
\hline Year 2 & $\begin{array}{c}\text { Academic Competence } \\
\text { (CR) (.31) (.011) } \\
\text { Feelings of Safety } \\
(\text { TRCS) }(.75)(.003)\end{array}$ & $\begin{array}{l}\text { Altruistic Behavior } \\
\text { (CR) }(-.20)(0.029)\end{array}$ & $\begin{array}{c}\text { Student Support for Teachers (TRCS) } \\
(.27)(.276)\end{array}$ & \\
\hline Year 3 & $\begin{array}{l}\text { Positive Social Behavior } \\
\text { (PCR) (.21) (.041) }\end{array}$ & & $\begin{array}{l}\text { Feelings of Safety } \\
\text { (TRCS) (.31) (.235) }\end{array}$ & \\
\hline \multicolumn{5}{|l|}{ CSP } \\
\hline Year 2 & $\begin{array}{l}\text { Problem Behavior } \\
\text { (PCR) (-.21) (.042) }\end{array}$ & & $\begin{array}{c}\text { Altruistic Behavior } \\
\text { (TRS) }(.47)(.132) \\
\text { Student Afraid at School } \\
(\mathrm{CR})(-.26)(.090)\end{array}$ & \\
\hline Year 3 & & & & $\begin{array}{l}\text { Altruistic Behavior } \\
\text { (TRS) }(-.41)(.132) \\
\text { Feelings of Safety } \\
\text { (TRCS) }(-.36)(.246)\end{array}$ \\
\hline $\begin{array}{l}\text { LBW } \\
\text { Year } 1\end{array}$ & $\begin{array}{c}\text { Altruistic Behavior } \\
\text { (PCR) }(.31)(.005) \\
\text { Student Support for Teachers } \\
\text { (TRCS) }(.52)(.022) \\
\end{array}$ & & & \\
\hline Year 2 & & & $\begin{array}{l}\text { Student Support for Teachers } \\
\text { (TRCS) (.28) (.428) }\end{array}$ & $\begin{array}{l}\text { Altruistic Behavior } \\
\text { (TRS) (-.34) (.270) }\end{array}$ \\
\hline
\end{tabular}


Table 1.27. Individual program statistically significant impacts and nonsignificant but substantively important impacts-Continued

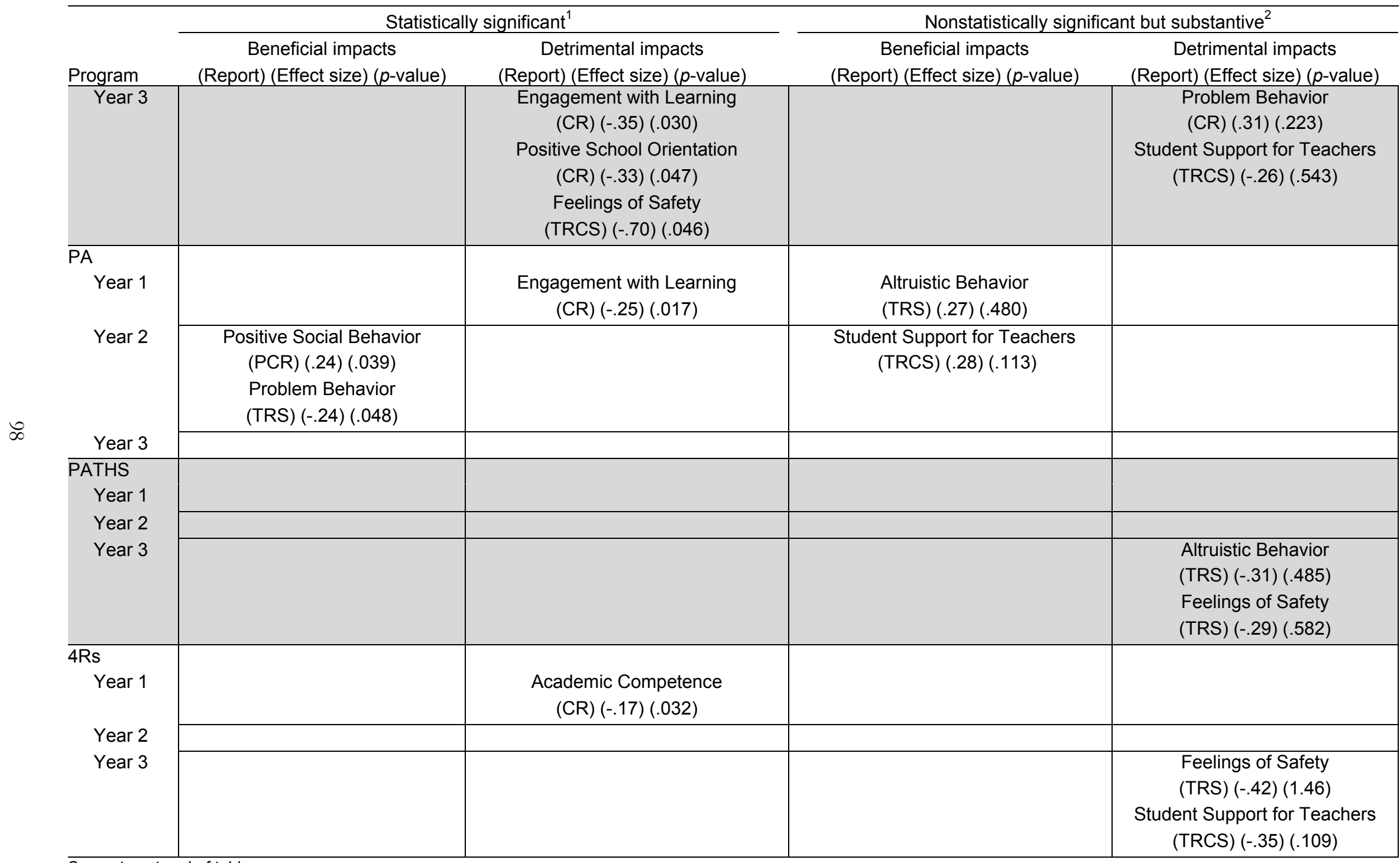


Table 1.27. Individual program statistically significant impacts and nonsignificant but substantively important impacts-Continued

\begin{tabular}{|c|c|c|c|c|}
\hline \multirow{2}{*}{$\begin{array}{l}\text { Program } \\
\text { SS }\end{array}$} & \multicolumn{2}{|c|}{ Statistically significant $^{1}$} & \multicolumn{2}{|c|}{ Nonstatistically significant but substantive ${ }^{2}$} \\
\hline & $\begin{array}{c}\text { Beneficial impacts } \\
\text { (Report) (Effect size) ( } p \text {-value) }\end{array}$ & $\begin{array}{c}\text { Detrimental impacts } \\
\text { (Report) (Effect size) ( } p \text {-value) }\end{array}$ & $\begin{array}{c}\text { Beneficial impacts } \\
\text { (Report) (Effect size) ( } p \text {-value) }\end{array}$ & $\begin{array}{c}\text { Detrimental impacts } \\
\text { (Report) (Effect size) ( } p \text {-value) }\end{array}$ \\
\hline $\begin{array}{l}\text { SS } \\
\text { Year } 1\end{array}$ & & & $\begin{array}{l}\text { Feelings of Safety } \\
\text { (TRCS) }(.37)(.216)\end{array}$ & \\
\hline Year 2 & & $\begin{array}{c}\text { Positive Social Behavior } \\
\text { (PCR) (-.14) (.050) }\end{array}$ & $\begin{array}{l}\text { Feelings of Safety } \\
\text { (TRCS) }(.39)(.197)\end{array}$ & \\
\hline Year 3 & & & $\begin{array}{l}\text { Feelings of Safety } \\
\text { (TRCS) }(.52)(.062)\end{array}$ & \\
\hline
\end{tabular}

${ }^{1}$ Of the 140 comparisons made for each year, 7 would be expected to be statistically significant at the .05 level by chance (for a total of 21 ).

${ }^{2}$ Defined as impacts that were not statistically significant but were .25 standard deviation units (absolute value) or more in magnitude.

NOTE: Abbreviations are

ABC: Academic and Behavioral Competencies Program

CSP: Competence Support Program

LBW: Love In a Big World

PATHS: Promoting Alternative Thinking Strategies

4Rs: The 4Rs Program (Reading, Writing, Respecting, and Resolution)

SS: Second Step

CR: Child Report

PCR: Primary Caregiver Report

TRS: Teacher Report on Student

TRCS: Teacher Report on Classroom and School

Blank cell: Finding of no impact.

All impact estimates were calculated using regression models in which each school within a program was weighted equally. The standard errors of all estimates account for design effects due to unequal weighting and the clustering of students within schools. Significance is based on $p \leq .05$. The number of results found significant was no more than expected by chance.

SOURCE: The Social and Character Development (SACD) Research Program. 


\section{Sensitivity Analyses}

To estimate the multilevel models, it was necessary to make decisions about key model parameter specifications and estimation methods. These decisions had the potential to affect the results. A set of sensitivity analyses was done to determine if these model assumptions affected the results from the combined-program impact analysis. Ten sensitivity tests were done, and these included the following variations:

1. The models were estimated without the initial covariates.

2. The models were estimated without sample weights and also with weights that were not adjusted for nonconsent and nonresponse.

3. Classroom-level random effects were included in the error structure.

4. The pairwise matching of schools was accounted for in the error structure.

5. The pretests were treated as dependent variables rather than as covariates.

6. The models were estimated using alternative statistical software packages.

7. Missing outcome measures were imputed using multiple imputation procedures.

8. Combined-program impact estimates were obtained by averaging the program-level impact estimates.

9. Restricted sets of covariates were included in the models.

10. New entrants were excluded from the analysis.

The number of sensitivity analyses done each year declined as the pattern of impact results from the original model proved robust to a variety of model specifications. All 10 sensitivity analyses were done with the Year 1 data. The first nine sensitivity tests were done with the Year 2 data. The sample of new entrants grew large enough in Years 2 and 3 to do separate analyses of new entrants versus stayers (in place of the 10th sensitivity test) and these were included in the subgroup analyses discussed in chapter 1. The first, second (except for the estimation without weights), third, and fourth sensitivity tests were done using the Year 3 data.

The results from the sensitivity analyses were similar to those of the original combined-program analysis and did not produce additional evidence of impacts on the outcome measures. Of the 10 sensitivity analyses, 5 found no significant impacts on the 20 outcomes, 4 found one significant impact, and 1 found two significant impacts. The sensitivity analyses and their results are discussed in appendix B.

\section{Year-by-Year Analysis of Impacts on Student Subgroups}

The social and character development evaluation research questions included the expectation that the SACD programs, considered together, might be more effective for some groups of children than others. These subgroups were based on (1) student gender; (2) student risk factors; (3) student status as a stayer (member of the original sample from fall 2004) or a new entrant to the study; and (4) fidelity of implementation in the student's school. Descriptive analyses, discussed earlier, of the initial data confirmed that the characteristics used to form the first two subgroups were randomly distributed between the treatment and control groups, and found no statistically significant difference in the composition of the treatment and control groups by stayers and new entrants. These subgroups were hypothesized to respond differently to the SACD programs based on (1) indications in the literature that gender, socioeconomic risk, family risk, and community risk are associated with children's behavioral and academic outcomes; and (2) results from previous evaluations of universal school-based SACD interventions, which have found that impacts can differ for children at high risk for behavior problems and academic failure, and that impacts can be greater for children who have received greater program exposure.

The identification of gender and of stayer versus new entrant status was straightforward because these were 


\section{Chapter 1. The Social and Character Development Multiprogram Evaluation}

clearly distinctive subgroups of boys versus girls and students who were in the sample from the initial data collection versus those who joined afterward. Identification of the subgroups defined by initial risk and fidelity of implementation required the use of scales.

To identify students with initial risks, four domains of initial risk were examined:

1. Socioeconomic risk was measured by the number of the following risk factors the child faced at the beginning of the evaluation: (1) the child was in a single-parent household, (2) the child was in a low-income household (below 135 percent of the federal poverty level), and (3) the child's primary caregiver was a high school dropout. The risk measure used in the analysis was a cumulative score across the three risk variables with the following values: 0 (no risk factors), 1 (one risk factor), and 2 (two or three risk factors).

2. Family risk was defined as poor parental supervision and taken from the Alabama: Poor Supervision Scale from the Primary Caregiver Report data.

3. Perceived community risk was defined as perceived neighborhood risk measured through items from the Community Risk Scale from the Primary Caregiver Report data.

4. Child behavior risk was measured by the BASC Conduct Problems Subscale, responses to which were collected in both the Teacher Report on Student and the Primary Caregiver Report.

Thus, there were five risk measures used to examine the four initial risk domains: (1) one measure for socioeconomic risk, which consisted of a scale based on three variables; (2) one measure for family risk, which was based on one variable; (3) one measure for community risk, which was based on one variable; and (4) two measures for child behavior risk. Other variables were considered for each risk measure (e.g., parents' employment status for socioeconomic risk, positive parenting for family risk, and community resources for community risk) but, in a regression analysis of the initial data, these variables were not found to predict the outcome measures. The five selected risk measures were treated in the analysis as continuous, rather than categorical, variables to preserve all risk information, and because there were no well-established rules for defining risk cutoffs and groups for which the effects of the SACD evaluation were likely to differ.

Fidelity of implementation of the SACD programs was measured differently in each of the three years. In Year 1, treatment schools were divided into two fidelity groups: (1) high implementers (20 schools) and (2) low implementers (22 schools). In Years 2 and 3, schools were again divided into the high (20 schools in Year 2, 19 schools in Year 3) and low implementers (22 schools in Year 2, 23 schools in Year 3) but the fidelity measure combined the rankings from multiple years into three categories: (1) high implementers for all years, (2) low implementers for all years, and (3) mixed implementers (high and low implementers in different years). The discussion of the construction of the fidelity of implementation variables noted that the fidelity analysis was considered exploratory, both because of how the variable was constructed and because of the nonrandom assignment of high and low fidelity. As a result, differences in estimated impacts by fidelity group could reflect differences in the level of implementation and/or underlying differences between the students, the schools, and the SACD programs.

\section{Analysis}

The subgroup analyses were conducted at the combined-program level. The 18 student-level outcomes were used. The degree of power available for testing the differences between the subgroups was lower than for the whole-group analysis and depended on the number and sizes of the subgroups. Therefore the results were measured less precisely than for the year-by-year impacts at the combined-program level. Partly as a result of this, and because the What Works Clearinghouse heuristics do not specify how to conduct multiple comparison tests across subgroups, the heuristics were not applied to examine subgroup impact results by domain. ${ }^{36}$

\footnotetext{
36 The comparison approach used was to assess whether there were differences in impacts across subgroups (e.g.,
} 


\section{Chapter 1. The Social and Character Development Multiprogram Evaluation}

Two of the subgroups were discrete binary variables (boy/girl or stayer/new entrant) as was Year 1 fidelity (high/low), one subgroup included three discrete binary variables (fidelity for Years 2 and 3), and the initial risk variables were continuous (and so were not truly discrete subgroups). For all the subgroup analyses, the model used to test the equality of the subgroup impacts can be represented in a unified equation as

$$
Y_{i s p}=\gamma_{o}+\gamma_{1} T_{s p}+\theta_{p}+X_{i s p} \beta+G_{i s p} \lambda+G_{i s p} T_{s p} \rho+\left[u_{s p}+e_{i s p}\right]
$$

where $\mathrm{Y}_{\text {isp }}$ is an outcome for a student; $\mathrm{T}_{\mathrm{sp}}$ is a binary variable equal to 1 for treatment group schools and 0 for control schools; $\theta_{\mathrm{p}}$ are program-specific fixed effects coefficients to be estimated; $\mathrm{X}_{\text {isp }}$ are student- or teacher-level baseline covariates that do not include the subgroup of interest; $G_{\text {isp }}$ is the variable to represent the subgroup of interest; $\beta, \gamma_{0}, \gamma_{1}, \lambda$, and $\rho$ are fixed parameter vectors to be estimated; $e_{\text {isp }}$ are assumed to be independent and identically distributed $\mathrm{N}\left(0, \sigma_{\mathrm{e}}^{2}\right)$ student- or teacher-level random error terms; and $\mathrm{u}_{\mathrm{sp}}$ are independent and identically distributed $\mathrm{N}\left(0, \sigma_{\mathrm{u}}^{2}\right)$ school-specific error terms that capture the correlation between the outcomes of students in the same schools and are assumed to be distributed independently of the $\mathrm{e}_{\text {isp }}$ error terms. When subgroups are discrete, $\mathrm{G}_{\text {isp }}$ is a binary variable for the nonexcluded subgroup of interest (such as females, when males are the excluded subgroup). ${ }^{37}$ For the risk variables that were continuously defined, $G_{\text {isp }}$ is a continuous variable.

In this model, $\rho$ is the coefficient on the interaction term between the subgroup of interest and the treatment group indicator variable. The value of $\rho$ estimates the additional effect on the impact estimate of switching subgroups (through a one-unit change in the $G_{\text {isp }}$ variable). A test of the hypothesis that $\rho$ equals 0 is conducted to determine whether the subgroups have statistically significantly different impacts.

This equation is the same for the subgroup analyses in which there are only two subgroups and for the subgroup analyses that use a continuous variable. In the case of three subgroups (such as with the three-tiered fidelity categorization), $G_{\text {isp }}$ includes two subgroups (because the third one is excluded), and there are two subgroup-by-treatment-status interaction terms. The joint test of whether the coefficients on these terms equal 0 is conducted to determine whether the three subgroups have different impacts. For the discrete binary variables, $\rho$ represents the additional effect of changing from boy to girl or from stayer to new entrant. For continuous variables, $\rho$ represents the additional effect of a one-unit change in the $G_{\text {isp }}$ variable. For presentation purposes, because one-unit changes in the risk measures might be hard to interpret because the risk measures are scales, the point estimates of the impacts are presented at the mean risk level, one standard deviation above the mean risk level, and one standard deviation below the mean risk level.

The subgroup analyses determined if there was a differential impact of the SACD programs on the subgroups. In cases where such a difference was found, a secondary analysis was done to obtain more information on this difference by testing the statistical significance of the impact estimates for each subgroup separately. These supplemental analyses could help identify why a differential impact occurred. For example, if a significant differential impact was found that favored girls, the supplemental analysis might determine that the difference was due to either a beneficial impact on girls or a detrimental impact on boys. ${ }^{38}$ Impacts for

impacts for boys versus girls) for each outcome and then to examine impacts on the individual subgroups (e.g., boys). The latter were to be examined only when the former were found significant. The alternative approach of applying multiple comparisons corrections for all the outcomes under each subgroup was not applied because it would have reduced the alpha levels for significance testing to such low values (e.g., from .05 to .005) that there would be little statistical power to detect impacts.

${ }^{37}$ For the subgroup analyses, (1) girls were included and boys excluded, (2) new entrants were included and stayers excluded, and (3) low fidelity was excluded.

38 The student gains for some of the outcomes are represented by positive coefficients (an increase in that outcome is desired) while for others a gain is represented by a negative coefficient (a decrease is desired). To reduce confusion, impacts are described as beneficial or detrimental for a subgroup. A beneficial outcome means that a desired outcome 


\section{Chapter 1. The Social and Character Development Multiprogram Evaluation}

discrete (binary or categorical) subgroups were estimated using the equation (2) regression models (described in Year-by-Year Impacts on Students and Perceptions of School Climate) separately for each subgroup-for example, separately for boys and for girls. For the continuous initial risk variables, equation (2) was estimated three times for each risk variable: once for each level of risk reported (mean risk level, one standard deviation above the mean risk level, and one standard deviation below the mean risk level).

It is possible to have a statistically significant difference in estimated impacts between subgroups and not to have statistically significant estimated impacts for one or all of the subgroups. In a similar way, there can be statistically significant estimated impacts for the subgroups, but no statistically significant difference between these impacts. These patterns can occur because the tests of statistical significance are asking slightly different questions. For each subgroup-specific regression, the hypothesis that is being tested is whether the impact coefficient is statistically significantly different from zero, when the coefficients for the regressor variables are fit specifically for that subgroup. For the test of the significance of the difference in the impact estimates, the hypothesis is testing whether the difference in the impact estimates for each subgroup is statistically significantly different from zero, when the coefficients for the regressor variables are fit for the full sample (all subgroups combined).

\section{Results}

For each subgroup, the results of the primary and supplemental subgroup tests are discussed. The test of the significance of the difference in the impact estimates for each subgroup is discussed first. This test directly compares the point estimates of the impacts for each level of the subgroup, while taking into account the variance around each point estimate. Formally, it is a test of the null hypothesis that the difference in impact between subgroup levels equals zero. The test establishes whether differences in impacts between levels of the subgrouping variable exist. Second, the results of the $t$ tests from the subgroup-specific regressions are discussed. These tests determine the significance of the impact of the intervention on each of the subgroups. The findings from the subgroup-specific regressions are discussed only if the test of the significance of the difference in the impact estimates results rejects the hypothesis that the difference between the impacts for the subgroups is zero (although for completeness, the tables present all the subgroup-specific regression results).

Tables 1.28 through 1.35 present the year-by-year results for the subgroup analyses. In the tables, the $p$-value for the difference in the impact estimates for each subgroup is labeled " $p$-Value for Difference" for the discrete subgroups (gender, stayer/new entrant, and fidelity of implementation) and "Marginal Effect" for the initial risk subgroups. The "Marginal Effect" column contains both the $p$-value and the effect of moving from one level of risk up to the next level. ${ }^{39}$ The other columns give the coefficients converted into effect sizes and the $p$-values from the subgroup-specific regressions, and are labeled by their subgroup (e.g., "Boys" and "Girls" in table 1.28).

\section{Gender}

There were 8 cases of significant differences between the impacts of the seven SACD programs on boys versus girls (table 1.28, last column under each year). From the 54 comparisons made, 3 significant differences would be expected by chance. When examining the results of the $t$ tests from subgroup-specific regressions for these 8 cases, 1 case was based on a significant beneficial program impact for boys (an increase in Positive Social Behavior in Year 2); 3 were based on significant detrimental program impacts for boys (declines in Altruistic Behavior in Years 1 and 2, and Engagement with Learning in Year 2); 1 was based

has increased or an undesired outcome has decreased for that subgroup. A detrimental outcome means that a desired outcome has decreased or an undesired outcome has increased for that subgroup.

39 The marginal effects for the discrete binary subgroups (gender and stayer/new entrant) can be approximated by subtracting the effect sizes from the subgroup-specific regressions because the differences between subgroups in standard deviation estimates are small. For the fidelity subgroups, this approach can be used to identify pairwise differences between the impacts for the low-, mixed-, and high-fidelity subgroups. 
on a significant beneficial impact for girls (a decline in Negative School Orientation in Year 2); and 1 was based on a significant detrimental impact for girls (a decline in Academic Competence in Year 1). Of the remaining 2, the first showed more beneficial impacts for girls (a gain in Normative Beliefs About Aggression in Year 2) while the second showed more beneficial impacts for boys (a decline in ADHD-related behavior in Year 3) but neither was linked to a significant program impact on either gender. Because there were few significant differences and they did not provide consistent results (e.g., half showed a detrimental program impact), these results provide little evidence that the SACD programs, as a group, differentially improved outcomes for one gender. 
Table 1.28. Combined-program impacts on child outcomes, by gender

\begin{tabular}{|c|c|c|c|c|c|c|c|c|c|c|c|c|c|c|c|}
\hline \multirow[b]{3}{*}{ Scale-Report } & \multicolumn{5}{|c|}{$\begin{array}{c}\text { Year } 1 \\
\text { (Spring 3rd grade) }\end{array}$} & \multicolumn{5}{|c|}{$\begin{array}{c}\text { Year } 2 \\
\text { (Spring 4th grade) }\end{array}$} & \multicolumn{5}{|c|}{$\begin{array}{c}\text { Year } 3 \\
\text { (Spring 5th grade) }\end{array}$} \\
\hline & \multicolumn{2}{|c|}{ Boys } & \multicolumn{2}{|c|}{ Girls } & \multirow{2}{*}{$\begin{array}{r}p \text {-value } \\
\text { for } \\
\text { differ- } \\
\text { ence }^{1}\end{array}$} & \multicolumn{2}{|c|}{ Boys } & \multicolumn{2}{|c|}{ Girls } & \multirow{2}{*}{$\begin{array}{r}p \text {-value } \\
\text { for } \\
\text { differ- } \\
\text { ence }^{1}\end{array}$} & \multicolumn{2}{|c|}{ Boys } & \multicolumn{2}{|c|}{ Girls } & \multirow{2}{*}{$\begin{array}{r}p \text {-value } \\
\text { for } \\
-\quad \text { differ- }^{-} \\
\text {ence }^{1}\end{array}$} \\
\hline & $\begin{array}{r}\text { Effect } \\
\text { size }\end{array}$ & $\begin{array}{r}p- \\
\text { value }\end{array}$ & $\begin{array}{r}\text { Effect } \\
\text { size }\end{array}$ & $\begin{array}{r}p- \\
\text { value }\end{array}$ & & $\begin{array}{c}\text { Effect } \\
\text { size }\end{array}$ & $\begin{array}{r}p- \\
\text { value }\end{array}$ & $\begin{array}{l}\text { Effect } \\
\text { size }\end{array}$ & $\begin{array}{r}p- \\
\text { value }\end{array}$ & & $\begin{array}{c}\text { Effect } \\
\text { size }\end{array}$ & $\begin{array}{r}p- \\
\text { value }\end{array}$ & $\begin{array}{r}\text { Effect } \\
\text { size }\end{array}$ & $\begin{array}{r}p- \\
\text { value }\end{array}$ & \\
\hline \multicolumn{16}{|l|}{$\begin{array}{l}\text { Social and Emotional } \\
\text { Competence Domain }\end{array}$} \\
\hline $\begin{array}{l}\text { Self-Efficacy for Peer } \\
\text { Interactions-CR (+) }\end{array}$ & 0.01 & 0.907 & -0.05 & 0.345 & 0.558 & $-0.10^{\wedge}$ & 0.076 & -0.04 & 0.479 & 0.281 & $-0.09^{\wedge}$ & 0.083 & 0.01 & 0.833 & $0.092^{\wedge}$ \\
\hline $\begin{array}{l}\text { Normative Beliefs } \\
\text { About Aggression- } \\
\text { CR (-) }\end{array}$ & -0.01 & 0.842 & -0.01 & 0.899 & 0.788 & 0.04 & 0.574 & $-0.10^{\wedge}$ & 0.095 & $0.023^{*}$ & -0.04 & 0.545 & 0.02 & 0.768 & 0.245 \\
\hline Empathy-CR (+) & 0.04 & 0.500 & 0.08 & 0.133 & 0.705 & -0.05 & 0.401 & 0.02 & 0.685 & 0.165 & -0.06 & 0.248 & -0.03 & 0.661 & 0.841 \\
\hline \multicolumn{16}{|l|}{ Behavior Domain } \\
\hline $\begin{array}{l}\text { Altruistic Behavior- } \\
\text { CR }(+)\end{array}$ & $-0.13^{*}$ & 0.014 & 0.01 & 0.921 & $0.023^{*}$ & $-0.13^{*}$ & 0.020 & 0.00 & 0.967 & $0.022^{*}$ & -0.04 & 0.453 & -0.03 & 0.580 & 0.784 \\
\hline $\begin{array}{l}\text { Altruistic Behavior- } \\
\text { PCR (+) }\end{array}$ & 0.07 & 0.199 & $0.09^{\wedge}$ & 0.081 & 0.754 & -0.07 & 0.173 & 0.07 & 0.177 & $0.063^{\wedge}$ & -0.10 & 0.102 & 0.05 & 0.343 & 0.101 \\
\hline $\begin{array}{l}\text { Altruistic Behavior- } \\
\text { TRS }(+)\end{array}$ & 0.04 & 0.667 & 0.09 & 0.398 & 0.330 & 0.01 & 0.924 & 0.02 & 0.918 & 0.972 & -0.01 & 0.940 & -0.03 & 0.785 & 0.981 \\
\hline $\begin{array}{l}\text { Positive Social } \\
\text { Behavior-PCR (+) }\end{array}$ & 0.00 & 0.934 & -0.01 & 0.790 & 0.904 & $0.10^{*}$ & 0.032 & -0.02 & 0.653 & $0.033^{*}$ & 0.04 & 0.512 & 0.00 & 0.985 & 0.826 \\
\hline $\begin{array}{l}\text { Positive Social } \\
\text { Behavior-TRS (+) }\end{array}$ & 0.01 & 0.755 & 0.01 & 0.750 & 0.993 & -0.02 & 0.830 & -0.02 & 0.769 & 0.978 & 0.10 & 0.200 & -0.01 & 0.864 & $0.058^{\wedge}$ \\
\hline $\begin{array}{l}\text { Problem Behavior- } \\
\text { CR (-) }\end{array}$ & 0.01 & 0.897 & 0.00 & 0.993 & 0.927 & -0.01 & 0.852 & -0.01 & 0.900 & 0.810 & 0.03 & 0.675 & 0.02 & 0.735 & 0.990 \\
\hline $\begin{array}{l}\text { Problem Behavior- } \\
\text { PCR (-) }\end{array}$ & 0.02 & 0.630 & -0.01 & 0.875 & 0.851 & -0.08 & 0.138 & 0.03 & 0.599 & $0.089^{\wedge}$ & -0.03 & 0.697 & -0.04 & 0.493 & 0.895 \\
\hline $\begin{array}{l}\text { Problem Behavior- } \\
\text { TRS (-) }\end{array}$ & 0.02 & 0.715 & 0.03 & 0.577 & 0.865 & -0.02 & 0.720 & -0.03 & 0.601 & 0.788 & -0.08 & 0.346 & -0.03 & 0.569 & 0.621 \\
\hline $\begin{array}{l}\text { ADHD-Related } \\
\text { Behavior-TRS (-) }\end{array}$ & -0.03 & 0.518 & 0.02 & 0.619 & 0.254 & -0.06 & 0.346 & -0.02 & 0.745 & 0.529 & $-0.15^{\wedge}$ & 0.064 & -0.02 & 0.736 & $0.043^{*}$ \\
\hline
\end{tabular}


Table 1.28. Combined-program impacts on child outcomes, by gender-Continued

\begin{tabular}{|c|c|c|c|c|c|c|c|c|c|c|c|c|c|c|c|}
\hline \multirow[b]{3}{*}{ Scale-Report } & \multicolumn{5}{|c|}{$\begin{array}{c}\text { Year } 1 \\
\text { (Spring 3rd grade) } \\
\end{array}$} & \multicolumn{5}{|c|}{$\begin{array}{c}\text { Year } 2 \\
\text { (Spring 4th grade) } \\
\end{array}$} & \multicolumn{5}{|c|}{$\begin{array}{c}\text { Year } 3 \\
\text { (Spring 5th grade) }\end{array}$} \\
\hline & \multicolumn{2}{|c|}{ Boys } & \multicolumn{2}{|c|}{ Girls } & \multirow{2}{*}{$\begin{array}{r}p \text {-value } \\
\text { for } \\
\text { differ- } \\
\text { ence }^{1}\end{array}$} & \multicolumn{2}{|c|}{ Boys } & \multicolumn{2}{|c|}{ Girls } & \multirow{2}{*}{$\begin{array}{r}p \text {-value } \\
\text { for } \\
\text { differ- } \\
\text { ence }^{1}\end{array}$} & \multicolumn{2}{|c|}{ Boys } & \multicolumn{2}{|c|}{ Girls } & \multirow{2}{*}{$\begin{array}{r}p \text {-value } \\
\text { for } \\
\text { differ- }^{1} \\
\text { ence }^{1}\end{array}$} \\
\hline & $\begin{array}{r}\text { Effect } \\
\text { size }\end{array}$ & $\begin{array}{c}p- \\
\text { value }\end{array}$ & $\begin{array}{c}\text { Effect } \\
\text { size }\end{array}$ & $\begin{array}{c}p- \\
\text { value }\end{array}$ & & $\begin{array}{r}\text { Effect } \\
\text { size }\end{array}$ & $\begin{array}{r}p- \\
\text { value }\end{array}$ & $\begin{array}{r}\text { Effect } \\
\text { size }\end{array}$ & $\begin{array}{r}p- \\
\text { value }\end{array}$ & & $\begin{array}{r}\text { Effect } \\
\text { size }\end{array}$ & $\begin{array}{r}p- \\
\text { value }\end{array}$ & $\begin{array}{r}\text { Effect } \\
\text { size }\end{array}$ & $\begin{array}{r}p- \\
\text { value }\end{array}$ & \\
\hline \multicolumn{16}{|l|}{ Academics Domain } \\
\hline \multicolumn{16}{|l|}{ Engagement with } \\
\hline Learning-CR (+) & -0.01 & 0.872 & -0.08 & 0.133 & 0.178 & $-0.10^{*}$ & 0.050 & 0.05 & 0.297 & $0.011^{*}$ & 0.00 & 0.998 & -0.09 & 0.100 & 0.317 \\
\hline $\begin{array}{l}\text { Academic } \\
\text { Competence and }\end{array}$ & & & & & & & & & & & & & & & \\
\hline Motivation-TRS (+) & 0.04 & 0.331 & $-0.07^{*}$ & 0.017 & $0.003^{*}$ & 0.02 & 0.684 & -0.04 & 0.424 & 0.242 & 0.05 & 0.386 & -0.05 & 0.443 & $0.093^{\wedge}$ \\
\hline \multicolumn{16}{|l|}{$\begin{array}{l}\text { Perceptions of School } \\
\text { Climate Domain }\end{array}$} \\
\hline $\begin{array}{l}\text { Positive School } \\
\text { Orientation-CR (+) }\end{array}$ & 0.04 & 0.529 & 0.02 & 0.728 & 0.593 & -0.01 & 0.872 & 0.06 & 0.393 & $0.081^{\wedge}$ & -0.09 & 0.291 & -0.04 & 0.617 & 0.345 \\
\hline $\begin{array}{l}\text { Negative School } \\
\text { Orientation-CR (-) }\end{array}$ & 0.01 & 0.815 & $-0.10^{*}$ & 0.040 & $0.065^{\wedge}$ & 0.09 & 0.126 & $-0.14^{*}$ & 0.011 & $0.000^{*}$ & -0.01 & 0.914 & 0.00 & 0.943 & 0.842 \\
\hline $\begin{array}{l}\text { Student Afraid at } \\
\text { School-CR (-) }\end{array}$ & -0.02 & 0.654 & -0.08 & 0.102 & 0.299 & -0.10 & 0.102 & -0.02 & 0.716 & 0.214 & 0.01 & 0.818 & -0.02 & 0.666 & 0.445 \\
\hline $\begin{array}{l}\text { Victimization at } \\
\text { School-CR (-) }\end{array}$ & -0.02 & 0.748 & -0.01 & 0.817 & 0.983 & -0.07 & 0.223 & -0.01 & 0.876 & 0.262 & -0.01 & 0.850 & 0.01 & 0.809 & 0.683 \\
\hline
\end{tabular}

* Treatment group significantly different from control group at the .05 level.

$\wedge$ Significantly different from zero at the .10 to $>.05$ level.

${ }^{1}$ From the test of a significant difference between Boys' effect size and Girls' effect size.

NOTE: Abbreviations are

CR: Child Report

PCR: Primary Caregiver Report

TRS: Teacher Report on Student

ADHD: Attention deficit hyperactivity disorder

The +/- signs in parentheses indicate the direction of a beneficial outcome. All impact estimates were calculated using regression models in which each program and school within a program was weighted equally. The standard errors of all estimates account for design effects due to unequal weighting and the clustering of students within schools. The effect size was calculated by dividing the estimated impact by the standard deviation of the outcome measure for the control group.

SOURCE: The Social and Character Development (SACD) Research Program. 


\section{Stayer Versus New Entrant}

For Years 2 and 3, no significant differences between the impacts on stayers versus new entrants were found (table 1.29). From the 36 comparisons made, 2 outcomes would have been expected to be statistically significant by chance. These results provide little evidence that the SACD programs, as a group, differentially improved outcomes for stayers or for new entrants.

The results comparing new entrants and stayers subgroups might have been sensitive to the methods used to fill in missing values in the initial data for new entrants. This could be a concern, especially because timevarying characteristics were measured at the start of the evaluation for stayers, but no data were available for new entrants. Information collected during the follow-up periods was used to fill in missing values for initial data items that were not expected to vary much over time. For characteristics that were likely to vary considerably over time, including initial values of the outcome measures, values were imputed based on cell means, where cells were defined by students' schools, gender, and race/ethnicity. To check the sensitivity of these results to the imputation of covariates that might vary over time, results were estimated for the stayer and new entrant subgroups using only covariates that were unlikely to vary over time. The subgroup results were similar (these data are not shown in a table). 
Table 1.29. Combined-program impacts on child outcomes, by stayer versus new entrant

\begin{tabular}{|c|c|c|c|c|c|c|c|c|c|c|}
\hline \multirow[b]{3}{*}{ Scale-Report } & \multicolumn{5}{|c|}{$\begin{array}{c}\text { Year } 2 \\
\text { (Spring 4th grade) }\end{array}$} & \multicolumn{5}{|c|}{$\begin{array}{c}\text { Year } 3 \\
\text { (Spring 5th grade) }\end{array}$} \\
\hline & \multicolumn{2}{|c|}{ Stayers } & \multicolumn{2}{|c|}{ New entrants } & \multirow{2}{*}{$\begin{array}{r}p \text {-value } \\
\text { for } \\
\text { difference }^{1}\end{array}$} & \multicolumn{2}{|c|}{ Stayers } & \multicolumn{2}{|c|}{ New entrants } & \multirow{2}{*}{$\begin{array}{r}p \text {-value } \\
\text { for } \\
\text { difference }^{1}\end{array}$} \\
\hline & $\begin{array}{r}\text { Effect } \\
\text { size }\end{array}$ & $p$-value & $\begin{array}{r}\text { Effect } \\
\text { size }\end{array}$ & $p$-value & & $\begin{array}{r}\text { Effect } \\
\text { size }\end{array}$ & $p$-value & $\begin{array}{r}\text { Effect } \\
\text { size }\end{array}$ & $p$-value & \\
\hline \multicolumn{11}{|l|}{ Social and Emotional Competence Domain } \\
\hline Self-Efficacy for Peer Interactions-CR (+) & -0.06 & 0.176 & -0.14 & 0.117 & 0.319 & -0.04 & 0.326 & -0.10 & 0.184 & 0.723 \\
\hline Normative Beliefs About Aggression-CR (-) & 0.00 & 0.988 & -0.11 & 0.136 & 0.140 & 0.00 & 0.957 & -0.05 & 0.491 & 0.542 \\
\hline Empathy-CR (+) & -0.01 & 0.798 & -0.04 & 0.566 & 0.785 & -0.05 & 0.353 & 0.01 & 0.847 & 0.794 \\
\hline \multicolumn{11}{|l|}{ Behavior Domain } \\
\hline Altruistic Behavior-CR (+) & -0.03 & 0.516 & $-0.14^{\wedge}$ & 0.066 & 0.132 & -0.03 & 0.496 & 0.02 & 0.832 & 0.966 \\
\hline Altruistic Behavior-PCR (+) & -0.01 & 0.866 & 0.02 & 0.820 & 0.618 & -0.04 & 0.443 & 0.01 & 0.950 & 0.246 \\
\hline Altruistic Behavior-TRS (+) & 0.02 & 0.903 & -0.01 & 0.971 & 0.793 & -0.02 & 0.868 & -0.05 & 0.676 & 0.420 \\
\hline Positive Social Behavior-PCR (+) & 0.01 & 0.813 & $0.13^{\wedge}$ & 0.093 & $0.067^{\wedge}$ & 0.02 & 0.691 & 0.02 & 0.825 & 0.444 \\
\hline Positive Social Behavior-TRS (+) & -0.02 & 0.818 & -0.06 & 0.462 & 0.680 & 0.05 & 0.460 & -0.03 & 0.679 & 0.361 \\
\hline Problem Behavior-CR (-) & -0.01 & 0.871 & 0.02 & 0.827 & 0.473 & 0.01 & 0.852 & 0.02 & 0.747 & 0.380 \\
\hline Problem Behavior-PCR (-) & -0.05 & 0.244 & -0.11 & 0.160 & 0.195 & -0.05 & 0.426 & -0.04 & 0.610 & 0.634 \\
\hline Problem Behavior-TRS (-) & -0.04 & 0.486 & 0.04 & 0.648 & 0.370 & -0.07 & 0.293 & 0.02 & 0.826 & 0.353 \\
\hline ADHD-Related Behavior-TRS (-) & -0.03 & 0.590 & -0.01 & 0.880 & 0.913 & -0.09 & 0.121 & 0.01 & 0.873 & 0.333 \\
\hline \multicolumn{11}{|l|}{ Academics Domain } \\
\hline Engagement with Learning-CR (+) & -0.03 & 0.533 & -0.06 & 0.396 & 0.773 & -0.05 & 0.331 & 0.01 & 0.876 & 0.443 \\
\hline Academic Competence and Motivation-TRS (+) & -0.07 & 0.170 & -0.05 & 0.494 & 0.645 & -0.02 & 0.739 & -0.07 & 0.363 & 0.275 \\
\hline
\end{tabular}




\section{Table 1.29. Combined-program impacts on child outcomes, by stayer versus new entrant-Continued}

\begin{tabular}{|c|c|c|c|c|c|c|c|c|c|c|}
\hline \multirow[b]{3}{*}{ Scale-Report } & \multicolumn{5}{|c|}{$\begin{array}{c}\text { Year } 2 \\
\text { (Spring 4th grade) }\end{array}$} & \multicolumn{5}{|c|}{$\begin{array}{c}\text { Year } 3 \\
\text { (Spring 5th grade) }\end{array}$} \\
\hline & \multicolumn{2}{|c|}{ Stayers } & \multicolumn{2}{|c|}{ New entrants } & \multirow[b]{2}{*}{$\begin{array}{l}p \text {-value for } \\
\text { difference }^{1}\end{array}$} & \multicolumn{2}{|c|}{ Stayers } & \multicolumn{2}{|c|}{ New entrants } & \multirow[b]{2}{*}{$\begin{array}{l}p \text {-value for } \\
\text { difference }^{1}\end{array}$} \\
\hline & $\begin{array}{r}\text { Effect } \\
\text { size }\end{array}$ & $p$-value & $\begin{array}{r}\text { Effect } \\
\text { size }\end{array}$ & $p$-value & & $\begin{array}{r}\text { Effect } \\
\text { size }\end{array}$ & $p$-value & $\begin{array}{r}\text { Effect } \\
\text { size }\end{array}$ & $p$-value & \\
\hline \multicolumn{11}{|l|}{ Perceptions of School Climate Domain } \\
\hline Positive School Orientation-CR (+) & 0.05 & 0.561 & 0.05 & 0.595 & 0.225 & -0.05 & 0.526 & -0.07 & 0.430 & 0.559 \\
\hline Negative School Orientation-CR (-) & -0.05 & 0.432 & 0.08 & 0.280 & $0.053^{\wedge}$ & -0.04 & 0.493 & 0.05 & 0.524 & 0.230 \\
\hline Student Afraid at School-CR (-) & -0.05 & 0.418 & -0.01 & 0.889 & 0.676 & 0.02 & 0.717 & -0.02 & 0.824 & 0.329 \\
\hline Victimization at School-CR (-) & -0.05 & 0.353 & -0.04 & 0.626 & 0.622 & 0.01 & 0.845 & 0.02 & 0.830 & 0.663 \\
\hline
\end{tabular}

$\wedge$ Significantly different from zero at the .10 to $>.05$ level.

'From the test of a significant difference between Stayers' effect size and New Entrants' effect size.

NOTE: Abbreviations are

CR: Child Report

PCR: Primary Caregiver Report

TRS: Teacher Report on Student

ADHD: Attention deficit hyperactivity disorder

The +/- signs in parentheses indicate the direction of a beneficial outcome. No findings were found statistically significant at or below the .05 level. All impact estimates were calculated using regression models in which each program and school within a program was weighted equally. The standard errors of all estimates account for design effects due to unequal weighting and the clustering of students within schools. The effect size was calculated by dividing the estimated impact by the standard deviation of the outcome measure for the SOURCE: The Social and Character Development (SACD) Research Program. 


\section{Chapter 1. The Social and Character Development Multiprogram Evaluation}

\section{Initial Risk}

The impacts of the seven SACD programs, considered together, on initial student risk were examined using five risk measures (one measure each for socioeconomic risk, family risk, and perceptions of community risk, and two measures for child behavior risk). The significance of the change in the impact estimate over a oneunit change (moving one level between the three risk levels) in the risk measure (termed the marginal effect) was tested (see tables 1.30 to 1.34). A total of 270 marginal effects were tested over the 3 years ( 90 per year), and 13 to 14 would be expected to be significant by chance. A total of 41 were found significant-13 from Year 1, 17 from Year 2, and 11 from Year 3. Of these 41 significant findings, 26 showed a more beneficial marginal impact for high-risk students and 15 showed a more detrimental impact for high-risk students compared to lower risk students. Six of these findings were repeated in at least 2 different years, with 1 of these repeated all 3 years ( 4 showing a more beneficial marginal effect for high-risk students and 2 showing a detrimental impact).

For 24 of the 41 significant marginal effects, there were no significant findings from the subgroup-specific regressions. In 12 of the 41 significant marginal effects, the subgroup-specific regressions supported the interpretation of the marginal effect ( 6 results supported a more beneficial impact for high-risk students and 6 results supported a more detrimental impact for high-risk students). In the remaining 5 significant marginal effects, the subgroup-specific regressions supported a different interpretation: (1) a detrimental effect on lower risk students rather than a beneficial impact on higher risk students in two cases, and (2) a beneficial effect on lower risk students rather than a detrimental impact on higher risk students in three cases.

The low number, mixed direction (beneficial and detrimental), and lack of repeated findings of the significant results provide little evidence of a relationship between risk levels and the impact of the seven SACD programs considered together. Discussions of the results for each type of risk follow.

\section{Socioeconomic Risk}

For initial socioeconomic risk, there were 5 significant marginal effects, all showing detrimental impacts on high-risk students. From the 54 comparisons made, 3 significant differences would be expected by chance. Table 1.30 presents the impacts of the seven programs together on the outcome measures by level of student socioeconomic risk. An example may help in the interpretation of the table. For the outcome Engagement with Learning under the Academics domain, in Year 1 the estimated marginal effect of -0.131 indicates that, as the risk level increased one unit, the estimated impact of the seven SACD programs together decreased by 0.131. This estimate of the marginal effect was statistically significantly different from zero, providing evidence that the estimated impact of the seven SACD programs, as a group, on this outcome varied across socioeconomic risk levels (in this case it was detrimental as Engagement with Learning declined as risk increased). The results from the subgroup-specific regressions are provided at three levels of initial risk: (1) low, which is one standard deviation below the mean socioeconomic risk level; (2) average, which is the mean risk level; and (3) high, which is one standard deviation above the mean risk level. In Year 1, at the low level of socioeconomic risk, the estimated impact was 0.041 and nonsignificant. As the level of socioeconomic risk increased to the mean level, with all else held equal, the point estimate for the impact estimate changed to a nonsignificant -0.049 . As the level of socioeconomic risk continued to increase to one standard deviation above the mean level, all else held equal, the estimated impact changed to -0.154 . The point estimate for the impact at the high level of risk was statistically significantly different from zero, providing additional evidence that the seven SACD programs, together, had a detrimental impact on Engagement with Learning for students at high socioeconomic risk. However, as these results were not repeated for Years 2 and 3, no clear pattern of impact on this outcome emerged.

In addition to a reduction in Engagement with Learning, the high-risk students experienced a detrimental program impact on four other outcomes: declines in Altruistic Behavior (Teacher Report in Year 1) and Positive School Orientation (Year 1) and gains in Negative School Orientation (Year 1) and Student Afraid at School (Year 3). None of the significant marginal effects occurred for more than 1 year. 
Table 1.30. Combined-program impacts on child outcomes, by initial socioeconomic risk

\begin{tabular}{|c|c|c|c|c|c|c|c|c|c|c|c|c|}
\hline \multirow[b]{3}{*}{ Scale-Report } & \multicolumn{4}{|c|}{$\begin{array}{c}\text { Year } 1 \\
\text { (Spring 3rd grade) }\end{array}$} & \multicolumn{4}{|c|}{$\begin{array}{c}\text { Year } 2 \\
\text { (Spring 4th grade) }\end{array}$} & \multicolumn{4}{|c|}{$\begin{array}{c}\text { Year 3 } \\
\text { (Spring 5th grade) }\end{array}$} \\
\hline & \multicolumn{3}{|c|}{$\begin{array}{l}\text { Effect size at risk level } \\
(p \text {-value })\end{array}$} & \multirow{2}{*}{$\begin{array}{r}\text { Marg- } \\
\text { inal } \\
\text { effect }^{4} \\
(p \text {-value }) \\
\end{array}$} & \multicolumn{3}{|c|}{$\begin{array}{l}\text { Effect size at risk level } \\
(p \text {-value })\end{array}$} & \multirow{2}{*}{$\begin{array}{r}\text { Marg- } \\
\text { inal } \\
\text { effect }^{4} \\
(p \text {-value })\end{array}$} & \multicolumn{3}{|c|}{$\begin{array}{l}\text { Effect size at risk level } \\
(p \text {-value })\end{array}$} & \multirow{2}{*}{$\begin{array}{r}\text { Marg- } \\
\text { inal } \\
\text { effect }^{4} \\
(p \text {-value })\end{array}$} \\
\hline & Low $^{1}$ & $\begin{array}{l}\text { Aver- } \\
\text { age }^{2}\end{array}$ & $\mathrm{High}^{3}$ & & Low $^{1}$ & $\begin{array}{l}\text { Aver- } \\
\text { age }^{2}\end{array}$ & $\mathrm{High}^{3}$ & & Low $^{1}$ & $\begin{array}{l}\text { Aver- } \\
\text { age }^{2}\end{array}$ & $\mathrm{High}^{3}$ & \\
\hline \multicolumn{13}{|l|}{$\begin{array}{l}\text { Social and Emotional } \\
\text { Competence Domain }\end{array}$} \\
\hline $\begin{array}{l}\text { Self-Efficacy for Peer } \\
\text { Interactions-CR }(+)\end{array}$ & $\begin{array}{r}-0.005 \\
(0.922)\end{array}$ & $\begin{array}{l}-0.027 \\
(0.490)\end{array}$ & $\begin{array}{r}-0.052 \\
(0.298)\end{array}$ & $\begin{array}{r}-0.032 \\
(0.433)\end{array}$ & $\begin{array}{l}-0.075 \\
(0.165)\end{array}$ & $\begin{array}{l}-0.077^{\wedge} \\
(0.089)\end{array}$ & $\begin{array}{l}-0.079 \\
(0.161)\end{array}$ & $\begin{array}{r}-0.003 \\
(0.955)\end{array}$ & $\begin{array}{l}-0.065 \\
(0.190)\end{array}$ & $\begin{array}{l}-0.042 \\
(0.284)\end{array}$ & $\begin{array}{r}-0.015 \\
(0.779)\end{array}$ & $\begin{array}{r}0.038 \\
(0.439)\end{array}$ \\
\hline $\begin{array}{l}\text { Normative Beliefs } \\
\text { About Aggression-CR (-) }\end{array}$ & $\begin{array}{r}-0.024 \\
(0.655)\end{array}$ & $\begin{array}{r}0.001 \\
(0.982)\end{array}$ & $\begin{array}{r}0.026 \\
(0.642)\end{array}$ & $\begin{array}{r}0.033 \\
(0.449)\end{array}$ & $\begin{array}{r}-0.002 \\
(0.976)\end{array}$ & $\begin{array}{r}-0.009 \\
(0.881)\end{array}$ & $\begin{array}{r}-0.018 \\
(0.801)\end{array}$ & $\begin{array}{r}-0.012 \\
(0.810)\end{array}$ & $\begin{array}{r}0.047 \\
(0.479)\end{array}$ & $\begin{array}{r}0.032 \\
(0.576)\end{array}$ & $\begin{array}{r}0.015 \\
(0.822)\end{array}$ & $\begin{array}{r}-0.024 \\
(0.637)\end{array}$ \\
\hline Empathy-CR (+) & $\begin{array}{c}0.124^{*} \\
(0.038)\end{array}$ & $\begin{array}{r}0.077 \\
(0.129)\end{array}$ & $\begin{array}{r}-0.022 \\
(0.713)\end{array}$ & $\begin{array}{r}-0.069 \\
(0.110)\end{array}$ & $\begin{array}{r}-0.009 \\
(0.891)\end{array}$ & $\begin{array}{c}-0.027 \\
(0.632)\end{array}$ & $\begin{array}{r}-0.048 \\
(0.457)\end{array}$ & $\begin{array}{r}-0.031 \\
(0.533)\end{array}$ & $\begin{array}{r}-0.019 \\
(0.777)\end{array}$ & $\begin{array}{r}-0.068 \\
(0.255)\end{array}$ & $\begin{array}{c}-0.126^{\wedge} \\
(0.073)\end{array}$ & $\begin{array}{r}-0.081 \\
(0.122)\end{array}$ \\
\hline \multicolumn{13}{|l|}{ Behavior Domain } \\
\hline $\begin{array}{l}\text { Altruistic Behavior- } \\
\text { CR (+) }\end{array}$ & $\begin{array}{r}-0.012 \\
(0.800)\end{array}$ & $\begin{array}{r}-0.054 \\
(0.169)\end{array}$ & $\begin{array}{l}-0.102^{*} \\
(0.044)\end{array}$ & $\begin{array}{r}-0.060 \\
(0.138)\end{array}$ & $\begin{array}{r}-0.081 \\
(0.139)\end{array}$ & $\begin{array}{r}-0.067 \\
(0.143)\end{array}$ & $\begin{array}{r}-0.051 \\
(0.375)\end{array}$ & $\begin{array}{r}0.024 \\
(0.628)\end{array}$ & $\begin{array}{r}-0.073 \\
(0.171)\end{array}$ & $\begin{array}{r}-0.031 \\
(0.470)\end{array}$ & $\begin{array}{r}0.018 \\
(0.744)\end{array}$ & $\begin{array}{r}0.069 \\
(0.168)\end{array}$ \\
\hline $\begin{array}{l}\text { Altruistic Behavior- } \\
\text { PCR }(+)\end{array}$ & $\begin{array}{r}0.047 \\
(0.322)\end{array}$ & $\begin{array}{r}0.032 \\
(0.396)\end{array}$ & $\begin{array}{r}0.014 \\
(0.781)\end{array}$ & $\begin{array}{r}-0.023 \\
(0.590)\end{array}$ & $\begin{array}{r}-0.008 \\
(0.884)\end{array}$ & $\begin{array}{r}0.006 \\
(0.900)\end{array}$ & $\begin{array}{r}0.022 \\
(0.697)\end{array}$ & $\begin{array}{r}0.023 \\
(0.643)\end{array}$ & $\begin{array}{r}0.010 \\
(0.882)\end{array}$ & $\begin{array}{r}-0.013 \\
(0.811)\end{array}$ & $\begin{array}{r}-0.040 \\
(0.549)\end{array}$ & $\begin{array}{r}-0.038 \\
(0.495)\end{array}$ \\
\hline $\begin{array}{l}\text { Altruistic Behavior- } \\
\text { TRS (+) }\end{array}$ & $\begin{array}{r}0.164 \\
(0.102)\end{array}$ & $\begin{array}{r}0.085 \\
(0.365)\end{array}$ & $\begin{array}{r}-0.006 \\
(0.950)\end{array}$ & $\begin{array}{l}-0.115^{*} \\
(0.011)\end{array}$ & $\begin{array}{r}0.035 \\
(0.827)\end{array}$ & $\begin{array}{r}0.014 \\
(0.931)\end{array}$ & $\begin{array}{r}-0.012 \\
(0.940)\end{array}$ & $\begin{array}{r}-0.037 \\
(0.492)\end{array}$ & $\begin{array}{r}-0.030 \\
(0.808)\end{array}$ & $\begin{array}{r}-0.052 \\
(0.661)\end{array}$ & $\begin{array}{r}-0.078 \\
(0.526)\end{array}$ & $\begin{array}{r}-0.037 \\
(0.457)\end{array}$ \\
\hline $\begin{array}{l}\text { Positive Social } \\
\text { Behavior-PCR (+) }\end{array}$ & $\begin{array}{r}-0.012 \\
(0.751)\end{array}$ & $\begin{array}{r}-0.026 \\
(0.394)\end{array}$ & $\begin{array}{r}-0.041 \\
(0.298)\end{array}$ & $\begin{array}{r}-0.020 \\
(0.555)\end{array}$ & $\begin{array}{r}0.025 \\
(0.603)\end{array}$ & $\begin{array}{r}0.042 \\
(0.285)\end{array}$ & $\begin{array}{r}0.062 \\
(0.207)\end{array}$ & $\begin{array}{r}0.029 \\
(0.509)\end{array}$ & $\begin{array}{r}0.027 \\
(0.619)\end{array}$ & $\begin{array}{r}0.036 \\
(0.429)\end{array}$ & $\begin{array}{r}0.045 \\
(0.425)\end{array}$ & $\begin{array}{r}0.014 \\
(0.786)\end{array}$ \\
\hline $\begin{array}{l}\text { Positive Social } \\
\text { Behavior-TRS (+) }\end{array}$ & $\begin{array}{r}0.020 \\
(0.693)\end{array}$ & $\begin{array}{r}-0.002 \\
(0.968)\end{array}$ & $\begin{array}{r}-0.027 \\
(0.594)\end{array}$ & $\begin{array}{r}-0.031 \\
(0.315)\end{array}$ & $\begin{array}{r}0.002 \\
(0.979)\end{array}$ & $\begin{array}{r}-0.032 \\
(0.670)\end{array}$ & $\begin{array}{r}-0.072 \\
(0.370)\end{array}$ & $\begin{array}{r}-0.058 \\
(0.212)\end{array}$ & $\begin{array}{r}0.058 \\
(0.459)\end{array}$ & $\begin{array}{r}0.009 \\
(0.906)\end{array}$ & $\begin{array}{r}-0.050 \\
(0.530)\end{array}$ & $\begin{array}{l}-0.082^{\wedge} \\
(0.089)\end{array}$ \\
\hline $\begin{array}{l}\text { Problem Behavior- } \\
\text { CR (-) }\end{array}$ & $\begin{array}{r}-0.029 \\
(0.620)\end{array}$ & $\begin{array}{r}-0.001 \\
(0.983)\end{array}$ & $\begin{array}{r}0.031 \\
(0.597)\end{array}$ & $\begin{array}{r}0.040 \\
(0.318)\end{array}$ & $\begin{array}{r}0.000 \\
(0.997)\end{array}$ & $\begin{array}{r}-0.002 \\
(0.971)\end{array}$ & $\begin{array}{r}-0.006 \\
(0.940)\end{array}$ & $\begin{array}{r}-0.005 \\
(0.925)\end{array}$ & $\begin{array}{r}0.028 \\
(0.708)\end{array}$ & $\begin{array}{r}0.073 \\
(0.293)\end{array}$ & $\begin{array}{r}0.124 \\
(0.108)\end{array}$ & $\begin{array}{r}0.073 \\
(0.151)\end{array}$ \\
\hline $\begin{array}{l}\text { Problem Behavior- } \\
\text { PCR (-) }\end{array}$ & $\begin{array}{r}-0.015 \\
(0.752)\end{array}$ & $\begin{array}{r}0.010 \\
(0.801)\end{array}$ & $\begin{array}{r}0.039 \\
(0.423)\end{array}$ & $\begin{array}{r}0.037 \\
(0.327)\end{array}$ & $\begin{array}{r}0.005 \\
(0.910)\end{array}$ & $\begin{array}{r}-0.013 \\
(0.743)\end{array}$ & $\begin{array}{r}-0.034 \\
(0.493)\end{array}$ & $\begin{array}{r}-0.030 \\
(0.509)\end{array}$ & $\begin{array}{r}-0.070 \\
(0.230)\end{array}$ & $\begin{array}{r}-0.034 \\
(0.478)\end{array}$ & $\begin{array}{r}0.009 \\
(0.877)\end{array}$ & $\begin{array}{r}0.061 \\
(0.267)\end{array}$ \\
\hline $\begin{array}{l}\text { Problem Behavior- } \\
\text { TRS (-) }\end{array}$ & $\begin{array}{r}-0.009 \\
(0.871)\end{array}$ & $\begin{array}{r}0.052 \\
(0.293)\end{array}$ & $\begin{array}{l}0.101^{\wedge} \\
(0.066)\end{array}$ & $\begin{array}{l}0.062^{\wedge} \\
(0.056)\end{array}$ & $\begin{array}{r}-0.004 \\
(0.950)\end{array}$ & $\begin{array}{r}-0.006 \\
(0.914)\end{array}$ & $\begin{array}{r}-0.009 \\
(0.891)\end{array}$ & $\begin{array}{r}-0.004 \\
(0.931)\end{array}$ & $\begin{array}{r}-0.043 \\
(0.572)\end{array}$ & $\begin{array}{r}-0.034 \\
(0.621)\end{array}$ & $\begin{array}{r}-0.024 \\
(0.752)\end{array}$ & $\begin{array}{r}0.014 \\
(0.768)\end{array}$ \\
\hline $\begin{array}{l}\text { ADHD-Related } \\
\text { Behavior-TRS (-) }\end{array}$ & $\begin{array}{r}0.022 \\
(0.645)\end{array}$ & $\begin{array}{r}0.020 \\
(0.635)\end{array}$ & $\begin{array}{r}0.018 \\
(0.716)\end{array}$ & $\begin{array}{r}-0.003 \\
(0.923)\end{array}$ & $\begin{array}{r}-0.004 \\
(0.953)\end{array}$ & $\begin{array}{r}-0.019 \\
(0.724)\end{array}$ & $\begin{array}{r}-0.038 \\
(0.546)\end{array}$ & $\begin{array}{r}-0.026 \\
(0.565)\end{array}$ & $\begin{array}{r}-0.053 \\
(0.459)\end{array}$ & $\begin{array}{r}-0.067 \\
(0.297)\end{array}$ & $\begin{array}{r}-0.084 \\
(0.243)\end{array}$ & $\begin{array}{r}-0.024 \\
(0.615)\end{array}$ \\
\hline
\end{tabular}


Table 1.30. Combined-program impacts on child outcomes, by initial socioeconomic risk-Continued

\begin{tabular}{|c|c|c|c|c|c|c|c|c|c|c|c|c|}
\hline \multirow[b]{3}{*}{ Scale-Report } & \multicolumn{4}{|c|}{$\begin{array}{c}\text { Year } 1 \\
\text { (Spring 3rd grade) } \\
\end{array}$} & \multicolumn{4}{|c|}{$\begin{array}{c}\text { Year } 2 \\
\text { (Spring 4th grade) }\end{array}$} & \multicolumn{4}{|c|}{$\begin{array}{c}\text { Year } 3 \\
\text { (Spring 5th grade) }\end{array}$} \\
\hline & \multicolumn{3}{|c|}{$\begin{array}{l}\text { Effect size at risk level } \\
(p \text {-value })\end{array}$} & \multirow{2}{*}{$\begin{array}{r}\text { Marg- } \\
\text { inal } \\
\text { effect }^{4} \\
(p \text {-value }) \\
\end{array}$} & \multicolumn{3}{|c|}{$\begin{array}{l}\text { Effect size at risk level } \\
\text { (p-value) }\end{array}$} & \multirow{2}{*}{$\begin{array}{r}\text { Marg- } \\
\text { inal } \\
\text { effect }^{4} \\
(p \text {-value })\end{array}$} & \multicolumn{3}{|c|}{$\begin{array}{l}\text { Effect size at risk level } \\
\text { ( } p \text {-value })\end{array}$} & \multirow{2}{*}{$\begin{array}{r}\text { Marg- } \\
\text { inal } \\
\text { effect }^{4} \\
(p \text {-value })\end{array}$} \\
\hline & Low $^{1}$ & $\begin{array}{l}\text { Aver- } \\
\text { age }^{2}\end{array}$ & $\mathrm{High}^{3}$ & & Low $^{1}$ & $\begin{array}{l}\text { Aver- } \\
\text { age }^{2}\end{array}$ & $\mathrm{High}^{3}$ & & Low $^{1}$ & $\begin{array}{l}\text { Aver- } \\
\text { age }^{2}\end{array}$ & $\mathrm{High}^{3}$ & \\
\hline \multicolumn{13}{|l|}{ Academics Domain } \\
\hline $\begin{array}{l}\text { Engagement with } \\
\text { Learning-CR (+) }\end{array}$ & $\begin{array}{r}0.041 \\
(0.394)\end{array}$ & $\begin{array}{r}-0.049 \\
(0.202)\end{array}$ & $\begin{array}{l}-0.154^{\star *} \\
(0.003)\end{array}$ & $\begin{array}{l}-0.131^{* *} \\
(0.003)\end{array}$ & $\begin{array}{l}-0.037 \\
(0.421)\end{array}$ & $\begin{array}{l}-0.030 \\
(0.412)\end{array}$ & $\begin{array}{l}-0.021 \\
(0.668)\end{array}$ & $\begin{array}{r}0.012 \\
(0.796)\end{array}$ & $\begin{array}{l}-0.041 \\
(0.460)\end{array}$ & $\begin{array}{l}-0.046 \\
(0.318)\end{array}$ & $\begin{array}{l}-0.051 \\
(0.377)\end{array}$ & $\begin{array}{r}-0.008 \\
(0.882)\end{array}$ \\
\hline $\begin{array}{l}\text { Academic Competence and } \\
\text { Motivation-TRS }(+)\end{array}$ & $\begin{array}{r}-0.013 \\
(0.688)\end{array}$ & $\begin{array}{r}-0.002 \\
(0.941)\end{array}$ & $\begin{array}{r}-0.011 \\
(0.743)\end{array}$ & $\begin{array}{r}0.017 \\
(0.532)\end{array}$ & $\begin{array}{l}-0.014 \\
(0.760)\end{array}$ & $\begin{array}{r}-0.016 \\
(0.687)\end{array}$ & $\begin{array}{r}-0.018 \\
(0.703)\end{array}$ & $\begin{array}{l}-0.003 \\
(0.936)\end{array}$ & $\begin{array}{r}0.029 \\
(0.622)\end{array}$ & $\begin{array}{r}0.019 \\
(0.713)\end{array}$ & $\begin{array}{r}0.008 \\
(0.899)\end{array}$ & $\begin{array}{r}-0.016 \\
(0.707)\end{array}$ \\
\hline \multicolumn{13}{|l|}{$\begin{array}{l}\text { Perceptions of School } \\
\text { Climate Domain }\end{array}$} \\
\hline $\begin{array}{l}\text { Positive School } \\
\text { Orientation-CR (+) }\end{array}$ & $\begin{array}{r}0.092 \\
(0.237)\end{array}$ & $\begin{array}{r}0.011 \\
(0.876)\end{array}$ & $\begin{array}{r}-0.083 \\
(0.286)\end{array}$ & $\begin{array}{l}-0.118^{* *} \\
(0.009)\end{array}$ & $\begin{array}{r}0.058 \\
(0.509)\end{array}$ & $\begin{array}{r}0.028 \\
(0.732)\end{array}$ & $\begin{array}{r}-0.008 \\
(0.930)\end{array}$ & $\begin{array}{l}-0.051 \\
(0.315)\end{array}$ & $\begin{array}{r}-0.049 \\
(0.609)\end{array}$ & $\begin{array}{r}-0.090 \\
(0.311)\end{array}$ & $\begin{array}{r}-0.140 \\
(0.146)\end{array}$ & $\begin{array}{l}-0.070 \\
(0.178)\end{array}$ \\
\hline $\begin{array}{l}\text { Negative School } \\
\text { Orientation-CR (-) }\end{array}$ & $\begin{array}{l}-0.103^{\wedge} \\
(0.057)\end{array}$ & $\begin{array}{r}-0.045 \\
(0.319)\end{array}$ & $\begin{array}{r}0.023 \\
(0.672)\end{array}$ & $\begin{array}{c}0.085^{*} \\
(0.043)\end{array}$ & $\begin{array}{r}-0.019 \\
(0.783)\end{array}$ & $\begin{array}{r}-0.013 \\
(0.827)\end{array}$ & $\begin{array}{l}-0.007 \\
(0.922)\end{array}$ & $\begin{array}{r}0.009 \\
(0.852)\end{array}$ & $\begin{array}{r}-0.024 \\
(0.745)\end{array}$ & $\begin{array}{r}0.000 \\
(0.996)\end{array}$ & $\begin{array}{r}0.029 \\
(0.699)\end{array}$ & $\begin{array}{r}0.040 \\
(0.427)\end{array}$ \\
\hline $\begin{array}{l}\text { Student Afraid at } \\
\text { School-CR (-) }\end{array}$ & $\begin{array}{r}-0.088 \\
(0.139)\end{array}$ & $\begin{array}{r}-0.058 \\
(0.242)\end{array}$ & $\begin{array}{r}-0.024 \\
(0.688)\end{array}$ & $\begin{array}{r}0.043 \\
(0.331)\end{array}$ & $\begin{array}{r}-0.043 \\
(0.522)\end{array}$ & $\begin{array}{r}-0.049 \\
(0.410)\end{array}$ & $\begin{array}{r}-0.056 \\
(0.417)\end{array}$ & $\begin{array}{l}-0.010 \\
(0.849)\end{array}$ & $\begin{array}{r}-0.081 \\
(0.224)\end{array}$ & $\begin{array}{r}-0.019 \\
(0.743)\end{array}$ & $\begin{array}{r}0.054 \\
(0.427)\end{array}$ & $\begin{array}{r}0.103 \\
(0.047)\end{array}$ \\
\hline $\begin{array}{l}\text { Victimization at } \\
\text { School-CR (-) }\end{array}$ & $\begin{array}{r}-0.027 \\
(0.600)\end{array}$ & $\begin{array}{r}-0.009 \\
(0.835)\end{array}$ & $\begin{array}{r}0.012 \\
(0.814)\end{array}$ & $\begin{array}{r}0.026 \\
(0.528)\end{array}$ & $\begin{array}{r}-0.029 \\
(0.603)\end{array}$ & $\begin{array}{r}-0.048 \\
(0.303)\end{array}$ & $\begin{array}{r}-0.071 \\
(0.216)\end{array}$ & $\begin{array}{r}-0.033 \\
(0.503)\end{array}$ & $\begin{array}{r}0.012 \\
(0.838)\end{array}$ & $\begin{array}{r}0.014 \\
(0.771)\end{array}$ & $\begin{array}{r}0.017 \\
(0.777)\end{array}$ & $\begin{array}{r}0.004 \\
(0.938)\end{array}$ \\
\hline
\end{tabular}

* Significantly different from zero at the .05 level.

** Significantly different from zero at the .01 level.

$\wedge$ Significantly different from zero at the .10 to $>.05$ level.

${ }_{2}^{1}$ One standard deviation below the mean risk level.

${ }^{2}$ At the mean risk level.

${ }^{3}$ One standard deviation above the mean risk level.

${ }^{4}$ Change in impact as risk level increases by one unit.

NOTE: Abbreviations are

CR: Child Report

PCR: Primary Caregiver Report

TRS: Teacher Report on Student

ADHD: Attention deficit hyperactivity disorder

The +/- signs in parentheses indicate the direction of a beneficial outcome. All impact estimates were calculated using regression models in which each program and school within a program was weighted equally. The standard errors of all estimates account for design effects due to unequal weighting and the clustering of students within schools. The effect size was calculated by dividing the estimated impact by the standard deviation of the outcome measure for the control group.

SOURCE: The Social and Character Development (SACD) Research Program. 


\section{Family Risk}

Over the 3 years, there were 6 statistically significant marginal effects regarding level of family risk (table 1.31). From the 54 comparisons made, 3 significant differences would be expected by chance. Five of the significant results showed beneficial impacts for high-risk students: increases in Empathy (Year 1), Engagement with Learning (Year 3), and Academic Competence (Year 3), and declines in Problem Behavior (Child Report in Year 3) and Negative School Orientation (Year 3). The results from the subgroup-specific regressions provided support for the Empathy finding but offered an alternative explanation for the Engagement with Learning finding, as they suggested that the significant marginal effect was due to a detrimental effect on low-risk students rather than a beneficial impact on high-risk students.

The sixth significant marginal effect showed a detrimental impact on high-risk students of an increase in Student Afraid at School (Year 2). The subgroup-specific regression results suggested that this significant marginal effect was due to a beneficial effect on low-risk students rather than a detrimental impact on highrisk students. 
Table 1.31. Combined-program impacts on child outcomes, by initial family risk

\begin{tabular}{|c|c|c|c|c|c|c|c|c|c|c|c|c|}
\hline \multirow[b]{3}{*}{ Scale-Report } & \multicolumn{4}{|c|}{$\begin{array}{c}\text { Year } 1 \\
\text { (Spring 3rd grade) }\end{array}$} & \multicolumn{4}{|c|}{$\begin{array}{c}\text { Year } 2 \\
\text { (Spring 4th grade) }\end{array}$} & \multicolumn{4}{|c|}{$\begin{array}{c}\text { Year } 3 \\
\text { (Spring 5th grade) }\end{array}$} \\
\hline & \multicolumn{3}{|c|}{$\begin{array}{l}\text { Effect size at risk level } \\
(p \text {-value })\end{array}$} & \multirow{2}{*}{$\begin{array}{r}\text { Marg- } \\
\text { inal } \\
\text { effect }^{4} \\
(p \text {-value })\end{array}$} & \multicolumn{3}{|c|}{$\begin{array}{l}\text { Effect size at risk level } \\
(p \text {-value })\end{array}$} & \multirow{2}{*}{$\begin{array}{r}\text { Marg- } \\
\text { inal } \\
\text { effect }^{4} \\
(p \text {-value })\end{array}$} & \multicolumn{3}{|c|}{$\begin{array}{l}\text { Effect size at risk level } \\
(p \text {-value })\end{array}$} & \multirow{2}{*}{$\begin{array}{r}\text { Marg- } \\
\text { inal } \\
\text { effect }^{4} \\
(p \text {-value })\end{array}$} \\
\hline & Low $^{1}$ & $\begin{array}{l}\text { Aver- } \\
\text { age }^{2}\end{array}$ & $\mathrm{High}^{3}$ & & Low $^{1}$ & $\begin{array}{l}\text { Aver- } \\
\text { age }^{2}\end{array}$ & $\mathrm{High}^{3}$ & & Low $^{1}$ & $\begin{array}{l}\text { Aver- } \\
\text { age }^{2}\end{array}$ & $\mathrm{High}^{3}$ & \\
\hline \multicolumn{13}{|l|}{$\begin{array}{l}\text { Social and Emotional } \\
\text { Competence Domain }\end{array}$} \\
\hline $\begin{array}{l}\text { Self-Efficacy for Peer } \\
\text { Interactions-CR (+) }\end{array}$ & $\begin{array}{r}0.007 \\
(0.890)\end{array}$ & $\begin{array}{r}-0.031 \\
(0.434)\end{array}$ & $\begin{array}{r}-0.068 \\
(0.170)\end{array}$ & $\begin{array}{r}-0.169 \\
(0.215)\end{array}$ & $\begin{array}{r}-0.063 \\
(0.278)\end{array}$ & $\begin{array}{r}-0.052 \\
(0.261)\end{array}$ & $\begin{array}{r}-0.041 \\
(0.470)\end{array}$ & $\begin{array}{r}0.049 \\
(0.751)\end{array}$ & $\begin{array}{r}-0.059 \\
(0.309)\end{array}$ & $\begin{array}{r}-0.020 \\
(0.641)\end{array}$ & $\begin{array}{r}0.019 \\
(0.749)\end{array}$ & $\begin{array}{r}0.175 \\
(0.313)\end{array}$ \\
\hline $\begin{array}{l}\text { Normative Beliefs } \\
\text { About Aggression-CR (-) }\end{array}$ & $\begin{array}{r}0.036 \\
(0.532)\end{array}$ & $\begin{array}{r}-0.008 \\
(0.859)\end{array}$ & $\begin{array}{r}-0.052 \\
(0.359)\end{array}$ & $\begin{array}{l}-0.198 \\
(0.178)\end{array}$ & $\begin{array}{r}0.034 \\
(0.690)\end{array}$ & $\begin{array}{r}-0.003 \\
(0.969)\end{array}$ & $\begin{array}{r}-0.040 \\
(0.635)\end{array}$ & $\begin{array}{r}-0.165 \\
(0.301)\end{array}$ & $\begin{array}{r}0.072 \\
(0.396)\end{array}$ & $\begin{array}{r}-0.002 \\
(0.974)\end{array}$ & $\begin{array}{r}-0.076 \\
(0.362)\end{array}$ & $\begin{array}{l}-0.333^{\wedge} \\
(0.056)\end{array}$ \\
\hline Empathy-CR (+) & $\begin{array}{r}0.000 \\
(0.996)\end{array}$ & $\begin{array}{r}0.073 \\
(0.171)\end{array}$ & $\begin{array}{l}0.146^{*} \\
(0.019)\end{array}$ & $\begin{array}{l}0.329 * \\
(0.018)\end{array}$ & $\begin{array}{l}-0.056 \\
(0.400)\end{array}$ & $\begin{array}{r}-0.014 \\
(0.807)\end{array}$ & $\begin{array}{r}0.028 \\
(0.667)\end{array}$ & $\begin{array}{r}0.191 \\
(0.213)\end{array}$ & $\begin{array}{r}-0.084 \\
(0.277)\end{array}$ & $\begin{array}{l}-0.066 \\
(0.318)\end{array}$ & $\begin{array}{l}-0.049 \\
(0.523)\end{array}$ & $\begin{array}{r}0.079 \\
(0.650)\end{array}$ \\
\hline \multicolumn{13}{|l|}{ Behavior Domain } \\
\hline Altruistic Behavior-CR (+) & $\begin{array}{l}-0.124^{*} \\
(0.016)\end{array}$ & $\begin{array}{r}-0.067 \\
(0.104)\end{array}$ & $\begin{array}{r}-0.010 \\
(0.847)\end{array}$ & $\begin{array}{l}0.258^{\wedge} \\
(0.057)\end{array}$ & $\begin{array}{r}-0.100 \\
(0.109)\end{array}$ & $\begin{array}{r}-0.039 \\
(0.446)\end{array}$ & $\begin{array}{r}0.022 \\
(0.714)\end{array}$ & $\begin{array}{l}0.275^{\wedge} \\
(0.081)\end{array}$ & $\begin{array}{r}-0.068 \\
(0.299)\end{array}$ & $\begin{array}{r}-0.032 \\
(0.532)\end{array}$ & $\begin{array}{r}0.003 \\
(0.960)\end{array}$ & $\begin{array}{r}0.160 \\
(0.367)\end{array}$ \\
\hline Altruistic Behavior-PCR (+) & $\begin{array}{r}0.036 \\
(0.476)\end{array}$ & $\begin{array}{r}0.033 \\
(0.416)\end{array}$ & $\begin{array}{r}0.029 \\
(0.565)\end{array}$ & $\begin{array}{r}-0.017 \\
(0.905)\end{array}$ & $\begin{array}{r}0.021 \\
(0.720)\end{array}$ & $\begin{array}{r}0.000 \\
(0.996)\end{array}$ & $\begin{array}{l}-0.022 \\
(0.707)\end{array}$ & $\begin{array}{r}-0.097 \\
(0.532)\end{array}$ & $\begin{array}{r}-0.029 \\
(0.694)\end{array}$ & $\begin{array}{r}-0.041 \\
(0.505)\end{array}$ & $\begin{array}{r}-0.053 \\
(0.469)\end{array}$ & $\begin{array}{r}-0.053 \\
(0.767)\end{array}$ \\
\hline Altruistic Behavior-TRS (+) & $\begin{array}{r}0.095 \\
(0.353)\end{array}$ & $\begin{array}{r}0.080 \\
(0.414)\end{array}$ & $\begin{array}{r}0.064 \\
(0.527)\end{array}$ & $\begin{array}{r}-0.069 \\
(0.609)\end{array}$ & $\begin{array}{r}0.016 \\
(0.925)\end{array}$ & $\begin{array}{r}0.026 \\
(0.878)\end{array}$ & $\begin{array}{r}0.036 \\
(0.836)\end{array}$ & $\begin{array}{r}0.045 \\
(0.783)\end{array}$ & $\begin{array}{r}-0.093 \\
(0.480)\end{array}$ & $\begin{array}{r}-0.022 \\
(0.863)\end{array}$ & $\begin{array}{r}0.049 \\
(0.706)\end{array}$ & $\begin{array}{l}0.321^{\wedge} \\
(0.053)\end{array}$ \\
\hline $\begin{array}{l}\text { Positive Social } \\
\quad \text { Behavior-PCR (+) }\end{array}$ & $\begin{array}{l}-0.053 \\
(0.199)\end{array}$ & $\begin{array}{l}-0.025 \\
(0.439)\end{array}$ & $\begin{array}{r}0.003 \\
(0.940)\end{array}$ & $\begin{array}{r}0.125 \\
(0.267)\end{array}$ & $\begin{array}{r}-0.054 \\
(0.279)\end{array}$ & $\begin{array}{l}-0.005 \\
(0.891)\end{array}$ & $\begin{array}{r}0.043 \\
(0.373)\end{array}$ & $\begin{array}{l}0.218^{\wedge} \\
(0.094)\end{array}$ & $\begin{array}{l}-0.041 \\
(0.542)\end{array}$ & $\begin{array}{r}0.010 \\
(0.865)\end{array}$ & $\begin{array}{r}0.060 \\
(0.364)\end{array}$ & $\begin{array}{r}0.226 \\
(0.146)\end{array}$ \\
\hline $\begin{array}{l}\text { Positive Social } \\
\quad \text { Behavior-TRS (+) }\end{array}$ & $\begin{array}{r}-0.043 \\
(0.407)\end{array}$ & $\begin{array}{r}-0.005 \\
(0.920)\end{array}$ & $\begin{array}{r}0.033 \\
(0.515)\end{array}$ & $\begin{array}{l}0.171^{\wedge} \\
(0.077)\end{array}$ & $\begin{array}{r}-0.064 \\
(0.460)\end{array}$ & $\begin{array}{r}-0.037 \\
(0.653)\end{array}$ & $\begin{array}{r}-0.009 \\
(0.917)\end{array}$ & $\begin{array}{r}0.125 \\
(0.354)\end{array}$ & $\begin{array}{r}-0.012 \\
(0.887)\end{array}$ & $\begin{array}{r}0.030 \\
(0.712)\end{array}$ & $\begin{array}{r}0.072 \\
(0.409)\end{array}$ & $\begin{array}{r}0.190 \\
(0.209)\end{array}$ \\
\hline Problem Behavior-CR (-) & $\begin{array}{r}0.051 \\
(0.392)\end{array}$ & $\begin{array}{r}0.004 \\
(0.933)\end{array}$ & $\begin{array}{r}-0.060 \\
(0.314)\end{array}$ & $\begin{array}{c}-0.251^{\wedge} \\
(0.053)\end{array}$ & $\begin{array}{r}0.018 \\
(0.827)\end{array}$ & $\begin{array}{r}-0.025 \\
(0.737)\end{array}$ & $\begin{array}{r}-0.069 \\
(0.402)\end{array}$ & $\begin{array}{r}-0.196 \\
(0.182)\end{array}$ & $\begin{array}{r}0.141 \\
(0.106)\end{array}$ & $\begin{array}{r}0.034 \\
(0.666)\end{array}$ & $\begin{array}{r}-0.073 \\
(0.398)\end{array}$ & $\begin{array}{l}-0.483^{* *} \\
(0.004)\end{array}$ \\
\hline Problem Behavior-PCR (-) & $\begin{array}{r}-0.007 \\
(0.871)\end{array}$ & $\begin{array}{r}0.012 \\
(0.740)\end{array}$ & $\begin{array}{r}0.032 \\
(0.481)\end{array}$ & $\begin{array}{r}0.089 \\
(0.459)\end{array}$ & $\begin{array}{r}0.002 \\
(0.974)\end{array}$ & $\begin{array}{r}0.033 \\
(0.397)\end{array}$ & $\begin{array}{r}0.065 \\
(0.187)\end{array}$ & $\begin{array}{r}0.142 \\
(0.299)\end{array}$ & $\begin{array}{r}0.013 \\
(0.842)\end{array}$ & $\begin{array}{r}-0.019 \\
(0.720)\end{array}$ & $\begin{array}{r}-0.052 \\
(0.426)\end{array}$ & $\begin{array}{r}-0.147 \\
(0.377)\end{array}$ \\
\hline Problem Behavior-TRS (-) & $\begin{array}{r}0.090 \\
(0.108)\end{array}$ & $\begin{array}{r}0.053 \\
(0.301)\end{array}$ & $\begin{array}{r}-0.016 \\
(0.780)\end{array}$ & $\begin{array}{l}-0.168^{\wedge} \\
(0.097)\end{array}$ & $\begin{array}{r}0.031 \\
(0.677)\end{array}$ & $\begin{array}{r}-0.013 \\
(0.854)\end{array}$ & $\begin{array}{r}-0.057 \\
(0.448)\end{array}$ & $\begin{array}{r}-0.198 \\
(0.142)\end{array}$ & $\begin{array}{r}0.026 \\
(0.770)\end{array}$ & $\begin{array}{r}-0.033 \\
(0.685)\end{array}$ & $\begin{array}{r}-0.093 \\
(0.297)\end{array}$ & $\begin{array}{l}-0.267^{\wedge} \\
(0.082)\end{array}$ \\
\hline $\begin{array}{l}\text { ADHD-Related } \\
\text { Behavior-TRS (-) }\end{array}$ & $\begin{array}{r}0.026 \\
(0.593)\end{array}$ & $\begin{array}{r}0.016 \\
(0.714)\end{array}$ & $\begin{array}{r}-0.060 \\
(0.907)\end{array}$ & $\begin{array}{l}-0.045 \\
(0.648)\end{array}$ & $\begin{array}{r}-0.007 \\
(0.919)\end{array}$ & $\begin{array}{r}-0.029 \\
(0.636)\end{array}$ & $\begin{array}{l}-0.051 \\
(0.452)\end{array}$ & $\begin{array}{r}-0.100 \\
(0.460)\end{array}$ & $\begin{array}{r}-0.079 \\
(0.301)\end{array}$ & $\begin{array}{r}-0.091 \\
(0.184)\end{array}$ & $\begin{array}{r}-0.103 \\
(0.177)\end{array}$ & $\begin{array}{l}-0.053 \\
(0.730)\end{array}$ \\
\hline
\end{tabular}


Table 1.31. Combined-program impacts on child outcomes, by initial family risk-Continued

\begin{tabular}{|c|c|c|c|c|c|c|c|c|c|c|c|c|}
\hline \multirow[b]{3}{*}{ Scale-Report } & \multicolumn{4}{|c|}{$\begin{array}{c}\text { Year } 1 \\
\text { (Spring 3rd grade) } \\
\end{array}$} & \multicolumn{4}{|c|}{$\begin{array}{c}\text { Year } 2 \\
\text { (Spring 4th grade) }\end{array}$} & \multicolumn{4}{|c|}{$\begin{array}{c}\text { Year } 3 \\
\text { (Spring 5th grade) }\end{array}$} \\
\hline & \multicolumn{3}{|c|}{$\begin{array}{l}\text { Effect size at risk level } \\
(p \text {-value })\end{array}$} & \multirow{2}{*}{$\begin{array}{r}\text { Marg- } \\
\text { inal } \\
\text { effect }^{4} \\
(p \text {-value })\end{array}$} & \multicolumn{3}{|c|}{$\begin{array}{c}\text { Effect size at risk level } \\
(p \text {-value })\end{array}$} & \multirow{2}{*}{$\begin{array}{r}\text { Marg- } \\
\text { inal } \\
\text { effect }^{4} \\
(p \text {-value })\end{array}$} & \multicolumn{3}{|c|}{$\begin{array}{l}\text { Effect size at risk level } \\
(p \text {-value })\end{array}$} & \multirow{2}{*}{$\begin{array}{r}\text { Marg- } \\
\text { inal } \\
\text { effect }^{4} \\
(p \text {-value })\end{array}$} \\
\hline & Low $^{1}$ & $\begin{array}{r}\text { Aver- } \\
\text { age }^{2}\end{array}$ & $\mathrm{High}^{3}$ & & Low $^{1}$ & $\begin{array}{r}\text { Aver- } \\
\text { age }^{2}\end{array}$ & $\mathrm{High}^{3}$ & & Low $^{1}$ & $\begin{array}{r}\text { Aver- } \\
\text { age }^{2}\end{array}$ & $\mathrm{High}^{3}$ & \\
\hline \multicolumn{13}{|l|}{ Academics Domain } \\
\hline $\begin{array}{l}\text { Engagement with } \\
\text { Learning-CR }(+)\end{array}$ & $\begin{array}{l}-0.090^{\wedge} \\
(0.086)\end{array}$ & $\begin{array}{l}-0.056 \\
(0.170)\end{array}$ & $\begin{array}{l}-0.022 \\
(0.676)\end{array}$ & $\begin{array}{r}0.155 \\
(0.294)\end{array}$ & $\begin{array}{l}-0.081 \\
(0.159)\end{array}$ & $\begin{array}{l}-0.013 \\
(0.765)\end{array}$ & $\begin{array}{r}0.054 \\
(0.338)\end{array}$ & $\begin{array}{l}0.304^{\wedge} \\
(0.060)\end{array}$ & $\begin{array}{l}-0.152^{*} \\
(0.025)\end{array}$ & $\begin{array}{r}-0.067 \\
(0.206)\end{array}$ & $\begin{array}{r}0.018 \\
(0.790)\end{array}$ & $\begin{array}{l}0.382^{*} \\
(0.040)\end{array}$ \\
\hline $\begin{array}{l}\text { Academic Competence } \\
\text { and Motivation-TRS }(+)\end{array}$ & $\begin{array}{r}-0.013 \\
(0.694)\end{array}$ & $\begin{array}{r}-0.004 \\
(0.893)\end{array}$ & $\begin{array}{r}0.020 \\
(0.540)\end{array}$ & $\begin{array}{r}0.075 \\
(0.386)\end{array}$ & $\begin{array}{r}-0.043 \\
(0.387)\end{array}$ & $\begin{array}{r}-0.011 \\
(0.784)\end{array}$ & $\begin{array}{r}0.020 \\
(0.686)\end{array}$ & $\begin{array}{r}0.140 \\
(0.218)\end{array}$ & $\begin{array}{r}-0.069 \\
(0.291)\end{array}$ & $\begin{array}{r}0.003 \\
(0.953)\end{array}$ & $\begin{array}{r}0.075 \\
(0.243)\end{array}$ & $\begin{array}{l}0.324^{*} \\
(0.015)\end{array}$ \\
\hline \multicolumn{13}{|l|}{$\begin{array}{l}\text { Perceptions of School } \\
\text { Climate Domain }\end{array}$} \\
\hline $\begin{array}{l}\text { Positive School } \\
\text { Orientation-CR (+) }\end{array}$ & $\begin{array}{r}0.007 \\
(0.931)\end{array}$ & $\begin{array}{r}0.006 \\
(0.931)\end{array}$ & $\begin{array}{r}0.006 \\
(0.941)\end{array}$ & $\begin{array}{r}-0.003 \\
(0.985)\end{array}$ & $\begin{array}{r}0.002 \\
(0.983)\end{array}$ & $\begin{array}{r}0.040 \\
(0.647)\end{array}$ & $\begin{array}{r}0.079 \\
(0.402)\end{array}$ & $\begin{array}{r}0.173 \\
(0.256)\end{array}$ & $\begin{array}{r}-0.115 \\
(0.245)\end{array}$ & $\begin{array}{r}-0.085 \\
(0.353)\end{array}$ & $\begin{array}{r}-0.054 \\
(0.579)\end{array}$ & $\begin{array}{r}0.136 \\
(0.414)\end{array}$ \\
\hline $\begin{array}{l}\text { Negative School } \\
\text { Orientation-CR (-) }\end{array}$ & $\begin{array}{r}-0.065 \\
(0.272)\end{array}$ & $\begin{array}{r}-0.044 \\
(0.389)\end{array}$ & $\begin{array}{l}-0.023 \\
(0.699)\end{array}$ & $\begin{array}{r}0.096 \\
(0.478)\end{array}$ & $\begin{array}{r}0.000 \\
(0.997)\end{array}$ & $\begin{array}{r}-0.051 \\
(0.489)\end{array}$ & $\begin{array}{r}-0.101 \\
(0.211)\end{array}$ & $\begin{array}{r}-0.226 \\
(0.140)\end{array}$ & $\begin{array}{r}0.052 \\
(0.505)\end{array}$ & $\begin{array}{r}-0.051 \\
(0.461)\end{array}$ & $\begin{array}{l}-0.153^{\wedge} \\
(0.051)\end{array}$ & $\begin{array}{l}-0.461^{* *} \\
(0.006)\end{array}$ \\
\hline $\begin{array}{l}\text { Student Afraid at } \\
\text { School-CR (-) }\end{array}$ & $\begin{array}{r}-0.096 \\
(0.113)\end{array}$ & $\begin{array}{r}-0.058 \\
(0.257)\end{array}$ & $\begin{array}{r}-0.020 \\
(0.735)\end{array}$ & $\begin{array}{r}0.170 \\
(0.228)\end{array}$ & $\begin{array}{l}-0.175^{*} \\
(0.020)\end{array}$ & $\begin{array}{r}-0.084 \\
(0.192)\end{array}$ & $\begin{array}{r}0.006 \\
(0.932)\end{array}$ & $\begin{array}{c}0.408^{*} \\
(0.012)\end{array}$ & $\begin{array}{l}-0.001 \\
(0.989)\end{array}$ & $\begin{array}{r}0.003 \\
(0.968)\end{array}$ & $\begin{array}{r}0.007 \\
(0.933)\end{array}$ & $\begin{array}{r}0.018 \\
(0.918)\end{array}$ \\
\hline $\begin{array}{l}\text { Victimization at } \\
\text { School-CR (-) }\end{array}$ & $\begin{array}{r}-0.055 \\
(0.298)\end{array}$ & $\begin{array}{r}-0.004 \\
(0.935)\end{array}$ & $\begin{array}{r}0.048 \\
(0.361)\end{array}$ & $\begin{array}{c}0.232^{\wedge} \\
(0.090)\end{array}$ & $\begin{array}{r}-0.030 \\
(0.622)\end{array}$ & $\begin{array}{r}-0.042 \\
(0.396)\end{array}$ & $\begin{array}{r}-0.054 \\
(0.367)\end{array}$ & $\begin{array}{r}-0.054 \\
(0.727)\end{array}$ & $\begin{array}{r}0.036 \\
(0.604)\end{array}$ & $\begin{array}{r}0.008 \\
(0.894)\end{array}$ & $\begin{array}{r}-0.021 \\
(0.766)\end{array}$ & $\begin{array}{r}-0.128 \\
(0.451)\end{array}$ \\
\hline
\end{tabular}

* Significantly different from zero at the .05 level.

** Significantly different from zero at the .01 level.

$\wedge$ Significantly different from zero at the .10 to $>.05$ level.

${ }_{1}^{1}$ One standard deviation below the mean risk level.

${ }^{2}$ At the mean risk level.

${ }^{3}$ One standard deviation above the mean risk level.

${ }^{4}$ Change in impact as risk level increases by one unit.

NOTE: Abbreviations are

CR: Child Report

PCR: Primary Caregiver Report

TRS: Teacher Report on Student

ADHD: Attention deficit hyperactivity disorder

The +/- signs in parentheses indicate the direction of a beneficial outcome. All impact estimates were calculated using regression models in which each program and school within a program was weighted equally. The standard errors of all estimates account for design effects due to unequal weighting and the clustering of students within schools. The effect size was calculated by dividing the estimated impact by the standard deviation of the outcome measure for the control group.

SOURCE: The Social and Character Development (SACD) Research Program. 


\section{Perceptions of Community Risk.}

Over the 3 years, there were 10 significant marginal effects regarding level of perception of community risk (table 1.32). From the 54 comparisons made, 3 significant differences would be expected by chance. Six of the significant results showed beneficial marginal impacts for high-risk students: increases in Positive School Orientation (Year 2) and declines in Problem Behavior (Teacher Report in Year 2), ADHD-related behavior (Year 2), and Victimization at School (all 3 years). Only 1 of these 6 was supported by the subgroup-specific regressions with the finding of a beneficial impact of the decline in Victimization at School (Year 2) for highrisk students.

The 4 detrimental marginal impacts for high-risk students included declines in Empathy (Year 3) and Altruistic Behavior (Primary Caregiver Report in Year 3), and increases in Problem Behavior (Primary Caregiver Report in Years 1 and 2). In all four cases, the subgroup-specific regressions supported the finding of detrimental impact on all 4 outcomes for high-risk students. 
Table 1.32. Combined-program impacts on child outcomes, by initial perceptions of community risk

\begin{tabular}{|c|c|c|c|c|c|c|c|c|c|c|c|c|}
\hline \multirow[b]{3}{*}{ Scale-Report } & \multicolumn{4}{|c|}{$\begin{array}{c}\text { Year } 1 \\
\text { (Spring 3rd grade) }\end{array}$} & \multicolumn{4}{|c|}{$\begin{array}{c}\text { Year } 2 \\
\text { (Spring 4th grade) }\end{array}$} & \multicolumn{4}{|c|}{$\begin{array}{c}\text { Year 3 } \\
\text { (Spring 5th grade) }\end{array}$} \\
\hline & \multicolumn{3}{|c|}{$\begin{array}{l}\text { Effect size at risk level } \\
(p \text {-value })\end{array}$} & \multirow{2}{*}{$\begin{array}{r}\text { Marg- } \\
\text { inal } \\
\text { effect }^{4} \\
(p-v a l u e)\end{array}$} & \multicolumn{3}{|c|}{$\begin{array}{l}\text { Effect size at risk level } \\
(p \text {-value })\end{array}$} & \multirow{2}{*}{$\begin{array}{r}\text { Marg- } \\
\text { inal } \\
\text { effect }^{4} \\
(p \text {-value })\end{array}$} & \multicolumn{3}{|c|}{$\begin{array}{l}\text { Effect size at risk level } \\
(p \text {-value })\end{array}$} & \multirow{2}{*}{$\begin{array}{r}\text { Marg- } \\
\text { inal } \\
\text { effect }^{4} \\
(p \text {-value })\end{array}$} \\
\hline & Low $^{1}$ & $\begin{array}{r}\text { Aver- } \\
\text { age }^{2}\end{array}$ & $\overline{\mathrm{High}^{3}}$ & & Low $^{1}$ & $\begin{array}{r}\text { Aver- } \\
\text { age }^{2}\end{array}$ & $\mathrm{High}^{3}$ & & Low $^{1}$ & $\begin{array}{r}\text { Aver- } \\
\text { age }^{2}\end{array}$ & $\mathrm{High}^{3}$ & \\
\hline \multicolumn{13}{|l|}{$\begin{array}{l}\text { Social and Emotional } \\
\text { Competence Domain }\end{array}$} \\
\hline $\begin{array}{l}\text { Self-Efficacy for Peer } \\
\text { Interactions-CR }(+)\end{array}$ & $\begin{array}{r}-0.025 \\
(0.642)\end{array}$ & $\begin{array}{r}-0.029 \\
(0.491)\end{array}$ & $\begin{array}{r}-0.032 \\
(0.550)\end{array}$ & $\begin{array}{r}-0.005 \\
(0.923)\end{array}$ & $\begin{array}{l}-0.121^{\wedge} \\
(0.067)\end{array}$ & $\begin{array}{r}-0.064 \\
(0.204)\end{array}$ & $\begin{array}{r}-0.008 \\
(0.905)\end{array}$ & $\begin{array}{r}0.085 \\
(0.159)\end{array}$ & $\begin{array}{r}-0.061 \\
(0.323)\end{array}$ & $\begin{array}{r}-0.024 \\
(0.596)\end{array}$ & $\begin{array}{r}0.014 \\
(0.832)\end{array}$ & $\begin{array}{r}0.056 \\
(0.395)\end{array}$ \\
\hline $\begin{array}{l}\text { Normative Beliefs About } \\
\text { Aggression-CR (-) }\end{array}$ & $\begin{array}{r}0.033 \\
(0.582)\end{array}$ & $\begin{array}{r}-0.003 \\
(0.948)\end{array}$ & $\begin{array}{r}-0.040 \\
(0.504)\end{array}$ & $\begin{array}{r}-0.055 \\
(0.328)\end{array}$ & $\begin{array}{r}0.005 \\
(0.959)\end{array}$ & $\begin{array}{r}-0.008 \\
(0.914)\end{array}$ & $\begin{array}{r}-0.021 \\
(0.807)\end{array}$ & $\begin{array}{r}0.019 \\
(0.768)\end{array}$ & $\begin{array}{l}-0.035 \\
(0.699)\end{array}$ & $\begin{array}{r}-0.012 \\
(0.873)\end{array}$ & $\begin{array}{r}0.011 \\
(0.901)\end{array}$ & $\begin{array}{r}0.035 \\
(0.632)\end{array}$ \\
\hline Empathy-CR (+) & $\begin{array}{r}0.087 \\
(0.171)\end{array}$ & $\begin{array}{r}0.073 \\
(0.153)\end{array}$ & $\begin{array}{r}0.059 \\
(0.337)\end{array}$ & $\begin{array}{r}-0.021 \\
(0.698)\end{array}$ & $\begin{array}{r}0.013 \\
(0.860)\end{array}$ & $\begin{array}{r}-0.005 \\
(0.934)\end{array}$ & $\begin{array}{r}-0.022 \\
(0.747)\end{array}$ & $\begin{array}{r}-0.026 \\
(0.671)\end{array}$ & $\begin{array}{r}0.080 \\
(0.341)\end{array}$ & $\begin{array}{l}-0.054 \\
(0.423)\end{array}$ & $\begin{array}{l}-0.187^{*} \\
(0.023)\end{array}$ & * $\begin{array}{l}-0.200 \text { ** } \\
(0.006)\end{array}$ \\
\hline \multicolumn{13}{|l|}{ Behavior Domain } \\
\hline $\begin{array}{l}\text { Altruistic Behavior- } \\
\text { CR (+) }\end{array}$ & $\begin{array}{r}-0.035 \\
(0.523)\end{array}$ & $\begin{array}{r}-0.062 \\
(0.136)\end{array}$ & $\begin{array}{l}-0.089^{\wedge} \\
(0.095)\end{array}$ & $\begin{array}{r}-0.041 \\
(0.422)\end{array}$ & $\begin{array}{r}-0.060 \\
(0.356)\end{array}$ & $\begin{array}{r}-0.031 \\
(0.539)\end{array}$ & $\begin{array}{r}-0.001 \\
(0.990)\end{array}$ & $\begin{array}{r}0.045 \\
(0.460)\end{array}$ & $\begin{array}{r}-0.017 \\
(0.808)\end{array}$ & $\begin{array}{r}-0.023 \\
(0.647)\end{array}$ & $\begin{array}{r}-0.030 \\
(0.661)\end{array}$ & $\begin{array}{r}-0.010 \\
(0.881)\end{array}$ \\
\hline $\begin{array}{l}\text { Altruistic Behavior- } \\
\text { PCR (+) }\end{array}$ & $\begin{array}{r}0.030 \\
(0.538)\end{array}$ & $\begin{array}{r}0.036 \\
(0.315)\end{array}$ & $\begin{array}{r}0.042 \\
(0.386)\end{array}$ & $\begin{array}{r}0.008 \\
(0.864)\end{array}$ & $\begin{array}{r}0.079 \\
(0.205)\end{array}$ & $\begin{array}{r}0.004 \\
(0.927)\end{array}$ & $\begin{array}{r}-0.070 \\
(0.238)\end{array}$ & $\begin{array}{l}-0.112^{\wedge} \\
(0.060)\end{array}$ & $\begin{array}{l}0.129^{\wedge} \\
(0.082)\end{array}$ & $\begin{array}{r}-0.024 \\
(0.670)\end{array}$ & $\begin{array}{l}-0.176^{*} \\
(0.015)\end{array}$ & $\begin{array}{l}-0.228^{* *} \\
(0.001)\end{array}$ \\
\hline $\begin{array}{l}\text { Altruistic Behavior- } \\
\text { TRS }(+)\end{array}$ & $\begin{array}{r}0.159 \\
(0.141)\end{array}$ & $\begin{array}{r}0.096 \\
(0.333)\end{array}$ & $\begin{array}{r}0.033 \\
(0.753)\end{array}$ & $\begin{array}{r}-0.094 \\
(0.104)\end{array}$ & $\begin{array}{r}-0.009 \\
(0.961)\end{array}$ & $\begin{array}{r}0.027 \\
(0.875)\end{array}$ & $\begin{array}{r}0.063 \\
(0.723)\end{array}$ & $\begin{array}{r}0.054 \\
(0.451)\end{array}$ & $\begin{array}{r}-0.004 \\
(0.978)\end{array}$ & $\begin{array}{r}-0.013 \\
(0.919)\end{array}$ & $\begin{array}{r}-0.023 \\
(0.871)\end{array}$ & $\begin{array}{l}-0.014 \\
(0.853)\end{array}$ \\
\hline $\begin{array}{l}\text { Positive Social } \\
\text { Behavior-PCR (+) }\end{array}$ & $\begin{array}{r}0.001 \\
(0.977)\end{array}$ & $\begin{array}{r}-0.014 \\
(0.657)\end{array}$ & $\begin{array}{r}-0.030 \\
(0.476)\end{array}$ & $\begin{array}{r}-0.023 \\
(0.576)\end{array}$ & $\begin{array}{r}0.044 \\
(0.407)\end{array}$ & $\begin{array}{r}0.016 \\
(0.693)\end{array}$ & $\begin{array}{r}-0.012 \\
(0.805)\end{array}$ & $\begin{array}{r}-0.042 \\
(0.392)\end{array}$ & $\begin{array}{r}0.088 \\
(0.220)\end{array}$ & $\begin{array}{r}0.013 \\
(0.822)\end{array}$ & $\begin{array}{r}-0.063 \\
(0.359)\end{array}$ & $\begin{array}{l}-0.112^{\wedge} \\
(0.076)\end{array}$ \\
\hline $\begin{array}{l}\text { Positive Social } \\
\text { Behavior-TRS (+) }\end{array}$ & $\begin{array}{r}0.002 \\
(0.966)\end{array}$ & $\begin{array}{r}-0.004 \\
(0.926)\end{array}$ & $\begin{array}{r}-0.011 \\
(0.834)\end{array}$ & $\begin{array}{r}-0.010 \\
(0.800)\end{array}$ & $\begin{array}{r}-0.074 \\
(0.405)\end{array}$ & $\begin{array}{r}-0.045 \\
(0.569)\end{array}$ & $\begin{array}{r}-0.015 \\
(0.859)\end{array}$ & $\begin{array}{r}0.044 \\
(0.441)\end{array}$ & $\begin{array}{r}0.096 \\
(0.295)\end{array}$ & $\begin{array}{r}0.038 \\
(0.631)\end{array}$ & $\begin{array}{r}-0.020 \\
(0.819)\end{array}$ & $\begin{array}{r}-0.087 \\
(0.187)\end{array}$ \\
\hline $\begin{array}{l}\text { Problem Behavior- } \\
\text { CR (-) }\end{array}$ & $\begin{array}{r}0.022 \\
(0.732)\end{array}$ & $\begin{array}{r}-0.008 \\
(0.880)\end{array}$ & $\begin{array}{r}-0.037 \\
(0.543)\end{array}$ & $\begin{array}{r}-0.044 \\
(0.391)\end{array}$ & $\begin{array}{r}-0.022 \\
(0.798)\end{array}$ & $\begin{array}{r}-0.027 \\
(0.715)\end{array}$ & $\begin{array}{r}-0.032 \\
(0.698)\end{array}$ & $\begin{array}{r}-0.008 \\
(0.900)\end{array}$ & $\begin{array}{r}-0.002 \\
(0.982)\end{array}$ & $\begin{array}{r}0.032 \\
(0.680)\end{array}$ & $\begin{array}{r}0.067 \\
(0.457)\end{array}$ & $\begin{array}{r}0.052 \\
(0.457)\end{array}$ \\
\hline $\begin{array}{l}\text { Problem Behavior- } \\
\text { PCR (-) }\end{array}$ & $\begin{array}{l}-0.100^{\wedge} \\
(0.053)\end{array}$ & $\begin{array}{r}0.005 \\
(0.909)\end{array}$ & $\begin{array}{l}0.109^{*} \\
(0.028)\end{array}$ & $\begin{array}{l}0.157^{* * *} \\
(0.001)\end{array}$ & $\begin{array}{r}-0.045 \\
(0.381)\end{array}$ & $\begin{array}{r}0.028 \\
(0.446)\end{array}$ & $\begin{array}{r}0.101^{*} \\
(0.041)\end{array}$ & $\begin{array}{c}0.109^{*} \\
(0.032)\end{array}$ & $\begin{array}{r}-0.005 \\
(0.940)\end{array}$ & $\begin{array}{r}0.000 \\
(0.994)\end{array}$ & $\begin{array}{r}0.006 \\
(0.929)\end{array}$ & $\begin{array}{r}0.009 \\
(0.896)\end{array}$ \\
\hline $\begin{array}{l}\text { Problem Behavior- } \\
\text { TRS (-) }\end{array}$ & $\begin{array}{r}0.044 \\
(0.464)\end{array}$ & $\begin{array}{r}0.054 \\
(0.304)\end{array}$ & $\begin{array}{r}0.063 \\
(0.278)\end{array}$ & $\begin{array}{r}0.014 \\
(0.732)\end{array}$ & $\begin{array}{r}0.087 \\
(0.268)\end{array}$ & $\begin{array}{r}-0.001 \\
(0.994)\end{array}$ & $\begin{array}{r}-0.089 \\
(0.243)\end{array}$ & $\begin{array}{l}-0.132^{*} \\
(0.022)\end{array}$ & $\begin{array}{l}-0.087 \\
(0.370)\end{array}$ & $\begin{array}{r}-0.047 \\
(0.577)\end{array}$ & $\begin{array}{r}-0.007 \\
(0.939)\end{array}$ & $\begin{array}{r}0.059 \\
(0.374)\end{array}$ \\
\hline $\begin{array}{l}\text { ADHD-Related Behavior- } \\
\text { TRS (-) }\end{array}$ & $\begin{array}{l}-0.016 \\
(0.748)\end{array}$ & $\begin{array}{r}0.022 \\
(0.605)\end{array}$ & $\begin{array}{r}0.028 \\
(0.576)\end{array}$ & $\begin{array}{r}0.008 \\
(0.835)\end{array}$ & $\begin{array}{r}0.062 \\
(0.389)\end{array}$ & $\begin{array}{r}-0.021 \\
(0.722)\end{array}$ & $\begin{array}{r}-0.104 \\
(0.132)\end{array}$ & $\begin{array}{l}-0.124^{*} \\
(0.029)\end{array}$ & $\begin{array}{r}-0.073 \\
(0.375)\end{array}$ & $\begin{array}{l}-0.102 \\
(0.134)\end{array}$ & $\begin{array}{r}-0.132 \\
(0.100)\end{array}$ & $\begin{array}{l}-0.045 \\
(0.494)\end{array}$ \\
\hline
\end{tabular}


Table 1.32. Combined-program impacts on child outcomes, by initial perceptions of community risk-Continued

\begin{tabular}{|c|c|c|c|c|c|c|c|c|c|c|c|c|}
\hline \multirow[b]{3}{*}{ Scale-Report } & \multicolumn{4}{|c|}{$\begin{array}{c}\text { Year } 1 \\
\text { (Spring 3rd grade) } \\
\end{array}$} & \multicolumn{4}{|c|}{$\begin{array}{c}\text { Year } 2 \\
\text { (Spring 4th grade) } \\
\end{array}$} & \multicolumn{4}{|c|}{$\begin{array}{c}\text { Year 3 } \\
\text { (Spring 5th grade) }\end{array}$} \\
\hline & \multicolumn{3}{|c|}{$\begin{array}{l}\text { Effect size at risk level } \\
(p \text {-value })\end{array}$} & \multirow{2}{*}{$\begin{array}{r}\text { Marg- } \\
\text { inal } \\
\text { effect }^{4} \\
(p \text {-value })\end{array}$} & \multicolumn{3}{|c|}{$\begin{array}{l}\text { Effect size at risk level } \\
(p \text {-value })\end{array}$} & \multirow{2}{*}{$\begin{array}{r}\text { Marg- } \\
\text { inal } \\
\text { effect }^{4} \\
(p \text {-value })\end{array}$} & \multicolumn{3}{|c|}{$\begin{array}{l}\text { Effect size at risk level } \\
(p \text {-value })\end{array}$} & \multirow{2}{*}{$\begin{array}{r}\text { Marg- } \\
\text { inal } \\
\text { effect }^{4} \\
(p \text {-value })\end{array}$} \\
\hline & Low $^{1}$ & $\begin{array}{r}\text { Aver- } \\
\text { age }^{2}\end{array}$ & $\mathrm{High}^{3}$ & & Low $^{1}$ & $\begin{array}{c}\text { Aver- } \\
\text { age }^{2}\end{array}$ & $\mathrm{High}^{3}$ & & Low $^{1}$ & $\begin{array}{r}\text { Aver- } \\
\text { age }^{2}\end{array}$ & $\mathrm{High}^{3}$ & \\
\hline \multicolumn{13}{|l|}{ Academics Domain } \\
\hline $\begin{array}{l}\text { Engagement with } \\
\text { Learning-CR }(+)\end{array}$ & $\begin{array}{l}-0.016 \\
(0.766)\end{array}$ & $\begin{array}{r}-0.054 \\
(0.187)\end{array}$ & $\begin{array}{l}-0.091^{\wedge} \\
(0.095)\end{array}$ & $\begin{array}{l}-0.056 \\
(0.302)\end{array}$ & $\begin{array}{r}-0.020 \\
(0.728)\end{array}$ & $\begin{array}{l}-0.003 \\
(0.943)\end{array}$ & $\begin{array}{r}0.014 \\
(0.804)\end{array}$ & $\begin{array}{r}0.026 \\
(0.657)\end{array}$ & $\begin{array}{l}-0.052 \\
(0.463)\end{array}$ & $\begin{array}{r}-0.053 \\
(0.313)\end{array}$ & $\begin{array}{l}-0.055 \\
(0.439)\end{array}$ & $\begin{array}{l}-0.002 \\
(0.972)\end{array}$ \\
\hline $\begin{array}{l}\text { Academic Competence } \\
\text { and Motivation-TRS (+) }\end{array}$ & $\begin{array}{r}0.017 \\
(0.640)\end{array}$ & $\begin{array}{l}-0.002 \\
(0.956)\end{array}$ & $\begin{array}{l}-0.014 \\
(0.695)\end{array}$ & $\begin{array}{l}-0.023 \\
(0.489)\end{array}$ & $\begin{array}{r}0.036 \\
(0.483)\end{array}$ & $\begin{array}{l}-0.015 \\
(0.719)\end{array}$ & $\begin{array}{r}-0.066 \\
(0.188)\end{array}$ & $\begin{array}{l}-0.077^{\wedge} \\
(0.092)\end{array}$ & $\begin{array}{r}0.058 \\
(0.396)\end{array}$ & $\begin{array}{r}0.017 \\
(0.762)\end{array}$ & $\begin{array}{r}-0.024 \\
(0.720)\end{array}$ & $\begin{array}{l}-0.061 \\
(0.275)\end{array}$ \\
\hline \multicolumn{13}{|l|}{$\begin{array}{l}\text { Perceptions of School } \\
\text { Climate Domain }\end{array}$} \\
\hline $\begin{array}{l}\text { Positive School } \\
\text { Orientation-CR (+) }\end{array}$ & $\begin{array}{r}0.011 \\
(0.895)\end{array}$ & $\begin{array}{r}0.013 \\
(0.855)\end{array}$ & $\begin{array}{r}0.015 \\
(0.850)\end{array}$ & $\begin{array}{l}-0.003 \\
(0.957)\end{array}$ & $\begin{array}{l}-0.086 \\
(0.361)\end{array}$ & $\begin{array}{r}0.030 \\
(0.719)\end{array}$ & $\begin{array}{r}0.146 \\
(0.111)\end{array}$ & $\begin{array}{l}0.174^{* *} \\
(0.007)\end{array}$ & $\begin{array}{l}-0.091 \\
(0.378)\end{array}$ & $\begin{array}{l}-0.094 \\
(0.293)\end{array}$ & $\begin{array}{l}-0.098 \\
(0.331)\end{array}$ & $\begin{array}{l}-0.005 \\
(0.945)\end{array}$ \\
\hline $\begin{array}{l}\text { Negative School } \\
\text { Orientation-CR (-) }\end{array}$ & $\begin{array}{c}-0.047 \\
(0.435)\end{array}$ & $\begin{array}{r}-0.040 \\
(0.395)\end{array}$ & $\begin{array}{l}-0.034 \\
(0.561)\end{array}$ & $\begin{array}{r}0.010 \\
(0.855)\end{array}$ & $\begin{array}{l}-0.079 \\
(0.342)\end{array}$ & $\begin{array}{l}-0.055 \\
(0.432)\end{array}$ & $\begin{array}{l}-0.031 \\
(0.700)\end{array}$ & $\begin{array}{r}0.036 \\
(0.561)\end{array}$ & $\begin{array}{l}-0.063 \\
(0.435)\end{array}$ & $\begin{array}{l}-0.052 \\
(0.429)\end{array}$ & $\begin{array}{r}-0.041 \\
(0.607)\end{array}$ & $\begin{array}{r}0.017 \\
(0.805)\end{array}$ \\
\hline $\begin{array}{l}\text { Student Afraid at } \\
\text { School-CR (-) }\end{array}$ & $\begin{array}{l}-0.062 \\
(0.331)\end{array}$ & $\begin{array}{r}-0.061 \\
(0.233)\end{array}$ & $\begin{array}{l}-0.060 \\
(0.334)\end{array}$ & $\begin{array}{r}-0.002 \\
(0.976)\end{array}$ & $\begin{array}{r}-0.017 \\
(0.836)\end{array}$ & $\begin{array}{r}-0.078 \\
(0.240)\end{array}$ & $\begin{array}{l}-0.139^{\wedge} \\
(0.073)\end{array}$ & $\begin{array}{l}-0.091 \\
(0.157)\end{array}$ & $\begin{array}{r}0.003 \\
(0.973)\end{array}$ & $\begin{array}{r}-0.010 \\
(0.881)\end{array}$ & $\begin{array}{r}-0.023 \\
(0.777)\end{array}$ & $\begin{array}{r}-0.020 \\
(0.783)\end{array}$ \\
\hline $\begin{array}{l}\text { Victimization at } \\
\text { School-CR (-) }\end{array}$ & $\begin{array}{l}0.094^{\wedge} \\
(0.093)\end{array}$ & $\begin{array}{l}-0.001 \\
(0.988)\end{array}$ & $\begin{array}{l}-0.093^{\wedge} \\
(0.091)\end{array}$ & $\begin{array}{l}-0.139^{\star *} \\
(0.008)\end{array}$ & $\begin{array}{r}0.068 \\
(0.298)\end{array}$ & $\begin{array}{r}-0.035 \\
(0.485)\end{array}$ & $\begin{array}{l}-0.138^{*} \\
(0.030)\end{array}$ & $\begin{array}{l}-0.154^{*} \\
(0.011)\end{array}$ & $\begin{array}{l}0.132^{\wedge} \\
(0.066)\end{array}$ & $\begin{array}{r}0.021 \\
(0.702)\end{array}$ & $\begin{array}{r}-0.090 \\
(0.205)\end{array}$ & $\begin{array}{l}-0.166^{\star} \\
(0.016)\end{array}$ \\
\hline
\end{tabular}

* Significantly different from zero at the .05 level.

** Significantly different from zero at the .01 level.

*** Significantly different from zero at the .001 level.

$\wedge$ Significantly different from zero at the .10 to $>.05$ level.

One standard deviation below the mean risk level.

${ }^{2}$ At the mean risk level.

${ }^{3}$ One standard deviation above the mean risk level.

${ }^{4}$ Change in impact as risk level increases by one unit.

NOTE: Abbreviations are

CR: Child Report

PCR: Primary Caregiver Report

TRS: Teacher Report on Student

ADHD: Attention deficit hyperactivity disorder

The +/- signs in parentheses indicate the direction of a beneficial outcome. All impact estimates were calculated using regression models in which each program and school within a program was weighted equally. The standard errors of all estimates account for design effects due to unequal weighting and the clustering of students within schools. The effect size was calculated by dividing the estimated impact by the standard deviation of the outcome measure for the control group.

SOURCE: The Social and Character Development (SACD) Research Program. 


\section{Child Behavior Risk (Teacher and Primary Caregiver Reports)}

Over the 3 years, the Teacher Report showed 10 significant marginal effects regarding level of child behavior risk (table 1.33). From the 54 comparisons made, 3 significant differences would be expected by chance. Seven of the significant results showed beneficial marginal impacts for high-risk students: increases in Altruistic Behavior (Primary Caregiver Report in Year 1) and Academic Competence (Years 2 and 3), and declines in Normative Beliefs About Aggression (Year 2), Problem Behavior (Child Report and Teacher Report in Year 2), and Negative School Orientation (Year 2). Results from the subgroup-specific regressions supported the beneficial impacts for higher risk students for Altruistic Behavior and Negative School Orientation, and also provided evidence that the marginal effect on Academic Competence (Year 2) was due to a detrimental impact on low-risk students.

The 3 detrimental marginal impacts for high-risk students included declines in Engagement with Learning (Year 1) and increases in Problem Behavior (Primary Caregiver Report in Year 3) and Student Afraid at School (Year 1). Results from the subgroup-specific regressions supported the interpretation that there were detrimental impacts on Engagement with Learning for high-risk students but that the marginal impacts on Problem Behavior and Student Afraid at School were due to beneficial impacts on low-risk students.

When child behavior risk was measured using the Primary Caregiver Report, there were 10 significant marginal effects in contrast to the 3 expected by chance from the 54 comparisons (table 1.34). Eight of these showed beneficial marginal impacts for high-risk students: increases in Empathy (Years 1 and 2), Altruistic Behavior (Teacher Report in Year 2), Positive Social Behavior (Primary Caregiver Report in Year 2), and Engagement with Learning (Year 2), and declines in Normative Beliefs About Aggression (Year 2) and Negative School Orientation (Years 1 and 2). Results from the subgroup-specific regressions supported the interpretation that there were beneficial impacts on Empathy (Year 1) and Negative School Orientation (Year 2) for high-risk students. The 2 detrimental marginal impacts for high-risk students were found for Problem Behavior (Primary Caregiver Report in Years 1 and 3). 
Table 1.33. Combined-program impacts on child outcomes, by initial child behavior risk as reported by teacher

\begin{tabular}{|c|c|c|c|c|c|c|c|c|c|c|c|c|}
\hline \multirow[b]{3}{*}{ Scale-Report } & \multicolumn{4}{|c|}{$\begin{array}{c}\text { Year } 1 \\
\text { (Spring 3rd grade) } \\
\end{array}$} & \multicolumn{4}{|c|}{$\begin{array}{c}\text { Year } 2 \\
\text { (Spring 4th grade) }\end{array}$} & \multicolumn{4}{|c|}{$\begin{array}{c}\text { Year } 3 \\
\text { (Spring 5th grade) }\end{array}$} \\
\hline & \multicolumn{3}{|c|}{$\begin{array}{l}\text { Effect size at risk level } \\
(p \text {-value })\end{array}$} & \multirow{2}{*}{$\begin{array}{r}\text { Marg- } \\
\text { inal } \\
\text { effect }^{4} \\
(p \text {-value })\end{array}$} & \multicolumn{3}{|c|}{$\begin{array}{l}\text { Effect size at risk level } \\
(p \text {-value })\end{array}$} & \multirow{2}{*}{$\begin{array}{r}\text { Marg- } \\
\text { inal } \\
\text { effect }^{4} \\
(p \text {-value })\end{array}$} & \multicolumn{3}{|c|}{$\begin{array}{l}\text { Effect size at risk level } \\
(p \text {-value })\end{array}$} & \multirow{2}{*}{$\begin{array}{r}\text { Marg- } \\
\text { inal } \\
\text { effect }^{4} \\
(p \text {-value })\end{array}$} \\
\hline & Low $^{1}$ & $\begin{array}{c}\text { Aver- } \\
\text { age }^{2}\end{array}$ & $\mathrm{High}^{3}$ & & Low $^{1}$ & $\begin{array}{r}\text { Aver- } \\
\text { age }^{2}\end{array}$ & $\mathrm{High}^{3}$ & & Low $^{1}$ & $\begin{array}{r}\text { Aver- } \\
\text { age }\end{array}$ & $\mathrm{High}^{3}$ & \\
\hline \multicolumn{13}{|l|}{$\begin{array}{l}\text { Social and Emotional } \\
\text { Competence Domain }\end{array}$} \\
\hline $\begin{array}{l}\text { Self-Efficacy for Peer } \\
\text { Interactions-CR }(+)\end{array}$ & $\begin{array}{r}0.006 \\
(0.904)\end{array}$ & $\begin{array}{r}-0.037 \\
(0.336)\end{array}$ & $\begin{array}{r}-0.080 \\
(0.109)\end{array}$ & $\begin{array}{r}-0.004 \\
(0.169)\end{array}$ & $\begin{array}{r}-0.040 \\
(0.510)\end{array}$ & $\begin{array}{r}-0.059 \\
(0.230)\end{array}$ & $\begin{array}{r}-0.077 \\
(0.228)\end{array}$ & $\begin{array}{r}-0.002 \\
(0.640)\end{array}$ & $\begin{array}{r}-0.028 \\
(0.653)\end{array}$ & $\begin{array}{r}-0.041 \\
(0.397)\end{array}$ & $\begin{array}{r}-0.053 \\
(0.424)\end{array}$ & $\begin{array}{r}-0.001 \\
(0.771)\end{array}$ \\
\hline $\begin{array}{l}\text { Normative Beliefs About } \\
\text { Aggression-CR (-) }\end{array}$ & $\begin{array}{l}-0.010 \\
(0.851)\end{array}$ & $\begin{array}{l}-0.015 \\
(0.742)\end{array}$ & $\begin{array}{l}-0.019 \\
(0.734)\end{array}$ & $\begin{array}{r}0.000 \\
(0.897)\end{array}$ & $\begin{array}{r}0.127 \\
(0.134)\end{array}$ & $\begin{array}{r}0.007 \\
(0.923)\end{array}$ & $\begin{array}{l}-0.113 \\
(0.191)\end{array}$ & $\begin{array}{l}-0.012^{\star *} \\
(0.005)\end{array}$ & $\begin{array}{r}0.014 \\
(0.867)\end{array}$ & $\begin{array}{r}0.021 \\
(0.770)\end{array}$ & $\begin{array}{r}0.028 \\
(0.741)\end{array}$ & $\begin{array}{r}0.001 \\
(0.870)\end{array}$ \\
\hline Empathy-CR (+) & $\begin{array}{r}0.035 \\
(0.575)\end{array}$ & $\begin{array}{r}0.044 \\
(0.418)\end{array}$ & $\begin{array}{r}0.052 \\
(0.404)\end{array}$ & $\begin{array}{r}0.001 \\
(0.786)\end{array}$ & $\begin{array}{r}-0.093 \\
(0.171)\end{array}$ & $\begin{array}{l}-0.018 \\
(0.748)\end{array}$ & $\begin{array}{r}0.057 \\
(0.416)\end{array}$ & $\begin{array}{l}0.007^{\wedge} \\
(0.055)\end{array}$ & $\begin{array}{r}-0.027 \\
(0.728)\end{array}$ & $\begin{array}{l}-0.061 \\
(0.351)\end{array}$ & $\begin{array}{l}-0.095 \\
(0.234)\end{array}$ & $\begin{array}{r}-0.003 \\
(0.430)\end{array}$ \\
\hline \multicolumn{13}{|l|}{ Behavior Domain } \\
\hline $\begin{array}{l}\text { Altruistic Behavior- } \\
\text { CR (+) }\end{array}$ & $\begin{array}{l}-0.071 \\
(0.136)\end{array}$ & $\begin{array}{l}-0.077^{*} \\
(0.036)\end{array}$ & $\begin{array}{l}-0.083^{\wedge} \\
(0.085)\end{array}$ & $\begin{array}{l}-0.001 \\
(0.844)\end{array}$ & $\begin{array}{l}-0.074 \\
(0.227)\end{array}$ & $\begin{array}{r}-0.048 \\
(0.321)\end{array}$ & $\begin{array}{r}-0.022 \\
(0.734)\end{array}$ & $\begin{array}{r}0.003 \\
(0.510)\end{array}$ & $\begin{array}{r}-0.036 \\
(0.578)\end{array}$ & $\begin{array}{r}-0.029 \\
(0.561)\end{array}$ & $\begin{array}{r}-0.023 \\
(0.740)\end{array}$ & $\begin{array}{r}0.001 \\
(0.878)\end{array}$ \\
\hline $\begin{array}{l}\text { Altruistic Behavior- } \\
\text { PCR (+) }\end{array}$ & $\begin{array}{r}-0.065 \\
(0.217)\end{array}$ & $\begin{array}{r}0.046 \\
(0.265)\end{array}$ & $\begin{array}{l}0.156^{* *} \\
(0.003)\end{array}$ & $\begin{array}{l}0.011^{* *} \\
(0.001)\end{array}$ & $\begin{array}{l}-0.011 \\
(0.855)\end{array}$ & $\begin{array}{r}-0.025 \\
(0.565)\end{array}$ & $\begin{array}{l}-0.040 \\
(0.505)\end{array}$ & $\begin{array}{l}-0.001 \\
(0.706)\end{array}$ & $\begin{array}{r}0.001 \\
(0.987)\end{array}$ & $\begin{array}{r}-0.063 \\
(0.308)\end{array}$ & $\begin{array}{l}-0.128 \\
(0.119)\end{array}$ & $\begin{array}{l}-0.006 \\
(0.187)\end{array}$ \\
\hline $\begin{array}{l}\text { Altruistic Behavior- } \\
\text { TRS }(+)\end{array}$ & $\begin{array}{r}0.083 \\
(0.531)\end{array}$ & $\begin{array}{r}0.119 \\
(0.353)\end{array}$ & $\begin{array}{r}0.156 \\
(0.237)\end{array}$ & $\begin{array}{r}0.004 \\
(0.222)\end{array}$ & $\begin{array}{r}0.013 \\
(0.941)\end{array}$ & $\begin{array}{r}0.030 \\
(0.858)\end{array}$ & $\begin{array}{r}0.048 \\
(0.783)\end{array}$ & $\begin{array}{r}0.002 \\
(0.673)\end{array}$ & $\begin{array}{l}-0.024 \\
(0.853)\end{array}$ & $\begin{array}{l}-0.014 \\
(0.910)\end{array}$ & $\begin{array}{r}-0.004 \\
(0.975)\end{array}$ & $\begin{array}{r}0.001 \\
(0.809)\end{array}$ \\
\hline $\begin{array}{l}\text { Positive Social } \\
\text { Behavior-PCR (+) }\end{array}$ & $\begin{array}{l}-0.014 \\
(0.716)\end{array}$ & $\begin{array}{r}-0.016 \\
(0.600)\end{array}$ & $\begin{array}{r}-0.017 \\
(0.667)\end{array}$ & $\begin{array}{r}0.000 \\
(0.961)\end{array}$ & $\begin{array}{l}-0.028 \\
(0.588)\end{array}$ & $\begin{array}{r}0.021 \\
(0.601)\end{array}$ & $\begin{array}{r}0.069 \\
(0.192)\end{array}$ & $\begin{array}{r}0.005 \\
(0.148)\end{array}$ & $\begin{array}{l}-0.008 \\
(0.898)\end{array}$ & $\begin{array}{r}0.021 \\
(0.700)\end{array}$ & $\begin{array}{r}0.050 \\
(0.477)\end{array}$ & $\begin{array}{r}0.003 \\
(0.481)\end{array}$ \\
\hline $\begin{array}{l}\text { Positive Social } \\
\text { Behavior-TRS (+) }\end{array}$ & $\begin{array}{l}-0.049 \\
(0.355)\end{array}$ & $\begin{array}{r}-0.017 \\
(0.717)\end{array}$ & $\begin{array}{r}0.014 \\
(0.789)\end{array}$ & $\begin{array}{r}0.003 \\
(0.145)\end{array}$ & $\begin{array}{r}-0.067 \\
(0.433)\end{array}$ & $\begin{array}{l}-0.056 \\
(0.477)\end{array}$ & $\begin{array}{l}-0.045 \\
(0.599)\end{array}$ & $\begin{array}{r}0.001 \\
(0.745)\end{array}$ & $\begin{array}{r}0.037 \\
(0.663)\end{array}$ & $\begin{array}{r}0.038 \\
(0.630)\end{array}$ & $\begin{array}{r}0.038 \\
(0.663)\end{array}$ & $\begin{array}{r}0.000 \\
(0.993)\end{array}$ \\
\hline $\begin{array}{l}\text { Problem Behavior- } \\
\text { CR (-) }\end{array}$ & $\begin{array}{r}-0.012 \\
(0.840)\end{array}$ & $\begin{array}{r}0.036 \\
(0.480)\end{array}$ & $\begin{array}{r}0.061 \\
(0.312)\end{array}$ & $\begin{array}{r}0.002 \\
(0.424)\end{array}$ & $\begin{array}{r}0.075 \\
(0.348)\end{array}$ & $\begin{array}{c}-0.007 \\
(0.922)\end{array}$ & $\begin{array}{r}-0.089 \\
(0.275)\end{array}$ & $\begin{array}{l}-0.008^{*} \\
(0.032)\end{array}$ & $\begin{array}{r}0.042 \\
(0.621)\end{array}$ & $\begin{array}{r}0.023 \\
(0.765)\end{array}$ & $\begin{array}{r}0.003 \\
(0.969)\end{array}$ & $\begin{array}{l}-0.002 \\
(0.630)\end{array}$ \\
\hline $\begin{array}{l}\text { Problem Behavior- } \\
\text { PCR (-) }\end{array}$ & $\begin{array}{r}-0.019 \\
(0.698)\end{array}$ & $\begin{array}{r}-0.005 \\
(0.898)\end{array}$ & $\begin{array}{r}0.009 \\
(0.857)\end{array}$ & $\begin{array}{r}0.001 \\
(0.619)\end{array}$ & $\begin{array}{r}0.017 \\
(0.735)\end{array}$ & $\begin{array}{l}-0.007 \\
(0.849)\end{array}$ & $\begin{array}{l}-0.031 \\
(0.549)\end{array}$ & $\begin{array}{r}-0.002 \\
(0.484)\end{array}$ & $\begin{array}{l}-0.202^{* *} \\
(0.009)\end{array}$ & $\begin{array}{r}-0.051 \\
(0.423)\end{array}$ & $\begin{array}{r}0.101 \\
(0.211)\end{array}$ & $\begin{array}{l}0.015^{* * *} \\
(0.001)\end{array}$ \\
\hline $\begin{array}{l}\text { Problem Behavior- } \\
\text { TRS (-) }\end{array}$ & $\begin{array}{r}-0.007 \\
(0.890)\end{array}$ & $\begin{array}{r}0.048 \\
(0.322)\end{array}$ & $\begin{array}{c}0.088^{\wedge} \\
(0.099)\end{array}$ & $\begin{array}{l}0.004^{\wedge} \\
(0.078)\end{array}$ & $\begin{array}{r}0.064 \\
(0.389)\end{array}$ & $\begin{array}{l}-0.011 \\
(0.872)\end{array}$ & $\begin{array}{r}-0.085 \\
(0.255)\end{array}$ & $\begin{array}{l}-0.007^{*} \\
(0.029)\end{array}$ & $\begin{array}{r}-0.014 \\
(0.873)\end{array}$ & $\begin{array}{r}-0.030 \\
(0.697)\end{array}$ & $\begin{array}{r}-0.046 \\
(0.593)\end{array}$ & $\begin{array}{r}-0.002 \\
(0.670)\end{array}$ \\
\hline $\begin{array}{l}\text { ADHD-Related Behavior- } \\
\text { TRS (-) }\end{array}$ & $\begin{array}{r}-0.031 \\
(0.512)\end{array}$ & $\begin{array}{r}0.039 \\
(0.335)\end{array}$ & $\begin{array}{r}0.048 \\
(0.299)\end{array}$ & $\begin{array}{r}0.001 \\
(0.689)\end{array}$ & $\begin{array}{r}0.036 \\
(0.589)\end{array}$ & $\begin{array}{r}-0.007 \\
(0.902)\end{array}$ & $\begin{array}{r}-0.051 \\
(0.456)\end{array}$ & $\begin{array}{r}-0.004 \\
(0.199)\end{array}$ & $\begin{array}{r}-0.080 \\
(0.298)\end{array}$ & $\begin{array}{r}-0.071 \\
(0.296)\end{array}$ & $\begin{array}{r}-0.062 \\
(0.431)\end{array}$ & $\begin{array}{r}0.001 \\
(0.808)\end{array}$ \\
\hline
\end{tabular}


Table 1.33. Combined-program impacts on child outcomes, by initial child behavior risk as reported by teacher-Continued

\begin{tabular}{|c|c|c|c|c|c|c|c|c|c|c|c|c|}
\hline \multirow[b]{3}{*}{ Scale-Report } & \multicolumn{4}{|c|}{$\begin{array}{c}\text { Year } 1 \\
\text { (Spring 3rd grade) }\end{array}$} & \multicolumn{4}{|c|}{$\begin{array}{c}\text { Year } 2 \\
\text { (Spring 4th grade) }\end{array}$} & \multicolumn{4}{|c|}{$\begin{array}{c}\text { Year } 3 \\
\text { (Spring 5th grade) }\end{array}$} \\
\hline & \multicolumn{3}{|c|}{$\begin{array}{l}\text { Effect size at risk level } \\
\text { (p-value) }\end{array}$} & \multirow{2}{*}{$\begin{array}{r}\text { Marg- } \\
\text { inal } \\
\text { effect }^{4} \\
(p \text {-value })\end{array}$} & \multicolumn{3}{|c|}{$\begin{array}{l}\text { Effect size at risk level } \\
(p \text {-value })\end{array}$} & \multirow{2}{*}{$\begin{array}{r}\text { Marg- } \\
\text { inal } \\
\text { effect }^{4} \\
(p \text {-value })\end{array}$} & \multicolumn{3}{|c|}{$\begin{array}{l}\text { Effect size at risk level } \\
\text { ( } p \text {-value) }\end{array}$} & \multirow{2}{*}{$\begin{array}{r}\text { Marg- } \\
\text { inal } \\
\text { effect }^{d} \\
(p \text {-value })\end{array}$} \\
\hline & Low $^{1}$ & $\begin{array}{l}\text { Aver- } \\
\text { age }^{2}\end{array}$ & $\mathrm{High}^{3}$ & & Low $^{1}$ & $\begin{array}{l}\text { Aver- } \\
\text { age }^{2}\end{array}$ & $\mathrm{High}^{3}$ & & Low $^{1}$ & $\begin{array}{l}\text { Aver- } \\
\text { age }^{2}\end{array}$ & $\mathrm{High}^{3}$ & \\
\hline \multicolumn{13}{|l|}{ Academics Domain } \\
\hline $\begin{array}{l}\text { Engagement with } \\
\text { Learning-CR (+) }\end{array}$ & $\begin{array}{r}0.041 \\
(0.413)\end{array}$ & $\begin{array}{r}-0.051 \\
(0.185)\end{array}$ & $\begin{array}{l}-0.143^{* *} \\
(0.006)\end{array}$ & $\begin{array}{l}-0.009^{* *} \\
(0.007)\end{array}$ & $\begin{array}{l}-0.069 \\
(0.228)\end{array}$ & $\begin{array}{r}-0.016 \\
(0.711)\end{array}$ & $\begin{array}{r}0.038 \\
(0.532)\end{array}$ & $\begin{array}{r}0.005 \\
(0.187)\end{array}$ & $\begin{array}{r}0.006 \\
(0.925)\end{array}$ & $\begin{array}{r}-0.043 \\
(0.420)\end{array}$ & $\begin{array}{r}-0.092 \\
(0.199)\end{array}$ & $\begin{array}{r}-0.005 \\
(0.272)\end{array}$ \\
\hline $\begin{array}{l}\text { Academic Competence } \\
\text { and Motivation-TRS }(+)\end{array}$ & $\begin{array}{r}-0.052 \\
(0.123)\end{array}$ & $\begin{array}{r}-0.022 \\
(0.429)\end{array}$ & $\begin{array}{r}0.008 \\
(0.808)\end{array}$ & $\begin{array}{r}0.003 \\
(0.111)\end{array}$ & $\begin{array}{l}-0.108^{*} \\
(0.035)\end{array}$ & $\begin{array}{r}-0.032 \\
(0.455)\end{array}$ & $\begin{array}{r}0.044 \\
(0.391)\end{array}$ & $\begin{array}{l}0.007^{* *} \\
(0.008)\end{array}$ & $\begin{array}{r}-0.088 \\
(0.149)\end{array}$ & $\begin{array}{r}-0.006 \\
(0.909)\end{array}$ & $\begin{array}{r}0.076 \\
(0.225)\end{array}$ & $\begin{array}{l}0.008^{*} \\
(0.013)\end{array}$ \\
\hline \multicolumn{13}{|l|}{$\begin{array}{l}\text { Perceptions of School } \\
\text { Climate Domain }\end{array}$} \\
\hline $\begin{array}{l}\text { Positive School } \\
\text { Orientation-CR (+) }\end{array}$ & $\begin{array}{r}0.013 \\
(0.866)\end{array}$ & $\begin{array}{r}-0.012 \\
(0.867)\end{array}$ & $\begin{array}{r}-0.037 \\
(0.635)\end{array}$ & $\begin{array}{r}-0.002 \\
(0.430)\end{array}$ & $\begin{array}{r}0.040 \\
(0.668)\end{array}$ & $\begin{array}{r}0.043 \\
(0.612)\end{array}$ & $\begin{array}{r}0.046 \\
(0.622)\end{array}$ & $\begin{array}{r}0.000 \\
(0.933)\end{array}$ & $\begin{array}{r}-0.069 \\
(0.472)\end{array}$ & $\begin{array}{r}-0.065 \\
(0.452)\end{array}$ & $\begin{array}{r}-0.062 \\
(0.525)\end{array}$ & $\begin{array}{r}0.000 \\
(0.935)\end{array}$ \\
\hline $\begin{array}{l}\text { Negative School } \\
\text { Orientation-CR (-) }\end{array}$ & $\begin{array}{r}-0.019 \\
(0.749)\end{array}$ & $\begin{array}{r}-0.012 \\
(0.801)\end{array}$ & $\begin{array}{r}-0.006 \\
(0.915)\end{array}$ & $\begin{array}{r}-0.001 \\
(0.843)\end{array}$ & $\begin{array}{r}0.057 \\
(0.467)\end{array}$ & $\begin{array}{l}-0.072 \\
(0.300)\end{array}$ & $\begin{array}{l}-0.202^{*} \\
(0.013)\end{array}$ & $\begin{array}{l}-0.013^{* *} \\
(0.001)\end{array}$ & $\begin{array}{r}0.027 \\
(0.728)\end{array}$ & $\begin{array}{l}-0.048 \\
(0.478)\end{array}$ & $\begin{array}{r}-0.122 \\
(0.128)\end{array}$ & $\begin{array}{l}-0.007^{\wedge} \\
(0.072)\end{array}$ \\
\hline $\begin{array}{l}\text { Student Afraid at } \\
\text { School-CR (-) }\end{array}$ & $\begin{array}{l}-0.140^{*} \\
(0.018)\end{array}$ & $\begin{array}{r}-0.068 \\
(0.162)\end{array}$ & $\begin{array}{r}0.004 \\
(0.942)\end{array}$ & $\begin{array}{l}0.007^{*} \\
(0.029)\end{array}$ & $\begin{array}{l}-0.041 \\
(0.572)\end{array}$ & $\begin{array}{r}-0.054 \\
(0.384)\end{array}$ & $\begin{array}{l}-0.066 \\
(0.375)\end{array}$ & $\begin{array}{r}-0.001 \\
(0.755)\end{array}$ & $\begin{array}{r}0.030 \\
(0.705)\end{array}$ & $\begin{array}{r}0.033 \\
(0.631)\end{array}$ & $\begin{array}{r}0.035 \\
(0.664)\end{array}$ & $\begin{array}{r}0.000 \\
(0.949)\end{array}$ \\
\hline $\begin{array}{l}\text { Victimization at } \\
\text { School-CR (-) }\end{array}$ & $\begin{array}{l}-0.008 \\
(0.873)\end{array}$ & $\begin{array}{l}-0.005 \\
(0.896)\end{array}$ & $\begin{array}{r}-0.019 \\
(0.716)\end{array}$ & $\begin{array}{l}-0.001 \\
(0.670)\end{array}$ & $\begin{array}{r}-0.010 \\
(0.867)\end{array}$ & $\begin{array}{r}-0.043 \\
(0.337)\end{array}$ & $\begin{array}{r}-0.076 \\
(0.208)\end{array}$ & $\begin{array}{r}-0.003 \\
(0.390)\end{array}$ & $\begin{array}{r}0.045 \\
(0.511)\end{array}$ & $\begin{array}{r}0.011 \\
(0.841)\end{array}$ & $\begin{array}{r}-0.023 \\
(0.751)\end{array}$ & $\begin{array}{r}-0.003 \\
(0.425)\end{array}$ \\
\hline
\end{tabular}

* Significantly different from zero at the .05 level.

** Significantly different from zero at the .01 level.

*** Significantly different from zero at the .001 level.

^ Significantly different from zero at the .10 to $>.05$ level.

${ }^{1}$ One standard deviation below the mean risk level.

${ }^{2}$ At the mean risk level.

${ }^{3}$ One standard deviation above the mean risk level.

${ }^{4}$ Change in impact as risk level increases by one unit.

NOTE: Abbreviations are

CR: Child Report

PCR: Primary Caregiver Report

TRS: Teacher Report on Student

ADHD: Attention deficit hyperactivity disorder

The +/- signs in parentheses indicate the direction of a beneficial outcome. All impact estimates were calculated using regression models in which each program and school within a program was weighted equally. The standard errors of all estimates account for design effects due to unequal weighting and the clustering of students within schools. The effect size was calculated by dividing the estimated impact by the standard deviation of the outcome measure for the control group.

SOURCE: The Social and Character Development (SACD) Research Program. 
Table 1.34. Combined-program impacts on child outcomes, by child behavior risk as reported by primary caregiver

\begin{tabular}{|c|c|c|c|c|c|c|c|c|c|c|c|c|}
\hline \multirow[b]{3}{*}{ Scale-Report } & \multicolumn{4}{|c|}{$\begin{array}{c}\text { Year } 1 \\
\text { (Spring 3rd grade) }\end{array}$} & \multicolumn{4}{|c|}{$\begin{array}{c}\text { Year } 2 \\
\text { (Spring 4th grade) }\end{array}$} & \multicolumn{4}{|c|}{$\begin{array}{c}\text { Year } 3 \\
\text { (Spring 5th grade) }\end{array}$} \\
\hline & \multicolumn{3}{|c|}{$\begin{array}{l}\text { Effect size at risk level } \\
(p \text {-value })\end{array}$} & \multirow{2}{*}{$\begin{array}{r}\text { Marg- } \\
\text { inal } \\
\text { effect }^{4} \\
(p \text {-value }) \\
\end{array}$} & \multicolumn{3}{|c|}{$\begin{array}{l}\text { Effect size at risk level } \\
\quad(p \text {-value })\end{array}$} & \multirow{2}{*}{$\begin{array}{r}\text { Marg- } \\
\text { inal } \\
\text { effect }^{4} \\
(p \text {-value }) \\
\end{array}$} & \multicolumn{3}{|c|}{$\begin{array}{l}\text { Effect size at risk level } \\
(p \text {-value })\end{array}$} & \multirow{2}{*}{$\begin{array}{r}\text { Marg- } \\
\text { inal } \\
\text { effect }^{4} \\
(p \text {-value })\end{array}$} \\
\hline & Low $^{1}$ & $\begin{array}{l}\text { Aver- } \\
\text { age }^{2}\end{array}$ & $\mathrm{High}^{3}$ & & Low $^{1}$ & $\begin{array}{l}\text { Aver- } \\
\text { age }^{2}\end{array}$ & $\mathrm{High}^{3}$ & & Low $^{1}$ & $\begin{array}{l}\text { Aver- } \\
\text { age }^{2}\end{array}$ & $\mathrm{High}^{3}$ & \\
\hline \multicolumn{13}{|l|}{$\begin{array}{l}\text { Social and Emotional } \\
\text { Competence Domain }\end{array}$} \\
\hline $\begin{array}{l}\text { Self-Efficacy for Peer } \\
\text { Interactions-CR }(+)\end{array}$ & $\begin{array}{r}0.027 \\
(0.582)\end{array}$ & $\begin{array}{r}-0.031 \\
(0.421)\end{array}$ & $\begin{array}{l}-0.090^{\wedge} \\
(0.072)\end{array}$ & $\begin{array}{l}-0.006^{\wedge} \\
(0.061)\end{array}$ & $\begin{array}{r}-0.015 \\
(0.798)\end{array}$ & $\begin{array}{r}-0.054 \\
(0.247)\end{array}$ & $\begin{array}{r}-0.093 \\
(0.125)\end{array}$ & $\begin{array}{r}-0.004 \\
(0.295)\end{array}$ & $\begin{array}{l}-0.001 \\
(0.986)\end{array}$ & $\begin{array}{l}-0.022 \\
(0.609)\end{array}$ & $\begin{array}{r}-0.043 \\
(0.474)\end{array}$ & $\begin{array}{r}-0.002 \\
(0.599)\end{array}$ \\
\hline $\begin{array}{l}\text { Normative Beliefs } \\
\text { About Aggression-CR (-) }\end{array}$ & $\begin{array}{r}0.020 \\
(0.725)\end{array}$ & $\begin{array}{r}-0.012 \\
(0.802)\end{array}$ & $\begin{array}{r}-0.044 \\
(0.446)\end{array}$ & $\begin{array}{r}-0.003 \\
(0.338)\end{array}$ & $\begin{array}{r}0.071 \\
(0.403)\end{array}$ & $\begin{array}{r}-0.010 \\
(0.893)\end{array}$ & $\begin{array}{r}-0.092 \\
(0.287)\end{array}$ & $\begin{array}{l}-0.008^{*} \\
(0.036)\end{array}$ & $\begin{array}{l}-0.017 \\
(0.847)\end{array}$ & $\begin{array}{l}-0.010 \\
(0.893)\end{array}$ & $\begin{array}{l}-0.004 \\
(0.965)\end{array}$ & $\begin{array}{r}0.001 \\
(0.876)\end{array}$ \\
\hline Empathy-CR (+) & $\begin{array}{l}-0.013 \\
(0.838)\end{array}$ & $\begin{array}{r}0.077 \\
(0.148)\end{array}$ & $\begin{array}{l}0.166^{\star *} \\
(0.008)\end{array}$ & $\begin{array}{l}0.009^{* *} \\
(0.005)\end{array}$ & $\begin{array}{r}-0.083 \\
(0.217)\end{array}$ & $\begin{array}{l}-0.007 \\
(0.897)\end{array}$ & $\begin{array}{r}0.068 \\
(0.318)\end{array}$ & $\begin{array}{c}0.008^{*} \\
(0.042)\end{array}$ & $\begin{array}{l}-0.021 \\
(0.786)\end{array}$ & $\begin{array}{l}-0.063 \\
(0.352)\end{array}$ & $\begin{array}{l}-0.105 \\
(0.189)\end{array}$ & $\begin{array}{l}-0.004 \\
(0.306)\end{array}$ \\
\hline \multicolumn{13}{|l|}{ Behavior Domain } \\
\hline $\begin{array}{l}\text { Altruistic Behavior- } \\
\text { CR (+) }\end{array}$ & $\begin{array}{l}-0.110^{*} \\
(0.029)\end{array}$ & $\begin{array}{r}-0.064 \\
(0.108)\end{array}$ & $\begin{array}{r}-0.017 \\
(0.734)\end{array}$ & $\begin{array}{r}0.005 \\
(0.128)\end{array}$ & $\begin{array}{r}-0.090 \\
(0.148)\end{array}$ & $\begin{array}{r}-0.031 \\
(0.539)\end{array}$ & $\begin{array}{r}0.029 \\
(0.651)\end{array}$ & $\begin{array}{r}0.006 \\
(0.118)\end{array}$ & $\begin{array}{r}-0.074 \\
(0.248)\end{array}$ & $\begin{array}{r}-0.030 \\
(0.547)\end{array}$ & $\begin{array}{r}0.014 \\
(0.838)\end{array}$ & $\begin{array}{r}0.004 \\
(0.287)\end{array}$ \\
\hline $\begin{array}{l}\text { Altruistic Behavior- } \\
\qquad \operatorname{PCR}(+)\end{array}$ & $\begin{array}{r}0.081 \\
(0.199)\end{array}$ & $\begin{array}{r}0.037 \\
(0.350)\end{array}$ & $\begin{array}{r}-0.007 \\
(0.890)\end{array}$ & $\begin{array}{r}-0.004 \\
(0.178)\end{array}$ & $\begin{array}{r}-0.040 \\
(0.500)\end{array}$ & $\begin{array}{r}0.001 \\
(0.986)\end{array}$ & $\begin{array}{r}0.042 \\
(0.485)\end{array}$ & $\begin{array}{r}0.004 \\
(0.281)\end{array}$ & $\begin{array}{l}-0.030 \\
(0.695)\end{array}$ & $\begin{array}{l}-0.038 \\
(0.540)\end{array}$ & $\begin{array}{l}-0.046 \\
(0.548)\end{array}$ & $\begin{array}{l}-0.001 \\
(0.856)\end{array}$ \\
\hline $\begin{array}{l}\text { Altruistic Behavior- } \\
\text { TRS (+) }\end{array}$ & $\begin{array}{r}0.077 \\
(0.431)\end{array}$ & $\begin{array}{r}0.072 \\
(0.439)\end{array}$ & $\begin{array}{r}0.066 \\
(0.496)\end{array}$ & $\begin{array}{l}-0.001 \\
(0.860)\end{array}$ & $\begin{array}{r}-0.049 \\
(0.780)\end{array}$ & $\begin{array}{r}0.029 \\
(0.864)\end{array}$ & $\begin{array}{r}0.107 \\
(0.542)\end{array}$ & $\begin{array}{c}0.008^{*} \\
(0.050)\end{array}$ & $\begin{array}{r}-0.010 \\
(0.938)\end{array}$ & $\begin{array}{l}-0.015 \\
(0.907)\end{array}$ & $\begin{array}{l}-0.019 \\
(0.885)\end{array}$ & $\begin{array}{r}0.000 \\
(0.910)\end{array}$ \\
\hline $\begin{array}{l}\text { Positive Social } \\
\text { Behavior-PCR }(+)\end{array}$ & $\begin{array}{r}0.013 \\
(0.745)\end{array}$ & $\begin{array}{r}-0.027 \\
(0.384)\end{array}$ & $\begin{array}{l}-0.066^{\wedge} \\
(0.097)\end{array}$ & $\begin{array}{r}-0.004 \\
(0.127)\end{array}$ & $\begin{array}{l}-0.086^{\wedge} \\
(0.083)\end{array}$ & $\begin{array}{l}-0.007 \\
(0.852)\end{array}$ & $\begin{array}{r}0.072 \\
(0.147)\end{array}$ & $\begin{array}{c}0.008^{*} \\
(0.015)\end{array}$ & $\begin{array}{r}-0.013 \\
(0.845)\end{array}$ & $\begin{array}{l}-0.003 \\
(0.961)\end{array}$ & $\begin{array}{r}0.008 \\
(0.909)\end{array}$ & $\begin{array}{r}0.001 \\
(0.786)\end{array}$ \\
\hline $\begin{array}{l}\text { Positive Social } \\
\text { Behavior-TRS (+) }\end{array}$ & $\begin{array}{l}-0.010 \\
(0.849)\end{array}$ & $\begin{array}{r}-0.009 \\
(0.835)\end{array}$ & $\begin{array}{r}-0.009 \\
(0.854)\end{array}$ & $\begin{array}{r}0.000 \\
(0.992)\end{array}$ & $\begin{array}{r}-0.016 \\
(0.854)\end{array}$ & $\begin{array}{r}0.038 \\
(0.630)\end{array}$ & $\begin{array}{r}-0.061 \\
(0.480)\end{array}$ & $\begin{array}{r}-0.002 \\
(0.483)\end{array}$ & $\begin{array}{r}0.010 \\
(0.904)\end{array}$ & $\begin{array}{r}0.033 \\
(0.674)\end{array}$ & $\begin{array}{r}0.056 \\
(0.522)\end{array}$ & $\begin{array}{r}0.002 \\
(0.528)\end{array}$ \\
\hline $\begin{array}{l}\text { Problem Behavior- } \\
\text { CR (-) }\end{array}$ & $\begin{array}{r}0.025 \\
(0.677)\end{array}$ & $\begin{array}{r}-0.003 \\
(0.953)\end{array}$ & $\begin{array}{r}-0.031 \\
(0.603)\end{array}$ & $\begin{array}{l}-0.003 \\
(0.346)\end{array}$ & $\begin{array}{r}0.014 \\
(0.865)\end{array}$ & $\begin{array}{l}-0.037 \\
(0.612)\end{array}$ & $\begin{array}{r}-0.089 \\
(0.281)\end{array}$ & $\begin{array}{l}-0.005 \\
(0.143)\end{array}$ & $\begin{array}{r}0.040 \\
(0.638)\end{array}$ & $\begin{array}{r}0.032 \\
(0.677)\end{array}$ & $\begin{array}{r}0.024 \\
(0.781)\end{array}$ & $\begin{array}{l}-0.001 \\
(0.830)\end{array}$ \\
\hline $\begin{array}{l}\text { Problem Behavior- } \\
\text { PCR (-) }\end{array}$ & $\begin{array}{l}-0.076 \\
(0.109)\end{array}$ & $\begin{array}{r}0.003 \\
(0.943)\end{array}$ & $\begin{array}{l}0.081^{\wedge} \\
(0.083)\end{array}$ & $\begin{array}{l}0.008^{* *} \\
(0.006)\end{array}$ & $\begin{array}{l}-0.021 \\
(0.691)\end{array}$ & $\begin{array}{r}0.036 \\
(0.363)\end{array}$ & $\begin{array}{l}0.092^{\wedge} \\
(0.080)\end{array}$ & $\begin{array}{r}0.006 \\
(0.101)\end{array}$ & $\begin{array}{l}-0.101 \\
(0.135)\end{array}$ & $\begin{array}{r}-0.017 \\
(0.749)\end{array}$ & $\begin{array}{r}0.066 \\
(0.328)\end{array}$ & $\begin{array}{l}0.008^{*} \\
(0.043)\end{array}$ \\
\hline $\begin{array}{l}\text { Problem Behavior- } \\
\text { TRS (-) }\end{array}$ & $\begin{array}{r}0.043 \\
(0.428)\end{array}$ & $\begin{array}{r}0.053 \\
(0.288)\end{array}$ & $\begin{array}{r}0.062 \\
(0.256)\end{array}$ & $\begin{array}{r}0.001 \\
(0.686)\end{array}$ & $\begin{array}{r}-0.010 \\
(0.894)\end{array}$ & $\begin{array}{r}-0.008 \\
(0.908)\end{array}$ & $\begin{array}{r}-0.006 \\
(0.940)\end{array}$ & $\begin{array}{r}0.000 \\
(0.949)\end{array}$ & $\begin{array}{r}-0.017 \\
(0.846)\end{array}$ & $\begin{array}{r}-0.044 \\
(0.587)\end{array}$ & $\begin{array}{c}-0.071 \\
(0.427)\end{array}$ & $\begin{array}{r}-0.003 \\
(0.457)\end{array}$ \\
\hline $\begin{array}{l}\text { ADHD-Related } \\
\text { Behavior-TRS (-) }\end{array}$ & $\begin{array}{r}0.000 \\
(0.996)\end{array}$ & $\begin{array}{r}0.020 \\
(0.619)\end{array}$ & $\begin{array}{r}0.041 \\
(0.379)\end{array}$ & $\begin{array}{r}0.002 \\
(0.357)\end{array}$ & $\begin{array}{r}-0.002 \\
(0.982)\end{array}$ & $\begin{array}{l}-0.021 \\
(0.732)\end{array}$ & $\begin{array}{r}-0.040 \\
(0.563)\end{array}$ & $\begin{array}{r}-0.002 \\
(0.556)\end{array}$ & $\begin{array}{l}-0.107 \\
(0.168)\end{array}$ & $\begin{array}{r}-0.096 \\
(0.163)\end{array}$ & $\begin{array}{r}-0.085 \\
(0.278)\end{array}$ & $\begin{array}{r}0.001 \\
(0.763)\end{array}$ \\
\hline
\end{tabular}




\section{Table 1.34. Combined-program impacts on child outcomes, by child behavior risk as reported by primary caregiver-Continued}

\begin{tabular}{|c|c|c|c|c|c|c|c|c|c|c|c|c|}
\hline \multirow[b]{3}{*}{ Scale-Report } & \multicolumn{4}{|c|}{$\begin{array}{c}\text { Year } 1 \\
\text { (Spring 3rd grade) } \\
\end{array}$} & \multicolumn{4}{|c|}{$\begin{array}{c}\text { Year } 2 \\
\text { (Spring 4th grade) } \\
\end{array}$} & \multicolumn{4}{|c|}{$\begin{array}{c}\text { Year 3 } \\
\text { (Spring 5th grade) } \\
\end{array}$} \\
\hline & \multicolumn{3}{|c|}{$\begin{array}{l}\text { Effect size at risk level } \\
(p \text {-value })\end{array}$} & \multirow{2}{*}{$\begin{array}{r}\text { Marg- } \\
\text { inal } \\
\text { effect }^{4} \\
(p \text {-value }) \\
\end{array}$} & \multicolumn{3}{|c|}{$\begin{array}{l}\text { Effect size at risk level } \\
(p \text {-value })\end{array}$} & \multirow{2}{*}{$\begin{array}{r}\text { Marg- } \\
\text { inal } \\
\text { effect }^{4} \\
(p \text {-value }) \\
\end{array}$} & \multicolumn{3}{|c|}{$\begin{array}{c}\text { Effect size at risk level } \\
(p \text {-value })\end{array}$} & \multirow{2}{*}{$\begin{array}{r}\text { Marg } \\
\text { ina } \\
\text { effect } \\
(p \text {-value }\end{array}$} \\
\hline & Low $^{1}$ & $\begin{array}{c}\text { Aver- } \\
\text { age }^{2}\end{array}$ & $\mathrm{High}^{3}$ & & Low $^{1}$ & $\begin{array}{c}\text { Aver- } \\
\text { age }^{2}\end{array}$ & $\mathrm{High}^{3}$ & & Low $^{1}$ & $\begin{array}{l}\text { Aver- } \\
\text { age }^{2}\end{array}$ & $\mathrm{High}^{3}$ & \\
\hline \multicolumn{13}{|l|}{ Academics Domain } \\
\hline $\begin{array}{l}\text { Engagement with } \\
\text { Learning-CR }(+)\end{array}$ & $\begin{array}{r}-0.074 \\
(0.151)\end{array}$ & $\begin{array}{l}-0.057 \\
(0.149)\end{array}$ & $\begin{array}{r}-0.039 \\
(0.443)\end{array}$ & $\begin{array}{r}0.002 \\
(0.599)\end{array}$ & $\begin{array}{r}-0.089 \\
(0.127)\end{array}$ & $\begin{array}{l}-0.004 \\
(0.925)\end{array}$ & $\begin{array}{r}0.081 \\
(0.178)\end{array}$ & $\begin{array}{l}0.009^{*} \\
(0.028)\end{array}$ & $\begin{array}{r}-0.004 \\
(0.954)\end{array}$ & $\begin{array}{l}-0.057 \\
(0.278)\end{array}$ & $\begin{array}{l}-0.110 \\
(0.109)\end{array}$ & $\begin{array}{r}-0.005 \\
(0.210)\end{array}$ \\
\hline $\begin{array}{l}\text { Academic Competence } \\
\text { and Motivation-TRS }(+)\end{array}$ & $\begin{array}{r}-0.001 \\
(0.979)\end{array}$ & $\begin{array}{r}-0.001 \\
(0.970)\end{array}$ & $\begin{array}{r}-0.003 \\
(0.930)\end{array}$ & $\begin{array}{r}0.000 \\
(0.923)\end{array}$ & $\begin{array}{r}-0.044 \\
(0.365)\end{array}$ & $\begin{array}{r}-0.013 \\
(0.754)\end{array}$ & $\begin{array}{r}0.019 \\
(0.705)\end{array}$ & $\begin{array}{r}0.003 \\
(0.247)\end{array}$ & $\begin{array}{r}-0.025 \\
(0.702)\end{array}$ & $\begin{array}{r}0.005 \\
(0.932)\end{array}$ & $\begin{array}{r}0.034 \\
(0.600)\end{array}$ & $\begin{array}{r}0.003 \\
(0.350)\end{array}$ \\
\hline \multicolumn{13}{|l|}{$\begin{array}{l}\text { Perceptions of School } \\
\text { Climate Domain }\end{array}$} \\
\hline $\begin{array}{l}\text { Positive School } \\
\text { Orientation-CR (+) }\end{array}$ & $\begin{array}{r}-0.050 \\
(0.534)\end{array}$ & $\begin{array}{r}0.008 \\
(0.912)\end{array}$ & $\begin{array}{r}0.066 \\
(0.408)\end{array}$ & $\begin{array}{l}0.006^{\wedge} \\
(0.067)\end{array}$ & $\begin{array}{r}-0.009 \\
(0.918)\end{array}$ & $\begin{array}{r}0.053 \\
(0.532)\end{array}$ & $\begin{array}{r}0.115 \\
(0.215)\end{array}$ & $\begin{array}{l}0.006^{\wedge} \\
(0.092)\end{array}$ & $\begin{array}{l}-0.022 \\
(0.819)\end{array}$ & $\begin{array}{r}-0.080 \\
(0.367)\end{array}$ & $\begin{array}{l}-0.138 \\
(0.158)\end{array}$ & $\begin{array}{r}-0.006 \\
(0.143)\end{array}$ \\
\hline $\begin{array}{l}\text { Negative School } \\
\text { Orientation-CR (-) }\end{array}$ & $\begin{array}{r}0.049 \\
(0.418)\end{array}$ & $\begin{array}{r}-0.034 \\
(0.513)\end{array}$ & $\begin{array}{l}-0.116^{\wedge} \\
(0.055)\end{array}$ & $\begin{array}{l}-0.008^{* *} \\
(0.009)\end{array}$ & $\begin{array}{r}0.055 \\
(0.492)\end{array}$ & $\begin{array}{r}0.055 \\
(0.492)\end{array}$ & $\begin{array}{l}-0.178^{*} \\
(0.030)\end{array}$ & $\begin{array}{l}-0.012^{\star *} \\
(0.002)\end{array}$ & $\begin{array}{r}-0.017 \\
(0.829)\end{array}$ & $\begin{array}{l}-0.054 \\
(0.433)\end{array}$ & $\begin{array}{l}-0.090 \\
(0.254)\end{array}$ & $\begin{array}{r}-0.004 \\
(0.341)\end{array}$ \\
\hline $\begin{array}{l}\text { Student Afraid at } \\
\text { School-CR (-) }\end{array}$ & $\begin{array}{r}-0.070 \\
(0.247)\end{array}$ & $\begin{array}{r}-0.055 \\
(0.274)\end{array}$ & $\begin{array}{r}-0.041 \\
(0.494)\end{array}$ & $\begin{array}{r}0.001 \\
(0.653)\end{array}$ & $\begin{array}{r}-0.073 \\
(0.317)\end{array}$ & $\begin{array}{r}-0.068 \\
(0.285)\end{array}$ & $\begin{array}{r}-0.062 \\
(0.406)\end{array}$ & $\begin{array}{r}0.001 \\
(0.879)\end{array}$ & $\begin{array}{r}0.068 \\
(0.385)\end{array}$ & $\begin{array}{r}0.006 \\
(0.932)\end{array}$ & $\begin{array}{r}-0.056 \\
(0.478)\end{array}$ & $\begin{array}{r}-0.006 \\
(0.123)\end{array}$ \\
\hline $\begin{array}{l}\text { Victimization at } \\
\text { School-CR (-) }\end{array}$ & $\begin{array}{r}0.026 \\
(0.621)\end{array}$ & $\begin{array}{l}-0.005 \\
(0.903)\end{array}$ & $\begin{array}{r}-0.016 \\
(0.763)\end{array}$ & $\begin{array}{r}-0.002 \\
(0.508)\end{array}$ & $\begin{array}{r}-0.032 \\
(0.598)\end{array}$ & $\begin{array}{r}-0.040 \\
(0.407)\end{array}$ & $\begin{array}{l}-0.048 \\
(0.432)\end{array}$ & $\begin{array}{r}-0.001 \\
(0.822)\end{array}$ & $\begin{array}{r}-0.010 \\
(0.888)\end{array}$ & $\begin{array}{r}0.010 \\
(0.865)\end{array}$ & $\begin{array}{r}0.030 \\
(0.678)\end{array}$ & $\begin{array}{r}0.002 \\
(0.621)\end{array}$ \\
\hline
\end{tabular}

* Significantly different from zero at the .05 level.

** Significantly different from zero at the .01 level.

$\wedge$ Significantly different from zero at the .10 to $>.05$ level.

${ }^{1}$ One standard deviation below the mean risk level.

${ }^{2}$ At the mean risk level.

${ }^{3}$ One standard deviation above the mean risk level.

${ }^{4}$ Change in impact as risk level increases by one unit.

NOTE: Abbreviations are

CR: Child Report

PCR: Primary Caregiver Report

TRS: Teacher Report on Student

ADHD: Attention deficit hyperactivity disorder

The +/- signs in parentheses indicate the direction of a beneficial outcome. All impact estimates were calculated using regression models in which each program and school within a program was weighted equally. The standard errors of all estimates account for design effects due to unequal weighting and the clustering of students within schools. The effect size was calculated by dividing the estimated impact by the standard deviation of the outcome measure for the control group.

SOURCE: The Social and Character Development (SACD) Research Program. 


\section{Fidelity of Implementation}

There were 5 cases of significant differences between the associations of the SACD programs with the outcomes for schools with different levels of fidelity of implementation (table 1.35). From the 54 comparisons made, 3 significant differences would be expected by chance. When examining the results of the $t$ tests from subgroup-specific regressions for these 5 cases, 4 cases were based on significant detrimental program associations for low-fidelity schools: declines in Altruistic Behavior (Child Report in Year 1) and Positive School Orientation (in Year 3) and increases in Problem Behavior (Child Report in Year 3) and Negative School Orientation (in Year 3). One was linked to a beneficial (though not significant) association for high-fidelity schools (a decline in Student Afraid at School in Year 3).

As a sensitivity test for the Year 2 and Year 3 data, the schools were divided into only two categories (high or low implementers) and the Year 1-type analysis was done (using two fidelity subgroups based on the most recent year of fidelity data; these data are not shown in a table). No significant differences in associations were found between high and low implementers in this analysis. Because the few significant findings from the first analysis were primarily due to detrimental associations between low fidelity and outcomes (rather than beneficial associations between high fidelity and outcomes), and because there were no significant findings in the sensitivity analysis, the fidelity analyses provide little support for the hypothesis of a relationship between high fidelity and more beneficial outcomes. 
Table 1.35. Combined-program results for child outcomes, by fidelity of implementation

\begin{tabular}{|c|c|c|c|c|c|c|c|c|c|c|c|}
\hline \multirow[b]{3}{*}{ Scale-Report } & \multicolumn{3}{|c|}{$\begin{array}{c}\text { Year } 1 \\
\text { (Spring 3rd grade) }\end{array}$} & \multicolumn{4}{|c|}{$\begin{array}{c}\text { Year } 2 \\
\text { (Spring 4th grade) }\end{array}$} & \multicolumn{4}{|c|}{$\begin{array}{c}\text { Year } 3 \\
\text { (Spring 5th grade) }\end{array}$} \\
\hline & \multicolumn{2}{|c|}{$\begin{array}{l}\text { Effect size } \\
(p \text {-value })\end{array}$} & \multirow{2}{*}{$\begin{array}{r}p \text {-value } \\
\text { for } \\
\text { differ- } \\
\text { ence }\end{array}$} & \multicolumn{3}{|c|}{$\begin{array}{l}\text { Effect size } \\
\text { (p-value) }\end{array}$} & \multirow{2}{*}{$\begin{array}{r}p \text {-value } \\
\text { for } \\
\text { differ- } \\
\text { ence }\end{array}$} & \multicolumn{3}{|c|}{$\begin{array}{l}\text { Effect size } \\
(p \text {-value })\end{array}$} & \multirow{2}{*}{$\begin{array}{r}p \text {-value } \\
\text { for } \\
\text { differ- } \\
\text { ence }\end{array}$} \\
\hline & Low & High & & Low & Mixed & High & & Low & Mixed & High & \\
\hline \multicolumn{12}{|l|}{$\begin{array}{l}\text { Social and Emotional } \\
\text { Competence Domain }\end{array}$} \\
\hline $\begin{array}{l}\text { Self-Efficacy for Peer } \\
\text { Interactions-CR (+) }\end{array}$ & $\begin{array}{r}-0.02 \\
(0.758)\end{array}$ & $\begin{array}{r}-0.04 \\
(0.397)\end{array}$ & 0.882 & $\begin{array}{l}-0.12^{\wedge} \\
(0.087)\end{array}$ & $\begin{array}{r}0.02 \\
(0.827)\end{array}$ & $\begin{array}{l}-0.13^{\wedge} \\
(0.063)\end{array}$ & 0.730 & $\begin{array}{r}-0.09 \\
(0.364)\end{array}$ & $\begin{array}{r}-0.01 \\
(0.909)\end{array}$ & $\begin{array}{r}-0.07 \\
(0.291)\end{array}$ & 0.841 \\
\hline $\begin{array}{c}\text { Normative Beliefs About } \\
\text { Aggression-CR (-) }\end{array}$ & $\begin{array}{r}0.04 \\
(0.438)\end{array}$ & $\begin{array}{r}-0.06 \\
(0.300)\end{array}$ & 0.160 & $\begin{array}{r}0.06 \\
(0.419)\end{array}$ & $\begin{array}{r}0.04 \\
(0.584)\end{array}$ & $\begin{array}{r}-0.14 \\
(0.148)\end{array}$ & $0.068^{\wedge}$ & $\begin{array}{c}0.17^{\wedge} \\
(0.091)\end{array}$ & $\begin{array}{r}-0.04 \\
(0.640)\end{array}$ & $\begin{array}{r}-0.10 \\
(0.235)\end{array}$ & $0.069^{\wedge}$ \\
\hline Empathy-CR (+) & $\begin{array}{r}-0.01 \\
(0.851)\end{array}$ & $\begin{array}{c}0.15^{*} \\
(0.024)\end{array}$ & $0.074^{\wedge}$ & $\begin{array}{r}-0.08 \\
(0.242)\end{array}$ & $\begin{array}{r}-0.03 \\
(0.736)\end{array}$ & $\begin{array}{r}0.02 \\
(0.797)\end{array}$ & 0.531 & $\begin{array}{r}-0.15 \\
(0.112)\end{array}$ & $\begin{array}{r}-0.08 \\
(0.359)\end{array}$ & $\begin{array}{r}0.05 \\
(0.449)\end{array}$ & 0.298 \\
\hline $\begin{array}{l}\text { Behavior Domain } \\
\text { Altruistic Behavior- } \\
\text { CR }(+)\end{array}$ & $\begin{array}{l}-0.13^{* *} \\
(0.010)\end{array}$ & $\begin{array}{r}0.01 \\
(0.810)\end{array}$ & $0.033^{*}$ & $\begin{array}{r}-0.05 \\
(0.474)\end{array}$ & $\begin{array}{r}-0.08 \\
(0.332)\end{array}$ & $\begin{array}{r}-0.08 \\
(0.336)\end{array}$ & 0.907 & $\begin{array}{r}-0.05 \\
(0.508)\end{array}$ & $\begin{array}{r}-0.03 \\
(0.663)\end{array}$ & $\begin{array}{r}-0.03 \\
(0.589)\end{array}$ & 0.904 \\
\hline $\begin{array}{l}\text { Altruistic Behavior- } \\
\text { PCR (+) }\end{array}$ & $\begin{array}{r}0.10^{\wedge} \\
(0.061)\end{array}$ & $\begin{array}{r}0.04 \\
(0.407)\end{array}$ & 0.283 & $\begin{array}{r}-0.03 \\
(0.693)\end{array}$ & $\begin{array}{r}0.13 \\
(0.135)\end{array}$ & $\begin{array}{r}-0.02 \\
(0.660)\end{array}$ & 0.248 & $\begin{array}{r}-0.05 \\
(0.565)\end{array}$ & $\begin{array}{r}0.00 \\
(0.995)\end{array}$ & $\begin{array}{r}-0.05 \\
(0.482)\end{array}$ & 0.896 \\
\hline $\begin{array}{l}\text { Altruistic Behavior- } \\
\text { TRS (+) }\end{array}$ & $\begin{array}{r}0.10 \\
(0.435)\end{array}$ & $\begin{array}{r}0.13 \\
(0.322)\end{array}$ & 0.888 & $\begin{array}{r}-0.10 \\
(0.589)\end{array}$ & $\begin{array}{r}0.07 \\
(0.845)\end{array}$ & $\begin{array}{r}0.12 \\
(0.648)\end{array}$ & 0.832 & $\begin{array}{r}0.25 \\
(0.359)\end{array}$ & $\begin{array}{r}-0.12 \\
(0.358)\end{array}$ & $\begin{array}{r}-0.21 \\
(0.366)\end{array}$ & 0.324 \\
\hline $\begin{array}{l}\text { Positive Social } \\
\text { Behavior-PCR (+) }\end{array}$ & $\begin{array}{r}0.00 \\
(0.958)\end{array}$ & $\begin{array}{r}-0.02 \\
(0.541)\end{array}$ & 0.692 & $\begin{array}{r}0.05 \\
(0.499)\end{array}$ & $\begin{array}{r}0.11 \\
(0.125)\end{array}$ & $\begin{array}{r}-0.01 \\
(0.843)\end{array}$ & 0.692 & $\begin{array}{r}0.01 \\
(0.910)\end{array}$ & $\begin{array}{r}0.08 \\
(0.232)\end{array}$ & $\begin{array}{r}-0.02 \\
(0.787)\end{array}$ & 0.719 \\
\hline $\begin{array}{l}\text { Positive Social } \\
\text { Behavior-TRS (+) }\end{array}$ & $\begin{array}{r}0.05 \\
(0.357)\end{array}$ & $\begin{array}{r}-0.01 \\
(0.831)\end{array}$ & 0.463 & $\begin{array}{r}0.07 \\
(0.439)\end{array}$ & $\begin{array}{r}-0.22^{\wedge} \\
(0.083)\end{array}$ & $\begin{array}{r}0.01 \\
(0.954)\end{array}$ & 0.190 & $\begin{array}{r}0.12 \\
(0.183)\end{array}$ & $\begin{array}{r}0.02 \\
(0.853)\end{array}$ & $\begin{array}{r}-0.09 \\
(0.582)\end{array}$ & 0.444 \\
\hline $\begin{array}{l}\text { Problem Behavior- } \\
\text { CR (-) }\end{array}$ & $\begin{array}{r}0.04 \\
(0.477)\end{array}$ & $\begin{array}{r}-0.02 \\
(0.748)\end{array}$ & 0.374 & $\begin{array}{r}0.04 \\
(0.751)\end{array}$ & $\begin{array}{r}0.09 \\
(0.323)\end{array}$ & $\begin{array}{r}-0.09 \\
(0.287)\end{array}$ & 0.229 & $\begin{array}{l}0.20^{* *} \\
(0.008)\end{array}$ & $\begin{array}{r}0.04 \\
(0.658)\end{array}$ & $\begin{array}{r}-0.10 \\
(0.236)\end{array}$ & $0.028^{*}$ \\
\hline $\begin{array}{l}\text { Problem Behavior- } \\
\text { PCR (-) }\end{array}$ & $\begin{array}{r}-0.03 \\
(0.587)\end{array}$ & $\begin{array}{r}0.02 \\
(0.759)\end{array}$ & 0.483 & $\begin{array}{r}-0.04 \\
(0.571)\end{array}$ & $\begin{array}{c}-0.12^{\wedge} \\
(0.094)\end{array}$ & $\begin{array}{r}-0.04 \\
(0.425)\end{array}$ & 0.983 & $\begin{array}{r}0.00 \\
(0.974)\end{array}$ & $\begin{array}{c}-0.14^{\wedge} \\
(0.074)\end{array}$ & $\begin{array}{r}-0.07 \\
(0.275)\end{array}$ & 0.898 \\
\hline $\begin{array}{l}\text { Problem Behavior- } \\
\text { TRS (-) }\end{array}$ & $\begin{array}{r}0.00 \\
(0.962)\end{array}$ & $\begin{array}{r}0.02 \\
(0.784)\end{array}$ & 0.752 & $\begin{array}{r}-0.05 \\
(0.589)\end{array}$ & $\begin{array}{r}0.12 \\
(0.173)\end{array}$ & $\begin{array}{r}-0.08 \\
(0.512)\end{array}$ & 0.184 & $\begin{array}{r}-0.03 \\
(0.732)\end{array}$ & $\begin{array}{r}0.02 \\
(0.805)\end{array}$ & $\begin{array}{r}-0.14 \\
(0.290)\end{array}$ & 0.349 \\
\hline $\begin{array}{l}\text { ADHD-Related } \\
\text { Behavior-TRS (-) }\end{array}$ & $\begin{array}{r}-0.02 \\
(0.618)\end{array}$ & $\begin{array}{r}-0.01 \\
(0.874)\end{array}$ & 0.787 & $\begin{array}{r}-0.05 \\
(0.599)\end{array}$ & $\begin{array}{r}0.06 \\
(0.538)\end{array}$ & $\begin{array}{r}-0.07 \\
(0.446)\end{array}$ & 0.474 & $\begin{array}{r}-0.09 \\
(0.295)\end{array}$ & $\begin{array}{r}-0.01 \\
(0.903)\end{array}$ & $\begin{array}{r}-0.08 \\
(0.226)\end{array}$ & 0.838 \\
\hline
\end{tabular}


Table 1.35. Combined-program results for child outcomes, by fidelity of implementation-Continued

\begin{tabular}{|c|c|c|c|c|c|c|c|c|c|c|c|}
\hline \multirow[b]{3}{*}{ Scale-Report } & \multicolumn{3}{|c|}{$\begin{array}{c}\text { Year } 1 \\
\text { (Spring 3rd grade) }\end{array}$} & \multicolumn{4}{|c|}{$\begin{array}{c}\text { Year } 2 \\
\text { (Spring 4th grade) }\end{array}$} & \multicolumn{4}{|c|}{$\begin{array}{c}\text { Year } 3 \\
\text { (Spring 5th grade) }\end{array}$} \\
\hline & \multicolumn{2}{|c|}{$\begin{array}{l}\text { Effect size } \\
(p \text {-value })\end{array}$} & \multirow{2}{*}{$\begin{array}{r}p \text {-value } \\
\text { for } \\
\text { differ- } \\
\text { ence }^{1}\end{array}$} & \multicolumn{3}{|c|}{$\begin{array}{c}\text { Effect size } \\
(p \text {-value })\end{array}$} & \multirow{2}{*}{$\begin{array}{r}p \text {-value } \\
\text { for } \\
\text { differ- } \\
\text { ence }^{1}\end{array}$} & \multicolumn{3}{|c|}{$\begin{array}{c}\text { Effect size } \\
(p \text {-value })\end{array}$} & \multirow{2}{*}{$\begin{array}{r}p \text {-value } \\
\text { for } \\
\text { differ- }^{1} \\
\text { ence }^{1}\end{array}$} \\
\hline & Low & High & & Low & Mixed & High & & Low & Mixed & High & \\
\hline \multicolumn{12}{|l|}{ Academics Domain } \\
\hline Engagement with & -0.02 & -0.07 & 0.442 & -0.03 & -0.06 & -0.05 & 0.772 & $-0.18^{*}$ & 0.06 & -0.02 & $0.075^{\wedge}$ \\
\hline Learning-CR (+) & $(0.670)$ & $(0.127)$ & & $(0.640)$ & $(0.410)$ & $(0.345)$ & & $(0.050)$ & $(0.406)$ & $(0.699)$ & \\
\hline Academic Competence & 0.02 & -0.06 & 0.225 & -0.04 & 0.01 & $-0.13^{*}$ & 0.559 & -0.05 & -0.04 & -0.09 & 0.965 \\
\hline and Motivation-TRS (+) & $(0.630)$ & $(0.226)$ & & $(0.628)$ & $(0.926)$ & $(0.033)$ & & $(0.606)$ & $(0.643)$ & $(0.261)$ & \\
\hline \multirow{2}{*}{\multicolumn{12}{|c|}{$\begin{array}{l}\text { Perceptions of School } \\
\text { Climate Domain }\end{array}$}} \\
\hline & & & & & & & & & & & \\
\hline Positive School & 0.02 & 0.06 & 0.670 & -0.07 & 0.04 & 0.09 & 0.409 & $-0.32^{* *}$ & -0.04 & 0.18 & $0.026^{*}$ \\
\hline Orientation-CR (+) & $(0.795)$ & $(0.488)$ & & $(0.427)$ & $(0.804)$ & $(0.478)$ & & $(0.001)$ & $(0.732)$ & $(0.242)$ & \\
\hline Negative School & -0.03 & -0.06 & 0.578 & 0.03 & -0.01 & -0.06 & 0.457 & $0.21^{*}$ & -0.02 & -0.19 & $0.021^{*}$ \\
\hline Orientation-CR (-) & $(0.411)$ & $(0.231)$ & & $(0.672)$ & $(0.928)$ & $(0.485)$ & & $(0.035)$ & $(0.841)$ & $(0.102)$ & \\
\hline Student Afraid at & -0.04 & -0.05 & 0.759 & -0.02 & 0.00 & -0.09 & 0.675 & 0.02 & 0.11 & $-0.20^{\wedge}$ & $0.016^{*}$ \\
\hline School-CR (-) & $(0.484)$ & $(0.255)$ & & $(0.780)$ & $(0.994)$ & $(0.234)$ & & $(0.823)$ & $(0.199)$ & $(0.062)$ & \\
\hline Victimization at & -0.02 & 0.01 & 0.700 & -0.04 & $-0.12^{\wedge}$ & 0.00 & 0.611 & 0.07 & -0.08 & 0.01 & 0.349 \\
\hline School-CR (-) & $(0.632)$ & $(0.879)$ & & $(0.658)$ & $(0.083)$ & $(0.982)$ & & $(0.557)$ & $(0.209)$ & $(0.948)$ & \\
\hline
\end{tabular}

* Significantly different from zero at the .05 level.

** Significantly different from zero at the .01 level.

$\wedge$ Significantly different from zero at the .10 to $>.05$ level, two-tailed test.

${ }^{1}$ Test of significant difference between Fidelity subgroups' effect sizes.

NOTE: Abbreviations are

CR: Child Report

PCR: Primary Caregiver Report

TRS: Teacher Report on Student

ADHD: Attention deficit hyperactivity disorder

The +/- signs in parentheses indicate the direction of a beneficial outcome. All impact estimates were calculated using regression models in which each program and school within a program was weighted equally. The standard errors of all estimates account for design effects due to unequal weighting and the clustering of students within schools. The effect size was calculated by dividing the estimated impact by the standard deviation of the outcome measure for the control group.

SOURCE: The Social and Character Development (SACD) Research Program. 


\section{Summary of Results Regarding Year-by-Year Impacts}

The combined-program analysis of the year-by-year impacts did not yield evidence that the seven SACD programs improved student outcomes. A small number of findings were statistically significant (but no more than expected by chance except for several of the subgroup analyses) or substantively important. These results were split into similar numbers of beneficial and detrimental impacts. In the majority of cases, the results (both beneficial and detrimental) occurred only in 1 year and were not replicated across the 3 years of the study.

Specifically, 2 of 60 estimated impacts for the seven SACD programs combined for the 3 years were found statistically significant (with beneficial impacts) and none were found to be substantively important. The lack of findings at the combined-program level was not found to be due to differences among the individual programs or such subgroups as males versus females, stayers versus new entrants, and students with different levels of initial risk. However, it should be noted that the smaller sample sizes available for these analyses reduced the ability to detect smaller statistically significant impacts compared to the analysis of all seven programs together.

For the individual SACD programs, 16 statistically significant impacts were found over the 3 years (9 beneficial and 7 detrimental) versus 21 that would be expected by chance. None occurred more than once per program. In addition, 19 nonsignificant substantively important impacts were found (10 beneficial and 9 detrimental). One program had a substantively important beneficial impact on an outcome for more than 1 year.

The subgroup analyses produced a low number of significant results, mixed impacts (both beneficial and detrimental), and a lack of repeated significant results, providing little evidence of a relationship between subgroups and the impact of the seven SACD programs considered together. The analysis by gender found eight significant differences in impacts but no pattern favoring one gender. No significant results were found for the analysis of stayers versus new entrants. For the analysis of five types of different initial risk, 41 significant marginal effects were found (versus 13 to 14 expected by chance), of which 26 showed more beneficial impacts for higher risk students and 15 found more detrimental impacts for higher risk students as compared to lower risk students. Six of these findings were repeated in at least 2 different years.

\section{Impacts on Growth of Student Outcomes}

A growth curve analysis was done with the 3 years of data to complement the three cross-sectional impact analyses comparing the outcomes of students in control and treatment schools at the end of their third-grade year (spring 2005), fourth-grade year (spring 2006), and fifth-grade year (spring 2007). The growth curve analysis examined the average change over time in the child outcomes between fall 2004 and spring 2007. Unlike the cross-sectional analysis, this was not a cumulative analysis but an analysis of the differences in growth rates between students. Specifically, it examined the estimated impacts on the trajectories of student outcomes over time. The growth curve analysis used the same covariates and compared results across the same subgroups as the cross-sectional analyses. In comparison to the cross-sectional analysis, the growth curve approach used all available data and multiple measures of the outcomes because students at any survey point contributed to the impact estimates.

The growth curve analysis addressed a subset of the research questions regarding the SACD evaluation (combined-program and individual program). These included the following:

1. What were the average impacts of the seven SACD programs together on the average growth over time in student outcomes during the study period, from implementation of the programs in fall 2004 through spring 2007? 


\section{Chapter 1. The Social and Character Development Multiprogram Evaluation}

2. What were the impacts on the average growth over time in student outcomes during the study period by individual SACD program?

3. Did the impacts on the average growth over time in student outcomes during the study period differ by gender, stayer versus new entrant status, and initial risk factors?

As in the case of the cross-sectional year-by-year analysis, the combined analysis used for the first question, with its larger sample size and associated greater power, would be able to detect smaller statistically significant impacts than the analyses for the second and third questions.

\section{Sample}

The sample of students for the growth curve analysis included all students who were enrolled in one of the study schools during the study period, who were eligible to complete a survey at the initial data collection or at any of the follow-up survey points, and who had data from one or more data collection points. ${ }^{40}$ Student outcomes were measured at five time points. Initial measures were collected in fall 2004, and follow-up measures were collected in spring 2005, fall 2005, spring 2006, and spring 2007. The outcomes included the 18 child-level outcome measures across the four outcome domains (Social and Emotional Competence, Behavior, Academics, and Perceptions of School Climate). Two additional outcomes, Feelings of Safety and Student Support for Teacher, were used in the cross-sectional analysis but were not used in the growth curve model because they were measured at the teacher level.

Table 1.36 displays the sample sizes and percentages of sample with a response across the three reports (Child, Primary caregiver, and Teacher). The sample sizes and percentages varied across survey instruments because of differences in survey consent and completion rates. At each survey period, the teachers were most likely to provide data on children (the percentage of the sample universe with responses ranged from $63 \%$ to $66 \%$ ). The primary caregivers were least likely to provide data on children (the percentage of the sample universe with responses ranged from $46 \%$ to $58 \%$ ). The percentage of the sample with responses was similar for treatment and control schools in most survey waves. However, it was statistically significantly higher for the treatment group for the Child Report and Primary Caregiver Report in fall 2004 and for the Child Report in spring 2005. Table 1.36 also shows the percentages of the follow-up sample members who were in the initial sample. There was considerable turnover, as evidenced by the decreasing percentage over time of students who were in the initial fall 2004 sample. By spring 2007, across the three survey instruments, about two-thirds of the sample had been part of the original fall 2004 survey $(66 \%$ for the Child Report and the Primary Caregiver Report, and 68\% for the Teacher Report on Student). There were no statistically significant differences in the level of turnover by treatment status.

\footnotetext{
40 Sensitivity analyses discussed later in this section examined the robustness of the findings when using smaller samples of students who had more rounds of data.
} 
Table 1.36. Growth curve analysis sample size, percentage of sample universe, and percentage of initial sample

\begin{tabular}{|c|c|c|c|c|c|c|c|c|c|}
\hline \multirow[b]{3}{*}{ Program } & \multicolumn{9}{|c|}{$\begin{array}{c}\text { Analysis sample size } \\
\text { (Percentage of sample universe) }\end{array}$} \\
\hline & \multicolumn{3}{|c|}{ Child Report } & \multicolumn{3}{|c|}{ Primary Caregiver Report } & \multicolumn{3}{|c|}{ Teacher Report on Student } \\
\hline & $\begin{array}{c}\text { Treat- } \\
\text { ment }\end{array}$ & Control & Total & $\begin{array}{c}\text { Treat- } \\
\text { ment }\end{array}$ & Control & Total & $\begin{array}{r}\text { Treat- } \\
\text { ment }\end{array}$ & Control & Total \\
\hline Fall 2004 Overall & 2,092 & 1,905 & 3,997 & 1,980 & 1,794 & 3,774 & 2,157 & 1,946 & 4,103 \\
\hline & $(62.1)^{* *}$ & $(59.5)$ & $(60.9)$ & $(58.8)^{* *}$ & $(56.1)$ & $(57.5)$ & $(64.1)$ & $(60.8)$ & $(62.5)$ \\
\hline \multicolumn{10}{|l|}{ Spring 2005} \\
\hline \multirow[t]{2}{*}{ Overall } & 2,200 & 1,967 & 4,167 & 1,768 & 1,613 & 3,381 & 2,264 & 2,029 & 4,293 \\
\hline & $(64.9)^{\star * \star}$ & $(61.3)$ & $(63.2)$ & $(52.2)$ & $(50.3)$ & $(51.3)$ & $(66.8)$ & $(63.2)$ & $(65.1)$ \\
\hline Percentage of sample in fall 2004 & 86.4 & 88.0 & 87.1 & 88.0 & 88.5 & 88.2 & 89.7 & 89.9 & 89.8 \\
\hline \multicolumn{10}{|l|}{ Fall 2005} \\
\hline \multirow[t]{2}{*}{ Overall } & 2,145 & 1,952 & 4,097 & 1,761 & 1,623 & 3,384 & 2,189 & 1,963 & 4,152 \\
\hline & $(65.4)$ & $(64.8)$ & $(65.1)$ & $(53.7)$ & $(53.8)$ & $(53.8)$ & $(66.7)$ & $(65.1)$ & $(66.0)$ \\
\hline Percentage of sample in fall 2004 & 74.9 & 76.3 & 75.6 & 74.4 & 75.9 & 75.1 & 77.7 & 77.7 & 77.7 \\
\hline \multicolumn{10}{|l|}{ Spring 2006} \\
\hline \multirow[t]{2}{*}{ Overall } & 2,146 & 1,926 & 4,072 & 1,682 & 1,517 & 3,199 & 2,239 & 2,014 & 4,253 \\
\hline & $(64.5)$ & $(62.4)$ & $(63.5)$ & $(50.6)$ & $(49.1)$ & $(49.9)$ & $(67.3)$ & $(65.2)$ & $(66.3)$ \\
\hline Percentage of sample in fall 2004 & 71.6 & 73.8 & 72.6 & 73.3 & 74.2 & 73.7 & 74.4 & 75.4 & 74.9 \\
\hline \multicolumn{10}{|l|}{ Spring 2007} \\
\hline \multirow[t]{2}{*}{ Overall } & 2,059 & 1,935 & 3,994 & 1,454 & 1,414 & 2,875 & 2,095 & 1,994 & 4,089 \\
\hline & (64.9) & $(62.9)$ & $(63.9)$ & $(46.1)$ & $(46.0)$ & $(46.0)$ & $(66.0)$ & $(64.8)$ & $(65.4)$ \\
\hline Percentage of sample in fall 2004 & 66.0 & 65.6 & 65.8 & 66.6 & 64.7 & 65.6 & 68.7 & 67.4 & 68.0 \\
\hline
\end{tabular}

** Treatment group significantly different from control group at the .01 level.

*** Treatment group significantly different from control group at the .001 level.

NOTE: This table is based on categorizing students according to their current treatment status at a point in time. During the course of the study about 2 percent of students changed

status when they moved from a treatment to a control school (or vice versa). These students were assigned to their baseline treatment status to preserve the random assignment

design.

SOURCE: The Social and Character Development (SACD) Research Program. 
Table 1.37 shows the average scores for each of the 18 outcome measures by treatment status and data collection point. All students with a response for an outcome measure are included in the data, regardless of when they entered the study schools. Because all students are included, the treatment-control differences reflect both behavioral changes within students who have data from more than one survey and compositional changes in the children for whom data were collected. These compositional changes were due to the mobility of the sample, and table 1.36 shows little evidence of differential mobility by treatment status. Table 1.37 shows that the outcome measures followed very similar trajectories for the students in the treatment and control schools (as described in detail later in this section). This holds true across domains and across the three data reports. 
Table 1.37. Child-level outcomes, by survey period and treatment group status

\begin{tabular}{|c|c|c|c|c|c|}
\hline \multirow[b]{2}{*}{ Average outcome of children with data in any wave ${ }^{1}$} & \multicolumn{5}{|c|}{ Child-level outcome } \\
\hline & $\begin{array}{r}\text { Fall } \\
2004 \\
\end{array}$ & $\begin{array}{r}\text { Spring } \\
2005\end{array}$ & $\begin{array}{r}\text { Fall } \\
2005\end{array}$ & $\begin{array}{r}\text { Spring } \\
2006 \\
\end{array}$ & $\begin{array}{r}\text { Spring } \\
2007\end{array}$ \\
\hline \multicolumn{6}{|l|}{ Social and Emotional Competence Domain } \\
\hline \multicolumn{6}{|l|}{ Self-Efficacy for Peer Interaction-(CR) (+) } \\
\hline Control group & 2.95 & 3.07 & 3.16 & 3.22 & 3.24 \\
\hline Treatment group & 2.93 & 3.04 & 3.14 & $3.18^{*}$ & 3.22 \\
\hline \multicolumn{6}{|l|}{ Normative Beliefs About Aggression-(CR) (-) } \\
\hline Control group & 1.23 & 1.30 & 1.30 & 1.36 & 1.45 \\
\hline Treatment group & 1.22 & 1.29 & 1.32 & 1.36 & 1.46 \\
\hline \multicolumn{6}{|l|}{ Empathy-(CR) $(+)$} \\
\hline Control group & 2.41 & 2.30 & 2.27 & 2.19 & 2.10 \\
\hline Treatment group & 2.42 & 2.32 & 2.25 & 2.17 & 2.08 \\
\hline \multicolumn{6}{|l|}{ Behavior Domain } \\
\hline \multicolumn{6}{|l|}{ Altruistic Behavior-(CR) (+) } \\
\hline Control group & 1.45 & 1.28 & 1.17 & 1.09 & 1.05 \\
\hline Treatment group & 1.45 & 1.24 & 1.14 & 1.05 & 1.05 \\
\hline \multicolumn{6}{|l|}{ Altruistic Behavior-(PCR) $(+)$} \\
\hline Control group & 2.29 & 2.23 & 2.23 & 2.23 & 2.26 \\
\hline Treatment group & 2.28 & 2.27 & 2.23 & 2.25 & 2.26 \\
\hline \multicolumn{6}{|l|}{ Altruistic Behavior-(TRS) (+) } \\
\hline Control group & 1.36 & 1.38 & 1.29 & 1.34 & 1.36 \\
\hline Treatment group & 1.40 & 1.44 & $1.34^{*}$ & 1.37 & 1.34 \\
\hline \multicolumn{6}{|l|}{ Positive Social Behavior-(PCR) $(+)$} \\
\hline Control group & 3.00 & 3.03 & 3.07 & 3.06 & 3.08 \\
\hline Treatment group & 3.00 & 3.02 & 3.06 & 3.07 & 3.09 \\
\hline \multicolumn{6}{|l|}{ Positive Social Behavior-(TRS) $(+)$} \\
\hline Control group & 3.05 & 3.02 & 3.01 & 3.06 & 3.10 \\
\hline Treatment group & 3.04 & 3.03 & 3.02 & 3.01 & 3.07 \\
\hline \multicolumn{6}{|l|}{ Problem Behavior-(CR) (-) } \\
\hline Control group & 0.23 & 0.29 & 0.28 & 0.34 & 0.46 \\
\hline Treatment group & 0.24 & 0.30 & 0.31 & 0.36 & 0.50 \\
\hline \multicolumn{6}{|l|}{ Problem Behavior-(PCR) (-) } \\
\hline Control group & 1.57 & 1.57 & 1.55 & 1.55 & 1.55 \\
\hline Treatment group & 1.56 & 1.55 & 1.53 & 1.53 & 1.53 \\
\hline \multicolumn{6}{|l|}{ Problem Behavior-(TRS) (-) } \\
\hline Control group & 1.35 & 1.45 & 1.38 & 1.44 & 1.46 \\
\hline Treatment group & 1.35 & 1.46 & 1.38 & 1.45 & 1.46 \\
\hline \multicolumn{6}{|l|}{ ADHD-Related Behavior-(TRS) (-) } \\
\hline Control group & 1.72 & 1.74 & 1.72 & 1.69 & 1.68 \\
\hline Treatment group & 1.73 & 1.75 & 1.69 & 1.69 & 1.67 \\
\hline
\end{tabular}


Table 1.37. Child-level outcomes, by survey period and treatment group status-Continued

\begin{tabular}{|c|c|c|c|c|c|}
\hline \multirow[b]{2}{*}{ Average outcome of children with data in any wave ${ }^{1}$} & \multicolumn{5}{|c|}{ Child-level outcome } \\
\hline & $\begin{array}{r}\text { Fall } \\
2004\end{array}$ & $\begin{array}{r}\text { Spring } \\
2005\end{array}$ & $\begin{array}{r}\text { Fall } \\
2005\end{array}$ & $\begin{array}{r}\text { Spring } \\
2006\end{array}$ & $\begin{array}{r}\text { Spring } \\
2007\end{array}$ \\
\hline \multicolumn{6}{|l|}{ Academics Domain } \\
\hline \multicolumn{6}{|l|}{ Engagement with Learning-(CR) (+) } \\
\hline Control group & 3.70 & 3.68 & 3.72 & 3.69 & 3.61 \\
\hline Treatment group & 3.66 & 3.66 & 3.70 & 3.66 & 3.58 \\
\hline \multicolumn{6}{|l|}{ Academic Competence and Motivation-(TRS) (+) } \\
\hline Control group & 2.95 & 3.02 & 2.93 & 3.01 & 3.02 \\
\hline Treatment group & 2.89 & 2.96 & 2.89 & 2.93 & 2.94 \\
\hline \multicolumn{6}{|l|}{ Perceptions of School Climate Domain } \\
\hline \multicolumn{6}{|l|}{ Positive School Orientation-(CR) (+) } \\
\hline Control group & 3.23 & 2.86 & 2.81 & 2.64 & 2.56 \\
\hline Treatment group & 3.21 & 2.86 & 2.82 & 2.65 & 2.51 \\
\hline \multicolumn{6}{|l|}{ Negative School Orientation-(CR) (-) } \\
\hline Control group & 1.82 & 1.90 & 1.87 & 1.97 & 2.09 \\
\hline Treatment group & 1.87 & 1.89 & 1.87 & 1.98 & 2.10 \\
\hline \multicolumn{6}{|l|}{ Student Afraid at School-(CR) (-) } \\
\hline Control group & 2.38 & 2.30 & 2.22 & 2.25 & 2.21 \\
\hline Treatment group & 2.43 & 2.27 & 2.21 & 2.22 & 2.20 \\
\hline \multicolumn{6}{|l|}{ Victimization at School-(CR) (-) } \\
\hline Control group & 0.76 & 0.77 & 0.65 & 0.69 & 0.73 \\
\hline Treatment group & 0.77 & 0.75 & 0.64 & 0.66 & 0.73 \\
\hline
\end{tabular}

* Treatment group significantly different from control group at the .05 level.

${ }^{1}$ Average outcome is the average unadjusted score on the outcome measure across all students in that wave of data.

NOTE: Abbreviations are

CR: Child Report

PCR: Primary Caregiver Report

TRS: Teacher Report on Student

ADHD: Attention deficit hyperactivity disorder

The +/- signs in parentheses indicate the direction of a beneficial outcome. All impact estimates were calculated using regression models in which each program and school within a program was weighted equally. The standard errors of all estimates account for design effects due to unequal weighting and the clustering of students within schools. The effect size was calculated by dividing the estimated impact by the standard deviation of the outcome measure for the control group. This table is based on categorizing students according to their current treatment status at a point in time. During the course of the study about 2 percent of students changed status when they moved from a treatment to a control school (or vice versa). These students were assigned to their baseline treatment status to preserve the random assignment design. The majority of the outcomes (13) were on a scale of 1-4. The scales for the others were as follows: Empathy 1-3, Altruistic Behavior (CR) 0-3, Problem Behavior (CR) 0-3, Academic Competence and Motivation 1-5, and Victimization at School 0-3.

SOURCE: The Social and Character Development (SACD) Research Program. 


\section{Analysis}

\section{The Growth Curve Model}

The SACD programs' impacts over time were estimated using growth curve models by examining treatment and control group differences in the trajectories of student outcomes during the follow-up period while accounting for clustering at the school level. The growth curve models were estimated using a three-level hierarchical linear model, where Level 1 corresponds to time, Level 2 to students, and Level 3 to schools:

Level 1 Model_Time

$$
\text { (1) } y_{t i s}=\alpha_{o i s}+\alpha_{1 i s}\left(T_{S I} I_{t i s}\right)+u_{t i s}
$$

where $\mathrm{y}_{\text {tis }}$ is the outcome variable of student $i$ in school $s$ at time $t, \mathrm{TSI}_{\mathrm{tis}}$ is the time measured in years between implementation of the SACD program and each survey date, ${ }^{41} u_{t i s}$ is a mean zero disturbance term, $\alpha_{0 i s}$ and $\alpha_{1 \text { is }}$ are random student-level intercepts and slopes, respectively, and the program-level subscript $p$ is omitted for simplicity. The growth curve models estimate the effect of the SACD programs (together and separately) on outcomes measured near the start of the implementation, and then at the time of the four follow-up data points (spring 2005, fall 2005, spring 2006, and spring 2007).

Level 2 Model_Students

$$
\begin{gathered}
\text { (2) } \alpha_{0 i s}=\beta_{s}+X_{i s} \theta+\varepsilon_{0 i s} \\
\text { (3) } \alpha_{1 i s}=\delta_{s}+\varepsilon_{1 i s}
\end{gathered}
$$

where $\mathrm{X}_{\mathrm{is}}$ is a vector of student-level characteristics measured initially (the covariates used in the crosssectional analyses), $\varepsilon_{0 i s}$ and $\varepsilon_{1 i s}$ are mean zero disturbance terms, $\beta_{s}$ and $\delta_{s}$ are random school-level coefficients, and $\theta$ is a vector of parameters to be estimated. The age of the child at the initial data collection was included as a control in the model.

Level 3 Model_Schools

$$
\begin{gathered}
\text { (4) } \beta_{s}=\lambda_{0}+\lambda_{1} T_{s}+\phi_{s} Z+\tau_{0 s} \\
\text { (5) } \delta_{s}=\gamma_{0}+\gamma_{1} T_{s}+\tau_{1 s}
\end{gathered}
$$

where $T_{s}$ is an indicator of whether the school is in the treatment group, $\phi_{\mathrm{s}}$ are program-specific fixed effects ( $Z$ indicates each of the seven SACD programs), $\tau_{0_{s}}$ and $\tau_{1 s}$ are mean zero disturbance terms (that are assumed to be correlated with each other and with the error term in equations (4) and (5) for the same school, but not across schools), and $\gamma_{0}, \gamma_{1}, \lambda_{0}$, and $\lambda_{1}$ are parameters to be estimated.

When the student- and school-level equations are substituted into equation (5), this results in the following unified model:

$$
\text { (6) } y_{t i s}=\lambda_{0}+\lambda_{1} T_{s}+X_{i s} \theta+\phi_{s} Z+\gamma_{0}\left(\text { TSI }_{t i s}\right)+\gamma_{1} T_{s}\left(T_{S I} I_{t i s}\right)+\text { error }
$$

where error $=\mathrm{u}_{\mathrm{tis}}+\varepsilon_{0 \mathrm{is}}+\tau_{0 \mathrm{~s}}+\varepsilon_{\mathrm{is}}\left(\mathrm{TSI}_{\mathrm{tis}}\right)+\tau_{1 \mathrm{~s}}\left(\mathrm{TSI}_{\mathrm{tis}}\right)$. In this formulation, the estimate of the slope, $\gamma_{1}$, represents the treatment and control group difference in the mean growth of the outcome measure between

\footnotetext{
41 Time of implementation was set at the program level. These dates were used both in treatment and control schools within that program. If the survey collection date for a student was missing in a round of data, it was imputed using the average date within the school for that round of data collection.
} 


\section{Chapter 1. The Social and Character Development Multiprogram Evaluation}

the first and last measurement points. The estimate of $\lambda_{1}$ represents the impact at the start of the evaluation and was expected not to differ significantly from zero. A linear specification of the time metric is used because the data indicate that the change in the outcomes followed a linear trajectory over time. ${ }^{42}$

The growth curve analysis included the same set of covariates- $X$ in equation (6) - that were used for the cross-sectional analysis (table 1.24) to ensure the comparability of the results. The only exception was the exclusion of the initial outcome measure because it was used as the outcome measure for the growth curve analysis at time 1 (fall 2004). As in the cross-sectional analysis, missing covariates were imputed using mean values for nonmissing cases, by school, gender, race, and ethnicity. Similarly, sample weights were used in all analyses to (1) give each program equal weight in the calculation of overall impact estimates, and (2) give each school equal weight in each program. However, the weights were not adjusted for consent and response differences across classrooms or schools because the population of students within the schools changed over time as students entered and left the schools. The weights were also constructed to give equal weight to each time period.

Equation (6) was estimated for all programs together and for each program separately. In the program-level models, the program-specific fixed effects were removed from the model by dropping $Z$. The key impact parameter in the growth curve model in equation (6) is $\gamma_{1}$, which represents the extent to which the growth in the outcome during the follow-up period differed between the treatment and control groups. The estimated intercept parameter $\left(\gamma_{0}\right)$ is of interest because it signifies a model-generated mean initial value of the outcome, and thus provides a base for interpreting the slope parameter. The model generated the following impact information for each child outcome: (1) the average intercept value for the treatment and control groups $\left(\lambda_{0}\right.$ $+\mathrm{p} \lambda_{1}+\bar{x} \theta$, where $\mathrm{p}$ is the percentage of the sample assigned to the treatment group); (2) the estimated growth for the treatment group $\left(\gamma_{1}+\gamma_{0}\right)$; (3) the estimated growth for the control group $\left(\gamma_{0}\right)$; and (4) the estimated impact of the SACD programs (and each program individually) on growth $\left(\gamma_{1}\right)$.

Growth curve effect sizes were calculated by dividing the estimated impact of the treatment on the outcome growth trajectory by the standard deviation of that outcome (which was calculated using the initial data for the weighted control group). One year was the unit of time used in the growth curve analysis, so the estimated impact of the treatment on the growth trajectory equals the difference between the treatment group's outcome and the control group's outcome, on average, after one year. ${ }^{43}$ After dividing by the standard deviation of the control group outcome, the effect size measures the number of standard deviations the treatment group differs from the control group after one average year of the SACD program. This approach was analogous to the effect size calculations for the cross-sectional analysis. The primary difference between the effect size for the cross-sectional analysis and the effect size for the growth curve trajectory is the time unit used in calculating the numerator. In the cross-sectional analysis, the numerator of the effect size is the estimated impact of the treatment on the outcome over the time period between the initial and the follow-up survey period. In the growth curve effect size, the numerator is the difference between the treatment and the control group after one year of the study, on average.

The growth curve analysis was extended to examine differences by subgroups. For the subgroup analyses, the interaction terms between treatment status, time since implementation, and indicators of membership in subgroups were included in equation (6). This produced an estimate of the slope for subgroup members in the treatment group, relative to subgroup members in the control group. The same subgroups were used in

\footnotetext{
42 Three sensitivity tests were done. First the assumption of linearity was tested through the inclusion of a TSI-squared term. Second, the potential for learning loss as a result of summer school breaks was modeled by including a time indicator that allowed the growth coefficient to decline (or increase) during the summer. Third, child's age was used in place of time since implementation to model growth. Child's age captures both the age of the child at the initial data collection and the time since implementation of the program in one variable.

43 This impact estimate takes into account differences between the initial levels of the outcome for the treatment and control groups, differences in their covariates, and the effects of clustering at the school level.
} 


\section{Chapter 1. The Social and Character Development Multiprogram Evaluation}

the growth curve analysis as were used in the cross-sectional analyses, and these included (1) student gender; (2) new entrants versus members of the original sample (stayers); and (3) levels of initial risk for socioeconomic risk, family risk, perceptions of community risk, and child behavior risk.

\section{Results}

None of the 18 estimated impacts on the trajectories of child outcomes from the seven SACD programs when combined were statistically significant (table 1.38). The estimated effect sizes were at or below .07 (absolute value). ${ }^{44}$

Estimated impacts could differ across programs if some SACD programs were more effective than others, or if the types of children or settings in some programs were more conducive to positive program effects than those found in others. Therefore, it is possible that there were no statistically significant impact estimates at the overall level because beneficial impacts in some programs were offset by negative or null impacts in others. To investigate this possibility, the impacts at the program level were tested.

Table 1.39 lists the outcomes on which each individual program had statistically significant impacts (a program's impacts on all the outcomes are given in the program-specific chapters). The results indicate that the lack of significant impacts in the overall evaluation reflected the lack of significant impacts at the program level. Six impacts would be expected to appear significant by chance at the 5 percent significance level, given that 126 impact estimates were made. Table 1.39 shows that there were 6 significant outcomes found: 2 with beneficial impacts on growth and 4 with detrimental impacts on growth. These outcomes, and the programs with which they were associated, follow. CSP showed a significant beneficial impact on growth for Victimization at School (Child Report) with an effect size of -.09. PATHS showed a significant beneficial impact on growth for Academic Competence (Teacher Report) with an effect size of 0.09. LBW showed a significant detrimental impact on growth for Positive School Orientation (Child Report) with an effect size of -0.13. SS showed three significant detrimental impacts on growth: for Engagement with Learning (Child Report) with an effect size of -0.09 , Positive Social Behavior (Teacher Report) with an effect size of -0.19 , and Empathy (Child Report) with an effect size of -0.13 .

\footnotetext{
44 When a squared value of the time since implementation was added to the sensitivity analysis, three of the outcomes (child-reported Altruistic Behavior, child-reported Victimization, and child-reported Student Afraid at School), showed a significant treatment effect on the growth trajectory. These results indicated that for child-reported Altruistic Behavior, the treatment had a short-term detrimental impact that converged with the control group over time. For child-reported Victimization at School and Student Afraid at School, the treatment had a short-term beneficial impact that converged with the control group over time. Because there were 3 significant results out of 18 and the direction of the effects was mixed, the linear specification of the growth curve model was retained.
} 
Table 1.38. Impacts on growth of child outcomes from combined program analysis

\begin{tabular}{|c|c|c|c|c|c|c|c|}
\hline \multirow[b]{2}{*}{ Scale-Report } & \multirow[b]{2}{*}{$\begin{array}{r}\text { Mean score at } \\
\text { implementation }^{2}\end{array}$} & \multicolumn{6}{|c|}{ Average growth in the score per year ${ }^{1}$} \\
\hline & & $\begin{array}{r}\text { Treatment } \\
\text { group } \\
\end{array}$ & $\begin{array}{r}\text { Control } \\
\text { group }\end{array}$ & $\begin{array}{l}\text { Impact on } \\
\text { growth }^{3}\end{array}$ & $\begin{array}{l}\text { Effect } \\
\text { size }^{4}\end{array}$ & $\begin{array}{r}\text { Standard } \\
\text { error of } \\
\text { impact } \\
\end{array}$ & $\begin{array}{r}p \text {-value of } \\
\text { impact }\end{array}$ \\
\hline \multicolumn{8}{|l|}{ Social and Emotional Competence Domain } \\
\hline Self-Efficacy for Peer Interactions-CR (+) & 2.95 & 0.13 & 0.13 & 0.00 & 0.00 & 0.01 & 0.942 \\
\hline Normative Beliefs About Aggression-CR (-) & 1.23 & 0.10 & 0.07 & 0.02 & 0.04 & 0.01 & 0.115 \\
\hline Empathy-CR (+) & 2.41 & $-0.14^{\wedge}$ & -0.12 & -0.02 & -0.05 & 0.01 & 0.070 \\
\hline \multicolumn{8}{|l|}{ Behavior Domain } \\
\hline Altruistic Behavior-CR (+) & 1.41 & -0.17 & -0.16 & -0.01 & -0.01 & 0.02 & 0.681 \\
\hline Altruistic Behavior-PCR (+) & 2.32 & -0.03 & -0.03 & 0.01 & 0.01 & 0.01 & 0.616 \\
\hline Altruistic Behavior-TRS (+) & 1.40 & -0.04 & 0.00 & -0.04 & -0.07 & 0.03 & 0.224 \\
\hline Positive Social Behavior-PCR (+) & 2.99 & 0.04 & 0.03 & 0.01 & 0.02 & 0.01 & 0.217 \\
\hline Positive Social Behavior-TRS (+) & 3.00 & 0.00 & 0.01 & -0.01 & -0.01 & 0.03 & 0.671 \\
\hline Problem Behavior-CR (-) & 0.24 & 0.10 & 0.08 & 0.01 & 0.02 & 0.01 & 0.351 \\
\hline Problem Behavior-PCR (-) & 1.58 & -0.01 & -0.01 & 0.00 & 0.00 & 0.01 & 0.843 \\
\hline Problem Behavior-TRS (-) & 1.38 & 0.05 & 0.05 & 0.00 & 0.00 & 0.01 & 0.909 \\
\hline ADHD-Related Behavior-TRS (-) & 1.75 & -0.02 & -0.01 & -0.01 & -0.01 & 0.02 & 0.707 \\
\hline \multicolumn{8}{|l|}{ Academics Domain } \\
\hline Engagement with Learning-CR (+) & 3.69 & -0.03 & -0.03 & 0.00 & -0.01 & 0.01 & 0.707 \\
\hline Academic Competence and Motivation-TRS (+) & 2.87 & 0.02 & 0.03 & -0.01 & -0.01 & 0.02 & 0.590 \\
\hline
\end{tabular}

See note at end of table. 
Table 1.38. Impacts on growth of child outcomes from combined-program analysis-Continued

\begin{tabular}{|c|c|c|c|c|c|c|c|}
\hline \multirow[b]{2}{*}{ Scale-Report } & \multirow[b]{2}{*}{$\begin{array}{r}\text { Mean score at } \\
\text { implementation }\end{array}$} & \multicolumn{6}{|c|}{ Average growth in the score per year ${ }^{1}$} \\
\hline & & $\begin{array}{r}\text { Treatment } \\
\text { group } \\
\end{array}$ & $\begin{array}{r}\text { Control } \\
\text { group }\end{array}$ & $\begin{array}{l}\text { Impact on } \\
\text { growth }^{3} \\
\end{array}$ & $\begin{array}{l}\text { Effect } \\
\text { size }^{4}\end{array}$ & $\begin{array}{r}\text { Standard } \\
\text { error of } \\
\text { impact } \\
\end{array}$ & $\begin{array}{r}p \text {-value of } \\
\text { impact } \\
\end{array}$ \\
\hline \multicolumn{8}{|l|}{ Perceptions of School Climate Domain } \\
\hline Positive School Orientation-CR (+) & 3.09 & -0.24 & -0.21 & -0.03 & -0.03 & 0.02 & 0.163 \\
\hline Negative School Orientation-CR (-) & 1.84 & 0.10 & 0.09 & 0.01 & 0.01 & 0.02 & 0.696 \\
\hline Student Afraid at School-CR (-) & 2.38 & -0.08 & -0.08 & 0.00 & 0.00 & 0.02 & 0.956 \\
\hline Victimization at School-CR (-) & 0.76 & -0.03 & -0.02 & -0.01 & -0.01 & 0.02 & 0.368 \\
\hline
\end{tabular}

$\wedge$ Treatment group significantly different from control group at the .10 to $>.05$ level.

${ }^{1}$ Significantly different from zero at the .05 level.

${ }^{2}$ The average score at implementation is calculated across treatment and control groups, using regression models for adjustment on covariates.

${ }^{3}$ Estimated difference between the slope of the treatment and control groups.

${ }^{4}$ The slope of the treatment group minus the slope of the control group divided by the standard deviation of the outcome for the multiprogram control group (the standard deviation is calculated without accounting for school-level clustering or regression adjustments).

NOTE: Abbreviations are

CR: Child Report

PCR: Primary Caregiver Report

TRS: Teacher Report on Student

ADHD: Attention deficit hyperactivity disorder

The +/- signs in parentheses indicate the direction of a beneficial outcome. No findings were found statistically significant at or below the .05 level. All impact estimates were calculated using HLM 6.06. Sample weights were used in all analyses to (1) give each program equal weight within each time period, (2) give each school equal weight in each program (within each time period), and (3) give each time period equal weight in the analysis.

SOURCE: The Social and Character Development (SACD) Research Program. 
Table 1.39. Significant impacts from the growth curve analyses of the individual programs

\begin{tabular}{|c|c|c|}
\hline Program & $\begin{array}{l}\text { Significant }{ }^{1} \text { beneficial impacts } \\
\text { (Report) (Effect size) ( } p \text {-value) }\end{array}$ & $\begin{array}{l}\text { Significant }{ }^{1} \text { detrimental impacts } \\
\text { (Report) (Effect size) ( } p \text {-value) }\end{array}$ \\
\hline Total & 2 & 4 \\
\hline \multicolumn{3}{|l|}{$\mathrm{ABC}$} \\
\hline CSP & $\begin{array}{l}\text { Victimization at School } \\
\text { (CR) (-.09) (.050) }\end{array}$ & \\
\hline LBW & & $\begin{array}{l}\text { Positive School Orientation } \\
\text { (CR) }(-.13)(.016)\end{array}$ \\
\hline \multicolumn{3}{|l|}{ PA } \\
\hline PATHS & $\begin{array}{l}\text { Academic Competence } \\
\text { (TRS) (.08) (.048) }\end{array}$ & \\
\hline \multicolumn{3}{|l|}{$4 \mathrm{Rs}$} \\
\hline SS & & $\begin{array}{c}\text { Engagement with Learning } \\
\text { (CR) (-.09) (.021) } \\
\text { Positive Social Behavior } \\
\text { (TRS) }(-.19)(.019) \\
\text { Empathy } \\
\text { (CR) }(-0.13)(.028)\end{array}$ \\
\hline
\end{tabular}

${ }^{1}$ Significantly different from zero at the .05 level.

NOTE: Abbreviations are

ABC: Academic and Behavioral Competencies Program

CSP: Competence Support Program

LBW: Love In a Big World

PA: Positive Action

PATHS: Promoting Alternative Thinking Strategies

4Rs: The 4Rs Program (Reading, Writing, Respect, and Resolution)

SS: Second Step

CR: Child Report

TRS: Teacher Report on Student

Blank cell: Finding of no impact

Out of the 126 comparisons made (7 programs times 18 outcomes), 6 would be expected to be statistically significant at the .05 level by chance. The number of results found significant was no more than expected by chance. All impact estimates were calculated using HLM 6.06. Sample weights were used in all analyses to (1) give each program equal weight within each time period, (2) give each school equal weight in each program (within each time period), and (3) give each time period equal weight in the analysis.

SOURCE: The Social and Character Development (SACD) Research Program.

The subgroup analyses found little evidence regarding differential impacts of the seven SACD programs, combined, on the subgroups' growth in outcomes. For the gender subgroup analysis, none of the 36 estimated impacts was statistically significant (table 1.40). For the new entrants analysis, 1 impact (on Negative School Orientation) was found to differ significantly and detrimentally for new entrants versus the impact on members of the original sample (table 1.41). From the 18 tests done, 1 significant impact would be expected by chance for the new entrants analysis. 
Table 1.40. Impacts on growth of child outcomes, by gender, from combined-program analysis

\begin{tabular}{|c|c|c|c|c|c|c|c|}
\hline \multirow[b]{2}{*}{ Scale-Report } & \multicolumn{3}{|c|}{ Boys } & \multicolumn{3}{|c|}{ Girls } & \multirow[b]{2}{*}{$\begin{array}{r}p \text {-value for } \\
\text { test of impact } \\
\text { differences } \\
\end{array}$} \\
\hline & $\begin{array}{l}\text { Impact on } \\
\text { annual } \\
\text { growth }\end{array}$ & $\begin{array}{l}\text { Effect } \\
\text { size }^{1}\end{array}$ & $p$-value & $\begin{array}{r}\text { Impact on } \\
\text { annual } \\
\text { growth }\end{array}$ & $\begin{array}{l}\text { Effect } \\
\text { size }\end{array}$ & $p$-value & \\
\hline \multicolumn{8}{|l|}{ Social and Emotional Competence Domain } \\
\hline Self-Efficacy for Peer Interactions-CR (+) & 0.00 & 0.01 & 0.785 & 0.00 & 0.00 & 0.885 & 0.347 \\
\hline Normative Beliefs About Aggression-CR (-) & 0.01 & 0.02 & 0.557 & 0.02 & 0.03 & 0.443 & 0.630 \\
\hline Empathy-CR (+) & -0.01 & -0.02 & 0.583 & -0.02 & -0.04 & 0.282 & 0.349 \\
\hline \multicolumn{8}{|l|}{ Behavior Domain } \\
\hline Altruistic Behavior-CR (+) & 0.01 & 0.01 & 0.673 & 0.00 & 0.00 & 0.888 & 0.153 \\
\hline Altruistic Behavior-PCR (+) & 0.01 & 0.01 & 0.612 & 0.00 & 0.00 & 0.864 & 0.925 \\
\hline Altruistic Behavior-TRS (+) & -0.04 & -0.06 & 0.211 & -0.05 & -0.10 & 0.104 & 0.379 \\
\hline Positive Social Behavior-PCR (+) & 0.01 & 0.02 & 0.446 & 0.00 & 0.01 & 0.687 & 0.933 \\
\hline Positive Social Behavior-TRS (+) & -0.01 & -0.01 & 0.674 & 0.00 & 0.00 & 0.995 & 0.519 \\
\hline Problem Behavior-CR (-) & 0.02 & 0.03 & 0.332 & 0.00 & 0.01 & 0.794 & 0.851 \\
\hline Problem Behavior-PCR (-) & 0.00 & -0.01 & 0.590 & 0.00 & -0.01 & 0.498 & 0.708 \\
\hline Problem Behavior-TRS (-) & -0.01 & -0.02 & 0.685 & -0.01 & -0.02 & 0.426 & 0.932 \\
\hline ADHD-Related Behavior-TRS (-) & -0.03 & -0.04 & 0.219 & -0.01 & -0.01 & 0.498 & 0.293 \\
\hline \multicolumn{8}{|l|}{ Academics Domain } \\
\hline Engagement with Learning-CR (+) & 0.01 & 0.02 & 0.489 & -0.01 & -0.01 & 0.581 & 0.933 \\
\hline Academic Competence and Motivation-TRS (+) & -0.01 & -0.01 & 0.756 & -0.02 & -0.02 & 0.291 & 0.495 \\
\hline
\end{tabular}


Table 1.40. Impacts on growth of child outcomes, by gender, from combined-program analysis—Continued

\begin{tabular}{|c|c|c|c|c|c|c|c|}
\hline \multirow[b]{2}{*}{ Scale-Report } & \multicolumn{3}{|c|}{ Boys } & \multicolumn{3}{|c|}{ Girls } & \multirow[b]{2}{*}{$\begin{array}{r}p \text {-value for } \\
\text { test of impact } \\
\text { differences } \\
\end{array}$} \\
\hline & $\begin{array}{r}\text { Impact on } \\
\text { annual } \\
\text { growth }\end{array}$ & $\begin{array}{l}\text { Effect } \\
\text { size }^{1}\end{array}$ & $p$-value & $\begin{array}{r}\text { Impact on } \\
\text { annual } \\
\text { growth } \\
\end{array}$ & $\begin{array}{r}\text { Effect } \\
\text { size }^{1} \\
\end{array}$ & $p$-value & \\
\hline \multicolumn{8}{|l|}{ Perceptions of School Climate Domain } \\
\hline Positive School Orientation-CR (+) & -0.01 & -0.01 & 0.680 & -0.01 & -0.01 & 0.742 & 0.571 \\
\hline Negative School Orientation-CR (-) & 0.00 & 0.00 & 0.970 & -0.01 & -0.02 & 0.386 & 0.408 \\
\hline Student Afraid at School-CR (-) & 0.00 & 0.00 & 0.880 & -0.04 & -0.03 & 0.149 & 0.213 \\
\hline Victimization at School-CR (-) & -0.02 & -0.02 & 0.205 & 0.00 & 0.00 & 0.930 & 0.349 \\
\hline
\end{tabular}

${ }^{1}$ The slope of the treatment group minus the slope of the control group divided by the standard deviation of the outcome for the combined-program control group (the standard deviation is calculated without accounting for school-level clustering or regression adjustments).

NOTE: Abbreviations are

CR: Child Report

PCR: Primary Caregiver Report

TRS: Teacher Report on Student

ADHD: Attention deficit hyperactivity disorder

The +/- signs in parentheses indicate the direction of a beneficial outcome. No findings were found statistically significant at or below the .05 level. All impact estimates were calculated using HLM 6.06. Sample weights were used in all analyses to (1) give each program equal weight within each time period, (2) give each school equal weight in each program (within each time period), and (3) give each time period equal weight in the analysis.

SOURCE: The Social and Character Development (SACD) Research Program. 
Table 1.41. Impacts on growth of child outcomes for new entrants versus original members, from combined-program analysis

\begin{tabular}{|c|c|c|c|c|c|c|c|}
\hline \multirow[b]{2}{*}{ Scale-Report } & \multicolumn{3}{|c|}{ Original members } & \multicolumn{3}{|c|}{ New entrants } & \multirow[b]{2}{*}{$\begin{array}{r}p \text {-value for } \\
\text { test of impact } \\
\text { differences }\end{array}$} \\
\hline & $\begin{array}{r}\text { Impact on } \\
\text { annual } \\
\text { growth }\end{array}$ & $\begin{array}{l}\text { Effect } \\
\text { size }^{1}\end{array}$ & $p$-value & $\begin{array}{r}\text { Impact on } \\
\text { annual } \\
\text { growth }\end{array}$ & $\begin{array}{c}\text { Effect } \\
\text { size }^{1}\end{array}$ & $p$-value & \\
\hline \multicolumn{8}{|l|}{ Social and Emotional Competence Domain } \\
\hline Self-Efficacy for Peer Interactions-CR (+) & 0.00 & 0.00 & 0.947 & 0.00 & 0.00 & 0.918 & 0.931 \\
\hline Normative Beliefs About Aggression-CR (-) & 0.02 & 0.05 & 0.256 & 0.01 & 0.02 & 0.725 & 0.867 \\
\hline Empathy-CR (+) & -0.02 & -0.05 & 0.107 & -0.02 & -0.05 & 0.441 & 0.475 \\
\hline \multicolumn{8}{|l|}{ Behavior Domain } \\
\hline Altruistic Behavior-CR (+) & -0.01 & -0.01 & 0.783 & 0.01 & 0.01 & 0.869 & 0.251 \\
\hline Altruistic Behavior-PCR (+) & 0.01 & 0.01 & 0.693 & 0.01 & 0.01 & 0.742 & 0.752 \\
\hline Altruistic Behavior-TRS (+) & -0.05 & -0.11 & 0.107 & 0.02 & 0.05 & 0.629 & 0.764 \\
\hline Positive Social Behavior-PCR (+) & 0.01 & 0.01 & 0.442 & -0.02 & -0.04 & 0.350 & 0.563 \\
\hline Positive Social Behavior-TRS (+) & 0.00 & 0.00 & 0.881 & -0.02 & -0.02 & 0.729 & 0.254 \\
\hline Problem Behavior-CR (-) & 0.01 & 0.01 & 0.732 & 0.00 & 0.01 & 0.922 & 0.320 \\
\hline Problem Behavior-PCR (-) & 0.00 & 0.01 & 0.707 & -0.01 & -0.02 & 0.629 & 0.851 \\
\hline Problem Behavior-TRS (-) & -0.01 & -0.01 & 0.710 & -0.01 & -0.01 & 0.838 & 0.427 \\
\hline ADHD-Related Behavior-TRS (-) & -0.02 & -0.02 & 0.318 & 0.02 & 0.02 & 0.694 & 0.107 \\
\hline \multicolumn{8}{|l|}{ Academics Domain } \\
\hline Engagement with Learning-CR (+) & -0.01 & -0.01 & 0.577 & -0.03 & -0.04 & 0.228 & 0.709 \\
\hline Academic Competence and Motivation-TRS (+) & -0.02 & -0.02 & 0.281 & -0.02 & -0.02 & 0.739 & 0.910 \\
\hline
\end{tabular}

Competence and Motivation-TRS (+)

$-0.02 \quad-0.02 \quad 0.281$

0.910

See notes at end of table. 
Table 1.41. Impacts on growth of child outcomes for new entrants versus original members, from combined-program analysisContinued

\begin{tabular}{|c|c|c|c|c|c|c|c|}
\hline \multirow[b]{2}{*}{ Scale-Report } & \multicolumn{3}{|c|}{ Original members } & \multicolumn{3}{|c|}{ New entrants } & \multirow[b]{2}{*}{$\begin{array}{r}p \text {-value for } \\
\text { test of impact } \\
\text { differences } \\
\end{array}$} \\
\hline & $\begin{array}{r}\text { Impact on } \\
\text { annual } \\
\text { growth } \\
\end{array}$ & $\begin{array}{l}\text { Effect } \\
\text { size }^{1}\end{array}$ & $p$-value & $\begin{array}{c}\text { Impact on } \\
\text { annual } \\
\text { growth }\end{array}$ & $\begin{array}{l}\text { Effect } \\
\text { size }^{1}\end{array}$ & $p$-value & \\
\hline \multicolumn{8}{|l|}{ Perceptions of School Climate Domain } \\
\hline Positive School Orientation-CR (+) & -0.01 & -0.01 & 0.592 & -0.05 & -0.06 & 0.161 & 0.113 \\
\hline Negative School Orientation-CR (-) & -0.01 & -0.01 & 0.627 & 0.05 & $0.06^{\wedge}$ & 0.067 & $0.012^{*}$ \\
\hline Student Afraid at School-CR (-) & -0.02 & -0.02 & 0.427 & -0.05 & -0.06 & 0.304 & 0.701 \\
\hline Victimization at School-CR (-) & -0.01 & -0.01 & 0.435 & 0.02 & 0.02 & 0.568 & 0.643 \\
\hline
\end{tabular}

* Significantly different from zero at the .05 level.

$\wedge$ Significantly different from zero at the .10 to $>.05$ level.

${ }^{1}$ The slope of the treatment group minus the slope of the control group divided by the standard deviation of the outcome for the multisite control group (the standard deviation is

calculated without accounting for school-level clustering or regression adjustments).

NOTE: Abbreviations are

CR: Child Report

PCR: Primary Caregiver Report

TRS: Teacher Report on Student

$\vec{A} \quad$ ADHD: Attention deficit hyperactivity disorder

The +/- signs in parentheses indicate the direction of a beneficial outcome. All impact estimates were calculated using HLM 6.06. Sample weights were used in all analyses to (1) give each program equal weight within each time period, (2) give each school equal weight in each program (within each time period), and (3) give each time period equal weight in the

SOURCE: The Social and Character Development (SACD) Research Program. 
Few of the growth trajectories differed across levels of initial risk (tables 1.42 through 1.46). An example illustrates how to interpret the tables. Table 1.42 shows the impacts on the growth trajectory of the outcome scales by the child's initial level of socioeconomic risk. The first row in the table displays the estimated impacts on the growth trajectory of child-reported Self-Efficacy for Peer Interactions at three levels of initial risk: (1) at one standard deviation below the mean risk level, (2) at the mean risk level, and (3) at one standard deviation above the mean risk level. When a child had a low level of risk (one standard deviation below the mean), the difference between the growth trajectories of the treatment group and the control group for SelfEfficacy for Peer Interactions was -0.01 . When a child had an average level of risk (at the mean), the difference between the treatment group and the control group was -0.01. When a child had a high level of risk (one standard deviation above the mean), the difference between the treatment group and the control group was 0.00 . The interaction term showed that with each one-unit increase in socioeconomic risk, the impact on the Self-Efficacy for Peer Interactions trajectory increased by 0.01 . In other words, the higher the child's initial level of socioeconomic risk, the more beneficial was the SACD program for the child's growth in SelfEfficacy for Peer Interactions. However, this difference in the SACD programs' impact across risk levels was not statistically significantly different from zero (interaction term $=0.01$; not significant at the .05 level).

There were 6 outcomes out of 90 estimated impacts for which growth differed significantly across initial risk levels (versus 4 to 5 expected by chance). For 4 outcomes, the seven SACD programs combined had more beneficial impacts on growth for children with higher initial risk levels. The SACD programs resulted in greater growth of parent-reported Altruistic Behavior for children with higher levels of socioeconomic risk (interaction term $=0.03$ on table 1.42); greater growth on Academic Competence and less growth of childreported Victimization at School among children with higher levels of family risk (interaction term $=0.13$ and -0.13 , respectively, on table 1.43); and less growth of child-reported Victimization at School among children with higher levels of perceived community risk (interaction term $=-0.06$ on table 1.44).

For two outcomes, the seven SACD programs combined had more detrimental impacts on growth for children with higher initial risk levels. The SACD programs resulted in less growth for child-reported Empathy among children with greater levels of family risk (interaction term $=-0.08$ on table 1.43 ), and greater growth on Normative Beliefs About Aggression among children with higher initial levels of teacherreported behavior risks (interaction term $=0.01$ on table 1.45 ). 
Table 1.42. Impacts on growth of child outcomes, by initial socioeconomic risk

Socioeconomic risk

$($ Mean $=.60 ;$ Standard deviation $=.71)$

Impact on growth at the specified risk level ( $p$-value)

\begin{tabular}{|c|c|c|c|c|}
\hline Scale-Report & $\begin{array}{r}\text { One standard } \\
\text { deviation below mean }\end{array}$ & Mean $^{2}$ & $\begin{array}{l}\text { One standard } \\
\text { deviation above mean }^{3}\end{array}$ & $\begin{array}{r}\text { Interaction term }^{4} \\
\text { ( } p \text {-value })\end{array}$ \\
\hline \multicolumn{5}{|l|}{ Social and Emotional Competence Domain } \\
\hline \multirow[t]{2}{*}{ Self-Efficacy for Peer Interactions-CR (+) } & -0.01 & -0.01 & 0.00 & 0.01 \\
\hline & $(0.500)$ & $(0.594)$ & $(0.500)$ & $(0.511)$ \\
\hline \multirow[t]{2}{*}{ Normative Beliefs About Aggression-CR (-) } & $0.03^{*}$ & $0.03^{*}$ & $0.03^{\wedge}$ & 0.00 \\
\hline & $(0.049)$ & $(0.027)$ & $(0.079)$ & $(0.842)$ \\
\hline \multirow[t]{2}{*}{ Empathy-CR (+) } & -0.01 & -0.02 & $-0.03^{\wedge}$ & -0.01 \\
\hline & $(0.500)$ & $(0.122)$ & $(0.059)$ & $(0.518)$ \\
\hline \multicolumn{5}{|l|}{ Behavior Domain } \\
\hline \multirow[t]{2}{*}{ Altruistic Behavior-CR (+) } & -0.02 & -0.01 & 0.01 & 0.02 \\
\hline & $(0.500)$ & $(0.628)$ & $(0.500)$ & $(0.341)$ \\
\hline \multirow[t]{2}{*}{ Altruistic Behavior-PCR (+) } & -0.01 & 0.01 & $0.04^{*}$ & 0.03 \\
\hline & $(0.500)$ & $(0.344)$ & $(0.045)$ & $(0.044)$ \\
\hline \multirow[t]{2}{*}{ Altruistic Behavior-TRS (+) } & -0.03 & -0.03 & -0.03 & 0.00 \\
\hline & $(0.500)$ & $(0.269)$ & $(0.214)$ & $(0.870)$ \\
\hline \multirow[t]{2}{*}{ Positive Social Behavior-PCR (+) } & 0.01 & 0.01 & $0.02^{\wedge}$ & 0.01 \\
\hline & $(0.500)$ & $(0.100)$ & $(0.090)$ & $(0.314)$ \\
\hline \multirow[t]{2}{*}{ Positive Social Behavior-TRS (+) } & -0.01 & -0.01 & -0.01 & 0.00 \\
\hline & $(0.500)$ & $(0.599)$ & $(0.500)$ & $(0.939)$ \\
\hline \multirow[t]{2}{*}{ Problem Behavior-CR (-) } & 0.01 & 0.02 & 0.02 & 0.01 \\
\hline & $(0.500)$ & $(0.277)$ & $(0.272)$ & $(0.677)$ \\
\hline \multirow[t]{2}{*}{ Problem Behavior-PCR (-) } & -0.01 & 0.00 & 0.00 & 0.01 \\
\hline & $(0.261)$ & $(0.720)$ & $(0.500)$ & $(0.324)$ \\
\hline \multirow[t]{2}{*}{ Problem Behavior-TRS (-) } & 0.00 & 0.00 & 0.00 & 0.00 \\
\hline & $(0.500)$ & (0.915) & $(0.500)$ & $(0.879)$ \\
\hline \multirow[t]{2}{*}{ ADHD-Related Behavior-TRS (-) } & 0.00 & -0.01 & -0.02 & -0.02 \\
\hline & $(0.500)$ & $(0.716)$ & $(0.500)$ & $(0.329)$ \\
\hline
\end{tabular}


Table 1.42. Impacts on growth of child outcomes, by initial socioeconomic risk-Continued

\begin{tabular}{|c|c|c|c|c|}
\hline \multirow[b]{3}{*}{ Scale-Report } & \multicolumn{4}{|c|}{$\begin{array}{c}\text { Socioeconomic risk } \\
(\text { Mean }=.60 ; \text { Standard deviation }=.71)\end{array}$} \\
\hline & \multicolumn{3}{|c|}{ Impact on growth at the specified risk level ( $p$-value) } & \multirow[b]{2}{*}{$\begin{array}{r}\text { Interaction term }^{4} \\
(p \text {-value })\end{array}$} \\
\hline & $\begin{array}{r}\text { One standard } \\
\text { deviation below mean }\end{array}$ & Mean $^{2}$ & $\begin{array}{r}\text { One standard } \\
\text { deviation above mean } \\
\end{array}$ & \\
\hline \multicolumn{5}{|l|}{ Academics Domain } \\
\hline \multirow[t]{2}{*}{ Engagement with Learning-CR (+) } & -0.02 & -0.01 & 0.01 & 0.02 \\
\hline & $(0.213)$ & $(0.644)$ & $(0.500)$ & $(0.249)$ \\
\hline \multirow[t]{2}{*}{ Academic Competence and Motivation-TRS (+) } & -0.01 & 0.00 & 0.01 & 0.01 \\
\hline & $(0.500)$ & $(0.861)$ & $(0.500)$ & $(0.559)$ \\
\hline \multicolumn{5}{|l|}{ Perceptions of School Climate Domain } \\
\hline \multirow[t]{2}{*}{ Positive School Orientation-CR (+) } & -0.02 & -0.03 & $-0.04^{\wedge}$ & -0.01 \\
\hline & $(0.500)$ & $(0.150)$ & $(0.087)$ & $(0.518)$ \\
\hline \multirow[t]{2}{*}{ Negative School Orientation-CR (-) } & 0.01 & 0.00 & -0.01 & -0.01 \\
\hline & $(0.500)$ & $(0.876)$ & $(0.500)$ & $(0.414)$ \\
\hline \multirow[t]{2}{*}{ Student Afraid at School-CR (-) } & -0.02 & 0.00 & 0.01 & 0.02 \\
\hline & $(0.500)$ & $(0.833)$ & $(0.500)$ & $(0.315)$ \\
\hline \multirow[t]{2}{*}{ Victimization at School-CR (-) } & -0.01 & -0.01 & -0.01 & 0.00 \\
\hline & $(0.500)$ & $(0.506)$ & $(0.500)$ & $(0.965)$ \\
\hline
\end{tabular}

* Significantly different from zero at the .05 level.

$\wedge$ Significantly different from zero at the .10 to $>.05$ level.

${ }^{1}$ The difference between the estimates of the treatment and control groups' rate of growth, for the average student who is one standard deviation below the mean for the risk measure.

${ }^{2}$ The difference between the estimates of the treatment and control groups' rate of growth, for the average student who is at the mean for the risk measure.

${ }^{3}$ The difference between the estimates of the treatment and control groups' rate of growth, for the average student who is one standard deviation above the mean for the risk measure.

${ }^{4}$ Estimated difference between the treatment and control groups in the incremental change in the rate of growth, with each unit increase in the risk measure.

NOTE: Abbreviations are

CR: Child Report

PCR: Primary Caregiver Report

TRS: Teacher Report on Student

ADHD: Attention deficit hyperactivity disorder

The +/- signs in parentheses indicate the direction of a beneficial outcome. All impact estimates were calculated using HLM 6.06. Sample weights were used in all analyses to (1) give each program equal weight within each time period, (2) give each school equal weight in each program (within each time period), and (3) give each time period equal weight in the analvsis.

SOURCE: The Social and Character Development (SACD) Research Program. 
Table 1.43. Impacts on growth of child outcomes, by initial family risk

Family risk

$($ Mean $=1.15 ;$ Standard deviation $=.18)$

Impact on growth at the specified risk level ( $p$-value)

\begin{tabular}{|c|c|c|c|c|}
\hline Scale-Report & $\begin{array}{r}\text { One standard } \\
\text { deviation below mean }^{1} \\
\end{array}$ & Mean $^{2}$ & $\begin{array}{r}\text { One standard } \\
\text { deviation above mean }^{3}\end{array}$ & $\begin{array}{r}\text { Interaction term }^{4} \\
(p \text {-value })\end{array}$ \\
\hline \multicolumn{5}{|l|}{ Social and Emotional Competence Domain } \\
\hline \multirow[t]{2}{*}{ Self-Efficacy for Peer Interactions-CR (+) } & -0.01 & 0.00 & 0.01 & 0.06 \\
\hline & $(0.500)$ & $(0.739)$ & $(0.500)$ & $(0.273)$ \\
\hline \multirow[t]{2}{*}{ Normative Beliefs About Aggression-CR (-) } & 0.02 & $0.03^{*}$ & $0.04^{\wedge}$ & 0.04 \\
\hline & $(0.142)$ & $(0.047)$ & $(0.052)$ & $(0.510)$ \\
\hline \multirow[t]{2}{*}{ Empathy-CR (+) } & 0.00 & -0.02 & $-0.03^{*}$ & $-0.08^{*}$ \\
\hline & $(0.500)$ & $(0.115)$ & $(0.014)$ & $(0.040)$ \\
\hline \multicolumn{5}{|l|}{ Behavior Domain } \\
\hline \multirow{2}{*}{ Altruistic Behavior-CR (+) } & 0.01 & -0.01 & -0.02 & -0.07 \\
\hline & $(0.500)$ & $(0.715)$ & $(0.300)$ & $(0.227)$ \\
\hline \multirow[t]{2}{*}{ Altruistic Behavior-PCR (+) } & 0.00 & 0.01 & 0.01 & 0.02 \\
\hline & $(0.500)$ & $(0.672)$ & $(0.500)$ & $(0.799)$ \\
\hline \multirow[t]{2}{*}{ Altruistic Behavior-TRS (+) } & $-0.05^{\wedge}$ & -0.04 & -0.02 & 0.07 \\
\hline & $(0.070)$ & $(0.225)$ & $(0.500)$ & $(0.129)$ \\
\hline \multirow[t]{2}{*}{ Positive Social Behavior-PCR (+) } & 0.01 & $0.02^{\wedge}$ & $0.02^{*}$ & $0.05^{\wedge}$ \\
\hline & $(0.500)$ & $(0.090)$ & $(0.018)$ & $(0.090)$ \\
\hline \multirow[t]{2}{*}{ Positive Social Behavior-TRS (+) } & -0.02 & -0.01 & -0.01 & 0.04 \\
\hline & $(0.500)$ & $(0.607)$ & $(0.500)$ & $(0.443)$ \\
\hline \multirow[t]{2}{*}{ Problem Behavior-CR (-) } & $0.03^{\wedge}$ & 0.02 & 0.01 & -0.05 \\
\hline & $(0.078)$ & $(0.241)$ & $(0.500)$ & $(0.983)$ \\
\hline \multirow[t]{2}{*}{ Problem Behavior-PCR (-) } & 0.00 & 0.00 & 0.00 & 0.00 \\
\hline & $(0.500)$ & $(0.440)$ & $(0.500)$ & $(0.983)$ \\
\hline \multirow[t]{2}{*}{ Problem Behavior-TRS (-) } & 0.00 & 0.00 & 0.00 & 0.01 \\
\hline & $(0.500)$ & $(0.858)$ & $(0.500)$ & $(0.891$ \\
\hline \multirow[t]{2}{*}{ ADHD-Related Behavior-TRS (-) } & 0.00 & -0.01 & -0.01 & -0.02 \\
\hline & $(0.500)$ & $(0.659)$ & $(0.500)$ & $(0.685)$ \\
\hline
\end{tabular}


Table 1.43. Impacts on growth of child outcomes, by initial family risk-Continued

\begin{tabular}{|c|c|c|c|c|}
\hline \multirow[b]{3}{*}{ Scale-Report } & \multicolumn{4}{|c|}{$\begin{array}{c}\text { Family risk } \\
\qquad(\text { Mean }=1.15 ; \text { Standard deviation }=.18)\end{array}$} \\
\hline & \multicolumn{3}{|c|}{ Impact on growth at the specified risk level ( $p$-value) } & \multirow[b]{2}{*}{$\begin{array}{r}\text { Interaction term } \\
(p \text {-value })\end{array}$} \\
\hline & $\begin{array}{r}\text { One standard } \\
\text { deviation below mean }\end{array}$ & Mean $^{2}$ & $\begin{array}{r}\text { One standard } \\
\text { deviation above mean } \\
\end{array}$ & \\
\hline \multicolumn{5}{|l|}{ Academics Domain } \\
\hline \multirow[t]{2}{*}{ Engagement with Learning-CR (+) } & 0.00 & -0.01 & -0.01 & -0.02 \\
\hline & $(0.500)$ & $(0.699)$ & $(0.500)$ & $(0.669)$ \\
\hline \multirow[t]{2}{*}{ Academic Competence and Motivation-TRS (+) } & -0.03 & 0.00 & 0.02 & $0.13^{*}$ \\
\hline & $(0.222)$ & $(0.844)$ & $(0.500)$ & $(0.031)$ \\
\hline \multicolumn{5}{|l|}{ Perceptions of School Climate Domain } \\
\hline \multirow[t]{2}{*}{ Positive School Orientation-CR (+) } & -0.01 & -0.03 & $-0.04^{*}$ & $-0.09^{\wedge}$ \\
\hline & $(0.500)$ & $(0.170)$ & $(0.028)$ & $(0.097)$ \\
\hline \multirow[t]{2}{*}{ Negative School Orientation-CR (-) } & 0.00 & 0.00 & 0.00 & 0.00 \\
\hline & $(0.500)$ & $(0.898)$ & $(0.500)$ & $(0.926)$ \\
\hline \multirow[t]{2}{*}{ Student Afraid at School-CR (-) } & -0.03 & -0.01 & 0.01 & 0.11 \\
\hline & $(0.257)$ & $(0.698)$ & $(0.500)$ & $(0.206)$ \\
\hline \multirow[t]{2}{*}{ Victimization at School-CR (-) } & 0.01 & -0.01 & $-0.04^{\wedge}$ & $-0.13^{*}$ \\
\hline & $(0.500)$ & $(0.466)$ & $(0.059)$ & $(0.032)$ \\
\hline
\end{tabular}

* Significantly different from zero at the .05 level.

$\wedge$ Significantly different from zero at the .10 to $>.05$ level.

The difference between the estimates of the treatment and control groups' rate of growth, for the average student who is one standard deviation below the mean for the risk measure.

${ }^{2}$ The difference between the estimates of the treatment and control groups' rate of growth, for the average student who is at the mean for the risk measure.

${ }^{3}$ The difference between the estimates of the treatment and control groups' rate of growth, for the average student who is one standard deviation above the mean for the risk measure.

${ }^{4}$ Estimated difference between the treatment and control groups in the incremental change in the rate of growth, with each unit increase in the risk measure.

NOTE: Abbreviations are

CR: Child Report

PCR: Primary Caregiver Report

TRS: Teacher Report on Student

ADHD: Attention deficit hyperactivity disorder

The +/- signs in parentheses indicate the direction of a beneficial outcome. All impact estimates were calculated using HLM 6.06. Sample weights were used in all analyses to (1) give each program equal weight within each time period, (2) give each school equal weight in each program (within each time period), and (3) give each time period equal weight in the analvsis.

SOURCE: The Social and Character Development (SACD) Research Program. 
Table 1.44. Impacts on growth of child outcomes, by initial perceptions of community risk

Community risk

$($ Mean $=1.52 ;$ Standard deviation $=.61)$

Impact on growth at the specified risk level ( $p$-value)

\begin{tabular}{|c|c|c|c|c|}
\hline Scale-Report & $\begin{array}{r}\text { One standard } \\
\text { deviation below mean }{ }^{1}\end{array}$ & Mean $^{2}$ & $\begin{array}{r}\text { One standard } \\
\text { deviation above mean } \\
\end{array}$ & $\begin{array}{r}\text { Interaction term }{ }^{4} \\
(p \text {-value })\end{array}$ \\
\hline \multicolumn{5}{|l|}{ Social and Emotional Competence Domain } \\
\hline \multirow{2}{*}{ Self-Efficacy for Peer Interactions-CR (+) } & -0.01 & 0.00 & 0.01 & 0.01 \\
\hline & $(0.500)$ & $(0.829)$ & $(0.500)$ & $(0.494)$ \\
\hline \multirow[t]{2}{*}{ Normative Beliefs About Aggression-CR (-) } & $0.04^{*}$ & $0.03^{*}$ & 0.02 & -0.02 \\
\hline & $(0.024)$ & $(0.028)$ & $(0.226)$ & $(0.384)$ \\
\hline \multirow[t]{2}{*}{ Empathy-CR (+) } & -0.02 & $-0.02^{\wedge}$ & -0.02 & 0.00 \\
\hline & $(0.200)$ & $(0.096)$ & $(0.145)$ & $(0.925)$ \\
\hline \multicolumn{5}{|l|}{ Behavior Domain } \\
\hline \multirow[t]{2}{*}{ Altruistic Behavior-CR (+) } & -0.01 & -0.01 & 0.00 & 0.01 \\
\hline & $(0.500)$ & $(0.743)$ & $(0.500)$ & $(0.669)$ \\
\hline \multirow{2}{*}{ Altruistic Behavior-PCR (+) } & 0.01 & 0.01 & 0.00 & -0.01 \\
\hline & $(0.500)$ & $(0.666)$ & $(0.500)$ & $(0.665)$ \\
\hline \multirow[t]{2}{*}{ Altruistic Behavior-TRS (+) } & -0.05 & -0.03 & -0.02 & 0.03 \\
\hline & $(0.129)$ & $(0.258)$ & $(0.500)$ & $(0.218)$ \\
\hline \multirow[t]{2}{*}{ Positive Social Behavior-PCR (+) } & 0.02 & $0.02^{\wedge}$ & 0.02 & 0.00 \\
\hline & $(0.146)$ & $(0.075)$ & $(0.208)$ & $(0.939)$ \\
\hline \multirow[t]{2}{*}{ Positive Social Behavior-TRS (+) } & -0.03 & -0.01 & 0.00 & 0.02 \\
\hline & $(0.286)$ & $(0.615)$ & $(0.500)$ & $(0.230)$ \\
\hline \multirow[t]{2}{*}{ Problem Behavior-CR (-) } & 0.01 & 0.02 & 0.02 & 0.00 \\
\hline & $(0.500)$ & $(0.255)$ & $(0.307)$ & $(0.871)$ \\
\hline \multirow[t]{2}{*}{ Problem Behavior-PCR (-) } & $-0.01^{*}$ & 0.00 & 0.01 & $0.02^{\wedge}$ \\
\hline & $(0.035)$ & $(0.908)$ & $(0.250)$ & $(0.051)$ \\
\hline \multirow[t]{2}{*}{ Problem Behavior-TRS (-) } & 0.01 & 0.00 & -0.01 & -0.02 \\
\hline & $(0.500)$ & $(0.899)$ & $(0.500)$ & $(0.222)$ \\
\hline \multirow[t]{2}{*}{ ADHD-Related Behavior-TRS (-) } & 0.02 & -0.01 & -0.03 & $-0.04^{\wedge}$ \\
\hline & $(0.500)$ & $(0.728)$ & $(0.195)$ & $(0.060)$ \\
\hline
\end{tabular}




\section{Table 1.44. Impacts on growth of child outcomes, by initial perceptions of community risk-Continued}

\begin{tabular}{|c|c|c|c|c|}
\hline \multirow[b]{3}{*}{ Scale-Report } & \multicolumn{4}{|c|}{$\begin{array}{c}\text { Community risk } \\
(\text { Mean }=1.52 ; \text { Standard deviation }=.61)\end{array}$} \\
\hline & \multicolumn{3}{|c|}{ Impact on growth at the specified risk level ( $p$-value) } & \multirow[b]{2}{*}{$\begin{array}{r}\text { Interaction term }^{4} \\
(p \text {-value })\end{array}$} \\
\hline & $\begin{array}{r}\text { One standard } \\
\text { deviation below mean } \\
\end{array}$ & Mean $^{2}$ & $\begin{array}{r}\text { One standard } \\
\text { deviation above mean } \\
\end{array}$ & \\
\hline \multirow{3}{*}{$\begin{array}{l}\text { Academics Domain } \\
\quad \text { Engagement with Learning-CR }(+)\end{array}$} & & & & \\
\hline & -0.01 & -0.01 & 0.00 & 0.00 \\
\hline & $(0.500)$ & $(0.661)$ & $(0.500)$ & $(0.866)$ \\
\hline \multirow[t]{2}{*}{ Academic Competence and Motivation-TRS (+) } & 0.00 & 0.00 & -0.01 & -0.01 \\
\hline & $(0.500)$ & $(0.968)$ & $(0.500)$ & $(0.732)$ \\
\hline \multicolumn{5}{|l|}{ Perceptions of School Climate Domain } \\
\hline \multirow[t]{2}{*}{ Positive School Orientation-CR (+) } & $-0.06^{*}$ & $-0.03^{\wedge}$ & -0.01 & $0.04^{\wedge}$ \\
\hline & $(0.017)$ & $(0.095)$ & $(0.500)$ & $(0.073)$ \\
\hline \multirow[t]{2}{*}{ Negative School Orientation-CR (-) } & 0.01 & 0.00 & 0.00 & -0.01 \\
\hline & $(0.500)$ & $(0.792)$ & $(0.500)$ & $(0.528)$ \\
\hline \multirow[t]{2}{*}{ Student Afraid at School-CR (-) } & -0.02 & -0.01 & 0.01 & 0.02 \\
\hline & $(0.500)$ & $(0.764)$ & $(0.500)$ & $(0.510)$ \\
\hline \multirow[t]{2}{*}{ Victimization at School-CR (-) } & 0.02 & -0.01 & $-0.05^{*}$ & $-0.06^{*}$ \\
\hline & $(0.224)$ & $0.386)$ & $(0.035)$ & $(0.014)$ \\
\hline
\end{tabular}

* Significantly different from zero at the .05 level.

$\wedge$ Significantly different from zero at the .10 to $>.05$ level.

${ }^{1}$ The difference between the estimates of the treatment and control groups' rate of growth, for the average student who is one standard deviation below the mean for the risk measure.

${ }^{2}$ The difference between the estimates of the treatment and control groups' rate of growth, for the average student who is at the mean for the risk measure.

${ }^{3}$ The difference between the estimates of the treatment and control groups' rate of growth, for the average student who is one standard deviation above the mean for the risk measure.

${ }^{4}$ Estimated difference between the treatment and control groups in the incremental change in the rate of growth, with each unit increase in the risk measure.

NOTE: Abbreviations are

CR: Child Report

PCR: Primary Caregiver Report

TRS: Teacher Report on Student

ADHD: Attention deficit hyperactivity disorder

The +/- signs in parentheses indicate the direction of a beneficial outcome. All impact estimates were calculated using HLM 6.06. Sample weights were used in all analyses to (1) give each program equal weight within each time period, (2) give each school equal weight in each program (within each time period), and (3) give each time period equal weight in the analysis.

SOURCE: The Social and Character Development (SACD) Research Program. 
Table 1.45. Impacts on growth of child outcomes, by child behavior risk as reported by teacher

\begin{tabular}{|c|c|c|c|c|}
\hline \multirow[b]{3}{*}{ Scale-Report } & \multirow{2}{*}{\multicolumn{4}{|c|}{$\begin{array}{c}\begin{array}{c}\text { Teacher-reported child behavior risk } \\
(\text { Mean }=1.79 ; \text { Standard deviation }=2.04)\end{array}\end{array}$}} \\
\hline & Impact on growth at the specified risk level ( $p$-value) & & & \multirow[b]{2}{*}{$\begin{array}{r}\text { Interaction term }{ }^{4} \\
(p \text {-value })\end{array}$} \\
\hline & $\begin{array}{r}\text { One standard } \\
\text { deviation below mean } \\
\end{array}$ & Mean $^{2}$ & $\begin{array}{r}\text { One standard } \\
\text { deviation above mean } \\
\end{array}$ & \\
\hline \\
\hline \multirow{2}{*}{ Self-Efficacy for Peer Interactions-CR (+) } & 0.00 & 0.00 & -0.01 & 0.00 \\
\hline & $(0.500)$ & $(0.699)$ & $(0.500)$ & $(0.929)$ \\
\hline \multirow[t]{2}{*}{ Normative Beliefs About Aggression-CR (-) } & 0.01 & $0.03^{*}$ & $0.05^{*}$ & $0.01^{*}$ \\
\hline & $(0.500)$ & $(0.038)$ & $(0.005)$ & $(0.047)$ \\
\hline \multirow[t]{2}{*}{ Empathy-CR (+) } & -0.01 & $-0.02^{\wedge}$ & $-0.02^{\wedge}$ & 0.00 \\
\hline & $(0.500)$ & $(0.098)$ & $(0.064)$ & $(0.585)$ \\
\hline \multicolumn{5}{|l|}{ Behavior Domain } \\
\hline \multirow[t]{2}{*}{ Altruistic Behavior-CR (+) } & -0.01 & -0.01 & 0.00 & 0.00 \\
\hline & $(0.500)$ & $(0.786)$ & $(0.500)$ & $(0.908)$ \\
\hline \multirow[t]{2}{*}{ Altruistic Behavior-PCR (+) } & 0.02 & 0.01 & -0.01 & -0.01 \\
\hline & $(0.188)$ & $(0.644)$ & $(0.500)$ & $(0.228)$ \\
\hline \multirow[t]{2}{*}{ Altruistic Behavior-TRS (+) } & $-0.05^{\wedge}$ & -0.03 & -0.02 & 0.01 \\
\hline & $(0.091)$ & $(0.241)$ & $(0.500)$ & $(0.142)$ \\
\hline \multirow[t]{2}{*}{ Positive Social Behavior-PCR (+) } & 0.00 & $0.02^{\wedge}$ & $0.03^{*}$ & $0.01^{\wedge}$ \\
\hline & $(0.500)$ & $(0.057)$ & $(0.017)$ & $(0.070)$ \\
\hline \multirow[t]{2}{*}{ Positive Social Behavior-TRS (+) } & -0.01 & -0.02 & -0.02 & 0.00 \\
\hline & $(0.500)$ & $(0.539)$ & $(0.500)$ & $(0.755)$ \\
\hline \multirow[t]{2}{*}{ Problem Behavior-CR (-) } & 0.01 & 0.02 & 0.02 & 0.00 \\
\hline & $(0.500)$ & $(0.248)$ & $(0.237)$ & $(0.584)$ \\
\hline \multirow[t]{2}{*}{ Problem Behavior-PCR (-) } & -0.01 & 0.00 & 0.00 & 0.00 \\
\hline & $(0.307)$ & $(0.541)$ & $(0.500)$ & $(0.431)$ \\
\hline \multirow[t]{2}{*}{ Problem Behavior-TRS (-) } & 0.01 & 0.01 & 0.00 & 0.00 \\
\hline & $(0.500)$ & $(0.745)$ & $(0.500)$ & $(0.563)$ \\
\hline \multirow[t]{2}{*}{ ADHD-Related Behavior-TRS (-) } & 0.01 & -0.01 & -0.02 & -0.01 \\
\hline & $(0.500)$ & $(0.760)$ & $(0.500)$ & $(0.173)$ \\
\hline
\end{tabular}


Table 1.45. Impacts on growth of child outcomes, by child behavior risk as reported by teacher-Continued

\begin{tabular}{|c|c|c|c|c|}
\hline \multirow[b]{3}{*}{ Scale-Report } & \multicolumn{4}{|c|}{$\begin{array}{c}\text { Teacher-reported child behavior risk } \\
(\text { Mean }=1.79 ; \text { Standard deviation }=2.04)\end{array}$} \\
\hline & \multicolumn{3}{|c|}{ Impact on growth at the specified risk level ( $p$-value) } & \multirow[b]{2}{*}{$\begin{array}{r}\text { Interaction term }{ }^{4} \\
(p \text {-value })\end{array}$} \\
\hline & $\begin{array}{r}\text { One standard } \\
\text { deviation below mean }^{1} \\
\end{array}$ & Mean $^{2}$ & $\begin{array}{r}\text { One standard } \\
\text { deviation above mean } \\
\end{array}$ & \\
\hline \multicolumn{5}{|l|}{ Academics Domain } \\
\hline \multirow[t]{2}{*}{ Engagement with Learning-CR (+) } & 0.01 & -0.01 & -0.03 & -0.01 \\
\hline & $(0.500)$ & $(0.544)$ & $(0.159)$ & $(0.114)$ \\
\hline \multirow[t]{2}{*}{ Academic Competence and Motivation-TRS (+) } & -0.03 & -0.01 & 0.02 & $0.01^{\wedge}$ \\
\hline & $(0.215)$ & $(0.799)$ & $(0.500)$ & $(0.092)$ \\
\hline \multicolumn{5}{|l|}{ Perceptions of School Climate Domain } \\
\hline \multirow[t]{2}{*}{ Positive School Orientation-CR (+) } & -0.02 & -0.03 & $-0.05^{*}$ & -0.01 \\
\hline & $(0.500)$ & $(0.108)$ & $(0.033)$ & $(0.257)$ \\
\hline Negative School Orientation-CR (-) & $\begin{array}{r}-0.01 \\
(0.500)\end{array}$ & $\begin{array}{r}0.00 \\
(0.762)\end{array}$ & $\begin{array}{r}0.02 \\
(0.500)\end{array}$ & $\begin{array}{r}0.01 \\
(0.208)\end{array}$ \\
\hline Student Afraid at School-CR (-) & $\begin{array}{r}0.00 \\
(0.500)\end{array}$ & $\begin{array}{r}-0.01 \\
(0.739)\end{array}$ & $\begin{array}{r}-0.01 \\
(0.500)\end{array}$ & $\begin{array}{r}0.00 \\
(0.896)\end{array}$ \\
\hline Victimization at School-CR (-) & $\begin{array}{r}-0.01 \\
(0.500)\end{array}$ & $\begin{array}{r}-0.01 \\
(0.518)\end{array}$ & $\begin{array}{r}-0.01 \\
(0.500)\end{array}$ & $\begin{array}{r}0.00 \\
(0.795)\end{array}$ \\
\hline
\end{tabular}

* Significantly different from zero at the .05 level.

$\wedge$ Significantly different from zero at the .10 to $>.05$ level.

${ }^{1}$ The difference between the estimates of the treatment and control groups' rate of growth, for the average student who is one standard deviation below the mean for the risk measure.

${ }^{2}$ The difference between the estimates of the treatment and control groups' rate of growth, for the average student who is at the mean for the risk measure.

${ }^{3}$ The difference between the estimates of the treatment and control groups' rate of growth, for the average student who is one standard deviation above the mean for the risk measure.

${ }^{4}$ Estimated difference between the treatment and control groups in the incremental change in the rate of growth, with each unit increase in the risk measure.

NOTE: Abbreviations are

CR: Child Report

PCR: Primary Caregiver Report

TRS: Teacher Report on Student

ADHD: Attention deficit hyperactivity disorder

The +/- signs in parentheses indicate the direction of a beneficial outcome. All impact estimates were calculated using HLM 6.06. Sample weights were used in all analyses to (1) give each program equal weight within each time period, (2) give each school equal weight in each program (within each time period), and (3) give each time period equal weight in the analvsis.

SOURCE: The Social and Character Development (SACD) Research Program. 
Table 1.46. Impacts on growth of child outcomes, by child behavior risk as reported by primary caregiver

\begin{tabular}{|c|c|c|c|c|}
\hline \multirow[b]{3}{*}{ Scale-Report } & \multicolumn{4}{|c|}{$\begin{array}{l}\text { Primary caregiver-reported child behavior risk } \\
\quad(\text { Mean }=3.43 ; \text { Standard deviation }=2.01)\end{array}$} \\
\hline & \multicolumn{3}{|c|}{ Impact on growth at the specified risk level ( $p$-value) } & \multirow[b]{2}{*}{$\begin{array}{r}\text { Interaction term } \\
(p \text {-value }\end{array}$} \\
\hline & $\begin{array}{r}\text { One standard } \\
\text { deviation below mean }^{1}\end{array}$ & Mean $^{2}$ & $\begin{array}{r}\text { One standard } \\
\text { deviation above mean }^{3}\end{array}$ & \\
\hline \multirow{3}{*}{$\begin{array}{l}\text { Social and Emotional Competence Domain } \\
\text { Self-Efficacy for Peer Interactions-CR (+) }\end{array}$} & & & & \\
\hline & -0.01 & 0.00 & 0.01 & 0.00 \\
\hline & $(0.500)$ & $(0.716)$ & $(0.500)$ & $(0.929)$ \\
\hline \multirow[t]{2}{*}{ Normative Beliefs About Aggression-CR (-) } & 0.02 & $0.03^{*}$ & $0.04^{*}$ & 0.00 \\
\hline & $(0.200)$ & $(0.036)$ & $(0.028)$ & $(0.416)$ \\
\hline \multirow[t]{2}{*}{ Empathy-CR (+) } & -0.01 & -0.02 & $-0.02^{\wedge}$ & 0.00 \\
\hline & $(0.299)$ & $(0.114)$ & $(0.088)$ & $(0.490)$ \\
\hline \multicolumn{5}{|l|}{ Behavior Domain } \\
\hline \multirow[t]{2}{*}{ Altruistic Behavior-CR (+) } & -0.01 & 0.00 & 0.00 & 0.00 \\
\hline & $(0.500)$ & $(0.803)$ & $(0.500)$ & $(0.854)$ \\
\hline \multirow[t]{2}{*}{ Altruistic Behavior-PCR (+) } & 0.02 & 0.01 & 0.00 & 0.00 \\
\hline & $(0.500)$ & $(0.531)$ & $(0.500)$ & $(0.472)$ \\
\hline \multirow[t]{2}{*}{ Altruistic Behavior-TRS (+) } & -0.04 & -0.03 & -0.03 & 0.00 \\
\hline & $(0.169)$ & $(0.246)$ & $(0.315)$ & $(0.319)$ \\
\hline \multirow[t]{2}{*}{ Positive Social Behavior-PCR (+) } & 0.01 & $0.02^{\wedge}$ & $0.02^{*}$ & 0.00 \\
\hline & $(0.500)$ & $(0.088)$ & $(0.042)$ & $(0.178)$ \\
\hline \multirow[t]{2}{*}{ Positive Social Behavior-TRS (+) } & -0.01 & -0.01 & -0.02 & 0.00 \\
\hline & $(0.500)$ & $(0.577)$ & $(0.500)$ & $(0.900)$ \\
\hline \multirow[t]{2}{*}{ Problem Behavior-CR (-) } & 0.01 & 0.02 & 0.02 & 0.00 \\
\hline & $(0.500)$ & $(0.246)$ & $(0.164)$ & $(0.429)$ \\
\hline \multirow[t]{2}{*}{ Problem Behavior-PCR (-) } & $-0.01^{*}$ & -0.01 & 0.00 & 0.00 \\
\hline & $(0.044)$ & $(0.419)$ & $(0.500)$ & $(0.157)$ \\
\hline \multirow[t]{2}{*}{ Problem Behavior-TRS (-) } & 0.00 & 0.00 & 0.00 & 0.00 \\
\hline & $(0.500)$ & $(0.886)$ & $(0.500)$ & $(0.724)$ \\
\hline \multirow[t]{2}{*}{ ADHD-Related Behavior-TRS (-) } & 0.00 & -0.01 & -0.02 & -0.01 \\
\hline & $(0.500)$ & $(0.620)$ & $(0.500)$ & $(0.113)$ \\
\hline
\end{tabular}




\section{Table 1.46. Impacts on growth of child outcomes, by child behavior risk as reported by primary caregiver-Continued}

\begin{tabular}{|c|c|c|c|c|}
\hline \multirow[b]{3}{*}{ Scale-Report } & \multicolumn{4}{|c|}{$\begin{array}{l}\text { Primary caregiver-reported child behavior risk } \\
(\text { Mean }=3.43 ; \text { Standard deviation }=2.01)\end{array}$} \\
\hline & \multicolumn{3}{|c|}{ Impact on growth at the specified risk level ( $p$-value) } & \multirow[b]{2}{*}{$\begin{array}{r}\text { Interaction term } \\
(p \text {-value }) \\
\end{array}$} \\
\hline & $\begin{array}{r}\text { One standard } \\
\text { deviation below mean }^{1} \\
\end{array}$ & Mean $^{2}$ & $\begin{array}{r}\text { One standard } \\
\text { deviation above mean } \\
\end{array}$ & \\
\hline \multicolumn{5}{|l|}{ Academics Domain } \\
\hline \multirow[t]{2}{*}{ Engagement with Learning-CR (+) } & -0.01 & -0.01 & 0.00 & 0.00 \\
\hline & $(0.500)$ & $(0.646)$ & $(0.500)$ & $(0.711)$ \\
\hline \multirow[t]{2}{*}{ Academic Competence and Motivation-TRS (+) } & -0.01 & 0.00 & 0.01 & 0.01 \\
\hline & $(0.500)$ & $(0.837)$ & $(0.500)$ & $(0.332)$ \\
\hline \multicolumn{5}{|l|}{ Perceptions of School Climate Domain } \\
\hline \multirow[t]{2}{*}{ Positive School Orientation-CR (+) } & -0.01 & -0.03 & $-0.05^{*}$ & -0.01 \\
\hline & $(0.500)$ & $(0.126)$ & $(0.039)$ & $(0.173)$ \\
\hline \multirow[t]{2}{*}{ Negative School Orientation-CR (-) } & 0.00 & 0.00 & 0.00 & 0.00 \\
\hline & $(0.500)$ & $(0.902)$ & $(0.500)$ & $(0.898)$ \\
\hline \multirow[t]{2}{*}{ Student Afraid at School-CR (-) } & 0.02 & -0.01 & -0.03 & -0.01 \\
\hline & $(0.500)$ & $(0.791)$ & $(0.287)$ & $(0.144)$ \\
\hline \multirow[t]{2}{*}{ Victimization at School-CR (-) } & -0.01 & -0.01 & -0.02 & 0.00 \\
\hline & $(0.500)$ & $(0.469)$ & $(0.500)$ & $(0.751)$ \\
\hline
\end{tabular}

* Significantly different from zero at the .05 level.

$\wedge$ Significantly different from zero at the .10 to $>.05$ level.

${ }^{1}$ The difference between the estimates of the treatment and control groups' rate of growth, for the average student who is one standard deviation below the mean for the risk measure.

${ }^{2}$ The difference between the estimates of the treatment and control groups' rate of growth, for the average student who is at the mean for the risk measure.

${ }^{3}$ The difference between the estimates of the treatment and control groups' rate of growth, for the average student who is one standard deviation above the mean for the risk measure.

${ }^{4}$ Estimated difference between the treatment and control groups in the incremental change in the rate of growth, with each unit increase in the risk measure.

NOTE: Abbreviations are

CR: Child Report

PCR: Primary Caregiver Report

TRS: Teacher Report on Student

ADHD: Attention deficit hyperactivity disorder

The +/- signs in parentheses indicate the direction of a beneficial outcome. Sample weights were used in all analyses to (1) give each program equal weight in the calculation of pooled impact estimates and (2) give each school equal weight in each program.

SOURCE: The Social and Character Development (SACD) Research Program. 
Table 1.47. Sample size ranges for outcome analyses

\begin{tabular}{|c|c|c|c|c|c|c|c|c|}
\hline \multirow[b]{2}{*}{ Outcome analysis } & \multirow[b]{2}{*}{ Group } & \multirow[b]{2}{*}{ Report } & \multicolumn{2}{|c|}{ Year 1} & \multicolumn{2}{|c|}{ Year 2} & \multicolumn{2}{|c|}{ Year 3} \\
\hline & & & $\begin{array}{l}\text { Mini- } \\
\text { mum of } \\
\text { range }\end{array}$ & $\begin{array}{r}\text { Maxi- } \\
\text { mum of } \\
\text { range }\end{array}$ & $\begin{array}{l}\text { Mini- } \\
\text { mum of } \\
\text { range }\end{array}$ & $\begin{array}{l}\text { Maxi- } \\
\text { mum of } \\
\text { range }\end{array}$ & $\begin{array}{r}\text { Mini- } \\
\text { mum of } \\
\text { range }\end{array}$ & $\begin{array}{l}\text { Maxi- } \\
\text { mum of } \\
\text { range }\end{array}$ \\
\hline \multirow[t]{8}{*}{ Combined program } & Treatment & $\mathrm{CR}$ & 2,181 & 2,190 & 2,143 & 2,162 & 2,065 & 2,081 \\
\hline & & PCR & 1,728 & 1,760 & 1,668 & 1,691 & 1,452 & 1,473 \\
\hline & & TRS & 2,205 & 2,252 & 2,198 & 2,247 & 2,073 & 2,110 \\
\hline & & TRCS & 436 & 437 & 422 & 423 & 422 & 423 \\
\hline & Control & $\mathrm{CR}$ & 1,939 & 1,961 & 1,869 & 1,892 & 1,894 & 1,903 \\
\hline & & PCR & 1,587 & 1,611 & 1,475 & 1,493 & 1,363 & 1,383 \\
\hline & & TRS & 1,950 & 2,025 & 1,976 & 1,989 & 1,921 & 1,965 \\
\hline & & TRCS & 408 & 409 & 403 & 404 & 392 & 393 \\
\hline \multicolumn{9}{|l|}{ Individual programs } \\
\hline \multirow[t]{8}{*}{$\mathrm{ABC}$} & Treatment & CR & 245 & 257 & 234 & 235 & 242 & 245 \\
\hline & & PCR & 194 & 197 & 168 & 171 & 167 & 167 \\
\hline & & TRS & 248 & 250 & 233 & 245 & 261 & 262 \\
\hline & & TRCS & 54 & 54 & 49 & 49 & 51 & 51 \\
\hline & Control & $\mathrm{CR}$ & 292 & 297 & 308 & 311 & 302 & 307 \\
\hline & & PCR & 217 & 224 & 229 & 229 & 214 & 219 \\
\hline & & TRS & 287 & 305 & 322 & 322 & 322 & 323 \\
\hline & & TRCS & 66 & 66 & 67 & 67 & 64 & 64 \\
\hline \multirow[t]{8}{*}{ CSP } & Treatment & $\mathrm{CR}$ & 313 & 319 & 312 & 377 & 280 & 288 \\
\hline & & PCR & 239 & 245 & 243 & 246 & 211 & 211 \\
\hline & & TRS & 324 & 325 & 302 & 404 & 265 & 266 \\
\hline & & TRCS & 50 & 52 & 57 & 91 & 62 & 62 \\
\hline & Control & $\mathrm{CR}$ & 323 & 335 & 306 & 299 & 324 & 329 \\
\hline & & PCR & 279 & 280 & 257 & 209 & 231 & 231 \\
\hline & & TRS & 329 & 344 & 320 & 333 & 324 & 326 \\
\hline & & TRCS & 50 & 50 & 60 & 82 & 60 & 61 \\
\hline \multirow[t]{8}{*}{ LBW } & Treatment & CR & 345 & 347 & 338 & 339 & 331 & 332 \\
\hline & & PCR & 298 & 302 & 293 & 296 & 253 & 257 \\
\hline & & TRS & 380 & 382 & 358 & 366 & 355 & 358 \\
\hline & & TRCS & 79 & 79 & 68 & 69 & 75 & 75 \\
\hline & Control & $\mathrm{CR}$ & 264 & 265 & 238 & 240 & 220 & 221 \\
\hline & & PCR & 229 & 230 & 191 & 191 & 184 & 187 \\
\hline & & TRS & 273 & 284 & 250 & 252 & 240 & 242 \\
\hline & & TRCS & 62 & 62 & 47 & 47 & 50 & 50 \\
\hline \multirow[t]{8}{*}{ PA } & Treatment & CR & 296 & 298 & 280 & 284 & 258 & 259 \\
\hline & & PCR & 239 & 244 & 212 & 214 & 168 & 170 \\
\hline & & TRS & 275 & 304 & 289 & 302 & 242 & 262 \\
\hline & & TRCS & 49 & 50 & 43 & 43 & 39 & 39 \\
\hline & Control & $\mathrm{CR}$ & 277 & 280 & 220 & 225 & 241 & 242 \\
\hline & & PCR & 227 & 231 & 181 & 183 & 158 & 158 \\
\hline & & TRS & 280 & 302 & 249 & 251 & 215 & 250 \\
\hline & & TRCS & 45 & 45 & 39 & 39 & 38 & 38 \\
\hline
\end{tabular}


Chapter 1. The Social and Character Development Multiprogram Evaluation

Table 1.47. Sample size ranges for outcome analyses-Continued

\begin{tabular}{|c|c|c|c|c|c|c|c|c|}
\hline \multirow[b]{2}{*}{ Outcome analysis } & \multirow[b]{2}{*}{ Group } & \multirow[b]{2}{*}{ Report } & \multicolumn{2}{|c|}{ Year 1} & \multicolumn{2}{|c|}{ Year 2} & \multicolumn{2}{|c|}{ Year 3} \\
\hline & & & $\begin{array}{l}\text { Mini- } \\
\text { mum of } \\
\text { range }\end{array}$ & $\begin{array}{r}\text { Maxi- } \\
\text { mum of } \\
\text { range }\end{array}$ & $\begin{array}{l}\text { Mini- } \\
\text { mum of } \\
\text { range }\end{array}$ & $\begin{array}{l}\text { Maxi- } \\
\text { mum of } \\
\text { range }\end{array}$ & $\begin{array}{l}\text { Mini- } \\
\text { mum of } \\
\text { range }\end{array}$ & $\begin{array}{l}\text { Maxi- } \\
\text { mum of } \\
\text { range }\end{array}$ \\
\hline \multirow[t]{8}{*}{ PATHS } & Treatment & CR & 216 & 219 & 220 & 222 & 225 & 227 \\
\hline & & PCR & 191 & 198 & 181 & 186 & 169 & 174 \\
\hline & & TRS & 232 & 232 & 228 & 229 & 228 & 230 \\
\hline & & TRCS & 57 & 58 & 55 & 55 & 50 & 50 \\
\hline & Control & $\mathrm{CR}$ & 219 & 220 & 212 & 212 & 202 & 204 \\
\hline & & PCR & 179 & 180 & 166 & 168 & 161 & 164 \\
\hline & & TRS & 224 & 225 & 219 & 219 & 197 & 208 \\
\hline & & TRCS & 51 & 51 & 57 & 57 & 60 & 60 \\
\hline \multirow[t]{8}{*}{ 4Rs } & Treatment & CR & 401 & 403 & 372 & 377 & 350 & 355 \\
\hline & & PCR & 265 & 270 & 241 & 246 & 177 & 183 \\
\hline & & TRS & 387 & 403 & 399 & 404 & 360 & 361 \\
\hline & & TRCS & 87 & 88 & 90 & 91 & 87 & 88 \\
\hline & Control & $\mathrm{CR}$ & 301 & 303 & 292 & 299 & 306 & 309 \\
\hline & & PCR & 221 & 227 & 206 & 209 & 169 & 174 \\
\hline & & TRS & 303 & 306 & 307 & 320 & 321 & 322 \\
\hline & & TRCS & 85 & 85 & 82 & 82 & 75 & 75 \\
\hline \multirow[t]{8}{*}{ SS } & Treatment & $\mathrm{CR}$ & 358 & 361 & 383 & 387 & 375 & 376 \\
\hline & & PCR & 302 & 305 & 330 & 335 & 307 & 311 \\
\hline & & TRS & 357 & 361 & 381 & 383 & 357 & 376 \\
\hline & & TRCS & 58 & 58 & 59 & 60 & 58 & 58 \\
\hline & Control & $\mathrm{CR}$ & 259 & 261 & 288 & 291 & 293 & 297 \\
\hline & & PCR & 235 & 239 & 245 & 255 & 246 & 250 \\
\hline & & TRS & 254 & 263 & 292 & 293 & 296 & 298 \\
\hline & & TRCS & 49 & 50 & 51 & 52 & 45 & 45 \\
\hline \multicolumn{9}{|l|}{ Subgroups } \\
\hline \multirow[t]{6}{*}{ Gender } & Boys & CR & 1,983 & 1,998 & 1,913 & 1,933 & 1,899 & 1,915 \\
\hline & & PCR & 1,594 & 1,662 & 1,503 & 1,526 & 1,325 & 1,349 \\
\hline & & TRS & 2,010 & 2,067 & 2,027 & 2,048 & 1,927 & 1,965 \\
\hline & Girls & $\mathrm{CR}$ & 2,135 & 2,153 & 2,099 & 2,121 & 2,060 & 2,069 \\
\hline & & PCR & 1,688 & 1,716 & 1,626 & 1,645 & 1,473 & 1,490 \\
\hline & & TRS & 2,108 & 2,174 & 2,132 & 2,174 & 2,046 & 2,090 \\
\hline \multirow[t]{7}{*}{ New entrants } & Stayers & CR & $\dagger$ & $\dagger$ & 3,090 & 3,124 & 2,764 & 2,781 \\
\hline & & PCR & $\dagger$ & $\dagger$ & 2,444 & 2,470 & 1,953 & 1,976 \\
\hline & & TRS & $\dagger$ & $\dagger$ & 3,230 & 3,275 & 2,809 & 2,862 \\
\hline & New & & & & & & & \\
\hline & entrants & CR & $\dagger$ & $\dagger$ & 921 & 931 & 1,196 & 1,203 \\
\hline & & PCR & $\dagger$ & $\dagger$ & 699 & 714 & 862 & 879 \\
\hline & & TRS & $\dagger$ & $\dagger$ & 944 & 962 & 1,185 & 1,217 \\
\hline \multirow{3}{*}{\multicolumn{2}{|c|}{ Initial socioeconomic risk }} & CR & 3,292 & 3,311 & 3,649 & 3,693 & 3,565 & 3,584 \\
\hline & & PCR & 2,871 & 2,916 & 3,076 & 3,113 & 2,737 & 2,775 \\
\hline & & TRS & 3,312 & 3,411 & 3,799 & 3,843 & 3,588 & 3,662 \\
\hline
\end{tabular}

See notes at end of table. 
Chapter 1. The Social and Character Development Multiprogram Evaluation

Table 1.47. Sample size ranges for outcome analyses-Continued

\begin{tabular}{|c|c|c|c|c|c|c|c|c|}
\hline \multirow[b]{2}{*}{ Outcome analysis } & \multirow[b]{2}{*}{ Group } & \multirow[b]{2}{*}{ Report } & \multicolumn{2}{|c|}{ Year 1} & \multicolumn{2}{|c|}{ Year 2} & \multicolumn{2}{|c|}{ Year 3} \\
\hline & & & $\begin{array}{r}\text { Mini- } \\
\text { mum of } \\
\text { range }\end{array}$ & $\begin{array}{r}\text { Maxi- } \\
\text { mum of } \\
\text { range }\end{array}$ & $\begin{array}{r}\text { Mini- } \\
\text { mum of } \\
\text { range }\end{array}$ & $\begin{array}{r}\text { Maxi- } \\
\text { mum of } \\
\text { range }\end{array}$ & $\begin{array}{r}\text { Mini- } \\
\text { mum of } \\
\text { range }\end{array}$ & $\begin{array}{l}\text { Maxi- } \\
\text { mum of } \\
\text { range }\end{array}$ \\
\hline \multirow[t]{3}{*}{ Initial family risk } & & CR & 3,373 & 3,392 & 2,749 & 2,780 & 2,459 & 2,473 \\
\hline & & PCR & 2,893 & 2,939 & 2,297 & 2,322 & 1,834 & 1,854 \\
\hline & & TRS & 3,382 & 3,483 & 2,873 & 2,901 & 2,497 & 2,547 \\
\hline \multirow[t]{3}{*}{ Initial community risk } & & $\mathrm{CR}$ & 3,289 & 3,309 & 2,702 & 2,734 & 2,413 & 2,427 \\
\hline & & PCR & 2,839 & 2,884 & 2,266 & 2,290 & 1,813 & 1,830 \\
\hline & & TRS & 3,298 & 3,396 & 2,820 & 2,857 & 2,450 & 2,499 \\
\hline \multirow{4}{*}{$\begin{array}{l}\text { Initial child behavior } \\
\text { risk (Teacher Report) }\end{array}$} & & & & & & & & \\
\hline & & $\mathrm{CR}$ & 3,608 & 3,630 & 2,936 & 2,970 & 2,631 & 2,647 \\
\hline & & PCR & 2,940 & 2,988 & 2,341 & 2,364 & 1,870 & 1,893 \\
\hline & & TRS & 3,567 & 3,763 & 3,072 & 3,111 & 2,679 & 2,729 \\
\hline \multicolumn{9}{|l|}{$\begin{array}{l}\text { Initial child behavior } \\
\text { risk (Primary }\end{array}$} \\
\hline \multirow[t]{3}{*}{ Caregiver Report) } & & $\mathrm{CR}$ & 3,353 & 3,372 & 2,732 & 2,764 & 2,451 & 2,464 \\
\hline & & PCR & 2,876 & 2,923 & 2,289 & 2,313 & 1,828 & 1,847 \\
\hline & & TRS & 3,365 & 3,466 & 2,858 & 2,886 & 2,487 & 2,537 \\
\hline \multirow[t]{9}{*}{$\begin{array}{l}\text { Fidelity of } \\
\text { implementation }\end{array}$} & High & CR & 2,020 & 2,038 & 1,617 & 1,635 & 1,224 & 1,235 \\
\hline & & PCR & 1,675 & 1,697 & 1,323 & 1,340 & 908 & 926 \\
\hline & & TRS & 2,018 & 2,096 & 1,654 & 1,679 & 1,207 & 1,251 \\
\hline & Mixed & $\mathrm{CR}$ & $\dagger$ & $\dagger$ & 848 & 851 & 1,444 & 1,450 \\
\hline & & PCR & $\dagger$ & $\dagger$ & 677 & 684 & 1,036 & 1,052 \\
\hline & & TRS & $\dagger$ & $\dagger$ & 893 & 904 & 1,469 & 1,485 \\
\hline & Low & CR & 2,100 & 2,113 & 1,544 & 1,565 & 1,289 & 1,298 \\
\hline & & PCR & 1,640 & 1,675 & 1,140 & 1,158 & 870 & 877 \\
\hline & & TRS & 2,137 & 2,182 & 1,624 & 1,652 & 1,317 & 1,338 \\
\hline
\end{tabular}

† Not applicable.

NOTE: Abbreviations are

ABC: Academic and Behavioral Competencies Program

CSP: Competence Support Program

LBW: Love in a Big World

PA: Positive Action

PATHS: Promoting Alternative Thinking Strategies

4Rs: The 4Rs Program (Reading, Writing, Respect, and Resolution)

SS: Second Step

CR: Child Report

PCR: Primary Caregiver Report

TRS: Teacher Report on Student

TRCS: Teacher Report on Classroom and School

SOURCE: The Social and Character Development (SACD) Research Program. 


\section{Chapter 1. The Social and Character Development Multiprogram Evaluation}

\section{Sensitivity Analyses}

To implement the growth curve analyses, it was necessary to make decisions about key model parameter specifications and estimation methods. A set of sensitivity tests using variations in key model assumptions examined the original growth curve findings and found them robust.

\section{Time Metric}

Age of student provides a different time metric by which to measure the growth trajectory. The growth curve analysis was redone using age in years at the start of implementation of the program. The 18 impact estimates remained insignificant when using age as the time metric.

\section{Weights}

Weights were used to represent each program equally within each survey period, each school equally within each program, and each survey period equally within the analysis. To determine whether the weights affected the outcomes, an unweighted analysis was conducted. The 18 impact estimates remained insignificant in the unweighted model.

\section{Fitted Impacts}

"Fitted" impact estimates and significance levels were examined at follow-up points corresponding to the point-in-time analyses at 6 months, 12 months, 18 months, and 30 months after implementation, which correspond roughly to the times of the data collection efforts. Based on the fitted growth curve model, statistically significant impact estimates were found for three outcomes (these data are not shown in a table). ${ }^{45}$ One was in a detrimental direction and two were in a beneficial direction. At 12, 18, and 30 months after implementation, the seven SACD programs, together, lowered growth of child-reported Altruistic Behavior by .05 (significant at the .01 level), 0.05 (significant at the .01 level), and 0.06 (significant at the 0.05 level), respectively. At 12 months, 18 months, and 30 months after implementation, the SACD programs increased growth of parent-reported Positive Social Behavior by 0.03, 0.04, and 0.05, respectively (all significant at the .05 level). At 12 months, 18 months, and 30 months after implementation, the programs lowered growth of child-reported Victimization by $0.04,0.05$, and 0.06 , respectively (all significant at the .05 level).

\section{Fall 2005 Data}

The second follow-up point in fall 2005 occurred shortly after the summer, which could affect the outcome measures at fall 2005 through "learning loss" during the summer. The growth curve model was estimated using a time indicator that allows the growth coefficient to decline (or increase) following the summer. The 18 impact estimates remained insignificant after accounting for summer "learning loss."

\section{Missing Outcomes}

An advantage of the growth curve methodology is that it can accommodate all students who have at least one round of data. The information that was available for each student was used in estimating the intercept and slope, across all students. To assess the robustness of study findings to the assumptions underlying this approach, the model was estimated using only those students with (1) all rounds of follow-up data, and (2) the last round of follow-up data in spring 2007 and at least one earlier round. The impact estimates remained insignificant when using these restricted samples.

\footnotetext{
45 Point-in-time impacts were calculated by adding (1) the estimated impact of the treatment at initial data collection to (2) the estimated average annual impact of the treatment on the growth curve trajectory multiplied by the number of years since implementation. For the three significant outcomes, the estimated difference between the treatment and control groups at initial data collection, though insignificant, was in the same direction as the estimated slope. Thus, the cumulative impact of the estimated difference in the slope between the treatment group and control group, in addition to the estimated difference at initial data collection between the treatment group and control group, resulted in significant differences at later time points. However, the cumulative impact of the difference in the average annual slope between the treatment group and control group (that is, the estimated difference in the change in the outcomes of the treatment group and control group) resulted in no significant differences for any of the point-in-time estimates.
} 


\section{Chapter 1. The Social and Character Development Multiprogram Evaluation}

\section{Discussion}

IES and DVP established the SACD Research Program to rigorously evaluate the effects of seven universal, schoolwide programs to improve students' social and character development. The programs evaluated were chosen through a peer-review process of submitted applications. A separate experiment using random assignment of schools was done for each program. Within each program, participating schools were stratified into similar pairs then randomly assigned to receive the treatment of the intervention or continue with whatever SACD activities they were using. All students in the elementary grades within the treatment schools received the intervention program over the 3 years of the study. For the evaluation, one cohort of students was followed from the beginning of third grade through the end of fifth grade. A third party (Mathematica Policy Research, Inc.) provided technical assistance in the sampling design, helped design data collection, conducted and coordinated the data collection, and designed and conducted the analyses. Twenty outcomes were used to measure impacts on students and perceptions of school climate and these were grouped under four domains: Social and Emotional Competence, Behavior, Academics, and Perceptions of School Climate. The data were analyzed from all seven programs together and by individual program to determine the collective and individual program impacts.

Under such a design, inferences can be made regarding the programs, combined and individually, as the cause of any impacts on these domains and the outcomes that define them. Rigorous inferences can be drawn only about the specific programs tested in the context (including the schools) in which they were tested. Other programs tested in similar or different settings and these programs tested in different settings might have yielded different findings. Therefore, inferences cannot be made beyond this set of programs and contexts.

An analysis of the initial data found few significant differences between the family, teacher, and school characteristics of the treatment and control students, a sign that the randomization of the schools had created similar treatment and control groups (similar at least on the observed characteristics). Treatment teachers reported significantly greater use of and training in SACD activities than control teachers more often than would be expected by chance. Because the training of all treatment teachers and the implementation of six of the programs occurred before the initial data were collected, it could not be determined whether these differences resulted from actual baseline differences between treatment and control schools and teachers (i.e., that randomization did not create similar treatment and control groups) or from implementation occurring before the initial data collection. The control group for the SACD evaluation was a "standard practice" control, not a "no treatment" control, in that control teachers reported the use of SACD activities as well as related professional development.

The SACD programs were found to have a statistically significant impact on the reported use of SACD activities in the classroom and school. Treatment teachers reported significantly greater implementation of activities than control teachers for 127 of the 249 activity outcomes measured over the 3 years. In addition, in each year four of the six SACD activity domains were found to be significantly positively affected by the SACD programs. These four domains included the use of any SACD activities, the use of SACD activities linked to named programs, the use of classroom materials and instructional strategies when teaching SACD activities, and professional development in using SACD activities. The actual differences in reported use of SACD activities between the treatment and control groups varied from 5 to 34 percentage points. The results provided evidence that implementing the SACD programs increased the reported use of SACD activities in the schools.

To examine the average effects of the seven programs (combined and individually) on student outcomes, two sets of analyses were done. The first analyzed the outcomes on a year-by-year basis (from the fall of third grade to the spring of third grade, spring of fourth grade, and spring of fifth grade) for the entire sample, the individual programs, and a set of subgroups. The second analyzed the impacts on the average annual growth in student outcomes for the overall sample, the individual programs, and the subgroups. For both analyses, 


\section{Chapter 1. The Social and Character Development Multiprogram Evaluation}

the ability to detect smaller significant effects was greater when examining the programs all together versus examining the individual programs or the subgroups because of the differences in sample sizes.

Neither the year-by-year analysis nor the growth curve analysis found that the seven SACD programs improved student outcomes when considered together, individually by program, or for specific subgroups. For the combined-program analysis, the year-by-year analysis found fewer significant impacts than expected by chance ( 2 out of 60 estimated impacts) and the growth analysis found no significant impacts. For the individual program analysis, the year-by-year analysis found fewer significant impacts than expected by chance (16 out of 420 estimated impacts) with 9 having beneficial impacts and 7 having detrimental impacts. The growth analysis found the same number of impacts as expected by chance (6 out of 126 estimated impacts) with 2 having beneficial impacts and 4 having detrimental impacts. For the subgroup analyses, the year-byyear analysis found more significant impacts than expected by chance for gender ( 8 out of 54 estimated impacts) and initial risk levels (41 out of 270 estimated impacts) but not for stayers versus new entrants. For gender, half of the significant impacts showed a beneficial impact of the intervention and half showed a detrimental impact. For initial risk level, 26 showed a beneficial impact of the intervention on high-risk students and 15 showed a detrimental impact on high-risk students. The growth analysis found fewer significant impacts than expected by chance for all the subgroups except those based on initial risk levels, for which 6 out of 90 estimated impacts were significant. Four of these 6 significant impacts were beneficial and 2 were detrimental. In sum, the SACD multiprogram evaluation provides no evidence that the seven universal, schoolwide programs improved students' social and character development.

Several explanations for this finding can be considered: (1) failure of the conceptualization and design of the intervention, (2) weak implementation of the intervention, (3) nonsubstantial differences in the level of SACD activities in the treatment and control schools, and (4) methodological limitations of the evaluation.

Failure of the conceptualization and design of the intervention refers to the possibility that the seven programs tested might not have altered students' social and character development in the expected ways because the theories underlying them or the combinations of activities chosen to bring about the desired changes in students' attitudes and behaviors were inadequate for the purpose. For example, one alternative view to that adopted in the SACD evaluation is that only a subset of elementary-age children has deficits in social behavior and character, and these deficits require a more targeted, more intensive intervention than schoolwide programs can provide. Therefore, if a school-based program is to be effective, a combination of schoolwide and targeted activities might be required for the intervention to make a significant difference in students' outcomes (e.g., see Conduct Problems Prevention Research Group 1999). These kinds of explanations, if confirmed by other studies, would lead to focusing more effort on understanding how social and character development occurs among elementary-age children, how this development can be affected, and what types of practices in classrooms and schools can be used to bring about desired effects.

Weak implementation of the intervention refers to the possibility that, although the intervention might have been well conceived and well designed, the treatment schools did not implement these practices effectively on average. Weakly implemented programs may not have positive impacts on students. The SACD evaluation examined seven different SACD programs, each with unique features, and the fidelity rating used measured fidelity of implementation relative to the targets established for each specific intervention. In this way, the ratings were standardized relative to each site's program-specific benchmarks and could be compared across programs and years. The analysis of the fidelity data found little evidence of a relationship between high fidelity and more beneficial outcomes. The number of significant associations found between fidelity and beneficial outcomes was higher than expected by chance ( 5 versus 3 out of 54 estimated impacts) but 4 of the 5 significant results were due to detrimental associations between low fidelity and outcomes rather than beneficial associations between high fidelity and outcomes. The approach used to obtain comparable fidelity ratings required two compromises. First, it could not account for differences among the programs' implementation standards - for example, whether programs differed in how difficult they were to implement. Second, it provided no information on why implementation was of a certain quality. As a result, the SACD 


\section{Chapter 1. The Social and Character Development Multiprogram Evaluation}

evaluation fidelity measure may not provide adequate information regarding the issue of whether low fidelity might have been the reason behind the lack of significant findings. The fidelity measures used by each research team using team-chosen criteria may provide additional information on how well each program was implemented in each treatment school.

Nonsubstantial differences in the level of SACD activities refers to the possibility that the implementation differences between the treatment and control schools were not great enough to generate statistically significant differences in student outcomes. Like the treatment schools, the control schools joined the study with a willingness to implement a SACD program, showing a willingness to promote social and character development. In addition, some of the sites were located in states where legislation required or promoted such activities. The control group represented "standard practice," which included the reported use of SACD activities in the classroom. For example, 86 percent to 90 percent of control teachers reported using activities to promote any one of the six SACD goals. While a statistically significant larger percentage of teachers in the treatment schools reported conducting such activities (95\% to 96\%) the 5- to 10-percentage-point differences may not have been large enough to lead to improved student outcomes. At the same time, the significant differences between treatment and control teacher reports were larger for other responses regarding the use of SACD activities. For example, the differences between treatment and control teachers regarding the use of activities from named programs were 29 to 34 percentage points across the 3 years. These results, plus the finding that treatment teachers reported greater use of some instructional materials and methods to promote SACD goals, provide evidence that the treatment teachers were making a more intensive effort to promote social and character development.

There are three methodological limitations of the evaluation that may have contributed to the finding of no impacts on student outcomes. First, the evaluation relied on self-reported data by teachers and principals regarding the use of SACD activities. No observational studies were done to validate these reports. If treatment teachers over-reported their use of SACD activities (possibly because they felt an expectation to report high use given that a SACD program was being implemented in their school), the impacts of the treatment could be misestimated; that is, if there really were no differences in the level of SACD activities between the treatment and control groups then a lack of effects might be expected. The percentages of treatment teachers (95\% to $96 \%$ ) who reported using any activities to promote one of the six SACD goals differed from the percentages who reported using activities from named programs (68\% to $72 \%)$ for the same purpose. This difference does not rule out the possibility of systematic over-reporting; however, it does suggest that some teachers were candid in their reporting on their use of the treatment programs. The research teams used observations or product measures to check implementation of their specific programs, and the results from this work may provide additional evidence about the potential importance of overreporting of implementation by treatment teachers.

A second methodological limitation was that student-provided data (used for 12 of the 20 outcomes) were not available for 36 percent to 39 percent of students, depending on the year, because parents did not provide written consent or students did not assent to take part in the study. Primary caregiver data, used for three outcomes, were not available for 49 percent to 54 percent of students. It is possible that students included in the study differed from those not included due to an absence of data. As the study did not collect descriptive data on the nonobserved students, the existence of such differences could not be determined, and how the inclusion of these students in the study would have affected the findings is unknown. Given the few statistically significant and substantively important impacts found with the existing sample, there would need to be a large and consistent impact on the nonobserved students (had they been included) to change the findings. For example, because two-thirds of the population who were observed received an average impact of zero, the nonobserved one-third would need to have received an average impact of nearly one-third of a standard deviation to bring the overall mean to one-tenth of a standard deviation unit. In addition, because the subgroup analyses did not find systematically significant impacts, there is no evidence that should these 
missing students come from one of the subgroups (e.g., higher initial risk) their inclusion would change the findings.

A third methodological limitation was the sample size for the individual program evaluations. The combined analysis of all seven programs provided a sample size sufficient to detect student-level impacts at MDES ranging from 0.03 to 0.23 standard deviations (with more than $75 \%$ of them below 0.10 standard deviations). The power to detect impacts at the level of the individual programs was more limited (the MDES ranged from 0.1 to 0.9 over the 3 years) and individual program-level effects might have been missed. To address this limitation at the program level, nonsignificant impacts of at least 0.25 standard deviations were identified as substantively important results and only a small number were identified, with an almost equal division into beneficial and detrimental effects.

The seven programs tested in the SACD evaluation were similar in being coherent, universal, school-based programs to promote social and character development of third- to fifth-grade students. They were diverse both in their specific goals and in their approaches to promoting social and character development for all students. In addition, they were evaluated in diverse types of locales in which schools served communities with very different ethnic and socioeconomic compositions. On average, the seven programs did not improve students' social and emotional competence, behavior, academic achievement, and student and teacher perceptions of school climate. In addition, although the numbers of schools and students in each program were not always sufficient to draw firm conclusions at the program level, the patterns of estimated impacts for each program were largely similar: students' outcomes were not affected. 
This page is intentionally blank. 


\title{
Chapter 2. Academic and Behavioral Competencies Program
}

\author{
University at Buffalo, The State University of New York \\ (Buffalo Site)
}

\section{Intervention}

Researchers at the University at Buffalo, The State University of New York (SUNY) (Buffalo site) implemented and evaluated the Academic and Behavioral Competencies Program (ABC) (Pelham, Fabiano, and Massetti 2005; Smith et al. 2007; Waschbusch, Pelham, and Massetti 2005). ABC was developed at the Center for Children and Families at the University at Buffalo, SUNY. This program is designed to develop and maintain a positive learning environment that reduces misbehavior and promotes positive skills and competencies. It focuses on classroom behavior management and teaching and promoting social skills and includes multiple components. Table 2.1 describes ABC's general characteristics (panel 1), the types of instruction and strategies used (panel 2), the professional development provided for those implementing the program (panel 3), and the social and character development activities (panel 4) and outcomes (panel 5) addressed by the program.

- $\mathrm{ABC}$ components include schoolwide rules, a response/cost system for tracking and responding to disruptive student behavior (e.g., behavior color charts), a daily home note or communication tool for students who follow the school rules, a weekly reinforcement activity (Fun Friday), and a teacherled social skills program.

- ABC program staff conduct a program development workshop with a school committee of representative teachers, staff, and administrators during the summer prior to initial implementation. The workshop is intended to discuss components of the program and to modify the program within the designed framework to meet the needs of the school. The committee develops a set of schoolwide rules and consequences that form the backbone of the program's implementation in the school.

- Teachers and school staff are trained in behavior management skills and strategies and on delivery of the $\mathrm{ABC}$ components and structure. Teacher training covers general classroom behavior management skills for reducing disruptive behavior and promoting behavioral competencies and strategies specific to ABC. Teachers are taught skills such as building positive relationships with students, using labeled praise as social reinforcement, setting appropriate limits, and implementing effective discipline strategies.

- Consistent schoolwide rules are posted and monitored. Students who follow the rules earn daily notes, which are used to earn weekly Fun Friday activities and other events and privileges.

- Behavioral consultants are a standard feature of the $\mathrm{ABC}$ program. They spend 20 hours per week at the school and provide ongoing observations and consultations with teachers on the use of behavior management strategies and $\mathrm{ABC}$ components. Consultation with teachers ranges from discussing general program implementation to training on how to make program modifications to address the needs of children who could benefit from more intensive implementation of the program.

- Each day for 10 minutes, teachers implement scripted social skills training in the classroom. In these lessons, they illustrate the targeted social skill that is intended to enhance problem solving, communication, and cooperation, and then encourage practice among students. Teachers have 


\section{Chapter 2. Academic and Behavioral Competencies Program}

opportunities to reinforce and promote these social skills throughout the day using "caught being good" tickets and prizes.

- The behavioral consultants at the schools also deliver parenting workshops. Seven workshops are offered that address general parenting topics such as building positive relationships with children and using effective discipline strategies.

- A targeted recreational/peer skills program is delivered to schools for students who exhibit high rates of disruptive behavior in the school and classrooms. The recreational program takes place either during the school day or after school, and it focuses on building social competencies, enhancing rulefollowing behavior, and building positive relationships with peers.

- Individualized programs, typically in the form of modifications of the classwide program (e.g., more frequent feedback, changes in goal criteria or rewards) and daily report cards, are developed and implemented through consulting with teachers about students who have high rates of disruptive behaviors. 


\section{Table 2.1. Academic and Behavioral Competencies Program}

Panel 1: General characteristics

Target population

Universal and targeted

Program components

Peer: In and out of class

Parent: Daily positive notes and monthly parenting workshops

Classroom: Teacher training and coaching, behavior management, and lessons

Schoolwide: Planned events, reward programs, schoolwide rules, and discipline policies

Community: None or not major focus

Training: Pretraining and ongoing behavior consultation through school-based consultant

Level of integration

Add-on curriculum and classroom and schoolwide activities

Flexibility

Manualized: Manual includes modules for all program components (training, universal, and targeted levels); manual adapted for each school with input from school committees

Adaptability: Program may be individualized within the framework at the school, classroom, and individual child level

See notes at end of table.

Panel 2: Description of instruction and strategies

\section{Classroom}

Lessons

Who delivers: Teacher

Activities and tools: Social skill of the day description and classroom or schoolwide role-play

Content: Social skills, problem solving, classroom management, and peer relationships

Frequency: Social skills training: daily 5- to 10-minute lessons; reinforcement and application: daily throughout the day; recreational peer program: 45 minutes two times per week

Strategies

Who delivers: Teacher (universal); consultants and/or counselors (targeted)

Activities and tools: Schoolwide rules; social reinforcement for positive behavior; classroom management procedures; teacher training in classroom management, effective discipline, and building teacherchild relationships; rewards for rule-following and consequences for negative behavior (e.g., time out)

Frequency: Daily

Supplement to classroom

Behavioral consultant services to teachers/classrooms; peer mediation; discipline/office referral policies and procedures; parenting workshops; targeted peer program for disruptive children

Schoolwide activities

Schoolwide rules; classroom management procedures; behavior honor roll; schoolwide recognition and incentives; schoolwide discipline policies

See notes at end of table. 


\section{Table 2.1. Academic and Behavioral Competencies Program--Continued}

Panel 3: Professional development

Pre-implementation

Teachers

Content: Teacher training in classroom behavioral management concepts and strategies; development of schoolwide rules, discipline policies and procedures, and classroom management policies with school committee

Duration: 3 half-days (9 hours total)

Other

Content: Staff, same as teacher training

Duration: 3 half-days ( 9 hours total)

Ongoing consultation

Teachers

Content: Teacher consultation; coaching on use of classroom management; school consultation on policies and procedures

Duration: Monthly (at minimum) or more frequently per teacher or school request

Other

Content: Consultation on school discipline policies and procedures, such as lunchroom discipline, bus discipline, hallway policies, etc.

Duration: As needed, with regular follow-up

See notes at end of table.

Panel 4: Activities for SACD goals

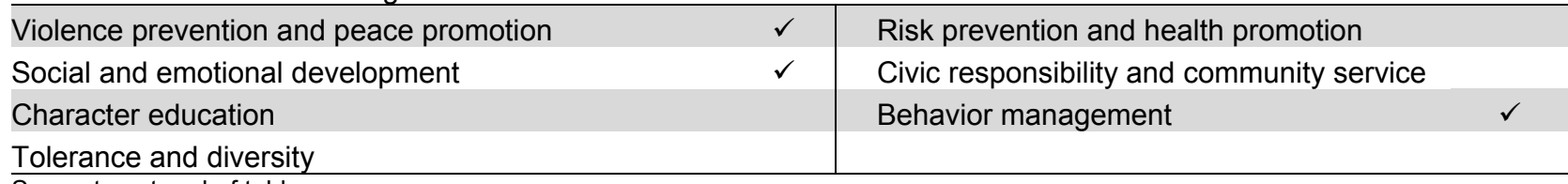

See notes at end of table.

Panel 5: SACD outcomes addressed

\begin{tabular}{|c|c|c|c|}
\hline Engagement with Learning & & Empathy & \\
\hline Academic Competence and Motivation & & Positive School Orientation & \\
\hline Altruistic Behavior & & Negative School Orientation & \\
\hline Positive Social Behavior & $\checkmark$ & Student Afraid at School & \\
\hline Problem Behavior & $\checkmark$ & Victimization at School & $\checkmark$ \\
\hline Self-Efficacy for Peer Interactions & & Feelings of Safety & $\checkmark$ \\
\hline Normative Beliefs About Aggression & & Student Support for Teachers & $\checkmark$ \\
\hline
\end{tabular}

NOTE: Abbreviations are

$\checkmark$ : Activity or outcome addressed

Blank cell: Activity or outcome not addressed

SOURCE: The Social and Character Development (SACD) Research Program. 


\section{Sample and Random Assignment}

The Buffalo research team recruited a total of 10 public and 2 charter elementary schools. The 12 schools were in 3 school districts in upstate New York. The schools were randomly assigned to treatment and control conditions prior to the fall 2004 initial data collection. ${ }^{46}$ A two-step process was used. First, a computergenerated pairwise matching algorithm developed by Mathematica Policy Research, Inc. (MPR) identified the best pairwise matches across the 12 schools based on variables identified by the Buffalo research team. The variables included (a) school district, (b) percentage of students eligible for free or reduced-price lunch during the 2003-04 school year, (c) total number of students enrolled during the 2003-04 school year, (d) percentage of minority children enrolled during the 2003-04 school year, and (e) percentage of students achieving mastery level or better scores on New York's fourth-grade English language arts standardized achievement test administered during the 2002-03 school year. Second, using a random numbers table, 1 school in each matched pair was assigned to either the intervention or the control condition, resulting in 6 schools receiving the ABC program and 6 schools acting as control schools. Control schools in this study were a "business as usual" comparison, meaning these schools implemented the social and character development activities that constituted their standard practice. The level of social and character development practices, including activities, materials, teacher strategies, and professional development activities, in both the treatment and control schools was documented in order to understand the nature of the comparison being made between the intervention schools and the standard practice control schools. Assignment to treatment or control condition at the school level limited the risk of contamination between treatment and control classrooms. All 12 schools remained in the study for the full 3 years. One school converted to a K-8 school but this did not affect the students in the study.

The original student sample (the cohort of students in the third grade in the 12 schools in fall 2004) numbered 879 students (380 treatment and 499 control). Table 2.2 documents the change in the sample over the three spring follow-up data collection periods. Over time, new entrants to the cohort became a larger percentage of the sample, eventually making up 32 percent of the sample by the spring of Year 3 . Only in Year 1 was there a statistically significant difference between the treatment and control groups in the number of new entrants (in this case, fewer new entrants in the treatment group). The percentage of the sample made up of the original cohort further declined as students left the schools. By Year 3, approximately 33 percent of the original sample had left. There were no significant differences between treatment and control leavers.

\footnotetext{
46 In Year 2 (fall 2005), the Buffalo research team recruited two more schools, one assigned to treatment and one assigned to control, which were followed to the end of the study (spring 2007). A description of this second cohort and all relevant findings can be found in appendix A. The data from this second cohort are not included in the analyses and results reported in this chapter.
} 
Table 2.2. Sample-ABC

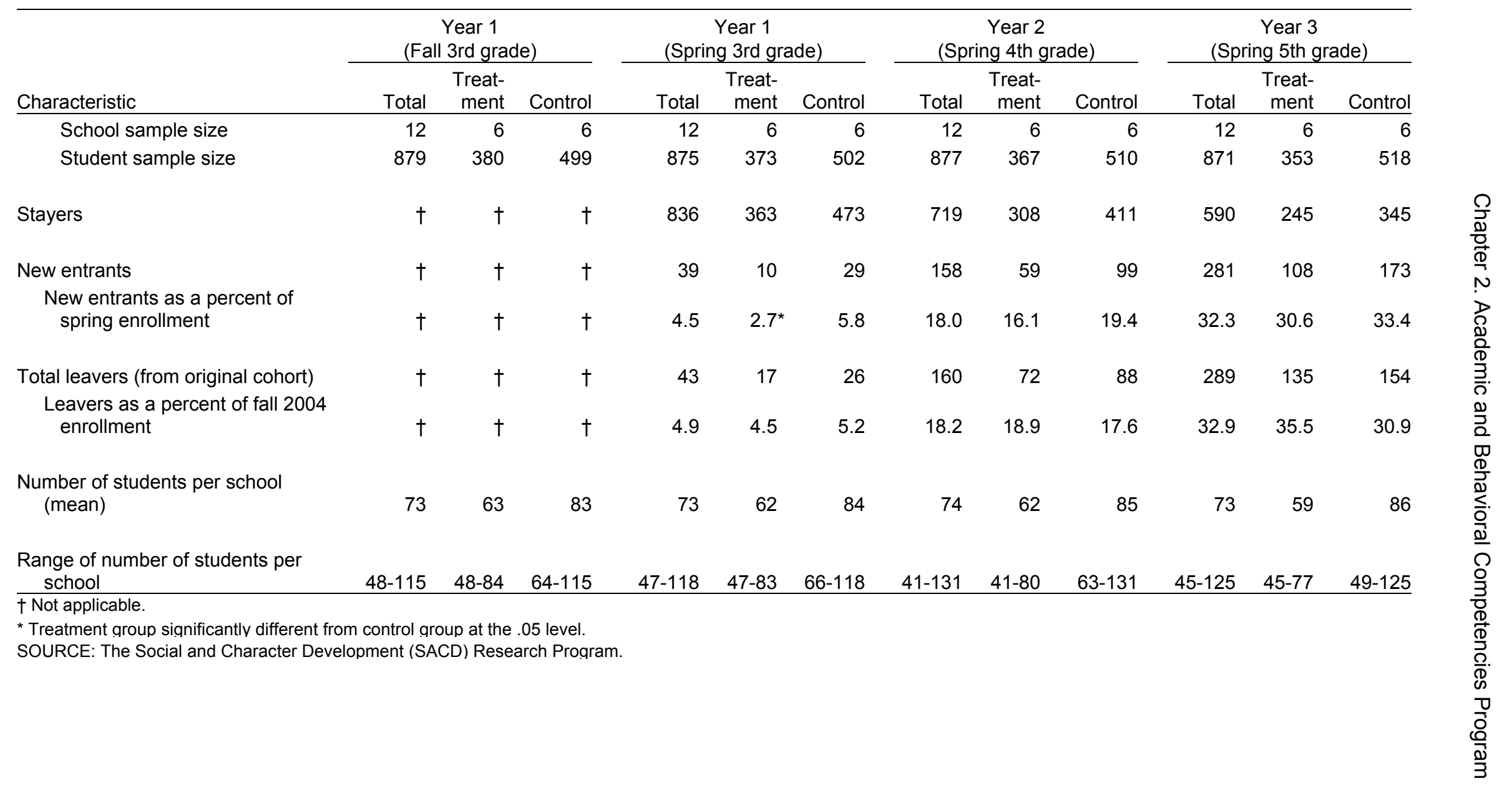




\section{Implementation}

\section{Training}

The intervention teachers received 9 hours of program implementation training prior to the beginning of the school year (see panel 3 of table 2.1). If teachers were unable to attend this initial training due to scheduling conflicts, they were provided with make-up training by the program staff and behavioral consultants. Teachers had access to ongoing program implementation support throughout the school year from behavioral consultants. For this study, the behavioral consultants were master's-level therapists or advanced graduate students. On average, behavioral consultants were at the participating schools for 20 hours each week, including scheduled activities such as administrative meetings, in-service presentations, and parent conferences. Consultation visits typically included classroom observations, an opportunity for teachers to ask questions about the curriculum, and implementation feedback from the consultant. In addition to the consultation visits, behavioral consultants and $\mathrm{ABC}$ staff provided approximately 15 hours per school of formal in-service training and group presentations throughout the year.

\section{Data Collection}

MPR's subcontractor, Decision Information Resources, Inc. (DIR), collected the child, teacher, and school data at the Buffalo site. Table 2.3 presents the data collection dates. Data were collected in the fall and spring of the first 2 years and the spring of Year 3. The fall 2004 (third-grade) data collection window began on October 18, 2004, and ended on November 12, 2004. The average time frame from the beginning of program implementation to the beginning of fall data collection was 6 weeks. As a result, initial data collection took place after $\mathrm{ABC}$ implementation began. Therefore, these data provide a measure of the students, teachers, and schools near the beginning of the school year, when $\mathrm{ABC}$ had been operating for a relatively short period of time.

The spring data collection window was from April 11, 2005, to May 6, 2005. ABC had been implemented for 31 weeks at the time of the spring data collection and for 21 weeks from the end of the fall data collection. Year 2 followed a similar pattern, with implementation occurring at the start of the school year, fall data collection occurring 5 weeks later, and spring data collection occurring 21 weeks after fall data collection (and 29 weeks after the start of implementation). In spring 2007, data collection occurred 32 weeks after the start of implementation. Data collection took from 3 to 5 weeks at each collection point. 
Table 2.3. Data collection dates-ABC

\begin{tabular}{|c|c|c|c|c|c|}
\hline Data collection schedule & $\begin{array}{c}\text { Year } 1 \\
\text { (Fall 3rd grade) }\end{array}$ & $\begin{array}{c}\text { Year } 1 \\
\text { (Spring 3rd grade) }\end{array}$ & $\begin{array}{c}\text { Year } 2 \\
\text { (Fall 4th grade) }\end{array}$ & $\begin{array}{c}\text { Year } 2 \\
\text { (Spring 4th grade) }\end{array}$ & $\begin{array}{c}\text { Year } 3 \\
\text { (Spring 5th grade) }\end{array}$ \\
\hline School sample size & 12 & 12 & 12 & 12 & 12 \\
\hline \multicolumn{6}{|l|}{ School year dates } \\
\hline First day of school & $9 / 7 / 04$ & $\dagger$ & $\begin{array}{l}8 / 15 / 05 \\
9 / 7 / 05^{2}\end{array}$ & $\dagger$ & $\begin{array}{l}8 / 15 / 05 \\
9 / 6 / 06^{2}\end{array}$ \\
\hline Start of implementation & 9/8/04 & $\dagger$ & First day & $\dagger$ & First day \\
\hline Last day of school & $\dagger$ & $6 / 24 / 05$ & $\dagger$ & $6 / 23 / 06$ & $6 / 22 / 07$ \\
\hline \multicolumn{6}{|l|}{ Data collection } \\
\hline Start & $10 / 18 / 04^{1}$ & $4 / 11 / 05$ & $10 / 10 / 05^{2}$ & $3 / 27 / 06$ & $4 / 18 / 07$ \\
\hline End & $11 / 12 / 04$ & $5 / 6 / 05$ & $10 / 27 / 05$ & $5 / 1 / 06$ & $5 / 8 / 07$ \\
\hline \multicolumn{6}{|l|}{$\begin{array}{l}\text { Calendar weeks from } \\
\text { program implementation } \\
\text { to start of fall } 2004\end{array}$} \\
\hline & 6 & $\dagger$ & $\dagger$ & $\dagger$ & $\dagger$ \\
\hline $\begin{array}{l}\text { Calendar weeks from } \\
\text { start of school to start of } \\
\text { fall } 2004 \text { data collection }\end{array}$ & 6 & $\dagger$ & $\dagger$ & $5^{2}$ & $\dagger$ \\
\hline $\begin{array}{l}\text { Calendar weeks from } \\
\text { end of fall data collection } \\
\text { to start spring data } \\
\text { collection }\end{array}$ & $\dagger$ & 21 & $\dagger$ & 21 & $\dagger$ \\
\hline $\begin{array}{l}\text { Calendar weeks from } \\
\text { program implementation } \\
\text { to start of spring data } \\
\text { collection }\end{array}$ & $\dagger$ & 31 & $t$ & 29 & 32 \\
\hline
\end{tabular}

† Not applicable.

${ }^{1}$ Data collection occurred at two schools on 9/21/04. The calculations that include the start of fall 2004 data collection use the $10 / 18 / 04$ date as the start date of the data collection.

${ }^{2}$ The two charter schools started earlier than the public schools and had earlier data collection.

NOTE: The dates provided in the table reflect the more common dates and are used to calculate the week's data. SOURCE: The Social and Character Development (SACD) Research Program. 


\section{Consent Rates, Completion Rates, and Percentage of Sample With Data}

The actual number of child, primary caregiver, and teacher reports available for analysis was smaller than the number in the sample because consent and completion rates were less than 100 percent. Primary caregivers had to provide consent before children could complete the Child Report, before their child's teacher could complete the Teacher Report on Student, and before they themselves completed the Primary Caregiver Report. Teachers also had to provide consent before completing the Teacher Report on Classroom and School. In addition, of those with consent, not all completed their respective reports. Table 2.4 shows the consent rates, completion rates, and percentages of sample with data for each of the four reports over the 3 years. For the Child Report and the two teacher reports, completion rates ranged from 91 percent to 100 percent. For the Primary Caregiver Report, the completion rates dropped over time from 90 percent to 64 percent.

The percentages of the sample with Child Report data ranged from 57 percent to 69 percent over the 3 years, with significantly higher percentages of treatment students having data in Years 1 and 3. The percentages of students with information from the Teacher Report on Student ranged from 56 percent to 74 percent, with significantly higher percentages of treatment students having data in Years 1 and 3. The percentages of students with data from the Primary Caregiver Report ranged from 42 percent to 60 percent and declined over time. The percentages of teachers with data from the Teacher Report on Classroom and School ranged from 78 percent to 92 percent. 
Table 2.4. Consent rates, completion rates, and percentage of sample with data from each report-ABC

\begin{tabular}{|c|c|c|c|c|c|c|c|c|c|c|c|c|}
\hline \multirow[b]{2}{*}{ Report } & \multicolumn{3}{|c|}{$\begin{array}{c}\text { Year } 1 \\
\text { (Fall 3rd grade) }\end{array}$} & \multicolumn{3}{|c|}{$\begin{array}{c}\text { Year } 1 \\
\text { (Spring 3rd grade) }\end{array}$} & \multicolumn{3}{|c|}{$\begin{array}{c}\text { Year } 2 \\
\text { (Spring 4th grade) } \\
\end{array}$} & \multicolumn{3}{|c|}{$\begin{array}{c}\text { Year } 3 \\
\text { (Spring 5th grade) }\end{array}$} \\
\hline & Total & $\begin{array}{l}\text { Treat- } \\
\text { ment }\end{array}$ & Control & Total & $\begin{array}{c}\text { Treat- } \\
\text { ment }\end{array}$ & Control & Total & $\begin{array}{r}\text { Treat- } \\
\text { ment }\end{array}$ & Control & Total & $\begin{array}{l}\text { Treat- } \\
\text { ment }\end{array}$ & Control \\
\hline Student sample size & 879 & 380 & 499 & 875 & 373 & 502 & 877 & 367 & 510 & 871 & 353 & 518 \\
\hline \multicolumn{13}{|l|}{ Child Report (percent) } \\
\hline Primary caregiver consent rate & 63.7 & $68.7^{*}$ & 59.7 & 64.0 & 67.3 & 61.6 & 64.7 & 65.4 & 64.1 & 67.7 & $73.7^{* *}$ & 63.7 \\
\hline Student completion rate & 93.2 & 91.2 & 95.0 & 97.5 & 98.0 & 97.1 & 96.3 & 95.8 & 96.6 & 93.6 & 93.8 & 93.3 \\
\hline Students with data ${ }^{1}$ & 59.4 & $62.7^{*}$ & 56.7 & 62.5 & 66.0 & 60.0 & 62.3 & 62.7 & 62.0 & 63.4 & $69.1^{* *}$ & 59.5 \\
\hline \multicolumn{13}{|l|}{ Primary Caregiver Report (percent) } \\
\hline Primary caregiver consent rate & 63.3 & $68.2^{*}$ & 59.5 & 63.9 & 67.3 & 61.4 & 64.7 & 65.4 & 64.1 & 67.7 & $73.7^{* *}$ & 63.7 \\
\hline Primary caregiver completion rate & 89.4 & 88.0 & 90.6 & 75.3 & 78.1 & 73.1 & 70.9 & 70.0 & 71.6 & 65.4 & 64.2 & 66.4 \\
\hline Primary caregivers with data ${ }^{1}$ & 56.6 & 60.0 & 53.9 & 48.1 & 52.5 & 44.8 & 45.8 & 45.8 & 45.9 & 44.3 & 47.3 & 42.3 \\
\hline \multicolumn{13}{|l|}{ Teacher Report on Student (percent) } \\
\hline Primary caregiver consent rate ${ }^{2}$ & 63.7 & $68.7^{*}$ & 59.7 & 64.0 & 67.3 & 61.6 & 64.7 & 65.4 & 64.1 & 67.7 & $73.7^{\star *}$ & 63.7 \\
\hline Teacher completion rate & 93.9 & 95.0 & 93.0 & 99.3 & 99.2 & 99.4 & 100.0 & 100.0 & 100.0 & 99.2 & $100.0^{*}$ & 98.5 \\
\hline Students with data ${ }^{1}$ & 59.7 & $65.3^{* *}$ & 55.5 & 63.7 & 66.8 & 61.4 & 64.7 & 65.4 & 64.1 & 67.2 & $73.7^{*}$ & 62.7 \\
\hline \multicolumn{13}{|c|}{$\begin{array}{l}\text { Teacher Report on Classroom and School } \\
\text { (3rd- to 5th-grade teachers) (percent) }\end{array}$} \\
\hline Teacher consent rate & 89.9 & $96.7^{*}$ & 84.6 & 92.1 & 91.8 & 92.3 & 91.9 & 93.2 & 90.9 & 85.8 & 90.0 & 82.7 \\
\hline Teacher completion rate & 95.2 & 94.9 & 95.5 & 91.4 & 91.1 & 91.7 & 93.6 & 90.9 & 95.7 & 95.0 & 96.3 & 94.0 \\
\hline Teachers with data $^{1}$ & 85.6 & 91.8 & 80.8 & 84.2 & 83.6 & 84.6 & 86.0 & 84.7 & 87.0 & 81.6 & 86.7 & 77.8 \\
\hline
\end{tabular}

* Treatment group significantly different from control group at the .05 level.

** Treatment group significantly different from control group at the .01 level.

${ }^{1}$ Calculated as consent rate $\mathrm{x}$ completion rate.

${ }^{2}$ The primary caregiver consent rates for the Child Report and the Teacher Report on Student are identical, as the primary caregiver gave consent to both together.

SOURCE: The Social and Character Development (SACD) Research Program. 
Responses from students in the original cohort (stayers) and new entrants in the $\mathrm{ABC}$ sample were examined to investigate possible differences between the two groups in consent rates, completion rates, and the percentages of sample with data that might affect outcome data (table 2.5). There were four statistically significant differences between the completion rates of these two groups across the 3 years: in Year 1, stayers completed more Child Reports than did new entrants (98\% versus 85\%); in Years 2 and 3, new entrants completed more Primary Caregiver Reports than did stayers (84\% versus $68 \%$ and $75 \%$ versus $62 \%$, respectively); and in Year 3, teachers of stayers completed more Teacher Reports on Students than did teachers of new entrants (100\% versus $97 \%)$. 
Table 2.5. Consent rates, completion rates, and percentage of sample with data: Stayers versus new entrants--ABC

\begin{tabular}{|c|c|c|c|c|c|c|c|c|c|}
\hline \multirow[b]{2}{*}{ Report } & \multicolumn{3}{|c|}{$\begin{array}{c}\text { Year } 1 \\
\text { (Spring 3rd grade) }\end{array}$} & \multicolumn{3}{|c|}{$\begin{array}{c}\text { Year } 2 \\
\text { (Spring 4th grade) }\end{array}$} & \multicolumn{3}{|c|}{$\begin{array}{c}\text { Year } 3 \\
\text { (Spring 5th grade) }\end{array}$} \\
\hline & Total & Stayers & $\begin{array}{r}\text { New } \\
\text { entrants }\end{array}$ & Total & Stayers & $\begin{array}{r}\text { New } \\
\text { entrants }\end{array}$ & Total & Stayers & $\begin{array}{r}\mathrm{New} \\
\text { entrants } \\
\end{array}$ \\
\hline Student sample size & 875 & 836 & 39 & 877 & 719 & 158 & 871 & 590 & 281 \\
\hline \multicolumn{10}{|l|}{ Child Report (percent) } \\
\hline Primary caregiver consent rate & 64.0 & 63.8 & 69.2 & 64.7 & 65.2 & 62.0 & 67.7 & 68.8 & 65.5 \\
\hline Student completion rate & 97.5 & $98.1^{* * *}$ & 85.2 & 96.3 & 96.4 & 95.9 & 93.6 & 93.3 & 94.0 \\
\hline Students with data ${ }^{1}$ & 62.4 & 62.6 & 59.0 & 62.3 & 62.9 & 59.5 & 63.4 & 64.2 & 61.6 \\
\hline \multicolumn{10}{|l|}{ Primary Caregiver Report (percent) } \\
\hline Primary caregiver consent rate & 63.9 & 63.8 & 66.7 & 64.7 & 65.2 & 62.0 & 67.7 & 68.8 & 65.5 \\
\hline Primary caregiver completion rate & 75.3 & 76.0 & 61.5 & 70.9 & $68.2^{* *}$ & 83.7 & 65.8 & $61.8^{* *}$ & 74.5 \\
\hline Primary caregivers with data ${ }^{1}$ & 48.1 & 48.4 & 41.0 & 45.8 & 44.5 & 51.9 & 44.5 & 42.5 & 48.8 \\
\hline \multicolumn{10}{|l|}{ Teacher Report on Student (percent) } \\
\hline Primary caregiver consent rate ${ }^{2}$ & 64.0 & 63.8 & 69.2 & 64.7 & 65.2 & 62.0 & 67.7 & 68.8 & 65.5 \\
\hline Teacher completion rate & 99.3 & 99.4 & 96.3 & 100.0 & 100.0 & 100.0 & 99.2 & $100.0^{* * *}$ & 97.3 \\
\hline Students with data ${ }^{1}$ & 63.5 & 63.4 & 66.7 & 64.7 & 65.2 & 62.0 & 67.2 & 68.8 & 63.7 \\
\hline
\end{tabular}

* Stayers significantly different from new entrants at the .05 level.

** Stayers significantly different from new entrants at the .01 level.

*** Stayers significantly different from new entrants at the .001 level.

${ }^{1}$ Calculated as consent rate $\mathrm{x}$ completion rate.

${ }^{2}$ The primary caregiver consent rates for the Child Report and the Teacher Report on Student are identical, as the primary caregiver gave consent to both together.

SOURCE: The Social and Character Development (SACD) Research Program. 


\section{Fidelity of Implementation}

Each year, the six $\mathrm{ABC}$ treatment schools were independently rated for quantity and quality of program implementation by two raters from the research team. The global measure of fidelity for the multisite study was used; inter-rater reliability was measured with Cronbach's alpha (1.00, 0.98, and 0.99) in all 3 years. The ratings were combined into a single consensus rating and used to identify schools with high implementation fidelity. In Year 1, four treatment schools were identified as having high fidelity, and in Years 2 and 3, three schools were identified as having high fidelity. Cohen's kappa was used as the measure of agreement when identifying schools as high fidelity, and it equaled 1.00 in Years 1 and 2, and 0.67 in Year 3.

\section{Initial Characteristics}

The initial characteristics of the students, teachers, and schools participating in the evaluation of the $\mathrm{ABC}$ program were collected from students enrolled in the third grade at the study schools in fall 2004, as well as from their primary caregivers and third-grade teachers. In addition, third-, fourth-, and fifth-grade teachers and principals in the study schools provided information about activities related to social and character development in these schools. Documenting the characteristics of students, teachers, and schools, and their status on key outcomes at a point before the intervention had been operating for an extended period, helps to determine whether the random assignment of schools to treatment and control status produces groups with similar distributions of observed characteristics. As noted in the following discussion, 6 significant differences (out of 62 comparisons, with 3 expected to be significant by chance) were found between the treatment and control students, teachers, and schools in the level of SACD activity in the classroom and school.

\section{Characteristics of Children, Their Families, and Communities}

There were no significant differences in the observed student, caregiver, and community characteristics between the treatment and control groups (table 2.6). For students, the mean age was 8 years. The sample contained almost equal percentages of girls and boys. The sample was ethnically diverse: White non-Hispanic students made up 33 percent of the sample, Black non-Hispanic students made up 41 percent, and Hispanic students made up 17 percent.

The sample was also diverse in levels of family income, education levels of primary caregivers of the children in the sample, and family situation. Fifty percent of the children lived in a household with an income at 135 percent of the federal poverty level or lower, which is the income threshold for eligibility for free school meals. Thirteen percent of primary caregivers did not complete high school. Half of the children lived with both their father and their mother. There were no significant differences between the treatment and control groups in these characteristics.

The mean values of the outcomes for children's behavior and attitudes as reported by the primary caregivers, children, and teachers at initial data collection in fall 2004 are shown in table 2.7. There were no significant differences between the treatment and control groups in these scores. 
Table 2.6. Initial characteristics of children, their families, and communities-ABC

\begin{tabular}{|c|c|c|c|}
\hline Characteristic & Total & Treatment & Control \\
\hline Student sample size & 497 & 228 & 269 \\
\hline \multicolumn{4}{|l|}{ Student demographics } \\
\hline \multicolumn{4}{|l|}{ Gender (percent) } \\
\hline Male & 50.1 & 46.4 & 53.9 \\
\hline Female & 49.9 & 53.6 & 46.1 \\
\hline \multicolumn{4}{|l|}{ Race/ethnicity (percent) } \\
\hline White (non-Hispanic) & 32.7 & 26.2 & 39.2 \\
\hline Black (non-Hispanic) & 41.2 & 48.6 & 33.8 \\
\hline Hispanic & 17.3 & 16.9 & 17.6 \\
\hline Other & 8.8 & 8.3 & 9.4 \\
\hline Age (in years) (mean) & 8.0 & 8.0 & 8.0 \\
\hline \multicolumn{4}{|l|}{ Primary caregiver and family characteristics } \\
\hline Primary caregiver's age (in years) (mean) & 35.3 & 35.9 & 34.7 \\
\hline \multicolumn{4}{|l|}{ Primary caregiver's race/ethnicity (percent) } \\
\hline White (non-Hispanic) & 38.3 & 31.3 & 45.3 \\
\hline Black (non-Hispanic) & 41.1 & 46.7 & 35.6 \\
\hline Hispanic & 14.9 & 15.4 & 14.3 \\
\hline Other & 5.7 & 6.6 & 4.8 \\
\hline \multicolumn{4}{|l|}{ Primary caregiver's education (percent) } \\
\hline Did not complete high school & 12.5 & 11.0 & 14.0 \\
\hline Completed high school or equivalent & 26.6 & 24.9 & 28.2 \\
\hline Some college & 49.4 & 52.6 & 46.2 \\
\hline Bachelor's or higher degree & 11.5 & 11.4 & 11.7 \\
\hline \multicolumn{4}{|l|}{ Primary caregiver's employment (percent) } \\
\hline Full-time & 45.1 & 43.0 & 47.1 \\
\hline Other & 54.9 & 57.0 & 52.9 \\
\hline \multicolumn{4}{|l|}{ Primary caregiver's marital status (percent) } \\
\hline Married & 47.3 & 43.5 & 51.2 \\
\hline Other & 52.7 & 56.5 & 48.8 \\
\hline Students who live in one household (percent) & 93.8 & 94.0 & 93.6 \\
\hline Number of individuals in household (mean) & 4.6 & 4.5 & 4.7 \\
\hline \multicolumn{4}{|l|}{ Primary caregiver's relationship to child (percent) } \\
\hline Mother (stepmother) & 86.0 & 86.7 & 85.3 \\
\hline Father (stepfather) & 7.7 & 6.0 & 9.5 \\
\hline Other relative/nonrelative & 6.3 & 7.4 & 5.3 \\
\hline
\end{tabular}


Table 2.6. Initial characteristics of children, their families, and communities-ABC—Continued

\begin{tabular}{|c|c|c|c|}
\hline Characteristic & Total & Treatment & Control \\
\hline \multicolumn{4}{|l|}{ Student lives with (percent) } \\
\hline Mother (stepmother) and father (stepfather) & 50.4 & 46.6 & 54.2 \\
\hline Mother (stepmother) only; father (stepfather) not present & 42.5 & 44.8 & 40.3 \\
\hline Father (stepfather) only; mother (stepmother) not present & 1.8 & 2.1 & 1.6 \\
\hline Other relative/nonrelative, parents not present & 5.2 & 6.6 & 3.9 \\
\hline \multicolumn{4}{|l|}{ Highest education of anyone in household (percent) } \\
\hline Did not complete high school & 8.7 & 5.2 & 12.1 \\
\hline Completed high school or equivalent & 23.3 & 22.5 & 24.0 \\
\hline Some college & 52.4 & 56.6 & 48.2 \\
\hline Bachelor's or higher degree & 15.6 & 15.7 & 15.6 \\
\hline \multicolumn{4}{|l|}{ Total household income (percent) } \\
\hline Less than $\$ 20,000$ & 40.7 & 39.8 & 41.6 \\
\hline$\$ 20,000$ to $\$ 39,999$ & 34.0 & 35.5 & 32.4 \\
\hline$\$ 40,000$ to $\$ 59,999$ & 16.2 & 17.9 & 14.5 \\
\hline$\$ 60,000$ or more & 9.1 & 6.7 & 11.5 \\
\hline Income-to-poverty-threshold ratio-Below 135 percent (percent) & 49.7 & 48.0 & 51.4 \\
\hline Income-to-poverty-threshold ratio-135 to 185 percent (percent) & 25.2 & 26.9 & 23.4 \\
\hline Income-to-poverty-threshold ratio-Above 185 percent (percent) & 25.2 & 25.1 & 25.3 \\
\hline \multicolumn{4}{|l|}{ Alabama Parenting Questionnaire-Poor Monitoring and } \\
\hline Supervision Subscale (mean) & 1.1 & 1.2 & 1.1 \\
\hline \multicolumn{4}{|l|}{ Alabama Parenting Questionnaire-_Positive Parenting } \\
\hline Subscale (mean) & 3.5 & 3.5 & 3.5 \\
\hline Confusion, Hubbub, and Order Scale (mean) & 2.2 & 2.2 & 2.2 \\
\hline \multicolumn{4}{|l|}{ Community characteristics (mean) } \\
\hline Community Risks Scale & 1.7 & 1.7 & 1.7 \\
\hline Community Resources Scale & 2.8 & 2.8 & 2.8 \\
\hline Child-Centered Social Control Scale & 3.0 & 3.0 & 3.0 \\
\hline
\end{tabular}

NOTE: No statistically significant differences were found between values for treatment and control groups. Weights, which assign equal weight to each school within the program, were used in producing the treatment, control, and overall means. Statistical tests were conducted using regressions that included program indicators to account for the sample design and adjusted for clustering at the school level.

SOURCE: The Social and Character Development (SACD) Research Program. 
Table 2.7. Mean scores and standard deviations for initial outcome measures of sample--ABC

\begin{tabular}{|c|c|c|c|c|c|c|c|}
\hline \multirow[b]{2}{*}{ Outcome measure-Report } & \multirow[b]{2}{*}{ Range } & \multicolumn{2}{|c|}{ Total } & \multicolumn{2}{|c|}{ Treatment } & \multicolumn{2}{|c|}{ Control } \\
\hline & & Mean & $S D$ & Mean & $S D$ & Mean & $S D$ \\
\hline \multicolumn{8}{|l|}{ Social and Emotional Competence Domain } \\
\hline Self-Efficacy for Peer Interaction-CR & $1-4$ & 3.0 & 0.7 & 3.0 & 0.7 & 3.0 & 0.7 \\
\hline Normative Beliefs About Aggression-CR & $1-4$ & 1.3 & 0.5 & 1.2 & 0.5 & 1.3 & 0.5 \\
\hline Empathy-CR & $1-3$ & 2.3 & 0.4 & 2.3 & 0.4 & 2.4 & 0.4 \\
\hline \multicolumn{8}{|l|}{ Behavior Domain } \\
\hline Altruistic Behavior-CR & $0-3$ & 1.5 & 0.9 & 1.5 & 0.9 & 1.5 & 0.9 \\
\hline Altruistic Behavior-TRS & $1-4$ & 1.3 & 0.4 & 1.4 & 0.4 & 1.3 & 0.4 \\
\hline Altruistic Behavior-PCR & $1-4$ & 2.3 & 0.7 & 2.3 & 0.7 & 2.3 & 0.7 \\
\hline Positive Social Behavior-TRS & $1-4$ & 2.9 & 0.7 & 2.9 & 0.7 & 2.9 & 0.7 \\
\hline Positive Social Behavior-PCR & $1-4$ & 2.9 & 0.5 & 2.9 & 0.5 & 3.0 & 0.5 \\
\hline Problem Behavior-CR & $0-3$ & 0.3 & 0.5 & 0.3 & 0.5 & 0.3 & 0.5 \\
\hline Problem Behavior-TRS & $1-4$ & 1.4 & 0.5 & 1.4 & 0.4 & 1.4 & 0.5 \\
\hline Problem Behavior-PCR & $1-4$ & 1.6 & 0.3 & 1.6 & 0.3 & 1.6 & 0.4 \\
\hline ADHD-Related Behavior-TRS & $1-4$ & 1.8 & 0.6 & 1.8 & 0.6 & 1.8 & 0.6 \\
\hline \multicolumn{8}{|l|}{ Academics Domain } \\
\hline Academic Competence and Motivation-TRS & $1-5$ & 2.8 & 0.8 & 2.7 & 0.9 & 2.8 & 0.8 \\
\hline Engagement with Learning-CR & $1-4$ & 3.7 & 0.6 & 3.6 & 0.7 & 3.7 & 0.6 \\
\hline \multicolumn{8}{|l|}{ Perceptions of School Climate Domain } \\
\hline Positive School Orientation-CR & $1-4$ & 3.2 & 0.7 & 3.2 & 0.7 & 3.3 & 0.7 \\
\hline Negative School Orientation-CR & $1-4$ & 1.9 & 0.7 & 2.0 & 0.7 & 1.9 & 0.7 \\
\hline Student Afraid at School-CR & $1-4$ & 2.3 & 1.0 & 2.4 & 1.0 & 2.3 & 1.0 \\
\hline Victimization at School-CR & $0-3$ & 0.8 & 0.8 & 0.7 & 0.8 & 0.8 & 0.8 \\
\hline Student sample size_-PCR & & \multicolumn{2}{|c|}{497} & \multicolumn{2}{|c|}{228} & \multicolumn{2}{|c|}{269} \\
\hline Student sample size-CR & & \multicolumn{2}{|c|}{521} & \multicolumn{2}{|c|}{238} & \multicolumn{2}{|c|}{283} \\
\hline Student sample size-TRS & & \multicolumn{2}{|c|}{525} & \multicolumn{2}{|c|}{248} & \multicolumn{2}{|c|}{277} \\
\hline
\end{tabular}

NOTE: Abbreviations are

CR: Child Report

PCR: Primary Caregiver Report

TRS: Teacher Report on Student

ADHD: Attention deficit hyperactivity disorder

$S D$ : Standard deviation

No statistically significant differences were found between values for treatment and control groups. Weights, which assign equal weight to each school within the program, were used in producing the treatment, control, and overall means. Statistical tests were conducted using regressions that included program indicators to account for the sample design and adjusted for clustering at the school level. Sample size may differ for some outcomes due to nonresponse.

SOURCE: The Social and Character Development (SACD) Research Program. 


\section{Characteristics of Teachers and Schools}

The third-, fourth-, and fifth-grade teachers at the study schools were predominantly White non-Hispanic $(80 \%)$ and female $(90 \%)$, had an average of 12.3 years of total teaching experience, and about three-fourths $(77 \%)$ held an advanced or specialist degree (table 2.8$)$. There were no statistically significant differences between the treatment and control groups of teachers.

Data regarding school characteristics were drawn from the Common Core of Data in order to compare treatment and control schools. There were no significant differences between the two groups of schools in terms of student composition (race/ethnicity and school lunch eligibility), number of students enrolled, number of full-time teachers, Title I status, or number of years the principal had been at the school (see table 2.9). In addition, there were no significant differences between treatment and control schools in terms of location (urban, suburban, or rural) or lowest and highest grade offered (these data are not shown in a table). 
Table 2.8. Initial characteristics of teachers in sample-ABC

\begin{tabular}{|c|c|c|c|}
\hline Characteristic & Total & Treatment & Control \\
\hline Teacher sample size & 119 & 56 & 63 \\
\hline \multicolumn{4}{|l|}{ Gender (percent) } \\
\hline Male & 9.7 & 9.4 & 10.1 \\
\hline Female & 90.3 & 90.6 & 89.9 \\
\hline \multicolumn{4}{|l|}{ Race/ethnicity (percent) } \\
\hline White (non-Hispanic) & 80.1 & 73.2 & 86.9 \\
\hline Other & 19.9 & 26.8 & 13.1 \\
\hline Number of years teaching experience (mean) & 12.3 & 12.7 & 11.9 \\
\hline Number of years teaching experience in this school (mean) & 4.9 & 4.5 & 5.3 \\
\hline \multicolumn{4}{|l|}{ Type of teaching certificate (percent) } \\
\hline Regular state certificate or advanced professional certificate & 65.7 & 63.4 & 68.0 \\
\hline Other & 34.3 & 36.6 & 32.0 \\
\hline \multicolumn{4}{|l|}{ Education (percent) } \\
\hline Bachelor's degree & 23.0 & 24.0 & 22.0 \\
\hline Advanced degree/other & 77.0 & 76.0 & 78.0 \\
\hline
\end{tabular}

NOTE: No statistically significant differences were found between values for treatment and control groups. Weights, which assign equal weight to each school within the program, were used in producing the treatment, control, and overall means. Statistical tests were conducted using regressions that included program indicators to account for the sample design and adjusted for clustering at the school level. Sample size may differ for some outcomes due to nonresponse.

SOURCE: The Social and Character Development (SACD) Research Program. 
Table 2.9. Initial characteristics of schools in sample--ABC

\begin{tabular}{|c|c|c|c|}
\hline Characteristic & Total & Treatment & Control \\
\hline School sample size & 12 & 6 & 6 \\
\hline \multicolumn{4}{|l|}{ Student race/ethnicity (percent) } \\
\hline White (non-Hispanic) & 34.3 & 29.1 & 39.6 \\
\hline Black (non-Hispanic) & 48.8 & 54.9 & 42.7 \\
\hline Hispanic & 14.8 & 14.6 & 15.0 \\
\hline Other & 2.0 & 1.4 & 2.7 \\
\hline Students eligible for free or reduced-price lunch (percent) & 66.7 & 68.5 & 65.3 \\
\hline Number of students enrolled (mean) & 679.2 & 584.3 & 774.0 \\
\hline Number of full-time teachers (mean) & 46.5 & 41.6 & 51.5 \\
\hline \multicolumn{4}{|l|}{ Title I status (percent) } \\
\hline Title I eligible school & 83.3 & 83.3 & 83.3 \\
\hline Schoolwide Title I & 90.0 & 80.0 & 100.0 \\
\hline Number of years principal has been at this school (mean) & 4.3 & 4.5 & 4.2 \\
\hline
\end{tabular}

NOTE: No statistically significant differences were found between values for treatment and control groups. Weights, which assign equal weight to each school within the program, were used in producing the treatment, control, and overall means. Statistical tests were conducted using regressions that included program indicators to account for the sample design and adjusted for clustering at the school level. Sample size may differ for some outcomes due to nonresponse.

SOURCE: NCES Common Core of Data (2003-04), the Social and Character Development (SACD) Research Program.

In the Teacher Report on Classroom and School, teachers reported on nine dimensions of school environment (these data are not shown in a table): feelings of safety, adequacy of resources, student support, freedom to teach as desired, affiliation with and ties to colleagues, innovation regarding new approaches to teaching, professional interest, participatory decisionmaking, and work pressure. There were no statistically significant differences between treatment and control schools in these reports.

\section{The Level of SACD in the Schools Near the Beginning of the Study}

During the initial data collection period, principals and teachers reported on the SACD activities used in the schools and classrooms, the availability of SACD materials, and the professional development provided on SACD (see tables 2.10, 2.11, and 2.12, respectively). It is important to note that data collection at the beginning of the school year took place 6 weeks after the start of ABC implementation; therefore the SACDrelated activities and practices in the treatment and control schools are a measure of what was happening in the study schools near the beginning of the study. The principals at the 12 schools reported on activities to promote six social and character development goals (see table 2.10): violence prevention and peace promotion $(83 \%)$, social and emotional development $(92 \%)$, character education $(100 \%)$, tolerance and diversity (75\%), risk prevention and health promotion $(83 \%)$, and civic responsibility and community service (83\%). In addition, all 12 principals reported activities directed toward behavior management. There were no statistically significant differences between the treatment and control schools in the percentages of principal reports, although this may be due to the relatively small principal sample size. The percentages of teachers who reported the use of these activities in their classrooms ranged from 63 percent to 93 percent; there were no significant differences between treatment and control teachers. With respect to the use of schoolwide activities, 59 percent to 81 percent of teachers reported that their schools used such activities, and there were no significant differences between treatment and control teachers in reported use. 
Table 2.10. Principal and teacher initial reports on use of SACD programs or activities in sample-ABC

\begin{tabular}{|c|c|c|c|}
\hline SACD program or activity & Total & Treatment & Control \\
\hline Principal sample size & 12 & 6 & 6 \\
\hline Teacher sample size & 119 & 56 & 63 \\
\hline \multicolumn{4}{|c|}{$\begin{array}{l}\text { Principals reporting that school had programs or activities } \\
\text { to promote the following SACD goals (percent) }\end{array}$} \\
\hline Violence prevention and peace promotion & 83.3 & 66.7 & 100.0 \\
\hline Social and emotional development & 91.7 & 83.3 & 100.0 \\
\hline Character education & 100.0 & 100.0 & 100.0 \\
\hline Tolerance and diversity & 75.0 & 66.7 & 83.3 \\
\hline Risk prevention and health promotion & 83.3 & 83.3 & 83.3 \\
\hline Civic responsibility and community service & 83.3 & 83.3 & 83.3 \\
\hline Behavior management & 100.0 & 100.0 & 100.0 \\
\hline None of the above & 0.0 & 0.0 & 0.0 \\
\hline \multicolumn{4}{|c|}{$\begin{array}{l}\text { Teachers reporting on using programs or activities in their } \\
\text { class to promote the following SACD goals (percent) }\end{array}$} \\
\hline Violence prevention and peace promotion & 74.7 & 82.1 & 67.2 \\
\hline Social and emotional development & 81.9 & 87.1 & 76.8 \\
\hline Character education & 88.5 & 93.1 & 83.8 \\
\hline Tolerance and diversity & 71.6 & 70.2 & 73.0 \\
\hline Risk prevention and health promotion & 64.1 & 66.7 & 61.6 \\
\hline Civic responsibility and community service & 63.0 & 71.1 & 54.9 \\
\hline Behavior management & 93.4 & 98.6 & 88.2 \\
\hline None of the above & 0.0 & 0.0 & 0.0 \\
\hline \multicolumn{4}{|l|}{$\begin{array}{l}\text { Teachers reporting schoolwide use of the following } \\
\text { activities to promote SACD (percent) }\end{array}$} \\
\hline Morning announcements or videos & 80.9 & 81.1 & 80.8 \\
\hline School assemblies & 76.2 & 70.4 & 82.1 \\
\hline School newspapers or bulletins & 64.4 & 67.6 & 61.3 \\
\hline Special school days & 59.2 & 66.6 & 51.8 \\
\hline Special events & 78.4 & 80.3 & 76.6 \\
\hline Other activities & 17.5 & 19.4 & 15.6 \\
\hline
\end{tabular}

NOTE: No statistically significant differences were found between values for treatment and control groups. Weights, which assign equal weight to each school within each of the programs and to each program across programs, were used in producing the treatment, control, and overall means. Statistical tests were conducted using regressions that included program indicators to account for the sample design and adjusted for clustering at the school level. Sample size may differ for some outcomes due to nonresponse.

SOURCE: The Social and Character Development (SACD) Research Program. 


\section{Chapter 2. Academic and Behavioral Competencies Program}

Teachers reported using a broad range of teaching materials (table 2.11). The materials most used in support of SACD activities were teacher guides (used by 59\% of teachers), giveaways (used by 55\%), children's literature (used by 47\%), and student materials (used by 46\%). There were no significant differences between treatment and control teachers in the use of materials.

Teachers reported using a wide variety of teaching strategies (table 2.11). All teachers in the sample reported using any of the 20 strategies, and, on average, they used 12 of the strategies. There were no significant differences between treatment and control teachers in the average number of strategies used. In regard to the specific strategies, there were 5 significant differences out of 29 comparisons made (with 1 expected to be significant by chance). A significantly greater number of treatment teachers reported incorporating SACD into the academic curriculum (87\% versus $62 \%$ ), sending home good behavior notes $(93 \%$ versus $64 \%$ ), presenting role models ( $76 \%$ versus $59 \%$ ), using an honor roll for positive behavior $(76 \%$ versus $45 \%$ ), and using time-outs for negative behavior (94\% versus $73 \%$ ). These differences between treatment and control teachers at the start of the study may reflect the fact that program implementation at the treatment schools began before data collection at the start of the school year. 
Table 2.11. Teacher initial reports on use of SACD materials and classroom strategies in sample--ABC

\begin{tabular}{crrr}
\hline SACD material and classroom strategy & Total & Treatment & Control \\
\hline Teacher sample size & 119 & 56 & 63
\end{tabular}

Teachers using the following materials in conjunction with social and character development activities (percent)

Teacher guides (manuals, curricula)

$\begin{array}{lll}59.4 & 48.1 & 70.7 \\ 46.2 & 46.1 & 46.2 \\ 26.8 & 29.3 & 24.3 \\ 55.3 & 59.5 & 51.2 \\ 47.3 & 52.3 & 42.3 \\ 11.4 & 11.2 & 11.7 \\ 13.3 & 14.3 & 12.4 \\ & & \\ 100.0 & 100.0 & 100.0\end{array}$

Teachers using any of the strategies listed below to promote social and character development in the classroom (percent)

100.0

Teachers using each of the following strategies to promote social and character development (percent)

Role-playing

67.1

63.1

71.1

Cooperative learning

99.4

100.0

98.7

Peer group discussions

86.3

91.4

81.1

Direct instruction of social and character development

82.9

88.8

77.0

Skill training

47.6

46.2

49.0

Incorporating social and character development into academic curriculum

74.6

$87.2^{* *}$

62.0

Parent training

Parent/community involvement in program development or delivery

19.4

19.6

19.2

Mentoring

Good behavior notes sent home daily or weekly

78.2

$92.6^{*}$

63.9

Presenting role models

67.5

$75.6^{*}$

59.3

Targeted story reading or writing on SACD themes

72.6

77.3

67.9

Peer mediation

36.0

36.9

35.1

Honor roll for positive behavior

60.0

$75.5^{*}$

44.6

Pledges or recitations on social and character development themes

41.1

37.8

44.4

Guided visualization

45.1

49.9

40.3

Student-led/student-assisted instruction

42.3

41.4

43.2

Journaling

70.5

80.3

60.7

Time out for negative behavior

83.6

$94.0^{*}$

73.2

Daily or weekly rewards for positive behavior

93.7

98.1

* Treatment group significantly different from control group at the .05 level.

** Treatment group significantly different from control group at the .01 level.

NOTE: Weights, which assign equal weight to each school within each of the programs and to each program across programs, were used in producing the treatment, control, and overall means. Statistical tests were conducted using regressions that included program indicators to account for the sample design and adjusted for clustering at the school level. Sample size may differ for some outcomes due to nonresponse.

SOURCE: The Social and Character Development (SACD) Research Program. 
Principals and teachers reported on participation in and amount of SACD training and staff development provided over the previous 12 months (table 2.12). Principals reported higher participation rates than did teachers $(100 \%$ versus $76 \%$ ), and teachers reported more training hours (11 versus 8 ). There were no significant differences between treatment and control principals and teachers in overall training and hours. Out of seven targeted areas for professional development, there was one statistically significant difference in the area of behavior management, with more treatment teachers than control teachers reporting attending training in this area $(71 \%$ versus $41 \%)$.

Table 2.12. Principal and teacher initial reports on SACD professional development in sample-ABC

\begin{tabular}{|c|c|c|c|}
\hline SACD professional development & Total & Treatment & Control \\
\hline Principal sample size & 12 & 6 & 6 \\
\hline Teacher sample size & 119 & 56 & 63 \\
\hline $\begin{array}{l}\text { Principals reporting that staff participated in social and character } \\
\text { development training within the past year (percent) }\end{array}$ & 100.0 & 100.0 & 100.0 \\
\hline $\begin{array}{l}\text { Teachers reporting participation in social and character } \\
\text { development training within the past } 12 \text { months (percent) }\end{array}$ & 76.2 & 81.9 & 70.5 \\
\hline $\begin{array}{l}\text { Number of hours of social and character development training } \\
\text { principals report were provided to each staff person last year (mean) }\end{array}$ & 7.8 & 8.0 & 7.5 \\
\hline $\begin{array}{l}\text { Number of hours of social and character development training } \\
\text { teachers report receiving during the past } 12 \text { months (mean) }\end{array}$ & 10.8 & 11.9 & 9.6 \\
\hline $\begin{array}{l}\text { Teachers reporting receiving training in the past } 12 \text { months } \\
\text { in the following areas (percent) }\end{array}$ & & & \\
\hline Violence prevention and peace promotion & 22.5 & 13.7 & 31.2 \\
\hline Social and emotional development & 25.2 & 23.1 & 27.2 \\
\hline Character education & 37.4 & 35.5 & 39.3 \\
\hline Tolerance and diversity & 20.5 & 17.6 & 23.5 \\
\hline Risk prevention and health promotion & 6.4 & 5.8 & 7.0 \\
\hline Civic responsibility and community service & 3.0 & $\ddagger$ & $\ddagger$ \\
\hline Behavior management & 56.0 & $71.2^{*}$ & 40.7 \\
\hline
\end{tabular}

$\ddagger$ Reporting standards not met. Values suppressed to protect confidentiality.

* Treatment group significantly different from control group at the .05 level.

NOTE: Weights, which assign equal weight to each school within each of the programs and to each program across programs, were used in producing the treatment, control, and overall means. Statistical tests were conducted using regressions that included program indicators to account for the sample design and adjusted for clustering at the school level. Sample size may differ for some outcomes due to nonresponse.

SOURCE: The Social and Character Development (SACD) Research Program.

The data on the initial level of SACD activity illustrate that the control condition was a "standard practice" control. Standard practice at the control schools included using SACD activities, materials, and practices, along with professional development for staff, at rates and in types and amounts similar to the treatment schools. For example, the percentages of teachers who reported using programs or activities to promote specific SACD goals ranged from 67 percent to 99 percent in the treatment schools and from 55 percent to 88 percent in the control schools. However, the 6 significant differences between the treatment and control conditions in the use of SACD activities were more than would be expected by chance (3 out of 62 comparisons), and in all cases they favored the treatment group. Because initial data collection happened after 
program implementation began, these differences may reflect that program implementation and program training for staff started before initial data collection.

\section{Impacts on Use of SACD Activities}

The introduction of the formal ABC program would be expected to increase the use of SACD activities in the treatment schools in comparison to the control schools. The analysis of this impact is based on the Teacher Report on Classroom and School (TRCS). Every spring, third-, fourth-, and fifth-grade teachers in the schools provided information through the TRCS about the social and character development activities they used in their classrooms. Specifically, information from the TRCS was used to determine the difference between treatment and control teachers in the following areas:

1. the use of SACD activities in their classrooms overall and by SACD goal;

2. the use of materials and strategies to implement the SACD activities within classrooms and within the entire school;

3. the use of staff development to support the teachers; and

4. teacher support for SACD efforts in the school and the use of practices conducive to the social and character development of students.

TRCS consent and completion rates (table 2.4) led to 82 percent to 86 percent of teachers overall having data for the 3 years, with greater percentages of treatment teachers providing data in most of the years. To estimate intervention impacts for each of the outcomes, the statistical significance of the differences in means was assessed. Preliminary analysis using covariates indicated little or no gains in precision. Before testing the mean differences, the data were weighted such that each school received equal weight. Standard errors of the impact estimates accounted for the clustering of teachers within schools. In addition, a set of heuristics (described in chapter 1) was applied to determine whether each outcome domain was statistically significant after adjustments were made for the multiple tests conducted.

\section{Use of Activities}

The percentages of control teachers who reported using any SACD activities in their classrooms ranged from 85 percent to 97 percent over the 3 years (table 2.13, panel 1). For the six individual SACD goals, the percentages varied from 52 percent to 87 percent in Year 1, 54 percent to 71 percent in Year 2, and 42 percent to 69 percent in Year 3. Control teachers' use of behavior management activities ranged from 80 percent to 86 percent over this period. The percentages of control teachers who reported using any SACD activities in their classrooms for at least 1 hour per week ranged from 78 percent to 80 percent over the 3 years (table 2.13, panel 2). For the six individual SACD goals, the range varied from 20 percent to 55 percent in Year 1, 14 percent to 38 percent in Year 2, and 14 percent to 35 percent in Year 3. Their use of behavior management activities for at least 1 hour per week ranged from 62 percent to 74 percent over this period. These findings show that the control schools were using these activities as part of their standard practice related to social and character development.

For teachers' reported use of any SACD activity (panels 1 and 2), 48 comparisons were made, with 2 expected to be significant by chance. The percentages of treatment teachers using any SACD activity were not significantly different from the percentages of control teachers in any year (panel 1). A significantly larger percentage of treatment teachers reported using civic responsibility activities (impact $=23$ percentage points) in Year 1. In Year 2, more treatment teachers reported using activities for social and emotional development (impact $=24$ percentage points), character education (impact $=20$ percentage points), tolerance and diversity (impact $=24$ percentage points), and behavior management (impact $=16$ percentage points). There were no significant differences between treatment and control teacher reports of using activities for at least 1 hour a 


\section{Chapter 2. Academic and Behavioral Competencies Program}

week (panel 2). After the heuristics were applied, the domain for engagement in any SACD activities showed the $\mathrm{ABC}$ program had statistically significant impacts in Year 1.

For teachers' reported use of any named SACD activity (panels 3 and 4), 42 comparisons were made, with 2 expected to be significant by chance. None of the impact estimates were statistically significant over the 3 years. The overall impact of the ABC program on the domain for engagement in named SACD activities was not significant in any year. 
Table 2.13. Impacts on teacher-reported SACD classroom activities-ABC

Panel 1: Engagement in any activities to promote SACD goals ${ }^{1}$

\begin{tabular}{|c|c|c|c|c|c|c|c|c|c|c|c|c|}
\hline \multirow[b]{2}{*}{ SACD activity } & \multicolumn{4}{|c|}{$\begin{array}{c}\text { Year } 1 \\
\text { (Spring 3rd grade) }\end{array}$} & \multicolumn{4}{|c|}{$\begin{array}{c}\text { Year } 2 \\
\text { (Spring 4th grade) }\end{array}$} & \multicolumn{4}{|c|}{$\begin{array}{c}\text { Year } 3 \\
\text { (Spring 5th grade) }\end{array}$} \\
\hline & $\begin{array}{r}\text { Treat- } \\
\text { ment }\end{array}$ & Control & Impact & $p$-value & $\begin{array}{r}\text { Treat- } \\
\text { ment }\end{array}$ & Control & Impact & $p$-value & $\begin{array}{r}\text { Treat- } \\
\text { ment }\end{array}$ & Control & Impact & $p$-value \\
\hline Teacher sample size & 63 & 73 & & & 50 & 67 & & & 51 & 64 & & \\
\hline
\end{tabular}

Violence prevention and peace promotion (percent)

ocial and

\begin{tabular}{rrrrrrrrrrrr}
70.3 & 77.0 & -6.8 & 0.587 & 74.8 & 63.3 & 11.5 & 0.339 & 63.5 & 62.0 & 1.5 & 0.882 \\
77.7 & 86.5 & -8.8 & 0.474 & $85.6^{*}$ & 61.9 & 23.8 & 0.044 & 69.2 & 55.2 & 14.0 & 0.111 \\
91.4 & 83.5 & 7.9 & 0.383 & $90.9^{*}$ & 71.1 & 19.8 & 0.044 & 69.6 & 69.0 & 0.6 & 0.961 \\
78.7 & 71.1 & 7.7 & 0.451 & $77.9^{*}$ & 54.2 & 23.7 & 0.014 & $66.4^{\wedge}$ & 44.8 & 21.6 & 0.072 \\
74.8 & 80.2 & -5.4 & 0.664 & 65.5 & 68.4 & -2.9 & 0.833 & 57.3 & 56.6 & 0.7 & 0.955 \\
$74.7^{*}$ & 51.8 & 22.9 & 0.038 & 62.9 & 53.9 & 9.1 & 0.571 & $65.6^{\wedge}$ & 41.6 & 24.0 & 0.094 \\
94.0 & 97.1 & -3.2 & 0.454 & 98.8 & 92.6 & 6.2 & 0.108 & 93.8 & 84.6 & 9.2 & 0.214 \\
92.7 & 79.6 & 13.1 & 0.186 & $96.9^{*}$ & 81.1 & 15.7 & 0.022 & 94.1 & 85.8 & 8.3 & 0.179 \\
\hline
\end{tabular}


Table 2.13. Impacts on teacher-reported SACD classroom activities-ABC-Continued

Panel 2: Engagement in any activities to promote SACD goals for at least 1 hour per week

\begin{tabular}{|c|c|c|c|c|c|c|c|c|c|c|c|c|}
\hline \multirow[b]{2}{*}{ SACD activity } & \multicolumn{4}{|c|}{$\begin{array}{c}\text { Year } 1 \\
\text { (Spring 3rd grade) }\end{array}$} & \multicolumn{4}{|c|}{$\begin{array}{c}\text { Year } 2 \\
\text { (Spring 4th grade) }\end{array}$} & \multicolumn{4}{|c|}{$\begin{array}{c}\text { Year } 3 \\
\text { (Spring 5th grade) }\end{array}$} \\
\hline & $\begin{array}{r}\text { Treat- } \\
\text { ment }\end{array}$ & Control & Impact & $p$-value & $\begin{array}{r}\text { Treat- } \\
\text { ment }\end{array}$ & Control & Impact & $p$-value & $\begin{array}{r}\text { Treat- } \\
\text { ment }\end{array}$ & Control & Impact & $p$-value \\
\hline Teacher sample size & 63 & 73 & & & 50 & 67 & & & 51 & 64 & & \\
\hline $\begin{array}{l}\text { Violence prevention and peace promotion } \\
\text { (percent) }\end{array}$ & 32.9 & 44.0 & -11.2 & 0.341 & 41.0 & 37.2 & 3.8 & 0.797 & 27.5 & 34.9 & -7.4 & 0.537 \\
\hline $\begin{array}{l}\text { Social and emotional development } \\
\text { (percent) }\end{array}$ & 40.4 & 54.5 & -14.0 & 0.314 & 38.2 & 34.9 & 3.2 & 0.827 & 33.2 & 29.6 & 3.5 & 0.748 \\
\hline Character education (percent) & 45.5 & 50.2 & -4.7 & 0.747 & $61.2^{\wedge}$ & 34.1 & 27.0 & 0.059 & 38.5 & 34.6 & 4.0 & 0.723 \\
\hline Tolerance and diversity (percent) & 30.8 & 38.7 & -7.9 & 0.568 & 23.2 & 22.2 & 1.0 & 0.913 & 20.1 & 19.9 & 0.3 & 0.968 \\
\hline $\begin{array}{l}\text { Risk prevention and health promotion } \\
\text { (percent) }\end{array}$ & 38.9 & 46.7 & -7.8 & 0.433 & 22.9 & 37.5 & -14.6 & 0.304 & 17.1 & 17.2 & 0.0 & 0.996 \\
\hline $\begin{array}{l}\text { Civic responsibility and community service } \\
\text { (percent) }\end{array}$ & 25.4 & 20.1 & 5.4 & 0.522 & 15.6 & 14.1 & 1.5 & 0.886 & 14.0 & 14.0 & 0.0 & 0.997 \\
\hline Any SACD goal (percent) & 74.8 & 80.1 & -5.3 & 0.560 & 77.6 & 78.3 & -0.7 & 0.952 & 84.0 & 79.6 & 4.4 & 0.567 \\
\hline Behavior management (percent) & 78.8 & 61.5 & 17.3 & 0.232 & 79.9 & 68.7 & 11.2 & 0.454 & 79.4 & 73.8 & 5.6 & 0.527 \\
\hline
\end{tabular}

Behavior management (percent)

79.9

See notes at end of table. 
Table 2.13. Impacts on teacher-reported SACD classroom activities-ABC-Continued

Panel 3: Engagement in activities to promote SACD goals linked to named SACD programs

\begin{tabular}{|c|c|c|c|c|c|c|c|c|c|c|c|c|}
\hline \multirow[b]{2}{*}{ SACD activity } & \multicolumn{4}{|c|}{$\begin{array}{c}\text { Year } 1 \\
\text { (Spring 3rd grade) }\end{array}$} & \multicolumn{4}{|c|}{$\begin{array}{c}\text { Year 2 } \\
\text { (Spring 4th grade) }\end{array}$} & \multicolumn{4}{|c|}{$\begin{array}{c}\text { Year } 3 \\
\text { (Spring 5th grade) }\end{array}$} \\
\hline & $\begin{array}{r}\text { Treat- } \\
\text { ment }\end{array}$ & Control & Impact & $p$-value & $\begin{array}{c}\text { Treat- } \\
\text { ment }\end{array}$ & Control & Impact & $p$-value & $\begin{array}{r}\text { Treat- } \\
\text { ment }\end{array}$ & Control & Impact & $p$-value \\
\hline Teacher sample size & 63 & 73 & & & 50 & 67 & & & 51 & 64 & & \\
\hline $\begin{array}{l}\text { Violence prevention and peace promotion } \\
\text { (percent) }\end{array}$ & 30.8 & 28.9 & 1.8 & 0.856 & 26.2 & 30.2 & -4.0 & 0.670 & 14.1 & 24.9 & -10.9 & 0.280 \\
\hline $\begin{array}{l}\text { Social and emotional development } \\
\text { (percent) }\end{array}$ & 28.1 & 12.5 & 15.6 & 0.160 & 28.4 & 17.6 & 10.8 & 0.264 & 9.8 & 16.7 & -7.0 & 0.474 \\
\hline Character education (percent) & 33.1 & 20.6 & 12.5 & 0.317 & 25.9 & 13.6 & 12.3 & 0.219 & 11.6 & 13.9 & -2.3 & 0.768 \\
\hline Tolerance and diversity (percent) & 20.0 & 10.1 & 9.8 & 0.233 & 19.4 & 6.8 & 12.6 & 0.125 & 8.0 & 7.9 & 0.2 & 0.979 \\
\hline $\begin{array}{l}\text { Risk prevention and health promotion } \\
\text { (percent) }\end{array}$ & 21.7 & 37.2 & -15.5 & 0.156 & 21.8 & 37.1 & -15.3 & 0.252 & 17.1 & 16.3 & 0.8 & 0.941 \\
\hline $\begin{array}{l}\text { Civic responsibility and community service } \\
\text { (percent) }\end{array}$ & $\ddagger$ & $\ddagger$ & 1.6 & 0.717 & $\ddagger^{\wedge}$ & $\ddagger$ & 9.7 & 0.059 & 9.8 & 8.1 & 1.7 & 0.773 \\
\hline Any named activity (percent) & 50.8 & 55.2 & -4.4 & 0.742 & 42.7 & 55.1 & -12.4 & 0.244 & 31.1 & 46.6 & -15.6 & 0.283 \\
\hline
\end{tabular}




\section{Table 2.13. Impacts on teacher-reported SACD classroom activities-ABC-Continued}

Panel 4: Engagement in activities to promote SACD goals linked to named SACD programs for at least 1 hour per week

\begin{tabular}{|c|c|c|c|c|c|c|c|c|c|c|c|c|}
\hline \multirow[b]{2}{*}{ SACD activity } & \multicolumn{4}{|c|}{$\begin{array}{c}\text { Year } 1 \\
\text { (Spring 3rd grade) }\end{array}$} & \multicolumn{4}{|c|}{$\begin{array}{c}\text { Year } 2 \\
\text { (Spring 4th grade) }\end{array}$} & \multicolumn{4}{|c|}{$\begin{array}{c}\text { Year } 3 \\
\text { (Spring 5th grade) }\end{array}$} \\
\hline & $\begin{array}{r}\text { Treat- } \\
\text { ment }\end{array}$ & Control & Impact & $p$-value & $\begin{array}{r}\text { Treat- } \\
\text { ment }\end{array}$ & Control & Impact & $p$-value & $\begin{array}{l}\text { Treat- } \\
\text { ment }\end{array}$ & Control & Impact & $p$-value \\
\hline Teacher sample size & 63 & 73 & & & 50 & 67 & & & 51 & 64 & & \\
\hline $\begin{array}{l}\text { Violence prevention and peace promotion } \\
\text { (percent) }\end{array}$ & 25.2 & 18.4 & 6.7 & 0.381 & 21.8 & 24.9 & -3.2 & 0.735 & 8.6 & 13.4 & -4.8 & 0.537 \\
\hline $\begin{array}{l}\text { Social and emotional development } \\
\text { (percent) }\end{array}$ & 23.6 & 7.8 & 15.8 & 0.141 & 20.7 & 11.5 & 9.2 & 0.327 & 6.3 & 10.0 & -3.7 & 0.553 \\
\hline Character education (percent) & 21.9 & 13.6 & 8.3 & 0.420 & $25.4^{\wedge}$ & 8.9 & 16.5 & 0.073 & 7.2 & 9.3 & -2.1 & 0.767 \\
\hline Tolerance and diversity (percent) & 8.4 & 4.3 & 4.1 & 0.397 & $13.7^{\wedge}$ & 3.9 & 9.8 & 0.073 & $\ddagger$ & $\ddagger$ & -0.8 & 0.760 \\
\hline $\begin{array}{l}\text { Risk prevention and health promotion } \\
\text { (percent) }\end{array}$ & $13.3^{\wedge}$ & 29.1 & -15.7 & 0.088 & 15.8 & 25.5 & -9.7 & 0.464 & 5.3 & 7.3 & -2.0 & 0.706 \\
\hline $\begin{array}{l}\text { Civic responsibility and community service } \\
\text { (percent) }\end{array}$ & 5.3 & 3.5 & 1.8 & 0.690 & $\ddagger$ & $\ddagger$ & 2.9 & 0.348 & 4.1 & 0.0 & 4.1 & $\dagger$ \\
\hline Any named activity (percent) & 34.4 & 44.5 & -10.1 & 0.410 & 32.2 & 41.0 & -8.7 & 0.498 & 14.5 & 20.5 & -6.0 & 0.606 \\
\hline
\end{tabular}

\footnotetext{
$\dagger$ Not applicable.
}

‡ Reporting standards not met. Values suppressed to protect confidentiality.

* Treatment group significantly different from control group at the .05 level.

$\wedge$ Treatment group significantly different from control group at the .10 to $>.05$ level.

${ }^{1}$ In Year 1, the omnibus impact for all the outcomes measured together was positive and statistically significant on the basis of a multivariate statistical test

NOTE: Weights, which assign equal weight to each school within the program, were used in producing the treatment, control, and overall means. The number of results found significant was no more than expected by chance.

SOURCE: The Social and Character Development (SACD) Research Program. 


\section{Use of Materials and Strategies}

For use of materials and strategies to support SACD goals, 87 comparisons were made, with 4 expected to be significant by chance. A significant impact was found on treatment teachers' use of giveaways in Year 2 (impact $=31$ percentage points) (table 2.14). Regarding use of instructional techniques, significantly greater percentages of treatment teachers reported using journaling in Year 1 (impact $=17$ percentage points), behavior honor roll in Year 2 (impact $=32$ percentage points), and mentoring in Year 3 (impact $=17$ percentage points). No significant impact on the domain of materials and strategies was found in any year. 
Table 2.14. Impacts on use of SACD classroom materials and teaching strategies-ABC

\begin{tabular}{|c|c|c|c|c|c|c|c|c|c|c|c|c|}
\hline \multirow[b]{2}{*}{ SACD material and teaching strategy } & \multicolumn{4}{|c|}{$\begin{array}{c}\text { Year } 1 \\
\text { (Spring 3rd grade) }\end{array}$} & \multicolumn{4}{|c|}{$\begin{array}{c}\text { Year } 2 \\
\text { (Spring 4th grade) }\end{array}$} & \multicolumn{4}{|c|}{$\begin{array}{c}\text { Year } 3 \\
\text { (Spring 5th grade) }\end{array}$} \\
\hline & $\begin{array}{r}\text { Treat- } \\
\text { ment }\end{array}$ & Control & Impact & $p$-value & $\begin{array}{c}\text { Treat- } \\
\text { ment }\end{array}$ & Control & Impact & $p$-value & $\begin{array}{r}\text { Treat- } \\
\text { ment } \\
\end{array}$ & Control & Impact & $p$-value \\
\hline Teacher sample size & 63 & 73 & & & 50 & 67 & & & 51 & 64 & & \\
\hline \multicolumn{13}{|l|}{ Use of SACD materials (percent) } \\
\hline Teacher guides (manuals, curricula) & 57.9 & 64.4 & -6.5 & 0.578 & 57.7 & 64.7 & -7.0 & 0.528 & 50.6 & 47.8 & 2.8 & 0.796 \\
\hline Student materials (workbooks or sheets) & 49.6 & 63.1 & -13.5 & 0.295 & 57.3 & 68.0 & -10.6 & 0.261 & 51.8 & 51.3 & 0.5 & 0.957 \\
\hline Instructional aids (games, software, videos) & 38.3 & 43.6 & -5.3 & 0.644 & 37.0 & 31.2 & 5.8 & 0.581 & 26.9 & 29.9 & -3.0 & 0.768 \\
\hline Giveaways (bookmarks, stickers) & 58.4 & 51.9 & 6.5 & 0.571 & $77.3^{*}$ & 46.0 & 31.2 & 0.015 & $61.2^{\wedge}$ & 43.5 & 17.7 & 0.099 \\
\hline Children's literature & 62.6 & 47.0 & 15.6 & 0.138 & 58.2 & 50.4 & 7.8 & 0.518 & 48.5 & 38.8 & 9.7 & 0.420 \\
\hline Other types of materials & 6.5 & 10.0 & -3.5 & 0.563 & 10.9 & 11.4 & -0.5 & 0.937 & 10.4 & 11.1 & -0.6 & 0.924 \\
\hline Did not use any of these materials & 7.7 & 9.3 & -1.6 & 0.818 & $\ddagger$ & $\ddagger$ & -7.7 & 0.179 & 13.5 & 19.2 & -5.7 & 0.336 \\
\hline \multicolumn{13}{|l|}{ Use of teaching strategies (percent) } \\
\hline Role-playing & 77.3 & 76.3 & 1.0 & 0.941 & 84.8 & 74.1 & 10.7 & 0.316 & 77.9 & 71.5 & 6.4 & 0.489 \\
\hline Cooperative learning & 97.6 & 96.6 & 1.0 & 0.761 & 100.0 & 97.9 & 2.1 & $\dagger$ & 100.0 & 98.9 & 1.1 & $\dagger$ \\
\hline Peer group discussions & 85.5 & 89.6 & -4.1 & 0.513 & 85.0 & 89.9 & -4.9 & 0.554 & 94.9 & 87.6 & 7.3 & 0.190 \\
\hline Direct instruction of SACD & 82.1 & 78.9 & 3.2 & 0.755 & 79.7 & 67.5 & 12.2 & 0.471 & 90.4 & 81.7 & 8.7 & 0.287 \\
\hline Skill training & 44.9 & 50.5 & -5.6 & 0.685 & 47.7 & 37.4 & 10.3 & 0.395 & 66.3 & 59.7 & 6.5 & 0.437 \\
\hline $\begin{array}{l}\text { Incorporating SACD into academic } \\
\text { curriculum }\end{array}$ & 82.5 & 79.7 & 2.8 & 0.776 & 80.6 & 71.6 & 9.1 & 0.368 & 82.3 & 80.6 & 1.7 & 0.848 \\
\hline Parent training & 7.1 & 7.2 & -0.1 & 0.977 & 17.8 & 8.3 & 9.5 & 0.186 & 13.0 & 12.8 & 0.2 & 0.984 \\
\hline Parent and community involvement & 20.6 & 20.7 & -0.1 & 0.988 & 23.7 & 10.6 & 13.1 & 0.150 & 39.1 & 33.9 & 5.2 & 0.546 \\
\hline Mentoring & 39.1 & 41.6 & -2.6 & 0.814 & 46.5 & 39.9 & 6.7 & 0.518 & $59.9^{*}$ & 42.7 & 17.2 & 0.036 \\
\hline $\begin{array}{l}\text { Good behavior notes sent home daily } \\
\text { or weekly }\end{array}$ & $96.2^{\wedge}$ & 80.4 & 15.9 & 0.053 & $91.3^{\wedge}$ & 72.5 & 18.8 & 0.072 & 94.4 & 86.4 & 8.0 & 0.254 \\
\hline Presenting role models & 74.3 & 84.5 & -10.2 & 0.344 & $82.0^{\wedge}$ & 70.2 & 11.8 & 0.066 & 78.2 & 78.3 & -0.1 & 0.977 \\
\hline
\end{tabular}


Table 2.14. Impacts on use of SACD classroom materials and teaching strategies-ABC—Continued

\begin{tabular}{|c|c|c|c|c|c|c|c|c|c|c|c|c|}
\hline \multirow[b]{2}{*}{ SACD material and teaching strategy } & \multicolumn{4}{|c|}{$\begin{array}{c}\text { Year } 1 \\
\text { (Spring 3rd grade) } \\
\end{array}$} & \multicolumn{4}{|c|}{$\begin{array}{c}\text { Year } 2 \\
\text { (Spring 4th grade) }\end{array}$} & \multicolumn{4}{|c|}{$\begin{array}{c}\text { Year } 3 \\
\text { (Spring 5th grade) }\end{array}$} \\
\hline & $\begin{array}{r}\text { Treat- } \\
\text { ment }\end{array}$ & Control & Impact & $p$-value & $\begin{array}{r}\text { Treat- } \\
\text { ment }\end{array}$ & Control & Impact & $p$-value & $\begin{array}{r}\text { Treat- } \\
\text { ment }\end{array}$ & Control & Impact & p-value \\
\hline \multicolumn{13}{|l|}{$\begin{array}{l}\text { Use of teaching strategies (percent)- } \\
\text { Continued }\end{array}$} \\
\hline $\begin{array}{l}\text { Targeted story reading or writing on social } \\
\text { and character development themes }\end{array}$ & 80.4 & 76.2 & 4.3 & 0.656 & 79.2 & 77.2 & 2.0 & 0.825 & 87.7 & 80.7 & 7.0 & 0.278 \\
\hline Peer mediation & 35.7 & 47.8 & -12.1 & 0.170 & $52.9^{\wedge}$ & 34.5 & 18.4 & 0.071 & 62.0 & 51.7 & 10.3 & 0.278 \\
\hline Honor roll for positive behavior & 71.2 & 57.9 & 13.3 & 0.471 & $76.0^{*}$ & 43.8 & 32.1 & 0.037 & 79.0 & 65.9 & 13.1 & 0.259 \\
\hline $\begin{array}{l}\text { Pledges or recitations on social and } \\
\text { character development themes }\end{array}$ & 39.4 & 56.3 & -16.9 & 0.257 & 34.9 & 45.2 & -10.3 & 0.542 & 32.8 & 61.3 & -28.5 & 0.105 \\
\hline Guided visualization & 49.3 & 53.6 & -4.3 & 0.740 & 49.1 & 41.9 & 7.1 & 0.588 & 51.8 & 51.1 & 0.7 & 0.900 \\
\hline Student-led/student-assisted instruction & 60.2 & 50.9 & 9.3 & 0.218 & 53.4 & 47.8 & 5.6 & 0.491 & 65.7 & 54.2 & 11.5 & 0.306 \\
\hline Journaling & $90.4^{*}$ & 73.4 & 17.0 & 0.014 & 83.0 & 65.6 & 17.5 & 0.176 & 84.6 & 76.7 & 7.9 & 0.290 \\
\hline Time out for negative behavior & 78.4 & 82.6 & -4.3 & 0.725 & 78.9 & 73.1 & 5.8 & 0.458 & 90.6 & 82.9 & 7.7 & 0.408 \\
\hline $\begin{array}{l}\text { Daily or weekly rewards for positive } \\
\text { behavior }\end{array}$ & 97.1 & 93.7 & 3.3 & 0.441 & 95.0 & 88.4 & 6.6 & 0.297 & 100.0 & 94.4 & 5.6 & $\dagger$ \\
\hline Any strategy & 100.0 & 100.0 & $\dagger$ & $\dagger$ & 100.0 & 100.0 & 0.0 & $\dagger$ & 100.0 & 100.0 & 0.0 & $\dagger$ \\
\hline Number of strategies (mean) & 13.0 & 12.9 & 0.0 & 0.980 & 13.3 & 11.5 & 1.8 & 0.163 & 14.2 & 13.4 & 0.8 & 0.258 \\
\hline
\end{tabular}

$\dagger$ Not applicable

‡ Reporting standards not met. Values suppressed to protect confidentiality.

* Treatment group significantly different from control group at the .05 level.

$\wedge$ Treatment group significantly different from control group at the .10 to $>.05$ level.

NOTE: Weights, which assign equal weight to each school within the program, were used in producing the treatment, control, and overall means. The number of results found

significant was no more than expected by chance.

SOURCE: The Social and Character Development (SACD) Research Program. 
Regarding the use of schoolwide strategies, 18 comparisons were made between treatment and control teacher reports, with 1 expected to be significant by chance. In Year 1, a significantly greater percentage of treatment teachers reported that their schools used three of five specific schoolwide strategies (these data are not shown in a table): newspapers or bulletins (impact $=29$ percentage points), special school days (impact $=$ 16 percentage points), and special events (impact $=24$ percentage points). In Years 2 and 3, no significant impacts were found for the individual schoolwide strategies. ABC did have a significant impact on the domain of schoolwide strategies in Year 1.

\section{Participation in Professional Development}

Regarding reported participation in professional development, 27 comparisons were made over 3 years, with 1 expected to be significant by chance. In all 3 years, the intervention had no statistically significant effects on teachers' participation in professional development for activities related to social and character development overall or on training for specific SACD goals (table 2.15). No significant impacts were found on the domain in all 3 years. 
Table 2.15. Impacts on teacher-reported SACD professional development--ABC

\begin{tabular}{|c|c|c|c|c|c|c|c|c|c|c|c|c|}
\hline \multirow[b]{2}{*}{ SACD professional development } & \multicolumn{4}{|c|}{$\begin{array}{c}\text { Year } 1 \\
\text { (Spring 3rd grade) }\end{array}$} & \multicolumn{4}{|c|}{$\begin{array}{c}\text { Year } 2 \\
\text { (Spring 4th grade) }\end{array}$} & \multicolumn{4}{|c|}{$\begin{array}{c}\text { Year } 3 \\
\text { (Spring 5th grade) }\end{array}$} \\
\hline & $\begin{array}{r}\text { Treat- } \\
\text { ment }\end{array}$ & Control & Impact & $p$-value & $\begin{array}{r}\text { Treat- } \\
\text { ment }\end{array}$ & Control & Impact & $p$-value & $\begin{array}{r}\text { Treat- } \\
\text { ment }\end{array}$ & Control & Impact & $p$-value \\
\hline Teacher sample size & 63 & 73 & & & 50 & 67 & & & 51 & 64 & & \\
\hline SACD training in past 12 months (percent) & 77.3 & 61.9 & 15.3 & 0.293 & 51.4 & 46.8 & 4.6 & 0.713 & 40.4 & 37.9 & 2.5 & 0.799 \\
\hline Hours of SACD training (mean) & 9.8 & 8.3 & 1.4 & 0.682 & 7.4 & 7.2 & 0.2 & 0.993 & 2.5 & 2.6 & -0.2 & 0.854 \\
\hline \multicolumn{13}{|l|}{ Training by goal (percent) } \\
\hline Violence prevention and peace promotion & 13.8 & 27.7 & -13.9 & 0.154 & 17.9 & 14.6 & 3.2 & 0.732 & 13.1 & 8.4 & 4.7 & 0.578 \\
\hline Social and emotional development & 23.6 & 27.4 & -3.8 & 0.751 & 14.3 & 14.6 & -0.4 & 0.966 & $\ddagger$ & $\ddagger$ & -6.2 & 0.251 \\
\hline Character education & 33.7 & 39.3 & -5.6 & 0.691 & 16.2 & 19.6 & -3.4 & 0.694 & 9.1 & 14.3 & -5.2 & 0.464 \\
\hline Tolerance and diversity & 9.1 & 19.4 & -10.3 & 0.223 & 13.3 & 19.0 & -5.6 & 0.505 & $\ddagger$ & $\ddagger$ & 1.6 & 0.749 \\
\hline Risk prevention and health promotion & 6.5 & 16.6 & -10.1 & 0.110 & 10.3 & 5.5 & 4.8 & 0.321 & 13.9 & 4.3 & 9.6 & 0.164 \\
\hline Civic responsibility and community service & 6.5 & 4.4 & 2.1 & 0.679 & 10.6 & 6.1 & 4.6 & 0.440 & $\ddagger$ & $\ddagger$ & 0.7 & 0.794 \\
\hline Behavior management & 53.6 & 31.6 & 21.9 & 0.211 & 28.6 & 25.6 & 3.0 & 0.829 & 16.9 & 20.0 & -3.2 & 0.704 \\
\hline
\end{tabular}

$\ddagger$ Reporting standards not met. Values suppressed to protect confidentiality.

NOTE: No findings were found statistically significant at or below the .05 level. Weights, which assign equal weight to each school within the program, were used in producing the treatment, control, and overall means.

SOURCE: The Social and Character Development (SACD) Research Program. 


\section{Attitudes and Practices}

Teachers reported on their enthusiasm for SACD efforts in their schools (these data are not shown in a table) by indicating enthusiasm, cooperation, or open dislike. They also reported on the SACD practices of teachers and staff members in their schools (these data are not shown in a table). These practices included modeling positive character and behavior traits with students and fellow teachers, involving students in making decisions, giving students a voice in school governance, the school encouraging parent involvement in children's social and character development, and using developmentally appropriate discipline strategies rather than punishment for misbehavior. In each year, 9 comparisons were made between treatment and control teachers on attitudes and practices ( 27 total), with 1 expected to be significant by chance. In Year 1 there was a statistically significant negative impact on enthusiasm (impact $=-5$ percentage points). There were significant positive impacts on encouraging parent involvement in Years 2 and 3 (impact $=20$ and 37 percentage points) and on developmentally appropriate discipline strategies in Year 2 (impact $=26$ percentage points). $\mathrm{ABC}$ had a significant positive effect on the domain in Year 3.

\section{Year-by-Year Impacts on Students and Perceptions of School Climate}

The primary research question for the $\mathrm{ABC}$ evaluation was this:

What is the average effect of the $\mathrm{ABC}$ program on children's social and emotional competence, behavior, academics, and perceptions of school climate?

The first approach to answering this question was to examine the year-by-year impacts of $\mathrm{ABC}$ on these student and school climate outcomes over the 3 years as the students progressed from third through fifth grades.

Equation (2) (described in chapter 1) was estimated to provide ABC's impacts on the 20 outcomes based on data from the 12 treatment and control schools. For the $\mathrm{ABC}$ evaluation, equation (2) excluded the program fixed effects $\left(\theta_{p}\right)$ and included program-specific covariates and random school effects covariates. Table 2.16 lists the covariates used with outcomes from each report in the $\mathrm{ABC}$ analysis. 
Table 2.16. Covariates used with outcomes from each report for analysis-ABC

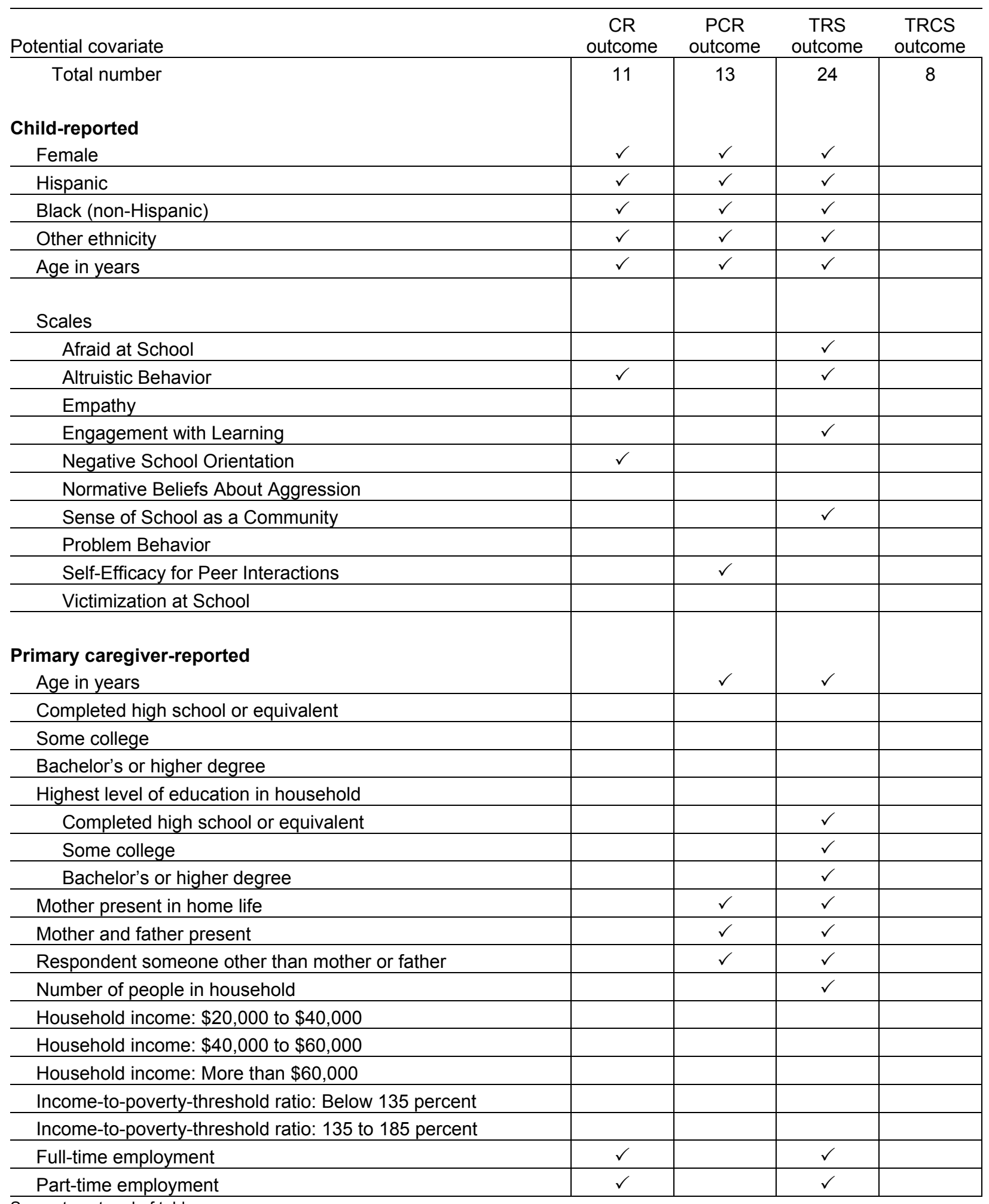

See notes at end of table. 
Table 2.16. Covariates used with outcomes from each report for analysis-ABC-Continued

\begin{tabular}{|c|c|c|c|c|}
\hline Potential covariate & $\begin{array}{c}\text { CR } \\
\text { outcome }\end{array}$ & $\begin{array}{c}\text { PCR } \\
\text { outcome }\end{array}$ & $\begin{array}{c}\text { TRS } \\
\text { outcome }\end{array}$ & $\begin{array}{c}\text { TRCS } \\
\text { outcome }\end{array}$ \\
\hline \multicolumn{5}{|l|}{ Parental scales } \\
\hline APQ-Poor Monitoring and Supervision Subscale & $\checkmark$ & $\checkmark$ & $\checkmark$ & \\
\hline \multicolumn{5}{|l|}{ APQ-Positive Parenting Subscale } \\
\hline \multicolumn{5}{|l|}{ Child-Centered Social Control } \\
\hline Confusion, Hubbub, and Order & & $\checkmark$ & $\checkmark$ & \\
\hline \multicolumn{5}{|l|}{ Community Resources } \\
\hline \multicolumn{5}{|l|}{ Community Risk } \\
\hline \multicolumn{5}{|l|}{ Parent and Teacher Involvement } \\
\hline \multicolumn{5}{|l|}{ Child scales } \\
\hline \multicolumn{5}{|l|}{ Altruistic Behavior } \\
\hline Positive Social Behavior & $\checkmark$ & $\checkmark$ & $\checkmark$ & \\
\hline \multicolumn{5}{|l|}{ Problem Behavior } \\
\hline \multicolumn{5}{|l|}{ Teacher-reported } \\
\hline Hispanic & & & & $\checkmark$ \\
\hline Black (non-Hispanic) & & & & $\checkmark$ \\
\hline Other ethnicity & & & & $\checkmark$ \\
\hline Total teaching experience & & & & $\checkmark$ \\
\hline \multicolumn{5}{|l|}{ Total experience in current school } \\
\hline Regular certificate & & & & $\checkmark$ \\
\hline Other certificate & & & & $\checkmark$ \\
\hline Highest degree-bachelor's & & & & $\checkmark$ \\
\hline \multicolumn{5}{|l|}{ Child scales } \\
\hline \multicolumn{5}{|l|}{ Academic Competence and Motivation } \\
\hline \multicolumn{5}{|l|}{ ADHD-Related Behavior } \\
\hline \multicolumn{5}{|l|}{ Altruistic Behavior } \\
\hline \multicolumn{5}{|l|}{ Positive Social Behavior } \\
\hline Problem Behavior & & & $\checkmark$ & \\
\hline \multicolumn{5}{|l|}{ Parent and Teacher Involvement } \\
\hline \multicolumn{5}{|l|}{ NOTE: Abbreviations are } \\
\hline \multicolumn{5}{|l|}{ CR: Child Report } \\
\hline \multicolumn{5}{|l|}{ PCR: Primary Caregiver Report } \\
\hline \multicolumn{5}{|l|}{ TRS: Teacher Report on Student } \\
\hline \multicolumn{5}{|l|}{ TRCS: Teacher Report on Classroom and School } \\
\hline \multicolumn{5}{|l|}{ ADHD: Attention deficit hyperactivity disorder } \\
\hline \multicolumn{5}{|l|}{ APQ: Alabama Parenting Questionnaire } \\
\hline \multicolumn{5}{|l|}{$\checkmark:$ Covariate used } \\
\hline \multicolumn{5}{|l|}{ Blank cell: Covariate not used } \\
\hline SOURCE: The Social and Character Develc & & & & \\
\hline
\end{tabular}




\section{Chapter 2. Academic and Behavioral Competencies Program}

To assess the statistical power of the program-level impact estimates, minimum detectable impacts in effect size units (MDES) for each outcome measure were calculated for the ABC evaluation (table 2.17). MDES represent the smallest impacts in effect size (standard deviation) units that can be detected with a high probability (80\%). MDES are primarily a function of study sample sizes, the degrees of freedom available for statistical tests, and design effects due to clustering (Schochet 2005). For the ABC evaluation, the MDES ranged from 0.110 to 0.551 for the child-level outcomes and from 0.396 to 0.629 for the perception of school climate outcomes based on the Teacher Report on Classroom and School. In general, the MDES for the school climate outcomes were larger than those for the child-level outcomes. 
Table 2.17. Adjusted minimum detectable effect sizes for impact evaluation--ABC

\begin{tabular}{|c|c|c|c|}
\hline Outcome measure-Report & Year 1 & Year 2 & Year 3 \\
\hline \multicolumn{4}{|l|}{ Social and Emotional Competence Domain } \\
\hline Self-Efficacy for Peer Interaction-CR & 0.110 & 0.130 & 0.173 \\
\hline Normative Beliefs About Aggression-CR & 0.159 & 0.159 & 0.315 \\
\hline Empathy-CR & 0.133 & 0.225 & 0.262 \\
\hline \multicolumn{4}{|l|}{ Behavior Domain } \\
\hline Altruistic Behavior-CR & 0.155 & 0.110 & 0.124 \\
\hline Altruistic Behavior-PCR & 0.189 & 0.170 & 0.236 \\
\hline Altruistic Behavior-TRS & 0.214 & 0.551 & 0.353 \\
\hline Positive Social Behavior-PCR & 0.166 & 0.148 & 0.130 \\
\hline Positive Social Behavior-TRS & 0.190 & 0.423 & 0.381 \\
\hline Problem Behavior-CR & 0.221 & 0.184 & 0.244 \\
\hline Problem Behavior-PCR & 0.231 & 0.167 & 0.143 \\
\hline Problem Behavior-TRS & 0.297 & 0.295 & 0.304 \\
\hline ADHD-Related Behavior-TRS & 0.297 & 0.381 & 0.402 \\
\hline \multicolumn{4}{|l|}{ Academics Domain } \\
\hline Engagement with Learning-CR & 0.181 & 0.110 & 0.175 \\
\hline Academic Competence and Motivation-TRS & 0.149 & 0.189 & 0.320 \\
\hline \multicolumn{4}{|l|}{ Perceptions of School Climate Domain } \\
\hline Positive School Orientation-CR & 0.163 & 0.311 & 0.320 \\
\hline Negative School Orientation-CR & 0.110 & 0.189 & 0.286 \\
\hline Student Afraid at School-CR & 0.242 & 0.240 & 0.243 \\
\hline Victimization at School-CR & 0.156 & 0.110 & 0.211 \\
\hline Feelings of Safety-TRCS & 0.491 & 0.396 & 0.586 \\
\hline Student Support for Teachers-TRCS & 0.474 & 0.474 & 0.629 \\
\hline
\end{tabular}

NOTE: Abbreviations are

CR: Child Report

PCR: Primary Caregiver Report

TRS: Teacher Report on Student

TRCS: Teacher Report on Classroom and School

ADHD: Attention deficit hyperactivity disorder

The minimum detectable effect (MDE) formula used in the calculations is as follows:

$M D E=\operatorname{factor}(d f) * \sqrt{\rho_{1}\left(\frac{1}{s_{T}}+\frac{1}{s_{C}}\right)+\left(1-\rho_{1}\right)\left(\frac{1}{s_{T} n_{T}}+\frac{1}{s_{C} n_{C}}\right)}$

where $s_{T}$ and $s_{C}$ are the number of treatment and comparison schools; $n_{T}$ and $n_{C}$ are the average number of students per classroom; $\rho_{1}$ is the intraclass correlation (ICC) at the school level; and factor(df) is a constant that depends on the number of degrees of freedom ( $d f$ ) available for analysis (and is 2.802 for the pooled analysis).

SOURCE: The Social and Character Development (SACD) Research Program. 
Table 2.18 provides the estimates of ABC's impacts on each of the 20 outcomes over each of the 3 years (60 comparisons in total, with 3 expected to be statistically significant by chance). Of the 60 results, 5 were statistically significant, with 4 having beneficial impacts. ABC had a significant positive impact on thirdgraders' Altruistic Behavior (Teacher Report on Student, effect size [ES] = 0.39); on fourth-graders' Academic Competence and Motivation (Teacher Report on Student, ES = 0.31) and Feelings of Safety (Teacher Report on Classroom and School, ES = 0.75); and on fifth-graders' Positive Social Behavior (Primary Caregiver Report, ES = 0.21). A negative impact was found on fourth-graders' Altruistic Behavior (Child Report, ES $=-0.20$ ). ABC had two beneficial impacts that were substantively important but not statistically significant: (1) on fourth-graders' Student Support for Teachers (Teacher Report on Classroom and School, ES = 0.27) and (2) on fifth-graders' Feelings of Safety (Teacher Report on Classroom and School, ES = 0.31). Application of the heuristics to adjust for multiple comparisons within each outcome domain indicated significant beneficial impacts on the domains of Academics and Perceptions of School Climate in Year 2. 
Table 2.18. Impacts on child and school outcomes-ABC

\begin{tabular}{|c|c|c|c|c|c|c|c|c|c|c|c|c|}
\hline \multirow[b]{2}{*}{ Scale-Report } & \multicolumn{4}{|c|}{$\begin{array}{c}\text { Year } 1 \\
\text { (Spring 3rd grade) }\end{array}$} & \multicolumn{4}{|c|}{$\begin{array}{c}\text { Year } 2 \\
\text { (Spring 4th grade) }\end{array}$} & \multicolumn{4}{|c|}{$\begin{array}{c}\text { Year } 3 \\
\text { (Spring 5th grade) }\end{array}$} \\
\hline & $\begin{array}{r}\text { Treat- } \\
\text { ment }\end{array}$ & Control & $\begin{array}{r}\text { Effect } \\
\text { size }\end{array}$ & $p$-value & $\begin{array}{r}\text { Treat- } \\
\text { ment }\end{array}$ & Control & $\begin{array}{r}\text { Effect } \\
\text { size }\end{array}$ & $p$-value & $\begin{array}{r}\text { Treat- } \\
\text { ment }\end{array}$ & Control & $\begin{array}{r}\text { Effect } \\
\text { size }\end{array}$ & $p$-value \\
\hline \multicolumn{13}{|l|}{ Social and Emotional Competence Domain } \\
\hline Self-Efficacy for Peer Interactions-CR (+) & 3.15 & 3.11 & 0.06 & 0.464 & 3.31 & 3.29 & 0.03 & 0.770 & 3.31 & 3.23 & 0.11 & 0.315 \\
\hline Normative Beliefs About Aggression-CR (-) & 1.35 & 1.30 & 0.09 & 0.440 & 1.39 & 1.29 & 0.18 & 0.141 & 1.51 & 1.51 & 0.00 & 0.981 \\
\hline Empathy-CR (+) & 2.27 & 2.26 & 0.02 & 0.823 & 2.08 & 2.19 & -0.21 & 0.144 & 2.00 & 2.01 & -0.03 & 0.859 \\
\hline \multicolumn{13}{|l|}{ Behavior Domain } \\
\hline Altruistic Behavior-CR (+) & 1.29 & 1.35 & -0.07 & 0.449 & $0.94^{*}$ & 1.09 & -0.20 & 0.029 & 1.01 & 0.98 & 0.04 & 0.656 \\
\hline Altruistic Behavior-PCR (+) & 2.25 & 2.15 & 0.15 & 0.249 & 2.14 & 2.19 & -0.06 & 0.595 & 2.28 & 2.32 & -0.04 & 0.767 \\
\hline Altruistic Behavior-TRS (+) & $1.44^{*}$ & 1.29 & 0.39 & 0.026 & 1.24 & 1.26 & -0.03 & 0.914 & 1.21 & 1.22 & -0.05 & 0.789 \\
\hline Positive Social Behavior-PCR (+) & 2.96 & 2.96 & 0.00 & 0.993 & $3.06^{\wedge}$ & 2.96 & 0.16 & 0.071 & $3.06^{*}$ & 2.94 & 0.21 & 0.041 \\
\hline Positive Social Behavior-TRS (+) & 2.90 & 2.89 & 0.02 & 0.800 & 3.01 & 3.02 & -0.01 & 0.962 & 3.03 & 3.16 & -0.19 & 0.406 \\
\hline Problem Behavior-CR (-) & 0.36 & 0.34 & 0.04 & 0.713 & 0.33 & 0.36 & -0.05 & 0.659 & 0.51 & 0.53 & -0.03 & 0.812 \\
\hline Problem Behavior-PCR (-) & 1.60 & 1.60 & 0.00 & 0.976 & 1.56 & 1.61 & -0.11 & 0.229 & 1.58 & 1.61 & -0.08 & 0.465 \\
\hline Problem Behavior-TRS (-) & 1.53 & 1.52 & 0.03 & 0.850 & 1.43 & 1.46 & -0.07 & 0.655 & 1.54 & 1.44 & 0.21 & 0.262 \\
\hline ADHD-Related Behavior-TRS (-) & 1.84 & 1.85 & -0.01 & 0.958 & 1.69 & 1.77 & -0.13 & 0.525 & 1.72 & 1.62 & 0.17 & 0.447 \\
\hline \multicolumn{13}{|l|}{ Academics Domain ${ }^{1}$} \\
\hline Engagement with Learning-CR (+) & 3.61 & 3.61 & 0.00 & 0.986 & 3.68 & 3.63 & 0.10 & 0.281 & 3.58 & 3.58 & 0.00 & 0.964 \\
\hline $\begin{array}{l}\text { Academic Competence and Motivation- } \\
\text { TRS }(+)\end{array}$ & 2.81 & 2.79 & 0.03 & 0.719 & $2.92^{*}$ & 2.65 & 0.31 & 0.011 & 2.76 & 2.77 & -0.02 & 0.924 \\
\hline
\end{tabular}

See notes at end of table. 


\section{Table 2.18. Impacts on child and school outcomes-ABC—Continued}

\begin{tabular}{|c|c|c|c|c|c|c|c|c|c|c|c|c|}
\hline \multirow[b]{2}{*}{ Scale-Report } & \multicolumn{4}{|c|}{$\begin{array}{c}\text { Year } 1 \\
\text { (Spring 3rd grade) }\end{array}$} & \multicolumn{4}{|c|}{$\begin{array}{c}\text { Year } 2 \\
\text { (Spring 4th grade) }\end{array}$} & \multicolumn{4}{|c|}{$\begin{array}{c}\text { Year } 3 \\
\text { (Spring 5th grade) }\end{array}$} \\
\hline & $\begin{array}{c}\text { Treat- } \\
\text { ment }\end{array}$ & Control & $\begin{array}{r}\text { Effect } \\
\text { size }\end{array}$ & $p$-value & $\begin{array}{c}\text { Treat- } \\
\text { ment }\end{array}$ & Control & $\begin{array}{c}\text { Effect } \\
\text { size }\end{array}$ & $p$-value & $\begin{array}{c}\text { Treat- } \\
\text { ment }\end{array}$ & Control & $\begin{array}{c}\text { Effect } \\
\text { size }\end{array}$ & $p$-value \\
\hline \multicolumn{13}{|l|}{ Perceptions of School Climate Domain ${ }^{2}$} \\
\hline Positive School Orientation-CR (+) & 2.82 & 2.94 & -0.17 & 0.143 & 2.67 & 2.61 & 0.07 & 0.668 & 2.41 & 2.45 & -0.05 & 0.773 \\
\hline Negative School Orientation-CR (-) & 1.94 & 1.85 & 0.16 & 0.108 & 1.97 & 1.96 & 0.01 & 0.963 & 2.16 & 2.12 & 0.07 & 0.680 \\
\hline Student Afraid at School-CR (-) & 2.23 & 2.28 & -0.06 & 0.707 & 2.21 & 2.36 & -0.17 & 0.263 & 2.19 & 2.35 & -0.19 & 0.218 \\
\hline Victimization at School-CR (-) & 0.74 & 0.81 & -0.08 & 0.417 & 0.58 & 0.66 & -0.11 & 0.213 & 0.66 & 0.82 & -0.19 & 0.151 \\
\hline Feelings of Safety-TRCS (+) & 3.42 & 3.25 & 0.21 & 0.353 & $3.59^{*}$ & 2.97 & 0.75 & 0.003 & 3.29 & 3.03 & $0.31^{\circ}$ & 0.235 \\
\hline Student Support for Teachers-TRCS (+) & 3.27 & 3.28 & 0.00 & 0.979 & 3.48 & 3.26 & $0.27^{\circ}$ & 0.276 & 3.25 & 3.21 & 0.05 & 0.847 \\
\hline
\end{tabular}

* Treatment group significantly different from control group at the .05 level.

$\wedge$ Treatment group significantly different from control group at the .10 to $>.05$ level.

${ }^{\circ}$ Substantive (but nonsignificant at .05 level) effect size of $\geq .25$ or $\leq-.25$.

1 In Year 2, at least half of the impacts were positive and statistically significant and no impact was negative and statistically significant based on univariate statistical tests. In addition, at least one outcome remained positive and statistically significant and no outcome was negative and statistically significant after applying the Benjamini-Hochberg (1995) procedure to adjust significance levels downward to account for the multiple testing of impacts.

${ }^{2}$ In Year 2, at least one outcome remained positive and statistically significant and no outcome was negative and statistically significant after applying the Benjamini-Hochberg (1995) procedure to adjust significance levels downward to account for the multiple testing of impacts.

NOTE: Abbreviations are

CR: Child Report

PCR: Primary Caregiver Report

TRS: Teacher Report on Student

TRCS: Teacher Report on Classroom and School

ADHD: Attention deficit hyperactivity disorder

The +/- signs in parentheses indicate the direction of a beneficial outcome. All Impact estimates were calculated using regression models, where each program and school within a program was weighted equally. The standard errors of all estimates account for design effects due to unequal weighting and the clustering of students within schools. The effect size was calculated by dividing the estimated Impact by the standard deviation of the outcome measure for the control group. See table 1.5 for information about the measures used to create the outcome variables.

SOURCE: The Social and Character Development (SACD) Research Program. 


\section{Impacts on Child Outcomes Over Time}

$\mathrm{ABC}$ impacts on the child outcomes over time were estimated using growth curve models by examining treatment and control group differences in the trajectories of student outcomes during the follow-up period while accounting for clustering at the school level. The growth curve models are estimated using a three-level hierarchical linear model, where Level 1 corresponds to time, Level 2 to students, and Level 3 to schools (described in chapter 1).

Table 2.19 provides the estimates of the $\mathrm{ABC}$ impacts on the growth in student outcomes over the 3 years. The estimated impacts range in effect size units (absolute value) from 0.01 to 0.12 . ABC did not have a statistically significant effect on any of the 18 estimated impacts ( 1 is expected to be significant by chance). 
Table 2.19. Impacts on growth of child outcomes-ABC

\begin{tabular}{|c|c|c|c|c|c|c|c|}
\hline \multirow[b]{2}{*}{ Scale-Report } & \multirow[b]{2}{*}{$\begin{array}{r}\text { Mean score at } \\
\text { implementation }\end{array}$} & \multicolumn{6}{|c|}{ Average growth in the score per year ${ }^{1}$} \\
\hline & & Treatment & Control & $\begin{array}{l}\text { Impact on } \\
\text { growth }^{3}\end{array}$ & $\begin{array}{c}\text { Effect } \\
\text { size }^{4}\end{array}$ & $\begin{array}{r}\text { Standard } \\
\text { error of } \\
\text { impact }\end{array}$ & $\begin{array}{r}p \text {-value of } \\
\text { impact }\end{array}$ \\
\hline \multicolumn{8}{|l|}{ Social and Emotional Competence Domain } \\
\hline Self-Efficacy for Peer Interactions-CR (+) & 3.05 & 0.13 & 0.07 & 0.06 & 0.07 & 0.03 & 0.116 \\
\hline Normative Beliefs About Aggression-CR (-) & 1.28 & $0.10^{\wedge}$ & 0.02 & 0.08 & 0.12 & 0.04 & 0.078 \\
\hline Empathy-CR (+) & 2.35 & $-0.15^{\wedge}$ & -0.10 & -0.05 & -0.11 & 0.03 & 0.096 \\
\hline \multicolumn{8}{|l|}{ Behavior Domain } \\
\hline Altruistic Behavior-CR (+) & 1.47 & -0.20 & -0.21 & 0.01 & 0.01 & 0.05 & 0.908 \\
\hline Altruistic Behavior-PCR (+) & 2.29 & -0.04 & -0.02 & -0.02 & -0.02 & 0.04 & 0.654 \\
\hline Altruistic Behavior-TRS (+) & 1.33 & -0.06 & -0.01 & -0.05 & -0.10 & 0.05 & 0.325 \\
\hline Positive Social Behavior-PCR (+) & 2.91 & $0.05^{\wedge}$ & 0.00 & 0.05 & 0.08 & 0.03 & 0.097 \\
\hline Positive Social Behavior-TRS (+) & 2.89 & 0.05 & 0.11 & -0.07 & -0.08 & 0.06 & 0.293 \\
\hline Problem Behavior-CR (-) & 0.29 & 0.08 & 0.06 & 0.02 & 0.04 & 0.03 & 0.451 \\
\hline Problem Behavior-PCR (-) & 1.63 & -0.01 & 0.00 & -0.01 & -0.02 & 0.02 & 0.611 \\
\hline Problem Behavior-TRS (-) & 1.45 & $0.05^{\wedge}$ & -0.01 & 0.06 & 0.11 & 0.03 & 0.057 \\
\hline ADHD-Related Behavior-TRS (-) & 1.84 & -0.06 & -0.05 & 0.00 & -0.01 & 0.06 & 0.935 \\
\hline \multicolumn{8}{|l|}{ Academics Domain } \\
\hline Engagement with Learning-CR (+) & 3.64 & -0.02 & -0.01 & -0.01 & -0.01 & 0.04 & 0.835 \\
\hline Academic Competence and Motivation-TRS (+) & 2.70 & 0.02 & 0.01 & 0.01 & 0.01 & 0.05 & 0.858 \\
\hline
\end{tabular}
See notes at end of table. 
Table 2.19. Impacts on growth of child outcomes-ABC-Continued

\begin{tabular}{|c|c|c|c|c|c|c|c|}
\hline \multirow[b]{2}{*}{ Scale-Report } & \multirow[b]{2}{*}{$\begin{array}{l}\text { Mean score at } \\
\text { implementation }^{2}\end{array}$} & \multicolumn{6}{|c|}{ Average growth in the score per year ${ }^{1}$} \\
\hline & & Treatment & Control & $\begin{array}{r}\text { Impact on } \\
\text { growth }^{3}\end{array}$ & $\begin{array}{c}\text { Effect } \\
\text { size }^{4}\end{array}$ & $\begin{array}{r}\text { Standard } \\
\text { error of } \\
\text { impact }\end{array}$ & $\begin{array}{r}p \text {-value of } \\
\text { impact }\end{array}$ \\
\hline \multicolumn{8}{|l|}{ Perceptions of School Climate Domain } \\
\hline Positive School Orientation-CR (+) & 3.12 & -0.27 & -0.22 & -0.05 & -0.06 & 0.05 & 0.343 \\
\hline Negative School Orientation-CR (-) & 1.85 & 0.09 & 0.07 & 0.02 & 0.02 & 0.05 & 0.691 \\
\hline Student Afraid at School-CR (-) & 2.29 & -0.02 & 0.02 & -0.04 & -0.04 & 0.06 & 0.484 \\
\hline Victimization at School-CR (-) & 0.74 & -0.03 & 0.01 & -0.05 & -0.05 & 0.04 & 0.248 \\
\hline
\end{tabular}

$\wedge$ Treatment group significantly different from control group at the .10 to $>.05$ level.

${ }^{1}$ Pertains to the estimated slope of the outcome for the treatment or control groups.

${ }^{2}$ The average score at implementation is calculated across treatment and control groups, using regression models for adjustment on covariates.

${ }^{3}$ Estimated difference between the slope of the treatment and control groups.

${ }^{4}$ Effect size: the slope of the treatment group minus the slope of the control group divided by the standard deviation of the outcome for the program's control group (the standard deviation is calculated without accounting for school-level clustering or regression adjustments).

NOTE: Abbreviations are

CR: Child Report

PCR: Primary Caregiver Report

TRS: Teacher Report on Student

ADHD: Attention deficit hyperactivity disorder

No findings were found statistically significant at or below the .05 level. The $+/$ - signs in parentheses indicate the direction of a beneficial outcome. All Impact estimates were calculated using HLM 6.06. Sample weights were used in all analyses to give (1) each school equal weight in each program (within each time period) and (2) each time period equal weight within the analysis. See table 1.5 for information about the measures used to create the outcome variables.

SOURCE: The Social and Character Development (SACD) Research Program. 


\section{Chapter 2. Academic and Behavioral Competencies Program}

\section{Summary}

As part of the Social and Character Development (SACD) initiative, researchers at the Buffalo site implemented and evaluated the ABC program, which consists of multiple components related to classroom behavior management and teaching and promoting social skills. Twelve public schools in three school districts in upstate New York were recruited by the Buffalo research team and randomly assigned to treatment and control conditions to determine the impact of $\mathrm{ABC}$ on social and character development activities in the schools and on the child outcome domains of Social and Emotional Competence, Behavior, Academics, and Perceptions of School Climate.

Analyses of the initial characteristics of the sample (students, caregivers, communities, teachers, and schools) indicated that randomization to treatment and control status produced groups that were similar on the observed characteristics near the start of the study (none of the comparisons were statistically significantly different). Documentation of the initial level of social and character development activities in the schools revealed six differences between the treatment and control teachers and classrooms, more than would be expected by chance.

The data on the initial level of SACD activity led to two findings. First, treatment teachers reported greater use of and training in SACD activities than did control teachers, and they did so more often than would be expected by chance. There are two potential causes for this finding, and the analysis cannot be used to determine whether the reason for such a difference was that the two groups did differ on their initial use of SACD activities (i.e., that randomization did not create similar treatment and control groups) or the fact that the training of all treatment teachers and the implementation of the program before the initial data were collected influenced the teacher reports (program implementation began at the treatment schools on average 6 weeks before the fall 2004 data collection occurred). Because it is likely (though unproven) that the training and implementation affected the teacher reports, these data were not considered appropriate for use as a baseline measure of SACD activities and training in the treatment schools.

Second, these data indicated that the control condition for the SACD project was not a "no treatment" control but a "standard practice" control. Because the control teachers were not affected by the implementation of the SACD programs before data collection, their reports reflect standard practice in the control schools. Standard practice at the control schools included reports of 55 percent to 88 percent of teachers using SACD activities, 88 percent of teachers reporting the use of specific materials in conjunction with these activities, 100 percent reporting the use of at least one of the specified instructional strategies, and 71 percent reporting participation in SACD training over the past 12 months.

Analyses of $\mathrm{ABC}$ impacts on the use of SACD activities in the schools revealed few differences between treatment and control schools. Five of the 90 program impacts on SACD activities, 4 of the 87 impacts on SACD materials and strategies, 3 of the 18 impacts on schoolwide strategies, and 4 of the 27 impacts on attitudes and practices (1 negative) were statistically significant. No impacts on professional development were found in any of the years.

Of the 20 child-level outcomes representing the four domains of Social and Emotional Competence, Behavior, Academics, and Perceptions of School Climate assessed in each of the 3 years of the study (a total of 60 results), 5 were statistically significant. One of these 5 was a detrimental impact and 4 were beneficial impacts. There were no effects of the $\mathrm{ABC}$ program over time as assessed using growth curve models.

The SACD evaluation did not find evidence to support the hypothesis that the ABC program had beneficial impacts on students' social and character development. These results could have been due to the inability of the program to cause such change, possibly because the theory of action was incomplete or because the activities to carry out that theory were not effective. 


\section{Chapter 2. Academic and Behavioral Competencies Program}

These results may also be due to the inability of the evaluation to observe such an impact due to the control condition, the level of nonparticipation, or the sample size. The control schools continued using their standard SACD activities, and these turned out to be high in quantity and broad in scope. New York passed the Safe Schools Against Violence in Education Act of 2001 to encourage districts to promote instruction in civility, citizenship, and character education, and this may have been a factor in high SACD activity in the control schools. The high level of control school activity, combined with relatively few significant impacts by the ABC program on the use of SACD activities in the treatment schools, may have caused the resulting difference in the amount of SACD activities between the treatment and control schools to be too small to cause significant differences in the student outcomes. In addition, about one-third of the students in the sample universe did not take part because of nonconsent or noncompletion of the surveys. As a determination could not be made as to whether these students significantly differed from those who did take part, the evaluation's results are valid only for the students who took part. If the students not taking part were different, and if they would have responded better to the ABC program than to the SACD activities occurring in the control schools, then the evaluation could have underestimated the program's impact. Also, the sample size of 12 schools and the resulting higher MDES compared to those for the multiprogram evaluation may have reduced the likelihood of detecting statistically significant effects. However, it should be noted that 58 percent of the MDES for the 60 outcomes used in the year-by-year analysis were below 0.25 (47\% were below 0.20 ). In addition, only 2 of the 60 outcomes were found to be substantively important. 
This page is intentionally blank. 


\title{
Chapter 3. Competence Support Program
}

\author{
University of North Carolina at Chapel Hill \\ (North Carolina Site)
}

\section{Intervention}

Researchers at the University of North Carolina at Chapel Hill (North Carolina site) implemented and evaluated the Competence Support Program (CSP). The program, developed at the School of Social Work at the University of North Carolina at Chapel Hill, is a combination of three programs: the Making Choices program (Fraser et al. 2000), the Competence Enhancement Behavior Management program (Farmer et al. 2006), and the Social Dynamics Training program (Farmer 2000). It is a universal, classroom-level intervention that functions as an add-on curriculum made up of scripted lessons and training for teachers in behavior management and social dynamics. Table 3.1 describes CSP's general characteristics (panel 1), the types of instruction and strategies used (panel 2), the professional development provided for those implementing the program (panel 3), and the social and character development activities (panel 4) and outcomes (panel 5) addressed by the program.

- In the third grade, the Making Choices curriculum consists of 28 scripted lessons that focus on social problem solving and involve learning about emotions and feelings, identifying social cues, making sense of social cues, setting social goals, choosing options, making choices, and acting on choices. The third grade is considered a keystone year. In the first and second grades, the Making Choices curriculum includes eight scripted lessons per year that prepare children for the third-grade program and focus on emotions and simple emotion regulation techniques (e.g., stop and think). In the fourth and fifth grades, the program consists of eight scripted lessons per year that focus on the application of problem-solving skills to routine peer situations (e.g., social aggression and bullying). Across all grades, teachers engage students by using a variety of learning strategies_-story reading, discussion, role-playing, worksheets, art projects, and games. Lessons are designed to last approximately 45 minutes.

- The Competence Enhancement Behavior Management component is an in-service training and direct consultation program for teachers and is developed from evidenced-based behavioral and ecological best practices for promoting positive classroom behavior. It includes training in establishing proactive behavior management aims and goals, establishing productive classroom routines and structures, teaching and reinforcing alternative behaviors, building supportive relationships, communicating with troubled students, using constructive discipline and natural consequences, and preventing and managing behavioral crises.

- Social Dynamics Training is an in-service teacher training and consultation model that includes training teachers to recognize the influence of peer social structures on students' behavior and to manage classroom social dynamics. Teachers are trained to monitor and intervene in processes of social aggression, prevent the establishment of social hierarchies that promote jealousy and conflict, prevent social roles that promote aggression and violence (e.g., bullies), and monitor and prevent the establishment of antisocial and enemy peer groups. 


\section{Table 3.1. Competence Support Program}

Panel 1: General characteristics

Target population

Universal

Program components

Peer: In and out of class

Parent: None

Classroom: Lessons, behavior management, and social dynamics

Schoolwide: None or not major focus

Community: None or not major focus

Training: Pretraining and ongoing for teachers and counselors

Level of integration

Add-on curriculum

Flexibility

Manualized: Scripted lessons for teachers

Adaptability: Teachers may adapt program to setting

See notes at end of table.

Panel 2: Description of instruction and strategies

Classroom

Lessons

Who delivers: Teacher

Activities and tools: Story reading, discussion, role-playing, worksheets, games, artifacts (e.g., turtle puppet), art projects

Content: Problem solving, emotion identification and regulation, identifying social cues, goal formation, choosing options, behavior regulation

Frequency: 45 minutes, once per week, 28 lessons

Strategies

Who delivers: Teacher

Activities and tools: Prevention of social hierarchies that promote conflict, social reinforcement for positive behavior

Frequency: Daily

Supplement to classroom

None

Schoolwide activities

None

See notes at end of table. 
Table 3.1. Competence Support Program-Continued

Panel 3: Professional development

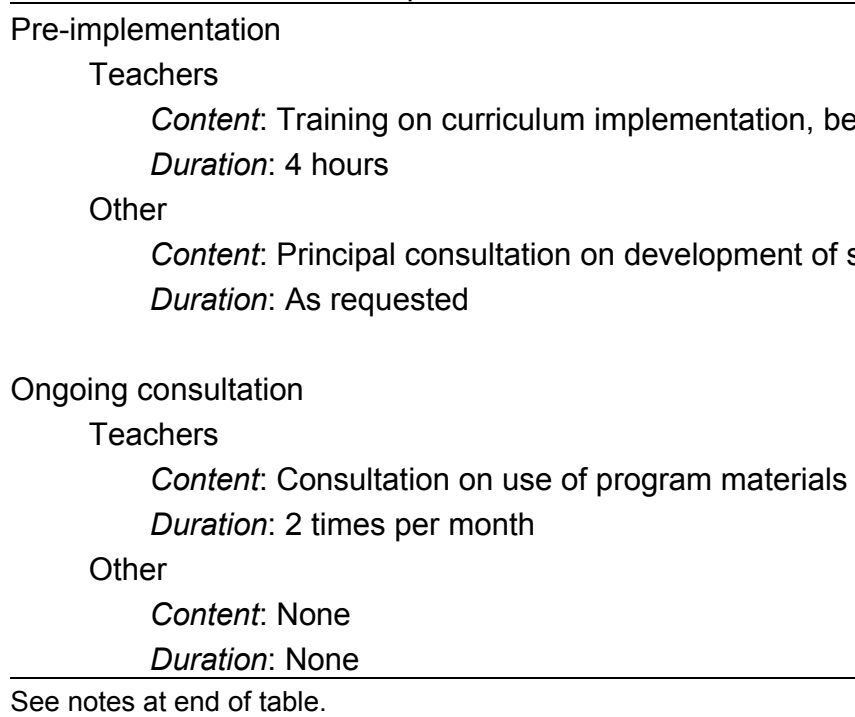

Panel 4: Activities for SACD goals

\begin{tabular}{ll|l}
\hline Violence prevention and peace promotion & $\checkmark$ & Risk prevention and health promotion \\
Social and emotional development & $\checkmark$ & Civic responsibility and community service \\
Character education & & Behavior management \\
Tolerance and diversity & \\
\hline
\end{tabular}

See notes at end of table.

Panel 5: SACD outcomes addressed

\begin{tabular}{ll|l}
\hline Engagement with Learning & $\checkmark$ & Empathy \\
Academic Competence and Motivation & & Positive School Orientation \\
Altruistic Behavior & & Negative School Orientation \\
Positive Social Behavior & $\checkmark$ & Student Afraid at School \\
Problem Behavior & $\checkmark$ & Victimization at School \\
Self-Efficacy for Peer Interactions & $\checkmark$ & Feelings of Safety \\
Normative Beliefs About Aggression & $\checkmark$ & Student Support for Teachers \\
\hline
\end{tabular}

NOTE: Abbreviations are

$\checkmark$ : Activity or outcome addressed

Blank cell: Activity or outcome not addressed

SOURCE: The Social and Character Development (SACD) Research Program. 
- Teachers receive 4 hours of training on curriculum implementation, behavior management strategies, and social dynamics. Principals receive consultation on the development of schoolwide management policy, as requested. Teachers receive consultations on the use of program materials twice a month.

- Consultation to school staff is a standard element of CSP. This consultation is provided by school personnel, such as guidance counselors, master teachers, school psychologists, or school social workers, who are trained to be program specialists.

\section{Sample and Random Assignment}

The North Carolina research team recruited a total of 10 public elementary schools in 2 school districts in 2 counties in North Carolina. The 10 schools were randomly assigned to treatment and control conditions prior to the fall 2004 data collection. ${ }^{47} \mathrm{~A}$ two-step process was used. First, a computer-generated pairwise matching algorithm developed by Mathematica Policy Research, Inc. (MPR) was used to identify the best pairwise matches across the 10 schools based on variables identified by the North Carolina research team. The variables used in the pairwise matching for North Carolina included (a) total number of students; (b) percentages of students eligible for free and reduced-price lunch; (c) percentages of students who were White/Black/Hispanic/Other; (d) math achievement scores; and (e) reading achievement scores. Then, using the flip of a coin, 1 school in each matched pair was assigned to either the intervention or control condition, resulting in 5 schools receiving CSP and 5 schools acting as control schools and continuing to implement the social and character development activities that constituted their standard practice. Assignment to treatment or control condition was at the school level and therefore limited the risk of contamination between treatment and control classrooms.

All 10 schools remained in the study for the full 3 years; however, one K-5 school in the treatment group became a K-4 school and continued implementation of the intervention. The cohort of students from that school who were in fifth grade during the 2006-07 school year went to an intermediate school that had fifth and sixth grades. The intermediate school did not implement the intervention. These fifth-grade students who were part of the original cohort were followed to their intermediate school, and they, their primary caregivers, and their fifth-grade teachers at the intermediate school provided data that were used in all analyses of the impact of CSP on children and on the use of activities related to social and character development in the schools. This change in grade configuration, which resulted in the absence of the intervention for that subgroup of fifth-graders and their teachers, should be noted when considering the results for the North Carolina site.

The original student sample (the cohort of students in the third grade in the 10 schools in fall 2004) numbered 959 students (476 treatment and 483 control). Table 3.2 documents the change in the sample over the 3 spring follow-up data collection periods. Over time, new entrants to the cohort became a larger percentage of the sample, eventually making up 24 percent of the sample by the spring of Year 3. In Year 2 there was a statistically significant difference between the treatment and control groups in the number of new entrants (in this case, fewer in the control group). The percentage of the sample made up of the original cohort further declined as students left the schools. By Year 3, approximately 25 percent of the original sample had left. In Years 2 and 3 there was a statistically significant difference between treatment and control groups, with a larger percentage of leavers in the treatment group.

\footnotetext{
${ }^{47}$ In Year 2 (fall 2005), the North Carolina research team recruited four more schools from an additional county, two assigned to treatment and two assigned to control, which were followed to the end of the study (spring 2007). A description of this second cohort and all relevant findings can be found in appendix A. The data from this second cohort are not included in the analyses and results reported in this chapter.
} 
Table 3.2. Sample-CSP

\begin{tabular}{|c|c|c|c|c|c|c|c|c|c|c|c|c|}
\hline \multirow[b]{2}{*}{ Characteristic } & \multicolumn{3}{|c|}{$\begin{array}{c}\text { Year } 1 \\
\text { (Fall 3rd grade) }\end{array}$} & \multicolumn{3}{|c|}{$\begin{array}{c}\text { Year } 1 \\
\text { (Spring 3rd grade) }\end{array}$} & \multicolumn{3}{|c|}{$\begin{array}{c}\text { Year } 2 \\
\text { (Spring 4th grade) }\end{array}$} & \multicolumn{3}{|c|}{$\begin{array}{c}\text { Year } 3 \\
\text { (Spring 5th grade) }\end{array}$} \\
\hline & Total & $\begin{array}{r}\text { Treat- } \\
\text { ment }\end{array}$ & Control & Total & $\begin{array}{r}\text { Treat- } \\
\text { ment }\end{array}$ & Control & Total & $\begin{array}{r}\text { Treat- } \\
\text { ment }\end{array}$ & Control & Total & $\begin{array}{r}\text { Treat- } \\
\text { ment }\end{array}$ & Control \\
\hline School sample size & 10 & 5 & 5 & 10 & 5 & 5 & 10 & 5 & 5 & $10^{1}$ & 5 & 5 \\
\hline Student sample size & 959 & 476 & 483 & 975 & 485 & 490 & 969 & 474 & 495 & 947 & 458 & 489 \\
\hline Stayers & $\dagger$ & $\dagger$ & $\dagger$ & 923 & 456 & 467 & 729 & 341 & 388 & 721 & 337 & 384 \\
\hline New entrants & $\dagger$ & $\dagger$ & $\dagger$ & 52 & 29 & 23 & 240 & 133 & 107 & 226 & 121 & 105 \\
\hline $\begin{array}{l}\text { New entrants as a percent of } \\
\text { spring enrollment }\end{array}$ & $\dagger$ & $\dagger$ & $\dagger$ & 5.3 & 6.0 & 4.7 & 24.8 & $28.1^{*}$ & 21.6 & 23.9 & 26.4 & 21.5 \\
\hline Total leavers (from original cohort) & $\dagger$ & $\dagger$ & $\dagger$ & 36 & 20 & 16 & 230 & 135 & 95 & 238 & 139 & 99 \\
\hline $\begin{array}{l}\text { Leavers as a percent of fall } 2004 \\
\text { enrollment }\end{array}$ & $\dagger$ & $\dagger$ & $\dagger$ & 3.8 & 4.2 & 3.3 & 24.0 & $28.4^{* *}$ & 19.7 & 24.8 & $29.2^{* *}$ & 20.5 \\
\hline $\begin{array}{l}\text { Number of students per school } \\
\text { (mean) }\end{array}$ & 96 & 95 & 97 & 98 & 97 & 98 & 97 & 95 & 99 & 95 & 92 & 98 \\
\hline $\begin{array}{l}\text { Range of number of students per } \\
\text { school }\end{array}$ & $46-148$ & $85-106$ & $46-148$ & 47-155 & 86-117 & 47-155 & $46-144$ & 84-121 & $46-144$ & 47-139 & 73-105 & $47-139$ \\
\hline
\end{tabular}

† Not applicable.

* Treatment group significantly different from control group at the .05 level.

** Treatment group significantly different from control group at the .01 level.

${ }^{1}$ One of the treatment group schools that had been a K-5 school in prior years became a K-4 school and continued implementation of the intervention. The Cohort 1 students, who were in fifth grade during the 2006-07 school year, went to an intermediate school that had fifth and sixth grades. The intermediate school did not implement the intervention. These fifth-grade students, their primary caregivers, and their teachers were included in the spring 2007 data collection and all analyses based upon spring 2007 data.

SOURCE: The Social and Character Development (SACD) Research Program. 


\section{Implementation}

\section{Training}

The intervention teachers received 4 hours of program implementation training prior to or within the first 2 weeks of the beginning of the school year (see panel 3 of table 3.1). Teachers had access to ongoing program implementation support throughout the school year from two consultants. One consultant was a program specialist who focused on the Making Choices Program. She provided onsite consultation in the form of biweekly planning meetings with teachers to go over lesson content and to discuss any implementation issues. The second consultant, a program specialist for the Competence Enhancement and Social Dynamics Training components, conducted biweekly consultation meetings with teacher teams to discuss key concepts in program implementation and issues and strategies around specific case examples generated by the teachers. In addition, each program specialist met at least once per semester with each principal to report on program activities. These two consultants also consulted with principals on the development of schoolwide management policy on an as-needed basis.

\section{Data Collection}

MPR collected the child, teacher, and school data at the North Carolina site. Table 3.3 presents the data collection dates. Data were collected in the fall and spring of the first 2 years and the spring of Year 3 . The fall 2004 data collection began on August 30, 2004, and ended on September 16, 2004. The average time frame from the beginning of program implementation to the beginning of fall data collection was 4 weeks. As a result, initial data collection took place after CSP implementation began. Therefore, these data provide a measure of the students, teachers, and schools near the beginning of the school year, at a time when CSP had been operating for a relatively short period of time. The spring data collection window was from April 11, 2005, to April 29, 2005. CSP had been implemented for 36 weeks at the time of the spring data collection and for 30 weeks from the end of the fall data collection. Year 2 followed a similar pattern, with implementation occurring at the start of the school year, fall data collection occurring 5 weeks later, and spring data collection occurring 27 weeks after fall data collection (and 35 weeks after the start of implementation). In spring 2007, data collection occurred 35 weeks after the start of implementation. During the 2005-06 and 2006-07 school years, one school operated on a year-round schedule. Data collection took from 3 to 5 weeks at each collection point. 
Table 3.3. Data collection dates-CSP

\begin{tabular}{|c|c|c|c|c|c|}
\hline Data collection schedule & $\begin{array}{c}\text { Year } 1 \\
\text { (Fall 3rd grade) } \\
\end{array}$ & $\begin{array}{c}\text { Year } 1 \\
\text { (Spring 3rd grade) }\end{array}$ & $\begin{array}{c}\text { Year } 2 \\
\text { (Fall 4th grade) } \\
\end{array}$ & $\begin{array}{c}\text { Year } 2 \\
\text { (Spring 4th grade) }\end{array}$ & $\begin{array}{c}\text { Year } 3 \\
\text { (Spring 5th grade) }\end{array}$ \\
\hline School sample size & 10 & 10 & 10 & 10 & 10 \\
\hline $\begin{array}{l}\text { School year dates } \\
\text { First day of school }\end{array}$ & $\begin{array}{l}7 / 26 / 04 \\
8 / 2 / 04^{1}\end{array}$ & $\dagger$ & $8 / 25 / 05^{2}$ & $\dagger$ & $8 / 25 / 06^{2}$ \\
\hline Start of implementation & $8 / 4 / 04$ & $\dagger$ & First day & $\dagger$ & First day \\
\hline Last day of school & $\dagger$ & $5 / 24 / 05$ & $\dagger$ & $5 / 23 / 06^{2}$ & $6 / 7 / 07^{2,3}$ \\
\hline Data collection & & & & & \\
\hline Start & $8 / 30 / 04$ & $4 / 11 / 05$ & $9 / 26 / 05^{4}$ & $4 / 24 / 06$ & $4 / 26 / 07$ \\
\hline End & $9 / 16 / 04$ & $4 / 29 / 05$ & $10 / 20 / 05$ & $5 / 5 / 06$ & $5 / 10 / 07$ \\
\hline $\begin{array}{l}\text { Calendar weeks from } \\
\text { program implementation } \\
\text { to start of fall } 2004 \text { data } \\
\text { collection }\end{array}$ & 4 & $\dagger$ & $\dagger$ & $\dagger$ & $\dagger$ \\
\hline $\begin{array}{l}\text { Calendar weeks from } \\
\text { start of school to start } \\
\text { of fall data collection }\end{array}$ & $5^{1}$ & $\dagger$ & 5 & $\dagger$ & $\dagger$ \\
\hline $\begin{array}{l}\text { Calendar weeks from end } \\
\text { of fall data collection to } \\
\text { start of spring data } \\
\text { collection }\end{array}$ & $\dagger$ & 30 & $\dagger$ & 27 & $\dagger$ \\
\hline $\begin{array}{l}\text { Calendar weeks from } \\
\text { program implementation } \\
\text { to start of spring data } \\
\text { collection }\end{array}$ & $\dagger$ & 36 & $\dagger$ & 35 & $35^{2}$ \\
\hline
\end{tabular}

† Not applicable.

${ }^{1}$ Five schools started on $7 / 26 / 04$ and five started on $8 / 2 / 04$. The calculation of weeks from the start of school to the start of fall 2004 data collection uses $7 / 26 / 04$ as the first day of the school year.

${ }^{2}$ During the 2005-06 school year and the 2006-07 school year, one school operated on a year-round schedule.

${ }^{3}$ Schools ended between 6/7/07 and 6/8/07, with most ending on 6/7/07.

${ }^{4}$ Data collection at one school occurred 3 weeks earlier.

SOURCE: The Social and Character Development (SACD) Research Program. 


\section{Consent Rates, Completion Rates, and Percentage of Sample With Data}

The actual number of student, primary caregiver, and teacher reports available for analysis was smaller than the number in the sample because consent and completion rates were less than 100 percent. Primary caregivers had to provide consent before children could complete the Child Report, before their child's teacher could complete the Teacher Report on Student, and before they themselves completed the Primary Caregiver Report. Teachers also had to provide consent before completing the Teacher Report on Classroom and School. Of those with consent, not all completed their respective reports. Table 3.4 shows the consent rates, completion rates, and percentages of sample with data for each of the four reports over the 3 years. For the Child Report and the Teacher Report on Student, completion rates ranged from 91 percent to 100 percent. In Year 3, a significantly higher percentage of control than treatment students had consent for all three reports on students. For the Primary Caregiver Report, the completion rates dropped over time from 91 percent to 74 percent.

The percentages of the sample with Child Report data ranged from 59 percent to 71 percent over the 3 years, with a significantly higher percentage of control students having data in Year 3. The percentages of students with information from the Teacher Report on Student similarly ranged from 55 percent to 70 percent, with a significantly higher percentage of control students having data in Year 3. The percentages of students with data from the Primary Caregiver Report ranged from 43 percent to 63 percent and declined over time. In Year 1, the percentage of primary caregivers with data was significantly less in the treatment group than in the control group (56\% versus 63\%). The percentages of teachers with data from the Teacher Report on Classroom and School ranged from 78 percent to 95 percent. 
Table 3.4. Consent rates, completion rates, and percentage of sample with data from each report—CSP

\begin{tabular}{|c|c|c|c|c|c|c|c|c|c|c|c|c|}
\hline \multirow[b]{2}{*}{ Report } & \multicolumn{3}{|c|}{$\begin{array}{c}\text { Year } 1 \\
\text { (Fall 3rd grade) }\end{array}$} & \multicolumn{3}{|c|}{$\begin{array}{c}\text { Year } 1 \\
\text { (Spring 3rd grade) }\end{array}$} & \multicolumn{3}{|c|}{$\begin{array}{c}\text { Year } 2 \\
\text { (Spring 4th grade) } \\
\end{array}$} & \multicolumn{3}{|c|}{$\begin{array}{c}\text { Year } 3 \\
\text { (Spring 5th grade) } \\
\end{array}$} \\
\hline & Total & $\begin{array}{r}\text { Treat- } \\
\text { ment }\end{array}$ & Control & Total & $\begin{array}{r}\text { Treat- } \\
\text { ment }\end{array}$ & Control & Total & $\begin{array}{r}\text { Treat- } \\
\text { ment }\end{array}$ & Control & Total & $\begin{array}{c}\text { Treat- } \\
\text { ment }\end{array}$ & Control \\
\hline Student sample size & 959 & 476 & 483 & 975 & 485 & 490 & 969 & 474 & 495 & 947 & $458^{3}$ & 489 \\
\hline \multicolumn{13}{|l|}{ Child Report (percent) } \\
\hline Primary caregiver consent rate & 70.0 & 68.7 & 71.2 & 69.4 & 68.7 & 70.2 & 68.5 & 67.3 & 69.7 & 66.4 & $60.0^{* * *}$ & 72.4 \\
\hline Student completion rate & 92.5 & 91.4 & 93.6 & 97.6 & 97.9 & 97.4 & 97.0 & 98.4 & 95.7 & 98.4 & 98.5 & 98.3 \\
\hline Students with data ${ }^{1}$ & 64.8 & 62.8 & 66.6 & 67.8 & 67.2 & 68.4 & 66.5 & 66.2 & 66.7 & 65.4 & $59.2^{* * *}$ & 71.2 \\
\hline \multicolumn{13}{|l|}{ Primary Caregiver Report (percent) } \\
\hline Primary caregiver consent rate & 65.9 & 63.4 & 68.3 & 67.4 & 66.6 & 68.2 & 65.1 & 63.9 & 66.3 & 62.8 & $57.0^{* * *}$ & 68.3 \\
\hline Primary caregiver completion rate & 90.5 & 88.7 & 92.1 & 80.1 & $76.5^{\star}$ & 83.5 & 80.0 & 78.5 & 81.4 & 74.3 & 76.2 & 72.8 \\
\hline Primary caregivers with data ${ }^{1}$ & 59.6 & $56.3^{*}$ & 62.9 & 53.9 & 50.9 & 56.9 & 52.1 & 50.2 & 53.9 & 46.7 & 43.4 & 49.7 \\
\hline \multicolumn{13}{|l|}{ Teacher Report on Student (percent) } \\
\hline Primary caregiver consent rate ${ }^{2}$ & 70.0 & 68.7 & 71.2 & 69.4 & 68.7 & 70.2 & 68.5 & 67.3 & 69.7 & 66.4 & $60.0^{* * *}$ & 72.4 \\
\hline Teacher completion rate & 94.9 & $93.3^{*}$ & 96.5 & 99.0 & 98.8 & 99.1 & 99.7 & 100.0 & 99.4 & 94.6 & $91.6^{* * *}$ & 96.9 \\
\hline Students with data ${ }^{1}$ & 66.4 & 64.1 & 68.7 & 68.7 & 67.8 & 69.6 & 68.3 & 67.3 & 69.3 & 62.8 & $55.0^{* * *}$ & 70.1 \\
\hline \multicolumn{13}{|c|}{$\begin{array}{l}\text { Teacher Report on Classroom and School } \\
\text { (3rd- to 5th- grade teachers) (percent) }\end{array}$} \\
\hline Teacher consent rate & 100.0 & 100.0 & 100.0 & 100.0 & 100.0 & 100.0 & 99.2 & 98.5 & 100.0 & 100.0 & 100.0 & 100.0 \\
\hline Teacher completion rate & 84.1 & 83.1 & 85.2 & 78.5 & 77.9 & 79.0 & 88.6 & 86.4 & 90.9 & 90.6 & 86.3 & 95.4 \\
\hline Teachers with data ${ }^{1}$ & 84.1 & 83.1 & 85.2 & 78.5 & 77.9 & 79.0 & 88.0 & 85.1 & 90.9 & 90.6 & 86.3 & 95.4 \\
\hline
\end{tabular}

* Treatment group significantly different from control group at the .05 level.

*** Treatment group significantly different from control group at the .001 level.

${ }^{1}$ Calculated as consent rate $x$ completion rate.

${ }^{2}$ The primary caregiver consent rates for the Child Report and the Teacher Report on Student are identical, as the primary caregiver gave consent to both together.

${ }^{3}$ One of the treatment group schools that had been a K-5 school in prior years became a K-4 school and continued implementation of the intervention. The Cohort 1 students, who were in fifth grade during the 2006-07 school year, went to an intermediate school that had fifth and sixth grades. The intermediate school did not implement the intervention. These fifth-grade students, their primary caregivers, and their teachers were included in the spring 2007 data collection and all analyses based upon spring 2007 data.

SOURCE: The Social and Character Development (SACD) Research Program. 


\section{Chapter 3. Competence Support Program}

Responses from students in the original cohort (stayers) and new entrants in the CSP sample were examined to investigate possible differences between the two groups in consent rates, completion rates, and the percentages of sample with data that might affect outcome data (table 3.5). In Year 1, stayers completed more Child Reports than did new entrants (98\% versus 93\%), a statistically significant difference. In Years 2 and 3, primary caregivers of the stayers had significantly higher consent rates for both child and primary caregiver, which led to significantly higher percentages of data on all three reports in these 2 years for the stayers. The difference in consent rates for these two groups was significantly different by 14 to 35 percentage points. 
Table 3.5. Consent rates, completion rates, and percentage of sample with data: Stayers versus new entrants--CSP

\begin{tabular}{|c|c|c|c|c|c|c|c|c|c|}
\hline \multirow[b]{2}{*}{ Report } & \multicolumn{3}{|c|}{$\begin{array}{c}\text { Year } 1 \\
\text { (Spring 3rd grade) }\end{array}$} & \multicolumn{3}{|c|}{$\begin{array}{c}\text { Year } 2 \\
\text { (Spring 4th grade) }\end{array}$} & \multicolumn{3}{|c|}{$\begin{array}{c}\text { Year } 3 \\
\text { (Spring 5th grade) }\end{array}$} \\
\hline & Total & Stayers & $\begin{array}{r}\text { New } \\
\text { entrants }\end{array}$ & Total & Stayers & $\begin{array}{r}\text { New } \\
\text { entrants }\end{array}$ & Total & Stayers & $\begin{array}{r}\mathrm{New} \\
\text { entrants } \\
\end{array}$ \\
\hline Student sample size & 975 & 923 & 52 & 969 & 729 & 240 & 947 & 721 & 226 \\
\hline \multicolumn{10}{|l|}{ Child Report (percent) } \\
\hline Primary caregiver consent rate & 69.4 & 69.0 & 76.9 & 68.5 & $77.2^{\star \star \star}$ & 42.1 & 66.4 & $69.8^{* * *}$ & 55.8 \\
\hline Student completion rate & 97.6 & $98.0^{*}$ & 92.5 & 97.0 & 97.0 & 97.0 & 98.4 & 98.4 & 98.4 \\
\hline Students with data ${ }^{1}$ & 67.8 & 67.6 & 71.2 & 66.5 & $74.9^{\star \star *}$ & 40.8 & 65.4 & $68.7^{* * *}$ & 54.9 \\
\hline \multicolumn{10}{|l|}{ Primary Caregiver Report (percent) } \\
\hline Primary caregiver consent rate & 67.4 & 67.0 & 75.0 & 65.1 & $73.8^{* * *}$ & 38.8 & 62.8 & $66.2^{* \star *}$ & 52.2 \\
\hline Primary caregiver completion rate & 80.1 & 80.1 & 79.5 & 80.0 & 81.2 & 73.1 & 75.1 & 75.1 & 75.4 \\
\hline Primary caregivers with data ${ }^{1}$ & 53.9 & 53.6 & 59.6 & 52.1 & $59.9^{* * *}$ & 28.3 & 47.2 & $49.7^{* *}$ & 39.4 \\
\hline \multicolumn{10}{|l|}{ Teacher Report on Student (percent) } \\
\hline Primary caregiver consent rate ${ }^{2}$ & 69.4 & 69.0 & 76.9 & 68.5 & $77.2^{\star \star \star}$ & 42.1 & 66.4 & $69.8^{* * *}$ & 55.8 \\
\hline Teacher completion rate & 99.0 & 98.9 & 100.0 & 99.7 & 99.8 & 99.0 & 94.6 & 94.6 & 94.4 \\
\hline Students with data ${ }^{1}$ & 68.7 & 68.3 & 76.9 & 68.3 & $77.1^{\star \star \star}$ & 41.7 & 62.8 & $66.0^{* * *}$ & 52.7 \\
\hline
\end{tabular}

* Stayers significantly different from new entrants at the .05 level.

** Stayers significantly different from new entrants at the .01 level.

*** Stayers significantly different from new entrants at the .001 level.

${ }^{1}$ Calculated as consent rate $\mathrm{x}$ completion rate.

${ }^{2}$ The primary caregiver consent rates for the Child Report and the Teacher Report on Student are identical, as the primary caregiver gave consent to both together. SOURCE: The Social and Character Development (SACD) Research Program. 


\section{Fidelity of Implementation}

Each year, CSP's five treatment schools were independently rated for quantity and quality of the program's implementation by two raters from the research team. The global measure of fidelity for the multisite study was used; inter-rater reliability was measured using Cronbach's alpha (0.70, 0.80, and 0.99 across the 3 years). The ratings were combined into a single consensus rating and used to identify schools with high implementation fidelity. In all 3 years, two treatment schools were identified as having high fidelity. Cohen's kappa was used as the measure of agreement when identifying schools as high fidelity, and it equaled 0.62 in Year 1, 0.55 in Year 2, and 1.00 in Year 3.

\section{Initial Characteristics}

This section examines the initial characteristics of the students, teachers, and schools participating in the CSP evaluation. These characteristics were collected from students who were enrolled in the third grade at the study schools in fall 2004, as well as from their primary caregivers and third-grade teachers. In addition, third-, fourth-, and fifth-grade teachers and principals in the study schools provided information about activities related to social and character development in these schools. Documenting the characteristics of students, teachers, and schools and initial measures of key outcomes at a point before the intervention had been operating for an extended period helps to determine whether the random assignment of schools to treatment and control status produced treatment and control groups with similar distributions of observed characteristics. As noted in the following discussion, 7 significant differences were found in the observed characteristics, 6 of which (out of 62 comparisons, with 3 expected to be significant by chance) related to differences between the treatment and control groups in the level of SACD activity in the classroom and school.

\section{Characteristics of Children, Their Families, and Communities}

There were no significant differences in the observed student, caregiver, and community characteristics between the treatment and control groups (see table 3.6). For students, the mean age was 8.1 years. The sample contained roughly equal percentages of girls $(53 \%)$ and boys $(47 \%)$. The sample was ethnically diverse. White non-Hispanic students made up 47 percent of the sample, Black non-Hispanic students made up 35 percent, and Hispanic students made up 10 percent.

The sample was also diverse in its levels of family income, the education levels of primary caregivers of the children in the sample, and family situation. Thirty-three percent of the children lived in a household where the income was 135 percent of the federal poverty level or lower, which is the income threshold for eligibility for free school meals. Ten percent of the primary caregivers had not completed high school. About twothirds of the children (65\%) lived with both their mother and their father. There were no significant differences between the treatment and control groups in these characteristics.

The mean values of the outcomes for children's behavior and attitudes as reported by the primary caregiver, child, and teacher in fall 2004 are shown in table 3.7. There was 1 significant difference (out of 18 comparisons) in these scores between the treatment and control groups; children in the treatment group reported a more negative school orientation than did those in the control group. 
Table 3.6. Initial characteristics of children, their families, and communities-CSP

\begin{tabular}{|c|c|c|c|}
\hline Characteristic & Total & Treatment & Control \\
\hline Student sample size & 572 & 268 & 304 \\
\hline \multicolumn{4}{|l|}{ Student demographics } \\
\hline \multicolumn{4}{|l|}{ Gender (percent) } \\
\hline Male & 46.9 & 45.2 & 48.7 \\
\hline Female & 53.1 & 54.8 & 51.3 \\
\hline \multicolumn{4}{|l|}{ Race/ethnicity (percent) } \\
\hline White (non-Hispanic) & 46.6 & 35.4 & 57.7 \\
\hline Black (non-Hispanic) & 34.5 & 43.5 & 25.4 \\
\hline Hispanic & 9.9 & 8.7 & 11.1 \\
\hline Other & 9.1 & 12.4 & 5.7 \\
\hline Age (in years) (mean) & 8.1 & 8.1 & 8.1 \\
\hline \multicolumn{4}{|l|}{ Primary caregiver and family characteristics } \\
\hline Primary caregiver's age (in years) (mean) & 34.7 & 34.3 & 35.1 \\
\hline \multicolumn{4}{|l|}{ Primary caregiver's race/ethnicity (percent) } \\
\hline White (non-Hispanic) & 51.2 & 41.0 & 61.3 \\
\hline Black (non-Hispanic) & 33.4 & 42.7 & 24.1 \\
\hline Hispanic & 8.6 & 6.8 & 10.4 \\
\hline Other & 6.9 & 9.5 & 4.2 \\
\hline \multicolumn{4}{|l|}{ Primary caregiver's education (percent) } \\
\hline Did not complete high school & 9.5 & 8.0 & 11.0 \\
\hline Completed high school or equivalent & 27.7 & 25.4 & 30.1 \\
\hline Some college & 47.3 & 51.0 & 43.5 \\
\hline Bachelor's or higher degree & 15.5 & 15.6 & 15.4 \\
\hline \multicolumn{4}{|l|}{ Primary caregiver's employment (percent) } \\
\hline Full-time & 54.1 & 51.5 & 56.7 \\
\hline Other & 45.9 & 48.5 & 43.3 \\
\hline \multicolumn{4}{|l|}{ Primary caregiver's marital status (percent) } \\
\hline Married & 64.2 & 60.7 & 67.7 \\
\hline Other & 35.8 & 39.3 & 32.3 \\
\hline Students who live in one household (percent) & 95.2 & 95.9 & 94.6 \\
\hline Number of individuals in household (mean) & 4.5 & 4.4 & 4.5 \\
\hline \multicolumn{4}{|l|}{ Primary caregiver's relationship to child (percent) } \\
\hline Mother (stepmother) & 85.7 & 84.8 & 86.5 \\
\hline Father (stepfather) & 8.0 & 7.8 & 8.2 \\
\hline Other relative/nonrelative & 6.3 & 7.4 & 5.2 \\
\hline
\end{tabular}


Table 3.6. Initial characteristics of children, their families, and communities-CSP-Continued

\begin{tabular}{|c|c|c|c|}
\hline Characteristic & Total & Treatment & Control \\
\hline \multicolumn{4}{|l|}{ Student lives with (percent) } \\
\hline Mother (stepmother) and father (stepfather) & 64.6 & 60.3 & 68.8 \\
\hline Mother (stepmother) only; father (stepfather) not present & 28.5 & 32.3 & 24.8 \\
\hline Father (stepfather) only; mother (stepmother) not present & 1.6 & 1.4 & 1.8 \\
\hline Other relative/nonrelative, parents not present & 5.3 & 6.0 & 4.6 \\
\hline \multicolumn{4}{|l|}{ Highest education of anyone in household (percent) } \\
\hline Did not complete high school & 6.8 & 7.3 & 6.3 \\
\hline Completed high school or equivalent & 21.1 & 17.5 & 24.7 \\
\hline Some college & 51.5 & 54.6 & 48.4 \\
\hline Bachelor's or higher degree & 20.7 & 20.7 & 20.7 \\
\hline \multicolumn{4}{|l|}{ Total household income (percent) } \\
\hline Less than $\$ 20,000$ & 29.1 & 30.3 & 27.9 \\
\hline$\$ 20,000$ to $\$ 39,999$ & 31.7 & 35.3 & 28.2 \\
\hline$\$ 40,000$ to $\$ 59,999$ & 21.2 & 18.8 & 23.6 \\
\hline$\$ 60,000$ or more & 18.0 & 15.6 & 20.3 \\
\hline Income-to-poverty-threshold ratio-Below 135 percent (percent) & 33.1 & 34.1 & 32.0 \\
\hline Income-to-poverty-threshold ratio-135 to 185 percent (percent) & 25.1 & 26.3 & 24.0 \\
\hline Income-to-poverty-threshold ratio-Above 185 percent (percent) & 41.8 & 39.6 & 44.0 \\
\hline \multicolumn{4}{|l|}{ Alabama Parenting Questionnaire-Poor Monitoring and } \\
\hline Supervision Subscale (mean) & 1.2 & 1.2 & 1.2 \\
\hline \multicolumn{4}{|l|}{ Alabama Parenting Questionnaire-Positive Parenting } \\
\hline Subscale (mean) & 3.6 & 3.6 & 3.6 \\
\hline Confusion, Hubbub, and Order Scale (mean) & 2.2 & 2.1 & 2.2 \\
\hline \multicolumn{4}{|l|}{ Community characteristics (mean) } \\
\hline Community Risks Scale & 1.2 & 1.2 & 1.2 \\
\hline Community Resources Scale & 2.2 & 2.3 & 2.2 \\
\hline Child-Centered Social Control Scale & 3.2 & 3.1 & 3.2 \\
\hline
\end{tabular}

NOTE: No statistically significant differences were found between values for treatment and control groups. Weights, which assign equal weight to each school within the program, were used in producing the treatment, control, and overall means. Statistical tests were conducted using regressions that included program indicators to account for the sample design and adjusted for clustering at the school level.

SOURCE: The Social and Character Development (SACD) Research Program. 
Table 3.7. Mean scores and standard deviations for initial outcome measures of sample--CSP

\begin{tabular}{|c|c|c|c|c|c|c|c|}
\hline \multirow[b]{2}{*}{ Outcome measure-Report } & \multirow[b]{2}{*}{ Range } & \multicolumn{2}{|c|}{ Total } & \multicolumn{2}{|c|}{ Treatment } & \multicolumn{2}{|c|}{ Control } \\
\hline & & Mean & $S D$ & Mean & $S D$ & Mean & $S D$ \\
\hline \multicolumn{8}{|l|}{ Social and Emotional Competence Domain } \\
\hline Self-Efficacy for Peer Interaction-CR & $1-4$ & 2.9 & 0.6 & 2.9 & 0.6 & 3.0 & 0.6 \\
\hline Normative Beliefs About Aggression-CR & $1-4$ & 1.2 & 0.4 & 1.2 & 0.4 & 1.2 & 0.4 \\
\hline Empathy-CR & $1-3$ & 2.4 & 0.4 & 2.4 & 0.4 & 2.4 & 0.4 \\
\hline \multicolumn{8}{|l|}{ Behavior Domain } \\
\hline Altruistic Behavior-CR & $0-3$ & 1.5 & 0.8 & 1.5 & 0.9 & 1.4 & 0.8 \\
\hline Altruistic Behavior-TRS & $1-4$ & 1.4 & 0.5 & 1.5 & 0.5 & 1.3 & 0.4 \\
\hline Altruistic Behavior-PCR & $1-4$ & 2.3 & 0.7 & 2.3 & 0.7 & 2.3 & 0.7 \\
\hline Positive Social Behavior-TRS & $1-4$ & 3.0 & 0.6 & 3.0 & 0.6 & 3.0 & 0.6 \\
\hline Positive Social Behavior-PCR & $1-4$ & 3.0 & 0.5 & 3.0 & 0.5 & 3.0 & 0.5 \\
\hline Problem Behavior-CR & $0-3$ & 0.2 & 0.4 & 0.2 & 0.4 & 0.2 & 0.4 \\
\hline Problem Behavior-TRS & $1-4$ & 1.4 & 0.4 & 1.4 & 0.4 & 1.3 & 0.3 \\
\hline Problem Behavior-PCR & $1-4$ & 1.5 & 0.3 & 1.5 & 0.3 & 1.6 & 0.3 \\
\hline ADHD-Related Behavior-TRS & $1-4$ & 1.8 & 0.7 & 1.8 & 0.7 & 1.7 & 0.6 \\
\hline \multicolumn{8}{|l|}{ Academics Domain } \\
\hline Academic Competence and Motivation-TRS & $1-5$ & 3.0 & 0.8 & 3.0 & 0.8 & 2.9 & 0.9 \\
\hline Engagement with Learning-CR & $1-4$ & 3.7 & 0.7 & 3.6 & 0.7 & 3.7 & 0.6 \\
\hline \multicolumn{8}{|l|}{ Perceptions of School Climate Domain } \\
\hline Positive School Orientation-CR & $1-4$ & 3.1 & 0.7 & 3.1 & 0.7 & 3.1 & 0.7 \\
\hline Negative School Orientation-CR & $1-4$ & 1.9 & 0.6 & $2.0^{*}$ & 0.7 & 1.8 & 0.6 \\
\hline Student Afraid at School-CR & $1-4$ & 2.5 & 0.9 & 2.5 & 0.9 & 2.5 & 0.9 \\
\hline Victimization at School-CR & $0-3$ & 0.8 & 0.8 & 0.9 & 0.8 & 0.8 & 0.8 \\
\hline Student sample size-PCR & & \multicolumn{2}{|c|}{572} & \multicolumn{2}{|c|}{268} & \multicolumn{2}{|c|}{304} \\
\hline Student sample size—CR & & \multicolumn{2}{|c|}{621} & \multicolumn{2}{|c|}{299} & \multicolumn{2}{|c|}{322} \\
\hline Student sample size-TRS & & \multicolumn{2}{|c|}{638} & \multicolumn{2}{|c|}{306} & \multicolumn{2}{|c|}{332} \\
\hline
\end{tabular}

* Treatment group significantly different from control group at the .05 level.

NOTE: Abbreviations are

CR: Child Report

PCR: Primary Caregiver Report

TRS: Teacher Report on Student

ADHD: Attention deficit hyperactivity disorder

$S D$ : Standard deviation

Weights, which assign equal weight to each school within the program, were used in producing the treatment, control, and overall means. Statistical tests were conducted using regressions that included program indicators to account for the sample design and adjusted for clustering at the school level. Sample size may differ for some outcomes due to nonresponse.

SOURCE: The Social and Character Development (SACD) Research Program. 


\section{Characteristics of Teachers and Schools}

The third-, fourth-, and fifth-grade teachers at the study schools were predominantly White non-Hispanic $(77 \%)$ and female (93\%), had an average of 14.8 years of total teaching experience, and about 26 percent held an advanced or specialist degree (see table 3.8). There was one statistically significant difference between the groups of teachers; control group teachers had been teaching in their current schools for a greater number of years on average than had treatment group teachers ( 7.7 versus 4.9 years).

Data regarding school characteristics were drawn from the Common Core of Data in order to compare treatment and control schools. There were no significant differences between the two groups of schools in terms of student composition (race/ethnicity and school lunch eligibility), number of students enrolled, number of full-time teachers, Title I status, or number of years the principal had been at the school (table 3.9). In addition, there were no significant differences between treatment and control schools in terms of location (urban, suburban, or rural) or lowest and highest grade offered (these data are not shown in a table).

Table 3.8. Initial characteristics of teachers in sample-CSP

\begin{tabular}{|c|c|c|c|}
\hline Characteristic & Total & Treatment & Control \\
\hline Teacher sample size & 106 & 54 & 52 \\
\hline \multicolumn{4}{|l|}{ Gender (percent) } \\
\hline Male & 7.2 & 7.1 & 7.4 \\
\hline Female & 92.8 & 92.9 & 92.6 \\
\hline \multicolumn{4}{|l|}{ Race/ethnicity (percent) } \\
\hline White (non-Hispanic) & 77.1 & 74.8 & 79.4 \\
\hline Other & 22.9 & 25.2 & 20.6 \\
\hline Number of years teaching experience (mean) & 14.8 & 14.7 & 14.9 \\
\hline Number of years teaching experience in this school (mean) & 6.3 & $4.9^{*}$ & 7.7 \\
\hline \multicolumn{4}{|l|}{ Type of teaching certificate (percent) } \\
\hline Regular state certificate or advanced professional certificate & 95.0 & $\ddagger$ & $\ddagger$ \\
\hline Other & 5.0 & $\ddagger$ & $\ddagger$ \\
\hline \multicolumn{4}{|l|}{ Education (percent) } \\
\hline Bachelor's degree & 74.3 & 66.7 & 81.9 \\
\hline Advanced degree/other & 25.7 & 33.3 & 18.1 \\
\hline
\end{tabular}

¥ Reporting standards not met. Values suppressed to protect confidentiality.

* Treatment group significantly different from control group at the .05 level.

NOTE: Weights, which assign equal weight to each school within the program, were used in producing the treatment, control, and overall means. Statistical tests were conducted using regressions that included program indicators to account for the sample design and adjusted for clustering at the school level. Sample size may differ for some outcomes due to nonresponse.

SOURCE: The Social and Character Development (SACD) Research Program. 
Chapter 3. Competence Support Program

Table 3.9. Initial characteristics of schools in sample-CSP

\begin{tabular}{|c|c|c|c|}
\hline Characteristic & Total & Treatment & Control \\
\hline School sample size & 10 & 5 & 5 \\
\hline \multicolumn{4}{|l|}{ Student race/ethnicity (percent) } \\
\hline White (non-Hispanic) & 44.0 & 34.8 & 53.3 \\
\hline Black (non-Hispanic) & 41.3 & 51.0 & 31.5 \\
\hline Hispanic & 10.3 & 8.0 & 12.7 \\
\hline Other & 4.4 & 6.2 & 2.5 \\
\hline Students eligible for free or reduced-price lunch (percent) & 57.0 & 63.8 & 50.2 \\
\hline Number of students enrolled (mean) & 626.5 & 657.8 & 595.2 \\
\hline Number of full-time teachers (mean) & 38.9 & 40.8 & 37.0 \\
\hline \multicolumn{4}{|l|}{ Title I status (percent) } \\
\hline Title I eligible school & 100.0 & 100.0 & 100.0 \\
\hline Schoolwide Title I & 100.0 & 100.0 & 100.0 \\
\hline Number of years principal has been at this school (mean) & 4.9 & 2.5 & 6.8 \\
\hline \multicolumn{4}{|c|}{$\begin{array}{l}\text { NOTE: No statistically significant differences were found between values for treatment and control groups. Weights, which assign } \\
\text { equal weight to each school within the program, were used in producing the treatment, control, and overall means. Statistical tests } \\
\text { were conducted using regressions that included program indicators to account for the sample design and adjusted for clustering at } \\
\text { the school level. Sample size may differ for some outcomes due to nonresponse. }\end{array}$} \\
\hline
\end{tabular}

In the Teacher Report on Classroom and School, teachers reported on nine dimensions of school environment (these data are not shown in a table): feelings of safety, adequacy of resources, student support, freedom to teach as desired, affiliation with and ties to colleagues, innovation regarding new approaches to teaching, professional interest, participatory decisionmaking, and work pressure. There were no statistically significant differences between treatment and control schools in these reports.

\section{The Level of SACD in the Schools Near the Beginning of the Study}

During the initial data collection, principals and teachers reported on the SACD activities used in the schools and classrooms, the availability of SACD materials, and the professional development provided on SACD. It is important to note that this data collection at the beginning of the school year took place, on average, 4 weeks after the start of the CSP implementation; therefore the activities and practices related to SACD in the treatment and control schools are a measure of what was happening in the study schools near the beginning of the study. Table 3.10 shows that the majority of the school principals reported activities to promote six social and character development goals: violence prevention and peace promotion (100\%), social and emotional development $(100 \%)$, character education $(100 \%)$, tolerance and diversity $(80 \%)$, risk prevention and health promotion (80\%), and civic responsibility and community service $(90 \%)$. In addition, all of the principals reported activities directed toward behavior management. There were no statistically significant differences between the treatment group and the control group in the percentages on principal reports, although this may be due to the relatively small principal sample size. Teachers' reports on the use of these activities in their classrooms ranged from 60 percent to 93 percent, with no significant difference between treatment and control teachers. With respect to the use of schoolwide activities, 64 percent to 97 percent of teachers reported that their schools used such activities, and again there were no significant differences between treatment and control teachers in reported use. 


\section{Table 3.10. Principal and teacher initial reports on use of SACD programs or activities in} sample-CSP

\begin{tabular}{|c|c|c|c|}
\hline SACD program or activity & Total & Treatment & Control \\
\hline Principal sample size & 10 & 5 & 5 \\
\hline Teacher sample size & 106 & 54 & 52 \\
\hline
\end{tabular}

Principals reporting that school had programs or activities

to promote the following SACD goals (percent)

Violence prevention and peace promotion

$100.0 \quad 100.0 \quad 100.0$

Social and emotional development

100.0

$100.0 \quad 100.0$

Character education

100.0

$100.0 \quad 100.0$

Tolerance and diversity

80.0

$80.0 \quad 80.0$

Risk prevention and health promotion

80.0

$100.0 \quad 60.0$

Civic responsibility and community service

90.0

$80.0 \quad 100.0$

Behavior management

100.0

$100.0 \quad 100.0$

None of the above

0.0

0.0

0.0

Teachers reporting on using programs or activities in their class to promote the following SACD goals (percent)

Violence prevention and peace promotion

60.2

$67.9 \quad 52.4$

Social and emotional development

76.5

$77.4 \quad 75.6$

Character education

84.6

88.2

80.9

Tolerance and diversity

66.4

$67.3 \quad 65.6$

Risk prevention and health promotion

67.4

60.8

74.1

Civic responsibility and community service

62.1

62.7

61.6

Behavior management

93.4

94.1

92.7

None of the above

0.0

0.0

0.0

Teachers reporting schoolwide use of the following activities to promote SACD (percent)

Morning announcements or videos

\begin{tabular}{lll}
97.2 & 95.6 & 98.8 \\
75.8 & 74.2 & 77.3 \\
73.5 & 67.4 & 79.6 \\
63.9 & 57.7 & 70.0 \\
80.5 & 83.0 & 78.1 \\
17.2 & 18.9 & 15.6 \\
\hline
\end{tabular}

School assemblies

School newspapers or bulletins

Special school days

Special events

17.2

18.9

15.6

NOTE: No statistically significant differences were found between values for treatment and control groups. Weights, which assign equal weight to each school within each of the programs and to each program across programs, were used in producing the treatment, control, and overall means. Statistical tests were conducted using regressions that included program indicators to account for the sample design and adjusted for clustering at the school level. Sample size may differ for some outcomes due to nonresponse.

SOURCE: The Social and Character Development (SACD) Research Program.

Teachers reported using a broad range of teaching materials to support SACD activities (table 3.11), including teacher guides $(69 \%)$, student materials (69\%), giveaways (50\%), instructional aids (45\%), and children's literature $(42 \%)$. There were statistically significant differences in the use of teacher guides $(81 \%$ versus $57 \%)$ and instructional aids (53\% versus 38\%), with treatment teachers reporting greater use of these two types of materials than control teachers.

Teachers also reported using a wide variety of teaching strategies (table 3.11). All teachers reported using any of the 20 strategies asked about, and teachers used an average of 12.3 of the strategies. There were no significant differences in the average number of strategies, or in the specific strategies, used by treatment versus control teachers. 
Table 3.11. Teacher initial reports on use of SACD materials and classroom strategies in sample-CSP

\begin{tabular}{crrr}
\hline SACD material and classroom strategy & Total & Treatment & Control \\
\hline Teacher sample size & 106 & 54
\end{tabular}

Teachers using the following materials in conjunction with social and character development activities (percent)

Teacher guides (manuals, curricula)

Student materials (workbooks, worksheets)

Instructional aids (games, software, videos)

68.8

$81.0^{*}$

57.0

Giveaways (bookmarks, stickers)

45.3

74.4

63.1

Children's literature

50.3

53.0 *

37.6

Other types of materials

42.3

$49.9 \quad 50.8$

Do not use any of the materials listed above

14.6

8.3

35.5

49.0

12.8

16.3

Teachers using any of the strategies listed below to promote social and character development in the classroom (percent)

100.0

100.0

100.0

Number of strategies (listed below) used by teachers to promote social and character development in the classroom (mean)

Teachers using each of the following strategies to promote social and character development (percent)

Role-playing

Cooperative learning

Peer group discussions

Direct instruction of social and character development

Skill training

40.1

Parent training

Parent/community involvement in program development or delivery

Mentoring

Good behavior notes sent home daily or weekly

90.3

85.5

95.1

Presenting role models

71.9

64.2

79.5

Targeted story reading or writing on SACD themes

75.0

82.5

67.5

Peer mediation

56.8

40.8

Honor roll for positive behavior

Pledges or recitations on social and character development themes

42.2

$53.3 \quad 31.1$

Guided visualization

54.4

$61.6 \quad 47.2$

Student-led/student-assisted instruction

45.0

$54.9 \quad 35.0$

Journaling

58.9

$57.4 \quad 60.5$

Time out for negative behavior

94.4

$98.3 \quad 90.5$

Daily or weekly rewards for positive behavior

96.5

95.6

97.5

$\ddagger$ Values suppressed to protect confidentiality.

* Treatment group significantly different from control group at the .05 level.

NOTE: Weights, which assign equal weight to each school within each of the programs and to each program across programs, were used in producing the treatment, control, and overall means. Statistical tests were conducted using regressions that included program indicators to account for the sample design and adjusted for clustering at the school level. Sample size may differ for some outcomes due to nonresponse.

SOURCE: The Social and Character Development (SACD) Research Program. 
Principals and teachers reported on participation in and amount of SACD training and staff development provided over the previous 12 months (table 3.12). Principals reported higher participation rates $(100 \%$ versus $72 \%$ ) and reported more training hours (8.9 versus 7.2$)$ than did teachers. There was a significant difference in the percentages of teachers reporting participation in training, with more treatment teachers reporting participation in SACD training than control teachers ( $93 \%$ versus $52 \%)$. In addition, a significantly greater percentage of treatment teachers than control teachers reported receiving training in three of the seven targeted SACD goals: social and emotional development (38\% versus $9 \%$ ), character education $(62 \%$ versus $14 \%)$, and behavior management (60\% versus $26 \%)$.

\section{Table 3.12. Principal and teacher initial reports on SACD professional development in sample-- CSP}

\begin{tabular}{|c|c|c|c|}
\hline SACD professional development & Total & Treatment & Control \\
\hline Principal sample size & 10 & 5 & 5 \\
\hline Teacher sample size & 106 & 54 & 52 \\
\hline $\begin{array}{l}\text { Principals reporting that staff participated in social and character } \\
\text { development training within the past year (percent) }\end{array}$ & 100.0 & 100.0 & 100.0 \\
\hline $\begin{array}{l}\text { Teachers reporting participation in social and character development } \\
\text { training within the past } 12 \text { months (percent) }\end{array}$ & 72.2 & $93.0^{* *}$ & 51.5 \\
\hline $\begin{array}{l}\text { Number of hours of social and character development training } \\
\text { principals report were provided to each staff person last year (mean) }\end{array}$ & 8.9 & 9.6 & 8.2 \\
\hline $\begin{array}{l}\text { Number of hours of social and character development training } \\
\text { teachers report receiving during the past } 12 \text { months (mean) }\end{array}$ & 7.2 & 8.1 & 6.4 \\
\hline $\begin{array}{l}\text { Teachers reporting receiving training in the past } 12 \text { months } \\
\text { in the following areas (percent) }\end{array}$ & & & \\
\hline Violence prevention and peace promotion & 7.9 & $\ddagger$ & $\ddagger$ \\
\hline Social and emotional development & 23.3 & $37.8^{*}$ & 8.8 \\
\hline Character education & 37.6 & $61.6^{* *}$ & 13.6 \\
\hline Tolerance and diversity & 20.5 & 24.0 & 17.0 \\
\hline Risk prevention and health promotion & 8.6 & 11.9 & 5.3 \\
\hline Civic responsibility and community service & 3.0 & $\ddagger$ & $\ddagger$ \\
\hline Behavior management & 43.1 & $60.0^{*}$ & 26.1 \\
\hline
\end{tabular}

¥ Reporting standards not met. Values suppressed to protect confidentiality.

${ }^{*}$ Treatment group significantly different from control group at the .05 level.

** Treatment group significantly different from control group at the .01 level.

NOTE: Weights, which assign equal weight to each school within each of the programs and to each program across programs, were used in producing the treatment, control, and overall means. Statistical tests were conducted using regressions that included

program indicators to account for the sample design and adjusted for clustering at the school level. Sample size may differ for some outcomes due to nonresponse.

SOURCE: The Social and Character Development (SACD) Research Program.

The data on the initial levels of SACD activity emphasize that the control condition was a "standard practice" control. Standard practice at the control schools included using SACD activities, materials, and practices, along with professional development for staff, at rates and in types and amounts similar to the treatment schools. For example, the percentages of teachers who reported using programs or activities to promote specific SACD goals ranged from 61 percent to 94 percent in the treatment schools and from 52 percent to 93 percent in the control schools. However, the 6 significant differences between the treatment and control conditions in the use of SACD activities was more than expected by chance ( 3 out of 62 comparisons), and in 
all cases they favored the treatment group. An important point about this difference between treatment and control teachers is that this training took place just prior to the start of the school year. Because initial data collection happened after program implementation began, these differences may reflect the fact that program implementation and program training for staff started before initial data collection.

\section{Impacts on Use of SACD Activities}

The introduction of the formal CSP program would be expected to increase the use of SACD activities in the treatment schools in comparison to the control schools. The analysis of this impact is based on the Teacher Report on Classroom and School. Every spring, third-, fourth-, and fifth-grade teachers provided information through the Teacher Report on Classroom and School about the social and character development activities they used in their classrooms. Specifically, information from the Teacher Report on Classroom and School was used to determine the difference between treatment and control teachers in the following areas:

1. the use of SACD activities in their classrooms overall and by SACD goal;

2. the use of materials and strategies to implement the SACD activities within classrooms and within the entire school;

3. the use of staff development to support the teachers; and

4. teacher support for SACD efforts in the school and the use of practices conducive to the social and character development of students.

Teacher Report on Classroom and School consent and completion rates (table 3.4) led to 78 percent to 95 percent of all teachers having data for the 3 years. To estimate intervention impacts for each of the outcomes, testing of the statistical significance of the differences in means was used. Preliminary analysis indicated little or no gains in precision from using covariates. Before testing the mean differences, the data were weighted such that each school received equal weight. Standard errors of the impact estimates accounted for the clustering of teachers within schools. In addition, a set of heuristics (described in chapter 1) was applied to determine whether each outcome domain was statistically significant after adjustments were made for the multiple tests conducted.

\section{Use of Activities}

The percentages of control teachers who reported using any SACD activities in their classrooms ranged from 87 percent to 96 percent over the 3 years (table 3.13, panel 1). For the six individual SACD goals, the ranges varied from 67 percent to 84 percent in Year 1, 67 percent to 88 percent in Year 2, and 57 percent to 81 percent in Year 3. Control teachers' use of behavior management activities ranged from 85 percent to 91 percent over this period. The percentages of control teachers who reported using any SACD activities in their classrooms for at least 1 hour per week (panel 2) ranged from 63 percent to 82 percent over the 3 years. For the six individual SACD goals, the ranges varied from 18 percent to 37 percent in Year 1, 20 percent to 40 percent in Year 2, and 11 percent to 37 percent in Year 3. Control teachers' use of behavior management activities for 1 hour per week ranged from 75 percent to 79 percent over this period. These findings show that the control schools were using these activities as part of their standard practice related to social and character development.

For teachers' reported use of any SACD activity (panels 1 and 2), 48 comparisons were made, with 2 expected to be significant by chance. The percentages of treatment teachers using any SACD activity, or specific SACD activities, at any point in the previous year were not significantly different from the percentages of control teachers in any year. There was a significant difference between treatment and control teacher reports of using behavior management activities for at least 1 hour per week in Year 3, with more control teachers reporting these activities (impact $=-14$ percentage points). After the heuristics were applied, the domain for engagement in SACD activities showed CSP had a statistically significant impact in Year 1. 


\section{Chapter 3. Competence Support Program}

For teachers' reported use of any named SACD activity (panels 3 and 4), 42 comparisons were made, with 2 expected to be significant by chance. Eight of the 14 impact estimates in Year 1, 5 of the 14 in Year 2, and 4 of the 14 in Year 3 were statistically significant. Impacts on the use of a named activity at any point in the previous year (panel 3) were as follows: violence prevention and peace promotion in all 3 years (impact $=28$, 30, and 38 percentage points), social and emotional development in Year 1 (impact $=40$ percentage points) and Year 2 (impact $=44$ percentage points), character education in Year 2 (impact $=37$ percentage points) and Year 3 (impact $=29$ percentage points), tolerance and diversity in Year 1 (impact $=20$ percentage points) and Year 2 (impact $=33$ percentage points), and the use of any named activity in all 3 years (impact $=32,34$, and 40 percentage points). In Year 1 there were significant impacts on the use of any named activity for at least 1 hour per week (panel 4) for violence prevention and peace promotion (impact $=18$ percentage points), social and emotional development (impact $=21$ percentage points), and character education (impact $=23$ percentage points). The impact on the use of any named activity for at least 1 hour per week was significant in Year 1 (impact $=34$ percentage points) and Year 3 (impact $=23$ percentage points). The overall impact of CSP on the domain for engagement in named SACD activities was significant in all 3 years. 
Table 3.13. Impacts on teacher-reported SACD classroom activities--CSP

Panel 1: Engagement in any activities to promote SACD goals ${ }^{1}$

Year 1

Year 2

Year 3

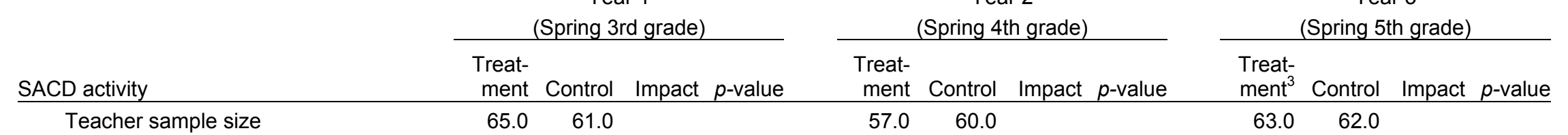

Violence prevention and peace promotion (percent)

$\begin{array}{llllllllllll}77.4 & 67.1 & 10.3 & 0.287 & 73.0 & 72.3 & 0.8 & 0.935 & 72.6 & 61.8 & 10.8 & 0.205 \\ 88.4 & 72.5 & 16.0 & 0.151 & 79.0 & 73.2 & 5.8 & 0.358 & 72.3 & 65.1 & 7.2 & 0.449 \\ 95.2^{\wedge} & 84.0 & 11.2 & 0.097 & 91.6 & 87.5 & 4.1 & 0.382 & 83.0 & 80.6 & 2.4 & 0.751 \\ 84.9 & 74.7 & 10.2 & 0.420 & 73.5 & 72.4 & 1.1 & 0.795 & 64.9 & 60.0 & 4.9 & 0.684 \\ 76.4 & 73.8 & 2.6 & 0.804 & 62.0 & 73.3 & -11.2 & 0.341 & 66.6 & 68.8 & -2.2 & 0.844 \\ 72.4 & 78.7 & -6.3 & 0.650 & 65.2 & 67.1 & -1.9 & 0.819 & 58.7 & 56.5 & 2.2 & 0.861 \\ 96.7 & 90.8 & 5.9 & 0.288 & 94.3 & 96.3 & -2.0 & 0.550 & 94.1 & 87.3 & 6.8 & 0.283 \\ 96.9 & 90.6 & 6.3 & 0.144 & 89.2 & 85.2 & 3.9 & 0.565 & 80.3 & 88.6 & -8.3 & 0.110\end{array}$

Social and emotional development (percent)

Character education (percent)

Tolerance and diversity (percent)

Risk prevention and health promotion (percent)

Civic responsibility and community service (percent)

Any SACD goal (percent)

Behavior management (percent)

89.2

80.3 


\section{Table 3.13. Impacts on teacher-reported SACD classroom activities-CSP-Continued}

Panel 2: Engagement in any activities to promote SACD goals for at least 1 hour per week

\begin{tabular}{|c|c|c|c|c|c|c|c|c|c|c|c|c|}
\hline \multirow[b]{2}{*}{ SACD activity } & \multicolumn{4}{|c|}{$\begin{array}{c}\text { Year } 1 \\
\text { (Spring 3rd grade) } \\
\end{array}$} & \multicolumn{4}{|c|}{$\begin{array}{c}\text { Year } 2 \\
\text { (Spring 4th grade) }\end{array}$} & \multicolumn{4}{|c|}{$\begin{array}{c}\text { Year } 3 \\
\text { (Spring 5th grade) }\end{array}$} \\
\hline & $\begin{array}{r}\text { Treat- } \\
\text { ment }\end{array}$ & Control & Impact & $p$-value & $\begin{array}{r}\text { Treat- } \\
\text { ment }\end{array}$ & Control & Impact & $p$-value & $\begin{array}{l}\text { Treat- } \\
\text { ment }^{3}\end{array}$ & Control & Impact & $p$-value \\
\hline Teacher sample size & 65.0 & 61.0 & & & 57.0 & 60.0 & & & 63.0 & 62.0 & & \\
\hline $\begin{array}{l}\text { Violence prevention and peace promotion } \\
\text { (percent) }\end{array}$ & 28.5 & 29.6 & -1.0 & 0.932 & 24.9 & 28.8 & -3.9 & 0.623 & 26.1 & 27.4 & -1.3 & 0.867 \\
\hline $\begin{array}{l}\text { Social and emotional development } \\
\text { (percent) }\end{array}$ & $39.2^{\wedge}$ & 26.7 & 12.6 & 0.087 & 32.5 & 27.5 & 4.9 & 0.654 & 21.6 & 24.9 & -3.3 & 0.748 \\
\hline Character education (percent) & $55.2^{\wedge}$ & 36.9 & 18.2 & 0.098 & 48.6 & 39.6 & 9.0 & 0.411 & 31.3 & 37.3 & -6.0 & 0.547 \\
\hline Tolerance and diversity (percent) & 27.1 & 18.0 & 9.0 & 0.363 & 24.5 & 30.9 & -6.3 & 0.496 & 27.1 & 11.4 & 15.7 & 0.145 \\
\hline $\begin{array}{l}\text { Risk prevention and health promotion } \\
\text { (percent) }\end{array}$ & 35.6 & 24.7 & 10.9 & 0.427 & 30.1 & 29.0 & 1.0 & 0.904 & 24.0 & 29.3 & -5.3 & 0.659 \\
\hline $\begin{array}{l}\text { Civic responsibility and community service } \\
\text { (percent) }\end{array}$ & 27.4 & 28.3 & -1.0 & 0.933 & 18.2 & 20.1 & -1.8 & 0.876 & 31.8 & 15.0 & 16.8 & 0.133 \\
\hline Any SACD goal (percent) & 68.8 & 62.8 & 6.0 & 0.431 & 76.2 & 78.1 & -1.8 & 0.824 & 76.8 & 81.5 & -4.7 & 0.373 \\
\hline Behavior management (percent) & 80.6 & 78.8 & 1.8 & 0.789 & 70.8 & 74.6 & -3.8 & 0.720 & $61.3^{*}$ & 75.3 & -14.0 & 0.046 \\
\hline
\end{tabular}

See notes at end of table. 


\section{Table 3.13. Impacts on teacher-reported SACD classroom activities-CSP-Continued}

Panel 3: Engagement in activities to promote SACD goals linked to named SACD programs ${ }^{2}$

\begin{tabular}{|c|c|c|c|c|c|c|c|c|c|c|c|c|}
\hline \multirow[b]{2}{*}{ SACD activity } & \multicolumn{4}{|c|}{$\begin{array}{c}\text { Year 1 } \\
\text { (Spring 3rd grade) } \\
\end{array}$} & \multicolumn{4}{|c|}{$\begin{array}{c}\text { Year } 2 \\
\text { (Spring 4th grade) } \\
\end{array}$} & \multicolumn{4}{|c|}{$\begin{array}{c}\text { Year } 3 \\
\text { (Spring 5th grade) } \\
\end{array}$} \\
\hline & $\begin{array}{c}\text { Treat- } \\
\text { ment }\end{array}$ & Control & Impact & $p$-value & $\begin{array}{c}\text { Treat- } \\
\text { ment }\end{array}$ & Control & Impact & $p$-value & $\begin{array}{l}\text { Treat- } \\
\text { ment }^{3}\end{array}$ & Control & Impact & $p$-value \\
\hline Teacher sample size & 65.0 & 61.0 & & & 57.0 & 60.0 & & & 63.0 & 62.0 & & \\
\hline $\begin{array}{l}\text { Violence prevention and peace promotion } \\
\text { (percent) }\end{array}$ & $38.8^{*}$ & 10.5 & 28.3 & 0.022 & $50.4^{*}$ & 20.5 & 29.9 & 0.016 & $51.5^{*}$ & 13.3 & 38.2 & 0.003 \\
\hline $\begin{array}{l}\text { Social and emotional development } \\
\text { (percent) }\end{array}$ & $\ddagger^{*}$ & $\ddagger$ & 39.7 & 0.003 & $54.5^{*}$ & 10.3 & 44.3 & 0.007 & 47.0 & 0.0 & 47.0 & $\dagger$ \\
\hline Character education (percent) & $35.8^{\wedge}$ & 7.1 & 28.7 & 0.063 & $49.0^{*}$ & 11.7 & 37.3 & 0.001 & $33.7^{*}$ & 4.9 & 28.8 & 0.018 \\
\hline Tolerance and diversity (percent) & $\ddagger^{*}$ & $\ddagger$ & 19.6 & 0.015 & $\ddagger^{*}$ & $\ddagger$ & 32.5 & 0.014 & 15.6 & 0.0 & 15.6 & $\dagger$ \\
\hline $\begin{array}{l}\text { Risk prevention and health promotion } \\
\text { (percent) }\end{array}$ & 36.8 & 23.0 & 13.8 & 0.381 & 28.6 & 23.8 & 4.8 & 0.569 & 26.0 & 18.9 & 7.1 & 0.545 \\
\hline $\begin{array}{l}\text { Civic responsibility and community service } \\
\text { (percent) }\end{array}$ & $\ddagger$ & $\ddagger$ & 1.5 & $\dagger$ & 9.5 & 8.9 & 0.6 & 0.936 & 6.3 & 5.6 & 0.7 & 0.811 \\
\hline Any SACD goal (percent) & $67.8^{*}$ & 35.7 & 32.1 & 0.025 & $74.1^{*}$ & 39.8 & 34.3 & 0.005 & $69.7^{*}$ & 29.9 & 39.8 & 0.007 \\
\hline
\end{tabular}




\section{Table 3.13. Impacts on teacher-reported SACD classroom activities-CSP-Continued}

Panel 4: Engagement in activities to promote SACD goals linked to named SACD programs for at least 1 hour per week

\begin{tabular}{|c|c|c|c|c|c|c|c|c|c|c|c|c|}
\hline \multirow[b]{2}{*}{ SACD activity } & \multicolumn{4}{|c|}{$\begin{array}{c}\text { Year } 1 \\
\text { (Spring 3rd grade) }\end{array}$} & \multicolumn{4}{|c|}{$\begin{array}{c}\text { Year } 2 \\
\text { (Spring 4th grade) }\end{array}$} & \multicolumn{4}{|c|}{$\begin{array}{c}\text { Year } 3 \\
\text { (Spring 5th grade) }\end{array}$} \\
\hline & $\begin{array}{r}\text { Treat- } \\
\text { ment }\end{array}$ & Control & Impact & $p$-value & $\begin{array}{r}\text { Treat- } \\
\text { ment }\end{array}$ & Control & Impact & $p$-value & $\begin{array}{l}\text { Treat- } \\
\text { ment }^{3}\end{array}$ & Control & Impact & $p$-value \\
\hline Teacher sample size & 65.0 & 61.0 & & & 57.0 & 60.0 & & & 63.0 & 62.0 & & \\
\hline $\begin{array}{l}\text { Violence prevention and peace promotion } \\
\text { (percent) }\end{array}$ & $\ddagger^{*}$ & $\ddagger$ & 17.8 & 0.009 & 21.1 & 14.4 & 6.7 & 0.334 & 19.9 & 11.8 & 8.0 & 0.2 \\
\hline $\begin{array}{l}\text { Social and emotional development } \\
\text { (percent) }\end{array}$ & $\ddagger^{*}$ & $\ddagger$ & 21.4 & 0.012 & 23.9 & 5.8 & 18.1 & 0.145 & 13.5 & 0.0 & 13.5 & \\
\hline Character education (percent) & $\ddagger^{*}$ & $\ddagger$ & 23.4 & 0.005 & $28.0^{\wedge}$ & 10.9 & 17.1 & 0.055 & $\ddagger^{\wedge}$ & $\ddagger$ & 8.3 & 0.097 \\
\hline Tolerance and diversity (percent) & $\ddagger^{\wedge}$ & $\ddagger$ & 8.3 & 0.057 & 16.2 & 0.0 & 16.2 & $\dagger$ & 8.4 & 0.0 & 8.4 & \\
\hline $\begin{array}{l}\text { Risk prevention and health promotion } \\
\text { (percent) }\end{array}$ & 18.1 & 6.4 & 11.8 & 0.157 & 17.0 & 18.6 & -1.6 & 0.834 & 13.5 & 11.8 & 1.7 & 0.860 \\
\hline $\begin{array}{l}\text { Civic responsibility and community service } \\
\text { (percent) }\end{array}$ & $\ddagger$ & $\ddagger$ & 1.7 & $\dagger$ & $\ddagger$ & $\ddagger$ & -2.9 & 0.664 & 0.0 & 0.0 & 0.0 & \\
\hline Any SACD goal (percent) & $45.1^{*}$ & 10.8 & 34.3 & 0.008 & $36.8^{\wedge}$ & 25.5 & 11.3 & 0.097 & $38.7^{*}$ & 16.0 & 22.7 & 0.047 \\
\hline
\end{tabular}

$\dagger$ Not applicable.

¥ Reporting standards not met. Values suppressed to protect confidentiality.

* Treatment group significantly different from control group at the .05 level.

$\wedge$ Treatment group significantly different from control group at the .10 to $>.05$ level.

${ }^{1}$ In Year 1, the omnibus impact for all the outcomes measured together was positive and statistically significant on the basis of a multivariate statistical test.

${ }^{2}$ In Year 1 , based on univariate statistical tests, at least half of the impacts were positive and statistically significant and no impact was negative and statistically significant. In all 3 years, at least one outcome remained positive and statistically significant and no outcome was negative and statistically significant after applying the Benjamini-Hochberg (1995) procedure to adjust significance levels downward to account for the multiple testing of impacts.

${ }^{3}$ One of the treatment group schools that had been a K-5 school in prior years became a K-4 school and continued implementation of the intervention. The Cohort 1 students, who were in fifth grade during the 2006-07 school year, went to an intermediate school that had fifth and sixth grades. The intermediate school did not implement the intervention. These fifth-grade students, their primary caregivers, and their teachers were included in the spring 2007 data collection and all analyses based upon spring 2007 data.

NOTE: Weights, which assign equal weight to each school within the program, were used in producing the treatment, control, and overall means. SOURCE: The Social and Character Development (SACD) Research Program. 


\section{Use of Materials and Strategies}

For use of materials and strategies to support SACD goals, 87 comparisons were made, with 4 expected to be significant by chance. Several significant impacts were found on treatment teachers' use of materials and strategies in all 3 years. In Year 1, more treatment teachers used role-playing (impact $=20$ percentage points), direct instruction of SACD (impact $=16$ percentage points), skill training (impact $=33$ percentage points), and guided visualization (impact $=36$ percentage points) (table 3.14). In Year 2, more treatment teachers continued to use direct instruction of SACD (impact $=18$ percentage points), and more treatment teachers used teacher guides (impact $=19$ percentage points) and student materials (impact $=16$ percentage points). In Year 3, more treatment teachers used teacher guides (impact $=21$ percentage points). The average number of strategies used was significantly different in Year 1 (by 1.6 activities on average). The impact on the domain of materials and strategies was not statistically significant in any of the 3 years. Regarding the use of schoolwide strategies, 18 comparisons were made between treatment and control teacher reports, with 1 expected to be significant by chance. There were no statistically significant differences between treatment and control teacher reports on use of schoolwide strategies in any year (these data are not shown in a table). 
Table 3.14. Impacts on use of SACD classroom materials and teaching strategies-CSP

\begin{tabular}{|c|c|c|c|c|c|c|c|c|c|c|c|c|}
\hline \multirow[b]{2}{*}{ SACD material and teaching strategy } & \multicolumn{4}{|c|}{$\begin{array}{c}\text { Year } 1 \\
\text { (Spring 3rd grade) }\end{array}$} & \multicolumn{4}{|c|}{$\begin{array}{c}\text { Year } 2 \\
\text { (Spring 4th grade) }\end{array}$} & \multicolumn{4}{|c|}{$\begin{array}{c}\text { Year } 3 \\
\text { (Spring 5th grade) }\end{array}$} \\
\hline & $\begin{array}{c}\text { Treat- } \\
\text { ment }\end{array}$ & Control & Impact & $p$-value & $\begin{array}{c}\text { Treat- } \\
\text { ment }\end{array}$ & Control & Impact & $p$-value & $\begin{array}{l}\text { Treat- } \\
\text { ment }^{1} \\
\end{array}$ & Control & Impact & $p$-value \\
\hline Teacher sample size & 65 & 61 & & & 57 & 60 & & & 63 & 62 & & \\
\hline \multicolumn{13}{|l|}{ Use of SACD materials (percent) } \\
\hline Teacher guides (manuals, curricula) & 87.1 & 69.7 & 17.4 & 0.109 & $88.0^{*}$ & 69.4 & 18.6 & 0.002 & $84.1^{*}$ & 62.8 & 21.3 & 0.015 \\
\hline Student materials (workbooks or sheets) & 78.4 & 70.7 & 7.6 & 0.405 & $87.7^{*}$ & 71.8 & 15.9 & 0.004 & 74.6 & 65.7 & 9.0 & 0.221 \\
\hline Instructional aids (games, software, videos) & 49.2 & 53.9 & -4.7 & 0.690 & 54.0 & 46.0 & 7.9 & 0.469 & $60.5^{\wedge}$ & 40.4 & 20.1 & 0.096 \\
\hline Giveaways (bookmarks, stickers) & 48.1 & 72.5 & -24.4 & 0.136 & 51.1 & 52.1 & -1.0 & 0.940 & 46.4 & 60.2 & -13.9 & 0.187 \\
\hline Children's literature & 69.6 & 48.2 & 21.4 & 0.102 & 68.9 & 53.8 & 15.1 & 0.119 & 48.7 & 45.6 & 3.1 & 0.637 \\
\hline Other types of materials & 5.3 & 6.2 & -0.9 & 0.857 & $\ddagger$ & $\ddagger$ & -5.5 & 0.296 & 10.9 & 11.6 & -0.7 & 0.915 \\
\hline Did not use any of these materials & $\ddagger$ & $\ddagger$ & -6.6 & 0.206 & $\ddagger$ & $\ddagger$ & -2.5 & 0.520 & $\ddagger$ & $\ddagger$ & -8.6 & 0.111 \\
\hline \multicolumn{13}{|l|}{ Use of teaching strategies (percent) } \\
\hline Role-playing & $83.0^{*}$ & 62.6 & 20.4 & 0.034 & 85.7 & 72.3 & 13.5 & 0.111 & 87.5 & 79.9 & 7.6 & 0.282 \\
\hline Cooperative learning & $91.2^{\wedge}$ & 98.8 & -7.6 & 0.083 & 96.0 & 98.9 & -2.9 & 0.294 & 100.0 & 98.7 & 1.3 & $\dagger$ \\
\hline Peer group discussions & $94.2^{\wedge}$ & 82.8 & 11.4 & 0.064 & 93.2 & 88.5 & 4.7 & 0.249 & 98.3 & 94.1 & 4.2 & 0.255 \\
\hline Direct instruction of SACD & $98.3^{*}$ & 82.9 & 15.5 & 0.043 & $97.0^{*}$ & 79.5 & 17.6 & 0.013 & 99.0 & 95.0 & 4.1 & 0.181 \\
\hline Skill training & $69.0^{*}$ & 36.2 & 32.8 & 0.023 & 53.1 & 40.9 & 12.1 & 0.344 & 80.2 & 84.3 & -4.1 & 0.533 \\
\hline $\begin{array}{l}\text { Incorporating SACD into academic } \\
\text { curriculum }\end{array}$ & 90.6 & 78.1 & 12.5 & 0.248 & $88.1^{\wedge}$ & 74.5 & 13.6 & 0.082 & 96.3 & 93.5 & 2.8 & 0.492 \\
\hline Parent training & 10.2 & 12.8 & -2.6 & 0.700 & $\ddagger$ & $\ddagger$ & -5.2 & 0.146 & 39.6 & 30.4 & 9.3 & 0.367 \\
\hline Parent/community involvement & 25.4 & 34.5 & -9.1 & 0.397 & 31.5 & 23.1 & 8.4 & 0.424 & 51.7 & 46.9 & 4.7 & 0.600 \\
\hline Mentoring & 59.5 & 48.2 & 11.3 & 0.293 & 53.4 & 56.7 & -3.2 & 0.863 & $84.6^{\wedge}$ & 67.7 & 16.9 & 0.080 \\
\hline $\begin{array}{l}\text { Good behavior notes sent home daily } \\
\text { or weekly }\end{array}$ & 80.3 & 92.2 & -11.9 & 0.308 & 86.9 & 93.0 & -6.1 & 0.128 & 96.3 & 97.5 & -1.2 & 0.734 \\
\hline Presenting role models & 73.8 & 79.1 & -5.3 & 0.596 & 75.7 & 67.9 & 7.8 & 0.472 & 85.8 & 91.0 & -5.3 & 0.394 \\
\hline
\end{tabular}


Table 3.14. Impacts on use of SACD classroom materials and teaching strategies-CSP-Continued

\begin{tabular}{|c|c|c|c|c|c|c|c|c|c|c|c|c|}
\hline \multirow[b]{2}{*}{ SACD material and teaching strategy } & \multicolumn{4}{|c|}{$\begin{array}{c}\text { Year } 1 \\
\text { (Spring 3rd grade) } \\
\end{array}$} & \multicolumn{4}{|c|}{$\begin{array}{c}\text { Year } 2 \\
\text { (Spring 4th grade) }\end{array}$} & \multicolumn{4}{|c|}{$\begin{array}{c}\text { Year } 3 \\
\text { (Spring 5th grade) }\end{array}$} \\
\hline & $\begin{array}{c}\text { Treat- } \\
\text { ment }\end{array}$ & Control & Impact & $p$-value & $\begin{array}{r}\text { Treat- } \\
\text { ment }\end{array}$ & Control & Impact & $p$-value & $\begin{array}{l}\text { Treat- } \\
\text { ment }^{1}\end{array}$ & Control & Impact & $p$-value \\
\hline \multicolumn{13}{|l|}{$\begin{array}{l}\text { Use of teaching strategies (percent)- } \\
\text { Continued }\end{array}$} \\
\hline $\begin{array}{l}\text { Targeted story reading or writing on social } \\
\text { and character development themes }\end{array}$ & 86.2 & 75.8 & 10.4 & 0.186 & 95.8 & 85.4 & 10.3 & 0.104 & 98.0 & 93.3 & 4.7 & 0.278 \\
\hline Peer mediation & 60.3 & 40.9 & 19.4 & 0.288 & 60.0 & 59.7 & 0.3 & 0.975 & 72.2 & 68.0 & 4.2 & 0.738 \\
\hline Honor roll for positive behavior & 69.1 & 70.5 & -1.4 & 0.889 & 75.8 & 84.7 & -8.9 & 0.311 & 81.5 & 79.8 & 1.7 & 0.843 \\
\hline $\begin{array}{l}\text { Pledges or recitations on social and } \\
\text { character development themes }\end{array}$ & 51.6 & 33.7 & 17.8 & 0.228 & 49.6 & 48.8 & 0.8 & 0.962 & 74.8 & 65.7 & 9.1 & 0.578 \\
\hline Guided visualization & $74.9^{*}$ & 38.5 & 36.4 & 0.004 & 58.5 & 55.0 & 3.5 & 0.673 & 75.3 & 59.0 & 16.2 & 0.134 \\
\hline Student-led/student-assisted instruction & 67.2 & 50.9 & 16.2 & 0.198 & 57.8 & 46.2 & 11.6 & 0.245 & 78.7 & 75.2 & 3.5 & 0.697 \\
\hline Journaling & 66.8 & 76.0 & -9.1 & 0.469 & 61.0 & 62.7 & -1.7 & 0.881 & 86.2 & 81.1 & 5.1 & 0.484 \\
\hline $\begin{array}{l}\text { Time out for negative behavior } \\
\text { Daily or weekly rewards for positive }\end{array}$ & 93.7 & 93.0 & 0.7 & 0.905 & 87.9 & 88.2 & -0.3 & 0.971 & 93.2 & 93.3 & -0.1 & 0.985 \\
\hline behavior & 94.4 & 87.9 & 6.5 & 0.453 & 96.4 & 97.0 & -0.6 & 0.836 & 100.0 & 96.3 & 3.7 & $\dagger$ \\
\hline Any strategy & 100.0 & 100.0 & 0.0 & $\dagger$ & 100.0 & 100.0 & 0.0 & $\dagger$ & 100.0 & 100.0 & 0.0 & $\dagger$ \\
\hline Number of strategies (mean) & $14.2^{*}$ & 12.6 & 1.6 & 0.029 & 13.9 & 13.3 & 0.6 & 0.296 & 16.5 & 15.5 & 1.0 & 0.278 \\
\hline
\end{tabular}

† Not applicable.

† Reporting standards not met. Values suppressed to protect confidentiality.

* Treatment group significantly different from control group at the .05 level.

$\wedge$ Treatment group significantly different from control group at the .10 to $>.05$ level.

${ }^{1}$ One of the treatment group schools that had been a K-5 school in prior years became a K-4 school and continued implementation of the intervention. The Cohort 1 students, who were in fifth grade during the 2006-07 school year, went to an intermediate school that had fifth and sixth grades. The intermediate school did not implement the intervention. These fifth-grade students, their primary caregivers, and their teachers were included in the spring 2007 data collection and all analyses based upon spring 2007 data.

NOTE: Weights, which assign equal weight to each school within the program, were used in producing the treatment, control, and overall means.

SOURCE: The Social and Character Development (SACD) Research Program. 


\section{Participation in Professional Development}

Regarding reported participation in professional development, 27 comparisons were made over 3 years, with 2 expected to be significant by chance. In Year 1, CSP had a statistically significant effect on treatment teachers' participation in professional development, with more treatment teachers reporting SACD training in the past 12 months (impact $=39$ percentage points) and more hours of training (by 5 hours on average). In terms of specific SACD goals, more treatment teachers reported training in character education (impact $=38$ percentage points) and behavior management (impact $=16.3$ percentage points). In Year 3 , there was a significant impact on teachers' training in violence prevention and peace promotion (impact $=13$ percentage points). CSP had a significant impact on the domain of professional development in Year 1. 
Table 3.15. Impacts on teacher-reported SACD professional development-CSP

\begin{tabular}{|c|c|c|c|c|c|c|c|c|c|c|c|c|}
\hline \multirow[b]{2}{*}{ SACD professional development ${ }^{1}$} & \multicolumn{4}{|c|}{$\begin{array}{c}\text { Year } 1 \\
\text { (Spring 3rd grade) }\end{array}$} & \multicolumn{4}{|c|}{$\begin{array}{c}\text { Year } 2 \\
\text { (Spring 4th grade) }\end{array}$} & \multicolumn{4}{|c|}{$\begin{array}{c}\text { Year } 3 \\
\text { (Spring 5th grade) }\end{array}$} \\
\hline & $\begin{array}{r}\text { Treat- } \\
\text { ment }\end{array}$ & Control & Impact & $p$-value & $\begin{array}{r}\text { Treat- } \\
\text { ment } \\
\end{array}$ & Control & Impact & $p$-value & $\begin{array}{r}\text { Treat- } \\
\text { ment } \\
\end{array}$ & Control & Impact & $p$-value \\
\hline Teacher sample size & 65 & 61 & & & 57 & 60 & & & 63 & 62 & & \\
\hline SACD training in past 12 months (percent) & $82.0^{*}$ & 43.0 & 39.0 & 0.009 & 54.9 & 51.1 & 3.8 & 0.723 & 56.1 & 49.3 & 6.8 & 0.524 \\
\hline Hours of SACD training (mean) & $7.9^{*}$ & 2.9 & 5.0 & 0.006 & 3.8 & 6.2 & -2.4 & 0.375 & 4.9 & 4.6 & 0.3 & 0.899 \\
\hline \multicolumn{13}{|l|}{ Training by goal (percent) } \\
\hline Violence prevention and peace promotion & 21.0 & 8.2 & 12.9 & 0.143 & 8.4 & 10.8 & -2.4 & 0.753 & $\ddagger^{*}$ & $\ddagger$ & 13.1 & 0.036 \\
\hline Social and emotional development & 29.4 & 9.3 & 20.1 & 0.118 & 18.4 & 18.6 & -0.2 & 0.978 & 13.3 & 9.7 & 3.6 & 0.561 \\
\hline Character education & $57.6^{*}$ & 19.7 & 37.9 & 0.016 & 32.7 & 16.2 & 16.5 & 0.106 & 25.8 & 12.9 & 13.0 & 0.122 \\
\hline Tolerance and diversity & $23.5^{\wedge}$ & 6.9 & 16.6 & 0.071 & 8.1 & 18.2 & -10.2 & 0.273 & 21.0 & 12.9 & 8.1 & 0.231 \\
\hline Risk prevention and health promotion & 14.1 & 8.2 & 5.9 & 0.387 & 8.1 & 20.1 & -12.0 & 0.171 & 16.9 & 11.7 & 5.3 & 0.333 \\
\hline Civic responsibility and community service & 15.1 & 19.7 & -4.7 & 0.601 & $\ddagger$ & $\ddagger$ & 1.8 & 0.566 & 6.4 & 0.0 & 6.4 & $\dagger$ \\
\hline Behavior management & $35.6^{*}$ & 19.3 & 16.3 & 0.021 & 27.8 & 26.2 & 1.6 & 0.904 & 31.3 & 22.2 & 9.1 & 0.351 \\
\hline
\end{tabular}

Not applicable.

$35.6^{*} \quad 19.3 \quad 16.3 \quad 0.021$

$\ddagger$ Reporting standards not met. Values suppressed to protect confidentiality.

* Treatment group significantly different from control group at the .05 level.

$\wedge$ Treatment group significantly different from control group at the .10 to $>.05$ level.

In Year 1, at least one outcome remained positive and statistically significant and no outcome was negative and statistically significant after applying the Benjamini-Hochberg (1995) procedure to adjust significance levels downward to account for the multiple testing of impacts.

${ }^{2}$ One of the treatment group schools that had been a K-5 school in prior years became a K-4 school and continued implementation of the intervention. The Cohort 1 students, who were in fifth grade during the 2006-07 school year, went to an intermediate school that had fifth and sixth grades. The intermediate school did not implement the intervention. These fifth-grade students, their primary caregivers, and their teachers were included in the spring 2007 data collection and all analyses based upon spring 2007 data.

NOTE: Weights, which assign equal weight to each school within the program, were used in producing the treatment, control, and overall means.

SOURCE: The Social and Character Development (SACD) Research Program. 


\section{Attitudes and Practices}

Teachers reported on their enthusiasm for SACD efforts in their schools (these data are not shown in a table) by indicating enthusiasm, cooperation, or open dislike. They also reported on the SACD practices of teachers and staff members in their school (these data are not shown in a table). These practices included modeling positive character and behavior traits with students and fellow teachers, involving students in making decisions, giving students a voice in school governance, the school encouraging parent involvement in children's social and character development, and using developmentally appropriate discipline strategies rather than punishment for misbehavior. Twenty-seven comparisons were made over 3 years, with 1 expected to be significant by chance. There were no statistically significant estimated impacts on teachers' enthusiasm for SACD efforts in their schools in any of the years. There were 2 significant differences in the treatment and control teacher reports of the overall use of practices conducive to students' social and character development (out of 6 comparisons made in each year, or 18 overall); in Year 1, fewer treatment teachers reported modeling positive traits with students (impact $=-22$ percentage points), and in Year 3 more treatment teachers reported using discipline strategies that focused on promoting development rather than simply punishing for misbehavior (impact $=25$ percentage points). There was no significant impact on the domain in any year.

\section{Year-by-Year Impacts on Students and Perceptions of School Climate}

The primary research question for the CSP evaluation was this:

What is the average effect of CSP on children's social and emotional competence, behavior, academics, and perceptions of school climate?

The first approach to answering this question was to examine the year-by-year impacts of CSP on these student and school climate outcomes over the 3 years as the students progressed from third through fifth grades.

Equation (2) (described in chapter 1) was estimated to provide CSP impacts on the 20 outcomes using data from the 10 treatment and control schools. For the CSP evaluation, equation (2) excluded the program fixed effects $\left(\theta_{p}\right)$ and included program-specific covariates and random school effects covariates. Table 3.16 lists the covariates used with outcomes from each report in the CSP analysis. 
Table 3.16. Covariates used with outcomes from each report for analysis-CSP

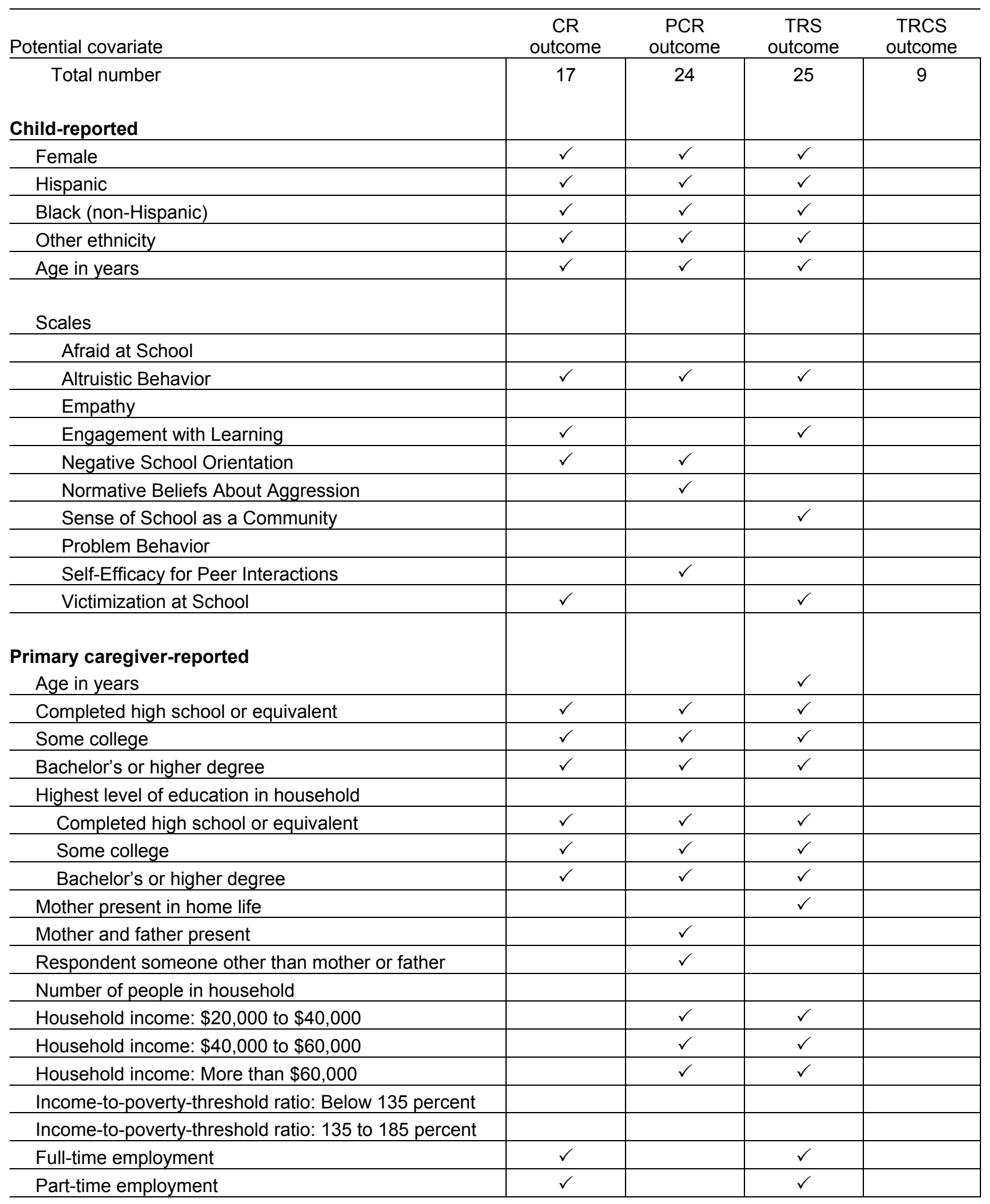

See notes at end of table. 
Table 3.16. Covariates used with outcomes from each report for analysis-CSP-Continued

\begin{tabular}{|c|c|c|c|c|}
\hline Potential covariate & $\begin{array}{c}\text { CR } \\
\text { outcome }\end{array}$ & $\begin{array}{c}\text { PCR } \\
\text { outcome }\end{array}$ & $\begin{array}{c}\text { TRS } \\
\text { outcome }\end{array}$ & $\begin{array}{c}\text { TRCS } \\
\text { outcome }\end{array}$ \\
\hline \multicolumn{5}{|l|}{ Parental scales } \\
\hline \multicolumn{5}{|c|}{ APQ-Poor Monitoring and Supervision Subscale } \\
\hline \multicolumn{5}{|c|}{ APQ-Positive Parenting Subscale } \\
\hline Child-Centered Social Control & & $\checkmark$ & & \\
\hline Confusion, Hubbub, and Order & & $\checkmark$ & & \\
\hline \multicolumn{5}{|l|}{ Community Resources } \\
\hline \multicolumn{5}{|l|}{ Community Risk } \\
\hline \multicolumn{5}{|l|}{ Parent and Teacher Involvement } \\
\hline \multicolumn{5}{|l|}{ Child scales } \\
\hline \multicolumn{5}{|l|}{ Altruistic Behavior } \\
\hline Positive Social Behavior & & & $\checkmark$ & \\
\hline \multicolumn{5}{|l|}{ Problem Behavior } \\
\hline $\begin{array}{l}\text { Teacher-reported } \\
\text { Female }\end{array}$ & & & & $\checkmark$ \\
\hline Hispanic & & & & $\checkmark$ \\
\hline Black (non-Hispanic) & & & & $\checkmark$ \\
\hline Other ethnicity & & & & $\checkmark$ \\
\hline Total teaching experience & & & & $\checkmark$ \\
\hline Total experience in current school & & & & $\checkmark$ \\
\hline Regular certificate & & & & $\checkmark$ \\
\hline Other certificate & & & & $\checkmark$ \\
\hline Highest degree-bachelor's & & & & $\checkmark$ \\
\hline \multicolumn{5}{|l|}{ Child scales } \\
\hline Academic Competence and Motivation & & $\checkmark$ & & \\
\hline ADHD-Related Behavior & & & $\checkmark$ & \\
\hline Altruistic Behavior & & $\checkmark$ & & \\
\hline \multicolumn{5}{|l|}{ Positive Social Behavior } \\
\hline Problem Behavior & & & $\checkmark$ & \\
\hline Parent and Teacher Involvement & & & & \\
\hline
\end{tabular}

NOTE: Abbreviations are

CR: Child Report

PCR: Primary Caregiver Report

TRS: Teacher Report on Student

TRCS: Teacher Report on Classroom and School

ADHD: Attention deficit hyperactivity disorder

APQ: Alabama Parenting Questionnaire

$\checkmark$ : Covariate used

Blank cell: Covariate not used

SOURCE: The Social and Character Development (SACD) Research Program. 


\section{Chapter 3. Competence Support Program}

To assess statistical power of the program-level impact estimates, minimum detectable impacts in effect size units (MDES) for each outcome measure were calculated for the CSP evaluation (table 3.17). MDES represent the smallest impacts in effect size (standard deviation) units that can be detected with a high probability $(80 \%)$. MDES are primarily a function of study sample sizes, the degrees of freedom available for statistical tests, and design effects due to clustering (Schochet 2005). For the CSP evaluation, the MDES ranged from 0.113 to 0.57 for the child-level outcomes based on the Child, Caregiver, and Teacher Report on Student and from 0.258 to 0.625 for the school climate outcomes based on the Teacher Report on Classroom and School. In general, the MDES for the school climate outcomes were larger than those for the child-level outcomes. 
Table 3.17. Adjusted minimum detectable effect sizes for impact evaluation--CSP

\begin{tabular}{|c|c|c|c|}
\hline Outcome measure-Report & Year 1 & Year 2 & Year 3 \\
\hline \multicolumn{4}{|l|}{ Social and Emotional Competence Domain } \\
\hline Self-Efficacy for Peer Interaction-CR & 0.129 & 0.184 & 0.116 \\
\hline Normative Beliefs About Aggression-CR & 0.113 & 0.154 & 0.161 \\
\hline Empathy-CR & 0.238 & 0.114 & 0.182 \\
\hline \multicolumn{4}{|l|}{ Behavior Domain } \\
\hline Altruistic Behavior-CR & 0.146 & 0.202 & 0.171 \\
\hline Altruistic Behavior-PCR & 0.216 & 0.239 & 0.169 \\
\hline Altruistic Behavior-TRS & 0.185 & 0.436 & 0.570 \\
\hline Positive Social Behavior-PCR & 0.172 & 0.172 & 0.170 \\
\hline Positive Social Behavior-TRS & 0.310 & 0.301 & 0.247 \\
\hline Problem Behavior-CR & 0.182 & 0.334 & 0.168 \\
\hline Problem Behavior-PCR & 0.210 & 0.136 & 0.226 \\
\hline Problem Behavior-TRS & 0.352 & 0.304 & 0.369 \\
\hline ADHD-Related Behavior-TRS & 0.290 & 0.206 & 0.250 \\
\hline \multicolumn{4}{|l|}{ Academics Domain } \\
\hline Engagement with Learning-CR & 0.117 & 0.173 & 0.201 \\
\hline Academic Competence and Motivation-TRS & 0.194 & 0.142 & 0.118 \\
\hline \multicolumn{4}{|l|}{ Perceptions of School Climate Domain } \\
\hline Positive School Orientation-CR & 0.113 & 0.310 & 0.371 \\
\hline Negative School Orientation-CR & 0.162 & 0.251 & 0.354 \\
\hline Student Afraid at School-CR & 0.135 & 0.222 & 0.215 \\
\hline Victimization at School-CR & 0.210 & 0.237 & 0.284 \\
\hline Feelings of Safety-TRCS & 0.541 & 0.447 & 0.562 \\
\hline Student Support for Teachers-TRCS & 0.625 & 0.309 & 0.258 \\
\hline
\end{tabular}

NOTE: Abbreviations are

CR: Child Report

PCR: Primary Caregiver Report

TRS: Teacher Report on Student

TRCS: Teacher Report on Classroom and School

ADHD: Attention deficit hyperactivity disorder

The minimum detectable effect (MDE) formula used in the calculations is as follows:

$M D E=\operatorname{factor}(d f) * \sqrt{\rho_{1}\left(\frac{1}{s_{T}}+\frac{1}{s_{C}}\right)+\left(1-\rho_{1}\right)\left(\frac{1}{s_{T} n_{T}}+\frac{1}{s_{C} n_{C}}\right)}$

where $s_{T}$ and $s_{C}$ are the number of treatment and comparison schools; $n_{T}$ and $n_{C}$ are the average number of students per classroom; $\rho_{1}$ is the intraclass correlation (ICC) at the school level; and factor(df) is a constant that depends on the number of degrees of freedom ( $d f$ ) available for analysis (and is 2.802 for the pooled analysis).

SOURCE: The Social and Character Development (SACD) Research Program. 


\section{Chapter 3. Competence Support Program}

Table 3.18 provides the estimates of CSP's impacts on each of the 20 outcomes over each of the 3 years (60 impacts in total, with 3 expected to be statistically significant by chance). Of the 60 results, 1 was statistically significant. A beneficial impact was found on fourth-graders' Problem Behavior (Primary Caregiver Report, effect size $[\mathrm{ES}]=-0.21)$. Substantively important but nonsignificant beneficial impacts were found in Year 2 for Altruistic Behavior (Teacher Report on Student, ES = 0.47) and Student Afraid at School (Child Report, ES $=-0.26$. Substantively important but nonsignificant detrimental impacts were found on fifth-graders' Altruistic Behavior (Teacher Report on Student, ES = -0.41), Positive Social Behavior (Primary Caregiver Report, ES = -0.25), and Feelings of Safety (Teacher Report on Classroom and School, ES $=-0.36$ ). Application of the heuristics to adjust for multiple comparisons within each outcome domain indicated that CSP had a significant detrimental impact on the domain of Behavior in Year 1 and a significant detrimental impact on the domain of Perceptions of School Climate in Year 3. 
Table 3.18. Impacts on child and school outcomes-CSP

\begin{tabular}{|c|c|c|c|c|c|c|c|c|c|c|c|c|}
\hline \multirow[b]{2}{*}{ Scale-Report } & \multicolumn{4}{|c|}{$\begin{array}{c}\text { Year } 1 \\
\text { (Spring 3rd grade) }\end{array}$} & \multicolumn{4}{|c|}{$\begin{array}{c}\text { Year 2 } \\
\text { (Spring 4th grade) }\end{array}$} & \multicolumn{4}{|c|}{$\begin{array}{c}\text { Year 3 } \\
\text { (Spring 5th grade) }\end{array}$} \\
\hline & $\begin{array}{r}\text { Treat- } \\
\text { ment }\end{array}$ & Control & $\begin{array}{r}\text { Effect } \\
\text { size }\end{array}$ & $p$-value & $\begin{array}{c}\text { Treat- } \\
\text { ment }\end{array}$ & Control & $\begin{array}{r}\text { Effect } \\
\text { size }\end{array}$ & $p$-value & $\begin{array}{l}\text { Treat- } \\
\text { ment }^{1}\end{array}$ & Control & $\begin{array}{r}\text { Effect } \\
\text { size }\end{array}$ & $p$-value \\
\hline \multicolumn{13}{|l|}{ Social and Emotional Competence Domain } \\
\hline Self-Efficacy for Peer Interactions-CR (+) & 3.04 & 2.97 & 0.12 & 0.199 & 3.15 & 3.15 & 0.00 & 0.978 & 3.19 & 3.22 & -0.05 & 0.581 \\
\hline Normative Beliefs About Aggression-CR (-) & 1.30 & 1.26 & 0.07 & 0.401 & 1.35 & 1.29 & 0.12 & 0.273 & 1.48 & 1.52 & -0.05 & 0.624 \\
\hline Empathy-CR (+) & 2.34 & 2.26 & 0.17 & 0.168 & 2.18 & 2.23 & -0.11 & 0.206 & 2.07 & 2.07 & -0.02 & 0.888 \\
\hline \multicolumn{13}{|l|}{ Behavior Domain ${ }^{2}$} \\
\hline Altruistic Behavior-CR (+) & 1.21 & 1.30 & -0.11 & 0.221 & 1.06 & 1.00 & 0.08 & 0.505 & 0.99 & 1.03 & -0.06 & 0.606 \\
\hline Altruistic Behavior-PCR (+) & 2.29 & 2.25 & 0.04 & 0.773 & 2.33 & 2.31 & 0.03 & 0.849 & 2.25 & 2.28 & -0.04 & 0.733 \\
\hline Altruistic Behavior-TRS (+) & 1.42 & 1.41 & 0.04 & 0.713 & 1.39 & 1.25 & $0.47^{\circ}$ & 0.132 & 1.31 & 1.55 & $-0.41^{\circ}$ & 0.132 \\
\hline Positive Social Behavior-PCR (+) & 3.04 & 3.01 & 0.06 & 0.515 & 3.11 & 3.02 & 0.17 & 0.125 & $3.03^{\wedge}$ & 3.16 & $-0.25^{\circ}$ & 0.056 \\
\hline Positive Social Behavior-TRS (+) & 2.95 & 3.05 & -0.16 & 0.241 & 3.02 & 2.93 & 0.12 & 0.426 & 3.09 & 3.01 & 0.12 & 0.386 \\
\hline Problem Behavior-CR (-) & 0.27 & 0.25 & 0.04 & 0.671 & 0.32 & 0.26 & 0.15 & 0.428 & 0.52 & 0.51 & 0.01 & 0.929 \\
\hline Problem Behavior-PCR (-) & 1.54 & 1.57 & -0.11 & 0.330 & $1.50^{*}$ & 1.56 & -0.21 & 0.042 & 1.65 & 1.50 & 0.20 & 0.218 \\
\hline Problem Behavior-TRS (-) & 1.42 & 1.38 & 0.09 & 0.566 & 1.48 & 1.50 & -0.03 & 0.852 & 1.48 & 1.44 & 0.07 & 0.712 \\
\hline ADHD-Related Behavior-TRS (-) & 1.73 & 1.74 & -0.03 & 0.826 & 1.70 & 1.74 & -0.06 & 0.585 & 1.71 & 1.74 & -0.04 & 0.764 \\
\hline \multicolumn{13}{|l|}{ Academics Domain } \\
\hline Engagement with Learning-CR (+) & 3.70 & 3.68 & 0.04 & 0.645 & 3.71 & 3.71 & -0.01 & 0.952 & 3.61 & 3.58 & 0.04 & 0.745 \\
\hline $\begin{array}{l}\text { Academic Competence and Motivation- } \\
\text { TRS (+) }\end{array}$ & 3.05 & 2.97 & 0.08 & 0.245 & 2.96 & 2.93 & 0.04 & 0.622 & 2.99 & 2.96 & 0.03 & 0.680 \\
\hline
\end{tabular}

See notes at end of table. 


\section{Table 3.18. Impacts on child and school outcomes--CSP-Continued}

\begin{tabular}{|c|c|c|c|c|c|c|c|c|c|c|c|c|}
\hline \multirow[b]{2}{*}{ Scale-Report } & \multicolumn{4}{|c|}{$\begin{array}{c}\text { Year } 1 \\
\text { (Spring 3rd grade) }\end{array}$} & \multicolumn{4}{|c|}{$\begin{array}{c}\text { Year } 2 \\
\text { (Spring 4th grade) }\end{array}$} & \multicolumn{4}{|c|}{$\begin{array}{c}\text { Year } 3 \\
\text { (Spring 5th grade) }\end{array}$} \\
\hline & $\begin{array}{r}\text { Treat- } \\
\text { ment }\end{array}$ & Control & $\begin{array}{r}\text { Effect } \\
\text { size }\end{array}$ & $p$-value & $\begin{array}{r}\text { Treat- } \\
\text { ment }\end{array}$ & Control & $\begin{array}{r}\text { Effect } \\
\text { size }\end{array}$ & $p$-value & $\begin{array}{l}\text { Treat- } \\
\text { ment }^{1}\end{array}$ & Control & $\begin{array}{c}\text { Effect } \\
\text { size }\end{array}$ & $p$-value \\
\hline \multicolumn{13}{|l|}{ Perceptions of School Climate Domain ${ }^{3}$} \\
\hline Positive School Orientation-CR (+) & $2.81^{\wedge}$ & 2.71 & 0.15 & 0.081 & 2.64 & 2.65 & -0.02 & 0.922 & 2.37 & 2.46 & -0.13 & 0.527 \\
\hline Negative School Orientation-CR (-) & 1.90 & 1.96 & -0.11 & 0.274 & 1.95 & 1.98 & -0.05 & 0.699 & 2.13 & 2.19 & -0.10 & 0.590 \\
\hline Student Afraid at School-CR (-) & 2.26 & 2.40 & -0.15 & 0.103 & $2.17^{\wedge}$ & 2.38 & $-0.26^{\circ}$ & 0.090 & 2.34 & 2.38 & -0.04 & 0.728 \\
\hline Victimization at School-CR (-) & 0.84 & 0.78 & 0.08 & 0.529 & 0.69 & 0.70 & -0.01 & 0.947 & 0.74 & 0.75 & -0.02 & 0.896 \\
\hline Feelings of Safety-TRCS (+) & 3.42 & 3.44 & -0.03 & 0.927 & 3.60 & 3.64 & -0.05 & 0.834 & 3.35 & 3.58 & $-0.36^{\circ}$ & 0.246 \\
\hline Student Support for Teachers-TRCS (+) & 3.53 & 3.56 & -0.05 & 0.890 & 3.55 & 3.48 & 0.10 & 0.551 & 3.37 & 3.45 & -0.11 & 0.550 \\
\hline
\end{tabular}

${ }^{*}$ Treatment group significantly different from control group at the .05 level.

$\wedge$ Treatment group significantly different from control group at the .10 to $>.05$ level.

- Substantive (but nonsignificant at .05 level) effect size of $\geq .25$ or $\leq-.25$.

${ }^{1}$ One of the treatment group schools that had been a K-5 school in prior years became a K-4 school and continued implementation of the intervention. The Cohort 1 students, who were in fifth grade during the 2006-07 school year, went to an intermediate school that had fifth and sixth grades. The intermediate school did not implement the intervention. These fifth-grade students, their primary caregivers, and their teachers were included in the spring 2007 data collection and all analyses based upon spring 2007 data.

${ }^{2}$ In Year 1, the statistical model used to estimate impacts on the individual outcomes was re-estimated using a composite of all the outcome variables under a domain. The domain was found significant if the impact on the composite was significant. The composite was formed by standardizing each outcome variable using its standard deviation, combining the values of the outcome variables, and taking the average of the final value.

${ }^{3}$ Impact on domain found statistically significant and negative in Year 3 based on the fourth heuristic in which the statistical model used to estimate impacts on the individual outcomes was re-estimated using a composite of all the outcome variables under a domain. The domain was found significant if the impact on the composite was significant. The composite was formed by standardizing each outcome variable using its standard deviation, combining the values of the outcome variables, and taking the average of the final value.

NOTE: Abbreviations are

CR: Child Report

PCR: Primary Caregiver Report

TRS. Teacher Report on Student

TRCS: Teacher Report on Classroom and School

ADHD: Attention deficit hyperactivity disorder

The $+/$ - signs in parentheses indicate the direction of a beneficial outcome. All Impact estimates were calculated using regression models where each program and school within a program was weighted equally. The standard errors of all estimates account for design effects due to unequal weighting and the clustering of students within schools. See Table 1.5 for information about the measures used to create the outcome variables. The effect size was calculated by dividing the estimated Impact by the standard deviation of the outcome measure for the control group. The number of results found significant was no more than expected by chance.

SOURCE: The Social and Character Development (SACD) Research Program. 


\section{Impacts on Child Outcomes Over Time}

CSP impacts on the child outcomes over time were estimated using growth curve models by examining treatment and control group differences in the trajectories of student outcomes during the follow-up period while accounting for clustering at the school level. The growth curve models are estimated using a three-level hierarchical linear model, where Level 1 corresponds to time, Level 2 to students, and Level 3 to schools (described in chapter 1).

Table 3.19 provides the estimates of CSP impacts on the growth in student outcomes over the 3 years. The estimated impacts range in effect size units (absolute value) from 0.00 to 0.30 . CSP had a statistically significant beneficial effect on 1 of the 18 estimated impacts ( 1 of 18 is expected to be significant by chance), Victimization at School (Child Report), with an effect size of -0.09 . There was a substantively important but nonsignificant detrimental impact on Altruistic Behavior (Teacher Report on Student). 
Table 3.19. Impacts on growth of child outcomes-CSP

\begin{tabular}{|c|c|c|c|c|c|c|c|}
\hline \multirow[b]{2}{*}{ Scale-Report } & \multirow[b]{2}{*}{$\begin{array}{r}\text { Mean score at } \\
\text { implementation }\end{array}$} & \multicolumn{6}{|c|}{ Average growth in the score per year ${ }^{1}$} \\
\hline & & Treatment & Control & $\begin{array}{l}\text { Impact on } \\
\text { growth }^{3}\end{array}$ & $\begin{array}{l}\text { Effect } \\
\text { size }^{4}\end{array}$ & $\begin{array}{r}\text { Standard } \\
\text { error of } \\
\text { impact }\end{array}$ & $\begin{array}{r}p \text {-value of } \\
\text { impact }\end{array}$ \\
\hline \multicolumn{8}{|l|}{ Social and Emotional Competence Domain } \\
\hline Self-Efficacy for Peer Interactions-CR (+) & 2.94 & 0.13 & 0.12 & 0.00 & 0.00 & 0.03 & 0.974 \\
\hline Normative Beliefs About Aggression-CR (-) & 1.20 & 0.12 & 0.06 & 0.05 & 0.11 & 0.04 & 0.207 \\
\hline Empathy-CR (+) & 2.40 & -0.12 & -0.12 & -0.01 & -0.03 & 0.02 & 0.560 \\
\hline \multicolumn{8}{|l|}{ Behavior Domain } \\
\hline Altruistic Behavior-CR (+) & 1.41 & -0.20 & -0.16 & -0.04 & -0.04 & 0.03 & 0.208 \\
\hline Altruistic Behavior-PCR (+) & 2.31 & -0.01 & -0.01 & 0.01 & 0.01 & 0.03 & 0.872 \\
\hline Altruistic Behavior-TRS (+) & 1.40 & $-0.08^{\wedge}$ & 0.07 & -0.15 & -0.30 & 0.07 & 0.075 \\
\hline Positive Social Behavior-PCR (+) & 3.01 & 0.01 & 0.04 & -0.02 & -0.04 & 0.02 & 0.247 \\
\hline Positive Social Behavior-TRS (+) & 2.96 & 0.04 & 0.01 & 0.03 & 0.03 & 0.05 & 0.580 \\
\hline Problem Behavior-CR (-) & 0.19 & 0.12 & 0.08 & 0.03 & 0.07 & 0.03 & 0.273 \\
\hline Problem Behavior-PCR (-) & 1.57 & 0.01 & -0.01 & 0.02 & 0.05 & 0.01 & 0.219 \\
\hline Problem Behavior-TRS (-) & 1.36 & 0.07 & 0.05 & 0.02 & 0.05 & 0.03 & 0.563 \\
\hline ADHD-Related Behavior-TRS (-) & 1.76 & -0.02 & 0.00 & -0.01 & -0.02 & 0.03 & 0.717 \\
\hline \multicolumn{8}{|l|}{ Academics Domain } \\
\hline Engagement with Learning-CR (+) & 3.69 & -0.02 & -0.01 & -0.01 & -0.01 & 0.03 & 0.871 \\
\hline Academic Competence and Motivation-TRS (+) & 2.94 & 0.01 & 0.03 & -0.02 & -0.02 & 0.03 & 0.593 \\
\hline
\end{tabular}


Table 3.19. Impacts on growth of child outcomes-CSP-Continued

\begin{tabular}{|c|c|c|c|c|c|c|c|}
\hline \multirow[b]{2}{*}{ Scale-Report } & \multirow[b]{2}{*}{$\begin{array}{r}\text { Mean score at } \\
\text { implementation }\end{array}$} & \multicolumn{6}{|c|}{ Average growth in the score per year ${ }^{1}$} \\
\hline & & Treatment & Control & $\begin{array}{r}\text { Impact on } \\
\text { growth }^{3}\end{array}$ & $\begin{array}{l}\text { Effect } \\
\text { size }^{4}\end{array}$ & $\begin{array}{r}\text { Standard } \\
\text { error of } \\
\text { impact } \\
\end{array}$ & $\begin{array}{r}p \text {-value of } \\
\text { impact }\end{array}$ \\
\hline \multicolumn{8}{|l|}{ Perceptions of School Climate Domain } \\
\hline Positive School Orientation-CR (+) & 3.03 & -0.26 & -0.19 & -0.07 & -0.09 & 0.05 & 0.213 \\
\hline Negative School Orientation-CR (-) & 1.87 & 0.08 & 0.10 & -0.01 & -0.02 & 0.04 & 0.744 \\
\hline Student Afraid at School-CR (-) & 2.41 & -0.09 & -0.03 & -0.06 & -0.06 & 0.03 & 0.111 \\
\hline Victimization at School-CR (-) & 0.82 & $-0.09^{*}$ & -0.01 & -0.08 & -0.09 & 0.03 & 0.050 \\
\hline
\end{tabular}

* Treatment group significantly different from control group at the .05 level.

$\wedge$ Treatment group significantly different from control group at the .10 to $>.05$ level.

${ }^{1}$ Pertains to the estimated slope of the outcome for the treatment or control groups.

${ }^{2}$ The average score at implementation is calculated across treatment and control groups, using regression models for adjustment on covariates.

${ }^{3}$ Estimated difference between the slope of the treatment and control groups.

${ }^{4}$ Effect size: The slope of the treatment group minus the slope of the control group divided by the standard deviation of the outcome for the program's control group (the standard deviation is calculated without accounting for school-level clustering or regression adjustments).

NOTE: Abbreviations are

CR: Child Report

PCR: Primary Caregiver Report

TRS: Teacher Report on Student

ADHD: Attention deficit hyperactivity disorder

The +/- signs in parentheses indicate the direction of a beneficial outcome. All impact estimates were calculated using HLM 6.06. Sample weights were used in all analyses to give (1) each school equal weight in each program (within each time period) and (2) each time period equal weight within the analysis. See table 1.5 for information about the measures used to create the outcome variables.

SOURCE: The Social and Character Development (SACD) Research Program. 


\section{Summary}

As part of the Social and Character Development (SACD) Research Program, researchers at the North Carolina site implemented and evaluated CSP, a program focused on social skills training, social and emotional learning, behavior management, and social dynamics management. Ten public schools in two school districts in North Carolina were recruited by the research team and randomly assigned to treatment and control conditions to determine the impact of CSP on social and character development activities in the schools and on the child outcome domains of Social and Emotional Competence, Behavior, Academics, and Perceptions of School Climate.

Analyses of the initial characteristics of the sample (students, caregivers, communities, teachers, and schools) indicated that randomization to treatment and control status produced groups that were relatively similar at the start of the study (with 2 out of 84 comparisons statistically significantly different, fewer than would be expected by chance). The data on the initial level of SACD activity led to two findings. First, treatment teachers reported greater use of and training in SACD activities than did control teachers, and they did so more often than would be expected by chance ( 6 out of 62 comparisons, with 3 expected significant by chance). There are two potential causes for this finding, and the analysis cannot be used to determine whether the reason for such a difference was that the two groups did differ on their initial use of SACD activities (i.e., that randomization did not create similar treatment and control groups) or the fact that the training of all treatment teachers and CSP implementation began before the initial data were collected (by 4 weeks), which may have influenced the teacher reports. Because it is likely (though unproven) that the training and implementation affected the teacher reports, these data were not considered appropriate for use as a baseline measure of SACD activities and training in the treatment schools.

Second, these data indicate that the control condition for the SACD project was not a "no treatment" control but a "standard practice" control. Because the control teachers were not affected by the implementation of the SACD programs before data collection, their reports reflected standard practice in the control schools. Standard practice at the control schools included 52 percent to 93 percent of teachers reporting the use of any SACD activities, 88 percent of teachers reporting the use of specific materials in conjunction with these activities, 100 percent reporting the use of at least one of the specified instructional strategies, and 52 percent reporting participation in SACD training over the past 12 months.

Analyses of CSP impacts on the use of SACD activities in the schools revealed impacts on the use of such activities (18 out of 90 comparisons) and related materials and strategies ( 8 out of 87 comparisons) across the 3 years, and use of more professional development activities for treatment teachers (5 out of 27 comparisons). These same measures in the control schools across the 3 years of the study confirm that use of these activities in the control schools constituted their standard practice.

Of the 20 child-level outcomes representing the four domains of Social and Emotional Competence, Behavior, Academics, and Perceptions of School Climate assessed in each of the 3 years of the study (a total of 60 results), CSP had a statistically significant beneficial impact on Problem Behavior (Primary Caregiver Report) in Year 2. A growth curve analysis was used to analyze the change over time in these same outcomes between initial data collection and the final outcome data collection at the end of the study. Of the 18 childlevel outcomes assessed, CSP had a significant beneficial impact on the trajectory of 1, Victimization at School (Child Report).

The SACD evaluation did not find evidence to support the hypothesis that CSP had beneficial impacts on students' social and character development. Such results could be caused by the inability of the program to cause such change, possibly because the theory of action for the program is incomplete or the activities to carry out that theory are not effective.

However, these results may also be due to the inability of the evaluation to observe such a change due to the control condition, differences in initial conditions, the level of nonparticipation, or the sample size. The 


\section{Chapter 3. Competence Support Program}

control schools continued using their standard SACD activities, and these turned out to be high in quantity and broad in scope. Under the Student Citizen Act of 2001, character education was made a required part of the standard curriculum for North Carolina schools starting in the 2002-03 school year, and this may have been a factor in high SACD activity in the control schools. While the CSP program had significant positive impact on the amount and type of SACD activities, the resulting difference in the amount of SACD activities between the treatment and control school may not have been large enough to cause significant differences in the student outcomes.

Second, there were differences between the treatment and control groups that might also be related to differences in outcomes. Treatment teachers had less teaching experience in their current schools and treatment students reported greater negative school orientation (both statistically significant differences, although no more than expected by chance). For Year 3, the treatment students at one school did not receive the intervention when they were transferred to a new school for fifth grade when their former school dropped fifth grade.

Third, about one-third of the students in the sample universe did not take part because of nonconsent or noncompletion of the surveys. As a determination could not be made as to whether the students not taking part differed significantly from those who did take part, the evaluation's results are valid only for the students who took part. If the students not taking part were different, and if they would have responded better to CSP than to the SACD activities occurring in the control schools, then the evaluation could have underestimated the program's impact. In addition, significantly lower percentages of treatment teachers and students provided data in Year 3, and there were significantly larger percentages of treatment leavers in Years 2 and 3.

Finally, the sample size of 10 schools and the resulting higher MDES than for the multiprogram evaluation may have reduced the likelihood of detecting statistically significant effects. However, it should be noted that 67 percent of the MDES for the 60 outcomes used in the year-by-year analysis were below 0.25 (42\% were below 0.20 ). In addition, 5 of the 60 outcomes were found to be substantively important, but 3 of these had detrimental impacts. 


\title{
Chapter 4. Love In a Big World
}

\author{
Vanderbilt University \\ (Tennessee Site)
}

\section{Intervention}

Researchers at Vanderbilt University (Tennessee site) evaluated the Love In a Big World (LBW) program as implemented by program staff. The curriculum is based on research conducted by the Social Development Research Group at the University of Washington and on asset development research conducted by the Search Institute. This character education program includes classroom lesson plans, staff and principal training, a peer recognition program, service projects, assembly programs, motivational morning announcements, and newsletters that aim to teach children positive character traits and moral principles and how to apply them in their lives. Table 4.1 describes LBW's general characteristics (panel 1), the types of instruction and strategies used (panel 2), the professional development provided for those implementing the program (panel 3), and the social and character development activities (panel 4) and outcomes (panel 5) addressed by the program. The program is designed to encourage wise decisionmaking, improve peer relationships, and promote dialogue about character choices. The program includes the following elements:

- Adults teach and model character traits such as honesty, kindness, responsibility, self-control, moderation, perseverance, respect, fairness, cooperation, and love.

- Classroom strategies for teaching character traits involve story reading, writing, discussion, song, and other classroom activities that occur daily in 10- to 15-minute lessons for 30 weeks. Teachers utilize behavior management strategies to reward exhibition of character traits and are encouraged to model and reinforce social skills throughout the day.

- Schoolwide strategies for teaching character traits include weekly announcements, assemblies, service projects, parent newsletters, and visual artifacts that illustrate character traits (e.g., posters and banners).

- Principals, teachers, and school staff participate in a workshop on lesson planning and on the logistics of program implementation at the start of each school year. In the first year of implementation, this workshop is 3 hours long, and in subsequent years it is 1 hour long. 


\section{Table 4.1. Love In a Big World}

Panel 1: General characteristics

Target population

Universal

Program components

Peer: In and out of class

Parent: Contact and involvement

Classroom: Lessons and behavior management

Schoolwide: Planned events, modeling, and program artifacts

Community: None or not major focus

Training: Pretraining and ongoing

Level of integration

Add-on curriculum and schoolwide activities

Flexibility

Manualized: Curriculum guidebook

Adaptability: Less adaptable

See notes at end of table.

Panel 2: Description of instruction and strategies

Classroom

Lessons

Who delivers: Teacher

Activities and tools: Story reading, writing, interdisciplinary activities, rewards, singing

Content: Character traits and moral virtues

Frequency: Daily 10- to 15-minute lessons for 30 weeks

Strategies

Who delivers: Teacher

Activities and tools: Recognition and reinforcement of good behavior; modeling of character traits

Frequency: Daily

Supplement to classroom

Parent newsletters

Schoolwide activities

Weekly announcements, occasional assemblies, two service projects, program artifacts

See notes at end of table. 
Table 4.1. Love In a Big World-Continued

Panel 3: Professional development

Pre-implementation

Teachers

Content: Workshop on lesson plans and logistics of program

Duration: 3 hours

Other

Content: Principal and staff training on same material as teachers

Duration: 3 hours

Ongoing consultation

Teachers

Content: Faculty boosters with reminders about program implementation and discussion of challenges

Duration: 24 weekly sessions; biannual meeting

Other

Content: Program coordinator; calls with program developer to improve schoolwide implementation

Duration: Once every 6 months

See notes at end of table.

Panel 4: Activities for SACD goals

\begin{tabular}{ll|l}
\hline Violence prevention and peace promotion & $\checkmark$ & Risk prevention and health promotion \\
Social and emotional development & $\checkmark$ & Civic responsibility and community service \\
Character education & $\checkmark$ & Behavior management \\
Tolerance and diversity & $\checkmark$ & \\
\hline
\end{tabular}

See notes at end of table.

Panel 5: SACD outcomes addressed

\begin{tabular}{ll|ll}
\hline Engagement with Learning & & Empathy & $\checkmark$ \\
Academic Competence and Motivation & & Positive School Orientation & $\checkmark$ \\
Altruistic Behavior & $\checkmark$ & Negative School Orientation & $\checkmark$ \\
Positive Social Behavior & $\checkmark$ & Student Afraid at School & $\checkmark$ \\
Problem Behavior & $\checkmark$ & Victimization at School & $\checkmark$ \\
Self-Efficacy for Peer Interactions & & Feelings of Safety & $\checkmark$ \\
Normative Beliefs About Aggression & & Student Support for Teachers & \\
\hline
\end{tabular}

NOTE: Abbreviations are

$\checkmark$ : Activity or outcome addressed

Blank cell: Activity or outcome not addressed

SOURCE: The Social and Character Development (SACD) Research Program. 


\section{Sample and Random Assignment}

The Tennessee research team recruited a total of 12 public elementary schools in 2 school districts in 2 separate counties in Tennessee. The 12 schools were randomly assigned to treatment and control conditions prior to the fall 2004 data collection period.48 A two-step process was used. First, a computer-generated pairwise matching algorithm developed by Mathematica Policy Research, Inc. (MPR) identified the best pairwise matches across the 12 schools based on (a) school district, (b) percentages of students eligible for free or reduced-price lunch, (c) total mobility rate, (d) Tennessee assessment scores, (e) total number of students, ( $f$ ) promotion level, and $(\mathrm{g})$ percentages of students who were members of a minority population. Second, using the flip of a coin, 1 school in each matched pair was assigned to either the intervention or control condition, resulting in 6 schools receiving LBW and 6 schools acting as control schools that continued to implement the social and character development activities that constituted their standard practice. Assignment to the treatment or control condition was at the school level and therefore limited the risk of contamination between treatment and control classrooms. After the first year, 1 control school discontinued involvement because it became a magnet school, resulting in a total of 11 schools in the study, with 6 in the treatment condition and 5 in the control condition.

The original student sample (the cohort of students in the third grade in the 12 schools in fall 2004) numbered 986 students (548 treatment and 438 control). Table 4.2 documents the changes in the sample over the three spring follow-up data collection points. Over time, new entrants to the cohort became a larger percentage of the sample, making up 28 percent of the sample by the spring of Year 3 . There were no statistically significant differences between the treatment and control groups in the numbers of new entrants. The percentage of the sample made up of the original cohort further declined as students left the schools. By Year 3, approximately 31 percent of the original sample had left. In Years 1 and 3 there were statistically significant differences in "leavers" between treatment and control groups (in both cases, there were fewer in the treatment group).

\footnotetext{
48 In Year 2 (fall 2005), the Tennessee research team recruited two more schools, one assigned to treatment and one assigned to control, which were followed to the end of the study (spring 2007). A description of this second cohort and all relevant findings can be found in appendix A. The data from this second cohort are not included in the analyses and results reported in this chapter.
} 
Table 4.2. Sample-LBW

\begin{tabular}{|c|c|c|c|c|c|c|c|c|c|c|c|c|}
\hline \multirow[b]{2}{*}{ Characteristic } & \multicolumn{3}{|c|}{$\begin{array}{c}\text { Year } 1 \\
\text { (Fall 3rd grade) }\end{array}$} & \multicolumn{3}{|c|}{$\begin{array}{c}\text { Year } 1 \\
\text { (Spring 3rd grade) }\end{array}$} & \multicolumn{3}{|c|}{$\begin{array}{c}\text { Year } 2 \\
\text { (Spring 4th grade) } \\
\end{array}$} & \multicolumn{3}{|c|}{$\begin{array}{c}\text { Year } 3 \\
\text { (Spring 5th grade) } \\
\end{array}$} \\
\hline & Total & $\begin{array}{r}\text { Treat- } \\
\text { ment }\end{array}$ & Control & Total & $\begin{array}{r}\text { Treat- } \\
\text { ment }\end{array}$ & Control & Total & $\begin{array}{r}\text { Treat- } \\
\text { ment }\end{array}$ & Control & Total & $\begin{array}{r}\text { Treat- } \\
\text { ment }\end{array}$ & Control \\
\hline School sample size & 12 & 6 & 6 & 12 & 6 & 6 & 11 & 6 & $5^{1}$ & 11 & 6 & $5^{1}$ \\
\hline Student sample size & 986 & 548 & 438 & 1,007 & 565 & 442 & 959 & 556 & 403 & 944 & 567 & 377 \\
\hline Stayers & $\dagger$ & $\dagger$ & $\dagger$ & 926 & 523 & 403 & 758 & 438 & 320 & 678 & 403 & 275 \\
\hline New entrants & $\dagger$ & $\dagger$ & $\dagger$ & 81 & 42 & 39 & 201 & 118 & 83 & 266 & 164 & 102 \\
\hline $\begin{array}{l}\text { New entrants as a percent of } \\
\text { spring enrollment }\end{array}$ & $\dagger$ & $\dagger$ & $\dagger$ & 8.0 & 7.4 & 8.8 & 21.0 & 21.2 & 20.6 & 28.2 & 28.9 & 27.1 \\
\hline $\begin{array}{l}\text { Total leavers (from original } \\
\text { cohort) }\end{array}$ & $\dagger$ & $\dagger$ & $\dagger$ & 60 & 25 & 35 & 228 & 110 & 118 & 308 & 145 & 163 \\
\hline $\begin{array}{l}\text { Leavers as a percent of fall } \\
2004 \text { enrollment }\end{array}$ & $\dagger$ & $\dagger$ & $\dagger$ & 6.1 & $4.6^{*}$ & 8.0 & 23.1 & 20.1 & 26.9 & 31.2 & $26.5^{* *}$ & 37.2 \\
\hline $\begin{array}{l}\text { Number of students per school } \\
\quad \text { (mean) }\end{array}$ & 82 & 91 & 73 & 84 & 94 & 74 & 87 & 93 & 76 & 86 & 95 & 75 \\
\hline $\begin{array}{l}\text { Range of number of students per } \\
\text { school }\end{array}$ & $40-138$ & $57-138$ & $40-111$ & $44-141$ & $58-141$ & $44-111$ & $45-151$ & $45-151$ & $45-112$ & $34-164$ & $47-164$ & $34-113$ \\
\hline
\end{tabular}

* Treatment group significantly different from control group at the .05 level.

** Treatment group significantly different from control group at the .01 level.

${ }^{1}$ One control group school discontinued involvement because it became a magnet school.

SOURCE: The Social and Character Development (SACD) Research Program. 


\section{Implementation}

\section{Training}

Teachers, principals, and school staff members in the intervention schools received 3 hours of program implementation training in the form of a workshop prior to the beginning of the first school year (table 4.1, panel 3). In the second and third years of the study, a 1-hour workshop was provided at the start of the school year. Teachers had access to ongoing program implementation support during the school year through 24 weekly faculty booster sessions that were provided to each school's program coordinator and could be emailed to the faculty. There were also biannual meetings that included reminders about lesson planning and discussions of program implementation challenges. In addition, the school program coordinator received monthly (in Year 1) or biannual (in later years, in accordance with school feedback) calls from program staff to answer questions and provide assistance or any required materials.

\section{Data Collection}

MPR collected the multiprogram child, teacher, and school data at the Tennessee site. Table 4.3 shows the school year milestones and dates of implementation for the Tennessee site. Data were collected in the fall and spring of the first 2 years and the spring of Year 3. The fall 2004 multiprogram data collection began on August 23, 2004, and ended on September 9, 2004. Fall data collection occurred before implementation of LBW began. The spring data collection window was from May 2, 2005, to May 20, 2005. The program had been implemented for 33 weeks at the time of the spring data collection and for 34 weeks from the end of the fall data collection. Year 2 followed a similar pattern, with implementation occurring at the start of the school year, fall data collection occurring 5 weeks later, and spring data collection occurring 31 weeks after fall data collection (and 40 weeks after the start of implementation). In spring 2007, data collection occurred 40 weeks after the start of implementation. Data collection took from 3 to 5 weeks at each collection point. 
Table 4.3. Data collection dates-LBW

\begin{tabular}{|c|c|c|c|c|c|}
\hline Data collection schedule & $\begin{array}{c}\text { Year } 1 \\
\text { (Fall 3rd grade) }\end{array}$ & $\begin{array}{c}\text { Year } 1 \\
\text { (Spring 3rd grade) }\end{array}$ & $\begin{array}{c}\text { Year } 2 \\
\text { (Fall 4th grade) }\end{array}$ & $\begin{array}{c}\text { Year } 3 \\
\text { (Spring 4th grade) }\end{array}$ & $\begin{array}{c}\text { Year } 4 \\
\text { (Spring 4th grade) }\end{array}$ \\
\hline School sample size & 12 & 12 & 11 & 10 & 10 \\
\hline \multicolumn{6}{|l|}{ School year dates } \\
\hline First day of school & $\begin{array}{l}7 / 14 / 04 \\
7 / 4 / 04^{1}\end{array}$ & $\dagger$ & $\begin{array}{l}7 / 26 / 05 \\
8 / 11 / 05^{4}\end{array}$ & $\dagger$ & $\begin{array}{l}7 / 24 / 06 \\
8 / 10 / 06\end{array}$ \\
\hline Start of implementation & $9 / 13 / 04$ & $\dagger$ & First day & $\dagger$ & First day \\
\hline Last day of school & $\dagger$ & $\begin{array}{c}5 / 26 / 05 \\
6 / 2 / 05^{2}\end{array}$ & $\dagger$ & $\begin{array}{c}5 / 25 / 06 \\
6 / 1 / 06^{5}\end{array}$ & $\begin{array}{c}5 / 25 / 07 \\
6 / 1 / 07^{7}\end{array}$ \\
\hline \multicolumn{6}{|l|}{ Data collection } \\
\hline Start & $8 / 23 / 04$ & $5 / 2 / 05$ & $8 / 29 / 05$ & $5 / 1 / 06$ & $5 / 1 / 07$ \\
\hline End & $9 / 9 / 04$ & $5 / 20 / 05$ & $9 / 23 / 05$ & $5 / 19 / 06$ & $5 / 16 / 07$ \\
\hline $\begin{array}{l}\text { Calendar weeks from } \\
\text { program implementation } \\
\text { to start of fall } 2004 \text { data } \\
\text { collection }\end{array}$ & $t^{3}$ & $\dagger$ & $\dagger$ & $\dagger$ & $\dagger$ \\
\hline $\begin{array}{l}\text { Calendar weeks from } \\
\text { start of school to start } \\
\text { of fall data collection }\end{array}$ & $6^{1}$ & $\dagger$ & $5^{4}$ & $\dagger$ & $\dagger$ \\
\hline $\begin{array}{l}\text { Calendar weeks from end } \\
\text { of fall data collection to } \\
\text { start of spring data } \\
\text { collection }\end{array}$ & $\dagger$ & 34 & $\dagger$ & 31 & $\dagger$ \\
\hline $\begin{array}{l}\text { Calendar weeks from } \\
\text { program implementation } \\
\text { to start of spring data } \\
\text { collection }\end{array}$ & $\dagger$ & 33 & $\dagger$ & $40^{4}$ & $40^{6}$ \\
\hline
\end{tabular}

† Not applicable.

${ }^{1}$ Eight schools started on $7 / 14 / 04$ and four started on $8 / 4 / 04$. The calculation of weeks from the start of school to the start of fall 2004 data collection uses $7 / 14 / 04$ as the first day of the school year.

${ }^{2}$ Eight schools ended on $5 / 26 / 05$ and four ended on 6/2/05. The calculation of weeks from program implementation to the end of the school year uses $5 / 26 / 05$ as the last day of the school year.

${ }_{3}^{3}$ Program implementation occurred after fall 2004 data collection.

${ }^{4}$ Eight schools started on $7 / 25 / 05$ and $7 / 27 / 05$ and four started on $8 / 11 / 05$. The calculation of weeks from the start of school to the start of data collection uses $7 / 26 / 05$ as the first day of the school year.

${ }^{5}$ Eight schools ended on 5/25/06 and four ended on 6/1/06.

${ }^{6}$ Nine schools started between $7 / 24 / 06$ and $7 / 26 / 06$ and two started on 8/10/06. The calculation of weeks from the start of school to the start of spring 2007 data collection uses $7 / 26 / 06$ as the first day of the school year.

${ }^{7}$ Six schools ended on 5/25/07, three ended on 5/31/07, and two ended on 6/1/07.

SOURCE: The Social and Character Development (SACD) Research Program. 


\section{Consent Rates, Completion Rates, and Percentage of Sample With Data}

The actual number of student, primary caregiver, and teacher reports available for analysis was smaller than the number in the sample because consent and completion rates were less than 100 percent. Primary caregivers had to provide consent before children could complete the Child Report, before teachers could complete the Teacher Report on Student, and before they themselves completed the Primary Caregiver Report. Teachers also had to provide consent before completing the Teacher Report on Classroom and School. Of those with consent, not all completed their respective reports. Table 4.4 shows the consent rates, completion rates, and percentages of sample with data for each of the four reports over the 3 years. For the Child Report and two teacher reports, completion rates ranged from 84 percent to 100 percent, so the consent rates had the most influence on what percentage of the sample had data. There were no statistically significant differences between treatment and control groups in consent rates for any of these reports. For the Primary Caregiver Report, the completion rates dropped over time from 95 percent to 74 percent.

The percentages of the sample with Child Report data ranged from 58 percent to 62 percent over the 3 years. The percentages of students with information from the Teacher Report on Student ranged from 62 percent to 68 percent. The percentages of students with data from the Primary Caregiver Report ranged from 46 percent to 65 percent and declined over time. The percentages of teachers with data from the Teacher Report on Classroom and School ranged from 84 percent to 97 percent. There were no statistically significant differences between treatment and control conditions in percentages of students with data for any of the four reports. 
Table 4.4. Consent rates, completion rates, and percentage of sample with data from each report-LBW

\begin{tabular}{|c|c|c|c|c|c|c|c|c|c|c|c|c|}
\hline \multirow[b]{2}{*}{ Report } & \multicolumn{3}{|c|}{$\begin{array}{c}\text { Year } 1 \\
\text { (Fall 3rd grade) } \\
\end{array}$} & \multicolumn{3}{|c|}{$\begin{array}{c}\text { Year } 1 \\
\text { (Spring 3rd grade) }\end{array}$} & \multicolumn{3}{|c|}{$\begin{array}{c}\text { Year } 2 \\
\text { (Spring 4th grade) }\end{array}$} & \multicolumn{3}{|c|}{$\begin{array}{c}\text { Year } 3 \\
\text { (Spring 5th grade) } \\
\end{array}$} \\
\hline & Total & $\begin{array}{c}\text { Treat- } \\
\text { ment }\end{array}$ & Control & Total & $\begin{array}{r}\text { Treat- } \\
\text { ment }\end{array}$ & Control & Total & $\begin{array}{r}\text { Treat- } \\
\text { ment }\end{array}$ & Control & Total & $\begin{array}{c}\text { Treat- } \\
\text { ment }\end{array}$ & Control \\
\hline Student sample size & 986 & 548 & 438 & 1,007 & 565 & 442 & 959 & 556 & 403 & 944 & 567 & 377 \\
\hline \multicolumn{13}{|l|}{ Child Report (percent) } \\
\hline Primary caregiver consent rate & 65.7 & 67.9 & 63.0 & 66.3 & 68.1 & 64.0 & 64.4 & 65.5 & 63.0 & 64.9 & 66.0 & 63.4 \\
\hline Student completion rate & 91.5 & 90.6 & 92.8 & 91.6 & 89.9 & 94.0 & 93.7 & 92.3 & 95.7 & 90.2 & 89.6 & 91.2 \\
\hline Students with data ${ }^{1}$ & 60.1 & 61.5 & 58.4 & 60.8 & 61.4 & 60.0 & 60.4 & 60.4 & 60.3 & 58.6 & 59.1 & 57.8 \\
\hline \multicolumn{13}{|l|}{ Primary Caregiver Report (percent) } \\
\hline Primary caregiver consent rate & 65.7 & 67.9 & 63.0 & 66.2 & 68.0 & 64.0 & 64.2 & 65.1 & 63.0 & 63.9 & 64.6 & 62.9 \\
\hline Primary caregiver completion rate & 95.2 & 95.4 & 94.9 & 80.2 & 79.2 & 81.6 & 79.7 & 81.2 & 77.6 & 73.5 & 70.8 & 77.6 \\
\hline Primary caregivers with data ${ }^{1}$ & 62.6 & 64.8 & 59.8 & 53.1 & 54.0 & 52.0 & 51.2 & 52.9 & 48.9 & 46.9 & 45.7 & 48.8 \\
\hline \multicolumn{13}{|l|}{ Teacher Report on Student (percent) } \\
\hline Primary caregiver consent rate ${ }^{2}$ & 65.7 & 67.9 & 63.0 & 66.3 & 68.1 & 64.0 & 64.4 & 65.5 & 63.0 & 64.9 & 66.0 & 63.4 \\
\hline Teacher completion rate & 97.8 & 97.6 & 98.2 & 99.7 & 99.5 & 100.0 & 100.0 & 100.0 & 100.0 & 98.0 & $96.8^{* *}$ & 100.0 \\
\hline Students with data ${ }^{1}$ & 64.3 & 66.3 & 61.9 & 66.1 & 67.8 & 63.8 & 64.4 & 65.5 & 63.0 & 63.7 & 63.8 & 63.4 \\
\hline \multicolumn{13}{|c|}{$\begin{array}{l}\text { Teacher Report on Classroom and School } \\
\text { (3rd- to 5th-grade teachers) (percent) }\end{array}$} \\
\hline Teacher consent rate & 99.3 & 100.0 & 98.5 & 100.0 & 100.0 & 100.0 & 97.0 & 97.4 & 96.3 & 100.0 & 100.0 & 100.0 \\
\hline Teacher completion rate & 89.0 & $84.0^{*}$ & 95.3 & 95.9 & 95.2 & 96.9 & 90.6 & 92.1 & 88.5 & 91.9 & 90.4 & 94.3 \\
\hline Teachers with data $^{1}$ & 88.4 & 84.0 & 93.8 & 95.9 & 95.2 & 96.9 & 87.9 & 89.7 & 85.2 & 91.9 & 90.4 & 94.3 \\
\hline
\end{tabular}

* Treatment group significantly different from control group at the .05 level.

** Treatment group significantly different from control group at the .01 level.

${ }^{1}$ Calculated as consent rate $x$ completion rate.

${ }^{2}$ The primary caregiver consent rates for the Child Report and the Teacher Report on Student are identical, as the primary caregiver gave consent to both together.

SOURCE: The Social and Character Development (SACD) Research Program. 
Responses from students in the original cohort (stayers) and new entrants in the LBW sample were examined to investigate possible differences between the two groups in consent rates, completion rates, and the percentages of sample with data that might affect outcome data (table 4.5). In all 3 years, stayers had significantly higher consent rates (by 18 to 32 percentage points) and higher percentages of sample with data (by 8 to 33 percentage points) than did new entrants. 
Table 4.5. Consent rates, completion rates, and percentage of sample with data: Stayers versus new entrants--LBW

\begin{tabular}{|c|c|c|c|c|c|c|c|c|c|}
\hline \multirow[b]{2}{*}{ Report } & \multicolumn{3}{|c|}{$\begin{array}{c}\text { Year } 1 \\
\text { (Spring 3rd grade) } \\
\end{array}$} & \multicolumn{3}{|c|}{$\begin{array}{c}\text { Year } 2 \\
\text { (Spring 4th grade) } \\
\end{array}$} & \multicolumn{3}{|c|}{$\begin{array}{c}\text { Year } 3 \\
\text { (Spring 5th grade) }\end{array}$} \\
\hline & Total & Stayers & $\begin{array}{r}\text { New } \\
\text { entrants }\end{array}$ & Total & Stayers & $\begin{array}{r}\text { New } \\
\text { entrants }\end{array}$ & Total & Stayers & $\begin{array}{r}\mathrm{New} \\
\text { entrants }\end{array}$ \\
\hline Student sample size & 1,007 & 926 & 81 & 959 & 758 & 201 & 944 & 678 & 266 \\
\hline \multicolumn{10}{|l|}{ Child Report (percent) } \\
\hline Primary caregiver consent rate & 66.3 & $68.9^{* * *}$ & 37.0 & 64.4 & $69.7^{* * *}$ & 44.8 & 64.9 & $70.1^{* * *}$ & 51.9 \\
\hline Student completion rate & 91.6 & 91.5 & 93.3 & 93.7 & 93.2 & 96.7 & 90.2 & 89.9 & 91.3 \\
\hline Students with data ${ }^{1}$ & 60.8 & $63.1^{* * *}$ & 34.6 & 60.4 & $64.9^{* * *}$ & 43.3 & 58.6 & $63.0^{* * *}$ & 47.4 \\
\hline \multicolumn{10}{|l|}{ Primary Caregiver Report (percent) } \\
\hline Primary caregiver consent rate & 66.2 & $68.9^{* * *}$ & 35.8 & 64.2 & $69.4^{* * *}$ & 44.8 & 63.9 & $68.9^{* * *}$ & 51.1 \\
\hline Primary caregiver completion rate & 80.2 & 80.1 & 82.8 & 79.7 & 80.0 & 77.8 & 73.6 & $71.5^{\star}$ & 80.9 \\
\hline Primary caregivers with data ${ }^{1}$ & 53.1 & $55.2^{* * *}$ & 29.6 & 51.2 & $55.5^{\star * *}$ & 34.8 & 47.0 & $49.3^{*}$ & 41.4 \\
\hline \multicolumn{10}{|l|}{ Teacher Report on Student (percent) } \\
\hline Primary caregiver consent rate ${ }^{2}$ & 66.3 & $68.9^{* * *}$ & 37.0 & 64.4 & $69.7^{* * *}$ & 44.8 & 64.9 & $70.1^{* * *}$ & 51.9 \\
\hline Teacher completion rate & 99.7 & 99.8 & 96.7 & 100.0 & 100.0 & 100.0 & 98.0 & 98.3 & 97.1 \\
\hline Students with data ${ }^{1}$ & 66.1 & $68.8^{* * *}$ & 35.8 & 64.4 & $69.7^{* * *}$ & 44.8 & 63.7 & $68.9^{* * *}$ & 50.4 \\
\hline
\end{tabular}

* Stayers significantly different from new entrants at the .05 level.

*** Stayers significantly different from new entrants at the .001 level.

${ }_{1}^{1}$ Calculated as consent rate $x$ completion rate.

${ }^{2}$ The primary caregiver consent rates for the Child Report and the Teacher Report on Student are identical, as the primary caregiver gave consent to both together.

SOURCE: The Social and Character Development (SACD) Research Program. 


\section{Fidelity of Implementation}

Each year, LBW's six treatment group schools were individually rated for quantity and quality of program implementation by two raters from the research team. The global measure of fidelity for the multisite study was used; inter-rater reliability was measured using Cronbach's alpha. In Years 2 and 3 these values were 0.83 and 0.97 , respectively; in Year 1, the inter-rater reliability coefficient was -0.08 , indicating that there was lack of agreement among the two raters, and thus Cronbach's alpha was not calculated. The ratings were combined into a single consensus rating and used to identify schools with high implementation fidelity. In Year 1 one treatment school was identified as having high fidelity and in Years 2 and 3 two treatment schools were identified as having high fidelity. Cohen's kappa was used as the measure of agreement when identifying schools as high fidelity, and it equaled 1.00 in Years 2 and 3.

\section{Initial Characteristics}

This section examines the initial characteristics of the students, teachers, and schools participating in the LBW evaluation. These characteristics were collected from students who were enrolled in the third grade at the study schools in fall 2004, as well as from their primary caregivers and third-grade teachers. In addition, third-, fourth-, and fifth-grade teachers and principals in the study schools provided information about activities related to social and character development in these schools. Documenting the characteristics of students, teachers, and schools and initial measures of key outcomes at a point before the intervention began operating helps to determine whether the random assignment of schools to treatment and control status produced treatment and control groups with similar distributions of observed characteristics. As noted in the following discussion, 4 significant differences between the treatment and control students, teachers, and schools were found in the observed characteristics, including the level of SACD activity in the classroom and school ( 3 of the 4 significant differences out of 62 comparisons, with 3 expected to be significant by chance).

\section{Characteristics of Children, Their Families, and Communities}

There were no significant differences between the treatment and control groups in the observed student, caregiver, and community characteristics (table 4.6). For students, the mean age was 8.1 years. The sample contained roughly equal percentages of girls $(52 \%)$ and boys $(48 \%)$. The sample was ethnically diverse. White non-Hispanic students made up 65 percent of the sample, Black non-Hispanic students made up 21 percent, and Hispanic students made up 8 percent.

The sample was also diverse in its levels of family income, education levels of primary caregivers of the children in the sample, and family situation. Twenty-eight percent of children lived in a household where the income was 135 percent of the federal poverty level or lower, which is the income threshold for eligibility for free school meals. Slightly less than 9 percent of primary caregivers had not completed high school. Nearly two-thirds of the children (64\%) lived with both their mother and their father. There were no significant differences between the treatment and control groups in these characteristics.

The mean values of the outcomes for children's behavior and attitudes as reported by the primary caregiver, child, and teacher at initial data collection in fall 2004 are shown in table 4.7. There was 1 significant difference (out of 18 comparisons) between the treatment and control groups: the treatment group had a lower Altruistic Behavior score (as reported by caregivers) than did the control group. 
Table 4.6. Initial characteristics of children, their families, and communities-LBW

\begin{tabular}{|c|c|c|c|}
\hline Characteristic & Total & Treatment & Control \\
\hline Student sample size & 617 & 355 & 262 \\
\hline \multicolumn{4}{|l|}{ Student demographics } \\
\hline \multicolumn{4}{|l|}{ Gender (percent) } \\
\hline Male & 48.0 & 47.7 & 48.4 \\
\hline Female & 52.0 & 52.3 & 51.6 \\
\hline \multicolumn{4}{|l|}{ Race/ethnicity (percent) } \\
\hline White (non-Hispanic) & 64.9 & 65.7 & 64.1 \\
\hline Black (non-Hispanic) & 21.1 & 22.4 & 19.8 \\
\hline Hispanic & 7.9 & 6.1 & 9.8 \\
\hline Other & 6.1 & 5.8 & 6.3 \\
\hline Age (in years) (mean) & 8.1 & 8.1 & 8.1 \\
\hline \multicolumn{4}{|l|}{ Primary caregiver and family characteristics } \\
\hline Primary caregiver's age (in years) (mean) & 35.5 & 35.8 & 35.2 \\
\hline \multicolumn{4}{|l|}{ Primary caregiver's race/ethnicity (percent) } \\
\hline White (non-Hispanic) & 70.3 & 70.0 & 70.7 \\
\hline Black (non-Hispanic) & 20.6 & 22.3 & 19.0 \\
\hline Hispanic & 6.7 & 6.2 & 7.2 \\
\hline Other & 2.3 & 1.5 & 3.1 \\
\hline \multicolumn{4}{|l|}{ Primary caregiver's education (percent) } \\
\hline Did not complete high school & 8.8 & 5.4 & 12.3 \\
\hline Completed high school or equivalent & 25.8 & 22.3 & 29.3 \\
\hline Some college & 40.4 & 42.2 & 38.6 \\
\hline Bachelor's or higher degree & 25.0 & 30.2 & 19.8 \\
\hline \multicolumn{4}{|l|}{ Primary caregiver's employment (percent) } \\
\hline Full-time & 54.5 & 56.9 & 52.1 \\
\hline Other & 45.5 & 43.1 & 47.9 \\
\hline \multicolumn{4}{|l|}{ Primary caregiver's marital status (percent) } \\
\hline Married & 63.9 & 65.9 & 61.8 \\
\hline Other & 36.1 & 34.1 & 38.2 \\
\hline Students who live in one household (percent) & 91.8 & 91.8 & 91.8 \\
\hline Number of individuals in household (mean) & 4.3 & 4.3 & 4.3 \\
\hline \multicolumn{4}{|l|}{ Primary caregiver's relationship to child (percent) } \\
\hline Mother (stepmother) & 84.9 & 86.0 & 83.8 \\
\hline Father (stepfather) & 10.4 & 9.6 & 11.2 \\
\hline Other relative/nonrelative & 4.7 & 4.4 & 4.9 \\
\hline
\end{tabular}


Table 4.6. Initial characteristics of children, their families, and communitiesLBW-Continued

\begin{tabular}{|c|c|c|c|}
\hline Characteristic & Total & Treatment & Control \\
\hline \multicolumn{4}{|l|}{ Student lives with (percent) } \\
\hline Mother (stepmother) and father (stepfather) & 64.3 & 66.6 & 61.9 \\
\hline Mother (stepmother) only; father (stepfather) not present & 28.2 & 27.3 & 29.1 \\
\hline Father (stepfather) only; mother (stepmother) not present & 3.8 & 2.9 & 4.7 \\
\hline Other relative/nonrelative, parents not present & 3.7 & 3.1 & 4.3 \\
\hline \multicolumn{4}{|l|}{ Highest education of anyone in household (percent) } \\
\hline Did not complete high school & 5.6 & 2.7 & 8.4 \\
\hline Completed high school or equivalent & 20.5 & 18.7 & 22.2 \\
\hline Some college & 40.6 & 40.8 & 40.5 \\
\hline Bachelor's or higher degree & 33.4 & 37.8 & 28.9 \\
\hline \multicolumn{4}{|l|}{ Total household income (percent) } \\
\hline Less than $\$ 20,000$ & 24.1 & 19.5 & 28.8 \\
\hline$\$ 20,000$ to $\$ 39,999$ & 22.4 & 20.2 & 24.6 \\
\hline$\$ 40,000$ to $\$ 59,999$ & 19.9 & 19.8 & 20.1 \\
\hline$\$ 60,000$ or more & 33.5 & 40.5 & 26.5 \\
\hline Income-to-poverty-threshold ratio-Below 135 percent (percent) & 28.1 & 24.6 & 31.6 \\
\hline Income-to-poverty-threshold ratio-135 to 185 percent (percent) & 18.1 & 14.0 & 22.1 \\
\hline Income-to-poverty-threshold ratio-Above 185 percent (percent) & 53.8 & 61.4 & 46.3 \\
\hline \multicolumn{4}{|l|}{ Alabama Parenting Questionnaire-Poor Monitoring and } \\
\hline Supervision Subscale (mean) & 1.1 & 1.1 & 1.2 \\
\hline \multicolumn{4}{|l|}{ Alabama Parenting Questionnaire-Positive Parenting } \\
\hline Subscale (mean) & 3.5 & 3.6 & 3.5 \\
\hline Confusion, Hubbub, and Order Scale (mean) & 2.2 & 2.2 & 2.2 \\
\hline \multicolumn{4}{|l|}{ Community characteristics (mean) } \\
\hline Community Risks Scale & 1.2 & 1.2 & 1.2 \\
\hline Community Resources Scale & 2.6 & 2.6 & 2.7 \\
\hline Child-Centered Social Control Scale & 3.1 & 3.2 & 3.1 \\
\hline
\end{tabular}

NOTE: No statistically significant differences were found between values for treatment and control groups. Weights, which assign equal weight to each school within the program, were used in producing the treatment, control, and overall means. Statistical tests were conducted using regressions that included program indicators to account for the sample design and adjusted for clustering at the school level.

SOURCE: The Social and Character Development (SACD) Research Program. 
Table 4.7. Mean scores and standard deviations for initial outcome measures of sample--LBW

\begin{tabular}{|c|c|c|c|c|c|c|c|}
\hline \multirow[b]{2}{*}{ Outcome measure-Report } & \multirow[b]{2}{*}{ Range } & \multicolumn{2}{|c|}{ Total } & \multicolumn{2}{|c|}{ Treatment } & \multicolumn{2}{|c|}{ Control } \\
\hline & & Mean & $S D$ & Mean & $S D$ & Mean & $S D$ \\
\hline \multicolumn{8}{|l|}{ Social and Emotional Competence Domain } \\
\hline Self-Efficacy for Peer Interaction-CR & $1-4$ & 3.0 & 0.6 & 3.0 & 0.6 & 3.0 & 0.7 \\
\hline Normative Beliefs About Aggression-CR & $1-4$ & 1.2 & 0.4 & 1.2 & 0.4 & 1.2 & 0.4 \\
\hline Empathy-CR & $1-3$ & 2.5 & 0.4 & 2.5 & 0.4 & 2.5 & 0.4 \\
\hline \multicolumn{8}{|l|}{ Behavior Domain } \\
\hline Altruistic Behavior-CR & $0-3$ & 1.4 & 0.9 & 1.5 & 0.9 & 1.4 & 0.9 \\
\hline Altruistic Behavior-TRS & $1-4$ & 1.3 & 0.4 & 1.3 & 0.4 & 1.4 & 0.4 \\
\hline Altruistic Behavior-PCR & $1-4$ & 2.3 & 0.7 & $2.2^{* \star}$ & 0.6 & 2.4 & 0.7 \\
\hline Positive Social Behavior-TRS & $1-4$ & 3.2 & 0.7 & 3.3 & 0.7 & 3.2 & 0.7 \\
\hline Positive Social Behavior-PCR & $1-4$ & 3.0 & 0.5 & 3.1 & 0.5 & 3.0 & 0.5 \\
\hline Problem Behavior-CR & $0-3$ & 0.1 & 0.3 & 0.1 & 0.3 & 0.2 & 0.3 \\
\hline Problem Behavior-TRS & $1-4$ & 1.3 & 0.3 & 1.3 & 0.4 & 1.3 & 0.3 \\
\hline Problem Behavior-CR & $1-4$ & 1.6 & 0.3 & 1.6 & 0.3 & 1.6 & 0.3 \\
\hline ADHD-Related Behavior-TRS & $1-4$ & 1.7 & 0.6 & 1.7 & 0.7 & 1.6 & 0.6 \\
\hline \multicolumn{8}{|l|}{ Academics Domain } \\
\hline Academic Competence and Motivation-TRS & $1-5$ & 3.1 & 0.9 & 3.1 & 0.9 & 3.1 & 0.9 \\
\hline Engagement with Learning-CR & $1-4$ & 3.7 & 0.5 & 3.7 & 0.6 & 3.8 & 0.5 \\
\hline \multicolumn{8}{|l|}{ Perceptions of School Climate Domain } \\
\hline Positive School Orientation-CR & $1-4$ & 3.3 & 0.6 & 3.4 & 0.6 & 3.3 & 0.6 \\
\hline Negative School Orientation-CR & $1-4$ & 1.7 & 0.6 & 1.7 & 0.6 & 1.6 & 0.5 \\
\hline Student Afraid at School-CR & $1-4$ & 2.4 & 0.9 & 2.4 & 0.9 & 2.3 & 0.9 \\
\hline Victimization at School-CR & $0-3$ & 0.7 & 0.8 & 0.7 & 0.8 & 0.7 & 0.8 \\
\hline Student sample size-PCR & & \multicolumn{2}{|c|}{617} & \multicolumn{2}{|c|}{355} & \multicolumn{2}{|c|}{262} \\
\hline Student sample size—CR & & \multicolumn{2}{|c|}{593} & \multicolumn{2}{|c|}{337} & \multicolumn{2}{|c|}{256} \\
\hline Student sample size-TRS & & \multicolumn{2}{|c|}{634} & \multicolumn{2}{|c|}{363} & \multicolumn{2}{|c|}{271} \\
\hline
\end{tabular}

** Treatment group significantly different from control group at the .01 level.

NOTE: Abbreviations are

CR: Child Report

PCR: Primary Caregiver Report

TRS: Teacher Report on Student

ADHD: Attention deficit hyperactivity disorder

$S D$ : Standard deviation

Weights, which assign equal weight to each school within the program, were used in producing the treatment, control, and overall means. Statistical tests were conducted using regressions that included program indicators to account for the sample design and adjusted for clustering at the school level. Sample size may differ for some outcomes due to nonresponse.

SOURCE: The Social and Character Development (SACD) Research Program. 


\section{Characteristics of Teachers and Schools}

Table 4.8 describes the third-, fourth-, and fifth-grade teachers at the study schools. They were predominantly White non-Hispanic (91\%) and female $(90 \%)$ and had an average of 14.9 years of total teaching experience. More than half $(55 \%)$ held an advanced or specialist degree. There were no statistically significant differences between the treatment and control groups of teachers.

Data regarding school characteristics were drawn from the Common Core of Data in order to compare treatment and control schools. ${ }^{49}$ There were no significant differences between the two groups of schools in terms of student composition (race/ethnicity and free lunch eligibility), number of students enrolled, number of full-time teachers, Title I status, or number of years the principal had been at the school (see table 4.9). In addition, there were no significant differences between treatment and control schools in terms of location (urban, suburban, or rural) or lowest and highest grade offered (these data are not shown in a table).

\section{Table 4.8. Initial characteristics of teachers in sample-LBW}

\begin{tabular}{|c|c|c|c|}
\hline Characteristic & Total & Treatment & Control \\
\hline Teacher sample size & 129 & 68 & 61 \\
\hline \multicolumn{4}{|l|}{ Gender (percent) } \\
\hline Male & 10.0 & 8.6 & 11.4 \\
\hline Female & 90.0 & 91.4 & 88.6 \\
\hline \multicolumn{4}{|l|}{ Race/ethnicity (percent) } \\
\hline White (non-Hispanic) & 90.5 & 92.7 & 88.4 \\
\hline Other & 9.5 & 7.3 & 11.6 \\
\hline Number of years teaching experience (mean) & 14.9 & 14.5 & 15.2 \\
\hline Number of years teaching experience in this school (mean) & 10.0 & 8.7 & 11.2 \\
\hline \multicolumn{4}{|l|}{ Type of teaching certificate (percent) } \\
\hline Regular state certificate or advanced professional certificate & 95.5 & $\ddagger$ & $\ddagger$ \\
\hline Other & 4.5 & $\ddagger$ & $\ddagger$ \\
\hline \multicolumn{4}{|l|}{ Education (percent) } \\
\hline Bachelor's degree & 44.7 & 40.0 & 49.4 \\
\hline Advanced degree/other & 55.3 & 60.0 & 50.6 \\
\hline
\end{tabular}

${ }^{49}$ Common Core of Data information on student race/ethnicity, percentage eligible for free or reduced-price lunch, and number of full-time teachers were missing for LBW treatment and control schools. 
Table 4.9. Initial characteristics of schools in sample-LBW

\begin{tabular}{|c|c|c|c|}
\hline Characteristic & Total & Treatment & Control \\
\hline School sample size & 12 & 6 & 6 \\
\hline \multicolumn{4}{|c|}{ Student race/ethnicity (percent) } \\
\hline White (non-Hispanic) & - & - & - \\
\hline Black (non-Hispanic) & - & - & - \\
\hline Hispanic & - & - & - \\
\hline Other & - & - & - \\
\hline
\end{tabular}

Students eligible for free or reduced-price lunch (percent)

Number of students enrolled (mean)

Number of full-time teachers (mean)

Title I status (percent)

Title I eligible school

66.7

66.7

66.7

Schoolwide Title I

Number of years principal has been at this school (mean)

6.7

4.8

8.5

- Not available.

‡ Reporting standards not met. Values suppressed to protect confidentiality.

NOTE: No statistically significant differences were found between values for treatment and control groups. Weights, which assign equal weight to each school within the program, were used in producing the treatment, control, and overall means. Statistical tests were conducted using regressions that included program indicators to account for the sample design and adjusted for clustering at the school level. Sample size may differ for some outcomes due to nonresponse.

SOURCE: NCES Common Core of Data (2003-04), the Social and Character Development (SACD) Research Program.

In the Teacher Report on Classroom and School, teachers reported on nine dimensions of school environment (these data are not shown in a table): feelings of safety, adequacy of resources, student support, freedom to teach as desired, affiliation with and ties to colleagues, innovation regarding new approaches to teaching, professional interest, participatory decisionmaking, and work pressure. There were no statistically significant differences in these reports between treatment and control schools.

\section{The Level of SACD in the Schools Near the Beginning of the Study}

During the initial data collection, principals and teachers reported on the SACD activities used in the schools and classrooms, the availability of SACD materials, and the professional development provided on SACD. Table 4.10 shows that the majority of the school principals reported activities to promote six social and character development goals: violence prevention and peace promotion $(92 \%)$, social and emotional development $(92 \%)$, character education $(92 \%)$, tolerance and diversity $(83 \%)$, risk prevention and health promotion (82\%), and civic responsibility and community service (91\%). In addition, all of the principals reported activities directed toward behavior management. There were no statistically significant differences between treatment and control groups in the percentages, although this may be due to the relatively small principal sample size. The percentages of teachers reporting the use of these activities in their classrooms ranged from 46 percent to 89 percent, and there were no significant differences between treatment and control teacher reports. With respect to the use of schoolwide activities, 42 percent to 83 percent of teachers reported that their schools used such activities, and there were no significant differences between treatment and control teacher reports. 
Table 4.10. Principal and teacher initial reports on use of SACD programs or activities in sample--LBW

\begin{tabular}{crrr}
\hline SACD program or activity & Total & Treatment & Control \\
\hline Principal sample size & 12 & 6 & 6 \\
Teacher sample size & 129 & 68 & 61
\end{tabular}

Principals reporting that school had programs or activities

to promote the following SACD goals (percent)

Violence prevention and peace promotion

$\begin{array}{rrr}91.7 & 83.3 & 100.0 \\ 91.7 & 83.3 & 100.0 \\ 91.7 & 83.3 & 100.0 \\ 83.3 & 66.7 & 100.0 \\ 81.8 & 83.3 & 80.0 \\ 90.9 & 83.3 & 100.0 \\ 100.0 & 100.0 & 100.0 \\ 0.0 & 0.0 & 0.0\end{array}$

None of the above

Teachers reporting on using programs or activities in their class to promote the following SACD goals (percent)

Violence prevention and peace promotion

58.2

65.3

51.1

Social and emotional development

55.2

59.6

50.7

Character education

68.9

70.3

67.5

Tolerance and diversity

$54.9 \quad 58.8 \quad 51.0$

Risk prevention and health promotion

46.2

46.9

45.5

Civic responsibility and community service

55.4

62.2

48.6

Behavior management

88.8

92.7

None of the above

Teachers reporting schoolwide use of the following activities to promote SACD (percent)

Morning announcements or videos

\begin{tabular}{rrr}
83.1 & 80.0 & 86.1 \\
61.3 & 70.5 & 52.1 \\
62.1 & 61.1 & 63.2 \\
42.0 & 45.2 & 38.9 \\
63.9 & 71.5 & 56.3 \\
9.6 & 10.3 & 8.8 \\
\hline
\end{tabular}

School assemblies

School newspapers or bulletins

groups. Weights, which assign

Special school days

Special events

Other activities

¥ Reporting standards not met. Values suppressed to protect confidentiality.

NOTE: No statistically significant differences were found between values for treatment and control groups. Weights, which assi
equal weight to each school within each of the programs and to each program across programs, were used in producing the treatment, control, and overall means. Statistical tests were conducted using regressions that included program indicators to account for the sample design and adjusted for clustering at the school level. Sample size may differ for some outcomes due to nonresponse.

SOURCE: The Social and Character Development (SACD) Research Program. 
Teachers reported using a broad range of teaching materials to support SACD activities (table 4.11), including teacher guides (46\%), student materials (31\%), instructional aids (29\%), giveaways (32\%), and children's literature $(41 \%)$. There was a statistically significant difference between the groups, with a greater percentage of treatment teachers reporting the use of children's literature (one out of seven materials asked about) than control teachers ( $58 \%$ versus $24 \%$ ).

Teachers also reported using a wide variety of teaching strategies (table 4.11). Nearly all teachers (99.5\%) reported using any of the 20 strategies asked about, and teachers used an average of 11.2 strategies. There were no significant differences in the average number of strategies, or in the specific strategies, used by treatment versus control teachers. 
Table 4.11. Teacher initial reports on use of SACD materials and classroom strategies in sample-LBW

\begin{tabular}{crrr}
\hline SACD material and classroom /strategy & Total & Treatment & Control \\
\hline Teacher sample size & 129 & 68 & 61
\end{tabular}

Teachers using the following materials in conjunction with social and character development activities (percent)

Teacher guides (manuals, curricula)

$\begin{array}{lcc}46.4 & 47.4 & 45.3 \\ 30.8 & 31.9 & 29.8 \\ 29.0 & 22.9 & 35.1 \\ 32.0 & 30.5 & 33.6 \\ 41.1 & 58.1^{\text {** }} & 24.0 \\ 11.1 & 8.1 & 14.1 \\ 22.3 & 22.7 & 21.9\end{array}$

Student materials (workbooks, worksheets)

Instructional aids (games, software, videos)

46.4

Giveaways (bookmarks, stickers)

Children's literature

Other types of materials

Do not use any of the materials listed above

22.3

22.7

99.5

99.0

100.0

social and character development in the classroom (percent)

Number of strategies (listed below) used by teachers to promote social and character development in the classroom (mean)

Teachers using each of the following strategies to promote social and character development (percent)

Role-playing

\begin{tabular}{rrr}
65.6 & 64.1 & 67.2 \\
94.7 & 93.7 & 95.8 \\
88.0 & 86.8 & 89.3 \\
66.8 & 70.5 & 63.0 \\
29.4 & 32.0 & 26.7 \\
62.6 & 66.7 & 58.6 \\
2.9 & $\ddagger$ & $\ddagger$ \\
14.3 & 15.9 & 12.7 \\
46.8 & 44.0 & 49.5 \\
80.2 & 87.3 & 73.1 \\
60.7 & 70.2 & 51.2 \\
63.9 & 65.8 & 62.1 \\
36.1 & 35.1 & 37.1 \\
43.4 & 37.1 & 49.8 \\
& & \\
35.3 & 39.3 & 31.3 \\
31.1 & 19.1 & 43.2 \\
45.8 & 41.6 & 50.0 \\
81.5 & 78.7 & 84.2 \\
95.1 & 92.1 & 98.1 \\
89.5 & 92.0 & 87.1 \\
\hline & &
\end{tabular}

Cooperative learning

Peer group discussions

Direct instruction of social and character development

Skill training

Incorporating social and character development into academic curriculum

Parent training

Parent/community involvement in program development or delivery

Mentoring

Good behavior notes sent home daily or weekly

Presenting role models

Targeted story reading or writing on SACD themes

Peer mediation

Honor roll for positive behavior

Pledges or recitations on social and character development themes

Guided visualization

Student-led/student-assisted instruction

Journaling

Time out for negative behavior

92.0

87.1

$\ddagger$ Values suppressed to protect confidentiality.

** Treatment group significantly different from control group at the .01 level.

NOTE: Weights, which assign equal weight to each school within each of the programs and to each program across programs, were used in producing the treatment, control, and overall means. Statistical tests were conducted using regressions that included program indicators to account for the sample design and adjusted for clustering at the school level. Sample size may differ for some outcomes due to nonresponse.

SOURCE: The Social and Character Development (SACD) Research Program. 
Principals and teachers reported on participation in and amount of SACD training and staff development provided over the previous 12 months (table 4.12). Principals reported higher participation rates than did teachers $(91 \%$ versus $73 \%$ ), although principals and teachers reported virtually the same number of training hours (5.8 versus 5.6). There was a significant difference in the percentages of teachers reporting participation in SACD training, with more treatment teachers reporting participation than control teachers $(84 \%$ versus $62 \%$ ). In addition, a significantly greater percentage of treatment teachers than control teachers reported receiving specific training in one of the seven targeted SACD goals (character education: 48\% versus 18\%).

\section{Table 4.12. Principal and teacher initial reports on SACD professional development in sample-- LBW}

\begin{tabular}{|c|c|c|c|}
\hline SACD professional development & Total & Treatment & Control \\
\hline Principal sample size & 12 & 6 & 6 \\
\hline Teacher sample size & 129 & 68 & 61 \\
\hline $\begin{array}{l}\text { Principals reporting that staff participated in social and character } \\
\text { development training within the past year (percent) }\end{array}$ & 90.9 & 83.3 & 100.0 \\
\hline $\begin{array}{l}\text { Teachers reporting participation in social and character } \\
\text { development training within the past } 12 \text { months (percent) }\end{array}$ & 72.9 & $83.6^{*}$ & 62.2 \\
\hline $\begin{array}{l}\text { Number of hours of social and character development training } \\
\text { principals report were provided to each staff person last year (mean) }\end{array}$ & 5.8 & 6.2 & 5.4 \\
\hline $\begin{array}{c}\text { Number of hours of social and character development training } \\
\text { teachers report receiving during the past } 12 \text { months (mean) }\end{array}$ & 5.6 & 6.4 & 4.8 \\
\hline $\begin{array}{l}\text { Teachers reporting receiving training in the past } 12 \text { months } \\
\text { in the following areas (percent) }\end{array}$ & & & \\
\hline Violence prevention and peace promotion & 21.3 & 26.8 & 15.8 \\
\hline Social and emotional development & 22.3 & 21.3 & 23.3 \\
\hline Character education & 33.1 & $47.9^{* *}$ & 18.3 \\
\hline Tolerance and diversity & 24.9 & 29.4 & 20.3 \\
\hline Risk prevention and health promotion & 18.5 & 20.0 & 17.0 \\
\hline Civic responsibility and community service & 7.3 & 5.9 & 8.6 \\
\hline Behavior management & 28.0 & 33.9 & 22.0 \\
\hline
\end{tabular}

${ }^{*}$ Treatment group significantly different from control group at the .05 level.

** Treatment group significantly different from control group at the .01 level.

NOTE: Weights, which assign equal weight to each school within each of the programs and to each program across programs, were used in producing the treatment, control, and overall means. Statistical tests were conducted using regressions that included program indicators to account for the sample design and adjusted for clustering at the school level. Sample size may differ for some outcomes due to nonresponse.

SOURCE: The Social and Character Development (SACD) Research Program.

The data on the initial level of SACD activity emphasized that the control condition was a "standard practice" control. Standard practice at the control schools included using SACD activities, materials, and practices, along with professional development for staff, at rates and in types and amounts similar to the treatment schools. For example, the percentage of teachers who reported using programs or activities to promote specific SACD goals ranged from 47 percent to 93 percent in the treatment schools and from 46 percent to 85 percent in the control schools. The 3 significant differences between the treatment and control conditions in the use of SACD activities equaled the number that would be expected by chance (3 out of 62 comparisons). 


\section{Impacts on Use of SACD Activities}

The introduction of the formal LBW program would be expected to increase the use of SACD activities in the treatment schools in comparison to the control schools. The analysis of this impact is based on the Teacher Report on Classroom and School (TRCS). Every spring, third-, fourth-, and fifth-grade teachers provided information through the TRCS about the social and character development activities they used in their classrooms. Specifically, information from the TRCS was used to determine the difference between treatment and control teachers in these areas:

1. the use of SACD activities in their classrooms overall and by SACD goal;

2. the use of materials and strategies to implement the SACD activities within classrooms and within the entire school;

3. the use of staff development to support the teachers; and

4. teacher support for SACD efforts in the school and the use of practices conducive to the social and character development of students.

TRCS consent and completion rates (table 4.4) led to 84 percent to 97 percent of all teachers having data for the 3 years, with greater percentages of control teachers providing data in Years 1 and 3. To estimate intervention impacts for each of the outcomes, testing of the statistical significance of the differences in means was used. Preliminary analysis indicated little or no gains in precision from using covariates. Before the mean differences were tested, the data were weighted such that each school received equal weight. Standard errors of the impact estimates accounted for the clustering of teachers within schools. In addition, a set of heuristics (described in chapter 1) was applied to determine whether each outcome domain was statistically significant after adjustments were made for the multiple tests conducted.

\section{Use of Activities}

The percentages of control teachers who reported using any SACD activities in their classrooms ranged from 82 percent to 87 percent over the 3 years (table 4.13, panel 1). For the six individual SACD goals, the ranges varied from 53 percent to 77 percent in Year 1, 52 percent to 70 percent in Year 2, and 64 percent to 81 percent in Year 3. Control teachers' use of behavior management activities ranged from 75 percent to 84 percent over this period. The percentages of control teachers who reported using any SACD activities in their classrooms for at least 1 hour per week (panel 2) ranged from 48 percent to 80 percent over the 3 years. For the six individual SACD goals, the percentages ranged from 6 percent to 29 percent in Year 1, 14 percent to 25 percent in Year 2, and 18 percent to 28 percent in Year 3. Control teachers' use of behavior management activities ranged from 43 percent to 57 percent over this period. These findings show that the control schools were using these activities as part of their standard practice related to social and character development.

For teachers' reported use of any SACD activity, 48 comparisons were made, with 3 expected to be significant by chance (panels 1 and 2). The percentage of treatment teachers using any SACD activity was significantly different from control teachers in Year 2 (impact $=17$ percentage points). For specific SACD activities, there was a significant difference for character education in Year 2 (impact $=24$ percentage points) and for behavior management activities in Year 3 (impact $=19$ percentage points), both favoring treatment teachers. Significant differences between treatment and control teachers who reported use of these activities for at least 1 hour a week occurred in all years, again favoring treatment teachers. In Year 1, there was an impact on social and emotional development (impact $=14$ percentage points), character education (impact $=$ 45 percentage points), tolerance and diversity (impact $=16$ percentage points), and any activity (impact $=32$ percentage points). In Year 2, impacts were seen for violence prevention and peace promotion (impact $=18$ percentage points), social and emotional development (impact $=23$ percentage points), character education (impact $=43$ percentage points), risk prevention and health promotion (impact $=16$ percentage points), any activity (impact $=29$ percentage points), and behavior management (impact $=33$ percentage points). In Year 
3 , there was an impact on behavior management (impact $=26$ percentage points). After the heuristics were applied to adjust for multiple comparisons, the data showed that LBW had statistically significant impacts in Years 1 and 2 on the domain for engagement in SACD activities.

Regarding the use of named SACD activities, 42 comparisons were made, with 2 expected to be significant by chance (panels 3 and 4). Five of the 12 impact estimates in Year 1, 6 of the 12 in Year 2, and 3 of the 12 in Year 3 were statistically significant. An impact on character education activities (impact $=44$, 59, and 31 percentage points) and any named activity (impact $=29,45$, and 20 percentage points) were seen in all 3 years. In Year 2, there was an impact on risk prevention and health promotion (impact $=26$ percentage points). For named activities used at least 1 hour per week, there were significant impacts on character education (impact $=52$ percentage points), tolerance and diversity (impact $=21$ percentage points), and any named activity (impact $=37$ percentage points) in Year 1 ; character education (impact $=43$ percentage points) and any named activity (impact $=38$ percentage points) in Year 2; and character education (impact $=$ 21 percentage points) in Year 3. LBW had significant impacts on the domain for engagement in named SACD activities in Years 1 and 2. 
Table 4.13. Impacts on teacher-reported SACD classroom activities--LBW

Panel 1: Engagement in any activities to promote SACD goals ${ }^{1}$

\begin{tabular}{|c|c|c|c|c|c|c|c|c|c|c|c|c|}
\hline \multirow[b]{2}{*}{ SACD activity } & \multicolumn{4}{|c|}{$\begin{array}{c}\text { Year } 1 \\
\text { (Spring 3rd grade) }\end{array}$} & \multicolumn{4}{|c|}{$\begin{array}{c}\text { Year } 2 \\
\text { (Spring 4th grade) }\end{array}$} & \multicolumn{4}{|c|}{$\begin{array}{c}\text { Year } 3 \\
\text { (Spring 5th grade) }\end{array}$} \\
\hline & $\begin{array}{r}\text { Treat- } \\
\text { ment }\end{array}$ & Control & Impact & $p$-value & $\begin{array}{c}\text { Treat- } \\
\text { ment }\end{array}$ & Control & Impact & $p$-value & $\begin{array}{r}\text { Treat- } \\
\text { ment }\end{array}$ & Control & Impact & $p$-value \\
\hline Teacher sample size & 85 & 64 & & & 69 & 47 & & & 75 & 50 & & \\
\hline $\begin{array}{l}\text { Violence prevention and peace promotion } \\
\text { (percent) }\end{array}$ & 65.6 & 61.2 & 4.4 & 0.698 & 58.8 & 51.5 & 7.3 & 0.337 & 72.0 & 71.9 & 0.1 & 0.989 \\
\hline $\begin{array}{l}\text { Social and emotional development } \\
\text { (percent) }\end{array}$ & 66.1 & 55.5 & 10.6 & 0.309 & 66.6 & 52.2 & 14.4 & 0.102 & 64.4 & 74.4 & -10.0 & 0.399 \\
\hline Character education (percent) & 92.5 & 77.0 & 15.4 & 0.106 & $93.8^{*}$ & 69.6 & 24.3 & 0.003 & 84.9 & 81.4 & 3.6 & 0.575 \\
\hline Tolerance and diversity (percent) & 66.4 & 62.7 & 3.7 & 0.704 & 61.6 & 59.9 & 1.7 & 0.862 & 61.5 & 70.6 & -9.2 & 0.457 \\
\hline $\begin{array}{l}\text { Risk prevention and health promotion } \\
\text { (percent) }\end{array}$ & 63.3 & 53.2 & 10.1 & 0.119 & 69.6 & 52.6 & 17.0 & 0.114 & 69.1 & 64.2 & 4.9 & 0.692 \\
\hline $\begin{array}{l}\text { Civic responsibility and community service } \\
\text { (percent) }\end{array}$ & 55.6 & 53.1 & 2.5 & 0.848 & 59.3 & 56.0 & 3.4 & 0.791 & 59.6 & 67.5 & -7.9 & 0.469 \\
\hline Any SACD goal (percent) & 93.5 & 83.2 & 10.3 & 0.190 & $98.3^{*}$ & 81.6 & 16.7 & 0.024 & 91.4 & 86.9 & 4.5 & 0.457 \\
\hline Behavior management (percent) & 85.6 & 84.0 & 1.7 & 0.780 & 90.9 & 80.2 & 10.7 & 0.211 & $93.6^{*}$ & 74.7 & 18.9 & 0.008 \\
\hline
\end{tabular}


Table 4.13. Impacts on teacher-reported SACD classroom activities-LBW-Continued

Panel 2: Engagement in any activities to promote SACD goals for at least 1 hour per week

\begin{tabular}{|c|c|c|c|c|c|c|c|c|c|c|c|c|}
\hline \multirow[b]{2}{*}{ SACD activity } & \multicolumn{4}{|c|}{$\begin{array}{c}\text { Year } 1 \\
\text { (Spring 3rd grade) }\end{array}$} & \multicolumn{4}{|c|}{$\begin{array}{c}\text { Year } 2 \\
\text { (Spring 4th grade) }\end{array}$} & \multicolumn{4}{|c|}{$\begin{array}{c}\text { Year } 3 \\
\text { (Spring 5th grade) }\end{array}$} \\
\hline & $\begin{array}{c}\text { Treat- } \\
\text { ment }\end{array}$ & Control & Impact & $p$-value & $\begin{array}{c}\text { Treat- } \\
\text { ment }\end{array}$ & Control & Impact & $p$-value & $\begin{array}{r}\text { Treat- } \\
\text { ment }\end{array}$ & Control & Impact & $p$-value \\
\hline Teacher sample size & 85 & 64 & & & 69 & 47 & & & 75 & 50 & & \\
\hline $\begin{array}{l}\text { Violence prevention and peace promotion } \\
\text { (percent) }\end{array}$ & 26.9 & 19.9 & 7.0 & 0.347 & $31.9^{*}$ & 14.0 & 17.8 & 0.034 & 25.2 & 17.8 & 7.4 & 0.497 \\
\hline $\begin{array}{l}\text { Social and emotional development } \\
\text { (percent) }\end{array}$ & $32.1^{*}$ & 18.5 & 13.6 & 0.016 & $40.8^{*}$ & 17.5 & 23.3 & 0.008 & 21.3 & 26.5 & -5.2 & 0.565 \\
\hline Character education (percent) & $74.1^{*}$ & 28.7 & 45.4 & 0.000 & $64.2^{*}$ & 21.6 & 42.5 & 0.000 & $37.4^{\wedge}$ & 21.5 & 15.8 & 0.061 \\
\hline Tolerance and diversity (percent) & $32.0^{*}$ & 16.1 & 15.9 & 0.020 & 24.9 & 25.4 & -0.5 & 0.944 & 16.9 & 23.2 & -6.3 & 0.512 \\
\hline $\begin{array}{l}\text { Risk prevention and health promotion } \\
\text { (percent) }\end{array}$ & 26.1 & 16.2 & 9.9 & 0.077 & $29.9^{*}$ & 14.0 & 15.9 & 0.046 & 29.6 & 28.1 & 1.5 & 0.920 \\
\hline $\begin{array}{l}\text { Civic responsibility and community service } \\
\text { (percent) }\end{array}$ & 9.4 & 5.7 & 3.7 & 0.503 & 25.2 & 16.8 & 8.4 & 0.419 & 11.4 & 17.9 & -6.6 & 0.374 \\
\hline Any SACD goal (percent) & $79.9^{*}$ & 47.8 & 32.1 & 0.001 & $91.7^{* *}$ & 62.8 & 28.9 & 0.008 & 84.0 & 79.9 & 4.1 & 0.609 \\
\hline Behavior management (percent) & 58.2 & 55.4 & 2.9 & 0.778 & $75.5^{\star \star}$ & 43.0 & 32.5 & 0.004 & $82.2^{*}$ & 56.7 & 25.6 & 0.025 \\
\hline
\end{tabular}

Behavior management (percent)

$82.2^{*}$ 
Table 4.13. Impacts on teacher-reported SACD classroom activities-LBW-Continued

Panel 3: Engagement in activities to promote SACD goals linked to named SACD programs ${ }^{2}$

\begin{tabular}{|c|c|c|c|c|c|c|c|c|c|c|c|c|}
\hline \multirow[b]{2}{*}{ SACD activity } & \multicolumn{4}{|c|}{$\begin{array}{c}\text { Year } 1 \\
\text { (Spring 3rd grade) }\end{array}$} & \multicolumn{4}{|c|}{$\begin{array}{c}\text { Year } 2 \\
\text { (Spring 4th grade) }\end{array}$} & \multicolumn{4}{|c|}{$\begin{array}{c}\text { Year } 3 \\
\text { (Spring 5th grade) }\end{array}$} \\
\hline & $\begin{array}{c}\text { Treat- } \\
\text { ment }\end{array}$ & Control & Impact & $p$-value & $\begin{array}{r}\text { Treat- } \\
\text { ment }\end{array}$ & Control & Impact & $p$-value & $\begin{array}{c}\text { Treat- } \\
\text { ment }\end{array}$ & Control & Impact & $p$-value \\
\hline Teacher sample size & 85 & 64 & & & 69 & 47 & & & 75 & 50 & & \\
\hline $\begin{array}{l}\text { Violence prevention and peace promotion } \\
\text { (percent) }\end{array}$ & 21.9 & 22.4 & -0.4 & 0.964 & 29.1 & 17.3 & 11.7 & 0.281 & 25.9 & 13.0 & 12.9 & 0.191 \\
\hline $\begin{array}{l}\text { Social and emotional development } \\
\text { (percent) }\end{array}$ & 25.6 & 10.0 & 15.6 & 0.311 & 31.6 & 14.4 & 17.2 & 0.172 & 10.4 & 15.2 & -4.8 & 0.605 \\
\hline Character education (percent) & $62.9^{*}$ & 18.5 & 44.4 & 0.003 & $75.4^{*}$ & 16.3 & 59.2 & 0.000 & $39.2^{*}$ & 8.0 & 31.2 & 0.047 \\
\hline Tolerance and diversity (percent) & 25.4 & 12.0 & 13.4 & 0.241 & $24.6^{\wedge}$ & 9.8 & 14.8 & 0.060 & $\ddagger$ & $\ddagger$ & 7.1 & 0.361 \\
\hline $\begin{array}{l}\text { Risk prevention and health promotion } \\
\text { (percent) }\end{array}$ & $38.5^{\wedge}$ & 25.8 & 12.7 & 0.075 & $52.3^{*}$ & 25.9 & 26.4 & 0.009 & 37.9 & 31.2 & 6.7 & 0.587 \\
\hline $\begin{array}{l}\text { Civic responsibility and community service } \\
\text { (percent) }\end{array}$ & $\ddagger$ & $\ddagger$ & 1.0 & $\dagger$ & $\ddagger$ & $\ddagger$ & 6.4 & 0.288 & 5.9 & 12.3 & -6.4 & 0.401 \\
\hline Any named activity (percent) & $69.1^{*}$ & 39.7 & 29.4 & 0.002 & $86.6^{*}$ & 42.1 & 44.6 & 0.001 & $63.0^{*}$ & 43.4 & 19.6 & 0.021 \\
\hline
\end{tabular}


Table 4.13. Impacts on teacher-reported SACD classroom activities-LBW-Continued

Panel 4: Engagement in activities to promote SACD goals linked to named SACD programs for at least 1 hour per week

\begin{tabular}{|c|c|c|c|c|c|c|c|c|c|c|c|c|}
\hline \multirow[b]{2}{*}{ SACD activity } & \multicolumn{4}{|c|}{$\begin{array}{c}\text { Year } 1 \\
\text { (Spring 3rd grade) }\end{array}$} & \multicolumn{4}{|c|}{$\begin{array}{c}\text { Year } 2 \\
\text { (Spring 4th grade) }\end{array}$} & \multicolumn{4}{|c|}{$\begin{array}{c}\text { Year } 3 \\
\text { (Spring 5th grade) }\end{array}$} \\
\hline & $\begin{array}{r}\text { Treat- } \\
\text { ment }\end{array}$ & Control & Impact & $p$-value & $\begin{array}{l}\text { Treat- } \\
\text { ment }\end{array}$ & Control & Impact & $p$-value & $\begin{array}{r}\text { Treat- } \\
\text { ment }\end{array}$ & Control & Impact & $p$-value \\
\hline Teacher sample size & 85 & 64 & & & 69 & 47 & & & 75 & 50 & & \\
\hline $\begin{array}{l}\text { Violence prevention and peace promotion } \\
\text { (percent) }\end{array}$ & $17.2^{\wedge}$ & 8.4 & 8.8 & 0.094 & $\ddagger^{*}$ & $\ddagger$ & 18.3 & 0.016 & 15.1 & 5.1 & 9.9 & 0.272 \\
\hline $\begin{array}{l}\text { Social and emotional development } \\
\text { (percent) }\end{array}$ & $\ddagger^{\wedge}$ & $\ddagger$ & 19.6 & 0.055 & 23.9 & 9.2 & 14.6 & 0.107 & 7.8 & 5.2 & 2.6 & 0.701 \\
\hline Character education (percent) & $59.1^{*}$ & 6.9 & 52.3 & 0.000 & $53.0^{*}$ & 8.2 & 44.8 & 0.000 & $\ddagger^{*}$ & $\ddagger$ & 21.3 & 0.014 \\
\hline Tolerance and diversity (percent) & $22.6^{*}$ & 1.7 & 20.9 & 0.016 & 14.9 & 8.8 & 6.1 & 0.337 & 6.9 & 0.0 & 6.9 & $\dagger$ \\
\hline $\begin{array}{l}\text { Risk prevention and health promotion } \\
\text { (percent) }\end{array}$ & $23.3^{\wedge}$ & 15.0 & 8.3 & 0.093 & 22.8 & 12.6 & 10.2 & 0.198 & 19.6 & 19.3 & 0.3 & 0.975 \\
\hline $\begin{array}{l}\text { Civic responsibility and community service } \\
\text { (percent) }\end{array}$ & $\ddagger$ & $\ddagger$ & 1.0 & $\dagger$ & 4.8 & 0.0 & 4.8 & $\dagger$ & $\ddagger$ & $\ddagger$ & -0.2 & 0.909 \\
\hline Any named activity (percent) & $59.7^{*}$ & 23.0 & 36.7 & 0.000 & $60.3^{*}$ & 22.1 & 38.2 & 0.000 & 38.1 & 20.7 & 17.4 & 0.131 \\
\hline
\end{tabular}

Any named activity (percent)

$\begin{array}{rrrr}59.7^{*} & 23.0 & 36.7 & 0.000\end{array}$

$60.3^{*}$

$38.2 \quad 0.000$

38.1

† Reporting standards not met. Values suppressed to protect confidentiality.

* Treatment group significantly different from control group at the .05 level.

${ }^{* *}$ Treatment group significantly different from control group at the .01 level.

$\wedge$ Treatment group significantly different than control group at the .10 to $>.05$ level.

${ }^{1}$ In Year 1, the omnibus impact for all the outcomes measured together was positive and statistically significant on the basis of a multivariate statistical test. In Years 1 and 2, at least one outcome remained positive and statistically significant and no outcome was negative and statistically significant after applying the Benjamini-Hochberg (1995) procedure to adjust significance levels downward to account for the multiple testing of impacts.

${ }^{2}$ In Years 1 and 2, at least one outcome remained positive and statistically significant and no outcome was negative and statistically significant after applying the Benjamini-Hochberg (1995) procedure to adjust significance levels downward to account for the multiple testing of impacts.

NOTE: Weights, which assign equal weight to each school within the program, were used in producing the treatment, control, and overall means

SOURCE: The Social and Character Development (SACD) Research Program. 


\section{Use of Materials and Strategies}

For use of materials and strategies to support SACD goals, 87 comparisons were made, with 5 expected to be significant by chance. Fifteen significant impacts were found on treatment teachers' use of materials and strategies in all 3 years (table 4.14). In Year 1, more treatment teachers than control teachers used teacher guides (impact $=43$ percentage points), children's literature (impact $=38$ percentage points), direct instruction of SACD (impact $=27$ percentage points), skill training (impact $=21$ percentage points), good behavior notes (impact $=24$ percentage points), and targeted story reading and writing on SACD themes (impact $=29$ percentage points). On average, treatment teachers also used more strategies than control teachers (by two strategies). In Year 2, more treatment teachers than control teachers continued to use children's literature (impact $=24$ percentage points), direct instruction of SACD (impact $=25$ percentage points), and skill training (impact $=22$ percentage points), and fewer treatment teachers reported not using any of the SACD materials (impact $=-16$ percentage points). In addition, more treatment teachers presented role models (impact $=22$ percentage points). In Year 3, more treatment teachers used teacher guides (impact $=22$ percentage points), instructional aids (impact $=17$ percentage points), and direct instruction of SACD (impact $=17$ percentage points). LBW's impact on the domain of materials and strategies was statistically significant in Year 1. 
Table 4.14. Impacts on use of SACD classroom materials and teaching strategies-LBW

\begin{tabular}{|c|c|c|c|c|c|c|c|c|c|c|c|c|}
\hline \multirow[b]{2}{*}{ SACD material and teaching strategy ${ }^{1}$} & \multicolumn{4}{|c|}{$\begin{array}{c}\text { Year } 1 \\
\text { (Spring 3rd grade) }\end{array}$} & \multicolumn{4}{|c|}{$\begin{array}{c}\text { Year } 2 \\
\text { (Spring 4th grade) }\end{array}$} & \multicolumn{4}{|c|}{$\begin{array}{c}\text { Year } 3 \\
\text { (Spring 5th grade) }\end{array}$} \\
\hline & $\begin{array}{r}\text { Treat- } \\
\text { ment }\end{array}$ & Control & Impact & $p$-value & $\begin{array}{r}\text { Treat- } \\
\text { ment }\end{array}$ & Control & Impact & $p$-value & $\begin{array}{r}\text { Treat- } \\
\text { ment }\end{array}$ & Control & Impact & $p$-value \\
\hline Teacher sample size & 85 & 64 & & & 69 & 47 & & & 75 & 50 & & \\
\hline \multicolumn{13}{|l|}{ Use of SACD materials (percent) } \\
\hline Teacher guides (manuals, curricula) & $87.3^{*}$ & 44.0 & 43.3 & 0.001 & 73.5 & 59.9 & 13.6 & 0.170 & $67.9^{*}$ & 46.2 & 21.7 & 0.028 \\
\hline Student materials (workbooks or sheets) & 45.7 & 54.8 & -9.2 & 0.337 & 46.5 & 38.3 & 8.2 & 0.425 & 46.7 & 34.7 & 12.0 & 0.142 \\
\hline Instructional aids (games, software, videos) & 43.4 & 40.5 & 3.0 & 0.803 & 40.3 & 44.1 & -3.8 & 0.791 & $45.3^{*}$ & 28.5 & 16.7 & 0.014 \\
\hline Giveaways (bookmarks, stickers) & 58.2 & 48.3 & 9.9 & 0.402 & 50.2 & 35.0 & 15.2 & 0.232 & 39.7 & 43.2 & -3.5 & 0.750 \\
\hline Children's literature & $75.0^{*}$ & 36.9 & 38.2 & 0.006 & $60.0^{*}$ & 35.7 & 24.2 & 0.012 & 51.3 & 51.8 & -0.5 & 0.953 \\
\hline Other types of materials & 10.1 & 5.0 & 5.1 & 0.275 & 10.2 & 8.5 & 1.7 & 0.726 & 7.7 & 6.9 & 0.8 & 0.875 \\
\hline Did not use any of these materials & 4.4 & 20.7 & -16.2 & 0.132 & $6.9^{*}$ & 22.4 & -15.5 & 0.035 & 16.8 & 14.7 & 2.1 & 0.776 \\
\hline \multicolumn{13}{|l|}{ Use of teaching strategies (percent) } \\
\hline Role-playing & 83.1 & 72.9 & 10.2 & 0.215 & 70.9 & 50.2 & 20.7 & 0.121 & 74.6 & 86.3 & -11.6 & 0.350 \\
\hline Cooperative learning & 94.3 & 92.7 & 1.5 & 0.669 & 92.8 & 90.7 & 2.1 & 0.680 & 98.4 & 95.8 & 2.7 & 0.405 \\
\hline Peer group discussions & 95.5 & 92.7 & 2.8 & 0.425 & 92.1 & 93.8 & -1.8 & 0.796 & 98.5 & 97.1 & 1.3 & 0.658 \\
\hline Direct instruction of SACD & $98.1^{*}$ & 71.3 & 26.8 & 0.003 & $94.3^{*}$ & 69.1 & 25.2 & 0.008 & $95.3^{*}$ & 78.7 & 16.6 & 0.014 \\
\hline Skill training & $57.8^{*}$ & 36.4 & 21.4 & 0.002 & $57.1^{*}$ & 35.3 & 21.8 & 0.047 & 75.2 & 61.6 & 13.6 & 0.305 \\
\hline $\begin{array}{l}\text { Incorporating SACD into academic } \\
\text { curriculum }\end{array}$ & $77.7^{\wedge}$ & 60.5 & 17.2 & 0.085 & 83.1 & 71.0 & 12.0 & 0.173 & 85.2 & 86.8 & -1.5 & 0.816 \\
\hline Parent training & 3.9 & 7.2 & -3.3 & 0.458 & 5.1 & 12.0 & -6.9 & 0.224 & 22.2 & 22.3 & 0.0 & 1.000 \\
\hline Parent/community involvement & 22.1 & 25.1 & -3.1 & 0.699 & 18.8 & 27.8 & -8.9 & 0.463 & 37.9 & 43.5 & -5.6 & 0.638 \\
\hline Mentoring & 65.0 & 65.6 & -0.7 & 0.956 & 62.6 & 61.9 & 0.6 & 0.958 & 72.5 & 75.1 & -2.6 & 0.834 \\
\hline $\begin{array}{l}\text { Good behavior notes sent home daily } \\
\text { or weekly }\end{array}$ & $91.0^{*}$ & 67.5 & 23.5 & 0.022 & 84.3 & 64.5 & 19.7 & 0.122 & 90.7 & 84.4 & 6.3 & 0.136 \\
\hline Presenting role models & 84.9 & 74.8 & 10.1 & 0.115 & $80.9^{*}$ & 59.4 & 21.5 & 0.012 & 82.3 & 83.6 & -1.3 & 0.874 \\
\hline
\end{tabular}

See notes at end of table. 
Table 4.14. Impacts on use of SACD classroom materials and teaching strategies—LBW-Continued

\begin{tabular}{|c|c|c|c|c|c|c|c|c|c|c|c|c|}
\hline \multirow[b]{2}{*}{ SACD material and teaching strategy ${ }^{1}$} & \multicolumn{4}{|c|}{$\begin{array}{c}\text { Year } 1 \\
\text { (Spring 3rd grade) }\end{array}$} & \multicolumn{4}{|c|}{$\begin{array}{c}\text { Year 2 } \\
\text { (Spring 4th grade) }\end{array}$} & \multicolumn{4}{|c|}{$\begin{array}{c}\text { Year 3 } \\
\text { (Spring 5th grade) }\end{array}$} \\
\hline & $\begin{array}{l}\text { Treat- } \\
\text { ment }\end{array}$ & Control & Impact & $p$-value & $\begin{array}{l}\text { Treat- } \\
\text { ment }\end{array}$ & Control & Impact & $p$-value & $\begin{array}{r}\text { Treat- } \\
\text { ment }\end{array}$ & Control & Impact & $p$-value \\
\hline \multicolumn{13}{|l|}{$\begin{array}{l}\text { Use of teaching strategies (percent)_- } \\
\text { Continued }\end{array}$} \\
\hline $\begin{array}{l}\text { Targeted story reading or writing on social } \\
\text { and character development themes }\end{array}$ & $98.0^{*}$ & 69.1 & 28.9 & 0.001 & 86.2 & 76.6 & 9.6 & 0.301 & 86.6 & 90.8 & -4.2 & 0.494 \\
\hline Peer mediation & 63.9 & 47.6 & 16.2 & 0.165 & 51.9 & 49.5 & 2.3 & 0.839 & 62.8 & 78.3 & -15.6 & 0.237 \\
\hline Honor roll for positive behavior & 57.8 & 57.3 & 0.5 & 0.955 & 56.1 & 59.1 & -3.0 & 0.795 & 67.2 & 61.6 & 5.6 & 0.529 \\
\hline $\begin{array}{l}\text { Pledges or recitations on social and } \\
\text { character development themes }\end{array}$ & 52.7 & 37.3 & 15.4 & 0.241 & 51.7 & 43.5 & 8.1 & 0.709 & 49.0 & 48.0 & 1.0 & 0.944 \\
\hline Guided visualization & 62.5 & 52.2 & 10.2 & 0.191 & 51.5 & 42.5 & 9.0 & 0.477 & 60.2 & 57.8 & 2.4 & 0.776 \\
\hline $\begin{array}{l}\text { Student-led/student-assisted } \\
\text { instruction }\end{array}$ & 44.7 & 54.6 & -9.9 & 0.269 & $36.2^{\wedge}$ & 59.3 & -23.1 & 0.074 & 71.3 & 65.8 & 5.5 & 0.631 \\
\hline Journaling & $93.0^{\wedge}$ & 78.8 & 14.2 & 0.097 & 87.4 & 93.6 & -6.2 & 0.323 & 90.3 & 87.5 & 2.8 & 0.723 \\
\hline Time out for negative behavior & $95.7^{\wedge}$ & 86.8 & 8.9 & 0.086 & 92.9 & 94.3 & -1.5 & 0.759 & 98.4 & 89.9 & 8.5 & 0.102 \\
\hline $\begin{array}{l}\text { Daily or weekly rewards for positive } \\
\text { behavior }\end{array}$ & 91.0 & 78.0 & 13.0 & 0.164 & $96.1^{\wedge}$ & 83.0 & 13.2 & 0.098 & 95.7 & 94.4 & 1.3 & 0.793 \\
\hline Any strategy & 100.0 & 100.0 & 0.0 & $\dagger$ & 100.0 & 100.0 & 0.0 & $\dagger$ & 98.5 & 100.0 & -1.5 & $\dagger$ \\
\hline Number of strategies (mean) & $14.2^{*}$ & 12.1 & 2.0 & 0.002 & 13.5 & 12.3 & 1.2 & 0.293 & 15.0 & 14.7 & 0.3 & 0.792 \\
\hline
\end{tabular}

† Not applicable.

* Treatment group significantly different from control group at the .05 level.

$\wedge$ Treatment group significantly different from control group at the .10 to $>.05$ level.

${ }^{1}$ In Year 1, at least one outcome remained positive and statistically significant and no outcome was negative and statistically significant after applying the Benjamini-Hochberg (1995) procedure to adjust significance levels downward to account for the multiple testing of impacts

NOTE: Weights, which assign equal weight to each school within the program, were used in producing the treatment, control, and overall means.

SOURCE: The Social and Character Development (SACD) Research Program. 
Regarding the use of schoolwide strategies, 18 comparisons were made between treatment and control teacher reports, with 1 expected to be significant by chance. There was 1 statistically significant difference between treatment and control teachers regarding use of schoolwide strategies in Year 3 (these data are not shown in a table), with treatment teachers reporting more use of school assemblies than control teachers (impact $=22$ percentage points). The overall impact of LBW on the domain for use of schoolwide strategies in named SACD activities was significant in Year 2; the omnibus impact for all the outcomes measured together was positive and statistically significant on the basis of a multivariate statistical test.

\section{Participation in Professional Development}

Regarding reported participation in professional development, 27 comparisons were made over 3 years, with 2 expected to be significant by chance. LBW had a statistically significant effect on treatment teachers' participation in professional development, with more treatment teachers reporting SACD training in the past 12 months in all years (impact $=29,31$, and 30 percentage points) and more hours of training in Years 1 and 2 (by 5.4 and 3.3 hours, on average). In terms of specific SACD goals, more treatment teachers reported training in character education in all 3 years (impact $=62,34$, and 37 percentage points). LBW had a significant impact on the domain of professional development in Year 1. 
Table 4.15. Impacts on teacher-reported SACD professional development--LBW

\begin{tabular}{|c|c|c|c|c|c|c|c|c|c|c|c|c|}
\hline \multirow[b]{2}{*}{ SACD professional development ${ }^{1}$} & \multicolumn{4}{|c|}{$\begin{array}{c}\text { Year } 1 \\
\text { (Spring 3rd grade) }\end{array}$} & \multicolumn{4}{|c|}{$\begin{array}{c}\text { Year } 2 \\
\text { (Spring 4th grade) }\end{array}$} & \multicolumn{4}{|c|}{$\begin{array}{c}\text { Year } 3 \\
\text { (Spring 5th grade) }\end{array}$} \\
\hline & $\begin{array}{c}\text { Treat- } \\
\text { ment }\end{array}$ & Control & Impact & $p$-value & $\begin{array}{r}\text { Treat- } \\
\text { ment }\end{array}$ & Control & Impact & $p$-value & $\begin{array}{r}\text { Treat- } \\
\text { ment }\end{array}$ & Control & Impact & $p$-value \\
\hline Teacher sample size & 85 & 64 & & & 69 & 47 & & & 75 & 50 & & \\
\hline SACD training in past 12 months (percent) & $89.5^{*}$ & 60.8 & 28.7 & 0.006 & $68.9^{*}$ & 37.7 & 31.2 & 0.027 & $73.4^{*}$ & 43.7 & 30.0 & 0.014 \\
\hline Hours of SACD training (mean) & $8.6^{*}$ & 3.1 & 5.4 & 0.000 & $5.3^{*}$ & 2.1 & 3.3 & 0.044 & 5.6 & 3.8 & 1.8 & 0.292 \\
\hline \multicolumn{13}{|l|}{ Training by goal (percent) } \\
\hline Violence prevention and peace promotion & 21.9 & 17.7 & 4.2 & 0.707 & 17.0 & 8.1 & 8.9 & 0.188 & 26.2 & 18.3 & 7.9 & 0.498 \\
\hline Social and emotional development & 21.8 & 16.9 & 4.8 & 0.474 & 16.5 & 7.8 & 8.7 & 0.452 & 12.7 & 5.9 & 6.7 & 0.339 \\
\hline Character education & $77.5^{*}$ & 15.3 & 62.2 & 0.000 & $45.4^{*}$ & 11.3 & 34.0 & 0.037 & $46.7^{*}$ & 9.8 & 37.0 & 0.015 \\
\hline Tolerance and diversity & 31.7 & 15.0 & 16.8 & 0.119 & 11.3 & 7.1 & 4.3 & 0.566 & 14.1 & 17.5 & -3.4 & 0.613 \\
\hline Risk prevention and health promotion & 18.3 & 12.5 & 5.8 & 0.483 & 22.1 & 14.8 & 7.3 & 0.516 & 17.5 & 12.0 & 5.6 & 0.339 \\
\hline Civic responsibility and community service & 8.2 & 5.7 & 2.5 & 0.642 & $\ddagger$ & $\ddagger$ & 2.1 & 0.678 & $\ddagger$ & $\ddagger$ & -1.9 & 0.623 \\
\hline Behavior management & 34.8 & 22.3 & 12.5 & 0.184 & 26.7 & 18.0 & 8.7 & 0.227 & 35.1 & 20.6 & 14.4 & 0.344 \\
\hline
\end{tabular}

¥ Reporting standards not met. Values suppressed to protect confidentiality.

* Treatment group significantly different from control group at the 05 level.

${ }^{1}$ In Year 1, at least one outcome remained positive and statistically significant and no outcome was negative and statistically significant after applying the Benjamini-Hochberg (1995) procedure to adjust significance levels downward to account for the multiple testing of impacts.

NOTE: Weights, which assign equal weight to each school within the program, were used in producing the treatment, control, and overall means.

SOURCE: The Social and Character Development (SACD) Research Program. 


\section{Attitudes and Practices}

Teachers reported on their enthusiasm for SACD efforts in their schools (these data are not shown in a table) by indicating enthusiasm, cooperation, or open dislike. They also reported on the SACD practices of teachers and staff members in their schools (these data are not shown in a table). The practices included modeling positive character and behavior traits with students and fellow teachers, involving students in making decisions, giving students a voice in school governance, the school encouraging parent involvement in children's social and character development, and using developmentally appropriate discipline strategies rather than punishment for misbehavior. Twenty-seven comparisons were made over 3 years, with 1 expected to be significant by chance. There were no statistically significant estimated impacts on teachers' enthusiasm for SACD efforts in their schools in any of the years, nor were there any significant differences in teacher reports of the overall use of practices conducive to students' social and character development. No significant impact was found on the domain in any of the 3 years.

\section{Year-by-Year Impacts on Students and Perceptions of School Climate}

The primary research question for the LBW evaluation was this:

What is the average effect of LBW on children's social and emotional competence, behavior, academics, and perceptions of school climate?

The first approach to answering this question was to examine the year-by-year impacts of LBW on these student and school climate outcomes over the 3 years as the students progressed from third through fifth grades.

Equation (2) (described in chapter 1) was estimated to provide LBW impacts on the 20 outcomes based on data from the 11 schools (6 treatment and 5 control). For the LBW evaluation, equation (2) excluded the program fixed effects $\left(\theta_{p}\right)$ and included program-specific covariates and random school effects covariates. Table 4.16 lists the covariates used, with outcomes from each report in the LBW analysis. 
Table 4.16. Covariates used with outcomes from each report for analysis-LBW

\begin{tabular}{|c|c|c|c|c|}
\hline Potential covariate & $\begin{array}{c}\text { CR } \\
\text { outcome }\end{array}$ & $\begin{array}{c}\text { PCR } \\
\text { outcome }\end{array}$ & $\begin{array}{c}\text { TRS } \\
\text { outcome }\end{array}$ & $\begin{array}{l}\text { TRCS } \\
\text { outcome }\end{array}$ \\
\hline Total number & 6 & 24 & 21 & 5 \\
\hline \multicolumn{5}{|l|}{ Child-reported } \\
\hline Female & $\checkmark$ & $\checkmark$ & $\checkmark$ & \\
\hline Hispanic & $\checkmark$ & $\checkmark$ & $\checkmark$ & \\
\hline Black (non-Hispanic) & $\checkmark$ & $\checkmark$ & $\checkmark$ & \\
\hline Other ethnicity & $\checkmark$ & $\checkmark$ & $\checkmark$ & \\
\hline Age in years & $\checkmark$ & $\checkmark$ & $\checkmark$ & \\
\hline \multicolumn{5}{|l|}{ Scales } \\
\hline \multicolumn{5}{|l|}{ Afraid at School } \\
\hline Altruistic Behavior & & & $\checkmark$ & \\
\hline Empathy & & $\checkmark$ & $\checkmark$ & \\
\hline \multicolumn{5}{|l|}{ Engagement with Learning } \\
\hline Negative School Orientation & & $\checkmark$ & & \\
\hline \multicolumn{5}{|l|}{ Normative Beliefs About Aggression } \\
\hline \multicolumn{5}{|l|}{ Sense of School as a Community } \\
\hline \multicolumn{5}{|l|}{ Problem Behavior } \\
\hline Self-Efficacy for Peer Interactions & & $\checkmark$ & $\checkmark$ & \\
\hline Victimization at School & & $\checkmark$ & & \\
\hline $\begin{array}{l}\text { Primary caregiver-reported } \\
\text { Age in years }\end{array}$ & & $\checkmark$ & & \\
\hline \multicolumn{5}{|l|}{ Completed high school or equivalent } \\
\hline \multicolumn{5}{|l|}{ Some college } \\
\hline \multicolumn{5}{|l|}{ Bachelor's or higher degree } \\
\hline \multicolumn{5}{|l|}{ Highest level of education in household } \\
\hline Completed high school or equivalent & & $\checkmark$ & & \\
\hline Some college & & $\checkmark$ & & \\
\hline Bachelor's or higher degree & & $\checkmark$ & & \\
\hline \multicolumn{5}{|l|}{ Mother present in home life } \\
\hline \multicolumn{5}{|l|}{ Mother and father present } \\
\hline \multicolumn{5}{|l|}{ Respondent someone other than mother or father } \\
\hline Number of people in household & & & $\checkmark$ & \\
\hline Household income: $\$ 20,000$ to $\$ 40,000$ & & $\checkmark$ & $\checkmark$ & \\
\hline Household income: $\$ 40,000$ to $\$ 60,000$ & & $\checkmark$ & $\checkmark$ & \\
\hline Household income: More than $\$ 60,000$ & & $\checkmark$ & $\checkmark$ & \\
\hline Income-to-poverty-threshold ratio: Below 135 percent & & & $\checkmark$ & \\
\hline Income-to-poverty-threshold ratio: 135 to 185 percent & & $\checkmark$ & $\checkmark$ & \\
\hline Full-time employment & & $\checkmark$ & $\checkmark$ & \\
\hline Part-time employment & & $\checkmark$ & $\checkmark$ & \\
\hline
\end{tabular}


Table 4.16. Covariates used with outcomes from each report for analysis-LBW-Continued

\begin{tabular}{|c|c|c|c|c|}
\hline Potential covariate & $\begin{array}{c}\text { CR } \\
\text { outcome }\end{array}$ & $\begin{array}{c}\text { PCR } \\
\text { outcome }\end{array}$ & $\begin{array}{c}\text { TRS } \\
\text { outcome }\end{array}$ & $\begin{array}{c}\text { TRCS } \\
\text { outcome }\end{array}$ \\
\hline \multicolumn{5}{|l|}{ Parental scales } \\
\hline APQ-Poor Monitoring and Supervision Subscale & & $\checkmark$ & $\checkmark$ & \\
\hline APQ-Positive Parenting Subscale & & $\checkmark$ & & \\
\hline \multicolumn{5}{|l|}{ Child-Centered Social Control } \\
\hline Confusion, Hubbub, and Order & & $\checkmark$ & & \\
\hline Community Resources & & $\checkmark$ & & \\
\hline Community Risk & & & $\checkmark$ & \\
\hline Parent and Teacher Involvement & & & $\checkmark$ & \\
\hline \multicolumn{5}{|l|}{ Child scales } \\
\hline Altruistic Behavior & $\checkmark$ & & $\checkmark$ & \\
\hline \multicolumn{5}{|l|}{ Positive Social Behavior } \\
\hline \multicolumn{5}{|l|}{ Problem Behavior } \\
\hline \multicolumn{4}{|l|}{ Teacher-reported } & $\checkmark$ \\
\hline Hispanic & & & & $\checkmark$ \\
\hline Black (non-Hispanic) & & & & $\checkmark$ \\
\hline Other ethnicity & & & & $\checkmark$ \\
\hline \multicolumn{5}{|l|}{ Total teaching experience } \\
\hline Total experience in current school & & & & $\checkmark$ \\
\hline \multicolumn{5}{|l|}{ Regular certificate } \\
\hline \multicolumn{5}{|l|}{ Other certificate } \\
\hline \multicolumn{5}{|l|}{ Highest degree-bachelor's } \\
\hline \multicolumn{5}{|l|}{ Child scales } \\
\hline \multicolumn{5}{|l|}{ Academic Competence and Motivation } \\
\hline ADHD-Related Behavior & & $\checkmark$ & & \\
\hline \multicolumn{5}{|l|}{ Altruistic Behavior } \\
\hline Positive Social Behavior & & & $\checkmark$ & \\
\hline \multicolumn{5}{|l|}{ Problem Behavior } \\
\hline Parent and Teacher Involvement & & & & \\
\hline
\end{tabular}

NOTE: Abbreviations are

CR: Child Report

PCR: Primary Caregiver Report

TRS: Teacher Report on Student

TRCS: Teacher Report on Classroom and School

ADHD: Attention deficit hypertensive disorder

APQ: Alabama Parenting Questionnaire

$\checkmark$ : Covariate used

Blank cell: Covariate not used

SOURCE: The Social and Character Development (SACD) Research Program. 
To assess the statistical power of the program-level impact estimates, minimum detectable impacts in effect size units (MDES) for each outcome measure were calculated for the LBW evaluation (table 4.17). MDES represent the smallest impacts in effect size (standard deviation) units that can be detected with a high probability (80\%). The MDES are primarily a function of study sample sizes, the degrees of freedom available for statistical tests, and design effects due to clustering (Schochet 2005). For the LBW evaluation, the MDES range from 0.099 to 0.637 for the child-level outcomes based on the Child, Caregiver, and Teacher Report on Student and from 0.536 to 0.763 for the school climate outcomes based on the Teacher Report on Classroom and School. In general, the MDES for the school climate outcomes were larger than those for the child-level outcomes. 
Table 4.17. Adjusted minimum detectable effect sizes for impact evaluation-_LBW

\begin{tabular}{|c|c|c|c|}
\hline Outcome measure-Report & Year 1 & Year 2 & Year 3 \\
\hline \multicolumn{4}{|l|}{ Social and Emotional Competence Domain } \\
\hline Self-Efficacy for Peer Interaction-CR & 0.104 & 0.107 & 0.126 \\
\hline Normative Beliefs About Aggression-CR & 0.104 & 0.178 & 0.154 \\
\hline Empathy-CR & 0.104 & 0.154 & 0.115 \\
\hline \multicolumn{4}{|l|}{ Behavior Domain } \\
\hline Altruistic Behavior-CR & 0.153 & 0.228 & 0.193 \\
\hline Altruistic Behavior-PCR & 0.116 & 0.155 & 0.148 \\
\hline Altruistic Behavior-TRS & 0.345 & 0.637 & 0.463 \\
\hline Positive Social Behavior-PCR & 0.184 & 0.210 & 0.157 \\
\hline Positive Social Behavior-TRS & 0.099 & 0.310 & 0.401 \\
\hline Problem Behavior-CR & 0.104 & 0.169 & 0.340 \\
\hline Problem Behavior-PCR & 0.152 & 0.196 & 0.135 \\
\hline Problem Behavior-TRS & 0.220 & 0.104 & 0.185 \\
\hline ADHD-Related Behavior-TRS & 0.227 & 0.104 & 0.295 \\
\hline \multicolumn{4}{|l|}{ Academics Domain } \\
\hline Engagement with Learning-CR & 0.104 & 0.107 & 0.164 \\
\hline Academic Competence and Motivation-TRS & 0.141 & 0.270 & 0.191 \\
\hline \multicolumn{4}{|l|}{ Perceptions of School Climate Domain } \\
\hline Positive School Orientation-CR & 0.231 & 0.202 & 0.212 \\
\hline Negative School Orientation-CR & 0.237 & 0.260 & 0.179 \\
\hline Student Afraid at School-CR & 0.223 & 0.322 & 0.283 \\
\hline Victimization at School-CR & 0.297 & 0.140 & 0.175 \\
\hline Feelings of Safety-TRCS & 0.763 & 0.611 & 0.552 \\
\hline Student Support for Teachers-TRCS & 0.536 & 0.631 & 0.726 \\
\hline
\end{tabular}

NOTE: Abbreviations are

CR: Child Report

PCR: Primary Caregiver Report

TRS: Teacher Report on Student

TRCS: Teacher Report on Classroom and School

ADHD: Attention deficit hyperactivity disorder

The minimum detectable effect (MDE) formula used in the calculations is as follows:

$M D E=$ factor $(d f) * \sqrt{\rho_{1}\left(\frac{1}{s_{T}}+\frac{1}{s_{C}}\right)+\left(1-\rho_{1}\right)\left(\frac{1}{s_{T} n_{T}}+\frac{1}{s_{C} n_{C}}\right)}$

where $s_{T}$ and $s_{C}$ are the number of treatment and comparison schools; $n_{T}$ and $n_{C}$ are the average number of students per classroom; $\rho_{1}$ is the intraclass correlation (ICC) at the school level; and factor(df) is a constant that depends on the number of degrees of freedom ( $d f$ ) available for analysis (and is 2.802 for the pooled analysis).

SOURCE: The Social and Character Development (SACD) Research Program. 
Table 4.18 provides the estimates of LBW's impacts on each of the 20 outcomes over each of the 3 years (60 impacts in total, with 3 expected to be statistically significant by chance). Of the 60 results, 5 were statistically significant ( 2 beneficial, 3 detrimental). In Year 1, LBW had beneficial impacts on Altruistic Behavior (Primary Caregiver Report, effect size $[E S]=0.31$ ) and Student Support for Teachers (Teacher Report on Classroom and School, ES = 0.52). In Year 3, LBW had detrimental impacts on Engagement with Learning (Child Report, ES = -0.35), Positive School Orientation (Child Report, ES = -0.33), and Feelings of Safety (Teacher Report on Classroom and School, ES = -0.70). There were also four substantively important but nonsignificant impacts (one beneficial, three detrimental): In Year 2, there was a detrimental impact on Altruistic Behavior (Teacher Report on Student, ES = -0.34) and a beneficial impact on Student Support for Teachers (Teacher Report on Classroom and School, ES =0.28); in Year 3, there were detrimental impacts on Problem Behavior (Child Report, ES = 0.31) and Student Support for Teachers (Teacher Report on Classroom and School, ES = -0.26). Application of the heuristic to adjust for multiple comparisons within each outcome domain indicates that LBW had a significant beneficial impact on the domain of Behavior in Year 1 and a significant detrimental impact on the domain of Academics in Year 3. 
Table 4.18. Impacts on child and school outcomes-LBW

\begin{tabular}{|c|c|c|c|c|c|c|c|c|c|c|c|c|}
\hline \multirow[b]{2}{*}{ Scale-Report } & \multicolumn{4}{|c|}{$\begin{array}{c}\text { Year } 1 \\
\text { (Spring 3rd grade) }\end{array}$} & \multicolumn{4}{|c|}{$\begin{array}{c}\text { Year } 2 \\
\text { (Spring 4th grade) }\end{array}$} & \multicolumn{4}{|c|}{$\begin{array}{c}\text { Year } 3 \\
\text { (Spring 5th grade) }\end{array}$} \\
\hline & $\begin{array}{c}\text { Treat- } \\
\text { ment }\end{array}$ & Control & $\begin{array}{r}\text { Effect } \\
\text { size }\end{array}$ & $p$-value & $\begin{array}{r}\text { Treat- } \\
\text { ment }\end{array}$ & Control & $\begin{array}{c}\text { Effect } \\
\text { size }\end{array}$ & $p$-value & $\begin{array}{c}\text { Treat- } \\
\text { ment }\end{array}$ & Control & $\begin{array}{r}\text { Effect } \\
\text { size }\end{array}$ & $p$-value \\
\hline \multicolumn{13}{|l|}{ Social and Emotional Competence Domain } \\
\hline Self-Efficacy for Peer Interactions-CR (+) & 3.03 & 3.04 & -0.01 & 0.894 & 3.19 & 3.21 & -0.04 & 0.674 & 3.25 & 3.24 & 0.02 & 0.810 \\
\hline Normative Beliefs About Aggression-CR (-) & 1.24 & 1.23 & 0.02 & 0.809 & 1.26 & 1.21 & 0.12 & 0.368 & 1.35 & 1.28 & 0.15 & 0.244 \\
\hline Empathy-CR $(+)$ & 2.37 & 2.38 & -0.02 & 0.793 & 2.30 & 2.30 & 0.00 & 0.963 & 2.21 & 2.26 & -0.13 & 0.176 \\
\hline \multicolumn{13}{|l|}{ Behavior Domain ${ }^{1}$} \\
\hline Altruistic Behavior-CR (+) & 1.19 & 1.31 & -0.15 & 0.147 & 1.02 & 1.16 & -0.19 & 0.191 & 0.99 & 1.13 & -0.20 & 0.121 \\
\hline Altruistic Behavior-PCR (+) & $2.33^{*}$ & 2.13 & 0.31 & 0.005 & 2.22 & 2.11 & 0.17 & 0.152 & 2.22 & 2.23 & 0.00 & 0.985 \\
\hline Altruistic Behavior-TRS (+) & 1.43 & 1.41 & 0.04 & 0.844 & 1.29 & 1.46 & $-0.34^{\circ}$ & 0.270 & 1.33 & 1.31 & 0.03 & 0.914 \\
\hline Positive Social Behavior-PCR (+) & 3.06 & 3.09 & -0.07 & 0.471 & 3.12 & 3.04 & 0.13 & 0.250 & 3.10 & 3.05 & 0.09 & 0.397 \\
\hline Positive Social Behavior-TRS (+) & 3.17 & 3.21 & -0.06 & 0.343 & 2.94 & 3.11 & -0.24 & 0.183 & 3.27 & 3.24 & 0.06 & 0.786 \\
\hline Problem Behavior-CR (-) & 0.22 & 0.21 & 0.05 & 0.541 & 0.25 & 0.23 & 0.04 & 0.728 & 0.41 & 0.29 & $0.31^{\circ}$ & 0.223 \\
\hline Problem Behavior-PCR (-) & 1.58 & 1.56 & 0.06 & 0.484 & 1.56 & 1.56 & -0.01 & 0.898 & 1.52 & 1.57 & -0.13 & 0.197 \\
\hline Problem Behavior-TRS (-) & 1.43 & 1.40 & 0.08 & 0.488 & 1.46 & 1.40 & 0.14 & 0.117 & 1.32 & 1.38 & -0.13 & 0.263 \\
\hline ADHD-Related Behavior-TRS (-) & 1.76 & 1.69 & 0.12 & 0.263 & 1.73 & 1.64 & 0.13 & 0.105 & 1.56 & 1.65 & -0.16 & 0.344 \\
\hline \multicolumn{13}{|l|}{ Academics Domain ${ }^{2}$} \\
\hline Engagement with Learning-CR (+) & 3.66 & 3.66 & 0.01 & 0.942 & 3.67 & 3.69 & -0.04 & 0.652 & $3.54^{*}$ & 3.68 & -0.35 & 0.030 \\
\hline $\begin{array}{l}\text { Academic Competence and Motivation- } \\
\text { TRS (+) }\end{array}$ & 3.06 & 3.09 & -0.03 & 0.666 & 3.05 & 2.99 & 0.06 & 0.622 & 3.15 & 3.17 & -0.02 & 0.871 \\
\hline
\end{tabular}




\section{Table 4.18. Impacts on child and school outcomes-LBW-Continued}

\begin{tabular}{|c|c|c|c|c|c|c|c|c|c|c|c|c|}
\hline \multirow[b]{2}{*}{ Scale-Report } & \multicolumn{4}{|c|}{$\begin{array}{c}\text { Year } 1 \\
\text { (Spring 3rd grade) }\end{array}$} & \multicolumn{4}{|c|}{$\begin{array}{c}\text { Year } 2 \\
\text { (Spring 4th grade) }\end{array}$} & \multicolumn{4}{|c|}{$\begin{array}{c}\text { Year } 3 \\
\text { (Spring 5th grade) }\end{array}$} \\
\hline & $\begin{array}{r}\text { Treat- } \\
\text { ment }\end{array}$ & Control & $\begin{array}{r}\text { Effect } \\
\text { size }\end{array}$ & $p$-value & $\begin{array}{r}\text { Treat- } \\
\text { ment }\end{array}$ & Control & $\begin{array}{r}\text { Effect } \\
\text { size }\end{array}$ & $p$-value & $\begin{array}{r}\text { Treat- } \\
\text { ment }\end{array}$ & Control & $\begin{array}{r}\text { Effect } \\
\text { size }\end{array}$ & $p$-value \\
\hline \multicolumn{13}{|l|}{ Perceptions of School Climate Domain } \\
\hline Positive School Orientation-CR (+) & 2.98 & 2.94 & 0.05 & 0.692 & 2.77 & 2.79 & -0.03 & 0.794 & $2.62^{*}$ & 2.82 & -0.33 & 0.047 \\
\hline Negative School Orientation-CR (-) & 1.76 & 1.86 & -0.17 & 0.201 & 1.87 & 1.89 & -0.03 & 0.846 & 2.05 & 1.95 & 0.18 & 0.178 \\
\hline Student Afraid at School-CR (-) & 2.28 & 2.30 & -0.02 & 0.859 & 2.28 & 2.22 & 0.06 & 0.777 & 2.26 & 2.16 & 0.11 & 0.508 \\
\hline Victimization at School-CR (-) & 0.73 & 0.79 & -0.07 & 0.657 & 0.70 & 0.71 & -0.01 & 0.929 & 0.70 & 0.70 & 0.00 & 0.993 \\
\hline Feelings of Safety-TRCS $(+)$ & 3.54 & 3.59 & -0.07 & 0.793 & 3.39 & 3.45 & -0.06 & 0.825 & $3.32^{*}$ & 3.67 & -0.70 & 0.046 \\
\hline Student Support for Teachers-TRCS (+) & $3.72^{*}$ & 3.37 & 0.52 & 0.022 & 3.57 & 3.40 & $0.28^{\circ}$ & 0.428 & 3.45 & 3.58 & $-0.26^{\circ}$ & 0.543 \\
\hline
\end{tabular}

* Treatment group significantly different from control group at the .05 level.

- Substantive (but nonsignificant at 05 level) effect size of $\geq 25$ or $\leq-25$.

${ }^{1}$ In Year 1, at least one outcome remained positive and statistically significant and no outcome was negative and statistically significant after applying the Benjamini-Hochberg (1995) procedure to adjust significance levels downward to account for the multiple testing of impacts.

${ }^{2}$ Based on univariate statistical tests, one of the two unadjusted impacts is statistically significantly negative, indicating a detrimental impact of the intervention on child outcomes in this domain in Year 3.

NOTE: Abbreviations are

No CR: Child Report

PCR: Primary Caregiver Report

TRS: Teacher Report on Student

TRCS: Teacher Report on Classroom and School

ADHD: Attention deficit hyperactivity disorder

The +/- signs in parentheses indicate the direction of a beneficial outcome. All impact estimates were calculated using regression models where each program and school within a program was weighted equally. The standard errors of all estimates account for design effects due to unequal weighting and the clustering of students within schools. See table 1.5 for information about the measures used to create the outcome variables. The effect size was calculated by dividing the estimated impact by the standard deviation of the outcome measure for the control group. The number of results found significant was no more than expected by chance.

SOURCE: The Social and Character Development (SACD) Research Program. 


\section{Impacts on Child Outcomes Over Time}

LBW's impacts on the child outcomes over time were estimated using growth curve models by examining treatment and control group differences in the trajectories of student outcomes during the follow-up period while accounting for clustering at the school level. The growth curve models are estimated using a three-level hierarchical linear model, where Level 1 corresponds to time, Level 2 to students, and Level 3 to schools (described in chapter 1).

Table 4.19 provides the estimates of LBW impacts on the growth in student outcomes over the 3 years. The estimated impacts range in effect size units (absolute value) from 0.01 to 0.13 . One of the 18 estimated LBW intervention impacts on the trajectories of child outcomes was statistically significant (no more than expected by chance); the program had a detrimental impact on Positive School Orientation (Child Report, ES = -0.13). 


\begin{tabular}{|c|c|c|c|c|c|c|c|}
\hline \multirow[b]{2}{*}{ Scale-Report } & \multirow[b]{2}{*}{$\begin{array}{r}\text { Mean score at } \\
\text { implementation }\end{array}$} & \multicolumn{6}{|c|}{ Average growth in the score per year ${ }^{1}$} \\
\hline & & Treatment & Control & $\begin{array}{r}\text { Impact on } \\
\text { growth }^{3}\end{array}$ & $\begin{array}{l}\text { Effect } \\
\text { size }^{4}\end{array}$ & $\begin{array}{r}\text { Standard } \\
\text { error of } \\
\text { impact }\end{array}$ & $\begin{array}{r}p \text {-value of } \\
\text { impact }\end{array}$ \\
\hline \multicolumn{8}{|l|}{ Social and Emotional Competence Domain } \\
\hline Self-Efficacy for Peer Interactions-CR (+) & 2.96 & 0.08 & 0.12 & -0.04 & -0.04 & 0.03 & 0.298 \\
\hline Normative Beliefs About Aggression-CR (-) & 1.17 & 0.06 & 0.04 & 0.01 & 0.03 & 0.03 & 0.620 \\
\hline Empathy-CR (+) & 2.48 & -0.10 & -0.10 & -0.01 & -0.02 & 0.02 & 0.693 \\
\hline \multicolumn{8}{|l|}{ Behavior Domain } \\
\hline Altruistic Behavior-CR (+) & 1.39 & -0.20 & -0.16 & -0.04 & -0.04 & 0.07 & 0.591 \\
\hline Altruistic Behavior-PCR (+) & 2.29 & -0.08 & -0.07 & -0.01 & -0.01 & 0.04 & 0.861 \\
\hline Altruistic Behavior-TRS (+) & 1.40 & 0.00 & -0.01 & 0.01 & 0.02 & 0.07 & 0.914 \\
\hline Positive Social Behavior-PCR (+) & 3.07 & 0.04 & 0.02 & 0.03 & 0.04 & 0.04 & 0.486 \\
\hline Positive Social Behavior-TRS (+) & 3.12 & 0.02 & -0.01 & 0.04 & 0.04 & 0.09 & 0.691 \\
\hline Problem Behavior-CR (-) & 0.14 & 0.06 & 0.08 & -0.02 & -0.04 & 0.04 & 0.706 \\
\hline Problem Behavior-PCR (-) & 1.59 & -0.03 & -0.02 & -0.01 & -0.01 & 0.02 & 0.813 \\
\hline Problem Behavior-TRS (-) & 1.36 & 0.02 & 0.04 & -0.03 & -0.06 & 0.02 & 0.242 \\
\hline ADHD-Related Behavior-TRS (-) & 1.71 & -0.09 & -0.01 & -0.08 & -0.11 & 0.05 & 0.144 \\
\hline \multicolumn{8}{|l|}{ Academics Domain } \\
\hline Engagement with Learning-CR (+) & 3.75 & -0.08 & -0.04 & -0.04 & -0.06 & 0.03 & 0.247 \\
\hline Academic Competence and Motivation-TRS (+) & 3.11 & 0.03 & 0.08 & -0.05 & -0.05 & 0.04 & 0.263 \\
\hline
\end{tabular}




\section{Table 4.19. Impacts on growth of child outcomes-LBW-Continued}

\begin{tabular}{|c|c|c|c|c|c|c|c|}
\hline \multirow[b]{2}{*}{ Scale-Report } & \multirow[b]{2}{*}{$\begin{array}{r}\text { Mean score at } \\
\text { implementation }\end{array}$} & \multicolumn{6}{|c|}{ Average growth in the score per year ${ }^{1}$} \\
\hline & & Treatment & Control & $\begin{array}{l}\text { Impact on } \\
\text { growth }^{3}\end{array}$ & $\begin{array}{l}\text { Effect } \\
\text { size }^{4}\end{array}$ & $\begin{array}{r}\text { Standard } \\
\text { error of } \\
\text { impact } \\
\end{array}$ & $\begin{array}{r}p \text {-value of } \\
\text { impact }\end{array}$ \\
\hline \multicolumn{8}{|l|}{ Perceptions of School Climate Domain } \\
\hline Positive School Orientation-CR (+) & 3.23 & $-0.31^{*}$ & -0.20 & -0.11 & -0.13 & 0.04 & 0.016 \\
\hline Negative School Orientation-CR (-) & 1.68 & $0.17^{\wedge}$ & 0.11 & 0.06 & 0.08 & 0.03 & 0.090 \\
\hline Student Afraid at School-CR (-) & 2.35 & -0.03 & -0.07 & 0.04 & 0.03 & 0.03 & 0.232 \\
\hline Victimization at School-CR (-) & 0.68 & $0.08^{\wedge}$ & -0.03 & 0.11 & 0.10 & 0.05 & 0.061 \\
\hline
\end{tabular}

* Treatment group significantly different from control group at the .05 level.

$\wedge$ Treatment group significantly different from control group at the .10 to $>.05$ level.

${ }^{1}$ Pertains to the estimated slope of the outcome for the treatment or control groups.

2 The average score at implementation is calculated across treatment and control groups, using regression models for adjustment on covariates.

${ }_{4}^{3}$ Estimated difference between the slope of the treatment and control groups.

${ }^{4}$ Effect size: The slope of the treatment group minus the slope of the control group divided by the standard deviation of the outcome for the program's control group (the standard deviation is calculated without accounting for school-level clustering or regression adjustments).

NOTE: Abbreviations are

CR: Child Report

PCR: Primary Caregiver Report

TRS: Teacher Report on Student

ADHD: Attention deficit hyperactivity disorder

The +/- signs in parentheses indicate the direction of a beneficial outcome. All impact estimates were calculated using HLM 6.06. Sample weights were used in all analyses to give (1) each school equal weight in each program (within each time period) and (2) each time period equal weight within the analysis. See table 1.5 for information about the measures used create the outcome variables.

SOURCE: The Social and Character Development (SACD) Research Program. 


\section{Summary}

As part of the Social and Character Development (SACD) Research Program, researchers at the Tennessee site implemented and evaluated the LBW program. This program focused on character education by teaching children positive character traits and moral virtues and how to apply them in their day-to-day activities. Twelve public schools in two school districts in two separate counties in Tennessee were recruited by the Tennessee research team and randomly assigned to treatment and control conditions to determine the LBW impact on social and character development activities in the schools and on the child outcome domains of Social and Emotional Competence, Behavior, Academics, and Perceptions of School Climate.

Analyses of the initial characteristics of the sample (students, caregivers, communities, teachers, and schools) indicated that randomization to treatment and control status produced groups that were relatively similar on the observed characteristics at the start of the study (1 statistically significant difference in children's behavior was found out of 83 comparisons, fewer than the 4 that would be expected by chance). Documentation of the initial level of social and character development activities in the schools also revealed few differences (3, no more than expected by chance out of 62 comparisons) between the treatment and control teachers and classrooms. This is important for two reasons: one, it indicates that randomization created comparable groups near the start of the study, and two, it shows that treatment and control schools both had high levels of SACD activities near the start of the study, indicating that social and character development activities are part of the "standard practice" of these schools in Tennessee. Standard practice at all of the schools included reports that 46 percent to 89 percent of teachers used SACD activities, 78 percent of teachers used specific materials in conjunction with these activities, 96 percent used at least one of the specified instructional strategies, and 73 percent participated in SACD training over the past 12 months.

Analyses of LBW impacts on use of SACD activities in the schools revealed impacts on the use of such activities (27 out of 90 ) and related materials and strategies (14 out of 87 ) across the 3 years, and use of more professional development activities for treatment teachers than control teachers in all years (8 out of 27). These same measures in the control schools across the 3 years of the study confirmed that use of these activities in the control schools constituted their standard practice.

Of the 20 child-level outcomes representing the four domains of Social and Emotional Competence, Behavior, Academics, and Perceptions of School Climate assessed in each of the 3 years of the study (a total of 60 results), 5 were statistically significant (2 beneficial and 3 detrimental). A growth curve analysis was used to analyze the change over time in these same outcomes between initial data collection and the final outcome data collection at the end of the study. One of the 18 child-level outcomes assessed showed a significant detrimental impact of the LBW program.

The SACD evaluation did not find evidence to support the hypothesis that LBW had beneficial impacts on students' social and character development. Such results could be caused by the inability of the program to cause such change, possibly because the theory of action for the program is incomplete or the activities to carry out that theory are not effective.

However, these results may also be due to the inability of the evaluation to observe such a change due to the control condition, the level of nonparticipation, or the sample size. The control schools continued using their standard SACD activities, and these turned out to be high in quantity and broad in scope. While LBW had a significant positive impact on the amounts and types of SACD activities, the resulting difference in the amount of SACD activities between the treatment and control schools may not have been large enough to cause significant differences in the student outcomes. In addition, about one-third of the students in the sample universe did not take part because of nonconsent or noncompletion of the surveys. As a determination could not be made as to whether the students not taking part significantly differed from those who did take part, the evaluation's results are valid only for the students who took part. If the students not taking part were different, and if they would have responded better to LBW than to the SACD activities 
occurring in the control schools, then the evaluation could have underestimated the program's impact. Third, the sample size of 12 schools and the resulting higher MDES compared to those for the multiprogram evaluation may have reduced the likelihood of detecting statistically significant effects. However, it should be noted that 70 percent of the MDES for the 60 outcomes used in the year-by-year analysis were below 0.25 ( $53 \%$ were below 0.20 ). In addition, none of the 60 outcomes were found to be substantively important. 
This page is intentionally blank. 


\section{Chapter 5. Positive Action}

\section{University of Illinois at Chicago/Oregon State University (Illinois Site)}

\section{Intervention}

Researchers at the University of Illinois at Chicago/Oregon State University (Illinois site) evaluated the Positive Action (PA) program (Flay, Allred, and Ordway 2001). The PA program consists of a school and home curriculum and a school climate program for teaching children about the benefits of physical, intellectual, social, and emotional positive actions, and for creating a supportive learning environment at school and at home. The curriculum is designed to build children's self-concept and self-management through identifying positive thoughts, feelings, and actions. Table 5.1 describes the PA program's general characteristics (panel 1), the types of instruction and strategies used (panel 2), the professional development provided for those implementing the program (panel 3), and the social and character development activities (panel 4) and outcomes (panel 5) addressed by the program.

- Teachers conduct 15- to 20-minute lessons, 4 days per week, with students. Lessons focus on positive actions for a healthy body and mind, social/emotional actions for managing oneself responsibly, ways to get along with others, how to be honest with oneself and others, and setting goals for self-improvement.

- Teachers engage in behavior management practices by recognizing and reinforcing positive behavior and by modeling and reinforcing social skills throughout the day.

- The school climate program is designed to reinforce positive actions throughout the school, using activities such as peer tutoring and mentoring, assemblies, service projects, PA days, and visual artifacts that illustrate positive actions.

- The parent and community program includes parent newsletters and parent night, which are designed to carry classroom concepts into homes and to help families learn and practice positive actions in their communities.

Teachers and staff receive a 4-hour training on the methods of instruction, role modeling, use of positive actions, and use of behavior management strategies at the beginning of the school year and a 2-hour training (refresher for teachers who continue in the same schools, new for new teachers) at the beginning of each subsequent year. Principals and the PA coordinator for each school receive an additional 2 hours of training on the program adoption process in a multischool setting. School counselors receive a kit that includes the curriculum and suggestions for activities with children and family groups. Ongoing consultation is provided to school staff by the PA research team as needed, as often as once per month. 


\section{Table 5.1. Positive Action}

Panel 1: General characteristics

Target population

Universal

Program components

Peer: In and out of class

Parent: Training, contact, and involvement

Classroom: Lessons and behavior management

Schoolwide: Planned events, includes program coordinator and committee

Community: Committees and groups

Training: Pretraining and ongoing

Level of integration

Add-on curriculum and schoolwide activities

Flexibility

Manualized: Scripted curriculum and guidebook

Adaptability: Program staff and principal adapt

See notes at end of table.

Panel 2: Description of instruction and strategies

\section{Classroom}

Lessons

Who delivers: Teacher

Activities and tools: Direct instruction, story reading, writing, role-playing, discussion, singing, games, worksheets, puppets, plays, poems

Content: Self-concept, physical health, intellectual growth, emotional and behavioral self-regulation, getting along with others (social skills), self-honesty, self-improvement, goal setting, character traits

Frequency: 15- to 20-minute lessons, 4 days per week

Strategies

Who delivers: Teacher

Activities and tools: Teaches, practices, recognizes, and models positive actions with curriculum and climate activities and materials

Frequency: Daily

Supplement to classroom

Parent newsletters, parent manual with PA activities, letters, strategies, and parent night

Schoolwide activities

Occasional assemblies, service projects, PA days and year-end event, principal climate program with reinforcement recognition activities

See notes at end of table. 


\section{Table 5.1. Positive Action-Continued}

Panel 3: Professional development

Pre-implementation

Teachers

Content: Training on concepts and delivery of curriculum, school climate activities to reinforce positive behaviors and parent involvement

Duration: $1 / 2$ day

Other

Content: Principal training and appointing committees on coordinating school climate activities with family groups

Duration: $1 / 2$ day

Ongoing consultation

Teachers

Content: Group session to provide technical assistance and share experiences and challenges; visits for technical support

Duration: Up to $1 / 2$ day once per year; up to $1 / 2$ day visits to schools monthly Other

Content: Meeting of principals and coordinators to provide technical assistance and share successes and challenges

Duration: 1 session of 3 hours per year

See notes at end of table.

Panel 4: Activities for SACD goals

\begin{tabular}{ll|ll}
\hline Violence prevention and peace promotion & $\checkmark$ & Risk prevention and health promotion & $\checkmark$ \\
Social and emotional development & $\checkmark$ & Civic responsibility and community service & $\checkmark$ \\
Character education & $\checkmark$ & Behavior management & $\checkmark$ \\
\hline Tolerance and diversity & $\checkmark$ & & \\
\hline
\end{tabular}

See notes at end of table.

Panel 5: SACD outcomes addressed

\begin{tabular}{ll|ll}
\hline Engagement with Learning & $\checkmark$ & Empathy & $\checkmark$ \\
Academic Competence and Motivation & $\checkmark$ & Positive School Orientation & $\checkmark$ \\
Altruistic Behavior & $\checkmark$ & Negative School Orientation & $\checkmark$ \\
Positive Social Behavior & $\checkmark$ & Student Afraid at School & $\checkmark$ \\
Problem Behavior & $\checkmark$ & Victimization at School & $\checkmark$ \\
Self-Efficacy for Peer Interactions & $\checkmark$ & Feelings of Safety & $\checkmark$ \\
Normative Beliefs About Aggression & $\checkmark$ & Student Support for Teachers & $\checkmark$ \\
\hline
\end{tabular}

NOTE: Abbreviations are

PA: Positive Action

$\checkmark$ : Activity or outcome addressed

Blank cell: Activity or outcome not addressed

SOURCE: The Social and Character Development (SACD) Research Program. 


\section{Sample and Random Assignment}

The Illinois research team recruited a total of 14 public elementary schools in a single large, urban school district in Illinois. The researchers deliberately selected a sample of high-risk schools from Chicago that had low achievement scores and families with low household incomes. The 14 schools were randomly assigned to treatment and control conditions prior to the fall 2004 data collection. A two-step process was used. First, a computer-generated pairwise matching algorithm developed by Mathematica Policy Research, Inc. (MPR) was used to identify the best pairwise matches across the 14 schools based on variables identified by the Illinois research team. The variables used in the pairwise matching for Illinois included these: (a) school schedule, (b) percentage of White students, (c) percentage of Black (non-Hispanic) students, (d) percentage of Hispanic students, (e) percentage of Asian students, ( $\mathrm{f}$ ) achievement scores, (g) percentage of attendance, (h) percentage of truancy, (i) percentage of poverty, (j) percentage of mobility, ( $k$ ) total enrollment, (l) percentage of parent participation, (m) quality of teachers, and (n) rate of crime in the community. Second, using a random number generator, 1 school in each matched pair was assigned to either the intervention or control condition. Seven schools received the PA program and 7 schools acted as control schools and continued to implement the social and character development activities that constituted their standard practice. Assignment to treatment or control condition was at the school level and therefore limited the risk of contamination between treatment and control classrooms.

The original student sample (the cohort of students in the third grade in the 14 schools in fall 2004) numbered 811 students (410 treatment and 401 control). Table 5.2 documents the change in the sample over the three spring follow-up data collection periods. Over time, new entrants to the cohort became a larger percentage of the sample, eventually making up 39 percent of the sample by the spring of Year 3 . There were no statistically significant differences between the treatment and control groups in the number of new entrants. The percentage of the sample made up of the original cohort further declined as students left the schools. By Year 3, approximately 50 percent of the original sample had left. In Year 2 there was a statistically significant difference between treatment and control groups in "leavers," with fewer in the treatment group. This difference had disappeared by the end of Year 3. 
Table 5.2. Sample-PA

\begin{tabular}{|c|c|c|c|c|c|c|c|c|c|c|c|c|}
\hline \multirow[b]{2}{*}{ Characteristic } & \multicolumn{3}{|c|}{$\begin{array}{c}\text { Year } 1 \\
\text { (Fall 3rd grade) }\end{array}$} & \multicolumn{3}{|c|}{$\begin{array}{c}\text { Year } 1 \\
\text { (Spring 3rd grade) }\end{array}$} & \multicolumn{3}{|c|}{$\begin{array}{c}\text { Year 2 } \\
\text { (Spring 4th grade) }\end{array}$} & \multicolumn{3}{|c|}{$\begin{array}{c}\text { Year } 3 \\
\text { (Spring 5th grade) }\end{array}$} \\
\hline & Total & $\begin{array}{r}\text { Treat- } \\
\text { ment }\end{array}$ & Control & Total & $\begin{array}{r}\text { Treat- } \\
\text { ment }\end{array}$ & Control & Total & $\begin{array}{c}\text { Treat- } \\
\text { ment }\end{array}$ & Control & Total & $\begin{array}{r}\text { Treat- } \\
\text { ment }\end{array}$ & Control \\
\hline School sample size & 14 & 7 & 7 & 14 & 7 & 7 & 14 & 7 & 7 & 14 & 7 & 7 \\
\hline Student sample size & 811 & 410 & 401 & 812 & 416 & 396 & 764 & 425 & 339 & 655 & 327 & 328 \\
\hline Stayers & $\dagger$ & $\dagger$ & $\dagger$ & 737 & 377 & 360 & 560 & 302 & 258 & 403 & 201 & 202 \\
\hline New entrants & $\dagger$ & $\dagger$ & $\dagger$ & 75 & 39 & 36 & 204 & 123 & 81 & 252 & 126 & 126 \\
\hline $\begin{array}{l}\text { New entrants as a percent of } \\
\text { spring enrollment }\end{array}$ & $\dagger$ & $\dagger$ & $\dagger$ & 9.2 & 9.4 & 9.1 & 26.7 & 28.9 & 23.9 & 38.5 & 38.5 & 38.4 \\
\hline $\begin{array}{l}\text { Total leavers (from original cohort) } \\
\text { Leavers as a percent of fall }\end{array}$ & $\dagger$ & $\dagger$ & $\dagger$ & 74 & 33 & 41 & 251 & 108 & 143 & 408 & 209 & 199 \\
\hline 2004 enrollment & $\dagger$ & $\dagger$ & $\dagger$ & 9.1 & 8.0 & 10.2 & 30.9 & $26.3^{* *}$ & 35.7 & 50.3 & 51.0 & 49.6 \\
\hline $\begin{array}{l}\text { Number of students per school } \\
\text { (mean) }\end{array}$ & 58 & 59 & 57 & 58 & 59 & 57 & 55 & 61 & 49 & 47 & 47 & 47 \\
\hline $\begin{array}{l}\text { Range of number of students per } \\
\text { school }\end{array}$ & $23-101$ & $38-92$ & $23-101$ & $26-103$ & $35-92$ & $26-103$ & $25-83$ & $36-83$ & $25-77$ & $25-74$ & $28-74$ & $25-65$ \\
\hline
\end{tabular}

$\uparrow$ Not applicable.

** Treatment group significantly different from control group at the .01 level.

SOURCE: The Social and Character Development (SACD) Research Program. 


\section{Implementation}

\section{Training}

Teachers, principals, and school staff members in the intervention schools received a half-day of program implementation training prior to the beginning of the first school year (table 5.1, panel 3). The Illinois research team provided an additional half-day of training to schools via professional development days in fall 2004 and in spring 2005, which also allowed continuing teachers and staff time to share stories and concerns about program implementation. In addition, the principal and PA coordinator from each school attended an annual meeting in the winter of each year to learn more about implementing the schoolwide component of the program and to share experiences.

\section{Data Collection}

MPR's subcontractor, Decision Information Resources, Inc. (DIR) collected the child, teacher, and school data at the Illinois site. Table 5.3 shows the school year milestones and dates of implementation for the Illinois site. Data were collected in the fall and spring of the first 2 years and the spring of Year 3 . The fall 2004 data collection began on October 12, 2004, and ended on October 28, 2004. The average time frame from the beginning of program implementation to the beginning of fall data collection was 2 weeks. As a result, initial data collection took place after implementation of the PA program began. Therefore, these data provide a measure of the students, teachers, and schools near the beginning of the school year, at a time when the PA program had been operating for a relatively short period of time. The spring data collection window was from May 16, 2005, to June 3, 2005. The PA program had been implemented for 33 weeks at the time of the spring data collection and for 29 weeks from the end of the fall data collection. Year 2 followed a similar pattern, with implementation occurring at the start of the school year, fall data collection occurring 5 weeks later, and spring data collection occurring 26 weeks after fall data collection (and 34 weeks after the start of implementation). In spring 2007, data collection occurred 35 weeks after the start of implementation. Data collection took from 3 to 5 weeks at each collection point. 
Table 5.3. Data collection dates-PA

\begin{tabular}{|c|c|c|c|c|c|}
\hline Data collection schedule & $\begin{array}{c}\text { Year } 1 \\
\text { (Fall 3rd grade) }\end{array}$ & $\begin{array}{c}\text { Year } 1 \\
\text { (Spring 3rd grade) }\end{array}$ & $\begin{array}{c}\text { Year } 2 \\
\text { (Fall 4th grade) }\end{array}$ & $\begin{array}{c}\text { Year } 2 \\
\text { (Spring 4th grade) }\end{array}$ & $\begin{array}{c}\text { Year } 3 \\
\text { (Spring 5th grade) }\end{array}$ \\
\hline School sample size & 14 & 14 & 14 & 14 & 14 \\
\hline \multicolumn{6}{|l|}{ School year dates } \\
\hline First day of school & $9 / 2 / 04$ & $\dagger$ & 9/6/05 & $\dagger$ & $9 / 5 / 06$ \\
\hline Start of implementation & $9 / 27 / 04$ & $\dagger$ & First day & $\dagger$ & First day \\
\hline Last day of school & $\dagger$ & $6 / 17 / 05$ & $\dagger$ & 6/16/06 & $6 / 15 / 07$ \\
\hline \multicolumn{6}{|l|}{ Data collection } \\
\hline Start & $10 / 12 / 04$ & $5 / 16 / 05$ & $10 / 11 / 05$ & $5 / 1 / 06$ & $5 / 7 / 07$ \\
\hline End & $10 / 28 / 04$ & $6 / 3 / 05$ & $11 / 2 / 05$ & $5 / 26 / 06$ & $6 / 1 / 07$ \\
\hline \multicolumn{6}{|l|}{$\begin{array}{l}\text { Calendar weeks from } \\
\text { program implementation } \\
\text { to start of fall } 2004\end{array}$} \\
\hline & 2 & $\dagger$ & $\dagger$ & $\dagger$ & $\dagger$ \\
\hline \multirow{2}{*}{\multicolumn{6}{|c|}{$\begin{array}{l}\text { Calendar weeks from start } \\
\text { of school to start of fall } \\
\text { data collection }\end{array}$}} \\
\hline & 6 & $\dagger$ & 5 & $\dagger$ & $\dagger$ \\
\hline \multicolumn{6}{|l|}{$\begin{array}{l}\text { Calendar weeks from end } \\
\text { of fall data collection to } \\
\text { start of spring data }\end{array}$} \\
\hline & $\dagger$ & 29 & $\dagger$ & 26 & $\dagger$ \\
\hline $\begin{array}{l}\text { Calendar weeks from } \\
\text { program implementation } \\
\text { to start of spring data } \\
\text { collection }\end{array}$ & $t$ & 33 & $t$ & 34 & 35 \\
\hline
\end{tabular}

† Not applicable.

SOURCE: The Social and Character Development (SACD) Research Program. 


\section{Consent Rates, Completion Rates, and Percentage of Sample With Data}

The actual number of student, primary caregiver, and teacher reports available for analysis was smaller than the number in the sample because consent and completion rates were below 100 percent. Primary caregivers had to provide consent before children could complete the Child Report, before their child's teacher could complete the Teacher Report on Student, and before they themselves completed the Primary Caregiver Report. Teachers also had to provide consent before completing the Teacher Report on Classroom and School. Of those with consent, not all completed their respective reports. Table 5.4 shows the consent rates, completion rates, and percentages of sample with data for each of the four reports over the 3 years. For the Child Report and two teacher reports, completion rates ranged from 78 percent to 100 percent, with no statistically significant differences between treatment and control groups in consent rates for any of these reports. For the Teacher Report on Student, completion rates ranged from 92 percent to 100 percent, with a statistically significant difference between treatment and control groups at two time points: in the fall of 2004 and the spring of 2005 the treatment group teachers completed fewer reports than the control teachers. For the Primary Caregiver Report, the completion rates dropped over time from 92 percent to 64 percent. There were no statistically significant differences between treatment and control groups for these reports.

The percentages of the sample with Child Report data ranged from 66 percent to 78 percent over the 3 years. The percentages of students with information from the Teacher Report on Student ranged from 71 percent to 80 percent. The percentages of students with data from the Primary Caregiver Report ranged from 49 percent to 73 percent and declined over time. The percentages of teachers with data from the Teacher Report on Classroom and School ranged from 78 percent to 91 percent. There were no statistically significant differences between treatment and control conditions in percentages of students with data for any of the four reports. 
Table 5.4. Consent rates, completion rates, and percentage of sample with data from each report-PA

\begin{tabular}{|c|c|c|c|c|c|c|c|c|c|c|c|c|}
\hline \multirow[b]{2}{*}{ Report } & \multicolumn{3}{|c|}{$\begin{array}{c}\text { Year } 1 \\
\text { (Fall 3rd grade) } \\
\end{array}$} & \multicolumn{3}{|c|}{$\begin{array}{c}\text { Year } 1 \\
\text { (Spring 3rd grade) }\end{array}$} & \multicolumn{3}{|c|}{$\begin{array}{c}\text { Year } 2 \\
\text { (Spring 4th grade) }\end{array}$} & \multicolumn{3}{|c|}{$\begin{array}{c}\text { Year } 3 \\
\text { (Spring 5th grade) }\end{array}$} \\
\hline & Total & $\begin{array}{c}\text { Treat- } \\
\text { ment } \\
\end{array}$ & Control & Total & $\begin{array}{r}\text { Treat- } \\
\text { ment }\end{array}$ & Control & Total & $\begin{array}{r}\text { Treat- } \\
\text { ment }\end{array}$ & Control & Total & $\begin{array}{r}\text { Treat- } \\
\text { ment }\end{array}$ & Control \\
\hline Student sample size & 811 & 410 & 401 & 812 & 416 & 396 & 764 & 425 & 339 & 655 & 327 & 328 \\
\hline \multicolumn{13}{|l|}{ Child Report (percent) } \\
\hline Primary caregiver consent rate & 78.5 & 79.0 & 78.1 & 76.7 & 76.4 & 77.0 & 72.4 & 71.1 & 74.0 & 79.2 & 80.1 & 78.4 \\
\hline Student completion rate & 94.7 & 93.5 & 95.8 & 92.8 & 93.7 & 91.8 & 92.0 & 94.0 & 89.6 & 96.5 & 97.7 & 95.3 \\
\hline Students with data ${ }^{1}$ & 74.4 & 73.9 & 74.8 & 71.2 & 71.6 & 70.7 & 66.6 & 66.8 & 66.4 & 76.5 & 78.3 & 74.7 \\
\hline \multicolumn{13}{|l|}{ Primary Caregiver Report (percent) } \\
\hline Primary caregiver consent rate & 78.3 & 79.0 & 77.6 & 76.7 & 76.4 & 77.0 & 70.9 & 69.6 & 72.6 & 78.3 & 79.5 & 77.1 \\
\hline Primary caregiver completion rate & 92.3 & 92.0 & 92.6 & 76.7 & 77.0 & 76.4 & 73.6 & 72.6 & 74.8 & 64.5 & 65.0 & 64.0 \\
\hline Primary caregivers with data ${ }^{1}$ & 72.3 & 72.7 & 71.8 & 58.9 & 58.9 & 58.8 & 52.2 & 50.6 & 54.3 & 50.5 & 51.7 & 49.4 \\
\hline \multicolumn{13}{|l|}{ Teacher Report on Student (percent) } \\
\hline Primary caregiver consent rate ${ }^{2}$ & 78.5 & 79.0 & 78.1 & 76.7 & 76.4 & 77.0 & 72.4 & 71.1 & 74.0 & 79.2 & 80.1 & 78.4 \\
\hline Teacher completion rate & 95.0 & $92.3^{* * *}$ & * 97.8 & 97.4 & $95.9^{*}$ & 99.0 & 100.0 & 100.0 & 100.0 & 98.8 & 99.2 & 98.4 \\
\hline Students with data ${ }^{1}$ & 74.6 & 72.9 & 76.3 & 74.8 & 73.3 & 76.3 & 72.4 & 71.1 & 74.0 & 78.3 & 79.5 & 77.1 \\
\hline \multicolumn{13}{|c|}{$\begin{array}{l}\text { Teacher Report on Classroom and School } \\
\text { (3rd- to 5th-grade teachers) (percent) }\end{array}$} \\
\hline Teacher consent rate & 100.0 & 100.0 & 100.0 & 99.1 & 98.4 & 100.0 & 100.0 & 100.0 & 100.0 & 100.0 & 100.0 & 100.0 \\
\hline Teacher completion rate & 89.5 & 90.0 & 88.9 & 83.3 & 83.3 & 83.3 & 86.3 & 86.0 & 86.7 & 83.7 & 78.0 & 90.5 \\
\hline Teachers with data $^{1}$ & 89.5 & 90.0 & 88.9 & 82.6 & 82.0 & 83.3 & 86.3 & 86.0 & 86.7 & 83.7 & 78.0 & 90.5 \\
\hline
\end{tabular}

* Treatment group significantly different from control group at the .05 level.

*** Treatment group significantly different from control group at the .001 level.

${ }^{1}$ Calculated as consent rate $x$ completion rate.

${ }^{2}$ The primary caregiver consent rates for the Child Report and the Teacher Report on Student are identical, as the primary caregiver gave consent to both together.

SOURCE: The Social and Character Development (SACD) Research Program. 
Responses from students in the original cohort (stayers) and new entrants in the PA sample were examined to investigate possible differences between the two groups in consent rates, completion rates, and the percentages of the sample with data that might affect outcome data (table 5.5). In Year 2, new entrants had significantly higher consent rates and percentages of sample with data than stayers on all three reports (by 12 to 17 percentage points). In Year 3, new entrants had significantly higher completion rates (by 10 percentage points) and percentages of sample with data (by 12 percentage points) than stayers for the Primary Caregiver Report. 
Table 5.5. Consent rates, completion rates, and percentage of sample with data: Stayers versus new entrants--PA

\begin{tabular}{|c|c|c|c|c|c|c|c|c|c|}
\hline \multirow[b]{2}{*}{ Report } & \multicolumn{3}{|c|}{$\begin{array}{c}\text { Year } 1 \\
\text { (Spring 3rd grade) }\end{array}$} & \multicolumn{3}{|c|}{$\begin{array}{c}\text { Year } 2 \\
\text { (Spring 4th grade) }\end{array}$} & \multicolumn{3}{|c|}{$\begin{array}{c}\text { Year } 3 \\
\text { (Spring 5th grade) }\end{array}$} \\
\hline & Total & Stayers & Entrants & Total & Stayers & Entrants & Total & Stayers & Entrants \\
\hline Student sample size & 812 & 737 & 75 & 764 & 560 & 204 & 655 & 403 & 252 \\
\hline \multicolumn{10}{|l|}{ Child Report (percent) } \\
\hline Primary caregiver consent rate & 76.7 & 77.3 & 70.7 & 72.4 & $68.9^{* * *}$ & 81.9 & 79.2 & 77.7 & 81.7 \\
\hline Student completion rate & 92.8 & 92.5 & 96.2 & 92.0 & $90.2^{*}$ & 96.4 & 96.5 & 96.5 & 96.6 \\
\hline Students with data ${ }^{1}$ & 71.2 & 71.5 & 68.0 & 66.6 & $62.1^{* * *}$ & 78.9 & 76.5 & 74.9 & 79.0 \\
\hline \multicolumn{10}{|l|}{ Primary Caregiver Report (percent) } \\
\hline Primary caregiver consent rate & 76.7 & 77.3 & 70.7 & 70.9 & $67.0^{* * *}$ & 81.9 & 78.3 & 76.2 & 81.7 \\
\hline Primary caregiver completion rate & 76.7 & 76.1 & 83.0 & 73.6 & 73.1 & 74.9 & 64.9 & $60.9^{*}$ & 70.9 \\
\hline Primary caregivers with data ${ }^{1}$ & 58.9 & 58.9 & 58.7 & 52.2 & $48.9^{* *}$ & 61.3 & 50.8 & $46.4^{\star *}$ & 57.9 \\
\hline \multicolumn{10}{|l|}{ Teacher Report on Student (percent) } \\
\hline Primary caregiver consent rate ${ }^{2}$ & 76.7 & 77.3 & 70.7 & 72.4 & $68.9^{* * *}$ & 81.9 & 79.2 & 77.7 & 81.7 \\
\hline Teacher completion rate & 97.4 & 97.7 & 94.3 & 100.0 & 100.0 & 100.0 & 98.8 & 98.7 & 99.0 \\
\hline Students with data ${ }^{1}$ & 74.8 & 75.6 & 66.7 & 72.4 & $68.9^{* * *}$ & 81.9 & 78.3 & 76.7 & 81.0 \\
\hline
\end{tabular}

* Stayers significantly different from new entrants at the .05 level.

** Stayers significantly different from new entrants at the .01 level.

*** Stayers significantly different from new entrants at the .001 level.

${ }^{1}$ Calculated as consent rate $\mathrm{x}$ completion rate.

${ }^{2}$ The primary caregiver consent rates for the Child Report and the Teacher Report on Student are identical, as the primary caregiver gave consent to both together.

SOURCE: The Social and Character Development (SACD) Research Program. 


\section{Fidelity of Implementation}

Each year, PA's seven treatment schools were independently rated for quantity and quality of program implementation by two raters from the research team. The global measure of fidelity for the multisite study was used; inter-rater reliability was measured using Cronbach's alpha (0.85 in Year 1, 0.74 in Year 2, and 0.98 in Year 3). The ratings were combined into a single consensus rating and used to identify schools with high implementation fidelity. In Years 1 and 2, four treatment schools were identified as having high fidelity, and in Year 3, three treatment schools were identified as having high fidelity. Cohen's kappa was used as the measure of agreement when identifying schools as high fidelity, and it equaled 0.72 in Year 1, 0.46 in Year 2, and 1.00 in Year 3.

\section{Initial Characteristics}

This section describes the initial characteristics of the students, teachers, and schools participating in the evaluation of the PA program. These characteristics were collected from students who were enrolled in the third grade at the study schools in fall 2004, as well as from their primary caregivers and third-grade teachers. In addition, third-, fourth-, and fifth-grade teachers and principals in the study schools provided information about activities related to social and character development in these schools. Documenting the characteristics of students, teachers, and schools and initial measures of key outcomes at a point before the interventions had been operating for an extended period helps to determine whether the random assignment of schools to treatment and control status produced treatment and control groups with similar distributions of observed characteristics. As noted in the following discussion, 3 significant differences (out of 62 comparisons, with 3 expected to be significant by chance) were found between the observed characteristics of the treatment and control students, teachers, and schools; all 3 reflected the use of SACD activities in the classroom and school.

\section{Characteristics of Children, Their Families, and Communities}

There were no significant differences between the treatment and control groups in the observed student, caregiver, and community characteristics (table 5.6). For students, the mean age was 8.3 years. The sample contained roughly equal percentages of girls (54\%) and boys (46\%). The sample was ethnically diverse, with Black non-Hispanic students making up the majority of the sample $(51 \%)$. White non-Hispanic students made up 6 percent of the sample and Hispanic students made up 37 percent of the sample.

The sample was diverse in its levels of family income, education levels of primary caregivers of the children in the sample, and family situation. For the total sample, 66 percent of the children lived in a household where the income was 135 percent of the federal poverty level or lower, which is the income threshold for eligibility for free school meals. More than one-quarter $(27 \%)$ of primary caregivers had not completed high school. Fewer than half of the children (47\%) lived with both their mother and their father. There were no significant differences between the treatment and control groups in these characteristics.

The mean values of the outcomes for children's behavior and attitudes as reported by the primary caregiver, child, and teacher at initial data collection in fall 2004 are shown in table 5.7. There were no significant differences between the treatment and control groups in these scores. 
Table 5.6. Initial characteristics of children, their families, and communities-PA

\begin{tabular}{|c|c|c|c|}
\hline Characteristic & Total & Treatment & Control \\
\hline Student sample size & 586 & 298 & 288 \\
\hline \multicolumn{4}{|l|}{ Student demographics } \\
\hline \multicolumn{4}{|l|}{ Gender (percent) } \\
\hline Male & 46.3 & 47.8 & 44.7 \\
\hline Female & 53.7 & 52.2 & 55.3 \\
\hline \multicolumn{4}{|l|}{ Race/ethnicity (percent) } \\
\hline White (non-Hispanic) & 6.0 & 5.0 & 7.0 \\
\hline Black (non-Hispanic) & 51.1 & 51.9 & 50.2 \\
\hline Hispanic & 37.4 & 39.2 & 35.5 \\
\hline Other & 5.5 & 3.8 & 7.3 \\
\hline Age (in years) (mean) & 8.3 & 8.3 & 8.3 \\
\hline \multicolumn{4}{|l|}{ Primary caregiver and family characteristics } \\
\hline Primary caregiver's age (in years) (mean) & 35.8 & 35.3 & 36.3 \\
\hline \multicolumn{4}{|l|}{ Primary caregiver's race/ethnicity (percent) } \\
\hline White (non-Hispanic) & 8.2 & 7.3 & 9.1 \\
\hline Black (non-Hispanic) & 51.2 & 52.2 & 50.2 \\
\hline Hispanic & 35.5 & 36.9 & 34.0 \\
\hline Other & 5.2 & 3.6 & 6.7 \\
\hline \multicolumn{4}{|l|}{ Primary caregiver's education (percent) } \\
\hline Did not complete high school & 27.4 & 26.3 & 28.5 \\
\hline Completed high school or equivalent & 30.9 & 27.1 & 34.7 \\
\hline Some college & 35.7 & 38.5 & 32.9 \\
\hline Bachelor's or higher degree & 6.1 & 8.1 & 4.0 \\
\hline \multicolumn{4}{|l|}{ Primary caregiver's employment (percent) } \\
\hline Full-time & 45.4 & 44.1 & 46.7 \\
\hline Other & 54.6 & 55.9 & 53.3 \\
\hline \multicolumn{4}{|l|}{ Primary caregiver's marital status (percent) } \\
\hline Married & 41.4 & 40.6 & 42.2 \\
\hline Other & 58.6 & 59.4 & 57.8 \\
\hline Students who live in one household (percent) & 92.7 & 93.5 & 92.0 \\
\hline Number of individuals in household (mean) & 5.1 & 4.9 & 5.3 \\
\hline \multicolumn{4}{|l|}{ Primary caregiver's relationship to child (percent) } \\
\hline Mother (stepmother) & 83.2 & 84.3 & 82.1 \\
\hline Father (stepfather) & 10.2 & 8.7 & 11.6 \\
\hline Other relative/nonrelative & 6.6 & 7.0 & 6.3 \\
\hline
\end{tabular}


Table 5.6. Initial characteristics of children, their families, and communities-PA--Continued

\begin{tabular}{|c|c|c|c|}
\hline Characteristic & Total & Treatment & Control \\
\hline \multicolumn{4}{|l|}{ Student lives with (percent) } \\
\hline Mother (stepmother) and father (stepfather) & 46.6 & 44.1 & 49.1 \\
\hline Mother (stepmother) only; father (stepfather) not present & 45.3 & 47.7 & 42.8 \\
\hline Father (stepfather) only; mother (stepmother) not present & 3.0 & 2.7 & 3.4 \\
\hline Other relative/nonrelative, parents not present & 5.1 & 5.5 & 4.8 \\
\hline \multicolumn{4}{|l|}{ Highest education of anyone in household (percent) } \\
\hline Did not complete high school & 18.8 & 17.1 & 20.5 \\
\hline Completed high school or equivalent & 31.1 & 29.7 & 32.5 \\
\hline Some college & 39.7 & 42.3 & 37.1 \\
\hline Bachelor's or higher degree & 10.4 & 11.0 & 9.9 \\
\hline \multicolumn{4}{|l|}{ Total household income (percent) } \\
\hline Less than $\$ 20,000$ & 55.4 & 53.6 & 57.2 \\
\hline$\$ 20,000$ to $\$ 39,999$ & 28.1 & 29.4 & 26.7 \\
\hline$\$ 40,000$ to $\$ 59,999$ & 10.2 & 10.7 & 9.8 \\
\hline$\$ 60,000$ or more & 6.3 & 6.3 & 6.4 \\
\hline Income-to-poverty-threshold ratio-Below 135 percent (percent) & 65.7 & 60.6 & 70.7 \\
\hline Income-to-poverty-threshold ratio-135 to 185 percent (percent) & 18.5 & 20.8 & 16.3 \\
\hline Income-to-poverty-threshold ratio-Above 185 percent (percent) & 15.8 & 18.6 & 12.9 \\
\hline \multicolumn{4}{|l|}{ Alabama Parenting Questionnaire-Poor Monitoring and } \\
\hline Supervision Subscale (mean) & 1.2 & 1.2 & 1.2 \\
\hline \multicolumn{4}{|l|}{ Alabama Parenting Questionnaire-Positive Parenting } \\
\hline Subscale (mean) & 3.5 & 3.5 & 3.5 \\
\hline Confusion, Hubbub, and Order Scale (mean) & 2.2 & 2.1 & 2.2 \\
\hline \multicolumn{4}{|l|}{ Community characteristics (mean) } \\
\hline Community Risks Scale & 1.9 & 1.8 & 1.9 \\
\hline Community Resources Scale & 2.7 & 2.7 & 2.6 \\
\hline Child-Centered Social Control Scale & 2.8 & 2.8 & 2.8 \\
\hline
\end{tabular}


Table 5.7. Mean scores and standard deviations for initial outcome measures of sample-PA

\begin{tabular}{|c|c|c|c|c|c|c|c|}
\hline \multirow[b]{2}{*}{ Outcome measure-Report } & \multirow[b]{2}{*}{ Range } & \multicolumn{2}{|c|}{ Total } & \multicolumn{2}{|c|}{ Treatment } & \multicolumn{2}{|c|}{ Control } \\
\hline & & Mean & $S D$ & Mean & $S D$ & Mean & $S D$ \\
\hline \multicolumn{8}{|l|}{ Social and Emotional Competence Domain } \\
\hline Self-Efficacy for Peer Interaction-CR & $1-4$ & 2.8 & 0.6 & 2.9 & 0.7 & 2.8 & 0.6 \\
\hline Normative Beliefs About Aggression-CR & $1-4$ & 1.3 & 0.4 & 1.3 & 0.5 & 1.2 & 0.4 \\
\hline Empathy-CR & $1-3$ & 2.4 & 0.4 & 2.4 & 0.4 & 2.4 & 0.4 \\
\hline \multicolumn{8}{|l|}{ Behavior Domain } \\
\hline Altruistic Behavior-CR & $0-3$ & 1.6 & 0.8 & 1.6 & 0.8 & 1.7 & 0.7 \\
\hline Altruistic Behavior-TRS & $1-4$ & 1.4 & 0.5 & 1.5 & 0.6 & 1.3 & 0.4 \\
\hline Altruistic Behavior-PCR & $1-4$ & 2.4 & 0.7 & 2.4 & 0.7 & 2.5 & 0.8 \\
\hline Positive Social Behavior-TRS & $1-4$ & 2.9 & 0.7 & 2.9 & 0.7 & 2.9 & 0.7 \\
\hline Positive Social Behavior-PCR & $1-4$ & 2.9 & 0.5 & 2.9 & 0.5 & 2.9 & 0.5 \\
\hline Problem Behavior-CR & $0-3$ & 0.3 & 0.5 & 0.4 & 0.5 & 0.3 & 0.4 \\
\hline Problem Behavior-TRS & $1-4$ & 1.4 & 0.5 & 1.4 & 0.4 & 1.5 & 0.5 \\
\hline Problem Behavior-PCR & $1-4$ & 1.6 & 0.4 & 1.5 & 0.3 & 1.6 & 0.4 \\
\hline ADHD-Related Behavior-TRS & $1-4$ & 1.7 & 0.6 & 1.7 & 0.6 & 1.8 & 0.6 \\
\hline \multicolumn{8}{|l|}{ Academics Domain } \\
\hline Academic Competence and Motivation-TRS & $1-5$ & 2.7 & 0.9 & 2.7 & 0.9 & 2.7 & 0.9 \\
\hline Engagement with Learning-CR & $1-4$ & 3.5 & 0.7 & 3.5 & 0.7 & 3.5 & 0.8 \\
\hline \multicolumn{8}{|l|}{ Perceptions of School Climate Domain } \\
\hline Positive School Orientation-CR & $1-4$ & 3.1 & 0.7 & 3.1 & 0.7 & 3.1 & 0.7 \\
\hline Negative School Orientation-CR & $1-4$ & 2.1 & 0.7 & 2.2 & 0.6 & 2.1 & 0.7 \\
\hline Student Afraid at School-CR & $1-4$ & 2.6 & 0.9 & 2.6 & 0.9 & 2.6 & 0.9 \\
\hline Victimization at School-CR & $0-3$ & 0.9 & 0.8 & 0.9 & 0.8 & 0.9 & 0.8 \\
\hline Student sample size_-PCR & & \multicolumn{2}{|c|}{586} & \multicolumn{2}{|c|}{298} & \multicolumn{2}{|c|}{288} \\
\hline Student sample size-CR & & \multicolumn{2}{|c|}{603} & \multicolumn{2}{|c|}{303} & \multicolumn{2}{|c|}{300} \\
\hline Student sample size-TRS & & \multicolumn{2}{|c|}{605} & \multicolumn{2}{|c|}{299} & \multicolumn{2}{|c|}{306} \\
\hline
\end{tabular}

NOTE: Abbreviations are

CR: Child Report

PCR: Primary Caregiver Report

TRS: Teacher Report on Student

ADHD: Attention deficit hyperactivity disorder

$S D$ : Standard deviation

No statistically significant differences were found between values for treatment and control groups. Weights, which assign equal weight to each school within the program, were used in producing the treatment, control, and overall means. Statistical tests were conducted using regressions that included program indicators to account for the sample design and adjusted for clustering at the school level. Sample size may differ for some outcomes due to nonresponse.

SOURCE: The Social and Character Development (SACD) Research Program. 


\section{Characteristics of Teachers and Schools}

Table 5.8 describes the third-, fourth-, and fifth-grade teachers at the study schools. Slightly fewer than half were White non-Hispanic (49\%). Most of the teachers were female $(85 \%)$ and had an average of 15 years of total teaching experience. Slightly fewer than half $(47 \%)$ held an advanced or specialist degree. There were no statistically significant differences between the treatment and control groups of teachers.

Data regarding school characteristics were drawn from the Common Core of Data in order to compare treatment and control schools. There were no significant differences between the two groups of schools in terms of student composition (race/ethnicity and school lunch eligibility), number of students enrolled, number of full-time teachers, Title 1 status, or number of years the principal had been at the school (table 5.9). In addition, there were no significant differences between treatment and control schools in terms of location (urban, suburban, or rural) or lowest and highest grade offered (these data are not shown in a table).

Table 5.8. Initial characteristics of teachers in sample-PA

\begin{tabular}{|c|c|c|c|}
\hline Characteristic & Total & Treatment & Control \\
\hline Teacher sample size & 102 & 54 & 48 \\
\hline \multicolumn{4}{|l|}{ Gender (percent) } \\
\hline Male & 14.9 & 22.2 & 7.5 \\
\hline Female & 85.1 & 77.8 & 92.5 \\
\hline \multicolumn{4}{|l|}{ Race/ethnicity (percent) } \\
\hline White (non-Hispanic) & 49.1 & 40.5 & 57.7 \\
\hline Other & 50.9 & 59.5 & 42.3 \\
\hline Number of years teaching experience (mean) & 15.0 & 15.7 & 14.3 \\
\hline Number of years teaching experience in this school (mean) & 9.0 & 10.0 & 8.1 \\
\hline \multicolumn{4}{|l|}{ Type of teaching certificate (percent) } \\
\hline Regular state certificate or advanced professional certificate & 90.5 & 92.9 & 88.1 \\
\hline Other & 9.5 & 7.1 & 11.9 \\
\hline \multicolumn{4}{|l|}{ Education (percent) } \\
\hline Bachelor's degree & 53.1 & 57.1 & 49.1 \\
\hline Advanced degree/other & 46.9 & 42.9 & 50.9 \\
\hline
\end{tabular}


Table 5.9. Initial characteristics of schools in sample-PA

\begin{tabular}{|c|c|c|c|}
\hline Characteristic & Total & Treatment & Control \\
\hline School sample size & 14 & 7 & 7 \\
\hline \multicolumn{4}{|l|}{ Student race/ethnicity (percent) } \\
\hline White (non-Hispanic) & 9.2 & 9.1 & 9.4 \\
\hline Black (non-Hispanic) & 55.1 & 53.6 & 56.5 \\
\hline Hispanic & 31.9 & 32.8 & 31.0 \\
\hline Other & 3.8 & 4.5 & 3.1 \\
\hline Students eligible for free or reduced-price lunch (percent) & 90.6 & 92.6 & 88.7 \\
\hline Number of students enrolled (mean) & 532.0 & 521.1 & 542.9 \\
\hline Number of full-time teachers (mean) & 30.0 & 28.5 & 331.5 \\
\hline \multicolumn{4}{|l|}{ Title I status (percent) } \\
\hline Title I eligible school & 100.0 & 100.0 & 100.0 \\
\hline Schoolwide Title I & 100.0 & 100.0 & 100.0 \\
\hline Number of years principal has been at this school (mean) & 5.9 & 5.9 & 5.9 \\
\hline
\end{tabular}

In the Teacher Report on Classroom and School, teachers reported on nine dimensions of school environment (these data are not shown in a table): feelings of safety, adequacy of resources, student support, freedom to teach as desired, affiliation with and ties to colleagues, innovation regarding new approaches to teaching, professional interest, participatory decisionmaking, and work pressure. There were no statistically significant differences between treatment and control schools in these reports.

\section{The Level of SACD in the Schools Near the Beginning of the Study}

During the initial data collection, principals and teachers reported on the SACD activities used in the schools and classrooms, the availability of SACD materials, and the professional development provided on SACD. Table 5.10 shows that the majority of the principals reported activities to promote six social and character development goals: violence prevention and peace promotion (100\%), social and emotional development (93\%), character education (93\%), tolerance and diversity (93\%), risk prevention and health promotion (93\%), and civic responsibility and community service (100\%). In addition, 86 percent of the principals reported the use of activities directed toward behavior management. There were no statistically significant differences between the treatment group and the control group in the percentages on principal reports, although this may be due to the small principal sample size. The percentages of teachers reporting the use of these activities in their classrooms ranged from 45 percent to 81 percent, and there were no significant differences between treatment and control teachers. With respect to the use of schoolwide activities, 52 percent to 76 percent of teachers reported that their schools used such activities. There was a significant difference between treatment and control teachers on reports of their use of unspecified schoolwide SACD activities (one out of six comparisons), with treatment teachers reporting fewer "other activities" than control teachers (values suppressed to protect confidentiality). 
Table 5.10. Principal and teacher initial reports on use of SACD programs or activities in sample-PA

\begin{tabular}{|c|c|c|c|}
\hline SACD program or activity & Total & Treatment & Control \\
\hline Principal sample size & 14 & 7 & 7 \\
\hline Teacher sample size & 102 & 54 & 48 \\
\hline \multicolumn{4}{|c|}{$\begin{array}{l}\text { Principals reporting that school had programs or activities } \\
\text { to promote the following SACD goals (percent) }\end{array}$} \\
\hline Violence prevention and peace promotion & 100.0 & 100.0 & 100.0 \\
\hline Social and emotional development & 92.9 & 100.0 & 85.7 \\
\hline Character education & 92.9 & 85.7 & 100.0 \\
\hline Tolerance and diversity & 92.9 & 100.0 & 85.7 \\
\hline Risk prevention and health promotion & 92.9 & 85.7 & 100.0 \\
\hline Civic responsibility and community service & 100.0 & 100.0 & 100.0 \\
\hline Behavior management & 85.7 & 100.0 & 71.4 \\
\hline None of the above & 0.0 & 0.0 & 0.0 \\
\hline \multicolumn{4}{|c|}{$\begin{array}{l}\text { Teachers reporting on using programs or activities in their } \\
\text { class to promote the following SACD goals (percent) }\end{array}$} \\
\hline Violence prevention and peace promotion & 63.0 & 60.2 & 65.8 \\
\hline Social and emotional development & 70.8 & 70.2 & 71.3 \\
\hline Character education & 81.0 & 79.4 & 82.5 \\
\hline Tolerance and diversity & 57.7 & 60.7 & 54.8 \\
\hline Risk prevention and health promotion & 54.6 & 58.8 & 50.4 \\
\hline Civic responsibility and community service & 44.6 & 45.8 & 43.4 \\
\hline Behavior management & 77.5 & 76.1 & 79.0 \\
\hline None of the above & 6.9 & 6.0 & 7.7 \\
\hline \multicolumn{4}{|l|}{$\begin{array}{l}\text { Teachers reporting schoolwide use of the following } \\
\text { activities to promote SACD (percent) }\end{array}$} \\
\hline Morning announcements or videos & 60.8 & 62.0 & 59.6 \\
\hline School assemblies & 75.7 & 70.4 & 81.0 \\
\hline School newspapers or bulletins & 67.1 & 61.8 & 72.4 \\
\hline Special school days & 52.3 & 52.9 & 51.7 \\
\hline Special events & 67.0 & 65.5 & 68.4 \\
\hline Other activities & 11.8 & $\ddagger^{*}$ & $\ddagger$ \\
\hline
\end{tabular}

$\ddagger$ Reporting standards not met. Values suppressed to protect confidentiality.

* Treatment group significantly different from control group at the .05 level.

NOTE: Weights, which assign equal weight to each school within each of the programs and to each program across programs, were used in producing the treatment, control, and overall means. Statistical tests were conducted using regressions that included program indicators to account for the sample design and adjusted for clustering at the school level. Sample size may differ for some outcomes due to nonresponse.

SOURCE: The Social and Character Development (SACD) Research Program. 
Teachers reported using a broad range of teaching materials to support SACD activities (table 5.11), including teacher guides $(70 \%)$, student materials $(68 \%)$, instructional aids (38\%), giveaways $(52 \%)$, and children's literature $(40 \%)$. There were no statistically significant differences between treatment and control teachers in their use of these materials.

Teachers also reported using a wide variety of teaching strategies (table 5.11). Nearly all teachers (99\%) reported using any of the 20 strategies asked about, and teachers used an average of 12.1 of the strategies. There were significant differences between treatment and control teacher reports on the use of 2 of the 20 strategies. One was a significant difference in peer mediation, with treatment teachers using this strategy more often than control teachers ( $54 \%$ versus 35\%). The other was a significant difference in the use of time out for negative behavior, with treatment teachers using this strategy less often than control teachers $(72 \%$ versus $87 \%)$. 


\section{Table 5.11. Teacher initial reports on use of SACD materials and classroom strategies in sample-PA}

SACD material and classroom strategy
Teacher sample size
Teachers using the following materials in conjunction with
social and character development activities (percent)

Teacher guides (manuals, curricula)

$\begin{array}{rrr}69.7 & 76.2 & 63.2 \\ 67.5 & 76.3 & 58.6 \\ 37.6 & 36.8 & 38.5 \\ 52.4 & 56.3 & 48.4 \\ 39.8 & 36.3 & 43.2 \\ 14.1 & 5.7 & 22.5 \\ 8.2 & 9.6 & 6.8\end{array}$

Teachers using any of the strategies listed below to promote social and character development in the classroom (percent)

Number of strategies (listed below) used by teachers to promote social and character development in the classroom (mean)

Teachers using each of the following strategies to promote social and character development (percent)

Role-playing

71.6

71.3

71.9

Cooperative learning

Peer group discussions

Direct instruction of social and character development

Skill training

Parent training

Parent/community involvement in program development or delivery

Mentoring

Good behavior notes sent home daily or weekly

Presenting role models

Targeted story reading or writing on SACD themes

Peer mediation

Honor roll for positive behavior

Pledges or recitations on social and character development themes

\begin{tabular}{lll}
47.1 & 50.7 & 43.6 \\
54.8 & 57.5 & 52.1 \\
50.8 & 55.5 & 46.2 \\
82.4 & 82.0 & 82.9 \\
79.7 & $72.1^{*}$ & 87.4 \\
93.8 & 91.2 & 96.4 \\
\hline
\end{tabular}

Guided visualization

Student-led/student-assisted instruction

Journaling

Time out for negative behavior

91.2

96.4

* Treatment group significantly different from control group at the .05 level.

NOTE: Weights, which assign equal weight to each school within each of the programs and to each program across programs, were used in producing the treatment, control, and overall means. Statistical tests were conducted using regressions that included program indicators to account for the sample design and adjusted for clustering at the school level. Sample size may differ for some outcomes due to nonresponse.

SOURCE: The Social and Character Development (SACD) Research Program. 
Principals and teachers reported on participation in and amount of SACD training and staff development provided over the previous 12 months (table 5.12). Principals reported higher participation rates ( $93 \%$ versus $68 \%$ ) than did teachers, although principals and teachers reported virtually the same number of training hours (5.0 versus 5.2). There were no significant differences between treatment and control principals or teachers on any of these measures.

Table 5.12. Principal and teacher initial reports on SACD professional development in sample-PA

\begin{tabular}{l} 
SACD professional development \\
\hline Principal sample size \\
Teacher sample size \\
Principals reporting that staff participated in social and character \\
development training within the past year (percent)
\end{tabular}
development training within the past year (percent)

100.0

Teachers reporting participation in social and character development training within the past 12 months (percent)

Number of hours of social and character development training principals report were provided to each staff person last year (mean)

Number of hours of social and character development training teachers report receiving during the past 12 months (mean)

Teachers reporting receiving training in the past 12 months in the following areas (percent)

Violence prevention and peace promotion

Social and emotional development

Character education

Tolerance and diversity

Risk prevention and health promotion

‡ Reporting standards not met. Values suppressed to protect confidentiality.

NOTE: No statistically significant differences were found between values for treatment and control groups. Weights, which assign equal weight to each school within each of the programs and to each program across programs, were used in producing the treatment, control, and overall means. Statistical tests were conducted using regressions that included program indicators to account for the sample design and adjusted for clustering at the school level. Sample size may differ for some outcomes due to nonresponse.

SOURCE: The Social and Character Development (SACD) Research Program.

The data on the initial level of SACD activity emphasize that the control condition was a "standard practice" control. Standard practice at the control schools included using SACD activities, materials, and practices, along with professional development for staff, at rates and in types and amounts similar to the treatment schools. For example, the percentages of teachers who reported using programs or activities to promote specific SACD goals ranged from 46 percent to 79 percent in the treatment schools and from 43 percent to 83 percent in the control schools. The 3 significant differences between the treatment and control conditions in the use of SACD activities was the number expected by chance ( 3 out of 62 comparisons); 2 of these differences favored the control group and 1 favored the treatment group. 


\section{Impacts on Use of SACD Activities}

The introduction of the formal PA program would be expected to increase the use of SACD activities in the treatment schools in comparison to the control schools. The analysis of this impact is based on the Teacher Report on Classroom and School (TRCS). Every spring, third-, fourth-, and fifth-grade teachers provided information through the TRCS about the social and character development activities they used in their classrooms. Specifically, information from the TRCS was used to determine difference between treatment and control teachers in several areas:

1. the use of SACD activities in their classrooms overall and by SACD goal;

2. the use of materials and strategies to implement the SACD activities within classrooms and within the entire school;

3. the use of staff development to support the teachers; and

4. teacher support for SACD efforts in the school and the use of practices conducive to the social and character development of students.

TRCS consent and completion rates (table 5.4) led to 78 percent to 91 percent of all teachers having data for the 3 years. To estimate intervention impacts for each of the outcomes, testing of the statistical significance of the differences in means was used. Preliminary analysis indicated little or no gains in precision from using covariates. Before testing the mean differences, the data were weighted such that each school received equal weight. Standard errors of the impact estimates account for the clustering of teachers within schools. In addition, a set of heuristics (described in chapter 1) was applied to determine whether each outcome domain was statistically significant after adjustments were made for the multiple tests conducted.

\section{Use of Activities}

The percentages of control teachers reporting using any SACD activities in their classroom ranged from 83 percent to 95 percent over the 3 years (table 5.13, panel 1). For the six individual SACD goals, the range varied from 38 percent to 71 percent in Year 1, 52 percent to 77 percent in Year 2, and 53 percent to 65 percent in Year 3. Control teachers' use of behavior management activities ranged from 76 percent to 82 percent over this period. The percentages of control teachers who reported using any SACD activities in their classrooms for at least 1 hour per week (panel 2) ranged from 36 percent to 77 percent over the 3 years. For the six individual SACD goals, the ranges varied from 13 percent to 26 percent in Year 1, 23 percent to 44 percent in Year 2, and 19 percent to 31 percent in Year 3. Their use of behavior management activities ranged from 42 percent to 69 percent over this period. These findings show that the control schools were using these activities as part of their standard practice related to social and character development.

For teachers' reported use of any SACD activity, 48 comparisons were made, with 2 expected to be significant by chance. There were 3 significant impacts in use of specific SACD activities (panels 1 and 2). In Years 2 and 3, more treatment teachers than control teachers reported using social and emotional development activities (impact $=26$ and 30 percentage points), and in Year 3 more treatment teachers reported using character education activities (impact $=32$ percentage points). More treatment teachers than control teachers reported using any activity for at least 1 hour per week in Year 1 (impact $=41$ percentage points). More treatment teachers also reported using specific activities for at least 1 hour per week: violence prevention and peace promotion in Years 1 and 3 (impact $=27$ and 26 percentage points), social and emotional development in all years (impact $=37,29$, and 44 percentage points), character education in Years 1 and 3 (impact $=41$ and 58 percentage points), and tolerance and diversity in Year 3 (impact $=27$ percentage points). After the heuristics were applied, the domain for engagement in SACD activities showed that the PA program had statistically significant impacts in Years 1 and 3.

For teachers' reported use of any named SACD activity (panels 3 and 4), 42 comparisons were made, with 2 expected to be significant by chance. Six of the 12 impact estimates in Year 1, 8 of the 12 in Year 2, and 8 of 
the 12 in Year 3 were statistically significant. In Year 1, impacts occurred on social and emotional development (impact $=39$ percentage points, and impact $=35$ percentage points for at least 1 hour per week), character education (impact $=47$ percentage points, and impact $=44$ percentage points for at least 1 hour per week), and any named activity (impact $=47$ percentage points, and impact $=47$ percentage points for at least 1 hour per week). In Year 2, impacts were seen for social and emotional development (impact $=$ 41 percentage points, and impact $=37$ percentage points for at least 1 hour per week), character education (impact $=45$ percentage points), tolerance and diversity (impact $=32$ percentage points), risk prevention and health promotion (impact $=35$ percentage points, and impact $=30$ percentage points for at least 1 hour per week), civic responsibility and community service (impact $=19$ percentage points), and any named activity for at least 1 hour per week (impact $=36$ percentage points). In Year 3, there were significant impacts on the use of named violence prevention and peace promotion activities (impact $=28$ percentage points) for at least 1 hour per week, social and emotional activities (impact $=37$ percentage points, impact $=34$ percentage points at least 1 hour per week), character education (impact $=49$ percentage points, impact $=46$ percentage points for at least 1 hour per week), tolerance and diversity (impact $=38$ percentage points, impact $=31$ percentage points for at least 1 hour per week), and risk prevention and health promotion (impact $=26$ percentage points). The overall impact of the PA program on the domain for engagement in named SACD activities was significant in all 3 years. 
Table 5.13. Impacts on teacher-reported SACD classroom activities--PA

Panel 1: Engagement in any activities to promote SACD goals ${ }^{1}$

\begin{tabular}{|c|c|c|c|c|c|c|c|c|c|c|c|c|}
\hline \multirow[b]{2}{*}{ SACD activity } & \multicolumn{4}{|c|}{$\begin{array}{c}\text { Year } 1 \\
\text { (Spring 3rd grade) }\end{array}$} & \multicolumn{4}{|c|}{$\begin{array}{c}\text { Year } 2 \\
\text { (Spring 4th grade) }\end{array}$} & \multicolumn{4}{|c|}{$\begin{array}{c}\text { Year 3 } \\
\text { (Spring 5th grade) }\end{array}$} \\
\hline & $\begin{array}{r}\begin{array}{r}\text { Treat- } \\
\text { ment }\end{array} \\
\end{array}$ & Control & Impact & $p$-value & $\begin{array}{r}\text { Treat- } \\
\text { ment }\end{array}$ & Control & Impact & $p$-value & $\begin{array}{r}\text { Treat- } \\
\text { ment }\end{array}$ & Control & Impact & $p$-value \\
\hline Teacher sample size & 60 & 54 & & & 43 & 39 & & & 39 & 38 & & \\
\hline $\begin{array}{l}\text { Violence prevention and peace promotion } \\
\text { (percent) } \\
\text { Social and emotion development }\end{array}$ & 66.1 & 58.5 & 7.6 & 0.523 & 71.6 & 77.4 & -5.8 & 0.594 & 68.2 & 60.7 & 7.5 & 0.590 \\
\hline (percent) & 67.7 & 54.7 & 13.0 & 0.259 & $88.7^{*}$ & 62.6 & 26.1 & 0.013 & $83.9^{*}$ & 53.6 & 30.3 & 0.019 \\
\hline Character education (percent) & $88.9^{\wedge}$ & 70.9 & 18.0 & 0.086 & $91.1^{\wedge}$ & 75.2 & 15.9 & 0.071 & $94.4^{*}$ & 62.4 & 32.0 & 0.017 \\
\hline Tolerance and diversity (percent) & $59.1^{\wedge}$ & 37.7 & 21.5 & 0.086 & 66.1 & 64.1 & 2.0 & 0.893 & 77.1 & 53.1 & 24.1 & 0.165 \\
\hline $\begin{array}{l}\text { Risk prevention and health promotion } \\
\text { (percent) }\end{array}$ & 62.0 & 47.5 & 14.5 & 0.128 & 66.8 & 70.9 & -4.1 & 0.769 & 67.1 & 61.6 & 5.6 & 0.748 \\
\hline $\begin{array}{l}\text { Civic responsibility and community service } \\
\text { (percent) }\end{array}$ & 43.7 & 46.2 & -2.4 & 0.815 & 55.4 & 51.7 & 3.6 & 0.818 & 53.5 & 65.1 & -11.6 & 0.325 \\
\hline Any SACD goal (percent) & 91.8 & 82.6 & 9.1 & 0.334 & 91.1 & 94.8 & -3.6 & 0.494 & 96.4 & 88.8 & 7.6 & 0.325 \\
\hline Behavior management (percent) & 80.9 & 81.6 & -0.8 & 0.937 & 91.7 & 76.3 & 15.3 & 0.139 & 81.2 & 81.1 & 0.1 & 0.995 \\
\hline
\end{tabular}

See note at end of table. 
Table 5.13. Impacts on teacher-reported SACD classroom activities-PA—Continued

Panel 2: Engagement in any activities to promote SACD goals for at least 1 hour per week

\begin{tabular}{|c|c|c|c|c|c|c|c|c|c|c|c|c|}
\hline \multirow[b]{2}{*}{ SACD activity } & \multicolumn{4}{|c|}{$\begin{array}{c}\text { Year } 1 \\
\text { (Spring 3rd grade) }\end{array}$} & \multicolumn{4}{|c|}{$\begin{array}{c}\text { Year } 2 \\
\text { (Spring 4th grade) }\end{array}$} & \multicolumn{4}{|c|}{$\begin{array}{c}\text { Year } 3 \\
\text { (Spring 5th grade) }\end{array}$} \\
\hline & $\begin{array}{c}\text { Treat- } \\
\text { ment }\end{array}$ & Control & Impact & $p$-value & $\begin{array}{r}\text { Treat- } \\
\text { ment }\end{array}$ & Control & Impact & $p$-value & $\begin{array}{r}\text { Treat- } \\
\text { ment }\end{array}$ & Control & Impact & $p$-value \\
\hline Teacher sample size & 60 & 54 & & & 43 & 39 & & & 39 & 38 & & \\
\hline $\begin{array}{l}\text { Violence prevention and peace promotion } \\
\text { (percent) }\end{array}$ & $43.6^{*}$ & 17.1 & 26.5 & 0.021 & 46.4 & 31.4 & 14.9 & 0.209 & $48.1^{*}$ & 22.1 & 26.0 & 0.028 \\
\hline $\begin{array}{l}\text { Social and emotional development } \\
\text { (percent) }\end{array}$ & $51.3^{*}$ & 14.7 & 36.7 & 0.011 & $57.2^{*}$ & 28.2 & 29.0 & 0.024 & $64.9^{*}$ & 21.4 & 43.6 & 0.007 \\
\hline Character education (percent) & $66.9^{*}$ & 26.3 & 40.6 & 0.001 & 64.1 & 43.5 & 20.6 & 0.129 & $86.4^{*}$ & 28.8 & 57.6 & 0.002 \\
\hline Tolerance and diversity (percent) & $37.8^{\wedge}$ & 13.9 & 23.9 & 0.081 & 38.6 & 28.2 & 10.4 & 0.249 & $46.2^{*}$ & 19.2 & 27.1 & 0.006 \\
\hline $\begin{array}{l}\text { Risk prevention and health promotion } \\
\text { (percent) }\end{array}$ & 29.4 & 13.2 & 16.2 & 0.134 & $43.6^{\wedge}$ & 25.0 & 18.6 & 0.087 & 37.0 & 31.0 & 6.0 & 0.546 \\
\hline $\begin{array}{l}\text { Civic responsibility and community service } \\
\text { (percent) }\end{array}$ & 13.5 & 12.5 & 1.1 & 0.844 & 26.9 & 22.7 & 4.2 & 0.687 & 26.5 & 27.6 & -1.1 & 0.930 \\
\hline Any SACD goal (percent) & $76.3^{*}$ & 35.5 & 40.7 & 0.002 & 84.1 & 76.6 & 7.6 & 0.323 & 80.3 & 76.4 & 3.9 & 0.724 \\
\hline Behavior management (percent) & 59.3 & 68.5 & -9.2 & 0.525 & $72.6^{\wedge}$ & 42.1 & 30.6 & 0.066 & 58.4 & 65.7 & -7.3 & 0.609 \\
\hline
\end{tabular}

Behavior management (percent)

See note at end of table. 
Table 5.13. Impacts on teacher-reported SACD classroom activities-PA-Continued

Panel 3: Engagement in activities to promote SACD goals linked to named SACD programs ${ }^{2}$

\begin{tabular}{|c|c|c|c|c|c|c|c|c|c|c|c|c|}
\hline \multirow[b]{2}{*}{ SACD activity } & \multicolumn{4}{|c|}{$\begin{array}{c}\text { Year } 1 \\
\text { (Spring 3rd grade) }\end{array}$} & \multicolumn{4}{|c|}{$\begin{array}{c}\text { Year } 2 \\
\text { (Spring 4th grade) }\end{array}$} & \multicolumn{4}{|c|}{$\begin{array}{c}\text { Year } 3 \\
\text { (Spring 5th grade) }\end{array}$} \\
\hline & $\begin{array}{r}\text { Treat- } \\
\text { ment }\end{array}$ & Control & Impact & $p$-value & $\begin{array}{r}\text { Treat- } \\
\text { ment }\end{array}$ & Control & Impact & $p$-value & $\begin{array}{r}\text { Treat- } \\
\text { ment }\end{array}$ & Control & Impact & $p$-value \\
\hline Teacher sample size & 60 & 54 & & & 43 & 39 & & & 39 & 38 & & \\
\hline $\begin{array}{l}\text { Violence prevention and peace promotion } \\
\text { (percent) }\end{array}$ & 36.9 & 23.4 & 13.5 & 0.152 & 36.2 & 22.5 & 13.7 & 0.215 & $47.1^{\wedge}$ & 16.7 & 30.5 & 0.066 \\
\hline $\begin{array}{l}\text { Social and emotional development } \\
\text { (percent) }\end{array}$ & $47.3^{*}$ & 8.3 & 39.0 & 0.007 & $48.4^{*}$ & 7.3 & 41.1 & 0.001 & $49.0^{*}$ & 11.9 & 37.1 & 0.019 \\
\hline Character education (percent) & $59.2^{*}$ & 11.8 & 47.4 & 0.001 & $\ddagger^{*}$ & $\ddagger$ & 45.4 & 0.001 & $60.4^{*}$ & 11.6 & 48.9 & 0.001 \\
\hline Tolerance and diversity (percent) & 31.2 & 0.0 & 31.2 & $\dagger$ & $\ddagger^{*}$ & $\ddagger$ & 32.2 & 0.014 & $45.3^{*}$ & 7.1 & 38.2 & 0.002 \\
\hline $\begin{array}{l}\text { Risk prevention and health promotion } \\
\text { (percent) }\end{array}$ & 37.9 & 19.4 & 18.4 & 0.110 & $48.6^{\star}$ & 14.0 & 34.6 & 0.002 & $44.6^{*}$ & 18.4 & 26.2 & 0.030 \\
\hline $\begin{array}{l}\text { Civic responsibility and community service } \\
\text { (percent) }\end{array}$ & 5.3 & 0.0 & 5.3 & $\dagger$ & $\ddagger^{*}$ & $\ddagger$ & 19.1 & 0.033 & 23.0 & 9.5 & 13.5 & 0.248 \\
\hline Any named activity (percent) & $77.3^{*}$ & 30.7 & 46.6 & 0.002 & 59.1 & 46.2 & 12.9 & 0.260 & 69.2 & 42.2 & 27.0 & 0.121 \\
\hline
\end{tabular}


Table 5.13. Impacts on teacher-reported SACD classroom activities-PA-Continued

Panel 4: Engagement in activities to promote SACD goals linked to named SACD programs for at least 1 hour per week

\begin{tabular}{|c|c|c|c|c|c|c|c|c|c|c|c|c|}
\hline \multirow[b]{2}{*}{ SACD activity } & \multicolumn{4}{|c|}{$\begin{array}{c}\text { Year } 1 \\
\text { (Spring 3rd grade) }\end{array}$} & \multicolumn{4}{|c|}{$\begin{array}{c}\text { Year } 2 \\
\text { (Spring 4th grade) }\end{array}$} & \multicolumn{4}{|c|}{$\begin{array}{c}\text { Year } 3 \\
\text { (Spring } 5 \text { th grade) }\end{array}$} \\
\hline & $\begin{array}{c}\text { Treat- } \\
\text { ment }\end{array}$ & Control & Impact & $p$-value & $\begin{array}{c}\text { Treat- } \\
\text { ment }\end{array}$ & Control & Impact & $p$-value & $\begin{array}{r}\text { Treat- } \\
\text { ment }\end{array}$ & Control & Impact & $p$-value \\
\hline Teacher sample size & 60 & 54 & & & 43 & 39 & & & 39 & 38 & & \\
\hline $\begin{array}{l}\text { Violence prevention and peace promotion } \\
\text { (percent) }\end{array}$ & $31.9^{\wedge}$ & 14.1 & 17.8 & 0.051 & 26.6 & 12.5 & 14.1 & 0.211 & $40.4^{*}$ & 12.2 & 28.2 & 0.050 \\
\hline $\begin{array}{l}\text { Social and emotional development } \\
\text { (percent) }\end{array}$ & $40.3^{*}$ & 4.8 & 35.4 & 0.027 & $\ddagger^{*}$ & $\ddagger$ & 36.9 & 0.004 & $43.7^{*}$ & 10.0 & 33.7 & 0.014 \\
\hline Character education (percent) & $49.2^{*}$ & 5.3 & 43.8 & 0.002 & 43.3 & 0.0 & 43.3 & $\dagger$ & $53.4^{*}$ & 7.5 & 46.0 & 0.005 \\
\hline Tolerance and diversity (percent) & 28.0 & 0.0 & 28.0 & $\dagger$ & 27.4 & 0.0 & 27.4 & $\dagger$ & $39.0^{*}$ & 7.6 & 31.4 & 0.002 \\
\hline $\begin{array}{l}\text { Risk prevention and health promotion } \\
\text { (percent) }\end{array}$ & $26.8^{\wedge}$ & 10.0 & 16.8 & 0.099 & $37.4^{*}$ & 7.8 & 29.5 & 0.031 & $30.2^{\wedge}$ & 9.6 & 20.6 & 0.060 \\
\hline $\begin{array}{l}\text { Civic responsibility and community service } \\
\text { (percent) }\end{array}$ & 5.3 & 0.0 & 5.3 & $\dagger$ & 18.7 & 0.0 & 18.7 & $\dagger$ & 17.3 & 7.9 & 9.4 & 0.441 \\
\hline Any named activity (percent) & $64.1^{*}$ & 17.0 & 47.1 & 0.000 & $52.4^{*}$ & 16.5 & 35.9 & 0.018 & 51.5 & 30.6 & 20.8 & 0.242 \\
\hline
\end{tabular}

$64.1^{*} \quad 17.0 \quad 47.1$

‡ Reporting standards not met. Values suppressed to protect confidentiality.

* Treatment group significantly different from control group at the .05 level.

$\wedge$ Treatment group significantly different from control group at the .10 to $>.05$ level.

${ }^{1}$ In Year 1, the omnibus impact for all the outcomes measured together was positive and statistically significant on the basis of a multivariate statistical test. In Years 1 and 3 , at least one outcome remained positive and statistically significant and no outcome was negative and statistically significant after applying the Benjamini-Hochberg (1995) procedure to adjust significance levels downward to account for the multiple testing of impacts.

${ }^{2}$ In Years 1 and 2, at least half of the impacts were positive and statistically significant and no impact was negative and statistically significant on the basis of univariate statistical tests. In all 3 years, at least one outcome remained positive and statistically significant and no outcome was negative and statistically significant after applying the Benjamini-Hochberg (1995) procedure to adjust significance levels downward to account for the multiple testing of impacts.

NOTE: Weights, which assign equal weight to each school within the program, were used in producing the treatment, control, and overall means.

SOURCE: The Social and Character Development (SACD) Research Program. 


\section{Use of Materials and Strategies}

For use of materials and strategies to support SACD goals, 87 comparisons were made, with 4 expected to be significant by chance. Eleven significant impacts were found on treatment teachers' use of materials and strategies in all 3 years. In Year 1, more treatment teachers used teacher guides (impact $=32$ percentage points), student materials such as workbooks or worksheets (impact $=33$ percentage points), giveaways (impact $=37$ percentage points), and student-led/student-assisted instruction (impact $=19$ percentage points) (table 5.14). In Year 2, more treatment teachers continued to use teacher guides (impact $=26$ percentage points), skill training (impact $=28$ percentage points), parent $/$ community involvement (impact $=25$ percentage points), targeted story reading or writing on SACD themes (impact $=19$ percentage points), and time-out for negative behavior (impact $=16$ percentage points). On average, treatment teachers also used more strategies than control teachers (by 1.5 strategies). In Year 3, a significant impact was seen for treatment teachers' use of giveaways (impact $=23$ percentage points). The impact on the domain of materials and strategies was statistically significant in Year 1. 
Table 5.14. Impacts on use of SACD classroom materials and teaching strategies-PA

\begin{tabular}{|c|c|c|c|c|c|c|c|c|c|c|c|c|}
\hline \multirow[b]{2}{*}{ SACD material and teaching strategy ${ }^{1}$} & \multicolumn{4}{|c|}{$\begin{array}{c}\text { Year } 1 \\
\text { (Spring 3rd grade) }\end{array}$} & \multicolumn{4}{|c|}{$\begin{array}{c}\text { Year } 2 \\
\text { (Spring 4th grade) }\end{array}$} & \multicolumn{4}{|c|}{$\begin{array}{c}\text { Year } 3 \\
\text { (Spring 5th grade) }\end{array}$} \\
\hline & $\begin{array}{c}\text { Treat- } \\
\text { ment }\end{array}$ & Control & Impact & $p$-value & $\begin{array}{c}\text { Treat- } \\
\text { ment }\end{array}$ & Control & Impact & $p$-value & $\begin{array}{c}\text { Treat- } \\
\text { ment }\end{array}$ & Control & Impact & $p$-value \\
\hline Teacher sample size & 60 & 54 & & & 43 & 39 & & & 39 & 38 & & \\
\hline \multicolumn{13}{|l|}{ Use of SACD materials (percent) } \\
\hline Teacher guides (manuals, curricula) & $86.7^{*}$ & 54.5 & 32.1 & 0.017 & $86.1^{*}$ & 60.5 & 25.6 & 0.012 & 90.5 & 66.8 & 23.7 & 0.178 \\
\hline Student materials (workbooks or sheets) & $84.8^{*}$ & 51.8 & 32.9 & 0.007 & 72.2 & 58.3 & 13.9 & 0.243 & $85.1^{\wedge}$ & 66.8 & 18.3 & 0.076 \\
\hline Instructional aids (games, software, videos) & 29.7 & 34.5 & -4.7 & 0.733 & 38.4 & 33.8 & 4.6 & 0.630 & 45.1 & 55.5 & -10.4 & 0.340 \\
\hline Giveaways (bookmarks, stickers) & $76.7^{*}$ & 39.6 & 37.1 & 0.004 & 68.7 & 55.6 & 13.1 & 0.314 & $79.0^{*}$ & 56.3 & 22.8 & 0.019 \\
\hline Children's literature & 33.9 & 36.4 & -2.5 & 0.823 & 36.0 & 49.4 & -13.5 & 0.341 & 34.2 & 26.4 & 7.8 & 0.557 \\
\hline Other types of materials & 6.9 & 15.2 & -8.4 & 0.230 & 19.7 & 16.2 & 3.5 & 0.686 & $\ddagger$ & $\ddagger$ & -5.4 & 0.265 \\
\hline Did not use any of these materials & $\ddagger^{\wedge}$ & $\ddagger$ & -20.5 & 0.069 & $\ddagger$ & $\ddagger$ & -5.7 & 0.299 & $\ddagger$ & $\ddagger$ & -3.3 & 0.630 \\
\hline \multicolumn{13}{|l|}{ Use of teaching strategies (percent) } \\
\hline Role-playing & 80.1 & 68.5 & 11.6 & 0.191 & 80.1 & 72.4 & 7.7 & 0.508 & 83.2 & 88.9 & -5.7 & 0.542 \\
\hline Cooperative learning & 97.6 & 96.3 & 1.3 & 0.706 & 100.0 & 97.1 & 2.9 & $\dagger$ & 100.0 & 100.0 & 0.0 & $\dagger$ \\
\hline Peer group discussions & 93.1 & 81.4 & 11.7 & 0.113 & 90.9 & 88.6 & 2.3 & 0.729 & 97.0 & 100.0 & -3.0 & $\dagger$ \\
\hline Direct instruction of SACD & 86.9 & 77.6 & 9.2 & 0.367 & 94.4 & 83.7 & 10.8 & 0.073 & 100.0 & 92.8 & 7.2 & $\dagger$ \\
\hline $\begin{array}{l}\text { Skill training } \\
\text { Incorporating SACD into academic }\end{array}$ & 59.7 & 46.7 & 13.1 & 0.187 & $64.7^{*}$ & 36.7 & 28.0 & 0.015 & 81.1 & 86.1 & -5.0 & 0.563 \\
\hline curriculum & 86.0 & 75.8 & 10.2 & 0.149 & 80.0 & 68.7 & 11.3 & 0.260 & 100.0 & 97.9 & 2.1 & $\dagger$ \\
\hline Parent training & $\ddagger$ & $\ddagger$ & -10.2 & 0.118 & $\ddagger$ & $\ddagger$ & 13.4 & 0.116 & $51.3^{\wedge}$ & 27.0 & 24.3 & 0.077 \\
\hline Parent/community involvement & 7.8 & 15.0 & -7.2 & 0.322 & $32.7^{*}$ & 7.6 & 25.1 & 0.011 & 60.1 & 39.4 & 20.7 & 0.100 \\
\hline $\begin{array}{l}\text { Mentoring } \\
\text { Good behavior notes sent home daily }\end{array}$ & 45.8 & 37.0 & 8.8 & 0.445 & 41.2 & 41.2 & 0.0 & 1.000 & 76.2 & 51.4 & 24.8 & 0.137 \\
\hline or weekly & 60.9 & 51.8 & 9.1 & 0.390 & 74.9 & 59.8 & 15.2 & 0.157 & 83.1 & 87.9 & -4.8 & 0.526 \\
\hline Presenting role models & 68.9 & 58.8 & 10.1 & 0.197 & 65.4 & 64.4 & 1.0 & 0.925 & 85.5 & 74.9 & 10.6 & 0.255 \\
\hline
\end{tabular}


Table 5.14. Impacts on use of SACD classroom materials and teaching strategies-PA-Continued

\begin{tabular}{|c|c|c|c|c|c|c|c|c|c|c|c|c|}
\hline \multirow[b]{2}{*}{ SACD material and teaching strategy ${ }^{1}$} & \multicolumn{4}{|c|}{$\begin{array}{c}\text { Year } 1 \\
\text { (Spring 3rd grade) } \\
\end{array}$} & \multicolumn{4}{|c|}{$\begin{array}{c}\text { Year } 2 \\
\text { (Spring 4th grade) }\end{array}$} & \multicolumn{4}{|c|}{$\begin{array}{c}\text { Year 3 } \\
\text { (Spring 5th grade) } \\
\end{array}$} \\
\hline & $\begin{array}{r}\text { Treat- } \\
\text { ment }\end{array}$ & Control & Impact & $p$-value & $\begin{array}{r}\text { Treat- } \\
\text { ment }\end{array}$ & Control & Impact & $p$-value & $\begin{array}{r}\text { Treat- } \\
\text { ment }\end{array}$ & Control & Impact & $p$-value \\
\hline \multicolumn{13}{|l|}{$\begin{array}{l}\text { Use of teaching strategies (percent)- } \\
\text { Continued }\end{array}$} \\
\hline $\begin{array}{l}\text { Targeted story reading or writing on social } \\
\text { and character development themes }\end{array}$ & $94.8^{\wedge}$ & 80.9 & 13.9 & 0.083 & $98.5^{*}$ & 79.6 & 18.9 & 0.015 & 97.6 & 97.9 & -0.2 & 0.939 \\
\hline Peer mediation & 59.7 & 56.0 & 3.8 & 0.619 & 61.3 & 62.1 & -0.9 & 0.917 & 92.0 & 80.2 & 11.9 & 0.174 \\
\hline Honor roll for positive behavior & 67.3 & 69.1 & -1.7 & 0.854 & 58.6 & 75.4 & -16.7 & 0.108 & 81.5 & 89.5 & -8.0 & 0.375 \\
\hline $\begin{array}{l}\text { Pledges or recitations on social and } \\
\text { character development themes }\end{array}$ & 48.9 & 54.0 & -5.0 & 0.664 & 57.2 & 55.9 & 1.4 & 0.934 & 75.6 & 72.0 & 3.7 & 0.774 \\
\hline Guided visualization & 62.5 & 53.4 & 9.0 & 0.492 & 69.6 & 60.7 & 9.0 & 0.485 & 77.1 & 76.8 & 0.3 & 0.977 \\
\hline Student-led/student-assisted instruction & $65.1^{*}$ & 45.9 & 19.2 & 0.039 & 59.6 & 48.8 & 10.8 & 0.265 & 90.6 & 79.1 & 11.5 & 0.115 \\
\hline Journaling & 81.8 & 80.3 & 1.5 & 0.880 & 77.6 & 87.8 & -10.2 & 0.411 & 95.2 & 97.6 & -2.3 & 0.631 \\
\hline Time out for negative behavior & 84.3 & 88.9 & -4.6 & 0.562 & $93.8^{*}$ & 77.6 & 16.2 & 0.031 & 100.0 & 97.6 & 2.4 & $\dagger$ \\
\hline $\begin{array}{l}\text { Daily or weekly rewards for positive } \\
\text { behavior }\end{array}$ & 91.8 & 89.9 & 1.9 & 0.696 & 97.6 & 92.7 & 4.9 & 0.344 & 98.0 & 97.9 & 0.1 & 0.986 \\
\hline Any strategy & 100.0 & 100.0 & 0.0 & $\dagger$ & 100.0 & 100.0 & 0.0 & $\dagger$ & 100.0 & 100.0 & 0.0 & $\dagger$ \\
\hline Number of strategies (mean) & 13.3 & 12.4 & 1.0 & 0.202 & $14.0^{*}$ & 12.5 & 1.5 & 0.042 & 16.9 & 16.0 & 0.9 & 0.170 \\
\hline
\end{tabular}

$\dagger$ Not applicable.
‡ Reporting standards not met. Values suppressed to protect confidentiality.

¥ Reporting standards not met. Values suppressed to protect confidentiality.
${ }^{*}$ Treatment group significantly different from control group at the .05 level.

$\wedge$ Treatment group significantly different from control group at the .05 level.
$\wedge$ Treatment group significantly different from control group at the .10 to $>.05$ level.

${ }^{1}$ In Year 1, at least one outcome remained positive and statistically significant and no outcome was negative and statistically significant after applying the Benjamini-Hochberg (1995) procedure to adjust significance levels downward to account for the multiple testing of impacts.

NOTE: Weights, which assign equal weight to each school within the program, were used in producing the treatment, control, and overall means.

SOURCE: The Social and Character Development (SACD) Research Program. 
Regarding the use of schoolwide strategies, 18 comparisons were made between treatment and control teacher reports, with 1 expected to be significant by chance. There were 2 statistically significant differences between treatment and control teachers' reported use of schoolwide strategies (these data are not shown in a table), with treatment teachers reporting more use of unspecified schoolwide activities than control teachers (impact $=13$ percentage points) in Year 2, and more use of morning announcements or videos (impact $=36$ percentage points) in Year 3. The overall impact of the PA program on the domain for use of schoolwide strategies in named SACD activities was not significant in any year.

\section{Participation in Professional Development}

Regarding reported participation in professional development, 27 comparisons were made over 3 years, with 1 expected to be significant by chance. The intervention had a statistically significant effect on treatment teachers' participation in professional development, with more treatment teachers than control teachers reporting SACD training in the past 12 months (impact $=35$ percentage points) and more hours of training (by 4.9 hours on average) in Year 1. In Years 1 and 2, there were significant impacts on training for character education (impact $=29$ and 28 percentage points). No significant impacts were found on the domain in any of the 3 years. 
Table 5.15. Impacts on teacher-reported SACD professional development-PA

\begin{tabular}{|c|c|c|c|c|c|c|c|c|c|c|c|c|}
\hline \multirow[b]{2}{*}{ SACD professional development } & \multicolumn{4}{|c|}{$\begin{array}{c}\text { Year } 1 \\
\text { (Spring 3rd grade) }\end{array}$} & \multicolumn{4}{|c|}{$\begin{array}{c}\text { Year } 2 \\
\text { (Spring 4th grade) }\end{array}$} & \multicolumn{4}{|c|}{$\begin{array}{c}\text { Year } 3 \\
\text { (Spring 5th grade) }\end{array}$} \\
\hline & $\begin{array}{c}\text { Treat- } \\
\text { ment }\end{array}$ & Control & Impact & $p$-value & $\begin{array}{r}\text { Treat- } \\
\text { ment }\end{array}$ & Control & Impact & $p$-value & $\begin{array}{c}\text { Treat- } \\
\text { ment }\end{array}$ & Control & Impact & $p$-value \\
\hline Teacher sample size & 60 & 54 & & & 43 & 39 & & & 39 & 38 & & \\
\hline SACD training in past 12 months (percent) & $89.3^{*}$ & 54.1 & 35.3 & 0.015 & 73.0 & 68.5 & 4.5 & 0.623 & 62.9 & 58.0 & 5.0 & 0.682 \\
\hline Hours of SACD training (mean) & $8.0^{*}$ & 3.1 & 4.9 & 0.011 & 4.2 & 4.3 & -0.1 & 0.944 & 4.0 & 4.5 & -0.5 & 0.737 \\
\hline \multicolumn{13}{|l|}{ Training by goal (percent) } \\
\hline Violence prevention and peace promotion & 21.2 & 13.1 & 8.1 & 0.447 & 18.5 & 24.7 & -6.2 & 0.528 & 13.0 & 8.8 & 4.2 & 0.543 \\
\hline Social and emotional development & 31.4 & 21.2 & 10.2 & 0.434 & 24.6 & 30.4 & -5.8 & 0.654 & 30.7 & 13.6 & 17.1 & 0.122 \\
\hline Character education & $63.1^{*}$ & 34.2 & 29.0 & 0.040 & $45.8^{*}$ & 18.2 & 27.6 & 0.025 & $35.5^{\wedge}$ & 13.6 & 21.9 & 0.086 \\
\hline Tolerance and diversity & 29.1 & 10.3 & 18.8 & 0.125 & 16.6 & 16.4 & 0.2 & 0.984 & 11.8 & 25.0 & -13.2 & 0.208 \\
\hline Risk prevention and health promotion & 11.2 & 9.0 & 2.1 & 0.778 & 9.6 & 15.2 & -5.6 & 0.491 & 20.2 & 17.7 & 2.5 & 0.822 \\
\hline Civic responsibility and community service & $\ddagger$ & $\ddagger$ & 8.2 & 0.179 & 7.3 & 7.5 & -0.2 & 0.974 & 0.0 & 6.8 & -6.8 & $\dagger$ \\
\hline Behavior management & 42.0 & 24.8 & 17.2 & 0.238 & 37.0 & 46.3 & -9.3 & 0.447 & 38.4 & 24.8 & 13.5 & 0.369 \\
\hline
\end{tabular}

manament

$\begin{array}{llll}42.0 & 24.8 & 17.2 & 0.238\end{array}$

$37.0 \quad 46.3$

¥ Reporting standards not met. Values suppressed to protect confidentiality.

* Treatment group significantly different from control group at the .05 level.

$\wedge$ Treatment group significantly different from control group at the .10 to $>.05$ level.

NOTE: Weights, which assign equal weight to each school within the program, were used in producing the treatment, control, and overall means

SOURCE: The Social and Character Development (SACD) Research Program. 


\section{Attitudes and Practices}

Teachers reported on their enthusiasm for SACD efforts in their schools (these data are not shown in a table) by indicating enthusiasm, cooperation, or open dislike. They also reported on the SACD practices of teachers and staff members in their schools (these data are not shown in a table). These practices included modeling positive character and behavior traits with students and fellow teachers, involving students in making decisions, giving students a voice in school governance, the school encouraging parent involvement in children's social and character development, and using developmentally appropriate discipline strategies rather than punishment for misbehavior. Twenty-seven comparisons were made over 3 years, with 1 expected to be significant by chance. In Year 1, there was a statistically significant impact on teachers' enthusiasm for SACD efforts in their schools (out of 9 comparisons made), with more treatment teachers reporting enthusiasm than control teachers (impact $=4$ percentage points). There were no significant differences in treatment and control teacher reports of the overall use of practices conducive to students' social and character development for any of the years. There was a significant positive impact on the domain in Year 1.

\section{Year-by-Year Impacts on Students and Perceptions of School Climate}

The primary research question for the PA evaluation was this:

What is the effect of the PA program on children's social and emotional competence, behavior, academics, and perceptions of school climate?

The first approach to answering this question was to examine the year-by-year impacts of the PA program on these student and school climate outcomes over the 3 years as the students progressed from third through fifth grades.

Equation (2) (described in chapter 1) was estimated to provide the impacts of the PA program on the 20 outcomes using data from the 14 treatment and control schools. For the PA evaluation, equation (2) excluded the program fixed effects $\left(\theta_{p}\right)$ and included program-specific covariates and random school effects covariates. Table 5.16 lists the covariates used with outcomes from each report in the PA analysis. 
Table 5.16. Covariates used with outcomes from each report for analysis-PA

\begin{tabular}{|c|c|c|c|c|}
\hline Potential covariate & $\begin{array}{c}\text { CR } \\
\text { outcome }\end{array}$ & $\begin{array}{c}\text { PCR } \\
\text { outcome }\end{array}$ & $\begin{array}{c}\text { TRS } \\
\text { outcome }\end{array}$ & $\begin{array}{c}\text { TRCS } \\
\text { outcome }\end{array}$ \\
\hline Total number & 20 & 26 & 22 & 7 \\
\hline \multicolumn{5}{|l|}{ Child-reported } \\
\hline Female & $\checkmark$ & $\checkmark$ & $\checkmark$ & \\
\hline Hispanic & $\checkmark$ & $\checkmark$ & $\checkmark$ & \\
\hline Black (non-Hispanic) & $\checkmark$ & $\checkmark$ & $\checkmark$ & \\
\hline Other ethnicity & $\checkmark$ & $\checkmark$ & $\checkmark$ & \\
\hline Age in years & $\checkmark$ & $\checkmark$ & $\checkmark$ & \\
\hline \multicolumn{5}{|l|}{ Scales } \\
\hline \multicolumn{5}{|l|}{ Afraid at School } \\
\hline Altruistic Behavior & $\checkmark$ & & & \\
\hline \multicolumn{5}{|l|}{ Empathy } \\
\hline Engagement with Learning & & $\checkmark$ & & \\
\hline Negative School Orientation & & & $\checkmark$ & \\
\hline Normative Beliefs About Aggression & $\checkmark$ & $\checkmark$ & $\checkmark$ & \\
\hline \multicolumn{5}{|l|}{ Sense of School as a Community } \\
\hline Problem Behavior & $\checkmark$ & $\checkmark$ & $\checkmark$ & \\
\hline Self-Efficacy for Peer Interactions & & & $\checkmark$ & \\
\hline Victimization at School & $\checkmark$ & $\checkmark$ & & \\
\hline \multicolumn{5}{|l|}{ Primary caregiver-reported } \\
\hline Age in years & & $\checkmark$ & $\checkmark$ & \\
\hline Completed high school or equivalent & $\checkmark$ & $\checkmark$ & $\checkmark$ & \\
\hline Some college & $\checkmark$ & $\checkmark$ & $\checkmark$ & \\
\hline Bachelor's or higher degree & $\checkmark$ & $\checkmark$ & $\checkmark$ & \\
\hline \multicolumn{5}{|l|}{ Highest level of education in household } \\
\hline Completed high school or equivalent & $\checkmark$ & & & \\
\hline Some college & $\checkmark$ & & & \\
\hline Bachelor's or higher degree & $\checkmark$ & & & \\
\hline \multicolumn{5}{|l|}{ Mother present in home life } \\
\hline Mother and father present & & $\checkmark$ & $\checkmark$ & \\
\hline Respondent someone other than mother or father & & $\checkmark$ & $\checkmark$ & \\
\hline Number of people in household & $\checkmark$ & $\checkmark$ & $\checkmark$ & \\
\hline \multicolumn{5}{|l|}{ Household income: $\$ 20,000$ to $\$ 40,000$} \\
\hline \multicolumn{5}{|l|}{ Household income: $\$ 40,000$ to $\$ 60,000$} \\
\hline \multicolumn{5}{|l|}{ Household income: More than $\$ 60,000$} \\
\hline Income-to-poverty-threshold ratio: Below 135 percent & $\checkmark$ & $\checkmark$ & & \\
\hline Income-to-poverty-threshold ratio: 135 to 185 percent & $\checkmark$ & $\checkmark$ & & \\
\hline Full-time employment & & $\checkmark$ & $\checkmark$ & \\
\hline Part-time employment & & $\checkmark$ & $\checkmark$ & \\
\hline
\end{tabular}


Table 5.16. Covariates used with outcomes from each report for analysis-PA—Continued

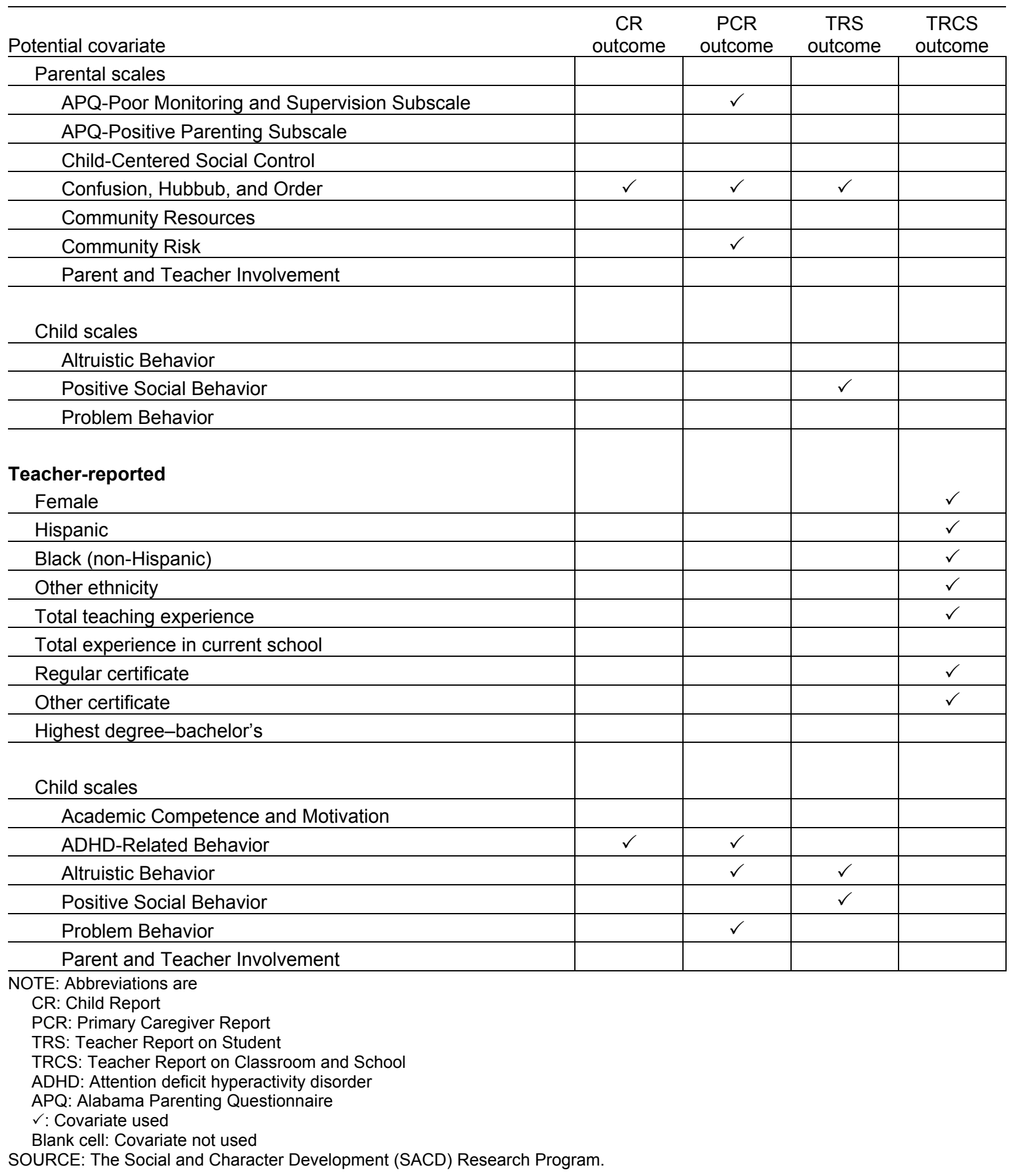


To assess the statistical power of the program-level impact estimates, minimum detectable impacts in effect size units (MDES) for each outcome measure were calculated for the PA evaluation (table 5.17). MDES represent the smallest impacts in effect size (standard deviation) units that can be detected with a high probability $(80 \%)$. MDES are primarily a function of study sample sizes, the degrees of freedom available for statistical tests, and design effects due to clustering (Schochet 2005). For the PA evaluation, the MDES range from 0.096 to 0.953 for the child-level outcomes based on the Child, Caregiver, and Teacher Report on Student and from 0.321 to 0.742 for the school climate outcomes based on the Teacher Report on Classroom and School. In general, the MDES for the school climate outcomes were larger than those for the child-level outcomes. 
Table 5.17. Adjusted minimum detectable effect sizes for impact evaluation--PA

\begin{tabular}{|c|c|c|c|}
\hline Outcome measure-Report & Year 1 & Year 2 & Year 3 \\
\hline \multicolumn{4}{|l|}{ Social and Emotional Competence Domain } \\
\hline Self-Efficacy for Peer Interaction-CR & 0.203 & 0.141 & 0.168 \\
\hline Normative Beliefs About Aggression-CR & 0.241 & 0.350 & 0.203 \\
\hline Empathy-CR & 0.256 & 0.296 & 0.178 \\
\hline \multicolumn{4}{|l|}{ Behavior Domain } \\
\hline Altruistic Behavior-CR & 0.096 & 0.278 & 0.103 \\
\hline Altruistic Behavior-PCR & 0.132 & 0.162 & 0.162 \\
\hline Altruistic Behavior-TRS & 0.631 & 0.953 & 0.784 \\
\hline Positive Social Behavior-PCR & 0.106 & 0.165 & 0.199 \\
\hline Positive Social Behavior-TRS & 0.310 & 0.392 & 0.285 \\
\hline Problem Behavior-CR & 0.231 & 0.291 & 0.233 \\
\hline Problem Behavior-PCR & 0.159 & 0.150 & 0.130 \\
\hline Problem Behavior-TRS & 0.268 & 0.206 & 0.244 \\
\hline ADHD-Related Behavior-TRS & 0.204 & 0.198 & 0.285 \\
\hline \multicolumn{4}{|l|}{ Academics Domain } \\
\hline Engagement with Learning-CR & 0.096 & 0.154 & 0.223 \\
\hline Academic Competence and Motivation-TRS & 0.145 & 0.174 & 0.263 \\
\hline \multicolumn{4}{|l|}{ Perceptions of School Climate Domain } \\
\hline Positive School Orientation-CR & 0.333 & 0.350 & 0.373 \\
\hline Negative School Orientation-CR & 0.096 & 0.259 & 0.335 \\
\hline Student Afraid at School-CR & 0.117 & 0.183 & 0.186 \\
\hline Victimization at School-CR & 0.097 & 0.393 & 0.175 \\
\hline Feelings of Safety-TRCS & 0.489 & 0.384 & 0.742 \\
\hline Student Support for Teachers-TRCS & 0.468 & 0.321 & 0.602 \\
\hline
\end{tabular}

NOTE: Abbreviations are

CR: Child Report

PCR: Primary Caregiver Report

TRS: Teacher Report on Student

TRCS: Teacher Report on Classroom and School

ADHD: Attention deficit hyperactivity disorder

The minimum detectable effect (MDE) formula used in the calculations is as follows:

$M D E=\operatorname{factor}(d f) * \sqrt{\rho_{1}\left(\frac{1}{s_{T}}+\frac{1}{s_{C}}\right)+\left(1-\rho_{1}\right)\left(\frac{1}{s_{T} n_{T}}+\frac{1}{s_{C} n_{C}}\right)}$

where $s_{T}$ and $s_{C}$ are the number of treatment and comparison schools; $n_{T}$ and $n_{C}$ are the average number of students per classroom; $\rho_{1}$ is the intraclass correlation (ICC) at the school level; and factor(df) is a constant that depends on the number of degrees of freedom ( $d f$ ) available for analysis (and is 2.802 for the pooled analysis).

SOURCE: The Social and Character Development (SACD) Research Program. 
Table 5.18 provides the estimates of the PA program's impacts on each of the 20 outcomes over each of the 3 years (60 impacts in total, with 3 expected to be statistically significant by chance). Of the 60 results, 3 were statistically significant ( 2 beneficial and 1 detrimental). In Year 1, the PA program had a detrimental impact on Engagement with Learning (Child Report, effect size $[\mathrm{ES}]=-0.25$ ) and a substantively important but nonsignificant beneficial impact on Altruistic Behavior (Teacher Report on Student, ES $=0.27$ ). In Year 2, beneficial impacts were found for Positive Social Behavior (Primary Caregiver Report, ES $=0.24$ ) and Problem Behavior (Teacher Report on Student, ES = -0.24). Substantively important but nonsignificant beneficial impact was found in Years 2 and 3 on Student Support for Teachers (Teacher Report on Classroom and School, ES $=0.28$ and 0.27). Application of the heuristic to adjust for multiple comparisons within each outcome domain indicates that PA had a statistically significant detrimental impact on Academics in Year 1. 
Table 5.18. Impacts on child and school outcomes--PA

\begin{tabular}{|c|c|c|c|c|c|c|c|c|c|c|c|c|}
\hline \multirow[b]{2}{*}{ Scale-Report } & \multicolumn{4}{|c|}{$\begin{array}{c}\text { Year } 1 \\
\text { (Spring } 3 r d \text { grade) }\end{array}$} & \multicolumn{4}{|c|}{$\begin{array}{c}\text { Year } 2 \\
\text { (Spring 4th grade) }\end{array}$} & \multicolumn{4}{|c|}{$\begin{array}{c}\text { Year } 3 \\
\text { (Spring 5th grade) }\end{array}$} \\
\hline & $\begin{array}{r}\text { Treat- } \\
\text { ment }\end{array}$ & Control & $\begin{array}{r}\text { Effect } \\
\text { size }\end{array}$ & $p$-value & $\begin{array}{r}\text { Treat- } \\
\text { ment }\end{array}$ & Control & $\begin{array}{r}\text { Effect } \\
\text { size }\end{array}$ & $p$-value & $\begin{array}{r}\text { Treat- } \\
\text { ment }\end{array}$ & Control & $\begin{array}{r}\text { Effect } \\
\text { size }\end{array}$ & $p$-value \\
\hline \multicolumn{13}{|l|}{ Social and Emotional Competence Domain } \\
\hline Self-Efficacy for Peer Interactions-CR (+) & $2.99^{\wedge}$ & 3.13 & -0.24 & 0.090 & 3.15 & 3.22 & -0.12 & 0.258 & 3.20 & 3.18 & 0.03 & 0.823 \\
\hline Normative Beliefs About Aggression-CR (-) & 1.34 & 1.42 & -0.13 & 0.388 & 1.48 & 1.65 & -0.21 & 0.303 & 1.50 & 1.60 & -0.16 & 0.264 \\
\hline Empathy-CR (+) & 2.28 & 2.18 & 0.21 & 0.176 & 2.14 & 2.07 & 0.14 & 0.422 & 2.05 & 1.99 & 0.16 & 0.255 \\
\hline \multicolumn{13}{|l|}{ Behavior Domain } \\
\hline Altruistic Behavior-CR (+) & 1.37 & 1.45 & -0.09 & 0.289 & 1.25 & 1.25 & 0.00 & 0.998 & 1.25 & 1.16 & 0.14 & 0.198 \\
\hline Altruistic Behavior-PCR (+) & 2.42 & 2.42 & 0.01 & 0.927 & 2.49 & 2.34 & 0.19 & 0.139 & 2.49 & 2.38 & 0.16 & 0.281 \\
\hline Altruistic Behavior-TRS (+) & 1.59 & 1.45 & $0.27^{\circ}$ & 0.480 & 1.62 & 1.50 & 0.21 & 0.728 & 1.40 & 1.38 & 0.03 & 0.958 \\
\hline Positive Social Behavior-PCR (+) & 2.99 & 2.95 & 0.07 & 0.342 & $3.03^{*}$ & 2.89 & 0.24 & 0.039 & 3.03 & 2.96 & 0.14 & 0.360 \\
\hline Positive Social Behavior-TRS (+) & 2.95 & 2.92 & 0.04 & 0.740 & 3.00 & 2.86 & 0.19 & 0.365 & 2.98 & 2.83 & 0.20 & 0.238 \\
\hline Problem Behavior-CR (-) & 0.51 & 0.47 & 0.07 & 0.632 & 0.59 & 0.58 & 0.01 & 0.948 & 0.67 & 0.74 & -0.10 & 0.494 \\
\hline Problem Behavior-PCR (-) & 1.55 & 1.60 & -0.10 & 0.261 & 1.57 & 1.53 & 0.11 & 0.320 & 1.52 & 1.55 & -0.08 & 0.485 \\
\hline Problem Behavior-TRS (-) & 1.53 & 1.58 & -0.08 & 0.486 & $1.48^{*}$ & 1.61 & -0.24 & 0.048 & 1.51 & 1.62 & -0.16 & 0.222 \\
\hline ADHD-Related Behavior-TRS (-) & 1.72 & 1.77 & -0.08 & 0.415 & 1.69 & 1.75 & -0.11 & 0.357 & 1.71 & 1.78 & -0.10 & 0.533 \\
\hline \multicolumn{13}{|l|}{ Academics Domain $^{1}$} \\
\hline $\begin{array}{l}\text { Engagement with Learning-CR (+) } \\
\text { Academic Competence and Motivation- }\end{array}$ & $3.56^{*}$ & 3.69 & -0.25 & 0.017 & 3.58 & 3.64 & -0.11 & 0.390 & 3.56 & 3.54 & 0.03 & 0.862 \\
\hline TRS $(+)$ & 2.78 & 2.80 & -0.02 & 0.783 & 2.80 & 2.79 & 0.01 & 0.933 & 2.67 & 2.70 & -0.03 & 0.818 \\
\hline
\end{tabular}




\section{Table 5.18. Impacts on child and school outcomes-PA-Continued}

\begin{tabular}{|c|c|c|c|c|c|c|c|c|c|c|c|c|}
\hline \multirow[b]{2}{*}{ Scale-Report } & \multicolumn{4}{|c|}{$\begin{array}{c}\text { Year } 1 \\
\text { (Spring 3rd grade) }\end{array}$} & \multicolumn{4}{|c|}{$\begin{array}{c}\text { Year } 2 \\
\text { (Spring 4th grade) }\end{array}$} & \multicolumn{4}{|c|}{$\begin{array}{c}\text { Year } 3 \\
\text { (Spring 5th grade) }\end{array}$} \\
\hline & $\begin{array}{r}\text { Treat- } \\
\text { ment }\end{array}$ & Control & $\begin{array}{r}\text { Effect } \\
\text { size }\end{array}$ & $p$-value & $\begin{array}{r}\text { Treat- } \\
\text { ment }\end{array}$ & Control & $\begin{array}{r}\text { Effect } \\
\text { size }\end{array}$ & $p$-value & $\begin{array}{r}\text { Treat- } \\
\text { ment }\end{array}$ & Control & $\begin{array}{r}\text { Effect } \\
\text { size }\end{array}$ & $p$-value \\
\hline \multicolumn{13}{|l|}{ Perceptions of School Climate Domain } \\
\hline Positive School Orientation-CR (+) & 2.73 & 2.65 & 0.11 & 0.576 & 2.44 & 2.47 & -0.04 & 0.833 & 2.41 & 2.32 & 0.14 & 0.565 \\
\hline Negative School Orientation-CR (-) & 2.14 & 2.15 & -0.02 & 0.837 & 2.17 & 2.22 & -0.08 & 0.628 & 2.24 & 2.30 & -0.12 & 0.558 \\
\hline Student Afraid at School-CR (-) & 2.53 & 2.55 & -0.02 & 0.788 & 2.41 & 2.42 & -0.02 & 0.892 & 2.35 & 2.39 & -0.05 & 0.716 \\
\hline Victimization at School-CR (-) & 0.90 & 0.82 & 0.10 & 0.228 & 0.77 & 0.67 & 0.13 & 0.578 & 0.95 & 0.83 & 0.16 & 0.244 \\
\hline Feelings of Safety-TRCS (+) & 3.25 & 3.09 & 0.15 & 0.473 & 3.19 & 3.31 & -0.13 & 0.494 & 3.07 & 3.23 & -0.18 & 0.618 \\
\hline Student Support for Teachers-TRCS (+) & 3.05 & 2.92 & 0.13 & 0.418 & 3.27 & 2.99 & $0.28^{\circ}$ & 0.113 & 3.12 & 2.91 & $0.27^{\circ}$ & 0.419 \\
\hline
\end{tabular}

* Treatment group significantly different from control group at the .05 level.

^ Treatment group significantly different from control group at the .10 to $>.05$ level.

- Substantive (but nonsignificant at 05 level) effect size of $\geq 25$ or $\leq-25$.

${ }^{1}$ In Year 1 , at least half of the impacts were positive and statistically significant and no impact was negative and statistically significant based on univariate statistical tests, and at least one outcome remained positive and statistically significant and no outcome was negative and statistically significant after applying the Benjamini-Hochberg (1995) procedure to adjust significance levels downward to account for the multiple testing of impacts. The number of results found significant was no more than expected by chance.

NOTE: Abbreviations are

CR: Child Report

PCR: Primary Caregiver Report

TRS. Teacher Report on Student

TRCS: Teacher Report on Classroom and School

ADHD: Attention deficit hyperactivity disorder

The +/- signs in parentheses indicate the direction of a beneficial outcome. All impact estimates were calculated using regression models where each program and school within a

program was weighted equally. The standard errors of all estimates account for design effects due to unequal weighting and the clustering of students within schools. See table 1.5 for information about the measures used to create the outcome variables. The effect size was calculated by dividing the estimated impact by the standard deviation of the outcome measure for the control group.

SOURCE: The Social and Character Development (SACD) Research Program. 


\section{Impacts on Child Outcomes Over Time}

PA impacts on the child outcomes over time were estimated using growth curve models by examining treatment and control group differences in the trajectories of student outcomes during the follow-up period while accounting for clustering at the school level. The growth curve models are estimated using a three-level hierarchical linear model, where Level 1 corresponds to time, Level 2 to students, and Level 3 to schools (described in chapter 1).

Table 5.19 provides the estimates of the PA program's impacts on the growth in student outcomes over the 3 years. The estimated impacts ranged in effect size units (absolute value) from 0.00 to 0.09 . None of the 18 estimated PA intervention impacts on the trajectories of child outcomes was statistically significant (1 in 18 is expected to be significant by chance). 
Table 5.19. Impacts on growth of child outcomes-PA

\begin{tabular}{|c|c|c|c|c|c|c|c|}
\hline \multirow[b]{2}{*}{ Scale-Report } & \multirow[b]{2}{*}{$\begin{array}{r}\text { Mean score at } \\
\text { implementation }\end{array}$} & \multicolumn{6}{|c|}{ Average growth in the score per year ${ }^{1}$} \\
\hline & & Treatment & Control & $\begin{array}{r}\text { Impact on } \\
\text { growth }^{3} \\
\end{array}$ & $\begin{array}{l}\text { Effect } \\
\text { size }^{4}\end{array}$ & $\begin{array}{r}\text { Standard } \\
\text { error of } \\
\text { impact } \\
\end{array}$ & $\begin{array}{r}p \text {-value of } \\
\text { impact }\end{array}$ \\
\hline \multicolumn{8}{|l|}{ Social and Emotional Competence Domain } \\
\hline Self-Efficacy for Peer Interactions-CR (+) & 2.92 & 0.14 & 0.13 & 0.01 & 0.02 & 0.03 & 0.756 \\
\hline Normative Beliefs About Aggression-CR (-) & 1.28 & 0.14 & 0.13 & 0.01 & 0.01 & 0.05 & 0.911 \\
\hline Empathy-CR (+) & 2.37 & -0.15 & -0.15 & 0.00 & 0.01 & 0.02 & 0.925 \\
\hline \multicolumn{8}{|l|}{ Behavior Domain } \\
\hline Altruistic Behavior-CR (+) & 1.59 & -0.14 & -0.19 & 0.05 & 0.06 & 0.03 & 0.150 \\
\hline Altruistic Behavior-PCR (+) & 2.43 & 0.01 & -0.07 & 0.08 & 0.09 & 0.05 & 0.100 \\
\hline Altruistic Behavior-TRS (+) & 1.45 & 0.00 & 0.00 & 0.00 & -0.01 & 0.09 & 0.965 \\
\hline Positive Social Behavior-PCR (+) & 2.92 & 0.03 & -0.01 & 0.04 & 0.07 & 0.03 & 0.119 \\
\hline Positive Social Behavior-TRS (+) & 2.85 & 0.02 & -0.05 & 0.07 & 0.08 & 0.06 & 0.310 \\
\hline Problem Behavior-CR (-) & 0.33 & 0.17 & 0.13 & 0.04 & 0.08 & 0.05 & 0.506 \\
\hline Problem Behavior-PCR (-) & 1.59 & -0.01 & 0.01 & -0.01 & -0.03 & 0.02 & 0.392 \\
\hline Problem Behavior-TRS (-) & 1.48 & 0.05 & 0.09 & -0.04 & -0.06 & 0.03 & 0.245 \\
\hline ADHD-Related Behavior-TRS (-) & 1.77 & 0.01 & 0.03 & -0.01 & -0.01 & 0.05 & 0.796 \\
\hline \multicolumn{8}{|l|}{ Academics Domain } \\
\hline Engagement with Learning-CR (+) & 3.60 & 0.00 & 0.01 & -0.01 & -0.01 & 0.04 & 0.834 \\
\hline Academic Competence and Motivation-TRS (+) & 2.71 & -0.05 & -0.02 & -0.03 & -0.02 & 0.05 & 0.609 \\
\hline
\end{tabular}




\section{Table 5.19. Impacts on growth of child outcomes-PA-Continued}

\begin{tabular}{|c|c|c|c|c|c|c|c|}
\hline \multirow[b]{2}{*}{ Scale-Report } & \multirow[b]{2}{*}{$\begin{array}{r}\text { Mean score at } \\
\text { implementation }\end{array}$} & \multicolumn{6}{|c|}{ Average growth in the score per year ${ }^{1}$} \\
\hline & & Treatment & Control & $\begin{array}{l}\text { Impact on } \\
\text { growth }^{3}\end{array}$ & $\begin{array}{l}\text { Effect } \\
\text { size }^{4}\end{array}$ & $\begin{array}{r}\text { Standard } \\
\text { error of } \\
\text { impact }\end{array}$ & $\begin{array}{r}p \text {-value of } \\
\text { impact }\end{array}$ \\
\hline \multicolumn{8}{|l|}{ Perceptions of School Climate Domain } \\
\hline Positive School Orientation-CR (+) & 2.93 & -0.24 & -0.24 & 0.00 & 0.00 & 0.05 & 0.977 \\
\hline Negative School Orientation-CR (-) & 2.10 & 0.05 & 0.08 & -0.03 & -0.04 & 0.03 & 0.338 \\
\hline Student Afraid at School-CR (-) & 2.59 & -0.05 & -0.13 & 0.07 & 0.09 & 0.05 & 0.156 \\
\hline Victimization at School-CR (-) & 0.87 & -0.04 & -0.02 & -0.02 & -0.02 & 0.05 & 0.639 \\
\hline
\end{tabular}

${ }_{1}^{1}$ Pertains to the estimated slope of the outcome for the treatment or control groups.

${ }^{2}$ The average score at implementation is calculated across treatment and control groups, using regression models for adjustment on covariates.

${ }^{3}$ Estimated difference between the slope of the treatment and control groups.

${ }^{4}$ Effect size: the slope of the treatment group minus the slope of the control group divided by the standard deviation of the outcome for the program's control group (the standard deviation is calculated without accounting for school-level clustering or regression adjustments).

NOTE: Abbreviations are

CR: Child Report

PCR: Primary Caregiver Report

TRS: Teacher Report on Student

ADHD: Attention deficit hyperactivity disorder

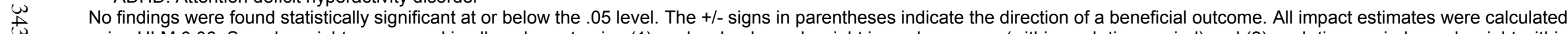
using HLM 6.06. Sample weights were used in all analyses to give (1) each school equal weight in each program (within each time period) and (2) each time period equal weight within the analysis. See table 1.5 for information about the measures used to create the outcome variables.

the analysis. See table 1.5 for information about the measures used to create the 


\section{Summary}

As part of the Social and Character Development (SACD) Research Program, researchers at the Illinois site implemented and evaluated the PA program. This program focused on teaching children about the benefits of physical, intellectual, social, and emotional positive actions with a curriculum designed to enhance children's self-concept and self-regulatory skills through the identification of positive thoughts, feelings, and actions. Fourteen public schools in a single large, urban school district in Illinois were recruited by the Illinois research team and randomly assigned to treatment and control conditions to determine the impact of the PA program on social and character development activities in the schools and on the child outcome domains of Social and Emotional Competence, Behavior, Academics, and Perceptions of School Climate.

Analyses of the initial characteristics of the sample (students, caregivers, communities, teachers, and schools) indicated that randomization to treatment and control status produced groups that were similar on the observed characteristics at the start of the study. Documentation of the initial level of social and character development activities in the schools revealed few differences (3, the number that would be expected by chance out of 62 comparisons) between the treatment and control teachers and classrooms. This is important for two reasons: one, it indicates that randomization created comparable groups near the start of the study, and two, it shows that treatment and control schools both had high levels of SACD activities near the start of the study, indicating that social and character development activities are part of the "standard practice" of these schools in Illinois. Standard practice at all of the schools included reports of 45 percent to 81 percent of teachers using SACD activities, 92 percent of teachers using specific materials in conjunction with these activities, 99 percent of teachers using at least one of the specified instructional strategies, and 68 percent of teachers participating in SACD training over the past 12 months.

Analyses of the impacts of the PA program on the use of SACD activities in the schools revealed impacts on the use of such activities (33 out of 90) and related materials and strategies (13 out of 87) across the 3 years, and use of more professional development activities for treatment teachers in all years (4 out of 27).

Of the 20 child-level outcomes representing the four domains of Social and Emotional Competence, Behavior, Academics, and Perceptions of School Climate assessed in each of the 3 years of the study (a total of 60 results), 3 were statistically significant (2 beneficial and 1 detrimental). A growth curve analysis was used to analyze the change over time in these same outcomes between initial data collection and the final outcome data collection at the end of the study. None of the 18 child-level outcomes assessed showed that PA had a significant impact.

The SACD evaluation did not find evidence to support the hypothesis that PA had beneficial impacts on students' social and character development. Such results could be caused by the inability of the program to cause such change, possibly because the theory of action for the program is incomplete or the activities to carry out that theory are not effective.

However, these results may also be due to the inability of the evaluation to observe such a change due to the control condition, the level of nonparticipation, or the sample size. The control schools continued using their standard SACD activities, and these turned out to be high in quantity and broad in scope. In 2004 Illinois passed the Illinois Children's Mental Health Act (Public Act 93-0495), Section 15(a), which calls on the Illinois State Board of Education to "develop and implement a plan to incorporate social and emotional development standards as part of the Illinois Learning Standards." This state-level change may have led control schools to implement increasing amounts of SACD activities during the course of this study. While the PA program had a significant positive impact on the amount and type of SACD activities, the resulting difference between the treatment and control schools in the amount of SACD activities may not have been large enough to cause significant differences in the student outcomes. 
Second, about one-quarter to one-third of the students in the sample universe did not take part (depending on year) because of nonconsent or noncompletion of the surveys. As a determination could not be made as to whether the students not taking part significantly differed from those who did take part, the evaluation's results are valid only for the students who took part. If the students not taking part were different, and if they would have responded better to PA than to the SACD activities occurring in the control schools, then the evaluation could have underestimated the program's impact. Third, the sample size of 14 schools and the resulting higher MDES compared to those for the multiprogram evaluation may have reduced the likelihood of detecting statistically significant effects. However, it should be noted that 57 percent of the MDES for the 60 outcomes used in the year-by-year analysis were below 0.25 ( $42 \%$ were below 0.20$)$. 
This page is intentionally blank. 


\title{
Chapter 6. Promoting Alternative Thinking Strategies (PATHS)
}

\author{
The Children's Institute \\ (New York/Minnesota site)
}

\section{Intervention}

Researchers at the Children's Institute in Rochester (New York/Minnesota site) evaluated the Promoting Alternative Thinking Strategies (PATHS) program (Kusche and Greenberg 1994). PATHS is designed to enhance social and emotional competence and understanding in children and to develop a caring, prosocial context that facilitates educational processes in the classroom. Table 6.1 describes PATHS' general characteristics (panel 1), the types of instruction and strategies used (panel 2), the professional development provided for those implementing the program (panel 3), and the social and character development activities (panel 4) and outcomes (panel 5) addressed by the program. The program includes the following components:

- The PATHS classroom curriculum is designed to facilitate the development of self-control, emotional understanding, positive self-esteem, relationships, and interpersonal problem-solving skills in children. For 20 to 30 minutes a day, 3 to 5 days per week, teachers engage students in lessons that involve discussion, role-playing, storytelling, and worksheets. Teachers are also encouraged to model and reinforce social skills throughout the day.

- Schoolwide activities include a PATHS party at the end of the year and visual artifacts that illustrate aspects of social and emotional competence.

- Parents are engaged in the program through parent newsletters and homework assignments that are to be completed with their children.

- Teachers, principals, and mental health staff participate in an initial 2-day training that presents the concepts of program implementation, lessons on integrating PATHS activities with traditional instruction, and methods for applying and transferring social skills to children over the entire school day and in the home. Program consultants provide weekly technical assistance on program implementation to teachers, a recommended practice in the PATHS program. Consultants hold biweekly calls with teachers to discuss implementation and challenges. In addition, a national PATHS-certified trainer is available to each intervention school 1 day in the fall and spring. A 1-day summer meeting for principals, teachers, and school staff after the first year of implementation provides additional technical assistance, addresses feedback on program implementation, and engages school staff in planning for the following year. 


\section{Table 6.1. Promoting Alternative Thinking Strategies}

Panel 1: General characteristics

Target population

Universal

Program components

Peer: In class

Parent: Contact and involvement

Classroom: Lessons

Schoolwide: Planned events and program artifacts

Community: None or not major focus

Training: Pretraining and ongoing

Level of integration

Add-on curriculum and schoolwide activities

Flexibility

Manualized: Scripted curriculum and guidebook

Adaptability: Less adaptable

See notes at end of table.

Panel 2: Description of instruction and strategies

\section{Classroom}

Lessons

Who delivers: Teacher

Activities and tools: Direct instruction, storytelling, discussion, role-playing, utilization of artifacts (e.g., posters, turtle puppet), worksheets

Content: Emotion understanding and control, behavior regulation, problem solving, making friends

Frequency: 20 to 30 minutes per day, 3 to 5 days per week

Strategies

Who delivers: Teacher

Activities and tools: Modeling of skills

Frequency: Daily

Supplement to classroom

Parent newsletter and engagement in homework

Schoolwide activities

End-of-year PATHS party and program artifacts

See notes at end of table. 


\section{Table 6.1. Promoting Alternative Thinking Strategies-Continued}

Panel 3: Professional development

Pre-implementation

Teachers

Content: Training on concepts, curriculum implementation, how to integrate activities with traditional instruction

Duration: 2 days

Other

Content: Principal and school mental health staff, same as teacher training

Duration: 2 days

Ongoing consultation

Teachers

Content: Technical assistance/consultation on implementation; individual meetings with each teacher; attendance at grade-level meetings; planning for following year

Duration: Weekly consultations; 2-day summer meeting

Other

Content: Principal and school staff; model lessons, team teaching, general feedback; planning for following year

Duration: Biweekly calls; 2-day summer meeting

See notes at end of table.

Panel 4: Activities for SACD goals

\begin{tabular}{ll|ll} 
Violence prevention and peace promotion & $\checkmark$ & Risk prevention and health promotion & $\checkmark$ \\
Social and emotional development & $\checkmark$ & Civic responsibility and community service & $\checkmark$ \\
Character education & $\checkmark$ & Behavior management & $\checkmark$ \\
Tolerance and diversity & $\checkmark$ & & \\
\hline
\end{tabular}

See notes at end of table.

Panel 5: SACD outcomes addressed

\begin{tabular}{ll|ll}
\hline Engagement with Learning & $\checkmark$ & Empathy & $\checkmark$ \\
Academic Competence and Motivation & $\checkmark$ & Positive School Orientation & $\checkmark$ \\
Altruistic Behavior & $\checkmark$ & Negative School Orientation & $\checkmark$ \\
Positive Social Behavior & $\checkmark$ & Student Afraid at School & \\
Problem Behavior & $\checkmark$ & Victimization at School & $\checkmark$ \\
Self-Efficacy for Peer Interactions & $\checkmark$ & Feelings of Safety \\
Normative Beliefs About Aggression & $\checkmark$ & Student Support for Teachers \\
\hline
\end{tabular}

NOTE: Abbreviations are

$\checkmark$ : Activity or outcome addressed

Blank cell: Activity or outcome not addressed

SOURCE: The Social and Character Development (SACD) Research Program. 


\section{Sample and Random Assignment}

The Children's Institute research team recruited a total of 10 public elementary schools, representing 1 school district in Minnesota (2 schools) and 2 school districts in New York (8 schools). The 10 schools were randomly assigned to treatment and control conditions prior to the fall 2004 data collection. ${ }^{50} \mathrm{~A}$ two-step process was used, stratified by the three participating school districts. First, a computer-generated pairwise matching algorithm developed by Mathematica Policy Research, Inc. (MPR) was used to identify the best pairwise matches across the 10 schools based on variables identified by the Children's Institute research team. The variables used in the pairwise matching for the 8 New York schools were as follows: (a) enrollment; (b) percentage of White students; (c) percentage of limited-English-proficient students; (d) student-teacher ratio; (e) percentage of students eligible for free lunch; (f) percentage of students eligible for reduced-price lunch; (g) percentage of students passing English language arts; and (h) percentage of students passing math. For the 2 Minnesota schools, the following variables were used: (a) enrollment; (b) percentage of White students; (c) number of suspensions per 100 students; (d) percentage of limitedEnglish-proficient students; (e) percentage of students eligible for free lunch; (f) percentage of students eligible for reduced-price lunch; (g) stability; (h) language test scores; and (i) math test scores. Second, using the flip of a coin, 1 school in each matched pair was assigned to either the intervention or control condition. Five schools received the PATHS program and 5 schools acted as control schools and continued to implement the social and character development activities that constituted their standard practice. Assignment to treatment or control condition was at the school level and therefore limited the risk of contamination between treatment and control classrooms.

The original student sample (the cohort of students in the third grade in the 10 schools in fall 2004) numbered 786 students (377 treatment and 409 control). Table 6.2 documents the change in the sample over the three spring follow-up data collection periods. Over time, new entrants to the cohort became a larger percentage of the sample, eventually making up 30 percent of the sample by the spring of Year 3 . There were no statistically significant differences between the treatment and control groups in the number of new entrants. The percentage of the sample made up of the original cohort further declined as students left the schools. By Year 3, approximately 31 percent of the original sample had left.

\footnotetext{
${ }^{50}$ In Year 2 (fall 2005), the Children's Institute research team recruited four more schools, two assigned to treatment and two assigned to control, which were followed to the end of the study (spring 2007). A description of this second cohort and all relevant findings can be found in appendix A. The data from this second cohort are not included in the analyses and results reported in this chapter.
} 
Table 6.2. Sample-PATHS

\begin{tabular}{|c|c|c|c|c|c|c|c|c|c|c|c|c|}
\hline \multirow[b]{2}{*}{ Characteristic } & \multicolumn{3}{|c|}{$\begin{array}{c}\text { Year } 1 \\
\text { (Fall 3rd grade) }\end{array}$} & \multicolumn{3}{|c|}{$\begin{array}{c}\text { Year } 1 \\
\text { (Spring 3rd grade) }\end{array}$} & \multicolumn{3}{|c|}{$\begin{array}{c}\text { Year } 2 \\
\text { (Spring 4th grade) }\end{array}$} & \multicolumn{3}{|c|}{$\begin{array}{c}\text { Year } 3 \\
\text { (Spring 5th grade) }\end{array}$} \\
\hline & Total & $\begin{array}{r}\text { Treat- } \\
\text { ment }\end{array}$ & Control & Total & $\begin{array}{r}\text { Treat- } \\
\text { ment }\end{array}$ & Control & Total & $\begin{array}{r}\text { Treat- } \\
\text { ment }\end{array}$ & Control & Total & $\begin{array}{r}\text { Treat- } \\
\text { ment }\end{array}$ & Control \\
\hline School sample size & 10 & 5 & 5 & 10 & 5 & 5 & 10 & 5 & 5 & 10 & 5 & 5 \\
\hline Student sample size & 786 & 377 & 409 & 783 & 374 & 409 & 778 & 373 & 405 & 778 & 378 & 400 \\
\hline Stayers & $\dagger$ & $\dagger$ & $\dagger$ & 747 & 356 & 391 & 636 & 311 & 325 & 543 & 263 & 280 \\
\hline New entrants & $\dagger$ & $\dagger$ & $\dagger$ & 36 & 18 & 18 & 142 & 62 & 80 & 235 & 115 & 120 \\
\hline $\begin{array}{l}\text { New entrants as a percent of } \\
\text { spring enrollment }\end{array}$ & $\dagger$ & $\dagger$ & $\dagger$ & 4.6 & 4.8 & 4.4 & 18.3 & 16.6 & 19.8 & 30.2 & 30.4 & 30.0 \\
\hline Total leavers (from original cohort) & $\dagger$ & $\dagger$ & $\dagger$ & 39 & 21 & 18 & 150 & 66 & 84 & 243 & 114 & 129 \\
\hline $\begin{array}{l}\text { Leavers as percent of fall } 2004 \\
\text { enrollment }\end{array}$ & $\dagger$ & $\dagger$ & $\dagger$ & 5.0 & 5.6 & 4.4 & 19.1 & 17.5 & 20.5 & 30.9 & 30.2 & 31.5 \\
\hline $\begin{array}{l}\text { Number of students per school } \\
\text { (mean) }\end{array}$ & 79 & 75 & 82 & 78 & 75 & 82 & 78 & 75 & 81 & 78 & 76 & 80 \\
\hline $\begin{array}{l}\text { Range of number of students per } \\
\text { school }\end{array}$ & $64-108$ & $64-83$ & $65-108$ & $63-105$ & $63-82$ & $64-105$ & $56-102$ & $68-85$ & $56-102$ & $49-97$ & $66-90$ & $49-97$ \\
\hline
\end{tabular}

† Not applicable.

NOTE: No statistically significant differences were found between values for treatment and control groups.

SOURCE: The Social and Character Development (SACD) Research Program. 


\section{Implementation}

\section{Training}

The intervention teachers received 2 days of program implementation training by PATHS-certified trainers prior to the beginning of the school year (table 6.1, panel 3). Teachers had access to ongoing program implementation support throughout the school year. Three program consultants went to schools at least once a week to visit classrooms, teach lessons, team teach, provide feedback to teachers, answer questions, and help with implementation as needed. These consultants were trained by the program developers. Each consultant was selected because of prior teaching experience and an ability to form close working relationships with teachers, students, and administrators at the schools. One consultant had extensive classroom experience, a second had both classroom and administrative experience, and the third had classroom experience as well as experience as a volunteer working in an urban community. In addition, a program trainer was made available to each intervention school during the initial 2-day training and during the 1-day summer meeting to answer questions, demonstrate lessons, provide feedback, and help with planning for the upcoming year. In addition, the lead national PATHS trainer participated in the biweekly calls approximately 50 percent of the time and made occasional visits to the schools during each school year.

\section{Data Collection}

MPR collected the multiprogram child, teacher, and school data at the Minnesota site, and MPR's subcontractor, Decision Information Resources, Inc. (DIR), collected the multiprogram child, teacher, and school data at the New York site. Table 6.3 shows the school year milestones and dates of implementation for the New York/Minnesota site. Data were collected in the fall and spring of the first 2 years and the spring of Year 3. The fall 2004 multiprogram data collection began on October 18, 2004, and ended on October 28, 2004. The average time frame from the beginning of program implementation to the beginning of fall data collection was 6 weeks. As a result, initial data collection took place after implementation of the PATHS program began. Therefore, these data provide a measure of the students, teachers, and schools near the beginning of the school year, at a time when the PATHS program had been operating for a relatively short period of time. The spring data collection window was from March 28, 2005, to April 28, 2005. PATHS had been implemented for 29 weeks at the time of the spring data collection and for 22 weeks from the end of the fall data collection. Year 2 followed a similar pattern, with implementation occurring at the start of the school year, fall data collection occurring 5 weeks later, and spring data collection occurring 20 weeks after fall data collection (and 29 weeks after the start of implementation). In spring 2007, data collection occurred 29 weeks after the start of implementation. Data collection took between 3 to 5 weeks at each collection point. 
Table 6.3. Data collection dates-PATHS

\begin{tabular}{|c|c|c|c|c|c|}
\hline Data collection schedule & $\begin{array}{c}\text { Year } 1 \\
\text { (Fall 3rd grade) }\end{array}$ & $\begin{array}{c}\text { Year } 1 \\
\text { (Spring 3rd grade) }\end{array}$ & $\begin{array}{c}\text { Year } 2 \\
\text { (Fall 4th grade) }\end{array}$ & $\begin{array}{c}\text { Year } 2 \\
\text { (Spring 4th grade) }\end{array}$ & $\begin{array}{c}\text { Year } 3 \\
\text { (Spring 5th grade) }\end{array}$ \\
\hline School sample size & 10 & 10 & 10 & 10 & 10 \\
\hline \multicolumn{6}{|l|}{ School-year dates } \\
\hline First day of school & 9/7/04 & $\dagger$ & 9/7/05 & $\dagger$ & $9 / 6 / 06^{1}$ \\
\hline Start of implementation & $9 / 8 / 04$ & $\dagger$ & First day & $\dagger$ & First day \\
\hline Last day of school & $\dagger$ & $6 / 23 / 05$ & $\dagger$ & $6 / 22 / 06$ & $\begin{array}{c}6 / 6 / 07 \\
6 / 21 / 07^{2}\end{array}$ \\
\hline \multicolumn{6}{|l|}{ Data collection } \\
\hline Start & $10 / 18 / 04$ & $3 / 28 / 05$ & $10 / 11 / 05$ & $3 / 20 / 06$ & $3 / 26 / 07$ \\
\hline End & $10 / 28 / 04$ & $4 / 28 / 05$ & $10 / 27 / 05$ & $4 / 11 / 06$ & $4 / 27 / 07$ \\
\hline \multicolumn{6}{|l|}{$\begin{array}{l}\text { Calendar weeks from } \\
\text { program implementation } \\
\text { to start of fall } 2004\end{array}$} \\
\hline data collection & 6 & $\dagger$ & $\dagger$ & $\dagger$ & $\dagger$ \\
\hline $\begin{array}{l}\text { Calendar weeks from } \\
\text { start of school to start of } \\
\text { fall } 2004 \text { data collection }\end{array}$ & 6 & $\dagger$ & 5 & $\dagger$ & $\dagger$ \\
\hline $\begin{array}{l}\text { Calendar weeks from } \\
\text { end of fall data collection } \\
\text { to start of spring data } \\
\text { collection }\end{array}$ & $\dagger$ & 22 & $\dagger$ & 20 & $\dagger$ \\
\hline $\begin{array}{l}\text { Calendar weeks from } \\
\text { program implementation } \\
\text { to start of spring data } \\
\text { collection }\end{array}$ & $\dagger$ & 29 & $\dagger$ & 29 & $29^{1}$ \\
\hline
\end{tabular}

\section{Consent Rates, Completion Rates, and Percentage of Sample With Data}

The actual number of student, primary caregiver, and teacher reports available for analysis was smaller than the number in the sample because consent and completion rates were below 100 percent. Primary caregivers had to provide consent before children could complete the Child Report, before their child's teacher could complete the Teacher Report on Student, and before they themselves completed the Primary Caregiver Report. In the spring of Years 1 and 3, significantly more primary caregivers in the treatment group than in the control group provided consent for their children and themselves. Teachers also had to provide consent before completing the Teacher Report on Classroom and School. In Year 1, significantly more teachers in the treatment group gave consent for both the fall and spring data collection.

Of those with consent, not all completed their respective reports. Table 6.4 shows the consent rates, completion rates, and percentages of sample with data for each of the four reports over the 3 years. For the 
Chapter 6. Promoting Alternative Thinking Strategies (PATHS)

Child Report and two teacher reports, completion rates ranged from 89 percent to 100 percent, with one statistically significant difference in completion rates between treatment and control groups for the Child Report in the spring of 2005. In this case, the treatment group had fewer completed reports than the control group (94\% versus 98\%). For the Teacher Report on Student, completion rates ranged from 96 percent to 100 percent. For the Primary Caregiver Report, the completion rates dropped over time from 95 percent to 79 percent. There was a statistically significant difference for the Primary Caregiver Report in Year 2, with more caregivers in the treatment group completing reports compared to the control group ( $83 \%$ versus $79 \%)$.

The percentages of the sample with Child Report data ranged from 50 percent to 60 percent over the 3 years, with a statistically significant difference in Year 3, when more students in the treatment group had data than did students in the control group (60\% versus $52 \%)$. The percentages of students with information from the Teacher Report on Student ranged from 53 percent to 62 percent, with statistically significant differences between treatment and control conditions in Years 1 and 3, both favoring the treatment group (62\% versus $55 \%$ and $60 \%$ versus 53\%). The percentages of students with data from the Primary Caregiver Report ranged from 42 percent to 56 percent. In general, this percentage declined over time, although the highest rates were seen in the spring of 2005. In Year 2, the treatment group had significantly more Primary Caregiver Report data than did the control group (50\% versus $42 \%)$. The percentages of teachers with data from the Teacher Report on Classroom and School ranged from 70 percent to 92 percent, with a statistically significant difference in Year 1, when treatment teachers had more data than control teachers in both the fall $(89 \%$ versus $70 \%$ ) and spring (92\% versus $70 \%)$. 
Table 6.4. Consent rates, completion rates, and percentage of sample with data from each report-PATHS

\begin{tabular}{|c|c|c|c|c|c|c|c|c|c|c|c|c|}
\hline \multirow[b]{2}{*}{ Report } & \multicolumn{3}{|c|}{$\begin{array}{c}\text { Year } 1 \\
\text { (Fall 3rd grade) }\end{array}$} & \multicolumn{3}{|c|}{$\begin{array}{c}\text { Year } 1 \\
\text { (Spring 3rd grade) }\end{array}$} & \multicolumn{3}{|c|}{$\begin{array}{c}\text { Year } 2 \\
\text { (Spring 4th grade) }\end{array}$} & \multicolumn{3}{|c|}{$\begin{array}{c}\text { Year } 3 \\
\text { (Spring 5th grade) }\end{array}$} \\
\hline & Total & $\begin{array}{r}\text { Treat- } \\
\text { ment }\end{array}$ & Control & Total & $\begin{array}{r}\text { Treat- } \\
\text { ment } \\
\end{array}$ & Control & Total & $\begin{array}{r}\text { Treat- } \\
\text { ment }\end{array}$ & Control & Total & $\begin{array}{c}\text { Treat- } \\
\text { ment }\end{array}$ & Control \\
\hline Student sample size & 786 & 377 & 409 & 783 & 374 & 409 & 778 & 373 & 405 & 778 & 378 & 400 \\
\hline \multicolumn{13}{|l|}{ Child Report (percent) } \\
\hline Primary caregiver consent rate & 58.4 & 60.5 & 56.5 & 58.5 & $62.3^{*}$ & 55.0 & 57.6 & 60.9 & 54.6 & 56.6 & $60.3^{*}$ & 53.0 \\
\hline Student completion rate & 89.3 & 89.9 & 88.7 & 95.9 & $94.0^{*}$ & 97.8 & 96.9 & 96.9 & 96.8 & 98.0 & 98.7 & 97.2 \\
\hline Students with data ${ }^{1}$ & 52.2 & 54.4 & 50.1 & 56.1 & 58.6 & 53.8 & 55.8 & 59.0 & 52.8 & 55.4 & $59.5^{\star}$ & 51.5 \\
\hline \multicolumn{13}{|l|}{ Primary Caregiver Report (percent) } \\
\hline Primary caregiver consent rate & 56.6 & 58.9 & 54.5 & 57.3 & $61.2^{*}$ & 53.8 & 56.0 & 59.5 & 52.8 & 55.1 & $58.7^{*}$ & 51.8 \\
\hline Primary caregiver completion rate & 94.6 & 95.0 & 94.2 & 84.2 & 86.5 & 81.8 & 81.2 & $83.3^{*}$ & 79.0 & 78.8 & 77.0 & 80.7 \\
\hline Primary caregivers with data ${ }^{1}$ & 53.6 & 56.0 & 51.3 & 48.3 & 52.9 & 44.0 & 45.5 & $49.6^{* *}$ & 41.7 & 43.4 & 45.2 & 41.8 \\
\hline \multicolumn{13}{|l|}{ Teacher Report on Student (percent) } \\
\hline Primary caregiver consent rate $^{2}$ & 58.4 & 60.5 & 56.5 & 58.5 & $62.3^{*}$ & 55.0 & 57.6 & 60.9 & 54.6 & 56.6 & $60.3^{*}$ & 53.0 \\
\hline Teacher completion rate & 96.5 & 96.9 & 96.1 & 99.8 & 99.6 & 100.0 & 100.0 & 100.0 & 100.0 & 99.5 & 100.0 & 99.1 \\
\hline Students with data ${ }^{1}$ & 56.4 & 58.6 & 54.3 & 58.4 & $62.0^{*}$ & 55.0 & 57.6 & 60.9 & 54.6 & 56.3 & $60.3^{*}$ & 52.5 \\
\hline \multicolumn{13}{|c|}{$\begin{array}{l}\text { Teacher Report on Classroom and School } \\
\text { (3rd- to 5th-grade teachers) (percent) }\end{array}$} \\
\hline Teacher consent rate & 83.8 & $93.7^{* *}$ & 75.3 & 83.8 & $95.2^{* *}$ & 74.0 & 84.3 & 90.0 & 79.7 & 93.2 & 90.0 & 95.9 \\
\hline Teacher completion rate & 93.9 & 94.9 & 92.7 & 95.6 & 96.7 & 94.4 & 99.1 & 100.0 & 98.3 & 89.5 & 90.7 & 88.6 \\
\hline Teachers with data ${ }^{1}$ & 78.7 & $88.9^{* *}$ & 69.9 & 80.1 & $92.1^{* *}$ & 69.9 & 83.6 & 90.0 & 78.4 & 83.5 & 81.7 & 84.9 \\
\hline
\end{tabular}

* Treatment group significantly different from control group at the 05 level.

** Treatment group significantly different from control group at the .01 level.

${ }^{1}$ Calculated as consent rate $\mathrm{x}$ completion rate.

${ }^{2}$ The primary caregiver consent rates for the Child Report and the Teacher Report on Student are identical, as the primary caregiver gave consent to both together.

SOURCE: The Social and Character Development (SACD) Research Program. 


\section{Chapter 6. Promoting Alternative Thinking Strategies (PATHS)}

Responses from students in the original cohort (stayers) and new entrants in the PATHS sample were examined to investigate possible differences between the two groups in consent rates, completion rates, and the percentages of the sample with data that might affect outcome data (table 6.5). In Years 1 and 3, consent rates for stayers were significantly higher than for new entrants (by 16 to 26 percentage points). These differences in consent rates led to similar differences between stayers and new entrants in percentages of the sample with data on all three reports (by 14 to 26 percentage points). In Year 2, stayers had a significantly higher percentage of Primary Caregiver report data than new entrants (by 10 percentage points). 
Table 6.5. Consent rates, completion rates, and percentage of sample with data: Stayers versus new entrants—PATHS

\begin{tabular}{|c|c|c|c|c|c|c|c|c|c|}
\hline \multirow[b]{2}{*}{ Report } & \multicolumn{3}{|c|}{$\begin{array}{c}\text { Year } 1 \\
\text { (Spring 3rd grade) }\end{array}$} & \multicolumn{3}{|c|}{$\begin{array}{c}\text { Year } 2 \\
\text { (Spring 4th grade) }\end{array}$} & \multicolumn{3}{|c|}{$\begin{array}{c}\text { Year } 3 \\
\text { (Spring 5th grade) } \\
\end{array}$} \\
\hline & Total & Stayers & $\begin{array}{r}\text { New } \\
\text { entrants }\end{array}$ & Total & Stayers & $\begin{array}{r}\text { New } \\
\text { entrants }\end{array}$ & Total & Stayers & $\begin{array}{r}\mathrm{New} \\
\text { entrants } \\
\end{array}$ \\
\hline Student sample size & 783 & 747 & 36 & 778 & 636 & 142 & 778 & 543 & 235 \\
\hline \multicolumn{10}{|l|}{ Child Report (percent) } \\
\hline Primary caregiver consent rate & 58.5 & $59.7^{* *}$ & 33.3 & 57.6 & 59.1 & 50.7 & 56.6 & $61.7^{* \star \star}$ & 44.7 \\
\hline Student completion rate & 95.9 & 95.7 & 100.0 & 96.9 & 96.3 & 100.0 & 98.0 & 97.9 & 98.1 \\
\hline Students with data ${ }^{1}$ & 56.1 & $57.2^{* *}$ & 33.3 & 55.8 & 56.9 & 50.7 & 55.4 & $60.4^{\star \star *}$ & 43.8 \\
\hline \multicolumn{10}{|l|}{ Primary Caregiver Report (percent) } \\
\hline Primary caregiver consent rate & 57.3 & $58.5^{\star *}$ & 33.3 & 56.0 & 57.5 & 49.3 & 55.1 & $60.0^{* * \star}$ & 43.8 \\
\hline Primary caregiver completion rate & 84.2 & 84.4 & 75.0 & 81.2 & 82.2 & 75.7 & 79.3 & 79.8 & 77.7 \\
\hline Primary caregivers with data ${ }^{1}$ & 48.3 & $49.4^{* *}$ & 25.0 & 45.5 & $47.3^{*}$ & 37.3 & 43.7 & $47.9^{* *}$ & 34.0 \\
\hline \multicolumn{10}{|l|}{ Teacher Report on Student (percent) } \\
\hline Primary caregiver consent rate ${ }^{2}$ & 58.5 & $59.7^{* *}$ & 33.3 & 57.6 & 59.1 & 50.7 & 56.6 & $61.7^{* * \star}$ & 44.7 \\
\hline Teacher completion rate & 99.8 & 99.8 & 100.0 & 100.0 & 100.0 & 100.0 & 99.5 & 99.7 & 99.0 \\
\hline Students with data ${ }^{1}$ & 58.4 & $59.6^{* *}$ & 33.3 & 57.6 & 59.1 & 50.7 & 56.3 & $61.5^{\star * *}$ & 44.3 \\
\hline
\end{tabular}

* Stayers significantly different from new entrants at the .05 level.

** Stayers significantly different from new entrants at the .01 level.

*** Stayers significantly different from new entrants at the .001 level.

Calculated as consent rate $\mathrm{x}$ completion rate.

${ }^{2}$ The primary caregiver consent rates for the Child Report and the Teacher Report on Student are identical, as the primary caregiver gave consent to both together.

SOURCE: The Social and Character Development (SACD) Research Program. 


\section{Fidelity of Implementation}

Each year, PATHS' five treatment schools were independently rated for quantity and quality of program implementation by two raters from the research team. The global measure of fidelity for the multisite study was used; inter-rater reliability was calculated using Cronbach's alpha (Year $1=0.78$, Year $2=0.93$, and Year $3=0.86$ ). The ratings were used to generate a single consensus rating with which schools were identified as being high or low in implementation fidelity. In Year 1, three treatment schools were identified as having high fidelity, and in Years 2 and 3, two treatment schools were identified as having high fidelity. Cohen's kappa was used as the measure of agreement when identifying schools as high fidelity, and it equaled 0.55 in Year 1, 0.17 in Year 2, and 0.29 in Year 3.

\section{Initial Characteristics}

This section examines the initial characteristics of the students, teachers, and schools participating in the evaluation of the PATHS program. These characteristics were collected from students who were enrolled in the third grade at the study schools in fall 2004, as well as from their primary caregivers and third-grade teachers. Third-, fourth-, and fifth-grade teachers and principals in the study schools also provided information about activities related to social and character development in these schools. Documenting the characteristics of students, teachers, and schools and initial measures of key outcomes at a point before the interventions had been operating for an extended period helped to determine whether the random assignment of schools to treatment and control status produced treatment and control groups with similar distributions of observed characteristics. As noted in the following discussion, there were 10 significant differences in the observed characteristics, 8 of which (out of 62 comparisons, with 3 expected to be significant by chance) reflected differences between the treatment and control students, teachers, and schools in the use of SACD activities in the classroom and school.

\section{Characteristics of Children, Their Families, and Communities}

There were no significant differences between the treatment and control groups in the observed student, caregiver, and community characteristics (table 6.6). For students, the mean age was 8.1 years. The sample contained roughly equal percentages of girls (58\%) and boys (43\%). The sample was ethnically diverse, with White non-Hispanic students making up 56 percent of the sample, Black non-Hispanic students making up 22 percent of the sample, and Hispanic students making up 12 percent of the sample.

The sample was also diverse in its levels of family income, education levels of primary caregivers of the children in the sample, and family situation. For the total sample, 34 percent of children lived in a household where the income was 135 percent of the federal poverty level or lower, which is the income threshold for eligibility for free school meals. Thirteen percent of primary caregivers had not completed high school. Nearly two-thirds of the children (66\%) lived with both their mother and their father. There were no significant differences between the treatment and control groups in these characteristics.

The mean values of the outcome measures for children's behavior and attitudes as reported by the primary caregiver, child, and teacher at initial data collection in fall 2004 are shown in table 6.7. There was 1 significant difference between the treatment and control groups (out of 18 comparisons): children in the treatment group reported lower Self-Efficacy for Peer Interaction (2.8 versus 3.0). 
Table 6.6. Initial characteristics of children, their families, and communities-PATHS

\begin{tabular}{|c|c|c|c|}
\hline Characteristic & Total & Treatment & Control \\
\hline Student sample size & 421 & 211 & 210 \\
\hline \multicolumn{4}{|l|}{ Student demographics } \\
\hline \multicolumn{4}{|l|}{ Gender (percent) } \\
\hline Male & 42.5 & 40.5 & 44.6 \\
\hline Female & 57.5 & 59.5 & 55.4 \\
\hline \multicolumn{4}{|l|}{ Race/ethnicity (percent) } \\
\hline White (non-Hispanic) & 56.1 & 52.7 & 59.4 \\
\hline Black (non-Hispanic) & 22.3 & 23.9 & 20.7 \\
\hline Hispanic & 11.5 & 12.3 & 10.7 \\
\hline Other & 10.1 & 11.0 & 9.2 \\
\hline Age (in years) (mean) & 8.1 & 8.1 & 8.1 \\
\hline \multicolumn{4}{|l|}{ Primary caregiver and family characteristics } \\
\hline Primary caregiver's age (in years) (mean) & 37.1 & 36.6 & 37.6 \\
\hline \multicolumn{4}{|l|}{ Primary caregiver's race/ethnicity (percent) } \\
\hline White (non-Hispanic) & 63.2 & 60.9 & 65.5 \\
\hline Black (non-Hispanic) & 20.6 & 22.9 & 18.4 \\
\hline Hispanic & 9.9 & 9.7 & 10.2 \\
\hline Other & 6.3 & 6.6 & 6.0 \\
\hline \multicolumn{4}{|l|}{ Primary caregiver's education (percent) } \\
\hline Did not complete high school & 12.7 & 13.0 & 12.4 \\
\hline Completed high school or equivalent & 18.5 & 19.0 & 17.9 \\
\hline Some college & 37.1 & 39.4 & 34.8 \\
\hline Bachelor's or higher degree & 31.7 & 28.5 & 34.8 \\
\hline \multicolumn{4}{|l|}{ Primary caregiver's employment (percent) } \\
\hline Full-time & 51.4 & 56.7 & 46.0 \\
\hline Other & 48.6 & 43.3 & 54.0 \\
\hline \multicolumn{4}{|l|}{ Primary caregiver's marital status (percent) } \\
\hline Married & 62.9 & 63.3 & 62.5 \\
\hline Other & 37.1 & 36.7 & 37.5 \\
\hline Students who live in one household (percent) & 93.7 & 92.8 & 94.5 \\
\hline Number of individuals in household (mean) & 4.6 & 4.6 & 4.6 \\
\hline \multicolumn{4}{|l|}{ Primary caregiver's relationship to child (percent) } \\
\hline Mother (stepmother) & 86.1 & 86.0 & 86.2 \\
\hline Father (stepfather) & 10.3 & 10.5 & 10.1 \\
\hline Other relative/nonrelative & 3.6 & 3.5 & 3.7 \\
\hline
\end{tabular}


Table 6.6. Initial characteristics of children, their families, and communities-PATHSContinued

\begin{tabular}{|c|c|c|c|}
\hline Characteristic & Total & Treatment & Control \\
\hline \multicolumn{4}{|l|}{ Student lives with (percent) } \\
\hline Mother (stepmother) and father (stepfather) & 66.3 & 65.7 & 66.9 \\
\hline Mother (stepmother) only; father (stepfather) not present & 29.2 & 28.9 & 29.4 \\
\hline Father (stepfather) only; mother (stepmother) not present & 1.6 & $\ddagger$ & $\ddagger$ \\
\hline Other relative/nonrelative, parents not present & 2.9 & 3.1 & 2.7 \\
\hline \multicolumn{4}{|l|}{ Highest education of anyone in household (percent) } \\
\hline Did not complete high school & 8.2 & 8.9 & 7.4 \\
\hline Completed high school or equivalent & 18.4 & 17.4 & 19.4 \\
\hline Some college & 33.8 & 39.4 & 28.2 \\
\hline Bachelor's or higher degree & 39.7 & 34.3 & 45.0 \\
\hline \multicolumn{4}{|l|}{ Total household income (percent) } \\
\hline Less than $\$ 20,000$ & 29.1 & 25.9 & 32.2 \\
\hline$\$ 20,000$ to $\$ 39,999$ & 18.3 & 22.1 & 14.4 \\
\hline$\$ 40,000$ to $\$ 59,999$ & 17.2 & 23.3 & 11.0 \\
\hline$\$ 60,000$ or more & 35.5 & 28.7 & 42.3 \\
\hline Income-to-poverty-threshold ratio-Below 135 percent (percent) & 33.6 & 31.7 & 35.5 \\
\hline Income-to-poverty-threshold ratio-135 to 185 percent (percent) & 14.1 & 16.6 & 11.6 \\
\hline Income-to-poverty-threshold ratio_Above 185 percent (percent) & 52.3 & 51.7 & 52.8 \\
\hline \multicolumn{4}{|l|}{ Alabama Parenting Questionnaire-Poor Monitoring and } \\
\hline Supervision Subscale (mean) & 1.1 & 1.1 & 1.1 \\
\hline \multicolumn{4}{|l|}{ Alabama Parenting Questionnaire-Positive Parenting } \\
\hline Subscale (mean) & 3.5 & 3.5 & 3.5 \\
\hline Confusion, Hubbub, and Order Scale (mean) & 2.2 & 2.2 & 2.2 \\
\hline \multicolumn{4}{|l|}{ Community characteristics (mean) } \\
\hline Community Risks Scale & 1.4 & 1.3 & 1.5 \\
\hline Community Resources Scale & 3.0 & 2.9 & 3.0 \\
\hline Child-Centered Social Control Scale & 3.1 & 3.0 & 3.2 \\
\hline
\end{tabular}

¥ Reporting standards not met. Values suppressed to protect confidentiality.

NOTE: No statistically significant differences were found between values for treatment and control groups. Weights, which assign equal weight to each school within the program, were used in producing the treatment, control, and overall means. Statistical tests were conducted using regressions that included program indicators to account for the sample design and adjusted for clustering at the school level.

SOURCE: The Social and Character Development (SACD) Research Program. 
Table 6.7. Mean scores and standard deviations for initial outcome measures of samplePATHS

\begin{tabular}{|c|c|c|c|c|c|c|c|}
\hline \multirow[b]{2}{*}{ Outcome measure-Report } & \multirow[b]{2}{*}{ Range } & \multicolumn{2}{|c|}{ Total } & \multicolumn{2}{|c|}{ Treatment } & \multicolumn{2}{|c|}{ Control } \\
\hline & & Mean & $S D$ & Mean & $S D$ & Mean & $S D$ \\
\hline \multicolumn{8}{|l|}{ Social and Emotional Competence Domain } \\
\hline Self-Efficacy for Peer Interaction-CR & $1-4$ & 2.9 & 0.6 & $2.8^{*}$ & 0.6 & 3.0 & 0.6 \\
\hline Normative Beliefs About Aggression-CR & $1-4$ & 1.2 & 0.3 & 1.2 & 0.4 & 1.1 & 0.3 \\
\hline Empathy-CR & $1-4$ & 2.4 & 0.4 & 2.4 & 0.4 & 2.5 & 0.4 \\
\hline \multicolumn{8}{|l|}{ Behavior Domain } \\
\hline Altruistic Behavior-CR & $0-3$ & 1.3 & 0.9 & 1.4 & 0.9 & 1.3 & 0.8 \\
\hline Altruistic Behavior-TRS & $1-4$ & 1.2 & 0.3 & 1.2 & 0.3 & 1.3 & 0.3 \\
\hline Altruistic Behavior-PCR & $1-4$ & 2.2 & 0.7 & 2.3 & 0.7 & 2.2 & 0.8 \\
\hline Positive Social Behavior-TRS & $1-4$ & 3.0 & 0.7 & 3.0 & 0.7 & 3.1 & 0.6 \\
\hline Positive Social Behavior-PCR & $1-4$ & 3.0 & 0.5 & 3.0 & 0.5 & 3.0 & 0.5 \\
\hline Problem Behavior-CR & $0-3$ & 0.2 & 0.3 & 0.2 & 0.4 & 0.2 & 0.3 \\
\hline Problem Behavior-TRS & $1-4$ & 1.3 & 0.5 & 1.4 & 0.5 & 1.3 & 0.4 \\
\hline Problem Behavior-PCR & $1-4$ & 1.6 & 0.3 & 1.6 & 0.3 & 1.6 & 0.3 \\
\hline ADHD-Related Behavior-TRS & $1-4$ & 1.8 & 0.7 & 1.8 & 0.7 & 1.7 & 0.7 \\
\hline \multicolumn{8}{|l|}{ Academics Domain } \\
\hline Academic Competence and Motivation-TRS & $1-5$ & 3.0 & 0.9 & 2.9 & 0.9 & 3.2 & 0.9 \\
\hline Engagement with Learning-CR & $1-4$ & 3.8 & 0.5 & 3.7 & 0.5 & 3.8 & 0.4 \\
\hline \multicolumn{8}{|l|}{ Perceptions of School Climate Domain } \\
\hline Positive School Orientation-CR & $1-4$ & 3.3 & 0.6 & 3.3 & 0.6 & 3.4 & 0.5 \\
\hline Negative School Orientation-CR & $1-4$ & 1.7 & 0.6 & 1.8 & 0.6 & 1.7 & 0.6 \\
\hline Student Afraid at School-CR & $1-4$ & 2.4 & 0.9 & 2.5 & 0.9 & 2.3 & 0.9 \\
\hline Victimization at School-CR & $0-3$ & 0.7 & 0.8 & 0.7 & 0.8 & 0.7 & 0.8 \\
\hline Student sample size-PCR & & \multicolumn{2}{|c|}{421} & \multicolumn{2}{|c|}{211} & \multicolumn{2}{|c|}{210} \\
\hline Student sample size-CR & & \multicolumn{2}{|c|}{410} & \multicolumn{2}{|c|}{205} & \multicolumn{2}{|c|}{205} \\
\hline Student sample size-TRS & & \multicolumn{2}{|c|}{443} & \multicolumn{2}{|c|}{221} & \multicolumn{2}{|c|}{222} \\
\hline
\end{tabular}

* Treatment group significantly different from control group at the .05 level.

NOTE: Abbreviations are

CR: Child Report

PCR: Primary Caregiver Report

TRS: Teacher Report on Student

ADHD: Attention deficit hyperactivity disorder

$S D$ : Standard deviation

Weights, which assign equal weight to each school within the program, were used in producing the treatment, control, and overall means. Statistical tests were conducted using regressions that included program indicators to account for the sample design and adjusted for clustering at the school level. Sample size may differ for some outcomes due to nonresponse.

SOURCE: The Social and Character Development (SACD) Research Program.

\section{Characteristics of Teachers and Schools}

Table 6.8 describes the third-, fourth-, and fifth-grade teachers at the study schools. The majority were White non-Hispanic $(88 \%)$. Most of the teachers were female $(74 \%)$, and there was a statistically significant difference in the percentages of male teachers, with fewer males in the treatment group than in the control group $(17 \%$ versus $35 \%)$. Overall, the teachers had an average of 11.5 years of total teaching experience. The majority $(77 \%)$ held an advanced or specialist degree. 
Data regarding school characteristics were drawn from the Common Core of Data in order to compare treatment and control schools. There were no significant differences between the two groups of schools in terms of student composition (race/ethnicity and school lunch eligibility), number of students enrolled, number of full-time teachers, Title I status, or number of years the principal had been at the school (see table 6.9). In addition, there were no significant differences between treatment and control schools in terms of location (urban, suburban, or rural) or lowest and highest grade offered (these data are not shown in a table).

Table 6.8. Initial characteristics of teachers in sample-PATHS

\begin{tabular}{|c|c|c|c|}
\hline Characteristic & Total & Treatment & Control \\
\hline Teacher sample size & 107 & 56 & 51 \\
\hline \multicolumn{4}{|l|}{ Gender (percent) } \\
\hline Male & 26.1 & $17.4^{*}$ & 34.8 \\
\hline Female & 73.9 & 82.6 & 65.2 \\
\hline \multicolumn{4}{|l|}{ Race/ethnicity (percent) } \\
\hline White (non-Hispanic) & 87.7 & 88.7 & 86.8 \\
\hline Other & 12.3 & 11.3 & 13.2 \\
\hline Number of years teaching experience (mean) & 11.5 & 10.0 & 13.0 \\
\hline Number of years teaching experience in this school (mean) & 7.7 & 6.5 & 8.9 \\
\hline \multicolumn{4}{|l|}{ Type of teaching certificate (percent) } \\
\hline Regular state certificate or advanced professional certificate & 81.0 & 82.4 & 79.6 \\
\hline Other & 19.0 & 17.6 & 20.4 \\
\hline \multicolumn{4}{|l|}{ Education (percent) } \\
\hline Bachelor's degree & 23.0 & 19.9 & 26.2 \\
\hline Advanced degree/other & 77.0 & 80.1 & 73.8 \\
\hline
\end{tabular}

${ }^{*}$ Treatment group significantly different from control group at the .05 level.

NOTE: Weights, which assign equal weight to each school within the program, were used in producing the treatment, control, and overall means. Statistical tests were conducted using regressions that included program indicators to account for the sample design and adjusted for clustering at the school level. Sample size may differ for some outcomes due to nonresponse.

SOURCE: The Social and Character Development (SACD) Research Program. 
Table 6.9. Initial characteristics of schools in sample-PATHS

\begin{tabular}{|c|c|c|c|}
\hline Characteristic & Total & Treatment & Control \\
\hline School sample size & 10 & 5 & 5 \\
\hline \multicolumn{4}{|l|}{ Student race/ethnicity (percent) } \\
\hline White (non-Hispanic) & 46.0 & 48.5 & 43.6 \\
\hline Black (non-Hispanic) & 35.6 & 31.1 & 40.2 \\
\hline Hispanic & 13.1 & 14.4 & 11.8 \\
\hline Other & 5.2 & 5.9 & 4.4 \\
\hline Students eligible for free or reduced-price lunch (percent) & 56.4 & 53.7 & 59.0 \\
\hline Number of students enrolled (mean) & 538.0 & 460.6 & 634.8 \\
\hline Number of full-time teachers (mean) & 45.1 & 42.8 & 47.4 \\
\hline \multicolumn{4}{|l|}{ Title I status (percent) } \\
\hline Title I eligible school & 60.0 & 60.0 & 60.0 \\
\hline Schoolwide Title I & 66.7 & 66.7 & 66.7 \\
\hline Number of years principal has been at this school (mean) & 5.8 & 4.0 & 7.6 \\
\hline
\end{tabular}

In the Teacher Report on Classroom and School, teachers reported on nine dimensions of school environment (these data are not shown in a table): feelings of safety, adequacy of resources, student support, freedom to teach as desired, affiliation with and ties to colleagues, innovation regarding new approaches to teaching, professional interest, participatory decisionmaking, and work pressure. There were no statistically significant differences between treatment and control schools in these reports.

\section{The Level of SACD in the Schools Near the Beginning of the Study}

During the initial data collection period, principals and teachers reported on the SACD activities used in the schools and classrooms, the availability of SACD materials, and the professional development provided on SACD. Table 6.10 shows that the majority of the school principals reported activities to promote six social and character development goals: violence prevention and peace promotion (90\%), social and emotional development $(89 \%)$, character education $(90 \%)$, tolerance and diversity $(78 \%)$, risk prevention and health promotion $(60 \%)$, and civic responsibility and community service $(80 \%)$. In addition, 90 percent of the principals reported activities directed toward behavior management. There were no statistically significant differences between the treatment group and the control group in the percentages reported by principals, although this may be due to the small principal sample size. Teachers' reports of the use of these activities in their classrooms ranged from 53 percent to 83 percent, and there were no significant differences between treatment and control teachers in their use. With respect to the use of schoolwide activities, 65 percent to 89 percent of teachers reported that their schools used such activities. There were no significant differences between treatment and control teachers in reports of their use of these specific SACD activities. 
Table 6.10. Principal and teacher initial reports on use of SACD programs or activities in sample-PATHS

\begin{tabular}{|c|c|c|c|}
\hline SACD program or activity & Total & Treatment & Control \\
\hline Principal sample size & 10 & 5 & $v$ \\
\hline Teacher sample size & 107 & 56 & 51 \\
\hline
\end{tabular}

Principals reporting that school had programs or activities

to promote the following SACD goals (percent)

Violence prevention and peace promotion

Social and emotional development

$\begin{array}{rrr}90.0 & 100.0 & 80.0 \\ 88.9 & 100.0 & 75.0 \\ 90.0 & 100.0 & 80.0 \\ 77.8 & 80.0 & 75.0 \\ 60.0 & 60.0 & 60.0 \\ 80.0 & 100.0 & 60.0 \\ 90.0 & 100.0 & 80.0 \\ \ddagger & \ddagger & \ddagger\end{array}$

Teachers reporting on using programs or activities in their class to promote the following SACD goals (percent)

Violence prevention and peace promotion

74.1

78.9

69.2

Social and emotional development

Character education

Tolerance and diversity

Risk prevention and health promotion

Civic responsibility and community service

Behavior management

Teachers reporting schoolwide use of the following activities to promote SACD (percent)

Morning announcements or videos

School assemblies

$\ddagger$ Reporting standards not met. Values suppressed to protect confidentiality.

NOTE: No statistically significant differences were found between values for treatment and control groups. Weights, which assign equal weight to each school within each of the programs and to each program across programs, were used in producing the treatment, control, and overall means. Statistical tests were conducted using regressions that included program indicators to account for the sample design and adjusted for clustering at the school level. Sample size may differ for some outcomes due to nonresponse.

SOURCE: The Social and Character Development (SACD) Research Program. 


\section{Chapter 6. Promoting Alternative Thinking Strategies (PATHS)}

Teachers reported using a broad range of teaching materials to support SACD activities (table 6.11), including teacher guides (55\%), student materials (51\%), instructional aids (28\%), giveaways (43\%), and children's literature $(65 \%)$. There were statistically significant differences in the use of two types of SACD materials (out of seven comparisons made); more treatment than control teachers used teacher guides (67\% versus $43 \%$ ) and fewer treatment than control teachers used giveaways (33\% versus 54\%).

Teachers also reported using a wide variety of teaching strategies (table 6.11). All teachers reported using any of the 20 strategies asked about, and teachers used an average of 11.7 of the strategies. There was a significant difference in the use of role-playing ( 1 of 20 strategies), with treatment teachers using this strategy more often than control teachers $(81 \%$ versus $44 \%)$. 
Table 6.11. Teacher initial reports on use of SACD materials and classroom strategies in sample-PATHS

\begin{tabular}{crrr}
\hline SACD material and classroom strategy & Total & Treatment & Control \\
\hline Teacher sample size & 107 & 56 & 51
\end{tabular}

Teachers using the following materials in conjunction with social and character development activities (percent)

Teacher guides (manuals, curricula)

$\begin{array}{lll}55.0 & 67.3^{*} & 42.8 \\ 51.1 & 55.6 & 46.7 \\ 28.0 & 30.5 & 25.6 \\ 43.4 & 33.0^{* *} & 53.9 \\ 65.3 & 66.7 & 63.9 \\ 15.8 & 6.5 & 25.0 \\ 10.7 & 9.8 & 11.7\end{array}$

Teachers using any of the strategies listed below to promote social and character development in the classroom (percent)

Number of strategies (listed below) used by teachers to promote social and character development in the classroom (mean)

Teachers using each of the following strategies to promote social and character development (percent)

Role-playing

Cooperative learning

Peer group discussions

Direct instruction of social and character development

Skill training

Incorporating social and character development into academic curriculum

Parent training

Parent/community involvement in program development or delivery

Mentoring

Good behavior notes sent home daily or weekly

Presenting role models

Targeted story reading or writing on SACD themes

Peer mediation

Honor roll for positive behavior

Pledges or recitations on social and character development themes

Guided visualization

Student-led/student-assisted instruction

Journaling

Time out for negative behavior

Daily or weekly rewards for positive behavior

† Reporting standards not met. Values suppressed to protect confidentiality.

* Treatment group significantly different from control group at the .05 level.

${ }^{* *}$ Treatment group significantly different from control group at the .01 level.

NOTE: Weights, which assign equal weight to each school within each of the programs and to each program across programs, were used in producing the treatment, control, and overall means. Statistical tests were conducted using regressions that included program indicators to account for the sample design and adjusted for clustering at the school level. Sample size may differ for some outcomes due to nonresponse.

SOURCE: The Social and Character Development (SACD) Research Program.

\begin{tabular}{rrr}
62.5 & $80.8^{\star *}$ & 44.2 \\
94.3 & 95.7 & 93.0 \\
90.0 & 93.0 & 87.0 \\
82.3 & 91.5 & 73.1 \\
49.6 & 52.6 & 46.6 \\
& & \\
67.6 & 75.2 & 59.9 \\
5.1 & $\ddagger$ & $\ddagger$ \\
31.3 & 33.8 & 28.8 \\
25.3 & 24.2 & 26.4 \\
78.5 & 79.7 & 77.4 \\
78.5 & 76.0 & 80.9 \\
73.3 & 78.2 & 68.4 \\
35.7 & 36.3 & 35.0 \\
37.3 & 39.3 & 35.4 \\
40.7 & 29.7 & 51.7 \\
44.0 & 43.8 & 44.2 \\
51.6 & 59.4 & 43.8 \\
68.6 & 69.0 & 68.2 \\
76.1 & 81.2 & 70.9 \\
93.1 & 92.0 & 94.1 \\
\hline
\end{tabular}

44.2

87.0

73.1

46.6

59.9

28.8

26.4

77.4

80.9

68.4

35.0

35.4

51.7

44.2

43.8

68.2

90.9 
Principals and teachers reported on participation in and amount of SACD training and staff development provided over the previous 12 months (table 6.12). Principals reported higher participation rates ( $89 \%$ versus $80 \%)$ and more hours of training (10.3 versus 9.5) than did teachers. There were significant differences between treatment and control principals on the number of hours of SACD training reported (15 versus 5) and between treatment and control teachers on both the percentages reporting participation in SACD training $(92 \%$ versus $68 \%)$ and the number of hours of SACD training received (13 versus 6). Treatment teachers also reported more training than control teachers on two of the seven specific SACD goals: social and emotional development (64.8\% versus $15.3 \%)$ and character education $(53.9 \%$ versus $17.2 \%)$.

\section{Table 6.12. Principal and teacher initial reports on use of SACD materials and classroom strategies in sample-PATHS}

\begin{tabular}{|c|c|c|c|}
\hline SACD professional development & Total & Treatment & Control \\
\hline Principal sample size & 10 & 5 & 5 \\
\hline Teacher sample size & 107 & 56 & 51 \\
\hline \multicolumn{4}{|l|}{$\begin{array}{l}\text { Principals reporting that staff participated in social and character } \\
\text { develooment trainina within the past vear (percent) }\end{array}$} \\
\hline $\begin{array}{l}\text { Teachers reporting participation in social and character } \\
\text { development training within the past } 12 \text { months (percent) }\end{array}$ & 79.6 & $91.7^{*}$ & 67.5 \\
\hline $\begin{array}{l}\text { Number of hours of social and character development training } \\
\text { principals report were provided to each staff person last year (mean) }\end{array}$ & 10.3 & $14.8^{*}$ & 4.8 \\
\hline $\begin{array}{l}\text { Number of hours of social and character development training } \\
\text { teachers report receiving during the past } 12 \text { months (mean) }\end{array}$ & 9.5 & $12.7^{\star *}$ & 6.2 \\
\hline \multicolumn{4}{|l|}{$\begin{array}{l}\text { Teachers reporting receiving training in the past } 12 \text { months } \\
\text { in the following areas (percent) }\end{array}$} \\
\hline Violence prevention and peace promotion & 36.7 & 30.1 & 43.4 \\
\hline Social and emotional development & 40.0 & $64.8^{* *}$ & 15.3 \\
\hline Character education & 35.5 & $53.9^{*}$ & 17.2 \\
\hline Tolerance and diversity & 18.5 & 22.0 & 14.9 \\
\hline Risk prevention and health promotion & 11.2 & 13.6 & 8.9 \\
\hline Civic responsibility and community service & 8.7 & 4.8 & 12.6 \\
\hline Behavior management & 31.4 & 36.2 & 26.5 \\
\hline
\end{tabular}

${ }^{*}$ Treatment group significantly different from control group at the .05 level.

** Treatment group significantly different from control group at the .01 level.

NOTE: Weights, which assign equal weight to each school within each of the programs and to each program across programs, were used in producing the treatment, control, and overall means. Statistical tests were conducted using regressions that included program indicators to account for the sample design and adjusted for clustering at the school level. Sample size may differ for some outcomes due to nonresponse.

SOURCE: The Social and Character Development (SACD) Research Program.

The data on the initial level of SACD activity emphasize that the control condition was a "standard practice" control. Standard practice at the control schools included using SACD activities, materials, and practices, along with professional development, at rates and in types and amounts similar to the treatment schools. For example, the percentages of teachers who reported using programs or activities to promote specific SACD goals ranged from 46 percent to 86 percent in the treatment schools and from 60 percent to 85 percent in the control schools. However, the 8 significant differences between the treatment and control conditions in the use of SACD activities was more than expected by chance (3 out of 62 comparisons), and in 7 of these cases 
the differences favored the treatment group. This may reflect the fact that program implementation and program training for staff started before initial data collection.

\section{Impacts on Use of SACD Activities}

The introduction of the formal PATHS program would be expected to increase the use of SACD activities in the treatment schools in comparison to the control schools. The analysis of this impact is based on the Teacher Report on Classroom and School (TRCS). Every spring, third-, fourth-, and fifth-grade teachers provided information through the TRCS about the social and character development activities they used in their classrooms. Specifically, information from the TRCS was used to determine the difference between treatment and control teachers in these areas:

1. the use of SACD activities in their classrooms overall and by SACD goal;

2. the use of materials and strategies to implement the SACD activities within classrooms and within the entire school;

3. the use of staff development to support the teachers; and

4. staff attitudes toward the use of SACD activities.

TRCS consent and completion rates (table 6.4) led to 70 percent to 92 percent of all teachers having data for the 3 years, with a significantly greater percentage of treatment than control teachers providing data in Year 1. To estimate intervention impacts for each of the outcome measures, testing of the statistical significance of the differences in means was used. Preliminary analysis indicated little or no gains in precision from using covariates. Before testing the mean differences, the data were weighted such that each school received equal weight. Standard errors of the impact estimates account for the clustering of teachers within schools. In addition, to estimate the impact on the individual outcome measures, a set of heuristics was applied to determine whether each outcome domain was statistically significant after adjustments were made for the multiple tests conducted.

\section{Use of Activities}

The percentages of control teachers who reported using any SACD activities in their classrooms ranged from 90 percent to 99 percent over the 3 years (table 6.13, panel 1). For the six individual SACD goals, the ranges varied from 71 percent to 86 percent in Year 1, 51 percent to 74 percent in Year 2, and 59 percent to 84 percent in Year 3. Control teachers' use of behavior management activities ranged from 89 percent to 93 percent over this period. The percentages of control teachers who reported using any SACD activities in their classroom for at least 1 hour per week (panel 2) ranged from 46 percent to 83 percent over the 3 years. For the six individual SACD goals, the ranges varied from 10 percent to 25 percent in Year 1, 11 percent to 40 percent in Year 2, and 6 percent to 37 percent in Year 3. Control teachers' use of behavior management activities ranged from 71 percent to 73 percent over this period.

For teachers' reported use of any SACD activity (panels 1 and 2), 48 comparisons were made, with 2 expected to be significant by chance. There were 14 significant impacts on teachers' reported use of specific SACD activities in all 3 years. In Year 1, PATHS had significant impacts on engagement in activities for at least 1 hour per week: violence prevention and peace promotion (impact $=32$ percentage points), social and emotional development (impact $=48$ percentage points), character education (impact $=28$ percentage points), and tolerance and diversity (impact $=20$ percentage points). In Year 2, there were significant impacts both overall and for 1 hour per week on social and emotional development (impact $=38$ and 36 percentage points), character education (impact $=23$ and 38 percentage points), and tolerance and diversity (impact $=33$ and 27 percentage points). There was also a significant impact on violence prevention and peace promotion overall (impact $=23$ percentage points). In Year 3, PATHS had an impact on social and emotional development overall (impact $=24$ percentage points) and for at least 1 hour per week (impact $=27$ 


\section{Chapter 6. Promoting Alternative Thinking Strategies (PATHS)}

percentage points). Civic responsibility and community service activities for at least 1 hour per week were also significantly impacted (impact $=18$ percentage points). After the heuristics were applied, the domain for engagement in SACD activities showed that PATHS had statistically significant impacts in Years 1 and 2.

For teachers' reported use of any named SACD activity (panels 3 and 4), 42 comparisons were made, with 2 expected to be significant by chance. Six of the 12 impact estimates in Year 1, 9 of the 12 in Year 2, and 9 of the 12 in Year 3 were statistically significant. In all 3 years, the use of named activities to promote violence prevention and peace promotion (impact $=41,50$, and 36 percentage points), social and emotional development (impact $=59,64$, and 53 percentage points), character education (impact $=49$, 65, and 40 percentage points), tolerance and diversity (impact $=42,31$, and 34 percentage points), and any named activity (impact $=44,37$, and 33 percentage points) were significantly impacted. In Year 2, named activities to promote civic responsibility and community service were significantly impacted (impact $=13$ percentage points). The use of named activities for at least 1 hour per week showed significant impacts on the use of any named activity in Year 1 (impact $=42$ percentage points). In Years 2 and 3, PATHS had significant impact on activities related to social and emotional development (impact $=43$ and 44 percentage points), character education (impact $=43$ and 41 percentage points), and tolerance and diversity (impact $=19$ and 24 percentage points). In Years 1 and 3, there were significant impacts on the use of any named activity for at least 1 hour per week (impact $=42$ and 40 percentage points). PATHS had a significant impact on the domain of engagement in named SACD activities in all 3 years. 
Table 6.13. Impacts on teacher-reported SACD classroom activities-PATHS

Panel 1: Engagement in any activities to promote SACD goals ${ }^{1}$

\begin{tabular}{|c|c|c|c|c|c|c|c|c|c|c|c|c|}
\hline \multirow[b]{2}{*}{ SACD activity } & \multicolumn{4}{|c|}{$\begin{array}{c}\text { Year } 1 \\
\text { (Spring 3rd grade) }\end{array}$} & \multicolumn{4}{|c|}{$\begin{array}{c}\text { Year } 2 \\
\text { (Spring 4th grade) }\end{array}$} & \multicolumn{4}{|c|}{$\begin{array}{c}\text { Year } 3 \\
\text { (Spring 5th grade) }\end{array}$} \\
\hline & $\begin{array}{r}\text { Treat- } \\
\text { ment }\end{array}$ & Control & Impact & $p$-value & $\begin{array}{r}\text { Treat- } \\
\text { ment }\end{array}$ & Control & Impact & $p$-value & $\begin{array}{c}\text { Treat- } \\
\text { ment }\end{array}$ & Control & Impact & $p$-value \\
\hline Teacher sample size & 60 & 56 & & & 55 & 57 & & & 50 & 61 & & \\
\hline $\begin{array}{l}\text { Violence prevention and peace promotion } \\
\text { (percent) }\end{array}$ & 85.0 & 78.9 & 6.1 & 0.554 & $85.9^{*}$ & 62.4 & 23.4 & 0.043 & 88.2 & 81.2 & 7.1 & 0.446 \\
\hline $\begin{array}{l}\text { Social and emotional development } \\
\text { (percent) }\end{array}$ & 89.0 & 71.5 & 17.4 & 0.122 & $93.5^{\star}$ & 55.1 & 38.4 & 0.006 & $98.0^{*}$ & 74.5 & 23.5 & 0.020 \\
\hline Character education (percent) & 87.7 & 85.8 & 1.9 & 0.861 & $95.5^{\star}$ & 72.2 & 23.3 & 0.015 & $95.9^{\wedge}$ & 83.6 & 12.3 & 0.091 \\
\hline Tolerance and diversity (percent) & 78.7 & 70.8 & 7.9 & 0.420 & $88.9^{*}$ & 56.2 & 32.7 & 0.025 & 86.5 & 72.3 & 14.2 & 0.142 \\
\hline $\begin{array}{l}\text { Risk prevention and health promotion } \\
\text { (percent) }\end{array}$ & 68.5 & 70.5 & -2.0 & 0.916 & 74.3 & 73.6 & 0.8 & 0.967 & 80.5 & 80.4 & 0.1 & 0.995 \\
\hline $\begin{array}{l}\text { Civic responsibility and community service } \\
\text { (percent) }\end{array}$ & 65.4 & 71.7 & -6.3 & 0.566 & 67.3 & 51.2 & 16.1 & 0.199 & 66.4 & 59.4 & 7.0 & 0.623 \\
\hline Any SACD goal (percent) & 94.3 & 93.7 & 0.5 & 0.922 & 97.0 & 90.1 & 6.8 & 0.185 & 100.0 & 98.5 & 1.5 & $\dagger$ \\
\hline Behavior management (percent) & 88.5 & 93.1 & -4.6 & 0.472 & 95.1 & 89.5 & 5.6 & 0.463 & 79.8 & 89.4 & -9.6 & 0.193 \\
\hline
\end{tabular}

Behavior management (percent)

See notes at end of table. 
Table 6.13. Impacts on teacher-reported SACD classroom activities-PATHS-Continued

Panel 2: Engagement in any activities to promote SACD goals for at least 1 hour per week

\begin{tabular}{|c|c|c|c|c|c|c|c|c|c|c|c|c|}
\hline \multirow[b]{2}{*}{ SACD activity } & \multicolumn{4}{|c|}{$\begin{array}{c}\text { Year } 1 \\
\text { (Spring 3rd grade) }\end{array}$} & \multicolumn{4}{|c|}{$\begin{array}{c}\text { Year } 2 \\
\text { (Spring 4th grade) }\end{array}$} & \multicolumn{4}{|c|}{$\begin{array}{c}\text { Year } 3 \\
\text { (Spring 5th grade) }\end{array}$} \\
\hline & $\begin{array}{r}\text { Treat- } \\
\text { ment }\end{array}$ & Control & Impact & $p$-value & $\begin{array}{r}\text { Treat- } \\
\text { ment }\end{array}$ & Control & Impact & $p$-value & $\begin{array}{r}\text { Treat- } \\
\text { ment }\end{array}$ & Control & Impact & $p$-value \\
\hline Teacher sample size & 60 & 56 & & & 55 & 57 & & & 50 & 61 & & \\
\hline $\begin{array}{l}\text { Violence prevention and peace promotion } \\
\text { (percent) }\end{array}$ & $48.0^{*}$ & 15.9 & 32.0 & 0.020 & 41.6 & 22.5 & 19.1 & 0.121 & 45.8 & 33.2 & 12.6 & 0.343 \\
\hline $\begin{array}{l}\text { Social and emotional development } \\
\text { (percent) }\end{array}$ & $60.0^{*}$ & 12.5 & 47.5 & 0.003 & $57.1^{*}$ & 21.3 & 35.8 & 0.023 & $59.2^{*}$ & 32.0 & 27.2 & 0.012 \\
\hline Character education (percent) & $52.6^{*}$ & 25.1 & 27.5 & 0.036 & $63.9^{*}$ & 25.5 & 38.4 & 0.001 & $60.2^{\wedge}$ & 37.1 & 23.1 & 0.078 \\
\hline Tolerance and diversity (percent) & $40.9^{*}$ & 21.3 & 19.6 & 0.031 & $43.3^{*}$ & 16.2 & 27.1 & 0.043 & 32.2 & 25.9 & 6.3 & 0.596 \\
\hline $\begin{array}{l}\text { Risk prevention and health promotion } \\
\text { (percent) }\end{array}$ & 32.8 & 18.5 & 14.3 & 0.288 & 34.5 & 39.9 & -5.4 & 0.699 & 30.8 & 27.2 & 3.6 & 0.778 \\
\hline $\begin{array}{l}\text { Civic responsibility and community service } \\
\text { (percent) }\end{array}$ & 19.8 & 10.0 & 9.8 & 0.374 & 17.1 & 10.9 & 6.2 & 0.239 & $24.0^{*}$ & 5.6 & 18.4 & 0.039 \\
\hline Any SACD goal (percent) & 74.7 & 45.6 & 29.1 & 0.053 & 86.7 & 82.8 & 3.9 & 0.663 & 82.4 & 77.0 & 5.4 & 0.599 \\
\hline Behavior management (percent) & 68.7 & 72.7 & -4.0 & 0.614 & 82.2 & 71.0 & 11.2 & 0.442 & 58.9 & 70.8 & -11.9 & 0.305 \\
\hline
\end{tabular}

Behavior management (percent)

See notes at end of table. 
Table 6.13. Impacts on teacher-reported SACD classroom activities-PATHS-Continued

Panel 3: Engagement in activities to promote SACD goals linked to named SACD programs ${ }^{2}$

\begin{tabular}{|c|c|c|c|c|c|c|c|c|c|c|c|c|}
\hline \multirow[b]{2}{*}{ SACD activity } & \multicolumn{4}{|c|}{$\begin{array}{c}\text { Year } 1 \\
\text { (Spring 3rd grade) }\end{array}$} & \multicolumn{4}{|c|}{$\begin{array}{c}\text { Year } 2 \\
\text { (Spring 4th grade) }\end{array}$} & \multicolumn{4}{|c|}{$\begin{array}{c}\text { Year } 3 \\
\text { (Spring 5th grade) }\end{array}$} \\
\hline & $\begin{array}{r}\text { Treat- } \\
\text { ment }\end{array}$ & Control & Impact & $p$-value & $\begin{array}{r}\text { Treat- } \\
\text { ment }\end{array}$ & Control & Impact & $p$-value & $\begin{array}{r}\text { Treat- } \\
\text { ment }\end{array}$ & Control & Impact & $p$-value \\
\hline Teacher sample size & 60 & 56 & & & 55 & 57 & & & 50 & 61 & & \\
\hline $\begin{array}{l}\text { Violence prevention and peace promotion } \\
\text { (percent) }\end{array}$ & $54.4^{*}$ & 13.8 & 40.6 & 0.009 & $60.8^{*}$ & 11.0 & 49.8 & 0.001 & $65.7^{*}$ & 30.2 & 35.5 & 0.034 \\
\hline $\begin{array}{l}\text { Social and emotional development } \\
\text { (percent) }\end{array}$ & $65.1^{*}$ & 6.0 & 59.1 & 0.003 & $78.1^{*}$ & 14.2 & 64.0 & 0.000 & $75.9^{*}$ & 22.6 & 53.3 & 0.000 \\
\hline Character education (percent) & $54.5^{\star}$ & 5.3 & 49.2 & 0.002 & $70.2^{*}$ & 5.1 & 65.2 & 0.000 & $63.8^{*}$ & 24.0 & 39.8 & 0.033 \\
\hline Tolerance and diversity (percent) & $\ddagger^{*}$ & $\ddagger$ & 42.1 & 0.006 & $41.8^{*}$ & 11.0 & 30.8 & 0.003 & $42.5^{*}$ & 8.4 & 34.1 & 0.016 \\
\hline $\begin{array}{l}\text { Risk prevention and health promotion } \\
\text { (percent) }\end{array}$ & 25.1 & 16.2 & 8.9 & 0.552 & 23.3 & 30.2 & -7.0 & 0.569 & 25.6 & 30.4 & -4.8 & 0.698 \\
\hline $\begin{array}{l}\text { Civic responsibility and community service } \\
\text { (percent) }\end{array}$ & 6.6 & 0.0 & 6.6 & $\dagger$ & $\ddagger^{*}$ & $\ddagger$ & 12.9 & 0.035 & 17.8 & 5.6 & 12.2 & 0.229 \\
\hline Any named activity (percent) & $66.3^{*}$ & 22.8 & 43.5 & 0.014 & $83.3^{*}$ & 45.9 & 37.4 & 0.003 & $82.3^{*}$ & 49.0 & 33.3 & 0.021 \\
\hline
\end{tabular}




\section{Table 6.13. Impacts on teacher-reported SACD classroom activities-PATHS—Continued}

Panel 4: Engagement in activities to promote SACD goals linked to named SACD programs for at least 1 hour per week

\begin{tabular}{|c|c|c|c|c|c|c|c|c|c|c|c|c|}
\hline \multirow[b]{2}{*}{ SACD activity } & \multicolumn{4}{|c|}{$\begin{array}{c}\text { Year } 1 \\
\text { (Spring 3rd grade) }\end{array}$} & \multicolumn{4}{|c|}{$\begin{array}{c}\text { Year } 2 \\
\text { (Spring 4th grade) }\end{array}$} & \multicolumn{4}{|c|}{$\begin{array}{c}\text { Year } 3 \\
\text { (Spring 5th grade) }\end{array}$} \\
\hline & $\begin{array}{r}\text { Treat- } \\
\text { ment }\end{array}$ & Control & Impact & $p$-value & $\begin{array}{l}\text { Treat- } \\
\text { ment }\end{array}$ & Control & Impact & $p$-value & $\begin{array}{r}\text { Treat- } \\
\text { ment }\end{array}$ & Control & Impact & $p$-value \\
\hline Teacher sample size & 60 & 56 & & & 55 & 57 & & & 50 & 61 & & \\
\hline $\begin{array}{l}\text { Violence prevention and peace promotion } \\
\text { (percent) }\end{array}$ & $37.5^{\wedge}$ & 11.7 & 25.8 & 0.100 & $34.5^{\wedge}$ & 7.7 & 26.8 & 0.062 & $40.8^{\wedge}$ & 17.2 & 23.6 & 0.094 \\
\hline $\begin{array}{l}\text { Social and emotional development } \\
\text { (percent) }\end{array}$ & 47.3 & 0.0 & 47.3 & $\dagger$ & $\ddagger^{*}$ & $\ddagger$ & 43.4 & 0.003 & $50.6^{*}$ & 6.9 & 43.7 & 0.000 \\
\hline Character education (percent) & 36.4 & 0.0 & 36.4 & $\dagger$ & $\ddagger^{*}$ & $\ddagger$ & 43.4 & 0.004 & $52.4^{*}$ & 11.7 & 40.7 & 0.015 \\
\hline Tolerance and diversity (percent) & 29.8 & 0.0 & 29.8 & $\dagger$ & $\ddagger^{*}$ & $\ddagger$ & 19.2 & 0.016 & $\ddagger^{*}$ & $\ddagger$ & 24.2 & 0.015 \\
\hline $\begin{array}{l}\text { Risk prevention and health promotion } \\
\text { (percent) }\end{array}$ & 16.7 & 7.8 & 8.9 & 0.499 & 10.9 & 21.7 & -10.7 & 0.388 & 18.9 & 7.9 & 11.0 & 0.305 \\
\hline $\begin{array}{l}\text { Civic responsibility and community service } \\
\text { (percent) }\end{array}$ & 5.5 & 0.0 & 5.5 & $\dagger$ & 4.6 & 0.0 & 4.6 & $\dagger$ & 12.2 & 0.0 & 12.2 & $\dagger$ \\
\hline Any named activity (percent) & $52.2^{*}$ & 10.2 & 42.0 & 0.040 & $57.3^{\wedge}$ & 28.4 & 28.8 & 0.060 & $61.9^{*}$ & 22.2 & 39.6 & 0.031 \\
\hline
\end{tabular}

‡ Reporting standards not met. Values suppressed to protect confidentiality

* Treatment group significantly different from control group at the .05 level.

$\wedge$ Treatment group significantly different from control group at the .10 to $>.05$ level.

In Year 1, the omnibus impact for all the outcomes measured together was positive and statistically significant on the basis of a multivariate statistical test. In Years 1 and 2, at least one outcome remained positive and statistically significant and no outcome was negative and statistically significant after applying the Benjamini-Hochberg (1995) procedure to adjust significance levels downward to account for the multiple testing of impacts.

${ }^{2}$ In all 3 years at least half of the impacts were positive and statistically significant and no impact was negative and statistically significant on the basis of univariate statistical tests, and at least one outcome remained positive and statistically significant and no outcome was negative and statistically significant after applying the Benjamini-Hochberg (1995) procedure to adjust significance levels downward to account for the multiple testing of impacts.

NOTE: Weights, which assign equal weight to each school within the program, were used in producing the treatment, control, and overall means.

SOURCE: The Social and Character Development (SACD) Research Program. 


\section{Use of Materials and Strategies}

For use of materials and strategies to support SACD goals, 87 comparisons were made, with 5 expected to be significant by chance. Six significant impacts were found on treatment teachers' use of materials and strategies. In Year 1, more treatment teachers used role-playing (impact $=34$ percentage points). In Year 2, more treatment teachers used instructional aids (impact $=30$ percentage points), children's literature (impact $=30$ percentage points), role-playing (impact $=29$ percentage points), and direct instruction of SACD (impact $=20$ percentage points), and these teachers also reported using a greater average number of strategies (by 1.6 strategies on average). The PATHS impact on the domain of materials and strategies was not statistically significant in any of the 3 years. 
Table 6.14. Impacts on use of SACD classroom materials and teaching strategies-PATHS

\begin{tabular}{|c|c|c|c|c|c|c|c|c|c|c|c|c|}
\hline \multirow[b]{2}{*}{ SACD material and teaching strategy } & \multicolumn{4}{|c|}{$\begin{array}{c}\text { Year } 1 \\
\text { (Spring 3rd grade) }\end{array}$} & \multicolumn{4}{|c|}{$\begin{array}{c}\text { Year } 2 \\
\text { (Spring 4th grade) }\end{array}$} & \multicolumn{4}{|c|}{$\begin{array}{c}\text { Year } 3 \\
\text { (Spring 5th grade) }\end{array}$} \\
\hline & $\begin{array}{r}\text { Treat- } \\
\text { ment }\end{array}$ & Control & Impact & $p$-value & $\begin{array}{r}\text { Treat- } \\
\text { ment }\end{array}$ & Control & Impact & $p$-value & $\begin{array}{r}\text { Treat- } \\
\text { ment }\end{array}$ & Control & Impact & $p$-value \\
\hline Teacher sample size & 60 & 56 & & & 55 & 57 & & & 50 & 61 & & \\
\hline \multicolumn{13}{|l|}{ Use of SACD materials (percent) } \\
\hline Teacher guides (manuals, curricula) & 74.8 & 64.7 & 10.1 & 0.409 & 83.9 & 56.9 & 27.0 & 0.116 & 89.5 & 79.0 & 10.5 & 0.239 \\
\hline Student materials (workbooks or sheets) & 64.1 & 66.6 & -2.5 & 0.776 & 72.0 & 70.6 & 1.4 & 0.891 & 77.4 & 72.1 & 5.3 & 0.679 \\
\hline Instructional aids (games, software, videos) & 50.0 & 49.0 & 1.0 & 0.952 & $61.9^{*}$ & 32.4 & 29.5 & 0.022 & $54.2^{\wedge}$ & 37.2 & 17.0 & 0.088 \\
\hline Giveaways (bookmarks, stickers) & $32.6^{\wedge}$ & 57.8 & -25.2 & 0.064 & 41.9 & 37.7 & 4.2 & 0.613 & 35.4 & 46.8 & -11.4 & 0.344 \\
\hline Children's literature & 73.3 & 63.2 & 10.1 & 0.432 & $75.2^{*}$ & 45.5 & 29.7 & 0.012 & 68.1 & 61.9 & 6.2 & 0.471 \\
\hline Other types of materials & 10.4 & 5.8 & 4.5 & 0.468 & 5.2 & 7.0 & -1.9 & 0.755 & $\ddagger$ & $\ddagger$ & 11.6 & 0.19 \\
\hline Did not use any of these materials & 9.3 & 7.5 & 1.8 & 0.765 & $\ddagger$ & $\ddagger$ & -9.2 & 0.125 & $\ddagger$ & $\ddagger$ & -5.7 & 0.254 \\
\hline \multicolumn{13}{|l|}{ Use of teaching strategies (percent) } \\
\hline Role-playing & $91.6^{*}$ & 58.1 & 33.5 & 0.024 & $90.4^{*}$ & 61.0 & 29.4 & 0.002 & 92.2 & 84.6 & 7.6 & 0.282 \\
\hline Cooperative learning & 98.8 & 100.0 & -1.3 & $\dagger$ & 100.0 & 100.0 & 0.0 & $\dagger$ & 100.0 & 100.0 & 0.0 & $\dagger$ \\
\hline Peer group discussions & 92.1 & 89.5 & 2.6 & 0.590 & 100.0 & 91.4 & 8.6 & $\dagger$ & 93.5 & 100.0 & -6.5 & $\dagger$ \\
\hline Direct instruction of SACD & 87.9 & 85.0 & 2.8 & 0.757 & $98.5^{*}$ & 79.0 & 19.5 & 0.021 & 100.0 & 98.1 & 1.9 & $\dagger$ \\
\hline Skill training & 54.8 & 45.3 & 9.5 & 0.324 & $67.9^{\wedge}$ & 44.1 & 23.8 & 0.058 & 87.8 & 81.0 & 6.8 & 0.360 \\
\hline Incorporating SACD into academic & & & & & & & & & & & & \\
\hline curriculum & 84.5 & 80.6 & 3.9 & 0.572 & $89.5^{\wedge}$ & 77.2 & 12.3 & 0.072 & 95.9 & 92.4 & 3.4 & 0.413 \\
\hline Parent training & 5.6 & 9.6 & -4.1 & 0.388 & 7.7 & 8.4 & -0.8 & 0.902 & 25.7 & 25.2 & 0.5 & 0.963 \\
\hline Parent/community involvement & 20.7 & 38.4 & -17.7 & 0.212 & 19.5 & 37.5 & -18.0 & 0.138 & 40.3 & 36.6 & 3.7 & 0.725 \\
\hline Mentoring & 29.0 & 40.4 & -11.5 & 0.289 & 24.8 & 24.0 & 0.8 & 0.932 & 54.1 & 54.4 & -0.3 & 0.961 \\
\hline $\begin{array}{l}\text { Good behavior notes sent home daily } \\
\text { or weekly }\end{array}$ & 82.0 & 73.9 & 8.1 & 0.344 & 81.3 & 74.5 & 6.9 & 0.642 & 93.1 & 98.1 & -5.1 & 0.268 \\
\hline Presenting role models & 86.6 & 81.2 & 5.4 & 0.363 & 75.7 & 71.6 & 4.0 & 0.663 & 94.1 & 87.8 & 6.3 & 0.184 \\
\hline
\end{tabular}


Table 6.14. Impacts on use of SACD classroom materials and teaching strategies-PATHS—Continued

\begin{tabular}{|c|c|c|c|c|c|c|c|c|c|c|c|c|}
\hline \multirow[b]{2}{*}{ SACD material and teaching strategy } & \multicolumn{4}{|c|}{$\begin{array}{c}\text { Year } 1 \\
\text { (Spring 3rd grade) }\end{array}$} & \multicolumn{4}{|c|}{$\begin{array}{c}\text { Year } 2 \\
\text { (Spring 4th grade) }\end{array}$} & \multicolumn{4}{|c|}{$\begin{array}{c}\text { Year } 3 \\
\text { (Spring 5th grade) }\end{array}$} \\
\hline & $\begin{array}{r}\text { Treat- } \\
\text { ment }\end{array}$ & Control & Impact & $p$-value & $\begin{array}{r}\text { Treat- } \\
\text { ment }\end{array}$ & Control & Impact & $p$-value & $\begin{array}{r}\text { Treat- } \\
\text { ment }\end{array}$ & Control & Impact & $p$-value \\
\hline \multicolumn{13}{|l|}{$\begin{array}{l}\text { Use of teaching strategies (percent)- } \\
\text { Continued }\end{array}$} \\
\hline $\begin{array}{l}\text { Targeted story reading or writing on social } \\
\text { and character development themes }\end{array}$ & 88.9 & 84.0 & 4.9 & 0.599 & 90.8 & 84.6 & 6.3 & 0.173 & 98.2 & 93.2 & 5.0 & 0.212 \\
\hline Peer mediation & 50.4 & 49.1 & 1.3 & 0.935 & 59.1 & 46.0 & 13.1 & 0.523 & 67.3 & 63.7 & 3.6 & 0.749 \\
\hline Honor roll for positive behavior & 40.7 & 40.1 & 0.5 & 0.974 & 45.3 & 28.3 & 17.0 & 0.253 & 69.3 & 55.4 & 13.9 & 0.341 \\
\hline $\begin{array}{l}\text { Pledges or recitations on social and } \\
\text { character development themes }\end{array}$ & 21.8 & 56.7 & -34.9 & 0.173 & 47.6 & 55.7 & -8.1 & 0.722 & 54.5 & 75.6 & -21.0 & 0.265 \\
\hline Guided visualization & 58.6 & 52.4 & 6.2 & 0.500 & 67.3 & 46.8 & 20.4 & 0.116 & 62.6 & 56.0 & 6.6 & 0.447 \\
\hline Student-led/student-assisted instruction & 54.9 & 54.4 & 0.5 & 0.952 & 70.3 & 57.0 & 13.4 & 0.185 & 78.5 & 70.0 & 8.5 & 0.377 \\
\hline Journaling & 75.9 & 77.9 & -1.9 & 0.853 & 85.7 & 79.2 & 6.5 & 0.261 & 84.0 & 85.5 & -1.5 & 0.778 \\
\hline Time out for negative behavior & 86.9 & 73.5 & 13.4 & 0.239 & 82.9 & 75.4 & 7.6 & 0.479 & 89.5 & 80.2 & 9.4 & 0.410 \\
\hline $\begin{array}{l}\text { Daily or weekly rewards for positive } \\
\text { behavior }\end{array}$ & 92.2 & 91.3 & 0.9 & 0.889 & 86.9 & 95.7 & -8.8 & 0.273 & 96.6 & 96.7 & -0.1 & 0.990 \\
\hline Any strategy & 100.0 & 100.0 & 0.0 & $\dagger$ & 100.0 & 100.0 & 0.0 & $\dagger$ & 100.0 & 100.0 & 0.0 & $\dagger$ \\
\hline Number of strategies (mean) & 12.9 & 12.7 & 0.2 & 0.715 & $13.9^{*}$ & 12.3 & 1.6 & 0.039 & 15.6 & 15.2 & 0.4 & 0.477 \\
\hline
\end{tabular}

† Not applicable.

‡ Reporting standards not met. Values suppressed to protect confidentiality.

* Treatment group significantly different from control group at the .05 level.

$\wedge$ Treatment group significantly different from control group at the .10 to $>.05$ level.

NOTE: Weights, which assign equal weight to each school within the program, were used in producing the treatment, control, and overall means

SOURCE: The Social and Character Development (SACD) Research Program. 
Regarding the use of schoolwide strategies, 18 comparisons were made between treatment and control teacher reports, with 1 expected to be significant by chance. There was 1 statistically significant difference between reports from treatment and control teachers on their use of schoolwide strategies in Year 1 (these data are not shown in a table), with fewer treatment teachers reporting use of special events than control teachers (impact $=-17$ percentage points). The overall impact of the PATHS program on the domain for use of schoolwide strategies in named SACD activities was not significant in any year.

\section{Participation in Professional Development}

Regarding reported participation in professional development, 27 comparisons were made over 3 years, with 2 expected to be significant by chance. In Year 1, the intervention had a statistically significant effect on treatment teachers' participation in professional development, with more treatment teachers than control teachers reporting SACD training in the past 12 months (impact $=32$ percentage points) and reporting more hours of training (by 10.6 hours on average). In terms of specific SACD goals, more treatment teachers reported training in violence prevention and peace promotion (impact $=24$ percentage points), social and emotional development (impact $=47$ percentage points), and character education (impact $=46$ percentage points). In Year 2, PATHS had an impact on social and emotional development training (impact $=17$ percentage points). There was a significant impact on the domain in Year 1. 
Table 6.15. Impacts on teacher-reported SACD professional development-PATHS

\begin{tabular}{|c|c|c|c|c|c|c|c|c|c|c|c|c|}
\hline \multirow[b]{2}{*}{ SACD professional development $^{1}$} & \multicolumn{4}{|c|}{$\begin{array}{c}\text { Year } 1 \\
\text { (Spring 3rd grade) }\end{array}$} & \multicolumn{4}{|c|}{$\begin{array}{c}\text { Year } 2 \\
\text { (Spring 4th grade) }\end{array}$} & \multicolumn{4}{|c|}{$\begin{array}{c}\text { Year } 3 \\
\text { (Spring 5th grade) }\end{array}$} \\
\hline & $\begin{array}{c}\text { Treat- } \\
\text { ment } \\
\end{array}$ & Control & Impact & $p$-value & $\begin{array}{c}\text { Treat- } \\
\text { ment } \\
\end{array}$ & Control & Impact & $p$-value & $\begin{array}{r}\text { Treat- } \\
\text { ment }\end{array}$ & Control & Impact & $p$-value \\
\hline Teacher sample size & 60 & 56 & & & 55 & 57 & & & 50 & 61 & & \\
\hline SACD training in past 12 months (percent) & $91.9^{*}$ & 60.1 & 31.8 & 0.020 & 76.4 & 66.9 & 9.5 & 0.294 & 63.8 & 70.0 & -6.2 & 0.461 \\
\hline Hours of SACD training (mean) & $14.0^{*}$ & 3.4 & 10.6 & 0.000 & 5.2 & 4.4 & 0.7 & 0.465 & 7.1 & 5.5 & 1.6 & 0.516 \\
\hline \multicolumn{13}{|l|}{ Training by goal (percent) } \\
\hline Violence prevention and peace promotion & $44.8^{*}$ & 20.6 & 24.2 & 0.034 & 18.7 & 14.6 & 4.0 & 0.737 & 20.3 & 11.5 & 8.8 & 0.432 \\
\hline Social and emotional development & $74.2^{*}$ & 27.5 & 46.7 & 0.005 & $37.6^{*}$ & 20.8 & 16.9 & 0.025 & 29.8 & 28.2 & 1.6 & 0.926 \\
\hline Character education & $67.1^{*}$ & 21.2 & 45.9 & 0.002 & $45.7^{\wedge}$ & 25.7 & 20.0 & 0.056 & 33.9 & 16.1 & 17.8 & 0.112 \\
\hline Tolerance and diversity & 16.3 & 17.0 & -0.7 & 0.945 & 31.4 & 41.6 & -10.2 & 0.257 & 41.3 & 40.1 & 1.2 & 0.937 \\
\hline Risk prevention and health promotion & 15.5 & 23.0 & -7.5 & 0.524 & 15.5 & 9.4 & 6.1 & 0.536 & 8.5 & 18.1 & -9.6 & 0.231 \\
\hline Civic responsibility and community service & 6.5 & 5.4 & 1.1 & 0.829 & 6.1 & 7.1 & -1.0 & 0.811 & $\ddagger$ & $\ddagger$ & -1.6 & 0.727 \\
\hline Behavior management & 40.5 & 32.7 & 7.8 & 0.697 & 30.6 & 27.7 & 2.9 & 0.842 & 22.5 & 30.7 & -8.2 & 0.554 \\
\hline
\end{tabular}

t Reporting standards not met. Values suppressed to protect confidentiality.

* Treatment group significantly different from control group at the .05 level.

$\wedge$ Treatment group significantly different from control group at the .10 to $>.05$ level.

${ }^{1}$ In Year 1, at least half of the impacts were positive and statistically significant and no impact was negative and statistically significant on the basis of univariate statistical tests, and at least one outcome remained positive and statistically significant and no outcome was negative and statistically significant after applying the Benjamini-Hochberg (1995) procedure to adjust significance levels downward to account for the multiple testing of impacts.

NOTE: Weights, which assign equal weight to each school within the program, were used in producing the treatment, control, and overall means.

SOURCE: The Social and Character Development (SACD) Research Program. 


\section{Attitudes and Practices}

Teachers reported on their enthusiasm for SACD efforts in their schools (these data are not shown in a table) by indicating enthusiasm, cooperation, or open dislike. They also reported on the SACD practices of teachers and staff members in their schools (these data are not shown in a table). These practices included modeling positive character and behavior traits with students and fellow teachers, involving students in making decisions, giving students a voice in school governance, the school encouraging parent involvement in children's social and character development, and using developmentally appropriate discipline strategies rather than punishment for misbehavior. Twenty-seven comparisons were made over 3 years, with 1 expected to be significant by chance. There were no statistically significant impacts on teachers' enthusiasm for SACD efforts in their schools in any of the years, nor were there significant differences in the treatment and control teachers' reports of the overall use of practices conducive to students' social and character development. PATHS had no impact on the domain in any year.

\section{Year-by-Year Impacts on Students and Perceptions of School Climate}

The primary research question for the PATHS evaluation was this:

What is the average effect of the PATHS program on children's social and emotional competence, behavior, academic achievement, and perceptions of school climate?

The first approach to answering this question was to examine the year-by-year impacts of PATHS on these student and school climate outcomes over the 3 years as the students progressed from third through fifth grades.

Equation (2) (described in chapter 1) was estimated to provide the impacts of the PATHS program on the 20 outcome measures using data from the 10 treatment and control schools. For the PATHS evaluation, equation (2) excluded the program fixed effects $\left(\theta_{p}\right)$ and included program-specific covariates and random school effects covariates. Table 6.16 lists the covariates used with outcomes from each report in the PATHS analysis. 
Table 6.16. Covariates used with outcomes from each report for analysis-PATHS

\begin{tabular}{|c|c|c|c|c|}
\hline Potential covariate & $\begin{array}{c}\text { CR } \\
\text { outcome } \\
\end{array}$ & $\begin{array}{c}\text { PCR } \\
\text { outcome }\end{array}$ & $\begin{array}{c}\text { TRS } \\
\text { outcome }\end{array}$ & $\begin{array}{c}\text { TRCS } \\
\text { outcome }\end{array}$ \\
\hline Total number & 18 & 27 & 27 & 5 \\
\hline \multicolumn{5}{|l|}{ Child-reported } \\
\hline Female & $\checkmark$ & $\checkmark$ & $\checkmark$ & \\
\hline Hispanic & $\checkmark$ & $\checkmark$ & $\checkmark$ & \\
\hline Black (non-Hispanic) & $\checkmark$ & $\checkmark$ & $\checkmark$ & \\
\hline Other ethnicity & $\checkmark$ & $\checkmark$ & $\checkmark$ & \\
\hline Age in years & $\checkmark$ & $\checkmark$ & $\checkmark$ & \\
\hline \multicolumn{5}{|l|}{ Scales } \\
\hline Afraid at School & & & $\checkmark$ & \\
\hline \multicolumn{5}{|l|}{ Altruistic Behavior } \\
\hline \multicolumn{5}{|l|}{ Empathy } \\
\hline \multicolumn{5}{|l|}{ Engagement with Learning } \\
\hline Negative School Orientation & & $\checkmark$ & $\checkmark$ & \\
\hline \multicolumn{5}{|l|}{ Normative Beliefs About Aggression } \\
\hline \multicolumn{5}{|l|}{ Sense of School as a Community } \\
\hline Problem Behavior & & $\checkmark$ & & \\
\hline Self-Efficacy for Peer Interactions & $\checkmark$ & $\checkmark$ & $\checkmark$ & \\
\hline Victimization at School & & & $\checkmark$ & \\
\hline \multicolumn{5}{|l|}{$\begin{array}{l}\text { Primary caregiver-reported } \\
\text { Age in years }\end{array}$} \\
\hline \multicolumn{5}{|l|}{ Completed high school or equivalent } \\
\hline \multicolumn{5}{|l|}{ Some college } \\
\hline \multicolumn{5}{|l|}{ Bachelor's or higher degree } \\
\hline \multicolumn{5}{|l|}{ Highest level of education in household } \\
\hline Completed high school or equivalent & $\checkmark$ & $\checkmark$ & $\checkmark$ & \\
\hline Some college & $\checkmark$ & $\checkmark$ & $\checkmark$ & \\
\hline Bachelor's or higher degree & $\checkmark$ & $\checkmark$ & $\checkmark$ & \\
\hline Mother present in home life & & $\checkmark$ & $\checkmark$ & \\
\hline Mother and father present & & $\checkmark$ & & \\
\hline Respondent someone other than mother or father & & $\checkmark$ & & \\
\hline \multicolumn{5}{|l|}{ Number of people in household } \\
\hline Household Income: $\$ 20,000$ to $\$ 40,000$ & $\checkmark$ & $\checkmark$ & $\checkmark$ & \\
\hline Household Income: $\$ 40,000$ to $\$ 60,000$ & $\checkmark$ & $\checkmark$ & $\checkmark$ & \\
\hline Household Income: More than $\$ 60,000$ & $\checkmark$ & $\checkmark$ & $\checkmark$ & \\
\hline Income-to-poverty-threshold ratio: Below 135 percent & & $\checkmark$ & & \\
\hline Income-to-poverty-threshold ratio: $135-185$ percent & & $\checkmark$ & & \\
\hline Full-time employment & $\checkmark$ & $\checkmark$ & $\checkmark$ & \\
\hline Part-time employment & $\checkmark$ & $\checkmark$ & $\checkmark$ & \\
\hline
\end{tabular}


Table 6.16. Covariates used with outcomes from each report for analysis-PATHS-Continued

\begin{tabular}{|c|c|c|c|c|}
\hline Potential covariate & $\begin{array}{c}\text { CR } \\
\text { outcome }\end{array}$ & $\begin{array}{c}\text { PCR } \\
\text { outcome } \\
\end{array}$ & $\begin{array}{c}\text { TRS } \\
\text { outcome }\end{array}$ & $\begin{array}{c}\text { TRCS } \\
\text { outcome } \\
\end{array}$ \\
\hline \multicolumn{5}{|l|}{ Parental scales } \\
\hline APQ-Poor Monitoring and Supervision Subscale & $\checkmark$ & $\checkmark$ & $\checkmark$ & \\
\hline \multicolumn{5}{|l|}{ APQ-Positive Parenting Subscale } \\
\hline Child-Centered Social Control & & & $\checkmark$ & \\
\hline \multicolumn{5}{|l|}{ Confusion, Hubbub, and Order } \\
\hline Community Resources & & & $\checkmark$ & \\
\hline Community Risk & $\checkmark$ & & $\checkmark$ & \\
\hline Parent and Teacher Involvement & & $\checkmark$ & $\checkmark$ & \\
\hline \multicolumn{5}{|l|}{ Child scales } \\
\hline \multicolumn{5}{|l|}{ Altruistic Behavior } \\
\hline Positive Social Behavior & & & $\checkmark$ & \\
\hline Problem Behavior & & $\checkmark$ & & \\
\hline $\begin{array}{l}\text { Teacher-reported } \\
\text { Female }\end{array}$ & & & & $\checkmark$ \\
\hline Hispanic & & & & $\checkmark$ \\
\hline Black (non-Hispanic) & & & & $\checkmark$ \\
\hline Other ethnicity & & & & $\checkmark$ \\
\hline Total teaching experience & & & & $\checkmark$ \\
\hline \multicolumn{5}{|l|}{ Total experience in current school } \\
\hline \multicolumn{5}{|l|}{ Regular certificate } \\
\hline \multicolumn{5}{|l|}{ Other certificate } \\
\hline \multicolumn{5}{|l|}{ Highest degree-bachelor's } \\
\hline \multicolumn{5}{|l|}{ Child scales } \\
\hline \multicolumn{5}{|l|}{ Academic Competence and Motivation } \\
\hline ADHD-Related Behavior & $\checkmark$ & & $\checkmark$ & \\
\hline Altruistic Behavior & & $\checkmark$ & & \\
\hline \multicolumn{5}{|l|}{ Positive Social Behavior } \\
\hline Problem Behavior & & $\checkmark$ & $\checkmark$ & \\
\hline Parent and Teacher Involvement & $\checkmark$ & $\checkmark$ & $\checkmark$ & \\
\hline
\end{tabular}

NOTES: Abbreviations are

CR: Child Report

PCR: Primary Caregiver Report

TRS: Teacher Report on Student

TRCS: Teacher Report on Classroom and School

ADHD: Attention deficit hyperactivity disorder

APQ: Alabama Parenting Questionnaire

$\checkmark$ : Covariate used

Blank cell: Covariate not used

SOURCE: The Social and Character Development (SACD) Research Program. 


\section{Chapter 6. Promoting Alternative Thinking Strategies (PATHS)}

To assess the statistical power of the program-level impact estimates, minimum detectable impacts in effect size units (MDES) for each outcome measure were calculated for the PATHS evaluation (table 6.17). MDES represent the smallest impacts in effect size (standard deviation) units that can be detected with a high probability (80\%). MDES are primarily a function of study sample sizes, the degrees of freedom available for statistical tests, and design effects due to clustering (Schochet 2005). For the PATHS evaluation, the MDES ranged from 0.137 to 0.709 for the child-level outcomes based on the Child, Primary Caregiver, and Teacher Report on Student and from 0.652 to 1.040 for the school climate outcomes based on the Teacher Report on Classroom and School. In general, the MDES for the school climate outcomes were larger than those for the child-level outcomes. 
Table 6.17. Adjusted minimum detectable effect sizes for impact evaluation-PATHS

\begin{tabular}{|c|c|c|c|}
\hline Outcome measure-Report & Year 1 & Year 2 & Year 3 \\
\hline \multicolumn{4}{|l|}{ Social and Emotional Competence Domain } \\
\hline Self-Efficacy for Peer Interaction-CR & 0.160 & 0.210 & 0.179 \\
\hline Normative Beliefs About Aggression-CR & 0.137 & 0.201 & 0.209 \\
\hline Empathy-CR & 0.252 & 0.171 & 0.239 \\
\hline \multicolumn{4}{|l|}{ Behavior Domain } \\
\hline Altruistic Behavior-CR & 0.230 & 0.159 & 0.228 \\
\hline Altruistic Behavior-PCR & 0.239 & 0.154 & 0.210 \\
\hline Altruistic Behavior-TRS & 0.423 & 0.282 & 0.573 \\
\hline Positive Social Behavior-PCR & 0.147 & 0.218 & 0.156 \\
\hline Positive Social Behavior-TRS & 0.188 & 0.467 & 0.395 \\
\hline Problem Behavior-CR & 0.137 & 0.138 & 0.213 \\
\hline Problem Behavior-PCR & 0.194 & 0.173 & 0.156 \\
\hline Problem Behavior-TRS & 0.181 & 0.419 & 0.230 \\
\hline ADHD-Related Behavior-TRS & 0.172 & 0.440 & 0.230 \\
\hline \multicolumn{4}{|l|}{ Academics Domain } \\
\hline Engagement with Learning-CR & 0.140 & 0.178 & 0.138 \\
\hline Academic Competence and Motivation-TRS & 0.217 & 0.169 & 0.312 \\
\hline \multicolumn{4}{|l|}{ Perceptions of School Climate Domain } \\
\hline Positive School Orientation-CR & 0.196 & 0.611 & 0.709 \\
\hline Negative School Orientation-CR & 0.256 & 0.332 & 0.246 \\
\hline Student Afraid at School-CR & 0.174 & 0.142 & 0.249 \\
\hline Victimization at School-CR & 0.164 & 0.151 & 0.252 \\
\hline Feelings of Safety-TRCS & 0.652 & 1.040 & 1.034 \\
\hline Student Support for Teachers-TRCS & 0.792 & 0.937 & 0.913 \\
\hline
\end{tabular}

NOTE: Abbreviations are

CR: Child Report

PCR: Primary Caregiver Report

TRS: Teacher Report on Student

TRCS: Teacher Report on Classroom and School

ADHD: Attention deficit hyperactivity disorder

The minimum detectable effect (MDE) formula used in the calculations is as follows:

$M D E=\operatorname{factor}(d f) * \sqrt{\rho_{1}\left(\frac{1}{s_{T}}+\frac{1}{s_{C}}\right)+\left(1-\rho_{1}\right)\left(\frac{1}{s_{T} n_{T}}+\frac{1}{s_{C} n_{C}}\right)}$

where $s_{T}$ and $s_{C}$ are the number of treatment and comparison schools; $n_{T}$ and $n_{C}$ are the average number of students per classroom; $\rho_{1}$ is the intraclass correlation (ICC) at the school level; and factor(df) is a constant that depends on the number of degrees of freedom ( $d f$ ) available for analysis (and is 2.802 for the pooled analysis).

SOURCE: The Social and Character Development (SACD) Research Program. 


\section{Chapter 6. Promoting Alternative Thinking Strategies (PATHS)}

Table 6.18 provides the estimates of the PATHS program's impacts on each of the 20 outcome measures over each of the 3 years ( 60 impacts in total, with 3 expected to be statistically significant by chance). Of the 60 results, none were statistically significant. In Year 3, substantively important but nonsignificant detrimental impacts were found for Altruistic Behavior (Teacher Report on Student, effect size [ES] = -0.31) and Feelings of Safety (Teacher Report on Classroom and School, ES = -0.29). Application of the heuristics to adjust for multiple comparisons within each outcome domain indicates a statistically significant detrimental effect on the Social and Emotional Competence domain in Year 2 and a statistically significant detrimental effect on the Academics domain in Year 3. 
Table 6.18. Impacts on child and school outcomes-PATHS

\begin{tabular}{|c|c|c|c|c|c|c|c|c|c|c|c|c|}
\hline \multirow[b]{2}{*}{ Scale-Report } & \multicolumn{4}{|c|}{$\begin{array}{c}\text { Year } 1 \\
\text { (Spring 3rd grade) }\end{array}$} & \multicolumn{4}{|c|}{$\begin{array}{c}\text { Year } 2 \\
\text { (Spring 4th grade) }\end{array}$} & \multicolumn{4}{|c|}{$\begin{array}{c}\text { Year } 3 \\
\text { (Spring 5th grade) }\end{array}$} \\
\hline & $\begin{array}{r}\text { Treat- } \\
\text { ment }\end{array}$ & Control & $\begin{array}{r}\text { Effect } \\
\text { size }\end{array}$ & $p$-value & $\begin{array}{r}\text { Treat- } \\
\text { ment }\end{array}$ & Control & $\begin{array}{r}\text { Effect } \\
\text { size }\end{array}$ & $p$-value & $\begin{array}{r}\text { Treat- } \\
\text { ment }\end{array}$ & Control & $\begin{array}{c}\text { Effect } \\
\text { size }\end{array}$ & $p$-value \\
\hline \multicolumn{13}{|l|}{ Social and Emotional Competence Domain ${ }^{1}$} \\
\hline Self-Efficacy for Peer Interactions-CR (+) & 3.06 & 3.06 & 0.01 & 0.953 & 3.18 & 3.28 & -0.16 & 0.261 & 3.21 & 3.30 & -0.16 & 0.238 \\
\hline Normative Beliefs About Aggression-CR (-) & 1.21 & 1.23 & -0.05 & 0.606 & 1.26 & 1.37 & -0.17 & 0.214 & 1.41 & 1.42 & -0.01 & 0.951 \\
\hline Empathy-CR (+) & 2.38 & 2.34 & 0.10 & 0.493 & 2.21 & 2.14 & 0.13 & 0.245 & 2.09 & 2.11 & -0.03 & 0.851 \\
\hline \multicolumn{13}{|l|}{ Behavior Domain } \\
\hline Altruistic Behavior-CR (+) & 1.25 & 1.13 & 0.15 & 0.320 & 1.00 & 0.96 & 0.06 & 0.635 & 0.98 & 0.98 & 0.00 & 0.991 \\
\hline Altruistic Behavior-PCR (+) & 2.15 & 2.13 & 0.03 & 0.827 & 2.06 & 2.19 & -0.16 & 0.140 & 2.12 & 2.16 & -0.06 & 0.665 \\
\hline Altruistic Behavior-TRS (+) & 1.26 & 1.25 & 0.02 & 0.932 & 1.22 & 1.18 & 0.17 & 0.395 & 1.27 & 1.37 & $-0.31^{\circ}$ & 0.485 \\
\hline Positive Social Behavior-PCR (+) & 2.96 & 3.03 & -0.13 & 0.159 & 3.05 & 3.06 & -0.01 & 0.953 & 3.04 & 3.09 & -0.08 & 0.413 \\
\hline Positive Social Behavior-TRS (+) & 3.01 & 2.98 & 0.05 & 0.590 & 3.14 & 3.04 & 0.15 & 0.503 & 3.18 & 3.14 & 0.06 & 0.778 \\
\hline Problem Behavior-CR (-) & 0.22 & 0.27 & -0.10 & 0.220 & 0.27 & 0.30 & -0.06 & 0.547 & 0.43 & 0.37 & 0.12 & 0.385 \\
\hline Problem Behavior-PCR (-) & 1.57 & 1.54 & 0.10 & 0.383 & 1.53 & 1.53 & 0.00 & 0.987 & 1.53 & 1.55 & -0.04 & 0.714 \\
\hline Problem Behavior-TRS (-) & 1.44 & 1.42 & 0.03 & 0.677 & 1.42 & 1.42 & 0.01 & 0.957 & 1.36 & 1.43 & -0.14 & 0.229 \\
\hline ADHD-Related Behavior-TRS (-) & 1.75 & 1.79 & -0.07 & 0.417 & 1.62 & 1.70 & -0.13 & 0.574 & 1.55 & 1.69 & -0.22 & 0.126 \\
\hline \multicolumn{13}{|l|}{ Academics Domain ${ }^{2}$} \\
\hline Engagement with Learning-CR (+) & 3.73 & 3.70 & 0.05 & 0.657 & 3.70 & 3.69 & 0.01 & 0.954 & 3.61 & 3.66 & -0.11 & 0.296 \\
\hline $\begin{array}{l}\text { Academic Competence and Motivation- } \\
\text { TRS }(+)\end{array}$ & 3.13 & 3.11 & 0.02 & 0.831 & 2.95 & 3.05 & -0.09 & 0.272 & 3.11 & 3.03 & 0.08 & 0.621 \\
\hline
\end{tabular}


Table 6.18. Impacts on child and school outcomes-PATHS-Continued

\begin{tabular}{|c|c|c|c|c|c|c|c|c|c|c|c|c|}
\hline \multirow[b]{2}{*}{ Scale-Report } & \multicolumn{4}{|c|}{$\begin{array}{c}\text { Year } 1 \\
\text { (Spring 3rd grade) }\end{array}$} & \multicolumn{4}{|c|}{$\begin{array}{c}\text { Year 2 } \\
\text { (Spring 4th grade) } \\
\end{array}$} & \multicolumn{4}{|c|}{$\begin{array}{c}\text { Year } 3 \\
\text { (Spring 5th grade) }\end{array}$} \\
\hline & $\begin{array}{r}\text { Treat- } \\
\text { ment }\end{array}$ & Control & $\begin{array}{r}\text { Effect } \\
\text { size }\end{array}$ & $p$-value & $\begin{array}{r}\text { Treat- } \\
\text { ment }\end{array}$ & Control & $\begin{array}{r}\text { Effect } \\
\text { size }\end{array}$ & $p$-value & $\begin{array}{r}\text { Treat- } \\
\text { ment }\end{array}$ & Control & $\begin{array}{r}\text { Effect } \\
\text { size }\end{array}$ & $p$-value \\
\hline \multicolumn{13}{|l|}{ Perceptions of School Climate Domain } \\
\hline Positive School Orientation-CR (+) & 2.96 & 2.98 & -0.03 & 0.826 & 2.79 & 2.67 & 0.15 & 0.640 & 2.66 & 2.66 & 0.00 & 0.997 \\
\hline Negative School Orientation-CR (-) & 1.76 & 1.81 & -0.08 & 0.587 & 1.87 & 1.90 & -0.05 & 0.765 & 1.93 & 2.04 & -0.19 & 0.214 \\
\hline Student Afraid at School-CR (-) & 2.17 & 2.18 & -0.01 & 0.945 & 2.08 & 2.09 & -0.01 & 0.909 & 2.09 & 2.28 & -0.22 & 0.180 \\
\hline Victimization at School-CR (-) & 0.68 & 0.65 & 0.04 & 0.681 & 0.65 & 0.56 & 0.12 & 0.306 & 0.71 & 0.57 & 0.20 & 0.284 \\
\hline Feelings of Safety-TRCS $(+)$ & 3.28 & 3.30 & -0.02 & 0.932 & 3.36 & 3.18 & 0.20 & 0.615 & 3.19 & 3.40 & $-0.29^{\circ}$ & 0.582 \\
\hline Student Support for Teachers-TRCS (+) & 3.54 & 3.53 & 0.01 & 0.980 & 3.52 & 3.46 & 0.07 & 0.838 & 3.57 & 3.70 & -0.20 & 0.631 \\
\hline
\end{tabular}

- Substantive (but nonsignificant at .05 level) effect size of $\geq .25$ or $\leq-.25$.

1 Impact on domain found statistically significant and detrimental in Year 2 based on the fourth heuristic in which the statistical model used to estimate impacts on the individual outcomes was re-estimated using a composite of all the outcome variables under a domain. The domain was found significant if the impact on the composite was significant. The composite was formed by standardizing each outcome variable using its standard deviation, combining the values of the outcome variables, and taking the average of the final value. ${ }^{2}$ Impact on domain found statistically significant and detrimental in Year 3 based on the fourth heuristic in which the statistical model used to estimate impacts on the individual outcomes was re-estimated using a composite of all the outcome variables under a domain. The domain was found significant if the impact on the composite was significant. The composite was formed by standardizing each outcome variable using its standard deviation, combining the values of the outcome variables, and taking the average of the final value. NOTE: Abbreviations are

PCR: Primary Caregiver Report

TRS: Teacher Report on Stud

TRCS: Teacher Report on Student

RCS. Teacher Report on Classroom and Schoo

ADHD: Attention deficit hyperactivity disorder

No findings were found statistically significant at or below the .05 level. The $+/$ - signs in parentheses indicate the direction of a beneficial outcome. All impact estimates were calculated using regression models where each program and school within a program was weighted equally. The standard errors of all estimates account for design effects due to unequal weighting and the clustering of students within schools. See table 1.5 for information about the measured used to create the outcome variables. The effect size was calculated by dividing the estimated impact by the standard deviation of the outcome measure for the control group.

SOURCE: The Social and Character Development (SACD) Research Program. 


\section{Impacts on Child Outcomes Over Time}

The PATHS program's impacts on the child outcomes over time were estimated using growth curve models by examining treatment and control group differences in the trajectories of student outcomes during the follow-up period while accounting for clustering at the school level. The growth curve models are estimated using a three-level hierarchical linear model, where Level 1 corresponds to time, Level 2 to students, and Level 3 to schools.

Table 6.19 provides the estimates of the PATHS program's impacts on the growth in student outcome measures over the 3 years. The estimated impacts ranged in effect size units (absolute value) from 0.01 to 0.12. One of the 18 estimated PATHS intervention impacts on the trajectories of child outcomes was statistically significant (no more than expected by chance); this was Academic Competence and Motivation (Teacher Report on Student, ES = 0.08). 
Table 6.19. Impacts on growth of child outcomes-PATHS

\begin{tabular}{|c|c|c|c|c|c|c|c|}
\hline \multirow[b]{2}{*}{ Scale-Report } & \multirow[b]{2}{*}{$\begin{array}{r}\text { Mean score at } \\
\text { implementation }\end{array}$} & \multicolumn{6}{|c|}{ Average growth in the score per year ${ }^{1}$} \\
\hline & & Treatment & Control & $\begin{array}{r}\text { Impact on } \\
\text { growth }^{3}\end{array}$ & $\begin{array}{l}\text { Effect } \\
\text { size }^{4}\end{array}$ & $\begin{array}{r}\text { Standard } \\
\text { error of } \\
\text { impact } \\
\end{array}$ & $\begin{array}{r}p \text {-value of } \\
\text { impact }\end{array}$ \\
\hline \multicolumn{8}{|l|}{ Social and Emotional Competence Domain } \\
\hline Self-Efficacy for Peer Interactions-CR (+) & 2.94 & 0.13 & 0.14 & -0.01 & -0.02 & 0.03 & 0.693 \\
\hline Normative Beliefs About Aggression-CR (-) & 1.17 & 0.11 & 0.08 & 0.03 & 0.07 & 0.04 & 0.512 \\
\hline Empathy-CR (+) & 2.44 & -0.18 & -0.13 & -0.05 & -0.12 & 0.04 & 0.179 \\
\hline \multicolumn{8}{|l|}{ Behavior Domain } \\
\hline Altruistic Behavior-CR (+) & 1.35 & -0.22 & -0.13 & -0.09 & -0.07 & 0.06 & 0.187 \\
\hline Altruistic Behavior-PCR (+) & 2.24 & -0.05 & -0.05 & -0.01 & -0.01 & 0.03 & 0.846 \\
\hline Altruistic Behavior-TRS (+) & 1.19 & 0.03 & 0.05 & -0.02 & -0.05 & 0.07 & 0.803 \\
\hline Positive Social Behavior-PCR (+) & 2.96 & 0.05 & 0.04 & 0.01 & 0.01 & 0.02 & 0.698 \\
\hline Positive Social Behavior-TRS (+) & 2.99 & 0.07 & 0.04 & 0.03 & 0.04 & 0.07 & 0.642 \\
\hline Problem Behavior-CR (-) & 0.17 & 0.09 & 0.08 & 0.01 & 0.02 & 0.04 & 0.812 \\
\hline Problem Behavior-PCR (-) & 1.60 & -0.03 & -0.02 & -0.01 & -0.01 & 0.01 & 0.672 \\
\hline Problem Behavior-TRS (-) & 1.38 & 0.00 & 0.01 & 0.00 & -0.01 & 0.02 & 0.852 \\
\hline ADHD-Related Behavior-TRS (-) & 1.81 & -0.09 & -0.06 & -0.03 & -0.03 & 0.04 & 0.535 \\
\hline \multicolumn{8}{|l|}{ Academics Domain } \\
\hline Engagement with Learning-CR (+) & 3.76 & -0.06 & -0.04 & -0.02 & -0.04 & 0.03 & 0.422 \\
\hline Academic Competence and Motivation-TRS (+) & 2.93 & $0.09^{*}$ & -0.02 & 0.11 & 0.08 & 0.05 & 0.048 \\
\hline
\end{tabular}


Table 6.19. Impacts on growth of child outcomes-PATHS-Continued

\begin{tabular}{|c|c|c|c|c|c|c|c|}
\hline \multirow[b]{2}{*}{ Scale-Report } & \multirow[b]{2}{*}{$\begin{array}{r}\text { Mean score at } \\
\text { implementation }^{2}\end{array}$} & \multicolumn{6}{|c|}{ Average growth in the score per year ${ }^{1}$} \\
\hline & & Treatment & Control & $\begin{array}{l}\text { Impact on } \\
\text { growth }^{3}\end{array}$ & $\begin{array}{l}\text { Effect } \\
\text { size }^{4}\end{array}$ & $\begin{array}{r}\text { Standard } \\
\text { error of } \\
\text { impact }\end{array}$ & $\begin{array}{r}p \text {-value of } \\
\text { impact }\end{array}$ \\
\hline \multicolumn{8}{|l|}{ Perceptions of School Climate Domain } \\
\hline Positive School Orientation-CR (+) & 3.24 & -0.25 & -0.22 & -0.04 & -0.05 & 0.06 & 0.552 \\
\hline Negative School Orientation-CR (-) & 1.70 & 0.13 & 0.08 & 0.05 & 0.06 & 0.05 & 0.258 \\
\hline Student Afraid at School-CR (-) & 2.31 & -0.07 & -0.08 & 0.01 & 0.01 & 0.05 & 0.790 \\
\hline Victimization at School-CR (-) & 0.69 & -0.04 & -0.02 & -0.02 & -0.01 & 0.04 & 0.719 \\
\hline
\end{tabular}

* Treatment group significantly different from control group at the .05 level.

${ }^{1}$ Pertains to the estimated slope of the outcome for the treatment or control groups.

${ }^{2}$ The average score at implementation is calculated across treatment and control groups, using regression models for adjustment on covariates.

${ }^{3}$ Estimated difference between the slope of the treatment and control groups.

${ }^{4}$ Effect size: the slope of the treatment group minus the slope of the control group divided by the standard deviation of the outcome for the program's control group (the standard deviation is calculated without accounting for school-level clustering or regression adjustments).

NOTE: Abbreviations are

CR: Child Report

PCR: Primary Caregiver Report

TRS: Teacher Report on Student

ADHD: Attention deficit hyperactivity disorder

The +/- signs in parentheses indicate the direction of a beneficial outcome. All impact estimates were calculated using HLM 6.06. Sample weights were used in all analyses to give (1) each school equal weight in each program (within each time period) and (2) each time period equal weight within the analysis. See table 1.5 for information about the measures used to create the outcome variables.

SOURCE: The Social and Character Development (SACD) Research Program. 


\section{Chapter 6. Promoting Alternative Thinking Strategies (PATHS)}

\section{Summary}

As part of the Social and Character Development (SACD) initiative, researchers at the New York/Minnesota site implemented and evaluated the PATHS program. This program focused on promoting children's selfcontrol, emotional understanding, positive self-esteem, relationships, and interpersonal problem-solving skills. Ten public schools, eight in New York and two in Minnesota, were recruited by the Children's Institute research team and randomly assigned to treatment and control conditions to determine the impact of the PATHS program on social and character development activities in the schools and on the child outcome domains of Social and Emotional Competence, Behavior, Academics, and Perceptions of School Climate.

Analyses of the initial characteristics of the sample (students, caregivers, communities, teachers, and schools) indicated that randomization to treatment and control status produced groups that were relatively similar at the start of the study (with 2 out of 84 comparisons statistically significantly different, fewer than would be expected by chance). The data on the initial level of SACD activity led to two findings. First, treatment teachers reported greater use of and training in SACD activities than control teachers, and they did so more often than would be expected by chance (8 out of 62 comparisons, with 3 expected significant by chance). There are two potential causes for this finding, and the analysis cannot be used to determine whether the reason for such a difference was that the two groups did differ on their initial use of SACD activities (i.e., that randomization did not create similar treatment and control groups) or the fact that the training of all treatment teachers and the implementation of the PATHS program began before the initial data were collected (by 6 weeks) influenced the teacher reports. Because it is likely (though unproven) that the training and implementation affected the teacher reports, these data were not considered appropriate for use as a baseline measure of SACD activities and training in the treatment schools.

Second, these data indicate that the control condition for the SACD project was not a "no treatment" control but a "standard practice" control. Because the control teachers were not affected by the implementation of the SACD programs before data collection, their reports reflected standard practice in the control schools. Standard practice at the control schools included reports of 60 percent to 85 percent of teachers using any SACD activities, 88 percent of teachers using specific materials in conjunction with these activities, 100 percent of teachers using at least one of the specified instructional strategies, and 68 percent of teachers participating in SACD training over the past 12 months.

Analyses of the impacts of the PATHS program on the level of SACD activities in the schools revealed impacts on the use of such activities (39 out of 90) and related materials and strategies (7 out of 87, 1 negative) across the 3 years, and use of more professional development activities for treatment teachers in the first 2 years (6 out of 27). These same measures in the control schools across the 3 years of the study confirmed that use of these activities in the control schools constituted their standard practice.

Of the 20 child-level outcomes representing the four domains of Social and Emotional Competence, Behavior, Academics, and Perceptions of School Climate assessed in each of the 3 years of the study (a total of 60 results), none were statistically significant. A growth curve analysis was used to analyze the change over time in these same outcomes between initial data collection and the final outcome data collection at the end of the study. One of the 18 child-level outcomes assessed showed a significant beneficial impact of the PATHS program.

The SACD evaluation did not find evidence to support the hypothesis that PATHS had beneficial impacts on students' social and character development. Such results could be caused by the inability of the program to cause such change, possibly because the theory of action for the program is incomplete or the activities to carry out that theory are not effective.

However, these results may also be due to the inability of the evaluation to observe such a change due to the control condition, the level of nonparticipation, or the sample size. The control schools continued using their standard SACD activities, and these turned out to be high in quantity and broad in scope. While PATHS had 
a significant positive impact on the amount and types of SACD activities, the resulting difference in the amount of SACD activities between the treatment and control schools may not have been large enough to cause significant differences in the student outcomes. Second, nearly one-half of the students in the sample universe did not take part because of nonconsent or noncompletion of the surveys. As a determination could not be made as to whether the students not taking part significantly differed from those who did take part, the evaluation's results are valid only for the students who took part. If the students not taking part were different, and if they would have responded better to PATHS than to the SACD activities occurring in the control schools, then the evaluation could have underestimated the program's impact. In addition, when looking at the percentages of the sample with data across the 3 study years and the four data sources (table 6.4) there were 6 comparisons out of 16 in which the percentages of data were greater for the treatment reports than for the control reports (all statistically significant differences at the .05 level). How these may have affected the results is not clear, as the differences between those with data and those without cannot be determined. Third, the sample size of 10 schools and the resulting higher MDES compared to those for the multiprogram evaluation may have reduced the likelihood of detecting statistically significant effects. However, it should be noted that 67 percent of the MDES for the 60 outcomes used in the year-by-year analysis were below 0.25 ( $42 \%$ were below 0.20 ). In addition, only 2 of the 60 outcomes were found to be substantively important, and both had detrimental impacts. 
This page is intentionally blank. 


\title{
Chapter 7. The 4Rs Program (Reading, Writing, Respect, and Resolution)
}

\author{
New York University \\ (New York City Site)
}

\section{Intervention}

Researchers at New York University and Fordham University (New York City site) evaluated The 4Rs Program (Reading, Writing, Respect, and Resolution) (4Rs) program as implemented by staff developers from the Morningside Center for Teaching Social Responsibility, the community-based nonprofit organization that developed the program. The 4Rs program integrates the teaching and promotion of social and emotional skills and conflict resolution lessons into the language arts curriculum and aims to create a caring classroom community. Table 7.1 describes the 4Rs program's general characteristics (panel 1), the types of instruction and strategies used (panel 2), the professional development provided for those implementing the program (panel 3), and the social and character development activities (panel 4) and outcomes (panel 5) addressed by the program. The program includes two primary components:

- The 4Rs consists of a comprehensive, seven-unit, 21- to 35-lesson, literacy-based curriculum on conflict resolution and social-emotional learning. Lesson units focus on building community, understanding and dealing with feelings, respecting others and becoming a better listener, standing up for oneself and learning to be assertive, understanding and dealing with conflict, celebrating diversity and countering prejudice, and sustaining a caring community and making a difference. Each unit is based on a high-quality children's book, around which discussions, writing, and role-playing activities are conducted. Teachers engage students in lessons for 1 hour at least once per week over the school year. Teachers are encouraged to model and reinforce social skills throughout the day.

- Teachers receive 25 hours of intensive introductory professional development designed to (a) introduce them to the curricular units and the children's books, specific lessons, and activities tied to each unit; (b) give them an opportunity to practice conflict resolution skills at the adult level through role-play and experiential learning; and (c) inspire them to employ the ideas and skills embodied in the curriculum in their own lives both professionally and personally. This training is followed by ongoing classroom coaching to support teachers in teaching the 4Rs curriculum, with a minimum of 12 contacts in each school year. Ongoing coaching encompasses class lesson modeling and workshops led by a program staff developer, coplanning and teaching of lessons by the teacher and staff developer, and lesson observations and feedback. Staff developers also convene regular conferences with teachers in a one-on-one format or with a group of teachers from one grade. 


\section{Table 7.1. The 4Rs Program (Reading, Writing, Respect, and Resolution)}

Panel 1: General characteristics

Target population

Universal

Program components

Peer: In class

Parent: Contact and involvement

Classroom: Lessons

Schoolwide: None or not major focus

Community: None or not major focus

Training: Pretraining and ongoing

Level of integration

Core curriculum

Flexibility

Manualized: Curriculum guidebook

Adaptability: Less adaptable

See notes at end of table.

Panel 2: Description of instruction and strategies

Classroom

Lessons

Who delivers: Teacher

Activities and tools: Story reading, role-playing, discussions, writing, reflections, sharing exercises, brainstorming, songs, worksheets

Content: Literacy focus; building community, feelings, listening, assertiveness, problem solving, diversity, making a difference

Frequency: 1-hour lessons at least once per week; minimum of 21 lessons

Strategies

Who delivers: Teacher

Activities and tools: Modeling and reinforcement of social skills

Frequency: Daily

Supplement to classroom

Family Connections homework and parent workshops

Schoolwide activities

None

See notes at end of table. 
Table 7.1. The 4Rs Program (Reading, Writing, Respect, and Resolution)—Continued

Panel 3: Professional development

Pre-implementation

Teachers

Content: Course to learn curriculum, improve on own skills, create a vision of community, set consistent Rules, and behavior management

Duration: 25 hours

Other

Content: None

Duration: None

Ongoing consultation

Teachers

Content: Training and support in mediation; negotiation; role-playing; class meetings; behavior management

Duration: Individualized coaching a minimum of 12 times per year; 3-day summer institute Other

Content: None

Duration: None

See notes at end of table.

Panel 4: Activities for SACD goals

\begin{tabular}{lc|ll}
\hline Violence prevention and peace promotion & $\checkmark$ & Risk prevention and health promotion & $\checkmark$ \\
Social and emotional development & $\checkmark$ & Civic responsibility and community service & $\checkmark$ \\
Character education & $\checkmark$ & Behavior management & $\checkmark$ \\
Tolerance and diversity & $\checkmark$ & & \\
\hline
\end{tabular}

See notes at end of table.

Panel 5: SACD outcomes addressed

\begin{tabular}{lc|l}
\hline Engagement with Learning & $\checkmark$ & Empathy \\
Academic Competence and Motivation & $\checkmark$ & Positive School Orientation \\
Altruistic Behavior & & Negative School Orientation \\
Positive Social Behavior & $\checkmark$ & Student Afraid at School \\
Problem Behavior & $\checkmark$ & Victimization at School \\
Self-Efficacy for Peer Interactions & $\checkmark$ & Feelings of Safety \\
Normative Beliefs About Aggression & $\checkmark$ & Student Support for Teachers \\
\hline
\end{tabular}

NOTE: Abbreviations are

$\checkmark$ : Activity or outcome addressed

Blank cell: Activity or outcome not addressed

SOURCE: The Social and Character Development (SACD) Research Program. 


\section{Sample and Random Assignment}

The New York City research team recruited a total of 14 public elementary schools in eight school districts in four boroughs in New York City. ${ }^{51}$ These 14 schools were randomly assigned to treatment and control conditions prior to the fall 2004 data collection. A two-step process was used. First, a computer-generated pairwise matching algorithm developed by Mathematica Policy Research, Inc. (MPR) was used to identify the best pairwise matches across the 14 schools based on variables identified by the New York University research team. The variables used in the pairwise matching for the New York City site included the following: (a) average spending per student, (b) percentage of part-time special education students, (c) percentage of students at level on the English language arts standardized achievement test, (d) attendance, (e) percentage of students eligible for free school lunch, (f) percentage of students who were recent immigrants, $(\mathrm{g}$ ) number of students, (h) percentage of Hispanic students, (i) percentage of Asian/Other students, (j) percentage of male students, (k) student stability, (l) average days teacher absent, (m) percentage of fully licensed teachers, (n) percentage of teachers with more than 2 years of teaching experience, (o) direct total classroom instruction expenditure, (p) percentage of foreign-born students, (q) Bloomberg School list, (r) No Child Left Behind improvement status school, ( $\mathrm{s}$ ) teacher organizational readiness, and (t) school organizational readiness. In early spring 2004, as part of the initial school recruitment process, organizational readiness was measured by assessing such important school dimensions as principal leadership style, openness of communication, administrative/teacher buy-in, administrative and staff stability, number and degree of other programs, demands on teacher time, and amount of professional development. Second, using a computerbased random number generator, 1 school in each matched pair was assigned to either the intervention or control condition. Seven schools received the 4Rs program and 7 schools acted as control schools and continued to implement the social and character development activities that constituted their standard practice. Assignment to treatment or control condition was at the school level and therefore limited the risk of contamination between treatment and control classrooms.

The original student sample (the cohort of students in the third grade in the 14 schools in fall 2004) numbered 1,202 students (652 treatment and 550 control). Table 7.2 documents the change in the sample over the three spring follow-up data collection periods. Over time, the percentage of new entrants to the cohort increased, eventually making up 33 percent of the sample by the spring of Year 3. There were no statistically significant differences between the treatment and control groups in the number of new entrants. The percentage of the sample made up of the original cohort further declined as students left the schools. By Year 3, approximately 41 percent of the original sample had left.

\footnotetext{
51 The New York University research team recruited 18 schools but only 14 were included in the multiprogram evaluation.
} 
Table 7.2. Sample-4Rs

\begin{tabular}{|c|c|c|c|c|c|c|c|c|c|c|c|c|}
\hline \multirow[b]{2}{*}{ Characteristic } & \multicolumn{3}{|c|}{$\begin{array}{c}\text { Year } 1 \\
\text { (Fall 3rd grade) }\end{array}$} & \multicolumn{3}{|c|}{$\begin{array}{c}\text { Year } 2 \\
\text { (Spring 3rd grade) } \\
\end{array}$} & \multicolumn{3}{|c|}{$\begin{array}{c}\text { Year } 3 \\
\text { (Spring 4th grade) }\end{array}$} & \multicolumn{3}{|c|}{$\begin{array}{c}\text { Year } 4 \\
\text { (Spring 5th grade) } \\
\end{array}$} \\
\hline & Total & $\begin{array}{r}\text { Treat- } \\
\text { ment }\end{array}$ & Control & Total & $\begin{array}{r}\text { Treat- } \\
\text { ment } \\
\end{array}$ & Control & Total & $\begin{array}{r}\text { Treat- } \\
\text { ment } \\
\end{array}$ & Control & Total & $\begin{array}{r}\text { Treat- } \\
\text { ment } \\
\end{array}$ & Control \\
\hline School sample size & 14 & 7 & 7 & 14 & 7 & 7 & 14 & 7 & 7 & 14 & 7 & 7 \\
\hline Student sample size & 1,202 & 652 & 550 & 1,194 & 647 & 547 & 1,109 & 599 & 510 & 1,065 & 556 & 509 \\
\hline Stayers & $\dagger$ & $\dagger$ & $\dagger$ & 1,116 & 603 & 513 & 882 & 469 & 413 & 710 & 373 & 337 \\
\hline New entrants & $\dagger$ & $\dagger$ & $\dagger$ & 78 & 44 & 34 & 227 & 130 & 97 & 355 & 183 & 172 \\
\hline $\begin{array}{l}\text { New entrants as a percent } \\
\text { of spring enrollment }\end{array}$ & $\dagger$ & $\dagger$ & $\dagger$ & 6.5 & 6.8 & 6.2 & 20.5 & 21.7 & 19.0 & 33.3 & 32.9 & 33.8 \\
\hline $\begin{array}{l}\text { Total leavers (from original } \\
\text { cohort) }\end{array}$ & $\dagger$ & $\dagger$ & $\dagger$ & 86 & 49 & 37 & 320 & 183 & 137 & 492 & 279 & 213 \\
\hline $\begin{array}{l}\text { Leavers as percent of fall } \\
2004 \text { enrollment }\end{array}$ & $\dagger$ & $\dagger$ & $\dagger$ & 7.2 & 7.5 & 6.7 & 26.6 & 28.1 & 24.9 & 40.9 & 42.8 & 38.7 \\
\hline $\begin{array}{l}\text { Number of students per } \\
\text { school (mean) }\end{array}$ & 86 & 93 & 79 & 85 & 92 & 78 & 80 & 86 & 73 & 76 & 79 & 73 \\
\hline $\begin{array}{l}\text { Range of number of students } \\
\text { per school }\end{array}$ & $58-149$ & 58-149 & $64-97$ & $58-147$ & $58-147$ & $66-94$ & $46-136$ & $52-136$ & $46-86$ & $43-126$ & $49-126$ & 43-101 \\
\hline
\end{tabular}

per school

NOTE: No statistically significant differences were found between values for treatment and control groups.

SOURCE: The Social and Character Development (SACD) Research Program. 


\section{Implementation}

\section{Training}

The intervention teachers received 25 hours of program implementation training prior to the beginning of the school year (table 7.1, panel 3). On average, teachers received an additional 2.5 days of training during the school year. Onsite coaching occurred throughout the year, with the average school receiving about 1 day per week of staff development visits. Coaching visits typically included a classroom experience (a demonstration lesson by the staff developer, a lesson cofacilitated by the staff developer and the teacher, or a lesson taught by the teacher and observed by the staff developer) and a conference with the teacher for debriefing.

\section{Data Collection}

MPR collected the child, teacher, and school data for the New York City site. Table 7.3 shows the school year milestones and dates of implementation for the New York City site. Data were collected in the fall and spring of the first 2 years and the spring of Year 3. The fall 2004 data collection began on October 18, 2004, and ended on November 19, 2004. The average time frame from the beginning of program implementation to the beginning of fall data collection was 4 weeks. As a result, initial data collection took place after 4Rs implementation began. Therefore, these data provide a measure of the students, teachers, and schools near the beginning of the school year, at a time when the program had been operating for a relatively short period of time. The spring data collection window was from March 21, 2005, to April 15, 2005. The 4Rs program had been implemented for 26 weeks at the time of the spring data collection and for 17 weeks from the end of the fall data collection. Year 2 followed a similar pattern, with implementation occurring at the start of the school year, fall data collection occurring 5 weeks later, and spring data collection occurring 20 weeks after fall data collection (and 29 weeks after the start of implementation). In spring 2007, data collection occurred 29 weeks after the start of implementation. Data collection took from 3 to 5 weeks at each collection point. 
Table 7.3. Data collection dates-4Rs

\begin{tabular}{|c|c|c|c|c|c|}
\hline Data collection schedule & $\begin{array}{c}\text { Year } 1 \\
\text { (Fall 3rd grade) }\end{array}$ & $\begin{array}{c}\text { Year } 1 \\
\text { (Spring 3rd grade) }\end{array}$ & $\begin{array}{c}\text { Year } 2 \\
\text { (Fall 4th grade) }\end{array}$ & $\begin{array}{c}\text { Year } 2 \\
\text { (Spring 4th grade) }\end{array}$ & $\begin{array}{c}\text { Year } 3 \\
\text { (Spring 5th grade) }\end{array}$ \\
\hline School sample size & 14 & 14 & 14 & 14 & 14 \\
\hline \multicolumn{6}{|l|}{ School year dates } \\
\hline First day of school & 9/7/04 & $\dagger$ & $9 / 8 / 05$ & $\dagger$ & 9/5/06 \\
\hline Start of implementation & 9/20/04 & $\dagger$ & First day & $\dagger$ & First day \\
\hline Last day of school & $\dagger$ & $6 / 28 / 05$ & $\dagger$ & $6 / 27 / 06$ & $6 / 27 / 07$ \\
\hline \multicolumn{6}{|l|}{ Data collection } \\
\hline Start & $10 / 18 / 04$ & 3/21/05 & 10/11/05 & $3 / 27 / 06$ & $3 / 26 / 07$ \\
\hline End & $11 / 19 / 04$ & $4 / 15 / 05$ & $11 / 16 / 05$ & $5 / 8 / 06$ & $4 / 26 / 07$ \\
\hline \multicolumn{6}{|l|}{$\begin{array}{l}\text { Calendar weeks from } \\
\text { program implementation } \\
\text { to start of fall } 2004\end{array}$} \\
\hline & 4 & $\dagger$ & $\dagger$ & $\dagger$ & $\dagger$ \\
\hline \multicolumn{6}{|l|}{$\begin{array}{l}\text { Calendar weeks from } \\
\text { start of school to start of } \\
\text { fall } 2004 \text { data collection }\end{array}$} \\
\hline \multirow{2}{*}{\multicolumn{6}{|c|}{$\begin{array}{l}\text { Calendar weeks from end } \\
\text { of fall data collection to } \\
\text { start of Spring data } \\
\text { collection }\end{array}$}} \\
\hline & & & $\dagger$ & 20 & $\dagger$ \\
\hline $\begin{array}{l}\text { Calendar weeks from } \\
\text { program implementation } \\
\text { to start of spring data } \\
\text { collection }\end{array}$ & $\dagger$ & 26 & $\dagger$ & 29 & 29 \\
\hline
\end{tabular}

† Not applicable.

SOURCE: The Social and Character Development (SACD) Research Program. 


\section{Consent Rates, Completion Rates, and Percentage of Sample With Data}

The actual number of student, primary caregiver, and teacher reports available for analysis was smaller than the number in the sample because consent and completion rates were below 100 percent. Primary caregivers had to provide consent before children could complete the Child Report, before their child's teacher could complete the Teacher Report on Student, and before they themselves completed the Primary Caregiver Report. Teachers also had to provide consent before completing the Teacher Report on Classroom and School. There were no statistically significant differences between treatment and control groups in consent rates for any of these reports.

Of those with consent, not all completed their respective reports. Table 7.4 shows the consent rates, completion rates, and percentages of sample with data for each of the four reports over the 3 years. For the Child Report and two teacher reports, completion rates ranged from 91 percent to 100 percent, with two statistically significant differences between treatment and control groups in completion rates. In Year 3, more Child Reports and, in Year 2, more Teacher Reports on Students were completed in the treatment group compared to the control group. For the Primary Caregiver Report, the completion rates dropped over time from 85 percent to 58 percent. There were no statistically significant differences for the Primary Caregiver Report completion rates.

The percentages of the sample with Child Report data ranged from 54 percent to 64 percent over the 3 years, with a statistically significant difference in Year 1, when more students in the treatment group had data compared to the control group. The percentages of students with information from the Teacher Report on Student ranged from 52 percent to 67 percent, with a statistically significant difference between treatment and control conditions in Year 1 favoring the treatment group. The percentages of students with data from the Primary Caregiver Report ranged from 32 percent to 42 percent. In general, this percentage declined over time, although the highest rates were seen in the spring of 2005. There were no statistically significant differences between treatment and control groups for this data. The percentages of teachers with data from the Teacher Report on Classroom and School ranged from 89 percent to 98 percent, with no statistically significant difference between treatment and control teachers. 
Table 7.4. Consent rates, completion rates, and percentage of sample with data from each report-4Rs

\begin{tabular}{|c|c|c|c|c|c|c|c|c|c|c|c|c|}
\hline \multirow[b]{2}{*}{ Report } & \multicolumn{3}{|c|}{$\begin{array}{c}\text { Year } 1 \\
\text { (Fall 3rd grade) }\end{array}$} & \multicolumn{3}{|c|}{$\begin{array}{c}\text { Year } 1 \\
\text { (Spring 3rd grade) }\end{array}$} & \multicolumn{3}{|c|}{$\begin{array}{c}\text { Year } 2 \\
\text { (Spring 4th grade) }\end{array}$} & \multicolumn{3}{|c|}{$\begin{array}{c}\text { Year } 3 \\
\text { (Spring } 5 \text { th grade) }\end{array}$} \\
\hline & Total & $\begin{array}{r}\text { Treat- } \\
\text { ment }\end{array}$ & Control & Total & $\begin{array}{c}\text { Treat- } \\
\text { ment }\end{array}$ & Control & Total & $\begin{array}{c}\text { Treat- } \\
\text { ment }\end{array}$ & Control & Total & $\begin{array}{c}\text { Treat- } \\
\text { ment }\end{array}$ & Control \\
\hline Student sample size & 1202 & 652 & 550 & 1194 & 647 & 547 & 1109 & 599 & 510 & 1065 & 556 & 509 \\
\hline \multicolumn{13}{|l|}{ Child Report (percent) } \\
\hline Primary caregiver consent rate & 56.8 & 58.4 & 54.9 & 61.5 & 64.1 & 58.3 & 66.3 & 67.3 & 65.1 & 64.3 & 64.6 & 64.0 \\
\hline Student completion rate & 96.6 & 95.8 & 97.7 & 96.2 & 97.1 & 95.0 & 92.4 & 93.3 & 91.3 & 97.1 & $98.3^{*}$ & 95.7 \\
\hline Students with data ${ }^{1}$ & 54.9 & 56.0 & 53.6 & 59.1 & $62.3^{*}$ & 55.4 & 61.2 & 62.8 & 59.4 & 62.4 & 63.5 & 61.3 \\
\hline \multicolumn{13}{|l|}{ Primary Caregiver Report (percent) } \\
\hline Primary caregiver consent rate & 47.8 & 49.4 & 46.0 & 52.8 & 54.9 & 50.5 & 58.3 & 58.8 & 57.8 & 57.1 & 56.3 & 58.0 \\
\hline Primary caregiver completion rate & 85.7 & 85.4 & 86.2 & 78.9 & 76.3 & 82.2 & 70.3 & 69.6 & 71.2 & 58.1 & 56.9 & 59.3 \\
\hline Primary caregivers with data ${ }^{1}$ & 41.0 & 42.2 & 39.6 & 41.7 & 41.9 & 41.5 & 41.0 & 40.9 & 41.2 & 33.1 & 32.0 & 34.4 \\
\hline \multicolumn{13}{|l|}{ Teacher Report on Student (percent) } \\
\hline Primary caregiver consent rate ${ }^{2}$ & 56.8 & 58.4 & 54.9 & 61.5 & 64.1 & 58.3 & 66.3 & 67.3 & 65.1 & 64.3 & 64.6 & 64.0 \\
\hline Teacher completion rate & 94.7 & 95.0 & 94.4 & 97.0 & 97.3 & 96.6 & 98.8 & $100.0^{* * *}$ & 97.3 & 99.7 & 99.7 & 99.7 \\
\hline Students with data ${ }^{1}$ & 53.8 & 55.5 & 51.8 & 59.6 & $62.4^{*}$ & 56.3 & 65.5 & 67.3 & 63.3 & 64.1 & 64.4 & 63.9 \\
\hline \multicolumn{13}{|c|}{$\begin{array}{l}\text { Teacher Report on Classroom and School } \\
\text { (3rd- to 5th-grade teachers) (percent) }\end{array}$} \\
\hline Teacher consent rate & 96.3 & 98.0 & 94.5 & 94.8 & 95.0 & 94.6 & 97.2 & 96.8 & 97.6 & 97.0 & 98.9 & 94.9 \\
\hline Teacher completion rate & 96.2 & 93.9 & 98.8 & 95.6 & 93.7 & 97.7 & 100.0 & 100.0 & 100.0 & 99.4 & 98.9 & 100.0 \\
\hline Teachers with data ${ }^{1}$ & 92.7 & 92.0 & 93.4 & 90.6 & 89.0 & 92.4 & 97.2 & 96.8 & 97.6 & 96.4 & 97.8 & 94.9 \\
\hline
\end{tabular}

* Treatment group significantly different from control group at the .05 level.

${ }^{* * *}$ Treatment group significantly different from control group at the .001 level.

${ }^{1}$ Calculated as consent rate $\mathrm{x}$ completion rate.

${ }^{2}$ The primary caregiver consent rates for the Child Report and the Teacher Report on Student are identical, as the primary caregiver gave consent to both together.

SOURCE: The Social and Character Development (SACD) Research Program. 


\section{Chapter 7. The 4Rs Program (Reading, Writing, Respect, and Resolution)}

Responses from students in the original cohort (stayers) and new entrants in the 4Rs sample were examined to investigate possible differences between the two groups in consent rates, completion rates, and the percentages of sample with data that might affect outcome data (table 7.5). In Years 2 and 3, consent rates for the child and the primary caregiver were significantly higher for the stayers than for the new entrants (by 17 to 23 percentage points), which resulted in significantly larger percentages of data on both the Child Report (by 15 to 21 percentage points) and the Teacher Report on Student (by 17 to 23 percentage points). In contrast, more primary caregivers in the new entrants group compared to the stayers completed the Primary Caregiver report (by 9 to 17 percentage points) in all 3 years. 
Table 7.5. Consent rates, completion rates, and percentage of sample with data: Stayers versus new entrants—4Rs

\begin{tabular}{|c|c|c|c|c|c|c|c|c|c|}
\hline \multirow[b]{2}{*}{ Report } & \multicolumn{3}{|c|}{$\begin{array}{c}\text { Year } 1 \\
\text { (Spring 3rd grade) }\end{array}$} & \multicolumn{3}{|c|}{$\begin{array}{c}\text { Year } 2 \\
\text { (Spring 4th grade) }\end{array}$} & \multicolumn{3}{|c|}{$\begin{array}{c}\text { Year } 3 \\
\text { (Spring 5th grade) }\end{array}$} \\
\hline & Total & Stayers & $\begin{array}{r}\text { New } \\
\text { entrants }\end{array}$ & Total & Stayers & $\begin{array}{r}\text { New } \\
\text { entrants }\end{array}$ & Total & Stayers & $\begin{array}{r}\text { New } \\
\text { entrants } \\
\end{array}$ \\
\hline Student sample size & 1,194 & 1,116 & 78 & 1,109 & 882 & 227 & 1,065 & 710 & 355 \\
\hline \multicolumn{10}{|l|}{ Child Report (percent) } \\
\hline Primary caregiver consent rate & 61.5 & 61.8 & 56.4 & 66.3 & $69.7^{* * *}$ & 52.9 & 64.3 & $72.1^{* * *}$ & 48.7 \\
\hline Student completion rate & 96.2 & 96.1 & 97.7 & 92.4 & 92.2 & 93.3 & 97.1 & 96.5 & 98.8 \\
\hline Students with data ${ }^{1}$ & 59.1 & 59.4 & 55.1 & 61.2 & $64.3^{* * *}$ & 49.3 & 62.4 & $69.6^{\star \star *}$ & 48.2 \\
\hline \multicolumn{10}{|l|}{ Primary Caregiver Report (percent) } \\
\hline Primary caregiver consent rate & 52.8 & 53.0 & 50.0 & 58.3 & $60.3^{* *}$ & 50.7 & 57.1 & $61.8^{* * *}$ & 47.6 \\
\hline Primary caregiver completion rate & 78.9 & $77.9^{*}$ & 94.9 & 70.3 & $67.9^{* *}$ & 81.7 & 59.4 & $56.9^{*}$ & 65.7 \\
\hline Primary caregivers with data ${ }^{1}$ & 41.7 & 41.3 & 47.4 & 41.0 & 40.9 & 41.4 & 33.9 & 35.2 & 31.3 \\
\hline \multicolumn{10}{|l|}{ Teacher Report on Student (percent) } \\
\hline Primary caregiver consent rate ${ }^{2}$ & 61.5 & 61.8 & 56.4 & 66.3 & $69.7^{\star \star *}$ & 52.9 & 64.3 & $72.1^{* * *}$ & 48.7 \\
\hline Teacher completion rate & 97.0 & 97.0 & 97.7 & 98.8 & 98.9 & 98.3 & 99.7 & 99.6 & 100.0 \\
\hline Students with data ${ }^{1}$ & 59.6 & 59.9 & 55.1 & 65.5 & $68.9^{* * *}$ & 52.0 & 64.1 & $71.8^{* * *}$ & 48.7 \\
\hline
\end{tabular}

* Stayers significantly different from new entrants at the .05 level.

** Stayers significantly different from new entrants at the .01 level.

*** Stayers significantly different from new entrants at the .001 level.

${ }^{1}$ Calculated as consent rate $\mathrm{x}$ completion rate.

${ }^{2}$ The primary caregiver consent rates for the Child Report and the Teacher Report on Student are identical, as the primary caregiver gave consent to both together.

SOURCE: The Social and Character Development (SACD) Research Program. 


\section{Fidelity of Implementation}

Each year, the seven 4Rs treatment schools were independently rated for quantity and quality of program implementation by two raters from the research team. The global measure of fidelity for the multisite study was used; inter-rater reliability was measured using Cronbach's alpha (0.84 in Year 1, 0.78 in Year 2, and 0.72 in Year 3). The ratings were combined into a single consensus rating and used to identify schools with high implementation fidelity. In Years 1 and 2, two treatment schools and, in Year 3, three treatment schools, were identified as having high fidelity. Cohen's kappa was used as the measure of agreement when identifying schools as high fidelity and it equaled 0.70 in Year 1, 0.59 in Year 2, and 0.30 in Year 3.

\section{Initial Characteristics}

This section examines the initial characteristics of the students, teachers, and schools participating in the 4Rs evaluation. These characteristics were collected from students who were enrolled in the third grade at the study schools in fall 2004, as well as from their primary caregivers and third-grade teachers. In addition, third-, fourth-, and fifth-grade teachers and principals in the study schools provided information about activities related to social and character development in these schools. Documenting the characteristics of students, teachers, and schools and initial measures of key outcomes at a point before the intervention had been operating for an extended period helped to determine whether the random assignment of schools to treatment and control status produced treatment and control groups with similar distributions of observed characteristics. As noted in the following discussion, there were 8 significant differences in the observed characteristics, 7 of which (out of 62 comparisons, with 3 expected to be significant by chance) reflected differences between the treatment and control students, teachers, and schools in the school and classroom use of SACD activities.

\section{Characteristics of Children, Their Families, and Communities}

There were no significant differences between the treatment and control groups in the observed student, caregiver, and community characteristics (table 7.6). For students, the mean age was 8.1 years. The sample contained roughly equal percentages of girls $(52 \%)$ and boys $(48 \%)$. The sample was ethnically diverse, with White non-Hispanic students making up 5 percent of the sample, Black non-Hispanic students making up 41 percent of the sample, and Hispanic students making up 46 percent of the sample.

The sample was also diverse in its levels of family income, education levels of primary caregivers of the children in the sample, and family situation. For the total sample, 58 percent of children lived in a household where the income was 135 percent of the federal poverty level or lower, which is the income threshold for eligibility for free school meals. Twenty-eight percent of primary caregivers had not completed high school. Less than half of the children (48\%) lived with both their mother and their father. There were no significant differences in these characteristics between the treatment and control groups.

The mean values of the outcomes for children's behavior and attitudes as reported by the primary caregiver, child, and teacher at initial data collection in fall 2004 are shown in table 7.7. There were no significant differences between the treatment and control groups. 
Table 7.6. Initial characteristics of children, their families, and communities-4Rs

\begin{tabular}{|c|c|c|c|}
\hline Characteristic & Total & Treatment & Control \\
\hline Student sample size & 493 & 275 & 218 \\
\hline \multicolumn{4}{|l|}{ Student demographics } \\
\hline \multicolumn{4}{|l|}{ Gender (percent) } \\
\hline Male & 48.3 & 49.3 & 47.3 \\
\hline Female & 51.7 & 50.7 & 52.7 \\
\hline \multicolumn{4}{|l|}{ Race/ethnicity (percent) } \\
\hline White (non-Hispanic) & 5.3 & 7.0 & 3.6 \\
\hline Black (non-Hispanic) & 40.5 & 43.4 & 37.6 \\
\hline Hispanic & 45.9 & 43.1 & 48.7 \\
\hline Other & 8.3 & 6.5 & 10.1 \\
\hline Age (in years) (mean) & 8.1 & 8.1 & 8.2 \\
\hline \multicolumn{4}{|l|}{ Primary caregiver and family characteristics } \\
\hline Primary caregiver's age (in years) (mean) & 35.1 & 36.0 & 34.3 \\
\hline \multicolumn{4}{|l|}{ Primary caregiver's race/ethnicity (percent) } \\
\hline White (non-Hispanic) & 7.1 & 7.9 & 6.2 \\
\hline Black (non-Hispanic) & 41.1 & 44.4 & 37.8 \\
\hline Hispanic & 43.4 & 41.0 & 45.8 \\
\hline Other & 8.4 & 6.7 & 10.2 \\
\hline \multicolumn{4}{|l|}{ Primary caregiver's education (percent) } \\
\hline Did not complete high school & 28.0 & 27.2 & 28.8 \\
\hline Completed high school or equivalent & 27.5 & 25.9 & 29.1 \\
\hline Some college & 32.2 & 31.2 & 33.3 \\
\hline Bachelor's or higher degree & 12.3 & 15.8 & 8.8 \\
\hline \multicolumn{4}{|l|}{ Primary caregiver's employment (percent) } \\
\hline Full-time & 38.9 & 37.5 & 40.3 \\
\hline Other & 61.1 & 62.5 & 59.7 \\
\hline \multicolumn{4}{|l|}{ Primary caregiver's marital status (percent) } \\
\hline Married & 40.3 & 41.6 & 39.0 \\
\hline Other & 59.7 & 58.4 & 61.0 \\
\hline Students who live in one household (percent) & 91.7 & 92.1 & 91.4 \\
\hline Number of individuals in household (mean) & 4.7 & 4.6 & 4.9 \\
\hline \multicolumn{4}{|l|}{ Primary caregiver's relationship to child (percent) } \\
\hline Mother (stepmother) & 86.5 & 85.9 & 87.2 \\
\hline Father (stepfather) & 8.6 & 7.3 & 9.8 \\
\hline Other relative/nonrelative & 4.9 & 6.8 & 3.0 \\
\hline
\end{tabular}


Table 7.6. Initial characteristics of children, their families, and communities-4Rs—Continued

\begin{tabular}{|c|c|c|c|}
\hline Characteristic & Total & Treatment & Control \\
\hline \multicolumn{4}{|l|}{ Student lives with (percent) } \\
\hline Mother (stepmother) and father (stepfather) & 47.9 & 46.7 & 49.0 \\
\hline Mother (stepmother) only; father (stepfather) not present & 46.1 & 47.1 & 45.0 \\
\hline Father (stepfather) only; mother (stepmother) not present & 2.9 & 1.9 & 3.9 \\
\hline Other relative/nonrelative, parents not present & 3.2 & 4.3 & 2.0 \\
\hline \multicolumn{4}{|l|}{ Highest education of anyone in household (percent) } \\
\hline Did not complete high school & 21.0 & 18.4 & 23.6 \\
\hline Completed high school or equivalent & 28.9 & 26.9 & 31.0 \\
\hline Some college & 32.6 & 32.3 & 32.9 \\
\hline Bachelor's or higher degree & 17.4 & 22.4 & 12.5 \\
\hline \multicolumn{4}{|l|}{ Total household income (percent) } \\
\hline Less than $\$ 20,000$ & 51.7 & 51.0 & 52.5 \\
\hline$\$ 20,000$ to $\$ 39,999$ & 25.9 & 24.2 & 27.7 \\
\hline$\$ 40,000$ to $\$ 59,999$ & 9.9 & 8.5 & 11.3 \\
\hline$\$ 60,000$ or more & 12.5 & 16.4 & 8.6 \\
\hline Income-to-poverty-threshold ratio-Below 135 percent (percent) & 57.8 & 55.2 & 60.5 \\
\hline Income-to-poverty-threshold ratio-135 to 185 percent (percent) & 19.3 & 20.1 & 18.5 \\
\hline Income-to-poverty-threshold ratio-Above 185 percent (percent) & 22.9 & 24.8 & 21.1 \\
\hline \multicolumn{4}{|l|}{ Alabama Parenting Questionnaire-Poor Monitoring and } \\
\hline Supervision Subscale (mean) & 1.2 & 1.2 & 1.2 \\
\hline \multicolumn{4}{|l|}{ Alabama Parenting Questionnaire-Positive Parenting } \\
\hline Subscale (mean) & 3.5 & 3.5 & 3.5 \\
\hline Confusion, Hubbub, and Order Scale (mean) & 2.2 & 2.1 & 2.2 \\
\hline \multicolumn{4}{|l|}{ Community characteristics (mean) } \\
\hline Community Risks Scale & 2.0 & 1.9 & 2.0 \\
\hline Community Resources Scale & 2.8 & 2.8 & 2.8 \\
\hline Child-Centered Social Control Scale & 2.7 & 2.7 & 2.8 \\
\hline
\end{tabular}

NOTE: No statistically significant differences were found between values for treatment and control groups. Weights, which assign equal weight to each school within the program, were used in producing the treatment, control, and overall means. Statistical tests were conducted using regressions that included program indicators to account for the sample design and adjusted for clustering at the school level.

SOURCE: The Social and Character Development (SACD) Research Program. 
Table 7.7. Mean scores and standard deviations for initial outcome measures of sample-4Rs

\begin{tabular}{|c|c|c|c|c|c|c|c|}
\hline \multirow[b]{2}{*}{ Outcome measure-Report } & \multirow[b]{2}{*}{ Range } & \multicolumn{2}{|c|}{ Total } & \multicolumn{2}{|c|}{ Treatment } & \multicolumn{2}{|c|}{ Control } \\
\hline & & Mean & $S D$ & Mean & $S D$ & Mean & $S D$ \\
\hline \multicolumn{8}{|l|}{ Social and Emotional Competence Domain } \\
\hline Self-Efficacy for Peer Interaction-CR & $1-4$ & 2.9 & 0.7 & 2.9 & 0.6 & 2.9 & 0.7 \\
\hline Normative Beliefs About Aggression-CR & $1-4$ & 1.3 & 0.5 & 1.3 & 0.5 & 1.3 & 0.6 \\
\hline Empathy-CR & $1-3$ & 2.4 & 0.4 & 2.4 & 0.4 & 2.4 & 0.4 \\
\hline \multicolumn{8}{|l|}{ Behavior Domain } \\
\hline Altruistic Behavior-CR & $0-3$ & 1.6 & 0.8 & 1.6 & 0.8 & 1.6 & 0.8 \\
\hline Altruistic Behavior-TRS & $1-4$ & 1.5 & 0.6 & 1.5 & 0.6 & 1.5 & 0.6 \\
\hline Altruistic Behavior-PCR & $1-4$ & 2.3 & 0.8 & 2.4 & 0.8 & 2.3 & 0.8 \\
\hline Positive Social Behavior-TRS & $1-4$ & 2.8 & 0.7 & 2.8 & 0.7 & 2.8 & 0.7 \\
\hline Positive Social Behavior-PCR & $1-4$ & 2.9 & 0.5 & 3.0 & 0.5 & 2.9 & 0.5 \\
\hline Problem Behavior-CR & $0-3$ & 0.4 & 0.5 & 0.3 & 0.5 & 0.4 & 0.6 \\
\hline Problem Behavior-TRS & $1-4$ & 1.5 & 0.5 & 1.5 & 0.6 & 1.4 & 0.4 \\
\hline Problem Behavior-PCR & $1-4$ & 1.5 & 0.3 & 1.5 & 0.3 & 1.5 & 0.3 \\
\hline ADHD-Related Behavior-TRS & $1-4$ & 1.8 & 0.7 & 1.8 & 0.7 & 1.8 & 0.6 \\
\hline \multicolumn{8}{|l|}{ Academics Domain } \\
\hline Academic Competence and Motivation-TRS & $1-5$ & 2.6 & 0.8 & 2.6 & 0.9 & 2.6 & 0.8 \\
\hline Engagement with Learning-CR & $1-4$ & 3.6 & 0.7 & 3.6 & 0.7 & 3.7 & 0.6 \\
\hline \multicolumn{8}{|l|}{ Perceptions of School Climate Domain } \\
\hline Positive School Orientation-CR & $1-4$ & 3.0 & 0.7 & 3.0 & 0.8 & 3.1 & 0.7 \\
\hline Negative School Orientation-CR & $1-4$ & 2.1 & 0.6 & 2.1 & 0.6 & 2.1 & 0.7 \\
\hline Student Afraid at School-CR & $1-4$ & 2.6 & 0.9 & 2.6 & 1.0 & 2.6 & 0.9 \\
\hline Victimization at School-CR & $0-3$ & 0.9 & 0.8 & 0.8 & 0.8 & 0.9 & 0.8 \\
\hline Student sample size-PCR & & \multicolumn{2}{|c|}{497} & \multicolumn{2}{|c|}{228} & \multicolumn{2}{|c|}{269} \\
\hline Student sample size-CR & & \multicolumn{2}{|c|}{521} & \multicolumn{2}{|c|}{238} & \multicolumn{2}{|c|}{283} \\
\hline Student sample size-TRS & & \multicolumn{2}{|c|}{525} & \multicolumn{2}{|c|}{248} & \multicolumn{2}{|c|}{277} \\
\hline
\end{tabular}

NOTE: Abbreviations are

CR: Child Report

PCR: Primary Caregiver Report

TRS: Teacher Report on Student

ADHD: Attention deficit hyperactivity disorder

$S D$ : Standard deviation

No statistically significant differences were found between values for treatment and control groups. Weights, which assign equal weight to each school within the program, were used in producing the treatment, control, and overall means. Statistical tests were conducted using regressions that included program indicators to account for the sample design and adjusted for clustering at the school level. Sample size may differ for some outcomes due to nonresponse.

SOURCE: The Social and Character Development (SACD) Research Program. 


\section{Characteristics of Teachers and Schools}

Table 7.8 describes the third-, fourth-, and fifth-grade teachers at the study schools. Half the members of this sample were White non-Hispanic (50\%), and most were female $(86 \%)$. They had an average of 8.5 years of total teaching experience, and there was a statistically significant difference between the treatment and control groups, with control teachers having more teaching experience than treatment teachers (10 years versus 7 years). The majority of the teachers $(78 \%)$ held an advanced or specialist degree.

Data related to school characteristics were drawn from the Common Core of Data in order to compare treatment and control schools. There were no significant differences between the two groups of schools in terms of student composition (race/ethnicity and school lunch eligibility), number of students enrolled, number of full-time teachers, Title I status, or number of years the principal had been at the school (see table 7.9). In addition, there were no significant differences between treatment and control schools in terms of location (urban, suburban, or rural) or lowest and highest grade offered (these data are not shown in a table).

Table 7.8. Initial characteristics of teachers in sample-4Rs

\begin{tabular}{|c|c|c|c|}
\hline Characteristic & Total & Treatment & Control \\
\hline Teacher sample size & 177 & 92 & 85 \\
\hline \multicolumn{4}{|l|}{ Gender (percent) } \\
\hline Male & 14.4 & 14.8 & 13.9 \\
\hline Female & 85.6 & 85.2 & 86.1 \\
\hline \multicolumn{4}{|l|}{ Race/ethnicity (percent) } \\
\hline White (non-Hispanic) & 50.0 & 47.9 & 52.2 \\
\hline Other & 50.0 & 52.1 & 47.8 \\
\hline Number of years teaching experience (mean) & 8.5 & $7.0^{*}$ & 10.0 \\
\hline Number of years teaching experience in this school (mean) & 5.6 & 5.0 & 6.2 \\
\hline \multicolumn{4}{|l|}{ Type of teaching certificate (percent) } \\
\hline Regular state certificate or advanced professional certificate & 68.0 & 62.4 & 73.5 \\
\hline Other & 32.0 & 37.6 & 26.5 \\
\hline \multicolumn{4}{|l|}{ Education (percent) } \\
\hline Bachelor's degree & 22.0 & 18.7 & 25.2 \\
\hline Advanced degree/other & 78.0 & 81.3 & 74.8 \\
\hline
\end{tabular}

* Treatment group significantly different from control group at the .05 level.

NOTE: Weights, which assign equal weight to each school within the program, were used in producing the treatment, control, and overall means. Statistical tests were conducted using regressions that included program indicators to account for the sample design and adjusted for clustering at the school level. Sample size may differ for some outcomes due to nonresponse.

SOURCE: The Social and Character Development (SACD) Research Program. 
Table 7.9. Initial characteristics of schools in sample-4Rs

\begin{tabular}{|c|c|c|c|}
\hline Characteristic & Total & Treatment & Control \\
\hline School sample size & 14 & 7 & 7 \\
\hline \multicolumn{4}{|l|}{ Student race/ethnicity (percent) } \\
\hline White (non-Hispanic) & 6.7 & 8.8 & 4.6 \\
\hline Black (non-Hispanic) & 47.1 & 47.7 & 46.5 \\
\hline Hispanic & 40.1 & 37.2 & 42.9 \\
\hline Other & 6.1 & 6.3 & 6.0 \\
\hline Students eligible for free or reduced-price lunch (percent) & 85.1 & 85.9 & 84.5 \\
\hline Number of students enrolled (mean) & 604.2 & 608.6 & 599.9 \\
\hline Number of full-time teachers (mean) & 44.2 & 43.4 & 44.8 \\
\hline \multicolumn{4}{|l|}{ Title I status (percent) } \\
\hline Title I eligible school & 92.9 & 85.7 & 100.0 \\
\hline Schoolwide Title I & 76.9 & 83.3 & 71.4 \\
\hline Number of years principal has been at this school (mean) & 6.4 & 7.4 & 5.0 \\
\hline
\end{tabular}

NOTE: No statistically significant differences were found between values for treatment and control groups. Weights, which assign equal weight to each school within the program, were used in producing the treatment, control, and overall means. Statistical tests were conducted using regressions that included program indicators to account for the sample design and adjusted for clustering at the school level. Sample size may differ for some outcomes due to nonresponse.

SOURCE: NCES Common Core of Data (2003-04), the Social and Character Development (SACD) Research Program.

In the Teacher Report on Classroom and School, teachers reported on nine dimensions of school environment (these data are not shown in a table): feelings of safety, adequacy of resources, student support, freedom to teach as desired, affiliation with and ties to colleagues, innovation regarding new approaches to teaching, professional interest, participatory decisionmaking, and work pressure. There were no statistically significant differences between treatment and control schools.

\section{The Level of SACD in the Schools Near the Beginning of the Study}

During the initial data collection, principals and teachers reported on the SACD activities used in the schools and classrooms, the availability of SACD materials, and the professional development provided on SACD. Table 7.10 shows that the majority of the school principals reported activities to promote six social and character development goals: violence prevention and peace promotion (93\%), social and emotional development $(100 \%)$, character education $(100 \%)$, tolerance and diversity $(100 \%)$, risk prevention and health promotion $(93 \%)$, and civic responsibility and community service $(100 \%)$. In addition, 64 percent of the principals reported activities directed toward behavior management. There were no statistically significant differences between the treatment and control schools in the percentages reported by principals, although this may be due to the small principal sample size. Teachers reported on use of these activities in their classrooms, ranging from 38 percent to 84 percent, and there was one significant difference (out of eight comparisons), with more treatment teachers than control teachers reporting the use of Social and Emotional Development activities in their classrooms ( $83 \%$ versus 64\%). With respect to the use of schoolwide activities, 33 percent to 61 percent of teachers reported that their schools used such activities. There was one significant difference here (out of six comparisons), with more control teachers reporting the use of school newspapers or bulletins than treatment teachers ( $54 \%$ versus $33 \%$ ). 
Table 7.10. Principal and teacher initial reports on use of SACD programs or activities in sample-4Rs

\begin{tabular}{crrr}
\hline SACD program or activity & Total & Treatment & Control \\
\hline Principal sample size & 14 & 7 & 7 \\
Teacher sample size & 177 & 92 & 85
\end{tabular}

Principals reporting that school had programs or activities

to promote the following SACD goals (percent)

Violence prevention and peace promotion

$\begin{array}{rrr}92.9 & 100.0 & 85.7 \\ 100.0 & 100.0 & 100.0 \\ 100.0 & 100.0 & 100.0 \\ 100.0 & 100.0 & 100.0 \\ 92.9 & 100.0 & 85.7 \\ 100.0 & 100.0 & 100.0 \\ 64.3 & 57.1 & 71.4 \\ 0.0 & 0.0 & 0.0\end{array}$

Teachers reporting on using programs or activities in their class

to promote the following SACD goals (percent)

Violence prevention and peace promotion

64.4

71.9

56.9

Social and emotional development

73.4

$83.1^{*}$

63.8

Character education

79.3

\section{2}

78.5

Tolerance and diversity

70.6

73.9

67.4

Risk prevention and health promotion

38.0

36.6

39.5

Civic responsibility and community service

60.2

61.7

58.8

Behavior management

84.3

None of the above

Teachers reporting schoolwide use of the following activities to promote SACD (percent)

Morning announcements or videos

School assemblies

School newspapers or bulletins

Special school days

61.4

29.0

36.0

Special events

$\ddagger$ Reporting standards not met. Values suppressed to protect confidentiality.

* Treatment group significantly different from control group at the .05 level.

NOTE: Weights, which assign equal weight to each school within each of the programs and to each program across programs, were used in producing the treatment, control, and overall means. Statistical tests were conducted using regressions that included program indicators to account for the sample design and adjusted for clustering at the school level. Sample size may differ for some outcomes due to nonresponse.

SOURCE: The Social and Character Development (SACD) Research Program. 


\section{Chapter 7. The 4Rs Program (Reading, Writing, Respect, and Resolution)}

Teachers reported using a broad range of teaching materials to support SACD activities (table 7.11), including teacher guides (73\%), student materials (41\%), instructional aids (31\%), giveaways (43\%), and children's literature $(77 \%)$. There was a statistically significant difference (out of seven comparisons) in the use of teacher guides, with more treatment teachers reporting their use than control teachers ( $88 \%$ versus 58\%), and in the use of unspecified SACD materials, with treatment teachers reporting using other types of materials more often than control teachers $(18 \%$ versus $6 \%)$.

Teachers also reported using a wide variety of teaching strategies (table 7.11). All teachers reported using any of the 20 strategies asked about, and teachers used an average of 11.5 of the strategies. There were no significant differences between treatment and control teachers in the use of any of these specific strategies. 
Table 7.11. Teacher initial reports on use of SACD materials and classroom strategies in sample-4Rs

\begin{tabular}{crrr}
\hline SACD material and classroom strategy & Total & Treatment & Control \\
\hline Teacher sample size & 177 & 92 & 85
\end{tabular}

Teachers using the following materials in conjunction with social and character development activities (percent)

Teacher guides (manuals, curricula)

Student materials (workbooks, worksheets)

72.9

$87.5^{* *}$

58.2

Instructional aids (games, software, videos)

41.2

39.6

42.9

Giveaways (bookmarks, stickers)

30.6

37.6

23.7

Children's literature

42.9

38.3

47.6

Other types of materials

77.0

81.7

72.3

Do not use any of the materials listed above

12.0

2.9

$18.2^{*}$

5.7

Teachers using any of the strategies listed below to promote social and character development in the classroom (percent)

100.0

100.0

100.0

Number of strategies (listed below) used by teachers to promote social and character development in the classroom (mean)

Teachers using each of the following strategies to promote social and character development (percent)

Role-playing

Cooperative learning

Peer group discussions

Direct instruction of social and character development

Skill training

Incorporating social and character development into academic curriculum

Parent training

Parent/community involvement in program development or delivery

Mentoring

20.5

Good behavior notes sent home daily or weekly

Presenting role models

Targeted story reading or writing on SACD themes

62.2

Peer mediation

Honor roll for positive behavior

40.3

40.9

39.8

Pledges or recitations on social and character development themes

53.6

45.8

61.3

Guided visualization

25.5

24.2

26.9

38.0

33.3

42.8

Student-led/student-assisted instruction

60.6

\section{5}

56.6

Journaling

75.4

79.4

71.4

Time out for negative behavior

85.5

87.7

83.2

Daily or weekly rewards for positive behavior

87.7

85.0

90.5

$\ddagger$ Reporting standards not met. Values suppressed to protect confidentiality.

* Treatment group significantly different from control group at the .05 level.

** Treatment group significantly different from control group at the .01 level.

NOTE: Weights, which assign equal weight to each school within each of the programs and to each program across programs, were used in producing the treatment, control, and overall means. Statistical tests were conducted using regressions that included program indicators to account for the sample design and adjusted for clustering at the school level. Sample size may differ for some outcomes due to nonresponse.

SOURCE: The Social and Character Development (SACD) Research Program. 
Principals and teachers reported on participation in and amount of SACD training and staff development provided over the previous 12 months (table 7.12). Principals reported higher participation rates ( $71 \%$ versus $70 \%)$ and more hours of training (10.5 versus 9.7) than did teachers. There was a significant difference between percentages of treatment and control teachers who reported participating in SACD training, and this favored the treatment group ( $84 \%$ versus $56 \%$ ). The treatment teachers also reported significantly more training than did the control teachers on two specific SACD activities (out of seven): Social and Emotional Development (51\% versus 17\%) and Character Education (54\% versus 20\%).

\section{Table 7.12. Principal and teacher initial reports on SACD professional development in sample- 4Rs}

SACD professional development
Principal sample size
Teacher sample size
Principals reporting that staff participated in social and character
development training within the past year (percent)
development training within the past year (percent)

Teachers reporting participation in social and character development training within the past 12 months (percent)

Number of hours of social and character development training principals report were provided to each staff person last year (mean)

Number of hours of social and character development training teachers report receiving during the past 12 months (mean)

Teachers reporting receiving training in the past 12 months in the following areas (percent)

Violence prevention and peace promotion

Social and emotional development

Character education

Tolerance and diversity

Risk prevention and health promotion

Civic responsibility and community service

Behavior management

* Treatment group significantly different from control group at the .05 level.

${ }^{* *}$ Treatment group significantly different from control group at the .01 level.

NOTE: Weights, which assign equal weight to each school within each of the programs and to each program across programs, were used in producing the treatment, control, and overall means. Statistical tests were conducted using regressions that included program indicators to account for the sample design and adjusted for clustering at the school level. Sample size may differ for some outcomes due to nonresponse.

SOURCE: The Social and Character Development (SACD) Research Program.

The data on the initial level of SACD activity emphasize that the control condition was a "standard practice" control. Standard practice at the control schools included using SACD activities, materials, and practices, along with professional development, at rates and in types and amounts similar to the treatment schools. For example, the percentages of teachers who reported using programs or activities to promote specific SACD goals ranged from 37 percent to 89 percent in the treatment schools and from 40 percent to 80 percent in the control schools. However, the 7 significant differences between the treatment and control conditions in the use of SACD activities was more than expected by chance ( 3 out of 62 comparisons), and 6 of these cases favored the treatment group. This may reflect the fact that program implementation and program training for staff started before initial data collection. 


\section{Impacts on Use of SACD Activities}

The introduction of the formal 4Rs program would be expected to increase the use of SACD activities in the treatment schools in comparison to the control schools. The analysis of this impact was based on the Teacher Report on Classroom and School. Every spring, third-, fourth-, and fifth-grade teachers provided information through the Teacher Report on Classroom and School about the social and character development activities they used in their classroom. Specifically, information from the TRCS was used to determine the difference between treatment and control teachers in these areas:

1. the use of SACD activities in their classrooms overall and by SACD goal;

2. the use of materials and strategies to implement the SACD activities within classrooms and within the entire school;

3. the use of staff development to support the teachers; and

4. teacher support for SACD efforts in the school and the use of practices conducive to the social and character development of students.

Teacher Report on Classroom and School consent and completion rates (table 7.4) led to 89 percent to 98 percent of all teachers having data for the 3 years. To estimate intervention impacts for each of the outcomes, testing of the statistical significance of the differences in means was used. Preliminary analysis indicated little or no gains in precision from using covariates. Before testing the mean differences, the data were weighted such that each school received equal weight. Standard errors of the impact estimates account for the clustering of teachers within schools. In addition, a set of heuristics was applied to determine whether each outcome domain was statistically significant after adjustments were made for the multiple tests conducted.

\section{Use of Activities}

The percentages of control teachers who reported using any SACD activities in their classrooms ranged from 76 percent to 86 percent over the 3 years (table 7.13, panels 1 and 2). For the six individual SACD goals, the percentages ranged from 47 percent to 67 percent in Year 1, 44 percent to 66 percent in Year 2, and 43 percent to 60 percent in Year 3. Control teachers' use of behavior management activities ranged from 68 percent to 76 percent over this period. The percentages of control teachers who reported using any SACD activities for at least 1 hour per week in their classrooms ranged from 51 percent to 69 percent over the 3 years. For the six individual SACD goals, the percentages ranged from 15 percent to 36 percent in Year 1, 11 percent to 28 percent in Year 2, and 11 percent to 31 percent in Year 3. Control teachers' use of behavior management activities ranged from 37 percent to 54 percent over this period.

For teachers' reported use of any SACD activity, 48 comparisons were made, with 2 expected to be significant by chance. The percentages of treatment teachers using any SACD activity (panel 1) were significantly different from the percentages of control teachers in Year 1 (impact $=15$ percentage points) and Year 3 (impact $=19$ percentage points). Significantly larger percentages of treatment teachers reported using activities targeting violence prevention and peace promotion (impact $=31,19$, and 31 percentage points), social and emotional development (impact $=33,27$, and 24 percentage points), character education (impact $=$ 26,18 , and 26 percentage points), and tolerance and diversity (impact $=25,27$, and 27 percentage points) in all 3 years. In Year 2, there was a significant difference between treatment and control teachers in their use of civic responsibility and community service activities, with more control teachers reporting their use (impact $=$ -16 percentage points). A similar overall pattern was seen in teachers' reported use of these activities for at least 1 hour per week (panel 2). Treatment teachers' use of any SACD activity for at least 1 hour per week was significant in all 3 years (impact $=32,17$, and 24 percentage points). Violence prevention and peace promotion was significantly impacted in Years 2 and 3 (impact $=30$ and 34 percentage points). Impacts on social and emotional development (impact $=31,36$, and 25 percentage points), character education (impact $=$ 29,35 , and 29 percentage points), and tolerance and diversity (impact $=30,34$, and 30 percentage points) 
were found in all 3 years. Civic responsibility and community service was positively significantly impacted in Year 2 (impact $=10$ percentage points). Behavior management was significantly impacted in Year 3 (impact $=$ 29 percentage points). After the heuristics were applied, the domain for engagement in SACD activities showed that the 4Rs program had statistically significant impacts in all 3 years.

For teachers' reported use of any named SACD activity (panels 3 and 4), 42 comparisons were made, with 2 expected to be significant by chance. Several of the impact estimates were statistically significant over the 3 years. This pattern holds for the use of named activities at least 1 hour per week. The use of any named activity was significantly impacted in all 3 years, both overall and for at least 1 hour per week (impacts ranged from 40 to 49 percentage points). Violence prevention and peace promotion was significantly impacted in all 3 years, both overall and for at least 1 hour per week (impacts ranged from 27 to 44 percentage points), as were social and emotional development (impacts ranged from 29 to 43 percentage points), character education (impacts ranged from 31 to 45 percentage points), and tolerance and diversity (impacts ranged from 21 to 49 percentage points). The use of risk prevention and health promotion activities overall and for at least 1 hour per week were significantly impacted in Year 2 (impact $=15$ and 11 percentage points). Civic responsibility and community service was significantly impacted in all 3 years (impact $=10$, 15, and 16 percentage points). The overall impact of the 4Rs program on the domain for engagement in named SACD activities was significant in all 3 years. 
Table 7.13. Impacts on teacher-reported SACD classroom activities-4Rs

Panel 1: Engagement in any activities to promote SACD goals ${ }^{1}$

\begin{tabular}{|c|c|c|c|c|c|c|c|c|c|c|c|c|}
\hline \multirow[b]{2}{*}{ SACD activity } & \multicolumn{4}{|c|}{$\begin{array}{c}\text { Year } 1 \\
\text { (Spring 3rd grade) }\end{array}$} & \multicolumn{4}{|c|}{$\begin{array}{c}\text { Year } 2 \\
\text { (Spring 4th grade) }\end{array}$} & \multicolumn{4}{|c|}{$\begin{array}{c}\text { Year } 3 \\
\text { (Spring 5th grade) }\end{array}$} \\
\hline & $\begin{array}{r}\text { Treat- } \\
\text { ment }\end{array}$ & Control & Impact & $p$-value & $\begin{array}{c}\text { Treat- } \\
\text { ment }\end{array}$ & Control & Impact & $p$-value & $\begin{array}{c}\text { Treat- } \\
\text { ment }\end{array}$ & Control & Impact & $p$-value \\
\hline Teacher sample size & 94 & 88 & & & 91 & 82 & & & 88 & 75 & & \\
\hline $\begin{array}{l}\text { Violence prevention and peace promotion } \\
\text { (percent) }\end{array}$ & $85.2^{*}$ & 53.9 & 31.3 & 0.004 & $76.5^{*}$ & 57.1 & 19.4 & 0.014 & $84.6^{*}$ & 53.3 & 31.3 & 0.000 \\
\hline $\begin{array}{l}\text { Social and emotional development } \\
\text { (percent) }\end{array}$ & $88.2^{*}$ & 55.7 & 32.5 & 0.004 & $80.2^{*}$ & 52.9 & 27.3 & 0.010 & $84.2^{*}$ & 60.1 & 24.1 & 0.012 \\
\hline Character education (percent) & $92.4^{*}$ & 66.9 & 25.5 & 0.007 & $83.4^{*}$ & 65.6 & 17.8 & 0.022 & $83.2^{*}$ & 57.7 & 25.6 & 0.042 \\
\hline Tolerance and diversity (percent) & $80.8^{*}$ & 56.0 & 24.7 & 0.032 & $76.1^{* *}$ & 49.0 & 27.1 & 0.011 & $83.5^{*}$ & 56.9 & 26.6 & 0.001 \\
\hline $\begin{array}{l}\text { Risk prevention and health promotion } \\
\text { (percent) }\end{array}$ & 28.7 & 46.6 & -17.9 & 0.174 & 48.2 & 44.1 & 4.1 & 0.550 & 45.8 & 42.8 & 3.0 & 0.696 \\
\hline $\begin{array}{l}\text { Civic responsibility and community service } \\
\text { (percent) }\end{array}$ & 61.6 & 56.6 & 5.0 & 0.694 & $44.4^{*}$ & 60.5 & -16.1 & 0.050 & 47.9 & 57.4 & -9.5 & 0.355 \\
\hline Any SACD goal (percent) & $97.1^{*}$ & 82.1 & 15.0 & 0.011 & 88.7 & 85.6 & 3.0 & 0.575 & $95.0^{*}$ & 75.6 & 19.4 & 0.017 \\
\hline Behavior management (percent) & 85.1 & 73.9 & 11.2 & 0.196 & $89.7^{\wedge}$ & 75.9 & 13.8 & 0.096 & $80.7^{\wedge}$ & 67.6 & 13.1 & 0.087 \\
\hline
\end{tabular}


Table 7.13. Impacts on teacher-reported SACD classroom activities-4Rs-Continued

Panel 2: Engagement in any activities to promote SACD goals for at least 1 hour per week

\begin{tabular}{|c|c|c|c|c|c|c|c|c|c|c|c|c|}
\hline \multirow[b]{2}{*}{ SACD activity } & \multicolumn{4}{|c|}{$\begin{array}{c}\text { Year } 1 \\
\text { (Spring 3rd grade) }\end{array}$} & \multicolumn{4}{|c|}{$\begin{array}{c}\text { Year } 2 \\
\text { (Spring 4th grade) }\end{array}$} & \multicolumn{4}{|c|}{$\begin{array}{c}\text { Year } 3 \\
\text { (Spring 5th grade) }\end{array}$} \\
\hline & $\begin{array}{c}\text { Treat- } \\
\text { ment }\end{array}$ & Control & Impact & $p$-value & $\begin{array}{r}\text { Treat- } \\
\text { ment }\end{array}$ & Control & Impact & $p$-value & $\begin{array}{r}\text { Treat- } \\
\text { ment }\end{array}$ & Control & Impact & $p$-value \\
\hline Teacher sample size & 94 & 88 & & & 91 & 82 & & & 88 & 75 & & \\
\hline $\begin{array}{l}\text { Violence prevention and peace promotion } \\
\text { (percent) }\end{array}$ & $53.1^{\wedge}$ & 27.0 & 26.2 & 0.053 & $57.7^{*}$ & 27.9 & 29.8 & 0.003 & $55.4^{*}$ & 21.8 & 33.7 & 0.002 \\
\hline $\begin{array}{l}\text { Social and emotional development } \\
\text { (percent) }\end{array}$ & $55.1^{*}$ & 23.7 & 31.4 & 0.006 & $63.8^{*}-1-x-10$ & 27.8 & 36.0 & 0.004 & $54.9^{*}$ & 29.8 & 25.1 & 0.028 \\
\hline Character education (percent) & $65.9^{*}$ & 36.4 & 29.4 & 0.013 & $61.0^{*}$ & 26.1 & 34.9 & 0.000 & $60.4^{*}$ & 31.0 & 29.3 & 0.006 \\
\hline Tolerance and diversity (percent) & $51.7^{*}$ & 21.6 & 30.1 & 0.008 & $56.3^{*}$ & 22.7 & 33.5 & 0.001 & $51.4^{*}$ & 21.8 & 29.6 & 0.001 \\
\hline $\begin{array}{l}\text { Risk prevention and health promotion } \\
\text { (percent) }\end{array}$ & 5.1 & 15.1 & -10.0 & 0.124 & 22.1 & 14.9 & 7.2 & 0.274 & 17.7 & 21.0 & -3.3 & 0.723 \\
\hline $\begin{array}{l}\text { Civic responsibility and community service } \\
\text { (percent) }\end{array}$ & 25.2 & 15.8 & 9.3 & 0.228 & $20.9^{*}$ & 10.7 & 10.2 & 0.044 & 22.1 & 11.1 & 11.0 & 0.147 \\
\hline Any SACD goal (percent) & $82.4^{*}$ & 50.8 & 31.6 & 0.003 & $85.7^{*}$ & 69.0 & 16.7 & 0.023 & $88.1^{*}$ & 63.8 & 24.3 & 0.017 \\
\hline Behavior management (percent) & $70.4^{\wedge}$ & 53.8 & 16.6 & 0.090 & 65.7 & 47.9 & 17.7 & 0.114 & $66.3^{*}$ & 37.2 & 29.1 & 0.015 \\
\hline
\end{tabular}

See notes at end of table. 
Table 7.13. Impacts on teacher-reported SACD classroom activities-4Rs-Continued

Panel 3: Engagement in activities to promote SACD goals linked to named SACD programs ${ }^{2}$

\begin{tabular}{|c|c|c|c|c|c|c|c|c|c|c|c|c|}
\hline \multirow[b]{2}{*}{ SACD activity } & \multicolumn{4}{|c|}{$\begin{array}{c}\text { Year } 1 \\
\text { (Spring 3rd grade) }\end{array}$} & \multicolumn{4}{|c|}{$\begin{array}{c}\text { Year } 2 \\
\text { (Spring 4th grade) }\end{array}$} & \multicolumn{4}{|c|}{$\begin{array}{c}\text { Year } 3 \\
\text { (Spring 5th grade) }\end{array}$} \\
\hline & $\begin{array}{r}\text { Treat- } \\
\text { ment }\end{array}$ & Control & Impact & $p$-value & $\begin{array}{c}\text { Treat- } \\
\text { ment }\end{array}$ & Control & Impact & $p$-value & $\begin{array}{r}\text { Treat- } \\
\text { ment }\end{array}$ & Control & Impact & $p$-value \\
\hline Teacher sample size & 94 & 88 & & & 91 & 82 & & & 88 & 75 & & \\
\hline $\begin{array}{l}\text { Violence prevention and peace promotion } \\
\text { (percent) }\end{array}$ & $42.0^{*}$ & 4.8 & 37.2 & 0.008 & $54.0^{*}$ & 12.4 & 41.6 & 0.000 & $52.4^{*}$ & 8.4 & 44.0 & 0.000 \\
\hline $\begin{array}{l}\text { Social and emotional development } \\
\text { (percent) }\end{array}$ & $46.6^{*}$ & 3.9 & 42.7 & 0.010 & $49.8^{*}$ & 9.3 & 40.5 & 0.000 & $52.9^{*}$ & 12.1 & 40.8 & 0.015 \\
\hline Character education (percent) & $47.7^{*}$ & 3.9 & 43.8 & 0.001 & $53.6^{*}$ & 11.7 & 41.9 & 0.002 & $51.1^{*}$ & 6.6 & 44.6 & 0.004 \\
\hline Tolerance and diversity (percent) & $\ddagger^{*}$ & $\ddagger$ & 31.8 & 0.001 & $48.4^{*}$ & 6.7 & 41.7 & 0.000 & $\ddagger^{*}$ & $\ddagger$ & 49.2 & 0.000 \\
\hline $\begin{array}{l}\text { Risk prevention and health promotion } \\
\text { (percent) }\end{array}$ & 5.9 & 8.7 & -2.9 & 0.719 & $23.0^{*}$ & 8.0 & 15.0 & 0.049 & 16.3 & 10.3 & 6.1 & 0.500 \\
\hline $\begin{array}{l}\text { Civic responsibility and community service } \\
\text { (percent) }\end{array}$ & $\ddagger^{*}$ & $\ddagger$ & 9.6 & 0.032 & $18.2^{*}$ & 3.3 & 14.9 & 0.004 & $\ddagger^{*}$ & $\ddagger$ & 15.8 & 0.040 \\
\hline Any named activity (percent) & $60.0^{*}$ & 12.4 & 47.6 & 0.006 & $66.8^{*}$ & 26.7 & 40.1 & 0.000 & $65.3^{*}$ & 21.9 & 43.4 & 0.013 \\
\hline
\end{tabular}

$\exists \quad$ Any named activity (percent)

See notes at end of table. 
Table 7.13. Impacts on teacher-reported SACD classroom activities-4Rs-Continued

Panel 4: Engagement in activities to promote SACD goals linked to named SACD programs for at least 1 hour per week

\begin{tabular}{|c|c|c|c|c|c|c|c|c|c|c|c|c|}
\hline \multirow[b]{2}{*}{ SACD activity } & \multicolumn{4}{|c|}{$\begin{array}{c}\text { Year } 1 \\
\text { (Spring 3rd grade) }\end{array}$} & \multicolumn{4}{|c|}{$\begin{array}{c}\text { Year } 2 \\
\text { (Spring 4th grade) }\end{array}$} & \multicolumn{4}{|c|}{$\begin{array}{c}\text { Year } 3 \\
\text { (Spring 5th grade) }\end{array}$} \\
\hline & $\begin{array}{c}\text { Treat- } \\
\text { ment }\end{array}$ & Control & Impact & $p$-value & $\begin{array}{c}\text { Treat- } \\
\text { ment }\end{array}$ & Control & Impact & $p$-value & $\begin{array}{c}\text { Treat- } \\
\text { ment }\end{array}$ & Control & Impact & $p$-value \\
\hline Teacher sample size & 94 & 88 & & & 91 & 82 & & & 88 & 75 & & \\
\hline $\begin{array}{l}\text { Violence prevention and peace promotion } \\
\text { (percent) }\end{array}$ & $31.6^{*}$ & 5.1 & 26.5 & 0.033 & $48.8^{*}$ & 9.4 & 39.4 & 0.000 & $\ddagger^{*}$ & $\ddagger$ & 40.4 & 0.005 \\
\hline $\begin{array}{l}\text { Social and emotional development } \\
\text { (percent) }\end{array}$ & $32.8^{*}$ & 4.1 & 28.7 & 0.034 & $45.4^{*}$ & 6.6 & 38.8 & 0.003 & $43.8^{*}$ & 7.3 & 36.6 & 0.020 \\
\hline Character education (percent) & $35.6^{*}$ & 4.2 & 31.4 & 0.006 & $48.2^{*}$ & 7.8 & 40.4 & 0.001 & $48.3^{*}$ & 3.5 & 44.8 & 0.001 \\
\hline Tolerance and diversity (percent) & $\ddagger^{*}$ & $\ddagger$ & 21.3 & 0.012 & $40.0^{*}$ & 3.6 & 36.4 & 0.002 & $\ddagger^{*}$ & $\ddagger$ & 40.1 & 0.001 \\
\hline $\begin{array}{l}\text { Risk prevention and health promotion } \\
\text { (percent) }\end{array}$ & $\ddagger$ & $\ddagger$ & -4.9 & 0.264 & $15.0^{*}$ & 3.7 & 11.4 & 0.018 & 10.1 & 6.8 & 3.3 & 0.660 \\
\hline $\begin{array}{l}\text { Civic responsibility and community service } \\
\text { (percent) }\end{array}$ & $\ddagger^{\wedge}$ & $\ddagger$ & 5.9 & 0.097 & 13.1 & 0.0 & 13.1 & $\dagger$ & 15.8 & 0.0 & 15.8 & $\dagger$ \\
\hline Any named activity (percent) & $48.6^{*}$ & 8.7 & 40.0 & 0.003 & $60.1^{*}$ & 16.5 & 43.6 & 0.000 & $59.1^{*}$ & 10.0 & 49.1 & 0.005 \\
\hline
\end{tabular}

$\stackrel{t}{*} \quad$ Any named activity (percent)

$\dagger$ Not applicable.

¥ Reporting standards not met. Values suppressed to protect confidentiality.

* Treatment group significantly different from control group at the .05 level.

${ }^{\wedge}$ Treatment group significantly different from control group at the .10 to $>.05$ level.

${ }^{1}$ In Year 1 at least half of the impacts were positive and statistically significant and no impact was negative and statistically significant based on univariate statistical tests, the omnibus impact for all the outcomes measured together was positive and statistically significant on the basis of a multivariate statistical test, and at least one outcome remained positive and statistically significant and no outcome was negative and statistically significant after applying the Benjamini-Hochberg (1995) procedure to adjust significance levels downward to account for the multiple testing of impacts. In Years 2 and 3 at least half of the impacts were positive and statistically significant and no impact was negative and statistically significant based on univariate tests, and at least one outcome remained positive and statistically significant and no outcome was negative and statistically significant after applying the Benjamini-Hochberg (1995) procedure to adjust significance levels downward to account for the multiple testing of impacts.

${ }^{2}$ In Years 1 and 3 at least half of the impacts were positive and statistically significant and no impact was negative and statistically significant based on univariate statistical tests, the omnibus impact for all the outcomes measured together was positive and statistically significant on the basis of a multivariate statistical test, and at least one outcome remained positive and statistically significant and no outcome was negative and statistically significant after applying the Benjamini-Hochberg (1995) procedure to adjust significance levels downward to account for the multiple testing of impacts. In Year 2 at least half of the impacts were positive and statistically significant and no impact was negative and statistically significant based on univariate tests, and at least one outcome remained positive and statistically significant and no outcome was negative and statistically significant after applying the Benjamini-Hochberg (1995) procedure to adjust significance levels downward to account for the multiple testing of impacts.

NOTE: Weights, which assign equal weight to each school within the program, were used in producing the treatment, control, and overall means.

SOURCE: The Social and Character Development (SACD) Research Program. 


\section{Use of Materials and Strategies}

For use of materials and strategies to support SACD goals, 87 comparisons were made, with 4 expected to be significant by chance. Several significant impacts were found on treatment teachers' use of SACD materials in all years (table 7.14). In Year 1, there was an effect on the use of teacher guides (impact $=42$ percentage points), which was also seen in Year 2 (impact $=37$ percentage points) and Year 3 (impact $=27$ percentage points). In Year 2, there was an impact on the use of student materials (impact $=27$ percentage points) and another in Year 3 (impact $=15$ percentage points). In Years 2 and 3, there was an impact on the use of children's literature (impact $=24$ and 27 percentage points). In Year 2, control teachers reported significantly greater use of other types of materials (impact $=-18$ percentage points). Regarding use of instructional techniques, there was a significant impact on use of role-playing in all 3 years (impact $=29$, 32, and 18 percentage points). In Year 2, there were significant impacts on the use of direct instruction of SACD (impact $=12$ percentage points) and on incorporating SACD into the academic curriculum (impact $=19$ percentage points). Other impacts were seen on targeted story reading or writing (impact $=11$ percentage points) and student-led/student-assisted instruction (impact $=18$ percentage points). In Year 3, there was an impact on skill training (impact $=11$ percentage points), guided visualization (impact $=21$ percentage points), and the average number of strategies teachers reported (by 1.3 strategies on average). The 4Rs program had significant impacts on the domain of materials and strategies in Years 1 and 3. 
Table 7.14. Impacts on use of SACD classroom materials and teaching strategies-4Rs

\begin{tabular}{|c|c|c|c|c|c|c|c|c|c|c|c|c|}
\hline \multirow[b]{2}{*}{ SACD material and teaching strategy } & \multicolumn{4}{|c|}{$\begin{array}{c}\text { Year } 1 \\
\text { (Spring 3rd grade) } \\
\end{array}$} & \multicolumn{4}{|c|}{$\begin{array}{c}\text { Year } 2 \\
\text { (Spring 4th grade) }\end{array}$} & \multicolumn{4}{|c|}{$\begin{array}{c}\text { Year } 3 \\
\text { (Spring 5th grade) }\end{array}$} \\
\hline & $\begin{array}{c}\text { Treat- } \\
\text { ment } \\
\end{array}$ & Control & Impact & $p$-value & $\begin{array}{c}\text { Treat- } \\
\text { ment } \\
\end{array}$ & Control & Impact & $p$-value & $\begin{array}{r}\text { Treat- } \\
\text { ment }\end{array}$ & Control & Impact & $p$-value \\
\hline Teacher sample size & 94 & 88 & & & 91 & 82 & & & 88 & 75 & & \\
\hline \multicolumn{13}{|l|}{ Use of SACD materials (percent) } \\
\hline Teacher guides (manuals, curricula) & $88.9^{*}$ & 46.9 & 42.0 & 0.001 & $87.6^{*}$ & 51.1 & 36.5 & 0.000 & $81.2^{*}$ & 54.3 & 26.9 & 0.002 \\
\hline Student materials (workbooks or sheets) & 34.3 & 39.0 & -4.7 & 0.621 & $62.5^{*}$ & 35.1 & 27.3 & 0.008 & $59.1^{*}$ & 43.9 & 15.2 & 0.029 \\
\hline Instructional aids (games, software, videos) & 31.3 & 22.3 & 8.9 & 0.233 & 28.0 & 29.5 & -1.6 & 0.825 & $40.0^{\wedge}$ & 25.7 & 14.3 & 0.056 \\
\hline Giveaways (bookmarks, stickers) & 39.0 & 42.7 & -3.7 & 0.530 & $23.3^{\wedge}$ & 36.9 & -13.6 & 0.080 & 42.6 & 56.2 & -13.5 & 0.170 \\
\hline Children's literature & 71.4 & 57.6 & 13.8 & 0.117 & $76.6^{*}$ & 52.5 & 24.0 & 0.023 & $81.1^{*}$ & 54.0 & 27.2 & 0.001 \\
\hline Other types of materials & 9.6 & 7.8 & 1.7 & 0.738 & $3.6^{*}$ & 21.7 & -18.1 & 0.004 & $\ddagger$ & $\ddagger$ & 3.9 & 0.236 \\
\hline Did not use any of these materials & $\ddagger^{*}$ & $\ddagger$ & -16.0 & 0.009 & $6.4^{\wedge}$ & 15.4 & -8.9 & 0.077 & 4.9 & 15.8 & -11.0 & 0.100 \\
\hline \multicolumn{13}{|l|}{ Use of teaching strategies (percent) } \\
\hline Role-playing & $85.9^{*}$ & 57.3 & 28.6 & 0.000 & $94.4^{*}$ & 62.7 & 31.6 & 0.000 & $94.1^{*}$ & 76.3 & 17.9 & 0.020 \\
\hline Cooperative learning & 97.6 & 95.6 & 1.9 & 0.427 & 99.0 & 97.6 & 1.5 & 0.433 & 100.0 & 98.7 & 1.3 & $\dagger$ \\
\hline Peer group discussions & 94.7 & 91.7 & 3.0 & 0.492 & 94.4 & 89.8 & 4.6 & 0.324 & 100.0 & 96.3 & 3.7 & $\dagger$ \\
\hline Direct instruction of SACD & 89.2 & 83.0 & 6.2 & 0.441 & $92.6^{*}$ & 81.0 & 11.6 & 0.006 & $95.3^{\wedge}$ & 83.1 & 12.2 & 0.077 \\
\hline Skill training & 66.2 & 57.4 & 8.7 & 0.282 & 60.7 & 52.8 & 7.9 & 0.327 & $90.4^{*}$ & 79.1 & 11.4 & 0.032 \\
\hline Incorporating SACD into academic & & & & & & & & & & & & \\
\hline curriculum & $87.1^{\wedge}$ & 71.2 & 16.0 & 0.063 & $88.6^{*}$ & 69.4 & 19.1 & 0.007 & 96.1 & 86.1 & 10.1 & 0.116 \\
\hline Parent training & 7.6 & 3.4 & 4.2 & 0.278 & 4.9 & 7.9 & -3.0 & 0.558 & 25.1 & 28.7 & -3.6 & 0.632 \\
\hline Parent/community involvement & 21.2 & 17.2 & 4.0 & 0.551 & 23.2 & 13.7 & 9.4 & 0.231 & 47.4 & 39.8 & 7.6 & 0.318 \\
\hline Mentoring & 30.4 & 28.5 & 1.9 & 0.817 & 35.9 & 34.0 & 1.9 & 0.866 & 54.4 & 49.3 & 5.1 & 0.591 \\
\hline $\begin{array}{l}\text { Good behavior notes sent home daily } \\
\text { or weekly }\end{array}$ & $465^{\wedge}$ & 5.0 & & 0.062 & 553 & 59.4 & -40 & 0650 & & 805 & 72 & 0229 \\
\hline Presenting role models & 60.5 & 65.4 & -4.9 & 0.598 & 63.5 & 72.3 & -8.8 & 0.235 & 78.3 & 77.5 & 0.8 & 0.906 \\
\hline
\end{tabular}


Table 7.14. Impacts on use of SACD classroom materials and teaching strategies-4Rs-Continued

\begin{tabular}{|c|c|c|c|c|c|c|c|c|c|c|c|c|}
\hline \multirow[b]{2}{*}{ SACD material and teaching strategy ${ }^{1}$} & \multicolumn{4}{|c|}{$\begin{array}{c}\text { Year } 1 \\
\text { (Spring 3rd grade) }\end{array}$} & \multicolumn{4}{|c|}{$\begin{array}{c}\text { Year } 2 \\
\text { (Spring 4th grade) }\end{array}$} & \multicolumn{4}{|c|}{$\begin{array}{c}\text { Year } 3 \\
\text { (Spring 5th grade) }\end{array}$} \\
\hline & $\begin{array}{r}\text { Treat- } \\
\text { ment }\end{array}$ & Control & Impact & $p$-value & $\begin{array}{r}\text { Treat- } \\
\text { ment }\end{array}$ & Control & Impact & $p$-value & $\begin{array}{r}\text { Treat- } \\
\text { ment }\end{array}$ & Control & Impact & $p$-value \\
\hline \multicolumn{13}{|l|}{$\begin{array}{l}\text { Use of teaching strategies (percent)- } \\
\text { Continued }\end{array}$} \\
\hline $\begin{array}{l}\text { Targeted story reading or writing on social } \\
\text { and character development themes }\end{array}$ & 94.2 & 85.4 & 8.8 & 0.113 & $98.8^{*}$ & 87.7 & 11.1 & 0.034 & 96.8 & 93.0 & 3.7 & 0.174 \\
\hline Peer mediation & $50.3^{\wedge}$ & 41.7 & 8.6 & 0.085 & 58.3 & 46.5 & 11.8 & 0.249 & 73.4 & 64.1 & 9.3 & 0.126 \\
\hline Honor roll for positive behavior & 40.3 & 56.3 & -15.9 & 0.297 & 49.0 & 56.2 & -7.1 & 0.633 & 68.2 & 69.2 & -1.0 & 0.924 \\
\hline $\begin{array}{l}\text { Pledges or recitations on social and } \\
\text { character development themes }\end{array}$ & 31.9 & 32.9 & -1.0 & 0.905 & 27.1 & 30.7 & -3.6 & 0.693 & 57.3 & 50.5 & 6.8 & 0.361 \\
\hline Guided visualization & 43.8 & 38.7 & 5.1 & 0.324 & 54.5 & 53.2 & 1.3 & 0.889 & $78.2^{*}$ & 57.7 & 20.5 & 0.002 \\
\hline Student-led/student-assisted instruction & 53.7 & 53.8 & -0.1 & 0.993 & $67.8^{*}$ & 50.2 & 17.6 & 0.014 & 82.4 & 76.5 & 5.9 & 0.455 \\
\hline Journaling & 67.4 & 69.0 & -1.5 & 0.865 & $75.6^{\wedge}$ & 61.5 & 14.1 & 0.093 & 85.1 & 77.4 & 7.7 & 0.275 \\
\hline Time out for negative behavior & 89.5 & 86.4 & 3.1 & 0.501 & 79.0 & 82.3 & -3.4 & 0.549 & 91.0 & 82.2 & 8.8 & 0.181 \\
\hline $\begin{array}{l}\text { Daily or weekly rewards for positive } \\
\text { behavior }\end{array}$ & 80.6 & 86.8 & -6.2 & 0.439 & 83.5 & 82.8 & 0.7 & 0.901 & 97.1 & 95.2 & 1.8 & 0.550 \\
\hline Any strategy & 100.0 & 99.0 & 1.0 & $\dagger$ & 100.0 & 100.0 & 0.0 & $\dagger$ & 100.0 & 98.7 & 1.3 & $\dagger$ \\
\hline Number of strategies (mean) & 12.2 & 11.8 & 0.3 & 0.612 & $12.9^{\wedge}$ & 11.8 & 1.1 & 0.073 & $15.6^{*}$ & 14.3 & 1.3 & 0.028 \\
\hline
\end{tabular}

(mean)

‡ Reporting standards not met. Values suppressed to protect confidentiality.

* Treatment group significantly different from control group at the .05 level.

$\wedge$ Treatment group significantly different from control group at the .10 to $>.05$ level.

${ }^{1}$ In Years 1 and 3 and at least one outcome remained positive and statistically significant and no outcome was negative and statistically significant after applying the Benjamini-

Hochberg (1995) procedure to adjust significance levels downward to account for the multiple testing of impacts.

NOTE: Weights, which assign equal weight to each school within the program, were used in producing the treatment, control, and overall means.

SOURCE: The Social and Character Development (SACD) Research Program. 
Regarding the use of schoolwide strategies, 18 comparisons were made between treatment and control teacher reports, with 1 expected to be significant by chance. There were no significant impacts on teacher reports of schools' use of specific schoolwide strategies (these data are not shown in a table).

\section{Participation in Professional Development}

Regarding reported participation in professional development, 27 comparisons were made over 3 years, with 1 expected to be significant by chance. In Year 1, the 4Rs intervention had a statistically significant impact on teachers' participation in professional development training (impact $=40$ percentage points); mean hours of SACD training (by 4.8 hours on average); and training in the specific goals of violence prevention and peace promotion (impact $=25$ percentage points), social and emotional development (impact $=25$ percentage points), character education (impact $=39$ percentage points), and tolerance and diversity (impact $=20$ percentage points) (table 7.15). There was also a significant impact on behavior management training (impact $=19$ percentage points). The impact on mean hours of SACD training remained significant in Year 3 (by 2.5 hours on average). The significant impacts on violence prevention and peace promotion training remained in Year 2 (impact $=19$ percentage points) and Year 3 (impact $=12$ percentage points), as did the impact on social and emotional development and character education in Year 2 (impact $=16$ and 11 percentage points). The impact on tolerance and diversity training was seen again in Year 3 (impact $=17$ percentage points). Significant impact was found on the domain in Years 1 and 3. 
Table 7.15. Impacts on teacher-reported SACD professional development-4Rs

\begin{tabular}{|c|c|c|c|c|c|c|c|c|c|c|c|c|}
\hline \multirow[b]{2}{*}{ SACD professional development ${ }^{1}$} & \multicolumn{4}{|c|}{$\begin{array}{c}\text { Year } 1 \\
\text { (Spring 3rd grade) }\end{array}$} & \multicolumn{4}{|c|}{$\begin{array}{c}\text { Year } 2 \\
\text { (Spring 4th grade) }\end{array}$} & \multicolumn{4}{|c|}{$\begin{array}{c}\text { Year } 3 \\
\text { (Spring 5th grade) }\end{array}$} \\
\hline & $\begin{array}{c}\text { Treat- } \\
\text { ment }\end{array}$ & Control & Impact & $p$-value & $\begin{array}{c}\text { Treat- } \\
\text { ment }\end{array}$ & Control & Impact & $p$-value & $\begin{array}{c}\text { Treat- } \\
\text { ment } \\
\end{array}$ & Control & Impact & $p$-value \\
\hline Teacher sample size & 94 & 88 & & & 91 & 82 & & & 88 & 75 & & \\
\hline SACD training in past 12 months (percent) & $81.6^{*}$ & 41.2 & 40.4 & 0.000 & $63.9^{\wedge}$ & 48.6 & 15.3 & 0.083 & $54.1^{\wedge}$ & 30.7 & 23.4 & 0.052 \\
\hline Hours of SACD training (mean) & $9.3^{*}$ & 4.4 & 4.8 & 0.005 & 7.4 & 4.8 & 2.5 & 0.448 & $\ddagger^{*}$ & $\ddagger$ & 2.5 & 0.037 \\
\hline \multicolumn{13}{|l|}{ Training by goal (percent) } \\
\hline Violence prevention and peace promotion & $44.0^{*}$ & 19.4 & 24.6 & 0.003 & $36.7^{*}$ & 17.4 & 19.3 & 0.031 & $25.0^{*}$ & 12.8 & 12.3 & 0.027 \\
\hline Social and emotional development & $40.8^{*}$ & 15.8 & 25.0 & 0.003 & $32.5^{\star}$ & 16.1 & 16.4 & 0.038 & $22.6^{\wedge}$ & 8.3 & 14.3 & 0.087 \\
\hline Character education & $50.2^{*}$ & 10.9 & 39.4 & 0.003 & $23.2^{*}$ & 12.3 & 10.9 & 0.038 & 20.1 & 9.4 & 10.7 & 0.133 \\
\hline Tolerance and diversity & $27.8^{*}$ & 8.0 & 19.8 & 0.001 & 23.1 & 12.1 & 11.1 & 0.109 & $\ddagger^{*}$ & $\ddagger$ & 17.3 & 0.005 \\
\hline Risk prevention and health promotion & 7.1 & 4.6 & 2.5 & 0.468 & 21.0 & 18.7 & 2.3 & 0.785 & 12.8 & 6.1 & 6.7 & 0.290 \\
\hline Civic responsibility and community service & 10.2 & 5.7 & 4.5 & 0.358 & $\ddagger$ & $\ddagger$ & 6.4 & 0.100 & 7.3 & 7.3 & 0.0 & 0.992 \\
\hline Behavior management & $35.0^{*}$ & 15.9 & 19.1 & 0.042 & 20.4 & 18.8 & 1.6 & 0.774 & 14.9 & 13.4 & 1.4 & 0.796 \\
\hline
\end{tabular}

$\ddagger$ Reporting standards not met. Values suppressed to protect confidentiality.

* Treatment group significantly different from control group at the .05 level.

$\wedge$ Treatment group significantly different from control group at the .10 to $>.05$ level.

In Years 1 and 3 at least one outcome remained positive and statistically significant and no outcome was negative and statistically significant after applying the Benjamini-Hochberg (1995) procedure to adjust significance levels downward to account for the multiple testing of impacts. In Year 1 at least half of the impacts were positive and statistically significant and no impact was negative and statistically significant based on univariate statistical tests.

NOTE: Weights, which assign equal weight to each school within the program, were used in producing the treatment, control, and overall means.

SOURCE: The Social and Character Development (SACD) Research Program. 


\section{Attitudes and Practices}

Teachers reported on their enthusiasm for SACD efforts in their schools (these data are not shown in a table) by indicating enthusiasm, cooperation, or open dislike. They also reported on the SACD practices of teachers and staff members in their schools (these data are not shown in a table). The practices included modeling positive character and behavior traits with students and fellow teachers, involving students in making decisions, giving students a voice in school governance, school encouragement of parent involvement in children's social and character development, and the use of developmentally appropriate discipline strategies rather than punishment for misbehavior. Twenty-seven comparisons were made over 3 years, with 1 expected to be significant by chance. There were no statistically significant impacts on teachers' enthusiasm for SACD efforts or reported SACD practices in their schools in any of the years (these data are not shown in a table). The 4Rs program had no impact on the domain in any year.

\section{Year-by-Year Impacts on Students and Perceptions of School Climate}

The primary research question for the 4Rs evaluation was this:

What is the average effect of the 4Rs program on children's social and emotional competence, behavior, academics, and perceptions of school climate?

The first approach to answering this question was to examine the year-by-year impacts of the 4Rs program on these student and school climate outcomes over the 3 years as the students progressed from third through fifth grades.

Equation (2) (described in chapter 1) was estimated to provide the impacts of the 4Rs program on the 20 outcomes using data from the 14 treatment and control schools. For the 4Rs evaluation, equation (2) excluded the program fixed effects $\left(\theta_{p}\right)$ and included program-specific covariates and random school effects covariates. Table 7.16 lists the covariates used with outcomes from each report in the 4Rs analysis. 
Table 7.16. Covariates used with outcomes from each report for analysis-4Rs

\begin{tabular}{|c|c|c|c|c|}
\hline Potential covariate & $\begin{array}{c}\text { CR } \\
\text { outcome }\end{array}$ & $\begin{array}{c}\text { PCR } \\
\text { outcome }\end{array}$ & $\begin{array}{c}\text { TRS } \\
\text { outcome }\end{array}$ & $\begin{array}{c}\text { TRCS } \\
\text { outcome }\end{array}$ \\
\hline Total number & 10 & 26 & 19 & 6 \\
\hline \multicolumn{5}{|l|}{ Child-reported } \\
\hline Female & $\checkmark$ & $\checkmark$ & $\checkmark$ & \\
\hline Hispanic & $\checkmark$ & $\checkmark$ & $\checkmark$ & \\
\hline Black (non-Hispanic) & $\checkmark$ & $\checkmark$ & $\checkmark$ & \\
\hline Other ethnicity & $\checkmark$ & $\checkmark$ & $\checkmark$ & \\
\hline Age in years & $\checkmark$ & $\checkmark$ & $\checkmark$ & \\
\hline \multicolumn{5}{|l|}{ Scales } \\
\hline Afraid at School & & $\checkmark$ & & \\
\hline \multicolumn{5}{|l|}{ Altruistic Behavior } \\
\hline Empathy & & $\checkmark$ & $\checkmark$ & \\
\hline Engagement with Learning & & & $\checkmark$ & \\
\hline Negative School Orientation & & $\checkmark$ & & \\
\hline Normative Beliefs About Aggression & $\checkmark$ & & $\checkmark$ & \\
\hline \multicolumn{5}{|l|}{ Sense of School as a Community } \\
\hline Problem Behavior & & $\checkmark$ & & \\
\hline \multicolumn{5}{|l|}{ Self-Efficacy for Peer Interactions } \\
\hline Victimization at School & & & $\checkmark$ & \\
\hline \multicolumn{5}{|l|}{ Primary caregiver-reported } \\
\hline Age in years & $\checkmark$ & $\checkmark$ & $\checkmark$ & \\
\hline Completed high school or equivalent & & $\checkmark$ & $\checkmark$ & \\
\hline Some college & & $\checkmark$ & $\checkmark$ & \\
\hline Bachelor's or higher degree & & $\checkmark$ & $\checkmark$ & \\
\hline \multicolumn{5}{|l|}{ Highest level of education in household } \\
\hline \multicolumn{5}{|l|}{ Completed high school or equivalent } \\
\hline \multicolumn{5}{|l|}{ Some college } \\
\hline \multicolumn{5}{|l|}{ Bachelor's or higher degree } \\
\hline Mother present in home life & & & $\checkmark$ & \\
\hline Mother and father present & & & $\checkmark$ & \\
\hline Respondent someone other than mother or father & & & $\checkmark$ & \\
\hline Number of people in household & $\checkmark$ & $\checkmark$ & & \\
\hline Household income: $\$ 20,000$ to $\$ 40,000$ & & $\checkmark$ & & \\
\hline Household income: $\$ 40,000$ to $\$ 60,000$ & & $\checkmark$ & & \\
\hline Household income: More than $\$ 60,000$ & & $\checkmark$ & & \\
\hline Income-to-poverty-threshold ratio: Below 135 percent & & $\checkmark$ & & \\
\hline Income-to-poverty-threshold ratio: $135-185$ percent & & $\checkmark$ & & \\
\hline Full-time employment & & $\checkmark$ & & \\
\hline Part-time employment & & $\checkmark$ & & \\
\hline
\end{tabular}


Table 7.16. Covariates used with outcomes from each report for analysis-4Rs-Continued

\begin{tabular}{|c|c|c|c|c|}
\hline Potential covariate & $\begin{array}{c}\text { CR } \\
\text { outcome }\end{array}$ & $\begin{array}{c}\text { PCR } \\
\text { outcome }\end{array}$ & $\begin{array}{c}\text { TRS } \\
\text { outcome }\end{array}$ & $\begin{array}{c}\text { TRCS } \\
\text { outcome }\end{array}$ \\
\hline \multicolumn{5}{|l|}{ Parental scales } \\
\hline APQ-Poor Monitoring and Supervision Subscale & & $\checkmark$ & & \\
\hline \multicolumn{5}{|l|}{ APQ-Positive Parenting Subscale } \\
\hline \multicolumn{5}{|l|}{ Child-Centered Social Control } \\
\hline Confusion, Hubbub, and Order & & $\checkmark$ & $\checkmark$ & \\
\hline \multicolumn{5}{|l|}{ Community Resources } \\
\hline Community Risk & & $\checkmark$ & & \\
\hline \multicolumn{5}{|l|}{ Parent and Teacher Involvement } \\
\hline \multicolumn{5}{|l|}{ Child scales } \\
\hline \multicolumn{5}{|l|}{ Altruistic Behavior } \\
\hline Positive Social Behavior & $\checkmark$ & & $\checkmark$ & \\
\hline Problem Behavior & $\checkmark$ & $\checkmark$ & & \\
\hline \multicolumn{5}{|l|}{ Teacher-reported } \\
\hline Hispanic & & & & $\checkmark$ \\
\hline Black (non-Hispanic) & & & & $\checkmark$ \\
\hline Other ethnicity & & & & $\checkmark$ \\
\hline Total teaching experience & & & & $\checkmark$ \\
\hline \multicolumn{5}{|l|}{ Total experience in current school } \\
\hline \multicolumn{5}{|l|}{ Regular certificate } \\
\hline \multicolumn{5}{|l|}{ Other certificate } \\
\hline Highest degree-bachelor's & & & & $\checkmark$ \\
\hline \multicolumn{5}{|l|}{ Child scales } \\
\hline \multicolumn{5}{|l|}{ Academic Competence and Motivation } \\
\hline ADHD-Related Behavior & & $\checkmark$ & & \\
\hline \multicolumn{5}{|l|}{ Altruistic Behavior } \\
\hline Positive Social Behavior & & & $\checkmark$ & \\
\hline \multicolumn{5}{|l|}{ Problem Behavior } \\
\hline Parent and Teacher Involvement & & & $\checkmark$ & \\
\hline
\end{tabular}

NOTE: Abbreviations are

CR: Child Report

PCR: Primary Caregiver Report

TRS: Teacher Report on Student

TRCS: Teacher Report on Classroom and School

ADHD: Attention deficit hyperactivity disorder

APQ: Alabama Parenting Questionnaire

$\checkmark$ : Covariate used

Blank cell: Covariate not used

SOURCE: The Social and Character Development (SACD) Research Program. 


\section{Chapter 7. The 4Rs Program (Reading, Writing, Respect, and Resolution)}

To assess the statistical power of the program-level impact estimates, minimum detectable impacts in effect size units (MDES) for each outcome measure were calculated for the 4Rs evaluation (table 7.17). MDES represent the smallest impacts in effect size (standard deviation) units that can be detected with a high probability (80\%). MDES are primarily a function of study sample sizes, the degrees of freedom available for statistical tests, and design effects due to clustering (Schochet 2005). For the 14 schools included in the 4Rs evaluation, the MDES ranged from 0.088 to 0.569 for the child-level outcomes based on the Child, Caregiver, and Teacher Report on Student and from 0.180 to 0.581 for the school climate outcomes based on the Teacher Report on Classroom and School. In general, the MDES for the school climate outcomes were larger than those for the child-level outcomes. 
Table 7.17. Adjusted minimum detectable effect sizes for impact evaluation-4Rs

\begin{tabular}{|c|c|c|c|}
\hline Outcome measure-Report & Year 1 & Year 2 & Year 3 \\
\hline \multicolumn{4}{|l|}{ Social and Emotional Competence Domain } \\
\hline Self-Efficacy for Peer Interaction-CR & 0.250 & 0.090 & 0.090 \\
\hline Normative Beliefs About Aggression-CR & 0.148 & 0.159 & 0.275 \\
\hline Empathy-CR & 0.326 & 0.213 & 0.180 \\
\hline \multicolumn{4}{|l|}{ Behavior Domain } \\
\hline Altruistic Behavior-CR & 0.118 & 0.150 & 0.183 \\
\hline Altruistic Behavior-PCR & 0.130 & 0.109 & 0.164 \\
\hline Altruistic Behavior-TRS & 0.323 & 0.540 & 0.569 \\
\hline Positive Social Behavior-PCR & 0.104 & 0.108 & 0.197 \\
\hline Positive Social Behavior-TRS & 0.268 & 0.117 & 0.354 \\
\hline Problem Behavior-CR & 0.148 & 0.253 & 0.135 \\
\hline Problem Behavior-PCR & 0.104 & 0.108 & 0.161 \\
\hline Problem Behavior-TRS & 0.213 & 0.218 & 0.404 \\
\hline ADHD-Related Behavior-TRS & 0.160 & 0.226 & 0.449 \\
\hline \multicolumn{4}{|l|}{ Academics Domain } \\
\hline Engagement with Learning-CR & 0.202 & 0.195 & 0.169 \\
\hline Academic Competence and Motivation-TRS & 0.159 & 0.303 & 0.335 \\
\hline \multicolumn{4}{|l|}{ Perceptions of School Climate Domain } \\
\hline Positive School Orientation-CR & 0.277 & 0.236 & 0.294 \\
\hline Negative School Orientation-CR & 0.088 & 0.190 & 0.225 \\
\hline Student Afraid at School-CR & 0.218 & 0.235 & 0.137 \\
\hline Victimization at School-CR & 0.157 & 0.116 & 0.218 \\
\hline Feelings of Safety-TRCS & 0.501 & 0.542 & 0.568 \\
\hline Student Support for Teachers-TRCS & 0.180 & 0.581 & 0.343 \\
\hline
\end{tabular}

NOTE: Abbreviations are

CR: Child Report

PCR: Primary Caregiver Report

TRS: Teacher Report on Student

TRCS: Teacher Report on Classroom and School

ADHD: Attention deficit hyperactivity disorder

The minimum detectable effect (MDE) formula used in the calculations is as follows:

$M D E=\operatorname{factor}(d f) * \sqrt{\rho_{1}\left(\frac{1}{s_{T}}+\frac{1}{s_{C}}\right)+\left(1-\rho_{1}\right)\left(\frac{1}{s_{T} n_{T}}+\frac{1}{s_{C} n_{C}}\right)}$

where $s_{T}$ and $s_{C}$ are the number of treatment and comparison schools; $n_{T}$ and $n_{C}$ are the average number of students per classroom; $\rho_{1}$ is the intraclass correlation (ICC) at the school level; and factor(df) is a constant that depends on the number of degrees of freedom ( $d f$ ) available for analysis (and is 2.802 for the pooled analysis).

SOURCE: The Social and Character Development (SACD) Research Program. 


\section{Chapter 7. The 4Rs Program (Reading, Writing, Respect, and Resolution)}

Table 7.18 provides the estimates of the 4Rs program's impacts on each of the 20 outcomes over each of the 3 years (60 impacts in total, with 3 expected to be statistically significant by chance). Of the 60 results, 1 was statistically significant. There was a detrimental impact on Academic Competence and Motivation (Teacher Report on Student, effect size [ES] $=-0.17$ ) in Year 1. In addition, there were substantively important but nonsignificant detrimental impacts on Feelings of Safety (Teacher Report on Classroom and School, ES = -0.42) and Student Support for Teachers (Teacher Report on Classroom and School, ES = -0.35) in Year 3. Application of the heuristics to adjust for multiple comparisons within each outcome domain indicated that 4Rs had a statistically significant detrimental effect on the Social and Emotional Competence domain in Year 3 and on the Behavior domain in Year 1. 
Table 7.18. Impacts on child and school outcomes-4Rs

\begin{tabular}{|c|c|c|c|c|c|c|c|c|c|c|c|c|}
\hline \multirow[b]{2}{*}{ Scale-Report } & \multicolumn{4}{|c|}{$\begin{array}{c}\text { Year } 1 \\
\text { (Spring 3rd grade) }\end{array}$} & \multicolumn{4}{|c|}{$\begin{array}{c}\text { Year } 2 \\
\text { (Spring 4th grade) }\end{array}$} & \multicolumn{4}{|c|}{$\begin{array}{c}\text { Year } 3 \\
\text { (Spring 5th grade) }\end{array}$} \\
\hline & $\begin{array}{c}\text { Treat- } \\
\text { ment }\end{array}$ & \multicolumn{2}{|c|}{$\begin{array}{rr}\text { Effect } \\
\text { Control } & \text { size }\end{array}$} & $p$-value & $\begin{array}{r}\text { Treat- } \\
\text { ment }\end{array}$ & \multicolumn{2}{|c|}{$\begin{array}{cr}\text { Effect } \\
\text { Control } & \text { size }\end{array}$} & $p$-value & $\begin{array}{c}\text { Treat- } \\
\text { ment }\end{array}$ & Control & $\begin{array}{r}\text { Effect } \\
\text { size }\end{array}$ & $p$-value \\
\hline \multicolumn{13}{|l|}{ Social and Emotional Competence Domain ${ }^{1}$} \\
\hline Self-Efficacy for Peer Interactions-CR (+) & 2.96 & 3.04 & -0.13 & 0.359 & 3.10 & 3.12 & -0.04 & 0.598 & 3.15 & 3.21 & -0.08 & 0.338 \\
\hline Normative Beliefs About Aggression-CR (-) & 1.39 & 1.44 & -0.09 & 0.324 & 1.47 & 1.49 & -0.03 & 0.778 & 1.59 & 1.65 & -0.09 & 0.545 \\
\hline Empathy-CR (+) & 2.24 & 2.27 & -0.07 & 0.674 & 2.08 & 2.10 & -0.05 & 0.701 & 1.95 & 2.00 & -0.10 & 0.382 \\
\hline \multicolumn{13}{|l|}{ Behavior Domain ${ }^{2}$} \\
\hline Altruistic Behavior-CR (+) & 1.30 & 1.40 & -0.13 & 0.137 & 1.14 & 1.22 & -0.09 & 0.365 & 1.18 & 1.18 & 0.00 & 0.985 \\
\hline Altruistic Behavior-PCR (+) & 2.38 & 2.38 & 0.00 & 0.989 & 2.36 & 2.43 & -0.11 & 0.270 & 2.33 & 2.43 & -0.13 & 0.375 \\
\hline Altruistic Behavior-TRS (+) & 1.48 & 1.58 & -0.17 & 0.262 & 1.48 & 1.53 & -0.10 & 0.730 & 1.62 & 1.55 & 0.11 & 0.698 \\
\hline Positive Social Behavior-PCR (+) & 2.97 & 2.98 & -0.03 & 0.756 & 3.02 & 3.04 & -0.03 & 0.757 & 3.11 & 3.05 & 0.13 & 0.422 \\
\hline Positive Social Behavior-TRS (+) & 2.81 & 2.78 & 0.03 & 0.788 & 2.84 & 2.90 & -0.08 & 0.310 & 2.81 & 2.81 & -0.01 & 0.969 \\
\hline Problem Behavior-CR (-) & 0.40 & 0.43 & -0.04 & 0.654 & 0.48 & 0.51 & -0.05 & 0.718 & 0.61 & 0.59 & 0.03 & 0.709 \\
\hline Problem Behavior-PCR (-) & 1.55 & 1.51 & 0.11 & 0.223 & 1.51 & 1.53 & -0.04 & 0.720 & 1.52 & 1.53 & -0.01 & 0.916 \\
\hline Problem Behavior-TRS (-) & 1.60 & 1.55 & 0.08 & 0.439 & 1.51 & 1.55 & -0.07 & 0.516 & 1.63 & 1.65 & -0.04 & 0.830 \\
\hline ADHD-Related Behavior-TRS (-) & 1.84 & 1.83 & 0.01 & 0.865 & 1.69 & 1.78 & -0.15 & 0.205 & 1.74 & 1.87 & -0.20 & 0.357 \\
\hline \multicolumn{13}{|l|}{ Academics Domain } \\
\hline $\begin{array}{l}\text { Engagement with Learning-CR (+) } \\
\text { Academic Competence and Motivation- }\end{array}$ & 3.63 & 3.67 & -0.08 & 0.541 & 3.63 & 3.64 & -0.03 & 0.815 & 3.63 & 3.59 & 0.07 & 0.508 \\
\hline TRS $(+)$ & $2.69^{*}$ & 2.84 & -0.17 & 0.032 & 2.80 & 2.88 & -0.10 & 0.513 & 2.73 & 2.89 & -0.16 & 0.309 \\
\hline
\end{tabular}


Table 7.18. Impacts on child and school outcomes—4Rs-Continued

\begin{tabular}{|c|c|c|c|c|c|c|c|c|c|c|c|c|}
\hline \multirow[b]{2}{*}{ Scale-Report } & \multicolumn{4}{|c|}{$\begin{array}{c}\text { Year } 1 \\
\text { (Spring 3rd grade) }\end{array}$} & \multicolumn{4}{|c|}{$\begin{array}{c}\text { Year } 2 \\
\text { (Spring 4th grade) }\end{array}$} & \multicolumn{4}{|c|}{$\begin{array}{c}\text { Year } 3 \\
\text { (Spring 5th grade) }\end{array}$} \\
\hline & $\begin{array}{r}\text { Treat- } \\
\text { ment }\end{array}$ & Control & $\begin{array}{r}\text { Effect } \\
\text { size }\end{array}$ & $p$-value & $\begin{array}{l}\text { Treat- } \\
\text { ment } \\
\end{array}$ & Control & $\begin{array}{r}\text { Effect } \\
\text { size }\end{array}$ & $p$-value & $\begin{array}{r}\text { Treat- } \\
\text { ment } \\
\end{array}$ & Control & $\begin{array}{r}\text { Effect } \\
\text { size }\end{array}$ & $p$-value \\
\hline \multicolumn{13}{|l|}{ Perceptions of School Climate Domain } \\
\hline Positive School Orientation-CR (+) & 2.70 & 2.64 & 0.08 & 0.577 & 2.39 & 2.38 & 0.01 & 0.950 & 2.31 & 2.36 & -0.08 & 0.617 \\
\hline Negative School Orientation-CR (-) & 2.04 & 2.07 & -0.06 & 0.439 & 2.20 & 2.19 & 0.02 & 0.841 & 2.26 & 2.25 & 0.02 & 0.862 \\
\hline Victimization at School-CR (-) & 0.83 & 0.89 & -0.08 & 0.436 & $0.74^{\wedge}$ & 0.87 & -0.17 & 0.069 & 0.75 & 0.78 & -0.04 & 0.785 \\
\hline Feelings of Safety-TRCS (+) & 3.15 & 3.22 & -0.09 & 0.606 & 3.08 & 3.12 & -0.05 & 0.817 & 2.93 & 3.27 & $-0.42^{\circ}$ & 0.146 \\
\hline Student Support for Teachers-TRCS (+) & 3.10 & 3.05 & 0.06 & 0.568 & 3.14 & 3.12 & 0.02 & 0.926 & 3.08 & 3.30 & $-0.35^{\circ}$ & 0.109 \\
\hline
\end{tabular}

* Treatment group significantly different from control group at the .05 level.

$\wedge$ Treatment group significantly different from control group at the .10 to $>.05$ level.

${ }^{\circ}$ Substantive (but nonsignificant at .05 level) effect size of $\geq .25$ or $\leq-.25$.

${ }^{1}$ Impact on domain found statistically significant and detrimental in Year 3 based on the fourth heuristic in which the statistical model used to estimate impacts on the individual outcomes was re-estimated using a composite of all the outcome variables under a domain. The domain was found significant if the impact on the composite was significant. The composite was formed by standardizing each outcome variable using its standard deviation, combining the values of the outcome variables, and taking the average of the final value. ${ }^{2}$ Impact on domain found statistically significant and detrimental in Year 1 based on the fourth heuristic in which the statistical model used to estimate impacts on the individual outcomes was re-estimated using a composite of all the outcome variables under a domain. The domain was found significant if the impact on the composite was significant. The composite was formed by standardizing each outcome variable using its standard deviation, combining the values of the outcome variables, and taking the average of the final value. NOTE: Abbreviations are

CR: Child Report

PCR: Primary Caregiver Report

TRS: Teacher Report on Student

TRCS: Teacher Report on Classroom and School

ADHD: Attention deficit hyperactivity disorder

The +/- signs in parentheses indicate the direction of a beneficial outcome. All impact estimates were calculated using regression models where each program and school within a program was weighted equally. The standard errors of all estimates account for design effects due to unequal weighting and the clustering of students within schools. See table 1.5 for information about the measures used to create the outcome variables. The effect size was calculated by dividing the estimated impact by the standard deviation of the outcome measure for the control group. The number of results found significant was no more than expected by chance.

SOURCE: The Social and Character Development (SACD) Research Program. 


\section{Impacts on Child Outcomes Over Time}

The 4Rs program's impacts on the child outcomes over time were estimated using growth curve models by examining treatment and control group differences in the trajectories of student outcomes during the followup period while accounting for clustering at the school level. The growth curve models are estimated using a three-level hierarchical linear model, where Level 1 corresponds to time, Level 2 to students, and Level 3 to schools (described in chapter 1).

Table 7.19 provides the estimates of the 4Rs program's impacts on the growth in student outcomes over the 3 years. The estimated impacts ranged in effect size units (absolute value) from 0.00 to 0.10 . None of the 18 estimated 4Rs intervention impacts on the trajectories of child outcomes was statistically significantly different from zero at the 5 percent level ( 1 in 18 would be expected to be significant by chance). 
Table 7.19. Impacts on growth of child outcomes-4Rs

\begin{tabular}{|c|c|c|c|c|c|c|c|}
\hline \multirow[b]{2}{*}{ Scale-Report } & \multirow[b]{2}{*}{$\begin{array}{r}\text { Mean score at } \\
\text { implementation }\end{array}$} & \multicolumn{6}{|c|}{ Average growth in the score per year ${ }^{1}$} \\
\hline & & Treatment & Control & $\begin{array}{r}\text { Impact on } \\
\text { growth }^{3} \\
\end{array}$ & $\begin{array}{l}\text { Effect } \\
\text { size }^{4}\end{array}$ & $\begin{array}{r}\text { Standard } \\
\text { error of } \\
\text { impact } \\
\end{array}$ & $\begin{array}{r}p \text {-value of } \\
\text { impact }\end{array}$ \\
\hline \multicolumn{8}{|l|}{ Social and Emotional Competence Domain } \\
\hline Self-Efficacy for Peer Interactions-CR (+) & 2.89 & 0.13 & 0.14 & -0.01 & -0.01 & 0.03 & 0.850 \\
\hline Normative Beliefs About Aggression-CR (-) & 1.31 & 0.13 & 0.13 & -0.01 & -0.01 & 0.04 & 0.840 \\
\hline Empathy-CR (+) & 2.37 & -0.18 & -0.17 & -0.01 & -0.02 & 0.03 & 0.756 \\
\hline \multicolumn{8}{|l|}{ Behavior Domain } \\
\hline Altruistic Behavior-CR (+) & 1.51 & -0.16 & -0.19 & 0.02 & 0.03 & 0.06 & 0.681 \\
\hline Altruistic Behavior-PCR (+) & 2.39 & -0.02 & 0.01 & -0.03 & -0.04 & 0.04 & 0.405 \\
\hline Altruistic Behavior-TRS (+) & 1.46 & 0.07 & 0.00 & 0.07 & 0.10 & 0.10 & 0.475 \\
\hline Positive Social Behavior-PCR (+) & 2.94 & 0.02 & 0.04 & -0.02 & -0.04 & 0.02 & 0.400 \\
\hline Positive Social Behavior-TRS (+) & 2.85 & -0.05 & 0.00 & -0.05 & -0.06 & 0.05 & 0.356 \\
\hline Problem Behavior-CR (-) & 0.36 & $0.12^{\wedge}$ & 0.09 & 0.03 & 0.04 & 0.02 & 0.067 \\
\hline Problem Behavior-PCR (-) & 1.54 & 0.00 & -0.02 & 0.02 & 0.04 & 0.02 & 0.391 \\
\hline Problem Behavior-TRS (-) & 1.47 & 0.06 & 0.11 & -0.04 & -0.09 & 0.05 & 0.361 \\
\hline ADHD-Related Behavior-TRS (-) & 1.77 & 0.01 & 0.05 & -0.04 & -0.05 & 0.05 & 0.464 \\
\hline \multicolumn{8}{|l|}{ Academics Domain } \\
\hline Engagement with Learning-CR (+) & 3.65 & 0.01 & -0.04 & 0.05 & 0.07 & 0.03 & 0.136 \\
\hline Academic Competence and Motivation-TRS (+) & 2.61 & 0.05 & 0.09 & -0.04 & -0.04 & 0.06 & 0.548 \\
\hline
\end{tabular}
See notes at end of table. 
Table 7.19. Impacts on growth of child outcomes-4Rs-Continued

\begin{tabular}{|c|c|c|c|c|c|c|c|}
\hline \multirow[b]{2}{*}{ Scale-Report } & \multirow[b]{2}{*}{$\begin{array}{r}\text { Mean score at } \\
\text { implementation }\end{array}$} & \multicolumn{6}{|c|}{ Average growth in the score per year ${ }^{1}$} \\
\hline & & Treatment & Control & $\begin{array}{l}\text { Impact on } \\
\text { growth }^{3}\end{array}$ & $\begin{array}{l}\text { Effect } \\
\text { size }^{4}\end{array}$ & $\begin{array}{r}\text { Standard } \\
\text { error of } \\
\text { impact }\end{array}$ & $\begin{array}{r}p \text {-value of } \\
\text { impact }\end{array}$ \\
\hline \multicolumn{8}{|l|}{ Perceptions of School Climate Domain } \\
\hline Positive School Orientation-CR (+) & 2.88 & -0.23 & -0.25 & 0.03 & 0.03 & 0.05 & 0.571 \\
\hline Negative School Orientation-CR (-) & 2.05 & 0.08 & 0.09 & 0.00 & 0.00 & 0.05 & 0.947 \\
\hline Student Afraid at School-CR (-) & 2.59 & -0.14 & -0.15 & 0.02 & 0.02 & 0.05 & 0.716 \\
\hline Victimization at School-CR (-) & 0.88 & -0.06 & -0.06 & 0.00 & 0.00 & 0.05 & 0.930 \\
\hline
\end{tabular}

$\wedge$ Treatment group significantly different from control group at the .05 level.

${ }^{1}$ Pertains to the estimated slope of the outcome for the treatment or control groups.

${ }^{2}$ The average score at implementation is calculated across treatment and control groups, using regression models for adjustment on covariates

${ }^{3}$ Estimated difference between the slope of the treatment and control groups.

${ }^{4}$ Effect size: the slope of the treatment group minus the slope of the control group divided by the standard deviation of the outcome for the program's control group (the standard deviation is calculated without accounting for school-level clustering or regression adjustments).

NOTE: Abbreviations are

CR: Child Report

PCR: Primary Caregiver Report

TRS: Teacher Report on Student

ADHD: Attention deficit hyperactivity disorder

No findings were found statistically significant at or below the .05 level. The $+/$ - signs in parentheses indicate the direction of a beneficial outcome. All impact estimates were

calculated using HLM 6.06. Sample weights were used in all analyses to give (1) each school equal weight in each program (within each time period) and (2) each time period equal weight within the analysis. See table 1.5 for information about the measures used to create the outcome variables.

SOURCE: The Social and Character Development (SACD) Research Program. 


\section{Chapter 7. The 4Rs Program (Reading, Writing, Respect, and Resolution)}

\section{Summary}

As part of the Social and Character Development (SACD) initiative, researchers at the New York site evaluated the 4Rs program. This program was designed to integrate the teaching and promoting of social and emotional skills and conflict resolution into the language arts curriculum and to create a caring classroom community. Fourteen public schools in New York City were recruited by the New York research team and randomly assigned to treatment and control conditions to determine the impact of 4Rs on social and character development activities in the schools and on the child outcome domains of Social and Emotional Competence, Behavior, Academics, and Perceptions of School Climate.

Analyses of the initial characteristics of the sample (students, caregivers, communities, teachers, and schools) indicated that randomization to treatment and control status produced groups that were relatively similar at the start of the study (with 1 out of 84 comparisons statistically significantly different, fewer than would be expected by chance). The data on the initial level of SACD activity led to two findings. First, treatment teachers reported greater use of and training in SACD activities than control teachers, and they did so more often than would be expected by chance ( 7 out of 62 comparisons, with 3 expected significant by chance). There are two potential causes for this finding, and the analysis cannot be used to determine whether the reason for such a difference was that the two groups did differ on their initial use of SACD activities (i.e., that randomization did not create similar treatment and control groups) or whether the fact that the training of all treatment teachers and the implementation of the 4Rs program began before the initial data were collected (by 4 weeks) influenced the teacher reports. Because it is likely (though unproven) that the training and implementation affected the teacher reports, these data were not considered appropriate for use as a baseline measure of SACD activities and training in the treatment schools.

Second, these data indicate that the control condition for the SACD project was not a "no treatment" control but a "standard practice" control. Because the control teachers were not affected by the implementation of the SACD programs before data collection, their reports reflect standard practice in the control schools. Standard practice at the control schools included reports of 40 percent to 80 percent of teachers using any SACD activities, 96 percent of teachers using specific materials in conjunction with these activities, 100 percent using at least one of the specified instructional strategies, and 56 percent participating in SACD training over the past 12 months.

Analyses of the impacts of the 4Rs program on the level of SACD activities in the schools revealed impacts on the use of such activities (66 out of 90, 1 negative) and related materials and strategies (18 out of 87, 1 negative) across the 3 years. Analyses also showed more use of professional development activities for treatment teachers in all years (13 out of 27).

Of the 20 child-level outcomes representing the four domains of Social and Emotional Competence, Behavior, Academics, and Perceptions of School Climate assessed in each of the 3 years of the study (a total of 60 results), 1 showed a statistically significant detrimental impact of the 4Rs intervention. A growth curve analysis was used to analyze the change over time in these same outcomes between initial data collection and the final outcome data collection at the end of the study. None of the 18 child-level outcomes assessed showed a significant impact of the 4Rs program.

The SACD evaluation did not find evidence to support the hypothesis that 4Rs had beneficial impacts on students' social and character development. Such results could be caused by the inability of the program to cause such change, possibly because the theory of action for the program is incomplete or the activities to carry out that theory are not effective.

However, these results may also be due to the inability of the evaluation to observe such a change due to the control condition, the level of nonparticipation, or the sample size. The control schools continued using their standard SACD activities, and these turned out to be high in quantity and broad in scope. While 4Rs had a significant positive impact on the amount and type of SACD activities, the resulting difference in the amount 


\section{Chapter 7. The 4Rs Program (Reading, Writing, Respect, and Resolution)}

of SACD activities between the treatment and control schools may not have been large enough to cause significant differences in the student outcomes. Second, 38 percent to 45 percent of the students in the sample universe did not take part (depending on year) because of nonconsent or noncompletion of the surveys. As a determination could not be made as to whether the students not taking part significantly differed from those who did take part, the evaluation's results are valid only for the students who took part. If the students not taking part were different, and if they would have responded better to 4Rs than to the SACD activities occurring in the control schools, then the evaluation could have underestimated the program's impact. Third, the sample size of 14 schools and the resulting higher MDES compared to those for the multiprogram evaluation may have reduced the likelihood of detecting statistically significant effects. However, it should be noted that 68 percent of the MDES for the 60 outcomes used in the year-by-year analysis were below 0.25 (50\% were below 0.20$)$. In addition, only 2 of the 60 outcomes were found to be substantively important, and they were detrimental. 
This page is intentionally blank. 


\title{
Chapter 8. Second Step
}

\author{
University of Maryland \\ (Maryland Site)
}

\section{Intervention}

Researchers at the University of Maryland (Maryland site) evaluated the Second Step (SS) program. This program, one of several disseminated by the Committee for Children, is designed to promote social competence and reduce children's social and emotional problems. Table 8.1 describes the SS program's general characteristics (panel 1), the types of instruction and strategies used (panel 2), the professional development provided for those implementing the program (panel 3), and the social and character development activities (panel 4) and outcomes (panel 5). SS includes the following components:

- The SS curriculum focuses on developing children's social and emotional skills in the areas of empathy, impulse control and problem solving, and anger management. Through storytelling, discussion, and role-playing, teachers deliver 30-minute classroom lessons to students, 1 to 2 days per week.

- Teachers learn to use classroom management practices and to model social-emotional skills to foster a positive classroom climate. Teachers give students opportunities to practice social-emotional skills in new situations; positively reinforce students' skill use; and utilize teachable moments to provide coaching, constructive feedback, and positive reinforcement to students to support skills used during real-life situations. Visual cues are utilized to illustrate aspects of social problem solving.

- SS extends into the home through newsletters, a family guide and video, and encouragement of parent involvement in helping children complete their SS homework.

- In this evaluation, treatment schools established Character Development Planning Teams (CDPTs), made up of counselors, the principal, and other school staff members (e.g., teachers, administrative or office personnel) who made decisions about program implementation and other social and character development activities. 


\section{Table 8.1. Second Step}

Panel 1: General characteristics

Target population

Universal

Program components

Peer: In class

Parent: Contact

Classroom: Lessons and transfer of training

Schoolwide: Program artifacts and modeling

Community: None or not major focus

Training: Pretraining and ongoing

Level of integration

Add-on curriculum

Flexibility

Manualized: Curriculum guidebook

Adaptability: Character development planning teams

See notes at end of table.

Panel 2: Description of instruction and strategies

Classroom

Lessons

Who delivers: Teacher

Activities and tools: Storytelling, discussion, videos, role-playing, anticipation, recall, learning points Content: Empathy, impulse control, problem solving, anger management

Frequency: 30-minute lessons, 1 to 2 days per week

Strategies

Who delivers: Teacher

Activities and tools: Modeling and reinforcement of skills

Frequency: Weekly lessons, daily generalization

Supplement to classroom

Take-home letters, homework, family guide, and video

Schoolwide activities

Program artifacts, training of school staff

See notes at end of table. 


\section{Table 8.1. Second Step-Continued}

Panel 3: Professional development

Pre-implementation

Teachers

Content: Training on child development, social skills, and curriculum delivery

Duration: 2 days

Other

Content: Character Development Planning Team, school counselor, and other staff; training on child development, social skills, and curriculum content

Duration: $2 \frac{1}{2}$ hours

Ongoing consultation

Teachers

Content: Year-end workshop to review student outcome data and plan for following year; ongoing program implementation support by school counselors

Duration: 1 day

Other

Content: School counselor guidance on strategies and challenges; principal and staff review student outcome data and plan for following year

Duration: $1 / 2$-day counselor meetings about monthly; 1 -day year-end workshop

See notes at end of table.

Panel 4: Activities for SACD goals

\begin{tabular}{lc|l}
\hline Violence prevention and peace promotion & $\checkmark$ & Risk prevention and health promotion \\
Social and emotional development & $\checkmark$ & Civic responsibility and community service \\
Character education & $\checkmark$ & Behavior management \\
Tolerance and diversity & & \\
\hline
\end{tabular}

See notes at end of table.

Panel 5: SACD outcomes addressed

\begin{tabular}{lc|l}
\hline Engagement with Learning & & Empathy \\
Academic Competence and Motivation & & Positive School Orientation \\
Altruistic Behavior & $\checkmark$ & Negative School Orientation \\
Positive Social Behavior & $\checkmark$ & Student Afraid at School \\
Problem Behavior & $\checkmark$ & Victimization at School \\
Self-Efficacy for Peer Interactions & $\checkmark$ & Feelings of Safety \\
Normative Beliefs About Aggression & & Student Support for Teachers \\
\hline
\end{tabular}

NOTE: Abbreviations are

$\checkmark$ : Activity or outcome addressed

Blank cell: Activity or outcome not addressed

SOURCE: The Social and Character Development (SACD) Research Program. 


\section{Sample and Random Assignment}

The Maryland research team recruited a total of 12 public elementary schools in a single school district in Maryland. The 12 schools were randomly assigned to treatment and control conditions prior to the fall 2004 data collection. A two-step process was used. First, a pairwise matching algorithm developed by Mathematica Policy Research, Inc. (MPR) was used to identify the best pairwise matches across the 12 schools based on variables identified by the Maryland research team. The variables used in the pairwise matching for the Maryland site included the following: (a) school mobility rate, (b) average daily attendance rate, (c) average national percentile rank of reading and math scores for fifth-graders, (d) average national percentile rank of reading and math scores for third-graders, (e) percentage of students eligible for free and reduced-price lunch, (f) school enrollment size, ( $g$ ) percentage of families in the community with children in female-headed households with no husband present, (h) percentage of persons in the community aged 25 years and older with bachelor's degrees, and (i) population density. Second, using a computer-based pseudo random number generator, 1 school in each matched pair was assigned to either the intervention or the control condition. Six schools received the SS program and 6 schools acted as control schools and continued to implement the social and character development activities that constituted their standard practice. Assignment to treatment or control condition was at the school level and therefore limited the risk of contamination between treatment and control classrooms.

The original student sample (the cohort of students in the third grade in the 12 schools in fall 2004) numbered 944 students (524 treatment and 420 control). Table 8.2 documents the change in the sample over the three spring follow-up data collection periods. Over time, new entrants to the cohort became a larger percentage of the sample, eventually making up 14 percent of the sample by the spring of Year 3. There were no statistically significant differences between the treatment and control groups in the numbers of new entrants. The percentage of the sample made up of the original cohort further declined as students left the schools. By Year 3, approximately 9 percent of the original sample had left. There was a statistically significant difference between treatment and control schools in the percentage of students who had left (i.e., "leavers") in Year 3; the treatment schools had a larger percentage of leavers than control schools $(11 \%$ versus $8 \%$ ). 
Table 8.2. Sample-SS

\begin{tabular}{|c|c|c|c|c|c|c|c|c|c|c|c|c|}
\hline \multirow[b]{2}{*}{ Characteristic } & \multicolumn{3}{|c|}{$\begin{array}{c}\text { Year } 1 \\
\text { (Fall 3rd grade) }\end{array}$} & \multicolumn{3}{|c|}{$\begin{array}{c}\text { Year } 1 \\
\text { (Spring 3rd grade) } \\
\end{array}$} & \multicolumn{3}{|c|}{$\begin{array}{c}\text { Year } 2 \\
\text { (Spring 4th grade) }\end{array}$} & \multicolumn{3}{|c|}{$\begin{array}{c}\text { Year } 3 \\
\text { (Spring 5th grade) }\end{array}$} \\
\hline & Total & $\begin{array}{r}\text { Treat- } \\
\text { ment }\end{array}$ & Control & Total & $\begin{array}{r}\text { Treat- } \\
\text { ment }\end{array}$ & Control & Total & $\begin{array}{r}\text { Treat- } \\
\text { ment }\end{array}$ & Control & Total & $\begin{array}{r}\text { Treat- } \\
\text { ment }\end{array}$ & Control \\
\hline School sample size & 12 & 6 & 6 & 12 & 6 & 6 & 12 & 6 & 6 & 12 & 6 & 6 \\
\hline Student sample size & 944 & 524 & 420 & 951 & 528 & 423 & 959 & 533 & 426 & 989 & 533 & 456 \\
\hline Stayers & $\dagger$ & $\dagger$ & $\dagger$ & 918 & 510 & 408 & 826 & 456 & 370 & 855 & 467 & 388 \\
\hline New entrants & $\dagger$ & $\dagger$ & $\dagger$ & 33 & 18 & 15 & 133 & 77 & 56 & 134 & 66 & 68 \\
\hline $\begin{array}{l}\text { New entrants as a percent of } \\
\text { spring enrollment }\end{array}$ & $\dagger$ & $\dagger$ & $\dagger$ & 3.5 & 3.4 & 3.5 & 13.9 & 14.4 & 13.1 & 13.5 & 12.4 & 14.9 \\
\hline Total leavers (from original cohort) & $\dagger$ & $\dagger$ & $\dagger$ & 26 & 14 & 12 & 118 & 68 & 50 & 89 & 57 & 32 \\
\hline $\begin{array}{l}\text { Leavers as a percent of fall } 2004 \\
\text { enrollment }\end{array}$ & $\dagger$ & $\dagger$ & $\dagger$ & 2.8 & 2.7 & 2.9 & 12.5 & 13.0 & 11.9 & 9.4 & $10.9^{*}$ & 7.6 \\
\hline $\begin{array}{l}\text { Number of students per school } \\
\text { (mean) }\end{array}$ & 79 & 87 & 70 & 79 & 88 & 71 & 80 & 89 & 71 & 82 & 89 & 76 \\
\hline $\begin{array}{l}\text { Range of number of students per } \\
\text { school }\end{array}$ & $46-123$ & $55-123$ & $46-102$ & $47-127$ & 54-127 & 47-104 & $39-125$ & $54-25$ & $39-110$ & $41-121$ & $52-121$ & $41-115$ \\
\hline
\end{tabular}
† Not applicable.

* Treatment group significantly different from control group at the .05 level.

SOURCE: The Social and Character Development (SACD) Research Program. 


\section{Implementation}

\section{Training}

The intervention teachers received 2 days of program implementation training prior to the beginning of the school year (table 8.1, panel 3). School counselors provided ongoing program implementation support to teachers throughout the school year. School counselors received ongoing guidance through half-day monthly project meetings from the Maryland research team. In these monthly meetings, the research team provided detailed implementation feedback to the school counselors, who then conveyed the information to participating teachers on an as-needed basis.

Teachers participated in a 2-day training that focused on child development, social skills, and program implementation. Members of the Character Development Planning Teams (CDPTs) and other school staff members (e.g., principal, school counselors) received a condensed, 2.5-hour version of the teacher training. During the school year, school counselors participated in monthly half-day meetings with the Maryland research team to discuss program implementation. Teachers and CDPT members were invited to participate in a 1-day end-of-the-year workshop to review data on student progress and to plan implementation activities for the following year. Teams opted to do this after the first year of implementation only.

\section{Data Collection}

MPR collected the multiprogram child, teacher, and school data for the Maryland site. Table 8.3 shows the school year milestones and dates of implementation for the Maryland site. Data were collected in the fall and spring of the first 2 years and in the spring of Year 3. The fall 2004 multiprogram data collection began on October 11, 2004, and ended on October 29, 2004. The average time frame from the beginning of program implementation to the beginning of fall data collection was 5 weeks. As a result, initial data collection took place after implementation of the SS program began. Therefore, these data provide a measure of the students, teachers, and schools near the beginning of the school year, at a time when the SS program had been operating for a relatively short period of time. The spring data collection window was from April 25, 2005, to May 13, 2005. The SS program had been implemented for 33 weeks at the time of the spring data collection and for 25 weeks from the end of the fall data collection. Year 2 followed a similar pattern, with implementation occurring at the start of the school year, fall data collection occurring 8 weeks later, and spring data collection occurring 23 weeks after fall data collection (and 34 weeks after the start of implementation). In spring 2007, data collection occurred 34 weeks after the start of implementation. Data collection took from 3 to 5 weeks at each collection point. 
Table 8.3. Data collection dates-SS

\begin{tabular}{|c|c|c|c|c|c|}
\hline & Year 1 & Year 1 & Year 2 & Year 2 & Year 3 \\
\hline Data collection schedule & (Fall 3rd grade) & (Spring 3rd grade) & (Fall 4th grade) & (Spring 4th grade) & (Spring 5th grade) \\
\hline School sample size & 12 & 12 & 12 & 12 & 12 \\
\hline \multicolumn{6}{|l|}{ School year dates } \\
\hline First day of school & $8 / 30 / 04$ & $\dagger$ & $8 / 29 / 05$ & $\dagger$ & $8 / 28 / 06$ \\
\hline Start of implementation & 9/6/04 & $\dagger$ & First day & $\dagger$ & First day \\
\hline Last day of school & $\dagger$ & $6 / 16 / 05$ & $\dagger$ & $6 / 15 / 06$ & $6 / 14 / 07$ \\
\hline \multicolumn{6}{|l|}{ Data collection } \\
\hline Start & $10 / 11 / 04$ & $4 / 25 / 05$ & $10 / 24 / 05$ & $4 / 24 / 06$ & $4 / 23 / 07$ \\
\hline End & $10 / 29 / 04$ & $5 / 13 / 05$ & $11 / 11 / 05$ & $5 / 12 / 06$ & $5 / 10 / 07$ \\
\hline $\begin{array}{l}\text { Calendar weeks from } \\
\text { program implementation } \\
\text { to start of fall } 2004\end{array}$ & & & & & \\
\hline data collection & 5 & $\dagger$ & $\dagger$ & $\dagger$ & $\dagger$ \\
\hline $\begin{array}{l}\text { Calendar weeks from } \\
\text { start of school to start of } \\
\text { fall } 2004 \text { data collection }\end{array}$ & 6 & $\dagger$ & 8 & $\dagger$ & $\dagger$ \\
\hline $\begin{array}{l}\text { Calendar weeks from } \\
\text { end of fall data collection } \\
\text { to start of spring data } \\
\text { collection }\end{array}$ & $\dagger$ & 25 & $\dagger$ & 23 & $\dagger$ \\
\hline $\begin{array}{l}\text { Calendar weeks from } \\
\text { program implementation } \\
\text { to start of spring data } \\
\text { collection }\end{array}$ & $\dagger$ & 33 & $\dagger$ & 34 & 34 \\
\hline
\end{tabular}

† Not applicable.

SOURCE: The Social and Character Development (SACD) Research Program.

\section{Consent Rates, Completion Rates, and Percentage of Sample With Data}

The actual number of student, primary caregiver, and teacher reports available for analysis was smaller than the number in the sample because consent and completion rates were less than 100 percent. Primary caregivers had to provide consent before children could complete the Child Report, before their child's teacher could complete the Teacher Report on Student, and before they themselves completed the Primary Caregiver Report. There were statistically significant differences in consent for child and primary caregiver in Year 1; treatment caregivers had higher consent rates than control caregivers. Teachers also had to provide consent before completing the Teacher Report on Classroom and School. There were no statistically significant differences between treatment and control groups in consent rates for teachers.

Of those with consent, not all completed their respective reports. Table 8.4 shows the consent rates, completion rates, and percentages of sample with data for each of the four reports over the 3 years. For the Child Report and two teacher reports, completion rates ranged from 87 percent to 100 percent, with no statistically significant difference in completion rates between treatment and control groups. For the Primary Caregiver Report, the completion rates dropped over time from 96 percent to 83 percent. There was one statistically significant difference for the Primary Caregiver Report completion rate; in the spring of Year 1, fewer treatment group caregivers completed reports than did control group caregivers. 
The percentages of the sample with Child Report data ranged from 58 percent to 72 percent over the 3 years, with one statistically significant difference in the fall of Year 1 . The percentages of students with information from the Teacher Report on Student ranged from 60 percent to 72 percent, again with one statistically significant difference in the fall of Year 1 . The percentages of students with data from the Primary Caregiver Report ranged from 55 percent to 66 percent, also with one statistically significant difference in the fall of Year 1. The percentages of teachers with data from the Teacher Report on Classroom and School ranged from 87 percent to 97 percent, with no statistically significant differences between treatment and control teachers. 
Table 8.4. Consent rates, completion rates, and percentage of sample with data from each report-SS

\begin{tabular}{|c|c|c|c|c|c|c|c|c|c|c|c|c|}
\hline \multirow[b]{2}{*}{ Report } & \multicolumn{3}{|c|}{$\begin{array}{c}\text { Year } 1 \\
\text { (Fall 3rd grade) }\end{array}$} & \multicolumn{3}{|c|}{$\begin{array}{c}\text { Year } 1 \\
\text { (Spring 3rd grade) }\end{array}$} & \multicolumn{3}{|c|}{$\begin{array}{c}\text { Year } 2 \\
\text { (Spring 4th grade) }\end{array}$} & \multicolumn{3}{|c|}{$\begin{array}{c}\text { Year } 3 \\
\text { (Spring 5th grade) }\end{array}$} \\
\hline & Total & $\begin{array}{r}\text { Treat- } \\
\text { ment }\end{array}$ & Control & Total & $\begin{array}{r}\text { Treat- } \\
\text { ment }\end{array}$ & Control & Total & $\begin{array}{r}\text { Treat- } \\
\text { ment }\end{array}$ & Control & Total & $\begin{array}{r}\text { Treat- } \\
\text { ment }\end{array}$ & Control \\
\hline Student sample size & 944 & 524 & 420 & 951 & 528 & 423 & 959 & 533 & 426 & 989 & 533 & 456 \\
\hline \multicolumn{13}{|l|}{ Child Report (percent) } \\
\hline Primary caregiver consent rate & 65.0 & $68.9^{* *}$ & 60.2 & 65.7 & $68.6^{*}$ & 62.2 & 71.1 & 72.4 & 69.5 & 68.4 & 70.4 & 66.0 \\
\hline Student completion rate & 95.9 & 95.6 & 96.4 & 99.8 & 99.7 & 100.0 & 99.9 & 100.0 & 99.7 & 99.6 & 100.0 & 99.0 \\
\hline Students with data ${ }^{1}$ & 62.3 & 65.7 & 58.0 & 65.6 & 68.4 & 62.2 & 71.0 & 72.4 & 69.2 & 68.0 & 70.4 & 65.4 \\
\hline \multicolumn{13}{|l|}{ Primary Caregiver Report (percent) } \\
\hline Primary caregiver consent rate & 65.0 & $68.9^{* *}$ & 60.2 & 65.7 & $68.8^{*}$ & 61.9 & 70.6 & 71.9 & 69.0 & 68.1 & 70.0 & 66.0 \\
\hline Primary caregiver completion rate & 95.8 & 95.6 & 96.0 & 87.2 & $84.3^{*}$ & 91.2 & 87.6 & 88.0 & 87.1 & 83.2 & 83.4 & 83.1 \\
\hline Primary caregivers with data ${ }^{1}$ & 62.3 & 65.7 & 57.8 & 57.3 & 58.0 & 56.5 & 61.8 & 63.2 & 60.1 & 56.7 & 58.3 & 54.8 \\
\hline \multicolumn{13}{|l|}{ Teacher Report on Student (percent) } \\
\hline Primary caregiver consent rate $^{2}$ & 65.0 & $68.9^{* *}$ & 60.2 & 65.7 & $68.6^{*}$ & 62.2 & 71.1 & 72.4 & 69.5 & 68.4 & 70.4 & 66.0 \\
\hline Teacher completion rate & 99.7 & 99.4 & 100.0 & 99.8 & 99.7 & 100.0 & 99.6 & 99.5 & 99.7 & 99.7 & 100.0 & 99.3 \\
\hline Students with data ${ }^{1}$ & 64.8 & 68.5 & 60.2 & 65.6 & 68.4 & 62.2 & 70.8 & 72.0 & 69.2 & 68.1 & 70.4 & 65.6 \\
\hline \multicolumn{13}{|c|}{$\begin{array}{l}\text { Teacher Report on Classroom and School } \\
\text { (3rd- to 5th-grade teachers) (percent) }\end{array}$} \\
\hline Teacher consent rate & 100.0 & 100.0 & 100.0 & 100.0 & 100.0 & 100.0 & 100.0 & 100.0 & 100.0 & 100.0 & 100.0 & 100.0 \\
\hline Teacher completion rate & 92.2 & 90.3 & 94.4 & 93.1 & 93.5 & 92.6 & 96.6 & 96.8 & 96.2 & 89.0 & 90.8 & 86.8 \\
\hline Teachers with data ${ }^{1}$ & 92.2 & 90.3 & 94.4 & 93.1 & 93.5 & 92.6 & 96.6 & 96.8 & 96.2 & 89.0 & 90.8 & 86.8 \\
\hline
\end{tabular}

* Treatment group significantly different from control group at the .05 level.

** Treatment group significantly different from control group at the .01 level.

${ }^{1}$ Calculated as consent rate $\mathrm{x}$ completion rate.

${ }^{2}$ The primary caregiver consent rates for the Child Report and the Teacher Report on Student are identical, as the primary caregiver gave consent to both together.

SOURCE: The Social and Character Development (SACD) Research Program. 
Responses from students in the original cohort (stayers) and new entrants in the SS sample were examined to investigate possible differences between the two groups in consent rates, completion rates, and the percentages of sample with data that might affect outcome data (table 8.5). In Years 1 and 2, the stayers had significantly higher consent rates than the new entrants (by 18 to 24 percentage points), and in Year 3, the opposite trend was found, with new entrants having significantly higher consent rates than stayers (by 18 percentage points). These differences in consent rates resulted in a similar pattern of differences for percentages of sample with data, with more data for the stayers in Years 1 and 2 on all three reports (by 17 to 22 percentage points), and more data for the new entrants in Year 3 on all three reports (by 15 to 16 percentage points). 
Table 8.5. Consent rates, completion rates, and percentage of sample with data: Stayers versus new entrants-SS

\begin{tabular}{|c|c|c|c|c|c|c|c|c|c|}
\hline \multirow[b]{2}{*}{ Report } & \multicolumn{3}{|c|}{$\begin{array}{c}\text { Year } 1 \\
\text { (Spring 3rd grade) }\end{array}$} & \multicolumn{3}{|c|}{$\begin{array}{c}\text { Year } 2 \\
\text { (Spring 4th grade) }\end{array}$} & \multicolumn{3}{|c|}{$\begin{array}{c}\text { Year } 3 \\
\text { (Spring 5th grade) }\end{array}$} \\
\hline & Total & Stayers & $\begin{array}{r}\text { New } \\
\text { entrants }\end{array}$ & Total & Stayers & $\begin{array}{r}\mathrm{New} \\
\text { entrants }\end{array}$ & Total & Stayers & $\begin{array}{r}\text { New } \\
\text { entrants }\end{array}$ \\
\hline Student sample size & 951 & 918 & 33 & 959 & 826 & 133 & 989 & 855 & 134 \\
\hline \multicolumn{10}{|l|}{ Child Report (percent) } \\
\hline Primary caregiver consent rate & 65.7 & $66.4^{*}$ & 45.5 & 71.7 & $73.7^{* * *}$ & 54.9 & 68.4 & $66.0^{* * *}$ & 83.6 \\
\hline Student completion rate & 99.8 & 99.8 & 100.0 & 99.9 & 99.8 & 100.0 & 99.6 & $99.8^{*}$ & 98.2 \\
\hline Students with data ${ }^{1}$ & 65.6 & $66.3^{*}$ & 45.5 & 71.0 & $73.6^{\star * *}$ & 54.9 & 68.0 & $65.8^{* * *}$ & 82.1 \\
\hline \multicolumn{10}{|l|}{ Primary Caregiver Report (percent) } \\
\hline Primary caregiver consent rate & 65.7 & $66.6^{* *}$ & 42.4 & 70.6 & $73.1^{* * *}$ & 54.9 & 68.1 & $65.7^{\star * *}$ & 83.6 \\
\hline Primary caregiver completion rate & 87.2 & 87.2 & 85.7 & 87.6 & 87.7 & 86.3 & 83.4 & 83.5 & 83.0 \\
\hline Primary caregivers with data ${ }^{1}$ & 57.3 & $58.1^{*}$ & 36.4 & 61.8 & $64.2^{\star * *}$ & 47.4 & 56.8 & $54.9^{* *}$ & 69.4 \\
\hline \multicolumn{10}{|l|}{ Teacher Report on Student (percent) } \\
\hline Primary caregiver consent rate ${ }^{2}$ & 65.7 & $66.4^{*}$ & 45.5 & 71.7 & $73.7^{* * *}$ & 54.9 & 68.4 & $66.0^{* * *}$ & 83.6 \\
\hline Teacher completion rate & 99.8 & 99.8 & 100.0 & 99.6 & 99.7 & 98.6 & 99.7 & $100.0^{* *}$ & 98.2 \\
\hline Students with data ${ }^{1}$ & 65.6 & $66.3^{*}$ & 45.5 & 70.8 & $73.5^{* * *}$ & 54.1 & 68.1 & $66.0^{* * *}$ & 82.1 \\
\hline
\end{tabular}

* Stayers significantly different from new entrants at the .05 level.

** Stayers significantly different from new entrants at the .01 level.

*** Stayers significantly different from new entrants at the .001 level.

${ }^{1}$ Calculated as consent rate $\mathrm{x}$ completion rate.

${ }^{2}$ The primary caregiver consent rates for the Child Report and the Teacher Report on Student are identical, as the primary caregiver gave consent to both together.

SOURCE: The Social and Character Development (SACD) Research Program. 


\section{Fidelity of Implementation}

In Years 2 and 3, the six SS treatment group schools were individually rated for the quantity and quality of the program's implementation by two raters from the research team (in Year 1, only one rater was used). The global measure of fidelity for the multisite study was used; inter-rater reliability was measured using Cronbach's alpha (Year $2=1.00$ and Year $3=0.99$ ). The ratings were combined into a single consensus rating and used to identify schools with high implementation fidelity. In Year 2, five treatment schools were identified as having high fidelity, and in Year 3 four schools were. Cohen's kappa was used as the measure of agreement when identifying schools as high fidelity, and it equaled 1.00 in both years. In Year 1, four treatment schools were identified as having high fidelity; however, only one rater was used, and therefore inter-rater reliability could not be determined.

\section{Initial Characteristics}

This section examines the initial characteristics of the students, teachers, and schools participating in the evaluation of the SS program. These characteristics were collected from students who were enrolled in the third grade at the study schools in fall 2004, as well as from their primary caregivers and third-grade teachers. In addition, third-, fourth-, and fifth-grade teachers and principals in the study schools provided information about activities related to social and character development in these schools. Documenting the characteristics of students, teachers, and schools and initial measures of key outcomes at a point before the interventions had been operating for an extended period helped to determine whether the random assignment of schools to treatment and control status produced treatment and control groups with similar distributions of observed characteristics. As noted in the following discussion, there were 13 significant differences in the observed characteristics, 12 of which (out of 62 comparisons, with 3 expected to be significant by chance) were related to differences between the treatment and control students, teachers, and schools in the use of SACD activities in the classroom and school.

\section{Characteristics of Children, Their Families, and Communities}

The mean age of students in the overall SS sample was 8.0 years. The sample contained equal percentages of girls $(50 \%)$ and boys $(50 \%)$. The sample had some ethnic diversity, with White non-Hispanic students making up 83 percent of the sample, Black non-Hispanic students making up 7 percent of the sample, and Hispanic students making up 5 percent of the sample.

The sample was also somewhat diverse in its levels of family income, education levels of primary caregivers of the children in the sample, and family situation. For the total sample, 5 percent of children lived in a household where the income was 135 percent of the federal poverty level or lower, which is the income threshold for eligibility for free school meals. About 4 percent of primary caregivers had not completed high school. There was a statistically significant difference between the groups, with more control group caregivers not having completed high school than treatment group caregivers ( $5 \%$ versus $4 \%$ ). The majority of the children $(80 \%)$ lived with both their mother and their father.

The mean values of the outcomes for children's behavior and attitudes as reported by the primary caregiver, child, and teacher at initial data collection in fall 2004 are shown in table 8.7. There were no significant differences between the treatment and control groups. 
Table 8.6. Initial characteristics of children, their families, and communities-SS

\begin{tabular}{|c|c|c|c|}
\hline Characteristic & Total & Treatment & Control \\
\hline Student sample size & 588 & 345 & 243 \\
\hline \multicolumn{4}{|l|}{ Student demographics } \\
\hline \multicolumn{4}{|l|}{ Gender (percent) } \\
\hline Male & 50.4 & 51.6 & 49.3 \\
\hline Female & 49.6 & 48.4 & 50.7 \\
\hline \multicolumn{4}{|l|}{ Race/ethnicity (percent) } \\
\hline White (non-Hispanic) & 82.9 & 85.8 & 80.0 \\
\hline Black (non-Hispanic) & 6.6 & 5.3 & 7.8 \\
\hline Hispanic & 4.7 & 2.9 & 6.5 \\
\hline Other & 5.8 & 6.0 & 5.6 \\
\hline Age (in years) (mean) & 8.0 & 8.0 & 8.0 \\
\hline \multicolumn{4}{|l|}{ Primary caregiver and family characteristics } \\
\hline Primary caregiver's age (in years) (mean) & 38.6 & 38.3 & 38.9 \\
\hline \multicolumn{4}{|l|}{ Primary caregiver's race/ethnicity (percent) } \\
\hline White (non-Hispanic) & 84.7 & 88.4 & 80.9 \\
\hline Black (non-Hispanic) & 7.0 & 5.6 & 8.3 \\
\hline Hispanic & 4.2 & 2.0 & 6.4 \\
\hline Other & 4.2 & 3.9 & 4.4 \\
\hline \multicolumn{4}{|l|}{ Primary caregiver's education (percent) } \\
\hline Did not complete high school & 4.1 & $3.5^{*}$ & 4.6 \\
\hline Completed high school or equivalent & 13.5 & 18.2 & 8.8 \\
\hline Some college & 36.1 & 34.5 & 37.6 \\
\hline Bachelor's or higher degree & 46.4 & 43.8 & 49.0 \\
\hline \multicolumn{4}{|l|}{ Primary caregiver's employment (percent) } \\
\hline Full-time & 49.2 & 50.3 & 48.0 \\
\hline Other & 50.8 & 49.7 & 52.0 \\
\hline \multicolumn{4}{|l|}{ Primary caregiver's marital status (percent) } \\
\hline Married & 79.3 & 79.4 & 79.3 \\
\hline Other & 20.7 & 20.6 & 20.7 \\
\hline Students who live in one household (percent) & 96.1 & 95.0 & 97.1 \\
\hline Number of individuals in household (mean) & 4.7 & 4.6 & 4.8 \\
\hline \multicolumn{4}{|l|}{ Primary caregiver's relationship to child (percent) } \\
\hline Mother (stepmother) & 90.1 & 90.1 & 90.1 \\
\hline Father (stepfather) & 7.6 & 6.9 & 8.3 \\
\hline Other relative/nonrelative & 2.3 & 3.0 & 1.5 \\
\hline
\end{tabular}


Table 8.6. Initial characteristics of children, their families, and communities-SS—Continued

\begin{tabular}{|c|c|c|c|}
\hline Characteristic & Total & Treatment & Control \\
\hline \multicolumn{4}{|l|}{ Student lives with (percent) } \\
\hline Mother (stepmother) and father (stepfather) & 80.3 & 79.3 & 81.2 \\
\hline Mother (stepmother) only; father (stepfather) not present & 15.3 & 15.9 & 14.8 \\
\hline Father (stepfather) only; mother (stepmother) not present & 2.8 & 2.7 & 3.0 \\
\hline Other relative/nonrelative, parents not present & 1.6 & $\ddagger$ & $\ddagger$ \\
\hline \multicolumn{4}{|l|}{ Highest education of anyone in household (percent) } \\
\hline Did not complete high school & 1.4 & 1.5 & 1.2 \\
\hline Completed high school or equivalent & 10.0 & 13.0 & 7.0 \\
\hline Some college & 31.3 & 30.5 & 32.1 \\
\hline Bachelor's or higher degree & 57.3 & 54.9 & 59.7 \\
\hline \multicolumn{4}{|l|}{ Total household income (percent) } \\
\hline Less than $\$ 20,000$ & 2.2 & 1.7 & 2.6 \\
\hline$\$ 20,000$ to $\$ 39,999$ & 10.1 & 10.3 & 10.0 \\
\hline$\$ 40,000$ to $\$ 59,999$ & 11.2 & 12.3 & 10.2 \\
\hline$\$ 60,000$ or more & 76.5 & 75.7 & 77.2 \\
\hline Income-to-poverty-threshold ratio-Below 135 percent (percent) & 5.1 & 4.9 & 5.3 \\
\hline Income-to-poverty-threshold ratio-135 to 185 percent (percent) & 7.2 & 7.5 & 6.8 \\
\hline Income-to-poverty-threshold ratio-Above 185 percent (percent) & 87.7 & 87.6 & 87.8 \\
\hline \multicolumn{4}{|l|}{ Alabama Parenting Questionnaire-Poor Monitoring and } \\
\hline Supervision Subscale (mean) & 1.1 & 1.1 & 1.1 \\
\hline \multicolumn{4}{|l|}{ Alabama Parenting Questionnaire-Positive Parenting } \\
\hline Subscale (mean) & 3.5 & 3.5 & 3.5 \\
\hline Confusion, Hubbub, and Order Scale (mean) & 2.2 & 2.3 & 2.2 \\
\hline \multicolumn{4}{|l|}{ Community characteristics (mean) } \\
\hline Community Risks Scale & 1.1 & 1.1 & 1.1 \\
\hline Community Resources Scale & 3.1 & 3.0 & 3.1 \\
\hline Child-Centered Social Control Scale & 3.5 & 3.5 & 3.5 \\
\hline
\end{tabular}

¥ Reporting standards not met. Values suppressed to protect confidentiality.

${ }^{*}$ Treatment group significantly different from control group at the .05 level.

NOTE: Weights, which assign equal weight to each school within the program, were used in producing the treatment, control, and overall means. Statistical tests were conducted using regressions that included program indicators to account for the sample design and adjusted for clustering at the school level.

SOURCE: The Social and Character Development (SACD) Research Program. 
Table 8.7. Mean scores and standard deviations for initial outcome measures of sample-SS

\begin{tabular}{|c|c|c|c|c|c|c|c|}
\hline \multirow[b]{2}{*}{ Outcome measure-Report } & \multirow[b]{2}{*}{ Range } & \multicolumn{2}{|c|}{ Total } & \multicolumn{2}{|c|}{ Treatment } & \multicolumn{2}{|c|}{ Control } \\
\hline & & Mean & $S D$ & Mean & $S D$ & Mean & $S D$ \\
\hline \multicolumn{8}{|l|}{ Social and Emotional Competence Domain } \\
\hline Self-Efficacy for Peer Interaction-CR & $1-4$ & 3.0 & 0.6 & 3.0 & 0.6 & 3.0 & 0.6 \\
\hline Normative Beliefs About Aggression-CR & $1-4$ & 1.2 & 0.4 & 1.2 & 0.4 & 1.2 & 0.4 \\
\hline Empathy-CR & $1-3$ & 2.4 & 0.4 & 2.5 & 0.3 & 2.4 & 0.4 \\
\hline \multicolumn{8}{|l|}{ Behavior Domain } \\
\hline Altruistic Behavior-Child & $0-3$ & 1.2 & 0.8 & 1.2 & 0.8 & 1.2 & 0.8 \\
\hline Altruistic Behavior-TRS & $1-4$ & 1.4 & 0.5 & 1.5 & 0.6 & 1.4 & 0.4 \\
\hline Altruistic Behavior-PCR & $1-4$ & 2.1 & 0.7 & 2.2 & 0.7 & 2.1 & 0.7 \\
\hline Positive Social Behavior-TRS & $1-4$ & 3.4 & 0.6 & 3.4 & 0.6 & 3.4 & 0.6 \\
\hline Positive Social Behavior-PCR & $1-4$ & 3.1 & 0.5 & 3.2 & 0.5 & 3.1 & 0.5 \\
\hline Problem Behavior-CR & $0-3$ & 0.1 & 0.2 & 0.1 & 0.2 & 0.1 & 0.2 \\
\hline Problem Behavior-TRS & $1-4$ & 1.2 & 0.3 & 1.2 & 0.3 & 1.2 & 0.3 \\
\hline Problem Behavior-PCR & $1-4$ & 1.5 & 0.3 & 1.5 & 0.3 & 1.5 & 0.3 \\
\hline ADHD-Related Behavior-TRS & $1-4$ & 1.5 & 0.6 & 1.5 & 0.6 & 1.5 & 0.6 \\
\hline \multicolumn{8}{|l|}{ Academics Domain } \\
\hline Academic Competence and Motivation-TRS & $1-5$ & 3.3 & 0.8 & 3.3 & 0.8 & 3.4 & 0.8 \\
\hline Engagement with Learning-CR & $1-4$ & 3.8 & 0.4 & 3.8 & 0.4 & 3.8 & 0.4 \\
\hline \multicolumn{8}{|l|}{ Perceptions of School Climate Domain } \\
\hline Positive School Orientation-CR & $1-4$ & 3.4 & 0.5 & 3.4 & 0.5 & 3.3 & 0.5 \\
\hline Negative School Orientation-CR & $1-4$ & 1.5 & 0.5 & 1.5 & 0.4 & 1.5 & 0.5 \\
\hline Student Afraid at School-CR & $1-4$ & 2.1 & 0.9 & 2.1 & 0.9 & 2.1 & 0.9 \\
\hline Victimization at School-CR & $0-3$ & 0.6 & 0.7 & 0.6 & 0.7 & 0.6 & 0.7 \\
\hline Student sample size-PCR & & \multicolumn{2}{|c|}{588} & \multicolumn{2}{|c|}{345} & \multicolumn{2}{|c|}{243} \\
\hline Student sample size-CR & & \multicolumn{2}{|c|}{589} & \multicolumn{2}{|c|}{345} & \multicolumn{2}{|c|}{244} \\
\hline Student sample size-TRS & & \multicolumn{2}{|c|}{612} & \multicolumn{2}{|c|}{359} & \multicolumn{2}{|c|}{253} \\
\hline
\end{tabular}

NOTE: Abbreviations are

CR: Child Report

PCR: Primary Caregiver Report

TRS: Teacher Report on Student

ADHD: Attention deficit hyperactivity disorder

$S D$ : Standard deviation

No statistically significant differences were found between values for treatment and control groups. Weights, which assign equal weight to each school within the program, were used in producing the treatment, control, and overall means. Statistical tests were conducted using regressions that included program indicators to account for the sample design and adjusted for clustering at the school level. Sample size may differ for some outcomes due to nonresponse.

SOURCE: The Social and Character Development (SACD) Research Program. 


\section{Characteristics of Teachers and Schools}

Table 8.8 describes the third-, fourth-, and fifth-grade teachers at the study schools. The majority were White non-Hispanic $(92 \%)$ and female $(96 \%)$. They had an average of 12.3 years of total teaching experience, and more than half $(59 \%)$ held an advanced or specialist degree. There were no significant differences between the treatment and control groups in these characteristics.

Data regarding school characteristics were drawn from the Common Core of Data in order to compare treatment and control schools. There were no significant differences between the two groups of schools in terms of student composition (race/ethnicity and school lunch eligibility), number of students enrolled, number of full-time teachers, Title I status, or number of years the principal had been at the school (see table 8.9). In addition, there were no significant differences between treatment and control schools in terms of location (urban, suburban, or rural) or lowest and highest grade offered (these data are not shown in a table).

Table 8.8. Initial characteristics of teachers in sample-SS

\begin{tabular}{|c|c|c|c|}
\hline Characteristic & Total & Treatment & Control \\
\hline Teacher sample size & 107 & 56 & 51 \\
\hline \multicolumn{4}{|l|}{ Gender (percent) } \\
\hline Male & 4.0 & $\ddagger$ & $\ddagger$ \\
\hline Female & 96.0 & $\ddagger$ & $\ddagger$ \\
\hline \multicolumn{4}{|l|}{ Race/ethnicity (percent) } \\
\hline White (non-Hispanic) & 92.1 & 93.9 & 90.3 \\
\hline Other & 7.9 & 6.1 & 9.7 \\
\hline Number of years teaching experience (mean) & 12.3 & 12.8 & 11.8 \\
\hline Number of years teaching experience this school (mean) & 7.5 & 8.2 & 6.7 \\
\hline \multicolumn{4}{|l|}{ Type of teaching certificate (percent) } \\
\hline Regular state certificate or advanced professional certificate & 97.5 & 95.1 & 100.0 \\
\hline Other & 2.5 & 4.9 & 0.0 \\
\hline \multicolumn{4}{|l|}{ Education (percent) } \\
\hline Bachelor's degree & 41.0 & 36.6 & 45.4 \\
\hline Advanced degree/other & 59.0 & 63.4 & 54.6 \\
\hline
\end{tabular}

$\ddagger$ Reporting standards not met. Values suppressed to protect confidentiality.

NOTE: No statistically significant differences were found between values for treatment and control groups. Weights, which assign equal weight to each school within the program, were used in producing the treatment, control, and overall means. Statistical tests were conducted using regressions that included program indicators to account for the sample design and adjusted for clustering at the school level. Sample size may differ for some outcomes due to nonresponse.

SOURCE: The Social and Character Development (SACD) Research Program. 
Table 8.9. Initial characteristics of schools in sample-SS

\begin{tabular}{|c|c|c|c|}
\hline Characteristic & Total & Treatment & Control \\
\hline School sample size & 12 & 6 & \\
\hline \multicolumn{4}{|l|}{ Student race/ethnicity (percent) } \\
\hline White (non-Hispanic) & 83.7 & 88.2 & 79.2 \\
\hline Black (non-Hispanic) & 10.4 & 7.1 & 13.6 \\
\hline Hispanic & 2.2 & 1.2 & 3.3 \\
\hline Other & 3.7 & 3.5 & 3.8 \\
\hline Students eligible for free or reduced-price lunch (percent) & 12.2 & 11.7 & 12. \\
\hline Number of students enrolled (mean) & 453.8 & 491.8 & 415. \\
\hline Number of full-time teachers (mean) & 26.1 & 27.1 & 25 \\
\hline \multicolumn{4}{|l|}{ Title I status (percent) } \\
\hline Title I eligible school & 16.7 & 16.7 & 16. \\
\hline Schoolwide Title I & 0.0 & 0.0 & \\
\hline Number of years principal has been at this school (mean) & 4.2 & 4.0 & \\
\hline
\end{tabular}

NOTE: No statistically significant differences were found between values for treatment and control groups. Weights, which assign equal weight to each school within the program, were used in producing the treatment, control, and overall means. Statistical tests were conducted using regressions that included program indicators to account for the sample design and adjusted for clustering at the school level. Sample size may differ for some outcomes due to nonresponse.

SOURCE: NCES Common Core of Data (2003-04), the Social and Character Development (SACD) Research Program.

In the Teacher Report on Classroom and School, teachers reported on nine dimensions of school environment (these data are not shown in a table): feelings of safety, adequacy of resources, student support, freedom to teach as desired, affiliation with and ties to colleagues, innovation regarding new approaches to teaching, professional interest, participatory decisionmaking, and work pressure. There were no statistically significant differences between treatment and control schools in these reports.

\section{The Level of SACD in the Schools Near the Beginning of the Study}

During the initial data collection, principals and teachers reported on the SACD activities used in the schools and classrooms, the availability of SACD materials, and the professional development provided on SACD. Table 8.10 shows that the majority of the school principals reported activities to promote six social and character development goals: violence prevention and peace promotion $(92 \%)$, social and emotional development $(100 \%)$, character education $(100 \%)$, tolerance and diversity $(92 \%)$, risk prevention and health promotion $(75 \%)$, and civic responsibility and community service (83\%). In addition, all of the principals reported activities directed toward behavior management. There were no statistically significant differences between the treatment and the control group schools in the percentages reported by principals, although this may be due to the small principal sample size. Teachers reported that use of these activities in their classrooms ranged from 47 percent to 92 percent, with three significant differences (out of eight comparisons) between treatment and control teachers: larger percentages of treatment teachers than control teachers reported the use of social and emotional development (89\% versus $61 \%)$ and character education (99\% versus $85 \%$ ) activities in their classrooms, while more control than treatment teachers reported the use of civic responsibility and community service activities $(69 \%$ versus $48 \%)$ in their classrooms. With respect to the use of schoolwide activities, 62 percent to 96 percent of teachers reported that their schools used such activities. There were no significant differences between treatment and control groups. 


\section{Table 8.10. Principal and teacher initial reports on use of SACD programs or activities in} sample-SS

\begin{tabular}{|c|c|c|c|}
\hline SACD program or activity & Total & Treatment & Control \\
\hline Principal sample size & 12 & 6 & 6 \\
\hline Teacher sample size & 107 & 56 & 5 \\
\hline
\end{tabular}

Principals reporting that school had programs or activities

to promote the following SACD goals (percent)

Violence prevention and peace promotion

Social and emotional development

$\begin{array}{rrr}91.7 & 100.0 & 83.3 \\ 100.0 & 100.0 & 100.0 \\ 100.0 & 100.0 & 100.0 \\ 91.7 & 100.0 & 83.3 \\ 75.0 & 83.3 & 66.7 \\ 83.3 & 100.0 & 66.7 \\ 100.0 & 100.0 & 100.0 \\ 0.0 & 0.0 & 0.0\end{array}$

Character education

Tolerance and diversity

Risk prevention and health promotion

Civic responsibility and community service

Behavior management

None of the above

(2)

Teachers reporting on using programs or activities in their class

to promote the following SACD goals (percent)

Violence prevention and peace promotion

57.

74.9

62.2

53.1

Social and emotional development

91.9

89.0 **

60.9

Character education

58.8

$98.6^{*}$

Tolerance and diversity

46.9

60.5

Risk prevention and health promotion

58.7

46.6

47.2

Civic responsibility and community service

89.4

$48.1^{*}$

69.3

Behavior management

None of the above

Teachers reporting schoolwide use of the following activities to promote SACD (percent)

Morning announcements or videos

\begin{tabular}{lrr}
96.2 & 94.8 & 97.6 \\
65.1 & 56.2 & 73.9 \\
84.1 & 83.0 & 85.2 \\
61.8 & 62.4 & 61.1 \\
68.1 & 65.4 & 70.8 \\
10.0 & 13.7 & 6.4 \\
\hline
\end{tabular}

School assemblies

School newspapers or bulletins

0.0

Special school days

Special events

10.0

13.7

‡ Reporting standards not met. Values suppressed to protect confidentiality.

* Treatment group significantly different from control group at the .05 level.

** Treatment group significantly different from control group at the .01 level.

NOTE: Weights, which assign equal weight to each school within each of the programs and to each program across programs, were used in producing the treatment, control, and overall means. Statistical tests were conducted using regressions that included program indicators to account for the sample design and adjusted for clustering at the school level. Sample size may differ for some outcomes due to nonresponse.

SOURCE: The Social and Character Development (SACD) Research Program. 
Teachers reported using a broad range of teaching materials to support SACD activities (table 8.11), including teacher guides $(85 \%)$, student materials $(45 \%)$, instructional aids $(35 \%)$, giveaways $(54 \%)$, and children's literature (38\%). There was one statistically significant difference (out of seven comparisons) in the use of instructional aids, with more treatment teachers than control teachers reporting their use (52\% versus 18\%).

Teachers also reported using a wide variety of teaching strategies (table 8.11). All teachers reported using any of the 20 strategies asked about, and teachers used an average of 12 of the strategies. There were 4 significant differences (out of 20 comparisons) between treatment and control teachers in the use of these specific strategies. More treatment teachers than control teachers reported using role-playing ( $98 \%$ versus $44 \%)$, direct instruction of SACD (98\% versus $73 \%$ ), skill training (68\% versus 34\%), and guided visualization $(65 \%$ versus $29 \%$ ). 


\section{Table 8.11. Teacher initial reports on use of SACD materials and classroom strategies in the} sample-SS

\begin{tabular}{|c|c|c|c|}
\hline SACD material and classroom strategy & Total & Treatment & Control \\
\hline Teacher sample size & 107 & 56 & 51 \\
\hline \multicolumn{4}{|l|}{$\begin{array}{l}\text { Teachers using the following materials in conjunction with } \\
\text { social and character development activities (percent) }\end{array}$} \\
\hline Teacher guides (manuals, curricula) & 84.9 & 93.5 & 76.3 \\
\hline Student materials (workbooks, worksheets) & 45.2 & 47.8 & 42.6 \\
\hline Instructional aids (games, software, videos) & 34.9 & $52.1^{* *}$ & 17.8 \\
\hline Giveaways (bookmarks, stickers) & 54.0 & 49.8 & 58.3 \\
\hline Children's literature & 37.5 & 43.7 & 31.4 \\
\hline Other types of materials & 13.6 & 11.6 & 15.5 \\
\hline Do not use any of the materials listed above & 4.8 & $\ddagger$ & $\ddagger$ \\
\hline $\begin{array}{l}\text { Teachers using any of the strategies listed below to promote } \\
\text { social and character development in the classroom (percent) }\end{array}$ & 100.0 & 100.0 & 100.0 \\
\hline $\begin{array}{l}\text { Number of strategies (listed below) used by teachers to promote } \\
\text { social and character development in the classroom (mean) }\end{array}$ & 12.0 & 12.6 & 11.3 \\
\hline \multicolumn{4}{|l|}{$\begin{array}{l}\text { Teachers using each of the following strategies to promote } \\
\text { social and character development (percent) }\end{array}$} \\
\hline Role-playing & 71.0 & $98.3^{* *}$ & 43.6 \\
\hline Cooperative learning & 95.6 & 98.3 & 92.9 \\
\hline Peer group discussions & 85.7 & 90.4 & 81.0 \\
\hline Direct instruction of social and character development & 85.5 & $97.9^{*}$ & 73.0 \\
\hline Skill training & 51.1 & $68.4^{*}$ & 33.8 \\
\hline $\begin{array}{l}\text { Incorporating social and character development into } \\
\text { academic curriculum }\end{array}$ & 80.1 & 80.4 & 79.8 \\
\hline Parent training & 10.3 & 11.0 & 9.7 \\
\hline $\begin{array}{l}\text { Parent/community involvement in program development } \\
\text { or delivery }\end{array}$ & 36.0 & 37.8 & 34.2 \\
\hline Mentoring & 43.3 & 37.0 & 49.7 \\
\hline Good behavior notes sent home daily or weekly & 77.2 & 75.1 & 79.3 \\
\hline Presenting role models & 69.3 & 74.6 & 64.0 \\
\hline Targeted story reading or writing on SACD themes & 67.1 & 73.8 & 60.3 \\
\hline Peer mediation & 30.1 & 26.2 & 34.0 \\
\hline Honor roll for positive behavior & 42.7 & 36.6 & 48.9 \\
\hline $\begin{array}{l}\text { Pledges or recitations on social and character } \\
\text { development themes }\end{array}$ & 34.6 & 35.0 & 34.1 \\
\hline Guided visualization & 47.0 & $65.2^{*}$ & 28.9 \\
\hline Student-led/student-assisted instruction & 43.4 & 38.6 & 48.2 \\
\hline Journaling & 66.4 & 68.7 & 64.1 \\
\hline Time out for negative behavior & 80.0 & 80.0 & 80.1 \\
\hline Daily or weekly rewards for positive behavior & 89.5 & 87.6 & 91.5 \\
\hline
\end{tabular}

¥ Reporting standards not met. Values suppressed to protect confidentiality.

${ }^{*}$ Treatment group significantly different from control group at the .05 level.

** Treatment group significantly different from control group at the .01 level.

NOTE: Weights, which assign equal weight to each school within each of the programs and to each program across programs, were used in producing the treatment, control, and overall means. Statistical tests were conducted using regressions that included program indicators to account for the sample design and adjusted for clustering at the school level. Sample size may differ for some outcomes due to nonresponse.

SOURCE: The Social and Character Development (SACD) Research Program. 
Principals and teachers reported on participation in and amount of SACD training and staff development provided over the previous 12 months (table 8.12). Principals reported higher participation rates $(100 \%$ versus $81 \%$ ) and more hours of training (9.7 versus 7.6$)$ than did teachers. There was a significant difference between treatment and control teachers on the percentages reporting participation in SACD training; this favored the treatment group ( $96 \%$ versus $67 \%$ ). The treatment teachers also reported significantly more training than did the control teachers on three out of seven specific SACD areas: violence prevention and peace promotion (24\% versus $9 \%$ ), social and emotional development (43\% versus $13 \%$ ), and character education $(90 \%$ versus $50 \%)$.

Table 8.12. Principal and teacher initial reports on SACD professional development in sampleSS

\begin{tabular}{|c|c|c|c|}
\hline SACD professional development & Total & Treatment & Control \\
\hline Principal sample size & 12 & 6 & 6 \\
\hline Teacher sample size & 107 & 56 & 51 \\
\hline $\begin{array}{l}\text { Principals reporting that staff participated in social and character } \\
\text { development training within the past year (percent) }\end{array}$ & 100.0 & 100.0 & 100.0 \\
\hline $\begin{array}{l}\text { Teachers reporting participation in social and character } \\
\text { development training within the past } 12 \text { months (percent) }\end{array}$ & 81.4 & $95.6^{\star \star}$ & 67.2 \\
\hline $\begin{array}{l}\text { Number of hours of social and character development training } \\
\text { principals report were provided to each staff person last year (mean) }\end{array}$ & 9.7 & 8.2 & 11.6 \\
\hline $\begin{array}{l}\text { Number of hours of social and character development training } \\
\text { teachers report receiving during the past } 12 \text { months (mean) }\end{array}$ & 7.6 & 9.3 & 5.8 \\
\hline \multicolumn{4}{|l|}{$\begin{array}{l}\text { Teachers reporting receiving training in the past } 12 \text { months } \\
\text { in the following areas (percent) }\end{array}$} \\
\hline Violence prevention and peace promotion & 16.5 & $24.2^{*}$ & 8.8 \\
\hline Social and emotional development & 27.7 & $42.5^{\star *}$ & 12.9 \\
\hline Character education & 69.9 & $89.8^{* *}$ & 50.0 \\
\hline Tolerance and diversity & 11.6 & 7.7 & 15.5 \\
\hline Risk prevention and health promotion & 14.7 & 13.1 & 16.4 \\
\hline Civic responsibility and community service & 3.1 & $\ddagger$ & $\ddagger$ \\
\hline Behavior management & 25.4 & 19.0 & 31.8 \\
\hline
\end{tabular}

¥ Reporting standards not met. Values suppressed to protect confidentiality.

${ }^{*}$ Treatment group significantly different from control group at the .05 level.

** Treatment group significantly different from control group at the .01 level.

NOTE: Weights, which assign equal weight to each school within each of the programs and to each program across programs, were used in producing the treatment, control, and overall means. Statistical tests were conducted using regressions that included program indicators to account for the sample design and adjusted for clustering at the school level. Sample size may differ for some outcomes due to nonresponse.

SOURCE: The Social and Character Development (SACD) Research Program. 
The data on the initial level of SACD activity emphasize that the control condition was a "standard practice" control. Standard practice at the control schools included using SACD activities, materials, and practices, along with professional development, at rates and in types and amounts similar to the treatment schools. For example, the percentages of teachers who reported using programs or activities to promote specific SACD goals ranged from 47 percent to 99 percent in the treatment schools and from 47 percent to 87 percent in the control schools. However, the 12 significant differences between the treatment and control schools in the use of SACD activities was more than expected by chance (which would be 3 out of 62 comparisons), and in all but 1 case the differences favored the treatment group. This may reflect the fact that program implementation and program training for staff started before initial data collection.

\section{Impacts on Use of SACD Activities}

The introduction of the formal SS program would be expected to increase the use of SACD activities in the treatment schools in comparison to the control schools. The analysis of this impact was based on the Teacher Report on Classroom and School. Every spring, third-, fourth-, and fifth-grade teachers provided information through the Teacher Report on Classroom and School about the social and character development activities they used in their classrooms. Specifically, information from the Teacher Report on Classroom and School was used to determine the difference between treatment and control teachers in these areas:

1. the use of SACD activities in their classrooms overall and by SACD goal;

2. the use of materials and strategies to implement the SACD activities within classrooms and within the entire school;

3. the use of staff development to support the teachers; and

4. teacher support for SACD efforts in the school and the use of practices conducive to the social and character development of students.

Teacher Report on Classroom and School consent and completion rates (table 8.4) led to 87 percent to 97 percent of teachers overall having data for the 3 years (with a greater percentage of treatment teachers providing data at all but one time point). To estimate intervention impacts for each of the outcomes, testing of the statistical significance of the differences in means was used. Preliminary analysis indicated little or no gains in precision from using covariates. Before testing the mean differences, the data were weighted such that each school received equal weight. Standard errors of the impact estimates account for the clustering of teachers within schools. In addition, a set of heuristics was applied to determine whether each outcome domain was statistically significant after adjustments were made for the multiple tests conducted.

\section{Use of Activities}

The percentages of control teachers who reported using any SACD activities in their classrooms ranged from 81 percent to 92 percent over the 3 years (table 8.13, panel 1). For the six individual SACD goals, the percentages ranged from 53 percent to 86 percent in Year 1, 51 percent to 89 percent in Year 2, and 45 percent to 74 percent in Year 3. Control teachers' use of behavior management activities ranged from 86 percent to 96 percent over this period. The percentages of control teachers who reported using any SACD activities in their classrooms for at least 1 hour per week (panel 2) ranged from 39 percent to 74 percent over the 3 years. For the six individual SACD goals, the percentages ranged from 0 percent to 20 percent in Year 1, 9 percent to 23 percent in Year 2, and 6 percent to 23 percent in Year 3. Control teachers' reported use of behavior management activities ranged from 67 percent to 77 percent over this period.

For teachers' reported use of any SACD activity (panels 1 and 2), 48 comparisons were made, with 2 expected to be significant by chance. The percentage of treatment teachers using any SACD activity was not significantly different from the percentage of control teachers in any year. There were significant impacts on the use of specific activities in all 3 years. In Year 1, there were significant impacts on violence prevention and 
peace promotion (impact $=31$ percentage points) and on social and emotional development (impact $=39$ percentage points). The same impacts were seen in Years 2 and 3 (impacts ranging from 25 to 40 percentage points). In Year 2, there was a significant impact on tolerance and diversity (impact $=23$ percentage points) and another in Year 3 (impact $=32$ percentage points). In Year 3, there was an impact on character education (impact $=22$ percentage points). A similar pattern was seen in the reports of engagement in these activities for at least 1 hour per week. Significant impacts occurred on violence prevention and peace promotion in Year 2 (impact $=37$ percentage points), social and emotional development activities in Year 1 (impact $=37$ percentage points) and Year 2 (impact $=40$ percentage points), character education in Year 1 (impact $=52$ percentage points) and Year 2 (impact $=37$ percentage points), and tolerance and diversity in Year 2 (impact $=26$ percentage points) and Year 3 (impact $=31$ percentage points). The use of any activity for at least 1 hour per week was significantly impacted in Year 1 (impact $=30$ percentage points). After the heuristics were applied, the domain for engagement in SACD activities showed that SS had statistically significant impacts for all 3 years.

For teachers' reported use of any named SACD activity (panels 3 and 4), 42 comparisons were made, with 2 expected to be significant by chance. Eight of the 14 impact estimates were statistically significant in Year 1, with a significant impact on the domain as well. Ten of the 14 tested impacts were significant in Year 2, and there was an overall impact on the domain. Seven of the 14 tested impacts were significant in Year 3, again with a significant impact on the domain. In all 3 years, impacts were seen on violence prevention (impact $=$ 53, 69, and 63 percentage points), social and emotional development (impact $=73,80$, and 81 percentage points), character education (impact $=45,53$, and 61 percentage points), tolerance and diversity (impact $=49$, 45, and 49 percentage points), and any named activity (impact $=40,49$, and 53 percentage points). For any named activity at least 1 hour per week, SS had significant impacts on violence prevention in Year 2 (impact $=40$ percentage points), social and emotional development in Years 1 and 2 (impact $=46$ and 50 percentage points), character education in Years 1 and 2 (impact $=46$ and 45 percentage points), tolerance and diversity in Years 2 and 3 (impact $=27$ and 28 percentage points), and any named activity in all 3 years (impact $=49$, 46, and 40 percentage points). After the heuristics were applied, SS had statistically significant impacts on the domain for engagement in named SACD activities in all 3 years. 
Table 8.13. Impacts on teacher-reported SACD classroom activities-SS

Panel 1: Engagement in any activities to promote SACD goals ${ }^{1}$

\begin{tabular}{|c|c|c|c|c|c|c|c|c|c|c|c|c|}
\hline \multirow[b]{2}{*}{ SACD activity } & \multicolumn{4}{|c|}{$\begin{array}{c}\text { Year } 1 \\
\text { (Spring 3rd grade) }\end{array}$} & \multicolumn{4}{|c|}{$\begin{array}{c}\text { Year 2 } \\
\text { (Spring 4th grade) }\end{array}$} & \multicolumn{4}{|c|}{$\begin{array}{c}\text { Year } 3 \\
\text { (Spring 5th grade) }\end{array}$} \\
\hline & $\begin{array}{c}\text { Treat- } \\
\text { ment }\end{array}$ & Control & Impact & $p$-value & $\begin{array}{c}\text { Treat- } \\
\text { ment }\end{array}$ & Control & Impact & $p$-value & $\begin{array}{c}\text { Treat- } \\
\text { ment }\end{array}$ & Control & Impact & $p$-value \\
\hline Teacher sample size & 61 & 52 & & & 60 & 52 & & & 59 & 46 & & \\
\hline $\begin{array}{l}\text { Violence prevention and peace promotion } \\
\text { (percent) }\end{array}$ & $87.3^{*}$ & 56.2 & 31.1 & 0.017 & $91.5^{*}$ & 66.2 & 25.3 & 0.011 & $88.5^{*}$ & 50.5 & 38.0 & 0.005 \\
\hline $\begin{array}{l}\text { Social and emotional development } \\
\text { (percent) }\end{array}$ & $91.9^{*}$ & 53.0 & 38.9 & 0.002 & $96.7^{*}$ & 64.9 & 31.8 & 0.002 & $94.9^{*}$ & 54.8 & 40.1 & 0.004 \\
\hline Character education (percent) & $98.1^{\wedge}$ & 86.4 & 11.8 & 0.083 & 100.0 & 88.8 & 11.2 & $\dagger$ & $96.1^{*}$ & 73.8 & 22.3 & 0.028 \\
\hline Tolerance and diversity (percent) & $80.9^{\wedge}$ & 62.0 & 19.0 & 0.092 & $85.1^{*}$ & 62.3 & 22.7 & 0.002 & $76.4^{*}$ & 44.7 & 31.8 & 0.022 \\
\hline $\begin{array}{l}\text { Risk prevention and health promotion } \\
\text { (percent) }\end{array}$ & 52.7 & 63.2 & -10.4 & 0.457 & 57.9 & 51.1 & 6.8 & 0.502 & 59.3 & 62.4 & -3.1 & 0.819 \\
\hline $\begin{array}{l}\text { Civic responsibility and community service } \\
\text { (percent) }\end{array}$ & 70.4 & 73.7 & -3.3 & 0.751 & 67.3 & 68.0 & -0.6 & 0.959 & 70.5 & 66.7 & 3.8 & 0.732 \\
\hline Any SACD goal (percent) & 100.0 & 87.8 & 12.2 & $\dagger$ & 100.0 & 91.5 & 8.5 & $\dagger$ & $97.9^{\wedge}$ & 80.7 & 17.2 & 0.076 \\
\hline Behavior management (percent) & 89.4 & 96.2 & -6.8 & 0.187 & 92.3 & 85.7 & 6.6 & 0.213 & 85.4 & 89.8 & -4.4 & 0.614 \\
\hline
\end{tabular}

Behavior management (percent)

See notes at end of table. 
Table 8.13. Impacts on teacher-reported SACD classroom activities-SS-Continued

Panel 2: Engagement in any activities to promote SACD goals for at least 1 hour per week

\begin{tabular}{|c|c|c|c|c|c|c|c|c|c|c|c|c|}
\hline \multirow[b]{2}{*}{ SACD activity } & \multicolumn{4}{|c|}{$\begin{array}{c}\text { Year } 1 \\
\text { (Spring 3rd grade) } \\
\end{array}$} & \multicolumn{4}{|c|}{$\begin{array}{c}\text { Year 2 } \\
\text { (Spring 4th grade) } \\
\end{array}$} & \multicolumn{4}{|c|}{$\begin{array}{c}\text { Year 3 } \\
\text { (Spring 5th grade) }\end{array}$} \\
\hline & $\begin{array}{r}\text { Treat- } \\
\text { ment }\end{array}$ & Control & Impact & $p$-value & $\begin{array}{c}\text { Treat- } \\
\text { ment }\end{array}$ & Control & Impact & $p$-value & $\begin{array}{c}\text { Treat- } \\
\text { ment }\end{array}$ & Control & Impact & $p$-value \\
\hline Teacher sample size & 61 & 52 & & & 60 & 52 & & & 59 & 46 & & \\
\hline $\begin{array}{l}\text { Violence prevention and peace promotion } \\
\text { (percent) }\end{array}$ & 42.7 & 0.0 & 42.7 & $\dagger$ & $50.2^{*}$ & 13.1 & 37.1 & 0.026 & 38.2 & 12.5 & 25.7 & 0.109 \\
\hline $\begin{array}{l}\text { Social and emotional development } \\
\text { (percent) }\end{array}$ & $49.8^{*}$ & 12.4 & 37.3 & 0.007 & $55.9^{*}$ & 16.1 & 39.8 & 0.005 & $48.2^{\wedge}$ & 16.9 & 31.3 & 0.079 \\
\hline Character education (percent) & $64.8^{*}$ & 13.2 & 51.5 & 0.002 & $60.2^{*}$ & 23.0 & 37.1 & 0.040 & $44.1^{\wedge}$ & 23.3 & 20.9 & 0.094 \\
\hline Tolerance and diversity (percent) & 36.1 & 19.6 & 16.5 & 0.199 & $41.9^{*}$ & 15.6 & 26.2 & 0.042 & $38.5^{*}$ & 7.4 & 31.1 & 0.010 \\
\hline $\begin{array}{l}\text { Risk prevention and health promotion } \\
\text { (percent) }\end{array}$ & 13.9 & 9.7 & 4.2 & 0.527 & 13.3 & 8.5 & 4.8 & 0.530 & 16.0 & 6.4 & 9.6 & 0.181 \\
\hline $\begin{array}{l}\text { Civic responsibility and community service } \\
\text { (percent) }\end{array}$ & 11.2 & 11.8 & -0.6 & 0.934 & 13.3 & 17.0 & -3.7 & 0.591 & $13.9^{\wedge}$ & 10.6 & 3.3 & 0.699 \\
\hline Any SACD goal (percent) & $69.2^{*}$ & 39.4 & 29.7 & 0.045 & $83.4^{\wedge}$ & 61.1 & 22.2 & 0.052 & 85.4 & 73.9 & 11.5 & 0.245 \\
\hline Behavior management (percent) & 63.1 & 76.6 & -13.5 & 0.417 & 79.3 & 67.4 & 11.9 & 0.331 & 73.0 & 77.3 & -4.3 & 0.688 \\
\hline
\end{tabular}

Behavior management (percent)

See notes at end of table. 
Table 8.13. Impacts on teacher-reported SACD classroom activities-SS-Continued

Panel 3: Engagement in activities to promote SACD goals linked to named SACD programs ${ }^{2}$

\begin{tabular}{|c|c|c|c|c|c|c|c|c|c|c|c|c|}
\hline \multirow[b]{2}{*}{ SACD activity } & \multicolumn{4}{|c|}{$\begin{array}{c}\text { Year } 1 \\
\text { (Spring 3rd grade) }\end{array}$} & \multicolumn{4}{|c|}{$\begin{array}{c}\text { Year } 2 \\
\text { (Spring 4th grade) }\end{array}$} & \multicolumn{4}{|c|}{$\begin{array}{c}\text { Year } 3 \\
\text { (Spring 5th grade) }\end{array}$} \\
\hline & $\begin{array}{r}\text { Treat- } \\
\text { ment }\end{array}$ & Control & Impact & $p$-value & $\begin{array}{r}\text { Treat- } \\
\text { ment }\end{array}$ & Control & Impact & $p$-value & $\begin{array}{r}\text { Treat- } \\
\text { ment }\end{array}$ & Control & Impact & $p$-value \\
\hline Teacher sample size & 61 & 52 & & & 60 & 52 & & & 59 & 46 & & \\
\hline $\begin{array}{l}\text { Violence prevention and peace promotion } \\
\text { (percent) }\end{array}$ & $68.0^{*}$ & 15.0 & 53.0 & 0.002 & $76.3^{*}$ & 7.3 & 69.0 & 0.001 & $78.4^{*}$ & 15.6 & 62.8 & 0.004 \\
\hline $\begin{array}{l}\text { Social and emotional development } \\
\text { (percent) }\end{array}$ & $86.8^{*}$ & 13.9 & 72.9 & 0.001 & $85.4^{*}$ & 5.8 & 79.6 & 0.000 & $93.4^{*}$ & 12.8 & 80.6 & 0.001 \\
\hline Character education (percent) & $85.9^{*}$ & 41.4 & 44.5 & 0.008 & $82.0^{*}$ & 29.5 & 52.6 & 0.003 & $85.1^{*}$ & 24.4 & 60.7 & 0.003 \\
\hline Tolerance and diversity (percent) & $62.4^{*}$ & 13.2 & 49.2 & 0.009 & $55.2^{*}$ & 10.2 & 45.0 & 0.000 & $58.9^{*}$ & 10.1 & 48.8 & 0.000 \\
\hline $\begin{array}{l}\text { Risk prevention and health promotion } \\
\text { (percent) }\end{array}$ & 28.0 & 21.6 & 6.4 & 0.520 & 18.3 & 12.8 & 5.5 & 0.487 & 30.2 & 15.6 & 14.6 & 0.267 \\
\hline $\begin{array}{l}\text { Civic responsibility and community service } \\
\text { (percent) }\end{array}$ & 5.6 & 0.0 & 5.6 & $\dagger$ & $\ddagger$ & $\ddagger$ & -3.8 & 0.310 & 13.8 & 6.8 & 7.0 & 0.294 \\
\hline Any named activity (percent) & $97.0^{*}$ & 57.3 & 39.7 & 0.001 & $91.0^{*}$ & 42.5 & 48.5 & 0.001 & $97.9^{*}$ & 45.0 & 53.0 & 0.004 \\
\hline
\end{tabular}




\section{Table 8.13. Impacts on teacher-reported SACD classroom activities-SS—Continued}

Panel 4: Engagement in activities to promote SACD goals linked to named SACD programs for at least 1 hour per week

\begin{tabular}{|c|c|c|c|c|c|c|c|c|c|c|c|c|}
\hline \multirow[b]{2}{*}{ SACD activity } & \multicolumn{4}{|c|}{$\begin{array}{c}\text { Year } 1 \\
\text { (Spring 3rd grade) }\end{array}$} & \multicolumn{4}{|c|}{$\begin{array}{c}\text { Year } 2 \\
\text { (Spring 4th grade) }\end{array}$} & \multicolumn{4}{|c|}{$\begin{array}{c}\text { Year } 3 \\
\text { (Spring 5th grade) }\end{array}$} \\
\hline & $\begin{array}{r}\text { Treat- } \\
\text { ment }\end{array}$ & Control & Impact & $p$-value & $\begin{array}{r}\text { Treat- } \\
\text { ment }\end{array}$ & Control & Impact & $p$-value & $\begin{array}{r}\text { Treat- } \\
\text { ment }\end{array}$ & Control & Impact & $p$-value \\
\hline Teacher sample size & 61 & 52 & & & 60 & 52 & & & 59 & 46 & & \\
\hline $\begin{array}{l}\text { Violence prevention and peace promotion } \\
\text { (percent) } \\
\text { Social and emotional development }\end{array}$ & 42.7 & 0.0 & 42.7 & $\dagger$ & $\ddagger^{*}$ & $\ddagger$ & 40.0 & 0.002 & 37.0 & 8.7 & 28.3 & 0.138 \\
\hline (percent) & $\ddagger^{*}$ & $\ddagger$ & 46.1 & 0.011 & $\ddagger^{*}$ & $\ddagger$ & 50.4 & 0.002 & $48.2^{\wedge}$ & 9.1 & 39.1 & 0.083 \\
\hline Character education (percent) & $57.3^{*}$ & 11.1 & 46.2 & 0.002 & $54.4^{*}$ & 9.4 & 45.0 & 0.002 & $42.5^{\wedge}$ & 12.8 & 29.7 & 0.089 \\
\hline $\begin{array}{l}\text { Tolerance and diversity (percent) } \\
\text { Risk prevention and health promotion }\end{array}$ & 36.1 & 0.0 & 36.1 & $\dagger$ & $\ddagger^{*}$ & $\ddagger$ & 26.8 & 0.005 & $\ddagger^{*}$ & $\ddagger$ & 28.1 & 0.006 \\
\hline (percent) & $\ddagger$ & $\ddagger$ & 7.1 & 0.187 & 10.1 & 7.3 & 2.9 & 0.688 & $\ddagger$ & $\ddagger$ & 9.6 & 0.119 \\
\hline $\begin{array}{l}\text { Civic responsibility and community service } \\
\text { (percent) }\end{array}$ & $\ddagger$ & $\ddagger$ & 2.7 & $\dagger$ & $\ddagger$ & $\ddagger$ & 0.4 & 0.904 & 6.5 & 0.0 & 6.5 & $\dagger$ \\
\hline Any named activity (percent) & $64.6^{*}$ & 15.7 & 49.0 & 0.015 & $59.5^{*}$ & 13.6 & 45.9 & 0.001 & $57.2^{*}$ & 17.5 & 39.7 & 0.039 \\
\hline
\end{tabular}

$\ddagger$ Reporting standards not met. Values suppressed to protect confidentiality.

* Treatment group significantly different from control group at the .05 level.

$\wedge$ Treatment group significantly different from control group at the .10 to $>.05$ level.

${ }^{1}$ In all 3 years at least one outcome remained positive and statistically significant and no outcome was negative and statistically significant after applying the Benjamini-Hochberg (1995) procedure to adjust significance levels downward to account for the multiple testing of impacts. In Year 2 at least half of the impacts were positive and statistically significant and no impact was negative and statistically significant based on univariate statistical tests.

${ }^{2}$ In all 3 years at least half of the impacts were positive and statistically significant and no impact was negative and statistically significant based on univariate statistical tests and at least one outcome remained positive and statistically significant and no outcome was negative and statistically significant after applying the Benjamini-Hochberg (1995) procedure to adjust significance levels downward to account for the multiple testing of impacts.

NOTE: Weights, which assign equal weight to each school within the program, were used in producing the treatment, control, and overall means.

SOURCE: The Social and Character Development (SACD) Research Program. 


\section{Use of Materials and Strategies}

For use of materials and strategies to support SACD goals, 87 comparisons were made, with 4 expected to be significant by chance. In Year 1, significant impacts were found for teachers' use of teacher guides (impact $=$ 30 percentage points), instructional aids (impact $=36$ percentage points), role-playing (impact $=37$ percentage points), skill training (impact $=59$ percentage points), incorporating SACD into the academic curriculum (impact $=27$ percentage points), presenting role models (impact $=17$ percentage points), using guided visualization (impact $=43$ percentage points), and the average number of strategies used (by 2.7 strategies on average). In Year 2, SS significantly affected the use of teacher guides (impact $=39$ percentage points), student materials (impact $=30$ percentage points), instructional aids (impact $=24$ percentage points), direct instruction of SACD (impact $=26$ percentage points), skill training (impact $=52$ percentage points), incorporating SACD into academic curriculum (impact $=21$ percentage points), guided visualization (impact $=40$ percentage points), and average number of strategies used (by 2.7 strategies on average). Significant impacts in Year 3 affected use of teacher guides (impact $=45$ percentage points), instructional aids (impact $=$ 28 percentage points), skill training (impact $=17$ percentage points), parent training (impact $=36$ percentage points), parent and community involvement (impact $=25$ percentage points), guided visualization (impact $=$ 38 percentage points), and average number of strategies (by 2.7 strategies on average). The SS impact on the domain of materials and strategies was significant in all 3 years. 
Table 8.14. Impacts on use of SACD classroom materials and teaching strategies-SS

\begin{tabular}{|c|c|c|c|c|c|c|c|c|c|c|c|c|}
\hline \multirow[b]{2}{*}{ SACD material and teaching strategy ${ }^{1}$} & \multicolumn{4}{|c|}{$\begin{array}{c}\text { Year } 1 \\
\text { (Spring 3rd grade) }\end{array}$} & \multicolumn{4}{|c|}{$\begin{array}{c}\text { Year } 2 \\
\text { (Spring 4th grade) }\end{array}$} & \multicolumn{4}{|c|}{$\begin{array}{c}\text { Year } 3 \\
\text { (Spring 5th grade) } \\
\end{array}$} \\
\hline & $\begin{array}{c}\text { Treat- } \\
\text { ment } \\
\end{array}$ & Control & Impact & $p$-value & $\begin{array}{c}\text { Treat- } \\
\text { ment }\end{array}$ & Control & Impact & $p$-value & $\begin{array}{r}\text { Treat- } \\
\text { ment }\end{array}$ & Control & Impact & $p$-value \\
\hline Teacher sample size & 61 & 52 & & & 60 & 52 & & & 59 & 46 & & \\
\hline \multicolumn{13}{|l|}{ Use of SACD materials (percent) } \\
\hline Teacher guides (manuals, curricula) & $93.0^{*}$ & 62.7 & 30.4 & 0.000 & $98.1^{*}$ & 59.1 & 39.0 & 0.005 & $94.7^{*}$ & 50.2 & 44.5 & 0.003 \\
\hline Student materials (workbooks or sheets) & 70.0 & 52.1 & 17.9 & 0.126 & $78.7^{*}$ & 48.6 & 30.1 & 0.021 & 67.1 & 52.9 & 14.3 & 0.192 \\
\hline Instructional aids (games, software, videos) & $64.6^{*}$ & 28.7 & 35.9 & 0.005 & $62.8^{*}$ & 38.6 & 24.2 & 0.015 & $61.5^{*}$ & 33.6 & 27.9 & 0.005 \\
\hline Giveaways (bookmarks, stickers) & 52.3 & 66.6 & -14.3 & 0.343 & 59.1 & 66.8 & -7.7 & 0.504 & 44.1 & 62.3 & -18.2 & 0.203 \\
\hline Children's literature & 40.8 & 35.4 & 5.4 & 0.765 & 46.7 & 38.7 & 8.0 & 0.587 & 40.6 & 33.9 & 6.8 & 0.381 \\
\hline Other types of materials & 8.5 & 9.7 & -1.1 & 0.843 & 10.9 & 12.2 & -1.2 & 0.875 & $\ddagger$ & $\ddagger$ & 4.7 & 0.463 \\
\hline Did not use any of these materials & 0.0 & 13.2 & -13.2 & $\dagger$ & 0.0 & 14.7 & -14.7 & $\dagger$ & 0.0 & 14.1 & -14.1 & $\dagger$ \\
\hline \multicolumn{13}{|l|}{ Use of teaching strategies (percent) } \\
\hline Role-playing & $97.5^{\star}$ & 60.2 & 37.2 & 0.008 & 100.0 & 62.9 & 37.1 & $\dagger$ & 100.0 & 73.1 & 27.0 & $\dagger$ \\
\hline Cooperative learning & 97.2 & 92.9 & 4.3 & 0.365 & 98.3 & 95.5 & 2.8 & 0.404 & 100.0 & 91.7 & 8.3 & $\dagger$ \\
\hline Peer group discussions & 95.4 & 86.1 & 9.3 & 0.153 & $91.4^{\wedge}$ & 75.4 & 16.0 & 0.064 & 100.0 & 90.4 & 9.6 & $\dagger$ \\
\hline Direct instruction of SACD & 100.0 & 72.8 & 27.2 & $\dagger$ & $97.9^{*}$ & 72.4 & 25.5 & 0.015 & 100.0 & 86.2 & 13.8 & $\dagger$ \\
\hline Skill training & $88.5^{*}$ & 29.5 & 59.1 & 0.000 & $89.0^{*}$ & 36.7 & 52.3 & 0.000 & $94.4^{*}$ & 77.8 & 16.5 & 0.047 \\
\hline $\begin{array}{l}\text { Incorporating SACD into academic } \\
\text { curriculum }\end{array}$ & $96.3^{*}$ & 69.1 & 27.2 & 0.003 & $87.4^{*}$ & 66.9 & 20.5 & 0.045 & 94.0 & 95.1 & -1.1 & 0.825 \\
\hline Parent training & 20.1 & 9.7 & 10.5 & 0.302 & $\ddagger$ & $\ddagger$ & 2.4 & 0.601 & $\ddagger^{*}$ & $\ddagger$ & 35.9 & 0.002 \\
\hline Parent/community involvement & 41.7 & 38.3 & 3.5 & 0.763 & $36.1^{\wedge}$ & 18.5 & 17.6 & 0.093 & $62.2^{*}$ & 37.5 & 24.6 & 0.020 \\
\hline Mentoring & 45.7 & 49.4 & -3.7 & 0.820 & 42.7 & 42.5 & 0.2 & 0.988 & 74.7 & 67.6 & 7.1 & 0.569 \\
\hline $\begin{array}{l}\text { Good behavior notes sent home daily } \\
\text { or weekly }\end{array}$ & 72.9 & 76.8 & -3.9 & 0.766 & 73.6 & 79.2 & -5.6 & 0.626 & 96.5 & 91.5 & 5.0 & 0.219 \\
\hline Presenting role models & $85.7^{*}$ & 69.1 & 16.5 & 0.009 & 87.6 & 73.5 & 14.1 & 0.117 & 92.5 & 77.9 & 14.6 & 0.131 \\
\hline
\end{tabular}


Table 8.14. Impacts on use of SACD classroom materials and teaching strategies-SS—Continued

\begin{tabular}{|c|c|c|c|c|c|c|c|c|c|c|c|c|}
\hline \multirow[b]{2}{*}{ SACD material and teaching strategy ${ }^{1}$} & \multicolumn{4}{|c|}{$\begin{array}{c}\text { Year } 1 \\
\text { (Spring 3rd grade) }\end{array}$} & \multicolumn{4}{|c|}{$\begin{array}{c}\text { Year } 2 \\
\text { (Spring 4th grade) }\end{array}$} & \multicolumn{4}{|c|}{$\begin{array}{c}\text { Year } 3 \\
\text { (Spring 5th grade) }\end{array}$} \\
\hline & $\begin{array}{r}\text { Treat- } \\
\text { ment }\end{array}$ & Control & Impact & $p$-value & $\begin{array}{r}\text { Treat- } \\
\text { ment }\end{array}$ & Control & Impact & $p$-value & $\begin{array}{r}\text { Treat- } \\
\text { ment }\end{array}$ & Control & Impact & $p$-value \\
\hline \multicolumn{13}{|l|}{$\begin{array}{l}\text { Use of teaching strategies (percent)- } \\
\text { Continued }\end{array}$} \\
\hline $\begin{array}{l}\text { Targeted story reading or writing on social } \\
\text { and character development themes }\end{array}$ & 75.3 & 60.1 & 15.2 & 0.266 & 67.6 & 55.9 & 11.7 & 0.303 & 89.9 & 85.9 & 4.0 & 0.614 \\
\hline Peer mediation & 38.8 & 37.0 & 1.9 & 0.887 & 38.0 & 41.4 & -3.4 & 0.822 & 52.4 & 49.4 & 3.0 & 0.833 \\
\hline Honor roll for positive behavior & 38.6 & 54.5 & -15.8 & 0.371 & 58.2 & 53.0 & 5.2 & 0.749 & 68.1 & 57.0 & 11.1 & 0.554 \\
\hline $\begin{array}{l}\text { Pledges or recitations on social and } \\
\text { character development themes }\end{array}$ & 43.2 & 29.2 & 14.0 & 0.451 & 35.3 & 32.1 & 3.2 & 0.838 & 56.8 & 40.9 & 16.0 & 0.317 \\
\hline Guided visualization & $73.9^{*}$ & 30.8 & 43.1 & 0.000 & $71.3^{*}$ & 31.5 & 39.9 & 0.006 & $92.0^{*}$ & 54.6 & 37.5 & 0.001 \\
\hline Student-led/student-assisted instruction & 46.4 & 38.3 & 8.1 & 0.553 & $55.1^{\wedge}$ & 33.3 & 21.8 & 0.051 & 63.4 & 71.9 & -8.5 & 0.362 \\
\hline Journaling & 68.7 & 50.0 & 18.7 & 0.099 & 67.4 & 50.1 & 17.2 & 0.106 & 84.3 & 68.9 & 15.4 & 0.264 \\
\hline Time out for negative behavior & 74.9 & 86.1 & -11.2 & 0.331 & 82.9 & 90.1 & -7.2 & 0.185 & 96.3 & 97.1 & -0.8 & 0.857 \\
\hline $\begin{array}{l}\text { Daily or weekly rewards for positive } \\
\text { behavior }\end{array}$ & 89.6 & 80.0 & 9.5 & 0.192 & 89.1 & 88.6 & 0.4 & 0.949 & 100.0 & 97.2 & 2.8 & $\dagger$ \\
\hline Any strategy & 100.0 & 98.6 & 1.4 & $\dagger$ & 100.0 & 100.0 & 0.0 & $\dagger$ & 100.0 & 97.2 & 2.8 & $\dagger$ \\
\hline Number of strategies (mean) & $13.8^{*}$ & 11.1 & 2.7 & 0.001 & $13.7^{*}$ & 10.9 & 2.7 & 0.002 & $16.3^{*}$ & 13.6 & 2.7 & 0.000 \\
\hline
\end{tabular}

T Not applicable.

† Reporting standards not met. Values suppressed to protect confidentiality.

* Treatment group significantly different from control group at the .05 level.

$\wedge$ Treatment group significantly different from control group at the .10 to $>.05$ level.

${ }^{1}$ In all 3 years at least one outcome remained positive and statistically significant and no outcome was negative and statistically significant after applying the Benjamini-Hochberg

(1995) procedure to adjust significance levels downward to account for the multiple testing of impacts.

NOTE: Weights, which assign equal weight to each school within the program, were used in producing the treatment, control, and overall means.

SOURCE: The Social and Character Development (SACD) Research Program. 
Regarding the use of schoolwide strategies, 18 comparisons were made between treatment and control teacher reports, with 1 expected to be significant by chance. There was no SS impact on teachers' reports of their schools' use of schoolwide strategies in any of the years (these data are not shown in a table), nor was there a significant impact on the domain in any year.

\section{Participation in Professional Development}

Regarding reported participation in professional development, 27 comparisons were made over 3 years, with 1 expected to be significant by chance. In Year 1, SS had an impact on SACD training (impact $=32$ percentage points) and training in the specific goal of character education (impact $=29$ percentage points). No significant impacts were found on the domain in any of the 3 years. 
Table 8.15. Impacts on teacher-reported SACD professional development-SS

\begin{tabular}{|c|c|c|c|c|c|c|c|c|c|c|c|c|}
\hline \multirow[b]{2}{*}{ SACD professional development } & \multicolumn{4}{|c|}{$\begin{array}{c}\text { Year } 1 \\
\text { (Spring 3rd grade) }\end{array}$} & \multicolumn{4}{|c|}{$\begin{array}{c}\text { Year } 2 \\
\text { (Spring 4th grade) }\end{array}$} & \multicolumn{4}{|c|}{$\begin{array}{c}\text { Year } 3 \\
\text { (Spring 5th grade) }\end{array}$} \\
\hline & $\begin{array}{c}\text { Treat- } \\
\text { ment }\end{array}$ & Control & Impact & $p$-value & $\begin{array}{r}\text { Treat- } \\
\text { ment }\end{array}$ & Control & Impact & $p$-value & $\begin{array}{c}\text { Treat- } \\
\text { ment } \\
\end{array}$ & Control & Impact & $p$-value \\
\hline Teacher sample size & 61 & 52 & & & 60 & 52 & & & 59 & 46 & & \\
\hline SACD training in past 12 months (percent) & $87.0^{*}$ & 54.7 & 32.3 & 0.009 & 60.2 & 48.1 & 12.1 & 0.295 & 44.9 & 42.8 & 2.1 & 0.864 \\
\hline Hours of SACD training (mean) & 6.4 & 4.5 & 1.9 & 0.302 & 4.3 & 4.8 & -0.4 & 0.859 & 3.1 & 2.9 & 0.1 & 0.934 \\
\hline \multicolumn{13}{|l|}{ Training by goal (percent) } \\
\hline Violence prevention and peace promotion & 21.0 & 13.5 & 7.5 & 0.267 & 10.6 & 10.4 & 0.2 & 0.973 & 12.9 & 9.0 & 3.9 & 0.581 \\
\hline Social and emotional development & 32.1 & 16.8 & 15.3 & 0.208 & 14.4 & 18.5 & -4.1 & 0.690 & $\ddagger$ & $\ddagger$ & 10.6 & 0.140 \\
\hline Character education & $75.5^{*}$ & 46.2 & 29.3 & 0.029 & 43.7 & 31.5 & 12.2 & 0.267 & 24.4 & 27.9 & -3.4 & 0.792 \\
\hline Tolerance and diversity & 9.7 & 9.0 & 0.7 & 0.919 & 13.5 & 18.4 & -4.9 & 0.647 & 4.5 & 8.3 & -3.8 & 0.394 \\
\hline Risk prevention and health promotion & 20.2 & 25.2 & -5.0 & 0.438 & 8.6 & 19.9 & -11.3 & 0.178 & 11.0 & 14.6 & -3.6 & 0.614 \\
\hline Civic responsibility and community service & $\ddagger$ & $\ddagger$ & 5.0 & 0.294 & $\ddagger$ & $\ddagger$ & 5.0 & 0.358 & $\ddagger$ & $\ddagger$ & -2.8 & 0.502 \\
\hline Behavior management & 13.8 & 27.9 & -14.1 & 0.269 & 16.2 & 17.3 & -1.1 & 0.891 & $4.9^{\wedge}$ & 18.3 & -13.5 & 0.073 \\
\hline
\end{tabular}

$\mp$ Reporting standards not met. Values suppressed to protect confidentiality.

* Treatment group significantly different from control group at the .05 level.

$\wedge$ Treatment group significantly different from control group at the .10 to $>.05$ level.

NOTE: Weights, which assign equal weight to each school within the program, were used in producing the treatment, control, and overall means

SOURCE: The Social and Character Development (SACD) Research Program. 


\section{Attitudes and Practices}

Teachers reported on their enthusiasm for SACD efforts in their schools (these data are not shown in a table) by indicating enthusiasm, cooperation, or open dislike. They also reported on the SACD practices of teachers and staff members in their schools (these data are not shown in a table). The practices included modeling positive character and behavior traits with students and fellow teachers, involving students in making decisions, giving students a voice in school governance, the school encouraging parent involvement in children's social and character development, and using developmentally appropriate discipline strategies rather than punishment for misbehavior. Twenty-seven comparisons were made over 3 years, with 1 expected to be significant by chance. Out of 9 comparisons made in Year 2, there was 1 significant impact on reported enthusiasm (impact $=24$ percentage points). There was no impact on the domain in any year.

\section{Year-by-Year Impacts on Students and Perceptions of School Climate}

The primary research question for the SS evaluation was this:

What is the average effect of the SS program on children's social and emotional competence, behavior, academics, and perceptions of school climate?

The first approach to answering this question was to examine the year-by-year impacts of the SS program on these student and school climate outcomes over the 3 years as the students progressed from third through fifth grades.

Equation (2) (described in chapter 1) was estimated to provide the SS impacts on the 20 outcomes using data from the 12 treatment and control schools. For the SS evaluation, equation (2) excluded the program fixed effects $\left(\theta_{p}\right)$ and included program-specific covariates and random school effects covariates. Table 8.16 lists the covariates used with outcomes from each report in the SS analysis. 
Table 8.16. Covariates used with outcomes from each report for analysis-SS

\begin{tabular}{|c|c|c|c|c|}
\hline Potential covariate & $\begin{array}{c}\text { CR } \\
\text { outcome }\end{array}$ & $\begin{array}{c}\text { PCR } \\
\text { outcome }\end{array}$ & $\begin{array}{c}\text { TRS } \\
\text { outcome }\end{array}$ & $\begin{array}{c}\text { TRCS } \\
\text { outcome }\end{array}$ \\
\hline Total number & 11 & 28 & 21 & 8 \\
\hline \multicolumn{5}{|l|}{ Child-reported } \\
\hline Female & $\checkmark$ & $\checkmark$ & $\checkmark$ & \\
\hline Hispanic & $\checkmark$ & $\checkmark$ & $\checkmark$ & \\
\hline Black (non-Hispanic) & $\checkmark$ & $\checkmark$ & $\checkmark$ & \\
\hline Other ethnicity & $\checkmark$ & $\checkmark$ & $\checkmark$ & \\
\hline Age in years & $\checkmark$ & $\checkmark$ & $\checkmark$ & \\
\hline \multicolumn{5}{|l|}{ Scales } \\
\hline Afraid at School & & $\checkmark$ & $\checkmark$ & \\
\hline \multicolumn{5}{|l|}{ Altruistic Behavior } \\
\hline Empathy & & $\checkmark$ & $\checkmark$ & \\
\hline \multicolumn{5}{|l|}{ Engagement with Learning } \\
\hline Negative School Orientation & & $\checkmark$ & $\checkmark$ & \\
\hline Normative Beliefs About Aggression & & $\checkmark$ & $\checkmark$ & \\
\hline Sense of School as a Community & $\checkmark$ & $\checkmark$ & $\checkmark$ & \\
\hline \multicolumn{5}{|l|}{ Problem Behavior } \\
\hline \multicolumn{5}{|l|}{ Self-Efficacy for Peer Interactions } \\
\hline \multicolumn{5}{|l|}{ Victimization at School } \\
\hline \multicolumn{5}{|l|}{$\begin{array}{l}\text { Primary caregiver-reported } \\
\text { Age in years }\end{array}$} \\
\hline Completed high school or equivalent & $\checkmark$ & $\checkmark$ & $\checkmark$ & \\
\hline Some College & $\checkmark$ & $\checkmark$ & $\checkmark$ & \\
\hline Bachelor's or higher degree & $\checkmark$ & $\checkmark$ & $\checkmark$ & \\
\hline \multicolumn{5}{|l|}{ Highest level of education in household } \\
\hline Completed high school or equivalent & & $\checkmark$ & & \\
\hline Some college & & $\checkmark$ & & \\
\hline Bachelor's or higher degree & & $\checkmark$ & & \\
\hline Mother present in home life & & $\checkmark$ & & \\
\hline \multicolumn{5}{|c|}{ Mother and father present } \\
\hline \multicolumn{5}{|c|}{ Respondent someone other than mother or father } \\
\hline Number of people in household & & $\checkmark$ & & \\
\hline Household income: $\$ 20,000$ to $\$ 40,000$ & & $\checkmark$ & & \\
\hline Household income: $\$ 40,000$ to $\$ 60,000$ & & $\checkmark$ & & \\
\hline Household income: More than $\$ 60,000$ & & $\checkmark$ & & \\
\hline \multicolumn{5}{|c|}{ Income-to-poverty-threshold ratio: Below 135 percent } \\
\hline \multicolumn{5}{|c|}{ Income-to-poverty-threshold ratio: $135-185$ percent } \\
\hline Full-time employment & & & $\checkmark$ & \\
\hline Part-time employment & & & $\checkmark$ & \\
\hline
\end{tabular}

See notes at end of table. 
Table 8.16. Covariates used with outcomes from each report for analysis-SS-Continued

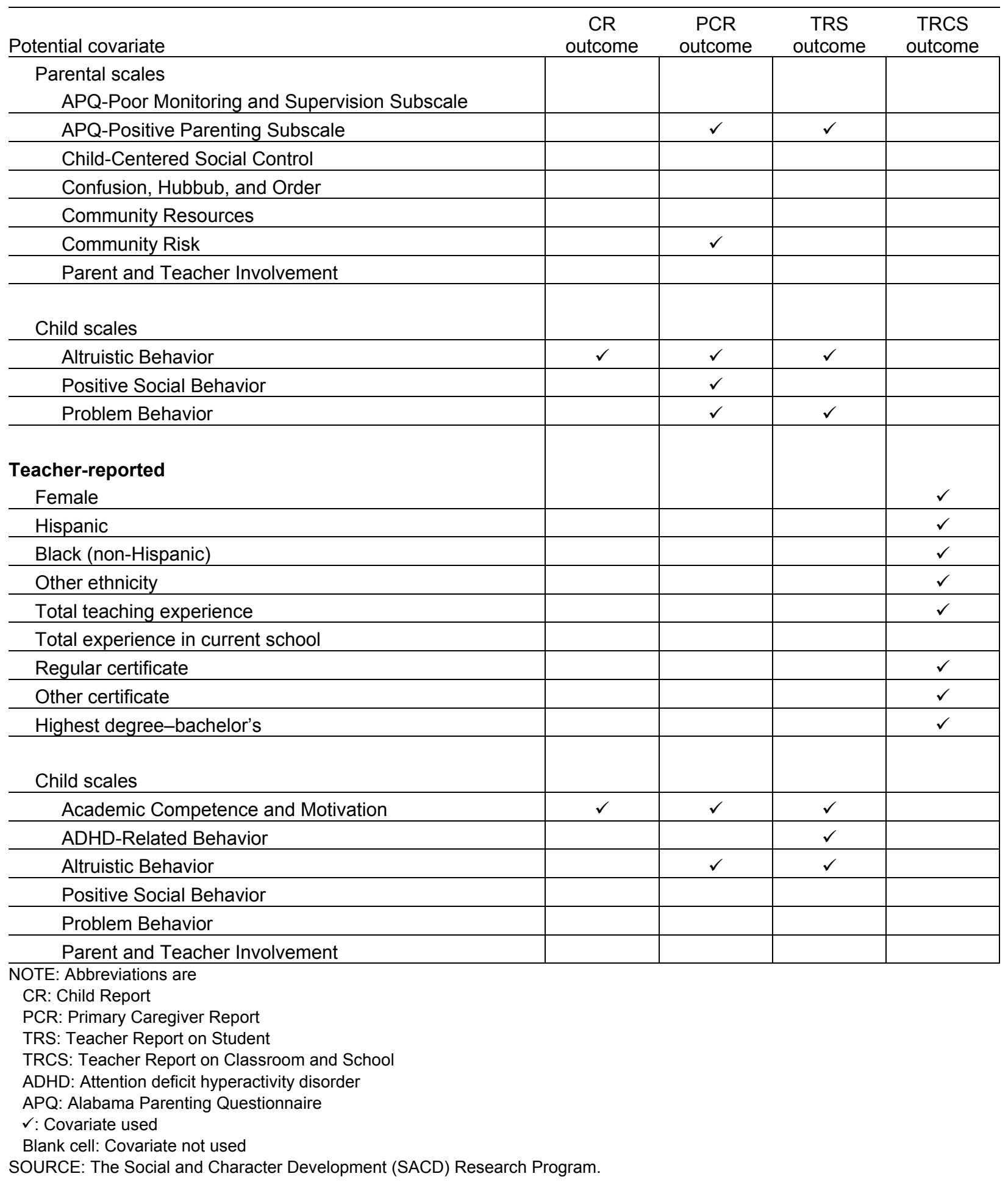


To assess the statistical power of the program-level impact estimates, minimum detectable impacts in effect size units (MDES) for each outcome measure were calculated for the SS evaluation (table 8.17). MDES represent the smallest impacts in effect size (standard deviation) units that can be detected with a high probability (80\%). MDES are primarily a function of study sample sizes, the degrees of freedom available for statistical tests, and design effects due to clustering (Schochet 2005). For the SS evaluation, the MDES ranged from 0.099 to 0.526 for the child-level outcomes based on the Child, Caregiver, and Teacher Report on Student and from 0.314 to 0.694 for the school climate outcomes based on the Teacher Report on Classroom and School. In general, the MDES for the school climate outcomes were larger than those for the child-level outcomes. 
Table 8.17. Adjusted minimum detectable effect sizes for impact evaluation-SS

\begin{tabular}{lccc}
\hline Outcome measure-Report & Year 1 & Year 2 & Year 3 \\
\hline Social and Emotional Competence Domain & & & \\
$\quad$ Self-Efficacy for Peer Interaction-CR & 0.156 & 0.252 & 0.105 \\
Normative Beliefs About Aggression-CR & 0.103 & 0.099 & 0.099 \\
Empathy-CR & 0.156 & 0.170 & 0.200 \\
& & & \\
Behavior Domain & & & \\
Altruistic Behavior-CR & 0.103 & 0.161 & 0.133 \\
Altruistic Behavior-PCR & 0.110 & 0.132 & 0.139 \\
Altruistic Behavior-TRS & 0.526 & 0.512 & 0.481 \\
Positive Social Behavior-PCR & 0.142 & 0.106 & 0.108 \\
Positive Social Behavior-TRS & 0.279 & 0.455 & 0.356 \\
Problem Behavior-CR & 0.106 & 0.166 & 0.099 \\
Problem Behavior-PCR & 0.183 & 0.142 & 0.149 \\
Problem Behavior-TRS & 0.275 & 0.404 & 0.348 \\
ADHD-Related Behavior-TRS & 0.264 & 0.296 & 0.342 \\
& & & \\
Academics Domain & & & \\
Engagement with Learning-CR & & & 0.099 \\
Academic Competence and Motivation-TRS & 0.103 & 0.106 & 0.277 \\
& 0.103 & 0.167 & \\
Perceptions of School Climate Domain & & & \\
Positive School Orientation-CR & & & \\
Negative School Orientation-CR & 0.192 & 0.259 & 0.270 \\
Student Afraid at School-CR & 0.201 & 0.198 & 0.123 \\
Victimization at School-CR & 0.103 & 0.197 & 0.204 \\
Feelings of Safety-TRCS & 0.103 & 0.185 & 0.209 \\
Student Support for Teachers-TRCS & 0.447 & 0.550 & 0.481 \\
NOIA A & 0.694 & 0.314 & 0.609 \\
\hline
\end{tabular}

NOTE: Abbreviations are

CR: Child Report

PCR: Primary Caregiver Report

TRS: Teacher Report on Student

TRCS: Teacher Report on Classroom and School

ADHD: Attention deficit hyperactivity disorder

The minimum detectable effect (MDE) formula used in the calculations is as follows:

$M D E=\operatorname{factor}(d f) * \sqrt{\rho_{1}\left(\frac{1}{s_{T}}+\frac{1}{s_{C}}\right)+\left(1-\rho_{1}\right)\left(\frac{1}{s_{T} n_{T}}+\frac{1}{s_{C} n_{C}}\right)}$

where $s_{T}$ and $s_{C}$ are the number of treatment and comparison schools; $n_{T}$ and $n_{C}$ are the average number of students per classroom; $\rho_{1}$ is the intraclass correlation (ICC) at the school level; and factor(df) is a constant that depends on the number of degrees of freedom ( $d f$ ) available for analysis (and is 2.802 for the pooled analysis).

SOURCE: The Social and Character Development (SACD) Research Program. 
Table 8.18 provides the estimates of the SS impacts on each of the 20 outcomes over each of the 3 years (60 impacts in total, with 3 expected to be statistically significant by chance). Of the 60 results, 1 was statistically significant: a detrimental impact was found on fourth-graders' Positive Social Behavior (Primary Caregiver Report, effect size $[E S]=-0.14$ ). A substantively important but nonsignificant beneficial impact was found in all 3 years for Feelings of Safety (Teacher Report on Classroom and School, ES = 0.37, 0.39, and 0.52). Application of the heuristics to adjust for multiple comparisons within each outcome domain indicates that SS had a statistically significant detrimental impact on the Social and Emotional Competence domain in Year 3. 
Table 8.18. Impacts on child and school outcomes-SS

\begin{tabular}{|c|c|c|c|c|c|c|c|c|c|c|c|c|}
\hline \multirow[b]{2}{*}{ Scale-Report } & \multicolumn{4}{|c|}{$\begin{array}{c}\text { Year } 1 \\
\text { (Spring 3rd grade) } \\
\end{array}$} & \multicolumn{4}{|c|}{$\begin{array}{c}\text { Year } 2 \\
\text { (Spring 4th grade) }\end{array}$} & \multicolumn{4}{|c|}{$\begin{array}{c}\text { Year } 3 \\
\text { (Spring 5th grade) }\end{array}$} \\
\hline & $\begin{array}{r}\text { Treat- } \\
\text { ment }\end{array}$ & Control & $\begin{array}{r}\text { Effect } \\
\text { size }\end{array}$ & $p$-value & $\begin{array}{r}\text { Treat- } \\
\text { ment }\end{array}$ & Control & $\begin{array}{r}\text { Effect } \\
\text { size }\end{array}$ & $p$-value & $\begin{array}{c}\text { Treat- } \\
\text { ment }\end{array}$ & Control & $\begin{array}{r}\text { Effect } \\
\text { size }\end{array}$ & $p$-value \\
\hline \multicolumn{13}{|l|}{ Social and Emotional Competence Domain ${ }^{1}$} \\
\hline Self-Efficacy for Peer Interactions-CR (+) & 3.09 & 3.03 & 0.09 & 0.337 & 3.20 & 3.24 & -0.08 & 0.562 & 3.24 & 3.31 & -0.12 & 0.146 \\
\hline Normative Beliefs About Aggression-CR (-) & 1.22 & 1.20 & 0.06 & 0.539 & 1.23 & 1.28 & -0.10 & 0.228 & 1.32 & 1.26 & 0.15 & 0.130 \\
\hline Empathy-CR (+) & 2.38 & 2.37 & 0.04 & 0.649 & 2.25 & 2.28 & -0.07 & 0.463 & 2.20 & 2.26 & -0.14 & 0.258 \\
\hline \multicolumn{13}{|l|}{ Behavior Domain } \\
\hline Altruistic Behavior-CR (+) & 1.03 & 1.10 & -0.09 & 0.249 & $0.89^{\wedge}$ & 1.00 & -0.18 & 0.094 & 0.88 & 0.95 & -0.12 & 0.184 \\
\hline Altruistic Behavior-PCR (+) & 2.08 & 2.10 & -0.03 & 0.671 & 2.06 & 2.15 & -0.13 & 0.144 & $2.02^{\wedge}$ & 2.13 & -0.16 & 0.098 \\
\hline Altruistic Behavior-TRS (+) & 1.37 & 1.40 & -0.08 & 0.757 & 1.30 & 1.29 & 0.03 & 0.919 & 1.27 & 1.32 & -0.10 & 0.675 \\
\hline Positive Social Behavior-PCR (+) & 3.18 & 3.17 & 0.03 & 0.739 & $3.20^{*}$ & 3.28 & -0.14 & 0.050 & 3.30 & 3.30 & 0.01 & 0.880 \\
\hline Positive Social Behavior-TRS (+) & 3.40 & 3.32 & 0.12 & 0.252 & 3.25 & 3.36 & -0.17 & 0.435 & 3.28 & 3.31 & -0.04 & 0.800 \\
\hline Problem Behavior-CR (-) & 0.12 & 0.13 & -0.04 & 0.659 & 0.20 & 0.17 & 0.09 & 0.406 & 0.26 & 0.22 & 0.12 & 0.201 \\
\hline Problem Behavior-PCR (-) & 1.53 & 1.52 & 0.03 & 0.727 & 1.48 & 1.50 & -0.05 & 0.566 & 1.47 & 1.50 & -0.10 & 0.280 \\
\hline Problem Behavior-TRS (-) & 1.26 & 1.27 & -0.02 & 0.896 & 1.29 & 1.26 & 0.10 & 0.599 & 1.33 & 1.32 & 0.02 & 0.905 \\
\hline ADHD-Related Behavior-TRS (-) & 1.59 & 1.55 & 0.07 & 0.517 & 1.60 & 1.53 & 0.13 & 0.412 & 1.57 & 1.57 & -0.01 & 0.969 \\
\hline \multicolumn{13}{|l|}{ Academics Domain } \\
\hline Engagement with Learning-CR (+) & 3.73 & 3.74 & -0.03 & 0.757 & 3.70 & 3.74 & -0.10 & 0.210 & 3.59 & 3.64 & -0.12 & 0.169 \\
\hline $\begin{array}{l}\text { Academic Competence and Motivation- } \\
\text { TRS (+) }\end{array}$ & 3.34 & 3.40 & -0.06 & 0.161 & $3.34^{\wedge}$ & 3.49 & -0.16 & 0.055 & 3.50 & 3.32 & 0.19 & 0.137 \\
\hline
\end{tabular}


Table 8.18. Impacts on child and school outcomes-SS-Continued

\begin{tabular}{|c|c|c|c|c|c|c|c|c|c|c|c|c|}
\hline \multirow[b]{2}{*}{ Scale-Report } & \multicolumn{4}{|c|}{$\begin{array}{c}\text { Year } 1 \\
\text { (Spring 3rd grade) }\end{array}$} & \multicolumn{4}{|c|}{$\begin{array}{c}\text { Year } 2 \\
\text { (Spring 4th grade) }\end{array}$} & \multicolumn{4}{|c|}{$\begin{array}{c}\text { Year } 3 \\
\text { (Spring 5th grade) }\end{array}$} \\
\hline & $\begin{array}{c}\text { Treat- } \\
\text { ment }\end{array}$ & Control & $\begin{array}{c}\text { Effect } \\
\text { size }\end{array}$ & $p$-value & $\begin{array}{c}\text { Treat- } \\
\text { ment }\end{array}$ & Control & $\begin{array}{c}\text { Effect } \\
\text { size }\end{array}$ & $\mathrm{p}$-value & $\begin{array}{c}\text { Treat- } \\
\text { ment }\end{array}$ & Control & $\begin{array}{c}\text { Effect } \\
\text { size }\end{array}$ & $p$-value \\
\hline \multicolumn{13}{|l|}{ Perceptions of School Climate Domain } \\
\hline Positive School Orientation-CR (+) & 3.13 & 3.08 & 0.09 & 0.425 & 2.91 & 2.89 & 0.05 & 0.763 & 2.83 & 2.80 & 0.06 & 0.720 \\
\hline Negative School Orientation-CR (-) & 1.62 & 1.65 & -0.06 & 0.571 & 1.73 & 1.72 & 0.03 & 0.780 & 1.87 & 1.83 & 0.08 & 0.375 \\
\hline Student Afraid at School-CR (-) & 1.93 & 2.00 & -0.08 & 0.332 & 1.87 & 1.95 & -0.10 & 0.402 & 1.86 & 1.82 & 0.05 & 0.691 \\
\hline Victimization at School-CR (-) & 0.56 & 0.62 & -0.09 & 0.283 & 0.55 & 0.62 & -0.11 & 0.306 & 0.62 & 0.60 & 0.03 & 0.833 \\
\hline Feelings of Safety-TRCS (+) & 4.19 & 4.04 & $0.37^{\circ}$ & 0.216 & 4.10 & 3.86 & $0.39^{\circ}$ & 0.197 & $4.02^{\wedge}$ & 3.63 & $0.52^{\circ}$ & 0.062 \\
\hline Student Support for Teachers-TRCS (+) & 4.89 & 4.11 & 0.13 & 0.663 & 4.27 & 4.22 & 0.08 & 0.678 & 4.17 & 4.12 & 0.08 & 0.768 \\
\hline
\end{tabular}

* Treatment group significantly different from control group at the 05 level.

$\wedge$ Treatment group significantly different from control group at the .10 to $>.05$ level.

- Substantive (but nonsignificant at .05 level) effect size of $\geq .25$ or $\leq-.25$.

Impact on domain found statistically significant and detrimental in Year 3 based on the fourth heuristic in which the statistical model used to estimate impacts on the individual

outcomes was re-estimated using a composite of all the outcome variables under a domain. The domain was found significant if the impact on the composite was significant. The

composite was formed by standardizing each outcome variable using its standard deviation, combining the values of the outcome variables, and taking the average of the final value.

NOTE: Abbreviations are

CR: Child Report

PCR: Primary Caregiver Report

TRS: Teacher Report on Student

TRCS: Teacher Report on Classroom and School

ADHD: Attention deficit hyperactivity disorder

The $+/$ - signs in parentheses indicate the direction of a beneficial outcome. All impact estimates were calculated using regression models where each program and school within a

program was weighted equally. The standard errors of all estimates account for design effects due to unequal weighting and the clustering of students within schools. See table 1.5 for information about the measures used to create the outcome variables. The effect size was calculated by dividing the estimated impact by the standard deviation of the outcome measure for the control group. The number of results found significant was no more than expected by chance.

SOURCE: The Social and Character Development (SACD) Research Program. 


\section{Impacts on Child Outcomes Over Time}

SS impacts on the child outcomes over time were estimated using growth curve models by examining treatment and control group differences in the trajectories of student outcomes during the follow-up period while accounting for clustering at the school level. The growth curve models are estimated using a three-level hierarchical linear model, where Level 1 corresponds to time, Level 2 to students, and Level 3 to schools (described in chapter 1).

Table 8.19 provides the estimates of the program's impacts on the growth in student outcomes over the 3 years. The estimated impacts ranged in effect size units (absolute value) from 0.00 to 0.19 . Three of the 18 (with 1 expected to be significant by chance) estimated SS impacts on the trajectories of child outcomes were statistically significant and showed a detrimental impact of the program on growth: Empathy (Child Report, ES = -0.13), Positive Social Behavior (Teacher Report on Student, ES = -0.19), and Engagement with Learning (Child Report, ES = -0.09). 
Table 8.19. Impacts on growth of child outcomes-SS

\begin{tabular}{|c|c|c|c|c|c|c|c|}
\hline \multirow[b]{2}{*}{ Scale-Report } & \multirow[b]{2}{*}{$\begin{array}{r}\text { Mean score at } \\
\text { implementation }\end{array}$} & \multicolumn{6}{|c|}{ Average growth in the score per year ${ }^{1}$} \\
\hline & & Treatment & Control & $\begin{array}{r}\text { Impact on } \\
\text { growth }^{3} \\
\end{array}$ & $\begin{array}{l}\text { Effect } \\
\text { size }^{4}\end{array}$ & $\begin{array}{r}\text { Standard } \\
\text { error of } \\
\text { impact } \\
\end{array}$ & $\begin{array}{r}p \text {-value of } \\
\text { impact }\end{array}$ \\
\hline \multicolumn{8}{|l|}{ Social and Emotional Competence Domain } \\
\hline Self-Efficacy for Peer Interactions-CR (+) & 2.95 & 0.12 & 0.15 & -0.02 & -0.03 & 0.03 & 0.495 \\
\hline Normative Beliefs About Aggression-CR (-) & 1.20 & $0.05^{\wedge}$ & 0.01 & 0.03 & 0.07 & 0.02 & 0.090 \\
\hline Empathy-CR (+) & 2.43 & $-0.11^{*}$ & -0.05 & -0.06 & -0.13 & 0.02 & 0.028 \\
\hline \multicolumn{8}{|l|}{ Behavior Domain } \\
\hline Altruistic Behavior-CR (+) & 1.21 & -0.13 & -0.12 & -0.01 & -0.01 & 0.04 & 0.755 \\
\hline Altruistic Behavior-PCR (+) & 2.14 & -0.05 & -0.02 & -0.04 & -0.04 & 0.02 & 0.159 \\
\hline Altruistic Behavior-TRS (+) & 1.42 & -0.04 & -0.07 & 0.03 & 0.05 & 0.06 & 0.666 \\
\hline Positive Social Behavior-PCR (+) & 3.12 & 0.05 & 0.08 & -0.03 & -0.04 & 0.01 & 0.101 \\
\hline Positive Social Behavior-TRS (+) & 3.39 & $-0.10^{*}$ & 0.06 & -0.16 & -0.19 & 0.06 & 0.019 \\
\hline Problem Behavior-CR (-) & 0.09 & 0.06 & 0.05 & 0.00 & 0.01 & 0.01 & 0.711 \\
\hline Problem Behavior-PCR (-) & 1.53 & -0.02 & -0.02 & 0.00 & 0.00 & 0.01 & 0.848 \\
\hline Problem Behavior-TRS (-) & 1.20 & $0.08^{\wedge}$ & 0.01 & 0.07 & 0.17 & 0.04 & 0.086 \\
\hline ADHD-Related Behavior-TRS (-) & 1.56 & 0.02 & -0.02 & 0.05 & 0.06 & 0.04 & 0.285 \\
\hline \multicolumn{8}{|l|}{ Academics Domain } \\
\hline Engagement with Learning-CR (+) & 3.80 & $-0.09^{*}$ & -0.04 & $-0.05^{*}$ & -0.09 & 0.02 & 0.021 \\
\hline Academic Competence and Motivation-TRS (+) & 3.35 & 0.04 & 0.03 & 0.01 & 0.01 & 0.04 & 0.808 \\
\hline
\end{tabular}


Table 8.19. Impacts on growth of child outcomes-SS-Continued

Average growth in the score per year ${ }^{1}$

\begin{tabular}{|c|c|c|c|c|c|c|c|}
\hline \multirow[b]{2}{*}{ Scale-Report } & \multirow[b]{2}{*}{$\begin{array}{r}\text { Mean score at } \\
\text { implementation }\end{array}$} & \multicolumn{6}{|c|}{ Average growth in the score per year ${ }^{1}$} \\
\hline & & Treatment & Control & $\begin{array}{r}\text { Impact on } \\
\text { growth }^{3} \\
\end{array}$ & $\begin{array}{l}\text { Effect } \\
\text { size }^{4}\end{array}$ & $\begin{array}{r}\text { Standard } \\
\text { error of } \\
\text { impact } \\
\end{array}$ & $\begin{array}{r}p \text {-value of } \\
\text { impact }\end{array}$ \\
\hline \multicolumn{8}{|l|}{ Perceptions of School Climate Domain } \\
\hline Positive School Orientation-CR (+) & 3.32 & -0.22 & -0.19 & -0.04 & -0.05 & 0.04 & 0.339 \\
\hline Negative School Orientation-CR (-) & 1.52 & 0.14 & 0.12 & 0.02 & 0.02 & 0.02 & 0.464 \\
\hline Student Afraid at School-CR (-) & 2.08 & -0.12 & -0.09 & -0.03 & -0.03 & 0.04 & 0.403 \\
\hline Victimization at School-CR (-) & 0.60 & 0.00 & 0.00 & 0.00 & 0.00 & 0.03 & 0.930 \\
\hline
\end{tabular}

${ }^{*}$ Treatment group significantly different from control group at the .05 level.

$\wedge$ Treatment group significantly different from control group at the .10 to $>.05$ level.

${ }^{1}$ Pertains to the estimated slope of the outcome for the treatment or control groups.

${ }^{2}$ The average score at implementation is calculated across treatment and control groups, using regression models for adjustment on covariates.

${ }^{3}$ Estimated difference between the slope of the treatment and control groups.

${ }^{4}$ Effect size: the slope of the treatment group minus the slope of the control group divided by the standard deviation of the outcome for the program's control group (the standard deviation is calculated without accounting for school-level clustering or regression adjustments).

NOTE: Abbreviations are

CR: Child Report

PCR: Primary Caregiver Report

TRS: Teacher Report on Student

$\stackrel{\infty}{\infty} \quad$ ADHD: Attention deficit hyperactivity disorder

The +/- signs in parentheses indicate the direction of a beneficial outcome. All impact estimates were calculated using HLM 6.06. Sample weights were used in all analyses to give (1) each school equal weight in each program (within each time period) and (2) each time period equal weight within the analysis. See table 1.5 for information about the measures used to create the outcome variables.

SOURCE: The Social and Character Development (SACD) Research Program. 


\section{Summary}

As part of the Social and Character Development (SACD) Research Program, researchers at the Maryland site evaluated the SS program. This program is designed to promote social competence and reduce children's social and emotional problems. Twelve public schools in a single school district in Maryland were recruited by the Maryland research team and randomly assigned to treatment and control conditions to determine the impact of SS on social and character development activities in the schools and on the child outcome domains of Social and Emotional Competence, Behavior, Academics, and Perceptions of School Climate.

Analyses of the initial characteristics of the sample (students, caregivers, communities, teachers, and schools) indicated that randomization to treatment and control status produced groups that were relatively similar at the start of the study (with 1 out of 84 comparisons statistically significantly different, fewer than would be expected by chance). The data on the initial level of SACD activity led to two findings. First, treatment teachers reported greater use of and training in SACD activities than control teachers, and they did so more often than would be expected by chance (11 out of 62 comparisons, with 3 expected to be significant by chance). There are two potential causes for this finding, and the analysis cannot be used to determine whether the reason for such a difference was that the two groups did differ on their initial use of SACD activities (i.e., that randomization did not create similar treatment and control groups) or whether the fact that the training of all treatment teachers and the implementation of the SS program began before the initial data were collected (by 5 weeks) influenced the teacher reports. Because it is likely (though unproven) that the training and implementation affected the teacher reports, these data were not considered appropriate for use as a baseline measure of SACD activities and training in the treatment schools.

Second, these data indicate that the control condition for the SACD project was not a "no treatment" control but a "standard practice" control. Because the control teachers were not affected by the implementation of the SACD programs before data collection, their reports reflect standard practice in the control schools. Standard practice at the control schools included reports of 47 percent to 87 percent of teachers using any SACD activities, 92 percent of teachers using specific materials in conjunction with these activities, 100 percent using at least one of the specified instructional strategies, and 67 percent participating in SACD training over the past 12 months.

Analyses of the SS impacts on level of SACD activities in the schools revealed impacts on the use of SACD activities ( 39 out of 90 ) and materials and strategies ( 23 out of 87 ) across the 3 years. There were impacts on two of the professional development activities for treatment teachers in Year 1 (two out of nine). These same measures in the control schools across the 3 years of the study confirmed that use of these activities in the control schools constituted their standard practice.

Of the 20 child-level outcomes representing the four domains of Social and Emotional Competence, Behavior, Academics, and Perceptions of School Climate assessed in each of the 3 years of the study (a total of 60 results), 1 showed a statistically significant detrimental impact of the SS intervention. A growth curve analysis was used to analyze the change over time in these same outcomes between initial data collection and the final outcome data collection at the end of the study. Three of the 18 child-level outcomes assessed showed a significant detrimental impact of the SS program.

The SACD evaluation did not find evidence to support the hypothesis that SS had beneficial impacts on students' social and character development. Such results could be caused by the inability of the program to cause such change, possibly because the theory of action for the program is incomplete or the activities to carry out that theory are not effective.

However, these results may also be due to the inability of the evaluation to observe such a change due to the control condition, the level of nonparticipation, or the sample size. The control schools continued using their standard SACD activities, and these turned out to be high in quantity and broad in scope. While SS had a significant positive impact on the amount and types of SACD activities, the resulting difference in the amount 
of SACD activities between the treatment and control schools may not have been large enough to cause significant differences in the student outcomes. Second, 29 percent to 38 percent of the students in the sample universe did not take part (depending on year) because of nonconsent or noncompletion of the surveys. As a determination could not be made as to whether the students not taking part differed significantly from those who did take part, the evaluation's results are valid only for the students who took part. If the students not taking part were different, and if they would have responded better to SS than to the SACD activities occurring in the control schools, then the evaluation could have underestimated the program's impact. Third, the sample size of 12 schools and the resulting higher MDES compared to those for the multiprogram evaluation may have reduced the likelihood of detecting statistically significant effects. However, it should be noted that 63 percent of the MDES for the 60 outcomes used in the year-by-year analysis were below 0.25 (58\% were below 0.20$)$. In addition, only 3 of the 60 outcomes were found to be substantively important; however, they were all beneficial and referred to the same outcome (Feelings of Safety). 
This page is intentionally blank. 


\section{References}

Achenbach, T.M. (1991). Manual for Teacher's Report Form and 1991 Profile. Burlington: University of Vermont, Department of Psychiatry.

American Psychiatric Association. (2000). Diagnostic and Statistical Manual of Mental Disorders (4th ed., revised text). Washington, DC: American Psychiatric Association.

Battistich, V., Solomon, D., Watson, M., and Schaps, E. (1997). Caring School Communities. Educational Psychologist, 32(3): 137-151.

Benjamini, Y., and Hochberg, Y. (1995). Controlling the False Discovery Rate-A New and Powerful Approach to Multiple Testing. Journal of the Royal Statistical Society: Series B, 59: 289-300.

Bennett, K.J., Brown, K.S., Boyle, M., Racine, Y., and Offord, D. (2003). Does Low Reading Achievement at School Entry Cause Conduct Problems? Social Science and Medicine, 56(11): 2443-2448.

Brooks-Gunn, J., and Duncan, G.J. (1997). The Effects of Poverty on Children. Children and Poverty, 7(2): 5571.

Bryk, A., and Raudenbush, S. (1992). Hierarchical Linear Models for Social and Behavioral Research: Applications and Data Analysis Methods. Newbury Park, CA: Sage.

Carlson, E.A., Sroufe, L.A., Collins, W.A., Jimerson, S., Weinfield, N., Hennighausen, K., Egeland, B., Hyson, D.M., Anderson, F., and Meyer, S.E. (1999). Early Environmental Support and Elementary School Adjustment as Predictors of School Adjustment in Middle Adolescence. Journal of Adolescent Research, 14(1): 72-94.

Caspi, A., Taylor, A., Moffitt, T.E., and Plomin, R. (2000). Neighborhood Deprivation Affects Children's Mental Health: Environmental Risks Identified in a Genetic Design. Psychological Science, 11: 338-342.

Catalano, R.F., Berglund, M.L., Ryan, J.A.M., Lonczak, H.S., and Hawkins, J.D. (2004). Positive Youth Development in the United States: Research Findings on Evaluations of Positive Youth Development Programs. The ANNALS of the American Academy of Political and Social Science, 591(1): 98124.

Conduct Problems Prevention Research Group (CPPRG). (1991). Parent \& Teacher Involvement Measure-Parent. Retrieved from http://www.fasttrackproject.org/techrept/p/ptp.

Conduct Problems Prevention Research Group (CPPRG). (1999). Initial Impact of the Fast Track Prevention Trial for Conduct Problems II: Classroom Effects. Journal of Consulting and Clinical Psychology, 67(5): 648-657.

Crandall, D., Loucks-Horsley, S., Baucher, J., Schmidt, W., Eisman, J., Cox, P., Miles, M., Huberman, A., Taylor, B., Goldberg, J., Shive, G., Thompson, C., and Taylor, J. (1982). People, Policies and Practices: Examining the Chain of School Improvement, Vols. 1-10. Andover, MA: Network.

Crosse, S., Burr, M., Cantor, D., Hagen, C.A., and Hantman, I. (2001). Wide Scope, Questionable Quality: Drug and Violence Prevention Efforts in American Schools: Report on the Study on School Violence and Prevention. Washington, DC: Planning and Evaluation Service, U.S. Department of Education.

Dahlberg, L.L. (1998). Youth Violence in the United States: Major Trends, Risk Factors, and Prevention Approaches. American Journal of Preventive Medicine, 14(4): 259-272. 


\section{References}

Dahlberg, L.L., and Simon, T.R. (2006). Predicting and Preventing Youth Violence: Developmental Pathways and Risk. In J. Lutzker (Ed.), Preventing Violence: Research and Evidence-Based Intervention Strategies (pp. 97124). Washington, DC: American Psychological Association.

Dahlberg, L.L., Toal, S.B., and Behrens, C.B. (1998). Measuring Violence-Related Attitudes, Beliefs, and Behaviors Among Youths: A Compendium of Assessment Tools. Atlanta, GA: Division of Violence Prevention, National Center for Injury Prevention, Centers for Disease Control and Prevention.

Damon, W. (1999). The Moral Development of Children. Scientific American, 281(2): 72-79.

Dempster, A.P., Laird, N.M., and Rubin, D.B. (1977). Maximum Likelihood Estimation From Incomplete Data via the EM Algorithm. Journal of the Royal Statistical Society: Series B, 39: 1-38.

Dinkes, R., Cataldi, E.F., and Lin-Kelly, W. (2007). Indicators of School Crime and Safety: 2007. (NCES 2008021, NCJ 219553). U.S. Departments of Education and Justice. Washington, DC: U.S. Government Printing Office.

Dodge, K.A., and Coie, J.D. (1987). Social-Information Processing Factors in Reactive and Proactive Aggression in Children's Peer Groups. Journal of Personality and Social Psychology, 53: 1146-1158.

Dodge, K.A., and Pettit, G.S. (2003). A Biopsychosocial Model of the Development of Chronic Conduct Problems in Adolescence. Developmental Psychology, 39: 349-371.

Dunford, F.W., and Elliott, D.S. (1984). Identifying Career Offenders Using Self-Reported Data. Journal of Research in Crime and Delinquency, 21: 57-86.

Eisenberg, N. (2000). Emotion, Regulation, and Moral Development. Annual Review of Psychology, 51: 665-697.

Emler, N. (1996). How Can We Decide Whether Moral Education Works? Journal of Moral Education, 25: 117126.

Farmer, T.W. (2000). Social Dynamics of Aggressive and Disruptive Behavior in School: Implications for Behavior Consultation. Journal of Educational and Psychological Consultation, 11: 299-322.

Farmer, T.W., Goforth, J.B., Hives, J., Aaron, A., Hunter, F., and Sgmatto, A. (2006). Competence Enhancement Behavior Management. Preventing School Failure, 50: 39-44.

Farrell, A.D., and Camou, S. (2006). School-Based Interventions for Youth Violence Prevention. In R.J. Lutzker (Ed.), Preventing Violence: Research and Evidence-Based Intervention Strategies (pp. 125-146). Washington, DC: American Psychological Association.

Farrell, A.D., and Meyer, A.L. (1997). The Effectiveness of a School-Based Curriculum for Reducing Violence Among Urban Sixth-Grade Students. American Journal of Public Health, 87: 979-984.

Farrington, D.P. (1989). Early Predictors of Adolescent Aggression and Adult Violence. Violence and Victims, 4: 79-100.

Farrington, D.P., and Hawkins, J.D. (1991). Predicting Participation, Early Onset and Later Persistence in Officially Recorded Offending. Criminal Behavior and Mental Health, 1: 1-33.

Flannery, D.J., Vazsonyi, A.T., Liau, A.K., Guo, S., Powell, K.E., Atha, H., Vesterdal, W., and Embry, D. (2003). Initial Behavior Outcomes for the PeaceBuilders Universal School-Based Violence Prevention Program. Developmental Psychology, 39: 292-308.

Flay, B.R. (2002). Positive Youth Development Requires Comprehensive Health Promotion Programs. American Journal of Health Behavior, 26(6): 407-424.

Flay, B.R., Allred, C.G., and Ordway, N. (2001). Effects of the Positive Action Program on Achievement and Discipline: Two Matched-Control Comparisons. Prevention Science, 2: 71-89. 


\section{References}

Flay, B.R., Graumlich, S., Segawa, E. Burns, J.L., and Holliday, M.Y. (2004). Effects of 2 Prevention Programs on High-Risk Behaviors Among African American Youth: A Randomized Trial. Archives of Pediatric \& Adolescent Medicine, 158: 377-384.

Forehand, R., Brody, G., Armistead, L., Dorsey, S., Morse, E., Morse, P., and Stock, M. (2000). The Role of Community Risks and Resources in the Psychosocial Adjustment of At-Risk Children: An Examination Across Two Community Contexts and Two Informants. Behavior Therapy, 31: 395-414.

Fors, S.W., Crepaz, N., and Hayes, D.M. (1999). Key Factors That Protect Against Health Risks in Youth: Further Evidence. American Journal of Health Behavior, 23: 368-380.

Fraser, M.W., Nash, J.K., Galinsky, M.J., and Darwin, K.E. (2000). Making Choices: Social Problem-Solving Skills for Children. Washington, DC: NASW Press.

Funk, J., Elliott, R., Bechtoldt, H., Pasold, T., and Tsavoussis, A. (2003). The Attitudes Toward Violence Scale. Journal of Interpersonal Violence, 18: 186-196.

Furrer C., and Skinner, E. (2003). Sense of Relatedness as a Factor in Children's Academic Engagement and Performance. Journal of Educational Psychology, 95: 148-162.

Gershoff, E.T., and Aber, J.L. (2006). Neighborhoods and Schools: Contexts and Consequences for the Mental Health and Risk Behaviors of Children and Youth. In L. Balta and C. Tamis-LeMonda (Eds.), Child Psychology: A Handbook of Issues (2nd ed.) (pp. 611-645). New York: Psychology Press/Taylor \& Francis.

Gorman-Smith, D., Tolan, P.H., Henry, D.B., and Florsheim, P. (2000). Patterns of Family Functioning and Adolescent Outcomes Among Urban African American and Mexican American Families. Journal of Family Psychology, 14: 436-457.

Gorman-Smith, D., Tolan, P.H., Zelli, A., and Huesmann, L.R. (1996). The Relation of Family Functioning to Violence Among Inner-City Minority Youths. Journal of Family Psychology, 10: 115-129.

Gottfredson, G.D., and Gottfredson, D.C. (2001). What Schools Do to Prevent Problem Behavior and Promote Safe Environments. Journal of Educational and Psychological Consultation, 12: 313-344.

Greenberg, M.T. (2004). Current and Future Challenges in School-Based Prevention: The Researcher Perspective. Prevention Science, 5: 5-13.

Greenberg, M.T., Weissberg, R.P., Utne O’Brian, M., Zins, J.E., Fredericks, L., Resnik, H., and Elias, M.J. (2003). Enhancing School-Based Prevention and Youth Development Through Coordinated Social, Emotional, and Academic Learning. American Psychologist, 58: 466-474.

Gresham, F.M., and Elliott, S.N. (1990). Social Skills Rating System. Circle Pines, MN: American Guidance Service.

Griffith, J. (1996). Relation of Parental Involvement, Empowerment, and School Traits to Student Academic Performance. Journal of Educational Research, 90(1): 33-41.

Grolnick, W.S., Ryan, R.M., and Deci, E.L. (1991). Inner Resources for Student Motivation: Motivational Mediators of Children's Perceptions of Their Parents. Journal of Educational Psychology, 83: 508-517.

Grossman, D., Neckerman, H.J., Koepsell, T.D., Liu, P., Asher, K., Beland, K., Frey, K., and Rivara, F.P. (1997). Effectiveness of a Violence Prevention Curriculum Among Children in Elementary School: A Randomized Controlled Trial. Journal of the American Medical Association, 277: 1605-1611.

Guerra, N.G., Huessman, L.R., Tolan, P.H., VanAcker, R. and Eron, L.D. (1995). Stressful Events and Individual Beliefs as Correlates of Economic Disadvantage and Aggression Among Urban Children. Journal of Consulting and Clinical Psychology, 63: 518-528.

Hahn, R., Fuqua-Whitley, D., Wethington, H., Lowy, J., Crosby, A., Fullilove, M., Johnson, R., Liberman, A., Moscicki, E., Price, L., Snyder, S., Tuma, F., Cory, S., Stone, G., Mukhopadhaya, K., Chattopadhyay, 


\section{References}

S., and Dahlberg, L. (2007). Effectiveness of Universal School-Based Programs to Prevent Violent and Aggressive Behavior: A Systematic Review. American Journal of Preventive Medicine, 33(2S): S114S129.

Harris, R.J. (1975). A Primer of Multivariate Statistics. New York: Academic Press.

Henry, D.B., Tolan, P.H., and Gorman-Smith, D. (2001). Longitudinal Family and Peer Group Effects on Violent and Non-Violent Delinquency. Journal of Child Clinical Psychology,16: 203-220.

Huesmann, L.R., and Guerra, N.G. (1997). Children's Normative Beliefs About Aggression and Aggressive Behavior. Journal of Personality and Social Psychology, 72: 408-419.

Joreskog, K.G., Sorbom, D., Du Toit, S., and Du Toit, M. (2003). LISREL 8: New Statistical Features (3rd printing, with revisions). Lincolnwood, IL: Scientific Software International.

Kazdin, A.E. (2001). Behavior Modification in Applied Settings (6th ed.). Belmont, CA: Wadsworth/Thomson Learning.

Kellam, S.G, Ling, X., Merisca, R., Brown, C.H., and Ialong, N. (1998). The Effect of the Level of Aggression in the First Grade Classroom on the Course and Malleability of Aggressive Behavior into Middle School. Development and Psychopathology, 10: 165-185.

Kusche, C.A., and Greenberg, M.T. (1994). The PATHS Curriculum. Seattle, WA: Developmental Research and Programs.

Larson, R. W. (2000). Toward a Psychology of Positive Youth Development. American Psychologist, 55: 170183.

Lewis, L., Parsad, B., Carey, N., Bartfai, N., Farris, E., and Smerdon, B. (1999). Teacher Quality: A Report on the Preparation and Qualifications of Public School Teachers (NCES 1999-080). Washington, DC: U.S. Department of Education.

Lickona, T. (1993). The Return of Character Education. Educational Leadership, 51: 6-11.

Limber, S.P., and Small, M.A. (2003). State Laws and Policies to Address Bullying in Schools. School Psychology Review, 32: 445-455.

Loeber, R., and Stouthamer-Loeber, M. (1998). Juvenile Aggression at Home and at School. In D.S. Elliott, B.A. Hamburg, and K.R. Williams (Eds.), Violence in American Schools (pp. 94-126). Cambridge: Cambridge University Press.

Loney, J., and Milich, R. (1982). Hyperactivity, Inattention, and Aggression in Clinical Practice. In M. Wolraich and D. Routh (Eds.), Advances in Developmental and Behavioral Pediatrics (Vol. 2, pp. 113-147). Greenwich, CT: JAI Press.

Malecki, C.K., and Elliot, S.N. (2002). Children's Social Behaviors as Predictors of Academic Achievement: A Longitudinal Analysis. School Psychology Quarterly, 17: 1-23.

Mansfield, W., Alexander, D., and Farris, E. (1991). Fast Response Survey System, Teacher Survey on Safe, Disciplined, and Drug-Free Schools (NCES 91-091). National Center for Education Statistics, Office of Educational Research and Improvement, U.S. Department of Education. Washington, DC: U.S. Government Printing Office.

Matheny, A.P., Wachs, T.D., Ludwig, J.L., and Phillips, K. (1995). Bringing Order Out of Chaos: Psychometric Characteristics of the Confusion, Hubbub, and Order Scale. Journal of Applied Developmental Psychology, 16: 429-444.

McCord, J., Widom, C.S., Bamba, M.I., and Crowell, N.A. (2000). Education and Delinquency: Summary of a Workshop. Washington, DC: National Academy of Sciences. 


\section{References}

McEvoy, A., and Welker, R. (2000). Antisocial Behavior, Academic Failure, and School Climate: A Critical Review. Journal of Emotional and Behavioral Disorders, 8: 130-141.

McMahon, R.J., and Frick, P.J. (2005). Evidence-Based Assessment of Conduct Problems in Children and Adolescents. Journal of Clinical Child and Adolescent Psychology, 34, 477-505.

Merrell, K., Gueldner, B.A., Ross, S.W., and Isava, D.M. (2008). How Effective Are School Bullying Intervention Programs? A Meta-Analysis of Intervention Research. School Psychology Quarterly, 23: 2642.

Moffit, T.E. (1993). Adolescence-Limited and Life-Course-Persistent Antisocial Behavior: A Developmental Taxonomy. Psychological Review, 100: 674-701.

Murray, D. (1998). Design and Analysis of Group-Randomized Trials. Oxford: Oxford University Press.

Mytton, J., DiGuiseppi, C., Gough, D., Taylor, R., and Logan, S. (2006). School-Based Secondary Prevention Programmes for Preventing Violence. Cochrane Database of Systematic Reviews, Issue 3. doi: 10.1002/14651858.CD004606.pub2.

Najaka, S.S., Gottfredson, D.C., and Wilson, D.B. (2001). A Meta-Analytic Inquiry Into the Relationship Between Selected Risk Factors and Problem Behavior. Prevention Science, 2: 257-271.

O’Donnell, J., Hawkins, J.D., and Abbott, R.D. (1995). Predicting Serious Delinquency and Substance Use Among Aggressive Boys. Journal of Consulting and Clinical Psychology, 63: 529-537.

Orpinas, P., and Frankowski, R. (2001). The Aggression Scale: A Self-Report Measure of Aggressive Behavior for Young Adolescents. Journal of Early Adolescence, 21(1): 50-67.

Orpinas, P., and Horne, A.M. (2006). Bullying Prevention: Creating a Positive School Climate and Developing Social Competence. Washington, DC: American Psychological Association.

Orpinas, P., and Kelder, S. (1995). Students for Peace Project: Second Student Evaluation (Unpublished manuscript). University of Texas Health Science Center at Houston, School of Public Health, Houston.

Park-Higgerson, H.-K., Perumean-Chaney, S.E., Bartolucci, A.A., Grimley, D.M., and Singh, K.P. (2008). The Evaluation of School-Based Violence Prevention Programs: A Meta-Analysis. Journal of School Health, 78: 465-479.

Pelham, W.E., Fabiano, G.A., and Massetti, G.M. (2005). Evidence-Based Assessment of Attention Deficit Hyperactivity Disorder in Children and Adolescents. Journal of Clinical Child and Adolescent Psychology, 34: 449-476.

Pelham, W.E., Gnagy, E.M., Greenslade, K.E., and Milich, R. (1992). Teacher Ratings of DSM-III-R Symptoms for the Disruptive Behavior Disorders. Journal of the American Academy of Child and Adolescent Psychiatry, 31: 210-218.

Rentoul, A.J., and Fraser, B.J. (1983). Development of a School-Level Environment Questionnaire. Journal of Educational Administration, 21(1): 21-39.

Rey, J.M., Sawyer, M.G., and Prior, M.R. (2005). Similarities and Differences Between Aggressive and Delinquent Children and Adolescents in a National Sample. Australian and New Zealand Journal of Psychiatry, 39: 366-372.

Reynolds, C.R., and Kamphaus, R.W. (1998). Behavioral Assessment System for Children. Circle Pines, MN: American Guidance Service, Inc.

Roberts, W., Horn, A., and Battistich, V. (1995). Assessing Students' and Teachers' Sense of School as a Caring Community. Paper presented at the Annual Meeting of the American Educational Research Association, San Francisco, CA.

Rubin, D. (1987). Multiple Imputation for Nonresponse in Surveys. New York: John Wiley \& Sons, Inc. 


\section{References}

Samples, F., and Aber, L. (1998). Evaluations of School-Based Violence Prevention Programs. In D.S. Elliott and B.A. Hamburg (Eds.), Violence in American Schools: A New Perspective (pp. 217-252). Cambridge: Cambridge University Press.

Sampson, R.J. (2000). A Neighborhood-Level Perspective on Social Change and the Social Control of Adolescent Delinquency. In L.J. Crocket and R.K. Silbereisen (Eds.), Negotiating Adolescence in Times of Social Change (pp. 178-188). New York: Cambridge University Press.

Sampson, R.J. Morenoff, J., and Earls, F. (1999). Beyond Social Capital: Spatial Dynamics of Collective Efficacy for Children. American Sociological Review, 64: 633-660.

Schochet, P. (2005). Statistical Power for Random Assignment Evaluations of Education Programs. Princeton, NJ: Mathematica Policy Research.

Schochet, P.Z. (2008a). Technical Methods Report. Guidelines for Multiple Testing in Impact Evaluations (NCEE 20084018). Washington, DC: National Center for Education Evaluation and Regional Assistance, Institute of Education Sciences, U.S. Department of Education.

Schochet, P.Z. (2008b). The Late Pretest Problem in Randomized Control Trials of Education Interventions (NCEE 2009-4033). Washington, DC: National Center for Education Evaluation and Regional Assistance, Institute of Education Sciences, U.S. Department of Education.

Schultz, D., Izard, C., and Bear, G. (2004). Children's Emotion Processing: Relations to Emotionality and Aggression. Development and Psychopathology, 16: 371-187.

Schwartz, D., and Proctor, L.J. (2000). Community Violence Exposure and Children's Social Adjustment in the School Peer Group: The Mediating Roles of Emotion Regulation and Social Cognition. Journal of Consulting and Clinical Psychology, 68: 670-683.

Seligman, M.E., and Csikszentmihalyi, M. (2000). Positive Psychology: An Introduction. American Psychologist, 56(1): 5-13.

Shaver, V., and Walls, R.T. (1998). Effect of Title I Parent Involvement on Student Reading and Mathematics Achievement. Journal of Research and Development in Education, 31: 90-97.

Shelton, K.K., Frick, P.J., and Wootton, J. (1996). Assessment of Parenting Practices in Families of Elementary School-Age Children. Journal of Clinical Child Psychology, 25: 317-329.

Slaby, R.G., and Guerra, N.G. (1988). Cognitive Mediators of Aggression in Adolescent Offenders: 1. Assessment. Developmental Psychology, 24: 580-588.

Smith, B.H., Molina, B.S.G., Massetti, G.M., Waschbusch, D.A., and Pelham, W.E. (2007). School-Wide Interventions: The Foundation of a Public Health Approach to School-Based Mental Health. In S.W. Evans, M. Weist, and Z. Serpell (Eds.), Advances in School-Based Mental Health Interventions: Best Practices and Program Models (Vol. 2, pp. 7-2-7-19). Kingston, NJ: Civic Research Institute

Solomon, D., Battistich, V., Watson, M., Schaps, E., and Lewis, C. (2000). A Six-District Study of Educational Change: Direct and Mediated Effects of the Child Development Project. Social Psychology of Education, 4(1): 3-51.

Stage, S.A., and Quiroz, D.R. (1997). A Meta-Analysis of Interventions to Decrease Disruptive Classroom Behavior in Public Education Settings. School Psychology Review, 26(3): 333-368.

Stringfield, S., Millsap, M., Herman, R., Yoder, N. Brigham, N., Nesselrodt, P., Schaffer, E., Karweit, N. Levin, M., and Stevens, R. (1997). Urban and Suburban/Rural Special Strategies for Educating Disadvantaged Children: Final Report. Washington, DC: U.S. Department of Education. 


\section{References}

Takeuchi, D., Williams, D.R., and Adair, R. (1991). Economic Stress and Children's Emotional and Behavioral Problems. Journal of Marriage and the Family, 53: 1031-1041.

Tolan, P.H., Guerra, N.G., and Kendall, P.C. (1995). A Developmental-Ecological Perspective on Antisocial Behavior in Children and Adolescents: Toward a Unified Risk and Intervention Framework. Journal of Consulting and Clinical Psychology, 63: 579-584.

Thornberry, T.P., Huizinga, D., and Loeber, R. (2004). The Causes and Correlates Studies: Findings and Policy Implications. Juvenile Justice, 9: 3-19.

Trzesniewski, K.H., Moffitt, T.E., Caspi, A., Taylor, A., and Maughan, B. (2006). Revisiting the Association Between Reading Achievement and Antisocial Behavior: New Evidence of Environmental Explanation From a Twin Study. Child Development, 77: 72-88.

U.S. Department of Education, National Center for Education Statistics, Common Core of Data. (2003-04). Data retrieved from http://nces.ed.gov/ccd.

Walker, H.M., and Shinn, M.R. (2002). Structuring School-Based Interventions to Achieve Integrated Primary, Secondary, and Tertiary Prevention Goals for Safe and Effective Schools (pp. 1-26). In M.R. Shin, H.M. Walker, and G. Stoner (Eds.), Interventions for Academic and Behavioral Problems II: Preventive and Remedial Approaches. Bethesda, MD: National Association of School Psychologists.

Waschbusch, D., Pelham, W., and Massetti, G. (2005). The Behavior Education Support and Treatment (BEST) School Intervention Program: Pilot Project Data Examining Schoolwide, Targeted-School, and Targeted-Home Approaches. Journal of Attention Disorders, 9: 313-322.

Weissberg, R.P., Kumpfer, K.L., and Seligman, M.E.P. (2003). Special Issue: Prevention That Works for Children and Youth: An Introduction. American Psychologist, 58: 425-432.

Wentzel, K.R. (1991). Relations Between Social Competence and Academic Achievement in Early Adolescence. Child Development, 62: 1066-1078.

Wentzel, K.R. (1993). Does Being Good Make the Grade? Social Behavior and Academic Competence in Middle School. Journal of Educational Psychology, 85: 357-364.

What Works Clearinghouse. (n.d.-a). Character Education. Retrieved August 24, 2007, from http://ies.ed.gov/ncee/wwc/reports/Topic.aspx?tid=12.

What Works Clearinghouse. (n.d.-b). What Works Clearinghouse Intervention Rating Scheme. U.S. Department of Education, National Center for Education Evaluation and Regional Assistance. Retrieved May 6, 2009, from http://ies.ed.gov/ncee/wwc/pdf/rating_scheme.pdf.

Wheeler, V.A., and Ladd, G.W. (1982). Assessment of Children's Self-Efficacy for Social Interactions With Peers. Developmental Psychology, 18: 795-805.

Wilson, D.B., Gottfredson, D.C., and Najaka, S.S. (2001). School-Based Prevention of Problem Behavior: A Meta-Analysis. Journal of Quantitative Criminology, 17: 247-272.

Wilson, S.J., and Lipsey, M.W. (2007). School-Based Interventions for Aggressive and Disruptive Behavior: Update of a Meta-Analysis. American Journal of Preventive Medicine, 33(2S): S130-S143.

Wilson, S.J., Lipsey, M.W., and Derzon, J.H. (2003). The Effects of School-Based Intervention Programs on Aggressive Behavior: A Meta-Analysis. Journal of Consulting and Clinical Psychology, 71: 136-149.

Zellman, G.L., and Waterman, J.M. (1998). Understanding the Impact of Parent School Involvement on Children's Educational Outcomes. Journal of Educational Research, 91: 370-380. 
Appendix A: Analysis of Cohorts 1 and 2 
This page is intentionally blank. 


\section{Analysis of Cohorts 1 and 2}

For Years 2 and 3 of the social and character development (SACD) multiprogram evaluation, additional funds were provided to enable research teams to add additional schools in order to increase the sample size and the corresponding statistical power of the analyses. Four teams added 2 or 4 schools and randomly assigned half to the treatment and half to the control groups using the same matching process as with the original schools. The additions were as follows: (1) University at Buffalo, The State University of New York (Academic and Behavioral Competencies Program $[\mathrm{ABC}]$ ) added 2 schools, (2) University of North Carolina at Chapel Hill (Competence Support Program [CSP]) added 4 schools, ${ }^{1}$ (3) Vanderbilt University (Love In a Big World [LBW]) added 2 schools, and (4) The Children's Institute (Promoting Alternative Thinking Strategies [PATHS]) added 4 schools. As a result, a second set of 12 schools (and a second cohort of students) was added to the SACD evaluation for Years 2 and 3, raising the total number of schools involved in the study from 84 to 96 (with the second cohort of schools making up 14 percent of the sample). ${ }^{2}$

Data collection at these schools followed the same process and used the same reports as at the first set of schools. Initial data collection with third-grade students in the second cohort began in fall 2005 (1 year later than the first cohort of third-graders), with the first follow-up at the end of third grade (spring 2006) and the second follow-up at the end of fourth grade (spring 2007). Students were followed for 2 years (through third and fourth grades) but not through fifth grade as was done with Cohort 1.

This appendix examines whether an analysis of the larger sample of both cohorts together (all Cohort 1 students plus all Cohort 2 students) gives similar or different results from those for Cohort 1 alone (presented in chapters 1 through 8). The two cohorts were combined into one sample by grouping all third-graders together and all fourth-graders together. Two analyses were done. The first compared student outcomes for treatment and control students at the end of their fourth-grade year, and the second looked at average yearly growth in student outcomes from the beginning of third grade to the end of fourth grade. As Cohort 2 was not followed through the fifth grade, both analyses are based on the third- and fourth-grade data only.

\section{Sample}

There were 7,255 fourth-graders enrolled in one of 95 study schools at the time of data collection in spring of the students' fourth grade (spring 2006 for Cohort 1 and spring 2007 for Cohort 2). These students included 5,750 original cohort "stayers" who were enrolled in a study school at the time of data collection in fall of their third grade and spring of fourth grade, and 1,505 new entrants who enrolled in a study school after the data collection in the fall of their third grade but before data collection in the spring of fourth grade. The sample universe excluded 1,607 original cohort "leavers" who were enrolled in a study school in fall of third grade but not in spring of fourth grade.

There were 1,064 third-, fourth-, or fifth-grade teachers in spring of fourth grade but 124 either did not give consent to participate or did not provide the requested data. As a result, the teacher samples for the spring of fourth-grade analysis included 940 third- to fifth-grade teachers (fourth-grade teachers completed the Teacher Report on Student and third- to fifth-grade teachers completed the Teacher Report on Classroom and School). Teachers who had been in the study in fall of third grade but were excluded from the fourth-grade

\footnotetext{
${ }^{1}$ One of CSP's Cohort 2 schools stopped implementing the intervention after the first year but remained in the study for the second year as a treatment school.

2 Of the original 84 schools, one control school dropped out of the study prior to Year 2 when it became a magnet school, leaving 95 schools available for the analysis of both cohorts together.
} 


\section{Appendix A: Analysis of Cohorts 1 and 2}

follow-up could either have (1) left the school between fall of third grade and spring of fourth grade or (2) remained at the school but discontinued teaching in the third, fourth, or fifth grade.

The consent and response rates led to the analysis sample sizes and the percentages of the universe of fourthgraders for which there were data (table A.1). The analysis sample for the Child Report was 4,549 (2,395 treatment group students and 2,154 control group students); the samples for the Primary Caregiver Report and Teacher Report on Student were 3,551 (1,856 treatment group students and 1,695 control group students) and 4,737 (2,492 treatment group students and 2,245 control group students), respectively. These Child Report, Primary Caregiver Report, and Teacher Report on Student samples reflected 63 percent, 49 percent, and 65 percent of the 7,255 students in the sample universe of students in the fourth grade in study schools (in spring 2006 for Cohort 1 and spring 2007 for Cohort 2, including both original cohort stayers and new entrants in each cohort). The analysis sample for the Teacher Report on Classroom and School was 940 teachers (482 treatment group and 458 control group), which was 88 percent of the universe of teachers in the study schools. None of the differences between treatment and control groups in the percentage of the universe for which data were collected was statistically significant when the data were pooled across programs. 
Table A.1. Combined Cohorts 1 and 2: Sample size and percentage of sample universe for fourth-graders, by program and by treatment group status

\begin{tabular}{|c|c|c|c|c|c|c|c|c|c|c|c|c|}
\hline \multirow[b]{3}{*}{ Program } & \multicolumn{12}{|c|}{ Analysis sample size (Percent of sample universe) } \\
\hline & \multicolumn{3}{|c|}{ Child Report } & \multicolumn{3}{|c|}{ Primary Caregiver Report } & \multicolumn{3}{|c|}{ Teacher Report on Student } & \multicolumn{3}{|c|}{$\begin{array}{c}\text { Teacher Report on } \\
\text { Classroom and School }\end{array}$} \\
\hline & Treatment & Control & Total & Treatment & Control & Total & Treatment & Control & Total & Treatment & Control & Total \\
\hline \multirow[t]{2}{*}{ All programs } & 2,395 & 2,154 & 4,549 & 1,856 & 1,695 & 3,551 & 2,492 & 2,245 & 4,737 & 482 & 458 & 940 \\
\hline & $(63.9)$ & $(61.4)$ & $(62.7)$ & $(49.5)$ & $(48.3)$ & $(48.9)$ & $(66.5)$ & (64.0) & (65.3) & (88.6) & (88.1) & (88.3) \\
\hline \multirow[t]{2}{*}{$A B C$} & 254 & 350 & 604 & 182 & 262 & 444 & 266 & 362 & 628 & 56 & 72 & 128 \\
\hline & $(59.8)^{* *}$ & (63.6) & (61.9) & $(42.8)$ & $(47.6)$ & (45.5) & $(62.6)^{\star \star \star}$ & (65.8) & $(64.4)$ & (77.8) & (85.7) & (82.1) \\
\hline \multirow[t]{2}{*}{ CSP } & 432 & 429 & 861 & 324 & 348 & 672 & 438 & 442 & 880 & 81 & 82 & 163 \\
\hline & (65.9) & $(60.2)$ & (62.9) & (49.4) & $(48.8)$ & (49.1) & $(66.8)$ & (62.0) & (64.3) & (85.3) & (85.4) & (85.3) \\
\hline \multirow[t]{2}{*}{ LBW } & 357 & 287 & 644 & 314 & 234 & 548 & 385 & 299 & 684 & 77 & 55 & 132 \\
\hline & (60.9) & (62.1) & (61.5) & (53.6) & (50.6) & (52.3) & (65.7) & (64.7) & (65.3) & $(90.6)$ & (87.3) & (89.2) \\
\hline \multirow[t]{2}{*}{ PA } & 284 & 225 & 509 & 215 & 184 & 399 & 302 & 251 & 553 & 43 & 39 & 82 \\
\hline & $(66.8)$ & $(66.4)$ & (66.6) & $(50.6)$ & $(54.3)$ & $(52.2)$ & (71.1) & $(74.0)$ & $(72.4)$ & $(86.0)$ & (86.7) & (86.3) \\
\hline \multirow[t]{2}{*}{ PATHS } & 306 & 265 & 571 & 239 & 201 & 440 & 314 & 273 & 587 & 73 & 77 & 150 \\
\hline & (58.5) & $(52.2)$ & (55.4) & $(45.7)^{\star *}$ & (39.6) & $(42.7)$ & $(60.0)$ & $(53.7)$ & (56.9) & (85.9) & (81.1) & (83.3) \\
\hline \multirow[t]{2}{*}{$4 \mathrm{Rs}$} & 376 & 303 & 679 & 245 & 210 & 455 & 403 & 323 & 726 & 91 & 82 & 173 \\
\hline & (62.8) & (59.4) & (61.2) & (40.9) & $(41.2)$ & $(41.0)$ & (67.3) & (63.3) & (65.5) & $(96.8)$ & (97.6) & (97.2) \\
\hline \multirow[t]{2}{*}{ SS } & 386 & 295 & 681 & 337 & 256 & 593 & 384 & 295 & 679 & 61 & 51 & 112 \\
\hline & $(72.4)$ & $(69.2)$ & $(71.0)$ & (63.2) & $(60.1)$ & (61.8) & $(72.0)$ & $(69.2)$ & $(70.8)$ & $(96.8)$ & $(96.2)$ & (96.6) \\
\hline
\end{tabular}

** Treatment group significantly different from control group at the .01 level.

*** Treatment group significantly different from control group at the .001 level.

NOTE: Abbreviations are

ABC: Academic and Behavioral Competencies Program

CSP: Competence Support Program

LBW: Love In a Big World

PA: Positive Action

PATHS: Promoting Alternative Thinking Strategies.

4Rs: The 4Rs Program (Reading, Writing, Respect, and Resolution).

SS: Second Step

SOURCE: The Social and Character Development (SACD) Research Program. 
Appendix A: Analysis of Cohorts 1 and 2

There were several significant differences at the program level. For the $\mathrm{ABC}$ program, there was a statistically significant treatment-control group difference in the percentages with Child Report data $60 \%$ for the treatment group and 64\% for the control group) and Teacher Report on Student data $(63 \%$ and $66 \%$, respectively). For the PATHS program, there was a statistically significant difference in the percentages with Primary Caregiver Report data (46\% and 40\%, respectively).

As in the Cohort 1 study, the sample for the evaluation of the two cohorts raised two cautions for the interpretation of the results. First, because of non-consent and non-response, the impact estimates might not generalize to the full sample universe if the characteristics of students in the study and students not in the study differed in ways that correlated with child outcomes. Second, because the study did not follow leavers from the original cohort, the intent-to-treat (ITT) impacts could not be estimated using all original cohort members. Instead, the evaluation used a repeated cross-sectional analysis approach to estimate impacts; this involved including all students in the study schools who had consent and who provided data at each followup point. These unbiased impact estimates for students in the study reflect (1) the extent to which the programs improved the outcomes of the average student in the study, and (2) treatment-induced "mobility effects" resulting from potential differences in the average outcomes of treatment and control students who entered and left the schools after random assignment.

\section{Initial Data}

The examination of the initial characteristics ${ }^{3}$ of students, families, teachers, and schools for the combined cohorts showed few significant differences between the treatment and control groups at the combinedprogram level and fewer differences among the programs than would be expected by chance. These results are similar to those of the Cohort 1 -only sample. The treatment and control groups in the combined sample were similar along all student and parent/caregiver characteristics except for household size (the treatment group students were more likely to come from smaller households: 4.6 people versus 4.7 per household) (table A.2). There were no significant differences between treatment and control groups in the mean values of the outcomes measuring children's behavior and attitudes (table A.3). There were no significant differences between the treatment and control groups in teachers' initial characteristics (table A.4), nor were there significant differences in the characteristics of treatment group schools and control group schools (though sample sizes were small for these comparisons) (table A.5). There were no differences between treatment and control groups in teacher-reported measures of the school environment on such dimensions as safety, participatory decision making, and work pressure (these data are not shown in a table).

\footnotetext{
${ }^{3}$ For a list of the characteristics, see Initial Characteristics in chapter 1.
} 
Table A.2. Combined Cohorts 1 and 2: Initial characteristics of children, their families, and communities

\begin{tabular}{|c|c|c|c|}
\hline Characteristic & Total & Treatment & Control \\
\hline Student sample size & 4,202 & 2,202 & 2,000 \\
\hline \multicolumn{4}{|l|}{ Student demographics } \\
\hline \multicolumn{4}{|l|}{ Gender (percent) } \\
\hline Male & 47.4 & 47.1 & 47.7 \\
\hline Female & 52.6 & 52.9 & 52.3 \\
\hline \multicolumn{4}{|l|}{ Race/ethnicity (percent) } \\
\hline White (non-Hispanic) & 40.7 & 39.0 & 42.5 \\
\hline Black (non-Hispanic) & 31.9 & 33.7 & 30.2 \\
\hline Hispanic & 19.9 & 19.8 & 20.0 \\
\hline Other & 7.4 & 7.5 & 7.3 \\
\hline Age (in years) (mean) & 8.1 & 8.1 & 8.1 \\
\hline \multicolumn{4}{|l|}{ Primary caregiver and family characteristics } \\
\hline Primary caregiver's age (in years) (mean) & 36.0 & 35.9 & 36.1 \\
\hline \multicolumn{4}{|l|}{ Primary caregiver's race/ethnicity (percent) } \\
\hline White (non-Hispanic) & 44.6 & 42.8 & 46.4 \\
\hline Black (non-Hispanic) & 31.9 & 33.8 & 30.0 \\
\hline Hispanic & 18.2 & 18.0 & 18.3 \\
\hline Other & 5.3 & 5.4 & 5.3 \\
\hline \multicolumn{4}{|l|}{ Primary caregiver's education (percent) } \\
\hline Did not complete high school & 15.5 & 14.5 & 16.5 \\
\hline Completed high school or equivalent & 24.7 & 24.2 & 25.3 \\
\hline Some college & 39.7 & 40.7 & 38.7 \\
\hline Bachelor's or higher degree & 20.0 & 20.6 & 19.5 \\
\hline \multicolumn{4}{|l|}{ Primary caregiver's employment (percent) } \\
\hline Full-time & 47.5 & 47.8 & 47.3 \\
\hline Part-time & 14.6 & 14.5 & 14.7 \\
\hline Student and employed & 4.4 & 4.9 & 3.9 \\
\hline Not employed & 32.4 & 31.7 & 33.0 \\
\hline Other & 1.1 & 1.1 & 1.1 \\
\hline \multicolumn{4}{|l|}{ Primary caregiver's marital status (percent) } \\
\hline Single & 25.0 & 25.6 & 24.4 \\
\hline Married & 55.2 & 54.5 & 56.0 \\
\hline Separated or divorced & 12.7 & 12.7 & 12.7 \\
\hline Widowed & 1.4 & 1.3 & 1.5 \\
\hline Other $^{1}$ & 5.6 & 5.9 & 5.4 \\
\hline Students who live in one household (percent) & 93.6 & 93.5 & 93.7 \\
\hline Number of individuals in household (mean) & 4.7 & $4.6^{*}$ & 4.7 \\
\hline
\end{tabular}


Table A.2. Combined Cohorts 1 and 2: Initial characteristics of children, their families, and communities-Continued

\begin{tabular}{|c|c|c|c|}
\hline Characteristic & Total & Treatment & Control \\
\hline \multicolumn{4}{|l|}{ Primary caregiver's relationship to child (percent) } \\
\hline Mother (stepmother) & 85.9 & 86.0 & 85.8 \\
\hline Father (stepfather) & 8.9 & 8.5 & 9.4 \\
\hline Grandparent & 3.1 & 3.2 & 3.0 \\
\hline Other relative & 1.3 & 1.4 & 1.3 \\
\hline Nonrelative & 0.8 & 1.0 & 0.6 \\
\hline \multicolumn{4}{|l|}{ Student lives with (percent) } \\
\hline Mother (stepmother) and father (stepfather) & 58.4 & 57.0 & 59.7 \\
\hline Mother (stepmother) only; father (stepfather) not present & 35.1 & 36.3 & 33.9 \\
\hline Father (stepfather) only; mother (stepmother) not present & 2.6 & 2.4 & 2.8 \\
\hline Other relative/nonrelative; parents not present & 4.0 & 4.3 & 3.6 \\
\hline \multicolumn{4}{|l|}{ Highest education of anyone in household (percent) } \\
\hline Did not complete high school & 10.7 & 9.6 & 11.9 \\
\hline Completed high school or equivalent & 22.4 & 21.7 & 23.1 \\
\hline Some college & 40.5 & 42.1 & 39.0 \\
\hline Bachelor's or higher degree & 26.3 & 26.6 & 26.0 \\
\hline \multicolumn{4}{|l|}{ Total household income (percent) } \\
\hline Less than $\$ 20,000$ & 34.6 & 33.7 & 35.4 \\
\hline$\$ 20,000$ to $\$ 39,999$ & 24.6 & 25.2 & 24.1 \\
\hline$\$ 40,000$ to $\$ 59,999$ & 15.0 & 15.4 & 14.5 \\
\hline$\$ 60,000$ or more & 25.9 & 25.7 & 26.0 \\
\hline \multicolumn{4}{|l|}{ Household income-to-poverty ratio (percent) } \\
\hline Below 135 percent & 40.8 & 39.3 & 42.3 \\
\hline 135 to 185 percent & 18.7 & 19.3 & 18.1 \\
\hline Above 185 percent & 40.5 & 41.4 & 39.6 \\
\hline $\begin{array}{l}\text { Alabama Parenting Questionnaire-Poor Monitoring } \\
\text { and Supervision Subscale (mean) }\end{array}$ & 1.2 & 1.2 & 1.2 \\
\hline \multicolumn{4}{|l|}{ Alabama Parenting Questionnaire-Positive Parenting } \\
\hline Subscale (mean) & 3.5 & 3.5 & 3.5 \\
\hline Confusion, Hubbub, and Order Scale (mean) & 2.2 & 2.2 & 2.2 \\
\hline \multicolumn{4}{|l|}{ Community characteristics (mean) } \\
\hline Community Risks Scale & 1.5 & 1.5 & 1.5 \\
\hline Community Resources Scale & 2.7 & 2.7 & 2.7 \\
\hline Child-Centered Social Control Scale & 3.1 & 3.0 & 3.1 \\
\hline \multicolumn{4}{|l|}{$\begin{array}{l}\text { * Treatment group significantly different from control group at the } .05 \text { level. } \\
{ }^{1} \text { Categories combined to protect confidentiality. }\end{array}$} \\
\hline $\begin{array}{l}\text { NOTE: Weights, which assign equal weight to each school within each o } \\
\text { used in producing the treatment, control, and overall means. Statistical te } \\
\text { indicators to account for the sample design and adjusted for clustering a }\end{array}$ & $\begin{array}{l}\text { ams an } \\
\text { conduct }\end{array}$ & $\begin{array}{l}\text { program acros } \\
\text { egressions the }\end{array}$ & $\begin{array}{l}\text { s, were } \\
\text { program }\end{array}$ \\
\hline
\end{tabular}


Table A.3. Combined Cohorts 1 and 2: Mean scores and standard deviations for initial outcome measures

\begin{tabular}{|c|c|c|c|c|c|c|c|}
\hline \multirow[b]{2}{*}{ Outcome measure-Report } & \multirow[b]{2}{*}{ Range } & \multicolumn{2}{|c|}{ Total } & \multicolumn{2}{|c|}{ Treatment } & \multicolumn{2}{|c|}{ Control } \\
\hline & & Mean & $S D$ & Mean & $S D$ & Mean & $S D$ \\
\hline \multicolumn{8}{|l|}{ Social and Emotional Competence Domain } \\
\hline Self-Efficacy for Peer Interaction-CR & $1-4$ & 2.9 & 0.6 & 2.9 & 0.6 & 2.9 & 0.6 \\
\hline Normative Beliefs About Aggression-CR & $1-4$ & 1.2 & 0.5 & 1.2 & 0.5 & 1.2 & 0.5 \\
\hline Empathy-CR & $1-3$ & 2.4 & 0.4 & 2.4 & 0.4 & 2.4 & 0.4 \\
\hline \multicolumn{8}{|l|}{ Behavior Domain } \\
\hline Altruistic Behavior-CR & $0-3$ & 1.5 & 0.8 & 1.4 & 0.8 & 1.5 & 0.8 \\
\hline Altruistic Behavior-TRS & $1-4$ & 1.4 & 0.5 & 1.4 & 0.5 & 1.4 & 0.4 \\
\hline Altruistic Behavior-PCR & $1-4$ & 2.3 & 0.7 & 2.3 & 0.7 & 2.3 & 0.8 \\
\hline Positive Social Behavior-TRS & $1-4$ & 3.0 & 0.7 & 3.0 & 0.7 & 3.0 & 0.7 \\
\hline Positive Social Behavior-PCR & $1-4$ & 3.0 & 0.5 & 3.0 & 0.5 & 3.0 & 0.5 \\
\hline Problem Behavior-CR & $0-3$ & 0.2 & 0.4 & 0.3 & 0.4 & 0.2 & 0.4 \\
\hline Problem Behavior-TRS & $1-4$ & 1.4 & 0.4 & 1.4 & 0.4 & 1.4 & 0.4 \\
\hline Problem Behavior-PCR & $1-4$ & 1.6 & 0.3 & 1.6 & 0.3 & 1.6 & 0.3 \\
\hline ADHD-Related Behavior-TRS & $1-4$ & 1.7 & 0.7 & 1.7 & 0.7 & 1.7 & 0.6 \\
\hline \multicolumn{8}{|l|}{ Academics Domain } \\
\hline Academic Competence and Motivation-TRS & $1-5$ & 2.9 & 0.9 & 2.9 & 0.9 & 2.9 & 0.9 \\
\hline Engagement with Learning-CR & $1-4$ & 3.7 & 0.6 & 3.7 & 0.7 & 3.7 & 0.6 \\
\hline \multicolumn{8}{|l|}{ Perceptions of School Climate Domain } \\
\hline Positive School Orientation-CR & $1-4$ & 3.2 & 0.7 & 3.2 & 0.7 & 3.2 & 0.7 \\
\hline Negative School Orientation-CR & $1-4$ & 1.9 & 0.7 & 1.9 & 0.7 & 1.9 & 0.7 \\
\hline Student Afraid at School-CR & $1-4$ & 2.4 & 0.9 & 2.4 & 0.9 & 2.4 & 0.9 \\
\hline Victimization at School-CR & $0-3$ & 0.8 & 0.8 & 0.8 & 0.8 & 0.8 & 0.8 \\
\hline Sample size-PCR ${ }^{1}$ & & \multicolumn{2}{|c|}{4,202} & \multicolumn{2}{|c|}{2,202} & \multicolumn{2}{|c|}{2,000} \\
\hline Sample size-CR ${ }^{1}$ & & \multicolumn{2}{|c|}{4,486} & \multicolumn{2}{|c|}{2,357} & \multicolumn{2}{|c|}{2,129} \\
\hline Sample size-TRS ${ }^{1}$ & & \multicolumn{2}{|c|}{4,578} & \multicolumn{2}{|c|}{2,405} & \multicolumn{2}{|c|}{2,173} \\
\hline
\end{tabular}

${ }^{1}$ Sample size may differ for some outcomes due to nonresponse.

NOTE: Abbreviations are

CR: Child Report

PCR: Primary Caregiver Report

TRS: Teacher Report on Student

ADHD: Attention deficit hyperactivity disorder

$S D$ : Standard deviation

No findings were found statistically significant at or below the .05 level. Weights, which assign equal weight to each school within each of the programs and to each program across programs, were used in producing the treatment, control, overall means, and standard deviations. Statistical tests were conducted using regressions that included program indicators to account for the sample design and adjusted for clustering at the school level.

SOURCE: The Social and Character Development (SACD) Research Program. 
Table A.4. Combined Cohorts 1 and 2: Initial characteristics of teachers

\begin{tabular}{|c|c|c|c|}
\hline Characteristic & Total & Treatment & Control \\
\hline Teacher sample size & 964 & 494 & 470 \\
\hline \multicolumn{4}{|l|}{ Gender (percent) } \\
\hline Male & 11.8 & 12.2 & 11.4 \\
\hline Female & 88.2 & 87.8 & 88.6 \\
\hline \multicolumn{4}{|l|}{ Race/ethnicity (percent) } \\
\hline White (non-Hispanic) & 76.0 & 74.5 & 77.4 \\
\hline Black (non-Hispanic) & 16.4 & 17.6 & 15.1 \\
\hline Hispanic & 4.7 & 5.7 & 3.7 \\
\hline Other & 3.0 & 2.1 & 3.8 \\
\hline Number of years teaching (mean) & 12.7 & 12.5 & 12.9 \\
\hline Number of years teaching in this school (mean) & 7.3 & 6.9 & 7.7 \\
\hline \multicolumn{4}{|l|}{ Type of teaching certificate (percent) } \\
\hline Regular state certificate or advanced professional certificate & 84.6 & 83.7 & 85.6 \\
\hline $\begin{array}{l}\text { Provisional certificate (for those in alternative certification } \\
\text { programs) }\end{array}$ & 5.8 & 6.7 & 4.8 \\
\hline $\begin{array}{l}\text { Probationary certificate (for those who have satisfied all } \\
\text { requirements except for completing the } \\
\text { probationary period) }\end{array}$ & 5.0 & 5.5 & 4.5 \\
\hline $\begin{array}{l}\text { Emergency certificate or waiver (for those who must } \\
\text { complete a certification program to continue teaching) }\end{array}$ & 0.0 & 0.0 & 0.0 \\
\hline Other $^{1}$ & 4.6 & 4.0 & 5.1 \\
\hline \multicolumn{4}{|l|}{ Education } \\
\hline Less than a bachelor's degree & 0.0 & 0.0 & 0.0 \\
\hline Bachelor's degree & 40.3 & 39.4 & 41.2 \\
\hline Master's degree, Ph.D. & 56.1 & 58.2 & 54.0 \\
\hline Specialist degree & 2.0 & 1.0 & 2.9 \\
\hline Other & 1.7 & 1.4 & \\
\hline
\end{tabular}

${ }^{1}$ Categories, including "no certificate" and "temporary certificate," combined to protect confidentiality.

NOTE: No findings were found statistically significant at or below the .05 level. Weights, which assign equal weight to each school within each of the programs and to each program across programs, were used in producing the treatment, control, and overall means. Statistical tests were conducted using regressions that included program indicators to account for the sample design and adjusted for clustering at the school level.

SOURCE: The Social and Character Development (SACD) Research Program. 
Table A.5. Combined Cohorts 1 and 2: Initial characteristics of schools

\begin{tabular}{|c|c|c|c|}
\hline Characteristic & Total & Treatment & Control \\
\hline School sample size & 96 & 48 & 48 \\
\hline \multicolumn{4}{|l|}{ Student race/ethnicity (percent) } \\
\hline White (non-Hispanic) & 36.4 & 36.6 & 36.1 \\
\hline Black (non-Hispanic) & 40.9 & 40.4 & 41.5 \\
\hline Hispanic & 18.8 & 18.7 & 18.9 \\
\hline Other & 3.9 & 4.3 & 3.5 \\
\hline Students eligible for free or reduced-price lunch (percent) & 63.2 & 64.1 & 62.4 \\
\hline Number of students enrolled (mean) & 552.1 & 541.3 & 563.3 \\
\hline Number of full-time teachers (mean) & 35.7 & 34.4 & 36.9 \\
\hline \multicolumn{4}{|l|}{ Title I status (percent) } \\
\hline Title I eligible school & 76.9 & 76.1 & 77.6 \\
\hline Schoolwide Title I & 68.4 & 66.8 & 69.9 \\
\hline \multicolumn{4}{|l|}{ Lowest grade offered (percent) } \\
\hline Prekindergarten & 59.1 & 51.4 & 67.0 \\
\hline Kindergarten & 40.9 & 48.6 & 33.0 \\
\hline \multicolumn{4}{|l|}{ Highest grade offered (percent) } \\
\hline 5 th grade & 54.0 & 57.5 & 50.5 \\
\hline $6 \mathrm{~h}$ grade & 23.5 & 20.2 & 26.8 \\
\hline 8th grade & 21.5 & 20.3 & 22.7 \\
\hline \multicolumn{4}{|l|}{ Location of school (percent) } \\
\hline City & 57.2 & 58.7 & 55.7 \\
\hline Suburbs & 23.7 & 22.4 & 25.1 \\
\hline Rural & 19.1 & 18.9 & 19.2 \\
\hline Number of years principal has been at this school (mean) & 5.5 & 5.0 & 5.9 \\
\hline
\end{tabular}

NOTE: No findings were found statistically significant at or below the .05 level. Weights, which assign equal weight to each school within each of the programs and to each program across programs, were used in producing the treatment, control, and overall means. Statistical tests were conducted using regressions that included program indicators to account for the sample design and adjusted for clustering at the school level. Data are missing from Love In a Big World for student race/ethnicity, percentage of students eligible for free or reduced-price lunch, and number of full-time teachers.

SOURCE: The Social and Character Development (SACD) Research Program. 
Large percentages of principals and teachers (treatment and control) reported using social and character development activities and receiving professional development in their use. The percentages reported were very similar to those reported for Cohort 1 , so only a selection of indicators are shown in table A.6. Where there were differences, they favored the treatment teachers, and all the differences that appeared here also appeared in the Cohort 1-only data. These differences may have reflected the fact that the programs had been implemented in most of the study schools before the teachers were surveyed about their use of activities. 
Table A.6. Combined Cohorts 1 and 2: Teacher initial reports on use of SACD activities and training in SACD activities

\begin{tabular}{|c|c|c|c|}
\hline Teacher report & Total & Treatment & Control \\
\hline \multicolumn{4}{|l|}{$\begin{array}{l}\text { Teachers reporting on using programs or activities in their } \\
\text { class to promote the following SACD goals (percent) }\end{array}$} \\
\hline Violence prevention and peace promotion & 64.4 & $68.2^{*}$ & 60.7 \\
\hline Social and emotional development & 72.2 & $76.3^{*}$ & 68.0 \\
\hline Character education & 82.8 & 84.2 & 81.4 \\
\hline Tolerance and diversity & 61.9 & 62.4 & 61.4 \\
\hline Risk prevention and health promotion & 52.0 & 50.8 & 53.1 \\
\hline Civic responsibility and community service & 59.1 & 58.2 & 60.0 \\
\hline Behavior management & 87.3 & 89.1 & 85.4 \\
\hline None of the above & 2.4 & 1.9 & 2.9 \\
\hline \multicolumn{4}{|l|}{$\begin{array}{l}\text { Teachers using the following materials in conjunction with social } \\
\text { and character development activities (percent) }\end{array}$} \\
\hline Teacher guides (manuals, curricula) & 66.0 & $72.0^{\star *}$ & 60.1 \\
\hline Student materials (workbooks, worksheets) & 50.1 & 51.4 & 48.9 \\
\hline Instructional aids (games, software, videos) & 32.6 & $36.0^{*}$ & 29.1 \\
\hline Giveaways (bookmarks, stickers) & 48.0 & 45.5 & 50.4 \\
\hline Children's literature & 49.7 & 52.5 & 46.9 \\
\hline Other types of materials & 12.9 & 10.9 & 14.9 \\
\hline Do not use any of the materials listed above & 10.1 & 9.8 & 10.4 \\
\hline \multicolumn{4}{|l|}{ Use of instructional strategies to promote SACD (percent) } \\
\hline $\begin{array}{l}\text { Teachers using any of } 20 \text { instructional strategies to promote } \\
\text { social and character development in the classroom (percent) }\end{array}$ & 99.8 & 99.6 & 100.0 \\
\hline $\begin{array}{l}\text { Number of the } 20 \text { strategies used by teachers to promote } \\
\text { social and character development in the classroom (mean) }\end{array}$ & 11.7 & $12.1^{*}$ & 11.4 \\
\hline \multicolumn{4}{|l|}{ Professional development on promoting SACD (percent) } \\
\hline $\begin{array}{l}\text { Teachers reporting participation in social and character } \\
\text { development training within the past } 12 \text { month (percent) }\end{array}$ & 73.7 & $84.7^{* * *}$ & 62.7 \\
\hline $\begin{array}{l}\text { Number of hours of social and character development } \\
\text { training teachers report receiving during the past } 12 \\
\text { months (mean) }\end{array}$ & 7.6 & $8.9^{\star *}$ & 6.3 \\
\hline
\end{tabular}

${ }^{*}$ Treatment group significantly different from control group at the .05 level.

** Treatment group significantly different from control group at the .01 level.

*** Treatment group significantly different from control group at the .001 level.

NOTE: Weights, which assign equal weight to each school within each of the programs and to each program across programs, were used in producing the treatment, control, and overall means. Statistical tests were conducted using regressions that included program indicators to account for the sample design and adjusted for clustering at the school level. Sample size may differ for some outcomes due to nonresponse.

SOURCE: The Social and Character Development (SACD) Research Program. 
Cohort 2 significantly differed in some ways from Cohort 1 when comparing students, teachers, and schools (these data are not shown in a table), although some of these comparisons were based on small samples sizes for Cohort 2. At the combined-program level, there were no statistically significant differences between Cohort 1 and Cohort 2 students in terms of gender, race/ethnicity, or age. However, students from Cohort 1 were reported to come from less disadvantaged families than students in Cohort 2. Cohort 1 parents or primary caregivers were statistically significantly more likely to have a bachelor's degree or higher, be employed, be married, live in a household that included both a mother (or stepmother) and a father (or stepfather), have a higher income-to-poverty threshold ratio, and have a lower average community risks scale score (as reported by primary caregivers). With respect to the outcome measures, Cohort 1 students had significantly higher Academic Competence and Motivation, higher Engagement with Learning, fewer Normative Beliefs About Aggression, and a more Positive Orientation Toward School, although they had lower Altruistic Behavior scores (Primary Caregiver Report). The characteristics of teachers were similar in Cohort 1 and Cohort 2, and there were no statistically significant differences between the cohorts in teachers' gender, race/ethnicity, years of experience, or education. The Cohort 1 schools had a statistically significantly greater average number of enrolled students and a greater average number of full-time teachers but there were no differences in the characteristics of the students at the schools, such as the distributions of students across racial/ethnic groups or percentages of students eligible for free or reduced-price lunches. Teacherreported measures of the school environment on such dimensions as safety, participatory decision making, and work pressure showed no statistically significant differences between Cohort 1 and Cohort 2. There were few significant differences in the use of SACD activities reported by the teachers in both cohorts. More Cohort 1 teachers reported using activities for tolerance and diversity (a difference of 10 percentile points). More Cohort 2 teachers reported using character education (with a difference of less than 2 percentile points) and behavior management activities (a difference of 7 percentile points). Teachers reported no significant differences in the use of materials and strategies for SACD activities and their participation in professional development; however, there was a difference between the cohorts in teacher reports on modeling positive social and character traits with students; this favored Cohort 1 (87\% versus $81 \%)$.

The addition of the Cohort 2 schools did not have a large impact on the percentages of data available for the analysis. Table A.7 compares the consent rates, completion rates, and percentages of sample with data for each report for Cohort 1 only versus Cohorts 1 and 2 combined. The rates for Cohorts 1 and 2 combined are very similar to those of Cohort 1 only. Significant differences between treatment and control groups occur, in most cases, similarly in both. In two cases, the combined cohort data show significant differences between the treatment and control groups (Child Report students with data and students with Teacher Report on Student data, both in spring fourth grade) that were not found for Cohort 1 only. However, the actual magnitudes of the differences are very similar for both. 
Table A.7. Cohort 1 versus combined Cohorts 1 and 2: Comparison of consent rates, completion rates, and percentage of sample with data

\begin{tabular}{|c|c|c|c|c|c|c|c|c|c|c|c|c|}
\hline \multirow[b]{2}{*}{ Report } & \multicolumn{3}{|c|}{$\begin{array}{c}\text { Cohort } 1 \\
\text { (Fall 3rd grade) }\end{array}$} & \multicolumn{3}{|c|}{$\begin{array}{l}\text { Cohorts } 1 \text { and } 2 \\
\text { (Fall 3rd grade) }\end{array}$} & \multicolumn{3}{|c|}{$\begin{array}{c}\text { Cohort } 1 \\
\text { (Spring 4th grade) }\end{array}$} & \multicolumn{3}{|c|}{$\begin{array}{c}\text { Cohorts } 1 \text { and } 2 \\
\text { (Spring 4th grade) }\end{array}$} \\
\hline & Total & $\begin{array}{r}\text { Treat- } \\
\text { ment }\end{array}$ & Control & Total & $\begin{array}{r}\text { Treat- } \\
\text { ment }\end{array}$ & Control & Total & $\begin{array}{r}\text { Treat- } \\
\text { ment }\end{array}$ & Control & Total & $\begin{array}{c}\text { Treat- } \\
\text { ment }\end{array}$ & Control \\
\hline Student sample size & 6,567 & 3,367 & 3,200 & 7,357 & 3,764 & 3,593 & 6,415 & 3,327 & 3,088 & 7,255 & 3,747 & 3,508 \\
\hline
\end{tabular}

Child Report (percent)

\begin{tabular}{|c|c|c|c|c|c|c|}
\hline at rate & 65 & $67^{* *}$ & 63 & 65 & $67^{\star \star \star}$ & 67 \\
\hline
\end{tabular}

Student completion rate

$94 \quad 93^{*} \quad 94 \quad 93$

Students with data ${ }^{1}$

$62^{*}$

60

61

$95 \quad 94$

95

96

95

96

Primary Caregiver Report (percent)

Primary caregiver consent rate

Primary caregiver completion rate

Primary caregivers with data ${ }^{1}$

$\begin{array}{llll}63 & 64^{* *} & 61 & 62 \\ 92 & 92 & 92 & 92 \\ 57 & 59^{* *} & 56 & 57\end{array}$

$63^{* *} \quad 59$

$63 \quad 65$

62

63

$96 \quad 95$

Teacher Report on Student (percent) Primary caregiver consent rate ${ }^{2}$

Teacher completion rate

Students with data ${ }^{1}$

$\begin{array}{lll}65 & 67^{* * *} & 63 \\ 96 & 96 & 96 \\ 62 & 64^{* *} & 61\end{array}$

$\begin{array}{ll}64^{* * *} & 60 \\ 91 & 92 \\ 59^{*} & 56\end{array}$

$\begin{array}{llllll}64 & 65 & 63 & 63 & 64 & 62 \\ 78 & 77 & 78 & 77 & 77 & 77 \\ 50 & 51 & 49 & 49 & 50 & 48\end{array}$

Teacher Report on Classroom and School

(3rd- to 5th-grade teachers) (percent)

\begin{tabular}{|c|c|c|c|c|c|c|c|c|c|c|c|c|}
\hline Teacher consent rate & 96 & $98^{* \star *}$ & 92 & 95 & $98^{\star * \star}$ & 93 & 95 & 97 & 94 & 95 & 95 & 94 \\
\hline Teacher completion rate & 91 & 90 & 93 & 91 & 90 & 93 & 94 & 94 & 94 & 93 & 93 & 93 \\
\hline Teachers with data $^{1}$ & 87 & 88 & 86 & 87 & 88 & 86 & 90 & 90 & 89 & 88 & 89 & 88 \\
\hline
\end{tabular}

* Treatment group significantly different from control group at the .05 level.

** Treatment group significantly different from control group at the .01 level.

${ }^{* * *}$ Treatment group significantly different from control group at the .001 level.

${ }^{1}$ Calculated as consent rate $x$ completion rate.

${ }^{2}$ The primary caregiver consent rates for the Child Report and the Teacher Report on Student are identical, as the primary caregiver gave consent to both together. SOURCE: The Social and Character Development (SACD) Research Program. 
The opportunity for the teams to add the Cohort 2 schools to the SACD multiprogram evaluation was planned as a means to increase the statistical power of the analyses by increasing the sample size. In practice, Cohort 2 added 12 schools to the sample of 84 schools. The addition of new schools also opened the possibility for a change in the intraclass correlations (the ICC, a measure of the percentage of the total variance in the outcomes that is between schools). An increase in the sample size would reduce the minimum detectable impacts in effect size units (MDES) for each outcome measure; however, changes in the ICCs could offset those reductions. In practice, the MDES for the outcome measures both increased and decreased, with 17 outcomes having changes in the thousandths of a point and 3 having changes in the hundredths (the largest being a decline of .027). Table A.8 compares the MDES for Cohort 1 versus the combined Cohorts 1 and 2 . 
Table A.8. Comparison of Cohort 1 and Cohorts 1 and 2: Adjusted minimum detectable effect sizes for fourth-grade outcomes for combined-program evaluation

\begin{tabular}{lcc}
\hline Outcome measure-Report & Cohort 1 & Cohorts 1 and 2 \\
\hline Social and Emotional Competence Domain & & \\
Self-Efficacy for Peer Interaction-CR & 0.048 & 0.049 \\
Normative Beliefs About Aggression-CR & 0.081 & 0.076 \\
Empathy-CR & 0.078 & 0.071 \\
& & \\
Behavior Domain & & 0.056 \\
Altruistic Behavior-CR & 0.057 & 0.039 \\
Altruistic Behavior-PCR & 0.044 & 0.211 \\
Altruistic Behavior-TRS & 0.238 & 0.048 \\
Positive Social Behavior-PCR & 0.042 & 0.113 \\
Positive Social Behavior-TRS & 0.115 & 0.090 \\
Problem Behavior-CR & 0.086 & 0.045 \\
Problem Behavior-PCR & 0.040 & 0.082 \\
Problem Behavior-TRS & 0.086 & 0.083 \\
ADHD-Related Behavior-TRS & 0.082 & \\
& & \\
Academics Domain & & 0.042 \\
Engagement with Learning-CR & 0.036 & 0.084 \\
Academic Competence and Motivation-TRS & 0.077 & \\
Perceptions of School Climate Domain & & \\
Positive School Orientation-CR & & 0.113 \\
Negative School Orientation-CR & & \\
Student Afraid at School-CR & 0.123 & 0.067 \\
Victimization at School-CR & 0.070 & 0.063 \\
Feelings of Safety-TRCS & 0.064 & 0.063 \\
Student Support for Teachers-TRCS & 0.179 & 0.154 \\
\hline NOTE:Abbriotions & & \\
\hline
\end{tabular}

NOTE: Abbreviations are

CR: Child Report

PCR: Primary Caregiver Report

TRS: Teacher Report on Student

TRCS: Teacher Report on Classroom and School

ADHD: Attention deficit hyperactivity disorder

The minimum detectable effect (MDE) formula used in the calculations is as follows:

$M D E=\operatorname{factor}(d f) * \sqrt{\rho_{1}\left(\frac{1}{s_{T}}+\frac{1}{s_{C}}\right)+\left(1-\rho_{1}\right)\left(\frac{1}{s_{T} n_{T}}+\frac{1}{s_{C} n_{C}}\right)}$

where $s_{T}$ and $s_{C}$ are the number of treatment and comparison schools; $n_{T}$ and $n_{C}$ are the average number of students per classroom; $\rho_{1}$ is the intraclass correlation (ICC) at the school level; and factor(df) is a constant that depends on the number of degrees of freedom ( $d f$ ) available for analysis (and is 2.802 for the pooled analysis). Estimates were adjusted for fixed program effects as well as baseline covariates.

SOURCE: The Social and Character Development (SACD) Research Program. 


\section{Analysis}

The analyses used for the combined cohort data were similar to those used with the Cohort 1 data and described in chapter 1. Adjustments were made to account for fewer data collection time points. For example, the analyses of the impacts on the use of SACD activities in the classroom and the school and of the impact on student outcomes used the same analytical methods as did the year-by-year analysis of Cohort 1 fourthgrade student outcomes.

In addition, a similar growth curve analysis was done with the combined cohort data, using student results from three time points (fall third grade, spring third grade, and spring fourth grade) rather than the five time points used with the Cohort 1 growth analysis. For this reason, the combined cohort growth analysis is not directly comparable to the Cohort 1 growth analysis.

\section{Impacts on Use of SACD Activities}

The analysis was based on the Teacher Report on Classroom and School data collected when the students were in the fourth grade (school year 2005-06 for Cohort 1 and school year 2006-07 for Cohort 2). In addition to information about the teachers' characteristics and backgrounds, this questionnaire asked third-, fourth-, and fifth-grade teachers in treatment and control group schools to provide information about the social and character development activities they used in their classrooms and about the climate in their schools.

The impacts of the SACD programs on teachers' reported use of SACD activities for the combined cohort analysis were consistent with results from the analyses of Cohort 1 data when students were in the fourth grade. Compared to control group teachers, treatment group teachers were more likely to report engaging in activities to promote social and character development on 12 out of 16 outcomes and to report engaging in similar activities linked to named programs on 14 out of 14 outcomes (table A.9). They also reported using more materials and strategies to promote social and character development for 13 out of 29 outcomes (table A.10) and more participation in SACD-related professional development for 2 out of 9 outcomes (table A.11). For engaging in any SACD activities, the difference between treatment and control group reports was small but significant (95\% versus $91 \%$ ), and for engaging in any SACD activities linked to named programs, the difference was larger (72\% versus 43\%). For professional development, 66 percent of treatment teachers reported receiving SACD training over the past 12 months versus 51 percent of control teachers. Treatment teachers were not more likely to report teacher and staff attitudes that might be conducive to promoting social and character development (these data are not shown in a table). 
Table A.9. Combined Cohorts 1 and 2: Impacts on classroom activities

\begin{tabular}{|c|c|c|c|c|}
\hline Classroom activity & Treatment & Control & Impact & $p$-value \\
\hline Teacher sample size & 481 & 459 & & \\
\hline \multicolumn{5}{|c|}{ Engagement in any activities to promote SACD goals ${ }^{1}$ (percent) } \\
\hline \multicolumn{5}{|c|}{ Activities } \\
\hline Violence prevention and peace promotion & $76.4^{*}$ & 66.1 & 10.3 & 0.002 \\
\hline Social and emotional development & $84.5^{*}$ & 61.2 & 23.4 & 0.000 \\
\hline Character education & $91.9^{*}$ & 77.6 & 14.3 & 0.000 \\
\hline Tolerance and diversity & $74.9^{*}$ & 61.9 & 13.0 & 0.000 \\
\hline Risk prevention and health promotion & 63.6 & 60.1 & 3.6 & 0.389 \\
\hline Civic responsibility and community service & 60.7 & 60.0 & 0.7 & 0.872 \\
\hline Any activity & $95.0^{*}$ & 90.8 & 4.2 & 0.025 \\
\hline Behavior management & $92.1^{*}$ & 83.3 & 8.8 & 0.000 \\
\hline \multicolumn{5}{|l|}{ At least 1 hour per week of activities } \\
\hline Violence prevention and peace promotion & $41.9^{*}$ & 25.3 & 16.7 & 0.000 \\
\hline Social and emotional development & $49.2^{*}$ & 25.7 & 23.5 & 0.000 \\
\hline Character education & $59.4^{*}$ & 31.7 & $27.7^{*}$ & 0.000 \\
\hline Tolerance and diversity & $35.9^{*}$ & 22.9 & 13.0 & 0.000 \\
\hline Risk prevention and health promotion & 26.9 & 22.0 & 4.9 & 0.174 \\
\hline Civic responsibility and community service & 20.8 & 16.1 & 4.7 & 0.111 \\
\hline Any activity & $83.7^{*}$ & 73.2 & 10.5 & 0.002 \\
\hline Behavior management & $74.9^{*}$ & 61.5 & 13.3 & 0.002 \\
\hline
\end{tabular}

Engagement in named activities to promote SACD goals ${ }^{1}$ (percent) Named activities

Violence prevention and peace promotion

Social and emotional development

Character education

Tolerance and diversity

Risk prevention and health promotion

Civic responsibility and community service

Any named activity

\begin{tabular}{rrrr}
$46.7^{*}$ & 18.1 & 28.6 & 0.000 \\
$53.2^{*}$ & 11.6 & 41.6 & 0.000 \\
$56.4^{*}$ & 14.9 & 41.5 & 0.000 \\
$36.4^{*}$ & 8.2 & 28.2 & 0.000 \\
$30.5^{*}$ & 18.9 & 11.5 & 0.001 \\
$14.4^{*}$ & 5.9 & 8.5 & 0.000 \\
$71.5^{*}$ & 42.5 & 29.0 & 0.000 \\
& & & \\
$31.5^{*}$ & 11.7 & 19.8 & 0.000 \\
$36.1^{*}$ & 7.0 & 29.1 & 0.000 \\
$41.8^{*}$ & 8.1 & 33.6 & 0.000 \\
$24.2^{*}$ & 4.2 & 20.0 & 0.000 \\
$17.4^{*}$ & 10.8 & 6.6 & 0.035 \\
$8.1^{*}$ & 2.2 & 6.0 & 0.003 \\
$50.7^{*}$ & 22.6 & 28.1 & 0.000 \\
\hline
\end{tabular}

At least 1 hour per week of named activities

Violence prevention and peace promotion

Social and emotional development

Character education

Tolerance and diversity

Risk prevention and health promotion

Civic responsibility and community service

Any named activity

* Treatment group significantly different from control group at the .05 level.

${ }^{1}$ Impact on domain found statistically significant after adjustments made for multiple comparisons within domain. NOTE: Weights, which assign equal weight to each school within each of the programs and to each program across programs, were used in producing the treatment, control, and overall means.

SOURCE: The Social and Character Development (SACD) Research Program. 


\section{Table A.10. Combined Cohorts 1 and 2: Impacts on use of SACD classroom materials and} teaching strategies

\begin{tabular}{|c|c|c|c|c|}
\hline SACD material and teaching strategy & Treatment & Control & Impact & $p$-value \\
\hline Teacher sample size & 481 & 459 & & \\
\hline \multicolumn{5}{|l|}{ Use of SACD materials (percent) } \\
\hline Teacher guides (manuals, curricula) & $80.4^{*}$ & 59.5 & 20.9 & 0.000 \\
\hline Student materials (workbooks or sheets) & $66.5^{*}$ & 54.3 & 12.3 & 0.001 \\
\hline Instructional aids (games, software, videos) & $46.2^{*}$ & 38.4 & 7.8 & 0.029 \\
\hline Giveaways (bookmarks, stickers) & 53.1 & 49.2 & 3.9 & 0.250 \\
\hline Children's literature & 57.8 & 48.2 & 9.6 & 0.027 \\
\hline Other types of materials & 9.1 & 12.3 & -3.3 & 0.147 \\
\hline Did not use any of these materials & $4.6^{*}$ & 13.1 & -8.5 & 0.000 \\
\hline \multicolumn{5}{|l|}{ Use of teaching strategies (percent) } \\
\hline Role-playing & $88.0^{\star}$ & 67.4 & 20.5 & 0.000 \\
\hline Cooperative learning & $98.2^{\wedge}$ & 96.3 & 2.0 & 0.075 \\
\hline Peer group discussions & 92.4 & 89.1 & 3.3 & 0.111 \\
\hline Direct instruction of SACD & $93.4^{*}$ & 78.0 & 15.4 & 0.000 \\
\hline Skill training & $65.3^{*}$ & 44.2 & 21.2 & 0.000 \\
\hline Incorporating SACD into academic curriculum & $86.3^{*}$ & 73.3 & 13.0 & 0.000 \\
\hline Parent training & 11.7 & 9.7 & 2.0 & 0.466 \\
\hline Parent and community involvement & $30.7^{*}$ & 22.0 & 8.7 & 0.023 \\
\hline Mentoring & 46.0 & 44.8 & 1.1 & 0.741 \\
\hline Good behavior notes sent home daily or weekly & 79.5 & 74.3 & 5.2 & 0.143 \\
\hline Presenting role models & $75.2^{\wedge}$ & 69.6 & 5.6 & 0.080 \\
\hline $\begin{array}{l}\text { Targeted story reading or writing on social } \\
\text { and character development themes }\end{array}$ & $88.5^{*}$ & 78.9 & 9.6 & 0.000 \\
\hline Peer mediation & 54.4 & 52.4 & 2.0 & 0.635 \\
\hline Honor roll for positive behavior & 62.0 & 59.9 & 2.1 & 0.639 \\
\hline Pledges or recitations on SACD themes & 48.0 & 44.9 & 3.1 & 0.598 \\
\hline Guided visualization & $60.9^{*}$ & 48.2 & 12.6 & 0.002 \\
\hline Student-led/student-assisted instruction & $59.6^{*}$ & 48.5 & 11.1 & 0.002 \\
\hline Journaling & 77.9 & 72.3 & 5.6 & 0.117 \\
\hline Time out for negative behavior & 86.1 & 85.3 & 0.8 & 0.720 \\
\hline Daily or weekly rewards for positive behavior & 93.0 & 90.2 & 2.8 & 0.190 \\
\hline Any strategy (percent) & 100.0 & 100.0 & 0.0 & $\dagger$ \\
\hline Number of strategies (mean) & $13.8^{*}$ & 12.4 & 1.5 & 0.000 \\
\hline
\end{tabular}

† Not applicable.

* Treatment group significantly different from control group at the .05 level.

$\wedge$ Treatment group significantly different from control group at the .10 to $>.05$ level.

NOTE: Weights, which assign equal weight to each school within each of the programs and to each program across programs, were used in producing the treatment, control, and overall means.

SOURCE: The Social and Character Development (SACD) Research Program. 
Table A.11. Combined Cohorts 1 and 2: Impacts on teacher-reported SACD professional development

\begin{tabular}{|c|c|c|c|c|}
\hline SACD professional development $^{1}$ & Treatment & Control & Impact & $p$-value \\
\hline Teacher sample size & 481 & 459 & & \\
\hline SACD training in past 12 months (percent) & $65.9^{*}$ & 51.3 & 14.6 & 0.000 \\
\hline Hours of SACD training (mean) & 5.8 & 4.9 & 0.9 & 0.404 \\
\hline \multicolumn{5}{|l|}{ Training by goal (percent) } \\
\hline Violence prevention and peace promotion & 19.1 & 14.8 & 4.3 & 0.180 \\
\hline Social and emotional development & $23.0^{\wedge}$ & 16.6 & 6.4 & 0.066 \\
\hline Character education & $35.1^{*}$ & 18.4 & 16.8 & 0.000 \\
\hline Tolerance and diversity & 17.5 & 18.9 & -1.4 & 0.650 \\
\hline Risk prevention and health promotion & 14.2 & 14.4 & -0.2 & 0.933 \\
\hline Civic responsibility and community service & 7.4 & 5.3 & 2.0 & 0.232 \\
\hline Behavior management & 29.6 & 25.0 & 4.6 & 0.210 \\
\hline
\end{tabular}

* Treatment group significantly different from control group at the .05 level.

$\wedge$ Treatment group significantly different from control group at the .10 to $>.05$ level.

${ }^{1}$ Impact on domain found statistically significant after adjustments made for multiple comparisons within domain for all years.

NOTE: Weights, which assign equal weight to each school within each of the programs and to each program across programs, were used in producing the treatment, control, and overall means.

SOURCE: The Social and Character Development (SACD) Research Program. 
The impacts of the programs on the SACD activity domains were consistent with results from the analyses of Cohort 1 data when students were in the fourth grade. Table A.12 shows that statistically significant larger percentages of treatment group teachers than control group teachers reported engaging in activities to promote social and character development, using more materials and strategies to promote social and character development, and participating in related professional development. Treatment group teachers were not more likely to report changes in the school environment or in teacher and staff attitudes that might be conducive to promoting social and character development.

Table A.12. Combined Cohorts 1 and 2: Significant impacts on domains of use of SACD activity overall and by program

\begin{tabular}{|c|c|c|c|c|c|c|}
\hline \multirow[b]{2}{*}{ Program } & \multicolumn{6}{|c|}{ SACD activity domain } \\
\hline & $\begin{array}{r}\text { SACD } \\
\text { activities }\end{array}$ & $\begin{array}{r}\text { SACD activities } \\
\text { linked to named } \\
\text { programs }\end{array}$ & $\begin{array}{r}\text { Classroom } \\
\text { materials } \\
\text { and strategies } \\
\end{array}$ & $\begin{array}{r}\text { Schoolwide } \\
\text { strategies }\end{array}$ & $\begin{array}{l}\text { Professional } \\
\text { development }\end{array}$ & $\begin{array}{r}\text { Attitudes } \\
\text { and } \\
\text { practices }\end{array}$ \\
\hline Overall & $+^{1,2,3}$ & $+^{1,2,3}$ & $+^{1,2,3}$ & & $+^{2,3}$ & \\
\hline $\mathrm{ABC}$ & & & & & & $+^{3}$ \\
\hline CSP & & $t^{3}$ & & & $+^{2}$ & \\
\hline LBW & $+^{3}$ & $+^{3}$ & & $+^{2}$ & $+^{3}$ & \\
\hline PA & & $+1,3$ & & & & \\
\hline PATHS & $++^{1,3}$ & $+1,3$ & & & & \\
\hline 4Rs & $++^{1,3}$ & $++^{1,3}$ & & & & \\
\hline SS & $+1,3$ & $+1,3$ & $+^{3}$ & & & \\
\hline
\end{tabular}

'Based on univariate statistical tests, at least half of the impacts were positive and statistically significant and no impact was negative and statistically significant.

${ }^{2}$ The omnibus impact for all the outcomes measured together was positive and statistically significant on the basis of a multivariate statistical test.

${ }^{3}$ At least one outcome remained positive and statistically significant and no outcome was negative and statistically significant after applying the Benjamini-Hochberg (1995) procedure to adjust significance levels downward to account for the multiple testing of impacts.

NOTE: Abbreviations are

ABC: Academic and Behavioral Competencies Program

CSP: Competence Support Program

LBW: Love In a Big World

PA: Positive Action

PATHS: Promoting Alternative Thinking Strategies

4Rs: The 4Rs Program (Reading, Writing, Respect, and Resolution)

SS: Second Step

+ Statistically significant beneficial impact on domain

Blank cell: Finding of no impact

No detrimental impact was found statistically significant at or below the .05 level. For a description of the heuristics used to determine the statistically significant beneficial impact on the domain, see chapter 1 .

SOURCE: The Social and Character Development (SACD) Research Program. 


\section{Impacts on Student Outcomes: Year-by-Year and Growth Analyses Results}

\section{Year-by-Year Analysis}

None of the 20 estimated combined-program impacts on fourth-grade child and school outcomes, based on the combined samples of Cohorts 1 and 2, were statistically significantly different from zero at the 5 percent level (table A.134). This varies from the finding of one statistically significant impact (for Student Support for Teachers) in the Cohort 1 analysis. The combined-sample analysis agreed with the Cohort 1 analysis that none of the impacts was substantively important. The estimated impacts in effect size units ranged from a detrimental effect of -0.06 (for child-reported Altruistic Behavior) to a beneficial effect of 0.12 standard deviations (for Student Support for Teachers). When the What Works Clearinghouse heuristics ${ }^{5}$ were applied to the domains to adjust for multiple comparisons within each outcome domain, the fourth heuristic identified the significance of a detrimental impact on children's Social and Emotional Competence (similar to the finding in the Cohort 1 analysis).

\footnotetext{
${ }^{4}$ Sample sizes are not reported in the Results tables because they vary by outcome. Table A.20 provides the range of sample sizes for the outcomes within each report.

${ }^{5}$ See the chapter 1 section headed Year-by-Year Impacts on Students and Perceptions of School Climate, subsection Statistical Significance and Substantively Important Effects, for a discussion of these heuristics.
} 
Table A.13. Combined Cohorts 1 and 2: Combined-program impacts on outcomes for fourthgraders

\begin{tabular}{|c|c|c|c|c|}
\hline Scale-Report & Treatment & Control & $\begin{array}{c}\text { Effect } \\
\text { size }^{1}\end{array}$ & $p$-value ${ }^{2}$ \\
\hline \multicolumn{5}{|l|}{ Social and Emotional Competence Domain ${ }^{3}$} \\
\hline Self-Efficacy for Peer Interactions-CR (+) & 3.17 & 3.20 & -0.05 & 0.194 \\
\hline Normative Beliefs About Aggression-CR (-) & 1.36 & 1.37 & -0.01 & 0.849 \\
\hline Empathy-CR (+) & 2.18 & 2.19 & -0.02 & 0.699 \\
\hline \multicolumn{5}{|l|}{ Behavior Domain } \\
\hline Altruistic Behavior-CR (+) & 1.06 & 1.10 & -0.06 & 0.154 \\
\hline Altruistic Behavior-PCR (+) & 2.27 & 2.25 & 0.03 & 0.364 \\
\hline Altruistic Behavior-TRS (+) & 1.38 & 1.36 & 0.05 & 0.686 \\
\hline Positive Social Behavior-PCR (+) & 3.06 & 3.04 & 0.05 & 0.177 \\
\hline Positive Social Behavior-TRS (+) & 3.02 & 3.05 & -0.04 & 0.533 \\
\hline Problem Behavior-CR (-) & 0.37 & 0.36 & 0.01 & 0.901 \\
\hline Problem Behavior-PCR (-) & 1.54 & 1.55 & -0.04 & 0.248 \\
\hline Problem Behavior-TRS (-) & 1.45 & 1.46 & -0.01 & 0.800 \\
\hline ADHD-Related Behavior-TRS (-) & 1.69 & 1.70 & -0.02 & 0.624 \\
\hline \multicolumn{5}{|l|}{ Academics Domain } \\
\hline Engagement with Learning-CR (+) & 3.66 & 3.67 & -0.02 & 0.680 \\
\hline Academic Competence and Motivation-TRS (+) & 2.97 & 2.99 & -0.02 & 0.651 \\
\hline \multicolumn{5}{|l|}{ Perceptions of School Climate Domain } \\
\hline Positive School Orientation-CR (+) & 2.65 & 2.62 & 0.04 & 0.508 \\
\hline Negative School Orientation-CR (-) & 1.99 & 2.00 & -0.02 & 0.653 \\
\hline Student Afraid at School-CR (-) & 2.24 & 2.28 & -0.04 & 0.402 \\
\hline Victimization at School-CR (-) & 0.68 & 0.71 & -0.03 & 0.533 \\
\hline Feelings of Safety-TRCS (+) & 3.42 & 3.36 & 0.08 & 0.325 \\
\hline Student Support for Teachers-TRCS (+) & 3.51 & 3.41 & 0.12 & 0.099 \\
\hline
\end{tabular}

${ }^{1}$ The effect size was calculated by dividing the estimated impact by the standard deviation of the outcome measure for the control group.

${ }^{2}$ The $p$-value is from a two-tailed $t$ test to gauge the statistical significance of the impact estimate.

${ }^{3}$ Impact on domain found statistically significant and detrimental based on the fourth heuristic, in which the statistical model used to estimate impacts on the individual outcomes was re-estimated using a composite of all the outcome variables under a domain. The domain was found significant if the impact on the composite was significant. The composite was formed by standardizing each outcome variable using its standard deviation, combining the values of the outcome variables, and taking the average of the final value.

NOTE: Abbreviations are

CR: Child Report

PCR: Primary Caregiver Report

TRS: Teacher Report on Student

TRCS: Teacher Report on Classroom and School

ADHD: Attention deficit hyperactivity disorder

The +/- signs in parentheses indicate the direction of a beneficial outcome. No findings were found statistically significant at or below the .05 level. All impact estimates were calculated using regression models in which each program and school within a program was weighted equally. The standard errors of all estimates account for design effects due to unequal weighting and the clustering of students within schools.

SOURCE: The Social and Character Development (SACD) Research Program. 
The lack of statistically significant beneficial impact estimates at the combined-program level might have been due to beneficial impacts in some programs that were offset by negative impacts in others. Differences in estimated impacts across programs were tested for as were the statistical significance of program-specific impact estimates.

With two exceptions, the 20 impact estimates did not significantly differ by program. For 18 of the 20 outcomes, the differences in pooled impact estimates across programs were not statistically significant at the 5 percent level. For these outcomes, one or two programs were not driving or masking the estimated impacts in the combined program data. For the other two outcomes (Academic Competence and Motivation, and Feelings of Safety) the ABC program showed a beneficial, statistically significant result so the hypothesis that the estimated impacts were equal across programs was rejected.

From the analyses of the individual SACD programs, 6 of 140 program impact estimates were statistically significant (versus 7 that would be expected by chance and the 7 that were found in the fourth-grade analysis of Cohort 1). Four of these were beneficial and 2 were detrimental (versus the 5 beneficial and 2 detrimental found in the analysis of Cohort 1). For the three programs that did not add a second cohort (Positive Action [PA], the 4Rs Program [4Rs], and Second Step [SS]), results remained the same as in the Cohort 1 analysis (2 significant beneficial impacts, 1 significant detrimental impact, and 2 non-significant but substantively important beneficial impacts: see table 1.27 in chapter 1). For the four programs that included a second cohort, table A.14 identifies the statistically significant and the non-significant substantively important results from the combined cohort analysis and compares them with the similar results found in the Cohort 1 only analysis (table A.15 compares all the results).

With respect to the $A B C$ program, statistically significant beneficial impacts were found on Academic Competence and Motivation (effect size of 0.35) and on Feelings of Safety (effect size of 0.67), and these align with findings from the Cohort 1 analysis. However, the combined cohort analysis did not find a significant detrimental impact on Altruistic Behavior (Child Report), which did appear in the Cohort 1 analysis. With respect to CSP, the combined cohort findings showed a statistically significant detrimental impact on Empathy (effect size of -0.18), which did not occur in the Cohort 1 analysis. CSP's Cohort 1 beneficial impact on Problem Behavior disappeared in the combined cohort analysis. LBW and PATHS had no significant impacts in either the Cohort 1 or the combined cohort analyses.

With respect to non-significant but substantively important results, when the combined cohort analyses were compared to the Cohort 1 analyses, ABC maintained its beneficial impact for Student Support for Teachers (effect size of .40). CSP lost its beneficial effect for Altruistic Behavior and Student Afraid at School. LBW lost its beneficial impact for Student Support for Teachers and its detrimental effect on Altruistic Behavior (Teacher Report on Student), and it gained a detrimental effect on Positive Social Behavior (Teacher Report on Student) (effect size of -.25). PATHS gained a beneficial impact on Altruistic Behavior (Teacher Report on Student). 
Table A.14. Comparison of individual programs' statistically significant impacts and nonsignificant substantive impacts between Cohort 1 and combined Cohort 1 and Cohort 2 fourth-graders

\begin{tabular}{|c|c|c|c|c|}
\hline \multirow[b]{2}{*}{ Program $^{3}$} & \multicolumn{2}{|c|}{ Statistically significant $^{1}$} & \multicolumn{2}{|c|}{ Nonstatistically significant but substantive $^{2}$} \\
\hline & $\begin{array}{c}\text { Beneficial impacts } \\
\text { (Report) (Effect size) ( } p \text {-value) }\end{array}$ & $\begin{array}{c}\text { Detrimental impacts } \\
\text { (Report) (Effect size) ( } p \text {-value) }\end{array}$ & $\begin{array}{c}\text { Beneficial impacts } \\
\text { (Report) (Effect size) ( } p \text {-value) }\end{array}$ & $\begin{array}{c}\text { Detrimental impacts } \\
\text { (Report) (Effect size) ( } p \text {-value) }\end{array}$ \\
\hline \multirow{3}{*}{$\begin{array}{l}\text { Total } \\
\text { Cohort } 1 \\
\text { Cohorts } \\
1 \text { and } 2\end{array}$} & & & & \\
\hline & 3 & 1 & 4 & 1 \\
\hline & 2 & 1 & 2 & 1 \\
\hline $\begin{array}{l}\mathrm{ABC} \\
\text { Cohort } 1\end{array}$ & $\begin{array}{l}\text { Academic Competence } \\
\text { (CR) (.31) (.011) } \\
\text { Feelings of Safety } \\
\text { (TRCS) (.75) (.003) }\end{array}$ & $\begin{array}{l}\text { Altruistic Behavior } \\
(\mathrm{CR})(-.20)(.029)\end{array}$ & $\begin{array}{l}\text { Student Support for Teachers } \\
\text { (TRCS) }(.27)(.276)\end{array}$ & \\
\hline $\begin{array}{l}\text { Cohorts } \\
1 \text { and } 2\end{array}$ & $\begin{array}{c}\text { Academic Competence } \\
\text { (CR) (.35) (.002) } \\
\text { Feelings of Safety } \\
\text { (TRCS) (.67) (.001) }\end{array}$ & & $\begin{array}{l}\text { Student Support for Teachers } \\
\text { (TRCS) }(.40)(.105)\end{array}$ & \\
\hline $\begin{array}{l}\text { CSP } \\
\text { Cohort } 1\end{array}$ & $\begin{array}{l}\text { Problem Behavior } \\
\text { (PCR) (-.21) (.042) }\end{array}$ & & $\begin{array}{c}\text { Altruistic Behavior } \\
\text { (TRS) }(.47)(.132) \\
\text { Student Afraid at School } \\
\text { (CR) }(-.26)(.090)\end{array}$ & \\
\hline $\begin{array}{l}\text { Cohorts } \\
1 \text { and } 2\end{array}$ & & $\begin{array}{c}\text { Empathy } \\
(\mathrm{CR})(-.18)(.041)\end{array}$ & & \\
\hline $\begin{array}{l}\text { LBW } \\
\text { Cohort } 1\end{array}$ & & & $\begin{array}{l}\text { Student Support for Teachers } \\
\text { (TRCS) }(.28)(.428)\end{array}$ & $\begin{array}{l}\text { Altruistic Behavior } \\
\text { (TRS) }(-.34)(.270)\end{array}$ \\
\hline $\begin{array}{l}\text { Cohorts } \\
1 \text { and } 2\end{array}$ & & & & $\begin{array}{c}\text { Positive Social Behavior } \\
\text { (TRS) }(-.25)(.205)\end{array}$ \\
\hline
\end{tabular}


Table A.14. Comparison of individual programs' statistically significant impacts and nonsignificant substantive impacts between Cohort 1 and combined Cohort 1 and Cohort 2 fourth-graders-Continued

\begin{tabular}{|c|c|c|c|c|}
\hline \multirow[b]{2}{*}{ Program $^{3}$} & \multicolumn{2}{|c|}{ Statistically significant $^{1}$} & \multicolumn{2}{|c|}{ Nonstatistically significant but substantive ${ }^{2}$} \\
\hline & $\begin{array}{c}\text { Beneficial impacts } \\
\text { (Report) (Effect size) ( } p \text {-value) }\end{array}$ & $\begin{array}{c}\text { Detrimental impacts } \\
\text { (Report) (Effect size) ( } p \text {-value) }\end{array}$ & $\begin{array}{c}\text { Beneficial impacts } \\
\text { (Report) (Effect size) ( } p \text {-value) }\end{array}$ & $\begin{array}{c}\text { Detrimental impacts } \\
\text { (Report) (Effect size) ( } p \text {-value) }\end{array}$ \\
\hline \multicolumn{5}{|l|}{$\begin{array}{l}\text { PATHS } \\
\text { Cohort } 1\end{array}$} \\
\hline $\begin{array}{l}\text { Cohorts } \\
1 \text { and } 2\end{array}$ & & & $\begin{array}{l}\text { Altruistic Behavior } \\
(\text { TRS) }(.34)(.250)\end{array}$ & \\
\hline
\end{tabular}

${ }_{1}^{1}$ Of the 80 comparisons (4 programs with 20 outcomes apiece) made, 4 would be expected to be statistically significant at the .05 level by chance.

${ }^{2}$ Defined as impacts that were not statistically significant but were .25 standard deviation units (absolute value) or more in magnitude.

${ }^{3}$ Only the four programs with a Cohort 2 are shown. The results for the other programs remained the same as those discussed in chapter 1.

NOTE: Abbreviations are

ABC: Academic and Behavioral Competencies Program

CSP: Competence Support Program

LBW: Love In a Big World

PATHS: Promoting Alternative Thinking Strategies

CR: Child Report

TRS: Teacher Report on Student

PCR: Primary Caregiver Report

TRCS: Teacher Report on Classroom and School

Blank cell: Finding of no impact

All impact estimates were calculated using regression models in which each school within a program was weighted equally. The standard errors of all estimates account for design effects due to unequal weighting and the clustering of students within schools.

SOURCE: The Social and Character Development (SACD) Research Program. 
Table A.15. Cohort 1 and combined Cohorts 1 and 2: Comparison of program effects

Panel 1: ABC Program

\begin{tabular}{|c|c|c|c|c|c|c|c|c|}
\hline \multirow[b]{2}{*}{ Scale-Report } & \multicolumn{4}{|c|}{$\begin{array}{c}\text { Cohort } 1 \\
\text { (Spring 4th grade) } \\
\end{array}$} & \multicolumn{4}{|c|}{$\begin{array}{c}\text { Combined Cohorts } 1 \text { and } 2 \\
\text { (Spring 4th grade) }\end{array}$} \\
\hline & $\begin{array}{r}\text { Treat- } \\
\text { ment }\end{array}$ & Control & $\begin{array}{r}\text { Effect } \\
\text { size }\end{array}$ & $p$-value & $\begin{array}{r}\text { Treat- } \\
\text { ment }\end{array}$ & Control & $\begin{array}{c}\text { Effect } \\
\text { size }\end{array}$ & $p$-value \\
\hline \multicolumn{9}{|l|}{ Social and Emotional Competence Domain } \\
\hline Self-Efficacy for Peer Interactions-CR (+) & 3.31 & 3.29 & 0.03 & 0.770 & 3.27 & 3.24 & 0.04 & 0.697 \\
\hline Normative Beliefs About Aggression-CR (-) & 1.39 & 1.29 & 0.18 & 0.141 & $1.38^{\wedge}$ & 1.28 & 0.18 & 0.082 \\
\hline Empathy-CR (+) & 2.08 & 2.19 & -0.21 & 0.144 & 2.09 & 2.17 & -0.17 & 0.156 \\
\hline \multicolumn{9}{|l|}{ Behavior Domain } \\
\hline Altruistic Behavior-CR (+) & $0.94^{*}$ & 1.09 & -0.20 & 0.029 & 1.00 & 1.13 & -0.16 & 0.121 \\
\hline Altruistic Behavior-PCR (+) & 2.14 & 2.19 & -0.06 & 0.595 & 2.19 & 2.23 & -0.04 & 0.710 \\
\hline Altruistic Behavior-TRS (+) & 1.24 & 1.26 & -0.03 & 0.914 & 1.24 & 1.25 & -0.03 & 0.920 \\
\hline Positive Social Behavior-PCR (+) & $3.06^{\wedge}$ & 2.96 & 0.16 & 0.071 & 3.01 & 2.90 & 0.18 & 0.187 \\
\hline Positive Social Behavior-TRS (+) & 3.01 & 3.02 & -0.01 & 0.961 & 3.05 & 2.95 & 0.13 & 0.504 \\
\hline Problem Behavior-CR (-) & 0.33 & 0.36 & -0.05 & 0.659 & 0.36 & 0.42 & -0.10 & 0.545 \\
\hline Problem Behavior-PCR (-) & 1.56 & 1.61 & -0.11 & 0.229 & 1.58 & 1.65 & -0.16 & 0.198 \\
\hline Problem Behavior-TRS (-) & 1.43 & 1.46 & -0.07 & 0.655 & 1.44 & 1.49 & -0.11 & 0.403 \\
\hline ADHD-Related Behavior-TRS (-) & 1.69 & 1.77 & -0.13 & 0.525 & 1.68 & 1.77 & -0.16 & 0.341 \\
\hline \multicolumn{9}{|l|}{ Academics Domain } \\
\hline Engagement with Learning-CR (+) & 3.68 & 3.63 & 0.10 & 0.281 & $3.69^{\wedge}$ & 3.60 & 0.14 & 0.093 \\
\hline Academic Competence and Motivation-TRS (+) & $2.92^{*}$ & 2.65 & 0.31 & 0.011 & $2.93^{*}$ & 2.63 & 0.35 & 0.002 \\
\hline \multicolumn{9}{|l|}{ Perceptions of School Climate Domain } \\
\hline Positive School Orientation-CR (+) & 2.67 & 2.61 & 0.07 & 0.668 & 2.62 & 2.56 & 0.08 & 0.639 \\
\hline Negative School Orientation-CR (-) & 1.97 & 1.96 & 0.01 & 0.963 & 2.01 & 2.01 & -0.01 & 0.960 \\
\hline Student Afraid at School-CR (-) & 2.21 & 2.36 & -0.17 & 0.263 & 2.23 & 2.39 & -0.17 & 0.211 \\
\hline Victimization at School-CR (-) & 0.58 & 0.66 & -0.11 & 0.213 & 0.71 & 0.70 & 0.02 & 0.923 \\
\hline Feelings of Safety-TRCS (+) & $3.59^{*}$ & 2.97 & 0.75 & 0.003 & $3.51^{*}$ & 2.94 & 0.67 & 0.001 \\
\hline Student Support for Teachers-TRCS (+) & 3.48 & 3.26 & $0.27^{\circ}$ & 0.276 & 3.49 & 3.15 & $0.40^{\circ}$ & 0.105 \\
\hline
\end{tabular}

See notes at end of table. 


\section{Table A.15. Cohort 1 and combined Cohorts 1 and 2: Comparison of program effects-Continued}

Panel 2: CSP

\begin{tabular}{|c|c|c|c|c|c|c|c|c|}
\hline \multirow[b]{2}{*}{ Scale-Report } & \multicolumn{4}{|c|}{$\begin{array}{c}\text { Cohort } 1 \\
\text { (Spring 4th grade) } \\
\end{array}$} & \multicolumn{4}{|c|}{$\begin{array}{c}\text { Combined Cohorts } 1 \text { and } 2 \\
\text { (Spring 4th grade) }\end{array}$} \\
\hline & $\begin{array}{r}\text { Treat- } \\
\text { ment }\end{array}$ & Control & $\begin{array}{r}\text { Effect } \\
\text { size }\end{array}$ & $p$-value & $\begin{array}{r}\text { Treat- } \\
\text { ment }\end{array}$ & Control & $\begin{array}{r}\text { Effect } \\
\text { size }\end{array}$ & $p$-value \\
\hline \multicolumn{9}{|l|}{ Social and Emotional Competence Domain } \\
\hline Self-Efficacy for Peer Interactions-CR (+) & 3.15 & 3.15 & 0.00 & 0.978 & 3.16 & 3.13 & 0.05 & 0.475 \\
\hline Normative Beliefs About Aggression-CR (-) & 1.35 & 1.29 & 0.12 & 0.273 & 1.42 & 1.29 & 0.24 & 0.133 \\
\hline Empathy-CR (+) & 2.18 & 2.23 & -0.11 & 0.206 & $2.15^{*}$ & 2.23 & -0.18 & 0.041 \\
\hline \multicolumn{9}{|l|}{ Behavior Domain } \\
\hline Altruistic Behavior-CR (+) & 1.06 & 1.00 & 0.08 & 0.505 & 1.01 & 1.00 & 0.01 & 0.889 \\
\hline Altruistic Behavior-PCR (+) & 2.33 & 2.31 & 0.03 & 0.849 & 2.34 & 2.28 & 0.08 & 0.452 \\
\hline Altruistic Behavior-TRS (+) & 1.39 & 1.25 & $0.47^{\circ}$ & 0.132 & 1.40 & 1.30 & 0.24 & 0.263 \\
\hline Positive Social Behavior-PCR (+) & 3.11 & 3.02 & 0.17 & 0.125 & 3.11 & 3.02 & 0.15 & 0.153 \\
\hline Positive Social Behavior-TRS (+) & 3.02 & 2.93 & 0.12 & 0.426 & 3.02 & 3.05 & -0.05 & 0.702 \\
\hline Problem Behavior-CR (-) & 0.32 & 0.26 & 0.15 & 0.428 & 0.36 & 0.27 & 0.21 & 0.254 \\
\hline Problem Behavior-PCR (-) & $1.50^{*}$ & 1.56 & -0.21 & 0.042 & $1.50^{\wedge}$ & 1.56 & -0.18 & 0.069 \\
\hline Problem Behavior-TRS (-) & 1.48 & 1.50 & -0.03 & 0.852 & 1.46 & 1.44 & 0.04 & 0.784 \\
\hline ADHD-Related Behavior-TRS (-) & 1.70 & 1.74 & -0.06 & 0.585 & 1.70 & 1.68 & 0.04 & 0.733 \\
\hline \multicolumn{9}{|l|}{ Academics Domain } \\
\hline Engagement with Learning-CR (+) & 3.71 & 3.71 & -0.01 & 0.952 & 3.67 & 3.68 & -0.02 & 0.889 \\
\hline Academic Competence and Motivation-TRS (+) & 2.96 & 2.93 & 0.04 & 0.622 & 3.04 & 3.09 & -0.05 & 0.484 \\
\hline \multicolumn{9}{|l|}{ Perceptions of School Climate Domain } \\
\hline Positive School Orientation-CR (+) & 2.64 & 2.65 & -0.02 & 0.922 & 2.56 & 2.58 & -0.02 & 0.898 \\
\hline Negative School Orientation-CR (-) & 1.95 & 1.98 & -0.05 & 0.699 & 2.02 & 2.00 & 0.04 & 0.794 \\
\hline Student Afraid at School-CR (-) & $2.17^{\wedge}$ & 2.38 & $-0.26^{\circ}$ & 0.090 & 2.26 & 2.31 & -0.06 & 0.697 \\
\hline Victimization at School-CR (-) & 0.69 & 0.70 & -0.01 & 0.947 & 0.69 & 0.71 & -0.03 & 0.756 \\
\hline Feelings of Safety-TRCS (+) & 3.60 & 3.64 & -0.05 & 0.834 & 3.63 & 3.65 & -0.02 & 0.919 \\
\hline Student Support for Teachers-TRCS (+) & 3.55 & 3.48 & 0.10 & 0.551 & 3.59 & 3.55 & 0.06 & 0.634 \\
\hline
\end{tabular}




\section{Table A.15. Cohort 1 and combined Cohorts 1 and 2: Comparison of program effects-Continued}

\begin{tabular}{|c|c|c|c|c|c|c|c|c|}
\hline \multirow[b]{2}{*}{ Scale-Report } & \multicolumn{4}{|c|}{$\begin{array}{c}\text { Cohort } 1 \\
\text { (Spring 4th grade) }\end{array}$} & \multicolumn{4}{|c|}{$\begin{array}{c}\text { Combined Cohorts } 1 \text { and } 2 \\
\text { (Spring 4th grade) }\end{array}$} \\
\hline & $\begin{array}{r}\text { Treat- } \\
\text { ment }\end{array}$ & Control & $\begin{array}{r}\text { Effect } \\
\text { size }\end{array}$ & $p$-value & $\begin{array}{l}\text { Treat- } \\
\text { ment }\end{array}$ & Control & $\begin{array}{c}\text { Effect } \\
\text { size }\end{array}$ & $p$-value \\
\hline \multicolumn{9}{|l|}{ Social and Emotional Competence Domain } \\
\hline Self-Efficacy for Peer Interactions-CR (+) & 3.19 & 3.21 & -0.04 & 0.674 & 3.20 & 3.17 & 0.05 & 0.602 \\
\hline Normative Beliefs About Aggression-CR (-) & 1.26 & 1.21 & 0.12 & 0.368 & 1.28 & 1.21 & 0.19 & 0.124 \\
\hline Empathy-CR (+) & 2.30 & 2.30 & -0.01 & 0.963 & 2.30 & 2.31 & -0.03 & 0.752 \\
\hline \multicolumn{9}{|l|}{ Behavior Domain } \\
\hline Altruistic Behavior-CR (+) & 1.02 & 1.16 & -0.20 & 0.191 & 1.00 & 1.13 & -0.18 & 0.192 \\
\hline Altruistic Behavior-PCR (+) & 2.22 & 2.11 & 0.17 & 0.152 & $2.26^{\wedge}$ & 2.11 & 0.23 & 0.092 \\
\hline Altruistic Behavior-TRS (+) & 1.29 & 1.46 & $-0.34^{\circ}$ & 0.270 & 1.34 & 1.41 & -0.16 & 0.607 \\
\hline Positive Social Behavior-PCR (+) & 3.12 & 3.04 & 0.13 & 0.250 & 3.10 & 3.03 & 0.12 & 0.262 \\
\hline Positive Social Behavior-TRS (+) & 2.94 & 3.11 & -0.23 & 0.183 & 2.95 & 3.13 & $-0.25^{\circ}$ & 0.205 \\
\hline Problem Behavior-CR (-) & 0.25 & 0.23 & 0.04 & 0.728 & 0.26 & 0.25 & 0.02 & 0.854 \\
\hline Problem Behavior-PCR (-) & 1.56 & 1.56 & -0.01 & 0.898 & 1.56 & 1.57 & -0.03 & 0.796 \\
\hline Problem Behavior-TRS (-) & 1.46 & 1.40 & 0.13 & 0.117 & $1.49^{\wedge}$ & 1.39 & 0.22 & 0.063 \\
\hline ADHD-Related Behavior-TRS (-) & 1.73 & 1.64 & 0.13 & 0.105 & $1.78^{\wedge}$ & 1.68 & 0.16 & 0.077 \\
\hline \multicolumn{9}{|l|}{ Academics Domain } \\
\hline Engagement with Learning-CR (+) & 3.67 & 3.69 & -0.04 & 0.652 & 3.64 & 3.68 & -0.08 & 0.370 \\
\hline Academic Competence and Motivation-TRS (+) & 3.05 & 2.99 & 0.07 & 0.622 & 3.09 & 2.94 & 0.15 & 0.378 \\
\hline \multicolumn{9}{|l|}{ Perceptions of School Climate Domain } \\
\hline Positive School Orientation-CR (+) & 2.77 & 2.79 & -0.03 & 0.794 & 2.77 & 2.82 & -0.07 & 0.551 \\
\hline Negative School Orientation-CR (-) & 1.87 & 1.89 & -0.03 & 0.846 & 1.90 & 1.90 & -0.01 & 0.960 \\
\hline Student Afraid at School-CR (-) & 2.27 & 2.23 & 0.06 & 0.777 & 2.27 & 2.22 & 0.06 & 0.727 \\
\hline Victimization at School-CR (-) & 0.70 & 0.71 & -0.01 & 0.929 & 0.69 & 0.70 & -0.02 & 0.828 \\
\hline Feelings of Safety-TRCS (+) & 3.39 & 3.45 & -0.06 & 0.825 & 3.35 & 3.53 & -0.24 & 0.349 \\
\hline Student Support for Teachers-TRCS $(+)$ & 3.57 & 3.40 & $0.28^{\circ}$ & 0.428 & 3.53 & 3.41 & 0.20 & 0.494 \\
\hline
\end{tabular}




\section{Table A.15. Cohort 1 and combined Cohorts 1 and 2: Comparison of program effects-Continued}

Panel 4: PATHS

\begin{tabular}{|c|c|c|c|c|c|c|c|c|}
\hline \multirow[b]{2}{*}{ Scale-Report } & \multicolumn{4}{|c|}{$\begin{array}{c}\text { Cohort } 1 \\
\text { (Spring 4th grade) }\end{array}$} & \multicolumn{4}{|c|}{$\begin{array}{c}\text { Combined Cohorts } 1 \text { and } 2 \\
\text { (Spring 4th grade) }\end{array}$} \\
\hline & $\begin{array}{r}\text { Treat- } \\
\text { ment }\end{array}$ & Control & $\begin{array}{r}\text { Effect } \\
\text { size }\end{array}$ & $p$-value & $\begin{array}{l}\text { Treat- } \\
\text { ment }\end{array}$ & Control & $\begin{array}{c}\text { Effect } \\
\text { size }\end{array}$ & $p$-value \\
\hline \multicolumn{9}{|l|}{ Social and Emotional Competence Domain } \\
\hline Self-Efficacy for Peer Interactions-CR (+) & 3.18 & 3.28 & -0.16 & 0.261 & $3.12^{\wedge}$ & 3.26 & -0.21 & 0.084 \\
\hline Normative Beliefs About Aggression-CR (-) & 1.26 & 1.37 & -0.17 & 0.214 & 1.28 & 1.37 & -0.14 & 0.251 \\
\hline Empathy-CR (+) & 2.21 & 2.14 & 0.13 & 0.245 & 2.23 & 2.16 & 0.13 & 0.317 \\
\hline \multicolumn{9}{|l|}{ Behavior Domain } \\
\hline Altruistic Behavior-CR (+) & 1.00 & 0.96 & 0.06 & 0.635 & 1.10 & 1.03 & 0.08 & 0.360 \\
\hline Altruistic Behavior-PCR (+) & 2.06 & 2.19 & -0.16 & 0.140 & 2.18 & 2.21 & -0.04 & 0.756 \\
\hline Altruistic Behavior-TRS (+) & 1.22 & 1.18 & 0.17 & 0.395 & 1.35 & 1.24 & $0.34^{\circ}$ & 0.250 \\
\hline Positive Social Behavior-PCR (+) & 3.05 & 3.06 & -0.01 & 0.953 & 3.03 & 3.03 & -0.01 & 0.878 \\
\hline Positive Social Behavior-TRS (+) & 3.14 & 3.04 & 0.15 & 0.503 & 3.06 & 3.06 & 0.00 & 0.997 \\
\hline Problem Behavior-CR (-) & 0.27 & 0.30 & -0.06 & 0.547 & 0.34 & 0.31 & 0.06 & 0.656 \\
\hline Problem Behavior-PCR (-) & 1.53 & 1.53 & 0.00 & 0.987 & 1.54 & 1.54 & 0.02 & 0.869 \\
\hline Problem Behavior-TRS (-) & 1.42 & 1.42 & 0.01 & 0.957 & 1.46 & 1.47 & -0.01 & 0.935 \\
\hline ADHD-Related Behavior-TRS (-) & 1.62 & 1.70 & -0.13 & 0.574 & 1.65 & 1.73 & -0.14 & 0.571 \\
\hline \multicolumn{9}{|l|}{ Academics Domain } \\
\hline Engagement with Learning-CR (+) & 3.70 & 3.69 & 0.01 & 0.954 & 3.68 & 3.69 & -0.03 & 0.758 \\
\hline Academic Competence and Motivation-TRS (+) & 2.95 & 3.05 & -0.09 & 0.272 & $2.85^{\wedge}$ & 3.03 & -0.21 & 0.093 \\
\hline
\end{tabular}




\section{Table A.15. Cohort 1 and combined Cohorts 1 and 2: Comparison of program effects-Continued}

Panel 4: PATHS

\begin{tabular}{|c|c|c|c|c|c|c|c|c|}
\hline \multirow[b]{2}{*}{ Scale-Report } & \multicolumn{4}{|c|}{$\begin{array}{c}\text { Cohort } 1 \\
\text { (Spring 4th grade) }\end{array}$} & \multicolumn{4}{|c|}{$\begin{array}{c}\text { Combined Cohorts } 1 \text { and } 2 \\
\text { (Spring 4th grade) }\end{array}$} \\
\hline & $\begin{array}{r}\text { Treat- } \\
\text { ment }\end{array}$ & Control & $\begin{array}{r}\text { Effect } \\
\text { size }\end{array}$ & $p$-value & $\begin{array}{r}\text { Treat- } \\
\text { ment }\end{array}$ & Control & $\begin{array}{r}\text { Effect } \\
\text { size }\end{array}$ & $p$-value \\
\hline \multicolumn{9}{|l|}{ Perceptions of School Climate Domain } \\
\hline Positive School Orientation-CR (+) & 2.79 & 2.67 & 0.15 & 0.640 & 2.81 & 2.67 & 0.18 & 0.461 \\
\hline Negative School Orientation-CR (-) & 1.87 & 1.90 & -0.05 & 0.765 & 1.95 & 1.93 & 0.02 & 0.825 \\
\hline Student Afraid at School-CR (-) & 2.08 & 2.09 & -0.01 & 0.909 & 2.22 & 2.20 & 0.02 & 0.844 \\
\hline Victimization at School-CR (-) & 0.65 & 0.56 & 0.12 & 0.306 & 0.69 & 0.63 & 0.08 & 0.382 \\
\hline Feelings of Safety-TRCS $(+)$ & 3.36 & 3.18 & 0.20 & 0.615 & 3.09 & 3.11 & -0.01 & 0.962 \\
\hline Student Support for Teachers-TRCS $(+)$ & 3.52 & 3.46 & 0.07 & 0.838 & 3.28 & 3.37 & -0.11 & 0.719 \\
\hline
\end{tabular}

* Treatment group significantly different from control group at the .05 level.

$\wedge$ Treatment group significantly different from control group at the .10 to $>.05$ level.

- Substantive (but nonsignificant at .05 level) effect size of $\geq .25$ or $\leq-.25$.

NOTE: Abbreviations are

ABC: Academic and Behavioral Competencies Program

CSP: Competence Support Program

LBW: Love In a Big World

PATHS: Promoting Alternative Thinking Strategies

CR: Child Report

PCR: Primary Caregiver Report

TRS: Teacher Report on Student

TRCS: Teacher Report on Classroom and School

ADHD: Attention deficit hyperactivity disorder

The +/- signs in parentheses indicate the direction of a beneficial outcome. All impact estimates were calculated using regression models in which each program and school within a

program was weighted equally. The standard errors of all estimates account for design effects due to unequal weighting and the clustering of students within schools. The effect size was calculated by dividing the estimated impact by the standard deviation of the outcome measure for the control group.

SOURCE: The Social and Character Development (SACD) Research Program. 
Eight subgroup analyses were done (as discussed in chapter 1) to determine whether the SACD programs might be more effective for some groups of children than for others. These subgroups were defined by gender, stayers versus new entrants, five types of risk faced by the children, and fidelity of implementation. The combined cohort subgroup analyses found a total of 20 significant impacts compared to the 22 found in the Cohort 1 subgroup analyses. The combined cohort analysis found 14 of the same significant impacts as the Cohort 1 analysis, failed to find 8 of the Cohort 1 impacts, and found 6 different significant impacts that did not appear in the Cohort 1 analyses. Of the 8 results that were significant in the Cohort 1 analyses but not in the combined cohort analyses, 7 were related to risk subgroups ( 5 beneficial impacts for high-risk students and 2 detrimental impacts for high-risk students), and 1 impact was beneficial for girls. Of the 6 new findings in the combined cohort analyses, 4 occurred in the stayer versus new entrant subgroup ( 2 beneficial impacts and 2 detrimental impacts for new entrants), 1 was a detrimental impact for high-risk students, and 1 was a beneficial impact for high-fidelity schools.

Overall, the differences between the subgroup findings from the combined cohort analyses versus the Cohort 1 analysis are primarily less evidence that impacts are more beneficial for higher risk students and mixed evidence on the impacts for stayers versus new entrants. Table A.16 compares the significant subgroup findings from the combined cohort analysis to those of the Cohort 1 analysis, showing each subgroup on a separate panel (exception: no panel displays the socioeconomic risk subgroup analysis as no significant results were found in either the Cohort 1 or the combined cohort analyses). 
Table A.16. Cohort 1 versus Cohorts 1 and 2: Comparison of significant impacts by subgroup

Panel 1: Gender

\begin{tabular}{|c|c|c|c|c|c|c|c|c|c|c|}
\hline \multirow[b]{3}{*}{ Scale-Report ${ }^{1}$} & \multicolumn{5}{|c|}{ Cohort 1} & \multicolumn{5}{|c|}{ Cohorts 1 and 2} \\
\hline & \multicolumn{2}{|c|}{ Boys } & \multicolumn{2}{|c|}{ Girls } & \multirow{2}{*}{$\begin{array}{r}p \text {-value for } \\
\text { test of } \\
\text { differences }\end{array}$} & \multicolumn{2}{|c|}{ Boys } & \multicolumn{2}{|c|}{ Girls } & \multirow{2}{*}{$\begin{array}{r}p \text {-value for } \\
\text { test of } \\
\text { differences }\end{array}$} \\
\hline & $\begin{array}{c}\text { Effect } \\
\text { size }\end{array}$ & $p$-value & $\begin{array}{c}\text { Effect } \\
\text { size }\end{array}$ & $p$-value & & $\begin{array}{c}\text { Effect } \\
\text { size }\end{array}$ & $p$-value & $\begin{array}{c}\text { Effect } \\
\text { size }\end{array}$ & $p$-value & \\
\hline Normative Beliefs About Aggression-CR (-) & 0.04 & 0.574 & $-0.10^{\wedge}$ & 0.095 & $0.023^{*}$ & 0.05 & 0.436 & -0.08 & 0.165 & $0.022^{*}$ \\
\hline Altruistic Behavior-CR (+) & $-0.13^{*}$ & 0.020 & -0.00 & 0.967 & $0.022^{*}$ & $-0.10^{\wedge}$ & 0.080 & -0.04 & 0.491 & 0.293 \\
\hline Positive Social Behavior-PCR (+) & $0.10^{*}$ & 0.032 & -0.02 & 0.653 & $0.033^{*}$ & $0.10^{*}$ & 0.036 & -0.02 & 0.658 & $0.021^{*}$ \\
\hline Engagement with Learning-CR (+) & $-0.10^{*}$ & 0.050 & 0.05 & 0.297 & $0.011^{*}$ & -0.07 & 0.183 & 0.05 & 0.306 & $0.035^{*}$ \\
\hline Negative School Orientation-CR (-) & 0.09 & 0.126 & $-0.14^{*}$ & 0.011 & $0.000^{*}$ & 0.06 & 0.303 & $-0.10^{\wedge}$ & 0.083 & $0.001^{* *}$ \\
\hline
\end{tabular}

See notes at end of table.

Panel 2: Stayers and new entrants

\begin{tabular}{|c|c|c|c|c|c|c|c|c|c|c|}
\hline \multirow[b]{3}{*}{ Scale-Report $^{1}$} & \multicolumn{5}{|c|}{ Cohort 1} & \multicolumn{5}{|c|}{ Cohorts 1 and 2} \\
\hline & \multicolumn{2}{|c|}{ Stayers } & \multicolumn{2}{|c|}{ Entrants } & \multirow{2}{*}{$\begin{array}{r}p \text {-value for } \\
\text { test of } \\
\text { differences }\end{array}$} & \multicolumn{2}{|c|}{ Stayers } & \multicolumn{2}{|c|}{ Entrants } & \multirow{2}{*}{$\begin{array}{r}p \text {-value for } \\
\text { test of } \\
\text { differences }\end{array}$} \\
\hline & $\begin{array}{r}\text { Effect } \\
\text { size } \\
\end{array}$ & $p$-value & $\begin{array}{c}\text { Effect } \\
\text { size }\end{array}$ & $p$-value & & $\begin{array}{r}\text { Effect } \\
\text { size }\end{array}$ & $p$-value & $\begin{array}{c}\text { Effect } \\
\text { size }\end{array}$ & $p$-value & \\
\hline Altruistic Behavior-CR (+) & -0.03 & 0.516 & $-0.14^{\wedge}$ & 0.066 & 0.132 & -0.03 & 0.565 & $-0.14^{\wedge}$ & 0.055 & $0.041^{*}$ \\
\hline Positive Social Behavior-PCR (+) & 0.01 & 0.813 & $0.13^{\wedge}$ & 0.093 & $0.067^{\wedge}$ & 0.00 & 0.970 & $0.13^{*}$ & 0.050 & $0.009^{* *}$ \\
\hline Problem Behavior-PCR (-) & -0.05 & 0.244 & -0.11 & 0.160 & 0.195 & -0.00 & 0.993 & $-0.14^{\wedge}$ & 0.074 & $0.005^{\star *}$ \\
\hline Negative School Orientation-CR (-) & -0.05 & 0.432 & 0.08 & 0.280 & $0.053^{\wedge}$ & -0.06 & 0.297 & 0.06 & 0.467 & $0.047^{*}$ \\
\hline
\end{tabular}

See notes at end of table. 


\section{Table A.16. Cohort 1 versus Cohorts 1 and 2: Comparison of significant impacts by subgroup-Continued}

Panel 3: Family risk

\begin{tabular}{|c|c|c|c|c|c|c|c|c|}
\hline \multirow[b]{2}{*}{ Scale-Report } & \multicolumn{4}{|c|}{ Cohort 1} & \multicolumn{4}{|c|}{ Cohorts 1 and 2} \\
\hline & $\begin{array}{l}\text { Low risk }^{1} \\
\text { ( } p \text {-value) }\end{array}$ & $\begin{array}{r}\text { Average } \\
\text { risk }^{2} \\
(p \text {-value })\end{array}$ & $\begin{array}{r}\text { High risk }^{3} \\
(p \text {-value })\end{array}$ & $\begin{array}{r}\text { Marginal } \\
\text { effect }^{4} \\
\text { ( } p \text {-value) }\end{array}$ & $\begin{array}{r}\text { Low Risk }^{1} \\
(p \text {-value })\end{array}$ & $\begin{array}{r}\text { Average } \\
\text { risk }^{2} \\
(p \text {-value })\end{array}$ & $\begin{array}{r}\text { High risk } \\
\text { ( } p \text {-value) }\end{array}$ & $\begin{array}{r}\text { Marginal } \\
\text { effect }^{4} \\
\text { (p-value) }\end{array}$ \\
\hline Student Afraid at School-CR (-) & $\begin{array}{c}-0.175^{\star} \\
(0.020)\end{array}$ & $\begin{array}{r}-0.084 \\
(0.192) \\
\end{array}$ & $\begin{array}{r}0.006 \\
(0.932) \\
\end{array}$ & $\begin{array}{c}0.408^{*} \\
(0.012)\end{array}$ & $\begin{array}{c}-0.157^{*} \\
(0.029)\end{array}$ & $\begin{array}{r}-0.063 \\
(0.311) \\
\end{array}$ & $\begin{array}{r}0.031 \\
(0.660) \\
\end{array}$ & $\begin{array}{r}0.414^{*} \\
(0.007)\end{array}$ \\
\hline
\end{tabular}

See notes at end of table.

Panel 4: Community risk

\begin{tabular}{|c|c|c|c|c|c|c|c|c|}
\hline \multirow[b]{2}{*}{ Scale-Report } & \multicolumn{4}{|c|}{ Cohort 1} & \multicolumn{4}{|c|}{ Cohorts 1 and 2} \\
\hline & $\begin{array}{l}\text { Low risk }^{1} \\
\text { (p-value) }\end{array}$ & $\begin{array}{r}\text { Average } \\
\text { risk }^{2} \\
(p \text {-value })\end{array}$ & $\begin{array}{r}\text { High risk }^{3} \\
(p \text {-value })\end{array}$ & $\begin{array}{r}\text { Marginal } \\
\text { effect }^{4} \\
\text { ( } p \text {-value) }\end{array}$ & $\begin{array}{l}\text { Low risk }^{1} \\
\text { (p-value) }\end{array}$ & $\begin{array}{r}\text { Average } \\
\text { risk }^{2} \\
(p \text {-value })\end{array}$ & $\begin{array}{r}\text { High risk }^{3} \\
(p \text {-value })\end{array}$ & $\begin{array}{r}\text { Marginal } \\
\text { effect }^{4} \\
\text { (p-value) }\end{array}$ \\
\hline Problem Behavior-PCR (-) & $\begin{array}{r}-0.045 \\
(0.381)\end{array}$ & $\begin{array}{r}0.028 \\
(0.446)\end{array}$ & $\begin{array}{c}0.101^{*} \\
(0.041)\end{array}$ & $\begin{array}{c}0.109^{*} \\
(0.032)\end{array}$ & $\begin{array}{r}-0.062 \\
(0.208)\end{array}$ & $\begin{array}{r}0.028 \\
(0.442)\end{array}$ & $\begin{array}{c}0.118^{*} \\
(0.013)\end{array}$ & $\begin{array}{c}0.136^{* *} \\
(0.005)\end{array}$ \\
\hline Problem Behavior-TRS (-) & $\begin{array}{r}0.087 \\
(0.268)\end{array}$ & $\begin{array}{l}-0.001 \\
(0.994)\end{array}$ & $\begin{array}{l}-0.089 \\
(0.243)\end{array}$ & $\begin{array}{c}-0.132^{*} \\
(0.022)\end{array}$ & $\begin{array}{r}0.087 \\
(0.254)\end{array}$ & $\begin{array}{r}0.020 \\
(0.764)\end{array}$ & $\begin{array}{l}-0.048 \\
(0.511)\end{array}$ & $\begin{array}{l}-0.101^{\wedge} \\
(0.060)\end{array}$ \\
\hline ADHD-Related Behavior-TRS (-) & $\begin{array}{r}0.062 \\
(0.389)\end{array}$ & $\begin{array}{l}-0.021 \\
(0.722)\end{array}$ & $\begin{array}{l}-0.104 \\
(0.132)\end{array}$ & $\begin{array}{l}-0.124^{*} \\
(0.029)\end{array}$ & $\begin{array}{r}0.048 \\
(0.481)\end{array}$ & $\begin{array}{l}-0.004 \\
(0.938)\end{array}$ & $\begin{array}{l}-0.057 \\
(0.380)\end{array}$ & $\begin{array}{l}-0.079 \\
(0.130)\end{array}$ \\
\hline Positive School Orientation-CR (+) & $\begin{array}{l}-0.086 \\
(0.361)\end{array}$ & $\begin{array}{r}0.030 \\
(0.719)\end{array}$ & $\begin{array}{r}0.146 \\
(0.111)\end{array}$ & $\begin{array}{c}0.174^{* *} \\
(0.007)\end{array}$ & $\begin{array}{l}-0.051 \\
(0.560)\end{array}$ & $\begin{array}{r}0.039 \\
(0.607)\end{array}$ & $\begin{array}{r}0.129 \\
(0.124)\end{array}$ & $\begin{array}{c}0.135^{\star} \\
(0.023)\end{array}$ \\
\hline Victimization at School-CR (-) & $\begin{array}{r}0.068 \\
(0.298)\end{array}$ & $\begin{array}{r}-0.035 \\
(0.485)\end{array}$ & $\begin{array}{c}-0.138^{*} \\
(0.030)\end{array}$ & $\begin{array}{c}-0.154^{*} \\
(0.011)\end{array}$ & $\begin{array}{r}0.054 \\
(0.432)\end{array}$ & $\begin{array}{l}-0.026 \\
(0.639)\end{array}$ & $\begin{array}{r}-0.106 \\
(0.106)\end{array}$ & $\begin{array}{l}-0.120^{*} \\
(0.037)\end{array}$ \\
\hline
\end{tabular}

See notes at end of table. 


\section{Table A.16. Cohort 1 versus Cohorts 1 and 2: Comparison of significant impacts by subgroup-Continued}

Panel 5: Initial child behavior risk as reported by teacher

\begin{tabular}{|c|c|c|c|c|c|c|c|c|}
\hline \multirow[b]{2}{*}{ Scale-Report } & \multicolumn{4}{|c|}{ Cohort 1} & \multicolumn{4}{|c|}{ Cohorts 1 and 2} \\
\hline & $\begin{array}{l}\text { Low risk }{ }^{1} \\
(p \text {-value })\end{array}$ & $\begin{array}{r}\text { Average } \\
\text { risk }^{2} \\
(p \text {-value })\end{array}$ & $\begin{array}{l}\text { High risk }^{3} \\
(p \text {-value })\end{array}$ & $\begin{array}{r}\text { Marginal } \\
\text { effect }^{4} \\
(p \text {-value })\end{array}$ & $\begin{array}{l}\text { Low risk }^{1} \\
(p \text {-value })\end{array}$ & $\begin{array}{r}\text { Average } \\
\text { risk }^{2} \\
\text { (p-value) }\end{array}$ & $\begin{array}{r}\text { High risk }^{3} \\
(p \text {-value })\end{array}$ & $\begin{array}{r}\text { Marginal } \\
\text { effect }^{4} \\
\text { ( } p \text {-value })\end{array}$ \\
\hline $\begin{array}{l}\text { Normative Beliefs About Aggression- } \\
\text { CR (-) }\end{array}$ & $\begin{array}{r}0.127 \\
(0.134)\end{array}$ & $\begin{array}{r}0.007 \\
(0.923)\end{array}$ & $\begin{array}{r}-0.113 \\
(0.191)\end{array}$ & $\begin{array}{l}-0.012^{* *} \\
(0.005)\end{array}$ & $\begin{array}{l}0.146^{\wedge} \\
(0.068)\end{array}$ & $\begin{array}{r}0.030 \\
(0.671)\end{array}$ & $\begin{array}{r}-0.086 \\
(0.285)\end{array}$ & $\begin{array}{l}-0.011^{* *} \\
(0.003)\end{array}$ \\
\hline Problem Behavior-CR (-) & $\begin{array}{r}0.075 \\
(0.348)\end{array}$ & $\begin{array}{l}-0.007 \\
(0.922)\end{array}$ & $\begin{array}{l}-0.089 \\
(0.275)\end{array}$ & $\begin{array}{l}-0.008^{*} \\
(0.032)\end{array}$ & $\begin{array}{r}0.077 \\
(0.320)\end{array}$ & $\begin{array}{r}0.013 \\
(0.856)\end{array}$ & $\begin{array}{r}-0.052 \\
(0.507)\end{array}$ & $\begin{array}{l}-0.006^{\wedge} \\
(0.068)\end{array}$ \\
\hline Problem Behavior-TRS (-) & $\begin{array}{r}0.064 \\
(0.389)\end{array}$ & $\begin{array}{r}-0.011 \\
(0.872)\end{array}$ & $\begin{array}{l}-0.085 \\
(0.255)\end{array}$ & $\begin{array}{l}-0.007^{*} \\
(0.029)\end{array}$ & $\begin{array}{r}0.075 \\
(0.323)\end{array}$ & $\begin{array}{r}0.022 \\
(0.746)\end{array}$ & $\begin{array}{r}-0.030 \\
(0.690)\end{array}$ & $\begin{array}{l}-0.005^{\wedge} \\
(0.099)\end{array}$ \\
\hline $\begin{array}{l}\text { Academic Competence and Motivation- } \\
\text { TRS (+) }\end{array}$ & $\begin{array}{l}-0.108^{*} \\
(0.035)\end{array}$ & $\begin{array}{r}-0.032 \\
(0.455)\end{array}$ & $\begin{array}{r}0.044 \\
(0.391)\end{array}$ & $\begin{array}{c}0.007^{* *} \\
(0.008)\end{array}$ & $\begin{array}{l}-0.119^{*} \\
(0.017)\end{array}$ & $\begin{array}{r}-0.046 \\
(0.277)\end{array}$ & $\begin{array}{r}0.027 \\
(0.587)\end{array}$ & $\begin{array}{c}0.007^{* *} \\
(0.006)\end{array}$ \\
\hline Negative School Orientation-CR (-) & $\begin{array}{r}0.057 \\
(0.467) \\
\end{array}$ & $\begin{array}{r}-0.072 \\
(0.300) \\
\end{array}$ & $\begin{array}{c}-0.202^{*} \\
(0.013)\end{array}$ & $\begin{array}{l}-0.013^{* *} \\
(0.001)\end{array}$ & $\begin{array}{r}0.066 \\
(0.364) \\
\end{array}$ & $\begin{array}{r}-0.047 \\
(0.457)\end{array}$ & $\begin{array}{l}-0.160 * \\
(0.031)\end{array}$ & $\begin{array}{l}-0.011^{* *} \\
(0.002)\end{array}$ \\
\hline
\end{tabular}




\section{Table A.16. Cohort 1 versus Cohorts 1 and 2: Comparison of significant impacts by subgroup-Continued}

Panel 6: Initial child behavior risk as reported by primary caregiver

\begin{tabular}{|c|c|c|c|c|c|c|c|c|}
\hline \multirow[b]{2}{*}{ Scale-Report } & \multicolumn{4}{|c|}{ Cohort 1} & \multicolumn{4}{|c|}{ Cohorts 1 and 2} \\
\hline & $\begin{array}{l}\text { Low risk }^{1} \\
(p \text {-value })\end{array}$ & $\begin{array}{r}\text { Average } \\
\text { risk }^{2} \\
(p \text {-value })\end{array}$ & $\begin{array}{r}\text { High risk }^{3} \\
(p \text {-value }) \\
\end{array}$ & $\begin{array}{r}\text { Marginal } \\
\text { effect }^{4} \\
\text { (p-value) }\end{array}$ & $\begin{array}{l}\text { Low risk }^{1} \\
(p \text {-value })\end{array}$ & $\begin{array}{r}\text { Average } \\
\text { risk }^{2} \\
(p \text {-value })\end{array}$ & $\begin{array}{r}\text { High risk }^{3} \\
(p \text {-value }) \\
\end{array}$ & $\begin{array}{r}\text { Marginal } \\
\text { effect }^{4} \\
(p \text {-value })\end{array}$ \\
\hline \multirow{2}{*}{$\begin{array}{l}\text { Normative Beliefs About Aggression- } \\
\text { CR (-) }\end{array}$} & 0.071 & -0.010 & -0.092 & $-0.008^{*}$ & 0.080 & 0.010 & -0.061 & $-0.007^{\wedge}$ \\
\hline & $(0.403)$ & $(0.893)$ & $(0.287)$ & $(0.036)$ & $(0.325)$ & $(0.989)$ & $(0.460)$ & $(0.062)$ \\
\hline \multirow[t]{2}{*}{ Empathy-CR (+) } & -0.083 & -0.007 & 0.068 & $0.008^{*}$ & -0.056 & -0.003 & 0.049 & 0.005 \\
\hline & $(0.217)$ & $(0.897)$ & $(0.318)$ & $(0.042)$ & $(0.375)$ & $(0.948)$ & $(0.445)$ & $(0.138)$ \\
\hline \multirow[t]{2}{*}{ Altruistic Behavior-TRS (+) } & -0.049 & 0.029 & 0.107 & $0.008^{*}$ & -0.004 & 0.060 & 0.123 & $0.006^{\wedge}$ \\
\hline & $(0.780)$ & $(0.864)$ & $(0.542)$ & $(0.050)$ & $(0.979)$ & $(0.693)$ & $(0.429)$ & $(0.095)$ \\
\hline \multirow[t]{2}{*}{ Positive Social Behavior-PCR (+) } & $-0.086^{\wedge}$ & -0.007 & 0.072 & $0.008^{*}$ & -0.080 & -0.015 & 0.051 & $0.006^{*}$ \\
\hline & $(0.083)$ & $(0.852)$ & $(0.147)$ & $(0.015)$ & $(0.106)$ & $(0.701)$ & $(0.310)$ & $(0.037)$ \\
\hline \multirow[t]{2}{*}{ Problem Behavior-PCR (-) } & -0.021 & 0.036 & $0.092^{\wedge}$ & 0.006 & -0.028 & 0.037 & $0.103^{*}$ & $0.007^{*}$ \\
\hline & $(0.691)$ & $(0.363)$ & $(0.080)$ & $(0.101)$ & $(0.571)$ & $(0.323)$ & $(0.043)$ & $(0.048)$ \\
\hline \multirow[t]{2}{*}{ Engagement with Learning-CR (+) } & -0.089 & -0.004 & 0.081 & $0.009^{*}$ & -0.071 & 0.016 & $0.102^{\wedge}$ & $0.009^{*}$ \\
\hline & $(0.127)$ & $(0.925)$ & $(0.178)$ & $(0.028)$ & $(0.196)$ & $(0.707)$ & $(0.070)$ & $(0.018)$ \\
\hline \multirow[t]{2}{*}{ Negative School Orientation-CR (-) } & 0.055 & 0.055 & $-0.178^{*}$ & $-0.012^{* *}$ & 0.056 & -0.044 & $-0.143^{\wedge}$ & $-0.010^{* *}$ \\
\hline & $(0.492)$ & $(0.492)$ & $(0.030)$ & $(0.002)$ & $(0.447)$ & $(0.501)$ & $(0.056)$ & $(0.006)$ \\
\hline
\end{tabular}




\section{Table A.16. Cohort 1 versus Cohorts 1 and 2: Comparison of significant impacts by subgroup-Continued}

Panel 7: Fidelity of implementation

\begin{tabular}{|c|c|c|c|c|c|c|c|c|c|c|c|c|c|c|}
\hline \multirow[b]{3}{*}{ Scale-Report } & \multicolumn{7}{|c|}{ Cohort 1} & \multicolumn{7}{|c|}{ Cohorts 1 and 2} \\
\hline & \multicolumn{2}{|c|}{$\begin{array}{l}\text { Low effect } \\
\text { size }\end{array}$} & \multicolumn{2}{|c|}{$\begin{array}{l}\text { Mixed effect } \\
\text { size }\end{array}$} & \multicolumn{2}{|c|}{$\begin{array}{l}\text { High effect } \\
\text { size }\end{array}$} & \multirow{2}{*}{$\begin{array}{r}p \text {-value for } \\
\text { test of } \\
\text { differences }\end{array}$} & \multicolumn{2}{|c|}{$\begin{array}{l}\text { Low effect } \\
\text { size }\end{array}$} & \multicolumn{2}{|c|}{$\begin{array}{l}\text { Mixed effect } \\
\text { size }\end{array}$} & \multicolumn{2}{|c|}{$\begin{array}{l}\text { High effect } \\
\text { size }\end{array}$} & \multirow{2}{*}{$\begin{array}{r}p \text {-value for } \\
\text { test of } \\
\text { differences }\end{array}$} \\
\hline & $\begin{array}{r}\text { Effect } \\
\text { size }\end{array}$ & $p$-value & $\begin{array}{r}\text { Effect } \\
\text { size }\end{array}$ & $p$-value & $\begin{array}{r}\text { Effect } \\
\text { size }\end{array}$ & $p$-value & & $\begin{array}{r}\text { Effect } \\
\text { size }\end{array}$ & $p$-value & $\begin{array}{r}\text { Effect } \\
\text { size }\end{array}$ & $p$-value & $\begin{array}{r}\text { Effect } \\
\text { size }\end{array}$ & $p$-value & \\
\hline $\begin{array}{c}\text { Normative Beliefs About } \\
\text { Aggression-CR (-) }\end{array}$ & 0.06 & 0.419 & 0.04 & 0.584 & -0.14 & 0.148 & $0.068^{\wedge}$ & 0.11 & 0.174 & 0.05 & 0.547 & -0.14 & 0.129 & $0.042^{*}$ \\
\hline
\end{tabular}

* Significantly different from zero at the .05 level.

** Significantly different from zero at the .01 level.

$\wedge$ Significantly different from zero at the .10 to $>.05$ level.

${ }^{1}$ One standard deviation below the mean risk level.

${ }^{2}$ At the mean risk level.

${ }^{3}$ One standard deviation above the mean risk level.

${ }^{4}$ Change in impact as risk level increases by one unit.

NOTE: Abbreviations are

CR: Child Report

PCR: Primary Caregiver Report

TRS: Teacher Report on Student

ADHD: Attention deficit hyperactivity disorder

The +/- signs in parentheses indicate the direction of a beneficial outcome. All impact estimates were calculated using regression models in which each program and school within a program was weighted equally. The standard errors of all estimates account for design effects due to unequal weighting and the clustering of students within schools. $P$-values for the effect sizes are shown within the parentheses below the effect size.

SOURCE: The Social and Character Development (SACD) Research Program. 
Appendix A: Analysis of Cohorts 1 and 2

\section{Growth Analysis}

Regarding the growth analysis, none of the 18 estimated combined program impacts on growth in fourthgrade child and school outcomes was statistically significantly different from zero at the 5 percent level (table A.17). The lack of statistically significant beneficial impact estimates at the combined-program level did not appear to be due to beneficial impacts in some programs or subgroups that were offset by negative impacts in others. 
Table A.17. Combined Cohorts 1 and 2: Impacts on growth of child outcomes from combined-program analysis

\begin{tabular}{|c|c|c|c|c|c|c|c|}
\hline \multirow[b]{2}{*}{ Scale-Report } & \multirow[b]{2}{*}{$\begin{array}{r}\text { Mean score at } \\
\text { implementation }\end{array}$} & \multicolumn{6}{|c|}{ Average growth in the score per year ${ }^{1}$} \\
\hline & & $\begin{array}{r}\text { Treatment } \\
\text { group }\end{array}$ & $\begin{array}{r}\text { Control } \\
\text { group }\end{array}$ & $\begin{array}{r}\text { Impact on } \\
\text { growth }^{3}\end{array}$ & $\begin{array}{l}\text { Effect } \\
\text { size }^{4}\end{array}$ & $\begin{array}{r}\text { Standard } \\
\text { error of } \\
\text { impact }\end{array}$ & $\begin{array}{r}p \text {-value of } \\
\text { impact }\end{array}$ \\
\hline \multicolumn{8}{|l|}{ Social and Emotional Competence Domain } \\
\hline Self-Efficacy for Peer Interactions-CR (+) & 2.92 & 0.18 & 0.18 & 0.00 & 0.00 & 0.02 & 0.854 \\
\hline Normative Beliefs About Aggression-CR (-) & 1.24 & 0.09 & 0.08 & 0.00 & 0.01 & 0.03 & 0.885 \\
\hline Empathy-CR (+) & 2.41 & -0.16 & -0.15 & -0.01 & -0.02 & 0.02 & 0.705 \\
\hline \multicolumn{8}{|l|}{ Behavior Domain } \\
\hline Altruistic Behavior-CR (+) & 1.45 & -0.25 & -0.24 & -0.02 & -0.02 & 0.03 & 0.549 \\
\hline Altruistic Behavior-PCR (+) & 2.31 & -0.06 & -0.05 & -0.01 & -0.02 & 0.02 & 0.559 \\
\hline Altruistic Behavior-TRS (+) & 1.40 & -0.02 & 0.01 & -0.04 & -0.08 & 0.05 & 0.498 \\
\hline Positive Social Behavior-PCR (+) & 2.98 & 0.05 & 0.04 & 0.01 & 0.03 & 0.01 & 0.371 \\
\hline Positive Social Behavior-TRS (+) & 3.03 & -0.04 & 0.01 & -0.05 & -0.07 & 0.04 & 0.205 \\
\hline Problem Behavior-CR (-) & 0.25 & 0.08 & 0.08 & 0.00 & 0.01 & 0.02 & 0.827 \\
\hline Problem Behavior-PCR (-) & 1.57 & -0.02 & -0.01 & -0.01 & -0.02 & 0.01 & 0.486 \\
\hline Problem Behavior-TRS (-) & 1.38 & 0.06 & 0.07 & -0.01 & -0.02 & 0.02 & 0.654 \\
\hline ADHD-Related Behavior-TRS (-) & 1.74 & -0.01 & 0.00 & -0.01 & -0.02 & 0.03 & 0.624 \\
\hline \multicolumn{8}{|l|}{ Academics Domain } \\
\hline Engagement with Learning-CR (+) & 3.67 & -0.01 & -0.02 & 0.01 & 0.02 & 0.02 & 0.591 \\
\hline Academic Competence-TRS (+) & 2.90 & 0.04 & 0.06 & -0.02 & -0.02 & 0.03 & 0.460 \\
\hline
\end{tabular}


Table A.17. Combined Cohorts 1 and 2: Impacts on growth of child outcomes from combined-program analysis-Continued

\begin{tabular}{|c|c|c|c|c|c|c|c|}
\hline \multirow[b]{2}{*}{ Scale-Report } & \multirow[b]{2}{*}{$\begin{array}{r}\text { Mean score at } \\
\text { implementation }\end{array}$} & \multicolumn{6}{|c|}{ Average growth in the score per year ${ }^{1}$} \\
\hline & & $\begin{array}{r}\text { Treatment } \\
\text { group } \\
\end{array}$ & $\begin{array}{r}\text { Control } \\
\text { group } \\
\end{array}$ & $\begin{array}{r}\text { Impact on } \\
\text { growth }^{3}\end{array}$ & $\begin{array}{l}\text { Effect } \\
\text { size }^{4}\end{array}$ & $\begin{array}{r}\text { Standard } \\
\text { error of } \\
\text { impact } \\
\end{array}$ & $\begin{array}{r}p \text {-value of } \\
\text { impact }\end{array}$ \\
\hline \multicolumn{8}{|l|}{ Perceptions of School Climate Domain } \\
\hline Positive School Orientation-CR (+) & 3.13 & -0.31 & -0.33 & 0.02 & 0.03 & 0.03 & 0.365 \\
\hline Negative School Orientation-CR (-) & 1.87 & 0.08 & 0.09 & -0.01 & -0.02 & 0.02 & 0.528 \\
\hline Student Afraid at School-CR (-) & 2.42 & -0.13 & -0.08 & -0.05 & -0.05 & 0.03 & 0.102 \\
\hline Victimization at School-CR (-) & 0.79 & -0.08 & -0.03 & -0.04 & -0.05 & 0.03 & 0.134 \\
\hline
\end{tabular}

${ }_{1}^{1}$ Pertains to the estimated slope of the outcome for the treatment or control groups.

${ }^{2}$ The average score at implementation was calculated across treatment and control groups, using regression models for adjustment on covariates.

${ }^{3}$ Estimated difference between the slope of the treatment and control groups.

${ }^{4}$ The slope of the treatment group minus the slope of the control group divided by the standard deviation of the outcome for the multisite control group (the standard deviation was calculated without accounting for school-level clustering or regression adjustments).

NOTE: Abbreviations are

CR: Child Report

PCR: Primary Caregiver Report

TRS: Teacher Report on Student

$\rightarrow \quad$ ADHD: Attention deficit hyperactivity disorder

The +/- signs in parentheses indicate the direction of a beneficial outcome. No findings were found statistically significant at or below the .05 level. All impact estimates were calculated using HLM 6.06. Sample weights were used in all analyses to (1) give each program equal weight within each time period, (2) give each school equal weight in each program (within each time period), and (3) give each time period equal weight in the analysis.

SOURCE: The Social and Character Development (SACD) Research Program. 
From the program-level analysis, 12 impact estimates were found to be statistically significant out of 126 results (more than the 6 that would be expected by chance). These are listed in table A.18, which shows that 4 were beneficial impacts on growth in student outcomes, and 8 were detrimental impacts.

Table A.18. Combined Cohorts 1 and 2: Statistically significant impacts from the growth curve analyses of the individual programs

\begin{tabular}{|c|c|c|}
\hline Program & $\begin{array}{l}\text { Significant beneficial impacts } \\
\text { (Report) (Effect size) ( } p \text {-value) }\end{array}$ & $\begin{array}{l}\text { Significant detrimental impacts } \\
\text { (Report) (Effect size) ( } p \text {-value) }\end{array}$ \\
\hline Total & 4 & 8 \\
\hline ABC & $\begin{array}{l}\text { Positive Social Behavior } \\
\text { (PCR) }(0.20)(0.046)\end{array}$ & \\
\hline \multirow[t]{2}{*}{ CSP } & $\begin{array}{l}\text { Victimization at School } \\
(C R)(-0.18)(0.038)\end{array}$ & $\begin{array}{l}\text { Academic Competence } \\
\text { (TRS) }(-0.15)(0.025)\end{array}$ \\
\hline & & $\begin{array}{c}\text { Normative Beliefs About Aggression } \\
\text { (CR) (0.33) (0.031) }\end{array}$ \\
\hline \multirow[t]{2}{*}{ LBW } & & $\begin{array}{l}\text { Problem Behavior } \\
(\mathrm{CR})(0.14)(0.031)\end{array}$ \\
\hline & & $\begin{array}{l}\text { Normative Beliefs About Aggression } \\
\text { (CR) (0.13) (0.030) }\end{array}$ \\
\hline PA & $\begin{array}{l}\text { Altruistic Behavior } \\
(\mathrm{PCR})(0.19)(0.021)\end{array}$ & \\
\hline \multicolumn{3}{|l|}{ PATHS } \\
\hline 4Rs & $\begin{array}{l}\text { Problem Behavior } \\
(\text { TRS) }(-0.21)(0.048)\end{array}$ & \\
\hline \multirow[t]{4}{*}{ SS } & & $\begin{array}{c}\text { Academic Competence } \\
\text { (TRS) }(-0.15)(0.013)\end{array}$ \\
\hline & & $\begin{array}{l}\text { Positive Social Behavior } \\
\text { (TRS) }(-0.35)(0.008)\end{array}$ \\
\hline & & $\begin{array}{l}\text { Problem Behavior } \\
(\text { TRS) }(0.40)(0.010)\end{array}$ \\
\hline & & $\begin{array}{l}\text { ADHD-Related Behavior } \\
\text { (TRS) }(0.28)(0.000)\end{array}$ \\
\hline
\end{tabular}

NOTE: Abbreviations are

ABC: Academic and Behavioral Competencies Program

CSP: Competence Support Program

LBW: Love In a Big World

PA: Positive Action

PATHS: Promoting Alternative Thinking Strategies

4Rs: The 4Rs Program (Reading, Writing, Respect, and Resolution)

SS: Second Step

CR: Child Report

PCR: Primary Caregiver Report

TRS: Teacher Report on Student

ADHD: Attention deficit hyperactivity disorder

Blank cell: Finding of no impact

All impact estimates were calculated using HLM 6.06. Sample weights were used in all analyses to (1) give each program equal weight within each time period, (2) give each school equal weight in each program (within each time period), and (3) give each time period equal weight in the analysis.

SOURCE: The Social and Character Development (SACD) Research Program. 


\section{Appendix A: Analysis of Cohorts 1 and 2}

The subgroup analyses found 12 impact estimates that significantly differed by subgroup out of the 126 results (more than the 6 that would be expected by chance). Table A.19 shows the statistically significant impacts for the subgroups. The gender analysis found 1 significant beneficial impact for girls: a decline in Negative School Orientation. New entrants had detrimental impacts for growth in both Positive School Orientation and Negative School Orientation. For the initial risk analyses, 9 impacts were found to be significant, with 8 showing beneficial impacts on growth for high-risk students and 1 showing detrimental impacts on high-risk students. Subgroup-specific regression results showed that 2 of the beneficial impacts were actually due to detrimental growth effects for low-risk students (Academic Competence in regards to child behavior risk as reported by both the teacher and the primary caregiver). In addition, they showed that the one finding of a detrimental impact on high-risk students was due to a beneficial impact on low-risk students (Problem Behavior reported in the Primary Caregiver Report in regards to community risk). 


\section{Table A.19. Combined Cohorts 1 and 2: Statistically significant impacts from the growth curve} analyses of the subgroups

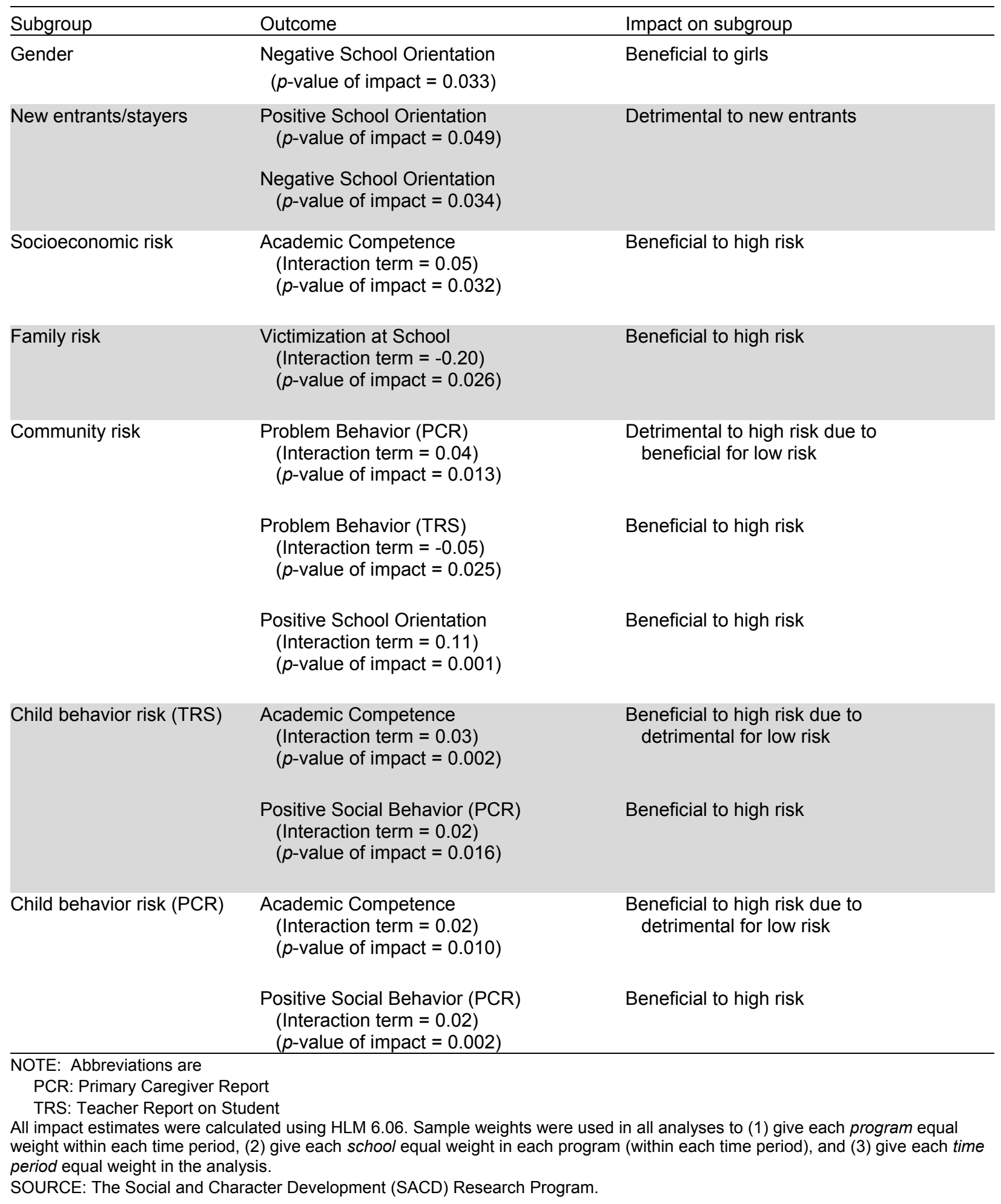




\section{Summary}

As a result of an effort to increase the sample size and corresponding statistical power of the SACD evaluation, a second cohort of 12 schools was added in Year 2. Six of the schools implemented one of four SACD programs while the other six acted as their control schools. Overall, the analyses of the combined cohort sample produced results similar to those of the analyses of the Cohort 1 data.

Responses from students, primary caregivers, and teachers from the original 83 and the 12 new schools during the year students were in the fourth grade were combined. The combined treatment and control groups remained similar, as they were in the Cohort 1 study, although the Cohort 2 students were significantly different from the Cohort 1 students in that they came from more disadvantaged households and communities. The analyses done with the fourth-grade Cohort 1 students were replicated with the students of Cohorts 1 and 2 combined.

The results of the analysis of teachers' activities and professional development, pooled across programs, were similar to the results for the Cohort 1 data. These results showed that statistically significant larger percentages of treatment group teachers than control group teachers reported engaging in activities to promote social and character development, using materials and strategies to promote social and character development, and participating in related professional development. Treatment group teachers were no more likely to report changes in the school environment or in teacher and staff's attitudes that might be conducive to promoting social and character development.

The findings from the combined cohort study were similar to those from the Cohort 1 study. In the year-byyear analysis, the seven SACD combined programs had no significant impact on the 20 outcomes as compared to the impact on one outcome (Student Support for Teachers) found in the analysis of Cohort 1. Regarding the domains, the analysis found a significant detrimental effect on the domain of Social and Emotional Competence. The lack of impacts at the combined-program level was not due to beneficial impacts of some programs being offset by detrimental impacts of other programs. For 18 of the 20 outcomes, there were no statistically significant differences in impacts across the programs (the two exceptions were due to significant positive impacts by the ABC Program).

The individual program impacts for the four programs that had Cohort 2 students showed little or no improvement over those of the Cohort 1 analysis. One program lost a significant beneficial impact and gained a significant detrimental impact (CSP). One program lost a substantively important beneficial impact and a substantively important detrimental impact and gained a substantively important detrimental impact (LBW). One program gained a substantively important beneficial impact (PATHS), and one program lost a significant detrimental effect $(\mathrm{ABC})$.

The findings from subgroup analyses of the combined cohorts were the same for 14 out of 22 impacts that were found significant in the Cohort 1 subgroup analysis. The differences between the findings were primarily that the analyses of the combined cohorts provided less evidence of more beneficial impacts for higher risk students and mixed evidence regarding impacts for stayers versus new entrants.

For the growth curve analysis, the results, though not directly comparable to the Cohort 1 analysis, were similar. The seven SACD programs, combined, had no significant impact on the 18 outcomes. The individual program analysis found a small number of significant impacts on student growth in outcomes but two-thirds of these were detrimental impacts. One difference was that the initial risk analyses had slightly more findings than would be expected by chance, and the majority of these showed more beneficial impacts for higher risk students. 
Appendix A: Analysis of Cohorts 1 and 2

Table A.20. Sample size ranges for outcome analyses

\begin{tabular}{|c|c|c|c|c|}
\hline Outcome analysis & Group & Report & $\begin{array}{l}\text { Minimum } \\
\text { of range }\end{array}$ & $\begin{array}{r}\text { Maximum } \\
\text { of range }\end{array}$ \\
\hline \multirow[t]{8}{*}{ Combined programs } & Treatment & CR & 2,389 & 2,409 \\
\hline & & PCR & 1,833 & 1,859 \\
\hline & & TRS & 2,450 & 2,498 \\
\hline & & TRCS & 478 & 479 \\
\hline & Control & $\mathrm{CR}$ & 2,098 & 2,121 \\
\hline & & PCR & 1,651 & 1,671 \\
\hline & & TRS & 2,208 & 2,221 \\
\hline & & TRCS & 458 & 459 \\
\hline \multicolumn{5}{|l|}{ Individual programs } \\
\hline \multirow[t]{8}{*}{$A B C$} & Treatment & $\mathrm{CR}$ & 258 & 259 \\
\hline & & PCR & 182 & 185 \\
\hline & & TRS & 259 & 271 \\
\hline & & TRCS & 55 & 55 \\
\hline & Control & $\mathrm{CR}$ & 342 & 345 \\
\hline & & PCR & 257 & 257 \\
\hline & & TRS & 357 & 357 \\
\hline & & TRCS & 72 & 72 \\
\hline \multirow[t]{8}{*}{ CSP } & Treatment & $\mathrm{CR}$ & 428 & 436 \\
\hline & & PCR & 323 & 326 \\
\hline & & TRS & 420 & 444 \\
\hline & & TRCS & 81 & 81 \\
\hline & Control & CR & 406 & 416 \\
\hline & & PCR & 339 & 341 \\
\hline & & TRS & 433 & 433 \\
\hline & & TRCS & 82 & 82 \\
\hline \multirow[t]{8}{*}{ LBW } & Treatment & $\mathrm{CR}$ & 359 & 360 \\
\hline & & PCR & 312 & 316 \\
\hline & & TRS & 379 & 387 \\
\hline & & TRCS & 75 & 76 \\
\hline & Control & $\mathrm{CR}$ & 282 & 284 \\
\hline & & PCR & 225 & 227 \\
\hline & & TRS & 295 & 297 \\
\hline & & TRCS & 56 & 56 \\
\hline \multirow[t]{8}{*}{ PA } & Treatment & $\mathrm{CR}$ & 280 & 284 \\
\hline & & PCR & 212 & 214 \\
\hline & & TRS & 289 & 302 \\
\hline & & TRCS & 43 & 43 \\
\hline & Control & $\mathrm{CR}$ & 220 & 225 \\
\hline & & PCR & 181 & 183 \\
\hline & & TRS & 249 & 251 \\
\hline & & TRCS & 39 & 39 \\
\hline
\end{tabular}


Appendix A: Analysis of Cohorts 1 and 2

Table A.20. Sample size ranges for outcome analyses-Continued

\begin{tabular}{|c|c|c|c|c|}
\hline Outcome analysis & Group & Report & $\begin{array}{l}\text { Minimum } \\
\text { of range }\end{array}$ & $\begin{array}{r}\text { Maximum } \\
\text { of range }\end{array}$ \\
\hline \multirow[t]{8}{*}{ PATHS } & Treatment & CR & 305 & 308 \\
\hline & & PCR & 233 & 239 \\
\hline & & TRS & 315 & 315 \\
\hline & & TRCS & 74 & 74 \\
\hline & Control & $\mathrm{CR}$ & 262 & 263 \\
\hline & & PCR & 198 & 199 \\
\hline & & TRS & 271 & 271 \\
\hline & & TRCS & 76 & 76 \\
\hline \multirow[t]{8}{*}{ 4Rs } & Treatment & $\mathrm{CR}$ & 372 & 377 \\
\hline & & PCR & 241 & 246 \\
\hline & & TRS & 399 & 404 \\
\hline & & TRCS & 90 & 91 \\
\hline & Control & CR & 292 & 299 \\
\hline & & PCR & 206 & 209 \\
\hline & & TRS & 307 & 320 \\
\hline & & TRCS & 82 & 82 \\
\hline \multirow[t]{8}{*}{ SS } & Treatment & $\mathrm{CR}$ & 383 & 387 \\
\hline & & PCR & 330 & 335 \\
\hline & & TRS & 381 & 383 \\
\hline & & TRCS & 59 & 60 \\
\hline & Control & CR & 288 & 291 \\
\hline & & PCR & 245 & 255 \\
\hline & & TRS & 292 & 293 \\
\hline & & TRCS & 51 & 52 \\
\hline \multicolumn{5}{|l|}{ Subgroups } \\
\hline \multirow[t]{6}{*}{ Gender } & Boys & $\mathrm{CR}$ & 2,124 & 2,144 \\
\hline & & PCR & 1,643 & 1,669 \\
\hline & & TRS & 2,240 & 2,261 \\
\hline & Girls & $\mathrm{CR}$ & 2,363 & 2,386 \\
\hline & & PCR & 1,825 & 1,845 \\
\hline & & TRS & 2,400 & 2,441 \\
\hline \multirow[t]{6}{*}{ New entrants } & Stayers & $\mathrm{CR}$ & 3,461 & 3,495 \\
\hline & & PCR & 2,699 & 2,731 \\
\hline & & TRS & 3,607 & 3,651 \\
\hline & New entrants & $\mathrm{CR}$ & 1,026 & 1,036 \\
\hline & & PCR & 785 & 799 \\
\hline & & TRS & 1,051 & 1,069 \\
\hline \multirow{3}{*}{\multicolumn{2}{|c|}{ Initial socioeconomic risk }} & $\mathrm{CR}$ & 4,062 & 4,106 \\
\hline & & PCR & 3,407 & 3,448 \\
\hline & & TRS & 4,218 & 4,261 \\
\hline
\end{tabular}

See notes at end of table. 
Appendix A: Analysis of Cohorts 1 and 2

Table A.20. Sample size ranges for outcome analyses-Continued

\begin{tabular}{|c|c|c|c|c|}
\hline Outcome analysis & Group & Report & $\begin{array}{l}\text { Minimum } \\
\text { of range }\end{array}$ & $\begin{array}{r}\text { Maximum } \\
\text { of range }\end{array}$ \\
\hline \multirow[t]{3}{*}{ Initial family risk } & & $\mathrm{CR}$ & 3,068 & 3,099 \\
\hline & & PCR & 2,531 & 2,561 \\
\hline & & TRS & 3,195 & 3,222 \\
\hline \multirow[t]{3}{*}{ Initial community risk } & & CR & 3,019 & 3,051 \\
\hline & & PCR & 2,501 & 2,529 \\
\hline & & TRS & 3,140 & 3,166 \\
\hline \multirow{4}{*}{$\begin{array}{l}\text { Initial child behavior risk } \\
\text { (Teacher Report) }\end{array}$} & & & & \\
\hline & & CR & 3,288 & 3,322 \\
\hline & & PCR & 2,582 & 2,610 \\
\hline & & TRS & 3,430 & 3,468 \\
\hline \multicolumn{5}{|l|}{$\begin{array}{l}\text { Initial child behavior risk } \\
\text { (Primary Caregiver }\end{array}$} \\
\hline \multirow[t]{3}{*}{ Report) } & & CR & 3,050 & 3,082 \\
\hline & & PCR & 2,522 & 2,551 \\
\hline & & TRS & 3,179 & 3,206 \\
\hline \multirow[t]{9}{*}{ Fidelity of implementation } & High & $\mathrm{CR}$ & 1,749 & 1,767 \\
\hline & & PCR & 1,423 & 1,442 \\
\hline & & TRS & 1,788 & 1,813 \\
\hline & Mixed & $\mathrm{CR}$ & 848 & 851 \\
\hline & & PCR & 677 & 684 \\
\hline & & TRS & 893 & 904 \\
\hline & Low & $\mathrm{CR}$ & 1,887 & 1,909 \\
\hline & & PCR & 1,381 & 1,402 \\
\hline & & TRS & 1,974 & 2,001 \\
\hline
\end{tabular}

NOTE: Abbreviations are

ABC: Academic and Behavioral Competencies Program

CSP: Competence Support Program

LBW: Love In a Big World

PA: Positive Action

PATHS: Promoting Alternative Thinking Strategies

4Rs: The 4Rs Program (Reading, Writing, Respect, and Resolution)

SS: Second Step

CR: Child Report

PCR: Primary Caregiver Report

TRS: Teacher Report on Student

TRCS: Teacher Report on Classroom and School

SOURCE: The Social and Character Development (SACD) Research Program. 
Appendix B: Technical Notes on the Development of Outcome Measures, Selection of Covariates, Construction of Sample Weights, and Sensitivity Analyses 
This page is intentionally blank. 


\section{Technical Notes on the Development of Outcome Measures, Selection of Covariates, Construction of Sample Weights, and Sensitivity Analyses}

This technical appendix supplements the Study Design and Methodology section of chapter 1 with additional details on the methods used for the SACD impact analysis. It provides information about the development of the outcome measures, the selection of covariates that were included in the regression models, the sample weights, and the sensitivity analysis used to examine the robustness of the impact estimates to alternative parameter assumptions and specifications.

\section{Development of the Outcome Measures}

This section describes the procedures used to create and validate the survey-based child and school outcome measures. The majority of the discussion concerns the 18 student-level outcome measures, with the 2 schoollevel outcome measures discussed at the end of the section. The development of the outcome measures was directed by the Social and Character Development (SACD) Statistical Workgroup, which was made up of representatives from the National Center for Education Research, Institute of Education Sciences (IES), U.S. Department of Education; the Division of Violence Prevention in the National Center for Injury Prevention and Control, Centers for Disease Control and Prevention (CDC); SACD grantees; Mathematica Policy Research, Inc. (MPR); and the University of Missouri-St. Louis. Each outcome measure is a scale composite of multiple Likert-type items, derived from initial (fall 2004) survey responses to the Child Report, Primary Caregiver Report, and the Teacher Report on Student. ${ }^{1}$ For example, the five student-level measures created from the Teacher Report on Student are Positive Social Behavior, Problem Behavior, Altruistic Behavior, ADHD-Related Behavior, and Academic Competence and Motivation. A list of all scales for each respondent group is provided in table B.1.

The surveys were either self-administered or, for some primary caregivers, administered as a computerassisted telephone interview. The items included in the initial versions of the teacher-, primary caregiver-, and child-report surveys were largely taken from instruments used in previous research. Four measures (child responsibility, child and teacher perceptions of school safety, and primary caregiver perceptions of community resources) were generated by SACD Consortium members due to a lack of adequate existing measures of those constructs. Preliminary analyses of the measures administered in the initial wave of data collection revealed that, although most of the scales performed adequately and as expected, some predefined scales had poor internal consistency (Cronbach's alphas $\leq 0.60$ for primary caregiver report on the Behavior Assessment System for Children [BASC] Conduct Problems Subscale and child report on the Nonconflict Subscale items of the Children's Self-Efficacy for Peer Interaction Scale). Furthermore, a small number of the scale or subscale scores were highly intercorrelated (for example, $r \geq 0.80$ for the correlation between teacher report on the Responsibility Scale and teacher report on the Social Competence Scale). Consequently, the SACD Statistical Workgroup conducted more rigorous analyses of the items to determine whether a set of outcome measures with better psychometric characteristics could be derived.

\footnotetext{
${ }^{1}$ In fall 2004, data collection began at an original cohort of schools and focused on students who were beginning third grade. Students at these schools were followed through spring of fifth grade. A second cohort of schools was subsequently included in the study; data collection at these schools focused on students who started third grade in fall 2005; these students were followed through the spring of fourth grade. The analyses discussed here pertain to the first cohort of schools and students.
} 
Table B.1. Scales and internal consistency for child outcomes, by report type

\begin{tabular}{lc}
\hline & Scale (Cronbach's $\alpha)$ \\
\hline Teacher Report on Student & Child Report \\
Positive Social Behavior (0.97) & Positive School Orientation (0.86) \\
Problem Behavior (0.95) & Engagement with Learning (0.84) \\
Altruistic Behavior (0.89) & Student Afraid at School $(0.79)$ \\
ADHD-Related Behavior (0.91) & Negative School Orientation (0.78) \\
Academic Competence and Motivation (0.95) & Self-Efficacy for Peer Interaction $(0.83)$ \\
& Normative Beliefs About Aggression (0.83) \\
Primary Caregiver Report & Empathy (0.78) \\
Positive Social Behavior (0.93) & Altruistic Behavior (0.88) \\
Problem Behavior (0.86) & Problem Behavior $(0.86)$ \\
Altruistic Behavior (0.88) & Victimization at School $(0.86)$ \\
\hline NOTE: Internal consistency is Cronbach's $\alpha$ (alpha), measured using a random sample of one-half of the respondents to the fall \\
2004 survey administration. Consistency remained similarly high at all waves. Listwise deletion of cases with missing data was used \\
in all analyses. ADHD is the abbreviation for attention deficit hyperactivity disorder. \\
SOURCE: The Social and Character Development (SACD) Research Program.
\end{tabular}

The approach the SACD Statistical Workgroup used was, first, to conduct exploratory factor analyses. Using half of the sample, selected randomly, researchers looked at the individual items of the fall 2004 survey separately for each group of respondents (teachers, primary caregivers, and children). These analyses were conducted separately for each group of respondents because the survey instruments for teachers, primary caregivers, and children contained different sets of items. Although a small number of measures were administered to more than one respondent group (see below), most of the measures were administered to only a single group of respondents. Potential outcome scales identified in these exploratory analyses were then subjected to confirmatory factor analyses with the remaining half of the sample (hereafter referred to as the "validation sample") using structural equation modeling procedures.

For each of the three survey respondent groups, a set of exploratory factor analyses was undertaken using the principal axis method. Based on both conceptual and empirical (such as eigenvalues) criteria, varying numbers of factors were extracted and rotated in these analyses, and then compared with respect to the conceptual clarity of the factors, the nature and extent of cross-loading of items, the extent to which factors were defined by a very small number of items (or single items), and parsimony (the absence of multiple factors appearing to assess the same basic construct). On the basis of these analyses, it was decided that the item responses of teachers, primary caregivers, and children were optimally represented by 5, 3, and 10 underlying factors, respectively. The names and internal consistencies of the scales are listed in table B.1.2

\section{Confirmatory Factor Analyses of Student-Level Outcome Measures}

The factors identified in the exploratory analyses were subjected to empirical confirmation using the validation samples. Analyses of model fit were conducted using LISREL software for the analysis of covariance structures. The focus was on two measures of model fit: the comparative fit index (CFI) and the root mean square error of approximation (RMSEA). The CFI runs from 0 to 1 and gauges the percentage improvement in reproducing the input covariance matrix obtained by using the proposed measurement model as compared to a null model that assumes no shared variance (and thus no latent factors). Higher

\footnotetext{
${ }^{2}$ A small number of items were dropped from further analyses because they did not load on any of the identified factors (loadings were not $\geq 0.30$ on any factor). Specifically, 8 of 91 items in the child survey ( $9 \%$ ), 3 of 74 items in the teacher survey (4\%), and 6 of 59 items in the primary caregiver survey $(10 \%)$ were dropped from analysis. Items that crossloaded on other factors (an item was considered to cross-load on two or more factors when factor loadings were greater than 0.30 ) were included on the factor for which the loading was stronger.
} 
values represent improved fit and, while all fit standards are somewhat arbitrary, researchers have variously suggested either .90 or .95 as cutoffs for good fit. The RMSEA is an index of lack of fit (based on the $\chi^{2}$ ) per degree of freedom. The RMSEA also runs from 0 to 1, but higher values reflect poorer fit. Suggested cutoffs for acceptable fit vary from .08 to .10 .

For the teacher, the primary caregiver, and the child respondents, the hypothesized factor representations provided a good fit to the data, as estimated using LISREL structural equations modeling software. As shown in table B.2, for the 71 items in the teacher survey, the confirmatory factor analysis of five latent factors yielded a CFI value of 0.98 and an RMSEA of 0.090 (90\% confidence interval [CI] $=0.089,0.091)$. For the 53 primary caregiver items, the confirmatory factor analysis of three latent factors yielded a CFI of 0.94 and an RMSEA of $0.087(90 \% \mathrm{CI}=0.086,0.088)$; for the 83 child items, the confirmatory factor analysis of 10 latent factors yielded a CFI of 0.91 and an RMSEA of 0.060 (90\% CI $=0.059,0.061)$. 
Table B.2. Fit indexes from confirmatory factor analyses, five-factor measurement model: First four waves of data collection, by respondent type

\begin{tabular}{lccc}
\hline Respondent type/Time of data collection & Sample size & RMSEA & CFI \\
\hline Teachers (5 factors) & & & \\
Initial & 2,040 & 0.090 & 0.980 \\
Follow-up 1 & 3,538 & 0.114 & 0.967 \\
Follow-up 2 & 3,410 & 0.102 & 0.969 \\
Follow-up 3 & 3,580 & 0.107 & 0.970 \\
Follow-up 4 & 3,178 & 0.110 & 0.969 \\
& & & \\
Primary Caregivers (3 factors) & & & \\
Initial & 1,389 & 0.087 & 0.940 \\
Follow-up 1 & 2,643 & 0.079 & 0.956 \\
Follow-up 2 & 2,745 & 0.081 & 0.957 \\
Follow-up 3 & 2,639 & 0.082 & 0.954 \\
Follow-up 4 & 2,355 & 0.084 & 0.957 \\
& & & \\
Children (10 factors) & & & \\
Initial & & & \\
Follow-up 1 & 1,314 & 0.060 & 0.910 \\
Follow-up 2 & 3,074 & 0.064 & 0.943 \\
Follow-up 3 & 3,247 & 0.067 & 0.947 \\
Follow-up 4 & 3,307 & 0.066 & 0.952 \\
\hline
\end{tabular}

NOTE: Abbreviations are

CFI: Comparative fit index

RMSEA: Root mean square error of approximation

Listwise deletion of cases with missing data was used in all analyses. Confirmatory factor models were estimated using the LISREL structural equation modeling package, with latent factor variances fixed to 1.0 to scale the factors. Initial data were collected in fall 2004. Follow-up 1 was in spring 2005, Follow-up 2 was in fall 2005, Follow-up 3 was in spring 2006, and Follow-up 4 was in spring 2007. The fall 2004 results are from analyses of random samples of one-half of the fall 2004 respondents of each respective respondent type. Results for the follow-ups are derived from analyses of full samples (after listwise deletion). SOURCE: The Social and Character Development (SACD) Research Program.

\section{Robustness Checks}

The analyses of the fall 2004 data indicated that, for the sample as a whole, the child outcome variables could be adequately represented by a relatively small number of scales. Further analyses were performed to test the robustness of the model (1) for major demographic subgroups, (2) across samples at different study sites, (3) to treatment of missing data, (4) to different estimation approaches, and (5) across different survey waves.

\section{Demographic and Site Checks}

A series of multigroup confirmatory analyses were conducted to investigate whether the identified measurement models held across major child demographic groups (gender and race/ethnicity) and across the seven individual SACD programs. In each case, a measurement model in which all factor loadings and factor covariances were constrained to be equal across groups (but error variances were allowed to vary) provided a 
good fit to the multigroup data. ${ }^{3}$ The basic measurement model thus proved to be valid across child gender, across child race/ethnicity, and for each of the seven SACD programs.

\section{Missing Items}

A second set of confirmatory analyses were conducted to examine whether the measurement models were robust to differences in the treatment of missing item-response data. Primary analyses were restricted to observations with no missing items. Although preliminary analyses indicated that missing responses to individual survey items were infrequent among each of the respondent groups (no more than $5 \%$ of the responses were missing for any survey item), listwise deletion had a cumulative effect of excluding one-third or more of the respondents in each group. Analyses of missing data showed that respondents with valid scores on the outcome measures were similar to those with missing data, suggesting that data were missing at random. Nonetheless, to investigate potential biases due to exclusion of cases with missing responses to survey items, the confirmatory factor analyses were re-run with missing item responses imputed using the Expectation-Maximization (EM) algorithm. ${ }^{4}$ For each respondent group, the use of EM imputation resulted in a fit as good as or better than that of models on samples that used listwise deletion.

\section{Estimation Procedures}

Approaches to evaluating model fit vary across software packages. LISREL uses a "weighted least squares" chi-square independence model. By contrast, another structural equation modeling package, EQS, uses a "minimum fit function" chi-square independence model. For equivalent models, LISREL and EQS should produce the same normal theory chi-square and RMSEA values but would produce different measures of relative fit, such as CFI, due to the use of different chi-square independence models. Analyses performed using EQS showed that, as expected, LISREL yielded a higher CFI for each model than EQS. ${ }^{5}$ However, the other fit indexes, which are not based on choice of chi-square independence model, were actually better as estimated by EQS than LISREL, and both software packages indicated that the measurement models provided a good fit to the data.

\section{Successive Data Waves}

Finally, it is possible that the SACD programs might influence not only the mean scores on the measured outcomes but also the correlations among the measured outcomes, and thus have an impact on the quality of the measurement model. Analyses were performed to test the continuing fit of the model with each new wave of data. In addition to presenting measures of model fit from the initial survey wave, table B.2 also presents corresponding measures for each of the succeeding follow-up waves for the original cohort. Those results confirm that the model has held up well over time. There was minimal variation in either of the fit statistics across survey waves.

\footnotetext{
${ }^{3}$ All multigroup confirmatory factor analyses were conducted using the random half-samples of respondents used in the initial confirmatory analyses.

${ }_{4}^{4}$ The EM algorithm (see Dempster, Laird, and Rubin 1977) is an iterative, maximum-likelihood procedure that uses information from observed data to successively estimate, evaluate, and re-estimate values for missing data until it converges on a unique maximum-likelihood estimate.

5 The independence model specifies that the covariance matrix of the observed variables is a diagonal matrix with all observed variables uncorrelated. Although the computational formulas are complicated (see Joreskog et al. 2003), the weighted least squares independence model chi-square (LISREL default) yields larger values than the minimum fit function independence model chi-square (EQS default). As a result, incremental fit indexes such as the CFI will be larger in LISREL than in EQS, because all such indexes are computed as some function of the chi square $(1-$ [model chisquare/independence chi-square]). As should be the case, when the same chi-square independence model is used to evaluate model fit in LISREL and EQS, the two software packages produce virtually identical estimates of CFI and all other model fit indexes that are evaluated against the independence model.
} 


\section{Construct and Reporter-Based Variance}

The measurement models described above all derived measures separately for each respondent group (children, primary caregivers, and teachers). However, comparable measures were found among the respondent groups—such as Altruistic Behavior, Positive Social Behavior, and Problem Behavior. A series of exploratory "multitrait, multirespondent" (MTMR) analyses were undertaken to investigate the extent of convergence across respondents in these commonly measured outcomes-whether responses predominantly reflected common perceptions of child behaviors across respondents or whether they were largely idiosyncratic to the respondent. That is, these efforts represented an attempt to distinguish construct variance from systematic variance due to the respondent (as well as random measurement error).

Systematic differences between respondents may represent reporter bias or may reflect differences associated with the different types of information available to each respondent when making judgments. For example, primary caregivers and teachers differ in their overall familiarity with a child and in the nature of the situations in which they are able to observe the child's behavior. These differences in available information are quite likely to influence their judgments about the child's characteristics. Thus it is important to acknowledge that systematic variance between respondents might not necessarily indicate error in observation, recollection, or reporting, but rather they could reflect real differences in child behavior in different environments and contexts.

The SACD Statistical Workgroup conducted multiple analyses with "construct" latent variables (e.g., Problem Behavior, Altruistic Behavior) and "reporter" latent variables (e.g., primary caregiver). The central finding of these MTMR analyses was that for the set of outcomes measured, there was substantial variance attributable to both the respondent and the constructs being measured. Thus, for example, the correlations between a single respondent's assessments across constructs—such as a teacher's perceptions of a child's Problem Behavior and Altruistic Behavior-were similar to the correlations between respondents for the same construct-such as the teacher's assessment of that child's Problem Behavior and the corresponding assessment by the primary caregiver. In addition, the path coefficients for the construct and reporter latent variables were of generally similar magnitude to one another. The data used in these analyses do not permit determination of whether the latent reporter effects reflected bias on the part of respondents or differences in the information available to different respondents.

\section{Psychometric Properties of School-Level Outcome Measures}

In addition to the individual, student-level outcome measures described above, two school-level measures of possible SACD program outcomes were included in the impact analyses. These measures were included in separate teacher surveys (Teacher Report on Classroom and School) administered in fall 2004 and each follow-up period, and the measures focused on assessments of the school environment. One of the measures, Student Support for Teachers, assessed teacher perceptions of student positive and negative behavior and teacher-student relations; the other, Feelings of Safety, assessed teacher perceptions of the extent to which students were not fearful of being psychologically or physically harmed at school. Principal components analyses revealed that both measures were unidimensional, with all items having large positive loadings $(\geq$ .69) on the first unrotated component and the component accounting for 62 percent to 77 percent of the variance in item responses. Similarly, internal consistency analyses revealed that both measures were highly reliable, with alpha coefficients between .89 and .91 at each survey wave for the Student Support for Teachers index and between .88 and .90 at each wave for the Feelings of Safety index.

\section{Selection of Covariates}

This section provides details on the selection of covariates for estimating regression-adjusted intervention impacts on the key child and school outcomes. The approach described here significantly benefited from discussions with the SACD Statistical Workgroup, composed of principal investigators across the seven SACD study sites and representatives of IES and CDC, in addition to staff at MPR and MPR's subcontractor, University of Missouri-St. Louis. This approach was used to choose the covariates for the Year 1 analysis and 
made use of the Year 1 outcome data. The covariates that were selected using the Year 1 data were also used in the Year 2 and Year 3 analyses to ensure comparability of results. ${ }^{6}$

\section{Objectives in Selecting Covariates}

Because the primary goal of the multiprogram study was to estimate program impacts, criteria were adopted for selecting covariates to improve the precision and accuracy of the impact estimates. The goal was not to build structural models explaining how the SACD interventions work or to identify mediating variables. Therefore, there was no focus on the signs or interpretations of the estimated coefficients on the covariates.

The random assignment design ensured that the main difference between treatment and control group schools at baseline was the opportunity to receive SACD program services. Therefore, simple differences in mean outcomes between the treatment and control groups provided unbiased impact estimates of the offer of SACD program services on key outcomes. However, regression models were used to estimate the impacts for the following two reasons:

\section{To Increase the Precision of Impact Estimates}

Statistical power was a particularly important issue for the SACD evaluation because of clustering effects due to the correlation of student outcomes within schools. This was particularly true at the site level due to the small number of schools. The inclusion of baseline covariates in the regression models increased the precision of the impact estimates (that is, reduced intraclass correlations) by explaining some of the variation in mean outcomes across schools. The inclusion of school-level covariates (which varied only between schools), however, also resulted in a loss in degrees of freedom available for statistical tests, which reduced statistical power. This precision loss was important at the site level, where there were relatively small numbers of schools.

\section{To Adjust for Baseline Differences Between the Treatment and Control Group Schools}

Although random assignment produced statistically equivalent treatment and control groups, there were some residual differences in the average characteristics of the two research groups due to random sampling. In the benchmark models, MPR adjusted for these residual differences using regression models. The inclusion of these baseline variables, however, affected the impact estimates only if they were also correlated with the outcome variables. Thus, as discussed in the following section, a covariate with a treatment-control group difference at baseline was selected only if it also had some predictive power in the regression models.

\section{Tailoring Covariates to Specific Outcomes and Sites}

The options for selecting covariates lie between picking a set that is the same across all outcomes and sites and picking a set that is tailored specifically for each outcome within each site. While the former is advantageous because of its parsimony, there is the risk of losing precision by including covariates that might not be correlated with the particular outcome (due to reductions in degrees of freedom) or by excluding covariates with predictive power. Completely tailoring sets for each outcome and site maximizes precision but is computationally intensive. Therefore, recognizing that outcomes obtained from a specific reporter tend to be somewhat correlated, and balancing the trade-offs between being too parsimonious and too unwieldy, covariate sets were chosen that differed by site but were the same within reporter in each site and for the pooled analysis. Thus, the same set of covariates was used to estimate impacts on child-reported outcomes in a particular site (or for the pooled analysis), but the set was allowed to vary across sites (and similarly for outcomes from the Primary Caregiver Report, Teacher Report on Student, and Teacher Report on Classroom and School).

\footnotetext{
${ }^{6}$ As a sensitivity analysis for the use of the covariates selected with the Year 1 outcome data in the analyses of all 3 years of data, the covariates were reselected with the same approach but using the Year 2 outcome data. For the combinedprogram analysis, the results of the Year 1 and Year 2 analyses were not sensitive to which set of covariates were included. There were several differences in the individual program analyses.
} 
The one exception to the rule of uniform sets within a reporter was that the baseline measure of the outcome (pretest) was always included as a covariate in the regression models. As noted in the following discussion, stepwise regressions found that the pretests explained a relatively large proportion of the variance in the outcomes.

\section{Implementation of the Covariate Selection Procedure}

Table B.3 lists the Year 1 (spring 2005) outcome variables for the analysis. The outcomes include 10 measures from the Child Report, three measures from the Primary Caregiver Report, five measures from the Teacher Report on Student, and two measures from the Teacher Report on Classroom and School. These measures were constructed from original scale items using factor analytic methods. 
Table B.3. Child and school outcomes used for covariate selection and the percentage missing at spring 2005 (Year 1) analysis

\begin{tabular}{|c|c|c|c|c|}
\hline Outcome & $\begin{array}{c}\text { Percent } \\
\text { missing } \\
\text { in combined- } \\
\text { program } \\
\text { sample } \\
\end{array}$ & $\begin{array}{r}\text { Average } \\
\text { percent } \\
\text { missing } \\
\text { across } \\
\text { programs } \\
\end{array}$ & $\begin{array}{r}\text { Minimum } \\
\text { missing } \\
\text { across } \\
\text { programs }\end{array}$ & $\begin{array}{r}\text { Maximum } \\
\text { missing } \\
\text { across } \\
\text { programs }\end{array}$ \\
\hline \multicolumn{5}{|l|}{ Child-reported } \\
\hline Positive School Orientation & 4.97 & 4.92 & 0.64 & 8.40 \\
\hline Engagement with Learning & 4.57 & 4.53 & 0.64 & 8.25 \\
\hline Student Afraid at School & 5.08 & 5.04 & 0.80 & 8.70 \\
\hline Negative School Orientation & 5.01 & 4.97 & 0.80 & 8.40 \\
\hline Self-Efficacy for Peer Interactions & 5.06 & 5.03 & 0.96 & 8.55 \\
\hline Normative Beliefs About Aggression & 5.22 & 5.17 & 0.80 & 8.55 \\
\hline Empathy & 5.10 & 5.06 & 0.80 & 8.40 \\
\hline Altruistic Behavior & 5.08 & 5.04 & 0.80 & 8.70 \\
\hline Problem Behavior & 5.20 & 5.14 & 1.28 & 8.55 \\
\hline Victimization at School & 5.06 & 5.03 & 1.12 & 8.55 \\
\hline \multicolumn{5}{|l|}{ Primary caregiver-reported } \\
\hline Positive Social Behavior & 22.53 & 22.14 & 12.96 & 33.02 \\
\hline Problem Behavior & 22.51 & 22.12 & 12.96 & 32.75 \\
\hline Altruistic Behavior & 23.79 & 23.43 & 14.08 & 34.24 \\
\hline \multicolumn{5}{|l|}{ Teacher-reported } \\
\hline Positive Social Behavior & 1.86 & 1.77 & 0.15 & 4.06 \\
\hline Problem Behavior & 1.70 & 1.61 & 0.15 & 4.06 \\
\hline ADHD-Related Behavior & 1.75 & 1.66 & 0.15 & 4.06 \\
\hline Altruistic Behavior & 4.48 & 4.33 & 0.87 & 10.77 \\
\hline Academic Competence and Motivation & 1.68 & 1.57 & 0.16 & 4.60 \\
\hline Student Support for Teachers & 0.59 & 0.65 & 0.00 & 2.91 \\
\hline Feelings of Safety & 0.59 & 0.57 & 0.00 & 1.15 \\
\hline
\end{tabular}

NOTE: ADHD is the abbreviation for attention deficit hyperactivity disorder.

SOURCE: The Social and Character Development (SACD) Research Program.

Table B.4 lists the full set of candidate covariates constructed from the baseline (fall 2004) data at the time of the Year 1 (spring 2005) analysis. (Note that because the first set of data was collected after program implementation began at many sites, these data are referred to as "initial data" rather than "baseline data" in the main body of this report.) The set of potential covariates included three types of baseline variables. ${ }^{7}$ First, the covariates included child demographic measures and, from the Child Report, pretest scores. Second, the covariates included primary caregiver characteristics and child pretest scores from the Primary Caregiver Report. Finally, the covariates included child and primary caregiver involvement pretest scores from the Teacher Report on Student.

\footnotetext{
${ }^{7}$ Including covariates to measure the characteristics of teachers was considered but this approach was rejected for the analysis of child outcomes because teachers were likely to change over the 3-year follow-up period, and because the SACD interventions might affect the types of teachers who entered and exited the study schools. Teacher demographic characteristics were included as covariates for the analysis of the two teacher-reported outcomes from the TRCS.
} 
Table B.4. Potential covariates and the percentage missing at spring 2005 (Year 1) analysis

\begin{tabular}{|c|c|c|c|c|}
\hline Potential covariate & $\begin{array}{r}\text { Percent } \\
\text { missing } \\
\text { in combined- } \\
\text { program } \\
\text { sample }\end{array}$ & $\begin{array}{r}\text { Average } \\
\text { percent } \\
\text { missing } \\
\text { across } \\
\text { programs }\end{array}$ & $\begin{array}{r}\text { Minimum } \\
\text { missing } \\
\text { across } \\
\text { programs }\end{array}$ & $\begin{array}{r}\text { Maximum } \\
\text { missing } \\
\text { across } \\
\text { programs } \\
\end{array}$ \\
\hline \multicolumn{5}{|l|}{ Child-reported } \\
\hline Female & 1.08 & 1.06 & 0.00 & 2.25 \\
\hline White (non-Hispanic) & 9.03 & 8.64 & 2.56 & 21.79 \\
\hline Black (non-Hispanic) & 9.03 & 8.64 & 2.56 & 21.79 \\
\hline Hispanic & 9.03 & 8.64 & 2.56 & 21.79 \\
\hline Other ethnicity & 9.03 & 8.64 & 2.56 & 21.79 \\
\hline Age (in years) & 1.08 & 1.06 & 0.00 & 2.25 \\
\hline \multicolumn{5}{|l|}{ Scales } \\
\hline Student Afraid at School & 13.61 & 13.47 & 8.64 & 17.19 \\
\hline Altruistic Behavior & 13.86 & 13.73 & 8.64 & 17.05 \\
\hline Empathy & 13.93 & 13.80 & 8.80 & 17.05 \\
\hline Engagement with Learning & 13.59 & 13.44 & 8.32 & 17.19 \\
\hline Negative School Orientation & 13.70 & 13.56 & 8.64 & 17.19 \\
\hline Normative Beliefs About Aggression & 13.75 & 13.61 & 8.64 & 17.05 \\
\hline Positive School Orientation & 13.49 & 13.35 & 8.32 & 17.19 \\
\hline Problem Behavior & 14.00 & 13.86 & 8.80 & 17.05 \\
\hline Self-Efficacy for Peer Interactions & 13.82 & 13.69 & 8.80 & 17.05 \\
\hline Victimization at School & 14.05 & 13.90 & 8.80 & 17.05 \\
\hline \multicolumn{5}{|l|}{ Primary caregiver-reported } \\
\hline Age (in years) & 10.57 & 10.04 & 3.04 & 27.47 \\
\hline Completed high school education or equivalent & 9.01 & 8.62 & 2.56 & 22.19 \\
\hline Some college & 9.01 & 8.62 & 2.56 & 22.19 \\
\hline Bachelor's or higher degree & 9.01 & 8.62 & 2.56 & 22.19 \\
\hline $\begin{array}{l}\text { Highest level of education in household- } \\
\text { Completed high school or equivalent }\end{array}$ & 9.08 & 8.67 & 2.56 & 22.46 \\
\hline $\begin{array}{l}\text { Highest level of education in household- } \\
\text { Some college }\end{array}$ & 9.08 & 8.67 & 2.56 & 22.46 \\
\hline $\begin{array}{l}\text { Highest level of education in household- } \\
\text { Bachelor's or higher degree }\end{array}$ & 9.08 & 8.67 & 2.56 & 22.46 \\
\hline Mother present in home life & 8.80 & 8.41 & 2.56 & 21.92 \\
\hline Mother and father present & 8.83 & 8.43 & 2.56 & 22.06 \\
\hline $\begin{array}{l}\text { Respondent someone other than mother } \\
\text { or father }\end{array}$ & 8.92 & 8.53 & 2.56 & 22.19 \\
\hline Number of people in household & 9.01 & 8.62 & 2.56 & 22.06 \\
\hline Household income: $\$ 20,000$ to $\$ 40,000$ & 11.63 & 11.14 & 3.52 & 27.20 \\
\hline Household income: $\$ 40,000$ to $\$ 60,000$ & 11.63 & 11.14 & 3.52 & 27.20 \\
\hline Household income: More than $\$ 60,000$ & 11.63 & 11.14 & 3.52 & 27.20 \\
\hline $\begin{array}{l}\text { Income-to-poverty-threshold ratio- } \\
\text { Below } 135 \text { percent }\end{array}$ & 11.61 & 11.12 & 3.52 & 27.33 \\
\hline $\begin{array}{l}\text { Income-to-poverty-threshold ratio- } \\
\text { Between } 135 \text { and } 185 \text { percent }\end{array}$ & 11.61 & 11.12 & 3.52 & 27.33 \\
\hline $\begin{array}{l}\text { Income-to-poverty-threshold ratio- } \\
\text { Above } 185 \text { percent }\end{array}$ & 11.61 & 11.12 & 3.52 & 27.33 \\
\hline
\end{tabular}

See notes at end of table. 
Table B.4. Potential covariates and the percentage missing at spring 2005 (Year 1) analysisContinued

\begin{tabular}{|c|c|c|c|c|}
\hline Potential covariate & $\begin{array}{r}\text { Percent } \\
\text { missing } \\
\text { in combined- } \\
\text { program } \\
\text { sample }\end{array}$ & $\begin{array}{r}\text { Average } \\
\text { percent } \\
\text { missing } \\
\text { across } \\
\text { programs }\end{array}$ & $\begin{array}{r}\text { Minimum } \\
\text { missing } \\
\text { across } \\
\text { programs }\end{array}$ & $\begin{array}{r}\text { Maximum } \\
\text { missing } \\
\text { across } \\
\text { programs }\end{array}$ \\
\hline Full-time employment & 9.13 & 8.73 & 2.72 & 22.60 \\
\hline Part-time employment & 9.13 & 8.73 & 2.72 & 22.60 \\
\hline \multicolumn{5}{|l|}{ Parental scales } \\
\hline APQ-Poor Monitoring and Supervision Subscale & 18.94 & 18.15 & 8.32 & 39.78 \\
\hline APQ-Positive Parenting Subscale & 18.97 & 18.18 & 8.48 & 39.51 \\
\hline Child-Centered Social Control & 18.87 & 18.08 & 8.32 & 39.51 \\
\hline Confusion, Hubbub, and Order & 19.24 & 18.45 & 8.80 & 39.78 \\
\hline Community Resources & 19.52 & 18.70 & 9.44 & 40.60 \\
\hline Community Risk & 20.99 & 20.19 & 9.60 & 43.30 \\
\hline Parent and Teacher Involvement & 21.10 & 20.41 & 11.36 & 42.49 \\
\hline \multicolumn{5}{|l|}{ Child scales } \\
\hline Altruistic Behavior & 18.90 & 18.08 & 8.48 & 39.51 \\
\hline Positive Social Behavior & 18.69 & 17.88 & 8.32 & 39.11 \\
\hline Problem Behavior & 19.29 & 18.52 & 8.80 & 39.24 \\
\hline \multicolumn{5}{|l|}{ Teacher-reported } \\
\hline \multicolumn{5}{|l|}{ Child scales } \\
\hline Academic Competence and Motivation & 11.33 & 10.95 & 5.28 & 19.76 \\
\hline ADHD-Related Behavior & 11.33 & 10.96 & 5.12 & 19.22 \\
\hline Altruistic Behavior & 12.55 & 12.13 & 6.24 & 21.52 \\
\hline Positive Social Behavior & 11.49 & 11.12 & 5.60 & 19.49 \\
\hline Problem Behavior & 11.33 & 10.96 & 5.12 & 19.22 \\
\hline \multicolumn{5}{|l|}{ Parent involvement } \\
\hline Parent-teacher involvement & 20.74 & 20.24 & 10.65 & 30.31 \\
\hline \multicolumn{5}{|l|}{ Teacher characteristics (for school outcomes only) } \\
\hline Teacher-Female & 0.00 & 0.00 & 0.00 & 0.00 \\
\hline Teacher_Black (non-Hispanic) & 0.24 & 0.27 & 0.00 & 0.97 \\
\hline Teacher-Hispanic & 0.24 & 0.27 & 0.00 & 0.97 \\
\hline Teacher-Other race & 0.24 & 0.27 & 0.00 & 0.97 \\
\hline Total experience & 0.00 & 0.00 & 0.00 & 0.00 \\
\hline Experience at current school & 0.12 & 0.15 & 0.00 & 1.05 \\
\hline Regular certification & 0.00 & 0.00 & 0.00 & 0.00 \\
\hline Other certification & 0.00 & 0.00 & 0.00 & 0.00 \\
\hline Teacher's highest degree-Bachelor's degree & 0.00 & 0.00 & 0.00 & 0.00 \\
\hline $\begin{array}{l}\text { NOTE: Abbreviations are } \\
\text { ADHD: Attention deficit hyperactivity disorder } \\
\text { APQ: Alabama Parenting Questionnaire } \\
\text { SOURCE: The Social and Character Development (SACD) }\end{array}$ & & & & \\
\hline
\end{tabular}




\section{Handling of Missing Values}

Before selecting covariates for Year 1 (spring 2005) impact analyses, the missing values of potential covariates and outcomes were considered. Tables B.3 and B.4 list the percentages of observations with missing values for each spring 2005 outcome measure and each potential covariate. The analysis to select covariates used a base for the child-related outcomes of all children with either a Child Report, a Primary Caregiver Report, or a Teacher Report on Student at the first follow-up (and excluded study non-consenters). This universe of children who had data on at least one of the three child-level reports (the Child Report, the Primary Caregiver Report, or the Teacher Report on Student) included 4,351 observations and varied from 460 to 739 observations across programs. The base for the school outcomes included 850 third-, fourth-, and fifth-grade teachers with Teacher Report on Classroom and School data and varied from 95 to 174 teachers across programs. Outcome measures were constructed if about 80 percent or more of pertinent scale items were completed. ${ }^{8}$ Thus, missing outcomes pertain to two types of cases in the sample universe: (1) survey respondents who completed fewer than 80 percent of scale items, and (2) survey non-respondents.

For the analysis, missing values for covariates were imputed using mean cell imputation procedures, but missing values were not imputed for outcome measures. The following steps were used for the covariate imputations in the child-level data:

- For covariates unlikely to vary over time, such as demographic characteristics, data that became available during follow-up data collection were used before conducting the cell mean imputations. Except for baseline values of the scales, these measures included all child and primary caregiver characteristics, such as the race/ethnicity of a child, the educational attainment of the primary caregiver, and whether the household income was within a certain range of income. Thus, if fall 2004 data on a covariate that was unlikely to vary over time were unavailable, spring 2005 data were used when available.

- Imputation cells were defined on the basis of school, gender, and race/ethnicity. Sample members were allocated to cells defined by school, gender, and, race/ethnicity (White non-Hispanic, Black non-Hispanic, Hispanic, and other). Excluded from the imputation analysis were cases with missing values for the variables used to define cells for the cell mean imputations, such as cases for which a child's gender or race/ethnicity was unknown.

- Imputations for cases with missing covariates in a particular cell were obtained using mean values for cases with nonmissing covariate values in the same cell. Where cases with missing covariates also had missing values for the data that defined the cells (such as school, race/ethnicity, or sex), the imputations were performed within broader cells defined by the nonmissing characteristics. In addition, if a cell size was below five, the definition of the cell was sequentially broadened until a cell size of at least five was obtained.

- Race/ethnicity was imputed using school and gender. After imputations on other covariates were performed, cases with missing values for race/ethnicity were imputed using mean cell imputations, where cells were defined by school and gender.

For teacher covariates used in estimating impacts on Teacher Report on Classroom and School school-level outcomes, a similar procedure was followed:

- For all covariates, the fall 2004 data were used if available.

- If fall 2004 data were missing, the spring 2005 data were used.

\footnotetext{
${ }^{8}$ The specific cutoff that was used for the construction of outcome measures depended on the number of scale items. For example, a cutoff of 75 percent (3 out of 4) was used when the outcome was based on four scale items.
} 
- If a value for the covariate was still missing, imputation was based on the mean value for all teachers in the school.

Filling in missing values of baseline data had two closely related benefits. First, the selection of covariates for the Year 1 impact analyses could be based on as many records as possible. After missing baseline covariate data were filled in through the use of follow-up data or cell mean imputation, the covariates used in the benchmark models were selected through a stepwise procedure that used Year 1 outcomes as dependent variables (see Stepwise Regression Procedures later in this appendix). Second, and similarly, after covariates were selected, the estimation procedure used to generate impact results could be based on as many records as possible. In this way, estimating the results was not hampered by missing initial data.

Filling in missing values for baseline data for the Year 2 and Year 3 impact analyses. After the benchmark model covariates were selected and the Year 1 analyses were conducted, additional follow-up data became available for the 2005-06 and 2006-07 school years. Data from these follow-up periods were used to fill in missing baseline covariate data for new students who entered the study schools after the spring 2005 data collection and for students who had been in the study schools from the start of the study (thus avoiding the need to use cell mean imputation). Tables B.5 and B.6 show the percentages of observations with missing values for each spring 2006 (Year 2) outcome measure and each potential covariate, and tables B.7 and B.8 show the percentages of observations with missing values for each spring 2007 (Year 3) outcome measure and each potential covariate.

The procedure to fill in missing data for the covariates used in the Year 2 (spring 2006) and the Year 3 (spring 2007) regression analyses was similar to that used for the Year 1 (spring 2005) analyses. If fall 2004 initial data were available, then those data were used. If not, then spring 2005 data on covariates, such as the race/ethnicity of the child and the educational attainment of the primary caregiver, were used if possible (that is, if the spring 2005 data item was available and if the data item was unlikely to vary over time). If fall 2004 data and spring 2005 data were unavailable, then fall 2005 data were used to fill in the baseline data. Next, spring 2006 data were used. Finally, spring 2007 data were used. If the information was unavailable from all these data collection efforts, or if the data item was likely to vary over time (as is the case with pretest data), the cell mean imputation process was used to fill in the missing data. 
Table B.5. Child and school outcomes used for covariate selection and the percentage missing at spring 2006 (Year 2) analysis

\begin{tabular}{lrrrr}
\hline & $\begin{array}{r}\text { Percent } \\
\text { missing } \\
\text { in combined- } \\
\text { program } \\
\text { sample }\end{array}$ & $\begin{array}{r}\text { Average } \\
\text { percent } \\
\text { missing } \\
\text { across } \\
\text { programs }\end{array}$ & $\begin{array}{r}\text { Minimum } \\
\text { missing } \\
\text { across } \\
\text { programs }\end{array}$ & $\begin{array}{r}\text { Maximum } \\
\text { missing } \\
\text { across } \\
\text { programs }\end{array}$ \\
Outcome & & & & \\
\hline Child-reported & 5.48 & 5.43 & 1.17 & 9.22 \\
Positive School Orientation & 5.10 & 5.06 & 0.73 & 8.32 \\
Engagement with Learning & 5.50 & 5.43 & 1.03 & 8.15 \\
Student Afraid at School & 5.50 & 5.44 & 0.73 & 9.04 \\
Negative School Orientation & 5.64 & 5.59 & 1.17 & 9.04 \\
Self-Efficacy for Peer Interactions & 5.85 & 5.77 & 1.32 & 9.38 \\
Normative Beliefs About Aggression & 5.74 & 5.66 & 0.88 & 9.65 \\
Empathy & 6.04 & 5.95 & 1.32 & 9.65 \\
Altruistic Behavior & 6.02 & 5.93 & 1.32 & 9.51 \\
Problem Behavior & 6.09 & 6.00 & 1.47 & 9.65 \\
Victimization at School & & & & \\
Primary caregiver-reported & & & & \\
Positive Social Behavior & 25.47 & 25.24 & 13.49 & 38.18 \\
Problem Behavior & 25.47 & 25.24 & 13.49 & 38.18 \\
Altruistic Behavior & 26.43 & 26.20 & 15.69 & 39.27 \\
Teacher-reported & & & & \\
Positive Social Behavior & & & & \\
Problem Behavior & 0.87 & 0.82 & 0.00 & 1.63 \\
ADHD-Related Behavior & 0.89 & 0.85 & 0.00 & 1.63 \\
Altruistic Behavior & 0.84 & 0.80 & 0.00 & 1.63 \\
Academic Competence and Motivation & 2.29 & 2.18 & 0.16 & 4.51 \\
Student Support for Teachers & 1.03 & 0.95 & 0.00 & 2.17 \\
Feelings of Safety & 0.36 & 0.33 & 0.00 & 0.89 \\
\hline
\end{tabular}

NOTE: ADHD is the abbreviation for attention deficit hyperactivity disorder. SOURCE: The Social and Character Development (SACD) Research Program. 
Table B.6. Potential covariates and the percentage missing at spring 2006 (Year 2) analysis

\begin{tabular}{|c|c|c|c|c|}
\hline Potential covariate & $\begin{array}{r}\text { Percent } \\
\text { missing } \\
\text { in combined- } \\
\text { program } \\
\text { sample }\end{array}$ & $\begin{array}{r}\text { Average } \\
\text { percent } \\
\text { missing } \\
\text { across } \\
\text { programs } \\
\end{array}$ & $\begin{array}{r}\text { Minimum } \\
\text { missing } \\
\text { across } \\
\text { programs }\end{array}$ & $\begin{array}{r}\text { Maximum } \\
\text { missing } \\
\text { across } \\
\text { programs } \\
\end{array}$ \\
\hline \multicolumn{5}{|l|}{ Child-reported } \\
\hline Female & 0.47 & 0.48 & 0.00 & 0.90 \\
\hline White (non-Hispanic) & 6.53 & 6.26 & 2.20 & 15.35 \\
\hline Black (non-Hispanic) & 6.53 & 6.26 & 2.20 & 15.35 \\
\hline Hispanic & 6.53 & 6.26 & 2.20 & 15.35 \\
\hline Other ethnicity & 6.53 & 6.26 & 2.20 & 15.35 \\
\hline Age (in years) & 0.23 & 0.24 & 0.00 & 0.54 \\
\hline \multicolumn{5}{|l|}{ Scales } \\
\hline Student Afraid at School & 27.57 & 27.54 & 23.61 & 34.36 \\
\hline Altruistic Behavior & 27.76 & 27.74 & 23.90 & 34.72 \\
\hline Empathy & 27.79 & 27.76 & 24.05 & 34.72 \\
\hline Engagement with Learning & 27.55 & 27.53 & 23.31 & 34.54 \\
\hline Negative School Orientation & 27.62 & 27.59 & 23.76 & 34.36 \\
\hline Normative Beliefs About Aggression & 27.65 & 27.62 & 23.90 & 34.36 \\
\hline Positive School Orientation & 27.48 & 27.46 & 23.46 & 34.36 \\
\hline Problem Behavior & 27.81 & 27.78 & 24.05 & 34.72 \\
\hline Self-Efficacy for Peer Interactions & 27.69 & 27.66 & 24.05 & 34.36 \\
\hline Victimization at School & 27.88 & 27.85 & 24.05 & 34.90 \\
\hline \multicolumn{5}{|l|}{ Primary caregiver-reported } \\
\hline Age (in years) & 6.84 & 6.53 & 2.64 & 16.30 \\
\hline Completed high school education or equivalent & 6.46 & 6.18 & 2.05 & 15.49 \\
\hline Some college & 6.46 & 6.18 & 2.05 & 15.49 \\
\hline Bachelor's or higher degree & 6.46 & 6.18 & 2.05 & 15.49 \\
\hline $\begin{array}{l}\text { Highest level of education in household- } \\
\text { Completed high school or equivalent }\end{array}$ & 6.44 & 6.17 & 2.05 & 15.35 \\
\hline $\begin{array}{l}\text { Highest level of education in household- } \\
\text { Some college }\end{array}$ & 6.44 & 6.17 & 2.05 & 15.35 \\
\hline $\begin{array}{l}\text { Highest level of education in household- } \\
\text { Bachelor's or higher degree }\end{array}$ & 6.44 & 6.17 & 2.05 & 15.35 \\
\hline Mother present in home life & 6.44 & 6.16 & 2.05 & 15.49 \\
\hline Mother and father present & 6.44 & 6.16 & 2.05 & 15.49 \\
\hline $\begin{array}{l}\text { Respondent someone other than mother } \\
\text { or father }\end{array}$ & 6.48 & 6.20 & 2.05 & 15.76 \\
\hline Number of people in household & 6.55 & 6.29 & 2.35 & 15.49 \\
\hline Household income: $\$ 20,000$ to $\$ 40,000$ & 8.12 & 7.77 & 2.79 & 19.43 \\
\hline Household income: $\$ 40,000$ to $\$ 60,000$ & 8.12 & 7.77 & 2.79 & 19.43 \\
\hline Household income: More than $\$ 60,000$ & 8.12 & 7.77 & 2.79 & 19.43 \\
\hline $\begin{array}{l}\text { Income-to-poverty-threshold ratio- } \\
\text { Below } 135 \text { percent }\end{array}$ & 8.22 & 7.86 & 3.08 & 19.57 \\
\hline $\begin{array}{l}\text { Income-to-poverty-threshold ratio- } \\
\text { Between } 135 \text { and } 185 \text { percent }\end{array}$ & 8.22 & 7.86 & 3.08 & 19.57 \\
\hline
\end{tabular}

See notes at end of table. 
Appendix B: Technical Notes

Table B.6. Potential covariates and the percentage missing at spring 2006 (Year 2) analysisContinued

\begin{tabular}{|c|c|c|c|c|}
\hline Potential covariate & $\begin{array}{c}\text { Percent } \\
\text { missing } \\
\text { in combined- } \\
\text { program } \\
\text { sample } \\
\end{array}$ & $\begin{array}{r}\text { Average } \\
\text { percent } \\
\text { missing } \\
\text { across } \\
\text { programs }\end{array}$ & $\begin{array}{r}\text { Minimum } \\
\text { missing } \\
\text { across } \\
\text { programs }\end{array}$ & $\begin{array}{r}\text { Maximum } \\
\text { missing } \\
\text { across } \\
\text { programs }\end{array}$ \\
\hline \multicolumn{5}{|l|}{ Income-to-poverty-threshold ratio- } \\
\hline Above 185 percent & 8.22 & 7.86 & 3.08 & 19.57 \\
\hline Full-time employment & 6.55 & 6.27 & 2.05 & 15.76 \\
\hline Part-time employment & 6.55 & 6.27 & 2.05 & 15.76 \\
\hline \multicolumn{5}{|l|}{ Parental scales } \\
\hline APQ_Poor Monitoring and Supervision & & & & \\
\hline Subscale & 31.60 & 30.99 & 23.02 & 50.68 \\
\hline APQ_Positive Parenting Subscale & 31.65 & 31.04 & 23.17 & 50.41 \\
\hline Child-Centered Social Control & 31.44 & 30.85 & 22.73 & 50.14 \\
\hline Confusion, Hubbub, and Order & 31.84 & 31.24 & 23.46 & 50.27 \\
\hline Community Resources & 31.93 & 31.31 & 24.00 & 50.68 \\
\hline Community Risk & 32.89 & 32.27 & 23.90 & 52.58 \\
\hline Parent and teacher Involvement & 33.47 & 32.92 & 25.37 & 52.85 \\
\hline \multicolumn{5}{|l|}{ Child scales } \\
\hline Altruistic Behavior & 31.53 & 30.91 & 23.17 & 50.54 \\
\hline Positive Social Behavior & 31.32 & 30.70 & 23.02 & 50.00 \\
\hline Problem Behavior & 31.91 & 31.30 & 23.61 & 50.41 \\
\hline \multicolumn{5}{|l|}{ Teacher-reported } \\
\hline \multicolumn{5}{|l|}{ Child scales } \\
\hline Academic Competence and Motivation & 25.63 & 25.39 & 19.33 & 34.54 \\
\hline ADHD-Related Behavior & 25.61 & 25.38 & 19.11 & 34.72 \\
\hline Altruistic Behavior & 26.66 & 26.40 & 19.11 & 37.43 \\
\hline Positive Social Behavior & 25.77 & 25.53 & 19.11 & 34.72 \\
\hline Problem Behavior & 25.61 & 25.38 & 19.11 & 34.72 \\
\hline \multicolumn{5}{|l|}{ Parent involvement } \\
\hline Parent and teacher involvement & 33.47 & 33.06 & 22.44 & 43.34 \\
\hline \multicolumn{5}{|l|}{$\begin{array}{l}\text { Teacher characteristics (for school } \\
\text { outcomes only) }\end{array}$} \\
\hline Teacher_Female & 0.00 & 0.00 & 0.00 & 0.00 \\
\hline Teacher-Black (non-Hispanic) & 0.48 & 0.41 & 0.00 & 1.16 \\
\hline Teacher-Hispanic & 0.48 & 0.41 & 0.00 & 1.16 \\
\hline Teacher_Other race & 0.48 & 0.41 & 0.00 & 1.16 \\
\hline Total experience & 0.24 & 0.30 & 0.00 & 1.22 \\
\hline Experience at current school & 0.24 & 0.30 & 0.00 & 1.22 \\
\hline Regular certification & 0.00 & 0.00 & 0.00 & 0.00 \\
\hline Other certification & 0.00 & 0.00 & 0.00 & 0.00 \\
\hline $\begin{array}{l}\text { Teacher's highest degree- } \\
\text { Bachelor's degree }\end{array}$ & 0.00 & 0.00 & 0.00 & 0.00 \\
\hline
\end{tabular}

NOTE: Abbreviations are

ADHD: Attention deficit hyperactivity disorder

APQ: Alabama Parenting Questionnaire

SOURCE: The Social and Character Development (SACD) Research Program. 
Table B.7. Child and school outcomes used for covariate selection and the percentage missing at spring 2007 (Year 3) analysis

\begin{tabular}{lrrrr}
\hline & $\begin{array}{r}\text { Percent } \\
\text { missing } \\
\text { in combined- } \\
\text { program } \\
\text { sample }\end{array}$ & $\begin{array}{r}\text { Average } \\
\text { percent } \\
\text { missing } \\
\text { across } \\
\text { programs }\end{array}$ & $\begin{array}{r}\text { Minimum } \\
\text { missing } \\
\text { across } \\
\text { programs }\end{array}$ & $\begin{array}{r}\text { Maximum } \\
\text { missing } \\
\text { across } \\
\text { programs }\end{array}$ \\
Outcome & & & & \\
\hline Child-reported & 4.33 & 4.34 & 0.44 & 9.79 \\
Positive School Orientation & 4.07 & 4.06 & 0.74 & 9.79 \\
Engagement with Learning & 4.43 & 4.44 & 0.30 & 9.95 \\
Student Afraid at School & 4.33 & 4.35 & 0.74 & 9.95 \\
Negative School Orientation & 4.41 & 4.42 & 0.59 & 9.79 \\
Self-Efficacy for Peer Interactions & 4.36 & 4.35 & 0.74 & 9.95 \\
Normative Beliefs About Aggression & 4.41 & 4.41 & 0.44 & 9.79 \\
Empathy & 4.53 & 4.53 & 0.74 & 9.79 \\
Altruistic Behavior & 4.62 & 4.63 & 0.44 & 9.79 \\
Problem Behavior & 4.65 & 4.64 & 0.89 & 9.95 \\
Victimization at School & & & & \\
Primary caregiver-reported & & & & \\
Positive Social Behavior & 31.28 & 31.04 & 16.89 & 48.10 \\
Problem Behavior & 31.25 & 31.02 & 16.89 & 47.96 \\
Altruistic Behavior & 32.22 & 31.98 & 18.07 & 49.56 \\
& & & & \\
Teacher-reported & & & & \\
Positive Social Behavior & 2.00 & 1.99 & 0.58 & 6.20 \\
Problem Behavior & 1.90 & 1.89 & 0.44 & 6.04 \\
ADHD-Related Behavior & 1.97 & 1.96 & 0.58 & 6.36 \\
Altruistic Behavior & 3.83 & 4.04 & 0.73 & 11.95 \\
Academic Competence and Motivation & 1.88 & 1.84 & 0.15 & 5.88 \\
Student Support for Teachers & 0.61 & 0.63 & 0.00 & 1.90 \\
Feelings of Safety & 0.85 & 0.83 & 0.00 & 2.40 \\
\hline NOTE: ADHD is the abbreviation for attention deficit hyperactivity disorder. & & & &
\end{tabular}

NOTE: ADHD is the abbreviation for attention deficit hyperactivity disorder.

SOURCE: The Social and Character Development (SACD) Research Program. 
Table B.8. Potential covariates and the percentage missing at spring 2007 (Year 3) analysis

\begin{tabular}{|c|c|c|c|c|}
\hline Potential covariate & $\begin{array}{c}\text { Percent } \\
\text { missing } \\
\text { in combined- } \\
\text { program } \\
\text { sample } \\
\end{array}$ & $\begin{array}{r}\text { Average } \\
\text { percent } \\
\text { missing } \\
\text { across } \\
\text { programs } \\
\end{array}$ & $\begin{array}{r}\text { Minimum } \\
\text { missing } \\
\text { across } \\
\text { programs }\end{array}$ & $\begin{array}{r}\text { Maximum } \\
\text { missing } \\
\text { across } \\
\text { programs } \\
\end{array}$ \\
\hline \multicolumn{5}{|l|}{ Child-reported } \\
\hline Female & 0.60 & 0.61 & 0.15 & 1.47 \\
\hline White (non-Hispanic) & 7.44 & 7.32 & 1.93 & 17.49 \\
\hline Black (non-Hispanic) & 7.44 & 7.32 & 1.93 & 17.49 \\
\hline Hispanic & 7.44 & 7.32 & 1.93 & 17.49 \\
\hline Other ethnicity & 7.44 & 7.32 & 1.93 & 17.49 \\
\hline Age (in years) & 12.91 & 13.14 & 6.81 & 19.85 \\
\hline \multicolumn{5}{|l|}{ Scales } \\
\hline Student Afraid at School & 34.48 & 34.68 & 27.41 & 43.55 \\
\hline Altruistic Behavior & 34.67 & 34.88 & 27.26 & 43.74 \\
\hline Empathy & 34.70 & 34.90 & 27.41 & 43.74 \\
\hline Engagement with Learning & 34.43 & 34.64 & 27.11 & 43.74 \\
\hline Negative School Orientation & 34.53 & 34.72 & 27.41 & 43.55 \\
\hline Normative Beliefs About Aggression & 34.58 & 34.78 & 27.26 & 43.55 \\
\hline Positive School Orientation & 34.41 & 34.61 & 27.11 & 43.55 \\
\hline Problem Behavior & 34.70 & 34.90 & 27.41 & 43.74 \\
\hline Self-Efficacy for Peer Interactions & 34.63 & 34.83 & 27.41 & 43.55 \\
\hline Victimization at School & 34.79 & 34.99 & 27.41 & 43.93 \\
\hline \multicolumn{5}{|l|}{ Primary caregiver-reported } \\
\hline Age (in years) & 7.95 & 7.82 & 1.93 & 18.51 \\
\hline Completed high school education or equivalent & 7.39 & 7.27 & 1.93 & 17.64 \\
\hline Some college & 7.39 & 7.27 & 1.93 & 17.64 \\
\hline Bachelor's or higher degree & 7.39 & 7.27 & 1.93 & 17.64 \\
\hline $\begin{array}{l}\text { Highest level of education in household- } \\
\text { Completed high school or equivalent }\end{array}$ & 7.44 & 7.31 & 2.07 & 17.49 \\
\hline $\begin{array}{l}\text { Highest level of education in household- } \\
\text { Some college }\end{array}$ & 7.44 & 7.31 & 2.07 & 17.49 \\
\hline $\begin{array}{l}\text { Highest level of education in household- } \\
\text { Bachelor's or higher degree }\end{array}$ & 7.44 & 7.31 & 2.07 & 17.49 \\
\hline Mother present in home life & 7.37 & 7.24 & 1.93 & 17.64 \\
\hline Mother and father present & 7.37 & 7.24 & 1.93 & 17.64 \\
\hline $\begin{array}{l}\text { Respondent someone other than mother } \\
\text { or father }\end{array}$ & 7.44 & 7.31 & 1.93 & 17.64 \\
\hline Number of people in household & 7.56 & 7.45 & 2.07 & 17.49 \\
\hline Household income: $\$ 20,000$ to $\$ 40,000$ & 9.03 & 8.87 & 2.67 & 21.28 \\
\hline Household income: $\$ 40,000$ to $\$ 60,000$ & 9.03 & 8.87 & 2.67 & 21.28 \\
\hline Household income: More than $\$ 60,000$ & 9.03 & 8.87 & 2.67 & 21.28 \\
\hline $\begin{array}{l}\text { Income-to-poverty-threshold ratio- } \\
\text { Below } 135 \text { percent }\end{array}$ & 9.15 & 9.00 & 2.67 & 21.28 \\
\hline $\begin{array}{l}\text { Income-to-poverty-threshold ratio- } \\
\text { Between } 135 \text { and } 185 \text { percent }\end{array}$ & 9.15 & 9.00 & 2.67 & 21.28 \\
\hline $\begin{array}{l}\text { Income-to-poverty-threshold ratio- } \\
\text { Above } 185 \text { percent }\end{array}$ & 9.15 & 9.00 & 2.67 & 21.28 \\
\hline Full-time employment & 7.49 & 7.36 & 1.93 & 17.78 \\
\hline Part-time employment & 7.49 & 7.36 & 1.93 & 17.78 \\
\hline
\end{tabular}

See notes at end of table. 
Appendix B: Technical Notes

Table B.8. Potential covariates and the percentage missing at spring 2007 (Year 3) analysisContinued

\begin{tabular}{|c|c|c|c|c|}
\hline Potential covariate & $\begin{array}{r}\text { Percent } \\
\text { missing } \\
\text { in combined- } \\
\text { program } \\
\text { sample } \\
\end{array}$ & $\begin{array}{r}\text { Average } \\
\text { percent } \\
\text { missing } \\
\text { across } \\
\text { programs } \\
\end{array}$ & $\begin{array}{r}\text { Minimum } \\
\text { missing } \\
\text { across } \\
\text { programs }\end{array}$ & $\begin{array}{r}\text { Maximum } \\
\text { missing across } \\
\text { programs } \\
\end{array}$ \\
\hline \multicolumn{5}{|l|}{ Parental scales } \\
\hline $\begin{array}{l}\text { APQ_Poor Monitoring and Supervision } \\
\text { Subscale }\end{array}$ & 38.02 & 37.73 & 26.67 & 55.69 \\
\hline APQ_Positive Parenting Subscale & 38.07 & 37.79 & 26.81 & 55.54 \\
\hline Child-Centered Social Control & 37.92 & 37.65 & 26.37 & 55.25 \\
\hline Confusion, Hubbub, and Order & 38.29 & 38.01 & 27.11 & 55.25 \\
\hline Community Resources & 38.43 & 38.13 & 27.56 & 55.83 \\
\hline Community Risk & 39.25 & 38.94 & 27.41 & 57.73 \\
\hline Parent and Teacher Involvement & 39.66 & 39.45 & 28.59 & 57.43 \\
\hline \multicolumn{5}{|l|}{ Child scales } \\
\hline Altruistic Behavior & 37.92 & 37.62 & 26.81 & 55.69 \\
\hline Positive Social Behavior & 37.76 & 37.46 & 26.67 & 55.10 \\
\hline Problem Behavior & 38.31 & 38.03 & 27.26 & 55.25 \\
\hline \multicolumn{5}{|l|}{ Teacher-reported } \\
\hline \multicolumn{5}{|l|}{ Child scales } \\
\hline Academic Competence and Motivation & 32.65 & 32.67 & 24.89 & 42.77 \\
\hline ADHD-Related Behavior & 32.65 & 32.69 & 24.89 & 43.16 \\
\hline Altruistic Behavior & 33.57 & 33.58 & 25.93 & 45.47 \\
\hline Positive Social Behavior & 32.80 & 32.82 & 25.33 & 43.16 \\
\hline Problem Behavior & 32.65 & 32.69 & 24.89 & 43.16 \\
\hline \multicolumn{5}{|l|}{ Parent involvement } \\
\hline Parent and teacher involvement & 39.73 & 39.51 & 29.25 & 49.52 \\
\hline \multicolumn{5}{|l|}{$\begin{array}{l}\text { Teacher characteristics (for school } \\
\text { outcomes only) }\end{array}$} \\
\hline Teacher-Female & 0.24 & 0.23 & 0.00 & 1.60 \\
\hline Teacher-Black (non-Hispanic) & 0.49 & 0.45 & 0.00 & 1.60 \\
\hline Teacher-Hispanic & 0.49 & 0.45 & 0.00 & 1.60 \\
\hline Teacher-Other race & 0.49 & 0.45 & 0.00 & 1.60 \\
\hline Total experience & 0.37 & 0.32 & 0.00 & 1.60 \\
\hline Experience at current school & 0.49 & 0.45 & 0.00 & 1.60 \\
\hline Regular certification & 0.00 & 0.00 & 0.00 & 0.00 \\
\hline Other certification & 0.00 & 0.00 & 0.00 & 0.00 \\
\hline $\begin{array}{l}\text { Teacher's highest degree- } \\
\text { Bachelor's degree }\end{array}$ & 0.24 & 0.23 & 0.00 & 1.60 \\
\hline
\end{tabular}

NOTE: Abbreviations are

ADHD: Attention deficit hyperactivity disorder

APQ: Alabama Parenting Questionnaire

SOURCE: The Social and Character Development (SACD) Research Program. 


\section{Stepwise Regression Procedures}

For the selection of covariates to be used in the benchmark impact models, stepwise regression methods were used to identify potential covariates with significant explanatory power. ${ }^{9}$ The treatment binary variable (measuring estimated impacts); program-specific binary variables (for the pooled models); and the age, gender, and race/ethnicity of the child were included (these covariates were separately tested as to whether they would be selected under the implementation rules). At each step of the stepwise procedure, the variable with the smallest $p$-value below a preset threshold level was included in the model while variables already selected were evaluated to see if any could be removed; the variable with a $p$-value greater than the critical $p$ value of 0.32 and whose removal would least lower the adjusted $R^{2}$ value was removed. The critical $p$-value was set at 0.32 to correspond to a $t$-statistic of 1 , which is the smallest value of the $t$-statistic at which the addition of a variable in a model increases the adjusted $R^{2}$ value. ${ }^{10}$

\section{Rules for Selecting Covariates Using Year 1 Data}

The rules for selecting covariates had two key features: (1) they identified covariates that had a treatmentcontrol group difference at baseline and that showed some explanatory power in the regression models, and (2) they identified covariates that had no treatment-control group difference at baseline and that had substantial explanatory power in the regression models for a majority of outcomes. Specifically, based on regressions using spring 2005 (Year 1) outcomes, a unique set of covariates by reporter and program were selected using sequential rules. First, a variable was included that had a statistically significant treatmentcontrol group baseline difference in the variable, and that was selected in the final stepwise model for at least one of the outcomes for a given reporter. Second, a variable with no treatment-control group difference at baseline was included if it was selected by the stepwise regressions for about 60 percent or more of the outcomes. Third, covariates were included to increase face validity. That is, variables that measured age, gender, race, and ethnicity of the child (or of the teacher for Teacher Report on Classroom and School outcomes) were included if they had not already been selected. Finally, for completeness, covariates were selected if they completed a set of categorical variables if one of the categories had been previously selected.

Tables B.9 through B.12 list the sets of covariates selected as a result of these rules. The covariates are listed separately for the combined-program analysis and the program-specific analyses. Table B.9 provides details for all child-reported outcomes, table B.10 provides details for all primary caregiver-reported outcomes, table B.11 does the same for all teacher-reported child outcomes, and table B.12 does so for all teacher-reported school outcomes.

Key features of the selected covariates are as follows:

- While baseline values of the scale under consideration were always selected as covariates, many scales were also selected across outcomes and reporters. For example, 7 of the 10 child-reported scales and 2 of the 6 teacher-reported scales were selected as covariates for child-reported outcomes in the combined-program sample (table B.9). Similarly, for primary caregiver-reported outcomes, 5 of the 10 child-reported scales, 2 of the 3 primary caregiver-reported scales, and 3 of the 6 teacher-reported scales were selected as covariates in the combined-program sample (table B.10). Finally, at the combined-program level, 3 of the 10 child-reported scales, all 3 primary caregiver-reported scales, and 4 of the 6 teacher-reported scales were selected as covariates for the teacher-reported child-level outcomes (table B.11).

\footnotetext{
9 The PROC REG procedure in SAS was used with the SELECTION option set to STEPWISE.

10 The stepwise procedure in SAS did not adjust for clustering effects. Thus, after selecting covariates from the stepwise procedure, these covariates were used to re-estimate the models in SAS PROC MIXED (which accounts for school-level clustering effects) and the final covariate sets were refined accordingly. Because of small clustering effects, however, these refinements were minor.
} 
- Most demographic and socioeconomic characteristics of the primary caregiver were selected as covariates for primary caregiver-reported outcomes. However, these measures were selected less consistently for the child- and teacher-reported outcomes.

- Considerable variation existed in the selected covariates across programs. This result likely reflected differences in study populations across programs.

- The baseline value of the outcome under consideration typically explained the highest proportion of variance in the outcome among all covariates. Using spring 2005 data, tables B.13 and B.14 compare the adjusted $R^{2}$ values of the models that included only the corresponding baseline pretest value with models that included the final selected set of covariates. Results are reported for models run at the child and school levels. The tables indicate that $R^{2}$ values did not increase substantially when covariates other than the pretests were included in the models. For Year 2 (spring 2006 data), tables B.15 and B.16 show similar information and results, and tables B.17 and B.18 show this information for Year 3 (spring 2007 data). 
Table B.9. Covariates selected for child-reported outcomes, for the combined-program sample and program-specific samples

\begin{tabular}{|c|c|c|c|c|c|c|c|c|}
\hline Potential covariate & $\begin{array}{l}\text { Combined- } \\
\text { program } \\
\text { sample }\end{array}$ & $\mathrm{ABC}$ & PA & SS & 4Rs & CSP & PATHS & LBW \\
\hline Total number of covariates & 26 & 11 & 20 & 11 & 10 & 17 & 18 & 6 \\
\hline \multicolumn{9}{|l|}{ Child-reported } \\
\hline Female & $\checkmark$ & $\checkmark$ & $\checkmark$ & $\checkmark$ & $\checkmark$ & $\checkmark$ & $\checkmark$ & $\checkmark$ \\
\hline Black (non-Hispanic) & $\checkmark$ & $\checkmark$ & $\checkmark$ & $\checkmark$ & $\checkmark$ & $\checkmark$ & $\checkmark$ & $\checkmark$ \\
\hline Hispanic & $\checkmark$ & $\checkmark$ & $\checkmark$ & $\checkmark$ & $\checkmark$ & $\checkmark$ & $\checkmark$ & $\checkmark$ \\
\hline Other ethnicity & $\checkmark$ & $\checkmark$ & $\checkmark$ & $\checkmark$ & $\checkmark$ & $\checkmark$ & $\checkmark$ & $\checkmark$ \\
\hline Age (in years) & $\checkmark$ & $\checkmark$ & $\checkmark$ & $\checkmark$ & $\checkmark$ & $\checkmark$ & $\checkmark$ & $\checkmark$ \\
\hline \multicolumn{9}{|l|}{ Scales } \\
\hline \multicolumn{9}{|l|}{ Student Afraid at School } \\
\hline Altruistic Behavior & $\checkmark$ & $\checkmark$ & $\checkmark$ & & & $\checkmark$ & & \\
\hline Empathy & $\checkmark$ & & & & & & & \\
\hline Engagement with Learning & $\checkmark$ & & & & & $\checkmark$ & & \\
\hline Negative School Orientation & $\checkmark$ & $\checkmark$ & & & & $\checkmark$ & & \\
\hline Normative Beliefs About Aggression & & & $\checkmark$ & & $\checkmark$ & & & \\
\hline Positive School Orientation & $\checkmark$ & & & $\checkmark$ & & & & \\
\hline Problem Behavior & & & $\checkmark$ & & & & & \\
\hline Self-Efficacy for Peer Interactions & $\checkmark$ & & & & & & $\checkmark$ & \\
\hline Victimization at School & $\checkmark$ & & $\checkmark$ & & & $\checkmark$ & & \\
\hline \multicolumn{9}{|l|}{ Primary caregiver-reported } \\
\hline $\begin{array}{l}\text { Completed high school } \\
\text { education or equivalent }\end{array}$ & $\checkmark$ & & $\checkmark$ & $\checkmark$ & & $\checkmark$ & & \\
\hline Some college & $\checkmark$ & & $\checkmark$ & $\checkmark$ & & $\checkmark$ & & \\
\hline Bachelor's or higher degree & $\checkmark$ & & $\checkmark$ & $\checkmark$ & & $\checkmark$ & & \\
\hline $\begin{array}{l}\text { Highest level of education in household- } \\
\text { Completed high school or equivalent }\end{array}$ & $\checkmark$ & & $\checkmark$ & & & $\checkmark$ & $\checkmark$ & \\
\hline $\begin{array}{l}\text { Highest level of education in household- } \\
\text { Some college }\end{array}$ & $\checkmark$ & & $\checkmark$ & & & $\checkmark$ & $\checkmark$ & \\
\hline $\begin{array}{l}\text { Highest level of education in household- } \\
\text { Bachelor's or higher degree }\end{array}$ & $\checkmark$ & & $\checkmark$ & & & $\checkmark$ & $\mathrm{v}$ & \\
\hline \multicolumn{9}{|l|}{ Mother present in home life } \\
\hline Mother and father present & $\checkmark$ & & & & & & & \\
\hline $\begin{array}{l}\text { Respondent someone other than mother } \\
\text { or father }\end{array}$ & $\checkmark$ & & & & & & & \\
\hline Number of people in household & $\checkmark$ & & $\checkmark$ & & $\checkmark$ & & & \\
\hline Household income: $\$ 20,000$ to $\$ 40,000$ & $\checkmark$ & & & & & & $\checkmark$ & \\
\hline Household income: $\$ 40,000$ to $\$ 60,000$ & $\checkmark$ & & & & & & $\checkmark$ & \\
\hline Household income: More than $\$ 60,000$ & $\checkmark$ & & & & & & $\checkmark$ & \\
\hline
\end{tabular}


Appendix B: Technical Notes

Table B.9. Covariates selected for child-reported outcomes, for the combined-program sample and program-specific samples-Continued

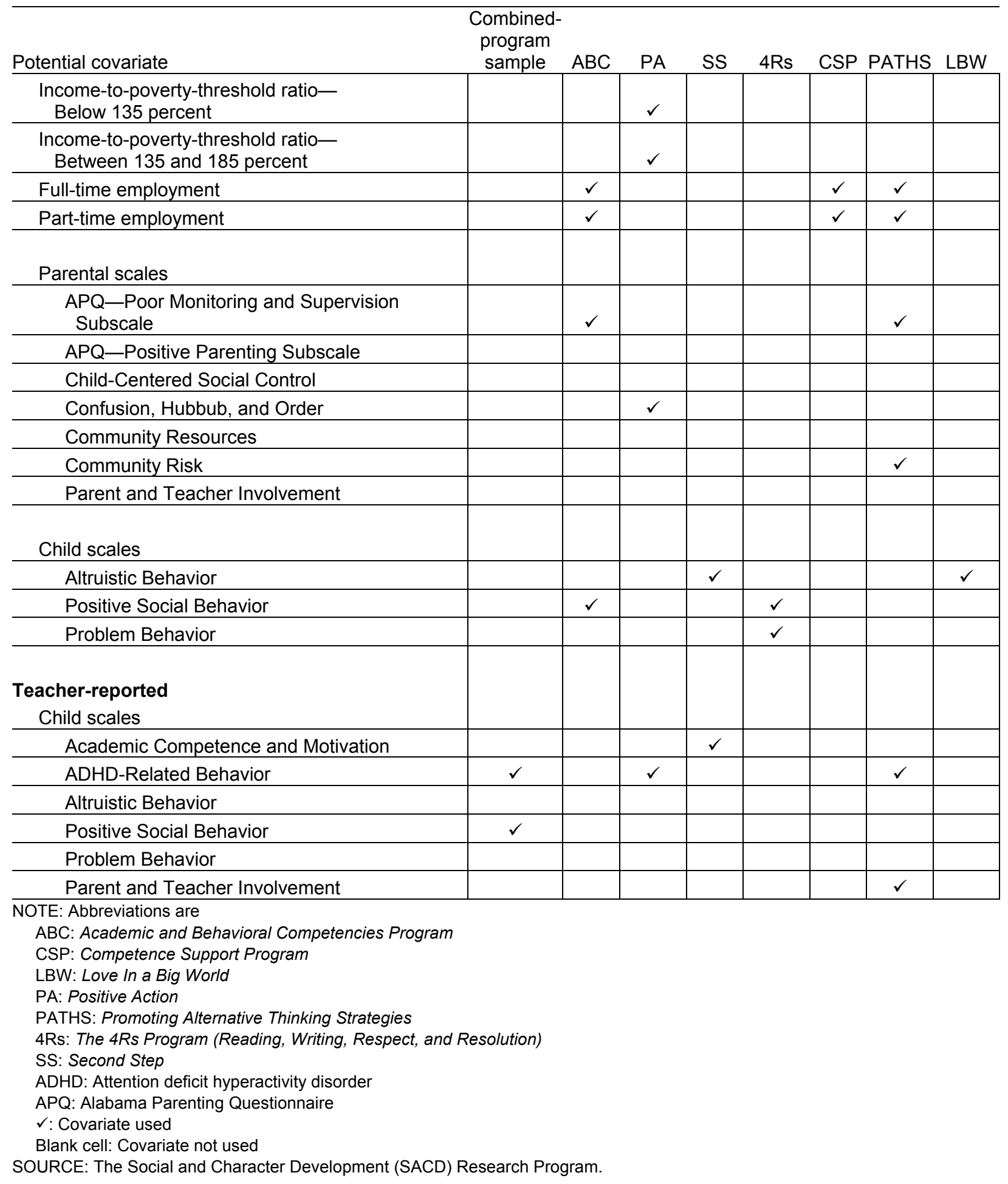


Table B.10. Covariates selected for primary caregiver-reported child outcomes, for the combined-program and program-specific samples

\begin{tabular}{|c|c|c|c|c|c|c|c|c|}
\hline Potential covariate & $\begin{array}{l}\text { Combined- } \\
\text { program } \\
\text { sample }\end{array}$ & $A B C$ & PA & SS & 4Rs & CSP & PATHS & LBW \\
\hline Total number & 35 & 13 & 26 & 28 & 26 & 24 & 27 & 25 \\
\hline \multicolumn{9}{|l|}{ Child-reported } \\
\hline Female & $\checkmark$ & $\checkmark$ & $\checkmark$ & $\checkmark$ & $\checkmark$ & $\checkmark$ & $\checkmark$ & $\checkmark$ \\
\hline Black (non-Hispanic) & $\checkmark$ & $\checkmark$ & $\checkmark$ & $\checkmark$ & $\checkmark$ & $\checkmark$ & $\checkmark$ & $\checkmark$ \\
\hline Hispanic & $\checkmark$ & $\checkmark$ & $\checkmark$ & $\checkmark$ & $\checkmark$ & $\checkmark$ & $\checkmark$ & $\checkmark$ \\
\hline Other ethnicity & $\checkmark$ & $\checkmark$ & $\checkmark$ & $\checkmark$ & $\checkmark$ & $\checkmark$ & $\checkmark$ & $\checkmark$ \\
\hline Age (in years) & $\checkmark$ & $\checkmark$ & $\checkmark$ & $\checkmark$ & $\checkmark$ & $\checkmark$ & $\checkmark$ & $\checkmark$ \\
\hline $\begin{array}{l}\text { Scales } \\
\quad \text { Student Afraid at School }\end{array}$ & & & & $\checkmark$ & $\checkmark$ & & & \\
\hline Altruistic Behavior & & & & & & $\checkmark$ & & \\
\hline Empathy & & & & $\checkmark$ & $\checkmark$ & & & $\checkmark$ \\
\hline Engagement with Learning & $\checkmark$ & & $\checkmark$ & & & & & \\
\hline Negative School Orientation & $\checkmark$ & & & $\checkmark$ & $\checkmark$ & $\checkmark$ & $\checkmark$ & $\checkmark$ \\
\hline Normative Beliefs About Aggression & $\checkmark$ & & $\checkmark$ & $\checkmark$ & & $\checkmark$ & & \\
\hline Positive School Orientation & $\checkmark$ & & & $\checkmark$ & & & & \\
\hline Problem Behavior & & & $\checkmark$ & & $\checkmark$ & & $\checkmark$ & \\
\hline Self-Efficacy for Peer Interactions & $\checkmark$ & $\checkmark$ & & & & $\checkmark$ & $\checkmark$ & $\checkmark$ \\
\hline Victimization at School & & & $\checkmark$ & & & & & $\checkmark$ \\
\hline $\begin{array}{l}\text { Primary caregiver-reported } \\
\text { Age (in years) }\end{array}$ & & $\checkmark$ & $\checkmark$ & & $\checkmark$ & & & $\checkmark$ \\
\hline Completed high school education or equivalent & $\checkmark$ & & $\checkmark$ & $\checkmark$ & $\checkmark$ & $\checkmark$ & & \\
\hline Some college & $\checkmark$ & & $\checkmark$ & $\checkmark$ & $\checkmark$ & $\checkmark$ & & \\
\hline Bachelor's or higher degree & $\checkmark$ & & $\checkmark$ & $\checkmark$ & $\checkmark$ & $\checkmark$ & & \\
\hline $\begin{array}{l}\text { Highest level of education in household- } \\
\text { Completed high school or equivalent }\end{array}$ & $\checkmark$ & & & $\checkmark$ & & $\checkmark$ & $\checkmark$ & $\checkmark$ \\
\hline $\begin{array}{l}\text { Highest level of education in household- } \\
\text { Some college }\end{array}$ & $\checkmark$ & & & $\checkmark$ & & $\checkmark$ & $\checkmark$ & $\checkmark$ \\
\hline $\begin{array}{l}\text { Highest level of education in household- } \\
\text { Bachelor's or higher degree }\end{array}$ & $\checkmark$ & & & $\checkmark$ & & $\checkmark$ & $\checkmark$ & $\checkmark$ \\
\hline Mother present in home life & $\checkmark$ & $\checkmark$ & & $\checkmark$ & & & $\checkmark$ & \\
\hline Mother and father present & $\checkmark$ & $\checkmark$ & $\checkmark$ & & & $\checkmark$ & $\checkmark$ & \\
\hline $\begin{array}{l}\text { Respondent someone other than mother } \\
\text { or father }\end{array}$ & $\checkmark$ & $\checkmark$ & $\checkmark$ & & & $\checkmark$ & $\checkmark$ & \\
\hline Number of people in household & $\checkmark$ & & $\checkmark$ & $\checkmark$ & $\checkmark$ & & & \\
\hline Household income: $\$ 20,000$ to $\$ 40,000$ & $\checkmark$ & & & $\checkmark$ & $\checkmark$ & $\checkmark$ & $\checkmark$ & $\checkmark$ \\
\hline Household income: $\$ 40,000$ to $\$ 60,000$ & $\checkmark$ & & & $\checkmark$ & $\checkmark$ & $\checkmark$ & $\checkmark$ & $\checkmark$ \\
\hline Household income: More than $\$ 60,000$ & $\checkmark$ & & & $\checkmark$ & $\checkmark$ & $\checkmark$ & $\checkmark$ & $\checkmark$ \\
\hline $\begin{array}{l}\text { Income-to-poverty-threshold ratio- } \\
\text { Below } 135 \text { percent }\end{array}$ & $\checkmark$ & & $\checkmark$ & & $\checkmark$ & & $\checkmark$ & $\checkmark$ \\
\hline $\begin{array}{l}\text { Income-to-poverty-threshold ratio- } \\
\text { Between } 135 \text { and } 185 \text { percent }\end{array}$ & $\checkmark$ & & $\checkmark$ & & $\checkmark$ & & $\checkmark$ & $\checkmark$ \\
\hline Full-time employment & $\checkmark$ & & $\checkmark$ & & $\checkmark$ & & $\checkmark$ & $\checkmark$ \\
\hline Part-time employment & $\checkmark$ & & $\checkmark$ & & $\checkmark$ & & $\checkmark$ & $\checkmark$ \\
\hline
\end{tabular}

See notes at end of table. 
Appendix B: Technical Notes

Table B.10. Covariates selected for primary caregiver-reported child outcomes, for the combined-program and program-specific samples-Continued

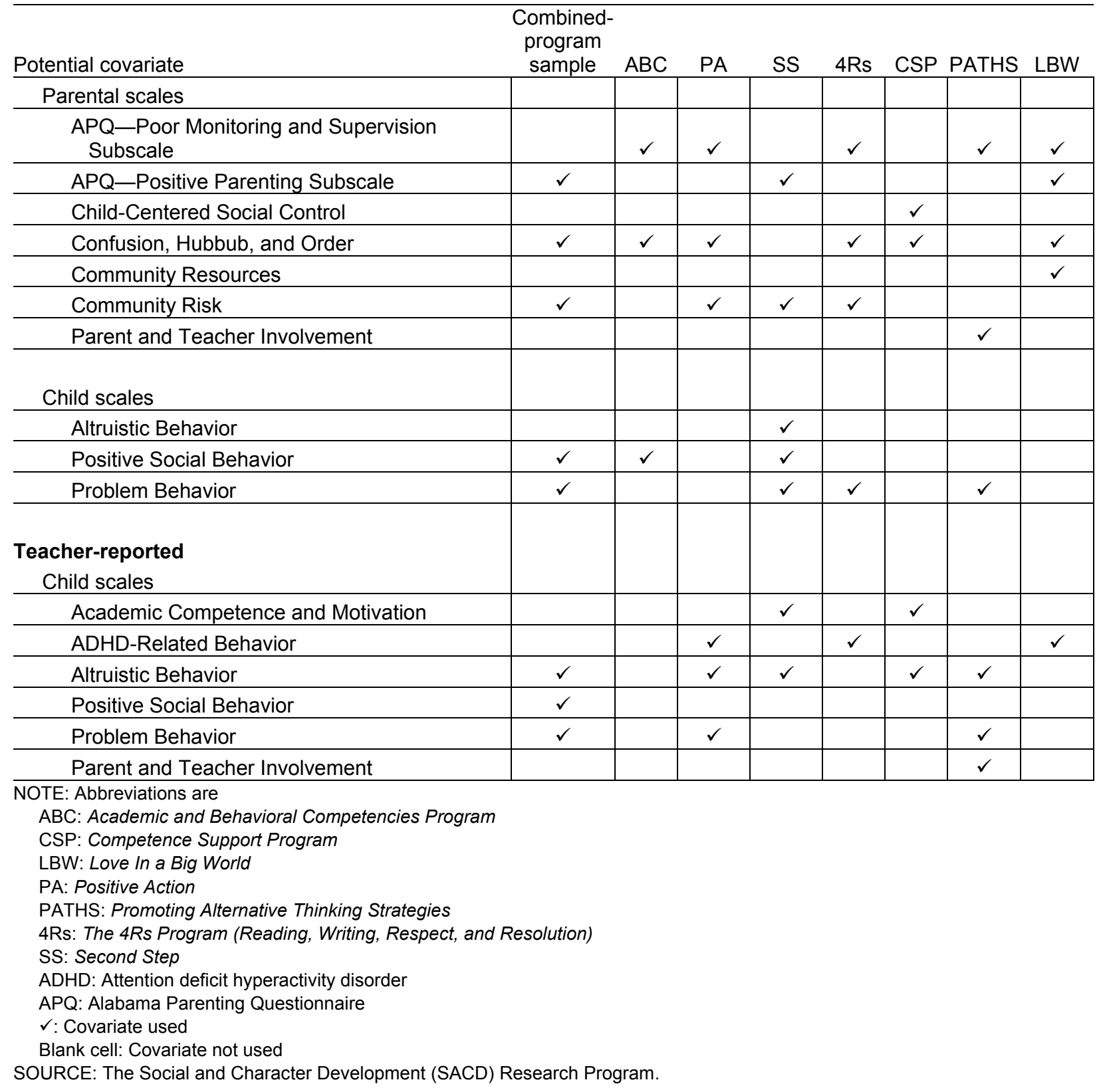


Table B.11. Covariates selected for teacher-reported child outcomes, for the combined-program and program-specific samples

\begin{tabular}{|c|c|c|c|c|c|c|c|c|}
\hline Potential covariate & $\begin{array}{c}\text { Combined- } \\
\text { program } \\
\text { sample }\end{array}$ & $\mathrm{ABC}$ & PA & SS & 4Rs & CSP & PATHS & LBW \\
\hline Total number of covariates & 28 & 24 & 22 & 21 & 20 & 25 & 27 & 21 \\
\hline \multicolumn{9}{|l|}{ Child-reported } \\
\hline Female & $\checkmark$ & $\checkmark$ & $\checkmark$ & $\checkmark$ & $\checkmark$ & $\checkmark$ & $\checkmark$ & $\checkmark$ \\
\hline Black (non-Hispanic) & $\checkmark$ & $\checkmark$ & $\checkmark$ & $\checkmark$ & $\checkmark$ & $\checkmark$ & $\checkmark$ & $\checkmark$ \\
\hline Hispanic & $\checkmark$ & $\checkmark$ & $\checkmark$ & $\checkmark$ & $\checkmark$ & $\checkmark$ & $\checkmark$ & $\checkmark$ \\
\hline Other ethnicity & $\checkmark$ & $\checkmark$ & $\checkmark$ & $\checkmark$ & $\checkmark$ & $\checkmark$ & $\checkmark$ & $\checkmark$ \\
\hline Age (in years) & $\checkmark$ & $\checkmark$ & $\checkmark$ & $\checkmark$ & $\checkmark$ & $\checkmark$ & $\checkmark$ & $\checkmark$ \\
\hline $\begin{array}{l}\text { Scales } \\
\text { Student Afraid at School }\end{array}$ & & $\checkmark$ & & $\checkmark$ & & & $\checkmark$ & \\
\hline Altruistic Behavior & $\checkmark$ & $\checkmark$ & & & & $\checkmark$ & & $\checkmark$ \\
\hline Empathy & & & & $\checkmark$ & $\checkmark$ & & & $\checkmark$ \\
\hline Engagement with Learning & $\checkmark$ & $\checkmark$ & & & $\checkmark$ & $\checkmark$ & & \\
\hline Negative School Orientation & & & $\checkmark$ & $\checkmark$ & & & $\checkmark$ & \\
\hline Normative Beliefs About Aggression & & & $\checkmark$ & $\checkmark$ & $\checkmark$ & & & \\
\hline Positive School Orientation & & $\checkmark$ & & $\checkmark$ & & $\checkmark$ & & \\
\hline Problem Behavior & $\checkmark$ & & $\checkmark$ & & & & & \\
\hline Self-Efficacy for Peer Interactions & & & $\checkmark$ & & & & $\checkmark$ & $\checkmark$ \\
\hline Victimization at School & & & & & $\checkmark$ & $\checkmark$ & $\checkmark$ & \\
\hline $\begin{array}{l}\text { Primary caregiver-reported } \\
\text { Age (in years) }\end{array}$ & & $\checkmark$ & $\checkmark$ & & $\checkmark$ & $\checkmark$ & & \\
\hline Completed high school education or equivalent & $\checkmark$ & & $\checkmark$ & $\checkmark$ & $\checkmark$ & $\checkmark$ & & \\
\hline Some college & $\checkmark$ & & $\checkmark$ & $\checkmark$ & $\checkmark$ & $\checkmark$ & & \\
\hline Bachelor's or higher degree & $\checkmark$ & & $\checkmark$ & $\checkmark$ & $\checkmark$ & $\checkmark$ & & \\
\hline $\begin{array}{l}\text { Highest level of education in household- } \\
\text { Completed high school or equivalent }\end{array}$ & $\checkmark$ & $\checkmark$ & & & & $\checkmark$ & $\checkmark$ & \\
\hline $\begin{array}{l}\text { Highest level of education in household- } \\
\text { Some college }\end{array}$ & $\checkmark$ & $\checkmark$ & & & & $\checkmark$ & $\checkmark$ & \\
\hline $\begin{array}{l}\text { Highest level of education in household- } \\
\text { Bachelor's or higher degree }\end{array}$ & $\checkmark$ & $\checkmark$ & & & & $\checkmark$ & $\checkmark$ & \\
\hline Mother present in home life & $\checkmark$ & $\checkmark$ & & & $\checkmark$ & $\checkmark$ & $\checkmark$ & \\
\hline Mother and father present & $\checkmark$ & $\checkmark$ & $\checkmark$ & & $\checkmark$ & & & \\
\hline $\begin{array}{l}\text { Respondent someone other than mother } \\
\text { or father }\end{array}$ & $\checkmark$ & $\checkmark$ & $\checkmark$ & & $\checkmark$ & & & \\
\hline Number of people in household & $\checkmark$ & $\checkmark$ & $\checkmark$ & & & & & $\checkmark$ \\
\hline Household income: $\$ 20,000$ to $\$ 40,000$ & & & & & & $\checkmark$ & $\checkmark$ & $\checkmark$ \\
\hline Household income: $\$ 40,000$ to $\$ 60,000$ & & & & & & $\checkmark$ & $\checkmark$ & $\checkmark$ \\
\hline Household income: More than $\$ 60,000$ & & & & & & $\checkmark$ & $\checkmark$ & $\checkmark$ \\
\hline $\begin{array}{l}\text { Income-to-poverty-threshold ratio- } \\
\text { Below } 135 \text { percent }\end{array}$ & $\checkmark$ & & & & & & & $\checkmark$ \\
\hline $\begin{array}{l}\text { Income-to-poverty-threshold ratio- } \\
\text { Between } 135 \text { and } 185 \text { percent }\end{array}$ & $\checkmark$ & & & & & & & $\checkmark$ \\
\hline Full-time employment & & $\checkmark$ & $\checkmark$ & $\checkmark$ & & $\checkmark$ & $\checkmark$ & $\checkmark$ \\
\hline Part-time employment & & $\checkmark$ & $\checkmark$ & $\checkmark$ & & $\checkmark$ & $\checkmark$ & $\checkmark$ \\
\hline
\end{tabular}


Appendix B: Technical Notes

Table B.11. Covariates selected for teacher-reported child outcomes, for the combinedprogram and program-specific samples-Continued

\begin{tabular}{|c|c|c|c|c|c|c|c|c|}
\hline Potential covariate & $\begin{array}{c}\text { Combined- } \\
\text { program } \\
\text { sample }\end{array}$ & $\mathrm{ABC}$ & PA & SS & 4Rs & CSP & PATHS & LBW \\
\hline \multicolumn{9}{|l|}{ Parental scales } \\
\hline $\begin{array}{l}\text { APQ_Poor Monitoring and Supervision } \\
\text { Subscale }\end{array}$ & & $\checkmark$ & & & & & $\checkmark$ & $\checkmark$ \\
\hline APQ_-Positive Parenting Subscale & $\checkmark$ & & & $\checkmark$ & & & & \\
\hline Child-Centered Social Control & & & & & & & $\checkmark$ & \\
\hline Confusion, Hubbub, and Order & & $\checkmark$ & $\checkmark$ & & $\checkmark$ & & & \\
\hline Community Resources & & & & & & & $\checkmark$ & \\
\hline Community Risk & & & & & & & $\checkmark$ & $\checkmark$ \\
\hline Parent and Teacher Involvement & & & & & & & $\checkmark$ & $\checkmark$ \\
\hline \multicolumn{9}{|l|}{ Child scales } \\
\hline Altruistic Behavior & $\checkmark$ & & & $\checkmark$ & & & & $\checkmark$ \\
\hline Positive Social Behavior & $\checkmark$ & $\checkmark$ & $\checkmark$ & & $\checkmark$ & $\checkmark$ & $\checkmark$ & \\
\hline Problem Behavior & $\checkmark$ & & & $\checkmark$ & & & & \\
\hline \multicolumn{9}{|l|}{$\begin{array}{l}\text { Teacher-reported } \\
\text { Child scales }\end{array}$} \\
\hline Academic Competence and Motivation & $\checkmark$ & & & $\checkmark$ & & & & \\
\hline ADHD-Related Behavior & $\checkmark$ & $\checkmark$ & & $\checkmark$ & & $\checkmark$ & $\checkmark$ & \\
\hline Altruistic Behavior & $\checkmark$ & & $\checkmark$ & $\checkmark$ & & & & \\
\hline Positive Social Behavior & & & $\checkmark$ & & $\checkmark$ & & & $\checkmark$ \\
\hline Problem Behavior & & $\checkmark$ & & & & $\checkmark$ & $\checkmark$ & \\
\hline Parent and Teacher Involvement & $\checkmark$ & & & & $\checkmark$ & & $\checkmark$ & \\
\hline
\end{tabular}

NOTE: Abbreviations are

ABC: Academic and Behavioral Competencies Program

CSP: Competence Support Program

LBW: Love In a Big World

PA: Positive Action

PATHS: Promoting Alternative Thinking Strategies

4Rs: The 4Rs Program (Reading, Writing, Respect, and Resolution)

SS: Second Step

ADHD: Attention deficit hyperactivity disorder

APQ: Alabama Parenting Questionnaire

$\checkmark$ : Covariate used

Blank cell: Covariate not used

SOURCE: The Social and Character Development (SACD) Research Program. 
Table B.12. Covariates selected for teacher-reported school outcomes, for the combinedprogram and program-specific samples

\begin{tabular}{|c|c|c|c|c|c|c|c|c|}
\hline Potential covariate & $\begin{array}{c}\text { Combined- } \\
\text { program } \\
\text { sample }\end{array}$ & $\mathrm{ABC}$ & PA & SS & 4Rs & CSP & PATHS & LBW \\
\hline Total number & 8 & 8 & 7 & 8 & 6 & 9 & 5 & 5 \\
\hline \multicolumn{9}{|l|}{ Teacher-reported } \\
\hline Female & $\checkmark$ & $\checkmark$ & $\checkmark$ & $\checkmark$ & $\checkmark$ & $\checkmark$ & $\checkmark$ & $\checkmark$ \\
\hline Black (non-Hispanic) & $\checkmark$ & $\checkmark$ & $\checkmark$ & $\checkmark$ & $\checkmark$ & $\checkmark$ & $\checkmark$ & $\checkmark$ \\
\hline Hispanic & $\checkmark$ & $\checkmark$ & $\checkmark$ & $\checkmark$ & $\checkmark$ & $\checkmark$ & $\checkmark$ & $\checkmark$ \\
\hline Other ethnicity & $\checkmark$ & $\checkmark$ & $\checkmark$ & $\checkmark$ & $\checkmark$ & $\checkmark$ & $\checkmark$ & $\checkmark$ \\
\hline Total teaching experience & $\checkmark$ & $\checkmark$ & $\checkmark$ & $\checkmark$ & $\checkmark$ & $\checkmark$ & $\checkmark$ & \\
\hline Total experience in current school & & & & & & $\checkmark$ & & $\checkmark$ \\
\hline Regular certificate & $\checkmark$ & $\checkmark$ & $\checkmark$ & $\checkmark$ & & $\checkmark$ & & \\
\hline Other certificate & $\checkmark$ & $\checkmark$ & $\checkmark$ & $\checkmark$ & & $\checkmark$ & & \\
\hline Highest degree-Bachelor's & $\checkmark$ & $\checkmark$ & & $\checkmark$ & $\checkmark$ & $\checkmark$ & & \\
\hline \multicolumn{9}{|c|}{ NOTE: Abbreviations are } \\
\hline \multicolumn{9}{|c|}{ ABC: Academic and Behavioral Competencies Program } \\
\hline \multicolumn{9}{|c|}{ CSP: Competence Support Program } \\
\hline \multicolumn{9}{|l|}{ LBW: Love In a Big World } \\
\hline \multicolumn{9}{|c|}{ PA: Positive Action } \\
\hline \multicolumn{9}{|c|}{ PATHS: Promoting Alternative Thinking Strategies } \\
\hline \multicolumn{9}{|c|}{ 4Rs: The 4Rs Program (Reading, Writing, Respect, and Resolution) } \\
\hline \multicolumn{9}{|c|}{ SS: Second Step } \\
\hline \multicolumn{9}{|l|}{$\checkmark:$ Covariate used } \\
\hline \multicolumn{9}{|l|}{ Blank cell: Covariate not used } \\
\hline SOURCE: The Social and Character Deve & & & & & & & & \\
\hline
\end{tabular}


Appendix B: Technical Notes

Table B.13. Adjusted $R^{2}$ values from models using spring 2005 (Year 1) outcomes, with pretest only and with the full covariate set, for the combined-program sample

\begin{tabular}{|c|c|c|c|c|}
\hline \multirow[b]{2}{*}{ Outcome } & \multicolumn{2}{|c|}{ Child level } & \multicolumn{2}{|c|}{ Collapsed to school level } \\
\hline & Pretest only & $\begin{array}{r}\text { Full } \\
\text { covariate } \\
\text { set }\end{array}$ & Pretest only & $\begin{array}{r}\text { Full } \\
\text { covariate } \\
\text { set }\end{array}$ \\
\hline \multicolumn{5}{|l|}{ Child-reported } \\
\hline Empathy & 0.19 & 0.24 & 0.34 & 0.56 \\
\hline Student Afraid at School & 0.13 & 0.18 & 0.64 & 0.76 \\
\hline Altruistic Behavior & 0.20 & 0.23 & 0.60 & 0.67 \\
\hline Engagement with Learning & 0.09 & 0.13 & 0.33 & 0.49 \\
\hline Negative School Orientation & 0.20 & 0.26 & 0.83 & 0.88 \\
\hline Problem Behavior & 0.26 & 0.31 & 0.71 & 0.82 \\
\hline Self-Efficacy for Peer Interactions & 0.20 & 0.21 & 0.22 & 0.54 \\
\hline Victimization at School & 0.20 & 0.21 & 0.47 & 0.60 \\
\hline Normative Beliefs About Aggression & 0.11 & 0.15 & 0.39 & 0.67 \\
\hline Positive School Orientation & 0.18 & 0.24 & 0.71 & 0.83 \\
\hline \multicolumn{5}{|l|}{ Primary caregiver-reported } \\
\hline Altruistic Behavior & 0.22 & 0.23 & 0.53 & 0.65 \\
\hline Positive Social Behavior & 0.43 & 0.46 & 0.74 & 0.83 \\
\hline Problem Behavior & 0.37 & 0.40 & 0.51 & 0.49 \\
\hline \multicolumn{5}{|l|}{ Teacher-reported (child) } \\
\hline ADHD-Related Behavior & 0.52 & 0.54 & 0.64 & 0.71 \\
\hline Academic Competence and Motivation & 0.60 & 0.62 & 0.85 & 0.88 \\
\hline Altruistic Behavior & 0.27 & 0.28 & 0.32 & 0.28 \\
\hline Positive Social Behavior & 0.55 & 0.58 & 0.81 & 0.87 \\
\hline Problem Behavior & 0.51 & 0.54 & 0.78 & 0.84 \\
\hline \multicolumn{5}{|l|}{ Teacher-reported (school) } \\
\hline Student Support for Teachers & 0.62 & 0.63 & 0.91 & 0.91 \\
\hline Feelings of Safety & 0.47 & 0.48 & 0.78 & 0.80 \\
\hline
\end{tabular}

NOTE: ADHD is the abbreviation for attention deficit hyperactivity disorder.

SOURCE: The Social and Character Development (SACD) Research Program. 
Table B.14. Adjusted $R^{2}$ values from models using spring 2005 (Year 1) outcomes with pretest only and with the full covariate set, by site

\begin{tabular}{|c|c|c|c|c|c|c|c|c|c|c|c|c|c|c|}
\hline \multirow[b]{2}{*}{ Outcome } & \multicolumn{2}{|c|}{ LBW } & \multicolumn{2}{|c|}{ CSP } & \multicolumn{2}{|c|}{ SS } & \multicolumn{2}{|c|}{$\mathrm{ABC}$} & \multicolumn{2}{|c|}{ PATHS } & \multicolumn{2}{|c|}{ PA } & \multicolumn{2}{|c|}{ 4Rs } \\
\hline & $\begin{array}{l}\text { Pre- } \\
\text { test } \\
\text { only } \\
\end{array}$ & $\begin{array}{r}\text { Full } \\
\text { set }\end{array}$ & $\begin{array}{c}\text { Pre- } \\
\text { test } \\
\text { only } \\
\end{array}$ & $\begin{array}{r}\text { Full } \\
\text { set }\end{array}$ & $\begin{array}{c}\text { Pre- } \\
\text { test } \\
\text { only } \\
\end{array}$ & $\begin{array}{r}\text { Full } \\
\text { set }\end{array}$ & $\begin{array}{c}\text { Pre- } \\
\text { test } \\
\text { only } \\
\end{array}$ & $\begin{array}{r}\text { Full } \\
\text { set }\end{array}$ & $\begin{array}{l}\text { Pre- } \\
\text { test } \\
\text { only } \\
\end{array}$ & $\begin{array}{r}\text { Full } \\
\text { set }\end{array}$ & $\begin{array}{r}\text { Pre- } \\
\text { test } \\
\text { only }\end{array}$ & $\begin{array}{r}\text { Full } \\
\text { set }\end{array}$ & $\begin{array}{l}\text { Pre- } \\
\text { test } \\
\text { only } \\
\end{array}$ & $\begin{array}{l}\text { Full } \\
\text { set }\end{array}$ \\
\hline \multicolumn{15}{|l|}{ Child-reported } \\
\hline Empathy & 0.21 & 0.24 & 0.19 & 0.27 & 0.25 & 0.26 & 0.22 & 0.24 & 0.19 & 0.26 & 0.11 & 0.18 & 0.13 & 0.17 \\
\hline Student Afraid at School & 0.05 & 0.08 & 0.10 & 0.15 & 0.20 & 0.21 & 0.09 & 0.13 & 0.15 & 0.20 & 0.07 & 0.11 & 0.09 & 0.13 \\
\hline Altruistic Behavior & 0.17 & 0.18 & 0.20 & 0.22 & 0.24 & 0.28 & 0.30 & 0.32 & 0.22 & 0.25 & 0.10 & 0.13 & 0.13 & 0.14 \\
\hline Engagement with Learning & 0.13 & 0.16 & 0.03 & 0.04 & 0.11 & 0.15 & 0.09 & 0.15 & 0.11 & 0.14 & 0.06 & 0.10 & 0.12 & 0.14 \\
\hline Negative School Orientation & 0.19 & 0.20 & 0.14 & 0.16 & 0.18 & 0.21 & 0.15 & 0.17 & 0.20 & 0.32 & 0.08 & 0.15 & 0.14 & 0.20 \\
\hline Problem Behavior & 0.23 & 0.26 & 0.18 & 0.26 & 0.28 & 0.30 & 0.29 & 0.33 & 0.28 & 0.35 & 0.10 & 0.17 & 0.27 & 0.32 \\
\hline Self-Efficacy for Peer Interactions & 0.19 & 0.20 & 0.14 & 0.14 & 0.25 & 0.27 & 0.23 & 0.23 & 0.25 & 0.26 & 0.16 & 0.21 & 0.17 & 0.17 \\
\hline Victimization at School & 0.18 & 0.20 & 0.17 & 0.18 & 0.21 & 0.22 & 0.19 & 0.21 & 0.27 & 0.27 & 0.16 & 0.18 & 0.13 & 0.13 \\
\hline Normative Beliefs About Aggression & 0.06 & 0.06 & 0.07 & 0.15 & 0.02 & 0.03 & 0.14 & 0.19 & 0.12 & 0.17 & 0.05 & 0.11 & 0.19 & 0.20 \\
\hline Positive School Orientation & 0.13 & 0.12 & 0.11 & 0.17 & 0.20 & 0.20 & 0.23 & 0.27 & 0.13 & 0.26 & 0.07 & 0.16 & 0.20 & 0.27 \\
\hline \multicolumn{15}{|l|}{ Primary caregiver-reported } \\
\hline Altruistic Behavior & 0.14 & 0.20 & 0.18 & 0.22 & 0.23 & 0.34 & 0.19 & 0.24 & 0.26 & 0.32 & 0.19 & 0.22 & 0.20 & 0.25 \\
\hline Positive Social Behavior & 0.35 & 0.39 & 0.42 & 0.46 & 0.47 & 0.50 & 0.54 & 0.56 & 0.50 & 0.54 & 0.40 & 0.46 & 0.32 & 0.36 \\
\hline Problem Behavior & 0.33 & 0.40 & 0.38 & 0.43 & 0.50 & 0.53 & 0.37 & 0.40 & 0.43 & 0.51 & 0.40 & 0.44 & 0.22 & 0.26 \\
\hline \multicolumn{15}{|l|}{ Teacher-reported (child) } \\
\hline ADHD-Related Behavior & 0.48 & 0.54 & 0.52 & 0.53 & 0.55 & 0.57 & 0.51 & 0.54 & 0.57 & 0.59 & 0.46 & 0.54 & 0.50 & 0.54 \\
\hline Academic Competence and & & & & & & & & & & & & & & \\
\hline Motivation & 0.53 & 0.56 & 0.61 & 0.63 & 0.70 & 0.72 & 0.51 & 0.55 & 0.69 & 0.72 & 0.51 & 0.56 & 0.54 & 0.57 \\
\hline Altruistic Behavior & 0.17 & 0.19 & 0.34 & 0.36 & 0.28 & 0.34 & 0.28 & 0.33 & 0.36 & 0.38 & 0.15 & 0.20 & 0.31 & 0.35 \\
\hline Positive Social Behavior & 0.51 & 0.56 & 0.42 & 0.47 & 0.55 & 0.59 & 0.51 & 0.56 & 0.58 & 0.64 & 0.54 & 0.60 & 0.52 & 0.54 \\
\hline Problem Behavior & 0.38 & 0.42 & 0.47 & 0.50 & 0.47 & 0.51 & 0.45 & 0.52 & 0.67 & 0.70 & 0.50 & 0.56 & 0.50 & 0.52 \\
\hline \multicolumn{15}{|l|}{ Teacher-reported (school) } \\
\hline Student Support for Teachers & 0.42 & 0.43 & 0.43 & 0.44 & 0.31 & 0.36 & 0.64 & 0.63 & 0.70 & 0.70 & 0.61 & 0.62 & 0.50 & 0.52 \\
\hline Feelings of Safety & 0.26 & 0.29 & 0.22 & 0.30 & 0.32 & 0.36 & 0.52 & 0.52 & 0.48 & 0.49 & 0.38 & 0.36 & 0.53 & 0.53 \\
\hline
\end{tabular}

NOTE: Abbreviations are

ABC: Academic and Behavioral Competencies Program

PA: Positive Action

CSP: Competence Support Program

LBW: Love In a Big World

PATHS: Promoting Alternative Thinking Strategies

SS: Second Step

4Rs: The 4Rs Program (Reading, Writing, Respect, and Resolution)

SOURCE: The Social and Character Development (SACD) Research Program. 
Table B.15. Adjusted $\mathrm{R}^{2}$ values from models using spring 2006 (Year 2) outcomes, with pretest only and with the full covariate set, for the combined-program sample

\begin{tabular}{|c|c|c|c|c|}
\hline \multirow[b]{3}{*}{ Outcome } & \multicolumn{2}{|c|}{ Child level } & \multicolumn{2}{|c|}{ Collapsed to school level } \\
\hline & & $\begin{array}{r}\text { Full } \\
\text { covariate }\end{array}$ & & $\begin{array}{r}\text { Full } \\
\text { covariate }\end{array}$ \\
\hline & Pretest only & set & Pretest only & set \\
\hline \multicolumn{5}{|l|}{ Child-reported } \\
\hline Empathy & 0.11 & 0.16 & 0.32 & 0.48 \\
\hline Student Afraid at School & 0.07 & 0.12 & 0.51 & 0.65 \\
\hline Altruistic Behavior & 0.09 & 0.11 & 0.34 & 0.42 \\
\hline Engagement with Learning & 0.03 & 0.07 & 0.25 & 0.30 \\
\hline Negative School Orientation & 0.13 & 0.19 & 0.71 & 0.72 \\
\hline Problem Behavior & 0.16 & 0.24 & 0.62 & 0.77 \\
\hline Self-Efficacy for Peer Interactions & 0.10 & 0.13 & 0.36 & 0.58 \\
\hline Victimization at School & 0.08 & 0.10 & 0.16 & 0.18 \\
\hline Normative Beliefs About Aggression & 0.08 & 0.14 & 0.30 & 0.57 \\
\hline Positive School Orientation & 0.13 & 0.18 & 0.63 & 0.69 \\
\hline \multicolumn{5}{|l|}{ Primary caregiver-reported } \\
\hline Altruistic Behavior & 0.19 & 0.21 & 0.43 & 0.67 \\
\hline Positive Social Behavior & 0.32 & 0.37 & 0.42 & 0.71 \\
\hline Problem Behavior & 0.27 & 0.30 & 0.37 & 0.52 \\
\hline \multicolumn{5}{|l|}{ Teacher-reported (child) } \\
\hline ADHD-Related Behavior & 0.23 & 0.29 & 0.31 & 0.46 \\
\hline Academic Competence and Motivation & 0.37 & 0.42 & 0.62 & 0.78 \\
\hline Altruistic Behavior & 0.06 & 0.09 & 0.09 & 0.01 \\
\hline Positive Social Behavior & 0.22 & 0.32 & 0.35 & 0.64 \\
\hline Problem Behavior & 0.24 & 0.31 & 0.62 & 0.76 \\
\hline \multicolumn{5}{|l|}{ Teacher-reported (school) } \\
\hline Student Support for Teachers & 0.49 & 0.49 & 0.85 & 0.85 \\
\hline Feelings of Safety & 0.37 & 0.38 & 0.68 & 0.69 \\
\hline
\end{tabular}

NOTE: ADHD is the abbreviation for attention deficit hyperactivity disorder.

SOURCE: The Social and Character Development (SACD) Research Program. 
Table B.16. Adjusted $\mathrm{R}^{2}$ values from models using spring 2006 (Year 2) outcomes with pretest only and with the full covariate set selected for each program, by program

\begin{tabular}{|c|c|c|c|c|c|c|c|c|c|c|c|c|c|c|}
\hline \multirow[b]{2}{*}{ Outcome } & \multicolumn{2}{|c|}{$\mathrm{ABC}$} & \multicolumn{2}{|c|}{ PA } & \multicolumn{2}{|c|}{ SS } & \multicolumn{2}{|c|}{ 4Rs } & \multicolumn{2}{|c|}{ CSP } & \multicolumn{2}{|c|}{ PATHS } & \multicolumn{2}{|c|}{ LBW } \\
\hline & $\begin{array}{l}\text { Pre- } \\
\text { test } \\
\text { only } \\
\end{array}$ & $\begin{array}{r}\text { Full } \\
\text { set }\end{array}$ & $\begin{array}{l}\text { Pre- } \\
\text { test } \\
\text { only } \\
\end{array}$ & $\begin{array}{r}\text { Full } \\
\text { set }\end{array}$ & $\begin{array}{l}\text { Pre- } \\
\text { test } \\
\text { only } \\
\end{array}$ & $\begin{array}{r}\text { Full } \\
\text { set }\end{array}$ & $\begin{array}{l}\text { Pre- } \\
\text { test } \\
\text { only } \\
\end{array}$ & $\begin{array}{r}\text { Full } \\
\text { set }\end{array}$ & $\begin{array}{l}\text { Pre- } \\
\text { test } \\
\text { only } \\
\end{array}$ & $\begin{array}{r}\text { Full } \\
\text { set }\end{array}$ & $\begin{array}{l}\text { Pre- } \\
\text { test } \\
\text { only } \\
\end{array}$ & $\begin{array}{r}\text { Full } \\
\text { set }\end{array}$ & $\begin{array}{l}\text { Pre- } \\
\text { test } \\
\text { only } \\
\end{array}$ & $\begin{array}{r}\text { Full } \\
\text { set } \\
\end{array}$ \\
\hline \multicolumn{15}{|l|}{ Child-reported } \\
\hline Empathy & 0.12 & 0.17 & 0.04 & 0.12 & 0.09 & 0.17 & 0.07 & 0.12 & 0.06 & 0.12 & 0.12 & 0.22 & 0.08 & 0.10 \\
\hline Student Afraid at School & 0.07 & 0.12 & 0.01 & 0.04 & 0.03 & 0.08 & 0.03 & 0.04 & 0.02 & 0.06 & 0.08 & 0.18 & 0.01 & 0.04 \\
\hline Altruistic Behavior & 0.10 & 0.13 & 0.06 & 0.08 & 0.06 & 0.11 & 0.05 & 0.06 & 0.09 & 0.14 & 0.11 & 0.12 & 0.05 & 0.07 \\
\hline Engagement with Learning & 0.03 & 0.04 & 0.02 & 0.04 & 0.04 & 0.05 & 0.03 & 0.09 & 0.01 & 0.05 & 0.05 & 0.10 & 0.03 & 0.05 \\
\hline Negative School Orientation & 0.04 & 0.07 & 0.04 & 0.10 & 0.08 & 0.12 & 0.03 & 0.09 & 0.03 & 0.06 & 0.20 & 0.29 & 0.08 & 0.09 \\
\hline Problem Behavior & 0.13 & 0.20 & 0.04 & 0.16 & 0.10 & 0.16 & 0.15 & 0.23 & 0.06 & 0.15 & 0.15 & 0.28 & 0.06 & 0.11 \\
\hline Self-Efficacy for Peer Interactions & 0.10 & 0.15 & 0.05 & 0.17 & 0.08 & 0.10 & 0.09 & 0.09 & 0.09 & 0.10 & 0.17 & 0.21 & 0.10 & 0.11 \\
\hline Victimization at School & 0.10 & 0.11 & 0.04 & 0.07 & 0.12 & 0.11 & 0.07 & 0.07 & 0.06 & 0.11 & 0.11 & 0.11 & 0.04 & 0.06 \\
\hline Normative Beliefs About Aggression & 0.07 & 0.12 & 0.03 & 0.09 & 0.01 & 0.06 & 0.08 & 0.10 & 0.02 & 0.09 & 0.04 & 0.16 & 0.14 & 0.15 \\
\hline Positive School Orientation & 0.12 & 0.17 & 0.06 & 0.24 & 0.03 & 0.03 & 0.07 & 0.12 & 0.03 & 0.10 & 0.17 & 0.33 & 0.06 & 0.06 \\
\hline \multicolumn{15}{|l|}{ Primary caregiver-reported } \\
\hline Altruistic Behavior & 0.15 & 0.16 & 0.18 & 0.19 & 0.22 & 0.26 & 0.17 & 0.17 & 0.13 & 0.12 & 0.24 & 0.32 & 0.10 & 0.15 \\
\hline Positive Social Behavior & 0.36 & 0.41 & 0.35 & 0.39 & 0.33 & 0.42 & 0.16 & 0.19 & 0.26 & 0.33 & 0.36 & 0.39 & 0.33 & 0.42 \\
\hline Problem Behavior & 0.34 & 0.36 & 0.31 & 0.32 & 0.27 & 0.33 & 0.09 & 0.12 & 0.23 & 0.30 & 0.41 & 0.45 & 0.26 & 0.32 \\
\hline \multicolumn{15}{|l|}{ Teacher-reported (child) } \\
\hline ADHD-Related Behavior & 0.22 & 0.25 & 0.14 & 0.24 & 0.27 & 0.33 & 0.20 & 0.26 & 0.25 & 0.29 & 0.33 & 0.36 & 0.20 & 0.28 \\
\hline Academic Competence and Motivation & 0.35 & 0.42 & 0.27 & 0.34 & 0.39 & 0.47 & 0.27 & 0.31 & 0.30 & 0.42 & 0.54 & 0.57 & 0.30 & 0.35 \\
\hline Altruistic Behavior & 0.02 & 0.05 & 0.00 & 0.08 & 0.00 & 0.04 & 0.00 & 0.03 & 0.02 & 0.05 & 0.01 & 0.00 & 0.02 & 0.10 \\
\hline Positive Social Behavior & 0.17 & 0.27 & 0.19 & 0.30 & 0.16 & 0.29 & 0.26 & 0.32 & 0.14 & 0.26 & 0.33 & 0.46 & 0.12 & 0.21 \\
\hline Problem Behavior & 0.20 & 0.28 & 0.20 & 0.30 & 0.18 & 0.32 & 0.20 & 0.25 & 0.25 & 0.29 & 0.36 & 0.46 & 0.17 & 0.21 \\
\hline \multicolumn{15}{|l|}{ Teacher-reported (school) } \\
\hline Student Support for Teachers & 0.28 & 0.26 & 0.53 & 0.54 & 0.30 & 0.28 & 0.31 & 0.29 & 0.29 & 0.31 & 0.56 & 0.56 & 0.18 & 0.23 \\
\hline Feelings of Safety & 0.42 & 0.42 & 0.48 & 0.50 & 0.12 & 0.11 & 0.36 & 0.35 & 0.12 & 0.18 & 0.41 & 0.41 & 0.16 & 0.21 \\
\hline
\end{tabular}

NOTE: Abbreviations are

ABC: Academic and Behavioral Competencies Program

CSP: Competence Support Program

PA: Positive Action

LBW: Love In a Big World

SS: Second Step

PATHS: Promoting Alternative Thinking Strategies

4Rs: The 4Rs Program (Reading, Writing, Respect, and Resolution)

SOURCE: The Social and Character Development (SACD) Research Program. 
Table B.17. Adjusted $\mathbf{R}^{2}$ values from models using spring 2007 (Year 3) outcomes, with pretest only and with the full covariate set, for the combined-program sample

\begin{tabular}{|c|c|c|c|c|}
\hline \multirow[b]{3}{*}{ Outcome } & \multicolumn{2}{|c|}{ Child level } & \multicolumn{2}{|c|}{ Collapsed to school level } \\
\hline & & $\begin{array}{r}\text { Full } \\
\text { covariate }\end{array}$ & & $\begin{array}{r}\text { Full } \\
\text { covariate }\end{array}$ \\
\hline & Pretest only & set & Pretest only & set \\
\hline \multicolumn{5}{|l|}{ Child-reported } \\
\hline Empathy & 0.09 & 0.14 & 0.40 & 0.67 \\
\hline Student Afraid at School & 0.06 & 0.12 & 0.51 & 0.70 \\
\hline Altruistic Behavior & 0.06 & 0.08 & 0.41 & 0.56 \\
\hline Engagement with Learning & 0.02 & 0.07 & 0.01 & 0.29 \\
\hline Negative School Orientation & 0.11 & 0.17 & 0.53 & 0.64 \\
\hline Problem Behavior & 0.14 & 0.23 & 0.55 & 0.74 \\
\hline Self-Efficacy for Peer Interactions & 0.06 & 0.08 & 0.15 & 0.30 \\
\hline Victimization at School & 0.06 & 0.07 & 0.25 & 0.28 \\
\hline Normative Beliefs About Aggression & 0.06 & 0.11 & 0.35 & 0.46 \\
\hline Positive School Orientation & 0.11 & 0.16 & 0.47 & 0.67 \\
\hline \multicolumn{5}{|l|}{ Primary caregiver-reported } \\
\hline Altruistic Behavior & 0.16 & 0.20 & 0.40 & 0.74 \\
\hline Positive Social Behavior & 0.26 & 0.32 & 0.54 & 0.69 \\
\hline Problem Behavior & 0.19 & 0.23 & 0.31 & 0.64 \\
\hline \multicolumn{5}{|l|}{ Teacher-reported (child) } \\
\hline ADHD-Related Behavior & 0.20 & 0.26 & 0.05 & 0.69 \\
\hline Academic Competence and Motivation & 0.32 & 0.37 & 0.49 & 0.70 \\
\hline Altruistic Behavior & 0.06 & 0.07 & 0.10 & 0.20 \\
\hline Positive Social Behavior & 0.22 & 0.30 & 0.30 & 0.60 \\
\hline Problem Behavior & 0.22 & 0.28 & 0.42 & 0.61 \\
\hline \multicolumn{5}{|l|}{ Teacher-reported (school) } \\
\hline Student Support for Teachers & 0.47 & 0.47 & 0.78 & 0.77 \\
\hline Feelings of Safety & 0.30 & 0.30 & 0.50 & 0.48 \\
\hline
\end{tabular}

NOTE: ADHD is the abbreviation for attention deficit hyperactivity disorder.

SOURCE: The Social and Character Development (SACD) Research Program. 
Table B.18. Adjusted $R^{2}$ values from models using spring 2007 (Year 3) outcomes, with pretest only and with the full covariate set selected for each program, by program

\begin{tabular}{|c|c|c|c|c|c|c|c|c|c|c|c|c|c|c|}
\hline \multirow[b]{2}{*}{ Outcome } & \multicolumn{2}{|c|}{ LBW } & \multicolumn{2}{|c|}{ CSP } & \multicolumn{2}{|c|}{ SS } & \multicolumn{2}{|c|}{$\mathrm{ABC}$} & \multicolumn{2}{|c|}{ PATHS } & \multicolumn{2}{|c|}{$\mathrm{PA}$} & \multicolumn{2}{|c|}{ 4Rs } \\
\hline & $\begin{array}{l}\text { Pre- } \\
\text { test } \\
\text { only }\end{array}$ & $\begin{array}{l}\text { Full } \\
\text { set }\end{array}$ & $\begin{array}{l}\text { Pre- } \\
\text { test } \\
\text { only }\end{array}$ & $\begin{array}{l}\text { Full } \\
\text { set }\end{array}$ & $\begin{array}{l}\text { Pre- } \\
\text { test } \\
\text { only }\end{array}$ & $\begin{array}{l}\text { Full } \\
\text { set }\end{array}$ & $\begin{array}{l}\text { Pre- } \\
\text { test } \\
\text { only }\end{array}$ & $\begin{array}{l}\text { Full } \\
\text { set }\end{array}$ & $\begin{array}{l}\text { Pre- } \\
\text { test } \\
\text { only } \\
\end{array}$ & $\begin{array}{l}\text { Full } \\
\text { set }\end{array}$ & $\begin{array}{l}\text { Pre- } \\
\text { test } \\
\text { only } \\
\end{array}$ & $\begin{array}{l}\text { Full } \\
\text { set }\end{array}$ & $\begin{array}{l}\text { Pre- } \\
\text { test } \\
\text { only } \\
\end{array}$ & $\begin{array}{l}\text { Full } \\
\text { set }\end{array}$ \\
\hline \multicolumn{15}{|l|}{ Child-reported } \\
\hline Empathy & 0.08 & 0.13 & 0.07 & 0.14 & 0.06 & 0.15 & 0.05 & 0.06 & 0.03 & 0.11 & 0.04 & 0.11 & 0.03 & 0.09 \\
\hline Student Afraid at School & 0.03 & 0.06 & 0.01 & 0.05 & 0.03 & 0.12 & 0.04 & 0.10 & 0.06 & 0.17 & 0.01 & 0.07 & 0.02 & 0.05 \\
\hline Altruistic Behavior & 0.04 & 0.08 & 0.08 & 0.08 & 0.05 & 0.09 & 0.05 & 0.08 & 0.03 & 0.09 & 0.04 & 0.05 & 0.03 & 0.04 \\
\hline Engagement with Learning & 0.06 & 0.07 & 0.00 & 0.04 & 0.09 & 0.13 & 0.02 & 0.04 & 0.05 & 0.12 & 0.02 & 0.07 & 0.01 & 0.07 \\
\hline Negative School Orientation & 0.05 & 0.08 & 0.04 & 0.10 & 0.07 & 0.14 & 0.07 & 0.08 & 0.19 & 0.28 & 0.04 & 0.12 & 0.01 & 0.05 \\
\hline Problem Behavior & 0.12 & 0.17 & 0.05 & 0.16 & 0.07 & 0.15 & 0.11 & 0.13 & 0.22 & 0.33 & 0.02 & 0.18 & 0.07 & 0.17 \\
\hline Self-Efficacy for Peer Interactions & 0.04 & 0.05 & 0.08 & 0.11 & 0.05 & 0.09 & 0.07 & 0.11 & 0.09 & 0.12 & 0.04 & 0.09 & 0.05 & 0.06 \\
\hline Victimization at School & 0.02 & 0.02 & 0.05 & 0.07 & 0.07 & 0.09 & 0.04 & 0.07 & 0.13 & 0.17 & 0.02 & 0.07 & 0.02 & 0.03 \\
\hline Normative Beliefs About Aggression & 0.07 & 0.12 & 0.01 & 0.14 & 0.01 & 0.06 & 0.01 & 0.05 & 0.03 & 0.13 & 0.03 & 0.08 & 0.07 & 0.12 \\
\hline Positive School Orientation & 0.07 & 0.07 & 0.02 & 0.08 & 0.02 & 0.07 & 0.09 & 0.12 & 0.09 & 0.28 & 0.04 & 0.18 & 0.02 & 0.07 \\
\hline \multicolumn{15}{|l|}{ Primary caregiver-reported } \\
\hline Altruistic Behavior & 0.08 & 0.21 & 0.15 & 0.16 & 0.13 & 0.24 & 0.13 & 0.19 & 0.20 & 0.28 & 0.09 & 0.16 & 0.17 & 0.17 \\
\hline Positive Social Behavior & 0.22 & 0.29 & 0.29 & 0.33 & 0.31 & 0.35 & 0.23 & 0.28 & 0.35 & 0.40 & 0.22 & 0.28 & 0.12 & 0.19 \\
\hline Problem Behavior & 0.23 & 0.26 & 0.19 & 0.24 & 0.21 & 0.28 & 0.17 & 0.23 & 0.25 & 0.28 & 0.18 & 0.20 & 0.09 & 0.17 \\
\hline \multicolumn{15}{|l|}{ Teacher-reported (child) } \\
\hline ADHD-Related Behavior & 0.19 & 0.25 & 0.25 & 0.32 & 0.26 & 0.28 & 0.14 & 0.20 & 0.24 & 0.28 & 0.13 & 0.25 & 0.15 & 0.26 \\
\hline Academic Competence and Motivation & 0.28 & 0.33 & 0.25 & 0.36 & 0.35 & 0.41 & 0.27 & 0.32 & 0.34 & 0.40 & 0.20 & 0.27 & 0.27 & 0.33 \\
\hline Altruistic Behavior & 0.00 & 0.02 & 0.06 & 0.11 & 0.01 & 0.05 & 0.00 & 0.01 & 0.01 & 0.05 & 0.03 & 0.07 & 0.00 & 0.06 \\
\hline Positive Social Behavior & 0.14 & 0.22 & 0.21 & 0.32 & 0.15 & 0.27 & 0.11 & 0.15 & 0.27 & 0.41 & 0.17 & 0.29 & 0.19 & 0.24 \\
\hline Problem Behavior & 0.19 & 0.24 & 0.19 & 0.26 & 0.09 & 0.21 & 0.15 & 0.19 & 0.36 & 0.48 & 0.24 & 0.31 & 0.13 & 0.18 \\
\hline \multicolumn{15}{|l|}{ Teacher-reported (school) } \\
\hline Student Support for Teachers & 0.11 & 0.14 & 0.19 & 0.22 & 0.27 & 0.27 & 0.37 & 0.43 & 0.55 & 0.54 & 0.58 & 0.59 & 0.23 & 0.22 \\
\hline Feelings of Safety & 0.21 & 0.20 & 0.17 & 0.27 & 0.08 & 0.11 & 0.31 & 0.30 & 0.32 & 0.29 & 0.39 & 0.41 & 0.19 & 0.20 \\
\hline
\end{tabular}

NOTE: Abbreviations are

ABC: Academic and Behavioral Competencies Program

PA: Positive Action

CSP: Competence Support Program

LBW: Love In a Big World

PATHS: Promoting Alternative Thinking Strategies

SS: Second Step

4Rs: The 4Rs Program (Reading, Writing, Respect, and Resolution)

SOURCE: The Social and Character Development (SACD) Research Program. 


\section{Construction of Sample Weights}

Two sets of weights were constructed for the year-by-year SACD analysis: (1) base weights assigned equal weight to each program and to each school within a program, and (2) adjusted weights modified the base weights for study nonconsent, interview nonresponse, and students who entered the study schools after fall 2004 (new entrants). The weighting approach means that the combined-program impacts were the simple averages of the program impacts (based on the same covariates within the regression), the program impacts were the simple averages of the school impacts, and the school impacts were weighted averages of the impacts in each classroom, with weights proportional to classroom size. The weighting approach was chosen to generate the average impact across schools (and programs) in the sample. This approach was grounded in the study design, in which random assignment was conducted at the school level within programs. This weighting approach produced unbiased estimates of the average treatment effect for the study schools and programs that were purposively selected for the evaluation. This approach was consistent with an analysis in which the 84 school means were used in the regression models (that is, a between-school analysis), and the model included treatment-by-program interactions that were weighted equally to estimate the overall crosssite impact.

\section{Base Weights}

For each spring (2005-07) follow-up instrument, base weights were constructed with the following properties:

- Within each school, each survey respondent had the same weight.

- Within each program, the weights in each school summed to the same value.

- The weights in each program summed to the same value (equal to the average program sample size).

- The sum of all the weights was equal to twice the original sample size (because, through random assignment, the control and treatment groups each represented the sample).

To satisfy these objectives, the base weights for the student-level outcome measures were calculated using the following formula:

$$
\text { (1) } \text { baseweight }_{s p}=\left(\frac{\bar{n}_{s p}}{n_{s p}}\right) *\left(\frac{\overline{s c h}_{p}}{s c h_{p}}\right)
$$

where baseweights is the weight for a child respondent in school $s$ and program $p, \bar{n}_{s p}$ is the average number of child respondents per study school, $n_{s p}$ is the number of respondents in school $s$ and program $p, \overline{s c h}_{p}$ is the average number of schools per program, and $s c h_{p}$ is the number of schools in program $p$.

Equation (1) was also used to construct base weights for the school-level outcome measures from the Teacher Report on Classroom and School data. However in this case, the first term on the right-hand side of equation (1) refers to the number of third-, fourth-, and fifth-grade teacher respondents in the school instead of the number of child respondents. That is, the numerator of the first term is the average number of teacher respondents per study school, and the denominator is the number of teacher respondents in school $s$ and $\operatorname{program} p$.

Base weights were constructed using the total number of respondents who completed each instrument, regardless of the incidence of missing data for specific variables in the instruments.

\section{Adjusted Weights}

To account for study nonconsent and interview nonresponse, adjusted weights were constructed for the student-level and the school-level outcome measures so that the impact estimates could be generalized to the 
full sample universe, rather than to those with follow-up data only. For the student-level outcome measures, the original cohort children (stayers) in a classroom who responded to an instrument were assumed to be representative of all original cohort children (stayers) in that classroom. This approach adjusted for different survey response rates across classrooms and used the following equation:

$$
\text { (2) } a d j_{-} w t_{-} c h i l d_{c s p}=\left(\frac{\bar{n}_{c s p}}{n_{c s p}}\right) *\left(\frac{\bar{c}_{s p}}{c_{s p}}\right) *\left(\frac{\overline{s c h}_{p}}{s c h_{p}}\right)
$$

Thus, adj_wt_child $d_{c p}$ is the adjusted weight based on enrollment for an original cohort child (stayer) in school $s$ and program $p, \bar{n}_{c s p}$ refers to the average number of fifth-grade stayers per classroom $c$ in school $s$ at program $p, n_{c s p}$ refers to the number of stayer respondents in a specific classroom $c$ in school $s$ at $\operatorname{program} p$, $\bar{c}_{s p}$ refers to the average number of classrooms in schools across programs, and $c_{s p}$ refers to the number of classrooms in school $s$ at program $p$.

Because new entrants were less likely to get parental consent than the original cohort of children, the adjusted weights for the child assessments were constructed separately for the two groups of children. There were very few new entrants within some classrooms, so the nonresponse and nonconsent adjustments were conducted at the school level for this group. The equation for the adjusted weights for new entrants, which does not include a classroom-level component, is as follows:

$$
\text { (3) adj_wt_new_entrant } t_{s p}=\left(\frac{\bar{n}_{s p}}{n_{s p}}\right) *\left(\frac{\overline{s c h}_{p}}{s c h_{p}}\right)
$$

where adj_wt_new_entrantsp is the adjusted weight based on enrollment for a new entrant child in school $s$ and program $p, \bar{n}_{s p}$ is the average population of new entrants per study school, and $n_{s p}$ is the number of new entrant respondents in school $s$ and program $p$.

For the school-level outcome measures, the responding teachers were assumed to be representative of third-, fourth-, and fifth-grade teachers in that school, which means that there is no classroom-level component in the construction of the Teacher Report on Classroom and School adjusted weights. The equation for these weights is as follows:

$$
\text { (4) } a d j_{-} w t_{-} T R C S_{s p}=\left(\frac{\bar{n}_{s p}}{n_{s p}}\right) *\left(\frac{\overline{s c h}_{p}}{s c h_{p}}\right)
$$

where $\bar{n}_{s p}$ is the average population of teachers per study school and $n_{s p}$ is the number of teacher respondents in school $s$ and program $p$.

\section{Weights for the Growth Curve Analysis}

The growth curve analysis included data from every survey wave. Weights were constructed specifically for the growth curve analysis in order to maintain the equal representation of programs in the analysis. The growth curve weights were constructed only at the child level because the growth curve analysis was only performed for child-level outcomes. Growth curve weights were constructed with the following properties:

- Within each school and survey period, each student had the same weight.

- Within each program and survey period, the weights in each school summed to the same value.

- Within each survey period, the weights in each program summed to the same value.

- The weights within each survey period summed to the same value for all survey periods. 
The formula for the growth weights is as follows:

$$
\text { (5) } \text { GCweight }_{t, i, p}=\left(\frac{\bar{r}}{r_{t}}\right) *\left(\frac{\bar{n}_{t, k i d s}}{n_{t, i, p}}\right) *\left(\frac{\overline{s c h}_{t}}{s c h_{t, p}}\right)
$$

where GC weight $t_{t, i, p}$ is the weight for students at survey period $t$, in school $i$ in program $p ; \bar{n}_{t, k i d s}$ represents the average number of students in a school at survey period $t ; n_{t, i, s}$ represents the number of students in school $i$ in program $s$ at survey period $t ; \overline{s c h}_{t}$ represents the average number of schools in a program at survey period $t$, and $s c_{t, s}$ represents the number of schools in program $s$ at survey period $t$. The average number of students in a survey period is represented by $\bar{r}$, while $r_{t}$ represents the number of students within survey period $t$.

\section{Sensitivity Analysis}

The hierarchical linear modeling (HLM) framework for estimating the impacts of the SACD programs on key child and school outcomes estimated impacts using regression models, where the standard errors of the impact estimates accounted for design effects due to school-level clustering and precision gains due to the inclusion of baseline covariates in the models (Bryk and Raudenbush 1992).

To implement the HLM framework, it was necessary to make decisions about key model parameter specifications and estimation methods. A set of sensitivity analyses was done to determine if these model assumptions affected the results from the combined-program impact analysis for the 18 student-level outcome measures. Ten sensitivity tests were done and these included the following variations:

- No initial covariates were included in the regression models.

- The sample weights were not adjusted for study nonconsent and interview nonresponse and when models were estimated without weights.

- The error structure included classroom-level random effects.

- The error structure accounted for the pairwise matching of schools.

- The pretests were treated as dependent variables rather than as covariates.

- The impacts were estimated using alternative estimation routines (statistical software packages).

- Missing outcome measures were imputed using multiple imputation procedures.

- Combined-program impact estimates were obtained by averaging the program-level impact estimates.

- Various sets of covariates were included in the regression models.

- New entrants were excluded from the analysis.

The number of sensitivity analyses done declined each year as the pattern of impact results from the original model proved robust to a variety of model specifications. All 10 sensitivity analyses were done with the Year 1 data. The first 9 sensitivity tests were done with the Year 2 data. The sample of new entrants grew large enough in Years 2 and 3 to do separate analyses of new entrants versus stayers (in place of the 10th sensitivity test) and these were included in the subgroup analyses discussed in chapter 1. The 1st, 2nd (except for the estimation without weights), 3rd, and 4th sensitivity tests were done using the Year 3 data. The sensitivity analyses and their results are discussed below. 


\section{Excluding Covariates}

Under the experimental design, the inclusion of baseline covariates was not required to obtain unbiased impact estimates. However, covariates were used because they increased the precision of the impact estimates by explaining some of the variations in the outcome measures between schools and across students within schools. In addition, covariates adjusted for residual differences between the baseline characteristics of treatment and control group members due to random sampling, study nonconsent, and interview nonresponse.

As a specification test, the combined-program models were estimated with no covariates except for site binary variables (table B.19). As with the original impact estimates, no significant impacts were found from these simple differences-in-means estimates. 
Table B.19. Combined-program impacts in effect size units when baseline covariates are excluded from the models

\begin{tabular}{|c|c|c|c|c|c|c|}
\hline \multirow[b]{2}{*}{ Scale-Report } & \multicolumn{2}{|c|}{$\begin{array}{c}\text { Year } 1 \\
\text { (Spring 2005) } \\
\end{array}$} & \multicolumn{2}{|c|}{$\begin{array}{c}\text { Year } 2 \\
\text { (Spring 2006) } \\
\end{array}$} & \multicolumn{2}{|c|}{$\begin{array}{c}\text { Year } 3 \\
\text { (Spring 2007) }\end{array}$} \\
\hline & Impact $^{1}$ & $\begin{array}{c}p \text {-value of } \\
\text { impact }^{2}\end{array}$ & Impact $^{1}$ & $\begin{array}{c}p \text {-value of } \\
\text { impact }^{2}\end{array}$ & Impact ${ }^{1}$ & $\begin{array}{r}p \text {-value of } \\
\text { impact }^{2}\end{array}$ \\
\hline \multicolumn{7}{|l|}{ Social and Emotional Competence Domain } \\
\hline Self-Efficacy for Peer Interactions-CR (+) & -0.05 & 0.281 & -0.07 & 0.164 & -0.04 & 0.295 \\
\hline Normative Beliefs About Aggression-CR (-) & -0.01 & 0.766 & -0.01 & 0.912 & 0.03 & 0.673 \\
\hline Empathy-CR (+) & 0.06 & 0.298 & -0.04 & 0.524 & -0.07 & 0.254 \\
\hline \multicolumn{7}{|l|}{ Behavior Domain } \\
\hline Altruistic Behavior-CR (+) & -0.06 & 0.295 & -0.06 & 0.208 & -0.02 & 0.626 \\
\hline Altruistic Behavior-PCR (+) & 0.05 & 0.274 & 0.01 & 0.836 & -0.01 & 0.861 \\
\hline Altruistic Behavior-TRS (+) & 0.12 & 0.253 & 0.02 & 0.910 & -0.05 & 0.695 \\
\hline Positive Social Behavior-PCR (+) & -0.01 & 0.898 & 0.04 & 0.532 & 0.01 & 0.907 \\
\hline Positive Social Behavior-TRS (+) & 0.02 & 0.830 & -0.05 & 0.597 & -0.01 & 0.917 \\
\hline Problem Behavior-CR (-) & 0.02 & 0.741 & 0.03 & 0.738 & 0.08 & 0.341 \\
\hline Problem Behavior-PCR (+) & -0.04 & 0.483 & -0.07 & 0.142 & -0.06 & 0.283 \\
\hline Problem Behavior-TRS (+) & 0.03 & 0.762 & 0.00 & 0.989 & 0.00 & 0.994 \\
\hline ADHD-Related Behavior-TRS (-) & 0.01 & 0.871 & -0.01 & 0.867 & -0.03 & 0.610 \\
\hline \multicolumn{7}{|l|}{ Academics Domain } \\
\hline Engagement with Learning-CR (+) & -0.06 & 0.183 & -0.05 & 0.217 & -0.06 & 0.237 \\
\hline $\begin{array}{l}\text { Academic Competence and } \\
\text { Motivation-TRS }(+)\end{array}$ & -0.06 & 0.333 & -0.07 & 0.298 & -0.07 & 0.290 \\
\hline \multicolumn{7}{|l|}{ Perceptions of School Climate Domain } \\
\hline Positive School Orientation-CR (+) & 0.01 & 0.933 & 0.00 & 0.993 & -0.09 & 0.363 \\
\hline Negative School Orientation-CR (-) & -0.02 & 0.735 & 0.01 & 0.942 & 0.02 & 0.753 \\
\hline Student Afraid at School-CR (-) & -0.04 & 0.480 & -0.05 & 0.488 & 0.00 & 0.981 \\
\hline Victimization at School-CR (-) & -0.02 & 0.637 & -0.04 & 0.458 & 0.00 & 0.978 \\
\hline
\end{tabular}

${ }^{1}$ Impacts are in effect size (standard deviation) units and were calculated by dividing the estimated impact by the standard deviation of the outcome measure for the control group.

${ }^{2}$ The $p$-value is from a two-tailed $t$ test to gauge the statistical significance of the impact estimate.

NOTE: Abbreviations are

CR: Child Report

PCR: Primary Caregiver Report

TRS: Teacher Report on Student

ADHD: Attention deficit hyperactivity disorder

The $+/$ - signs in parentheses indicate the direction of a beneficial outcome. No findings were found statistically significant at or below the .05 level. All impact estimates were calculated using regression models, where each program and school within a program was weighted equally. The standard errors of all estimates account for design effects due to unequal weighting and the clustering of students within schools.

SOURCE: The Social and Character Development (SACD) Research Program. 


\section{Employing Alternative Weighting Schemes}

As discussed earlier in this appendix, the impact models were estimated using sample weights. The weights were constructed so that each site and each school within a site were given equal weight in the analysis, and survey respondents were assumed to represent not only themselves but also study nonconsenters and survey nonrespondents in the same classroom (by new entrant/original cohort status).

To examine the sensitivity of results to different weighting schemes, models were estimated using weights not adjusted for study nonconsent and survey nonresponse for each of the 3 years (table B.20). In addition, models were estimated without weights for Years 1 and 2 (table B.21). The alternative weighting schemes did not change the statistical significance of the estimated impacts with one exception: a detrimental impact was found for Altruistic Behavior (CR) in Year 1 when weights were not adjusted for study nonconsent and survey nonresponse. 
Table B.20. Combined-program impacts in effect size units when weights are not adjusted for study nonconsent or survey nonresponse

\begin{tabular}{|c|c|c|c|c|c|c|}
\hline \multirow[b]{2}{*}{ Scale-Report } & \multicolumn{2}{|c|}{$\begin{array}{c}\text { Year } 1 \\
\text { (Spring 2005) }\end{array}$} & \multicolumn{2}{|c|}{$\begin{array}{c}\text { Year } 2 \\
\text { (Spring 2006) }\end{array}$} & \multicolumn{2}{|c|}{$\begin{array}{c}\text { Year } 3 \\
\text { (Spring 2007) }\end{array}$} \\
\hline & Impact $^{1}$ & $\begin{array}{r}p \text {-value of } \\
\text { impact }^{2}\end{array}$ & Impact $^{1}$ & $\begin{array}{r}p \text {-value of } \\
\text { impact }^{2}\end{array}$ & Impact $^{1}$ & $\begin{array}{r}p \text {-value of } \\
\text { impact }^{2}\end{array}$ \\
\hline \multicolumn{7}{|l|}{ Social and Emotional Competence Domain } \\
\hline Self-Efficacy for Peer Interactions-CR (+) & -0.05 & 0.236 & $-0.07^{\wedge}$ & 0.073 & -0.04 & 0.298 \\
\hline Normative Beliefs About Aggression-CR (-) & 0.00 & 0.950 & -0.02 & 0.773 & 0.02 & 0.788 \\
\hline Empathy-CR (+) & 0.05 & 0.272 & 0.00 & 0.962 & -0.03 & 0.529 \\
\hline \multicolumn{7}{|l|}{ Behavior Domain } \\
\hline Altruistic Behavior-CR (+) & $-0.07^{*}$ & 0.041 & -0.04 & 0.384 & -0.03 & 0.452 \\
\hline Altruistic Behavior-PCR (+) & $0.06^{\wedge}$ & 0.078 & -0.02 & 0.530 & 0.04 & 0.445 \\
\hline Altruistic Behavior-TRS (+) & 0.06 & 0.483 & -0.01 & 0.959 & -0.07 & 0.548 \\
\hline Positive Social Behavior-PCR (+) & 0.00 & 0.870 & 0.05 & 0.134 & 0.04 & 0.321 \\
\hline Positive Social Behavior-TRS (+) & 0.01 & 0.767 & -0.02 & 0.748 & 0.04 & 0.522 \\
\hline Problem Behavior-CR (-) & 0.01 & 0.819 & 0.00 & 0.942 & 0.04 & 0.396 \\
\hline Problem Behavior-PCR (+) & 0.00 & 0.985 & -0.06 & 0.119 & -0.03 & 0.504 \\
\hline Problem Behavior-TRS (+) & 0.03 & 0.503 & -0.04 & 0.402 & -0.06 & 0.279 \\
\hline ADHD-Related Behavior-TRS (-) & 0.01 & 0.866 & -0.05 & 0.347 & -0.13 & 0.122 \\
\hline \multicolumn{7}{|l|}{ Academics Domain } \\
\hline Engagement with Learning-CR $(+)$ & -0.05 & 0.154 & -0.01 & 0.721 & -0.04 & 0.308 \\
\hline $\begin{array}{l}\text { Academic Competence and } \\
\text { Motivation-TRS }(+)\end{array}$ & -0.02 & 0.365 & 0.00 & 0.929 & 0.01 & 0.924 \\
\hline \multicolumn{7}{|l|}{ Perceptions of School Climate Domain } \\
\hline Positive School Orientation-CR (+) & 0.03 & 0.547 & 0.04 & 0.634 & -0.07 & 0.387 \\
\hline Negative School Orientation-CR (-) & -0.03 & 0.320 & -0.04 & 0.365 & -0.02 & 0.726 \\
\hline Student Afraid at School-CR (-) & -0.05 & 0.211 & -0.07 & 0.145 & 0.00 & 0.970 \\
\hline Victimization at School-CR (-) & 0.00 & 0.940 & -0.04 & 0.391 & 0.00 & 0.959 \\
\hline
\end{tabular}

* Significantly different from zero at the .05 level.

$\wedge$ Significantly different from zero at the .10 to $>.05$ level.

${ }^{1}$ Impacts are in effect size (standard deviation) units and were calculated by dividing the estimated impact by the standard deviation of the outcome measure for the control group.

${ }^{2}$ The $p$-value is from a two-tailed $t$ test to gauge the statistical significance of the impact estimate.

NOTE: Abbreviations are

CR: Child Report

PCR: Primary Caregiver Report

TRS: Teacher Report on Student

ADHD: Attention deficit hyperactivity disorder

The +/- signs in parentheses indicate the direction of a beneficial outcome. All impact estimates were calculated using regression models, where each program and school within a program was weighted equally. The standard errors of all estimates account for design effects due to unequal weighting and the clustering of students within schools.

SOURCE: The Social and Character Development (SACD) Research Program. 
Table B.21. Combined-program impacts in effect size units when weights are not used

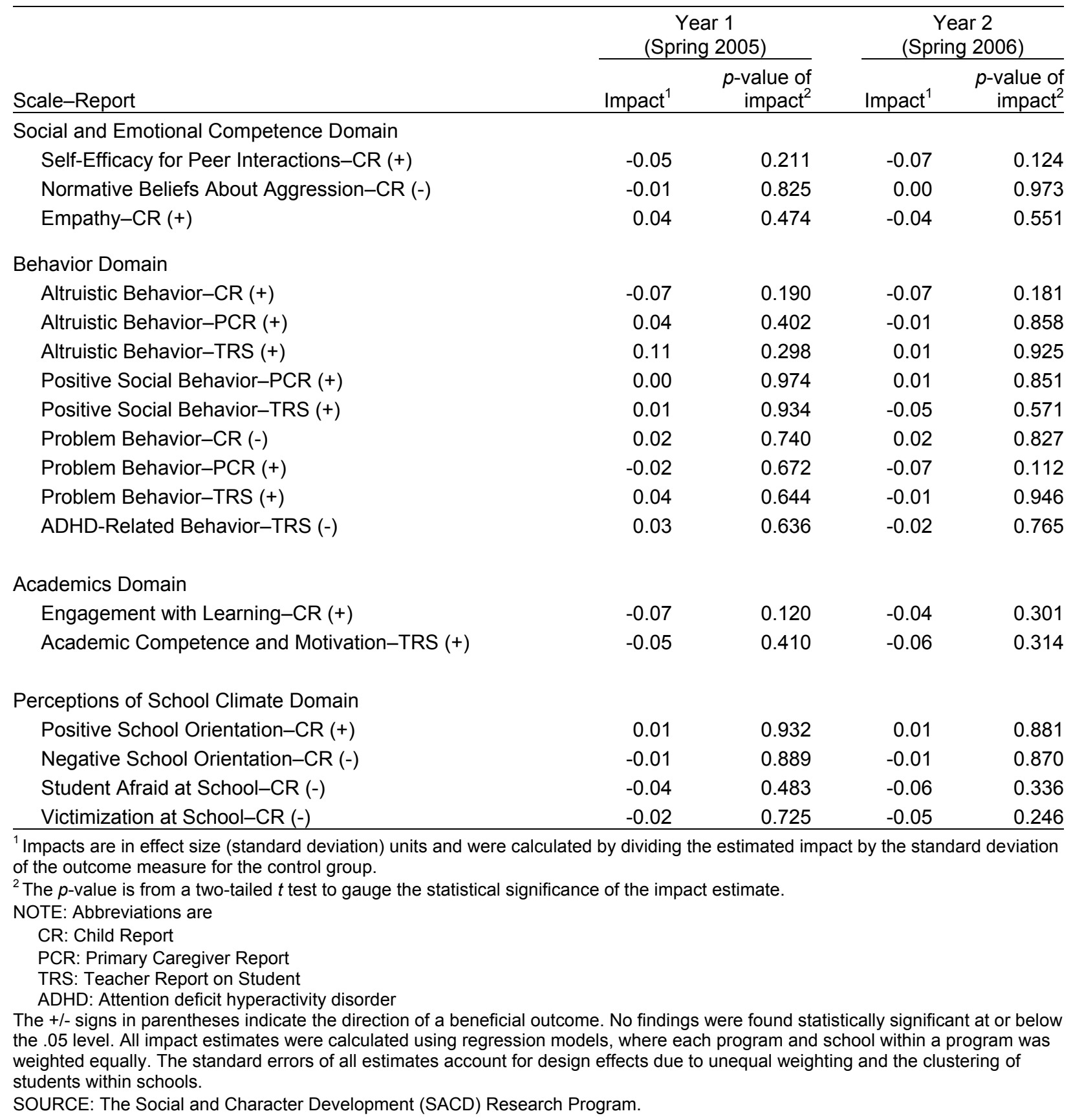




\section{Including Classroom-Level Random Effects in the Error Structure}

In the original models, adjustments were made for the clustering of students within schools but not for the clustering of students within classrooms. This is because classrooms were not sampled for the study; instead, all classrooms within the study schools were included in the evaluation. Thus, the impact estimates generalized to the set of classrooms and teachers that were in the study schools at the time of the evaluation.

An alternative view would be that the estimated impact findings generalized to a broader, but unknown, population of classrooms within the study schools. To accommodate this view, classroom-level random effects were included in the models using a three-level HLM model that was indexed by students $(i)$, classrooms $(c)$, schools $(s)$, and fixed site effects $(d)$ :

$$
\begin{array}{ll}
\text { Level 1: Students: } & Y_{i c s d}=\alpha_{0 c s d}+X_{i c s d} \beta+e_{i c s d} \\
\text { Level 2: Classrooms: } & \alpha_{0 c s d}=\lambda_{00 s d}+W_{c s d} \pi+\eta_{c s d} \\
\text { Level 3:Schools: } & \lambda_{00 s d}=\gamma_{0}+\gamma_{1} T_{s d}+\theta_{d} G_{d}+Z_{s d} \delta+u_{s d}
\end{array}
$$

In this model, $Y_{i s d}$ is an outcome measure for a student; $\alpha_{0 \text { ssd }}$ is a classroom-level random intercept; $\lambda_{00 s d}$ is school-level random intercept; $X_{i s d}$ are student-level baseline covariates; $W_{\text {ssd }}$ are teacher-level baseline covariates; $T_{s d}$ is a binary variable equal to 1 for treatment group schools and 0 for control group schools; $G_{d}$ are binary variables for each grantee; $Z_{s d}$ are school-level baseline covariates ${ }^{11} ; \beta, \pi, \gamma_{0}, \gamma_{l}, \theta_{d}$, and $\delta$ are parameter vectors to be estimated; $e_{i s s}$ are assumed to be iid $N\left(0, \sigma_{e}^{2}\right)$ student- or teacher-level random error terms; $\eta_{\text {csd }}$ are iid $N\left(0, \sigma_{\eta}^{2} \eta\right)$ classroom-specific error terms that are assumed to be distributed independently of the Level 1 error terms; and $u_{s d}$ are iid $\left(0, \sigma_{n}^{2}\right)$ school-specific error terms that are assumed to be distributed independently of the Level 1 and 2 error terms.

Inserting the Level 2 and 3 equations into the Level 1 equation yields the following unified model:

$$
\text { (7) } Y_{i c s d}=\gamma_{0}+\gamma_{1} T_{s d}+\theta_{d} G_{d}+Z_{s d} \delta+W_{c s d} \pi+X_{i c s d} \beta+\left[u_{s d}+\eta_{c s d}+e_{i c s d}\right]
$$

In this formulation, the estimate of the parameter, $\gamma_{1}$, is the regression-adjusted, multisite impact estimate. This equation is similar to the two-level benchmark model in equation (1) in the main report except that it includes the random classroom effect $\eta_{\text {ssd }}$ in the error term. As with the original impact estimates, no significant impacts were found when addressing the clustering of students within classroom (table B.22).

${ }^{11}$ In practice, school-level covariates were not used in estimation. 
Table B.22. Combined-program impacts in effect size units when accounting for classroom-level clustering

\begin{tabular}{|c|c|c|c|c|c|c|}
\hline \multirow[b]{2}{*}{ Scale-Report } & \multicolumn{2}{|c|}{$\begin{array}{c}\text { Year } 1 \\
\text { (Spring 2005) }\end{array}$} & \multicolumn{2}{|c|}{$\begin{array}{c}\text { Year } 2 \\
\text { (Spring 2006) }\end{array}$} & \multicolumn{2}{|c|}{$\begin{array}{c}\text { Year } 3 \\
\text { (Spring 2007) }\end{array}$} \\
\hline & Impact ${ }^{1}$ & $\begin{array}{r}p \text {-value of } \\
\text { impact }^{2}\end{array}$ & Impact $^{1}$ & $\begin{array}{c}p \text {-value of } \\
\text { impact }^{2}\end{array}$ & Impact $^{1}$ & $\begin{array}{r}p \text {-value of } \\
\text { impact }^{2} \\
\end{array}$ \\
\hline \multicolumn{7}{|l|}{ Social and Emotional Competence Domain } \\
\hline Self-Efficacy for Peer Interactions-CR (+) & -0.02 & 0.548 & $-0.07^{\wedge}$ & 0.055 & -0.06 & 0.114 \\
\hline Normative Beliefs About Aggression-CR (-) & -0.01 & 0.796 & -0.01 & 0.776 & 0.00 & 0.970 \\
\hline Empathy-CR (+) & 0.06 & 0.186 & -0.02 & 0.746 & -0.05 & 0.254 \\
\hline \multicolumn{7}{|l|}{ Behavior Domain } \\
\hline Altruistic Behavior-CR (+) & -0.06 & 0.115 & -0.06 & 0.162 & -0.03 & 0.408 \\
\hline Altruistic Behavior-PCR (+) & $0.07^{\wedge}$ & 0.066 & -0.01 & 0.871 & -0.02 & 0.609 \\
\hline Altruistic Behavior-TRS (+) & $0.15^{\wedge}$ & 0.077 & 0.05 & 0.545 & -0.03 & 0.671 \\
\hline Positive Social Behavior-PCR (+) & -0.01 & 0.632 & 0.04 & 0.264 & 0.02 & 0.526 \\
\hline Positive Social Behavior-TRS (+) & 0.01 & 0.703 & 0.01 & 0.849 & 0.05 & 0.400 \\
\hline Problem Behavior-CR (-) & 0.00 & 0.993 & 0.00 & 0.940 & 0.05 & 0.299 \\
\hline Problem Behavior-PCR (+) & 0.01 & 0.876 & -0.03 & 0.336 & -0.03 & 0.435 \\
\hline Problem Behavior-TRS (+) & 0.03 & 0.506 & -0.03 & 0.598 & -0.02 & 0.678 \\
\hline ADHD-Related Behavior-TRS (-) & 0.00 & 0.935 & -0.05 & 0.344 & -0.03 & 0.492 \\
\hline \multicolumn{7}{|l|}{ Academics Domain } \\
\hline Engagement with Learning-CR (+) & -0.04 & 0.240 & -0.02 & 0.643 & -0.03 & 0.509 \\
\hline Academic Competence and & & & & & & \\
\hline Motivation-TRS (+) & -0.01 & 0.614 & -0.01 & 0.772 & 0.00 & 0.928 \\
\hline \multicolumn{7}{|l|}{ Perceptions of School Climate Domain } \\
\hline Positive School Orientation-CR (+) & 0.03 & 0.554 & 0.04 & 0.611 & -0.08 & 0.310 \\
\hline Negative School Orientation-CR (-) & -0.05 & 0.180 & -0.04 & 0.451 & -0.01 & 0.885 \\
\hline Student Afraid at School-CR (-) & -0.06 & 0.144 & -0.08 & 0.101 & -0.01 & 0.867 \\
\hline Victimization at School-CR (-) & -0.02 & 0.661 & -0.05 & 0.321 & 0.00 & 0.958 \\
\hline
\end{tabular}

$\wedge$ Significantly different from zero at the .10 to $>.05$ level.

${ }^{1}$ Impacts are in effect size (standard deviation) units and were calculated by dividing the estimated impact by the standard deviation of the outcome measure for the control group.

${ }^{2}$ The $p$-value is from a two-tailed $t$ test to gauge the statistical significance of the impact estimate.

NOTE: Abbreviations are

CR: Child Report

PCR: Primary Caregiver Report

TRS: Teacher Report on Student

ADHD: Attention deficit hyperactivity disorder

The +/- signs in parentheses indicate the direction of a beneficial outcome. No findings were found statistically significant below the .05 level. All impact estimates were calculated using regression models, where each program and school within a program was weighted equally. The standard errors of all estimates account for design effects due to unequal weighting and the clustering of students within schools.

SOURCE: The Social and Character Development (SACD) Research Program. 


\section{Accounting for the Pairwise Matching of Schools}

Under an experimental design where the random assignment of units is conducted within strata, it is customary to account for the stratified design in the analysis by including binary variables of the strata as covariates in the regression models. Under a clustered design, the inclusion of these variables will reduce design effects to the extent that they are correlated with the outcome measures. Stated differently, under stratified designs, intraclass correlations (ICCs) pertain to design effects within strata. Thus, stratified sampling will reduce ICCs if mean school outcomes tend to be more similar within strata than across strata.

This procedure, however, cannot be used for a design where random assignment is conducted for units within matched pairs. This is because when pair binary variables and pair-by-treatment interaction terms are included as model covariates, the school-level variance term represents the extent to which mean school outcomes vary within pairs and within a research group (Murray 1998). Thus, because there is only one treatment and one control group unit per pair, there are not enough degrees of freedom to estimate the within-pair variance terms.

To account for this problem, the pairs were treated as another HLM level. Specifically, the following threelevel HLM model was estimated, where pairs were indexed by $p$ :

$$
\begin{array}{ll}
\text { Level 1: Students/Teachers: } & Y_{i s p d}=\alpha_{0 s p d}+X_{i s p d} \beta+e_{i s p d} \\
\text { Level 2: Schools: } & \alpha_{0 s p d}=\gamma_{0 p d}+\gamma_{1 p d} T_{s p d}+\theta_{d} G_{d}+Z_{s p d} \delta+u_{s p d} \\
\text { Level 3: Pairs: } & \gamma_{0 p d}=\lambda_{0}+\phi_{p d} ; \gamma_{1 p d}=\lambda_{1}+\tau_{p d}
\end{array}
$$

In this model, $\phi_{p d}$ and $\tau_{p d}$ are independent and identically distributed $N\left(0, \sigma_{\phi}^{2}\right)$ and independent and identically distributed $N\left(0, \sigma_{\tau}^{2}\right)$ pair-level random error terms, respectively. Recursively inserting the Level 2 and 3 equations into the Level 1 equation yields the following unified model:

$$
Y_{i s p d}=\lambda_{0}+\lambda_{1} T_{s p d}+\theta_{d} G_{d}+Z_{s p d} \delta+X_{i s p d} \beta+\left[\tau_{p} T_{s p d}+\emptyset_{p}+u_{s p d}+e_{i s p d}\right]
$$

Under this model, the key estimatable component of the variance expression for the impact estimate is $\left(\sigma_{\tau}^{2} / P\right)$, where $P$ is the total number of pairs. This variance component signifies the extent to which impacts vary across pairs. In contrast, the leading term in the variance expression for the benchmark approach is $\left(2 \sigma_{u}^{2} / P\right)$, which signifies the extent to which mean outcomes vary across schools.

It is unclear a priori whether the pairwise matching model will produce more precise impact estimates than the original approach. On the one hand, precision gains could occur if $\sigma_{\tau}^{2}<2 \sigma_{u}^{2}$ which will likely be the case as long as there is some correlation between mean outcomes for the treatment and control group schools within the same pairs (that is, if the matching was somewhat "successful"). On the other hand, precision losses will occur due to a reduction in the number of degrees of freedom available for analysis, because there are only half as many pairs as there are schools. Thus, it is an empirical issue as to which approach will yield more precise impact estimates.

Accounting for pairwise matching in the analysis did not change the statistical significance of the estimated impacts with one exception: a detrimental impact was found for Altruistic Behavior (CR) in Year 1 (table B.23). 
Table B.23. Combined-program impacts in effect size units when accounting for pairwise matching

\begin{tabular}{|c|c|c|c|c|c|c|}
\hline \multirow[b]{2}{*}{ Scale-Report } & \multicolumn{2}{|c|}{$\begin{array}{c}\text { Year } 1 \\
\text { (Spring 2005) } \\
\end{array}$} & \multicolumn{2}{|c|}{$\begin{array}{c}\text { Year } 2 \\
\text { (Spring 2006) } \\
\end{array}$} & \multicolumn{2}{|c|}{$\begin{array}{c}\text { Year } 3 \\
\text { (Spring 2007) } \\
\end{array}$} \\
\hline & Impact $^{1}$ & $\begin{array}{r}p \text {-value of } \\
\text { impact }^{2}\end{array}$ & Impact $^{1}$ & $\begin{array}{r}p \text {-value of } \\
\text { impact }^{2}\end{array}$ & Impact $^{1}$ & $\begin{array}{r}p \text {-value of } \\
\text { impact }^{2} \\
\end{array}$ \\
\hline \multicolumn{7}{|l|}{ Social and Emotional Competence Domain } \\
\hline Self-Efficacy for Peer Interactions-CR (+) & -0.03 & 0.386 & -0.07 & 0.135 & -0.05 & 0.217 \\
\hline Normative Beliefs About Aggression-CR (-) & 0.00 & 0.951 & 0.00 & 0.957 & 0.01 & 0.876 \\
\hline Empathy-CR (+) & 0.05 & 0.302 & -0.02 & 0.742 & -0.05 & 0.343 \\
\hline \multicolumn{7}{|l|}{ Behavior Domain } \\
\hline Altruistic Behavior-CR (+) & $-0.07^{*}$ & 0.036 & -0.03 & 0.444 & -0.03 & 0.477 \\
\hline Altruistic Behavior-PCR (+) & 0.05 & 0.118 & -0.03 & 0.420 & -0.06 & 0.157 \\
\hline Altruistic Behavior-TRS (+) & 0.08 & 0.374 & 0.02 & 0.910 & -0.02 & 0.868 \\
\hline Positive Social Behavior-PCR (+) & -0.02 & 0.528 & 0.01 & 0.772 & 0.02 & 0.606 \\
\hline Positive Social Behavior-TRS (+) & 0.01 & 0.709 & -0.03 & 0.618 & 0.05 & 0.470 \\
\hline Problem Behavior-CR (-) & 0.01 & 0.797 & -0.01 & 0.906 & 0.02 & 0.759 \\
\hline Problem Behavior-PCR (+) & -0.01 & 0.814 & -0.02 & 0.602 & -0.05 & 0.371 \\
\hline Problem Behavior-TRS (+) & 0.03 & 0.444 & -0.02 & 0.720 & -0.05 & 0.405 \\
\hline ADHD-Related Behavior-TRS (-) & 0.02 & 0.648 & -0.02 & 0.712 & -0.09 & 0.105 \\
\hline \multicolumn{7}{|l|}{ Academics Domain } \\
\hline Engagement with Learning-CR (+) & $-0.05^{\wedge}$ & 0.083 & -0.03 & 0.508 & -0.06 & 0.201 \\
\hline Academic Competence and & & & & & & \\
\hline Motivation-TRS (+) & -0.03 & 0.345 & -0.04 & 0.338 & -0.02 & 0.718 \\
\hline \multicolumn{7}{|l|}{ Perceptions of School Climate Domain } \\
\hline Positive School Orientation-CR (+) & 0.01 & 0.852 & 0.04 & 0.395 & -0.05 & 0.424 \\
\hline Negative School Orientation-CR (-) & -0.03 & 0.303 & -0.07 & 0.192 & -0.03 & 0.543 \\
\hline Student Afraid at School-CR (-) & $-0.06^{\wedge}$ & 0.089 & -0.05 & 0.328 & 0.04 & 0.440 \\
\hline Victimization at School-CR (-) & 0.00 & 0.999 & -0.03 & 0.370 & 0.01 & 0.791 \\
\hline
\end{tabular}

* Significantly different from zero at the .05 level.

$\wedge$ Significantly different from zero at the .10 to $>.05$ level.

${ }^{1}$ Impacts are in effect size (standard deviation) units and were calculated by dividing the estimated impact by the standard deviation of the outcome measure for the control group.

${ }^{2}$ The $p$-value is from a two-tailed $t$ test to gauge the statistical significance of the impact estimate.

NOTE: Abbreviations are

CR: Child Report

PCR: Primary Caregiver Report

TRS: Teacher Report on Student

ADHD: Attention deficit hyperactivity disorder

The +/- signs in parentheses indicate the direction of a beneficial outcome. All impact estimates were calculated using regression models, where each program and school within a program was weighted equally. The standard errors of all estimates account for design effects due to unequal weighting and the clustering of students within schools.

SOURCE: The Social and Character Development (SACD) Research Program. 


\section{Treating Pretest Measures as Dependent Variables}

In the original model, initial measures of the outcomes were included as covariates in the regression models. An alternative approach was to treat these pretests as dependent variables. This approach was implemented in two ways using Year 1 and Year 2 data. First, models were estimated where the dependent variable was defined as the difference between posttest and pretest scores (that is, gain scores), which yields a difference-indifference estimator. ${ }^{12}$ Second, the pretest and posttest scores were stacked as separate observations and the model included time-by-treatment interaction terms as covariates as shown here:

$$
Y_{i s d}=\gamma_{0}+\gamma_{1} T_{s d}+\gamma_{2} \text { Post }+\gamma_{3} \text { Post } * T_{s d}+X_{i s d} \beta+\theta_{d}+Z_{s d} \delta+\left[u_{s d}+\text { Post } * \eta_{s d}+e_{i s d}\right]
$$

where

- $\quad Y_{i s d}$ is an outcome measure for student (or teacher) $i$;

- $X_{i s d}$ are student-level (or teacher-level) baseline covariates;

- $T_{s d}$ is a binary variable equal to 1 for treatment group schools and 0 for control group schools;

- $\theta_{d}$ are site-specific fixed effects;

- $\quad Z_{s d}$ are school-level baseline covariates; $;^{13}$

- Post is a binary variable that equals 1 for the posttest observations and 0 for the pretest observations;

- $\quad \beta, \gamma_{0}, \gamma_{1}, \gamma_{2}, \gamma_{3}$, and $\delta$ are fixed parameter vectors to be estimated; and

- $e_{i s d}$ are independent and identically distributed $N\left(0, \sigma_{e}^{2}\right)$ student-level (or teacher-level) random error terms.

Furthermore, $u_{s d}$ and $\eta_{s d}$ are independent and identically distributed $N\left(0, \sigma_{u}^{2}\right)$ and $N\left(0, \sigma_{\eta}^{2}\right)$ school-level random error terms, respectively, that capture the correlations between the outcomes of students in the same schools and time periods and that are distributed independently of the student-level (or teacher-level) error terms. In this formulation, the estimate of $\gamma_{3}$ is the difference-in-difference impact estimate, and the leading term in the variance expression for the impact estimate is a function of $\sigma_{\eta}^{2}$, which signifies the extent to which gain scores vary across schools within programs.

For each estimation approach, the new entrants were excluded from the analysis sample because of missing pretest scores. ${ }^{14}$ Thus, the models were estimated using only original cohort members.

In the original model, none of the 36 estimated impacts was found to be significant. The treatment of the pretests as dependent variables rather than as covariates gave similar results with two exceptions. When using the gain score as the dependent variable, a statistically significant beneficial impact was found for Negative School Orientation (in Year 2 with an effect size of -0.15) and Student Afraid at School (in Year 1 with an effect size of 0.09) (table B.24). When using pretests and posttests as dependent variables, a beneficial impact on Negative School Orientation was found in Year 2 (effect size of -0.16) and on Student Afraid at School in Year 1 (effect size of 0.10) (table B.25).

\footnotetext{
${ }^{12}$ In these models, the pretests were excluded from the model covariates, although other covariates remained the same as in the benchmark models.

${ }^{13}$ For teacher-level outcomes, the $Z$ variables included teacher-level baseline covariates. Although the initial model specified the use of school-level covariates, none were used in the empirical estimation.

${ }^{14}$ Using the mean-imputed pretests for the new entrants would yield standard errors that are biased downward.
} 
Table B.24. Combined-program impacts in effect size units when dependent variable is the pretest-posttest difference (gain score)

\begin{tabular}{|c|c|c|c|c|}
\hline \multirow[b]{2}{*}{ Scale-Report } & \multicolumn{2}{|c|}{$\begin{array}{c}\text { Year } 1 \\
\text { (Spring 2005) }\end{array}$} & \multicolumn{2}{|c|}{$\begin{array}{c}\text { Year } 2 \\
\text { (Spring 2006) }\end{array}$} \\
\hline & Impact $^{1}$ & $\begin{array}{r}p \text {-value of } \\
\text { impact }^{2}\end{array}$ & Impact $^{1}$ & $\begin{array}{r}p \text {-value of } \\
\text { impact }^{2}\end{array}$ \\
\hline \multicolumn{5}{|l|}{ Social and Emotional Competence Domain } \\
\hline Self-Efficacy for Peer Interactions-CR (+) & 0.01 & 0.883 & -0.04 & 0.342 \\
\hline Normative Beliefs About Aggression-CR (-) & 0.02 & 0.628 & 0.01 & 0.864 \\
\hline Empathy-CR (+) & 0.03 & 0.663 & -0.01 & 0.805 \\
\hline \multicolumn{5}{|l|}{ Behavior Domain } \\
\hline Altruistic Behavior-CR (+) & $-0.09^{\wedge}$ & 0.057 & -0.04 & 0.482 \\
\hline Altruistic Behavior-PCR (+) & 0.04 & 0.356 & -0.04 & 0.430 \\
\hline Altruistic Behavior-TRS (+) & 0.08 & 0.585 & -0.08 & 0.603 \\
\hline Positive Social Behavior-PCR (+) & -0.02 & 0.569 & 0.03 & 0.546 \\
\hline Positive Social Behavior-TRS (+) & -0.03 & 0.599 & -0.08 & 0.360 \\
\hline Problem Behavior-CR (-) & 0.03 & 0.605 & -0.03 & 0.587 \\
\hline Problem Behavior-PCR (+) & 0.01 & 0.882 & 0.01 & 0.872 \\
\hline Problem Behavior-TRS (+) & 0.08 & 0.249 & 0.00 & 0.998 \\
\hline ADHD-Related Behavior-TRS (-) & 0.06 & 0.320 & 0.00 & 0.989 \\
\hline \multicolumn{5}{|l|}{ Academics Domain } \\
\hline Engagement with Learning-CR (+) & -0.03 & 0.444 & 0.03 & 0.539 \\
\hline Academic Competence and Motivation-TRS (+) & -0.04 & 0.470 & -0.04 & 0.540 \\
\hline \multicolumn{5}{|l|}{ Perceptions of School Climate Domain } \\
\hline Positive School Orientation-CR (+) & 0.00 & 0.989 & 0.07 & 0.239 \\
\hline Negative School Orientation-CR (-) & -0.06 & 0.126 & $-0.15^{\star}$ & 0.007 \\
\hline Student Afraid at School-CR (-) & $-0.09^{*}$ & 0.028 & -0.04 & 0.433 \\
\hline Victimization at School-CR (-) & 0.00 & 0.973 & -0.02 & 0.639 \\
\hline
\end{tabular}

* Significantly different from zero at the .05 level.

^ Significantly different from zero at the .10 to $>.05$ level.

${ }^{1}$ Impacts are in effect size (standard deviation) units and were calculated by dividing the estimated impact by the standard deviation of the outcome measure for the control group.

${ }^{2}$ The $p$-value is from a two-tailed $t$ test to gauge the statistical significance of the impact estimate.

NOTE: Abbreviations are

CR: Child Report

PCR: Primary Caregiver Report

TRS: Teacher Report on Student

ADHD: Attention deficit hyperactivity disorder

The +/- signs in parentheses indicate the direction of a beneficial outcome. All impact estimates were calculated using regression models, where each program and school within a program was weighted equally. The standard errors of all estimates account for design effects due to unequal weighting and the clustering of students within schools.

SOURCE: The Social and Character Development (SACD) Research Program. 
Table B.25. Combined-program impacts in effect size units when posttest and pretest are treated as separate dependent variables

\begin{tabular}{|c|c|c|c|c|}
\hline \multirow[b]{2}{*}{ Scale-Report } & \multicolumn{2}{|c|}{$\begin{array}{c}\text { Year 1 } \\
\text { (Spring 2005) }\end{array}$} & \multicolumn{2}{|c|}{$\begin{array}{c}\text { Year } 2 \\
\text { (Spring 2006) }\end{array}$} \\
\hline & Impact $^{1}$ & $\begin{array}{r}p \text {-value of } \\
\text { impact }^{2}\end{array}$ & Impact $^{1}$ & $\begin{array}{r}p \text {-value of } \\
\text { impact }^{2}\end{array}$ \\
\hline \multicolumn{5}{|l|}{ Social and Emotional Competence Domain } \\
\hline Self-Efficacy for Peer Interactions-CR (+) & 0.01 & 0.818 & -0.04 & 0.417 \\
\hline Normative Beliefs About Aggression-CR (-) & 0.03 & 0.486 & 0.02 & 0.799 \\
\hline Empathy-CR (+) & 0.02 & 0.708 & -0.03 & 0.654 \\
\hline \multicolumn{5}{|l|}{ Behavior Domain } \\
\hline Altruistic Behavior-CR (+) & $-0.09^{\wedge}$ & 0.062 & -0.07 & 0.341 \\
\hline Altruistic Behavior-PCR (+) & 0.03 & 0.567 & -0.04 & 0.461 \\
\hline Altruistic Behavior-TRS (+) & 0.07 & 0.607 & -0.09 & 0.627 \\
\hline Positive Social Behavior-PCR (+) & -0.03 & 0.544 & 0.02 & 0.598 \\
\hline Positive Social Behavior-TRS (+) & -0.02 & 0.645 & -0.08 & 0.369 \\
\hline Problem Behavior-CR (-) & 0.03 & 0.521 & -0.02 & 0.786 \\
\hline Problem Behavior-PCR (+) & 0.01 & 0.785 & 0.02 & 0.715 \\
\hline Problem Behavior-TRS (+) & 0.04 & 0.345 & 0.01 & 0.912 \\
\hline ADHD-Related Behavior-TRS (-) & 0.04 & 0.390 & 0.00 & 0.988 \\
\hline \multicolumn{5}{|l|}{ Academics Domain } \\
\hline Engagement with Learning-CR (+) & -0.05 & 0.419 & 0.01 & 0.843 \\
\hline Academic Competence and Motivation-TRS (+) & -0.01 & 0.683 & -0.03 & 0.535 \\
\hline \multicolumn{5}{|l|}{ Perceptions of School Climate Domain } \\
\hline Positive School Orientation-CR (+) & -0.01 & 0.827 & 0.07 & 0.311 \\
\hline Negative School Orientation-CR (-) & -0.06 & 0.238 & $-0.16^{*}$ & 0.024 \\
\hline Student Afraid at School-CR (-) & $-0.10^{*}$ & 0.043 & -0.05 & 0.394 \\
\hline Victimization at School-CR (-) & 0.00 & 0.944 & -0.02 & 0.692 \\
\hline
\end{tabular}

* Significantly different from zero at the .05 level.

^ Significantly different from zero at the .10 to $>.05$ level.

${ }^{1}$ Impacts are in effect size (standard deviation) units and were calculated by dividing the estimated impact by the standard deviation of the outcome measure for the control group.

${ }^{2}$ The $p$-value is from a two-tailed $t$ test to gauge the statistical significance of the impact estimate.

NOTE: Abbreviations are

CR: Child Report

PCR: Primary Caregiver Report

TRS: Teacher Report on Student

ADHD: Attention deficit hyperactivity disorder

The +/- signs in parentheses indicate the direction of a beneficial outcome. All impact estimates were calculated using regression models, where each program and school within a program was weighted equally. The standard errors of all estimates account for design effects due to unequal weighting and the clustering of students within schools.

SOURCE: The Social and Character Development (SACD) Research Program. 


\section{Using Alternative Software Packages}

The original models were estimated using the PROC MIXED procedure in SAS. To check the sensitivity of the results, the impacts were estimated using alternative statistical packages-SUDAAN PROC REGRESS and HLM6 - that account for clustering effects in slightly different ways than SAS PROC MIXED. SAS PROC MIXED uses a maximum-likelihood approach to general linear mixed models, whereas the SUDAAN procedure is based on the Taylor-series linearization method, combined with variance estimation formulas specific to the sample design. Similar to SAS PROC MIXED, HLM6 uses a restricted maximum likelihood approach to estimate the parameters, but HLM6 uses the Expectation-Maximization algorithm to obtain the estimates, whereas SAS PROC MIXED uses a ridge-stabilized Newton-Raphson algorithm.

The three statistical packages produced similar impact and standard error estimates (table B.26) with one exception. When SUDAAN was used, the estimate for Altruistic Behavior (Primary Caregiver Report) showed a beneficial statistically significant effect in Year 1 (with an effect size of 0.07). 
Table B.26. Combined-program impacts in effect size units when using different statistical software packages

\begin{tabular}{|c|c|c|c|c|c|c|c|c|}
\hline \multirow[b]{3}{*}{ Scale-Report } & \multicolumn{4}{|c|}{$\begin{array}{c}\text { Year } 1 \\
\text { (Spring 2005) } \\
\end{array}$} & \multicolumn{4}{|c|}{$\begin{array}{c}\text { Year } 2 \\
\text { (Spring 2006) } \\
\end{array}$} \\
\hline & \multicolumn{2}{|c|}{ SUDAAN } & \multicolumn{2}{|c|}{ HLM6 } & \multicolumn{2}{|c|}{ SUDAAN } & \multicolumn{2}{|c|}{ HLM6 } \\
\hline & Impact $^{1}$ & $\begin{array}{l}p \text {-value of } \\
\text { impact }^{2}\end{array}$ & Impact $^{1}$ & $\begin{array}{r}p \text {-value of } \\
\text { impact }^{2}\end{array}$ & Impact $^{1}$ & $\begin{array}{r}p \text {-value of } \\
\text { impact }^{2}\end{array}$ & Impact $^{1}$ & $\begin{array}{l}p \text {-value of } \\
\text { impact }^{2}\end{array}$ \\
\hline \multicolumn{9}{|l|}{ Social and Emotional Competence Domain } \\
\hline Self-Efficacy for Peer Interactions-CR (+) & -0.02 & 0.518 & -0.04 & 0.291 & $-0.07^{\wedge}$ & 0.084 & -0.06 & 0.209 \\
\hline Normative Beliefs About Aggression-CR (-) & -0.01 & 0.875 & 0.01 & 0.896 & -0.03 & 0.603 & 0.03 & 0.624 \\
\hline Empathy-CR (+) & 0.06 & 0.148 & 0.05 & 0.223 & -0.02 & 0.729 & -0.01 & 0.779 \\
\hline \multicolumn{9}{|l|}{ Behavior Domain } \\
\hline Altruistic Behavior-CR (+) & $-0.06^{\wedge}$ & 0.092 & -0.06 & 0.105 & -0.06 & 0.144 & -0.03 & 0.430 \\
\hline Altruistic Behavior-PCR (+) & $0.07^{*}$ & 0.037 & 0.05 & 0.213 & 0.00 & 0.963 & -0.02 & 0.605 \\
\hline Altruistic Behavior-TRS (+) & 0.08 & 0.288 & 0.08 & 0.480 & 0.06 & 0.629 & -0.09 & 0.617 \\
\hline Positive Social Behavior-PCR (+) & -0.01 & 0.707 & 0.00 & 0.901 & 0.04 & 0.178 & 0.01 & 0.787 \\
\hline Positive Social Behavior-TRS (+) & 0.02 & 0.625 & 0.01 & 0.812 & -0.02 & 0.728 & -0.03 & 0.691 \\
\hline Problem Behavior-CR (-) & 0.01 & 0.872 & 0.04 & 0.436 & -0.01 & 0.893 & 0.02 & 0.756 \\
\hline Problem Behavior-PCR (+) & 0.00 & 0.940 & -0.04 & 0.308 & -0.03 & 0.300 & -0.02 & 0.633 \\
\hline Problem Behavior-TRS (+) & 0.02 & 0.572 & 0.02 & 0.662 & -0.01 & 0.800 & -0.03 & 0.543 \\
\hline ADHD-Related Behavior-TRS (-) & 0.00 & 0.942 & 0.02 & 0.696 & -0.02 & 0.497 & -0.02 & 0.768 \\
\hline \multicolumn{9}{|l|}{ Academics Domain } \\
\hline Engagement with Learning-CR (+) & -0.04 & 0.182 & $-0.07^{\wedge}$ & 0.053 & -0.03 & 0.400 & -0.03 & 0.521 \\
\hline Academic Competence and Motivation-TRS (+) & -0.02 & 0.365 & $-0.08^{\wedge}$ & 0.053 & -0.02 & 0.498 & -0.05 & 0.282 \\
\hline
\end{tabular}


Table B.26. Combined-program impacts in effect size units when using different statistical software packages-Continued

\begin{tabular}{|c|c|c|c|c|c|c|c|c|}
\hline \multirow[b]{3}{*}{ Scale-Report } & \multicolumn{4}{|c|}{$\begin{array}{c}\text { Year } 1 \\
\text { (Spring 2005) }\end{array}$} & \multicolumn{4}{|c|}{$\begin{array}{c}\text { Year } 2 \\
\text { (Spring 2006) }\end{array}$} \\
\hline & \multicolumn{2}{|c|}{ SUDAAN } & \multicolumn{2}{|c|}{ HLM6 } & \multicolumn{2}{|c|}{ SUDAAN } & \multicolumn{2}{|c|}{ HLM6 } \\
\hline & Impact $^{1}$ & $\begin{array}{r}p \text {-value of } \\
\text { impact }^{2}\end{array}$ & Impact $^{1}$ & $\begin{array}{r}p \text {-value of } \\
\text { impact }^{2}\end{array}$ & Impact $^{1}$ & $\begin{array}{r}p \text {-value of } \\
\text { impact }^{2}\end{array}$ & Impact $^{1}$ & $\begin{array}{r}p \text {-value of } \\
\text { impact }^{2} \\
\end{array}$ \\
\hline \multicolumn{9}{|l|}{ Perceptions of School Climate Domain } \\
\hline Positive School Orientation-CR (+) & 0.03 & 0.467 & 0.00 & 0.973 & 0.05 & 0.432 & 0.03 & 0.703 \\
\hline Negative School Orientation-CR (-) & -0.05 & 0.127 & -0.01 & 0.869 & -0.04 & 0.344 & -0.06 & 0.364 \\
\hline Student Afraid at School-CR (-) & -0.06 & 0.127 & -0.04 & 0.391 & -0.06 & 0.166 & -0.04 & 0.500 \\
\hline Victimization at School-CR (-) & -0.01 & 0.765 & 0.02 & 0.648 & -0.04 & 0.370 & -0.03 & 0.506 \\
\hline
\end{tabular}

* Significantly different from zero at the .05 level.

^ Significantly different from zero at the .10 to $>.05$ level.

${ }^{1}$ Impacts are in effect size (standard deviation) units and were calculated by dividing the estimated impact by the standard deviation of the outcome measure for the control group.

${ }^{2}$ The $p$-value is from a two-tailed $t$ test to gauge the statistical significance of the impact estimate.

NOTE: Abbreviations are

CR: Child Report

PCR: Primary Caregiver Report

TRS: Teacher Report on Student

ADHD: Attention deficit hyperactivity disorder

The +/- signs in parentheses indicate the direction of a beneficial outcome. All impact estimates were calculated using regression models, where each program and school within a program was weighted equally. The standard errors of all estimates account for design effects due to unequal weighting and the clustering of students within schools.

SOURCE: The Social and Character Development (SACD) Research Program. 


\section{Imputing Missing Outcomes}

In the original models, missing outcome data were not imputed for (1) study nonconsenters, (2) survey nonrespondents, and (3) survey respondents who did not provide enough information to construct the outcomes. Instead, adjustments for missing outcome data were made using sample weights so that the impact estimates could be generalized to the full sample universe (and not just to survey respondents).

As a sensitivity test, models were estimated with imputed outcome data. Nearly all students with missing data were study nonconsenters for whom baseline data were not available. Thus, imputation methods that used covariates as predictor variables could not be used. Instead, missing outcome data were imputed using a hotdeck imputation procedure (Rubin 1987), where a missing value for a child was replaced by a nonmissing value for a randomly selected child in the same classroom. Five imputed data sets were generated and estimated impacts $\left(I_{i}\right)$ and variances $\left(V_{i}\right)$ were made for each one. The overall impact estimates were calculated as the average of the five impact estimates. Variances of the estimated impacts were obtained using the following formula:

$$
\text { (11) } \bar{V}+\left(1+\frac{1}{m}\right) B
$$

where $\bar{V}$ is the average of the $V_{i}$ s across the five data sets, $m=5$ is the number of imputed data sets, and $B$ is the following between-imputation variance estimate:

$$
\text { (12) } B=\frac{1}{m-1} \sum_{i=1}^{m}\left(I_{i}-\bar{I}\right)^{2}
$$

Because child-level covariates were not available for study nonconsenters, the regression models were estimated without covariates, except for program-level binary variables.

As with the original impact estimates, no significant impacts were found when using the multiple imputation approach (table B.27). 


\section{Averaging Program-Level Impact Estimates}

An alternative approach for estimating combined-program impacts was to calculate the simple average of the seven program-specific impact estimates. This procedure was done in two ways. First, the seven program-bytreatment interaction terms (that is, $\theta_{p} T_{s p}$ terms) were added as covariates to the original combined-program model, and the treatment status binary variable was excluded from the model. In this formulation, the parameter estimate on a specific program-by-treatment interaction term was the impact estimate for that program. Using this approach, the combined-program impact estimate was calculated as the simple average of the parameter estimates on the seven interaction terms, and the associated standard error (SE) was calculated using the following formula:

$$
\text { (13) } S E(\text { site average })=\frac{1}{7} \sqrt{\sum_{p=1}^{7} V_{p}+2 \sum_{j=1}^{7} \sum_{k>j}^{7} C_{j k}}
$$

where $V_{p}$ is the estimated variance of the impact in $\operatorname{program} p$ and $C_{j k}$ is the estimated covariance between the impacts in programs $j$ and $k$.

In the second approach, combined-program impact estimates were calculated by averaging the impact estimates from the HLM models that were estimated separately by program. Equation (13) was used to calculate the standard errors with $C_{j k}$ set to 0 (because observations were independent across programs). This approach differed slightly from the first approach for several reasons. First, a different set of baseline covariates was used for each program-specific model, whereas a common covariate set was used in the pooled model. Second, in the pooled model, a single (average) clustering effect was applied to all programs, whereas, in the program-specific models, the clustering effects were allowed to vary across programs.

As table B.28 shows, the combined-program impact estimates from these two approaches in which programspecific impact estimates were calculated directly and then averaged were very similar to the original results that relied on weights to give each program equal weight in the analysis. The only difference was that a beneficial significant impact (effect size of 0.07) was found for Positive Social Behavior (PCR) in Year 2 when using the average of the estimates from the seven program-level models. 
Table B.28. Combined-program impacts in effect size units using averages of program-specific impacts

\begin{tabular}{|c|c|c|c|c|c|c|c|c|}
\hline \multirow[b]{3}{*}{ Scale-Report } & \multicolumn{4}{|c|}{$\begin{array}{c}\text { Year 1 } \\
\text { (Spring 2005) } \\
\end{array}$} & \multicolumn{4}{|c|}{$\begin{array}{c}\text { Year 2 } \\
\text { (Spring 2006) }\end{array}$} \\
\hline & \multicolumn{2}{|c|}{$\begin{array}{l}\text { Program by } \\
\text { treatment }\end{array}$} & \multicolumn{2}{|c|}{$\begin{array}{c}\text { Seven separate } \\
\text { estimates }\end{array}$} & \multicolumn{2}{|c|}{$\begin{array}{c}\text { Program by } \\
\text { treatment }\end{array}$} & \multicolumn{2}{|c|}{$\begin{array}{c}\text { Seven separate } \\
\text { estimates }\end{array}$} \\
\hline & Impact $^{1}$ & $\begin{array}{r}p \text {-value of } \\
\text { impact }^{2}\end{array}$ & Impact $^{1}$ & $\begin{array}{r}p \text {-value of } \\
\text { impact }^{2}\end{array}$ & Impact $^{1}$ & $\begin{array}{r}p \text {-value of } \\
\text { impact }^{2}\end{array}$ & Impact $^{1}$ & $\begin{array}{r}p \text {-value of } \\
\text { impact }^{2}\end{array}$ \\
\hline \multicolumn{9}{|l|}{ Social and Emotional Competence Domain } \\
\hline Self-Efficacy for Peer Interactions-CR (+) & -0.02 & 0.543 & -0.01 & 0.717 & -0.07 & 0.107 & -0.06 & 0.145 \\
\hline Normative Beliefs About Aggression-CR (-) & -0.01 & 0.871 & -0.01 & 0.754 & -0.02 & 0.748 & -0.01 & 0.535 \\
\hline Empathy-CR (+) & 0.06 & 0.176 & 0.07 & 0.150 & -0.02 & 0.721 & -0.02 & 0.596 \\
\hline \multicolumn{9}{|l|}{ Behavior Domain } \\
\hline Altruistic Behavior-CR (+) & -0.06 & 0.107 & $-0.07^{\wedge}$ & 0.057 & -0.06 & 0.193 & -0.08 & 0.100 \\
\hline Altruistic Behavior-PCR (+) & $0.07^{\wedge}$ & 0.058 & $0.07^{\wedge}$ & 0.095 & 0.00 & 0.965 & -0.01 & 0.810 \\
\hline Altruistic Behavior-TRS (+) & 0.08 & 0.378 & 0.07 & 0.460 & 0.02 & 0.902 & 0.06 & 0.868 \\
\hline Positive Social Behavior-PCR (+) & -0.01 & 0.725 & -0.01 & 0.774 & 0.05 & 0.177 & $0.07^{*}$ & 0.037 \\
\hline Positive Social Behavior-TRS (+) & 0.01 & 0.709 & 0.01 & 0.860 & -0.02 & 0.768 & 0.00 & 0.957 \\
\hline Problem Behavior-CR (-) & 0.01 & 0.892 & 0.01 & 0.886 & 0.00 & 0.998 & 0.02 & 0.879 \\
\hline Problem Behavior-PCR (+) & 0.00 & 0.930 & 0.01 & 0.811 & -0.03 & 0.341 & -0.04 & 0.271 \\
\hline Problem Behavior-TRS (+) & 0.02 & 0.607 & 0.03 & 0.545 & -0.01 & 0.782 & -0.02 & 0.513 \\
\hline ADHD-Related Behavior-TRS (-) & 0.00 & 0.958 & 0.00 & 0.970 & -0.03 & 0.508 & -0.05 & 0.416 \\
\hline \multicolumn{9}{|l|}{ Academics Domain } \\
\hline Engagement with Learning-CR (+) & -0.04 & 0.217 & -0.04 & 0.345 & -0.03 & 0.490 & -0.03 & 0.555 \\
\hline Academic Competence and Motivation-TRS (+) & -0.02 & 0.433 & -0.02 & 0.448 & -0.02 & 0.653 & 0.01 & 0.835 \\
\hline
\end{tabular}




\section{Table B.28. Combined-program impacts in effect size units using averages of program-specific impacts-Continued}

\begin{tabular}{|c|c|c|c|c|c|c|c|c|}
\hline \multirow[b]{3}{*}{ Scale-Report } & \multicolumn{4}{|c|}{$\begin{array}{c}\text { Year } 1 \\
\text { (Spring 2005) } \\
\end{array}$} & \multicolumn{4}{|c|}{$\begin{array}{c}\text { Year } 2 \\
\text { (Spring 2006) } \\
\end{array}$} \\
\hline & \multicolumn{2}{|c|}{$\begin{array}{c}\text { Program by } \\
\text { treatment }\end{array}$} & \multicolumn{2}{|c|}{$\begin{array}{c}\text { Seven separate } \\
\text { estimates }\end{array}$} & \multicolumn{2}{|c|}{$\begin{array}{c}\text { Program by } \\
\text { treatment }\end{array}$} & \multicolumn{2}{|c|}{$\begin{array}{c}\text { Seven separate } \\
\text { estimates }\end{array}$} \\
\hline & Impact $^{1}$ & $\begin{array}{r}p \text {-value of } \\
\text { impact }^{2}\end{array}$ & Impact $^{1}$ & $\begin{array}{r}p \text {-value of } \\
\text { impact }^{2}\end{array}$ & Impact $^{1}$ & $\begin{array}{r}p \text {-value of } \\
\text { impact }^{2}\end{array}$ & Impact $^{1}$ & $\begin{array}{r}p \text {-value of } \\
\text { impact }^{2}\end{array}$ \\
\hline \multicolumn{9}{|l|}{ Perceptions of School Climate Domain } \\
\hline Positive School Orientation-CR (+) & 0.03 & 0.586 & 0.04 & 0.438 & 0.03 & 0.735 & 0.03 & 0.695 \\
\hline Negative School Orientation-CR (-) & -0.05 & 0.167 & -0.05 & 0.209 & -0.03 & 0.503 & -0.02 & 0.653 \\
\hline Student Afraid at School-CR (-) & -0.06 & 0.171 & -0.06 & 0.140 & -0.06 & 0.218 & -0.09 & 0.101 \\
\hline Victimization at School-CR (-) & -0.01 & 0.793 & -0.01 & 0.763 & -0.04 & 0.431 & -0.02 & 0.639 \\
\hline
\end{tabular}

* Significantly different from zero at the .05 level.

$\wedge$ Significantly different from zero at the .10 to $>.05$ level.

Impacts are in effect size (standard deviation) units and were calculated by dividing the estimated impact by the standard deviation of the outcome measure for the control group.

${ }^{2}$ The $p$-value is from a two-tailed $t$ test to gauge the statistical significance of the impact estimate.

Uु NOTE: Abbreviations are

CR: Child Report

PCR: Primary Caregiver Report

TRS: Teacher Report on Student

ADHD: Attention deficit hyperactivity disorder

The +/- signs in parentheses indicate the direction of a beneficial outcome. All impact estimates were calculated using regression models, where each program and school within a program was weighted equally. The standard errors of all estimates account for design effects due to unequal weighting and the clustering of students within schools.

SOURCE: The Social and Character Development (SACD) Research Program. 


\section{Excluding New Entrants}

About 7.5 percent of children in the spring 2005 follow-up sample were new entrants who enrolled in the study schools after fall 2004. For several reasons, the inclusion of these children in the analysis sample could have affected the impact estimates. First, new entrants were exposed to the SACD interventions for a shorter period than were original cohort children, which could have depressed the impact estimates. Second, new entrants may have had different characteristics than did original cohort members, which could have led to different program effects across the two groups. For example, the description of consent rates in chapter 1 showed that new entrants had lower consent rates (and percentages of the sample with data) than did original cohort members, potentially reflecting such differences. Third, the new entrants in the treatment schools could have differed from those in the control schools if the SACD interventions had an effect on school entry. ${ }^{15}$ Finally, the imputation of baseline pretest scores for the new entrants (based on mean pretest scores of original cohort members in the same class) could have influenced the impact estimates.

As a sensitivity test, models were estimated that excluded new entrants from the analysis sample using Year 1 and Year 2 data. As with the original impact estimates, no significant impacts were found when new entrants were excluded (table B.29).

For Years 2 and 3, the numbers of new entrants grew large enough to do separate analyses of new entrants and original members of the sample. These analyses are discussed in chapter 1 as part of the subgroup analyses. They include the finding of no significant impacts on the 18 outcomes for either group and the finding of no significant differences between the impacts on the new entrants versus the original cohort members.

\footnotetext{
${ }^{15}$ Similarly, the original cohort stayers in the treatment and control group schools could differ if the interventions had an
} effect on school exit rates. 
Table B.29. Combined-program impacts in effect size units when excluding new entrants

\begin{tabular}{|c|c|c|c|c|}
\hline \multirow[b]{2}{*}{ Scale-Report } & \multicolumn{2}{|c|}{$\begin{array}{c}\text { Year } 1 \\
\text { (Spring 2005) }\end{array}$} & \multicolumn{2}{|c|}{$\begin{array}{c}\text { Year } 2 \\
\text { (Spring 2006) }\end{array}$} \\
\hline & Impact $^{1}$ & $\begin{array}{r}p \text {-value of } \\
\text { impact }^{2}\end{array}$ & Impact $^{1}$ & $\begin{array}{l}p \text {-value of } \\
\text { impact }^{2}\end{array}$ \\
\hline \multicolumn{5}{|l|}{ Social and Emotional Competence Domain } \\
\hline Self-Efficacy for Peer Interactions-CR (+) & -0.06 & 0.139 & -0.06 & 0.176 \\
\hline Normative Beliefs About Aggression-CR (-) & 0.00 & 0.908 & 0.00 & 0.996 \\
\hline Empathy-CR (+) & 0.06 & 0.260 & -0.01 & 0.798 \\
\hline \multicolumn{5}{|l|}{ Behavior Domain } \\
\hline Altruistic Behavior-CR (+) & $-0.07^{\wedge}$ & 0.080 & -0.03 & 0.516 \\
\hline Altruistic Behavior-PCR (+) & 0.05 & 0.184 & -0.01 & 0.807 \\
\hline Altruistic Behavior-TRS (+) & 0.14 & 0.204 & 0.02 & 0.903 \\
\hline Positive Social Behavior-PCR (+) & -0.02 & 0.620 & 0.01 & 0.813 \\
\hline Positive Social Behavior-TRS (+) & 0.01 & 0.822 & -0.03 & 0.651 \\
\hline Problem Behavior-CR (-) & 0.01 & 0.887 & -0.02 & 0.759 \\
\hline Problem Behavior-PCR (+) & -0.04 & 0.411 & -0.05 & 0.244 \\
\hline Problem Behavior-TRS (+) & 0.03 & 0.438 & -0.03 & 0.534 \\
\hline ADHD-Related Behavior-TRS (-) & 0.02 & 0.721 & -0.03 & 0.590 \\
\hline \multicolumn{5}{|l|}{ Academics Domain } \\
\hline Engagement with Learning-CR (+) & $-0.08^{\wedge}$ & 0.064 & -0.03 & 0.533 \\
\hline Academic Competence and Motivation-TRS (+) & -0.07 & 0.108 & -0.07 & 0.170 \\
\hline \multicolumn{5}{|l|}{ Perceptions of School Climate Domain } \\
\hline Positive School Orientation-CR (+) & 0.01 & 0.927 & 0.05 & 0.561 \\
\hline Negative School Orientation-CR (-) & -0.01 & 0.805 & -0.05 & 0.432 \\
\hline Student Afraid at School-CR (-) & -0.06 & 0.167 & -0.05 & 0.359 \\
\hline Victimization at School-CR (-) & -0.01 & 0.879 & -0.05 & 0.353 \\
\hline
\end{tabular}

$\wedge$ Significantly different from zero at the .10 to $>.05$ level.

${ }^{1}$ Impacts are in effect size (standard deviation) units and were calculated by dividing the estimated impact by the standard deviation of the outcome measure for the control group.

${ }^{2}$ The $p$-value is from a two-tailed $t$ test to gauge the statistical significance of the impact estimate.

NOTE: Abbreviations are

CR: Child Report

PCR: Primary Caregiver Report

TRS: Teacher Report on Student

ADHD: Attention deficit hyperactivity disorder

The \pm signs in parentheses indicate the direction of a beneficial outcome. No findings were found statistically significant at or below the .05 level. All impact estimates were calculated using regression models, where each program and school within a program was weighted equally. The standard errors of all estimates account for design effects due to unequal weighting and the clustering of students within schools.

SOURCE: The Social and Character Development (SACD) Research Program.

\section{Including Restricted Sets of Covariates in the Regression Models}

Two sets of regression models were estimated using restricted sets of covariates. In the first set, the covariates included only the pretest of the outcome measure. In the second set, the covariates included only the child and primary caregiver demographic measures (listed in the first section of this appendix). As with the original impact estimates, no significant impacts were found when using the restricted sets of covariates (table B.30). 
Table B.30. Combined-program impacts in effect size units using restricted sets of covariates (pretest of outcomes only and child and primary caregiver demographic measures only)

\begin{tabular}{|c|c|c|c|c|c|c|c|c|}
\hline \multirow[b]{3}{*}{ Scale-Report } & \multicolumn{4}{|c|}{$\begin{array}{c}\text { Year } 1 \\
\text { (Spring 2005) }\end{array}$} & \multicolumn{4}{|c|}{$\begin{array}{c}\text { Year } 2 \\
\text { (Spring 2006) }\end{array}$} \\
\hline & \multicolumn{2}{|c|}{$\begin{array}{l}\text { Covariates for } \\
\text { pretest of } \\
\text { outcomes only }\end{array}$} & \multicolumn{2}{|c|}{$\begin{array}{c}\text { Covariates for } \\
\text { child and } \\
\text { primary caregiver }\end{array}$} & \multicolumn{2}{|c|}{$\begin{array}{l}\text { Covariates for } \\
\text { pretest of } \\
\text { outcomes only }\end{array}$} & \multicolumn{2}{|c|}{$\begin{array}{c}\text { Covariates for } \\
\text { child and } \\
\text { primary caregiver }\end{array}$} \\
\hline & Impact $^{1}$ & $\begin{array}{r}p \text {-value of } \\
\text { impact }^{2}\end{array}$ & Impact $^{1}$ & $\begin{array}{r}p \text {-value of } \\
\text { impact }^{2}\end{array}$ & Impact $^{1}$ & $\begin{array}{r}p \text {-value of } \\
\text { impact }^{2}\end{array}$ & Impact $^{1}$ & $\begin{array}{r}p \text {-value of } \\
\text { impact }^{2}\end{array}$ \\
\hline \multicolumn{9}{|l|}{ Social and Emotional Competence Domain } \\
\hline Self-Efficacy for Peer Interactions-CR (+) & -0.02 & 0.520 & -0.05 & 0.240 & -0.06 & 0.155 & $-0.08^{\wedge}$ & 0.082 \\
\hline Normative Beliefs About Aggression-CR (-) & 0.00 & 0.911 & -0.02 & 0.549 & -0.01 & 0.919 & -0.02 & 0.656 \\
\hline Empathy-CR (+) & 0.06 & 0.271 & 0.07 & 0.144 & -0.03 & 0.589 & -0.03 & 0.625 \\
\hline \multicolumn{9}{|l|}{ Behavior Domain } \\
\hline Altruistic Behavior-CR (+) & -0.07 & 0.103 & -0.07 & 0.125 & -0.07 & 0.125 & -0.07 & 0.122 \\
\hline Altruistic Behavior-PCR (+) & 0.06 & 0.148 & 0.04 & 0.307 & 0.01 & 0.866 & 0.00 & 0.919 \\
\hline Altruistic Behavior-TRS (+) & 0.07 & 0.424 & 0.13 & 0.236 & 0.01 & 0.964 & 0.02 & 0.914 \\
\hline Positive Social Behavior-PCR (+) & -0.01 & 0.745 & 0.01 & 0.893 & 0.05 & 0.230 & 0.06 & 0.219 \\
\hline Positive Social Behavior-TRS (+) & 0.01 & 0.864 & 0.04 & 0.568 & -0.05 & 0.517 & -0.03 & 0.719 \\
\hline Problem Behavior-CR (-) & 0.01 & 0.788 & 0.00 & 0.938 & 0.01 & 0.848 & 0.00 & 0.966 \\
\hline Problem Behavior-PCR (+) & 0.01 & 0.825 & -0.04 & 0.431 & -0.03 & 0.470 & $-0.08^{\wedge}$ & 0.062 \\
\hline Problem Behavior-TRS (+) & 0.03 & 0.593 & 0.00 & 0.948 & 0.00 & 0.937 & -0.02 & 0.765 \\
\hline ADHD-Related Behavior-TRS (-) & 0.00 & 0.917 & 0.00 & 0.933 & -0.02 & 0.664 & -0.04 & 0.661 \\
\hline \multicolumn{9}{|l|}{ Academics Domain } \\
\hline Engagement with Learning-CR (+) & -0.04 & 0.267 & -0.05 & 0.194 & -0.03 & 0.363 & -0.04 & 0.246 \\
\hline Academic Competence and Motivation-TRS (+) & -0.01 & 0.597 & -0.04 & 0.440 & -0.02 & 0.701 & -0.05 & 0.340 \\
\hline
\end{tabular}


Table B.30. Combined-program impacts in effect size units using restricted sets of covariates (pretest of outcomes only and child and primary caregiver demographic measures only)-Continued

\begin{tabular}{|c|c|c|c|c|c|c|c|c|}
\hline \multirow[b]{3}{*}{ Scale-Report } & \multicolumn{4}{|c|}{$\begin{array}{c}\text { Year } 1 \\
\text { (Spring 2005) }\end{array}$} & \multicolumn{4}{|c|}{$\begin{array}{c}\text { Year } 2 \\
\text { (Spring 2006) }\end{array}$} \\
\hline & \multicolumn{2}{|c|}{$\begin{array}{l}\text { Covariates for } \\
\text { pretest of } \\
\text { outcomes only }\end{array}$} & \multicolumn{2}{|c|}{$\begin{array}{c}\text { Covariates for } \\
\text { child and } \\
\text { primary caregiver }\end{array}$} & \multicolumn{2}{|c|}{$\begin{array}{l}\text { Covariates for } \\
\text { pretest of } \\
\text { outcomes only } \\
\end{array}$} & \multicolumn{2}{|c|}{$\begin{array}{c}\text { Covariates for } \\
\text { child and } \\
\text { primary caregiver }\end{array}$} \\
\hline & Impact $^{1}$ & $\begin{array}{r}p \text {-value of } \\
\text { impact }^{2}\end{array}$ & Impact $^{1}$ & $\begin{array}{r}p \text {-value of } \\
\text { impact }^{2}\end{array}$ & Impact $^{1}$ & $\begin{array}{r}p \text {-value of } \\
\text { impact }^{2}\end{array}$ & Impact $^{1}$ & $\begin{array}{r}p \text {-value of } \\
\text { impact }^{2}\end{array}$ \\
\hline \multicolumn{9}{|l|}{ Perceptions of School Climate Domain } \\
\hline Positive School Orientation-CR (+) & 0.02 & 0.747 & 0.02 & 0.772 & 0.02 & 0.824 & 0.01 & 0.887 \\
\hline Negative School Orientation-CR (-) & -0.05 & 0.354 & -0.04 & 0.496 & -0.02 & 0.729 & -0.01 & 0.868 \\
\hline Student Afraid at School-CR (-) & -0.05 & 0.258 & -0.04 & 0.397 & -0.05 & 0.424 & -0.05 & 0.394 \\
\hline Victimization at School-CR (-) & -0.02 & 0.609 & -0.03 & 0.593 & -0.04 & 0.420 & -0.05 & 0.389 \\
\hline
\end{tabular}

^ Significantly different from zero at the .10 to $>.05$ level.

${ }^{1}$ Impacts are in effect size (standard deviation) units and were calculated by dividing the estimated impact by the standard deviation of the outcome measure for the control group.

${ }^{2}$ The $p$-value is from a two-tailed $t$ test to gauge the statistical significance of the impact estimate.

NOTE: Abbreviations are

CR: Child Report

PCR: Primary Caregiver Report

TRS: Teacher Report on Student

ADHD: Attention deficit hyperactivity disorder

The $+/$ - signs in parentheses indicate the direction of a beneficial outcome. No findings were found statistically significant below the .05 level. All impact estimates were calculated using regression models, where each program and school within a program was weighted equally. The standard errors of all estimates account for design effects due to unequal weighting and the clustering of students within schools.

SOURCE: The Social and Character Development (SACD) Research Program. 